
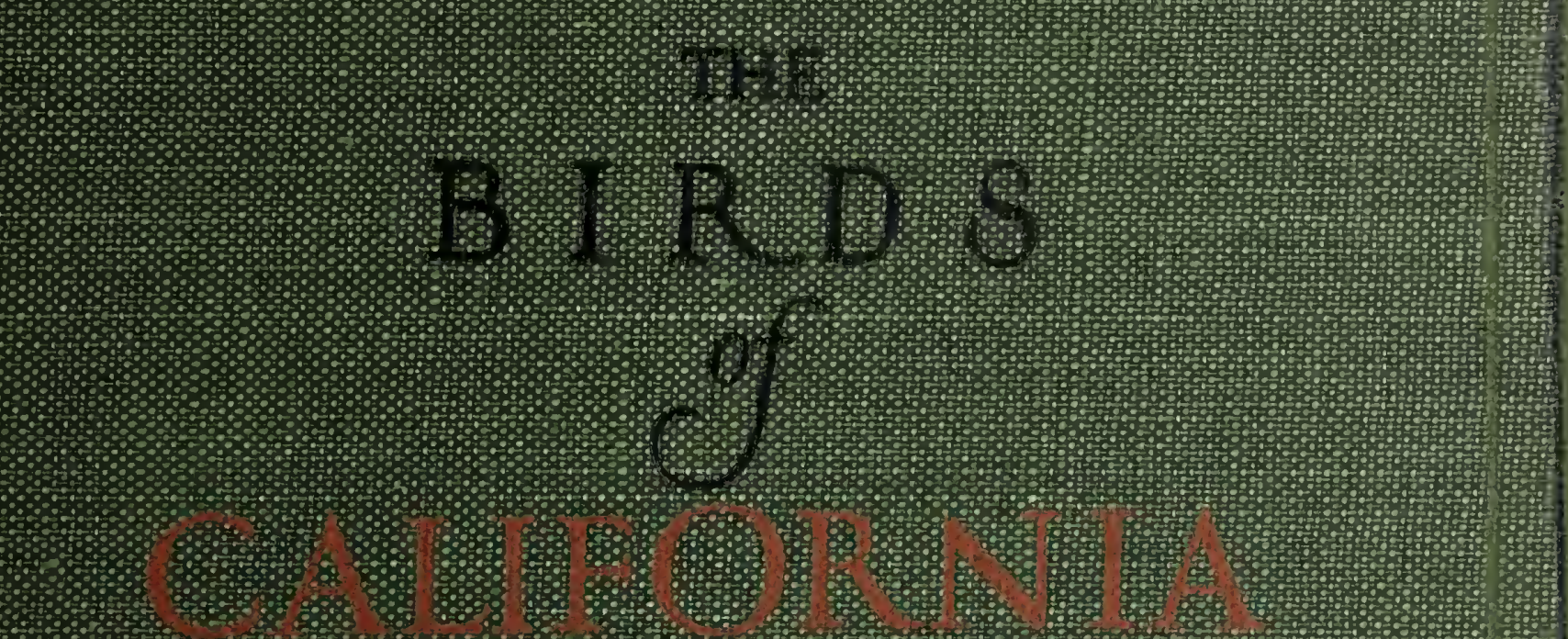

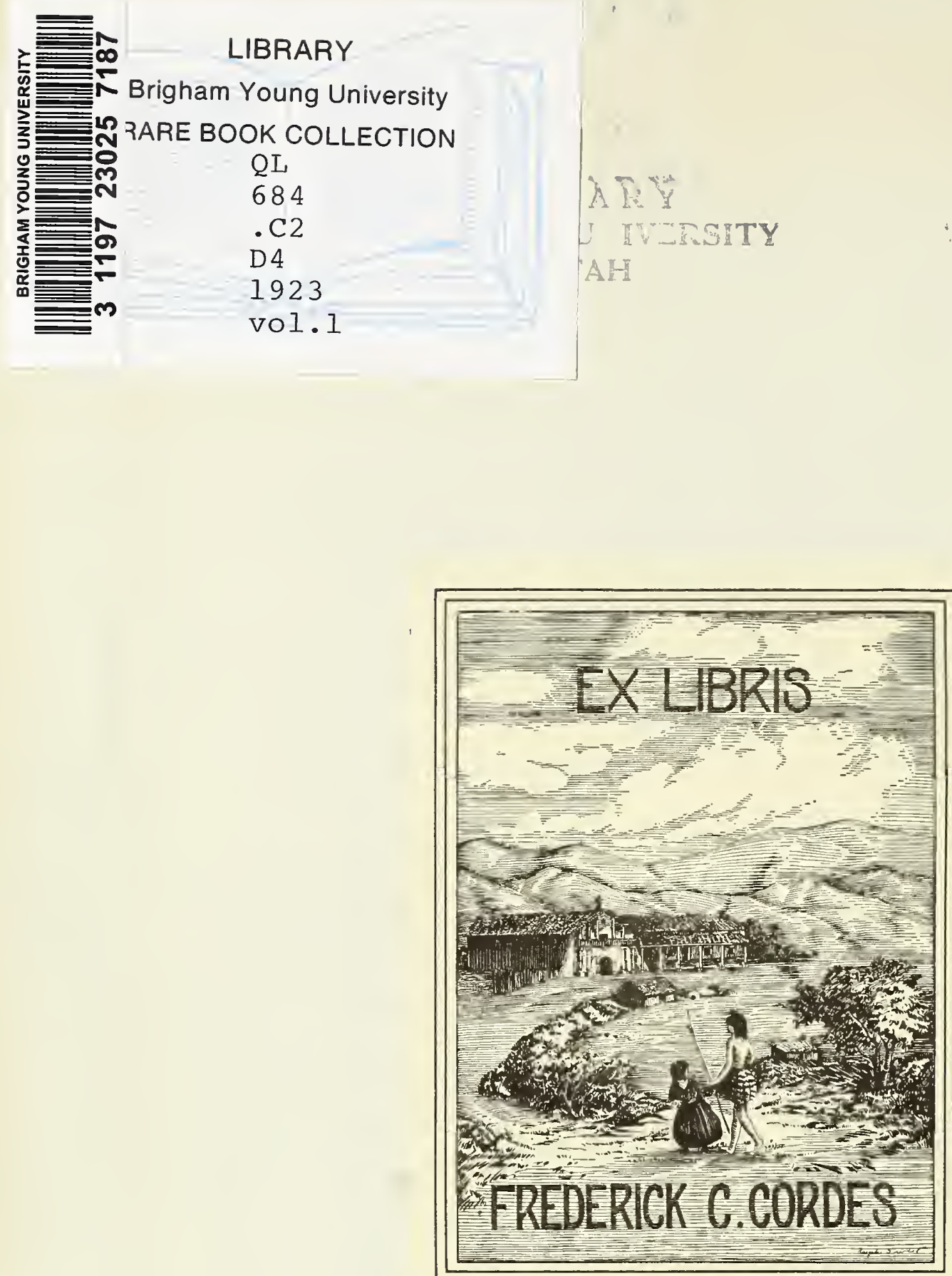

Digitized by the Internet Archive in 2019 with funding from Brigham Young University

https://archive.org/details/birdsofcalif192301daws 




The Birds of California

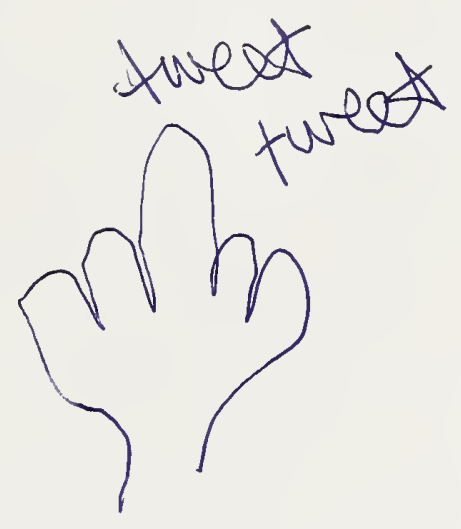



Students' Edition 




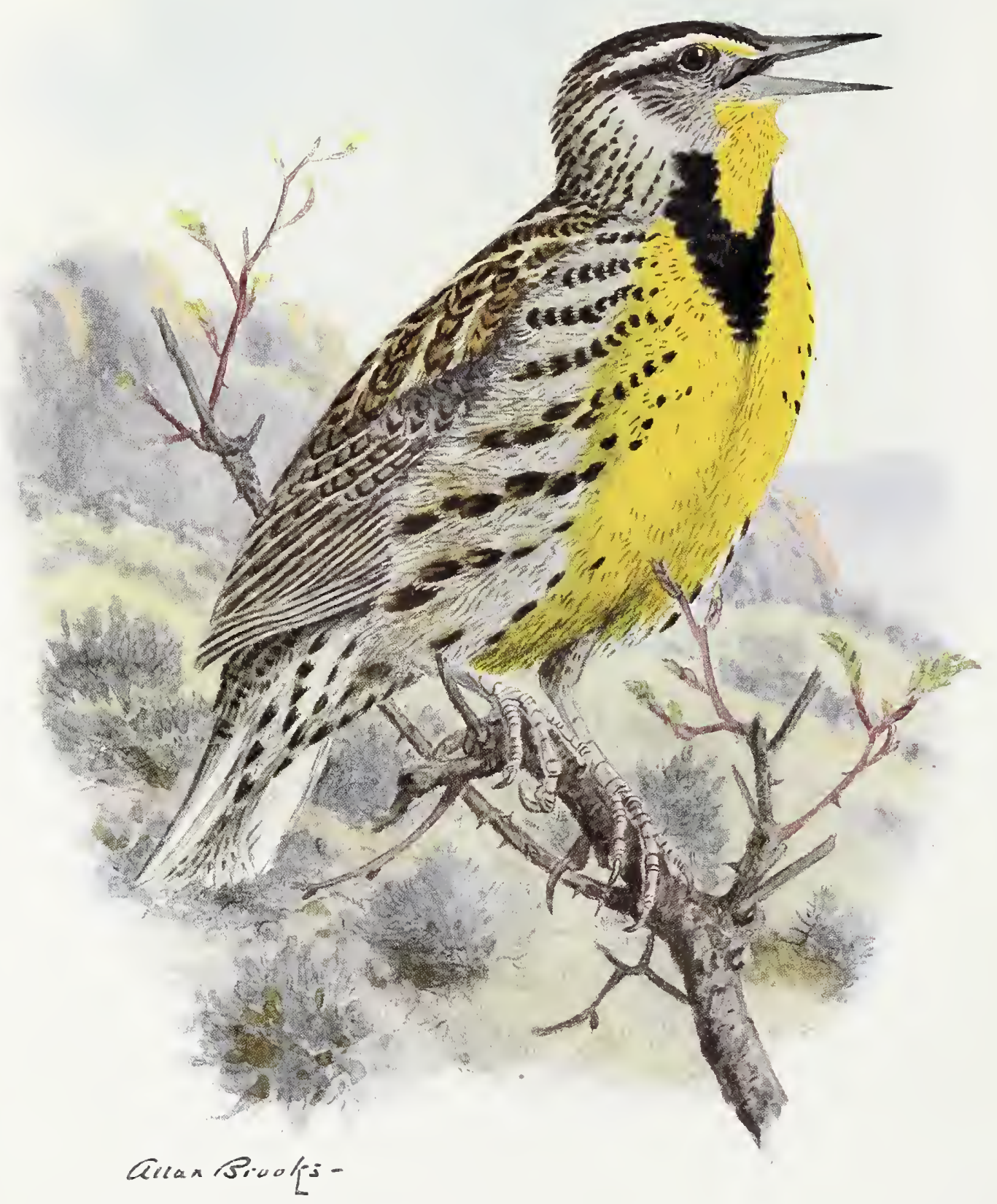


Western Meadowlark

About $1 / 2$ life size 
A้rselworgom mrotes W ssie stil st JuodA 


\section{The Birds of California}

A Complete, Scientific and

Popular Account of the 580 Species and Subspecies of Birds Found in the State

\section{By \\ William Leon Dawson \\ of Santa Barbara}

Director of the International Museum of Comparative Oölogy, Author of "The Birds of Ohio" and (with Mr. Bowles) of "The Birds of Washington"

Illustrated by More Than I 100 Half-tone Cuts of Birds in Life, Nests, Eggs, and Favorite Haunts, from Photographs

Chiefly by

Donald R. Dickey, Wright M. Pierce, Wm. L. Finley and the Author

Together with 44 Drawings in the Text and a Series of I 5 Full-page Color Plates

Chiefly by

Major Allan Brooks

\section{Students' Edition}

Complete in Three Volumes

Volume One

\section{South Moulton Company}

San Diego, Los Angeles, San Francisco

1923

Sold Only by Subscription. All Rights Reserved 
Text but not the COlor-Plates, Copyright 192 I AND 1923

BY

William LEON DAWSON

ALL RIGHTS RESERVED, INCLUDING THAT OF TRANSLATION

Composition by Typographic Service Co., Los Angeles.

Press-work by Wolfer Printing Co., Los Angeles.

Four-color half-tone plates chiefly by Star Engraving Co., Los Angeles.

Binding by Leather Products and Finishing Co., Los Angeles.

\section{THE LIBRARY}

BRIGHAN TOUNG U TVLRTTY

PROVO, UTAH 
TO

\section{Ellen Browning Scripps}

Lover of the human kind and of birds and of flowers and of books

Patron of science and of art and of education

Whose steadfast faith has made its publication possible

This work is gratefully

Dedicated 



\section{Preface}

SINCE the dawn of the scientific era the study of birds, ornithology, has occupied an honorable place. Men like Linnæus, Brisson and Cuvier, Temminck, Vieillot, Forbes and Gray, and more recently, Gadow, Evans and Hartert, Sharpe, Ridgway, Oberholser and Grinnell, have expounded its technique; while apostles like Audubon and Gould, Baird, Newton and Coues, Hudson. Chapman and Beebe, have published its gospel and immortalized its claims. Without claiming either the technical equipment of a Ridgway or the apostolic fervor of an Audubon, the author has tried nevertheless to do a rough justice to the dual claims of descriptive science and of artistic interpretation in a field which he realizes to be singularly favored, not alone for the variety and wealth of its bird life, but for the number and quality of its human inhabitants. As a citizen by choice of the Golden State, the writer can truly say that California seems to offer unparalleled advantages for bird study. Indeed, its range of avian interest is fairly typified by the fact that within its borders a bird of modest powers, as a Clark Nutcracker, might breakfast (somewhat sparingly) at the lowest point upon the American continent, viz., in the Death Valley, and lunch (even more austerely) upon the highest point of land in the United States, viz., the summit of Mt. Whitney, I4,50 I feet above the level of the sea. California is the land of contrasts, and the description of its vividly contrasting and kaleidoscopic bird-life is, perhaps, the most privileged task which might fall to the lot of an ornithologist.

It is the province of this work to appreciate and, so far as possible, to express, not alone the conceptual entities of science called species, but the very persons and lives of those hundreds of millions of our fellow travelers and sojourners, called birds, the birds of California. To this end the birds have been viewed not alone through the rigid eye of science, but through the more roving, or tolerant, or even penetrating eye of the poet, the interpreter, the apologist-the mystic even-the at-all-times bird-lover.

With such a broad claim of latitude, it goes without saying that "The Birds of California" is anything but "complete," in the sense of having said all that might be said about any given species. Our effort has been rather to present a conspectus of bird-life in California in its true proportions of interest. The commoner or more important species have been allowed a much greater space, precisely on this account, that they are common and important. Nor is it possible to claim completeness on the ground that all the conclusions of other workers are herein recorded. While it is true that all the major sources of information have been catalogued and consulted, it remains true also that this work is essentially an original and personal contribution. The author is a poor compiler. There are many who are gifted in this direction, and they have performed valuable service. Yet we have had so many digests and rehashes and ineticulous accumulations of disconnected notes, that it has seemed worth while, for 
once, to break away and start afresh. It is for this reason that the author has religiously abstained from reading Audubon or Wilson, or indeed any of the "old masters"to the end that he might see his birds with fresh eyes and use, if possible, an unworn language. This has entailed real sacrifice, but it may also prove to have been a real gain.

Yet having said so much by way of apology for alleged originality, I have done scant justice to the magnificent accumulations of the Cooper Ornithological Club in "The Condor" (now in its twenty-fifth year), or, indeed, to my own dependence upon it. Through the courtesy of the Club itself and of one of its business managers, Mr. W. Lee Chambers, I have been supplied with a double file of "The Condor" for clipping, and have made large use of it. "The Birds of California" is, therefore, essentially a free digest of the coöperative work accomplished in California during the past quarter of a century. My thanks are due, both individually and collectively, to all contributors of "The Condor," and to a lesser degree of "The Auk"; and my only regret is that the more impatient movement of my own particular genre has precluded the possibility of doing exact justice to all available sources.

Consistency in the interpretation of bird-life is as impossible today as it was twenty years ago. Most of us who follow the birds are partly scientist, partly sportsman, and partly poet. Each interest in turn combats the others, or is at least seen to be inconsistent with them. Nevertheless, even here some ground has been gained. The field of "sport," i. e., of bird-killing as sport, has been more and more sharply restricted, until its fundamental inconsistencies are beginning to appear. An outlet for honest energies has, however, been provided by bird photography and, indeed, by note-taking. In science, likewise, the ample accumulations of the larger museums have made it unnecessary that the serious student of ornithology should always lug about a shot-gun. Modern binoculars increase the field efficiency of the student eight or ten times, and the liabilities of error are correspondingly reduced. Here also the new scientific sport of bird-banding (accomplished by a painless method of trapping) is likely to displace the cruder method of bird-killing, and this bids fair to accomplish tenfold greater results for science.

A tremendous gain has been made during the last three decades in the sentimental attitude toward birds. The pursuit of birds with sticks and stones and guns and the indiscriminate robbing of birds' nests have given way to intelligent interest and a solicitous care for the welfare of the birds on the part of old and young. Too much credit for this salutary result cannot be given to the National Association of Audubon Societies, and to its affiliated societies which exist throughout the land. That the interest thus aroused has not always exhibited the characteristics of maturity, and that, in turn, some incidental injustice has been done to science, goes without saying. Nevertheless, there now exists a splendid and alert interest in birds on the part of the American people, and to such a body of interest science presents its case with confidence and rejoicing.

In the preparation of this work the author has enjoyed unusual opportunities of study and travel afield. Work has been conducted in all but four of California's fiftyeight counties, and the ones omitted are homogeneous in character with the regions visited. In a realm so vast and so varied as California, however, one must be privileged indeed who could claim complete understanding of its diverse topographical and faunistic elements. For myself, I confess to a sense of utter inadequacy. There are 
still uncharted depths and unscaled heights in California, and a wilderness so widespread and so near at hand that one might deliberately lose himself in its mazes within two hours of almost any given point. Field work has been conducted chiefly in the breeding season, say April to July, and one season was spent in Arizona with a view to getting a quicker, surer knowledge of the desert species which invade our own borders. If a disproportionate interest seems to attach to the treatments of the mountaindwelling species, it is with deliberate intention to promote a quicker enthusiasm for these unfrequented fastnesses.

The author is also under deep obligation to many years of bird questing spent in the State of Washington. The result of these experiences was embodied in a twovolume work, "The Birds of Washington," published in I909; and in the preparation of this work the author enjoyed the coöperation of Mr. John Hooper Bowles, of Tacoma. "The Birds of Washington" was obscurely published and of necessarily limited circulation; and inasmuch as a good deal of its matter was exactly descriptive of conditions obtaining in California, or at least concerned species found in California, it has been unhesitatingly used as a supplementary source-book for "The Birds of California." The adaptation of passages has been most conscientiously done (I have a horror of stale stuff), so that the northern flavor thus imparted to "The Birds of California" may be deemed to offset in a measure the stigma of residence south of the Tehachipe.

The plumage descriptions appearing in this work are based chiefly upon original studies of material in the very adequate collections of the Museum of Vertebrate Zoölogy in Berkeley. To the management of this institution and to its founder and patroness, Miss Alexander, I tender my sincerest thanks for every courtesy. The California Academy of Sciences, of San Francisco, and the Museum of History, Science and Art, in Los Angeles, likewise placed every facility at my disposal, and I only regret the limitations of time which precluded a more extended use of their excellent collections.

The order of treatment observed in the following pages is substantially the reverse of that long followed by the American Ornithologists' Union, and is justifiable principally on the ground that it follows a certain order of interest and convenience. Beginning, as it does, with the supposedly highest forms of bird-life, it brings to the fore the most familiar birds, and avoids that rude juxtaposition of the lowest form of one group with the highest of the one above it which has been the confessed weakness of the A. O. U. arrangement.

The outlines of classification have been rehearsed in the Table of Contents to each volume, and a brief synopsis of generic, family, and ordinal characters will be found in the Analytical Keys at the end of the work. It has not been thought best to give large place to these matters, nor to intrude them upon the text, both because of the enormous labor involved in a really original digest, and because the more technical character of these investigations would probably interest only a small proportion of our clientele. Several excellent manuals already exist in this field, and to these the more intrepid student is referred.

The nomenclature is chiefly that of the A. O. U. Check-List, Third Edition, revised to include more recent supplements. In a few instances attention has been paid to outside suggestions, especially such as would tend to link up some of our American species of wide distribution with closely related European or Asiatic forms. I must confess to having followed with a very special bias the opinions of our veteran taxono- 
mist, Dr. Joseph Grinnell, and his no less gifted brother-in-law, Mr. Harry Swarth. In some few cases I have differed from these authorities and have disallowed their claims, not as being mistaken in fact, but as being, on occasion, too fine-spun or ethereal for mortal allegiance. Other distinctions, no less finely shaded, I have allowed, for no better reason, perhaps, than inertia or to show esprit de corps, or else to provide a dainty target for a good-natured shaft. Taxonomy is not an exact science, and we are under no bonds to an artificial consistency. Furthermore, it may be as well at the outset to let the student into the secret of our perplexities. We have no wish either to mystify him or to impress him with a show of infallibility. The realm of ornithology, and especially the field of taxonomy, has been much trampled and much shot over, yet there may be rich ore just below the surface, or even veritable oil domes of truth awaiting release.

For subject headings I have selected names applicable to the species as a whole, wherever found, provided two or more races of the species appear on the California list. This will introduce certain names unfamiliar to western eyes, as, for example, "Solitary Vireo," instead of "Cassin Vireo"; but it will have a salutary effect in stressing the value of the species, and in restraining our tendency to regard geographical races as quasispecies, through the operation of the naming fallacy. Calling the bird a Cassin Vireo should not blind our eyes to the fact that it $i s$ a Solitary Vireo, only a shade different from the eastern representative of this species. For those cases where only one subspecies is found in California, there seems to be no recourse save to yield a quasi-specific value to the local name. In the case of Zonotrichia gambeli gambeli and Z. g. nuttalli, I have deliberately disregarded the rules, in order to stress the differences between the two races, as well as to exemplify the fact that consistency is impossible where a hard and fast mechanical device, like nomenclature, obscures phylogenetic differences infinitely varied.

Considerable care, too, has been taken in the readjustment or reappraising of common names; for experience shows that these may be more enduring than so-called "scientific" names. In some instances I have used one designation in the subject title and another for the same bird in the "running title." By placing both before the public it may be possible to establish through usage some ground of preference not now apparent. Some names previously in use were misleading and have been frankly discarded; but no departure from custom has been registered save for good reason.

In compiling General Ranges, I have been chiefly indebted to the A. O. U. CheckList (3rd Edition), but have supplemented its findings by reference to Ridgway or Bent, or to more explicitly western authorities. In determining the Ranges in California, I am under the deepest obligation, by permission, to Dr. Grinnell's "Distributional List" (1915), as well as to other pamphlets published by the Cooper Ornithological Club, notably those by Willett, Tyler and Howell. I have also kept accurate notes of all occurrences throughout my own ornithological wanderings, and have thus been able to confirm or to supplement Grinnell's well-balanced conclusions.

In presenting the "Authorities," I have been fortunate in enlisting the services of Dr. Tracy I. Storer (about 60 paragraphs) and Mr. Harry Swarth, and these gentlemen are responsible for the citations themselves. It was intended at first to offer only "first publication," the citation upon which inclusion as a bird of California rested, although it was not always possible to secure even such. But it would have seemed a pity not to 
point the student at the same time to at least the major sources of information, near or remote. Accordingly, leading references, to the limiting number of five or six, have been provided, solely for the benefit of those who wish to carry their studies further. Selections in many instances have had to be quite arbitrary; and in general the more obvious source books, monographs, and special treatises, as well as the more comprehensive works of reference have been dismissed after a few citations. Continued reference to these approved sources would suggest itself to the student in any event, so our effort has been directed rather to list the more fugitive and likely-to-be-overlooked articles and reports, or else those of more striking regional significance.

Readers will remark an insistent oölogical note in these pages. The author has long cherished a notion of the importance of the study of birds' eggs in seeking to resolve the problems of phylogenetic relationships, and indeed in arriving at some measure of understanding of the nature and methods of life itself. Privileged years have strengthened this conviction and have made clear to him the necessity of further devotion to this task. In January, 1916, with the help of indulgent (but non-professional) friends, the author established the Museum of Comparative Oölogy in Santa Barbara. This institution cultivated its special field, with distinction, for a number of years, and was, incidentally, of immense service to "The Birds of California:" but, later, when the distinctive character of the institution began to alter, the author withdrew and has since organized a new and purely scientific institution, the International Museum of Comparative Oölogy. The new movement, which proposes to correlate the interests of scientific oölogy throughout the world, boasts a membership in thirtyfour of the American States and in more than thirty foreign states and countries, and gives promise, thus, of a considerable usefulness to science. My sincerest thanks are, however, due to the old institution both for its practical support and for its consistent appreciation of the prior claims of the bird-book.

But with this hasty review of technical matters we gladly return to a consideration of the bird itself. Poet, legislator, scientist, sportsman, economist, sentimentalisthow shall we get on together? How shall we agree whether to attack, or to cherish, the traditions of bird lore? Who owns the birds? and what are they good for, anyhow? A real principle of unity can be found only when we come to regard the birds' value to society, that is, to all of us taken together. The question then becomes, not, Is this bird worth more to me in my collection or upon my plate than as a living actor in the drama of life? but, In what capacity can this bird best serve the interests of mankind? There can be no doubt that the answer to the latter question is usually and increasingly, As a living bird. Stuffed specimens we need, but only a representative number of them: only a limited few of us are fitted to enjoy the pleasures of the chase, and the objects of our passion are rapidly passing from view anyway; but never while the hearts of men are set on peace, and the minds of men are alert to receive the impressions of the Infinite, will there be too many birds to speak to eye and ear, and to minister to the hidden things of the spirit. The birds belong to the people, not to a clique or a coterie, but to all the people as heirs and stewards of the good things of God.

It is of the esthetic value of the bird that we have tried to speak, not alone in our descriptions but in our pictures. The author has a pleasant conviction, born of desire, perhaps, that the bird in art is destined to figure much more largely in future years than heretofore. We have learned something from the Japanese in this regard, but 
more, perhaps, from the camera, whose revelations have marvelously justined the conventional conclusions of Japanese decorative art. Nature is ever the nursing mother of Art. While our function in the text has necessarily been interpretative, we have preferred in the pictures to let Nature speak for herself, and we have held ourselves and our artists to the strictest accounting for any retouching or modification of photographs. Except, therefore, as explicitly noted, the half-tones from photographs are faithful presentations of life. If they inspire any with a sense of the beauty of things as they are, or suggest to any the theme for some composition, whether on canvas, fresco, vase, or tile, in things as they might be, then our labor will not have been in vain.

It affords us deep satisfaction to present 106 color plates from paintings by Major Allan Brooks, for in our opinion this artist is without a peer in the delineation of birds. Major Brooks, although a resident of British Columbia, has pursued extensive studies in California, and was a welcome guest at "Los Colibris" for two winters. We regret not having been able to avail ourselves further of the masterly work of Mr. Louis Agassiz Fuertes, nor of that of Mr. George Miksch Sutton, a younger artist of brilliant promise, although we are glad to present one plate each from these gentlemen.

The photographic work of Mr. Donald R. Dickey, of Pasadena, speaks for itself. The author is under the deepest personal obligation to Mr. Dickey for his able and enthusiastic coöperation, a service which of itself would have assured the worthy illustration of "The Birds of California." In like manner, Mr. Wright M. Pierce, of Claremont, has given without stint of the products of his photographic skill, and has set us wishing that he might be persuaded to undertake bird photography as a profession. Mr. William L. Finley, of Oregon, is a well-known star in his own realm, and he has generously spared us a few scintillations. Specific acknowledgement of welcome contributions from other artists, both amateur and professional, is made in connection with the half-tones themselves, and to all these gentlemen we extend our hearty thanks.

To the Patrons and Subscribers of this work, as such, the author wishes to express his sincerest thanks. The patience displayed by early subscribers to "The Birds of California" is probably without parallel in publishing history, for the present publishers hold, and honor, orders which were signed in November, 1910. While it is a satisfaction to note that the promises of the early days have been more than redeemed through the enlarged scope and enhanced illustrative equipment of the work itself, it remains true that save for the timely support accorded by people of good will in the old days (when the whole scheme was merely a vision on paper), the work could never have been accomplished. Well said the prophet, Cast your bread upon the waters and after many days it shall return unto you.

It is quite impossible for me to express the depth of my gratitude to Miss Ellen B. Scripps, of La Jolla, who has proved herself not only an astute benefactor but a courageous friend. From the time I first showed her some of Brooks's pictures, back in 1912 , the thing $I$ have been living for has appealed to her imagination, and the years of our acquaintance have been marked by spacious courtesies. It is faith like hers which sweetens life and answers our questions as to the compassion of the Infinite.

"The Birds of California" was from its inception a coöperative undertaking. Few editorial ventures have ever owed so much to the spirit of good will and to generous "boosting" by disinterested friends. Brother scientists, fellow members of the Cooper 
Ornithological Club, prominent subscribers, leaders of social activity and of opinion, financiers, government officials, Audubonists, bird-lovers, artists, editors, photographers, collectors, and business associates - all have coöperated with most commendable efficiency to make the production of the work an accomplished fact. It is impossible even to enumerate the scores upon scores of well-wishers who deserve honorable mention. In making, therefore, partial acknowledgement of courtesies and debts of honor to those preëminent in service, I ask the indulgence of others not less generous, if unnamed. To the following ladies and gentlemen and institutions my most grateful acknowledgements are due: To Dr. Joseph Grinnell for sponsorship and every courtesy; to Mr. William E. Colby for faithful and otherwise unrewarded service as President of "The Birds of California Publishing Company;" to Messrs. Harry Swarth, H. IV. Carriger, F. E. Newbury, A. B. Howell, W. Lee Chambers, H. C. Bryant, and D. H. Schauer for services as trustees in that Company; to Messrs. W. Lee Chambers, A. B. Howell, H. W. Carriger, and H. S. Swarth for personal and professional coöperation of the most unfaltering type; to Messrs. Leverett M. Loomis, Frank S. Daggett, Barton W. Evermann, Donald R. Dickey, John Rowley, Harold C. Bryant, Tracy I. Storer, Joseph Dixon, L. E. Wyman, Wright M. Pierce, and Adriaan van Rossem for personal and professional courtesies of every sort; to Messrs. A. G. Vrooman, C. I. Clay, Fred Truesdale, Robert Canterbury, and William O. Dawson for valued assistance afield; and to the following for coöperation of every sort, financial, social and personal: Mr. John W. Mailliard, Mr. Joseph Mailliard, Mr. William H. Crocker, Mr. Henry E. Huntington, Miss Annie M. Alexander, Mr. Robert Oxnard, Mr. Rowland G. Hazard, Mr. E. P. Ripley, Dr. David Starr Jordan, Dr. Ray Lyman Wilbur, Mrs. Elizabeth Grinnell, Mrs. Robert J. Burdette, Miss Mary Foy, Mr. O. IV. Howard, Mrs. Harriet Williams Myers, Judge H. W. O'Melveny, Dr. Chas. IV. Browning, Mr. A. P. Redington, Mr. H. G. Chase, Mr. George S. Edwards, Mr. Joel Remington Fithian, Mrs. Lora J. Moore Knight, Miss Caroline Hazard, Mr. Reginald Fernald, Mr. Frank M. Selover, Miss Donna I. Youmans, Mr. George O. Knapp, Mr. John B. Henck, Mr. Bernhard Hoff mann, Mr. J. R. Pemberton, Mr. Frank C. Willard, Mr. O. P. Silliman, Mr. W. A. Strong, Mr. George W. Marston, Mr. John G. Howell, Dr. William Frederick Badé, Prof. Charles E. Kofoid, Dr. Ralph Arnold, Mrs. Agnes Allerton, Miss Aurelia S. Harwood, Miss Kate Ellen Walker, Mr. Frank H. Holmes, Mr. John Lewis Childs, Mr. A. C. Bent, Hon. Theodore Roosevelt, Dr. Henry Fairfield Osborn, Mr. P. B. Philipp, Mr. J. C. Harper, Mr. Curtis Hillyer, and Mr. Joseph M. Burnett.

Mr. Frank Stephens, whose name is deeply imbedded in the annals of ornithology in California, has done me the incomparable courtesy of placing his MS copy of a projected "Birds of California" at my disposal. I am indebted to it for many citations and for additional light upon desert species which this veteran authority knows better, perhaps, than anyone else.

My special thanks are due to Dr. Harold C. Bryant, of Berkeley, who because of his more extended acquaintance with them has prepared several of the articles upon the geese, and to Mr. Griffing Bancroft, of San Diego, who has kindly supplied the account of the Xantus Murrelet.

To my wife, Frances, I owe an unpayable debt of gratitude for unsparing devotion through the years to the task of manuscript preparation and revision, and, latterly, 
for assistance in press supervision. Only Mrs. Dawson's defiant modesty precludes the appearance of her name with mine upon the title-page, for though she disclaims an exact knowledge of birds (the dear lady still asks "Now was that the Bewick Wren?"when the Titmouse yodels), she really knows about all there is to know of the making of bird-books, and as for grammatical distinctions I am putty in her hands. The reader perceives our common good fortune.

To Miss Fedora E. D. Brown the author is indebted for artistic coöperation in the handling of prints, and to Mrs. Cornelia N. Shup for unusually able assistance in proofreading. Mr. Ray Bradfish is chiefly responsible for the art work upon the half-tones and for the designing of the bindings. His capable coöperation is deeply appreciated.

No publication, I believe, has ever enlisted a more competent and devoted allegiance of the printing trades and of their trained workers. The very office boys have wrought on this work for the glory of accomplishment. My thanks are due to the several firms which executed the project and to their always courteous managers. In especial, whatever credit of workmanly finish is accruing for the physical volumes is due to A. R. Warren, foreman of composition, Carl Seybold, "lock-up man," James Butters, foreman of color engraving, Mickey Ferguson, press foreman, John Griesinger. binding supervisor, and John Cairncross, to whom was entrusted the delicate task of "chopping up" half a million dollars' worth of printed forms into the single sheets required by our revolutionary system of binding. These have been the real "captains of industry," and their troops have been, without exception, both skilled and loyal.

It is the valued privilege of one who promotes the circulation of a subscription work to establish a more or less personal relation with his subscribers. In view of this may I be permitted to speak a direct and concluding word regarding the work itself and regarding the future of the science in California? "The Birds of California" is more elaborately conceived than any previous work upon birds in America. It will no doubt disclose the lapses and omissions incident to so complex an undertaking. Will the reader feel free to point these out, with any other suggestions which may occur to him, with a view to future improvement? Such improvement could only be possible upon the basis of continued and thoroughgoing coöperation. It is hoped, therefore, that the publication of "The Birds of California" may quicken and focalize interest in the birds of our most favored State, to the end that our knowledge of them may become more accurate and more extended, that our materials for bird portraiture may be more complete and more satisfying, and that the emphasis of our interest may be shifted once and for all from slaughter to appreciation. The author, therefore, invites all those who are seriously minded to realize these ends, to coöperate with him in the development and in the defense of all the interests which are dear to the science and to the art and to the understanding of BIRDS

IVILLIAM LEON DAIVSON.

Santa Barbara, November Ioth, I923. 


\section{Contents of Volume I}

PAGE

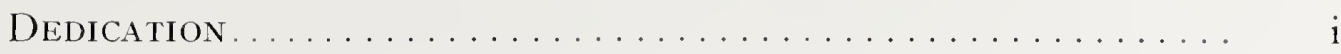

Preface..........................

Table of Contents ...................... xi

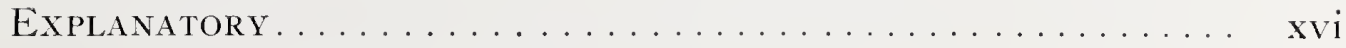

List of Full-Page Plates. . . . . . . . . . . . . . . . . xvii

Description of Species Nos. i-i 39

Order Passeres-Perching Birds.

Family Corvide-Crows and Jays.

I The Raven, Corvus corax simuatus................. I

2 The Western Crow, Corvus brachyrhynchos hesperis.......... I 6

3 The Clark Nutcracker, Nucifraga columbiana............. 23

4 The Pinyon Jay, Cyanocephalus cyanocephalus............. 28

5 The Black-billed Magpie, Pica pica hudsonia............. 3 I

6 The Yellow-billed Magpie, Pica muttalli............... 38

7 The California Jays, A phelocoma califormica............. 44

8 The Santa Cruz Jay, Aphelocoma insularis.............. 58

9 The Woodhouse Jay, Aphelocoma woodhousei............ 63

Io The Steller Jays, Cyanocitta stelleri................. 65

I I The Gray Jays, Perisoreus obscurus............... 70

Family Icteride-Troupials, American Starlings.

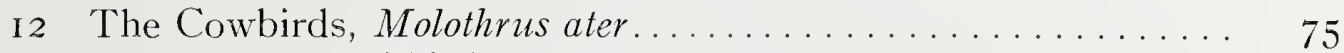

I3 The Rusty Blackbird, Euphagus carolinus............... 8 I

I4 The Brewer Blackbirds, Euphagus cyanocephalus........... 83

I5 The Arizona Hooded Oriole, Icterus cucullatus nelsoni........ 89

16 The Scott Oriole, Icterus parisorum . . . . . . . . . . . . . 93

I 7 The Bullock Oriole, Icterus bullocki................ 97

I 8 The Tricolored Redwing, Agelaius tricolor............... I 04

I9 The Red-winged Blackbirds, A gelaius phoniceus........... I I 4

20 The Yellow-headed Blackbird, Xanthocephalus xanthocephalus. I 24

2 I The Western Meadowlark, Sturnella neglecta.............. I 29

22 The Bobolink, Dolichonyx oryzivorus.............. I 36 
Family Fringillide-Sparrows.

23 The California Evening Grosbeak, Mesperiphona vespertina californica............................. I . . . . . . . . . . . .

24 The Red Crossbills, Loxia curvirostra.............. I 46

25 The California Pine Grosbeak, Pinicola enucleator californica. . I 52

26 The Sierra Nevada Rosy Finch, Leucosticte tephrocotis dawsoni $\quad$ I56

27 The Common Redpoll, Acanthis linaria linaria.......... I 78

28 The Pine Siskin, Spinus pinus.................. I 8 I

29 The Willow Goldfinch, Astragalinus tristis salicamans....... I 87

30 The Green-backed Goldfinch, Astragalinus psaltria hesperophilus ............................... I9I

3 I The Lawrence Goldfinch, Astragalinus lawrencei........... I9 197

32 The Cassin Purple Finch, Carpodacus cassini............ 20 I

33 The California Purple Finch, Carpodacus purpureus californicus............................... 208

34 The California Linnet, Carpodacus mexicanus frontalis....... 2 I 2

35 The English Sparrow, Passer domesticus............... 223

36 The Alaska Longspur, Calcarius lapponicus alascensis........ 228

37 The Chestnut-collared Longspur, Calcarius ornatus......... 230

38 The Lark Bunting, Calamospiza melanocorys............ 232

39 The Western Lark Sparrow, Chondestes grammacus strigatus... 234

40 The Vesper Sparrows, Poøcetes gramineus.............. 24 I

4I The Savanna Sparrows, Passerculus sandwichensis.......... 246

42 The Belding Marsh Sparrow, Passerculus beldingi.......... 256

43 The Large-billed Sparrows, Passerculus rostratus........... 259

44 The IVestern Grasshopper Sparrow, Ammodramus savannarum bimaculatus........................ 263

45 The Nelson Sparrow, Ammospiza caudacuta nelsoni.......... 266

46 The Rufous-crowned Sparrow, Aimophila ruficeps ruficeps..... 268

47 The Desert Sparrow, Amphispiza bilineata deserticola........ 273

48 The Bell Sparrow, Amphispiza belli............... 277

49 The Sage Sparrows, Amphispiza nevadensis............. 28 I

50 The Slate-colored Junco, Junco hyemalis. . . . . . . . . . . . . . 286

5I The Oregon Juncoes, Junco oreganus.... . . . . . . . . . . . 288

52 The Gray-headed Junco, Junco caniceps.................. 299

53 The Western Tree Sparrow, Spizella arborea ochracea........ 300

54 The Western Chipping Sparrow, Spizella passerina arizonce... 302

55 The Black-chinned Sparrow, Spizella atrogularis.......... 309

56 The Brewer Sparrow, Spizella breweri............... 3 I 2

57 The Harris Sparrow, Zonotrichia querula.............. 3 I5

58 The Golden-crowned Sparrow, Zonotrichia coronata........ 3 I 7 xii 
59 The White-crowned Sparrow, Zonotrichia leucophrys ........ 3 39

60 The Gambel Sparrow, Zonotrichia gambeli gambeli......... 326

The Nuttall Sparrow, Zonotrichia gambeli nuttalli........ 33 I

6I The White-throated Sparrow, Zonotrichia albicollis......... 335

62 The Song Sparrows, Melospiza melodia.............. 337

63 The Lincoln Sparrows, Melospiza lincolni... . . . . . . . . . . . 359

64 The Swamp Sparrow, Melospiza georgiana.............. . 365

65 The Fox Sparrows, Passerella iliaca................. 365

66 The Green-tailed Towhee, Oberholseria chlorura........... 386

67 The Spotted Towhees, Pipilo maculatus. . . . . . . . . . . . . . 390

68 The Abert Towhee, Pipilo aberti.................. 397

69 The Brown Towhees, Pipilo crissalis................ 4 . I

70 The Lazuli Bunting, Passerina amona............... 409

7 I The Beautiful Bunting, Passerina versicolor pulchra........ 4 I 2

72 The Blue Grosbeaks, Guiraca carulea............... 4 I 3

73 The Rose-breasted Grosbeak, Hedymeles ludovicianus........ . 4 I 7

74 The Black-headed Grosbeaks, Hedymeles melanocephalus..... . 4 I9

Family Tanagrida--Tanagers.

75 The Summer Tanagers, Piranga rubra.

76 The Western Tanager, Piranga ludoviciana............ 43 I

Family Mniotiltide-Wood Warblers.

77 The Black-and-white Warbler, Mniotilta varia............

78 The Tennessee Warbler, Vermivora peregrina............ 440

79 The Orange-crowned Warblers, Vermivora celata.......... 442

80 The Calaveras Warbler, Vermivora ruficapilla gutturalis...... 45 I

$8_{\mathbf{i}}$ The Lucy Warbler, Vermivora lucice................ 455

82 The Virginia Varbler, Vermivora virginice............. . . 459

83 The Yellow Warblers, Dendroica cestiva................ 460

84 The Magnolia Warbler, Dendroica magnolia............. 466

85 The Black-throated Blue Warbler, Dendroica carulescens ccerulescens........................... 468

86 The Alaska Myrtle Warbler, Dendoica coronata hooveri..... . . 469

87 The Audubon Warbler, Dendroica auduboni auduboni....... 472

88 The Black-throated Gray Warbler, Dendroica nigrescens... . . . 479

89 The Townsend Warbler, Dendroica townsendi............. 484

90 The Black-throated Green Warbler, Dendroica virens........ 488

9I The Hermit Warbler, Dendroica occidentalis............. . 490

92 The Chestnut-sided Warbler, Dendroica pensylvanica........ 495

93 The Palm Warbler, Dendroica palmarum palmarum......... 496 
94 The Tolmie Warbler, Cporomis tolmiei................ 497

95 The Oven-bird, Seiurus aurocapillus................ 50 I

96 The Louisiana Water-thrush, Seiurus motacilla.......... 502

97 The Alaska W'ater-thrush, Seiurus noveboracensis notabilis ... 503

98 The Yellow-throats, Geothlypis trichas.............. 504

99 The Western Chat, Icteria virens longicauda........... 5 Io

I oo The Wilson Warblers, Wilsonia pusilla............. 5 5 3

I I The American Redstart, Setophaga ruticilla............ 5 I 8

Family Iirundinida--Swallows.

I 02 The Mestern Martin, Progne subis hesperia............ 520

Family Hirundinida-(Continued)

I03 The Cliff Swallows, Petrochelidon albifrons............ 523

I 04 The Rough-winged Swallow, Stelgidopteryx serripennis.... . . 529

I 55 The Bank Swallow, Riparia riparia............... 533

I 06 The Barn Swallow, Hirundo rustica erythrogaster. . . . . . . 536

I07 The Tree Swallow, Iridoprocne bicolor............... 539

Io8 The Northern Violet-green Swallow, Tachycineta thalassina lepida........................... 543

Family Ampelide-Waxwings.

Io9 The Bohemian Waxwing, Bombycilla garrula pallidiceps..... 546

I Io The Cedar Waxwing, Bombycilla cedrorum ........... 550

Family Ptilogonatide-Silky Flycatchers.

I I The Phainopepla, Phainopepla nitens.

Family Vireonida-Vireos.

I 2 The Red-eyed Vireo, Vireosylva olivacea ............. . 563

I 3 The Yellow-green Vireo, Vireosylva flavoviridis............ 565

I 4 The Western IVarbling Vireo, Vireosylva gilva swainsoni. . . . 566

I 5 The Solitary Vireos, Lanivireo solitarius. . . . . . . . . . . 570

I 6 The Hutton Vireo, Vireo huttoni huttoni ............. 576

I 7 The Gray Vireo, Vireo vicinior................. 583

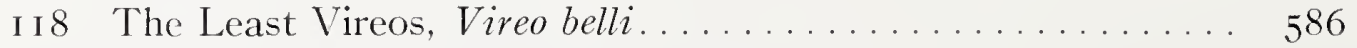

Family Laniida-Shrikes.

I 9 The Northwestern Shrike, Lanius borealis invictus. . . . . . . . 589

I20 The White-rumped Shrikes, Lanius ludovicianus.......... 59 I

xiv 
Family Paride-Titmice.

I 2 I The Plain Titmice, Baolophus inornatus............... 60 I

I22 The Oregon Chickadee, Penthestes atricapillus occidentalis... 607

I23 The Mountain Chickadees, Penthestes gambeli........... 6 I I

I24 The Chestnut-backed Chickadees, Penthestes rufescens...... 6 8

I25 The Verdin, Auriparus flaviceps flaviceps............... 623

I26 The Bush-Tits, Psaltriparus minimus.............. 628

I27 The Lead-colored Bush-Tit, Psaltriparus plumbeus........ 636

Family Sittide-Nuthatches.

I28 The White-breasted Nuthatches, Sitta carolinensis........6 638

I29 The Red-breasted Nuthatch, Sitta canadensis............ 643

I 30 The Pygmy Nuthatches, Sitta pygmaa............... 646

Family Certhiide-Creepers.

I3 I The Brown Creepers, Certhia familiaris........... 65 I

Family Troglodytide-Wrens.

I32 The Marsh Wrens, Telmatodytes palustris............. 657

I33 The Cactus Wren, Heleodytes brunneicapillus couesi........ 662

I34 The Bewick IVrens, Thryomanes bewicki............. 667

I35 The Western House Wren, Troglodytes aëdon parkmani...... 674

I36 The Western Winter Wren, Nanmus troglodytes pacificus...... 679

I37 The Rock Wren, Salpinctes obsoletus................ 683

I38 The Canyon Wrens, Catherpes mexicanus.............. 690

Family Mimide-Mockingbirds, Thrashers.

I39 The Palmer Thrasher, Toxostoma curvirostre palmeri....... . 694 


\section{Explanatory}

TABle OF CoMparisons

Millimeters

Inches

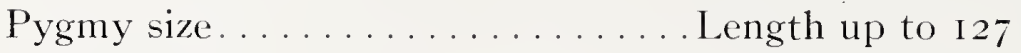
5.00

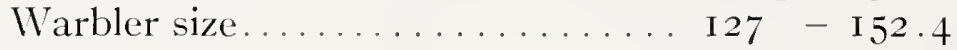
$5.00-6.00$

Sparrow size............... I $52.4^{-}$I 90.5 $6.00-7.50$

Towhee size................ I90.5-228.6 $7.50-9.00$

Robin size................ 228.6-304.8

$9.00-12.00$

Little Hawk size, Teal size, Tern size $304.8-406.4$ I $2.00-\mathrm{I} 6.00$

Crow size................ 406.4- 558.5 $16.00-22.00$

Gull size, Brant size.......... 5 558.5- 762

$22.00-30.00$

Eagle size, Goose size........... 762 -1066.8 $30.00-42.00$

Giant size.............. I066.8 and upward

Measurements are given in millimeters and in inches, the latter enclosed in parentheses.

xvi 


\section{List of Full-page Color Plates}

FACING PAGE

Western Meadowlark. Frontispiece

California Jay ............................ 44

Bullock's Oriole............................. 98

Sierra Nevada Rosy Finch. ................... I56

Audubon's WARBLER . . . . . . . . . . . . . . . . . . . 472

Violet-Green SWAllows. . . . . . . . . . . . . . . . . 542

Cactus Wren. . . . . . . . . . . . . . . . . . . . . . 662 



\section{The Birds of California}

No. 1

\section{Raven}

A. O. U. No. 486. Corvus corax sinuatus Wagler.

Synonyms.- Western Raven. Mexican Raven. American Raven.

Description.--Color, uniform lustrous black; plumage, especially on breast, scapulars, and back, showing steel-blue and violet, or purplish, iridescence; feathers of the throat long, narrow, pointed, light gray basally; primaries whitening at base. Bill and feet black; iris brown. Length, two feet or over; female a little smaller; wing 406-457 (I6.00-I 8.00); tail 233 (9.I7); bill 65-80 (2.56-3.I5); depth of bill at nostril 25.4 (I.00); tarsus 68 (2.68).

Recognition Marks.- - Large size,--more than twice the bulk of a Crow; long, rounded tail; harsh croaking notes; uniform black coloration.

Nesting.- Nest: a mass of sticks deeply hollowed and lined with wool or hair plucked from carcasses; placed in cranny of cliff or ledge, or, rarely, in trees. Eggs: 4-7, light bluish green (lichen green), spotted and marked or blotched (rarely streaked longitudinally) with olive or dark olive (or with deep olive and citrine drab dilutions) and, rarely or sparingly, with vinaceous gray. Specimens vary from those nearly immaculate to those nearly buried under pigment; but they average lighter than Crows' in respect to quantity of pigment. Av. of 56 eggs in the collections of the Museum of Comparative Oology, taken in San Luis Obispo County, 47.5 x 32.3 (I.87 x I.27); index 67.9. Range 4I.7-55.8 (I.64-2.I 8) x 28.5-34.5 (I.I2-I.36); indices 59-76. Av. of 42 eggs in M. C. O. colls. taken on Santa Cruz Island, $48.5 \times 32$ (I.9I x I.26); index 66. Range 45.5-56.6 (I.79-2.23) x 29.7-34 (I.17-I.34); indices 57-7I. Season: April, one brood.

Range of Corvus corax.-North America, Europe, Northern and Central Asia.

Range of $C$. c. sinuatus. - The Western United States except the Northwest Coast district, south to Central America.

Range in California.-Resident but wide ranging, hence, of casual occurrence nearly throughout the State; common or abundant locally. The chief centers of distribution are the semi-arid interior coast ranges of south-central California, the larger islands, and the northwestern humid coastal strip. Rare or wanting in the high Sierras and almost disappearing from the more thickly settled regions. 


\section{The Raven}

Authorities.-Gambel (Corvus cacalotl), Proc. Acad. Nat. Sci. Phila., vol. III, I 847 , p. 203; Heermann, Rept. Pac. R. R. Surv., vol. X, pt. VI, I 859, p. 54 (habits); Linton, Bull. Cooper Orn. Club, vol. I, I 899, pp. 68-69 (nest and eggs); Willett, Pac. Coast Avifauna No. 7, I912, p. 68 (status in So. Calif.; crit.); Dawson, Condor, vol. XVIII, 1916, p. 28 (status in Calif.); Howell, Pac. Coast Avifauna, No. 12, 1917, pp. 69-7I (critical; measurements; nesting habits on coastal islands).

IN THE Raven we behold not alone the ranking member of the order Passeres, but the most highly developed of birds. Quick-witted, cunning, and audacious, this fowl of sinister aspect has been invested by peoples in all ages with a mysterious and semi-sacred character. His ominous croakings were thought to have prophetic import, while his preternatural shrewdness has made him, with many, a symbol of divine knowledge. Primitive man, especially, felt the spell of his somber presence, and the Raven was as deeply imbedded in the folklore of the maritime Grecian tribes and of the hardy Norsemen, as he is today in that of the Haida Indians of Alaska or the Zuni of New Mexico.

That our own Indians held the Raven in the highest reverence is evidenced by the following curious fragment, attributed to Father Torquemada. 'The place is "the island of St. Catherine' [now Santa Cruz Island?], and the time about the middle of the Eighteenth Century. The Spaniards are visiting a heathen temple on the then populous island, where birds are sacrificed in great numbers to "some devil.",

"It happened that when the foldiers came to fee this temple, they found within the faid circle, two crows, confiderably larger than ordinary, which at the approach of the Spaniards flew away, but alighted among the rocks in the neighborhood. The foldiers feeing them of fuch uncommon fize, fired their guns and killed them. At this, an Indian, who had attended the Spaniards as a guide, fell into an agony. I was informed that they believed the devil fpoke to them in thefe crows, and thence held them in great veneration. Sometime after, one of the foldiers going that way, faw fome Indian women wafhing fifh on the shore, but fome crows came up to them, and with their beaks, took the fifh from their hands, whilst they observed a profound filence, not daring fo much as to look at them much lefs frighten them away. Nothing therefore could feem more horrible to the Californians, than that the Spaniards fhould fhoot at thefe refpectable birds."

Although confined now to the wilderness and the waste places, where his persistent misconduct has exiled him, the Raven is still in a sense the dominant bird of the Northern Hemisphere. No other bird, unless it be the regal falcon, successfully disputes his sway; and wherever

'By John Trusler in "The Habitable World Described," pub. 1788-1795. See Daggett in "The Condor," vol. X p. 135-137, July, 1918. 


\section{The Raven}

he deigns to dwell he becomes the bete noir, the sable satanic ruler, of the bird-world. In man alone has the Raven met his match; and the story of the eternal conflict between man, the supreme of the mammalian line, and Carava, the dusky apex of the avian succession, if it could be told. would afford some of the most thrilling chapters in the history of animal psychology.

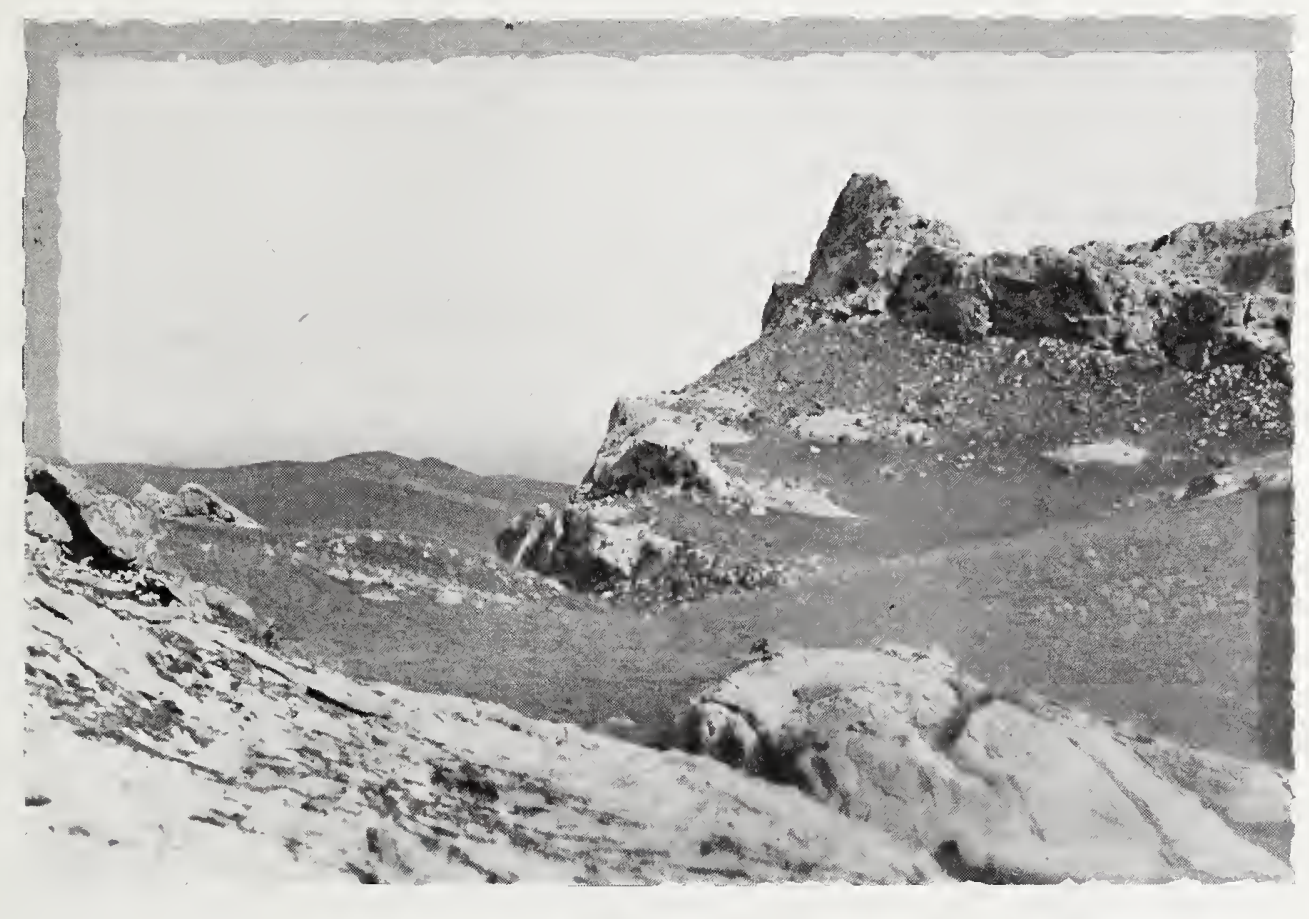

Taken in Kern County

Photo by the A uthor

THE RAVEN'S FIEF

The ancient occupation of the earth by this sable master is evidenced in part by the geographical races, some twenty in number, into which the virtually uniform and really implastic species, Corvus corax, has been divided. The differences recognized are chiefly those of size and of the relative proportions of beak and claw, according as the environment of the bird has made greater or less demands upon its hardihood and prowess. A host of the Raven's lesser brethren, crows and choughs and rooks, and what not, occupy pretty much the same territory, and they extend the corvine domain well over the southern hemisphere, save that no member of the genus is to be found in South America. In California, as elsewhere, southern examples of the Raven evince a ten- 


\section{The Raven}

dency to diminution of size, especially in case of the languid birds of the Santa Barbara Islands. ${ }^{1}$

In appearance the Raven presents several points of difference from the Western Crow, with which it is popularly confused. The Raven is not only larger, but its tail is relatively much longer, and the end of it is fully rounded. The head, too, is fuller, and the bill proportionately stouter, with a more rounded culmen. The feathers of the neck are more loosely arranged, resulting in an impressive shagginess; and there is a sort of primitive uncouthness about the entire appearance of these ancient birds, quite in contrast with the unctuous sleekness of the dapper crows.

Not even the Crow is fastidious in diet, but the Raven indulges propensities of appetite which have justly marked him an outlaw. Frequenting, as he does, the waste places of the earth, there are two situations, or ranges, which the Raven especially affects, the rugged portions of the seacoast and the cattle ranges of the interior (now, alas! largely transformed into sheep ranges). In the former situation the Raven subsists upon insects, shell-fish, and cast-up offal, together with those main staples of spring and summer, the eggs and young of birds. On the cattle ranges carrion becomes the staple of diet, or, in default of this, the birds eat insects, frogs, lizards, and to some extent, no doubt, the smaller mammals. The eggs and young of all ground-nesting and cliffhaunting birds are diligently sought for. The lake borders and interior marshes throughout the State suffer from the daily depredation of these patient marauders. In the pursuit of their nefarious trade the Ravens will endure almost any punishment of beak or claw, and the only limit to the mischief wrought would appear to be the corvine capacity.

Much stress has been laid elsewhere upon the destruction by Ravens of young and sickly stock - calves, lambs and pigs. There is little complaint of this in California. Whether the birds are better fed or better bred, I am unable to say. But at that, I have no doubt that in time of famine the exit of dying animals is often hastened by greedy Ravens. Whether dead or only dying, the victim may expect the first determined attack upon the eyes, for these the ghouls regard as their choicest perquisites. Poultry is sometimes laid under tribute, and isolated chicken ranches may suffer severely through the loss of young chickens. On the other hand, some Ravens appear to realize that they are being put upon their good behavior. Bendire records instances where they have shared commons with the chickens without offering them any indignity.

But to call these island birds clarionensis, as some have done on the strength of their likeness to a single specimen taken off the coast of Mexico, some thousand miles away, seems the height of absurdity. As a matter of fact, looking taken off the coast of Mexico, some thousand miles away, seems the height of absurdity. As a matter of fact, looking out of the window of Caire's slaughter house on Santa Cruz Island, I have seen some "sockdollagers," which I would
match against principalis himself. (Vide Ridgway, Birds of N.\& M. A m. vol. II. p. 265. Also cf. Bishop, "Condor," XVII., No. 5, Oct. 10, 1915, p. 186.) 


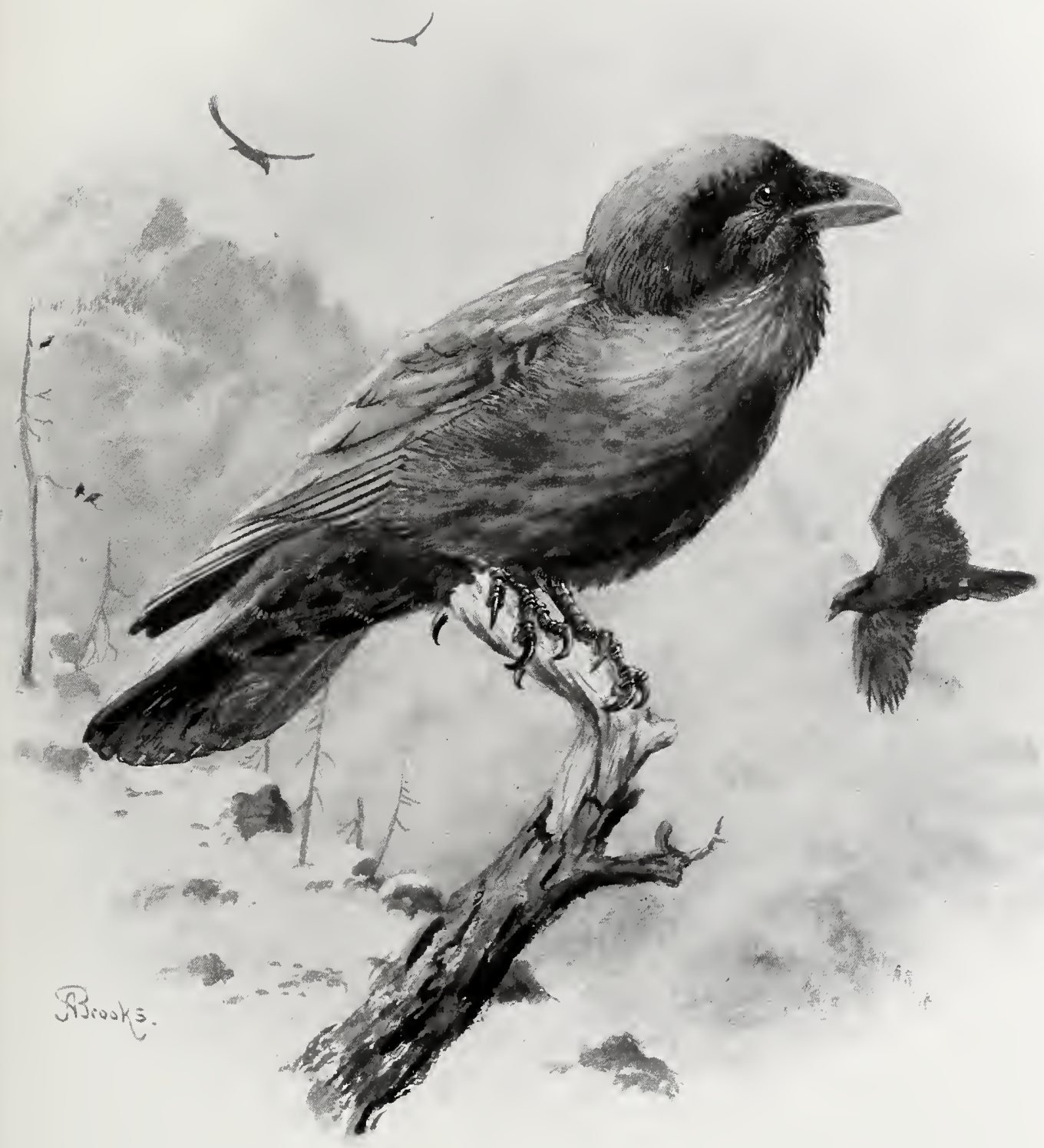

THE NORTHERN RAVEN 


\section{The Raven}

That Ravens display great sagacity in their quest of food is well known. Once in the Cholame country I lugged my photographic apparatus for a mile under a grilling sun to photograph a Killdeer's nest with four eggs, which I had located on the previous day. Only a little spilled yolk and empty shells remained. Then I recalled having seen, on the occasion of my former visit, a pair of Ravens circling high overhead, at least a quarter of a mile away. The birds could not possibly have seen the Killdeer's eggs at that range; but they heard the distress cries of the Killdeer, and they knew that there was something doing in their line. And at that, the crafty Ravens had retired until the coast should be entirely clear. "We never forget,' is the motto of Pinkerton Raven. Many observers testify that Ravens will take unopened clams to a considerable height and let them fall upon the rocks in order to smash them open. Beebel tells of a Raven in South Africa which, upon discovering an exposed ostrich nest, will hurry off for a stone, and returning, will drop it accurately from such a height that a feast of ostrich egg souffle is immediately assured.

As Bendire testifies,2 "Ravens are stately and rather sedate-looking birds. * * * On the ground their movements are deliberate and dignified; their walk is graceful and seldom varied by hurried hops or jumps. They appear to still better advantage on the wing, especially in winter and early spring, when pairs may frequently be seen playing with each other, performing extraordinary feats in the air, such as somersaults, trying to fly on their backs, etc. At this season they seem to enjoy life most and to give vent to their usually not very exuberant spirits by a series of low chuckling and gurgling notes, evidently indifferent efforts at singing." In my experience these springtime excesses are oftenest displayed in company. As is well known, the Raven remains mated for life. The companionship of his mate is quite sufficient for him, and the Raven usually shuns the society of his fellows. But in early springtime it is different. The social instinct overcomes both sexes alike. Besides that, vows must be redeclared, even though acceptance be assured. And how could the dutiful wife know that her hubby was keeping up with the procession unless he proved himself out in the lists annually, doing stunts with the other fellows? Anyhow, the court of Venus is set up every year in the neighborhood of some beetling seacliff, or before some huge monument of sandstone in the cattle country. One who has been privileged to see a Raven circus in session feels as though he had caught the Olympians at a backyard frolic. Dignity is thrown to the winds, and sable seigneurs don cap and bells, while prim

1"The Bird" by William Beebe; p. 158. 


\section{The Raven}

ladies do aerial skirt dances amid the debris of metaphorical champagne bottles.

One such Mardi Gras I witnessed on the I8th of February, I9I3. The rendezvous was the picturesque sandstone knob near Chatsworth. Ravens to the number of thirty-three joined the merry rout, and I watched their performances, a breathless Tam o' Shanter, for as much as two

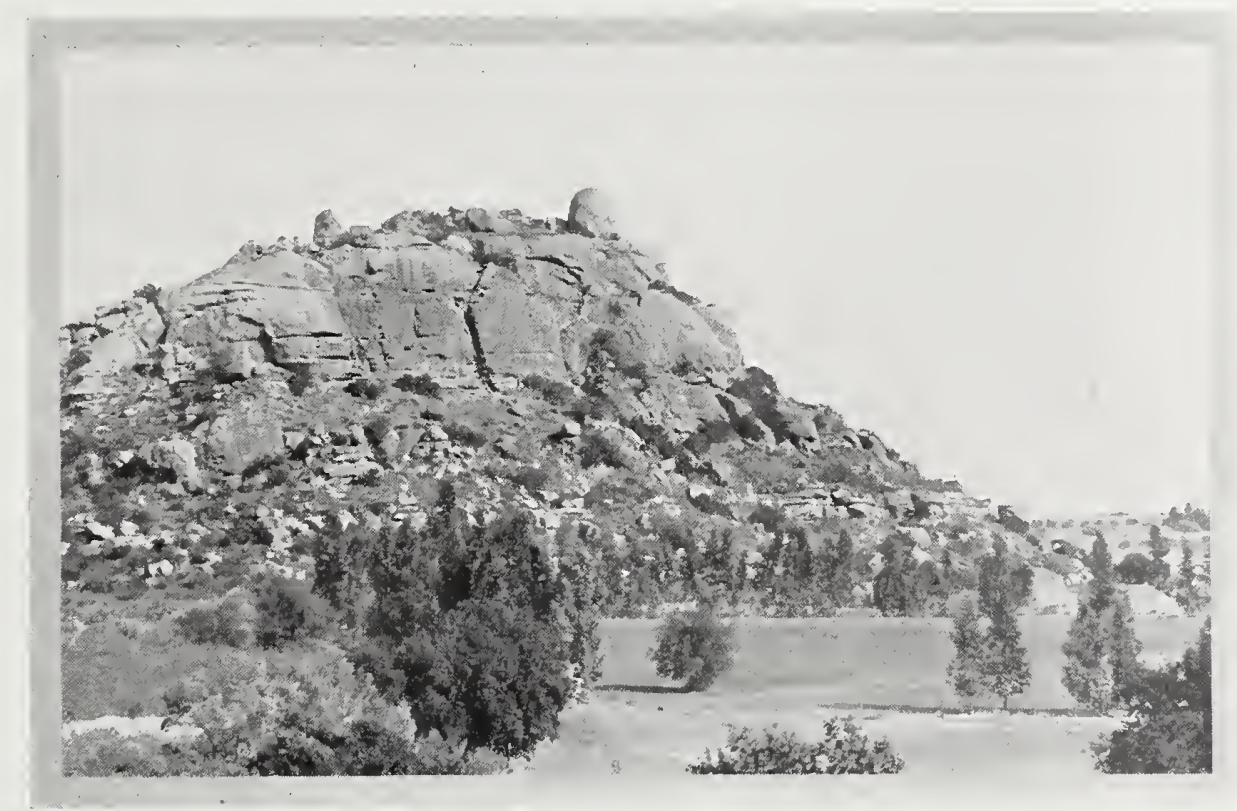

Taken in Los Angeles County

THE SPRING RENDEZVOUS NEAR CHATSWORTH

hours. What to the naked eye would have passed as rather meaningless evolutions, stood revealed under the eight-power binoculars as most superb aerial tactics. Stalls and nose-dives and Immelmann turns were interspersed with friendly bouts, mock chases, and figure flights by twos and threes. Outlandishness was part of the game; and a favorite stunt consisted of falling slowly with uplifted wings and legs down-stretched to their ridiculous utmost. Others tumbled as though they had been set spinning by some heavenly catapult; while others still engaged in spirited fisticuffs - all in a friendly spirit, apparently - whose intricacies of evolution are still beyond our returned heroes of the Western Front. A pair of Red-tailed Hawks, who claimed rightful ownership of this same ledge, were set upon playfully, or with great show of bravado. Usually two Ravens would join in the pursuit of a single Redtail. But the hawk took their attentions indulgently, much as a college president might a bevy 


\section{The Raven}

of hilarious freshmen. And ever and anon came the deep hunger oope cry, interspersed with many sharp, crow-like caws. One mellow note, which might have been purely individual, reminded me strikingly of the callnote of the Sandhill Crane.

Best of all was the game of tag [No, this is not nature-faking; I had

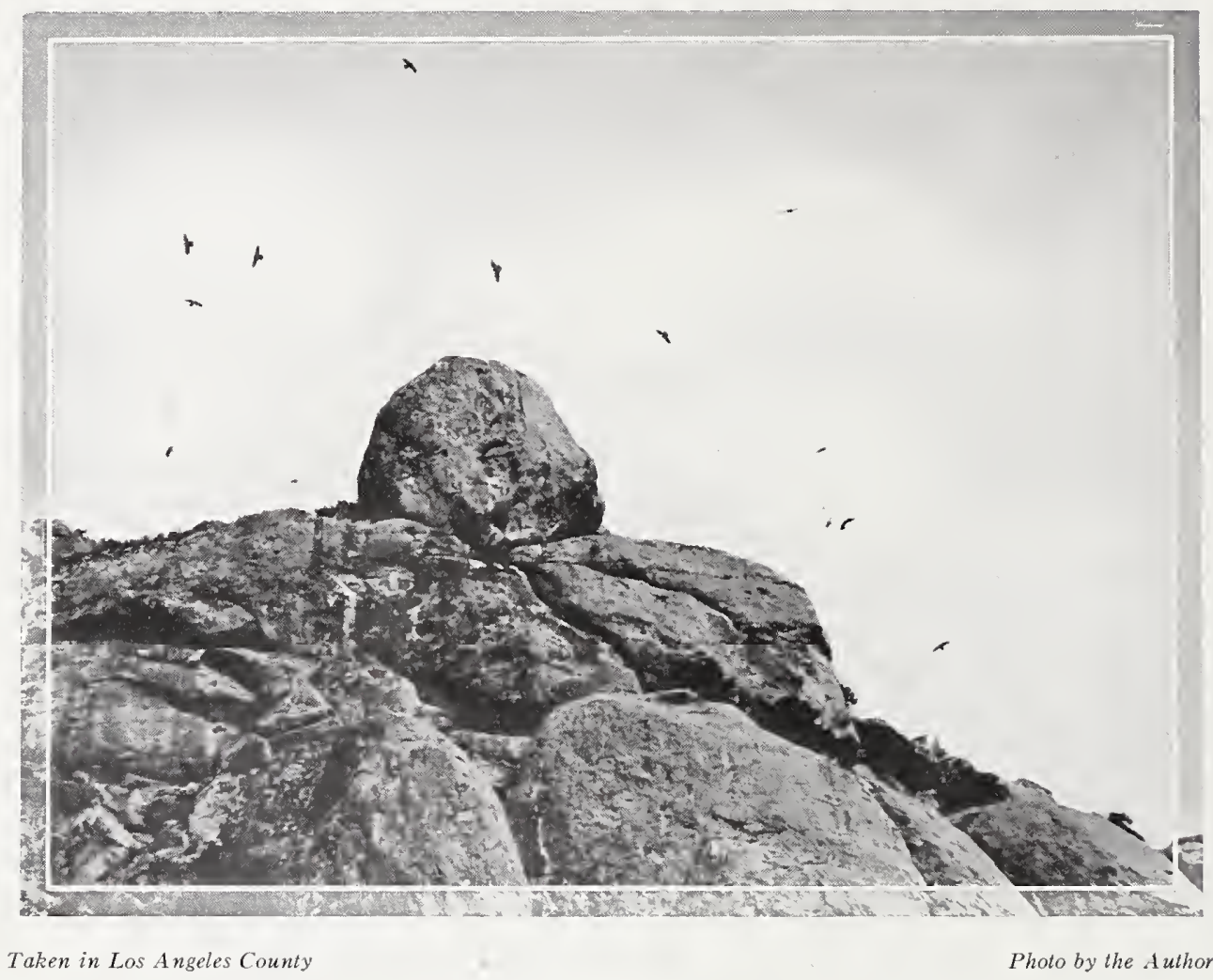

RAVENS AT PLAY

8-power binoculars]. One bird appeared with a yellow something in his talons; it might have been cheese, but probably it wasn't. The owner did not seem to want to eat it, for he courted pursuit by coming back ever and again close to the appointed tag-post. Finally, another bird did succeed in getting "it" away from him, though whether it was snatched from below or peacefully surrendered, I could not tell. At any rate, the new possessor was much more skilled than the old one, and he ventured a succession of acrobatic feats with his bauble. First he would drop it from his beak, and seize it with his claws the next instant. After carrying the object about in his claws for a while, he would reach under and seize it in his beak again-and all this time some other bird 


\section{The Raven}

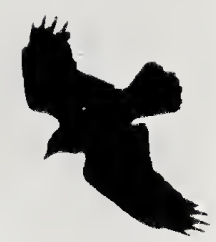

was making frantic efforts to get it away from him. Finally, in a scrimmage the ball was dropped and, though several birds dived after it, when it became evident that it would reach the ground first, no further effort was made to regain it.

After this I witnessed an aerial minuet by two gifted performers, - a tumbling contest, wherein touching hands (wing-tips), with one bird upside down, was varied with simultaneous somersaults and graceful upright, or stalling, presentations. Altogether it was a sight for the gods, and it gave one a new opinion of these erstwhile sullen and funereal bird-people.

Concerning the notes of the Raven, it is quite certain that a volume might be written; for this most intelligent bird succeeds in communicating his emotions very fully, at least to his mate. Yet for all the centuries of association, no discriminating ear has seriously analyzed the Raven's notes; or if so,

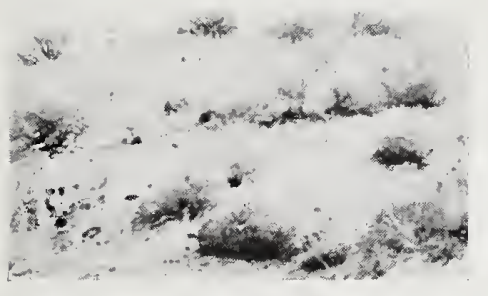

Photo by the Author

HURRYING OFF TO JOIN THE FUN no record has been left. Nor does the author feel competent to carry the attempt beyond the most casual sketch. Croak is the imitative word used oftenest to characterize the note of the Raven; but perhaps krawk would hit it more nearly. The note is, however, of great individual variety, whether uttered singly or in twos or threes, in accordance with the degree of emotion present in the bird; thus: krawk, or quawk quawk, or hawk hawk hawk. On any reckoning, it is a sonorous and gruesome sound - almost majestic. Any of these notes, by the way, may be easily recalled to memory (though not, of course reproduced in volume) by a snoring sound accomplished on an intaken breath. The notes themselves may, therefore, be properly described as stertorous. For song, the Raven offers a curious, mellow, hunger-o'ope, accompanied by an earnest bobbing of the foreparts. This utterance is closely imitated, or exactly parallelled, by the Crow (C. brachyrhynchos); and to my mind is, in turn, associated with the delar'y cry of the Eastern Bluejay (Cyanocitta cristata). In other words, it is of familiar rather than merely 


\section{The Raven}

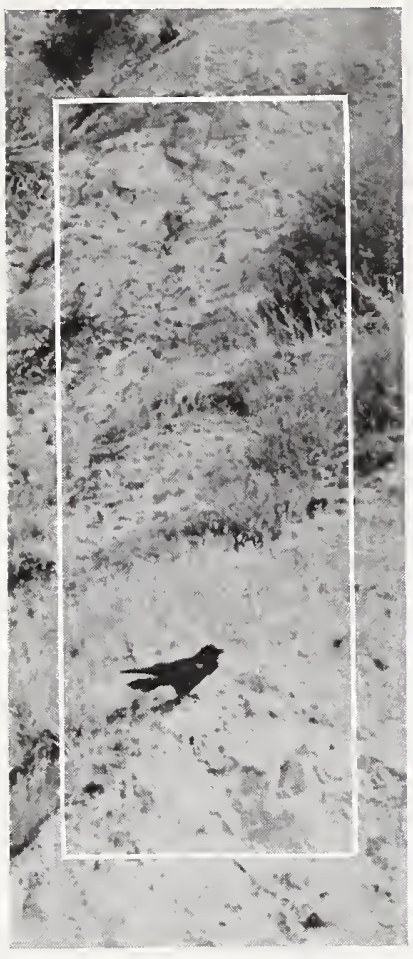

Photo by the Author

REGARDANT

individual significance. Look' looit, look' looit is another phrase I have often heard from birds under surveillance, but its precise meaning I never could make out. An alarm note used by a leader on the rare occasions of assembly is co co cawk', and this is promptly caught up and repeated by certain others, as though it were an order given by a colonel. Lastly, there is the low kut'ty kut'ty, or chut'to chut'to, a sound of deep disgust, possibly profane, with which a sitting bird quits her nest, upon discovery.

Of the nesting of the Raven a separate volume might be written, a romance of the wilderness. For, as the Raven's croak is the authentic voice of the wilderness, so is his nest its rightful citadel. To be sure, the pressure of civilization has brought the proud bird to some sorry passes. An observer in $\mathrm{Utah}^{1}$ tells of a pair of Ravens which nested on a railroad bridge; and I once found a nest in a deserted barn. This last, by the way, was of special interest because of a generous use of beef-ribs in the substructure. But cliffs are the Raven's proper home, and the further removed these are from the madding crowd, the better she likes it.

In seeking out the wild canyons and the "breaks" of semi-arid foothill ranges, the Raven finds himself, willy nilly, in close association with the Prairie Falcon (Falco mexicanus). This association must be the result of more than accident, for in a wide country I have found nests of more than a dozen paired couples, Falcons and Ravens, each placed within a few rods, or within a quarter of a mile at most, of the nest of the complementary species, and that although intervening canyons galore went unoccupied. On the whole, I am inclined to think the Prairie Falcon the offender. Coveting the more watchful guardianship of the Raven, the Falcon waits until the Ravens have indicated their choice of a nesting site for the season, and then heaves to in a neighboring cranny. Guarded by the trusty black sentinel, who never allows a stranger to approach his own nest unwarned, the Falcon despatches her chuckling mate to distant pastures, and puts her mind at ease as she settles to her eggs.

The Raven is true to his trust, but he cannot, of course, repel the

${ }^{1}$ H. C. Johnson, "Condor," Vol. 1, p. 72. 


\section{The Raven}

invading oologist. Perhaps this is why the unreasoning Falcon sometimes falls upon her neighbor Ravens so unmercifully when her own nest is threatened. Nowhere else in the bird-world have I seen such spirited encounters, or any where character shone out so clearly as in those between Hawk and Raven. One such I recall in particular. Having found a Raven's nest commanded by a facing bank, I planted myself opposite for photographic purposes. Warned by her mate, the sitting bird had stolen from her nest unseen, and the pair of them had been playing hide-and-seek with me ever since. Now and again one of them would sail over the hilltop, glance downward, and circle back. Or, again, I would descry them both down the valley, wheeling majestically, as is their wont, in paired flight, with stiff parallel wings, their bodies being mantained at a distance of about two feet. Their hearts were in the nest, no doubt, but their visible anxieties were greatly restrained by the petulant dashes of a Prairie Falcon who, some six numbers up the narrow canyon street, was dreading the hour of her own visitation. As often as the Ravens did venture near, the Falcon fell upon one or the other of them with raucous voice and eyes ablaze. In the rout which followed, the terror of the sable birds was evidenced not alone by the celerity of the pursued one, but by the distress cries of its anxious mate. As for the chasee, he (or she) never had time to " holler." I tried desperately to get a snapshot of one of these encounters, but the scene of battle shifted so rapidly, or was so often carried below the horizon line, that it proved quite baffling. Once I did press the button at close range, but that time the onslaught was so terrible that the birds passed off the plate in about one tenthousandth of a second, and they swept by within twenty feet of me with a noise like ripping canvas.

But at that I never saw a Raven hurt! For the Raven is not only

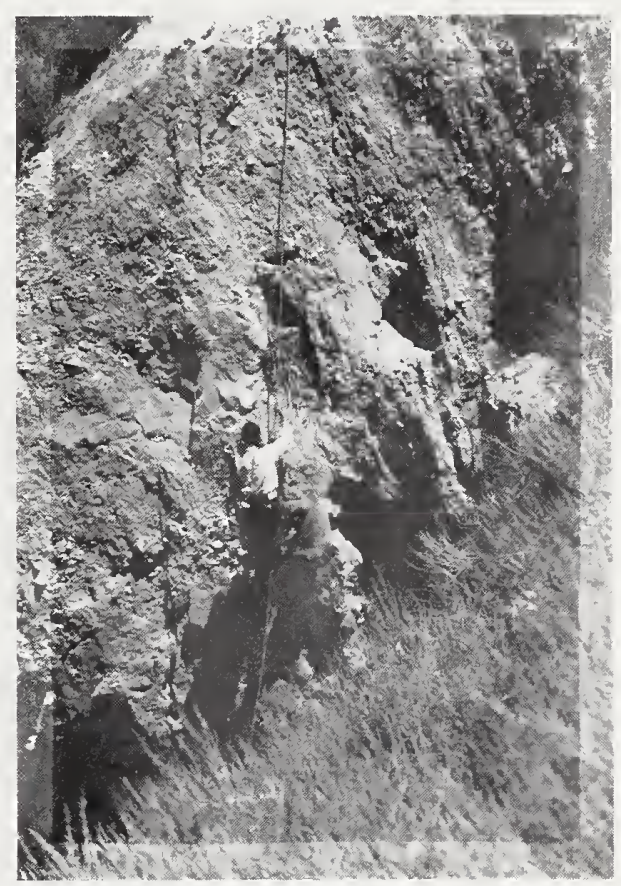

Taken in San Luis Obispo Counly

Photo by the Author

A SHORT SCRAMBLE

FRED TRUESDALE ON DUTY 


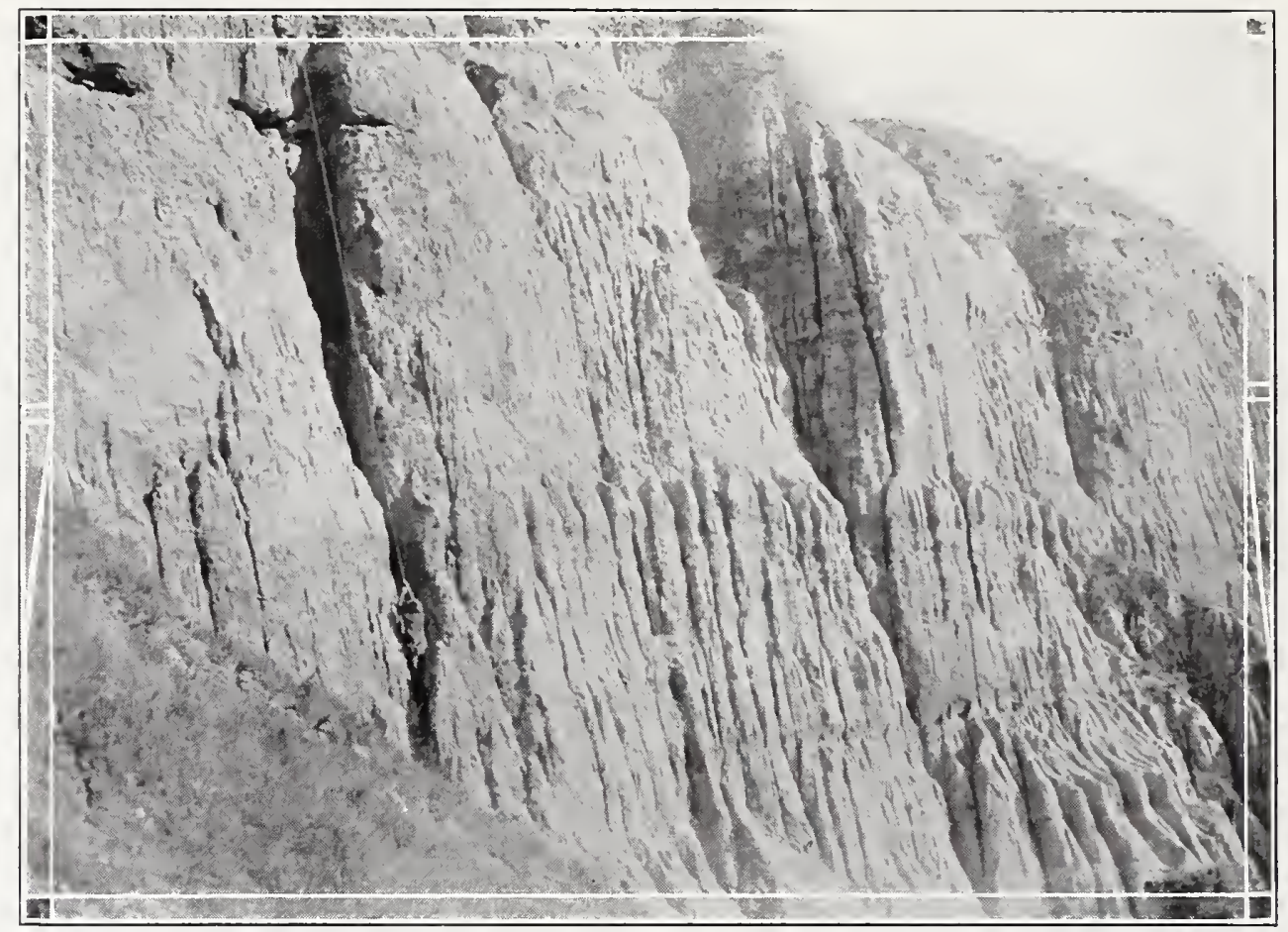

Taken in San Luis Obispo County

Photo by the Author

A LONG HAUL

THE NEST APPEARS ABOUT MIDWAY OF THE CRANNY

passed master of the art of flying, but he is an ace of aces for coolness. At the critical moment, by a dexterous side flip, too subtle for explanation, he always manages to avoid the fatal stroke. It is the supreme test of skill, and it is doubtful if any other bird could meet it. Lacking weapons of defense, such as, for example, the Redtail possesses in his big talons, it is no joke to meet an angry Falcon in midair. Our hero is playing with death, and he knows it.

A typical nest of the Raven is placed midway of some rock ledge, unapproachable save by rope either from above or below. If the recess in the wall is not shaped just to convenience, it must be filled level with crisscrossed sticks lodged at haphazard against the cranny's sides. In the top a relatively deep hollow is fashioned, and this bowl is lined with every soft substance available, basally with roots and shredded bark, interiorly and very bulkily with animal coverings, chiefly those reft from carcasses-horsehair and cowhair with hide adhering, or wool in great masses. Strips of cloth gleaned from deserted camps, tattered canvas, 
frayed rope-ends, anything, no matter how filthy, which promises elasticity, is pressed into service. The result is unsanitary and highly offensive to the nostrils; and as if this were not enough, the sitting bird drenches the whole recklessly with its own excrement, making of it a veritable abode of harpies.

Eggs to the number of five or six, rarely seven, are deposited, and these are singularly frail as to shell structure. Many eggs are dented, either by rough contact with their mates, or else by the impact of gravel showered down the face of the nesting cliff. In most full-sized sets there are one or two eggs notably lighter in color than their mates, and these are definitely known to be either the first or the last laid, sometimes one and sometimes the other, showing that the period of maximum pigment supply is not strictly coincident with the period of egg deposition.

The youngsters when hatched, and for a week or two thereafter, are exceptionally ugly, being sinfully naked, and of a nondescript greenish yellow and brownish color, with red mouth-linings. This latter point is always worth mentioning, for a touch on the nest of a food-laden parent is always taken as an order, Present mouths! And the display

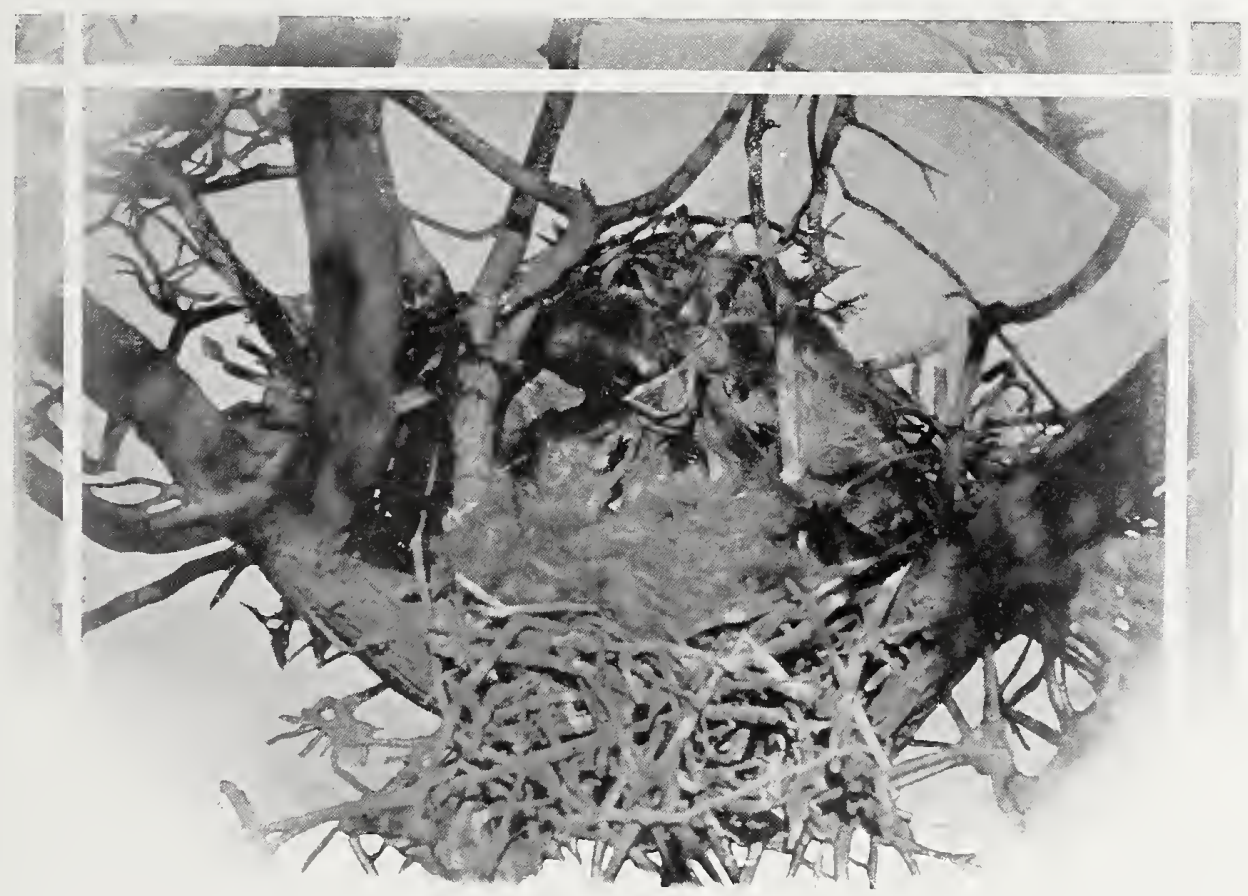

Taken in San Luis Obispo County

Photo by the A uthor

THE RAVEN'S BROOD THE BIRDMAN CRAMMED A WAIF (AND UNGUARANTEED) QUAIL'S EGg INTO THIS EXPECTANT MAW. THE RESULT WAS
HIGHLY SATISFACTORY 


\section{The Raven}

of red flannel thereupon ensuing is faultless from a technical standpoint.

April is the nesting month for Ravens in coastal California, but interior breeding ranges come on earlier, in February even. In ranges subject to considerable persecution, or, let us confess, oological attention, the Ravens learn to avoid the habitual season. On one famous trip, April I0-20, I9I6, through country much "shot over," we located nineteen pairs of Ravens. Of these, five pairs loitered over unfinished nests, six boasted young in various stages up to the flying point, and from the lot we gleaned only two perfect sets of fresh eggs. We felt, clearly, that we were being outwitted by the birds, and especially when one of them fled scornfully from a tree-top, a white oak, in which she had hidden

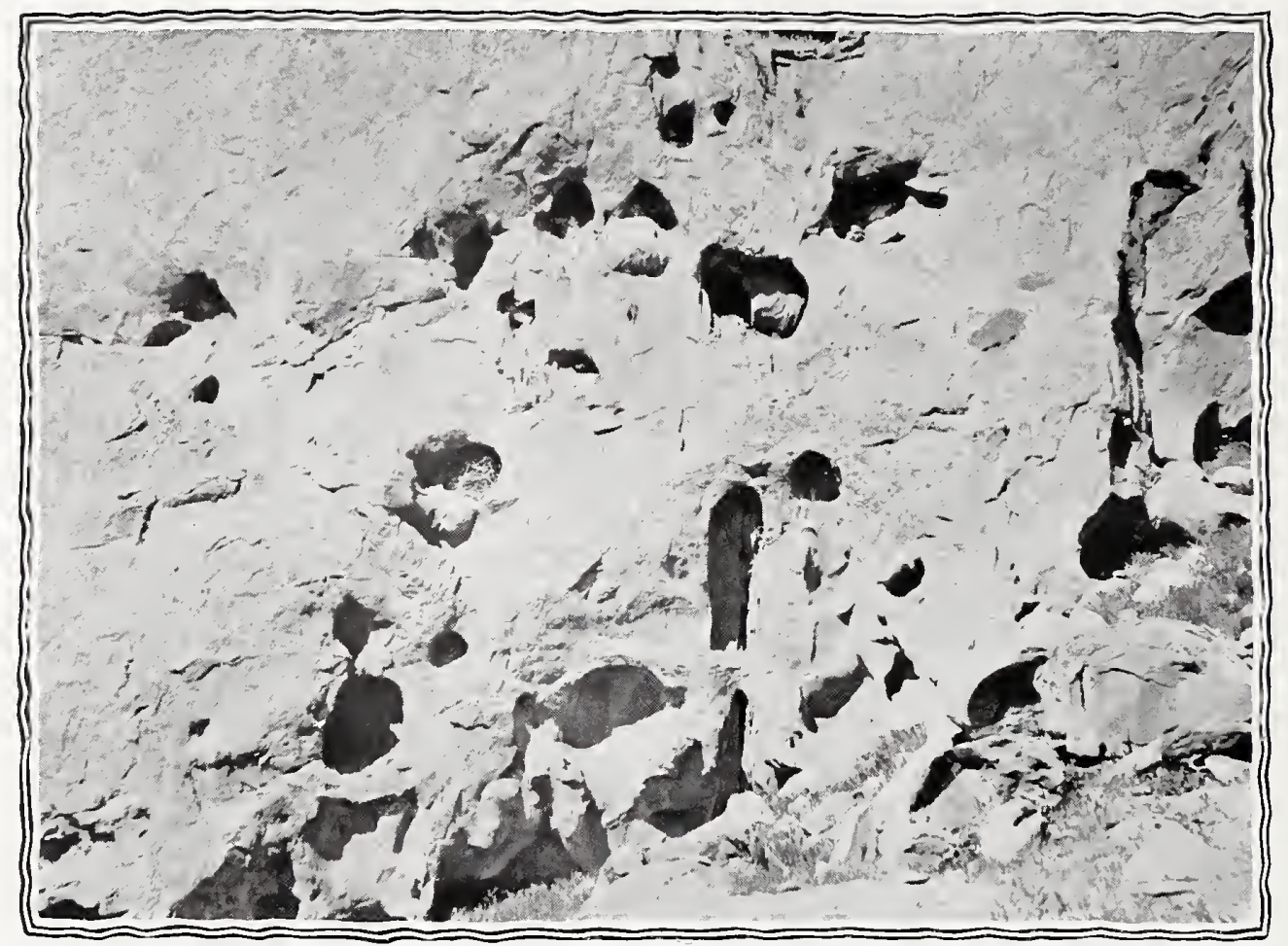

Taken in Kern Counly

Photo by the Author

"THE COLUMBARIUM"

FALCONS AND RAVENS HAVE NESTED IN THESE CRANNIES FOR AGES

a nestful of babies. In an experience covering some scores of nests, this was the only example of a tree-nesting Raven. I am told, however, that they do nest in trees in Mendocino and Del Norte Counties, where they are also exceptionally common. 


\section{The Raven}

The Raven's reputed wit failed him, however, in another instance recorded during the same season of I9I6. We were working in the juniper country west of the Carriso Plains, and we noticed a pair of birds engaged about a low cliff at the head of a small spur canyon. I watched them through binoculars as they brought several sticks to a certain point on the ledge. Investigation disclosed an astonishing condition of affairs. The daffy birds had been trying to lodge the foundations of a nest in a small sloping crevice where any sort of lodgment was practically impossible. As a result every stick had fallen, in its turn, until a pile six feet in diameter and not less than two feet high lay at the bottom of the cliff-two hundred pounds weight of wood, and not a mud-sill to the good yet! And about forty feet along under the same cliff was another stick pile, evidently the accumulation of the preceding season. These birds were obsessed with the determination to occupy this cliff whether or no, and had gone childless for two seasons! Manifestly a case for the alienist.

Of the Raven as a captive a separate volume might be written. When we shall have recovered somewhat from our present excessive devotion to protectionism, we may avail ourselves again of the unending interest which attaches to the study of the psychology of birds at close range. No fitter subject could be found than the Raven. Cunning, agile, adroit, and intensely mischievous, a Raven brought up by hand is, nevertheless, capable of a considerable affection. He is reputed a good talker, albeit with speech of a certain muffled quality, due no doubt to the "depth" of his voice. Having, like the Crow and the Magpie, an incurable fondness for bright articles, as well as a destructive disposition, he cannot be allowed to run at large; nor, indeed, to be caged with smaller birds. No one, therefore, ought to undertake the task of rearing a Raven who is not prepared to give it abundant cage room, and to profit fully by the opportunity for psychological study thereby afforded. For the rest, the Raven is likely to outlive its captor; for it is the very symbol of longevity, having attained in several instances, according to credible testimony, a full century. Think of it! A centenarian Mephistopheles with feathers still unsinged! 


\section{The Western Crow}

No. 2

\section{Western Crow}

A. O. U. No. 488b. Corvus brachyrhynchos hesperis Ridgway.

Synonyms.-California Crow. Common Crow. American Crow.

Description.-Entire plumage glossy black, for the most part with greenish blue, steel-blue, and violaceous reflections; feathers of the neck normal, rounded. Bill and feet black, iris brown. Length 406.4-508 (I6.00-20.00); wing 302 (I2.00); tail I $70(6.70)$; bill 46.5 (I.8.3); depth at nostril I6.5 (.65). Female averages smaller than male.

Recognition Marks.- "Crow-size"-much smaller than Raven; tail shorter, and only slightly rounded.

Nesting.- Nest: a neat hemisphere of sticks and twigs, carefully lined with soft bark strips, or, rarely, roots and grasses; placed at any height in trees, of ten well concealed. Eggs, 4 or 5, rarely 6; ovate or elongate ovate; pale bluish green (lichen green, glaucous green, or even dark greenish glaucous), spotted and marked with olive and related shades, sometimes so heavily as to appear almost uniform olive. Av. size (without distinction from typicus) $41.4 \times 29.1$ (I.63 x I.I5); index 70.5. Season: April 20-May 20; one brood.

Range of Corvus brachyrhynchos.-Temperate North America.

Range of $C . b$. hesperis.-Chiefly Western United States from Rocky Mountains to Pacific Coast, save shores of northwestern Washington; north into the interior of British Columbia, south to Southern California, Arizona, and Western Texas.

Range in California.-Resident; of very local distribution at the lower levels nearly throughout the State. Not found in the deserts nor in the higher ranges; of rare occurrence east of the Sierran divide (Davis Creek, Modoc Co., June Io, I9I2; Eagleville, June 30, I9I2; Mono Lake, June 3, I9I9). Favors riparian association, cultivated valleys, and the live oak association of the coastal districts.

Authorities.-Gambel (Corvus ossifragus and C. americanus), Journ. Acad. Nat. Sci. Phila., ser. 2, vol. I, 1847, p. 47; Henshaw, Rept. Orn. Wheeler Surv., 1876, p. 25I ; I 879, pp. 302-306 (crit.; habits); Ridgway, Manual N. Amer. Birds, I 887, p. 362 (description of hesperis); Kalmbach, Bull. U. S. Dept. Agric., no. 62 I, I9I8, 92 pp., 3 pls. (life history and food).

SINCE coming to California I cannot ridmyself of the impression that there is something childish about the Crow-scarcely "child-like and bland" either, for he is astute enough, and wary to a degree. It cannot be merely because he is noisy, or that he loves crowds, that he gives the impression of frivolity, or irresponsibility. Doubtless it is rather because of constant comparison with his somber kinsman, the Raven, self-contained black angel and villain of nature's plot. We have oftener heard in our wanderings the doomful croak of the larger Corvus, so when we come plump upon a roistering company of Crows, the lighter quality of their voices strikes us oddly, and we imagine ourselves with a company of school-children at recess time. 


\section{The Western Crow}

The Crow in California is no such constant factor of bird life as he is in the East. He is, instead, very local and sharply restricted in his distribution, so that to a traveller the appearance of Crows is rather a novelty, something to be jotted down in the field-book; and Crow country can scarcely comprise more than a twentieth part of the total area of the State. Confined for the most part to river bottoms or to rich

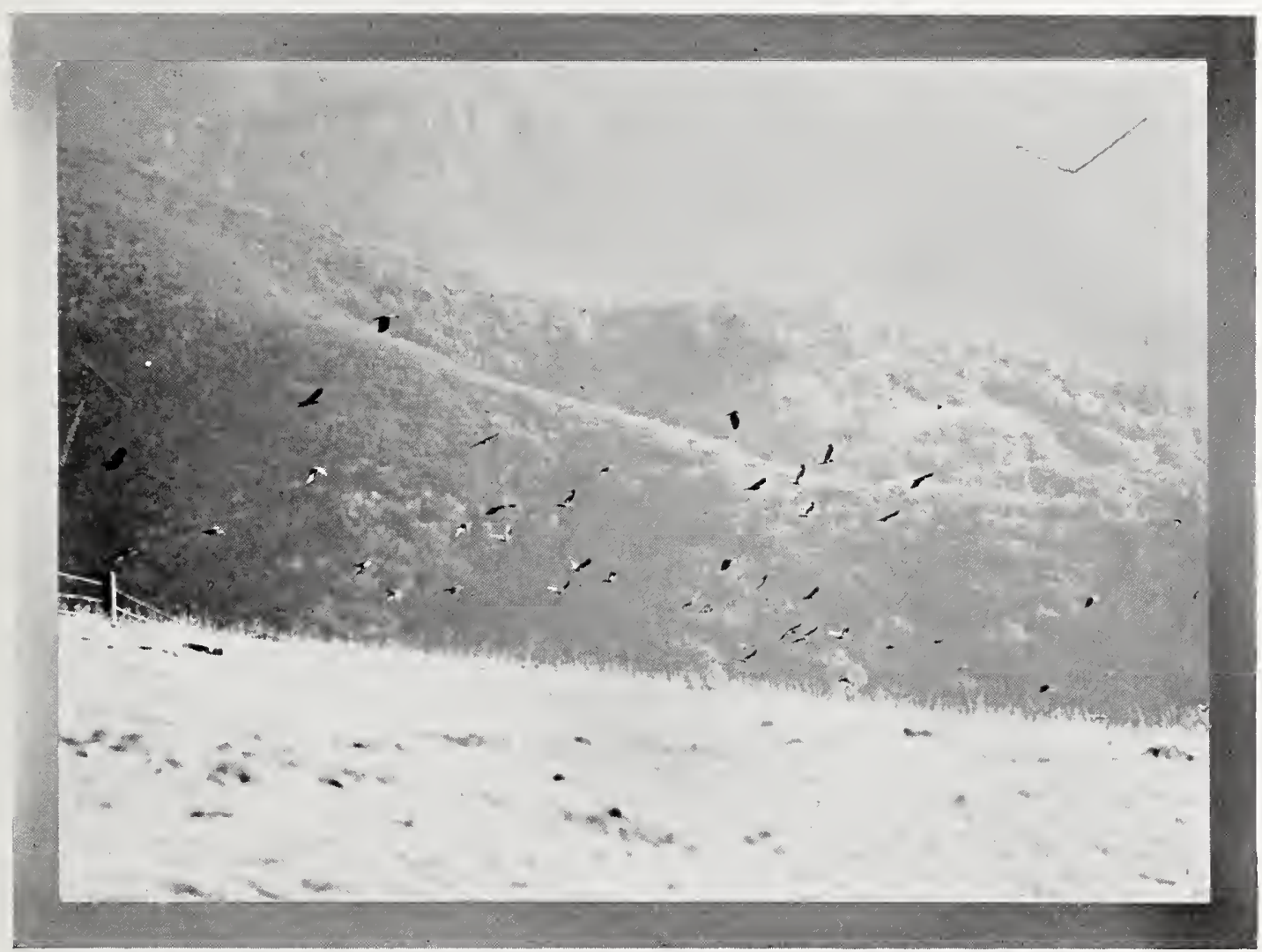

Taken in Santa Barbara Counly

Photo by the Author

A FLIGHT OF WESTERN CROWS

alluvial valleys, separated by wide stretches of crowless country, the behavior of these birds is so strongly influenced by local conditions, that generalizations as to nesting habits, absence of fear, etc., are futile. In some sections the birds mock at you from the wayside fence-posts. Elsewhere it may be difficult to obtain specimens. In one valley the Crows will nest in sycamores, in another in live oak trees, in another in the depths of the fir forest. 


\section{The Western Crow}

These dusky birds are notorious mischief-makers, no doubt of that. But they are not so black, perhaps, as they have been painted. More than any other bird, save the Raven, the Crow has successfully matched his wits against those of man, and his frequent easy victories and consequent boastings are responsible in large measure for the unsavory reputation in which he is held. It is a familiar adage in ebony circles that the proper study of Crow-kind is man; and so well has he pursued this study that he may fairly be said to hold his own in spite of fierce and ingenious persecution. He rejoices in the name of outlaw, and ages of ill-treatment have only served to sharpen his wits and intensify his cunning.

That the warfare waged against him is largely unnecessary, and partly unjust, has been pretty clearly proven of late by scientists who have investigated the Crow's food habits. It is true that he destroys large numbers of eggs and nestlings, and, if allowed to, that he will occasionally invade the poultry yard-and for such conduct there can be no apology. It is true, also, that some damage is inflicted upon corn in the roasting-ear stage, and that corn left out through the winter constitutes a staple article of Crow diet. But it is estimated that birds and eggs form only about one-half of one per cent of their total diet; and in the case of grain, certainly they perform conspicuous services in raising the crop. Besides the articles of food mentioned, great quantities of crickets, beetles, grasshoppers, caterpillars, cut-worms, and spiders, are consumed. Frogs, lizards, mice, and snakes also appear occasionally upon the bill of fare. On the whole, therefore, the Crow is not an economic Gorgon, and his destruction need not largely concern the farmer, although it is always well to teach the bird a proper reverence.

The psychology of the Crow is worthy of a separate treatise. All birds have a certain faculty of direct perception, which we are pleased to call instinct; but the Crow, at least, comes delightfully near to reasoning. It is on account of his phenomenal brightness that a Crow is among the most interesting of pets. If taken from the nest and well treated, a young. Crow can be given such a large measure of freedom as fully to justify the experiment from a humanitarian standpoint. Of course the sure end of such a pet is death by an ignorant neighbor's gun, but the dear departed is embalmed in memory to such a degree that all Crows are thereafter regarded as upon a higher plane.

Everyone knows that Crows talk. Their cry is usually represented by a single syllable, caw, but it is capable of many and important modifications. For instance, keraw, keraw, comes from some irritated and apprehensive female, who is trying to smuggle a stick into the grove; kawk-kawk-kawk proclaims sudden danger, and puts the flock into instant commotion; while caw-aw, caw-aw, caw-aw, reassures them. Once, in win- 


\section{The Western Crow}

ter when the bird-man, for sport, was mystifying the local bird population by reproducing the notes of the Screech Owl, a company of Crows settled in the tops of neighboring trees, and earnestly discussed the probable nature of the object half concealed under a c a mera cloth. Finally, they gave it up and withdrew - as I supposed.
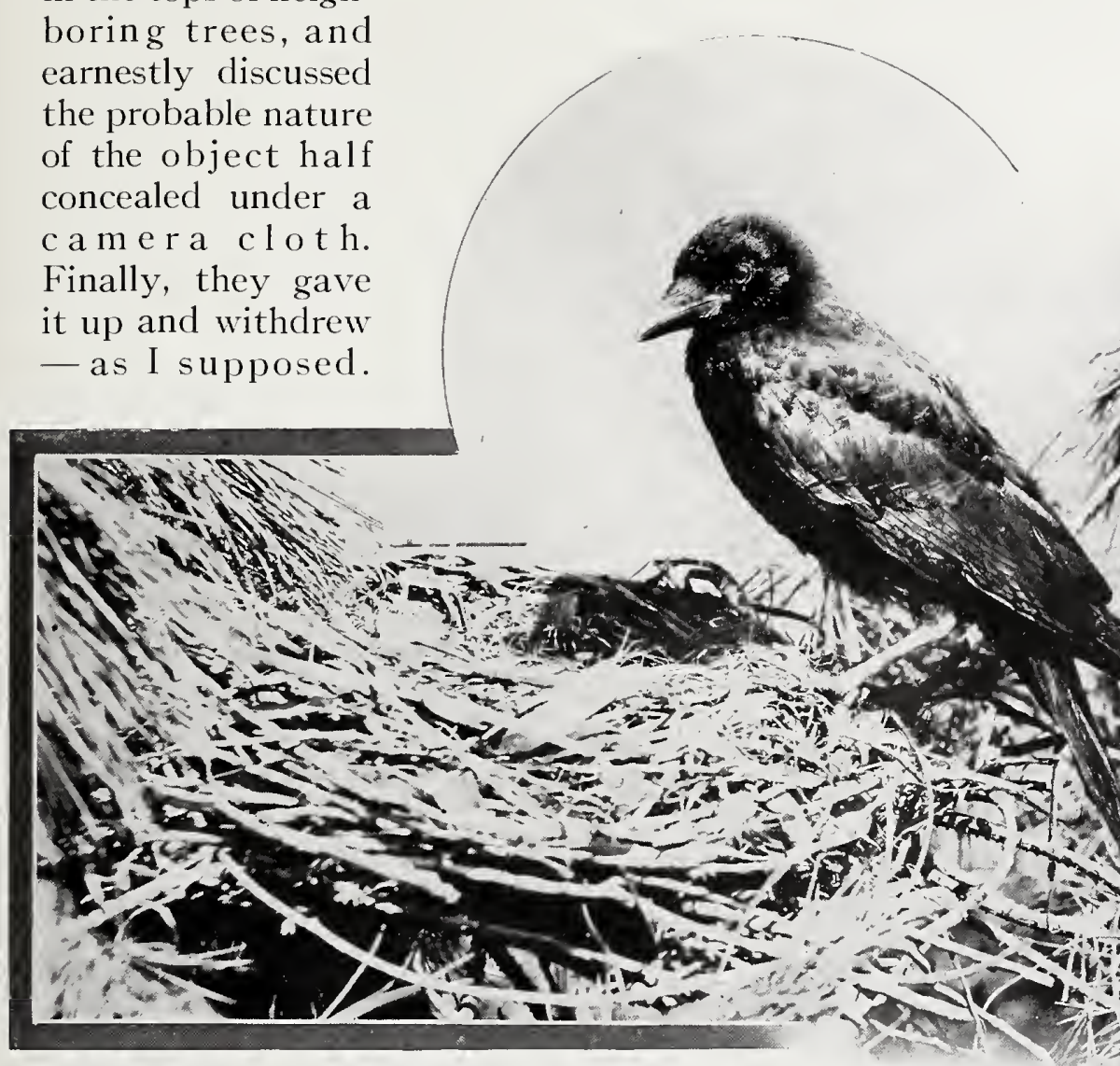

Taken in Oregon

Photo by Bohlman and Finley

WESTERN CROW AT NEST

It seems that one old fellow was not satisfied, for as I ventured to shift ever so little from my strained position, he set up a derisive Ca-a-a-aw from a branch over my head, as who should say, "Aw, ye can't fool me. Y're just a m-a-an," and flapped away in disgust.

Space fails in which to describe the elaborate structure of Crow society; to tell of the military and pedagogical systems which they enforce; of the courts of justice and penal institutions which they maintain; of the vigilantes who visit vengeance upon evil-minded owls and other offenders; or even of the games which they play, - tag, hide-and-seek, blind-man's-buff and pull-away. These things are sufficiently attested by competent observers: we may only spare a word for that most serious business of life, nesting. 


\section{The Western Crow}

A typical Crow's nest is a very substantial affair, as our illustration shows. Upon a basis of coarse sticks, a mat of dried leaves, grasses, barkstrips, and dirt, or mud, is impressed. The deep rounded bowl thus formed is carefully lined with the inner bark of the willow, or with twine, horse-hair, cow-hair, rabbit-fur, wool, or any other soft substance available. When completed, the nesting hollow is seven or eight inches across and three or four deep. The expression "Crow's nest," as used to indicate disarray, really arises from the consideration of old nests. Since the birds resort to the same locality year after year, but never use an old nest, the neighboring structures of successive years come to represent every stage of dilapidation.

North or South, April is the nesting month for all proper Crows. March eggs are of record, and, of course, a few laggards show up in May. Such matters as time and place appear to be pretty rigidly ordained by the clan or community council, for Crows are loosely gregarious, even in their nesting. While one rarely sees occupied nests in adjoining trees,

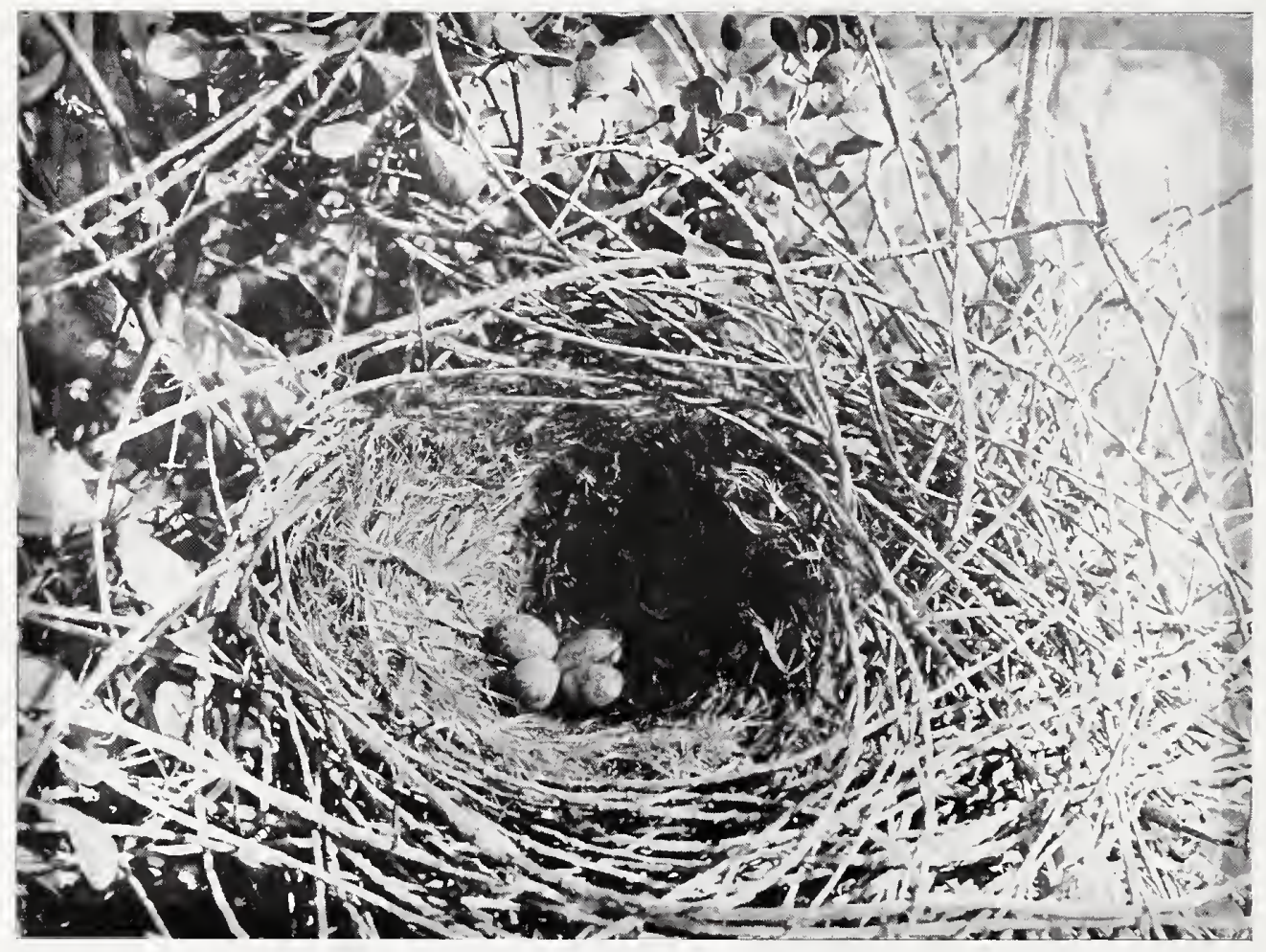

Taken in Riverside Counly 
to find a dozen or a score in a certain section of woodland, is the rule rather than the exception. Caution reigns here as at other times, and nest-building operations are suspended for the nonce if the Crows suspect the presence of a hated human. There is a way, however, by which an adroit observer may learn the Corvine secret, no matter how carefully hidden the domicile may be. In the honeymoon days attendant upon deposition, the amorous crow will call her mate to the nest-side from time to time by giving the hunger cry, anh annh,-identical in quality, apparently, with the sounds which will issue clamorously from the nest five or six weeks later. It is the coaxing, irresistible call of the eternal feminine, and the black swain will yield to its solicitations, even though it be against his better judgment. Alas, how many a poor wight has been trapped through his affections! The secret is out, Mr. Crow!

Fresh eggs may, therefore, be found by the second or third week in April. Incubation lasts from fourteen to eighteen days; and the young, commonly four or five in number, are born naked and blind. It is when the Crow children are hatched that Nature begins to groan. It is then that birds' eggs are quoted by the crate, and beetles by the hecatomb are sacrificed daily in a vain effort to satisfy the Gargantuan appetites of these young ebons. I once had the misfortune to pitch camp in a grove of willows which contained a nestful of Crows. The old birds never forgave me, but upbraided me in bitter language from early morn till dewy eve. The youngsters also suffered somewhat, I fear, for as often as a parent bird approached, cawing in a curiously muffled voice, choked with food, and detected me outside the tent, it

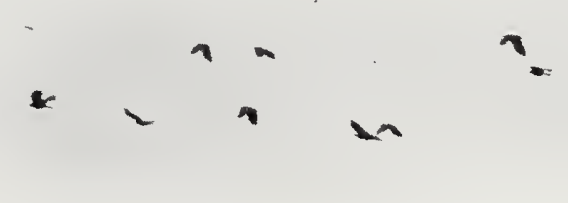




\section{The Western Crow}

swallowed its burden without compunction, in order that it might the more forcibly berate me.

If the male happened to discover my out-of-doorsness in the absence of his mate, he would rush at her when she hove in sight, in an officious, blustering way, and shout, "Look out there! Keep away! The Rhino is on the rampage again!"’

I learned, also, to recognize the appearance of hawks in the offing. At the first sign the Crow, presumably the male, begins to roll out objurgatory gutturals as he hurries forward to meet the intruder. His utterances, freely translated, run somewhat as follows: "That blank, blank, Swainson Hawk! I thought I told him to keep away from here. Arrah, there, you slab-sided son of an owl! What are ye doing here? Git out o' this! (Biff! Biff!) Git, I tell ye! (Biff!) If ever I set eyes on ye again, I'll feed ye to the coyotes. Git, now!' And all this without the slightest probability that the poor hawk would molest the hideous young pickaninnies if he did discover them. For when was a self-respecting hawk so lost to decency as to be willing to "eat crow?"

Crows, always sociable, become strictly gregarious after the young families are fully grown and ready to merge themselves into the clan. Again, under the rigors of winter, vast companies assemble into what are known as roosts, - nightly, communal associations, which sometimes number thousands. This institution, however, is very much more loosely observed in the West, and has not, apparently, been made the subject of special study. I well remember a trick which two mischievous bird-men played on a Crow roost in Ohio. The birds were using a certain stretch of "second growth" that season, and so were sleeping at a height of only fifteen or twenty feet. We stole out before a hint of dawn, and succeeded in getting to the very centre of the roost unsuspected. So when Brother Jones turned loose a good imitation of a Hoot Owl's cry, there was something doing. In a silence which could be felt every bird made a desperate leap into midair. And then ensued such a pandemonium of rage as I never was privileged to witness before. The air crashed with sound. Corvine expletives mingled with direst threats; and I suppose if there had been a veritable Horned Owl aloft, he would have been minced in a trice. As it was, our laughter bore witness to the Crows' discomfiture, though their disillusionment was slow, and they moved off grumbling and wondering. 


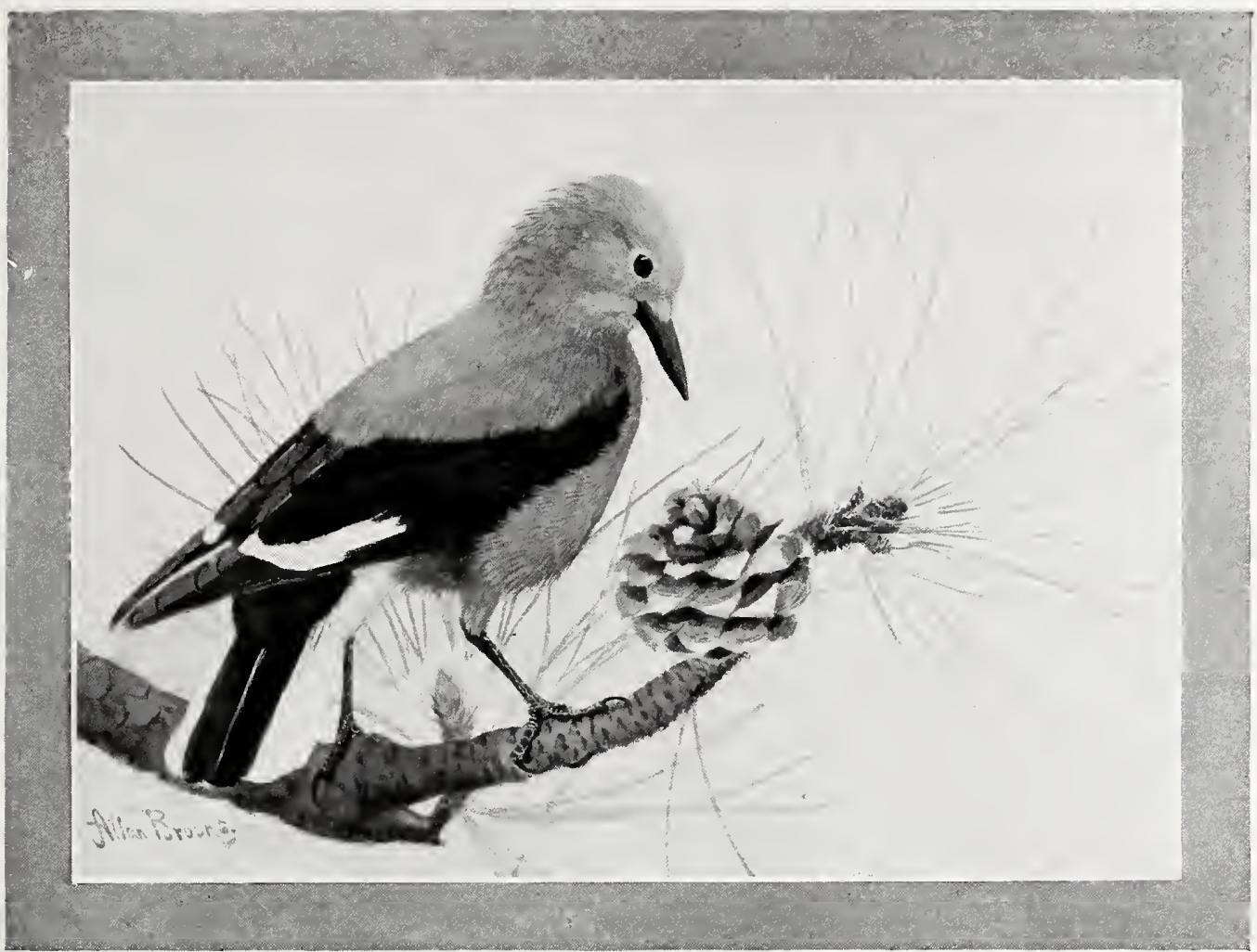

No. 3

\section{Clark's Nutcracker}

\section{A. O. U. No. 49I. Nucifraga columbiana (Wilson).}

Synonyms.-Clark's Crow. Pine Crow. Gray Crow. "Camp Robber" (Through confusion with the Gray Jay, Perisoreus sp.). "Clarke's" Crow, etc., (name misspelled, as conclusively demonstrated by Coues).

Description.-Adult in fresh plumage (fall and winter): General body color light neutral gray, changing to white on face all around, including circumocular area; wings glossy black, the secondaries broadly tipped with white; under tail-coverts and four outermost pairs of rectrices white, the fif th pair with outer web chiefly white and the inner web chiefly black, the remaining (central) pair of rectrices and the upper tail-coverts black; axillars and wing linings deep mouse gray to sooty black, often varied by white (in younger specimens?). Bill and feet black; iris brown. Adults in worn plumage (spring and summer): The gray element changing to brownish, light drab, or even drab (the breast of ten stained irregularly with olive-brown through 


\section{The Clark Nutcracker}

contact with pitch); the white of face soiled or brown-stained. Young birds are like adults in worn plumage. Length 279.4-330.2 (I I.OO-I3.00); wing I92 (7.00-8.00); tail I I 5 (4.50); bill 40.7 (I.60); tarsus 36.8 (I.45). Female smaller than male.

Recognition Marks.-Kingfisher size; gray plumage with abruptly contrasting black-and-white of wings and tail; harsh "char-r" note.

Nesting.- Nest: a thick-walled cup composed chiefly of fine barkstrips, externally of interlaced sticks: lining of finest shredded bark; placed at moderate heights in pinyon, juniper, or pine. Eggs: 2 or 3, or, rarely, 4. "Ground color light lichen green. Light mottlings or streakings of pale drab-gray and minute spottings of Saccardo's olive distributed over the entire surface, with a slight confluence at the larger end whence a faintly defined banded effect is noticeable" (Bradbury). Av. of I5 eggs: $33.3 \times 23 . \mathrm{I}$ ( I.3I X .9I); index 70. Season: March at the lower breeding levels; probably later with increase of elevation; one brood.

General Range.-Western North America in coniferous timber, from Arizona and New Mexico to Alaska; casual east of the Rockies.

Range in California.-Common resident in the higher timbered mountain ranges practically throughout the State, occurring from high Transition up to the summits. Also of sporadic occurrence at the lower levels in fall and winter-Point Reyes, Nov. I9, I900, (J. Mailliard); Point Pinos (II. K. Fisher); Carmel (J. L. Schlesinger); Santa Barbara (various occurrences, specimen taken Oct. I5, I9I9); Colorado Desert near Indio (C. O. Esterly); at sea near Los Angeles (G. F. Ferris).

Authorities.-Newberry (Picicorvts columbianus), Rept. Pac. R. R. Surv., vol. VI, pt. IV, I 857 , p. 83: Feilner, Ann. Rept. Smithsonian Inst., for I 864 (I 865), p. 427 (range; habits); Henshaw, Rept. Orn. Wheeler Surv., I 876, p. 252 (habits); Merriam, C. H., North Amer. Fauna, No. I6, I 899, pp. I I9-I2 I, 2 figs. (habits; food); Mailliard, $f .$, Condor. Vol. XXII, I920, pp. I60-I6I (at Carmel; habits).

NO BIRD-LOVER can forget his first encounter with this singular Old-Bird-of-the-Mountains. Ten to one the bird brought the man up standing by a stentorian char'r'r, char'r'r, char'r' $r$, which led him to search wildly in his memory whether Rocs are credited with voices. If the bird was particularly concerned at the man's intrusion, he presently revealed himself sitting rather stolidly on a high pine branch, repeating that harsh and deafening cry. The grating voice is decidedly unpleasant at close quarters, and it is quite out of keeping with the unquestioned sobriety of its grizzled owner. A company of Nutcrackers in the distance finds frequent occasion for outcry, and the din is only bearable as it is softened and modified by the re-echoing walls of some pine-clad gulch, or else dissipated by the winds which sweep over the listening glaciers.

- But the Nutcracker's repertory is not exhausted by a single cry. For years I was puzzled by sporadic eruptions of a strange, feline cry, meack, or mearrk, a piercing and rather frightful sound. The Clark Nutcracker proved at last to be responsible, and he was only at play! The very next morning after the mountain lion scare, we had the versatile 


\section{The Clark Nutcracker}

birds as musicians. Two of them got out their little toy trumpets, pitched about a fifth apart, and proceeded to give us the Sierran reveille: hee hee hee, hee hee, hee, hee, hee, hee, hee. hoo hoo hoo hoo hoo hoo hoo hoo hoo

The notes were really quite musical, and the comparison established of children's tin trumpets was irresistible. The effect produced by the

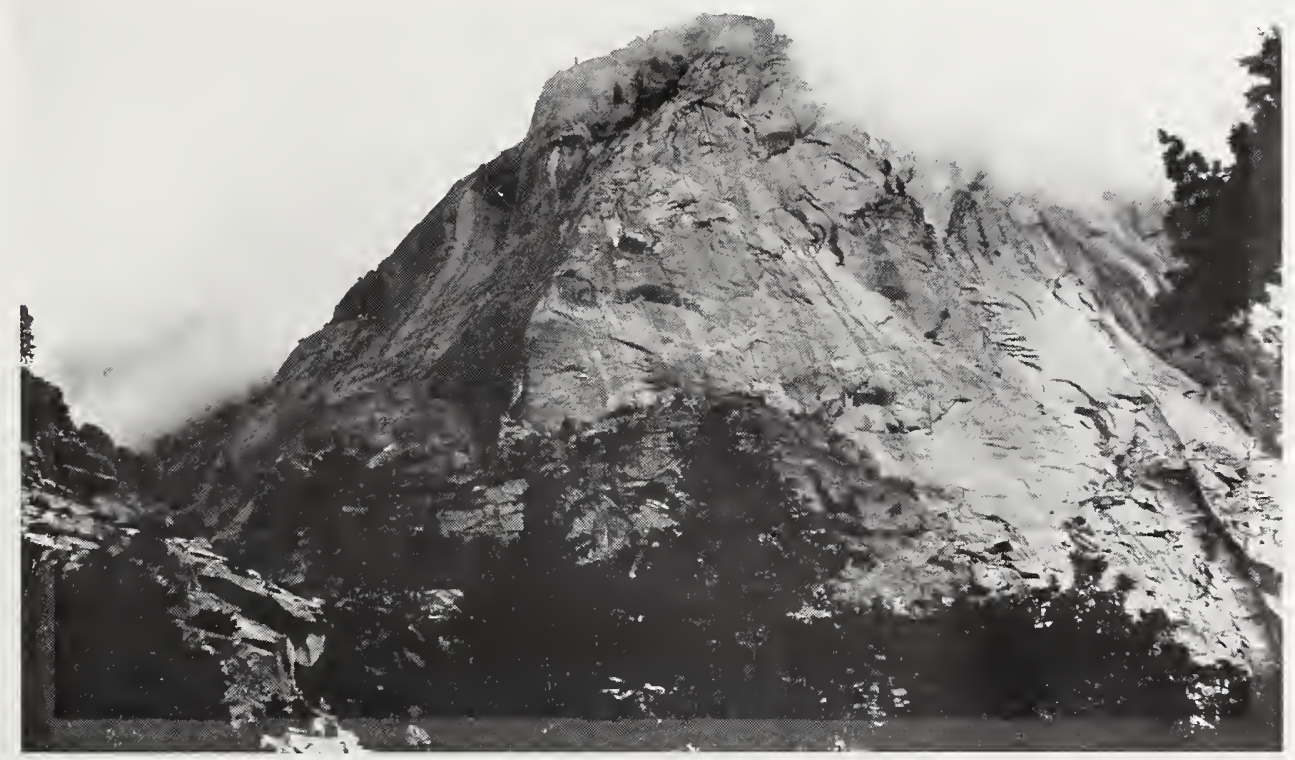

Taken in the Tehipite Valley

Photo by the Author

A HARD NUT TO CRACK

two birds sounding in different keys was both pleasant and amusingMerry Christmas in July! The concert lasted two or three minutes, and its conclusion was announced when one of the youngsters shouted Charr (as who should say, Rats!), and burst out of the tree.

Clark's Nutcracker is the presiding genius of all our higher mountain bodies, including in his regular haunts the pinyon-forested desert ranges, as well as the rugged fastnesses of the central Cordilleras. At the close of the breeding season, and especially in the late summer, the birds have a wider vertical range, pressing the limits of evergreen timber at the lower levels, as well as paying occasional visits to the topmost peaks. There is no migration in the proper sense, but occasional individuals turn up now and then in most unexpected places. For example, a stray bird appeared at Miramar, a fashionable seaside resort near Santa Barbara, on the 28th of January, 1917. And again in the fall of I9I9 there 


\section{The Clark Nutcracker}

was a visitation of Nutcrackers which involved most of the coastal counties from Monterey to the Colorado desert. A specimen now in the M. C. O. collection was taken in Montecito; and another bird spent fully three weeks in Alameda Park, in the heart of Santa Barbara.

This black-and-white-and-gray "Crow" curiously combines the characteristics of Woodpecker and Jay as well. Like the Lewis Woodpecker, he sometimes hawks at passing insects, eats berries from bushes, or alights on the ground to glean grubs, grasshoppers, and black crickets. In the mountains it shares with the Jays of the Perisoreus group the names "meat-bird" and "camp-robber," for nothing that is edible comes amiss to this bird, and instances are on record of its having invaded not only the open-air kitchen, but the tent, as well, in search of "supplies". Like all other members of the Corvidae, Clark's Crow bears a bad reputation among the lesser songsters. One that had been caught sneaking about in the pine-trees just below our Cottonwood Lakes camp, was fiercely set upon by a pair of Western Wood Pewees. The pursuers gave the rascal no rest, but drove the unhappy crow mercilessly from tree to tree, and with a persistence which left no room for doubt that they had real wrongs to avenge. At Mammoth we found them persecuting the Leucostictes, and knew of at least one nest being robbed by them.

Of its more staple food a more northern observer says: "Clark's Crows have, like the Crossbills, to get out the seeds from underneath the scaly coverings constituting the outward side of the fir cone. Nature has not given them crossed mandibles to lever open the scales, but instead, feet and claws, that serve the purpose of hands, and a powerful bill like a small crowbar. To use the crowbar to advantage the cone needs steadying, or it would snap at the stem and fall; to accomplish this one foot clasps it, and the powerful claws hold it firmly, whilst the other foot encircling the branch, supports the bird, either back downward, head downward, on its side, or upright like a woodpecker, the long clasping claws being equal to any emergency; the cone thus fixed and a firm hold maintained on the branch, the seeds are gouged out from under the scales."

These Nutcrackers are among the earliest and most hardy of nesters. They are practically independent of climate, but are found during the nesting months - March, or even late in February, and early April-only where there is a local abundance of pine (or fir) seeds. They are artfully silent at this season, and the impression prevails that they have "gone to the mountains"; or, if in the mountains already, the presence of a dozen feet of snow serves to allay the oologist's suspicions.

The nest is a very substantial affair of twigs and bark-strips, heavily lined, as befits a cold season, and placed at any height in a pine or fir 


\section{The Clark Nutcracker}

tree, without noticeable attempt at concealment. The birds take turns incubating and-again because of the cold season-are very close sitters. Three eggs are usually laid, of about the size and shape of Magpies' eggs but much more lightly colored. Incubation, Bendire thinks, lasts sixteen or seventeen days, and the young are fed chiefly on hulled pine seeds, at the first, presumably regurgitated.

If the Corvine affinities of this bird were nowhere else betrayed, they might be known from the hunger cries of the young. The importunate anh, anh, anh of the expectant bantling, and the subsequent gullu, gullu, gullu of median deglutition (and boundless satisfaction) will always serve to bind the Crow, Magpie, and Nutcracker together in one compact group. When the youngsters are "ready for college," the reserve of early spring is set aside and the hillsides are made to resound with much practice of that uncanny yell before mentioned. Family groups are gradually obliterated and, along in June, the birds of the foothills begin to deploy, or else to retire irregularly to the higher ranges, there to rest up after the exhausting labors of the season, or else to revel in midsummer gaiety with sundry scores of their fellows.

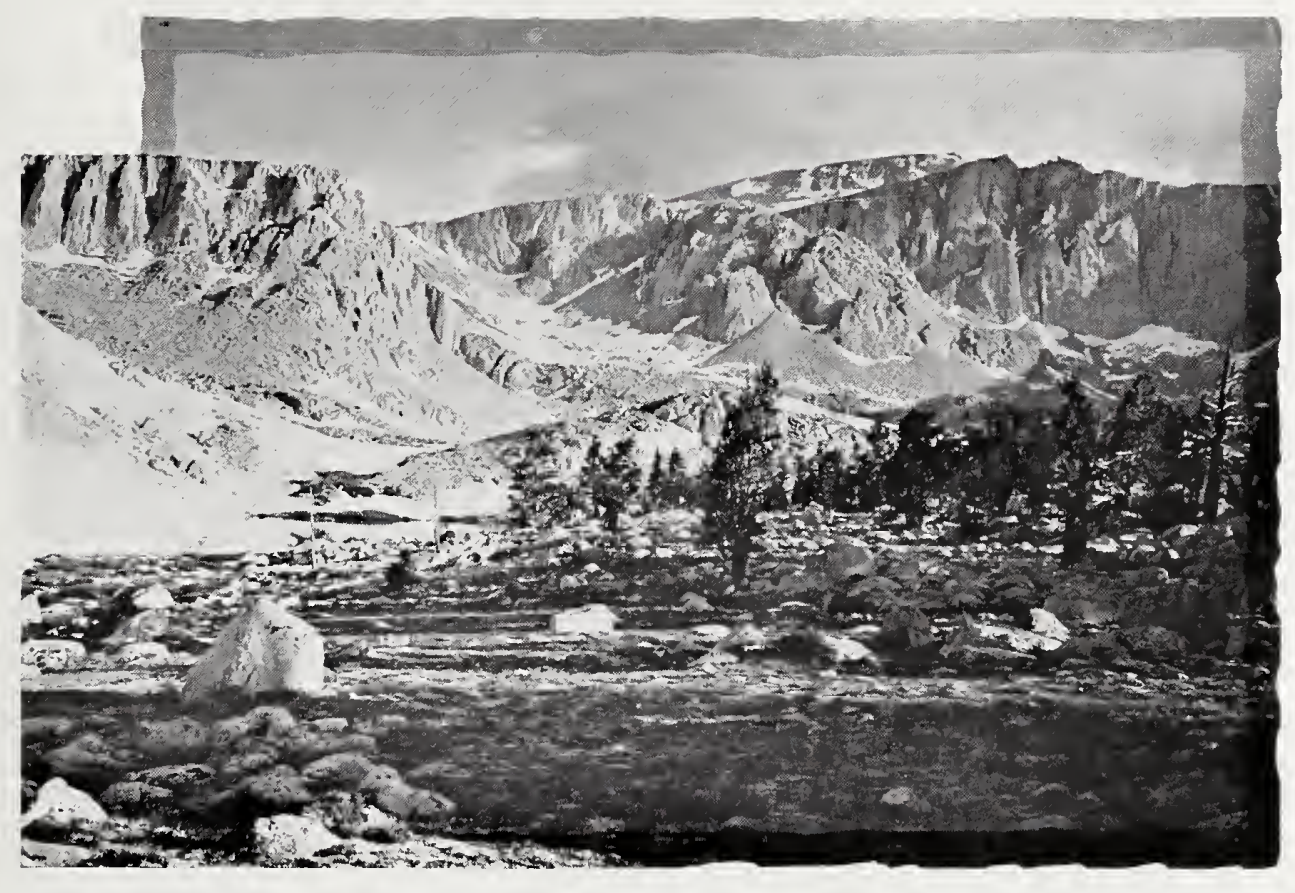

Taken in Inyo County

MOUNT LANGLEY FROM THE COTTONWOOD LAKES

A TYPICAL HAUNT OF THE CLARK NUTCRACKER 


\section{The Pinyon Jay}

Early on a July morning, having set ourselves the task of climbing Mt. Langley, we noted on the aneroid the attainment of the thirteen thousand foot level, and were gazing wistfully up at the rugged peak looming a thousand feet higher, when, suddenly, like a wisp of snowflakes caught up by the wind, or like a sudden bursting rocket, a flock of birds appeared right over the summit. Their breasts shone resplendent in the morning sun, and under this bright disguise it took some moments with the binoculars to make them out as Clark Crows. How jolly! these gifted creatures have held a sunrise prayer (?) meeting "already yet so soon," while we poor mortals must plod on and on under a blistering sun!

"The heights by great men won and kept

Were not attained by sudden flight:

But they while their companions slept

"Were toiling upward in the night"

evidently does not apply to the birds.

No. 4

\section{Pinyon Jay}

A. O. U. No. 492. Cyanocephalus cyanocephalus (Wied).

Synonyms.-Blue Crow. Maximilian's Jay. Pine Jay.

Description.-Adults: Plumage dull grayish blue (tyrian blue where pure) mingled with bluish gray and brownish gray, deepening on crown and nape (dusky slate-blue), brightening on cheeks (olympic blue), paling below posteriorly to neutral gray, streaked with dull white on chin, throat, and chest, centrally. Bill and feet black; iris brown. Adult female: Like male, but somewhat duller, with increase of gray. Young birds are still duller, gray rather than blue, except on wings and tail. Length of adult male: 279.4-304.8 (I I.00-I 2.00); wing I 54 (6.00); tail I I 4 (4.50); bill 36 (I.42); tarsus 38 (I.50). Adult female: wing I44.5 (5.68); tail IO4 (39.5); bill 3I.5 (I.24), tarsus $35.5(\mathrm{I} .4 \mathrm{O})$.

Recognition Marks.-Robin size; blue color; crow-like aspect.

Nesting. - Nest: composed of twigs, heavily lined with finely shredded bark strips; placed at moderate height in pinyon or juniper. Eggs: 4 or 5; pale greenish white, speckled quite uniformly with olive brown. Av. of 25 eggs in the U. S. National Museum $30.2 \times 22.1$ ( $1.19 \times .87$ ); index 73. Av. of 20 eggs from Santa $\mathrm{Fe}$ in the M. C. O.: $27.3 \times 21.9$ (1.075 x.846); index 78. Season: April-May Io; one brood.

General Range.-Pinyon and juniper woods of western United States; north to southern British Columbia (interior), Idaho, etc.; south to northern Lower California, Arizona, New Mexico, and western Texas; casually along the eastern slopes of the Rocky Mountains.

28 


\section{The Pinyon Jay}

Range in California.- " Common resident locally of arid Upper Sonoran and Transition, chiefly along the eastern base of the Sierra Nevada and ranges of Southern California, and on the desert ranges of the Inyo district. Its permanent habitat is closely coincident with the presence of the pinyon (Pinus monophylla) and juniper (Juniperus occidentalis)." (Grinnell). Also indulges in extraordinary wanderings in fall and winter. Has occurred thus at Pasadena (Gaylord), Santa Barbara (Dawson), Pacific Grove (J. Mailliard), Berkeley (J. Grinnell), and even Eureka (Grinnell).

Authorities.-Feilner (Gymnokitta cyanocephala), Ann. Rept. Smithsonian Inst. for I 864 (1865), p. 427 (habits); Fisher, A. K., North Amer. Fauna, No. 7, I 893. pp. 72-73 (range; food); Bendire, Life Hist. N. Amer. Birds, Vol. II, I 895, pp. 424-426, pl. III (figs. 24, 25) (habits, nest and eggs); Willett, Pac. Coast Avifauna, No. 7, I9I 2, p. 69 (status in S. Calif.); Van Rossem and Pierce, Condor, vol. XVII., I915, p. I64.

THE RANGE of the Pinyon Jay is normally coextensive with that of the pinyon (Pinus monophylla) plus that of the juniper (Juniperus occidentalis); hence, it is chiefly confined in California to the eastern slopes of the Sierras and the desert ranges of Riverside, San Bernardino and Inyo Counties. The bird is, however, a great wanderer, and sporadic occurrences have been recorded from several of the coastal counties, stretching from San Diego clear to Humboldt. The Santa Barbara record was made on October 9th, I9I 4 , when a flock of about two hundred birds flew westward over town at a height of about half a mile. They suggested Crows both in voice and appearance; but the "caws" were shorter, sharper, and thinner, and the wing-action more rapid.

Grinnell encountered this species commonly at several points in the San Bernardino Mountains, ${ }^{1}$ and noted its relative indifference to the human presence. The birds fed a good deal upon the ground, as well as in the pine trees; and on their foraging expeditions ventured far out into the sage flats. "A large scattering flock may be absolutely silent for minutes at a time, and then again indulge in a concert of nasal, mewing calls, which can be heard a long ways. In their method of spreading out over a sage flat, and working zigzag over the ground for insects, they closely resemble Brewer Blackbirds, both in flight and general behavior." Grinnell and Swarth also noted their ground-feeding habit in the San Jacinto Mountains; ${ }^{2}$ and Fisher found in a bird's crop sprouted pine seeds, which he judged must have been gleaned from the ground. Captain Bendire had perhaps the widest acquaintance with this erratic, desert-haunting species, and I record his testimony, even though it both duplicates and contradicts portions of the foregoing:

"Their call notes are quite variable; some of them are almost as harsh as the 'chaar' of the Clarke's Nutcracker, others partake much of the gabble of the Magpie, and still others resemble more those of the Jays. A shrill, querulous 'peeh, peeh,' or 'whee, whee,' is their common 


\section{The Pinyon Jay}

call note. While feeding on the ground they keep up a constant chattering, which can be heard for quite a distance, and in this way often betray their whereabouts."

"It is an eminently sociable species at all times, even during the breeding season, and is usually seen in large compact flocks, moving about from place to place in search of feeding grounds, being on the whole rather restless and erratic in its movements; you may meet with thousands in a place to-day and perhaps to-morrow you will fail to see a single one. It is rarely met with at altitudes of over 9,00o feet in summer, and scarcely ever in the higher coniferous forests; its favorite haunts are the pinyon-covered foothills of the minor mountain regions, the sweet and very palatable seeds of these trees furnishing its favorite food during a considerable portion of the year. In summer they feed largely on insects of all kinds, especially grasshoppers, and are quite expert in catching these on the wing; cedar and juniper berries, small seeds of various kinds, and different species of wild berries also enter largely into their bill of fare. A great deal of time is spent on the ground where they move along in compact bodies while feeding, much in the manner of Blackbirds, the rearmost birds rising from time to time, flying over the flock and alighting again in front of the main body; they are rather shy and alert while engaged in feeding. I followed a flock numbering several thousands which was feeding in the open pine forest bordering the Klamath Valley, Oregon, for more than half a mile, trying to get a shot at some of them, but in this I was unsuccessful. They would not allow me to get within range, and finally they became alarmed, took wing, and flew out of sight down the valley."

Although breeding within our borders to the number of thousands, perhaps tens of thousands, it is a matter of amused record (Oct. I918) that no occupied nest of the Pinyon Jay has ever been reported for California. Why sigh for Africa or Alaska with such unexploited fields at home! An observer in Utah, Mr. H. C. Johnson ${ }^{1}$, testifies that in its nesting habits this jay is decidedly erratic. Sometimes it nests singly, but oftener en colonie. While they nest preferably in some variety of conifer, pinyon, scrub cedar, juniper, and the like, they occur also in the mountain mahogany (Cercocarpus ledifolius Nutt.), or even in brushy thickets. One mountain mahogany he knows of that is "fairly full of nests, some nearly touching each other." Evidently the "Native Sons" have been caught napping.

'The Condor, vol. IV., p. 14. 


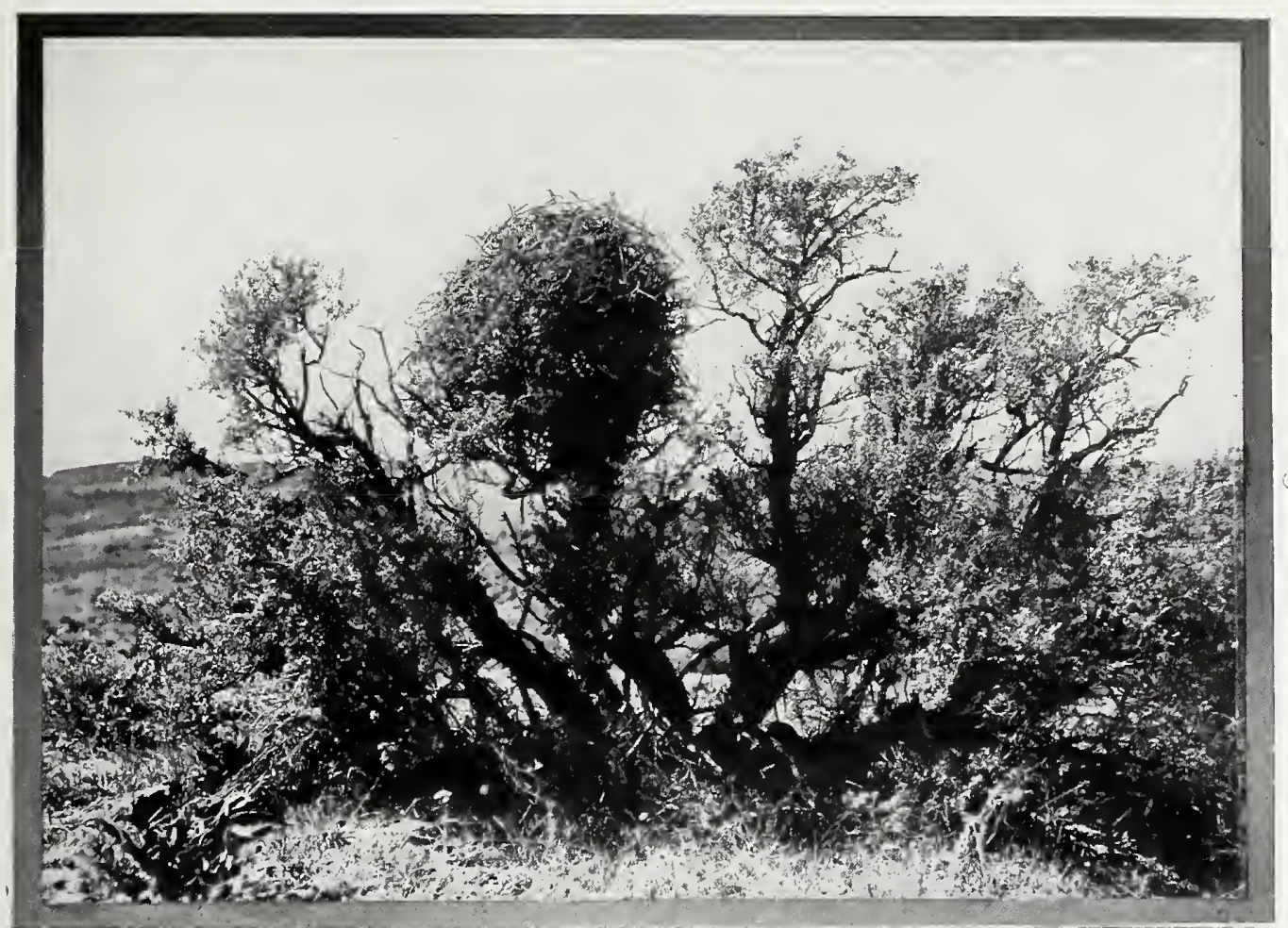

Taken in Washington

Photo by the Author

NEST OF MAGPIE IN GREASEWOOD

No. 5

\section{American Magpie}

A. O. U. No. 475. Pica pica hudsonia (Sabine).

Synonym.-Black-BILled MagPie.

Description.-Adults: Black and white; head and neck, breast, back, crissum, thighs and upper tail coverts, axillars and lining of wings, glossy black with steely purplish and bronzy green reflections; the throat with whitish shaft streaks; an elongated scapular patch pure white; lower breast, upper abdomen, flanks and sides broadly pure white; primaries extensively white on inner web; a broad band on rump with large admixture of white; remainder of wings and tail black, their exposed upper surfaces with shiny metallic reflections, those of the wing chiefly greenish blue, those of the tail bronzy green changing sub-terminally through purple and violet; tail narrowly graduated through terminal three-fifths. Bill, bare orbital space, legs, and feet, black; iris brown, surrounded by gray. Young birds lack iridescence on head and are elsewhere duller, the throat marked with whitish shaft lines and outcropping of basal white: relative length of tail sure index of age in juvenile specimens. Length of adults, 406.4- 


\section{The Black-billed Magpie}

508 (I6.00-20.00), of which tail, av. 265 (8.00 I 2.00$)$; wing 200 (7.85); bill (exposed culmen) 35 (I.35); tarsus 47 (I.85).

Recognition Marks.-Black and white plumage with long tail unmistakable, bill black as distinguished from $P$. nuttalli.

Nesting.- Nest: Normally a large sphere of interlaced sticks, "as big as a bushel basket," placed 5 to 40 feet high in willow, aspen, grease-wood or pine. The nest proper is a contained hemisphere of mud 8 to Io inches arross inside, and with walls I to 2 inches in thickness, carefully lined for half its depth with twigs surmounted by a mat of fine rootlets. Eggs: 7 or 8, rarely Io, pale grayish green, quite uniformly freckled and spotted with olive green or olive brown. Occasionally spots nearly confluent in heavy ring about larger end, in which case remainder of egg likely to be less heavily marked than usual. Shape variable, rounded ovate to elongate ovate. Av. size, $32.5 \times 22.9$ ( $1.28 \times .90)$; index 70.3. Season: March 20-May I; one brood.

Range of Pica pica.-Europe, the most of Asia, and North America south to Arizona and New Mexico.

Range of P. p. hudsonia.--Resident in the Western United States (except the Pa:ific Coast district), and interiorly in the British Provinces; from central New Mexico and western Texas north to central Manitoba, Saskatchewan, and Alberta, and northwestward to the middle Yukon and the eastern Aleutian Islands casually. eastward in the North Central States to Ontario and the Hudson Bay region.

Range in California.-Common resident in Upper Sonoran and Transition zones, northeast of the Sierran divide; less commonly east of the Sierras as far south as Independence in Inyo County, and (formerly at least) west along the northern border of the State to Shasta Valley.

Authorities.-Newberry, Rept. Pac. R. R. Surv., vol. VI, pt. IV, I 857, p. 84; IIenshaw, Rept. Orn. Wheeler Survey, I 879, pp. 306-307 (nesting habits); Bendire, Life Hist. N. Amer. Birds, vol II. I 895, pp. 349-353, (habits, nests and eggs); Fisher, W. K., Condor, vol. IV., I902, pp. 6, I (habits): Ray, Auk, vol. XX., I903, p. I85 (nesting).

HERE IS another of those rascals in feathers who keep one alternately grumbling and admiring. As an abstract proposition one would not stake a sou marquee on the virtue of a Magpie; but taken in the concrete, with a sly wink and a saucy tilt of the tail, one will rise to his feet, excitedly shouting, "Go it, Jackity," and place all his earnings on this pie-bald steed in the race for avian honors. It is impossible to exaggerate this curious contradiction in Magpie nature, and in our resulting attitude towards it. It is much the same with the mischievous small boy. He has surpassed the bounds of legitimate naughtiness, and we take him on the parental knee for well-deserved correction. But the saucy culprit manages to steal a roguish glance at us, - a glance which challenges the remembrance of our own boyish pranks, and bids us ask what difference it will make twenty years after; and it is all off with discipline for that occasion.

The Magpie is indisputably a wretch, a miscreant, a cunning thief, a heartless marauder, a brigand bold--Oh, call him what you will! But, withal, he is such a picturesque villain, that as often as you are stirred 


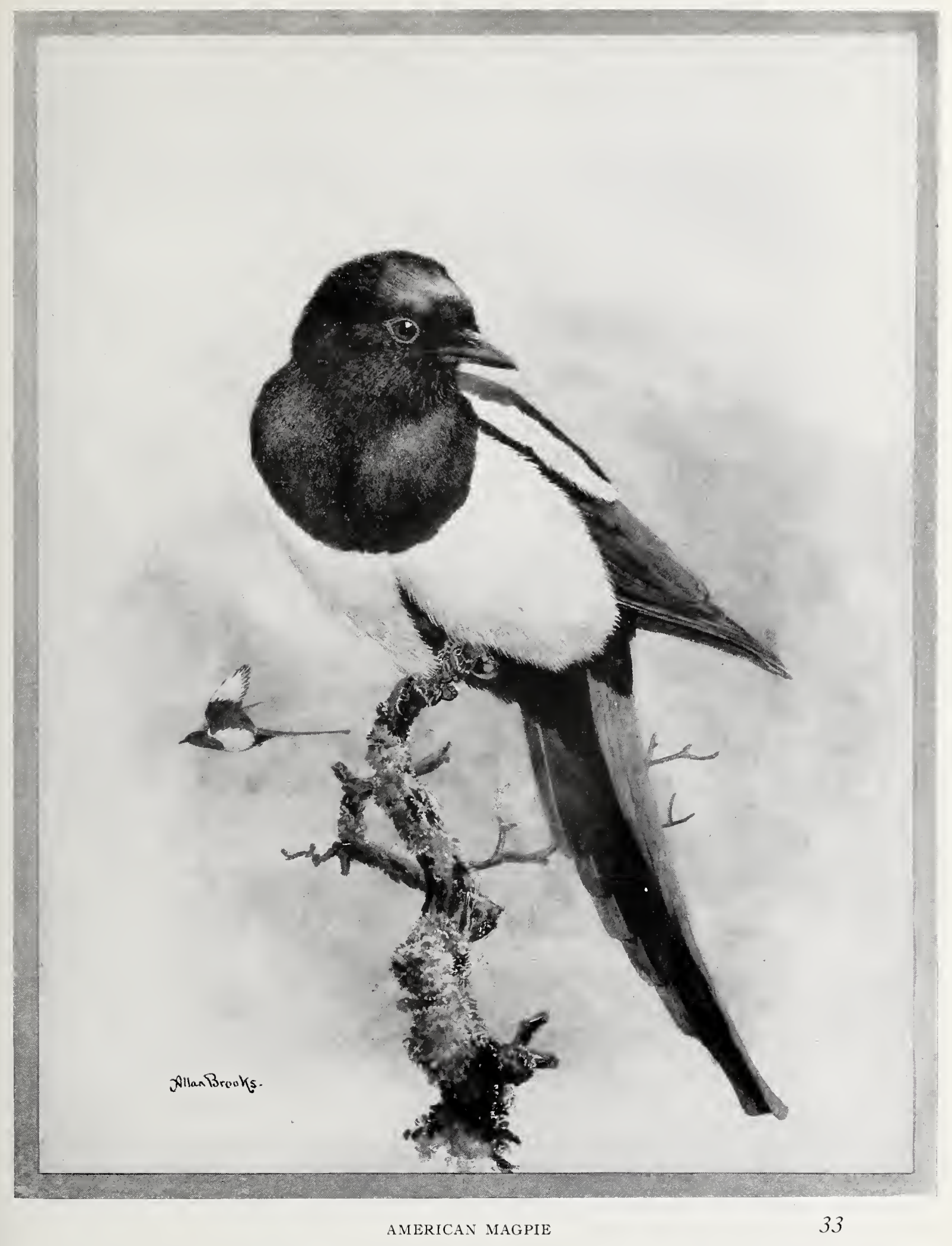




\section{The Black-billed Magpie}

with righteous indignation and impelled to punitive slaughter, you fall to wondering if your commission as avenger is properly countersigned, and-shirk the task outright.

The cattle-men have it in for him, because the persecutions of the Magpie sometimes prevent scars made by the branding iron from healing; and cases are known in which young stock has died because of malignant sores resulting. This is, of course, a grave misdemeanor; anything

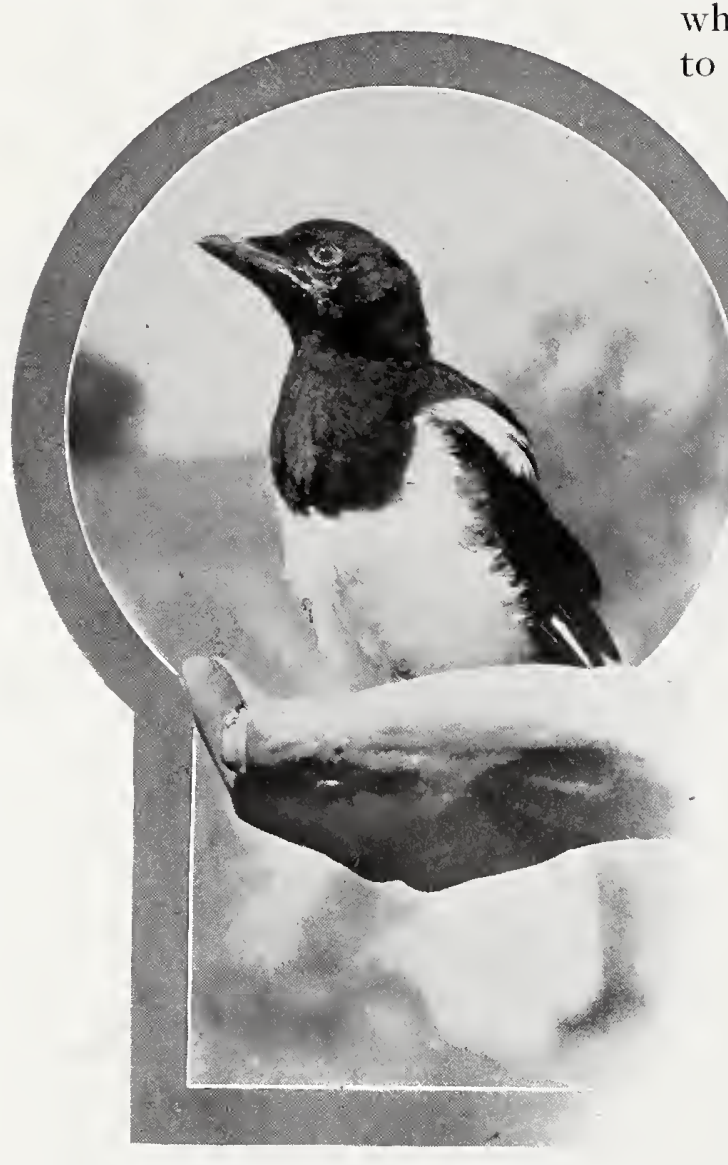

Taken in Inyo County

Photo by the 1 uthor

A BIRD IN THE HAND which affects our pocketbook is sure to be rated such. But when the inhumane custom of branding shall have been discontinued, as it will be when the fenceloving farmer triumphs over the freedom-loving cattleman (a sad day, however), we shall hear no more complaints of the Magpie on the score of cruelty to animals.

Beyond this it is indisputably true that Magpies are professional nest robbers. At times they will organize systematic searching parties, and advance through the sage-brush, poking, prying, spying, and devouring, with the ruthlessness and precision of a pestilence. Not only eggs but young birds are appropriated. I once saw a Magpie seize a half-grown Meadowlark from its nest, carry it to its own domicile, and parcel it out among its cla moring brood. Then, in spite of the best defense the agonized parents could institute, it calmly returned and

selected another. Sticks and stones shied by the birdman merely deferred the doom of the remaining larks. The Magpie was not likely to forget the whereabouts of such easy meat.

Nor is such a connoisseur of eggs likely to overlook the opportunities afforded by a poultry yard. He becomes an adept at purloining eggs, 
and can make off with his booty with astonishing ease. One early morning, seeing a Magpie fly over the corral with something large and white in his bill, and believing that he had alighted not far beyond, I followed quickly and frightened him from a large hen's egg, which bore externally the marks of the bird's bill, but which was unpierced. Of course the only remedy for such a habit is the shot-gun.

To say that Magpies are garrulous would be as trite as to say hens cackle, and the adjective could not be better defined than "talking like a Magpie." The Magpie is the symbol of loquacity. The very type in which this is printed is small pica; that is small Magpie. Much of this bird's conversation is undoubtedly unfit for print, but it has always the merit of vivacity. A party of Magpies will keep up a running commentary on current events, now facetious, now vehement, as they move about; while a comparative cessation of the racket means, as likely as not, that some favorite raconteur is holding forth, and that there will be an explosion of riotous laughter when his tale is done.

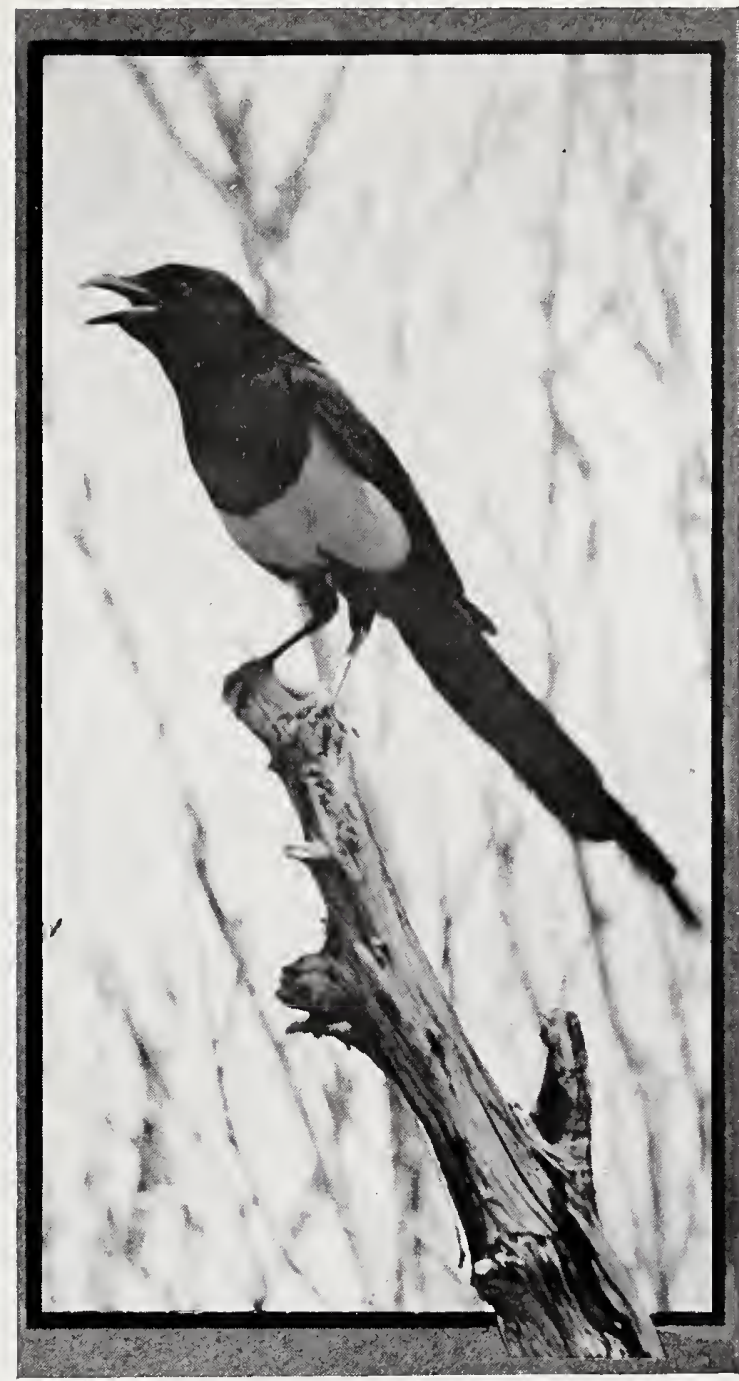

Taken in Inyo County

Photo by the Author

EXPOSTULATION

"UNDOUBTEDLY UNFIT FOR PRINT"

The pie, like Nero, aspires to song; but no sycophant will be found to praise him, for he intersperses his more tuneful musings with chacks and barks and harsh interjections which betray a disordered taste. In modulation and quality, however, the notes sometimes verge upon the human; and it is well known that Magpies can be instructed until they acquire a handsome repertoire of speech. 


\section{The Black-billed Magpie}

In order that their double quartet of youngsters may be lined up for the egg harvest, the Magpies take an early start at home building. April is

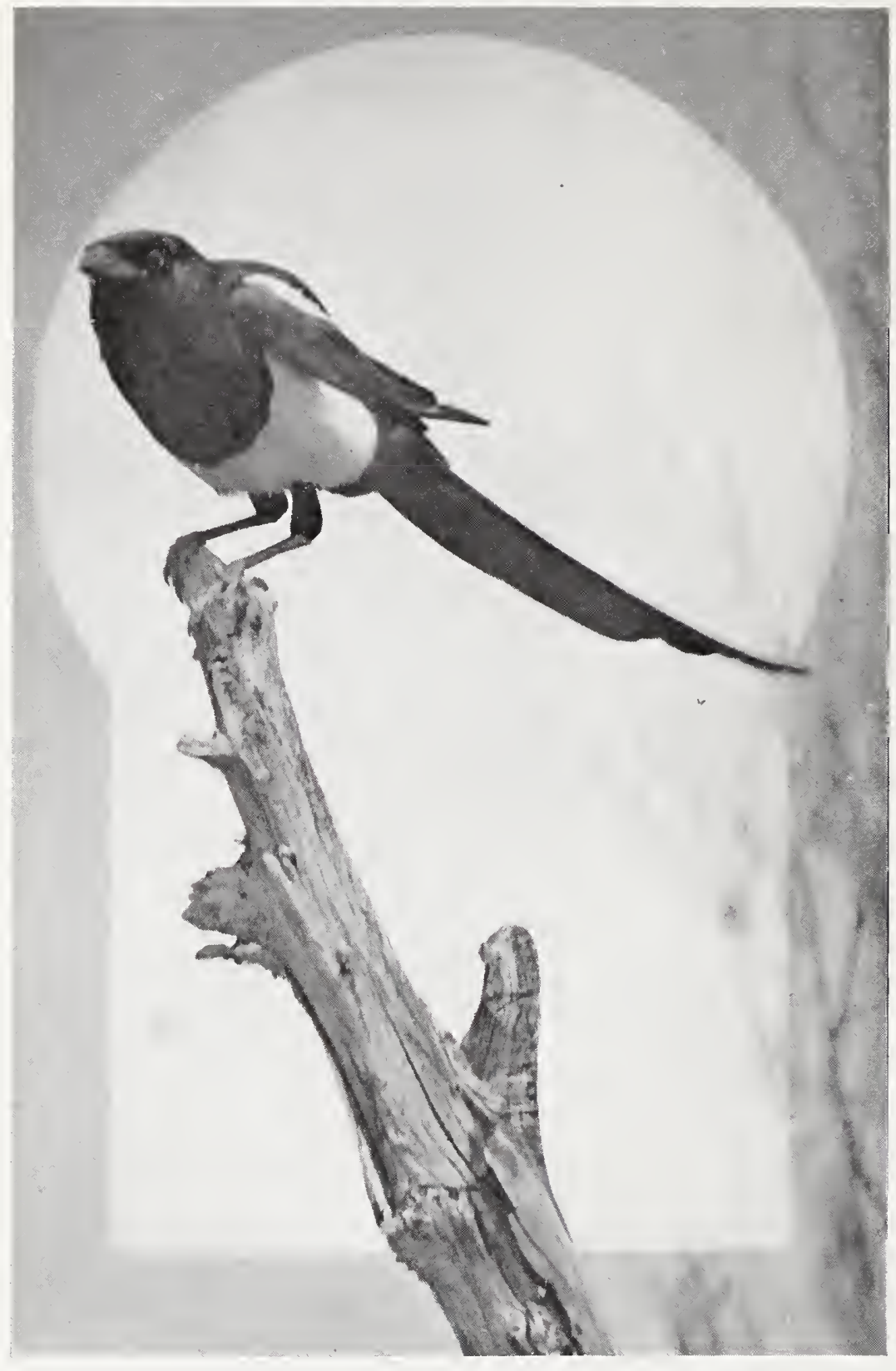

Taken in Inyo County

HERSELF

Photo by the Author

THIS MAGPIE IS THE MOTHER OF THE YOUNGSTER SHOWN ON PAGE 34 the normal nesting month, and there are late March records as far north as the northern border of the $\mathrm{U}$.S. In the high plateau region of northwestern California, however, early May eggs are the rule rather than the exception. The birds resort at nesting time to the most out-of-the-way places, where they breed in straggling colony fashion. The near vicinity of water is deemed a prime requisite, so spring "draws" covered with willows or quaking asps are favorite stations. Nests are, normally, at moderate heights, in willows, elders, or Crataegus bushes, but in regions where they have been subjected to persecution, the birds will resort to pine trees, if available, or in more desert situation to junipers, mountain mahogany, sage bushes, or 


\section{The Black-billed Magpie}

even the ground. The nest is a neat ball of interlacing sticks set about a hollow half-sphere of dried mud. The amount of labor expended upon one of these structures is prodigious. The greasewood nest shown at the head of this article is three feet deep and two feet through, and the component sticks are so firmly interwoven that no ordinary agency, short of the human hand, can effect an entrance. The bird enters through an obscure passage in one side, and, if surprised upon the nest, has always a way of escape planned through the opposite wall. The mud cup is carefully shaped with walls an inch or two in thickness, a total breadth of eight or ten inches, and a like depth. In the best construction this cavity is filled to a depth of three or four inches with a loose mat of fine twigs of a uniform size. Upon this, in turn, is placed a coiled mattress of fine, clean rootlets, the whole affording a very sanitary arrangement.

Magpies, like Blue Jays, are discreetly quiet in nesting time, and especially so if they have attempted to nest in the vicinity of a farmhouse. Else, and save for the presence of man, the Magpie has little to fear. His home is his castle in a very literal sense.

Young Magpies are unsightly when hatched,- " worse than naked," and repulsive to a degree equaled only by young Cormorants. Hideous as they unquestionably are, the devoted parents declare them angels, and are ready to back their opinions with most raucous vociferations. With the possible exception of Herons, who are plebes anyhow, Magpies are the most abusive and profane of birds. When a nest of young birds is threatened, they not only express such reasonable anxiety as any parent might feel, but they denounce, upbraid, anathematize, and vilify the intruder, and decry his lineage from Adam down. They show the ingenuity of Orientals in inventing opprobrious epithets, and when these run dry, they fall to tearing at the leaves, the twigs, the branches, or even light on the ground and rip up the soil with their beaks, in the mad extremity of their rage.

A pair with whom I experimented in Washington rather fell into the humor of the thing. The Magpie is ever a wag, and these must have known that repeated visits could mean no harm. Nevertheless, as often as I rattled the nest from my favorite perch on the willow tree, the old pies opened fresh vials of wrath and emptied their contents upon my devoted head. When mere utterance became inadequate, the male bird fell to hewing at the end of a broken branch in most eloquent indignation. He wore this down four inches in the course of my three visits. Once, when my attention was diverted, he took a sly crack at my outstretched fingers, which were hastily withdrawn; and, believe me, we both laughed. 


\section{The Yellow-billed Magpie}

The Black-billed Magpie winters practically throughout its breeding range. In the fall, however, it gathers into flocks, sometimes of quite considerable size. Such flocks, dependent upon the food supply, range widely, and as a result may be said to indulge in irregular migratory movements. Flock movements are sometimes performed with a unanimity of impulse akin to that of Sandpipers, and the sight of say fifty Magpies, black-and-white wings a-flutter and long tails streaming, slewing and tacking with the wind, is indeed a memorable one.

Wherever permitted, the Magpie becomes a faithful pensioner of the slaughter house. Stock men take advantage of the birds' weakness for meat, and assail them with shot-gun or poison. The birds learn to be wary of both, but between these attacks and the annual raiding of the nesting grounds, it is perfectly possible to clear the Magpies out of a given range. The first discovery of a "fallen hero" by one of his comrades is the invariable signal for a noisy wake. The clan is summoned by sharp cries, and the members assemble from far and near in quick response. Now one and now another hops up cautiously to view the remains, while all make strident cries which voice their undying indignation at man's cruelty. And, indeed, now that we think of it, what is the use in trying to reduce the varied offspring of nature to one dead level of mediocrity! If all birds were good little dickey birds, and said tweet tweet with pious uniformity, some men, now saintly, would undoubtedly be moved to profane utterance. Here, then, is a toast to the Magpie, cheerful, lovable devil of a bird that he is!

No. 6

\section{Yellow-billed Magpie}

\section{A. O. U. No. 476. Pica nuttalli (Audubon).}

Synonym.-California Magrie.

Description.--Exactly similar in body coloration to Pica pica hudsonia, but bill and bare orbital space yellow and smalier. Length 406.4-457.2 (I6.00-I8.00), wing I 87.5 (7.38); tail 238 (9.37); bill 3I (I.22); length at nostril I2.5 (.49); tarsus 48 (I.89).

Recognition Marks.-Black-and-white coloration; long tail; yellow bill.

Remarks. - The bright yellow bare skin below and behind eye and on the sides of the throat is a conspicuous feature of nestling birds, showing that the distinguishing characters of this bird are long established.

Nesting.- Nest: Nuch as in preceding; a sturdy sphere of interlaced twigs, penetrated obscurely by hole giving access to contained hemisphere of mud or dried cowdung; deeply cupped and cushioned with rootlets, or, rarely, horsehair; placed in trees at any height, chiefly in white oaks and cottonwoods. Eggs: 5-7, rarely 8, or even 9: yellowish glaucous or pale olive buff, finely and rather uniformly speckled and 


\section{The Yellow-billed Magpie}

spotted with buffy brown or citrine drab or grayish olive or deep grayish olive. Av. of 195 eggs in the M. C. O. collections: $30.8 \times 22.4(1.22 \times .88)$; index 72.I. Largest egg, $37 \times 23.4(1.46 \times .92)$; smallest, $26.7 \times 20.3(1.05 \times .80)$. Season: first week in April; one brood.

Range (Wholly included in California).-California west of the Sierras, chiefly in the Sacramento-San Joaquin Valley, and in the south central coastal counties; from Tehama County (Anderson, Shasta County, July 4, 1916-may possibly have been semi-domesticated birds at liberty), south to northern Ventura County and Santa Barbara County north of the Santa Ynez range (formerly to Santa Barbara, Santa Paula, Simi, etc.), east to central Butte County, Clipper Gap, Placer County, and Visalia in Tulare County, west to Mount St. Helena and the coast of Monterey County. Range thus included within about 35 contiguous counties, undoubtedly more restricted than formerly.

Authorities.-Audubon (Corvus Nuttallii), Birds of America (folio ed.), vol. IV., I 836, pl. 362, fig. I (orig. descr. from Santa Barbara, Calif.); Gambel, Journ. Acad. Nat. Sci. Phila., ser, 2, vol. I, 1847, pp. 46-47 (habits); Evermann, Amer. Nat., vol. XX, I 886, pp. 607-6I I (habits; nesting); Bendire, Life Hist. N. Amer. Birds., vol. II, I895, pp. 355-356, pl. III (fig. I4) (habits, nests and eggs); Noack, Condor, vol. IV, I902, pp. 78-79 (voice); Willett, Pac. Coast Avifauna, no. 7, 1912, p. 67 (status in S. Calif): Stone, Condor, vol. XVIII, I916, pp. 8-9 (history of discovery).

IN ALL the world there are but two distinct types of Magpie, the Black-billed and the Yellow-billed. The former is pretty well distributed over the Northern Hemisphere, while the latter is confined to California. We find California matching the world, therefore, in a situation which invites special attention. Where did the Magpies come from? and how did they get here? For both species have arrived in California. A study of the distribution of the black-billed species, the Pica pica type, quickly shows that its center of dispersal is north central Asia. Not impossibly, the genus Pica had its origin in the north Himalayan region, now emptied of its progeny, but which scientists assert to have been the ancient cradle of the human race. For the occurrence of seven or eight closely related subspecies at such extremes as Spain (melanonota), Northern Africa (mauritanica), Northern Europe (pica). Northern Asia (bactriana), China (sericea), and Northwestern America (hudsonia), clearly indicate a radial distribution. The American representative, therefore, of the black-billed species, arrived by the way of the wellknown land-bridge which once connected Siberia and Alaska. But when at last hudsonia reached California, it found Pica nuttalli anciently entrenched, and it recoiled. How did muttalli get here? Probably not by the Bering land-bridge, at least not at the time of the latest establishment of that bridge; else its progress could still be traced by a series of related forms. Two hypotheses only remain, both daring, and destitute alike of actual foundation. Either nuttalli is an ur-ancient emigrant from Asia, whose congeners were blotted out by the oncoming of the ice age, 


\section{The Yellow-billed Magpie}

or else the muttalli stock was planted here by direct, and of course, artificial, though prehistoric, importation from Eastern Asia. It is quite

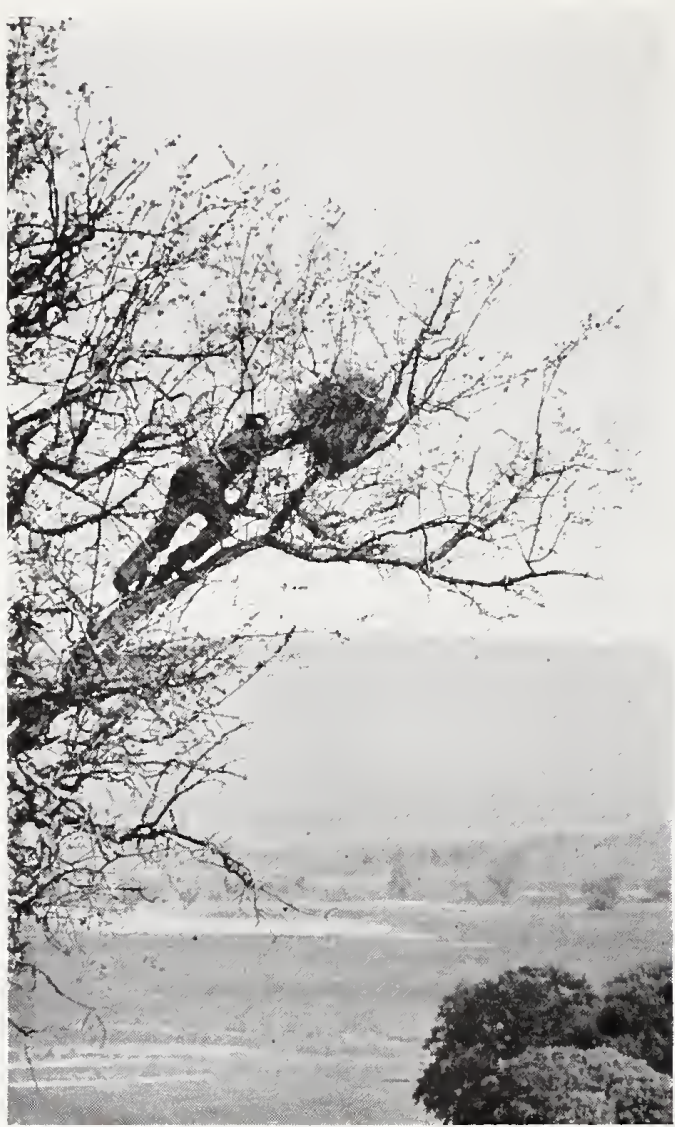

Taken in San Luis Obispo County Photo by the A uthor

A CRITICAL MOMENT-COUNTING THE EGGS conceivable that Pica pica stock, especially if represented by a single pair, suddenly released under absolutely different conditions, should develop a sharp variant which would soon achieve validity as an independent species. Against the former hypothesis should be urged the failure of the species to react from its narrow confines (in theoretical Southern California), when it was released by the ice. And in favor of the latter hypothesis may be urged the very limited distribution which the bird has attained, even in California. It is authoritatively reported from only thirty counties (or, by inclusion, thirty-seven), all contiguous, out of a possible fifty-nine. We cannot tell; but at any rate there is a profoundly interesting problem here.

One who is familiar with both species, pica and muttalli, finds it a little difficult to draw distinctions of any other sort save color and size between them. There are no recognizable peculiarities of voice, or motion, or nesting habit, which will serve to distinguish them. Yet I have a feeling that the Yellow-billed Magpie is a weaker stock, less aggressive and resourceful, than its northern kinsman. On the whole, too, I think it is a quieter bird. Occupying, as it does, a more favored area, with open winters, there is perhaps a less highly developed social instinct in the southern bird, with probably a less frequent resort to mob tactics. But none of these points can be pressed.

Whatever the cause, whether a less virile stock, or the more intimate pressure of civilization, it is certain that Yellow-billed Magpies are suffering a gradual reduction of distributional area, with steadily decreasing numbers. At the present rate of destruction (from injuries real 


\section{The Yellow-billed Magpie}

or fancied), it is not at all improbable that the species may be extirpated, a truly deplorable event.

The Yellow-billed Magpie usually breeds in scattered colonies, either in the cottonwoods of river-bottoms, in the oak trees, whether "live" or deciduous, which dot the lower levels of the foothills, or else in the mixed cover, oak, ceanothus, and digger pine, which clothes the middle levels of the hills. The birds are very much attached to the locality of their choice, returning year after year to occupy the same trees, and in some instances enduring persecution on this account to the point of extinction. At other times, and especially in level country dotted with white oaks, the colony will shift from year to year.

A Magpie's nest, big as a bushel basket, would seem to be about the most conspicuous artificial object in a tree-top;

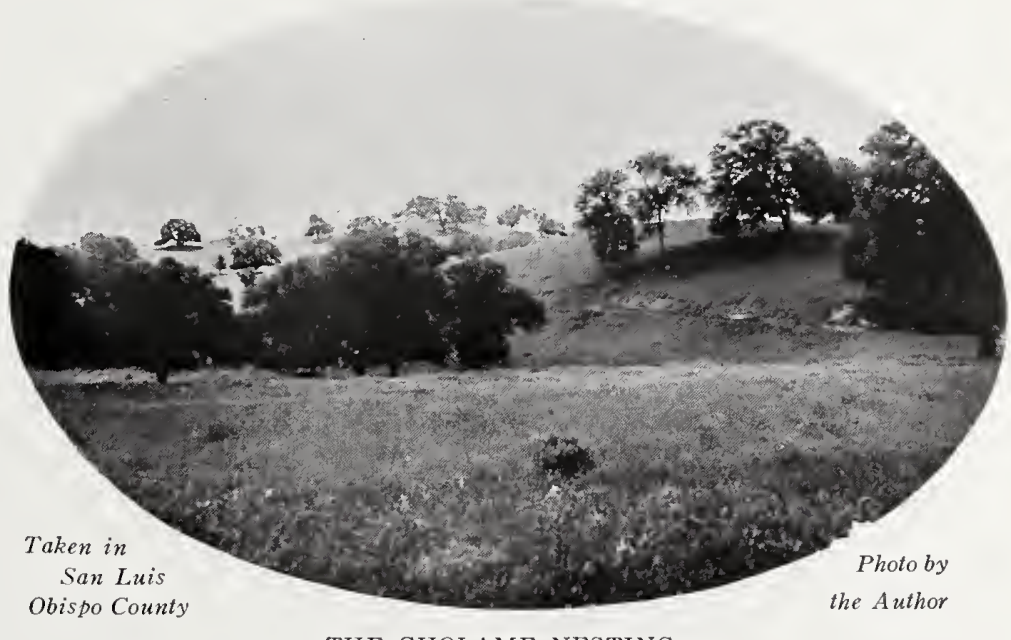

THE CHOLAME NESTING

but it so happens that the distributional area of Pica nuttalli nearly coincides with that of the mistletoe (Phoradendron flavescens Nutt. and $P$. villosum Nutt.). As a result we have trees full of Magpies' nests to appearance - with never a bird about. Or, if the birds are about, they are cunning enough to avail themselves of the mistletoe bunches, either building in the clump itself, or building in trees generously provided with these puzzling decoys. One Magpie's nest I found in San Luis Obispo County was only one of twenty-five likely-looking chances in a single tree.

If undisturbed, a pair of birds will usually return to the same tree each season, rarely, indeed to occupy last year's nest, but of ten to use it as a foundation for the new structure. Double nests, on this account are common, and I once found a composite structure, a huge pile, representing the work of four successive seasons. When approached, the sitting bird usually sits tight until the climber is within a few feet of the nest. Then she makes good her escape from the opposite side, and takes care for the nonce to keep the nest, or the tree, or both, between herself and the pursuer. 


\section{The Yellow-billed Magpie}

A bulky sphere, or inverted pear-shaped mass of sticks, greets the investigator, for the upper dome, or cover, is likely to be a little larger than the lower, which contains the nesting bowl proper. Three feet in depth by two and a half in width, over all, are the regulation dimensions for these castles; but I have seen splendid nests, all new construction, which measured $4 \frac{1}{2}$ by $3 \frac{1}{2}$ feet, roughly thirty-three and a half cubic feet of material, including house room. The bowl, or matrix, is sometimes formed of mud, but oftener of cow-dung, for this substance is both more convenient and more durable for birds in the cattle country. The wall of an experienced builder dips gracefully to the depth of an inch or two at the entrance; while the entire bowl is from seven to ten inches in diameter inside, by from four to seven in depth to the floor-lining. Of course this large space is not completely occupied by the body of the sitting bird. It is only a provision for that roomful of youngsters which is on the way. In at least one instance I have noted a second or inner hollow, in the mud cup, exactly fitted to the dimensions of the sitting bird.

Eggs to the number of seven, rarely more, are deposited upon a generous mattress lining of roots or coiled grasses. Incubation lasts twenty-one days, during which time the bared breast of the brooding bird is grievously tormented with fleas. There is no time for recuperation, though, after the youngsters come. Life, instead, becomes one long nightmare of effort to fill seven insatiable maws. What wonder, then, if milady, and milord as well, help themselves freely to certain storehouses of albuminous nourishment duly made and provided by their less fortunate feathered neighbors? Or what wonder if Lady Mourning Dove and Sir Meadowlark are requisitioned for squabs and broilers? Let him that is without sin among us cast the first stone.

Another brief, also, can be made out in defense of the Magpie. His deserted tenements are exceedingly useful both as retreats and as domiciles for certain other birds. Corre to think of it, though, the "other birds," Sparrow Hawk, Long-eared Owl, and Pacific Horned Owl, belong themselves to the brigand list. Perhaps we would better not press that plea.

One hesitates to recommend these vanishing fowls as cage-birds, not because they are not commendable, but because they are vanishing. Our legislature has placed wise restraints upon the use of native birds as captives. But those who will undertake the task of foster-parenthood seriously, and provide adequate quarters and abundant food for their pets-such will find the Magpie among their most interesting pensioners. An avicul turist of wide experience, Mr. H. R. Noack, of Oakland, secured two Yellow-billed Magpies which furnished him and his friends no end of sport. One of the birds, a male, "John Henry, " developed a gratifying 


\section{The Yellow-billed Magpie}

gift of speech, and that without the silly tongue-cutting operation, which some people advocate. He called his master and his mate by name, and made a delightful nuisance of himself by calling in the neighbors on various and sundry, but quite unnecessary, occasions. Mr. Noack

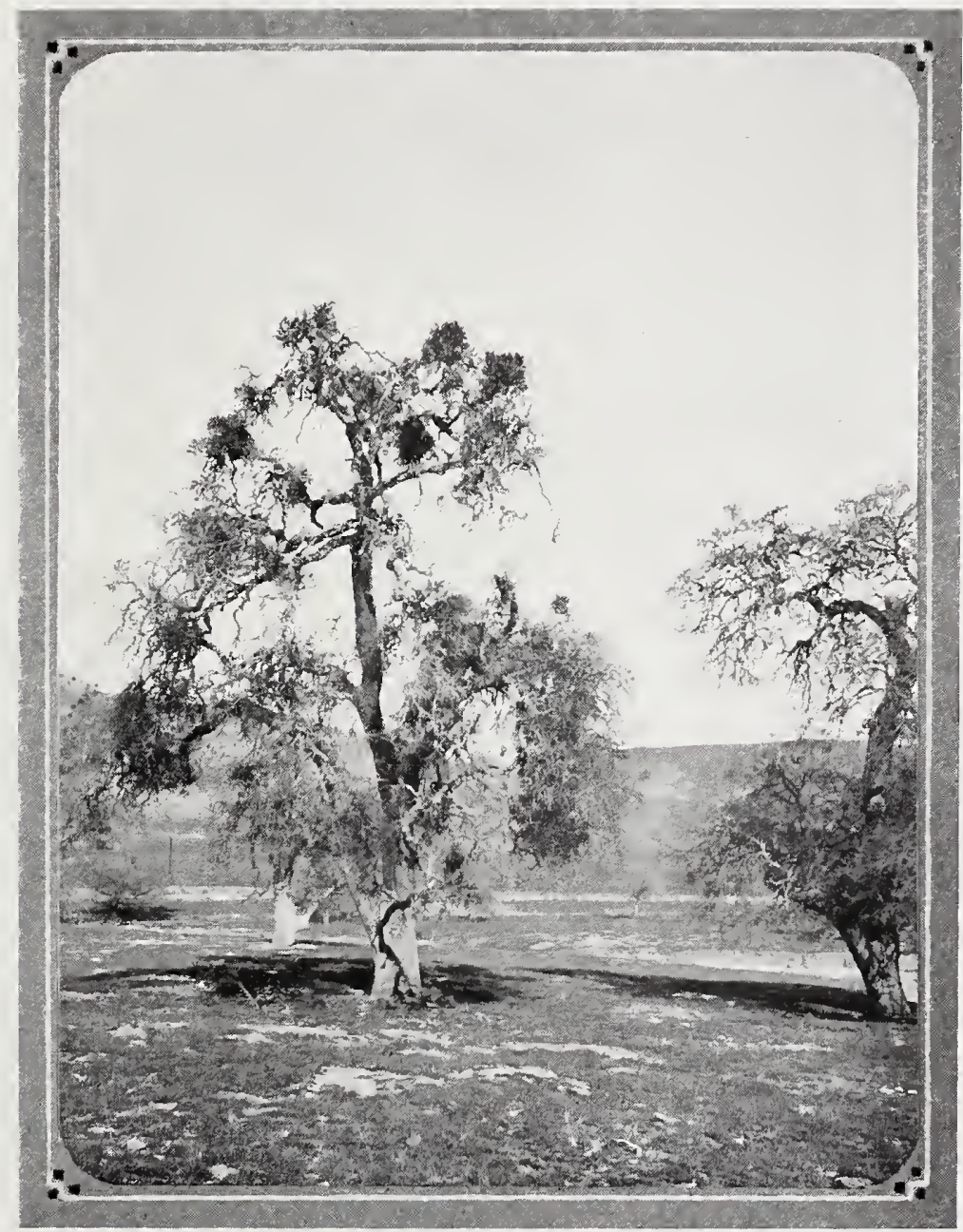

Taken in San Luis Obispo County

Photo by the A uthor

A WHITE OAK NESTING

THE TWO MAGPIES' NESTS WHICH THIS TREE CONTAINS ARE SCARCELY TO BE DISTINGUISHED FROM THE CLUMPS OF MISTLETOE

continues: "Our stable is within fifty feet of the Magpie's cage, and my brother, who was acting as hostler, was often about ready to swear when hitching up or currying the horse, when John Henry would cluck to the horse, 'ck ck ck', and then say 'Get up, Peter, get up, 'get up,' 


\section{The California Jays}

following immediately with 'Whoa boy, whoa,' and following with such a variation of 'whoas' and 'get-ups' and clucks, that the poor horse would not know what to do.

"One of the most amusing uses to which the Magpie puts his powers is to call the chickens-'chick, chick, chick, chick,' and when they have run, eager and expectant, in the direction from which the sound comes, which is, naturally, the cage, to seize one by the comb or the back of the neck and pull out a few feathers or spill a little blood. An old game hen used to respond to his calls, and as soon as she received a tweak on the head would ruffle up and begin a regular fight through the wire netting. At this time John Henry exhibited himself at his best. While flying at the hen he would keep saying 'Chick-chick-chick, come on, come on, Harry, Harry-get up, hello'. In fact he would go through almost his entire vocabulary while fighting and pulling out feathers."

No. 7

\section{California Jay}

\section{A. O. U. No. 48I. Aphelocoma californica californica (Vigors).}

Description.-Adult in fresh (fall and winter) plumage: Pileum, hind neck, sides of neck, and breast (with interrupted borders of jugular white patch) wings, upper tail-coverts, and tail, bright grayish blue (cadet blue to Venetian blue); darker (deep cadet blue) on crown and nape; lighter (king's blue) on wings and upper tailcoverts; tertials and rectrices finely and obscurely barred with darker; concealed webs of flight feathers, and inner edges of rectrices, dusky; the shafts of wing and tail black; cheeks dark blue (hortense blue) changing to slaty black on auriculars; a superciliary line of white streaks; chin, throat, and chest, white, the plumage loose and streaked with bluish dusky; back and scapulars warm brownish gray (benzo brown), sometimes glossed with blue, paling with eruptive white and mingled bluish on wing; breast, immediately below jugular area, warm grayish brown, fading quickly to pale brownish gray on belly and sides; crissum pale bluish white; axillars and lining of wings mouse gray, sometimes tinged with bluish. Bill and feet, black; iris, brown. Adult in worn (spring and summer) plumage: Blue wearing off on head, sides of breast, and tertials, with increasing exposure of dusky drab bases; brown of back fading irregularly to drab and light drab; underparts, duller, soiled and brownish. Young birds are much like adult in worn plumage, but duller,-blue scarcely discernible over the drabs of head, neck, and sides of breast. Length of adult male 292-3I8 (II.50I 2.50); average of 3 I (after Swarth): wing I I9.5 (4.70); tail I33.3 (5.24); culmen 25.6 (I.OI); depth at nostril $8.5(.33)$; tarsus $39.6(1.56)$. Females average smaller.

Recognition Marks.- Robin size; blue and gray coloration, without crest; underparts lighter than in $A$. woodhousei, and crissum white, or white tinged with bluish, instead of definitely blue. 


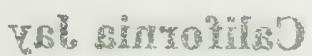

ssie sill ấ vuodA 
California Jay

About $3 / 5$ life size 


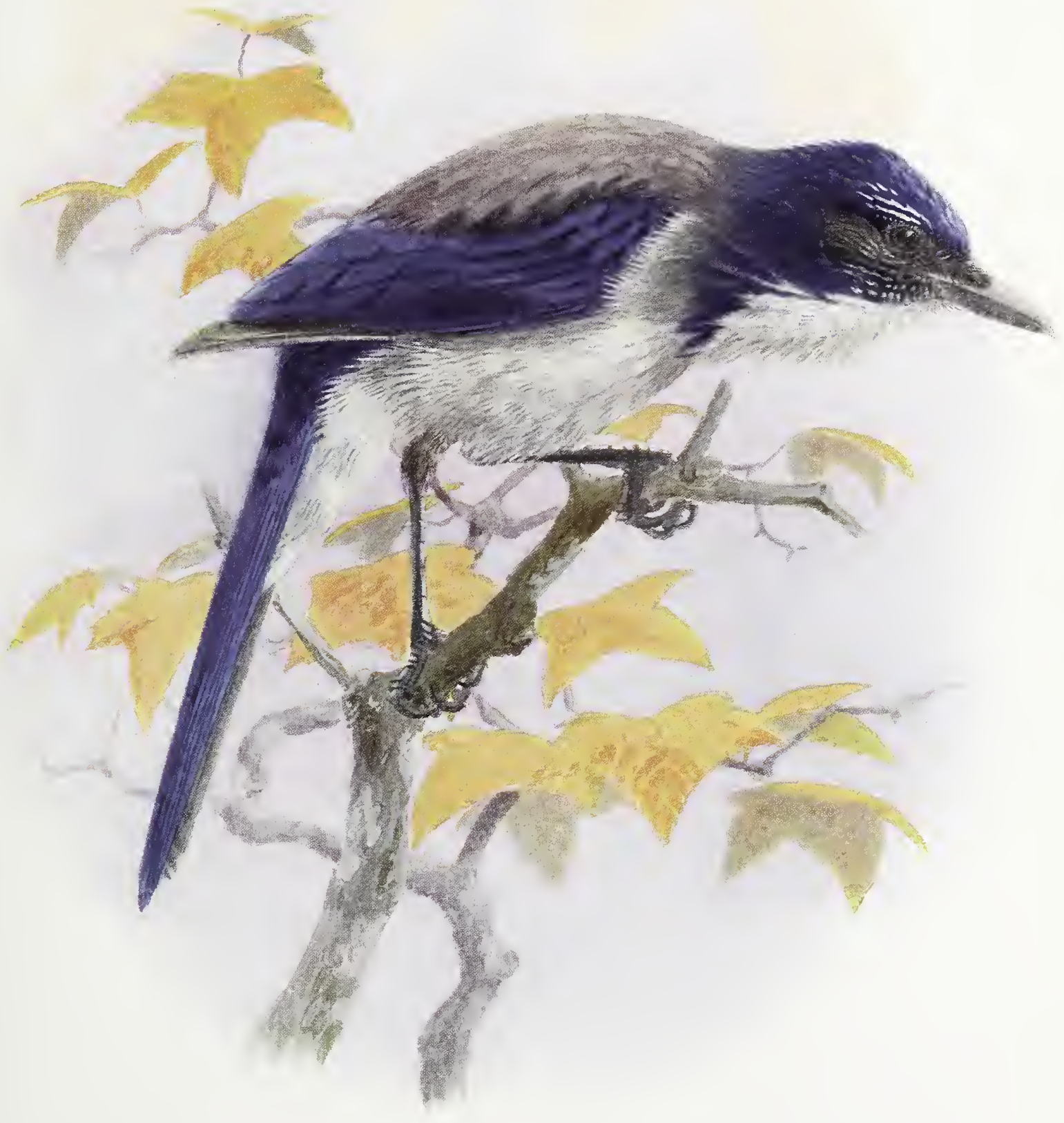

chelare STruale. 

Nesting.- Nest: Basally a crude criss-cross of long twigs; middle structure very scanty or wanting; lining, typically, of coiled rootlets, always of uniform derivation; innermost lining, or not, of coiled horsehair or matted cowhair; placed at any height in bush or tree. Eggs: 4-6, of two types: The green type, ground color pale sulphate green to lichen green, spotted or blotched, chiefly at larger end, with deep olive or Lincoln green; the "red" type, ground color clear grayish white to lichen green, spotted with warm sepia or bister to Rood's brown. Av. of I 40 eggs in the M. C. O. collection $27.4 \times 20.3$ (1.08 x .80); index 74. Extremes measure, $34.3 \times 19(1.35 \times .75)$; index 57 ; and $24.4 \times 20(.96 \times .79)$; index 82 . Season: April, one brood.

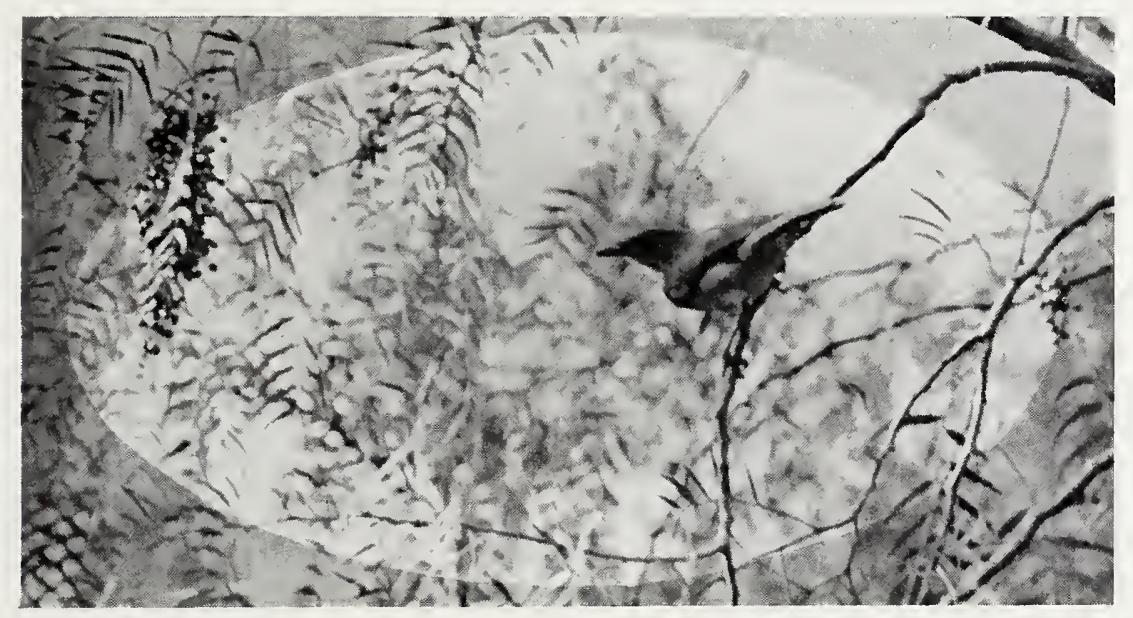

Taken at Los Colibris

Photo by the Author

DISTRUSTFUL

Range of Aphelocoma californica--California except the southeastern desert regions, northern Lower California, and western Oregon, north to and barely across the Columbia River in the neighborhood of Vancouver, Washington.

Range of $A$. c. californica.- "A relatively narrow strip along the coast of California and northern Lower California; from the San Pedro Martir Mountains, Lower California, north on the coastal slope of California, west of the southern Sierras and the Coast ranges, through the San Diegan and Santa Cruz districts to the south side of San Francisco Bay" (Swarth).

Authorities.-Vigors (Garrulus californicus), Zoology of Beechey's Voyage, I839, p. 2I, pl. V. (original description; type from Monterey, Calif.); Gambel, Proc. Acad. Nat. Sci. Phila., vol. III, I 847, pp. 20 I-202 (crit.); Bendire, Life Hist. N. Amer. Birds, vol. II, I 895, pp. 374-377 (part), pl. V (fig. I 7) (habits, nest and eggs); Merriam, F. A., Auk, vol. XIII, I 896, p. I20 (burying acorns); Beal, Biol. Surv. Bull., No. 34 , r9ıo, pp. 50-56, pl. III (part) (Food); Mailliard, J., Condor, vol. XIV, I9ı2, p. 42 (record of nests); Grinnell and Swarth, Univ. Calif. Publ. Zool., vol. Io, I9I3, pp. 26I-262 (crit. re obscura); Swarth, Univ. Calif. Publ. Zool., vol. I7, I918, pp. 410-4I3, I fig. (crit.; range). 


\section{The California Jays}

\section{No. 7a Grinnell's California Jay}

A. O. U. No. 48 I part. Aphelocoma californica immanis Grinnell.

Description.-Similar to $A$. c c californica, but slightly larger and paler both above and below, the blue areas "Chapman's blue" instead of cadet blue; the under tail coverts usually pure white. Av. of $3 \mathrm{I}$; wing I25.9 (4.96); tail I 38.5 (5.45); culmen 25.4 (I.00); depth at nostril 9.3 (.366); tarsus 40.8 (I.60).

Range.- "Extreme southern Washington; in Oregon those valleys lying between the Cascades and the Coast Ranges, and south in California through the Sacramento and San Joaquin valleys and the Sierra Nevada. East to the Warner Mountains and the eastern base of the Sierra Nevada." (Swarth).

Authorities.-Newberry (Cyanocitta californica), Rept. Pac. R. R. Surv., vol. VI, pt. IV, I 857 , p. 85; Bendire, Life Hist. N. Amer. Birds, vol. II, I 895, pp. 374-377 (part) (habits, nest and eggs); Beal, Biol. Surv. Bull. No. 34, I9Io, pp. 50-56, pl.III (part) (food); Grinnell, Condor, vol. XIII, I9II, p. I09 (relation to small birds);Oberholser, Condor, vol. XIX, I9I7, pp. 94, 95 (taxonomy); Swarth, Univ. Calif. Pub. Zool., vol. I7, I9I8, pp. 4I5-4I7, I fig. (descr.; range; crit.).

\section{No. 7b Swarth's California Jay}

A. O. U. No. 48I part. Aphelocoma californica oocleptica Swarth.

Description.-Like A. c. californica, but averaging slightly larger. Av. of 7 : wing I 25.4 (4.94); tail I36.7 (5.37); culmen 25.8 (I.02); depth at nostril 9.I (.36); tarsus 4I.5 (I.63).

Range.- "The Coast region of northern California, west from Mount Diablo and the Coast ranges. North to Humboldt Bay, south to the Golden Gate and the east side of San Francisco Bay." (Swarth).

Authorities.-Baird (Cyanocitta californica), Rept. Pac. R. R. Surv., vol. IX, I 858 , p. 585 ; Bendire, Life Hist. N. Amer. Birds, vol. II, I 895, pp. 374-377 (part) pl. V (fig. I 5) (habits, nest and eggs); Mailliard, J., Condor, vol. II, I 900, pp. 58-59, 94-95, I26 (habits); Cohen, Osprey, vol. VI, I902, pp. I-6, I fig. (habits); Mailliard, J. W., Condor, vol. XIV, I912, p. 42 (nesting); Swarth, Univ. Calif. Publ. Zool., vol. I7, I918, pp. 4I3-4I5, I fig. (description of oocleptica; range).

CALIFORNIA is the land of unfailing contrasts. Hot or cold, wet or dry, green or brown, low or high, you may order what you will (so you order your own movements to correspond), and lo, it is yours within the hour. But most striking of all Californian contrasts, is that ever recurring one between civilization and the wilderness. Does your soul abhor crowds, then escape to the wilderness forthwith and find solace. On a New Year's Day, when Pasadena was threatening to celebrate its annual Festival of Roses, the writer with a nature-loving companion fled to the hills, and at the very moment when the customary queen was being crowned amid the huzzas of a perspiring and dishevelled populace some seven miles away, we were ogling a band of deer as they picked their way daintily over the steep slopes of chaparral.

Finer yet was a contrast which met my immigrant eyes at Berkeley

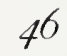




\section{The California Jays}

some ten years ago. Having dutifully done the honors of our imposing State educational plant, civilization's finest fruitage, I took leave of my punctilious host at the Greek Theater, sacred to the memory of our immortal Hearst, and within ten minutes had regained Eden, an Adamless and Eveless spot, hidden in a curve of the hills, choked with greenery, and where only the birds murmured. And, sure enough, there came the guardian angel (?) (I had entered by an unused trail, it seemed)-or was it a blue-coated gendarme noisily brandishing a flaming sword? "Jayick! jayick!" It is he! It is he! The sweet, authentic devil, the California Jay! He, the malaprop, the impertinent, the sly wag, thief, scoundrel, outcast, jackal of the bush, bon homme libre, as innocent as morning, as industrious as noon, as wicked as night. C'est le dermier des oiseaux.

But there is California for you! Within the academic shades the grave tread of the masters, masters of philosophies and of arts and of men. A shade removed, this master of obliquities, ruling his kingdom of the untrod.

The California Jay occupies a commanding position in the life of the chaparral and of oak-covered hillsides, throughout California. By "commanding" we do not mean exactly that everything is ordered according to the Blue Jay's will; but it is certain that little takes place without his knowledge; and, as we shall see, presently, he is undoubtedly the chief biological control factor in the distribution of bird-life throughout the area specified. The abundance of the jays and the thoroughness or uniformity of their distribution within any given area will astonish one who has not given close attention to the matter. Try this test: Kiss the moistened hand in such diligent fashion as to produce what Coues has so well called a screeping sound. This under a little practice sounds like the distress call of a wounded bird, and a distress note is the rally call of all jays. If you are in jay country at all, first one and then another of the blue-coated rascals will come slipping up through the shrubbery, until you may have a dozen of them poking and peering to discover the source of the commotion. To perfect the play rigid immobility is necessary on the part of the student. Birds detect motion before they do color or form, and at the first discovery of man's presence there is a vigorous outcry and a gradual edging away on the part of the crestfallen birds. But whatever the fashion of your luck at that particular siren station, you will have found at least that California Jays exist almost everywhere within earshot in suitable country.

The "screeping" test is also a good school for the study of Jay manners. Furtiveness, curiosity, impudence, drollery,-all these qualities come out. And Oh! the noise of it! The Jay's ordinary alarm note is 


\section{The California Jays}

an astonishing vocal outbreak, dzweep or $d z u e e p$, with which the groves are brought up standing. No masquerader at Mardi Gras ever sprung such a cacophonic device upon a quiveringly expectant public. Dzweep dzweep it curdles the blood, as it is meant to do. It costs the bird an effort, no doubt, for the whole body moves in sympathy. Could anything be more saucy than the mocking bow of the California Jay, as he dips his head and jerks his tail and asks, "Who the devil are you?" And there he shifts and scrapes and challenges until nervousness gets the better of valor, and he is off to a neighboring cover with exaggerated flirt and fluff of wing and pumping tail. He is Puck-of-the Woods, but not, alas! Robin Goodfellow.

Without doubt this Jay takes a conscious delight in mischief-making. If he sees a company of sparrows feeding in a little open space, he will slip up quietly, under cover, then plump down suddenly with a screech which sends the little fellows flying like bursting shrapnel. And the delighted Jay stands there like a drum-major before a cinematograph. "Oh, if Mary could see me now!" Mr. Mailliard has told us ${ }^{1}$, most entertainingly, of some jays which took to teasing the family cats at San Geronimo. It was not enough for a jay to steal up behind one of the cats while it was at supper, strike the hapless pussy a smart blow on the tail, and then, when tabby turned to defense, make off shrieking with the meat, cleverly snatched up. The cats got onto this, and not only kept their tails decorously between their legs, but continued to mind their muttons while the chewing was good. But if ever a jay caught a cat napping, with its tail partially extended, it approached with eyes snapping in delight. The situation had to be studied carefully and noiselessly, with head cocked first on one side and then upon the other. Finally, when the most vulnerable spot had been decided upon, the jay would give the poor tail a vicious peck, and then fly "screeching with joy" to the nearest bush.

But if the "Blue Jay" is active in the pursuit of mischief, he knows also how to become passive and to let Nature disclose her secrets to him. Especially in nesting time "watchful waiting" becomes the winning policy for the Blue Jay. Accordingly, he posts himself in some conspicuous place, a tree-top or a telephone wire, and looks and looks and looks. At such times he may be the very picture of innocence, or patience on a monument, until one is moved to ask him as the traveller did of the Tennesseean, "What do you do with yourself all day?" And the answer might be, "Wa-al, sometimes I sets and thinks, and sometimes I just sets." But the Blue Jay knows exactly what he is about, and every little bird of the forest knows that he knows-and shudders.

1"The Condor," Vol. VI., p. 94, July, 1904.

$$
48
$$


Although such an industrious creature when he, or she, isn't "settin",", the jay's flight is slow and labored. Extensive flights are never undertaken, and it would probably be impossible for a California Jay to fly from the mainland to the Farallones, for example.

The time of year or the nature of the season has a good deal to do with the jay's activities, and especially with the publicity thereof. As the time of its own nesting approaches, the jay falls silent, and the adroitness with which this bird will let himself be forgotten, is truly amazing. The birds may be nesting in your own

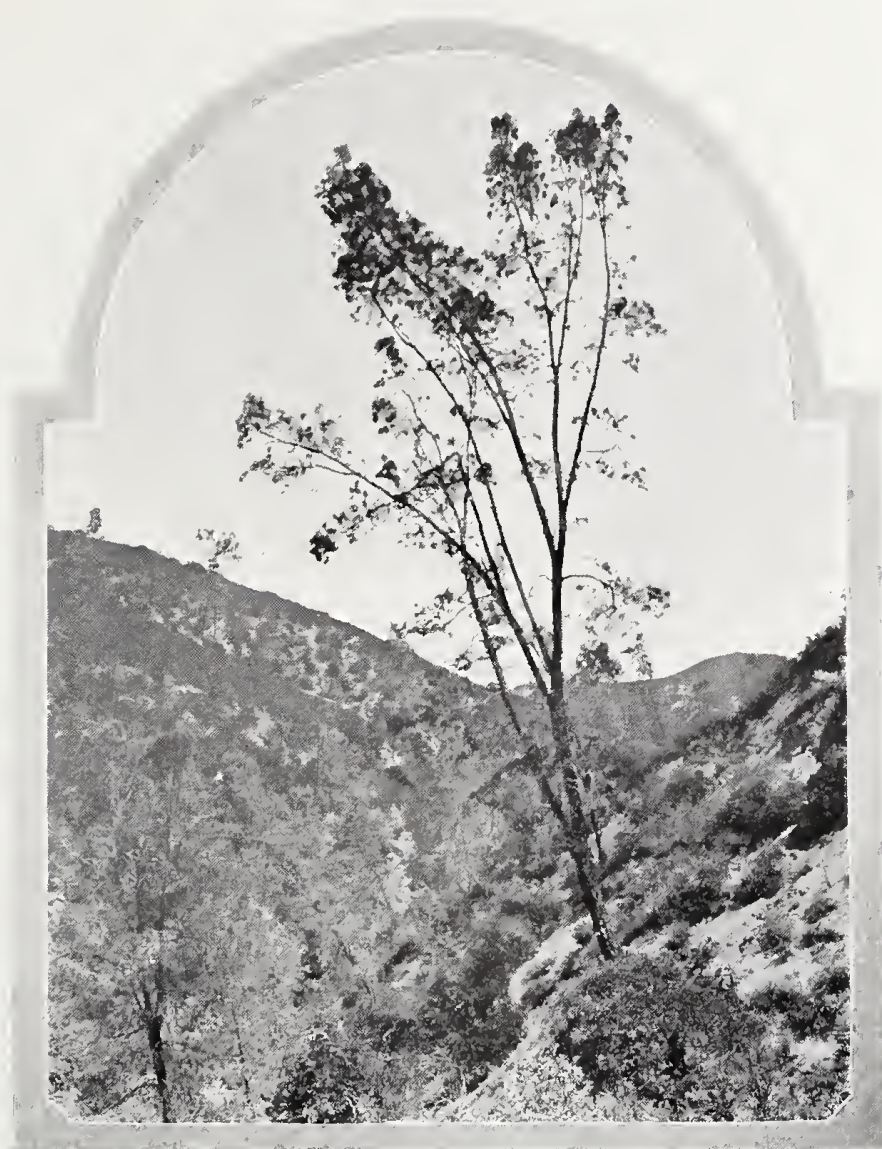

Taken in San Luis Obispo County

Photo by the A uthor

JAY COUNTRY

THE "DIGGER" PINE IS A CHARACTERISTIC TREE OF THE SOUTHWESTERN COASTAL RANGES

front yard; and now that you think of it, you do recall having seen the male bird pottering about on two or three occasions. But as for the California Jay of fame, he is dead. But when the birds have got by with it, when the youngsters, fullfledged, have joined the piratical push, and especially after the mid-summer molting season, then look out for noise! Caution is thrown to the winds, and the world becomes a vast screeching ground, made only for jays to practice in.

The Blue Jay, too, is a faithful chronicler of wet and dry. When the face of nature has become parched, when great heat fissures appear in the dobe soil, and when the cattle are quarreling feebly for a little wisp of last year's straw, the jay, too, falls silent. Dust is a poor lubricant for even raucous throats, and what villain could exult in such universal drought? 


\section{The California Jays}

But oh, how sweet is the smell of returning moisture! and how grateful the flick of tiny raindrops on the face! All nature is "swelling wisibly" with sap and satisfaction, and life begins over again in joyous earnest. The Meadowlarks exult, of course, and the lordly males chuckle, "I told you so," to their doubting mates. Bush-Tits lisp with treble emphasis, and, if it be early spring, the Robins go dashing about excitedly, packing their Alaska trunks, and bidding their friends good-bye. But it is the California Jay, the "Blue Jay," whose ear-splitting voice has most notably revived. We can almost forgive him all his mischief for the hearty, saucy stridor of his rain-wet tones.

But-but-mischief, thy name is Blue Jay. It falls, now, to the writer's unhappy lot to rehearse the sins of the California Jay, and surely, the recording angel himself has no more laborious task-unless, as we strongly suspect, the office keeps an extra clerk on this job. To see our jay munching an acorn, which is, by most accounts, his proper food, one would extol his exemplary virtue. [One correspondent, indeed, grumbles because the jay is robbing the hogs thereby; but we'll let that pass. We're not as hoggish as that yet.] Whack, whack, whack, goes the jay's intrepid beak, until Sir Acorn with a groan yields up his substance. Mast, according to Beal, forms 38 per cent of this Jay's food. Acorns are gathered and hoarded for future use also, not methodically, as in the case of the California Woodpecker, but still laboriously. Casual hidey holes in bark or broken limbs or rotting stumps are utilized, with now and then a more ambitious attempt to fill space, as in the case of Mark Twain's immortal bird. If the cache gets wormy, so much the better. So much better, in fact, that some observers have teigned to believe the birds, with conscious art, are preparing worm cultures.

Akin to this is their habit, well attested, of burying nuts, especially almonds, in the earth. Doubtless the bird intends to make inquiry later of his buried talent; but doubtless, also, this miserly trick has served Nature's purpose now and then in producing new trees.

Speaking of almonds, the depredations of the California Jay are such as to make the orchardist weep. Outlying trees are fairly stripped, and what the birds cannot eat they carry away. The case does not seem to be so bad with English walnuts, for although some are eaten at immature stages, the shell soon becomes too hard to interest the jays. As a pilferer of fruit, again, the jay has few rivals and no superiors. He is at it early and late. Nothing daunts him. Shot guns? Who would not run such risk for a juicy ripe cherry! "Bing" or bang, it is all one to a brave heart. Mr. Beal, the economic expert, tells of observations made on a small prune orchard, placed where a small ravine debouched from the wooded hills. "The fruit was just ripening and a continuous line of jays was 


\section{The California Jays}

seen passing from the hills down through the ravine to the orchard, while a return line, each jay bearing a prune, was flying up the ravine to the woods, where, probably, the fruit was secreted and left to rot. *** Several hours later the jays were still at work."

Grain is gleaned in a desultory fashion wherever it is exposed; but it is only in early spring that real damage is done. Mr. Joseph Mailliard ${ }^{1}$ observed their depredations closely at San Geronimo in Marin County, and he concluded that it was the softness of peas or corn in the sprouted state which appealed so strongly to the jay's taste. "I have had acres of peas that were sown in the end of March, to be cut green for feed when large enough, practically destroyed by these birds. * * I remember one spring when a patch of about an acre and a half was sown with a mixture of peas and oats, and the peas were pulled up as fast as sprouted, by the jay, so that the crop consisted of oats alone. In this instance the land was bordered by a growth of trees that made a fine shelter, to which the birds could retreat when disturbed. I shot over forty in one afternoon on this occasion, and a good many on succeeding days, but they soon became so wary that it was impossible to get another shot after one was killed-and yet the crop was destroyed."

On another occasion it was some late grown oats they took to. "They would dig away with their bills a little earth from the stalk where it just showed through, get a good grip and pull. If the stalk broke they would try the next one. When the whole plant came up by the roots they would jump to the nearest lump of earth and pick the kernel out of the husk, leaving husk, root and stalk lying on the lump.

Shooting one occasionally would cause them all to fly to the nearest trees, but they would be at it again in a few minutes, with some on watch."

But your jay is no vegetarian. He annexes bugs and slugs as matter of course, indulges a frog or a lizard now and then, and even aspires to mice and shrews. His long suit, however, is the destruction of eggs and young birds. This is his real function and raison d'etre. Beginning with the modest fruit of the hen, or the equally humble quail, he works up through successive deglutitive stages until he can boast a discriminating preference for Phainopeplas' eggs, or Hutton Vireo babies. Black-headed Grosbeaks' eggs are a staple in season, while Rufous-crowned Sparrows, Bell Sparrows, California Purple Finches, and Lutescent Warblers pay due toll to the epicurean fancy.

But I am getting ahead of my story. Let us consider the case of the poultry raiser first. Mr. Beal again ${ }^{1}$ is expert witness for the prosecution: "He is a persistent spy upon domestic fowls, and well knows the meaning

1"The Condor," Vol. II., May, 1900, p. 58 2"Birds of California in Relation to the Fruit Industry," Part. II., p. 50, U. S. Dept. of Agriculture Biol.
Surv. Bull. No. 34, 1910 . 


\section{The California Jays}

of the cackle of a hen. A woman whose home was at the mouth of a small ravine told the writer that one of her hens had a nest under a bush a short distance up the ravine from the cottage. A jay found this out, and every day when the hen went on her nest the jay would perch on a nearby tree. As soon as the cackle of the hen was heard, both woman and bird rushed to get the egg, but many times the jay reached the nest first and secured the prize. A man living in the thickly settled outskirts of a town said that jays came every morning and perched on some large trees that overhung his barnyards, where the hens had their nests, and that it was necessary for some member of the family to be on the lookout and start at the first sound of the hen's voice or a jay would get the egg.

"A still worse trait of the jay was described by a young man engaged in raising poultry on a ranch far up a canyon near wooded hills. When his white leghorn chicks were sma!l the jays would attack and kill them by a few blows of the beak, and then peck open the skull and eat the brains. In spite of all endeavors to protect the chicks and shoot the jays his losses were serious."

If this sort of thing befalls a closely protected fowl, and one in which man has a vital economic stake, what happens, think you, to the children of the wild which have no protector? My own belief, based on

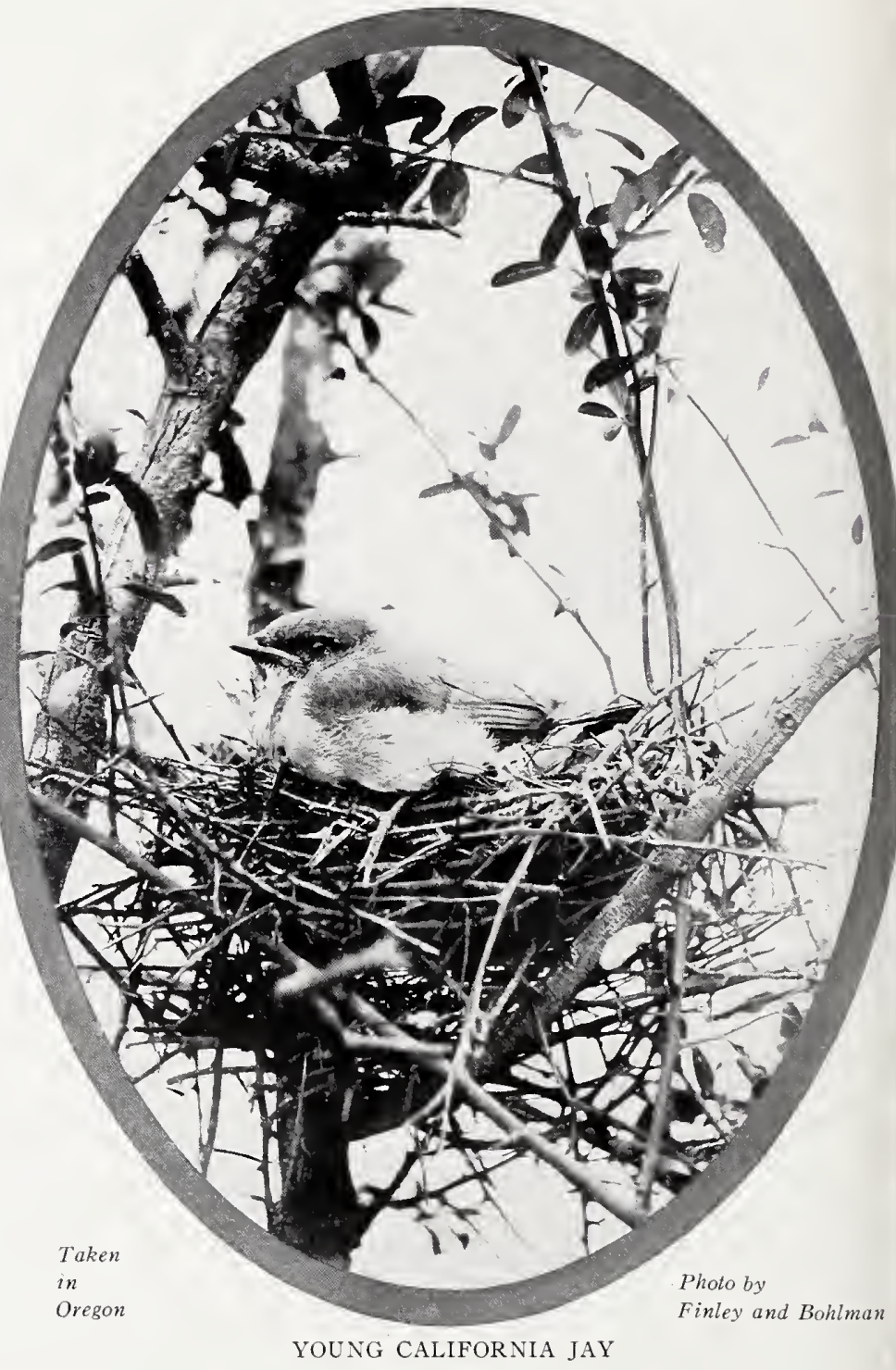


sound experience, is that within the normal range of the California Jay, fully one-half of the eggs laid by Passerine birds are destined, either as eggs or chicks, to find their way into the blue jay's maw. I know that there are those, and some of them high in authority, who will sharply challenge this statement. It is a familiar, and perhaps not altogether discreditable human fallacy, to refuse to believe ill of any creature. We recall (with mingled pity and contempt in this case) those who to the last refused to credit the reports of German atrocities committed during the Great War. Testimony, concrete evidence, had for them no value. The will to disbelieve was unconquerable. So it is with some of the friends of the Blue Jay. Some, indeed, will claim that our photograph is "faked." But the fact is that the California Jay is the most gifted, persistent, and methodical destroyer of bird-life that Nature has ever evolved. Nestrobbing is not the exception, the occasional crime of jaydom. The jay, rather, is a professional thug, and thugee is the rule of the clan. In this role the jay is feared and hated by every other bird, and he is the well-deserving butt of excoriations, vituperations, and personal assaults without number. It is worthy of note in this connection that the jay is not much of a fighter. He "takes punishment," or else flees before the avenging fury of a Vireo, a Titmouse, or a Pewee. All is, he never gives up; so that by hook or by crook he almost always manages to secure the contents of a bird's nest, if accessible, and if its whereabouts is known to him.

In this pursuit the jay not only displays a rare ingenuity, but a Satanic fastidiousness as well. He marks the building of a Phainopepla's nest and notes its progress from time to time with an approving eye, but he defers the sacking until the young are of just the right age, say, two days old. Again, he displays a devilish recklessness, for he, too, is an apostle of Schrecklichkeit. If the nest is empty, he pulls it to pieces in disgust; or if it is full, he gobbles the contents and then flings out the lining in boisterous contempt. One bird in sardonic mood returned to a Phainopepla's nest, which he had just robbed (within fifty feet of our porch roof), and deposited a half-eaten acorn in lieu of babies.

In view of this destructiveness it becomes of interest to estimate the total burden of taxation which the bird world is called upon to bear each season. The subject is a difficult one, and the results obtained by estimate can only represent the order of magnitude of the actual figures. We will do our "figuring" in the open, so that if the reader differs in any of our assumptions, the degree of modification deemed necessary may be apparent in the result. California has an area of 155,980 square miles. Although nearly one-fourth of this area is "Upper Sonoran," and as such suitable for occupation, I allow only one-tenth, or 15,598 square 


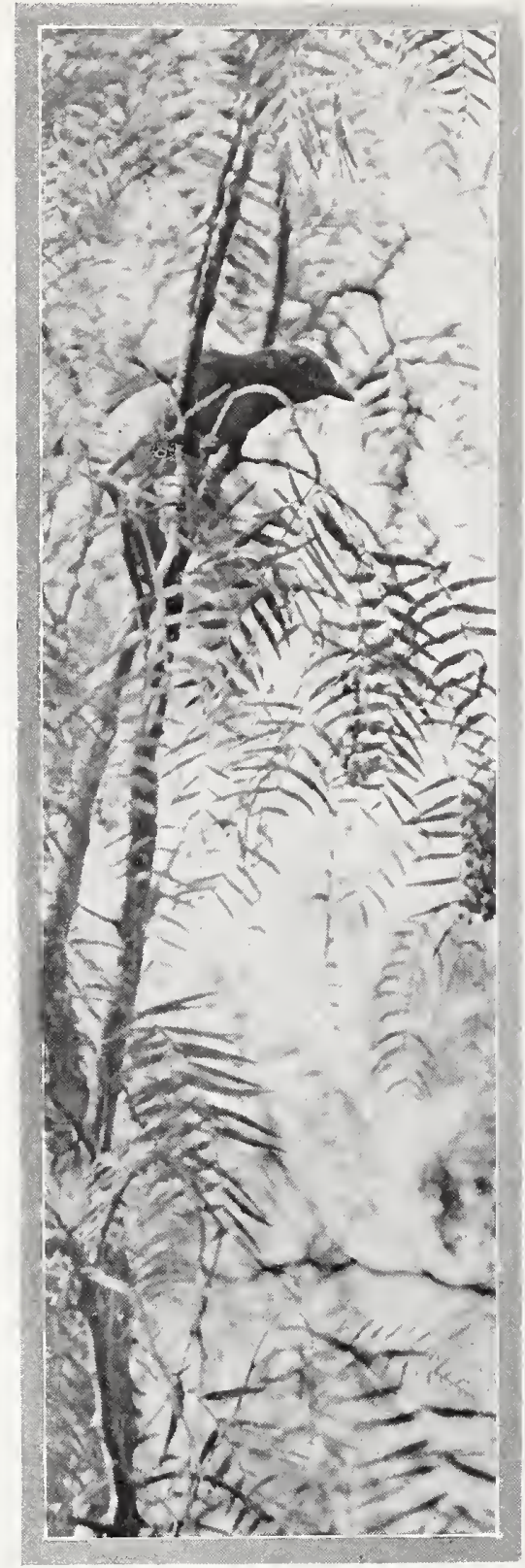

Taken at Los Colibris Photo by the Author INQUISITIVE

CALIFORNIA JAY IN PEPPER TREE miles, as the effective range of $A$ phelocoma californica. I 5,598 square miles is 9,982, 720 acres; and if we allow a range of twenty acres for each pair of jays, we have a total population of $499, \mathrm{I} 36$ pairs. If we allow only one set of eggs or nest of birds to each pair of jays per diem for a period of two months, we shall be well within the mark of actuality. Yet that will give us in a season a total destruction of 29,948, I60 nests, or, say, 100,000,000 eggs - in California alone!

Yet in the face of this destruction, which, somehow Nature does manage to cope with, there are those, over-zealous souls misusing the name of Audubon, who are disposed to grumble at the infinitesimal toll levied annually in the name of Science. Why, if every holder of a scientific permit in California - there are about two hundred of us - were to kill a single pair of blue jays each season, the total account with nature would be more than squared. If two pairs apiece were killed, we should be benefactors.

But how, you ask, does Nature stand this terrific strain? Well, there is no denying that it is terrific. Yet Nature is wonderfully fertile. We who idolize the birds are apt to forget that the "breeding cycle" is, after all, no such sacred or significant thing as is the rearing of a human family. The breasts of Nature are ample, and the sorrows of her children are short-lived. To offset this annual loss caused by the jays, other birds have to nest twice, or three times in a season, that's all. Doubtless if the jays and all other destructive agencies were gradually removed, a single nesting per season might come to suffice. But at that it is doubtful whether the sum of avian happiness would be thereby increased. Viewed dispassionately, there- 
fore, the situation is not one for alarm. The jays have been here for a long time, longer than we have even - say for a million years longer. Perhaps the average adjustment of Nature's forces has been pretty well attended to. Certainly we shall not set about the destruction of all jays. That would assure a violent reaction of some sort, and might entail infinite hardship. But $I$ agree with Beal $^{1}$ that a reduction of, say, one-half in the number of the now ubiquitous California Jay might be a good thing.

If ever an oologist had a clear commission for "intensive study" of birds' eggs, it exists in the case of the California Jay. He at least cannot complain when his nest is robbed. Accordingly, we rejoice at the presence in our State of some fine series of California Jays' eggs. Moreover, no fitter subject for intensive study could be chosen, for the eggs of the California Jay are abundant, highly variable, and of undeniable beauty. It is the variability of these eggs which interests us most; for in the consideration of almost any series two types present themselves, the "red" and the green. This dichromatism of the egg is a prominent factor in tropical bird life, notably that of India, where it occasionally becomes trichromatism; but Aphelocoma californica furnishes about the only instance, certainly the clearest instance (save for the circumpolar Murre), in America.

The red type is much the rarer. In this the ground color varies from clear grayish white to the normal green of the prevailing type; while the markings-fine dots or spots or, rarely, confluent blotches-are of a warm sepia, bister, verona brown, or Rood's brown. The ground color of the green type varies from pale sulphate green to lichen green, and the markings from deep olive to Lincoln green. In the Museum of Comparative Oology we have a set kindly furnished by Mr. H. W. Carriger, whose markings are reduced to the palest subdued freckling of pea-green. In another set, of the red type, fine Mars brown markings of absolute uniformity cover the egg; while the eggs of another set are covered as to their larger ends with an olive-green cloud cap, which leaves the remainder of the specimen almost free of markings.

The precise significance of this high degree of variability is not clear to our imperfect knowledge. It is one of those obscure Mendelian characters whose genesis we cannot trace, but whose continuance along definite lines of heredity we can confidently predict. We know now, for example, that these jays breed true to their own type year after year; that the owners of the coveted red type will present the enterprising oologist with another set precisely similar, if their nest is found on a

IOp. cit. p. 56. 


\section{The California Jays}

succeeding year. We hazard that this high variability in.the egg attests a certain virility, or adaptability, in the parent stock. Various incipient strains are held in leash by cross breeding, so that the stock as a whole has been "Americanized."

The significance of these interweaving strands of heredity is, however, strongly hinted at in the glaring exception which occurs on Santa Cruz Island. The eggs of the Santa Cruz Island Jay, Aphelocoma insularis (as elsewhere recited), are almost absolutely uniform in coloration. Presumably a single pair of birds was accidentally stranded on that island, and their progeny exhibit a single type of egg. Whether the other characters which the Island Jay displays were ontologically concomitant with, or implicit in a certain type of egg, or whether they are, rather, the product of recent development, we are unable to say; but the former is at least a tenable hypothesis.

The nests of the California Jay are also highly variable. Not only do they vary with locality and available material, but their differences express the individuality of the builders. Some are very compact, rigid structures. Others are flimsy and ill-kempt summer houses. In general, one may say, however, that upon a careless mass of crisscrossed sticks, a deep substantial cup of rootlets, or horsehair, or mingled roots and hair, is imposed. A phelocoma never uses a mud cup for mid structure, as Cyanocitta invariably does. The lining varies delightfully, but is largely dependent, it is only fair to say, upon the breed of horses or cattle affected on the nearest ranch. So we have nests with white, black, bay, and sorrel linings, not to mention dapple gray and pinto. One fastidious bird of my acquaintance, after she had constructed a dubious lining of mottled material, discovered a coal black steed overtaken by mortality. New furnishings were ordered forthwith. The old lining was pitched out bodily, and the coal black substitute installed immediately, to the bird's vast satisfaction-and mine.

Taking the country over, nests built in oak trees probably outnumber all others combined, yet the component members of the chaparral, ceanothus, chamissal, and the rest, must do duty in turn, and all species of the riparian sylva as well. The thick-set clumps of mistletoe are very hospitable to this bird, and since this occurs on oaks, cottonwoods, and, occasionally, digger pines, it follows that jayheim is found there also. As to height, that depends upon persecution. The birds will nest preferably at moderate heights, - three to ten feet up, in gooseberry, elder, or willow; but I have taken them at forty feet in oak trees, where the birds had found it necessary to secure the maximum of local cover.

The sitting bird usually flushes in silence, and with the least possible demonstration. If the visitor has not satisfied his curiosity or his cupid- 


\section{The California Jays}

ity, however, within five or ten minutes, the bird summons her mate, and together they proceed to denounce the order of the day. Beside the ordinary clamor, dzweep or jooreet jooreet, and the alternating klewk klewk klwek klwek (akin to the shook shook shook notes of $C$. stelleri) the attendant parents give vent to a soft clucking note, evidently a note of anxiety, although its quality is such as to belie the implication. These notes are often uttered with scarcely appreciable intervals, a mere droning pulsation, made with a closed beak-indeed, with scarcely a visible motion of the throat. If we mention here also a peculiar waggish creaking note, a subdued, toneless arrrrre, we shall have completed an in ventory of Aphelocoma's major vocal accomplishments. If speech fails, however, the birds give further vent to their indignation in the peculiar fashion of assaulting the

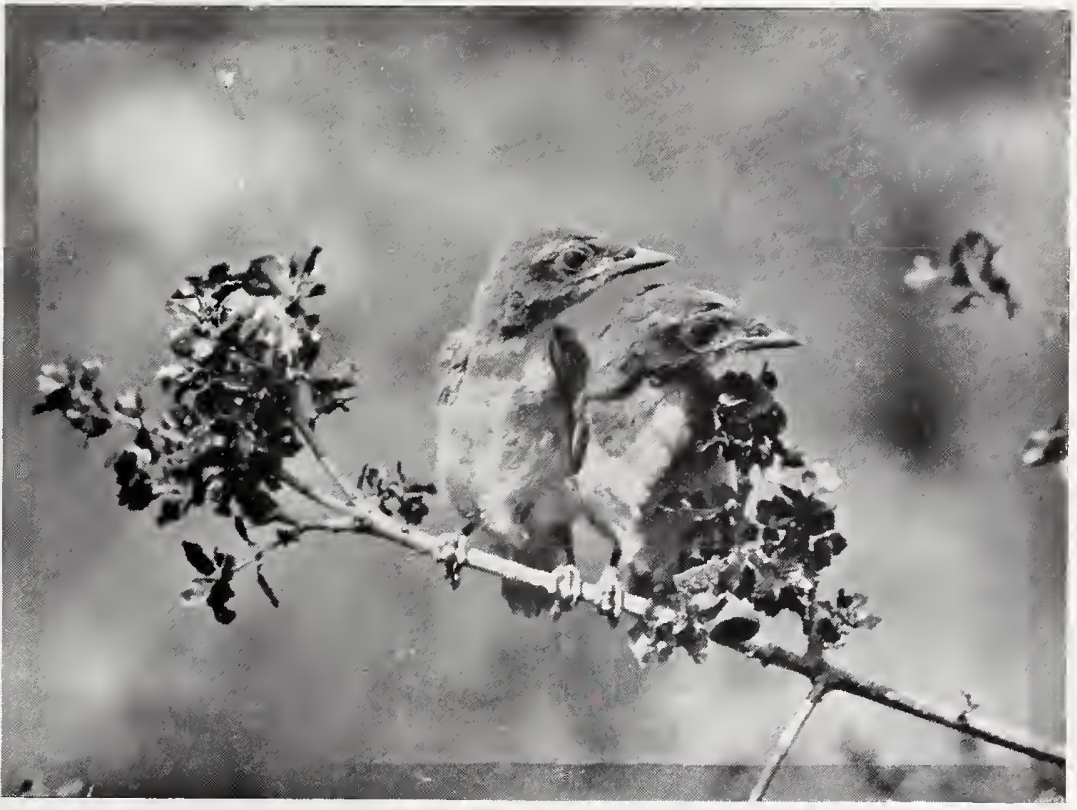

Taken in Los Angeles County
Photo by Donald R. Dickey

THE AGE OF INNOCENCE neighboring trees.

The bark is picked and shattered furiously, or the leaves are plucked off in whirlwind fashion. As a subsitute for bad language this has much to recommend it.

It goes without saying that Mr. and Mrs. Aphelocoma are models of conjugal fidelity, as well as exemplary parents. It always does stump the righteous to see the wicked observing the rules of the game in these essential matters, but they do. Mr. A. will proffer his spouse a mangled Chipping Sparrow chick, dripping with warm blood, with the same gentle courtesy which you would show in serving a portion of chicken to your lady love. Blue-jay children, I take it, are unusually well behaved, even if their tender nurture has left a woodside mourning. And for these children the jay has caressive and crooning notes which take hold of the very heart of comfort, notes of fond endearment which have come down 


\section{The Santa Cruz Jay}

the ages unmodified, whether by mouth of saint or mug of sinner. A truce to thee, then, old boy blue! Sweet villain! No doubt we'll fight again as we've fought before. And, beyond all peradventure, we'll confiscate those little eggles of yours as fast as found, be they on topmost branch or midmost tangle. But meanwhile, and between whiles, here's to thee, cunning, agile, inconsistent bird! Wag-in-feathers, Jack-o'dreams, rake-hell-Oh, I've a whole thesaurus to hurl at thee yet. Here, take the book! Bang!

No. 8

\section{Santa Cruz Jay}

A. O. U. No. 48 I.r. Aphelocoma insularis Henshaw.

Synonyms.-Island Jay. Santa Cruz Island Jay.

Description.-Similar to A. californi a (of which it is undoubtedly a localized race), but averaging larger, and with bill much larger (about 45 per cent bulkier, although relatively narrower); coloration richer and deeper; the blue element brighter (i. e. with less of neutral gray) and deeper (between Rood's blue and prussian blue); back and scapulars dusky drab; under tail-coverts pale blue (light cadet blue); thighs tinged with blue. Plumage changes as in California Jay. Length 336 (13.25) or over; wing I $35(5.70)$; tail I 48 (5.8.3); bill 33 (I.30); depth at nostril II.4 (.49); tarsus 46.5 ( 1.83 ).

Nesting. - Nest: a bulky mass of interlaced twigs of live oak tree, into which is set neatly and deeply a cup of coiled rootlets with some admixture of grasses and. rarely, horsehair; placed at moderate heights in live oak or lesser tree. Eggs: 3 or 4, rarely 5 , according to character of the season; in appearance remarkably uniform; ground color light bluish green (microcline green fading to pale Niagara green), lightly spotted with olive (Lincoln green to deep grape green). Av. size of 140 specimens in the Museum of Comparative Oology: $29 \times 21.3$ (1.14 x .84); index 73.7. Range 25.4$31.7(1.00-1.25)$ by $19.6-22.6(.77-.89)$. Extreme examples $30.5 \times 19.6(1.20 \times .77)$, index 64.1; 25.6 × 21.8 (1.01 x .86); index 85.1. Season: March Io-April Io; one brood.

Range.--Santa Cruz Island.

Authorities.-Henshaw (Cyanocitta floridana var. californica), Rept. Orn. Wheeler Surv., I876, p. 253 (part); Henshaw, Auk, vol. III, i 886, pp. 452-453 (description of insularis); Bendire, Life Hist. N. Amer. Birds, vol. II, 1895, pp. 379-380 (habits, nests and eggs); Mailliard, J.., Condor, vol. Il, 1900, p. 42 (measurements); Willett, Pac. Coast Avifauna, No. 7, i912, p. 68 (general); Howell, Pac. Coast Avifauna, No. I2, 1917, pp. 68-69 (general account; synonymy); Swarth. Univ. Calif. Publ. Zool.. vol. I7, I918, pp. 418-419, I fig. (critical).

"BLUE JAYS" of whatever type have a faculty of making themselves very much at home wherever found, whether in the firry depths of a Siskiyou forest, or in the fervent chaparral of Temecula; but of all 


\section{The Santa Cruz Jay}

recorded spots where the jaybird doth dwell Santa Cruz Island is undoubtedly the choicest. Here is Blue Jay paradise. And the Jay of Santa Cruz is almost an angel? Well, no; but he is somewhat less an imp. Early isolated from his mainland fellows, by what happy chance we know not, in an equable climate, with abundant and varied food, and measurably secure from human persecution, the Santa Cruz Island Jay has become a more beautiful, a more robust, and a much more demure bird than its co-type, A. californica. This gem of the islands belongs to him by unquestioned title, and he has no need to defend his claim by frantic protest or scurrilous abuse.

This demure quality shows itself to best advantage when his nest is threatened, for it is then, if ever, that a bird's soul is tried. Yet I have spent an hour beside a nestful of jay babies with never a word of protest from the closely attendant parents, beyond a mellow, and almost inaudible choop choop. This, and the sound of pecking on tree limbs, for even this gentle bird employs this familiar corvine device for relieving

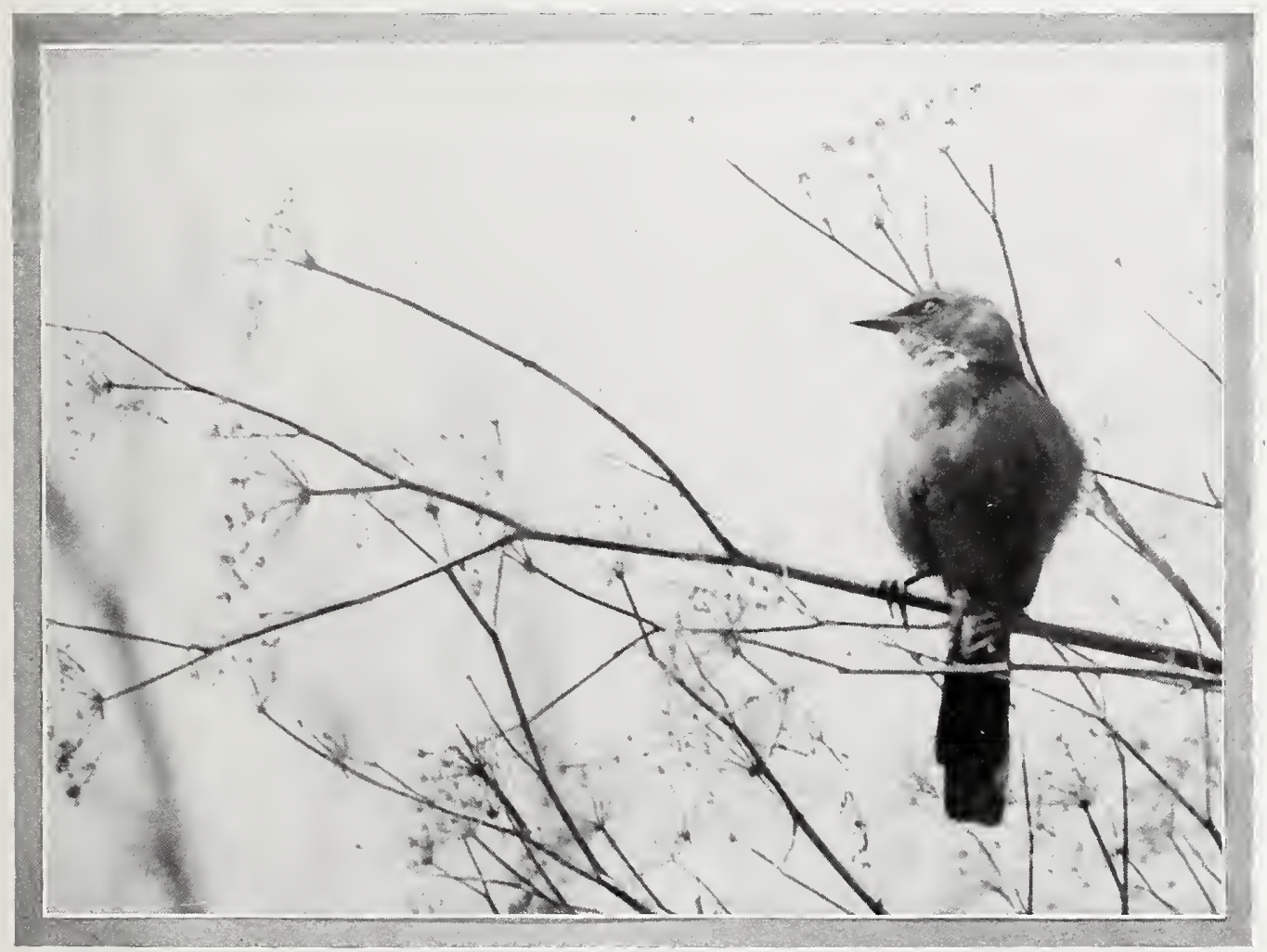

Taken on Santa Cruz Island

Photo by the Author

A PATIENT MODEL 


\section{The Santa Cruz Jay}

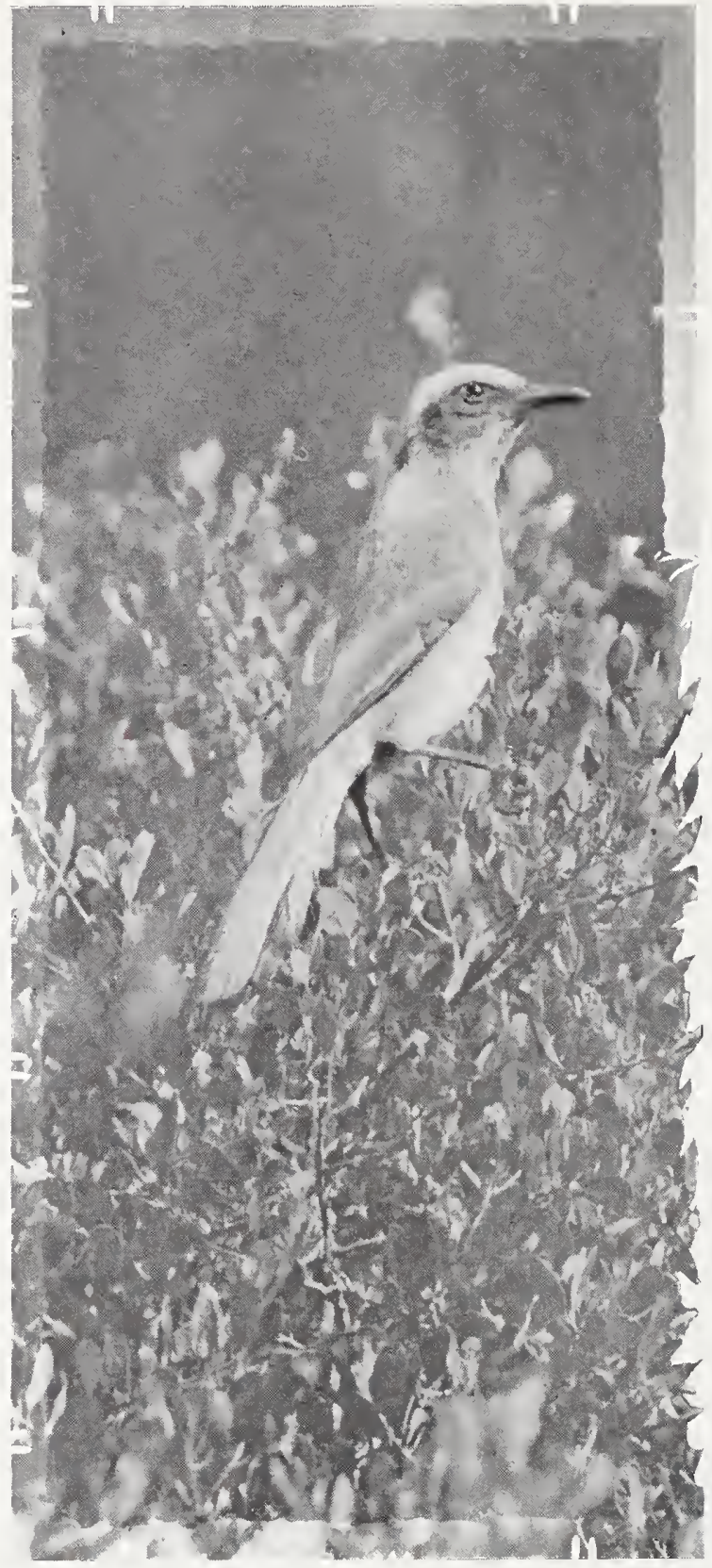

Taken on Santa Cruz Island

Photo by the Author

THE SENTINEL

these startling variants of song really primal? Is not this the authentic heir of the original cyano-corvine traits, narrowed and singled elsewhere

60

surcharged feelings. But this jay is capable of vigorous expression, and the variety and suggestive affinity of its notes are worth consideration. There is, first, the Aphelocomine scolding cry of common use, but this is fuller, rounder, and much less harsh. Then there is a djay djay note which distinctly recalls that of Cyanocitta stelleri. Lastly, this note is so modified and accelerated as to strikingly simulate the rickety rack rack rack or shack shack shack shack shack of the Magpies. I know the Magpie's voice better than the baying of a hound, but I have leaped to my feet and reached for the glasses at this jack jack call before realizing that there are no Magpies on Santa Cruz Island. And lastly, again (a preacher's "lastly" may be repeated indefinitely, so why not an ornithologist's?), some sotto voce musings lead me to believe that the bird is capable of real song. Exquisite warblings have I heard at a rod's remove, so delicate that a Wren's outburst would have drowned them utterly, but so musical that I had hoped the bird was only tuning his strings in preparation for a rhapsody.

All these comparisons lead one to ask where this most fortunate of Blue Jays got his gifts. He has seen neither magpies nor crested jays for ages. Are not 
by reason of excessive competition? Quien sabe? But he is a very gifted bird; and I warrant he makes a merry hullabaloo after the ban of silence, which affects all Blue Jays in the nesting season, is lifted.

The Santa Cruz Jay nests early. The last week in March is the height of the season, counting always by fresh eggs. We have found them as early as March Ioth. For nesting sites the California live oaks are leading favorites, but the birds nest indifferently throughout the scrub (It is hardly considered proper to speak of "chaparral" on this island, because the sheep keep the lesser undergrowths cleaned out) to the tops of the ranges. Manzanita, Christmas berry, holly-leaf cherry, ironwood, mountain mahogany, scrub and Wislizenus oaks, and Monterey pines, all serve as hosts, therefore, with little preference save for shade. Nests, although bulky, sometimes being as large as a crow's, are placed at moderate heights, usually from eight to twelve feet; and are, habitually, so well made that they may be lifted clean of their setting without injury. The jays evidently have assigned beats, or ranges, of mutual adjustment, and they are very loyal to a chosen locality at nesting time. Thus, the nests of succeeding years are grouped in a single tree, or scattered narrowly in a small section of the scrub.

It is in the uniform coloring of the egg that the Santa Cruz Island Jay most surely reveals its isolation, and its consequent inbreeding. The ground color of fresh eggs is a beautiful light blu is h-green (microcline green), and this is lightly

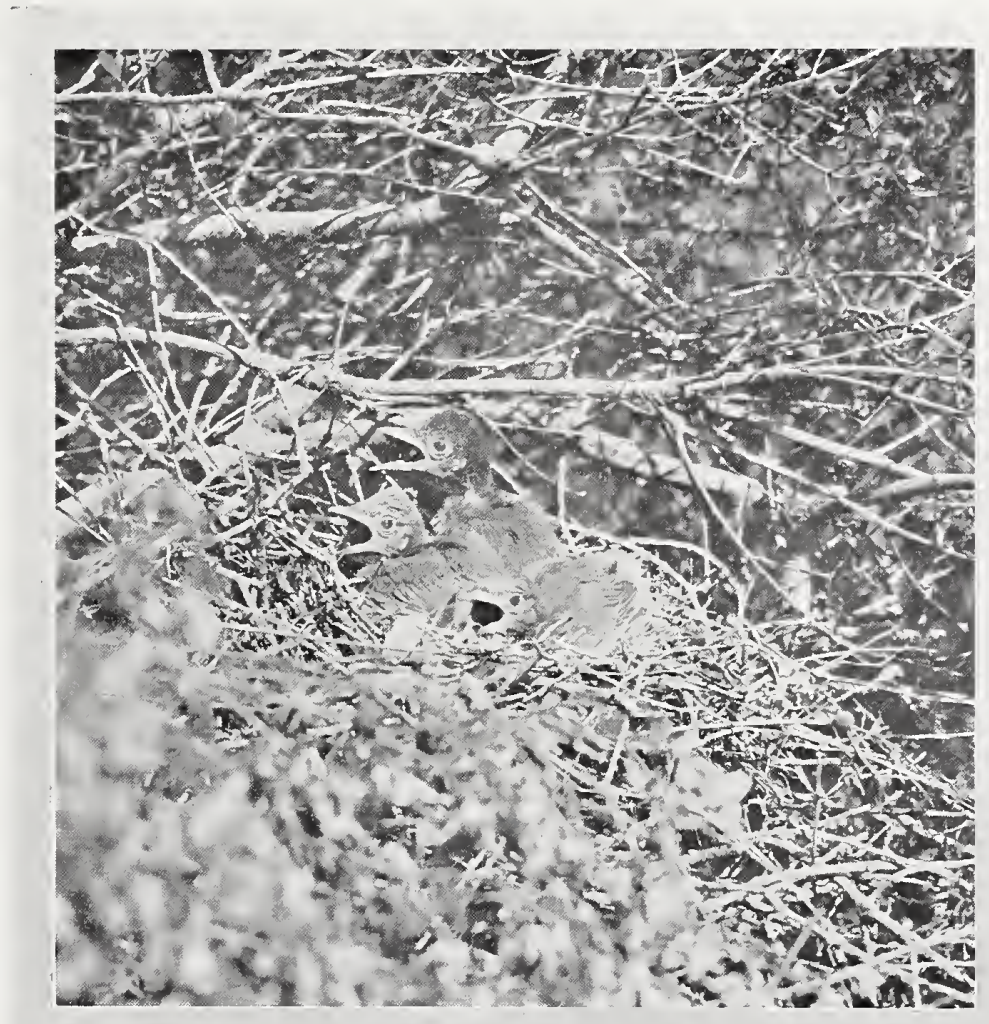

Taken on Santa Cruz Island

Photo by the Author 




Taken on Santa Cruz Island

"ALMOST AN ANGEL"

Photo by the A uthor

PORTRAIT OF SANTA CRUZ JAY spotted with olive (Lincoln green to deep grape green). The green element fades quickly, however, so that eggs advanced in incubation are of a pale Niagara green ground color. Among a dozen sets there are no color variants worth mentioning; nor have I seen a single example of the "red" type, which is so pleasing a feature of the mainland form. In size the eggs of the Santa Cruz form average slightly larger than those of A. californica.

Second sets are prepared with amazing alacrity if the first are destroyed. In two cases we noted complete sets of five thirteen days after the first had been taken. This quick recovery was the more remarkable in one instance, because the first set had been near hatching, and the reproductive organs of the birds were, therefore, in a state of quiescence.

One speaks without apology of "collecting" jays' eggs, for the jay is a master oologist himself. Doubtless he owes much of his sleek corpulence to a diet of Dusky Warblers' eggs; and as for those pleasing, but not humanly seductive ovals known as Mourning Doves' eggs, they are a thing almost unknown in jay territory. The poultry keeper, too, at the "big ranch" 


\section{The Woodhouse Jay}

has had to wage unceasing warfare on the Blue Jays - or rather, the "Corbales," for he speaks Italian — in order that El Superintendente may have hens' eggs for breakfast.

No. 9

\section{Woodhouse's Jay}

A. O. U. No. 480. Aphelocoma woodhousei (Baird).

Description.- Somewhat similar to A. californica, but pattern of color less accentuated; gray of back bluer, the underparts darker, the crissum blue; bill longer and narrower. Adult in fresh plumage: Pileum, hind neck, sides of neck, border of jugular white patch, wings, upper tail-coverts, and tail, jay blue; crissum a little lighter blue (about King's blue); malar region dark blue; lores and post-ocular area blackish; a superciliary line of white streaks; throat and chest white with diffused gray streaks, as in $A$. californica; upper back and scapulars mouse gray; rump mingled blue and bluish gray; remaining underparts light mouse gray. Bill and feet black; iris brown. Adult in worn plumage shows reduction of blue, especially on head and cervix, with attendant revelation of mouse gray; gray of back browner, with showing of drab; pattern of underparts nearly effaced, mingled whitish, pale drab, and bluish dusky. Young birds are like adults in worn plumage with further effacement of blue, the blue element almost confined to wings and tail. Length of adult male 279.4-304.8 (I I.OO-I2.00); wing I 33 (5.24); tail I 43 (5.63); bill 28.5 (I.I2); depth at nostril 9.4 (.37); tarsus 4I (I.6I). Females smaller.

Recognition Marks.- "Jay size;" jay blue and mouse gray coloration, without crest. Dintinguished with $A$. californica as above.

Nesting.-Much as in A. californica. Eggs not so highly differentiated. A set in the M. C. O. coll. has a water green (greenish yellow) ground color with sharp spots of warm sepia. Av. size $27.7 \times 20$ ( $1.09 \times .79$ ) (Bendire).

General Range.- "Great Basin and adjacent arid region, breeding in Upper Sonoran and Transition zones from southeastern Oregon, southern Idaho,, and southern Wyoming south to southeastern California (east of Sierra Nevada), Arizona, New Mexico, southeastern Colorado, and western Texas." (A. O. U. Com.).

Range in California.- "Upper Sonoran zone in the desert mountains of the eastern part of the State, in the Inyo and Mohave regions. At the eastern base of the Sierra Nevada, probably as a transient only." (Swarth).

Authorities.-Kennerly (Cyanocitta californica), Rept. Pac. R. R. Surv., vol. IV, pt. VI, I 856, p. I6; Baird, Rept. Pac. R. R. Surv., vol. IX, I 858, pp. 585-586 (description of woodhousei); Fisher, A. K., North Amer. Fauna No. 7, I893, p. 69 (distr.); Bendire, Life Hist. N. Amer. Birds, Vol. II, I 895, pp. 372-374, pl. V (fig. I4) (habits, nest and eggs); Oberholser, Condor, Vol. XIX, I9I7. pp. 94, 95 (taxonomy); Swarth, Univ. Calif. Publ. Zool., vol. I7, I9I8, pp. +I7-4I8 (descr; range). 


\section{The Woodhouse Jay}

THE question, much agitated of late, as to whether the Wroodhouse Jay may be only a subspecies of the californica type, is one which cannot be thrashed out in the closet. Differences sufficient to entitle a bird-type to specific recognition invariably record themselves in voice and action, as well as in plumage changes. The history of the race must have been different, and if so, something more than the mere fact of isolation, or incipient change, must be noted in order to establish that historical difference, and to gain for its subject credence as a species. This raises the very question that I am not qualified to answer, viz., Does the Woodhouse Jay differ sufficiently from the California Jay in voice and action to establish the presumption that there has been a markedly divergent history for the two species, and that their recently established occurrence together, upon the east slopes of the Sierras, is only the accidental meeting of two conquering types moving out from independent distributional centers long since established? I do not know, but my very brief acquaintance with woodhousei, in Southern Arizona, namely, leads me to think that it does. It seemed to me, fresh from association with californica, that the voice of woodhousei was, in general, notably weaker. And when first heard, the shook shook shook shook note of the Woodhouse deceived me, momentarily, into entering Long-crested Jay (Cyanocitta stelleri diademata) in my field book. This note occupies a middle position between the characteristic outcry of our stelleri type and a cry of the californica whose resemblance to that of stelleri I had, for lack of that mediating suggestion, never previously noted. This does not mean, of course, that Aphelocoma woodhousei resembles Cyanocitta stelleri in form and plumage in any such fashion as it resembles $A$. californica; but it does mean, if its significance be allowed, that $A$.woodhousei, along with $C$. stelleri, has preserved a certain ancestral tradition, or vocal habit, which californica has well nigh forgotten. These leadings, I take it, are of considerable importance.

The testimony of the egg is less clear, but in comparing a series of eggs of woodhousei with a like series of californica, I should say that the preponderance of the evidence favors specific recognition.

For the rest, in his native haunts of Arizona, Nevada, Utah, and upper southeastern California, Woodhouse's Jay is the animating spirit of the chaparral, as the California Jay is elsewhere in the State. Only an expert would sense differences between them in the hand or out of it. 
The Steller Jays

No. 10

\section{Steller Jay}

No. 10a Blue-fronted Jay

A. O. U. No. 478 a. Cyanocitta stelleri frontalis (Ridgway).

Synonyms.-Mountain Jay. "Blue Jay." "Jaybird."

Description.-Adults: Conspicuously crested. In general, foreparts sooty black, remaining plumage rich blue. Head including crest and jugulum sooty brown or sooty black, the longer feathers of crest bluish-tinged; chin and throat heavily streaked with grayish or bluish white (streaks nearly confluent in fresh plumage); forehead and forecrown sharply and heavily streaked with light blue and whitish (olympic blue to light sky blue); cervix (broadly), upper back, and scapulars, dark grayish brown (dusky drab to natal brown); rump, upper tail-coverts, outer webs of primaries, and posterior underparts light blue (pale cerulean blue to light squill blue); breast (shading each way) and wing-coverts darker blue (gendarme blue to dark cadet blue); exposed portions of inner primaries, secondaries, and rectrices dark blue (ranging from dusky greenish blue to grayish violaceous blue); the concealed portions blackish; the greater wing-coverts faintly, the inner secondaries, tertials, and rectrices sharply and rather finely barred with black. Bill and feet black; iris brown. Plumage wear shows chiefly in darkening of throat and in reduction of frontal streaking. Young birds have the wing colors of adult, with barring merely indicated, but lack the blue body plumage; foreparts and back sooty brown to dusky drab, changing posteriorly to plumbeous. Length of adult male 304.8 ( ( 2.00 ) or under; wing 146.5 (5.75); tail I36 (5.35); bill 29.5 (I.I6); tarsus 42 (I.65). Females decidedly smaller.

Recognition Marks.-Robin size; black crest; blue and sooty black coloration unmistakable; harsh notes.

Nesting.- Nest: Usually in top of evergreen sapling of thicket, or variously in evergreen trees; composed exteriorly of small sticks and trash, interiorly of coarse rootlets, or needles of some long-leafed pine; the whole strengthened by a nearly invisible bowl of mud. Eggs: 4, rarely 5; pale bluish green (pale glaucous green, pale Niagara green), spotted sparingly with deep olive or olive brown (also Saccardo's umber or sepia). Av. size $30.2 \times 22.6$ (I.I9 x .89); index 74.8. Season: April 20-June Io, according to altitude; one brood.

Range of Cyanocitta stelleri--Western North America from Alaska south to the highlands of Central America.

Range of $C$. $s$. frontalis (chiefly contained within California).-Common resident of Transition and Canadian zones throughout the Sierra Nevada and the neighboring non-arid ranges of northern and southern California, south to the San Pedro Martir Mountains of Lower California. According to Grinnell, this form occurs in the northern coast ranges south to Mount Saint Helena and Mount George, and pushes through to the coast; thus interrupting the range of carbonacea in Sonoma County. In all probability the birds which occur throughout the inner ranges of Santa Barbara County are also related to the Sierran type more closely than to that of the humid coastal belt. Ventures out somewhat upon the lower levels in fall and winter.

Authorities.-Gambel (Cyanocorax stelleri), Proc. Acad. Nat. Sci. Phila., vol. III, I 847, p. 20 I Feilner, Ann. Rept. Smithsonian Inst. for I 864 (I 865), P. 427 (habits); Ridgway, Amer. Journ. Sci., ser. 3, vol. V, I 873, p. 4 I (description of frontalis); Goss, 


\section{The Steller Jays}

Auk, vol. II, I 885, 217 (nesting in holes); Bendire, Life Hist. N. Amer. Birds, vol. II, I 895, pp. 365-367 (habits, nest and eggs); Sampson, Condor vol. III, Igor, p. 37 (at Stockton); Fisher, W. K., Condor, vol. IV, I902, pp. 4I-44 (critical; range); Mailliard, Condor, vol. X, I908, p. I34 (range in Sonoma Co.).

\section{No. 10b Coast Jay}

A. O. U. No. 478 e. Cyanocitta stelleri carbonacea Grinnell.

Synonyms.-Grinnell's Jay. "Blue Jay," etc.

Description.- Similar to C. s. frontalis, but darker throughout, and with reduction of frontal streaking; back and scapulars blackish brown, scarcely different from chest; belly jay blue; rump king's blue; size not appreciably different.

Nesting.- Nest: Much as in preceding form, save that coarse rootlets are inwardly employed as lining; of ten placed in deciduous saplings, especially tanbark oak. Eggs: 2-4, colored as in preceding race. Season: April 20-May 20; one brood.

Range of C. s. carbonacea.- Resident in the humid coastal strip from southern Oregon south to the Santa LuciaMountains of California. Intergrades with A. frontalis at western bases of inner coastal ranges, but distinctive characters apparently fail along the coast of northern Sonoma County. Relationships in southern portion of range not exact!y defined.

Authorities.-Newberry, Rept. Pac. R. R. Surv., vol. VI, pt. 4, I 857 , p. 85 ; Bendire, Life Hist. N. Amer. Birds, vol. II, I 895 , pp. 365-367, pl. V (fig. Io) (habits, nest and eggs); Mailliard, J., Condor, vol. II, I900, p. 58 and p. I26 (habits); Grinnell, Condor, vol. II, I900, p. I27 (description of carbonacea); Fisher, W. K., Condor, vol. IV. I902, pp. 4I-44, map (critical; range): Ray, Condor, vol. XI, I909, pp. I8-I9 habits); Beal, Biol. Survey Bull. No. 34, I910, pp. 47-49 (part) (food).

"OFFICER! arrest that bird!" It is Mountain Chickadee who enters complaint against a culprit Screech Owl blinking in the inadequate shade of a fir sapling. And it is Sergeant Steller Jay, one of the finest, who makes instant response, leading the attack upon the offender, buffetting, upbraiding, driving him from cover to cover, until his proper hideyhole is reached. And Arragh! What excited talk will follow! Corporal Flicker, who has lumbered up, full of curiosity, must hear all about it; and so must the Cassin Vireos, who, as everybody knows, are the world's great busy-bodies. Officer Jay is in his element, but he moves off importantly, before the little fellows are half satisfied, announcing, as he does so, that he must look after the movements of the Mountain Lion, who is due on his beat that day; but saying in an aside, "It doesn't do to let the small fry get too familiar."

And it is a true word which says, "It takes a thief to catch a thief." For, to do him justice, it is usually the Steller Jay who is first to make discovery and outcry if there is any mischief afoot in the woods. Time and again we have had our attention called to the presence of deer or foxes or Horned Owls, which would entirely have escaped our notice 
had it not been for the zealous proclamations of these birds. One April morning, in the hin terland of Santa Barbara, where Steller (Blue-fronted) Jays were not supposed to exist, I stopped the "Jolly Ellen" and turned aside in to a dense thicket, where a crested jay was vociferating. Arrived at the published spot, I saw nothing whatever, and sat down, grumbling, to await possible developments. Presently, through a dim, sequestered aisle in the lower growth I saw a "bob-cat" crouching and regarding me through narrowed slits. The jay was right, after all, and I apologized.

Be sure, also that the jay is keeping tab on your own movements. If he is feeling hilarious that morning, and he usually is, he will greet the explorer boisterously; but if he "has his doots," he will trail after silently in the tree-tops, "takin' notes" instead. Upon discovery the Steller Jay sets up a great outcry and makes off through the thickets shrieking lustily. A favorite method of retreat is to flit up in to the lower branches of a fir tree, and keeping close to the trunk, to ascend the succeeding limbs as by a spiral staircase. The bird, incleed, takes a childish delight in

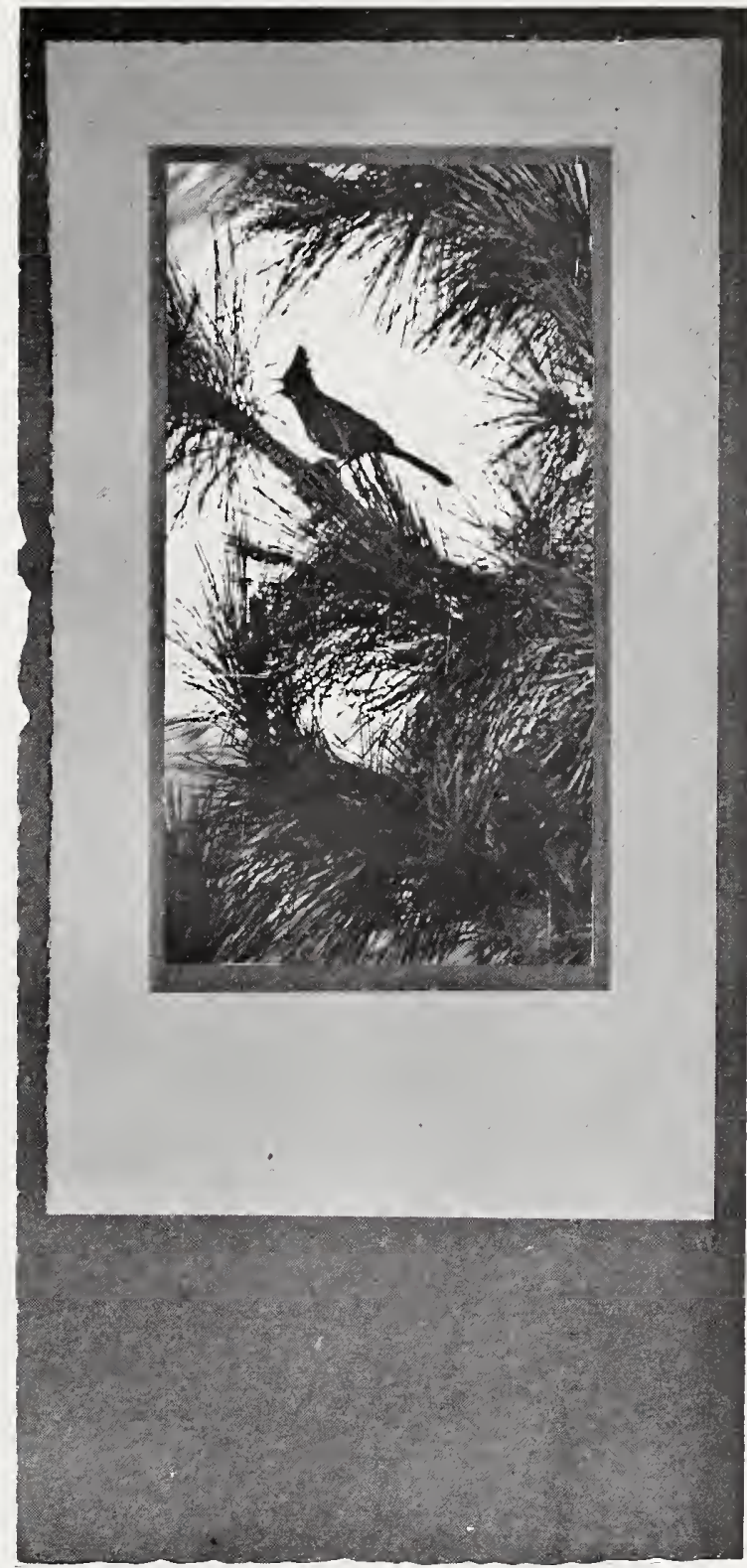

Taken in Riverside County

Photo by the Author

A SILHOUETTE

this mad exercise, and no sooner does he quit one tree-top than he dashes down to a neighboring tree to run another frenzied gamut. Upon a less strenuous occasion it is worth while to note the manner of that descending flight. A considerable space is to be crossed. The jay 


\section{The Steller Jays}

launches himself from the high point of one tree and aims for the lowermost limb across the interval, so he opens and closes his wings in the most leisurely manner, giving rise to a series of hitches, or parachute dives. At the climax of each spread, every feather of the wings and tail is clearly defined, and the whole makes a very pleasing picture. The purpose of this halting descent is evidently to afford the bird leisurely glimpses of the open country below, to give him time to focus accurately upon details of possible interest.

The notes of the Steller Jay are harsh and expletive to a degree. Shaack, shaack, shaack is a common (and most exasperating) form; or, by a little stretch of the imagination one may hear jay, jay, jay. A mellow klook, klook, klook sometimes varies the rasping imprecations and serves to remind one that the jay is cousin to the crow. Other and minor notes there are for the lesser and rarer emotions, and some of these not unmusical. At his task of counting the rungs of some heavenly ladder of fir or pine, he will indulge a sort of musical chatter entirely for his own benefit, singing snatches, as it were, of the latest opera, and then winding up suddenly with a horse-laugh. Very rarely the bird attempts song, and does succeed in producing a medley that quite satisfies her that he could if he would. I have fancied that the Steller Jays of California, frontalis and carbonacea, have somewhat lighter, clearer voices than those of stelleri typicus in the Northwest. And I am quite sure that carbonacea has a more extended repertory of cries than the other forms - a subject which would repay careful investigation.

C. stelleri, like C. cristata of the East, is something of a mimic. The notes of the Western Redtail (Buteo borealis calurus) and other hawks are reproduced with especial fidelity. For such an effort the jay conceals himself in the depths of a large-leafed maple or in a fir thicket, and his sole object appears to be that of terrorizing the neighboring song-birds. One such I heard holding forth from a shade tree on the grounds of a lunatic asylum. Uncanny sounds were, of course, not unknown in that section, but an exploratory pebble served to unmask the cheat, and drove forth a very much chastened "Blue Jay" before a company of applauding Juncoes. On another occasion when I was investigating the domestic affairs of a pair of "Long-crested" Jays, this self-same cry of the Redtail was hurled at me, not once but repeatedly, evidently with the expectation of exciting terror in the oological breast.

The diet of these jays is highly varied. They will "try anything once," and so, tiring of bugs and slugs, they are not averse to sampling corn, cabbage leaves, or, best of all, potatoes. While their depredations do not figure much in the larger scheme of things, their attentions to pioneer enterprises and modest "clearings" are a little exasperating. The 
birds have observed the tedious operations of the gardener in planting, and know precisely where the coveted tubers lie. Bright and early the following morning they slip to the edge of the clearing, post one of their number as lookout, then silently deploy upon their ghoulish task. If they weary of potatoes, sprouting peas or corn will do. Or perhaps there may be something interesting at the base of this young tomato plant. And when the irate farmer appears upon the scene, the marauders retire to the forest shrieking with laughter at the discomfitted swain. Ay! there's the rub! We may endure injury but not insult. Bang! Bang!

As a connoisseur of birds' eggs, too, the Steller Jay enjoys a bad eminence. The sufferers in this case are chiefly the lesser song birds; but no eggs whatever are exempt from his covetous glance, if left unguarded. The jay has become especially proficient in the discovery and sacking of Bush-tits' nests. Mr. D. E. Brown assures me that he has found as high as fifteen nests of this bird in a single swamp, all gutted by jays. When it is remembered that these busy little workers make one of the handsomest nests in the world, the shame of this piracy gets upon the nerves. The in-

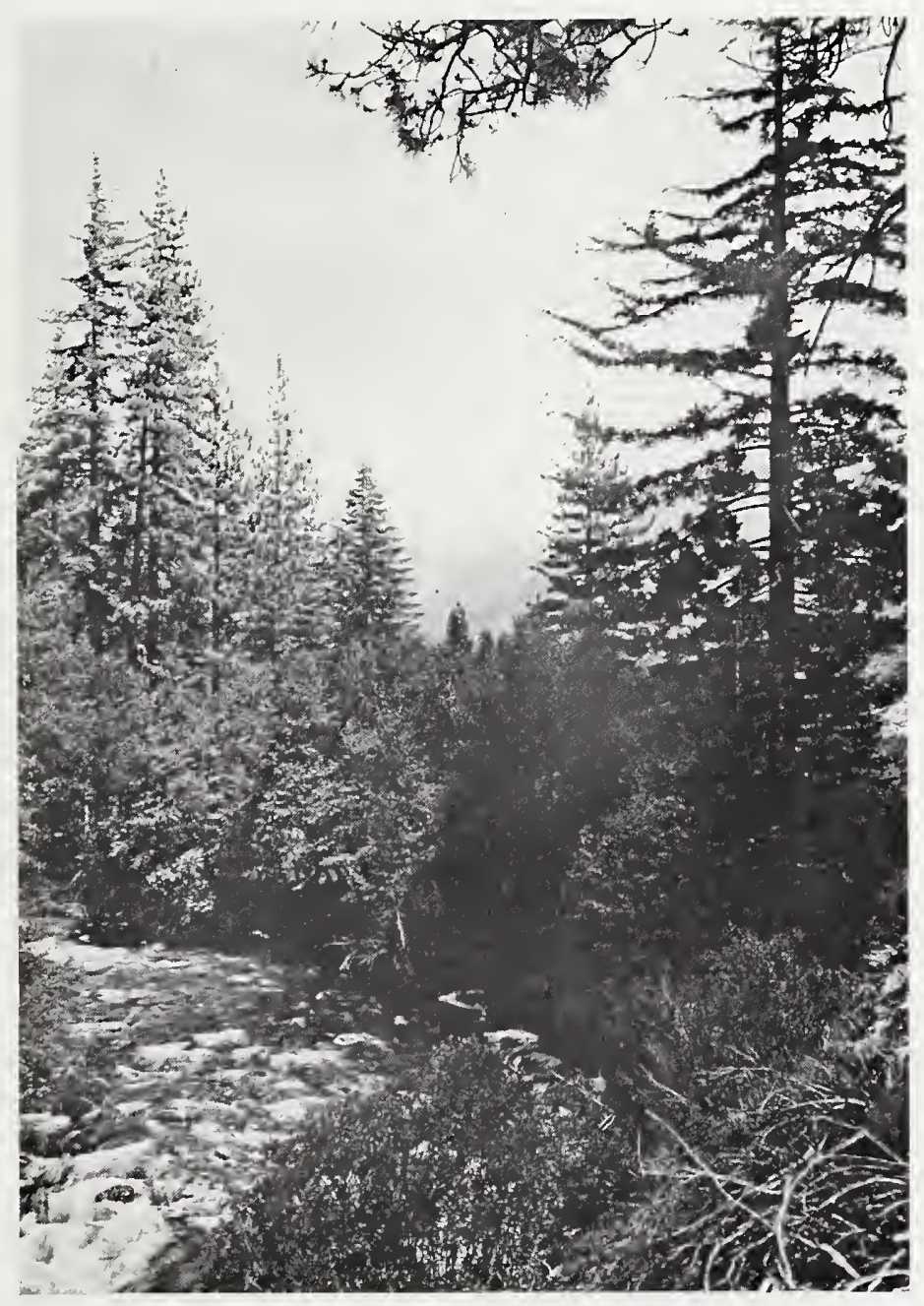

Taken in Fresno County

Photo by the Author

A HAUNT OF THE LONG-CRESTED JAY 


\section{The Gray Jays}

vestigation of 'Tits' nests has something of the fascination of the gaming table for the jay, since he never knows what the wonder pouches may contain until he has ripped a hole in the side and inserted a piratical beak.

It is well known that the gentleman burglar takes a conscientious pride in the safety and welfare of his own home. Nothing shall molest his dear ones. The jay becomes secretive and silent as the time for nest-building approaches. The nest is well concealed in a dense thicket of fir saplings, or else set at various heights in the larger fir trees. If one but looks at it before the complement of eggs is laid the locality is deserted forthwith. If, however, the enterprise is irretrievably launched, the birds take care not to be seen in the vicinity of their nest, unless they are certain of its discovery, in which case they call heaven and earth to witness that the man is a monster of iniquity, and that he is plotting against the innocent. The youngsters, too, quickly learn to assume the attitude of affronted innocence. At an age when most bird-babies would make a silent get-away under cover of the parental defense, young Steller Jays will turn to and berate the stranger in common with their parents, with all the virtuous zeal of ordained elders.

Mischief and the "Blue Jay" are synonymous. Alert, restless, saucy, inquisitive, and provoking, yet always interesting, this handsome brigand keeps his human critics in a perpetual see-saw between wrath and admiration. As a sprightly piece of Nature, the Steller Jay is an unqualified success. As the hero-subject of a guessing contest he is without a peer, for one never knows what he is doing until he has done it, and none may predict what he will do next.

\section{No. 11}

\section{Oregon Jay}

A. O. U. No. 485. Perisoreus obscurus obscurus Ridgway.

Synonyms.--(Properly) Oregon Gray Jay or Coastal Gray Jay. "Camp Robber. "Meat Bird." "Deer Hunter."

Description.--Adults: In general; upperparts deep brownish gray (nearest chaetura drab); underparts white tinged with brownish gray; forehead and nasal plumules most nearly clear white; cheeks, auriculars, and obscure band around neck, white, more or less tinged with brownish; crown and nape sooty brown, nearly black; feathers of back with white shafts more or less exposed; wings and tail drab gray (scarcely different from back), the former with narrow whitish tips on middle and greater coverts; tail tipped with paler gray. Bill and feet black; iris brown. Young birds are nearly uniform sooty brown, lightening below. Length about 254 (I0.00); wing I $35(5.30)$; tail I $27(5.00)$; bill I 8 (.7 I); tarsus 33 (I.30). 


\section{The Gray Jays}

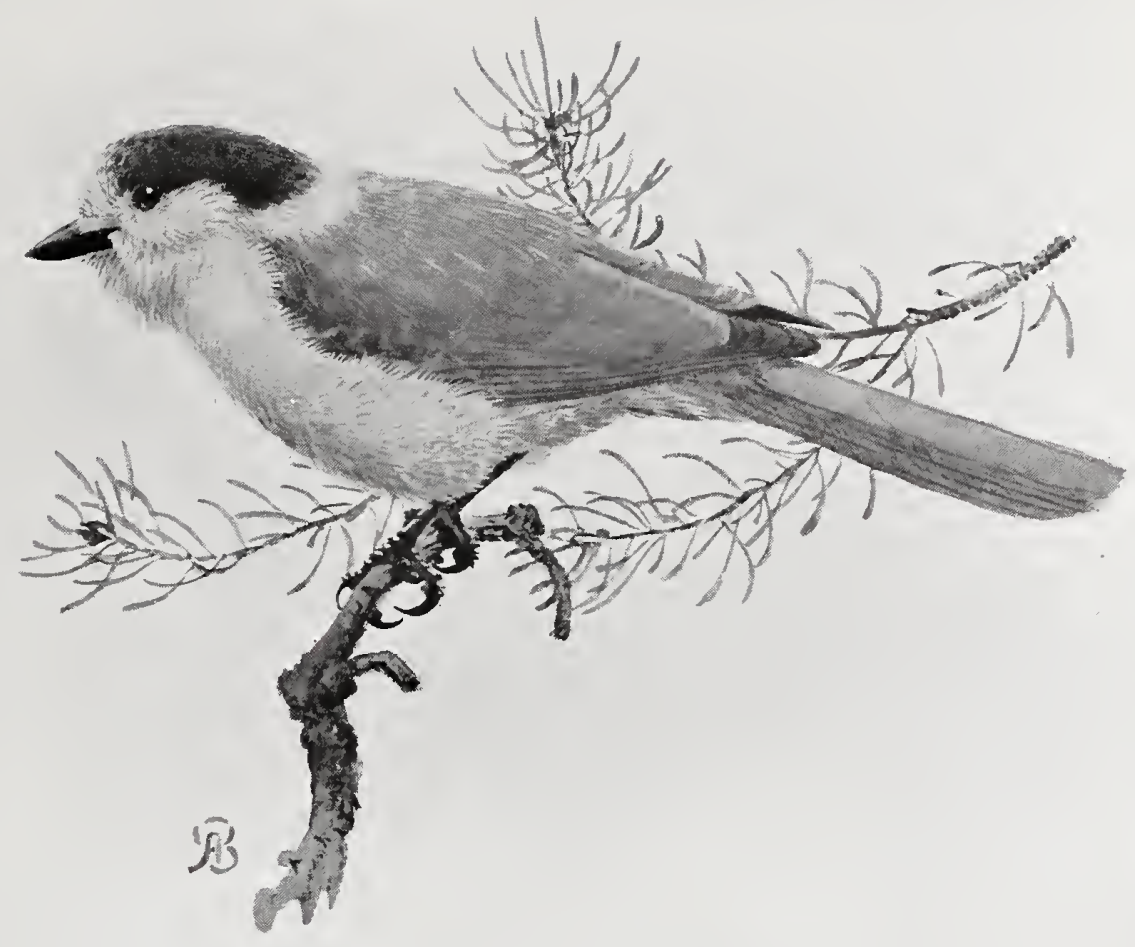

OREGON JAY

Recognition Marks.- Robin size; brownish gray coloration; familiar, fearless ways. Not certainly distinguishable afield from the next form.

Nesting.- Nest: a bulky, compacted structure of twigs, plant-fibers, and treemoss, with warm lining of fine mosses and feathers, placed well up in fir tree. Eggs: 4 or 5 ; light gray or pale greenish gray, spotted with grayish brown and vinaceous gray. Av. size $26.4 \times 20(1.04 \times .79)$. Season: February-April- one brood.

Range of Perisoreus obscurus.-British Columbia and the Pacific Coast States south to northern California.

Range in California.- Resident in the northwest humid coastal strip south to Mendocino, Mendocino County.

Authorities.- Townsend, Proc. U. S. National Mus., vul. X, I887, p. 2 I 2 (part); Bendire, Life Hist. N. Amer. Birds, vol. II, I 895, pp. 394-396 (part) • Heller, Condor, vol. IV, I902, p. 46 (in southern Mendocino Co.): Oberholser, Proc. Biol. Soc. Wash., vol. XXX, I9I7, pp. I85-I87 (critical; range); Swarth, Condor, vol. XX, I9I8, pp. 83-84 (systematic: range). 


\section{The Gray Jays}

\section{No. 11a Gray Jay}

A. O. U. No. 485 a. Perisoreus obscurus griseus Ridgway.

Synonyms. - As in preceding form.

Description.- "Similar to P. o. obscurus, but decidedly larger (except feet), and coloration much grayer; back, etc., deep mouse gray, instead of brown, remiges and tail between neutral gray and smoke gray, instead of drab gray, and under parts grayish white instead of brownish white." (Ridgway). Length (av. of three northern specimens): 283.5 (II.I6); wing I 47.6 (5.82); tail I39.I (5.48): bill I9 (.75); tarsus 3I.7 (1.25).

Range of $P . o$ griseus. - Interior of southern British Columbia and the central and eastern mountain systems of Washington, Oregon, and northern California.

Range in California.-Sparingly resident in the Boreal zone of northern California east of the humid coastal strip, south to MIt. Lassen.

Authorities.-Newberry (Perisoreus canadensis), Rept. Pac. R. R. Surv., vol. VI, pt. IV, I857, pp. 85-86; Feilner, Ann. Rept. Smithsonian Inst., for I 864 (I865), pp. 427-428 (habits); Henshaw, Rept. Orn. Wheeler Surv., I879, p. 308: (crit; habits); Townsend, Proc. U. S. National Mus., vol. X, I887, pp. 2I I-2I 2 (part) (habits); Oberholser, Proc. Biol. Soc. Wash., vol. XXX, I917, pp. I85-I87 (c.it., range); Swarth. Condor, vol. XX, I9I8, pp. 83-84 (systematic; range).

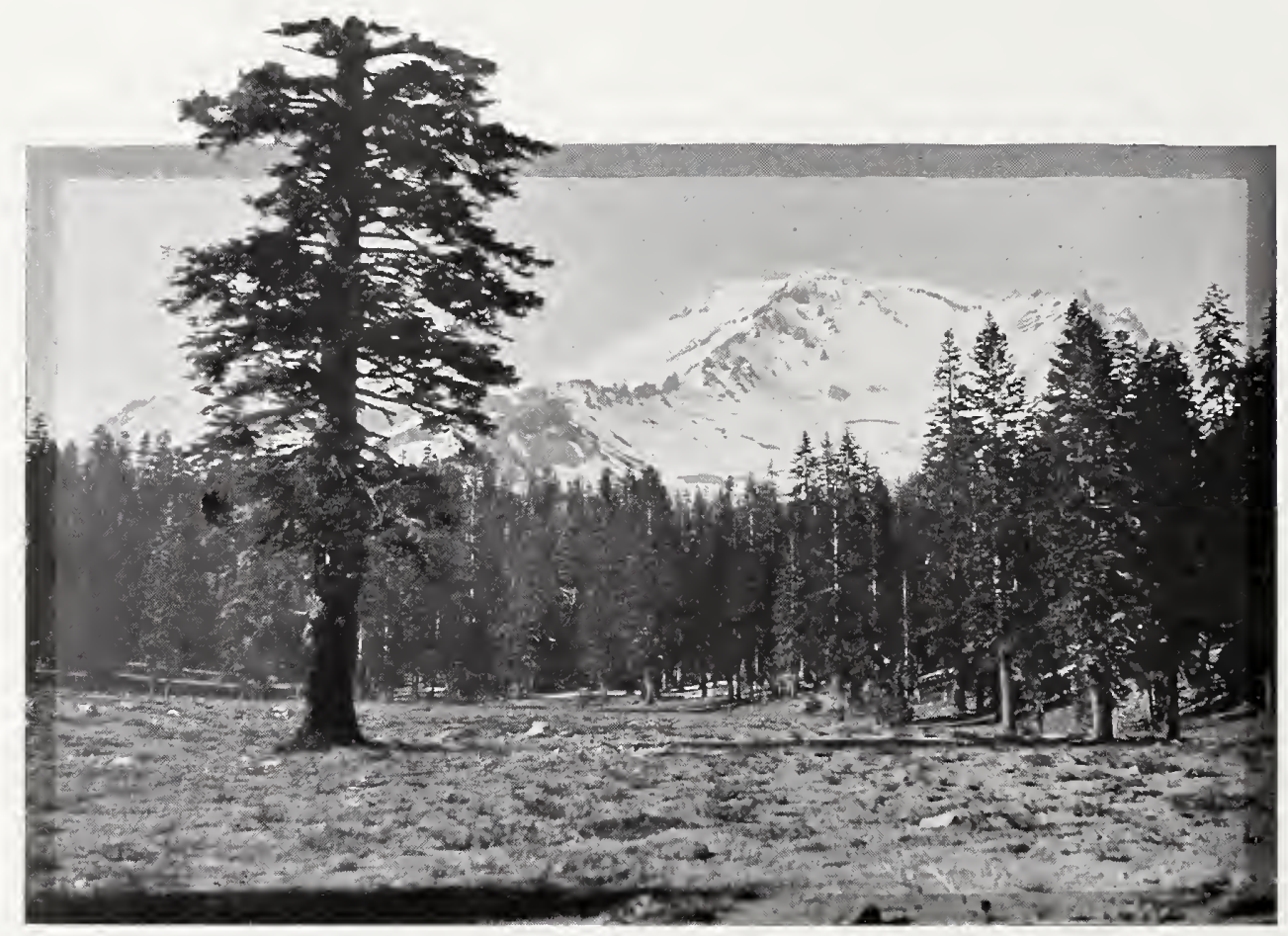

A NEAR ASPECT OF MOUNT SHASTA

Photo by the Author GRAY JAYS ARE FOUND THROUGHOUT THIS BELT OF SHASTA FIRS 


\section{The Gray Jays}

THE "Camp-Robber" appears promptly as interested neighbor and smell-feast before all who invade the precincts of the mountains. The hunter, the trapper, the prospector, the timber cruiser, the mere camperout, all know him, and they speak well or ill of him according to their kind. The Gray Jay appears to have forsworn the craftiness of his race, and he wins by an exhibition of artless simplicity, rather than by wiles. The bird is mildlycurious and hungry - oh, very hungry - but this is Arcadia, and the shepherd draws nigh with never a doubt of his welcome. There is a childlike insouciance about the way in which the bird annexes a piece of frizzled bacon, humbly intended for the man. “' 'Shoo,' did you say? Why, what do you mean? Can't I have it?", And the bird retires before a flying chip, baffled and

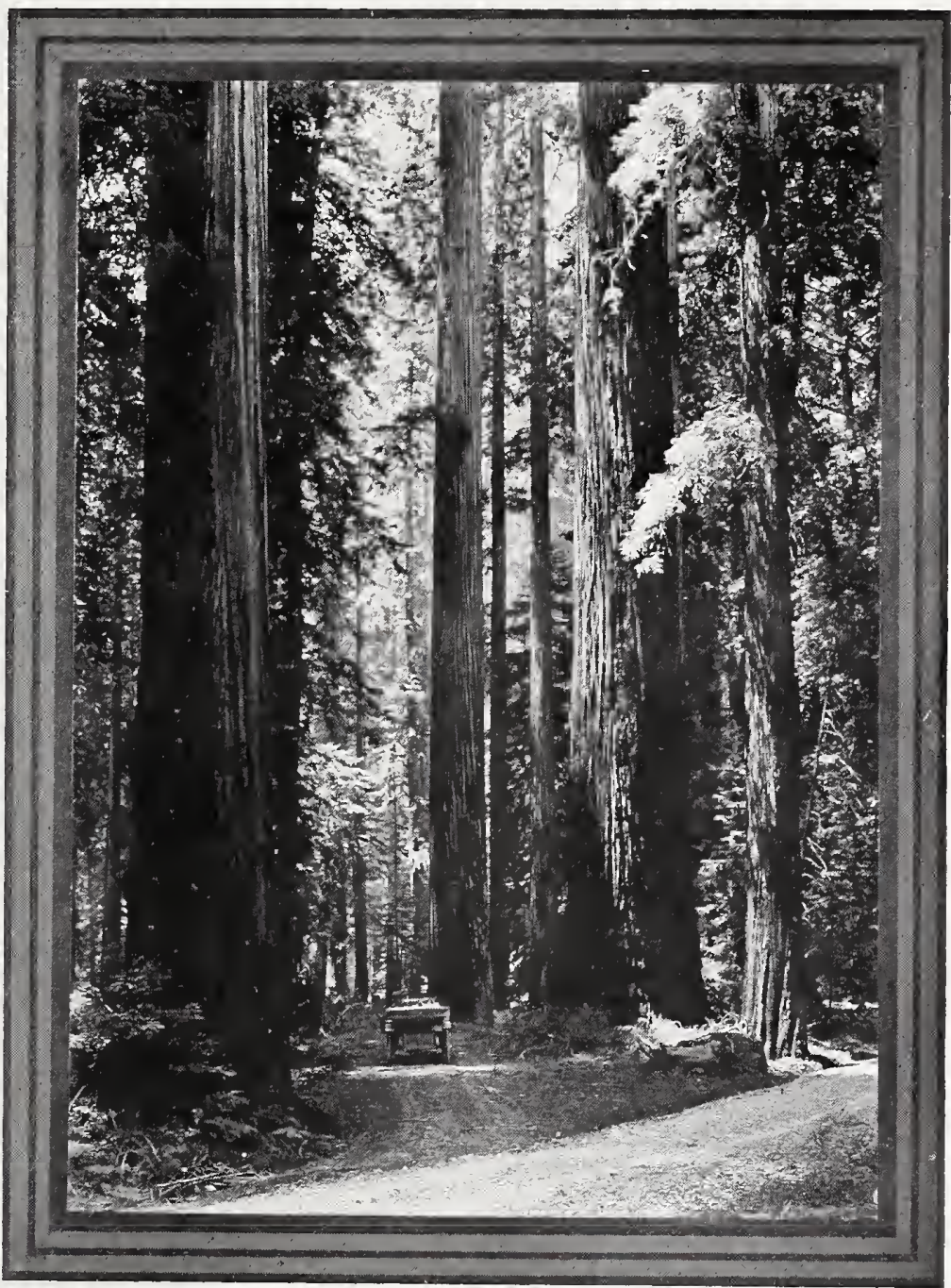

Taken in Humboldl County

IN THE REDWOODS injured by such a oregon JaYs ARE AMONG THE FEw hiRDS TO BE FOUND IN THE DEPTHS OF THESE FORESTS manifest token of ill-breeding. He complains mildly to his fellows. They discuss the question in gentle whews; generously conclude you didn't mean it, and return unabashed to the quest. 


\section{The Gray Jays}

Hunger is the chief characteristic of these docile birds, and no potential food is refused, nuts, acorns, insects, berries, or even, as a last resort, the buds of trees. Meat of any sort has an especial attraction to them; and they are the despair of the trapper because of their propensity for stealing bait. The hunter knows them for arch sycophants, and he is occasionally able to trace a wounded deer, or to locate a carcass by the movements of these expectant heirs. Says Mr. A. W. Anthony: "While dressing deer in the thick timber I have been almost covered with Jays flying down from the neighboring trees. They would settle on my back, head, or shoulders, tugging and pulling at each loose shred of my coat until one would think that their only object was to help me in all ways possible."

In the higher latitudes "Whisky Jack," in spite of carefully secreted stores, often becomes very emaciated in winter, a mere bunch of bones and feathers, no heavier than a Redpoll. While the Jays of our kindlier clime do not feel so keenly the belly pinch of winter, they have the same thrifty habits as their northern kin-

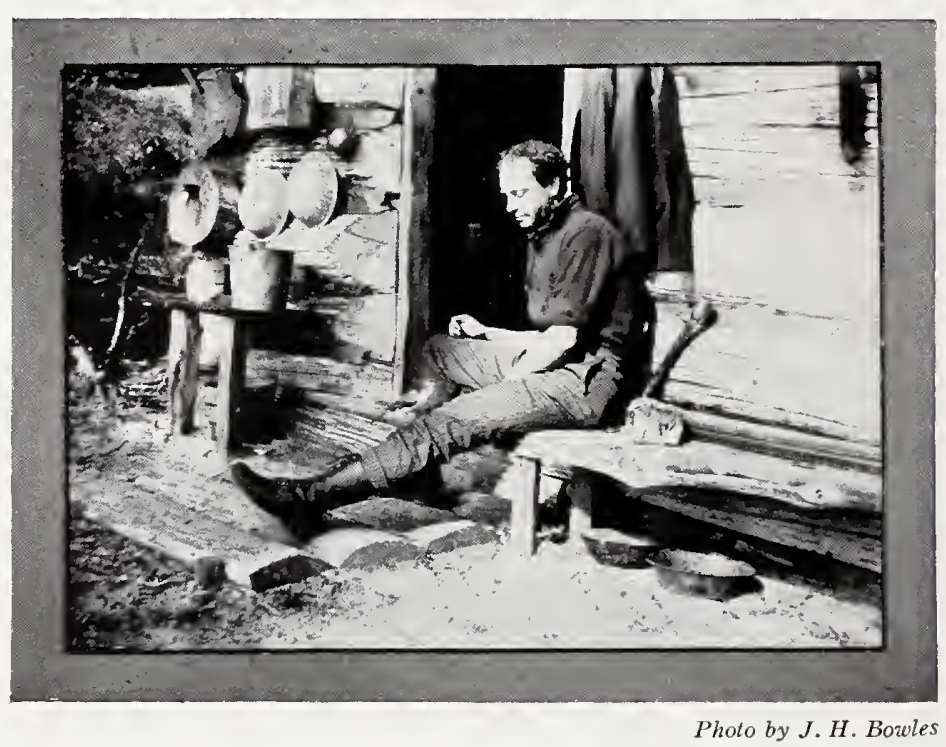

A BACHELOR'S PET

folk. Food is never refused, and a well-stuffed specimen will still carry grub from camp and secrete it in bark-crevice or hollow, against the unknown hour of need.

Though not a noisy bird after the fashion of Aphelocoma or Cyanocitta, the Gray Jay, nevertheless, gives rise to a considerable variety of sounds. Besides the soft cooing whee ew, with which the birds follow each other's movements, there is a drawling petulant squeal, curiously hawk-like in quality. By a great stretch of the imagination this could be rendered Jaaay, jaaay. On other occasions the resemblance to the quee e e er of the Western Redtail is inescapable. Then there is a "windingup note," not unlike the squeak of the Golden Eagle; a krowk krowk krowk of alarm; and the kooree kooree kroo kroo kroo kroo of more extended 


\section{The Cowbirds}

flight. And to these a low, rambling song, delivered sotto voce,-your jay of whatever species is always modestly "practicing"- - and you have quite an extended repertory.

Although common enough on Mt. Shasta, and of regular occurrence through the heavy forests of the northwestern counties, the eggs of Perisoreus jays have only once been reported from this State. The bird builds a very substantial nest of twigs, grasses, plant-fiber, and mosses, without mud, and it provides a heavy lining of soft, gray mosses for the gray-green eggs. The nest is placed, usually, in a fir sapling, at a height ranging from ten to eighty feet, and so well concealed that its discovery is well nigh impossible, save for the visits of the bird. Only one brood is reared in a season, and family groups hunt independently of their more distant kinsmen until late midsummer.

No. 12

\section{Cowbird}

\section{No. 12a Nevada Cowbird}

A. O. U. No. 495 part. Molothrus ater artemisiae Grinnell.

Description.-Adult male: Head, neck, and throat broadly light seal brown, or bone brown; remaining plumage black with metallic greenish or bluish reflections. Bill, feet, and legs black; iris brown. Adult female: General color fuscous above and drab be ow, the feathers chiefly with obscurely darker centers, or shaft-streaks, and occasionally showing faint greenish reflections; head paler; throat drabby white, unmarked. Very old birds are darker, with more iridescence and less streaking. Immature birds resemble adult female, but are lighter and more varied; above brownish gray (nearly hair brown), everywhere edged with grayish white; below grayish, heavily streaked everywhere (save on throat), and especially on breast, with fuscous, and varied by brownish buffy edgings. The young males present a striking appearance when they are assuming the adult black, on the instalment plan, by chunks and blotches. Length I 90.5-203.2 (7.50-8.00). Average of I I males from Humboldt County, Nevada, (after Grinnell): wing II3.5 (4.55); tail 79.4 (3.13); bill I $8.3(.72)$; depth of bill at base I 0.3 (.40); tarsus 27.7 (I.09). Females average decidedly less.

Recognition Marks. - Towhee size; brown head and black body of male; blended brown of female. Requires distinction from the resident Brewer Blackbird (Euphagus cyanocephalus), from which it differs in its much smaller size, brown instead of violaceous head of male; shorter, more turgid beak; female with much lighter throat; and posterior parts not glossy. Young Cowbirds bear a superficial resemblance to female Redwings (Agelaius sp.), but are smaller and less sharply streaked. Close attendance upon cattle distinctive.

Nesting.-Parasitic: the Cowbird invariably deposits her eggs in the nests of other birds. Eggs: I or 2, rarely 3 or 4, with a single hostess; white or grayish white, sprinkled or spotted with grayish brown (Natal brown to fuscous, or buffy brown to drab), if finely, then almost uniformly, if more coarsely, then sharply, and with tend- 


\section{The Cowbirds}

ency to cloud capping. Av. size (of ater ater) : $2 \mathrm{I} .5 \times \mathrm{I} 6.4(.84 \times .65)$. Season: Indeterminable, April to July.

Range of Molothrus ater.-North America from about Latitude $60^{\circ}$ in west central Canada south over the Mexican plateau.

Range of $M$. a. artemisiae.-Presumably the Great Basin region north into British Columbia. Breeds chiefly in the Upper Sonoran zone and winters south into Mexico.

Distribution in California.-Summer resident, not common, in the plateau region east of the Sierras, south perhaps to Death Valley (A. K. Fisher [Grinnell]) and Yermo on the Mohave desert (Lamb), although region of inte gradation with obscurus undefined. Casual (?) west of the Sierras (Farallon Ids., June 2, I9II).

Authorities.-Gambel, (Molothrus pecoris), Proc. Acad. Nat. Sci. Phila., vol. III, I 847, p. 204; Grinnell, Univ. Calif. Publ. Zool., vol. 5, I909, p. 276-28I, 2 figs. (description of artemisiae; critical); Dawson, Condor, vol. XIII, I9I I, p. I86 (occurrence on Farallons); Oberholser, Auk, vol. XXXIV, i917, pp. 327-328 (critical; range).

\section{No. 12b Dwarf Cowbird}

A. O. U. No. 495a. Molothrus ater obscurus (Gmelin).

Description.-Similar to M. a. artemiszae, but much smaller; the female slightly paler. Av. of II males (after Grinnell): wing Ioo.I (3.94); tail 68.4 (2.69); bill I6.5 $(.65)$; depth at base $9.2(.36)$; tarsus 24.1 ( .95$)$

Nesting.-As in preceding form. Eggs: decidedly smaller, Av. of 40 eggs from Arizona in the M. C. O. coll. $20 \times 14.5(.76 \times .57)$. Extremes: $17.5-20.8$ by $13.5-15.5$ (.69-.82 by $.53^{-.61}$ ).

Range of M.a.obscurus.-The southwestern United States from southern Texas west to southern California, and south in Mexico to Colima and Jalisco.

Distribution in California.-Summer resident in southern California and in the Tulare basin; commonly along the Colorado River and on the Colorado desert, north to Independence (Grinnell), Bakersfield (Grinnell), Buena Vista Lake (Mailliard), Weldon (Grinnell), and Fresno (Tyler, although possibly not breeding), and more sparingly in the San Diego district, west at least to Santa Barbara (Dawson, several occurrences). Winters in the Colorado River valley and on the Colorado desert, west at least to Mecca (January 30 and February 4, 1913; also van Rossem).

Authorities.-Cooper (Molothrus pecoris), Orn. Calif., I87o, pp. 257-260 (egg in Chat nest in Colorado Valley); Bendire, Rept. U. S. National Mus. for I893 (I 895), pp. 597-599 (general account); Grinnell, Univ. Calif. Publ. Zool., vol. 5, I909, pp. 27828I; ibid., vol. I2, I914, pp. I57-I60 (critical range); Law, Condor, vol. XII, I910, p. I74 (in Los Angeles Co.; habits); Tyler, Pac. Coast Avifauna, No. 9, 1913, pp. 67-68 (in Fresno district); Dawson, Condor, vol. XVIII, 1916, p. 27 (at Santa Barbara); Oberholser, Auk, vol. XXXIV, 1917, pp. 327, 328 (crit.; range); Hanna, Condor, vol. XX, I9I8, pp. 2II-2I2 (nests parasitized).

IT MAY be urged with some show of justice that every bird-persin deserves a sympathetic biographer. Even criminals on trial for their lives are entitled to legal defense. Well, then, let who will be defender. I will be prosecuting attorney. "J'accuse." The prisoner at the bar 
is a demirep, a ne'er-do-weel, a slattern, a shirk, a harpy, a traitor, an anarchist. Destitute of all natural affection, she cares neither for the wrongs of others nor for the undermined pillars of her own virtue. She is the unchaste mother of a race gone wrong, an enemy of bird-society, a blight upon the flower of Progress. Despised and hated by her fellow birds, harried and anathematized by her victims, this avian marplot lives only by stealth and by the secret practice of violence. All that may possibly be urged on behalf of this culprit is that she is the victim of an unfortunate heredity. Such a defense is in itself an accusation. The Cowbird stock is indeed polluted: of haphazard and unknown paternity, conceived in an infamy of indifference, she was dumped at birth into a strange cradle, and left to make shift as best she might, an unblessed and pitiless bastard. Nourished by uncomprehending or reluctant strangers, and winning a place in their affections solely at the cost of the lives of their own innocent babes, this foundling first accepts their untiring ministrations, and then escapes, an alien ingrate, to join herself to the beasts of the field. What wonder, then, that at maturity she welcomes the pirate band, joins them in their obscene revels, and perpetuates, in turn, her dissolute race. Out upon her!

Of course we are "anthropomorphizing"; but the case is really as bad as that. Taken on any plane of life and stated in its lowest terms, parasitism is mutiny, a breaking down of life's wholesome and necessary disciplines, a surrender of life's ends. A parasite is a failure. Evolution is at a standstill. Wherever parasitism succeeds, nature has to begin over again.

But even degeneracy may be picturesque,- of interest, that is, when viewed dispassionately as a phenomenon instead of a moral issue. Hear, then, with what tolerance you may, the story of a changeling:

Beginning, say, in mid-August, before the bird has ever seen another of its own kind, we find it closely attached to some group of horses or cows, following them about slavishly, now being nosed out of the way as the animals feed, or evading as by instinct the misplaced hoof. Perhaps it is oftenest the foregathering of the animals which leads the birds themselves together. At any rate, the corral soon boasts a little company of these dun-colored youngsters with light undervests, and, though they early learn to come and go freely, the association with horses and cattle is lifelong. In all probability the "Cowbird" once followed the buffalo in the same fashion, and was, prior to the introduction of cattle by Europeans in the I6th Century, the Buffalobird.

In September the males exchange the inconspicuous livery of youth for the rich iridescent black of adult plumage; and they do this on the instalment plan, by chunks and blotches, looking meanwhile like rag- 


\section{The Corbirds}

pickers tricked out in cast-off finery. The flocks increase in size as the season advances, and may reach into the thousands in regions where the species is abundant. The birds mingle more or less freely with Redwings, and occasionally with Brewer Blackbirds.

In feeding upon the ground about corrals the Cowbirds are quickly actuated by the flock impulse, rising as one bird at a fancied alarm. After alighting upon a fence or upon the unprotesting backs of cattle, they hop down again one by one as confidence becomes established. They greet each other always with quivering bodies and uptilted tails, and that upon the most trivial occasions. Inasmuch as this is the acceptted "sex call," reserved for rare occasions by all proper birds, one cannot escape the conviction that these Cowbircls are lewd fellows, habituated to the very attitudes of vice.

In winter there is a general retirement into Mexico, although a few of the dwarf variety linger through the season upon the Colorado desert and along the Colorado River: In February or March, according to altitude, there is a return movement of Cowbirds, oftenest in company with other blackbirds. But if the main flock halts for refreshments and discussion en route, a group of these rowdies will hunt up some disreputable female of their own kind, and make tipsy and insulting advances to her along some horizontal limb or fence rail. Taking a position about a foot away from the coy drab, the male will make two or three accelerating hops toward her, then stop suddenly, allowing the impulse of motion to tilt him violently forward and throw his tail up perpendicularly, while at the same moment he spews out the disgusting notes which voice his passion. As the mating season advances the male birds become very active, whether in the untiring pursuit of frailty or in a sympathetic search for prospective foundling homes which they may recommend to their paramours. At such times they move about singly, or by twos or threes, and post prominently in treetops. Any unusual noise, especially a slight one, attracts their attention; and if a human has business in the woodland his movements are sure to be spied upon from time to time by alert Cowbirds. Often the detective announces his discovery by a gurgling squeaky song, and he is quite sure to utter this once or twice just before quitting his observation post.

Of the mating, Chapman says: "They build no nest, and the females, lacking every moral instinct, leave their companions only long enough to deposit their eggs in the nests of other and smaller birds. I can imagine no sight more strongly suggestive of a thoroughly despicable nature than a female Cowbird sneaking through the trees and bushes in search of a victim upon whom to shift the duties of motherhood."

The egg, thus surreptitiously placed in another bird's nest, hatches 


\section{The Cowbirds}

in ten or eleven days, usually, therefore, two or three days before those of the foster mother, and the infant Cowbirl thus gains an advantage which he is not slow to improve. His loud clamoring for food often drives the old birds to abandon the task of incubation; or if the other eggs are allowed to remain until hatched, the uncouth stranger manages to usurp attention and food supplies, and not infrequently to override or stifle the other occupants of the nest, so that their dead bodies are by-and-by removed to make room for his hogship. It is asserted by some that in the absence of the foster parents the young thug forcibly ejects the rightful heirs from the nest, after the fashion of the Old World Cuckoos. I once found a nest which contained only a lusty Cowbird, while three proper fledglings clung to the shrubbery below, and one lay dead upon the ground.

When the misplaced tenderness of foster parents has done its utmost for the young upstart, he joins himself to some precious crew of his own blood, and the cycle of a changeling is complete.

There are endless details and variations to be noted in this exhibition of parasitism, here so hastily reviewed. Much remains yet to be learned by methodical observation, particularly of the western varieties. Especially interesting is the psychological reaction of the various victims to the infamous imposition practiced

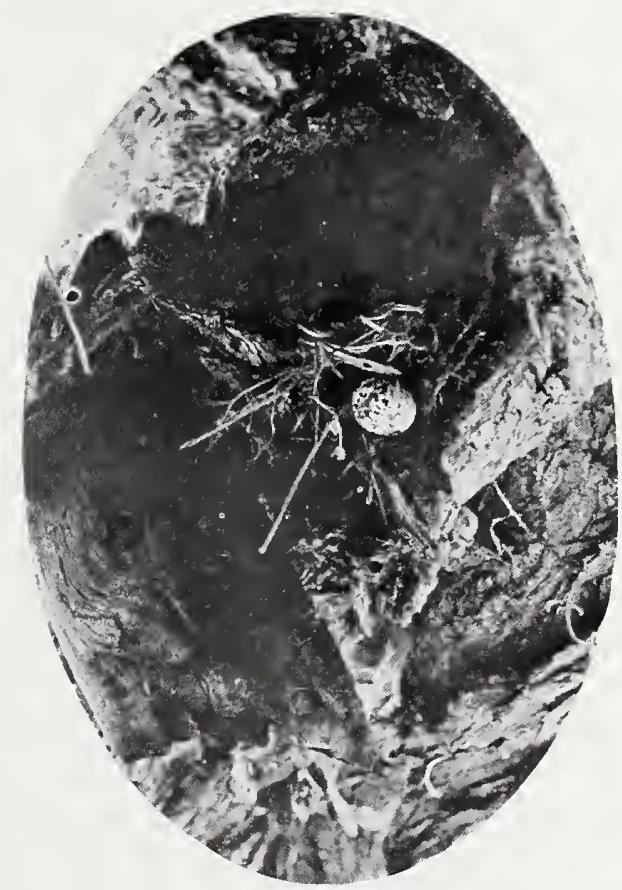

Taken in Arizono

Photo by the A whor

A DOORSTEP CHILD

THIS EGG OF THE DWARF COWBIRD RESTS ON THE SKIRTS OF A LUCY WARBLER'S NEST. THE CRANNY OCCUPIED BY THE NEST WAS TOO SMALI TO ACCOMMODATE THE INTERLOPER

or intended. Major Bendire has listed ${ }^{1}$ ninety species of involuntary hosts of the better known $M$. ater, and twenty-five for $M$. a. obscurus. Of these the most conspicuous victims upon our borders are the Arizona Least Vireo (Vireo belli arizonae), Lucy's Warbler (Helminthophila luciae), and the Western Chat (Icteria virens longicauda) It is rare to find Least Vireos' nests which have not been victimized, and the destruction caused to this one species is enormous. Sometimes the birds cease laying upon the advent of the foreign egg, and sometimes they desert

"The Cowbird" by Charles Bendire, Rep. of National Museum, 1893 (pub. 1895), p. 594-5. 


\section{The Cowbirds}

outright. Often their eggs are claw-marked by the careless intruder, and occasionally, if time allows, the rightful eggs are pitched out of the nest by the miscreant Cowbird. One pair of Least Vireos which built a nest near our camp on the Santa Cruz River (in Arizona) seemed especially apprehensive of the visits of the Dwarf Cowbird, and showed notable valor in driving off from time to time a snooping female who spied upon their progress. Rousing one morning to a sudden outcry, I arrived upon the scene in time to see an irate Vireo drag a Cowbird from the nest and hold her for a dramatic moment suspended in midair - until the Vireo's strength gave out and both fell struggling to the ground. But in spite of this instant and summary punishment, the Cowbird had accomplished her mission. [She had and I did.]

In a Cowbird country most efforts of the smaller birds are foredoomed to failure, for the miscreant exhibits a diabolical cunning not alone in finding nests, but in judging the proper time for deposition. Several "prospects" are kept under review at once, and inasmuch as the Cowbird matures her egg only every second or third day, she has little difficulty in finding fresh victims. Occasionally, however, two or three eggs are laid in the same nest by one individual, as may readily be determined by the close resemblance of eggs which in the species are wont to differ widely.

Eggs of the Dwarf Cowbird are notably smaller, and average lighter in coloration than those of the eastern form. They display also a higher degree of variation.

And while we are speaking of contrasts, it is well to note that the song of the western races is distinctly different from that of $M$. ater. The notes of the latter are described as a "shrill hissing squeak in two tones, with an interval of a descending third, uttered with great effort and apparent nausea." The notes of obscurus, on the other hand, I find to be rather sweet and not unattractive, glug, glug, zzt-a rich, deep gurgle, followed by an absurd squeak. In fact, care must be taken to distinguish them from utterances of the Brewer Blackbird; and there is no question that the birds themselves often escape attention because of a superficial resemblance to the more familiar Brewer.

In food habits the Cowbird is beneficial rather than otherwise. While it consumes some grain, it does no damage to fruit, and its consumption of weed-seed and injurious insects would entitle it to grateful protection were it not for the fact that its very existence involves the loss of three or four individuals of some other species quite as likely to be beneficial. Or if we could forget the blood-stained infancy, we should have to recall that an adult female Cowbird, functioning twice in a season with an average of six eggs to a "set," and reproducing for six 


\section{The Rusty Blackbird}

or eight years, will account for the loss of from sixty to one hundred broods of song-birds in a lifetime. It is with just alarm, therefore, that we note the steady increase of this parasitic species in California. The older authorities did not even mention the presence of $M$. a. obscurus in California, although it was perfectly well known from Arizona. It is not listed in Grinnell's first Check-List, because occurrences in the southeastern part of the State were attributed to $M$. a. ater. Dr. Grinnelli; however, found the Dwarf Cowbird abundant in the Colorado River Valley in the spring of I9I0. Records are now coming in from San Diego, from Los Angeles County, and from the San Joaquin Valley. I have seen it three times at Santa Barbara, and confidently expect to find it both in San Luis Obispo and Monterey Counties at no distant date.

No. 13

\section{Rusty Blackbird}

A. O. U. No. 509. Euphagus carolinus (Muller).

Synonym.-Rusty Grackle.

Description.-Adult male in breeding plumage: Uniform glossy black with steei blue reflections. Bill and feet black; iris pale straw. At other seasons the plumage bears rich brown, or "rusty" (mars brown to chestnut) tips above, especially anteriorly, and rufescent or buffy (cinnamon buff to pinkish buff) tips below; in varying proportions also a vague light line over eye. Adult female in breeding season: Above blackish slate, shading to deep neutral gray on underparts; faintly glossed above, and with some edging of rusty; vaguely lighter-edged below. At other seasons the general cast of plumage is lighter, and the overlap of rusty or buffy is similar to that of the male. Adult male length 228.6-243.8 (9.00-9.6o); wing II5 (4.53); tail 9o (3.54); bill I 8.8 (.74); tarsus 30 (I.I8). Female smaller.

Recognition Marks.-Towhee to robin size. Male entirely black, not so glossy as in E.c.cyanocephalus; female more slaty. Rusty markings usually distinctive during migrations; high-pitched whistling notes.

Nesting.-Does not breed in California. Nest: of sticks and coarse grasses, held together with mud, lined with rootlets or fine green grasses, placed in bushes or high in coniferous trees. Eggs: 4 to 7 ; grayish or pale green, speckled and mottled with chocolate and other reddish or grayish browns, very rarely marked with hairlines or scrolls. Av. size, $24.9 \times 18.3(.98 \times .72)$. Season: May, June; one or two broods.

General Range.-Eastern and northern North America. Breeds from the Kowak River in Alaska south to southern Alaska, and so in a broad belt in an eastsoutheasterly direction which eventually involves northern New York and the northern New England States. Winters chiefly east of the Mississippi River, from about the

1 Pacific Coast Avifauna, No. 3, June 25, 1902. 


\section{The Rusty Blackbird}

Fortieth Parallel south to the Gulf coast; west over the Great Plains in migrations: casually to Colorado, Montana, etc, ; accidental in California, Lower California, and in Greenland.

Occurrence in California.-A casual winter visitor. Two records: Amador County by H. B. Kaeding, Dec. I 5 , I 895 ; and San Clemente Island by C. B. Linton, Nov. 20, 1908.

Authorities.-Mailliard, J., Condor, vol. VI, I904, p. I6 (in Amador Co.); Linton, Condor, vol. XI, I909, p. I94 (on San Clemente Island); Grinnell, Pac. Coast Avifauna, No. II, I9I5, p. I05.

ANY migrant northern species which nests as far west as Alaska may be expected to miss now and then the arbitrary east-and-west route followed by the returning hosts of his compeers, and to straggle down into California instead. Only two such instances have been recorded in the case of this species; but there is always a delightful possibility before us. We have no details regarding the specimen taken by Mr. H. B. Kaedingl in Amador County (Dec. I 5, I 895); but the one taken by C. B. Linton $^{2}$ on San Clemente Island (Nov. 20, I908) was busily engaged in catching insects in the kelp along the beach. One would sooner expect a considerable company of these very sociable birds to go astray; and when they do, they will be found flocking by themselves, as they do in the East.

In their more familiar haunts, it is in some tiny glade in the heart of the budding forest that one comes upon a company of these sojourners, feeding, perhaps, upon the ground. They walk about with easy grace, or shift by little flights, males and females flocking together, and all engaged in a subdued but voluble chatter. An instant hush follows the signal of alarm, and the flock rises silently to the neighboring treetops, or passes to a distant spot, where their conversation is gradually resumed. As the alarm decreases the birds come dropping down, one by one, until confidence is completely restored.

"The notes of the Rusty Blackbird consist of a bubbling medley of l's and r's, through which clear, high-pitched whistles or squeaks are interspersed at will. Gorwhillier conveys some idea of the liquid quality of the former, and expresses also in part the effort which is required to produce them. The effect of a full chorus is really quite pleasing. If not 'music', it is at least among the less disagreeable noises."

'Reported by Joseph Mailliard, The Condor, Vol. VI., Jan, 1914, p. 16

${ }^{2}$ The Condor, Vol. XI., Nov. 1909, p. 194.

" "The Birds of Ohio." 
No. 14

\section{Brewer Blackbird}

A. O. U. No. 5 Io part. Euphagus cyanocephalus cyanocephalus (Wagler).

Description.-Adult male: Glossy black with steel blue and violet reflections on head; with fainter, greenish, steel blue, and bronzy reflections elsewhere. Bill and feet black; iris pale lemon yellow or light cream. Immature male: Like adult male, but feathers of foreparts margined with grayish brown, lightly on throat and chest, broadly on cervix and back. Adult female: Foreparts (head and neck all around, upper back and chest) grayish brown (hair brown to drab), the throat lighter, light drab; shading posteriorly into mingled drab and black of remaining plumage; the blacks with some metallic reflections, chiefly green and violet. Bill and feet as in male; but iris brown. Immature females and young birds of both sexes resemble adult female. Length about 254 (10.00). Av. of 8 males from Rocky Mountain section (Grinnell): wing I 3 I (5.16); tail (from base of uropygium) I I 4.5 (4.50); tarsus I9.6 (.77); exposed culmen I9.6 (.77); depth of bill at nostril 8.I (.32). Females slightly smaller.

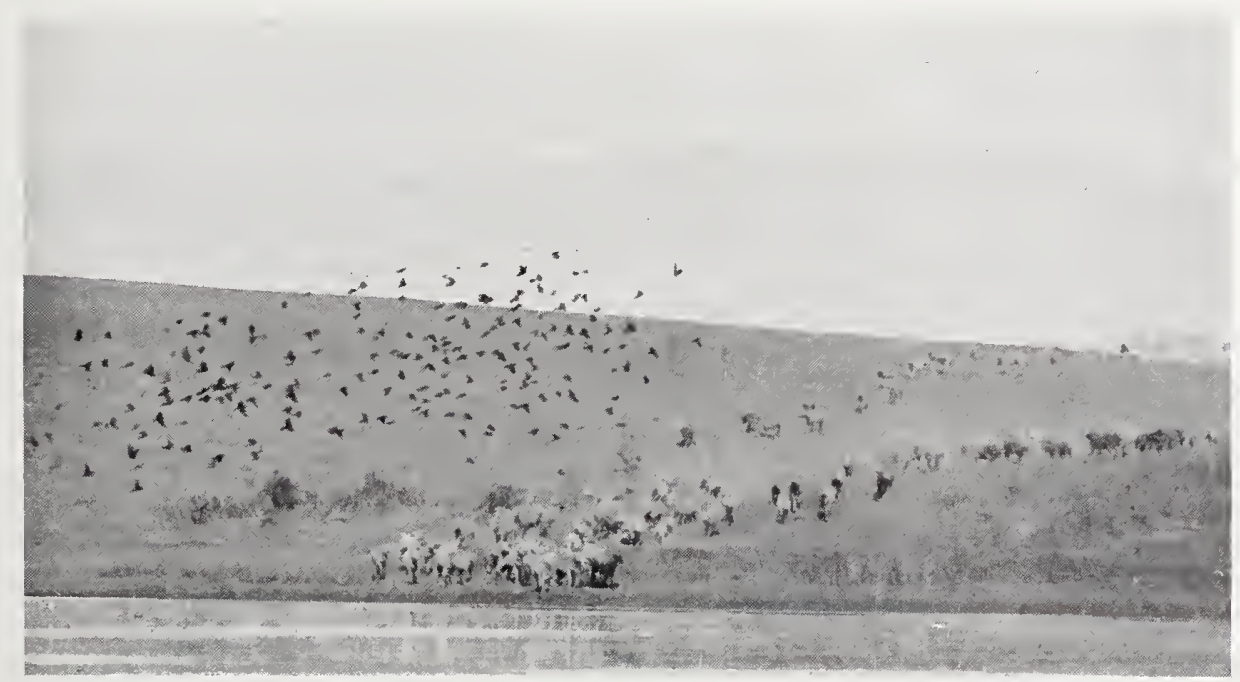

Taken in Santa Barbara County

Photo by the A whor

A PASTORAL.

Recognition Marks.--Robin size; pure black coloration with metallic reflections: and whitish eye of male. Larger than Cowbird (Molothrus ater), with which alone it is likely to be confused.

Nesting. - Nest: placed at moderate height in bush or tree; of ten in close colonies in trees (live oak, white oak, or cottonwood) infested by mistletoe; less frequently on ground at base of bush; more rarely in a cranny of cliff or cavity of decayed tree trunk; a sturdy, tidy structure of interlaced twigs and grasses, strengthened by a matrix of mud or of dried cowdung, and carefully lined with coiled rootlets or horsehair. Nests in colonies, usually straggling, of from six or eight to twenty or thirty pairs. Eggs: 


\section{The Brewer Blackbird}

4 to 7 , usually 5 or 6 , presenting two divergent types of coloration, with endless variations and intermediate phases. Light type: ground color light gray or greenish gray, spotted and blotched with grayish brown or, more sharply, with sepia. Eggs of this type rehearse relationships, now with the Quiscaline Grackles, and now with the Yellowheads (Xanthocephalus xanthocephalus), or the Cowbirds (Molothrus ater). An egg in the M. C. O. collection has a background of pale Niagara green sharply spotted with a blackish pigment which tones out to dusky drab, and is thus indistinguishable from the egg of an Agelaiine Blackbird. Dark type: Ground color completely obscured by overlay of fine brown dots, or else by confluent blotches of Rood's brown, walnut brown, or cameo brown. Av. of 245 specimens (Bendire): $25.5 \times$ I 8.6 (I.00 x .73). Extremes: 20.8-27.9 by I5.5-20. I (.82-I. Io by .6I-.79). Season: March I5 to June I5; one or two broods.

Range of Euphagus cyanocephalus.-Western North America. Breeds from northwestern Minnesota and western Kansas west to the Pacific; and from central British Columbia and the Saskatchewan region south to northern Lower California and western Texas. Winters from Kansas and southern British Columbia south to Guatemala. Casually east to and beyond the Mississippi River during migrations.

Range of E. c. cyanocephalus.-As that of species, minus range of E.c. minusculus, defined below. Breeds east of the Sierras, south to Owens Valley; in winter, south over the Mohave and Colorado deserts.

Authorities.-Gambel (Scolecophagus Mexicanus), Journ. Acad. Nat. Sci. Phila., ser. 2, vol. I, I 847 , p. 47 (part); Fisher, A.K., N. Amer. Fauna, No. 7, I 893, pp. 78-79 (range); Ray, Condor, vol. XI, I909, pp. I94-I96 (odd nest sites); vol. XII, I9IO, pp. 20, 2 I (variation in eggs); Grinnell, Condor, vol. XXII, I920, pp. I52-I54 (critical; range in Calif.)

\section{No. 14a California Brewer Blackbird}

A. O. U. No. 510 part. Euphagus cyanocephalus minusculus Grinnell.

Description.- "Similar to Euphagus cyanocephalus cyanocephalus but averaging smaller throughout; metallic sheen of back, rump, and posterior lower surface in male steely blue rather than brassy in tone." (Grinnell). Av. of Io males: wing I24.9 (4.92); tail (from base of uropygium) I05.9 (4.I7); bill I 8.8 (.74); tarsus 32.2 (I.27). Av. of 8 females: wing I I5 (4.53); tail 97.8 (3.85); bill I7.I (.67); tarsus 30.I (I.I 8).

Range of E. c. minusculus (chiefly contained within California).-Resident in California west of the Sierran divide, or else retiring from upper levels of Sierran range in winter; north to Siskiyou County; south to the line of Lower California, or a little beyond.

Authorities.-Gambel (Scolecophagus Mexicanus), Journ. Acad. Nat. Sci. Phila., ser. 2, vol. I, I847, p. 47 (part); Heermann, Rept. Pac. R. R. Surv., vol. X, pt. IV., I 859, pp. 53-54 habits); Bendire, Life Hist. N. Amer. Birds, vol. II, I 895, pp. 493496 (habits, nests and eggs); McGregor, Osprey, vol. I, I 897, pp. I03-I05 (roost); Beal, Bull. Div. Biol. Survey, No. I3, I900, pp. 50-52; No. 34, I9Io, pp. 59-65, pl. IV. (food); Grinnell, Condor, vol. XXII, I920, pp. I52-I54 (description of minusculus; range in Calif.)

WE SHALL never be able to escape the alliterative finality of Brewer's Blackbird. So where is the use of pointing out that this bird is really a grackle? or that the name "Blackbird" was pre-empted centuries 
Taken in Santa Barbara County

Photo by the Author

HIGH NOTES

BLACKBIRDS, CHIEFLY BREWERS

ago by an Old World thrush (Turdus merula)? The name "blackbird," moreover, in America, carries with it a strong suggestion of thievishness, an odium scarcely deserved by the subject of this sketch. He is a handsome fellow, our western grackle, sleek, vivacious, interesting, and serviceable withal. We know him best, perhaps, as an industrious gleaner of pastures, corrals, streets, and "made" lands. He is not only the farmer's "hired man," waging increasing warfare against insect life, especially in its noxious larval forms, but he has an accepted place in the economy of city and village as well.

As one approaches a feeding flock, he notes the eagerness with which the birds run forward, or rise and flit past their fellows, now diving at a nimble weevil, now leaping to catch a passing bug, but always pushing on until the onlooker perceives a curious rolling effect in the total movement.

As we draw near, some timid individual takes alarm, and instantly all are up, to alight again upon the fence or shrubbery, where they clack and whistle, not so much by way of apprehension as through sheer exuberance of nervous force. As we pass (we must not stop short, for they resent express attention) we note the droll white eyes of the males, as they twist and perk and chirp in friendly impudence, and the snuffy brown heads of the females with their soft hazel irides, as they give a motherly fluff of the feathers, or yawn with impatience over the interrupted meal. When we are fairly by, the most venturesome dives from his perch, and the rest follow by twos and tens, till the ground is again covered by a shifting, chattering band.

Like all blackbirds (grackles included), the Brewers are gregarious, 


\section{The Brewer Blackbird}

but they are somewhat more independent than most, flocks of one or two score being more frequent than those of a hundred. During migration and in winter flocking they associate more or less with Redwings; but, although they are devoted to the vicinity of water, they care nothing for the fastnesses of reed and rush, which are the delight of Redwing and Yellowhead. Their preference is for more open situations. The water may be that of river, lake, or horse-pond. A watering-trough, if its supply be constant, will have its devoted circle of black admirers, and especially if it also assures the presence of cattle. In some places their attendance upon horses or cattle is so close that they almost fulfil the function of Cowbirds. Being omnivorous as well as adaptable, the grain wasted by feeding animals is consumed by these birds as greedily as are the insects which annoy them. Familiarity with domestic animals may reach the point where the birds are suffered on the back; and Mrs. Bailey tells us that in the Escondido country the birds take toll of the sheep's backs at nesting time.

Although isolated nests may now and then be found, colonies are the rule; and we sometimes find as high as twenty nests in a single tree, or forty in a given patch of greenery. There is, of course, room even here for individual choice of nesting sites; but the community choice is far more striking. Thus, one recalls the grease-wood nesting, the mistletoe nesting, the rose-briar nesting, the Monterey Cypress nesting, where all the members of the colony conform to the locally established rule in nest position. J. H. Bowles records a most remarkable instance of this in Washington. One season the nests in the South Tacoma colony were all placed in small bushes, the highest not over four feet from the ground; but in the season following, the birds were all found nesting in cavities near the top of some giant fir stub, none of them less than I50 feet from the ground. ${ }^{1}$ Mr. Tyler ${ }^{2}$ found them breeding at Shaver Lake (elevation $5300 \mathrm{ft}$.) in the old dead pine stubs standing out in the water. And Mr. Ray $^{3}$ reports their nesting at Lake Tahoe in the crannies of rotting piles. Numerous instances are on record where nests have been placed on the ground, and sometimes entire colonies will adopt this indolent and unquestionably hazardous method.

In construction, the nest of the Brewer Blackbird varies considerably, but at its best it is quite a handsome affair. Composed externally of twigs, weed-stalks, and grasses, its characteristic feature is an interior mould, or matrix, of dried cow-dung or mud, which gives form and stability to the whole. The lining almost invariably includes fine brown rootlets, but horsehair is also welcomed wherever available.

"'The Birds of Washington," Vol. 1, p. 47, 1909.

"John G. Tyler in "The Condor," Vol. XI., May 1909, p. 83.

3Milton S. Ray, "The Condor," Vol. XI., Nov. 1909, p. 193-196. 
The eggs of Brewer's Blackbird are the admiration of oologists. Ranging in color from clear greenish gray with scattered markings through denser patterns to nearly uniform umber and chocolate, they are the natural favorites of "series" hunters. The range of variation is, indeed, curious, but it proves to be entirely individual and casual, without trace of local or constant differences. Eggs from the same nest are usually uniform in coloration, but even here there may be a notable diversity. In some instances, after three or four eggs are laid, the pigment gives out, and the remainder of the set is lighter colored. Again, single eggs are heavily pigmented half way, and finished with a clear green ground-color.

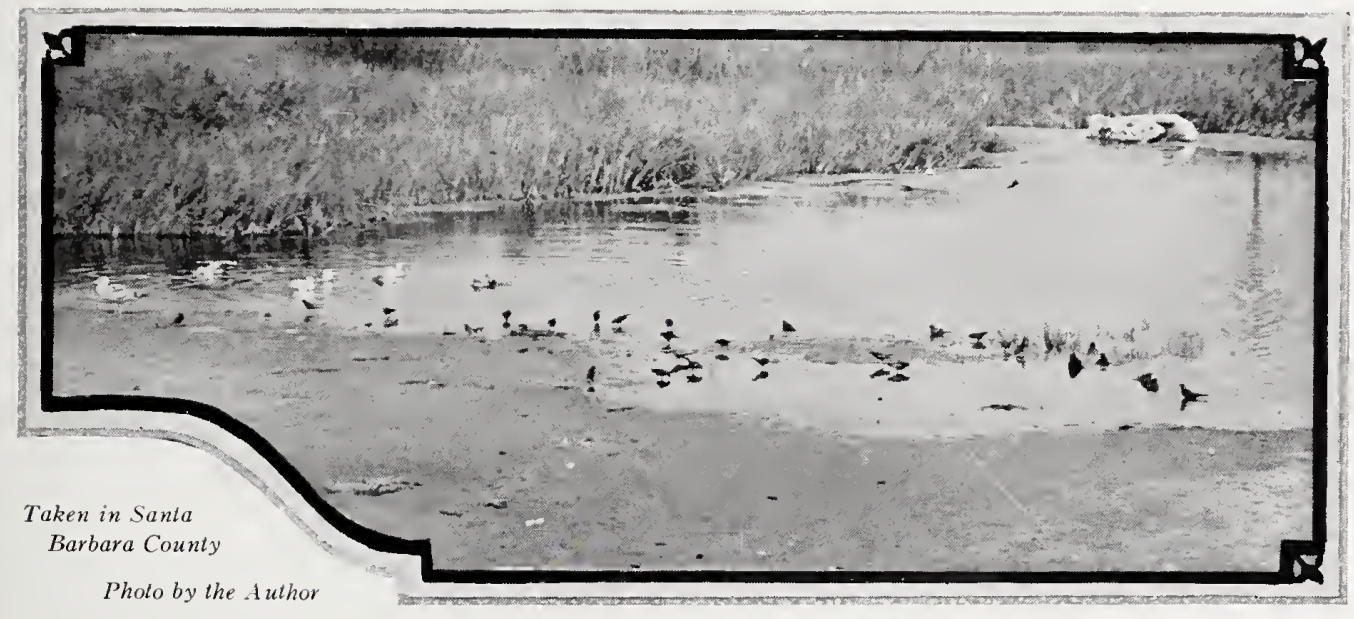

CONTENTMENT - A SCENE IN THE ESTERo

Fresh eggs have been taken as early as March 16 th $^{1}{ }^{1}$ but April is the proper nesting month at the lower levels. It is impossible, though, to lay down rules or strike averages for a bird which breeds from the level of the sea to the top of high Transition, and possibly into Boreal. I am not able to find a specific record of the Brewer Blackbird's nesting above 7000 feet, although Dr. Fisher ${ }^{2}$ mentions it as "breeding at Big Cottonwood Meadows [alt. I0,000] during the summer;" and I presume that the birds which appeared at the Cottonwood Lakes (alt. II,350) June 23rd, I9I I, fell to nesting forthwith, as did the Spotted Sandpipers, which did not arrive until the I 4 th of July.

This is but a characteristic example of the complexity of distributional problems in California. A precise account of the seasonal ranges in this State of the Brewer Blackbird alone would require a separate

${ }^{1}$ By Evan Davis near Orange: Grinnell, Pub. 2, Pasadena Acad. Sc1., 1898, p. 34.

${ }^{2}$ Birds of the Death Valley Expedition, p. 78. 


\section{The Brewer Blackbird}

volume. In general, we may say with Grinnell1 that "it breeds the whole length of the State - at the north chiefly east of the Sierran divide, south, east of the Sierras, to Owens Valley, west of the Sierras through the Sacramento Valley and marginal foothills of the San Joaquin Valley, and coastally from the San Francisco Bay region south through the San Diegan district." It summers, therefore, through upper Sonoran and Lower Transition and into Boreal of characteristically Sonoran complexion or approaches. In winter it probably retains its middle holdings, but its upper level population recedes to Lower Sonoran levels and to unoccupied Upper Sonoran areas, such as the southern central valleys.

We have called the Brewer Blackbird "Grackle," and are influenced, not alone by structure but as much, perhaps, by consideration of its economy, which is largely that of the "Crow Blackbird" (Quiscalus quiscalus and its allies). It is in his notes, however, that the Brewer Blackbird betrays his affinities best of all. The melodiously squeaking chatter of mating time is, of course, most like that of the Rusty Blackbird (E. carolinus), but it lacks the bubbling character. He has then the swelling note of the Grackles proper, $f f f$-weet, the latter part rendered with something of a trill, the former merely as an aspirate; and the whole accompanied by expansion of body, slight lifting of wings, and partial spreading of tail. This note is uttered not only during the courting season, but on the occasion of excitement of any kind. Kooree has a fine metallic quality which promptly links it to the Keyring note of the Redwing. Chup is the ordinary note of distrust and alarm, or of stern inquiry, as when the bird-man is caught fingering the forbidden ovals. A harsh, low rattle, or rolling note, is also used when the birds are squabbling among themselves, or fighting for position.

The menu of Euphagus cyanocephalus is highly varied, as becomes a bird which dwells from sea-level to timber-line. It consists in part of grain, but this is chiefly gleaned waste (remember that the bird is absent from much of the grain-growing area at harvest season). After this, come weed-seeds and insects of a thousand hues, chiefly injurious or superabundant. Dr. Bryant ${ }^{2}$, in investigating the butterfly scourge, which for several years past has been destroying the chaparral in the Mt. Shasta region, found that Brewer's Blackbird was the only species which was addressing itself resolutely to the task of keeping the butterflies (Eugonia californica) within bounds. Whole flocks of these blackbirds subsisted almost entirely upon the adult butterflies for the week during which they were under observation.

Garden fruits, especially cherries, are sometimes levied upon; but

${ }^{1}$ Pac. Coast Avifauna, No. II, p. 106.

${ }^{2}$ "The Condor," Vol. XIII., Nov. 1911, pp. 195-208. 


\section{The Arizona Hooded Oriole}

cast; chin and throat black. The approaching maturity of male birds is characterized by steady intensification of the yellows, and extension of the black "bib;" but the characters of the adult female are stubbornly retained above, and it is probable that the adult characters are not acquired until the third spring. In all males advancing age is betokened by increase of the orange element in the yellows, so that the color of the oldest birds is a little richer than "cadmium yellow." Length of adult male about 203.2 (8.00). Av. of Io (Ridgway): wing 88.4 (3.48); tail 89.9 (3.54); bill 2 I.6 (.85); tarsus 22.4 (.88). Females slightly smaller.

Recognition Marks.-Towhee size. As compared with Icterus bullocki, with which alone it is likely to be confused, note yellow head, or "hood," of male; much more extensive black of throat; tail black, not yellow, on under side; yel'ows less orange. Underparts entirely yellow in female and young.

Nesting.- Nest: a closely woven basket, or hanging pouch, of fine vegetable fiber, usually composed externally of a single, uniform, selected material, and in California almost invariably the shredded fibers of the Washington Palm ( Neowashingtonia filifera), with some inner felting of vegetable down or feathers; lashed to the under side of a palm leaf or of other large protecting leaves. Eggs: 3 or 4 , wh te or b u sh white, sharply, sparingly and irregularly spotted, chiefly about the larger end, with purplish black and purplish gray. Av. size 2 I.6 $\times$ I $5.4(.85 \times .61)$. Season: late April to July; two broods.

Range of Icterus cucullatus.-Southern California, southern Arizona, and the lower valley of the Rio Grande, south to Honduras.

Range of I. c. nelsoni.-Southern California, southern Arizona, and southwestern New Mexico, south to Lower California and Tepic, Mexico; winters south of the United States.

Distribution in California.-Common summer resident, of local distribution in the Lower Sonoran zone of the lower Colorado River valley, the Colorado desert and the San Diegan district, west to Santa Barbara and Santa Ynez (Aug. I9, I917). There is a record for Auburn, Placer County (Bendire, Life Histories, vol. II, I 895, p. 476); and the species is of probable occurrence in the Tulare basin.

Authorities.-Cooper, Proc. Calif. Acad. Nat. Sci., vol. II, I 86 I, p. I 22 ; Stephens, Auk, vol. I, I 884, p. 355 (nests); Ridgway, Proc. U. S. National Mus., vol. VIII, I 885, p. I9 (description of nelsoni); Illingworth, Condor, vol. III, I90I, pp. 98-IOo (nests); Bailey, F. M., Auk, vol. XXVII, I9Io, pp. 33-35, pls. IV, V (nests in S. Calif.); Wear, Condor, vol. XVII, I9I5, p. 234 (at Fresno).

EXACT information regarding the Arizona Hooded Oriole is curiously lacking. The bird is rated common in Southern California; and most of us have seen its nest, a sturdy fistful of twisted palm fibers lashed midway of some protecting cluster of large leaves (sycamore or fig), or hung from the under side of a palm-leaf. Its brilliant colors, goldenyellow and black, with touches of white, mark the male bird for distinction, yet the bird is so modest, so retiring, or else so crafty, and so reticent withal, that our impressions of his personality seem to be very hazy.

Much of our confusion is caused, no doubt, by the presence of its several-times more numerous, ten times noisier, and hundred times less 


\section{The Arizona Hooded Oriole}

bashful cousin, the Bullock Oriole. Indeed, our modest hero fairly skulks in the shadow cast by his more brilliant but not more beautiful kinsman. The writer once camped for a month under a tree which eventually cradled nests of both these species. Yet in that time I never heard a note which did not upon investigation trace to bullocki, nor see a distinctive movement of nelsoni, save of the female at her nest. In view of this experience, I mistrust some of the observations already in print, and offer meager notes of my own with the utmost diffidence. The biographer of Icterus cucullatus nelsoni is still in training.

The Arizona Hooded Oriole begins to arrive in California late in March. I say "begins to arrive" because I think it altogether probable that there are two streams or stocks of migrants, one arriving early and nesting in April and July, the other nesting only once, in late May or early June. Santa Barbara seems to be the usual limit of northern migration; but I once saw a pair east of Paso Robles (April 22, 1912); and Bendire gives it ${ }^{1}$, upon what authority I do not know, from Auburn, in Placer County. Late September, or earliest October, witnesses the departure of this species from the State.

Although coming of a family famous for tuneful good cheer, the Arizona Hooded Oriole gives a poor account of himself as a songster. This does not seem to be so much for lack of ability as for lack of impulse. He is not of the noisy kind. When he does condescend to sing, it will be briefly, at daybreak or thereabouts. His vocal efforts are exceedingly variable both as to length and quality, now a weak rasping phrase, now a succession of sputtering squeaks, half musical and half wooden, and now a wild medley wherein are imbedded notes of a liquid purity. At its best it reminds one, just distantly, of Bobolink's. Tsweetsee burr ho wick divoer, rendered in sprightly fashion, will give one a notion of its dashing inconsistency. But these singing phrases are exceedingily rare. And lest I be thought to exaggerate through lack of opportunity to observe, I may say that a pair of these birds has nested regularly in the yard of my next door neighbor since we came to California. The nest can be found at the appropriate season whenever we set out to look for it; yet so silent, so secretive, so utterly extra-mundane are the birds, we could forget their existence, were it not for an occasional chirp (or, more exactly, chweet) which is at least unmistakably Icterine.

This very day (July I6, I9I7), being reminded, I step over in to Neighbor Hoover's yard and search the nearest sycamore carefully. The tree is in high leaf, and the foliage fairly dense. Ah, there it is, nearly concealed in the drooping tip of one of the outermost branches, some twenty feet above the ground. By the help of some ladies (over-solicitous

${ }^{1}$ Life Histories, Vol. I., p. 475, 1895. 


\section{The Arizona Hooded Oriole}

of the bird-man's safety) I ascend a ladder balanced in an upright position. for the branch is a mere whip-end. There are three eggs, white, lightly spotted and briefly scrawled with dark reddish brown, utterly unlike the Bullock Oriole type. The nest is a rounded hammock, or deep cup, composed solely of fine, even strands of palm fiber, and made fast on its sides through numberless holes pierced in the substance of enveloping leaves. The cup is three inches wide and of a like depth, and boasts a scanty lining of white chicken-feathers. But all we hear of the owners is a faint chirp from the female, concealed in a distant thicket. It is not a time, evidently, for the risking of black-and-gold liveries.

One season this local pair of birds behaved very strangely. Instead of getting down to business, the birds idled away the month of July making trial, or decoy, nests. These were invariably of palm fiber, carefully moulded but not always lined; and we found two in our tree yucca, two in Neighbor Hoover's banana tree, and one in a small sycamore, all, apparently, the product of a single pair of birds. To what end was all the labor? Was milady so hard to please? Or were there possibly several miladies?

A possible key to this strange conduct is afforded by the experience of another observer, Mrs. Bagg, of Santa Barbara. According to this lady, a male Hooded Oriole was observed day after day as he constructed a nest on the under side of a palm leaf on the Bagg demesne. No sign of the female was at any time seen during construction. When the edifice was completed, however, the young swain appeared one morning with two females. The ladies inspected the quarters minutely, and each arriving at the decision that the situation was one to be desired, fell into a dispute as to whose it should be. Finally, they set to and fought bitterly. The quarrel could not be decided in a single day, for each lady was determined to win home and fortune. Each day, therefore, they fought, until both were exhausted. Again and again they carried their battle to the ground, and might have been caught, so bitter was their hatred. The male, it seems, took no part in the conflict, but either looked on disgustedly, or took himself off to moralize on the depravity of womankind. Finally, one suitress gave in and left her rival in possession. Peace being established, the winner laid two eggs and sat happily for a few days, sat until her old enemy, having recruited her strength, returned to give battle. A fight ensued. The eggs were broken in the scrimmage, the nest dishevelled, and the conflict was transferred to parts unknowncertainly a sad case of misguided judgment on the part of one member of the sterner sex. 


\section{The Scott Oriole}

No. 16

\section{Scott's Oriole}

\section{A. O. U. No. 504. Icterus parisorum Bonaparte.}

Description.- Adult male in breeding plumage: Head and neck all around, breast, and back, jet black; remaining underparts (including axillars and under wingcoverts), rump, tail-coverts, and basal three-fifths of tai! (one-third only on central pair), pure yellow (lemon chrome); bend of wing and lesser and middle wing-coverts yellow, the last-named tipped with lighter yellow; the greater coverts and tertials tipped with white; rest of wing and tail black. Adult male in win'er: "Similar to summer male, but white markings on wing much broader, feathers of back more or less margined with light gray, rump and upper tail coverts more strongly washed with olive or gray, and flanks more or less tinged with olive' (Ridgway). Adul female in breeding plumage: Somewhat similar to adult male in spring, but black pure only on throat and chest, and there reduced in area; feathers on the borders of this area tipped with yellow; remainder of head and neck mingled olive-yellow and black the former in fine skirting; the back olive gray with lighter skirtings and darker centers; rump and upper tail-coverts yellowish (citrine or oil yellow); the tail brownish olive centrally and terminally, shading into oil-yellow basally and marginally; underparts yellow, pure only centrally on wing-linings, elsewhere washed with olivaceous; lesser and middle wing-coverts mingled with olive-yellow and black; the middle and greater coverts broadly white-tipped; remainder of wing grayish brown with lighter edgings. Imma'ure male (through the second year?): Like adult female, but progressively blacker, anteriorly, especially below. Immature female: Like adult female but much duller; more sordid or olive gray below and without black-olive gray instead (through second year?); progressively brighter after first year (?), with gradual access of black anteriorly. The unmarked phase of the female Scott Oriole has been described as adult (i. e., Ridgway, Bull. 5o, U. S. N. M., pt. II, p. 309), but the logic of derelopment would seem to favor the explanation given, and black-throated examples abound. Juvenals (first plumage) differ from immature females, if at all, only in being more purely yellow on the posterior underparts. Length of males about 2 I I (8.30). Av. of I 6 specimens (after Ridgway): wing I04.4 (4.10); tail 88.4 (3.48); bill 22.9 (.90); tarsus 23.9 (.94). Females average smaller.

Recognition Marks.- Towhee size; foreparts entirely black, sharply contrasting with yellow rump and underparts of male. In all plumages greenish yellow as contrasted with the reddish yellow of Icterus bullocki.

Nesting.- Nest: a sturdy basket of twisted, interlaced, and broken grasses, plucked green; lined with finer grasses, seed pappus, or other sof t substances; lashed to, or impaled upon, the narrow sword-like leaves of the yucca, and especially (in California) of the tree yuccas (Yucca arborescens and Y. mohavensis) Eggs: 3 or 4, rarely 5, white or pale bluish white, marked sparingly with reddish brown or blackish. The markings are rounded, zigzag, or various, but show no tendency to scrolling, although there are occasiona hints of coronal wreathing. The colors too are oftenest partially self-toned by virtue of superimposed lime, and there are sometimes minute frecklings which impart a dirty appearance to the egg. Av. size $23.8 \times 17(.94 \times .67)$. Sea on: About May ist (on the Mohave desert); one (?) brood. 


\section{The Scott Oriole}

General Range.-Lower Sonoran zone from southern California, southwestern Utah, and western Texas, south to Lower California and through Mexico to Michoacan and Vera Cruz; winters south of the American border.

Distribution in California.- Resident in summer in the arid Upper Sonoran fringes of the southeastern deserts, breeding from the tree yucca to the pinyon associations, chiefly upon the flanks of the desert-facing mountains, north to the Inyo Mountains; also near San Diego (Browne), and on the west slope of the Sierra Nevada in Walker Pass, Kern County (Grinnell). Of casua' occurrence during migrations in the San Diegan district, west to Santa Barbara (May 7, I9I3).

Authorities.-Cooper, Orn. Calif., I870, p. 276; Browne, Auk. vol. VIII, I89I, p. 238; Fisher, A. K., N. Amer. Fauna, No. 7, I 893, pp. 67-68 (range and nest); Anthony, Auk, vol. X, I894, pp. 327-328 (in San Diego Co.); Bendire, Life Hist. N. Amer. Birds, vol. II, I 895, pp. 47 I-474, pl. VI (figs. 28, 29) (habits, nest and eggs); Grinnell, Condor, vol. XII, I9Io, p. 46 (range); Willett, Pac. Coast Avifauna, No. 7, I9I2, p. 7I (status in S. Calif.).

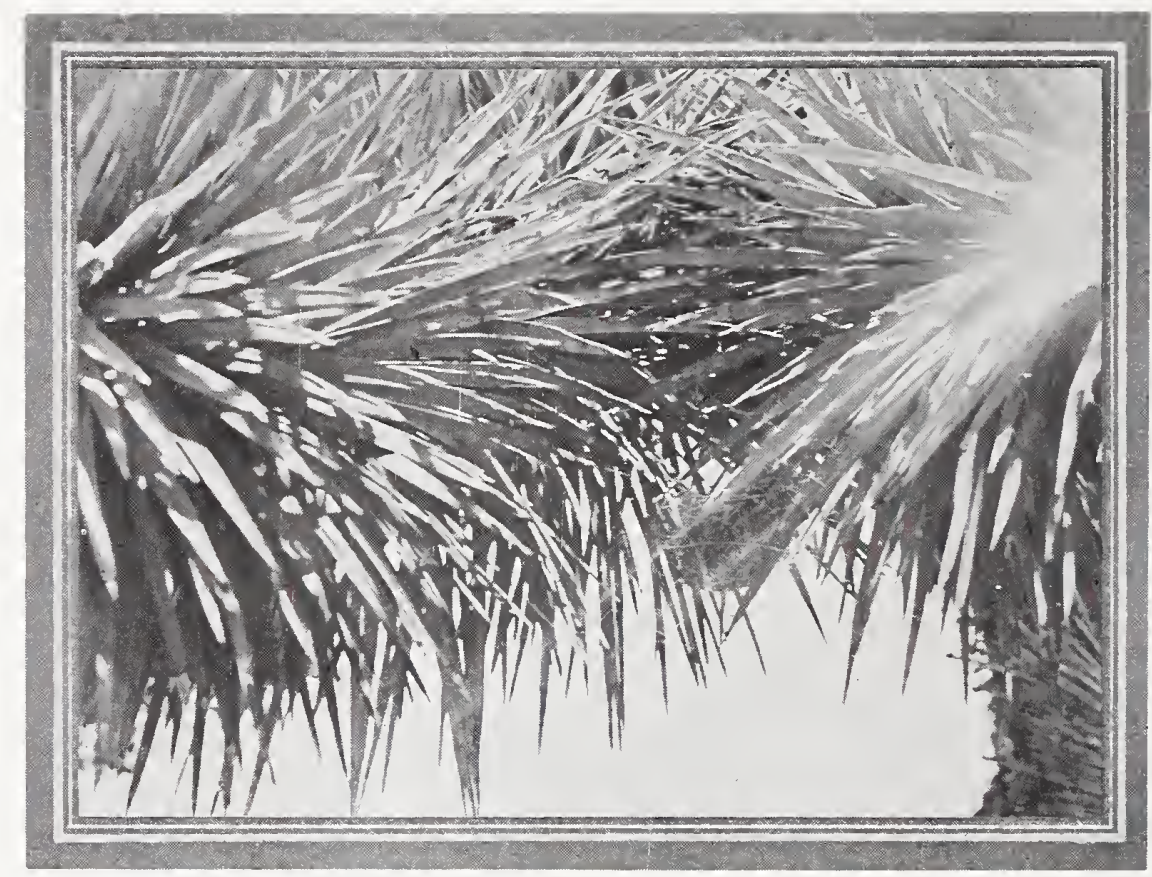

Taken in San Bernardino County

Photo by Wright M. Pierce

NEST OF SCOTT'S ORIOLE-SUSPENDED FROM YUCCA BRANCHES

" "AWAKENING SONGS" are all very well for poets and milk peddlers, who require little sleep, but they are much resented by the average Californian, and especially by those of us who affect sleeping porches. It is for this reason that the author, blessed (or plagued) with a keen sense of hearing, confesses to sleeping with a huge pillow plastered over his ear. But the angel of bird-men, relentless as a Pullman porter, 


\section{The Scott Oriole}

earned my special gratitude when on a certain May morning he roused me, regardless, to listen to a golden song which poured down from a sycamore tree hard by. Ly ti ti tee to, ti ly ti ti te to, came the compelling outburst. I took it for a freak Meadowlark song at first, but once t hor o u g h $1 \mathrm{y}$ aroused, knew it for an Icterine carol-ly ti ti tee to, ti ly ti ti tee tomolten notes with

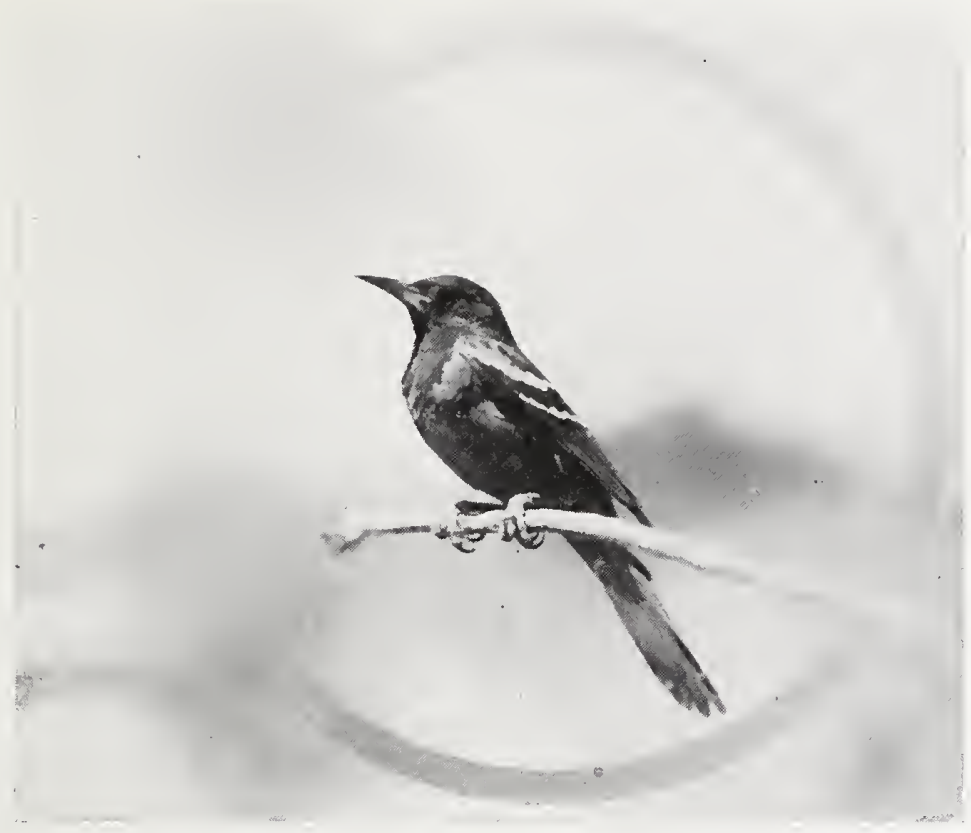

a fond thrill to them, more restrained than the clarion of the Meadowlark, smoother and sweeter than the tumult of a Bullock Oriole, and, of course, with the double repetition, a much longer song than either. This episode signalized the westernmost appearance of this gifted musician, and necessitated, I regret to say, mortuary rites. Maturer impressions obtained in Arizona in a more characteristic setting of pinyons, scattering live oaks, and the inevitable yuccas, confirmed the judgment of a rare quality in this Oriole's song. Again and again we started up with the thought of Meadowlark (at an unlikely altitude of 5000 feet), and were as of ten disarmed by the subtle restraint, the unexampled purity and the faint melancholy of the concluding notes. All around was tense silence, dryness, and appalling heat, the desolation of midday in the desert foothills. Ly ty ti ti tee to, ly ty ti ti tee to, cut across the dry silences like the voice of a spirit treading the plains of asphodel.

How important an element this song becomes in the life of the high deserts, Scott testifies in his classical first description of the bird's habits:1 "Few birds sing more incessantly, and in fact I do not recall a species in the Eastern or Middle States that is to be heard as frequently. The males are, of course, the chief performers, but now and again, near a nest, 


\section{The Scott Oriole}

while watching the birds, I would detect a female singing the same glad song, only more softly. At the earliest daybreak and all day long, even when the sun is at its highest, and during the great heat of the afternoon, its very musical whistle is one of the few bird songs that are ever present."

Unfortunately, the singers are very shy, and the pursuit of their ravishing notes all too rarely yields a view of the handsome singer, with his blackest of heads and his most intensely yellow under plumage. Even the females, who are much duller in appearance, will slyly forsake their nests upon the distant approach of the stranger, and will oftenest remain concealed, or absent themselves, while the nest is being examined.

Typically, the birds nest in the tree yuccas, whether in the Joshua tree (Yucca arborescens) of the eastern desert ranges and the Walker's Pass region, or in the Mohave Yucca ( $Y$.mohavensis Sargent) of the Antelope Valley and the northern slopes of the San Bernardino range. Further south yuccas of the sword-bayonette type ( $Y$. baccata and related forms) furnish shelter, and the palms (Washingtonia filifera) of Palm Canyon and other valleys, are accepted as substitutes. In default of these, Scott's Oriole has been known to nest in pinyons or live oaks or even sycamores. When in the yuccas, nests are of necessity placed at moderate heights, four to ten feet. The edges of descending leaves of the plant are frayed or notched, to serve for the attachment of the threads which support the nest. A deep cup is woven out of yucca fibers or grasses, occasionally supplemented by horsehair, and the linings boast either cotton waste or finely shredded hemp.

From its semi-desert association, the food of Scott's Oriole must consist chiefly of insects, supplemented, possibly, by nectar. Mrs. Kate Stephens once saw an Oriole drink deeply from the tubular orange flowers of the aloe, and thinks that they find nourishment also in the blossoms of tree tobacco. ${ }^{1}$ Bendire notes ${ }^{2}$ their eating the ripe fruit of the giant cactus; and Dr. Grinnell ${ }^{3}$ took specimens at Fairmont which were gorged with apricots.

We have, evidently, much to learn yet of the comings and goings of Scott's Oriole. Most recorded appearances fall within the dates April Ist and September I5th; but Stephens has seen them at San Diego as early as Feb. $26(1916)^{4}$; and W. B. Judson took a specimen in the San Fernando Valley, Nov. 2, $1903 .^{5}$ The vicinity of San Diego has been favored with many recent appearances, and it is quite possible that

'Condor, Vol. VIII., p. 130.

2 "Life Histories," Vol. I., p. 473.

${ }^{4}$ Condor, Vol. XVIII, May, 1916, p. 130.

5 Condor, Vol. VI., p. 25.

96 


\section{The Bullock Oriole}

the species is slowly extending its range. Its normal choice of altitude, however, from 4000 to 6000 , is rather narrowly represented in the Upper Sonoran zone of California, and its total population does not begin to compare with either I. bullocki or I. cucullatus nelsoni.

No. 17

\section{Bullock's Oriole}

\section{A. O. U. No. 508. Icterus bullocki (Swainson).}

Description.-Adult male: Black, white, and orange; bill, lore, a line through eye, and throat (narrowly) jet black; pileum, back, scapulars, lesser wing-coverts, primary coverts, and tertials, chiefly b'ack, or with a little yellowish skirting; remiges black edged with white; middle and greater coverts, continuous with edging of tertials and secondaries, white, forming a large patch; tail chiefly cadmium yellow, but central pair of rectrices black on exposed area, and remaining pairs tipped with blackish; remaining plumage, including supraloral areas continuous with superciliaries, orange (cadmium orange in oldest examples), most intense on sides of throat and chest, shading on lower breast to cadmium yellow posteriorly; rump washed with olivaceous. In younger adults the orange is less intense, and the tail is more extensively black. Bill black above, bluish below; feet and legs (drying) dusky horn color. Adult female: Above drab gray, clearest on rump and upper tail-coverts; washed with yellow on head; wings fuscous with whitish edging; pattern of white in coverts of male retained, but much reduced in area; tail nearly uniform dusky orange (aniline yellow to old gold); sides of throat and chest wax-yellow (with irruptions of orange in older birds); chin and throat (narrowly) and remaining underparts sordid white or pale creamy buff; the under tail-coverts usually (but not always) tinged with yellow. Immature male: Like adult female; yellows of head and throat stronger. Young male in first spring: Like adult female, but sides of head, throat, and breast aniline yellow; lores, chin, and throat narrowly black. Birds breed in this plumage, and it is uncertain whether or not it may be carried into the second year. Length of adult male about 210 (8.25); wing I00 (3.94); tail 79 (3.I I); bill I 8.5 (.73) tarsus 25 (.98). Female somewhat smaller.

Recognition Marks.- Towhee size; black, white, and orange coloration; top of head black, and under side of tail yellow, as contrasted with the Arizona Hooded Oriole. Females and young extensively whitish below. Note slender, blackish bill of female, as contrasted with heavy, light-colored bill of Western Tanager (Piranga ludoriciana); wing-bars white; underparts with contrasting yellow and whitish, where the Tanager is uniform greenish yellow.

Nesting.- Nest: A pendent pouch of elaborately interwoven grasses, vegetable fibers, string, or horsehair, either uniform or variously composed; 5 to 9 inches in depth, and lashed by brim, or suspended by lengthened filaments, to branches of deciduous trees, usually at moderate heights. Eggs: Usually 5; elongate ovate; grayish white or bluish white as to ground, or, rarely, tinged with claret, boldly and intricately scrawled with pen lines, fine or broad, of purplish black. The pattern tends to confluence in a coronal wreath, or cloud cap, and appears as though traced continuously through many 


\section{The Bullock Oriole}

revolutions. Av. size $23.9 \times 16(.94 \times .63)$. Season: May-June; one brood. Extreme nesting dates are: Claremont, April 25, I90I, by IW. M. Pierce; and Pasadena, July I 8 , I 894 , by H. A. Gaylord.

General Range.-Western North America, breeding from southern British Columbia and southern Saskatchewan south to northern Mexico, and from South Dakota and western Kansas to the Pacific; wintering in Mexico south to Colima, Guerrero, and Puebla.

Distribution in California.- "Abundant summer resident in many parts of the State-from the Nevada line to the seacoast, and from the Oregon line to the Mexican boundary. Of very general zonal and faunal preferences; breeds from Lower Sonoran up through Transition, and from the riparian association on the deserts (as along the Colorado River) to the San Francisco Bay region. Of least abundance in the northwest coast belt and on the Santa Barbara Islands, though there are records from both. Occurs in migrations even on the arid portions of the southeastern deserts, and up into the high mountains. Centers of abundance are the interior valleys north of Tehachapi." (Grinnell).

Authorities.-Audubon, Orn. Biog., vol. V, i 839, pp. 9-I I Gambel, Proc. Acad. Nat. Sci. Phila., vol. III, I 847 , p. 204 (migration; song; nest); Heermann, Rept. Pac. R. R. Surv., vol. X, pt. VI, I 859, p. 52 (habits, etc.); Illingworth, Condor, vol. III, I90I, pp. 98-100 (nests); Sharp, Condor, vol. V, I903, pp. 38-42, 3 figs. (unusual nests); Beal, Biol. Survey Bull., No. 34, i910, pp. 68-71, pl. X (food).

THANK God for Wonder! What is it but a pleased interest in the unfolding panorama of life? We consider it the special attribute of childhood, because life is new to the child; but woe to us when we cease to wonder! It is a sign that we have ceased to live. For in the last analysis, Wonder is Worship - a recognition of the presence of God and ecstatic joy thereat.

I bring a chance acquaintance to view my collection of eggs. He glances patronizingly at the painted ovals, murmurs "I see" when I point out an example of protective harmony, and stifles a yawn when I discourse upon the niceties of hummingbird architecture. He isn't interested. What I have proposed for common ground he cannot accept as such. His thoughts are elsewhere. He does not wonder! Another gazes with delight upon the unfolded treasures, gives little shrieks of appreciation at each successive burst of color, and marvels ecstatically over the exquisite traceries of the Oriole. He is manifestly interested in that which interests me. I have given him pleasure. He wonders, and is by so much more my friend.

It is not otherwise with the soul and God. Our Heavenly Father has devised the myriad show of Nature, and has brought us to view it. If we gaze with unseeing eyes, if we turn quickly away, we offend him. He has labored in vain, and the Creator's heart is in so far saddened. But if, on the other hand, we enter with deep appreciation into the storehouse 
sloiro a'x solled

sxiz ghil sts tuod sismot bas ols 


\section{Bullock's Oriole}

Male and female, about $2 / 3$ life size 


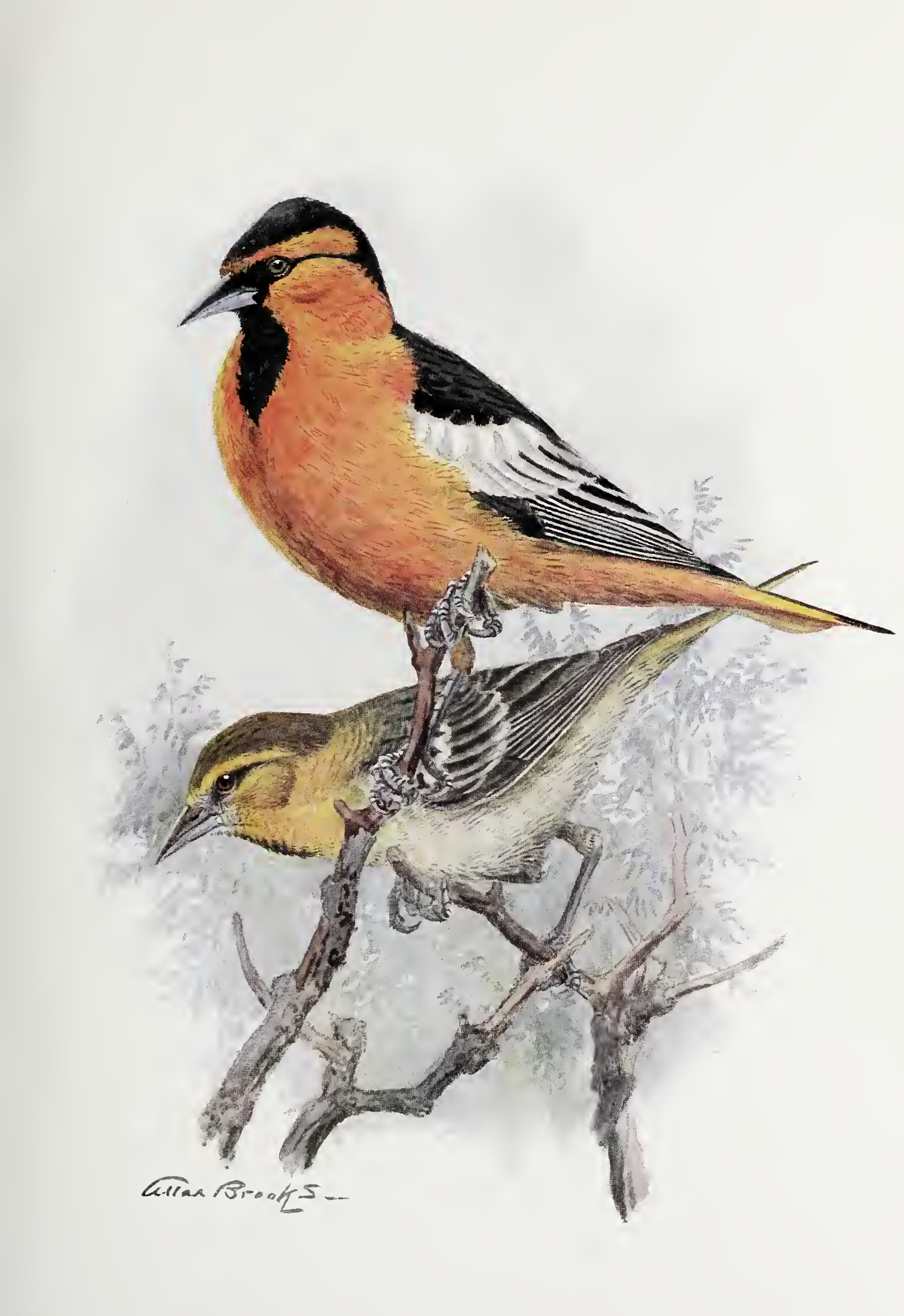





\section{The Bullock Oriole}

of Nature, if we pass with reverent ecstacy from one marvel to another, or if we gaze with kindling enthusiasm upon a single example of his perfect work, we declare ourselves to be of his sort. We are manifestly pleased, and his pleasure is in the sight of ours. We hold communion with him in wonder no less than in praise. Rightly considered, wonder is worship, and God hath not wrought in vain.

And what marvel in all nature shall exceed that offered in the delicate, fantastic traceries of a Bullock Oriole's egg! On a background of palest bluish gray, the calligraphist, having dipped his pen in a well of purplish black, proceeds to scrawl and shade, to zigzag and flourish and vibrateall this while the obedient oval turns round and round. Now as the egg revolves for a dozen turns, the artist bears on with laborious care. Now he lifts the pen; and now, returning, he loiters while the ink runs out upon the page in little pools of indelible blackness. Quaint and fanciful, indeed, are the divagations of the Icterine genius. With all the world before him, why should he not choose to be fantastic? On a specimen before me there are traceries which vary in width from one twentieth of an inch to one tenthousandth. Some of them stand forth like the lines of an engraved visiting card, while others require a magnif ying glass to recall their nebulous course to visi-

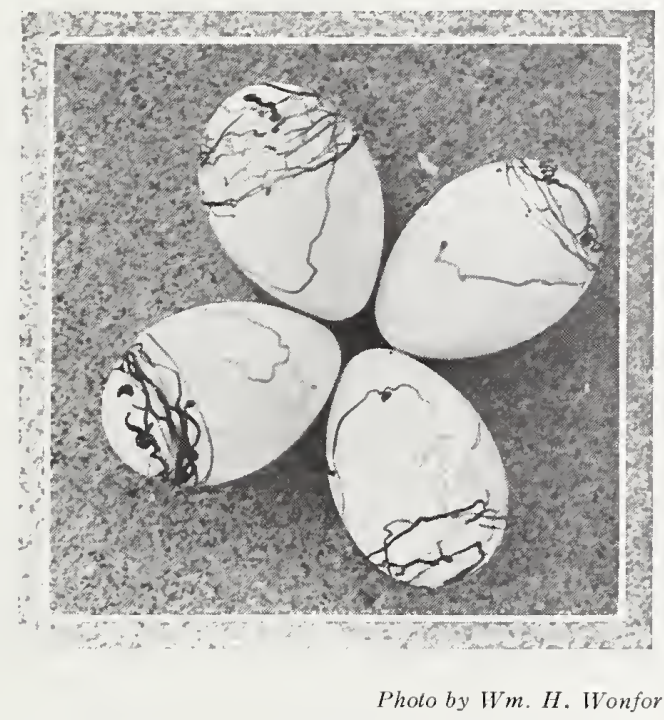

A TYPICAL SET OF BULLOCK ORIOLE'S EGGS bility. On another egg twelve independent lines pass unheeding within a total space of one tenth of an inch, while the smaller end of the same egg is perfectly bare. Here the weird image of a goblin piper braces itself on legs set rakishly awry, and strains away at a splintered flute-all within the space of a barley-corn. There a cable of twisted purple ropes frays suddenly and goes off into gossamer hysterics. Another egg, tottering under its burden of pigment, shows lines curiously shadowed, or "side-wiped." It is all so fascinating, so bewildering, and so mysterious! What is it all for?.

An easy answer would be that it is a phase of protective coloration. I can testify that in the special circumstances of a nest wherein scanty 


\section{The Bullock Oriole}

coils of black horsehair show up in high relief against the remaining background of normal white vegetable felt, these eggs are almost indis-

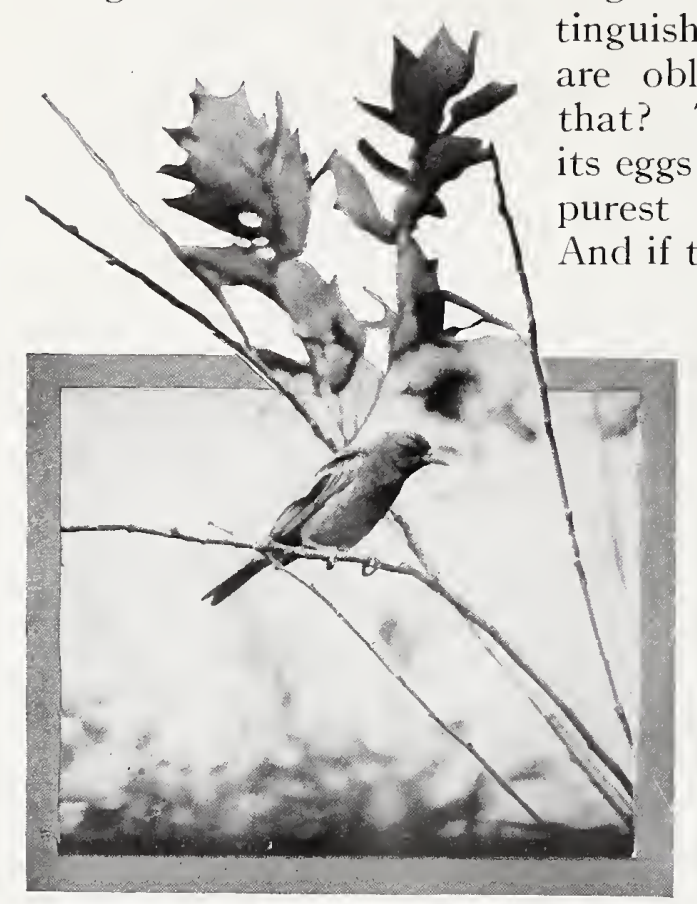

Photo by F. S. Merrill

FEMALE BULLOCK ORIOLE tinguishable from their surroundings. They are obliteratively colored. But what of that? The nest of the Oriole is so deep, and its eggs so much in shadow that, were they purest white, they would scarcely show. nd if they were green or blue, it would not matter. No; I prefer to think that the artist wishes to be fantastic. And he gets his way. While each set of eggs shows a prevailing or unifying motif, each component egg is individually distinct. No two objects in nature are exactly alike; and never by any chance does the master decorator of birds' eggs repeat himself.

But, after all, eggs are as may be. However curiously we may admire the Creator's versatility, it is in the conscious artistry of the bird herself that we most openly rejoice. The Oriole does not design her eggs, but she does design their receptacle; and perhaps nowhere else in nature are art and utility more happily blended. Certainly the selective process of art is nowhere else more clearly exemplified than in the nests of Bullock's Oriole. Guided, of necessity, by materials at hand, the bird, nevertheless, in each instance achieves something individual, distinctive. Even with a wealth of varied materials available, the artist either makes rigid selection of one, as, black horse-hair, white string, or gray bark fiber; or else works out some happy combination of two or three, as, black horse-hair decorated with tufts of cotton, white string relieved by strands of red, gray bark uniformly interspersed with bluish threads. Exceptions to this, the olla podrida sort, are very rare.

The artistry of the Bullock Oriole is strikingly comparable to that of the Baltimore Oriole, or "Hangnest," of the East, and its fabrications are similarly purse-shaped, of elaborate and highly finished weave. The Bullock's nests are not, however, so frequently secured by the brim alone, nor so conspicuously depended from the tips of drooping branches. They are apt to be, also, of a more open weave, as befits a warmer climate, and 
one wherein summer rains play little or no part. Nesting, as it does, from the highlands of Mexico north to British Columbia, the Bullock Oriole shelters in a great variety of host trees, mesquite, willow, sycamore, cottonwood, oak, pine even, not to mention every conceivable variety of the larger shrubs.

Because the variation in construction is so infinite, five examples from the M. C. O. collections, taken in California, must suffice:

Nest KI $60^{4} / 6$, lashed throughout to descending twigs of cottonwood; is composed of horse-hair of three shades, with slight admixture of string, and is decorated sparingly with small white feathers. Lining, confined to bottom third, of white feathers. Measures 7 inches deep by 4 wide over all. Inside depth, from lowest portion of brim, $3 \frac{1}{2} 2$ inches. Opening, $21 / 2$ by 3 . Weight with included twigs exactly half an ounce.

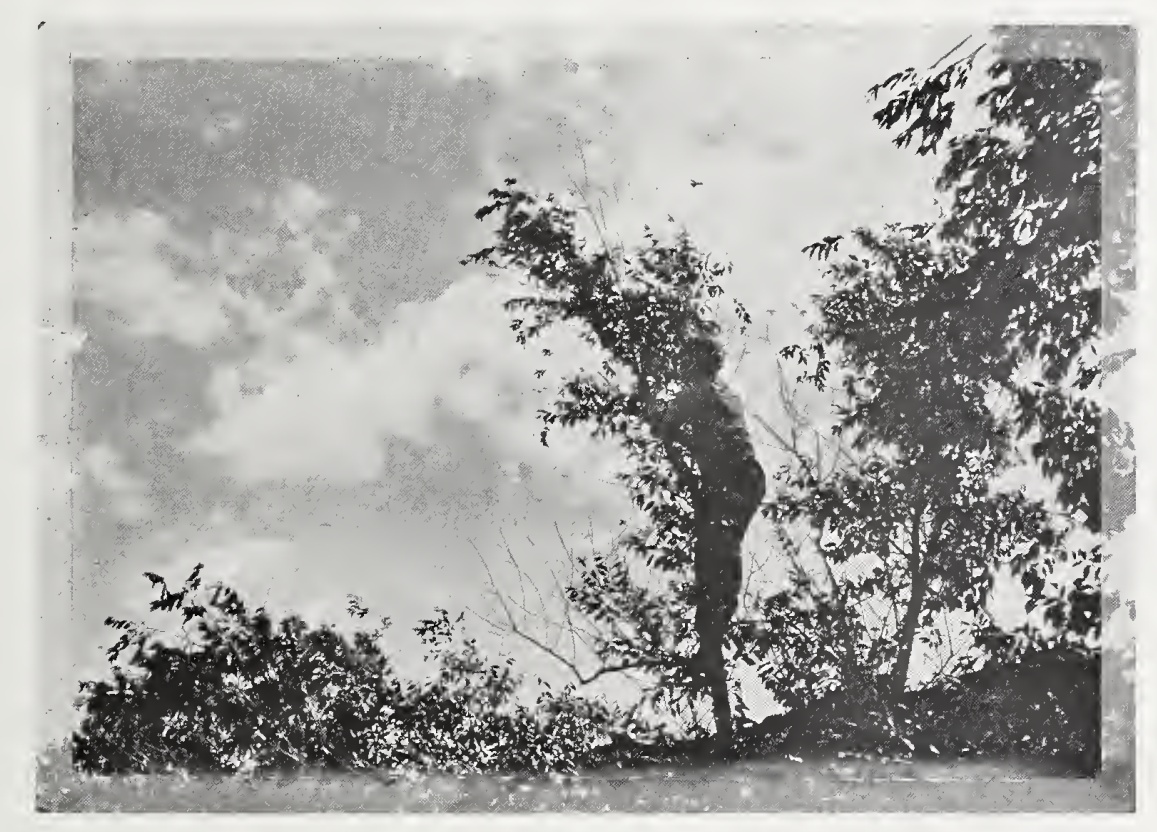

Taken in Washington

Photo by the Author

AN UNUSUAL NESTING SITE-IN THE TIP OF A WILlOW SAPLING

Nest KI394/6, likewise lashed to descending twigs of cottonwood; light open pattern of horsehair, chiefly black. Copious lining of white cotton batting is anchored by being pulled through the meshes from the outside, presenting a handsomely tufted appearance. Depth over all. 6 inches; breadth $4^{1 / 2}$. Inside depth from brim $3 \frac{1}{2}$ inches. Width of opening $2 \frac{1}{2}$ inches. 


\section{The Bullock Oriole}

Nest KII $2^{5} 16$, made fast by brim and side supports to branch of white oak; composed wholly of coarse dried grasses, chiefly fox-tail, the heads of which are turned outside and left as bristling decorations; a mere pinch of feathers in lining. Depth over all 7 inches; width 6 ; inside depth from brim 4 ; width of opening 2 by 3 .

Nest $44^{1} / 14$, composed of fine dry grasses well weathered. Completely invested by drooping cluster of white oak twigs; built up with gradual convergence until the opening, one inch by one and a half across, too small to be functional, and so abandoned.

Nest $R 95^{4} / 1$ (from Arizona). Rigidly supported by forking limbs of a horizontal branch of osage orange, and built up above supports; less pensile than a vireo's nest. A thick-walled structure of mingled horsehair, string, and cotton waste, so copious as not to require special lining. Measures, outside, 4 inches in depth by $4^{\mathrm{T}} / 2$ in width. Inside $3 \frac{1}{2}$ inches in depth. Opening 2 by 3 .

Some very interesting nests of this species have been described by Mr. C. S. Sharp ${ }^{1}$ from Escondido, in which the stems and heads of wild oats were almost the sole material employed. The straggly projecting heads of this grain made a striking and unusual effect for a bird whose habits are a synonym for neatness.

Most of the actual work of nest construction is carried out by the female, while her mate trails about helplessly, or else applauds her efforts in song. But one observer, Mr. J. F. Illingworth, ${ }^{2}$ declares that both birds labor in the construction of the walls, that one posts itself inside the nest and the other outside, and that the thread is passed back and forth from one to the other, until the nest is thoroughly "darned." Be this as it may, it is the female who makes the selection of material, and does all the "rustling." Watching a bird at this perennial quest is no end of fun. Once, in camp near Dos Palos, a Bullock Oriole paid us a visit just as the cook was announcing breakfast. All eyes were turned upon her. She spied the dish-towel drying on the fence, sidled up to it, sampled a thread, tested it carefully throughout its length, found it satisfactory, and flew off with it. While she was absent I put up two lengths of red string for her approval. On returning, she decided that the dishcloth was on the whole too weak for her purpose and passed it up. Then she nibbled at the red strings meditatively, as who should say, "Too bad these ar'n't white, now isn't it?" let them fall unheeded, and passed on. Next she lighted on the automobile, seized a tarpaulin tape, wrestled with it, and in the scrimmage fell over the corner and down with the unwinding tape, like a spider descending on its own belly-

1 Condor, Vol. V. March, 1903, pp. 38-42

${ }^{2}$ Condor, Vol. III, July, 1901, p. 99. 


\section{The Bullock Oriole}

string. But, nothing daunted, the Oriole returned and climbed up and down the fluttering sheet until she found it quite hopeless. Then she fell upon the thread which held the two halves of the tarpaulin together. This she pried and twisted and unthreaded until she had quite a respectable length loose. I thought she would have made off with it, but a fracas among her own kind hard by dissuaded her for the moment, and our appetites reasserted themselves.

Little space remains to recount the wonder of the birds themselves. They, or at least the males, are among the half dozen brightest of California's birds; and they are, perhaps, more widely distributed than any other of our "birds of plumage." Active, industrious, and not unconfiding bodies they are too, and a very im portant element in the good cheer of springtide. The males arrive a week or two in advance of their mates, and appear quite ill at ease until joined by their shy companions. "Arrangements" are, of course, not complete, and the ardent courtships

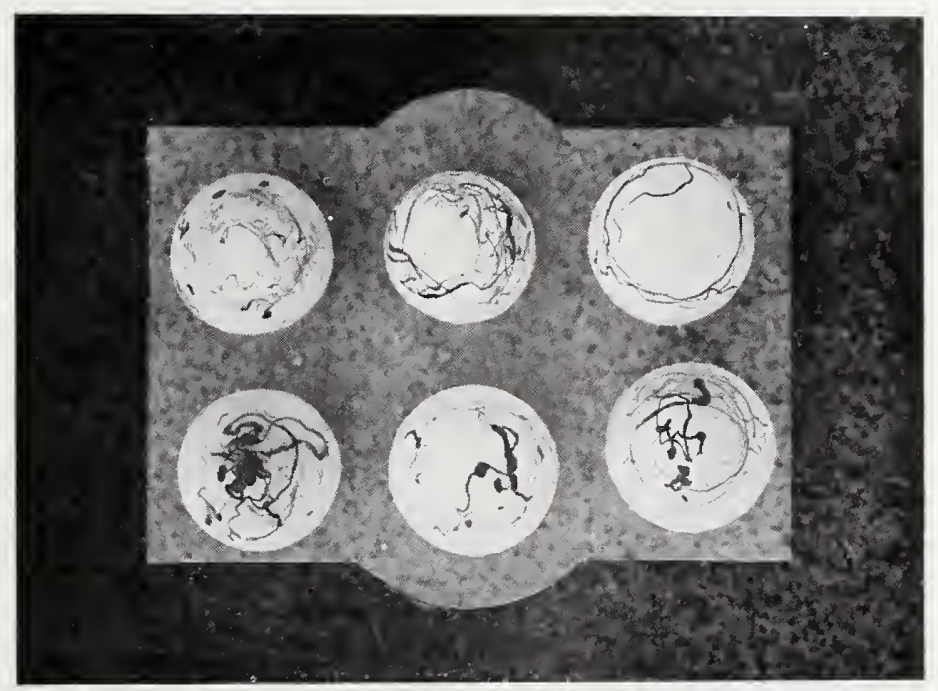

Photo by Wm. H. Wonfor

EGGS OF THE BULLOCK ORIOLE

SELECTED SPECIMENS-SAND BACKGROUND

which ensue are of interest to spectators as well as participants. Only a moment ago I saw two males pursuing a female who evidently wished very much to be excused from an immediate decision. One of the males was a dull-colored young bird, and the other was a gorgeous old major in full regimentals. The young fellow kept the lead and pursued his object with dogged persistence; but the old fellow, wiser in the ways of women, paused now and then to pour out his heart in song. My sympathies-awell - ahem - they used always to be with the young chap, but nowId aetatis jam sumus."

The Bullock Oriole is either musical or noisy, but oftener both together. Both sexes indulge a stirring rattle which seems to express nearly every variety of emotion. Upon this the male grafts a musical 


\section{The Tricolored Redwing}

outcry, so that the whole approaches song. A purer song phrase more rarely indulged in may be syllabized as follows: Cut cut cudut whee up chooup. The last note comes sharp and clear, or, as often, trails off into an indistinguishable jumble. The questing note, or single call, of the male is one of the sweetest sounds of springtime, but an even more domestic sound, chirp trap, uttered while he is trailing about after his swinking spouse, appears ridiculously prosaic.

Once, in a mesquite grove, under the influence, I doubt not, of the rowdy Chat, an infatuated Oriole did a clog dance across an open space. With exaggerated laboriousness he smote his wings together over his back half a dozen times, then dashed into a thicket, whither his Juliet had, no doubt, preceded him. Perridiculus!

No. 18

\section{Tricolored Redwing}

A. O. U. No. 500. Agelaius tricolor (Audubon).

Synonyms.-Tricolored Blackbird. Tricolored Red-winged Blackbird RED-AND-White-SHOUldered BlackBird.

Description.-Adult male in spring: Glossy black with greenish or bluish reflections (slightly more pronounced than in A. phoeniceus); the lesser wing-coverts rich red (carmine - darker than in A. phoeniceus); middle coverts pure white, appearing as a broad transverse band below the red. Bill and feet black. Adult male in fall and winter: As in spring, but feathers lightly skirted, especially on back, pileum, sides of neck, and breast, with rusty gray; the white of the middle wing-coverts more or less tinged with brownish buff. Immature males: (Not seen) probably exaggerate the characters of the adult male in autumn, and closely parallel the course of A. phoeniceus. Yearling male in first spring: Like adult, but lesser wing-coverts tawny or brownish red, variously admixed with black; the middle coverts wholly black, or variously mixed black and white; Adult female in spring: Similar to that of Agelaius phoeniceus, but more uniform in coloration and much darker; above sooty black, nearly uniform, from back posteriorly, but with some obscure skirtings of brownish gray on head and nape; below sooty black, nearly uniform, from breast posteriorly, although with faint skirtings of lighter, or whitish - these skirtings sharply defined on lower tail-coverts; breast mingled black and whitish in about equal proportions, clearing anteriorly to white, sparingly flecked with black on throat; an obscure whitish line over eye; lateral coloration throughout blending the characters of upper and lower plumage; a dull ruddy element of ten present in the whites, and (in older examples?) the lesser wing-coverts more or less skirted with dark red. Adult female in autumn: As in spring, but plumage softer and much more extensively margined above with brownish gray, below with whitish (in this stage closely resembling the female of $A$. phoeniceus in spring). Immature female: Like adult female in autumn, but still more heavily margined; a rusty element appearing 


\section{The Tricolored Redwing}

above. Length about 228.6 (9.00). Av. of males: wing I2I (4.76); tail 88 (3.46); bill 23.4 (.92); tarsus 29.7 (I.I 7 ). Av. of females: wing I06.7 (4.20); tail $75.4(2.97)$; bill 20.I (.79); tarsus 26.4 (I.04).

Remarks. - The occurrence of this closely related but perfectly distinct type of Agelaius in a field closely occupied by the more plastic and wide-spread phoeniceus, offers a pretty problem to the student of geographical distribution. On the whole, I think the presence of the buff element on the wing-coverts of the adult male in autumn affords us the best clue to the bird's phylogenetic history. As is commonly believed, autumnal plumages, when distinct from the breeding plumage, mark a partial reversion, a return to the more primitive or generalized form of the species. That the male tricolor, therefore, should exhibit in the fall a character which marks the utmost, or vernal, achievement of phoeniceus, indicates that the spring white of tricolor is an advance upon the primitive Agelaius type. Tricolor, that is, has evolved further in this direction.

If this conclusion is a correct one, we may assume that tricolor was the pioneer upon the Californian field. Coming at a much earlier day from the Mexican home of the race, it became thoroughly established, and geneodynamically static, within its chosen area. A succeeding wave of Agelaii, viz., phoeniceus, has since swept the continent, nearly to the Arctic zone; but it found tricolor stubbornly intrenched. As a consequence, it has partly swept around the domain of tricolor, and partly invaded it, so that we now have the phenomenon of two closely related members of the same genus breeding in the same swamp. And with this explanation the notably primitive behavior characters of tricolor agree.

Recognition Marks. - Towhee to robin size; red-and-white epaulets of male distinctive. Females notably darker than those of $A$. phoeniceus. Closely gregarious at all seasons. Notes quite different from those of $A$. phoeniceus.

Nesting. - In dense and of ten extended colonies. Nest: a stout basket of coarse grasses and pliant weeds, strengthened by a thin matrix of leaves laid in wet, and lined with coarse round grasses; lashed to stalks of narrow-leafed cattail (Typha angustifolia). Eggs: 4; pale niagara green (called pale "blue"), or pale olive buff, sharply and sparingly spotted or short-scrawled, chiefly at larger end, by brownish black (See text below). Av. size (one each of forty sets) $24.1 \times$ x $17(.95 \times .67)$. Extreme examples: $30.8 \times$ I 8 (I.2I X .7 I), and I $8.5 \times$ I $2.9(.73 \times .5 \mathrm{I})$. Season: May or early June; one brood.

General Range.- "Pacific Coast from valleys of northwestern Oregon (west of Cascade Range) south through California (west of Sierra Nevada) to northern Lower California" (A. O. U.).

Distribution in California.- Resident in central and southern California west of the Sierras; locally abundant in the Great Interior Valley, and in the San Diegan district, north, interiorly, to Shasta County, east to Lake Tahoe (where it has bred-Barlow), west to coast, southerly.

Authorities.-Audubon (Icterus tricolor), Ornithological Biog., vol. V, I 839. pp. I-5, (original description from Santa Barbara, Calif.); Heermann, Journ. Acad. Nat. Sci. Phila., ser. 2, vol. II, I853, p. 268 (nesting habits); IIenshaw, Rept. Orn. Wheeler Surv., I 876, pp. 249-250 (nesting habits); Bendire, Life Hist. N. Amer. Birds, vol. II, 456-458, pl. VI. (figs. I 8, I9) (habits, nests and eggs); Mailliard, J. W., Condor, vol. XII, I9Io, pp. 3I-4I (critical); Mailliard, J., Condor, vol. XVI, I9I4, pp. 204-207 (nesting colony). 


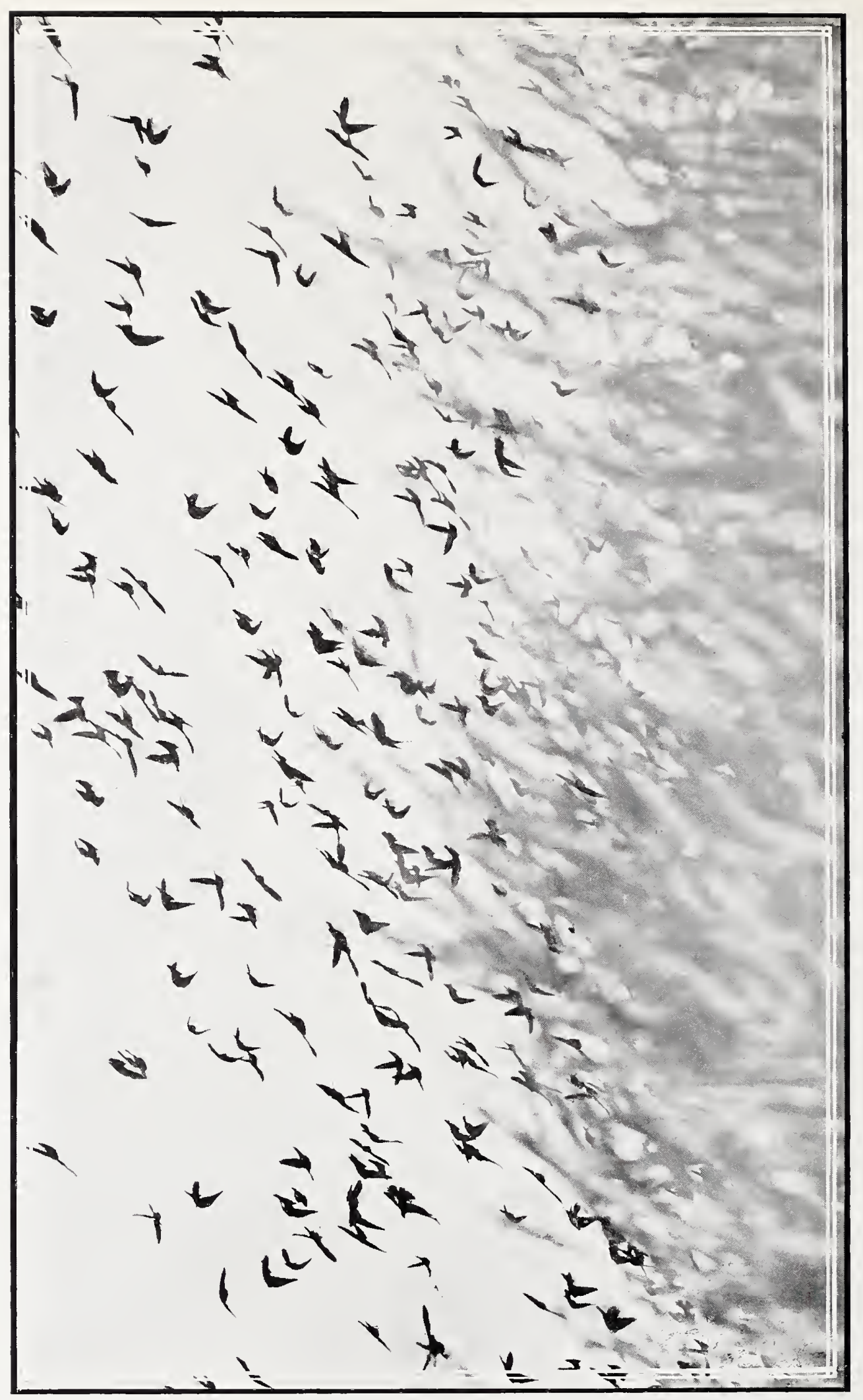




\section{The Tricolored Redwing}

TO ONE in search of something utterly different I can heartily recommend an hour, or a day, in a Tricolor swamp. The birds are themselves, to be sure, not so different in generic appearance from their more familiar and widely distributed cousins, the Redwings (Agelaius phoeniceus). Indeed, one would suppose at first sight that a plumage difference which is practically limited to the lesser wing-coverts, white instead of buff (or buff overlaid with black, as in A.p.californicus), would indicate merely one of those troublesome subspecific distinctions which practical field men wisely ignore. But such is far from being the case. For after we have conceded the all but identity of plumage in the male and the almost indistinguishable similarity of the eggs, we note with real surprise that we have to do here with a bird whose song, whose psychology and behavior, whose social arrangements, and presumed developmental history are entirely different from those of its phoenicean double, although the latter occupies closely the same general territory, and oftener than not the very edges of the swamps where tricolors are wont to assemble.

Agelaius tricolor is intensely gregarious, more so perhaps than any other American bird. Every major act of its life is performed in close association with its fellows. Not only does it roost, or ravage grain fields, or foregather for nesting, in hundreds and thousands, but the very day of its nesting is agreed upon in concert. In continuous procession the individuals of a colony repair to a field agreed upon in quest of building material; and when the babies are clamoring the loudest for food, the deploying foragers join their nearest fellows and return to the swamps by platoons and volleys, rather than as individuals. The normal flock movement is in itself distinctive. The birds fly silently, with not so much as a rustle of wings; and they pass close to the ground, or at most at an elevation of fifteen or twenty feet. Each member of the flock rises and falls with each recurrent effort of the wings, quite independently of his fellows; but there is no vacillation or disposition to break away. Each bird is solely and ominously intent upon "getting there."

A prosperous nesting colony of Tricolored Redwings is an enormous affair. At the height of building activities it seems a perfect bedlam, and the composite roar can be heard a mile away. At the same time, one rather wonders at the mildness and restraint of the individual utterance. The flock noise at its worst suggests a colony of a thousand birds, whereas there are in reality tens of thousands - say thirty thousand birds in a typical citadel. As one approaches the great green cover of cattails, he is reminded of circus day in the olden time. Everybody else is going too. Excited platoons and hurrying companies of birds sweep over the ground with rapid undulating flight, and lose themselves immediately in 


\section{The Tricolored Redwing}

the all-devouring green. The space immediately over the cattails is sometimes filled suddenly as by a volcanic irruption; but for the most part there is a wholesale coming and going as methodical as that of ants.

Our entrance into the swamp will not occasion any general alarm. A platoon, of say one hundred of the nearest birds, will rise as by a single impulse, and withdraw quietly to some distant rendezvous. After a decorous lapse of time they will return en masse prepared to resume duties; but if they find us still busy, they will flutter a moment overhead and then make off again. Only as incubation advances will some of the bolder females tarry to reprove. But ever in the offing there is the gentle roar of traffic, of life as it is lived in this wonderland of close-ranked greenery. Heard vaguely, as a sort of composite phonograph, the chorus of Tricolors impresses one by its quaintness, its restraint, and its mild good nature. More attentatively examined, it seems to consist of croaks, gurgles, squeaks, and whistles, the usual Agelaiine repertory played with the "mute" on. But critical attention to the notes of tricolor reveals a world of interest and suggestion. This mild and amiable socialist has preserved in speech the traditions of earlier associations and relationships. First, there is a jup note of frequent use, which is decidedly Quiscaline in character. Certain other call-notes are like those of their nearest congeners, the Redwings (A. phoeniceus and varieties). But their most characteristic song is a mild edition of the famous "stomach-ache song" of the Yellow-headed Blackbird, and as impossible of description. While this is of commonest occurrence in the swamp, I believe the true mating song is reserved for the official parties, which are invariably held in treetops at some remove from the swamps. These trysts, or courting fests, indulged in by parties of from ten to forty birds, are an established feature of early springtime; and I believe that those which occur as late as May or June are mere makeshifts, cramming classes for belated lovers. Anyhow, at such time I have heard such intimate phrases as Look awaaay choke, away awaay choke, varied by awaak or chwwaaack choke.

Then there is the queque note, entirely distinctive, and a rattle remotely like that of a Kingfisher, only smaller and more musical. Still another sound, impossible to characterize accurately, reminds one of a Raven's croak. Add to this the scolding chup of the female, which is exactly like that of a female phoeniceus, and you have the dictionary of tricolor compiled to date.

But what of the reeds themselves? And what of the baskets they contain? It is a different world we have entered, a simple, separate, mysterious realm where only the blackbirds dwell-and they have fled. The water stands knee-deep, or mid-thigh-deep, or perchance waist-deep, threatening ever to invade another dry inch, which the adventurer is 


\section{The Tricolored Redwing}

loth to yield. The bottom is deliciously oozy (if you like it so, but I prefer to keep my shoes on). The serried ranks of cattails stand close, so close that one must use a large knife to get about; and they stand so high above that one sees no horizon, and only guesses what may be in the sky. And everywhere there are nests, baskets of coiled grasses, lashed stoutly to the reeds. The nests, I say, are everywhere, now at middle levels, two or three feet above the water, where one may peep into them, now overhead where we must thrust in exploratory fingers, now hung perilously close to the water where a change in level may overwhelm them. Now and again they crowd each other, when two or three birds select the same stems. Here are two nests side by side, and here one above another. Here a bird has lashed her foundations too high, and the top will not go on because of a neighbor's foundation. No matter - try again. Never in the American swamps will another species of bird furnish such generous matter for the inquisitive birdnester. Here, by planting one foot for base and turning about freely, I am able to see into sixteen nests, all with eggs. Here, again, I touch twenty-six nests from one station, but I cannot see whether they are all occupied.

In the interests of comparative oology, the writer has ex-

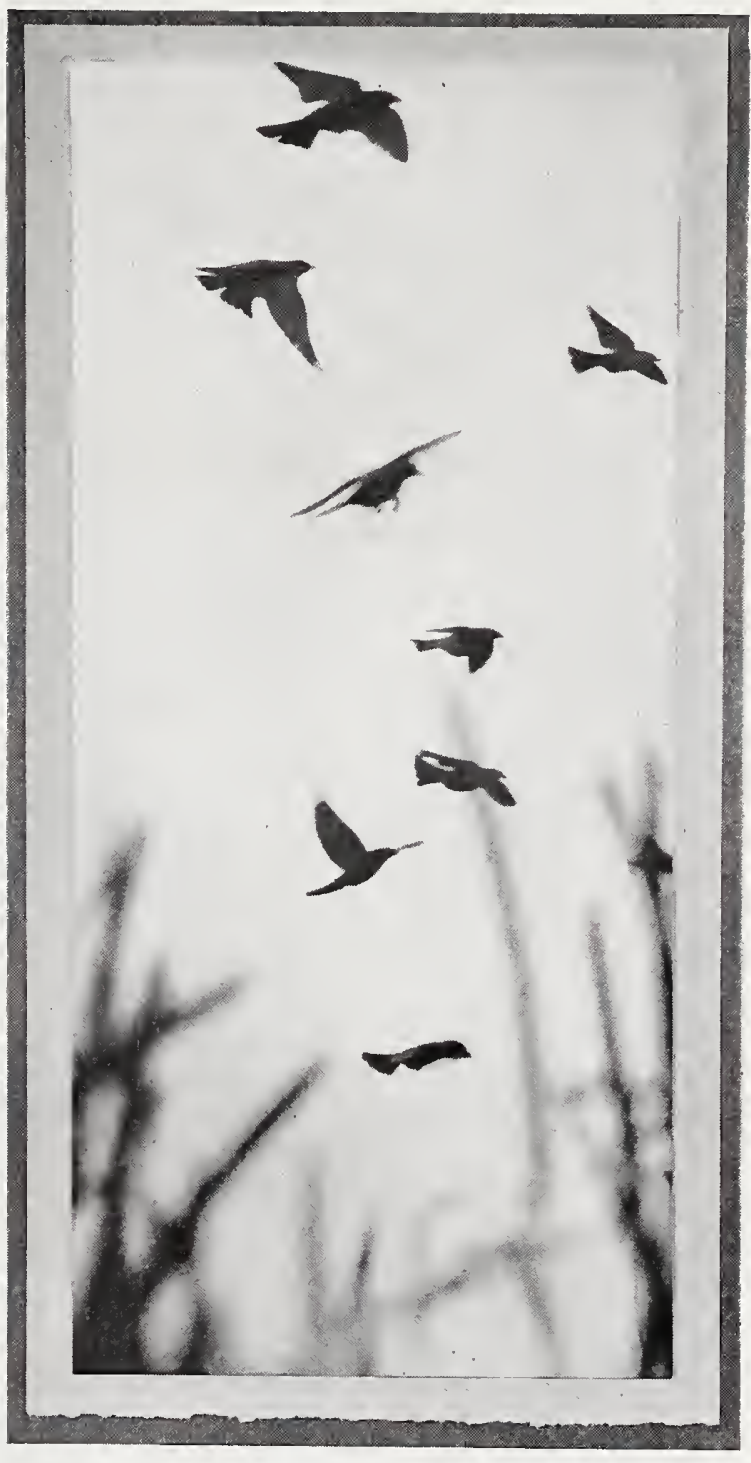

A. JAPANESQUE

Photo by the Author amined some 3500 nests of this Blackbird in the course of several seasons, but chiefly in that of I9I6. The study resulted not only in a handsome and 




Taken in Merced County

LIFE IN THE REEDY MAZES

FEMALE TRICOLORS ABOVE, MALE BELOW instructive series of eggs, but in the recognition of some facts which must have escaped attention on a more restricted search. Thus, abnormal or "freak" eggs, whether remarkable for size or shape or color, were found to be, almost without exception, the first laid of a given clutch. It is known, by now, that the secretion of pigment is not always exactly correlated in time with the deposition of the limy coat of the egg. If the activities of the pigment cells outrun those of shell secretion, an accumulated and excess amount of color will be deposited upon the first egg which presents itself for decoration. On the other hand, the first egg may find the pigment cells belated,

and may escape without a touch of color. This, I say, was well known. But it was more surprising to find that runts and giants, fusiforms, and other eccentrics, are usually first attempts. The exception was the case of last-laid eggs in sets abnormally large. Four eggs being the stern rule of $A$. tricolor, sets of five or six were pretty sure to contain an egg structurally weak. The lime had played out. Of the only set of seven found, one egg collapsed in the nest, and another in being transferred to the collecting box.

Abnormality, I take it, may be a result of the exertions attendant 


\section{The Tricolored Redwing}

upon nest-building. In I9I6 especially, nesting (in the San Joaquin Valley) had been delayed by an unusual cold spell accompanied by west winds. When at last, about May 2oth, nest-building was undertaken in spite of adverse weather conditions, many of the birds were overtaken with the duties of motherhood before the nests were finished. Eggs were deposited upon the undried muck, which affords the stiffening, or body, for the tricolor's basket. In most cases the nest was neatly lined with coiled grasses after the first egg was deposited, but a few birds immediately abandoned work upon the nest and left all their eggs upon a bare mud bottom. Others carefully worked the lining material under the egg or eggs. Many more, however, in their zeal for completing the nest in proper style, overlooked or failed to meet the claims of the eggs, and neglected to raise them with the new flooring. As a result, buried and half-buried eggs were very common. Some nests would contain one egg quite buried, another half buried, and two quite clear.

The nesting material is invariably laid on wet. This assures not only pliability in working, but rigidity in the finished product. Although I had always a wholesome respect for the ingenuity of these weavers, I received a most impressive lesson upon a late occasion. In the course of a laborious piece of census work, I had selected four choice sets of eggs for color variation, placing them, duly marked, for convenient carriage, in an empty nest, and covering them with another. Upon emerging from the swamp and crossing a bit of dry ground in the open, the basket bowl with its precious contents was suddenly snatched from my hand and precipitated to the ground. A long strand of grass had gradually unwound itself from the under nest until it trailed upon the ground, and I had stepped on it. So stout was the strand and so deeply was it imbedded into the structure of the nest that it tore the whole lot from my hand in a trice. Nearly every egg was smashed. The strand was five feet long, by measure, all once neatly coiled in the foundation of the blackbird's nest.

Unlike the eggs of most other birds, those of the Redwings (Agelaius $s p$.) are much handsomer after blowing than before. The semi-transparence of the blue shell allows the brilliant orange of the yolk to show through, thus producing a dirty, muddy, sickly color, which is anything but inviting. Cleared of this clashing orange, however, the Redwings' eggs, for such time as they do not fade, are of the handsomest.

The eggs of the Tricolored Redwing are normally of a pale Niagara green tint, sharply and sparingly marked-small-biotched or shortscrawled-with an intense brownish black pigment. The variation, not in the quality but in the application of this single pigment, determines 


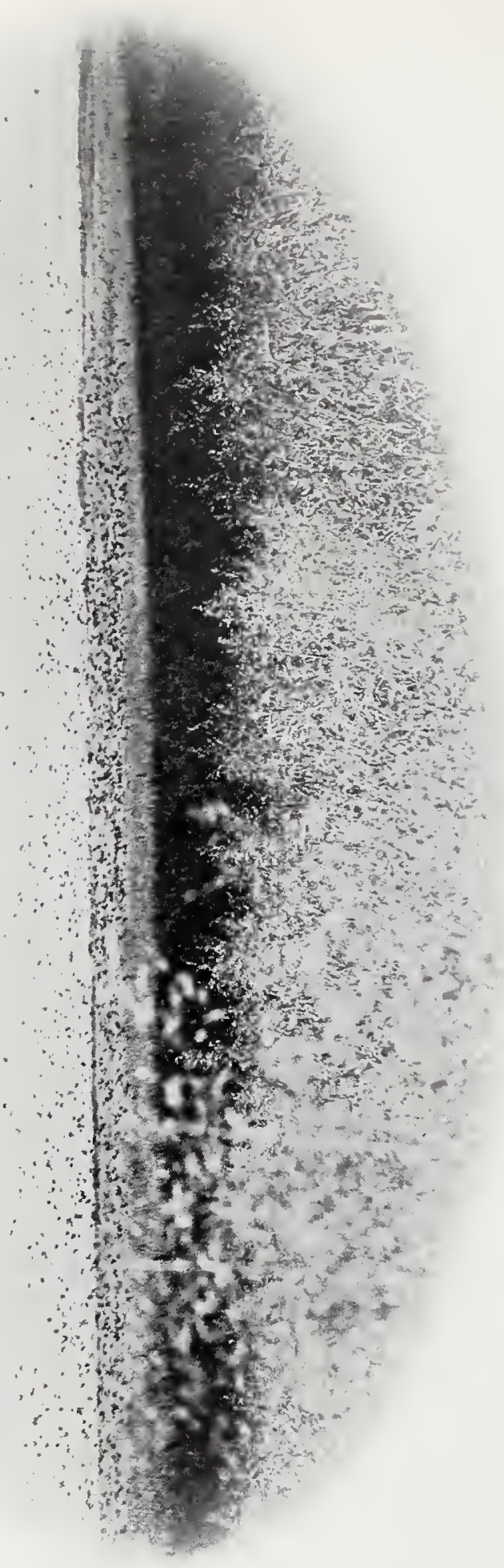

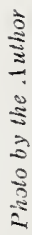

至 
the highly varied results secured. Often the pigment is shadowed, or "washed," along its edges, revealing thus its brown character. Not infrequently a tinge of the pigment is suffused throughout the shell, and we get such basic tints as glaucous, yellowish glaucous, "tilleul buff," and even deep olive buff. Again, and more rarely, the pigment is spread about superficially, in whole or in part, paling thus to vinaceous buff, or fawn color. In two instances in the M. C. O. collections the color appears as a uniform vinaceous clouding on a warm buff ground; and in one of these the freckling is so minute and so uniform as to render the egg almost indistinguishable from that of a Yellow-headed Blackbird.

While I have not been able to detect any constant or divisive element in local variations, i.e., no tendency to the formation of races; it is very instructive to note the power of the localized or neighborhood sentiment in the determination of the nesting dates. Thus, in a small colony, say one of 2000 pairs, every nest will be at approximately the same stage of construction on a given date. On a given day, four-fifths of the nests will contain one, and only one, egg, etc. On the other hand, a large colony, say one of 40,000 birds, will be divided up into a dozen separate clans, or behavior groups. In one section of the swamp the investigator will find only fresh-laid foundations; in another, nests with one egg each; in another, perchance, full sets well advanced in incubation. I can only account for this on the supposition that the nesting colony grows by accretion. Day after day new groups from the outside join themselves to the nesting, and immediately set to work on the occupation of some closely contiguous section of reeds. The nesting is, thus, a sort of continuous Chatauqua, with fresh delegations arriving daily and being assigned to reserved sections.

This supposition receives striking confirmation from an experience recorded by Mr. John G. Tyler, of Fresno'. At a point some thirty miles southwest of the city, Mr. Tyler found a colony of Tricolors occupying a dense but restricted patch of nettles. The center of the patch, where the cover was densest and presumably most desirable, the nests held young birds. Surrounding this choicest area was one in which the nests held incubated eggs. And so, moving progressively outwards, the cover dwindled and the eggs freshened, until the last comers were actually building their nests upon the ground without protection of any sort-gallery seats and standing room only.

It goes almost without saying that the farmers are not enthusiastic about this Summer Assembly of Blackbirds. It takes a very considerable ration to supply the wants of so many picnickers. Either because the morning hours are filled with labor, or because the grain is more easily

1"The Condor," Vol. IX., Nov. 1907, pp. 177-178. 


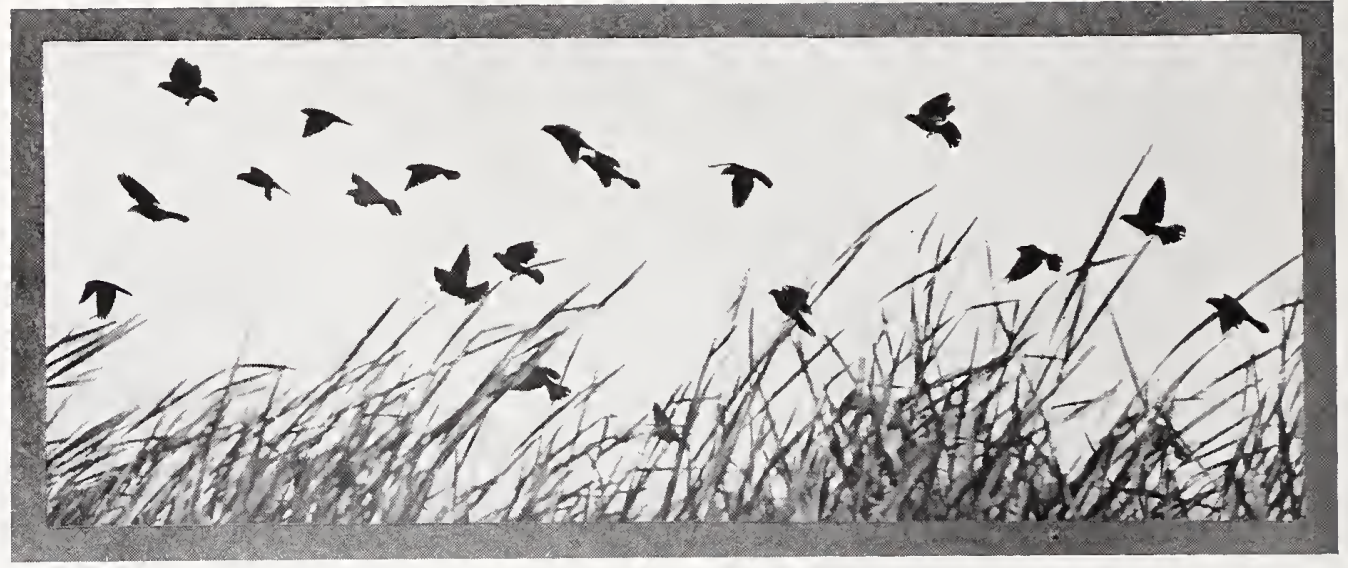

Taken in Merced County

BIRDS AND RUSHES

Photo by the Author

extracted at midday, high noon seems to be the appointed time for onslaught upon the grain fields. At such a time one may see countless thousands of blackbirds moving over the face of the fields with the inexorability of a threshing gang. The empty heads of oats or barley attest the fact that the birds are not looking for weevils. As in the reputed flock behavior of the Passenger Pigeon, there is always a vanguard working into new territory, as well as a steady stream of detached bevies making their way to and from the main camp. To say that the damage inflicted by these birds is inconsiderable is to prevaricate, and to invite ridicule. In especial, rice-growing, which might be developed into a leading industry in certain water-favored sections of the San Joaquin Valley, is at a standstill, and will be until sensible relief is afforded from the depredations of blackbirds.

No. 19

\section{Red-winged Blackbird}

\section{No. 19a San Diego Redwing}

A. O. U. No. 498e part. Agelaius phoeniceus neutralis Ridgway.

Synonyms. - San Diego Redwing. Red-shouldered Blackbird. Swamp Redwing. Marsh BlackBird.

Description.-Briefly: Male in spring: Plumage glossy black; the lesser wingcoverts red; the middle coverts ochraceous orange. Female: General plumage streaked dusky and white; above dusky bordered with grayish and dull ochraceous; below heavily streaked or striped dusky and white, clearing (nearly spotless) on chin and upper throat. More particularly (Descriptions based on 12 spring adults, 6 males and 6 


\section{The Red-rwinged Blackbirds}

females, from the San Diegan district. Characterization of immature and fall plumage partly inferential): Adult male in spring: Glossy black with faint bluish or greenish reflections; the lesser wing-coverts scarlet-red, or spectrum red, the middle coverts (largely concealed) ochraceous buff to ochraceous tawny, often shading on tips to whitish; or sometimes sharply tipped with black; the exposed portion of middle coverts forming a transverse bar 3 to 8 millimeters in width. Bill and feet black. Adult male in fall and winter: As in spring, but feathers of upperparts lightly (sometimes sides of neck, breast, and sides very lightly) fringed or tipped with light rusty or ochraceous buff; the black of middle wing-coverts, if present, also buffy-tipped. Immature male: Like adult male in autumn, but with strong increase of marginal edgings of ochraceous; markings heavier above, lighter below, but only throat, crissum, and tail immaculate; the lesser wing-coverts orange or tawny with skirtings of black; middle coverts entirely black, tipped with buffy white. Increasing age is marked by increasing redness of the lesser wing-coverts, so that only the oldest males achieve spectrum redness. Adult female in spring: Above grayish brown or fuscous, the head, neck, and back edged with light brownish gray and whitish; the feathers of wings, both coverts and flight feathers, narrowly and variously (according to age) margined with whitish and dull brownish gray; an obscure whitish line over eye; underparts heavily dusky-and-white-streaked, the dusky element preponderating posteriorly, the white anteriorly (the streaks become finer on throat and almost disappear on upper throat); a slight rosy or pinkish element manifest in the whites anteriorly. Bill dark horn-color above, much lighter below; legs and feet dusky brown. Adult female in autumn: As in spring, but marked by increase of an ochraceous element throughout, this element appearing as buffy suffusion in whites of underparts. Immature female: Like adult female and not certainly distinguishable. Young birds: Resemble the adu't female in autumn, but are more distinctly yellowish, especially on sides of head and underparts. Length of males about 228.6 (9.00). Av. of 6 adult males in M. V. Z. coll: wing I 25.2 (4.93); tail 90 (2.54); bill, length $22.2(.87)$; depth at base I $2.2(.48)$; depth at nostril $9.2(.36)$; tarsus 29.8 (I.I7). Av. of 6 adult females: wing 99.7 (3.92); tail 7I.4 (2.8I); bill, length I8.I (.7I); depth at base I0.3 (.40); depth at nostril 8.2(.32); tarsus 26.2 (I.03).

Recognition Marks. - Towhee to Robin size; red shoulder patch bordered by buff of male; general streaky appearance, dusky-and-white, of female.

Nesting of Agelaius phoeniceus. - Nest: A neatly woven but rather bulky basket of grasses, cattail leaves, or weed bark, usually lashed to upright stalks of cattail, or occasionally, in willows or other bushes, and in rank herbage; occasionally also nesting upon the ground, but if so, always supported upon the sides by vegetation. Eggs (in California): 3 or 4 , rarely 5 ; normally pale bluish green, more rarely pale olive buff, marked boldly and sparingly, often in broad scrawls and zigzags, and chiefly about the larger end, with brownish or purplish black. Av. size $24.4 \times 17.3$ (.96 x .68). California specimens average smaller than those of phoeniceus phoeniceus. Season: April-June; two broods.

Range of Agelaius phoeniceus.--North America from British Columbia, central Mackenzie, and Quebec, south to Costa Rica.

Range of $A$. p. neutralis.-Undefined; may include southwestern United States from western Texas to the Pacific, except lower Colorado River, etc. (range of $A . p$. sonoriensis); or may not impossibly be confined to southwestern California (leaving birds of remaining areas to be redescribed).

Distribution in California.-Southern portion of State west of desert divide northward, coastally at least to Parallel $36^{\circ}$, interiorly to southern portion of Tulare 


\section{The Red-winged Blackbirds}

Basin, thence intergrading indeterminably with californicus upon the north, and acicu. latus upon the northeast.

Authorities.-Gambel, Journ. Acad. Nat. Sci. Phila., ser. 2, vol I, I 847 , p. 48 (part); Henshaw, Rept. Orn. Wheeler Surv., I 876, p. 276 (critical); Beal, Bull. Div. Biol. Surv., No. I3, I9oo, pp. 44-45 (part) (food); Ridgway, Proc. Wash. Acad. Sci., vol. III, I9oI, Pp. I53, I54 (description and range of neutralis); Daggett, Condor, vol. V, I903, p. 52 (critical).

\section{No. 19b Sonora Redwing}

A. O. U. No. 498a. Agelaius phoeniceus sonoriensis Ridgway.

Description.-Similar to A. p. neutralis, but male slightly larger and with slenderer bill. The adult female lighter, with streaks more strongly contrasted above, those of lower parts rather narrower and not so dark, the upperparts more extensively rusty. Measurements, I 3 specimens (after Ridgway): IVing I25.5 (4.90); tail 93.5 (3.68); bill 23.9 (.94); depth at base I 2.4 (.49); tarsus 30.5 (I.20). 24 adult females: Wing 98.8 (3.89); tail (I7 birds) $72.9(2.87)$; bill $19.8(.78)$; depth at base $9.9(.39)$; tarsus 26.7 ( 1.05$)$.

Range of A. p. sonoriensis.-Southeastern California, southwestern Arizona (at least the valleys of the Gila and lower Colorado River), and the coastal plains of Sonora south to Tepic.

Distribution in California.-Resident in the Imperial Valley, on the Colorado Desert west (at least) to Mecca, and in the valley of the Colorado River north (at least) to Needles (Grinnell).

Authorities.-Gambel, Journ. Acad. Nat. Sci. Phila., ser. 2, vol. I, I 847, p. 48; Bendire, Life IIist. N. Amer. Birds, vol. II, I 895, p. 453; Ridgway, Proc. Wash. Acad. Sci., vol. III, I90I, p. I54 (range); Grimell, Univ. Calif. Publ. Zool., vol. I2, I9I4, pp. I6I-I63 (crit.; range; habits); Howell and van Rossem, Condor, vol. XVII, I9I5, p. 233.

\section{No. 19c Nevada Redwing}

A. O. U. No. $498 \mathrm{e}$ part. Agelaius phoeniceus nevadensis. Grinnell.

Description.- "In shape of bill and other general characters closely similar to A. p. sonoriensis; male scarcely distinguishable, but female conspicuously darker colored, on account of the great relative breadth of black streaking both above and below; in this respect similar to female of $A$. p. caurinus, but bright rusty edgings on back and wing replaced by ashy and pale ochraceous; bill in male of caurinus more slender than in either sonoriensis or nevad.nsis." (Orig. descr.).

Range of A. p. nevadensis.-Undefined. Originally described from northern Nevada, nevadensis is presumed to be the breeding form of the Great Basin region, and of the Columbian Plateau north into British Columbia.

Distribution in California.--The plateau region of northeastern California and the eastern slopes of the Sierras south (at least) to Lone Pine.

Authorities.-Grinnell, Proc. Biol. Soc. Wash., vol. XXVII, I9I4, pp. I07-Io8 (original description).

\section{No. 19d Northwestern Redwing}

A. O. U. No. $498 \mathrm{f}$. Agelaius phoeniceus caurinus Ridgway.

Description.--Similar to A. p. nevadensis, and males distinguishable only by somewhat slenderer bills; but females show slight increase of the ruddy element in the 


\section{The Red-winged Blackbirds}

under whites, and are more extensively rusty-bordered above (recalling in this respect A. p. sonoriensis). Measurements 9 adult males (Ridgway): Wing I 23.2 (4.85); tail 9 I.7 (3.6I); bill 24.4 (.96); depth at base I I.7 (.46); tarsus 29.5 (I.I6). Of 9 females: IIing I03.I (4.06); tail 77.5 (3.05); bill 20.8 (.82); tarsus 26.9 (1.06).

Range of $A$. p. caurinus.-Northwest Coast district from British Columbia south to Mendocino County, California.

Distribution in California.- Occurs sparingly (presumably resident) in the northwestern humid coastal strip.

Authorities.-Ridgway, Proc. Wash. Acad. Sci., vol. III, I90I, pp. I53-I54 (original description; in Mendocino Co., May 20); Stone, Proc. Acad. Nat. Sci. Phila., I904. p. 582 (Mt. Sanhedrin); Mailliard, J., Condor, vol. XVIII, I9 16, p. I99 (nesting at Humboldt Bay).

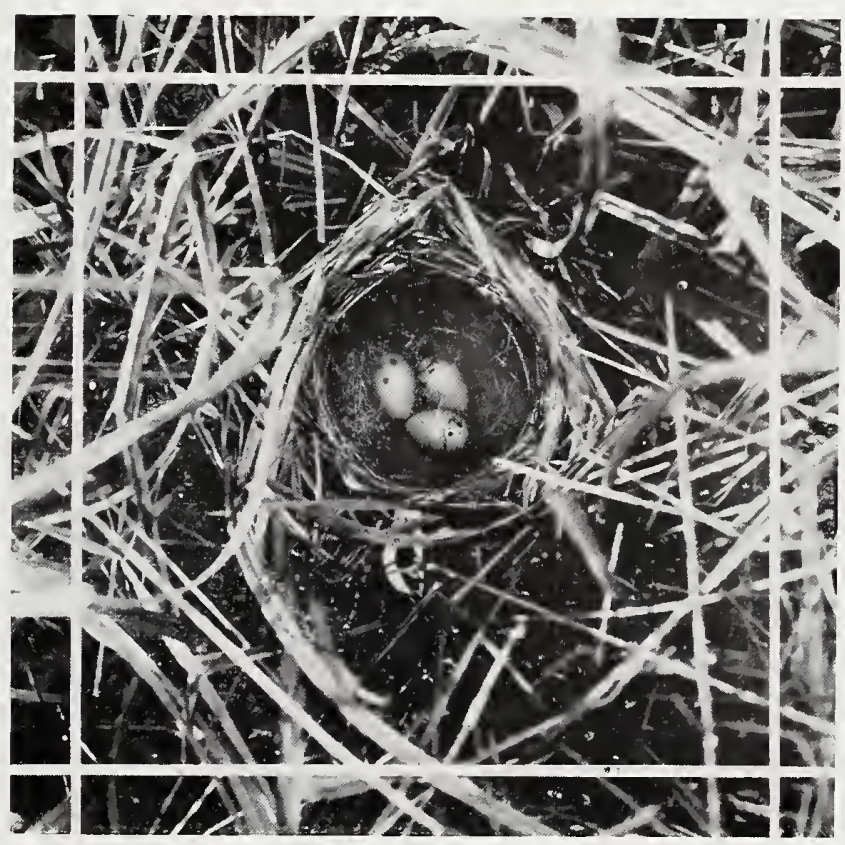

Taken in Washington

Photo by the Author

NEST AND EGGS OF THE NORTHWESTERN REDWING

\section{No. 19e Kern Redwing}

A. O. U. No. 498e part. Agelaius phoeniceus aciculatus Mailliard.

Description.- "Similar to Agelaius phoeniceus neutralis, but of larger size, feet averaging somewhat larger; but chiefly characterized by a longer, and comparatively more slender bill than any other form of this genus in the United States" (Orig. Desc.). Av, of 2 I males: Wing I26.2 (4.97); tail 92.4 (3.63); bill 27.2 (1.07); depth at base 12.4 (.49); tarsus 29.5 (I.I6). Of I I females: IVing I I3.9 (4.48); tail 76.3 (3.00); bill 22.9 (.90); depth at base I I (.43); tarsus 25.7 (I.OI).

Range (wholly included within California).-East-central Kern County. 


\section{The Red-winged Blackbirds}

Authorities.-Mailliard, J., Condor, vol. XVII, I9I 5,5 p. I3 (original description); ibid., pp. 228-230, (distribution); Grinnell and Storer, in Rules and Regl. Yosemite Natl. Park, I920, p. 52 (in Yosemite Valley).

\section{No. 19f Bicolored Redwing}

A. O. U. No. 499. Agelaius phoeniceus californicus Nelson.

Description.-Similar to A. p. neutralis, but male usually without, or with relatively small, exposure of ochraceous buff on middle wing coverts, the feathers broadly tipped with black instead (in extreme examples the feathers are black for the distal two-thirds, so that their ochraceous portion is not only completely overlaid by the red lesser coverts, but has a wide "margin of safety" so far as exposure is concerned). Adult female: Scarcely different from that of $A$. p. neutralis. The tradition of a darker bird is based on examples of $A$. tricolor, which have been widely confused with those of this species. Dimensions not conspicuously different in any respect from those of $A$. p. neutralis, although bills of extreme bicolored examples may average somewhat stouter.

Remarks.-The "Bicolored Blackbird" was long counted a subspecies of Agelaius gubernator, a form found centrally in the southwestern portion of the Mexican plateau. The resemblance between the males is indeed a striking one, but the females are quite different, the assumption of resemblance having been based in part upon examples of $A$. tricolor, which is excessively common throughout the region occupied by $A$. p. californicus. It is conceivable that both gubernator and californicus alike derive from urphoeniceus, but the hypothesis of a direct line of connection between them is discredited by three factors. In the first place the proportions of gubernator are quite different from those of western phoenicei, while those of californicus follow them closely. The ranges of the two forms are not only discontinuous, but they are separated by a space of a thousand miles, the northern portion of which is closely occupied by connected forms of phoeniceus. And, lastly, and most conclusively, californicus intergrades with the surrounding forms of phoeniceus in almost every conceivable degree.

Range of $A$. p. californicus (wholly contained within California).-Resident in the central portion of California west of the Sierras and roughly tributary to the San Francisco Bay region, north at least to Sonoma County and interiorly to Tehama County, east to western foothills of the Sierras, south coastwise to about Parallel $36,-$ interiorly, and typically, possibly not further south than Stanislaus County.

Authorities.-Vigors, Zoology of Beechey's Voyage, I839, p. 21; Heermann, Rept. Pac. R. R. Surv., vol. X, pt. IV, I 859, p. 53 (nest and eggs); Bendire, Life Hist. N. Amer. Birds, vol. II, I 895 , pp. 455-456, pl. VI (figs. I6, I 7) (habits, nest and eggs); Mailliard, J., Condor, vol. XI, I909, pp. I27-I28 (nesting; food habits); vol. XII, I9IO, pp. 63-70, 2 figs. (critical study); Mailliard, J. W., Condor, vol. XII, I9Io, pp. 39-4I (comparison with tricolor); Beal, Biol. Survey Bull., No. 34, I9Io, pp. 56-59 (food).

SPRING herself being listed as a "winter resident" in California, we are never quite certain when the official season does open. Certainly not, as elsewhere, with the coming of the Redwings. Such as are not already resident in the State, arrive from the North in late autumn, and spend the winter with us. Neither their comings nor their goings are as conspicuous with us as they are in the North; but if in mid-February or early March we come upon a boisterous company of Redwings crowding 
a treetop, we may be sure that they are mustering for the northern journey. What a world of jubilation there is in their voluble whistlings and chirpings and gurglings, a wild medley of conquest which will strike terror to the faltering heart of that northern winter. A sudden hush falls upon the company as the bird-man draws near the tree in which they are swarming; but a dusky maiden pouts, "Who cares?" and they all fall to again, hammer and tongs, timbrel, pipes, and hautboy. Brewer's Blackbirds and Cowbirds occasionally make common cause with the Redwings in the northern migrations, but it is always the last-named who preponderate, and it is they who are most vivacious, most resplendent, and inost nearly musical. The Redwing's mellow kongqueree or occasional tipsy $w h o o p-e r-w a y-u p$ is the life of the party.

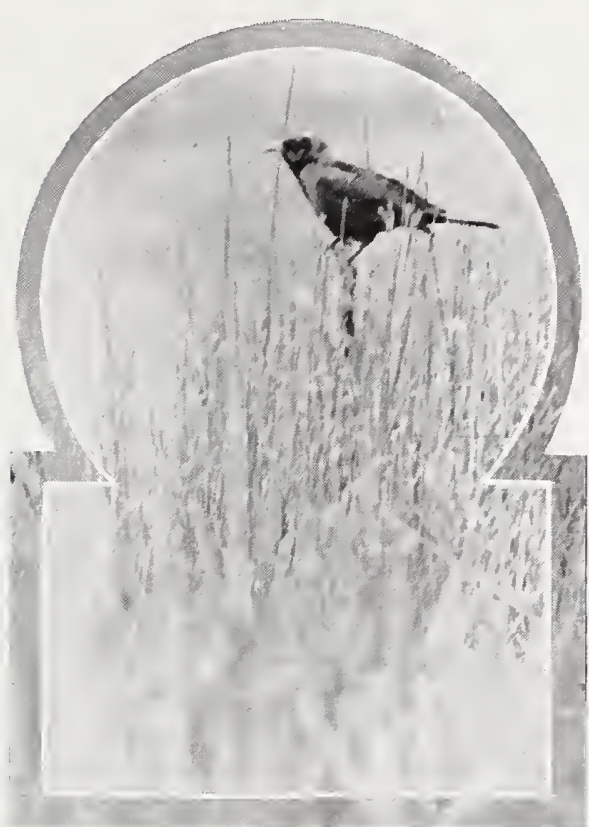

Taken in Inyo Counly

Photo by the Author

A NEVADA REDWING

Our more prosaic resident birds will yield more gradually to the seductions of springtime. Native Sons require to be shown wherein one day is better than another for the undertaking of that most important business of life, nesting. As a consequence, southerly ranging Redwings take small advantage, if any, of their earlier chances.

Once upon a time the bird-man was sitting, Turk-fashion, on a great mossy log which ran far out in to the rustling depths of a northern swamp. The April sun flooded the scene with warm light, and made one blink like a blissful, drowsy frog, while the marsh sent up a grateful incense of curling vapor. A pocket lunch of bread and cheese was the ostensible occasion of this noontide bliss, but victuals had small charms beside those of the sputtering Tule Wrens who played hide-and-seek among the stems, or the dun Coots, who sowed their pulque pulque pulque notes along the reedy depths.

Upon this scene of marshy content burst a vision of Phoenicean splendor, Caurinus I., the military satrap of Paludia, the authentic generalissimo of Blackbirds. He was a well-aged bird, and as is the proper way with feathered folk, resplendent in proportion to his years. His epaulets seemed a half larger again than others, and their scarlet was of the brightest hue, contrasting with a black mantle which fairly shone. 


\section{The Red-ringed Blackbirds}

He took pains that I should see them, too, and guess his rank, for these decorations were ostentatiously uplifted as the bearer slowly descended through the air. He appeared an amiable old fellow, and as he lighted ponderously on an uplifted branch of my tree, he remarked, "Whoo-kusweeung," so hospitably that I felt impelled to murmur, "Thanks," and assured him of my unhostile intent. "Conqueree?" he questioned, richly. "Er-well, yes, if you are the conqueror."

But the general had other interests to watch. An upstart male of the second year, with shoulder-straps of a sickly orange hue, was descried a rod away climbing hand-over-hand up a cat-tail stem. Keyring, keyring, the despot warned him; and because the presumptuous youth did not heed him quickly enough, he launched his splendor over the spot, whereat the youth sank in dire confusion. And next, our hero caught sight of a female, fair to look upon, peeping at him furtively from behind her lattice of reeds. To see was to act. He flung his heart at the maiden upon the instant, and followed headlong after, through I know not what reedy mazes. Oh, heart ever young, and pursuit never wearying!

An annual visit to the cattail swamp is as necessary as a birthday to the life of any well-regulated bird-lover. The reedy mazes grow ever dearer year by year, and the chorus of expostulating blackbirds, which is their inevitable accompaniment, renews our racial youth as if by magic. We must not forget the date of first nesting, April I5th, for almost before we know it, our friends to the number of a dozen pairs or more, have taken up their residence in the old cattail swamp-nowhere else, if you please, unless driven to it-and here a dozen baskets of matchless weave are swung, or lodged, midway of growing plants. Our distant approach has been commented upon from the tops of bordering willows by keyrings and other notes. Now at close range, the lordly male, he of the brilliant epaulets and the proper military swagger, shakes out his fine clothes and says, Kongqueree, in a voice wherein anxiety is quite outweighed by vanity and proffered good-fellowship withal. But if we push roughly through the outlying sedges, anxiety obtains the mastery. There is a hubbub in the marsh. Bustling, frowsy females appear and scold us roundly. The lazy gallants are all fathers now, and they join direful threats to courteous expostulations as they flutter wildly about our intruding heads. To the residual small boy in us the chance of calling out these frantic attentions is irresistible, even though no harm is intended, or done. Perhaps we love to play the part of bogey, that we may rejoice in our own restraint. Perhaps we perceive, if we stop to think at all, that our own anxieties may be as mildly amusing to some benevolent Presence, and as ill-founded. 
The Redwings of the phoeniceus type do not colonize closely, as do those of the tricolor group. If nests occur within ten or fifteen feet of each other, it is only because the cover is limited. The birds delight rather to scatter, one, say, to every fifty feet or so, that each may have a little freeway, or sphere of influence. Especially at second nesting, which is undertaken late in May or early in June, the birds are apt to deploy into the fields, now grown with weeds. Beds of wild mustard are favorite places of resort and of nest-building. Isolated tussocks of sedge or wiregrass, Kern greasewood even, are not despised. Willows may be resorted to as the swamps dry up; and H. F. Duprey records ${ }^{1}$ interesting instances of their nesting in live oak trees. At Los Banos I found that the Redwing nested in April in the cattails and tules, but forsook this cover in May, nesting at this season by preference in the overgrown meadows. Especially numerous were the nests lashed centrally to the stems of growing dock plants. These were sought, apparently, for the shade they afforded, and irrespective of the fact that the rising flood waters engulfed many, season by season.

Few eggs exceed in beauty those of the Red-winged Blackbird. The background is a pale bluish green of great delicacy, and upon this occur sharply-defined spots, marblings.



Taken in Los Angeles County

Photo by Donald R. Dickey NEST AND EGGS OF THE SAN DIEGO REDWING 


\section{The Red-winged Blackbirds}

traceries, and "pen-work" of lark sepia, purplish black, drab, and heliotrope purple. Or a spot of color appears to be deeply imbedded in the fine, strong texture of the shell, and carries about it an aura of diminishing color. Occasionally, the whole egg is suffused with pale brownish, or, more rarely, it is entirely unmarked.

Incubation lasts fourteen days and the young are ready to leave the nest in a little over two weeks more. They are frizzly, helpless, com-

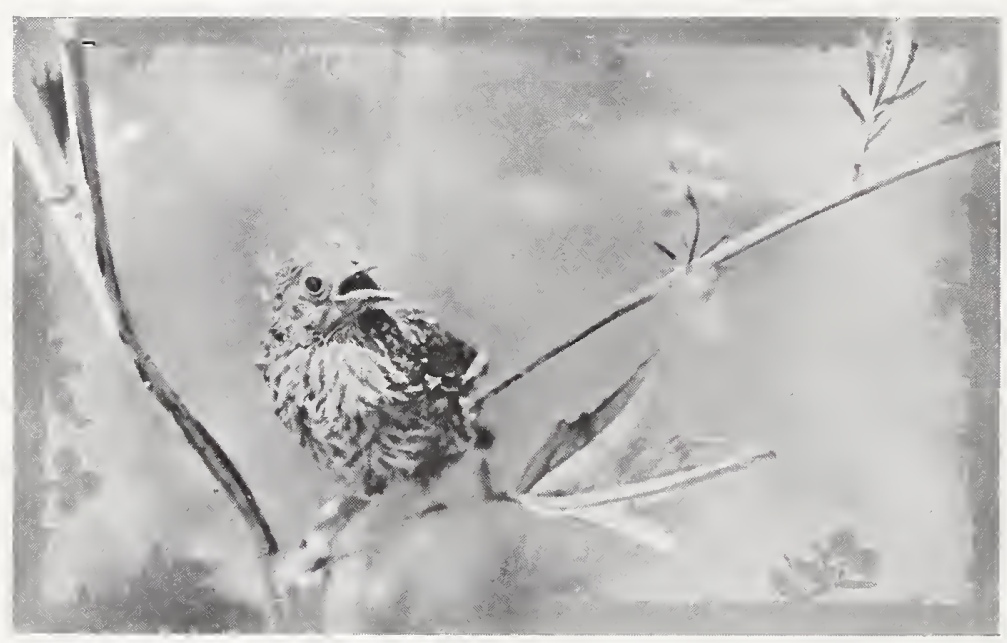

BABY ALL ALONE!

Photo by Donald R. Dickey plaining little creatures, but if they cannot fly well they can clamber, and they cling with the grip of terrified monkeys.

Of course the Redwings are the self-appointed guardians of the swamp. They are not less jealous of unlicensed avian intruders than of humans. Sometimes they fail to discriminate, and their pugnacity leads either to ridiculous or dangerous lengths. Once, at Los Banos, I saw a company of Bicolored Redwings set upon an unoffending Marsh Hawk, a handsome blue, male bird who was attending strictly to his own business. The big fellow stood the abuse for a while, then, quick as a flash, seized a blackbird in his talons and bore it away. A moment later, to our astonishment, he released the little bully, who flew off promptly and, let us hope, gratefully. It was just as though the Marsh Hawk had purposely restrained his power, and had done it all to teach the saucy little fellows a salutary lesson.

At another time a rascally Redwing was seen taking after a pair of Shovellers, as they rose from the creek. His act could have meant scarcely more than bravado, but, once launched, he seemed to find delight in the fact that the ducks would fly from him, and that he could nearly keep up with them. It was all as silly as little Willie playing at horse with Grandpa. The old gentleman prances off in mock terror, and little Willie toddles after shrieking with glee. Round and round and up 


\section{The Red-ringed Blackbirds}

and down, pursued the black imp, to our great astonishment, and why he ever stopped, the brave mannikin! I do not know.

Of the physical differences which distinguish the five Californian races, enough has been said above. The subject is a very technical one, of little interest to the general reader. The differences in habit are, so far as noted, merely those of adaptation to a highly varied setting. But it is well to admonish the observer who cares to pursue this subject further, that an interesting field opens up in the comparative study of Agelaiine songs. There are undoubtedly in this group provincialisms of speech even more distinctive than the variations of the buff shoulderband. It may be that "races" still more localized and restricted can be made out by philological methods. Anyhow, a practiced ear, wherever it goes, can note differences. For example, there is a colony in the San Joaquin River whose Konqueree note becomes Kaweeero, with a drawl and a roll to the $e r$ which is quite engaging and distinctive. The dink note, also, in this group has lost much of its music, and has become a mere noisy chup. On the lower Pajaro River, in Monterey County, the local Redwings exhibit notable differences. Their dink note is smaller, the kongqueree thinner, and, above all, they have a subdued chup, which sounds like nothing else so much as that of one of the Estreldid finches, or "Waxbills."

The Red-winged Blackbird eats insects and grain-chiefly the latter when it can be obtained. There has been much learned "investigation" of the food habits of this and related species, usually summarized as a suspended verdict, or else concluded with a lame apology for manifest faults, in view of no less manifest (but less remembered) virtues. But why blink the facts? In grain-growing sections contiguous to favorable breeding grounds, blackbirds do immense damage, whether to sprouting grain or grain in the ear. The only remedy is to protect the crops. If the crops are really worth anything, it will pay the rancher to maintain an armed patrol about his field during the critical seasons of seeding (and sprouting) and ripening. The residual blackbirds will still do some harm, but very wild blackbirds will do less harm than birds fed out of the hand. And remember, with equal fairness, that every bird kept out of the oat field with a whole skin is worth a dollar a year to the alfalfa crop. 


\section{Yellow-headed Blackbird}

\section{A. O. U. No. 497. Xanthocephalus xanthocephalus (Bonaparte).}

Description.-Adult male in breeding plumage: General body color black; also space about bill, including eye, black; remainder of head, neck and throat and breast, broadly rich yellow (straw yellow to wax yellow, or primuline yellow in younger examples: light cadmium, or even cadmium yellow in older birds); a dab of yellow on the vent, and occasionally touches on the lower tibiae; a large white patch near edge of wing formed by the primary coverts and three or four outermost feathers of the greater coverts, but interrupted by black alula. Bill and feet black. In anything but the highest plumage the yellow of the pileum and sides of neck is more or less skirted with black. Adult female: Brownish dusky, lighter, browner, anteriorly; a line over eye, and throat, outlining yellow malar patch, whitish; the chest dull yellow mingled with brown; no white on wing. Fall specimens show increase of yellow on chest; line over eye, malar patch, and throat, more or less yellow. Immature males resemble the adult female. but are blacker. In first spring they exhibit intermediary characters, and do not assume full plumage until the second season. Length of adult male about 266.7 (I0.50); wing I 4 I (5.55); tail IO2 (4.0I); bill 23 (.90); tarsus 36 (I.42). Length of female about 228.6 (9.00); wing I I 4 (4.49); tail 82 (.3.19); bill 20 (.78); tarsus 30 (I.I8).

Recognition Marks.-Robin size: black, with yellow foreparts and white wing-patches. Always enough yellow about females or immatures to indicate species.

Nesting. - Nest: a bulky but tidy basket of dried grasses, reeds, or cattails, lashed to growing ones; lined with coarse, flattened grasses, or variously, and deeply cupped. Eggs: 4, grayish or greenish white as to ground, but of ten nearly buried by dots and spots of brown (mikado brown, snuff brown, warm sepia, etc.); more rarely wreathed or cloud-capped with brown. Av. size, $25.8 \times 17.9(1.02 \times .71)$. Season: May or June; one brood.

General Range.-Western North America, breeding from south British Columbia, southern Mackenzie, northern Minnesota, southern Wisconsin, and northern Indiana, south to California and Mexico; wintering from southern California, Arizona, and southwestern Louisiana, to Michoacan and Puebla, Mexico. Accidental in Middle and Eastern States.

Distribution in California.-Common breeder in the San Joaquin-Sacramento basin, and throughout the area east of the Sierras and north of the desert; of irregular and local occurrence as a breeder elsewhere, save in the mountains and in the northwestern coastal section; White-water, May 27, I9I3; Goleta Marshes, Nigger Slough, Bear Lake (Morcom). Winters sparingly and irregularly in southern California and on the deserts; of more general distribution during migration-one record for Santa Cruz Island.

Authorities.-Gambel (Agela:us xanthocephalus), Journ. Acad. Nat. Sci. Phila., ser. 2, vol. I, I 847 , p. 48; Heermann, Journ. Acad. Nat. Sci. Phila., ser. 2, vol II, I853, p. 268 (nesting); Henshaw, Rept. Orn. Wheeler Surv., I879, p. 30 I (nesting habits); Bendire, Life Hist. N. Amer. Birds, vol II, I 895, pp. 446-449, pl. VI (figs. Io-I 2) (habits, nest and eggs); Beal, Bull. Div. Biol. Survey, No. I3, I90o, pp. 30-33 (food). 


\section{The Yellow-headed Blackbird}

OH, WELL for the untried nerves that the Yellow-headed Blackbird sings by day, when the sun is shining brightly, and there are no supporting signs of a convulsion of Nature! Verily, if love affected us all in similar fashion, the world would be a merry mad-house. The Yellow-head is an

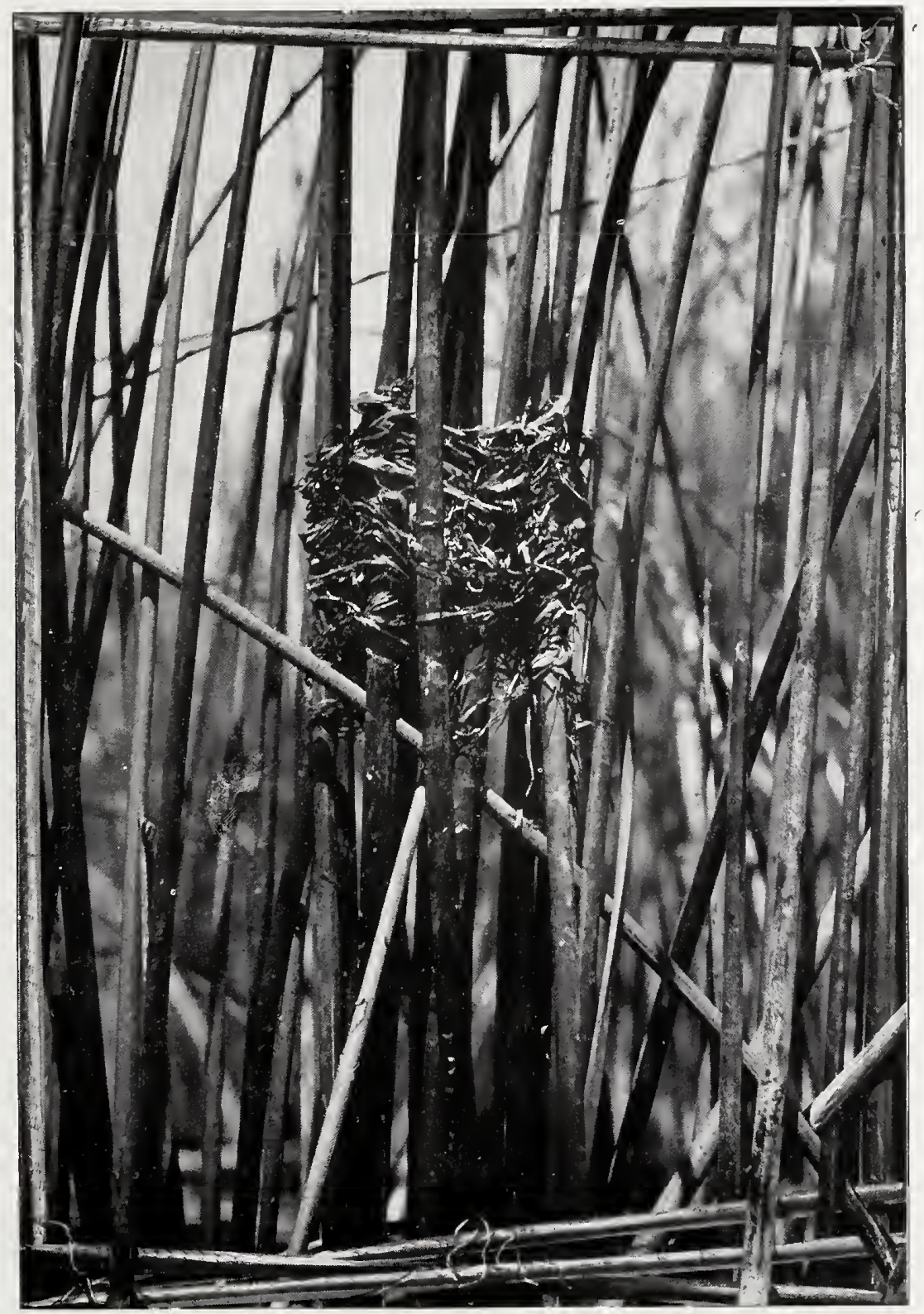

Photo by the Author

NEST OF YELLOW-HEADED BLACKBIRD IN TULE 


\section{The Yellow-headed Blackbird}

extraordinary person--you are prepared for that once you catch sight of his resplendent gold-upon-black livery-but his avowal of the tender passion is a revelation of incongruity. Grasping a reed firmly in both fists, he leans forward, and, after premonitory gulps and gasps, succeeds in pressing out a wail of despairing agony which would do credit to a dying catamount. When you have recovered from the first shock, you strain the eyes in astonishment that a mere bird, and a bird in love at that, should give rise to such a cataclysmic sound. But he can do it again, and his neighbor across the way can do as well-or worse. When your nerves have somewhat recovered, modesty overcomes you, and you retire, not without a chastened sense of privilege that you have lived to hear the Yellow-head pop the question,-- "and also you lived after."

The expiring Romeo cry is quite the finest of the Xanthocephaline repertory, but there are others not devoid of interest. Oh-eh-ah-oh-oo is a musical series of startling brilliancy, comparable in a degree to the yodelling of a street urchin,- - a succession of sounds of varying pitches, produced as though by altering the oral capacity. It may be noted thus: The last note is especially mellow and pleasing, recalling to some ears the liquid gurgle of the Bobolink, to which, of course, our bird is distinctly related.

Alternating with the last named, and more frequently heard from the depths of the nesting swamp is gur, gurrl; or, as oftenest, yewi $(n k)$, yewi $(n k)$, gur-gurrl. In this phrase the gurrl is drawn out with comical effect, as though the gallant were down on his knees before some unyielding maiden. From the depths of the swamp also comes a phrase which should be a fitting response to such a love-sick appeal, but alas for our logic, it also proceeds from "himself." Cut that aout, says his lordship, in the most matter of fact way. And a distant neighbor, believing that discipline is at stake, coincides, cut that a-out. The words say themselves, and the most ardent scoffer at "humanizing" cannot unthink them. But I do not expect all my readers to follow when I assert that, upon occasion, this bird becomes quite vehement, and shouts, You gotta cut that a-out.

The Yellow-head's ordinary note of distrust, equivalent to the dink note of the Redwing, is kluck or koluck'. In flight this becomes almost invariably oo'kluk, oo'kluk. At rest, again, this is sometimes prolonged into a thrilling passage of resonant " 1 " notes, probably remonstratory in character. The alarm cry is built upon the same basis, and is uttered with exceeding vehemence, klookoloy, klookoloy, klook ooooo.

Finally, if one may presume to speak finally of so versatile a genius, this bird has a harsh, rasping note very similar in quality to the scolding note of the Blue-fronted Jay, only lighter in weight and a little higher 
in pitch. This is the note of fierce altercation, or the distress cry in imminent danger. Once I heard it in the rank herbage bordering upon a shallow lake in Eastern Washington. I rushed in to find a big blow-snake coiling just below a nestful of young birds, w h i l e the agonized parents and sympathetic n e i g h bors hovered over the spot crying piteously. To stamp upon the reptile was the work of but a moment; and when I dropped the limp ophidian upon the ground, all the blackbird population gathered about the car-

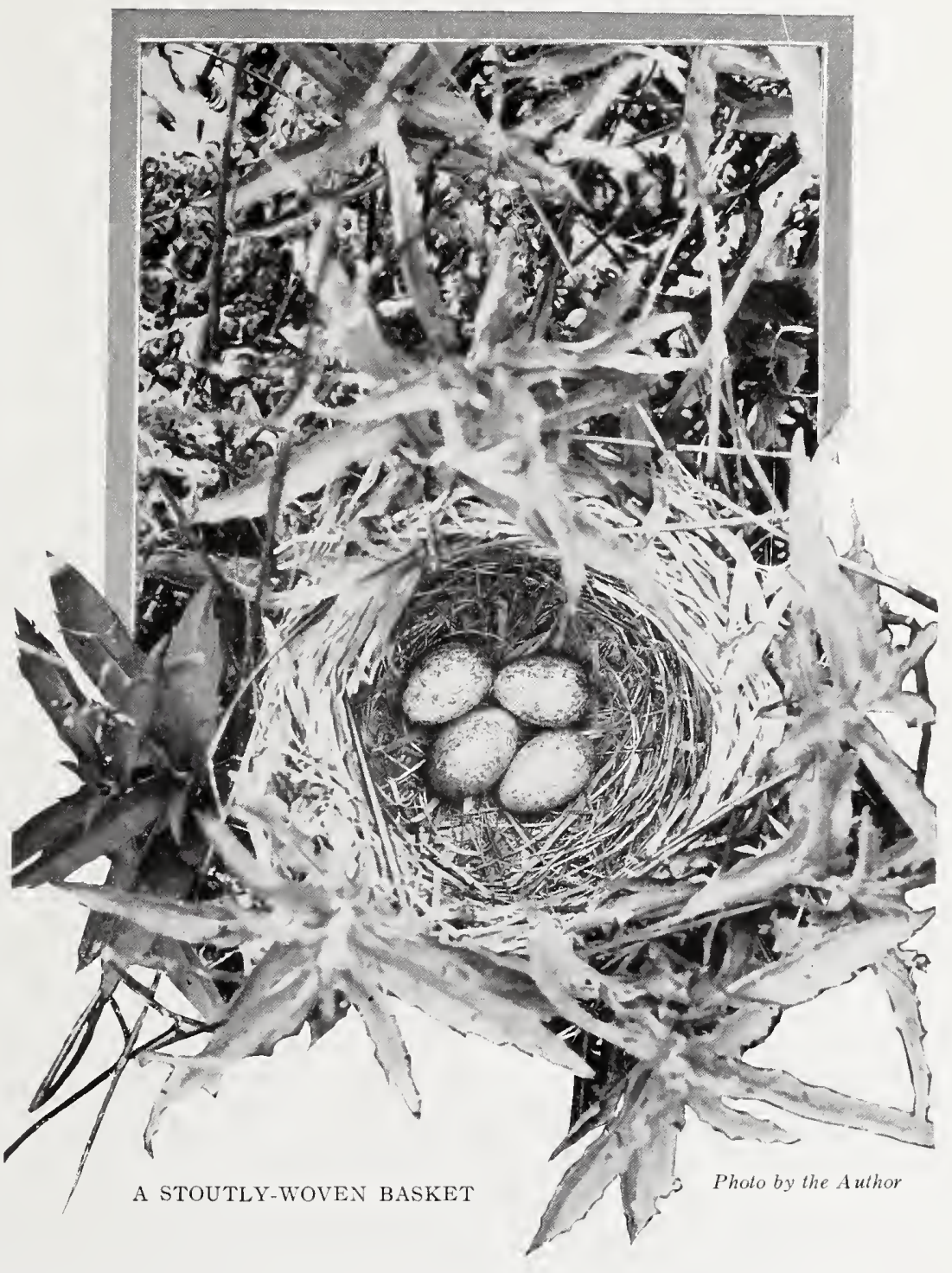
cass, shuddering but exultant, and--perhaps it was only fancy-grateful too.

For all the Yellow-head is so decided in utterance, in disposition he is somewhat phlegmatic, the male bird especially lacking the vivacity which characterizes the agile Brewer Blackbird. Except when hungry, or impelled by passion, he is quite content to mope for hours at a time in the depths of the reeds; and even in nesting time, when his precincts are invaded, he oftener falls to admiring his own plumage in the flooding sun- 


\section{The Yellow-headed Blackbird}

shine than tries to drive off the intruder. Let the homely and distrait female attend to that.

The nests are stoutly-woven baskets of reeds and grasses, light and dry and handsome. No mud or other matrix material is used in construction, and the interior is always carefully lined with fine, dry grass. Tules and cattails, especially of the narrow-leafed variety, are favorite cover, but rank herbage of any sort is used, if only it be near or over water. The most humble situations suffice; and the nest is often placed within a foot of the water, or its equivalent of black ooze.

Although the species is highly gregarious in late summer and in migrations, nests are thinly scattered through the reeds, like those of Redwings rather than like those of the Tricolored Blackbird. Neighbors are apt to be like-minded, and a given patch of tules will show a uniform stage of development-eggs or young. On the other hand, I have found communities so at loggerheads that nests ranged from "under construction " to "young ready-to-fly." In the San Joaquin-Sacramento basin, at least, four is the rigid rule for eggs. The only exception I ever noted contained ten, evidently the product of a single female.

Yellow-headed Blackbirds share the weakness of their kind for grain, whether fresh-sown, sprouting, in-the-milk, or ripening. Waste grain is gleaned from the ground, and enormous quantities of weed-seed are consumed. None of the blackbirds, however, are vegetarians. Insects are freely eaten at all seasons, while grubs and worms are much sought after. Alfalfa fields owe a great deal to their cleansing ministrations, and if a balance could be struck between profit and loss to the farmer, the bird might win. Anyhow, he is a splendid fellow, and his golden regalia should be passport enough to any mere barley-field.

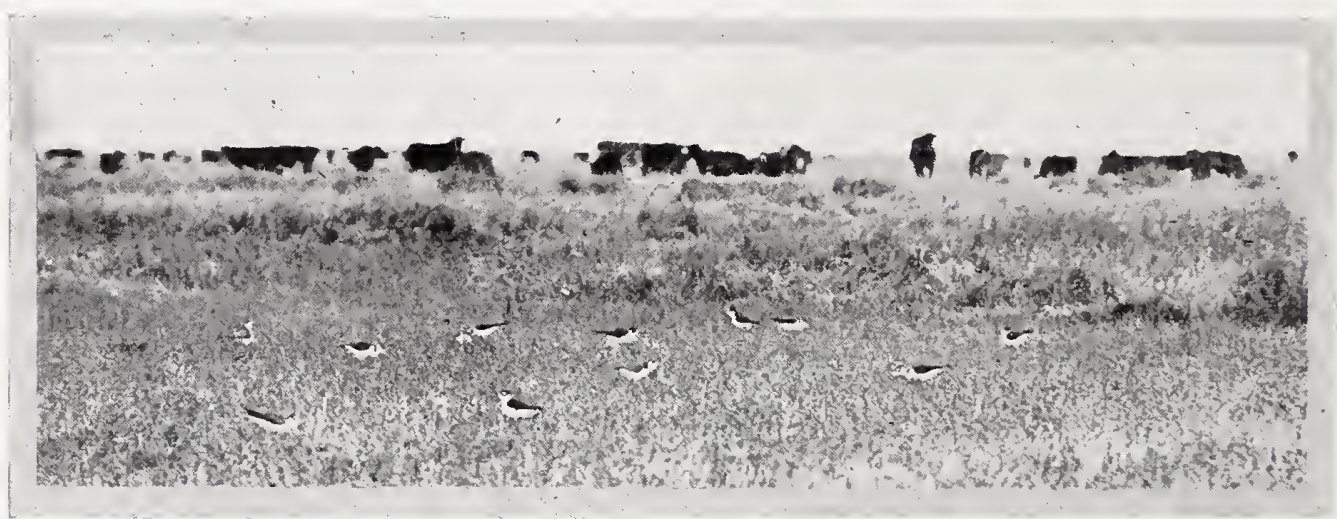

Taken in Merced County THESE BLACK-NECKED STILTS ARE "RUSTLING" BREAKFAST WITHIN A STONE'S THROW OF A COLONY OF NESTING YELLOW-HEADS 


\section{The Western Meadowlark}

No. 21

\section{Western Meadowlark}

\section{A. O. U. No. 50I.I. Sturnella neglecta Audubon.}

Synonyms.-Field Lark. Old-Field Lark. Medlark. Medlar (poetical). MUDLARK (corruption).

Description.-Adult male: General color of upperparts brownish black, modified by much tawny and buffy-gray edgings of the feathers, which throw the black into stripes and bars with suggestion of herring-bone pattern; the tawny heaviest on secondaries and upper tail-feathers, where taking the form of partial bands; a median crown-stripe and posterior portion of superciliary sordid white or buffy; anterior portion of superciliary, lower cheeks, chin, upper throat, breast (broadly), middle belly, and edge of wing, rich yellow (lemon-chrome, rarely strontian yellow); a large black crescent on upper breast; sides and flanks black-streaked, and spotted with pale brown on a buffy or whitish ground. Bill variegated,-tawny, black, and white. Female: Like male, but smaller and paler, with some substitutions of brown for black in streaking; black of jugulum veiled by grayish tips of feathers; yellow of breast, etc., duller. The plumage of both sexes is duller and more blended in fall and winter, the normal colors being everywhere restrained (save on abdomen) by heavy buffy overlay. Immature birds resemble parents, but are grayer, with (pale) yellow more confined, and they lack the jugular crescent. Length of adult male 254-279.4 (Io.oo-II.oo); wing I23.2 (4.85); tail 76.2 (3.00); bill 33 (I.30); tarsus 37.I (I.46). Female smaller.

Recognition Marks.- Robin size; yellow breast with black collar distinctive; general streaky appearance above; yellow on lower portion of cheek as distinguished from the eastern Meadowlark (Sturnella magna).

Nesting.-Nest: on the ground, chiefly in meadows or pastures, in thick grass or weeds; a slight depression, lined (caref ully or not) and usually overarched with dried grasses. Eggs: 4 or 5, rarely 6, 7 of record; white, speckled sparingly or very sparingly (much more so than in $S$. magna) with chocolate (of ten "self-toned," or diluted, to vinaceous russet, or "veiled" to vinaceous gray); very variable in shape,- - elliptical ovate to almost round. Av. size $28.3 \times 20.6$ (I.I2 x .8I). Season: April to June; two broods.

General Range.-Western North America, breeding from the southern provinces of Canada south to southern California, northern Mexico, and central Texas, east to central Iowa, Missouri, etc., retiring in winter from northeastern quarter of range and irregularly e'sewhere, and passing south through Lower California and Mexico to Jalisco and Guanajuato. Casual in several states of the "Old Northwest."

Distribution in California.- - Resident and of general distribution throughout the State, save arid portions of the desert, broken mountain sections, and the dense forests. Breeds from Lower Sonoran (Colorado Desert, at Indio, Apr. 27, 1917; Fish Springs, Apr. 28, I9I7) to Lower Boreal (or uppermost Transitional "islands" at Boreal levels), e. g., the Cottonwood Lakes in Inyo County, alt., I I,ooo ft. The species retires irregularly in winter to lower levels, invades the desert and (probably) suffers inundation by northern visitors. Found also upon all the Santa Barbara Islands, save, possibly, San Nicolas. 


\section{The Western Meadowlark}

Authorities.-Gambel, Proc. Acad. Nat. Sci. Phila., vol. iii., I 847 , p. 204; Bendire, Life Hist. N. Am. Birds, vol. ii., I 895, pp. 462-465, pl. vi., figs. 23, 24 (habits, nests and eggs); Belding, Auk, vol. xiii., I 896, pp. 29-30; vol. xv., I 898, pp. 56-57 (song); Chapman, Bull. Amer. Mus. Nat. Hist., vol. xiii., 1900, pp. 297-320, 8 figs. (crit. study); Bryant, H. C., Univ. Calif. Pub. Zool., vol. ii., I9I4, pp. 377-510, pls. $2 \mathbf{I}-24,5$ figs. (food and economic status in Calif.).

SUMMER silences the birds so gradually, and we ourselves have become so much absorbed in business during the prosy days of September, that we have almost forgotten the choruses of springtime, and have come to accept our uncheered lot as part of the established order of things. But on a nippy October morning, as we are bending over some dull task, there comes a sound which brings us to our feet. We hasten to the window, throw up the sash and lean out into the cool, fresh air, while a Meadowlark rehearses, all at a sitting, the melodies of the year's youth. It all comes back to us with a rush: the smell of lush grasses, the splendor of apple blossoms, the courage of lengthening days, the ecstacies of courtship-all these are recalled by the lark-song. It is as though this forethoughted soul had caught the music of a May day, just at its prime, in a crystal vase, and was now pouring out the imprisoned sound in a gurgling, golden flood. What cheer! What heartening! Yea; what rejuvenation it brings! Wine of youth! Splashes of color and gay delight!

It is impossible not to rhapsodize over the Meadowlark. He is a rhapsodist himself. Born of the soil and lost in its embraces for such time as it pleases him, he yet quits his lowly station ever and again, mounts some fence-post or tree-top, and publishes to the world an unquenchable gladness in things-as-they-are. If at sunrise, then the gleams of the early ray flash resplendent from his golden breastplate,--this highpriest of morning; and all Nature echoes his joyous blast: "Thank God for sunshine!" Or if the rain begins to fall, who so quickly grateful for its refreshment as this optimist of the ground, this prophet of good cheer! There is even an added note of exultation in his voice as he shouts: "Thank God for rain!" And who like him can sing farewell to parting day! Piercing sweet from the meadows come the last offerings of day's daysmen, peal and counterpeal from rival friendly throats, unfailing, unfaltering, unsubdued: "It is good to live. It is good to rest. Thank God for the day now done!"

The Meadowlark of the East has a poet's soul, but he lacks an adequate instrument of expression. His voice does not respond to his requirement. Perhaps his early education, as a species, was neglected. Certain it is that in passing westward across the prairies of Iowa or Kansas one notices an instant change in the voices of the Meadowlarks. 


\section{The Western Meadowlark}

The song of the western bird is sweeter, clearer, louder, longer and more varied. The difference is so striking that we can explain it only upon the supposition of an independent development. The western bird got his early training where prairie wild flowers of a thousand hues ministered to his senses, where breath of pine mingled faintly with the aroma of neighboring cactus bloom, and where the sight of distant mountains fired the imagination of a poet race. At any rate, we of the West are proud of the Western Meadowlark, and would have you believe that such a blithe spirit could evolve only under such circumstances.

Bird song never exactly conforms to our musical notation, and there is no instrument save the human "whistle" which will even passably reproduce the quality of the Meadowlark's song. Nevertheless, many interesting experiments have been made in recording these songs, and a little attention will convince the least accomplished musician that there is a fascinating field for study here.

A formal song of the Western Meadowlark comprises from four to a dozen notes, usually six or seven. The song phrases vary endlessly in detail, yet certain types are clearly distinguishable, types which reappear in different parts of the country, apparently without regard to local traditions or suppositional schools of song. Thus, a northern singer says, Oku wheel' er, $k u$ wheel' er, and he may not have a rival in a hundred miles; yet another bird across a mountain range sings, Eh heu, wheel'iky, wheel' iky, or even Eh heu wheel' iky, wheel' iky, wheel' iky, and you recognize it instantly as belonging to the same type. In like manner, Owy' hee, rec'itative was heard with perfect distinctness in localities three hundred miles apart.

Each bird has a characteristic song-phrase by which he may be recognized and traced through a season, or through succeeding years. One boisterous spirit near Lake Chelan, in Washington, I shall never forget, for he insisted on shouting hour after hour and day after day, "Hip! Hip! Hurrah! boys; three cheers!" Another bird near Auburn, in Placer County, amused us with his insistent Hick' o wee Willie Cook. Yet, while this is true, no bird is confined to a single style of song. A performer near Santa Barbara attracted notice by a rich, rolling Wheeeeeroo wheeeeeroo, which baffled imitation by the palatal trill (whistled), which the birds have taught the writer; but this intricate passage presently gave place to the "regular" song, a perfect clarion burst of Hay oh hee oh wee' erp. An autumnal soloist in a city park rendered no less than six distinct songs or song-phrases in a rehearsal lasting five minutes. He gave them without regard to sequence, now repeating the same phrase several times in succession, now hurrying on to new forms, pausing only after each utterance for breath. 


\section{The Western Meadowlark}

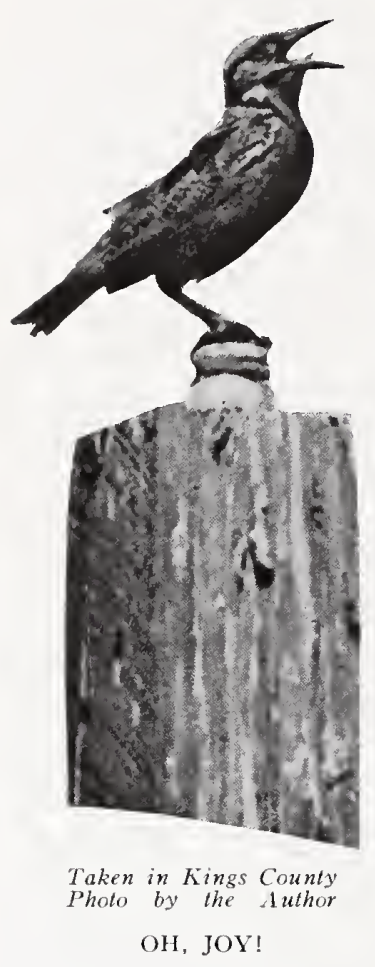

Nor is the effort of the Western Meadowlark confined to the formal song, for he often pours out a flood of warbling, chattering and gurgling notes which, at close range, are very attractive. Not infrequently he will interrupt one of these meditative rhapsodies with the clarion call, and return immediately to his minor theme.

In the presence of a stranger the lark serves frequent notice of intended departure in a vigorous toop, or toob, accompanying the sound with an emphatic flirt of the wings and jerk of the tail. Now and then the actual departure is accompanied by a beautiful yodelling song. After several preliminary toobs the bird launches himself with fantastic exaggeration of effort and rolls out, $O^{\prime} l y o^{\prime} l y o^{\prime} l y o^{\prime} l y o^{\prime} l y$, with ravishing sweetness.

At nesting time the parent birds have many causes for apprehension, and as they move about in search of food they give vent to the toob note of distrust in a fashion which soon becomes chronic. For one who studies the IVestern Meadowlark in several States, great interest attaches to the provincialisms of speech which characterize each locality. It is probable that this toob note of disgust, being more simple and primitive, will afford a better basis for local comparison than the more complex song. At any rate, it is more stereotyped and inflexible. Thus, on Santa Cruz Island, the toob note, while typical as to form, has a peculiarly "ancient" and plaintive quality. Elsewhere on the mainland one hears teuk or tew $(r) k$, very sharp and penetrating. In eastern Washington, again, this note has become doubled, too' bit or too' whit, and I think I have caught the same inflection in the highlands east of our Sierras.

At nesting time the Western Meadowlark enjoys a wide distribution in California. It is found, alike, at sea level, upon the cattail islands, over the grass-covered hills of the cattle country, in all cultivated sections, in the grassy openings of the northwestern forests, and over the stretches of the northeastern plateau. On the eastern slopes of the Sierras, the birds occur irregularly up to the lower levels of pine timber, and once, June 23, I9I I, I found them at an altitude of I I, ooo feet on Cottonwood Creek, in Inyo County.

The Meadowlark is an assiduous nester. This not because of any unusual amativeness, but because young Meadowlarks are the morceaux 


\section{The Western Meadowlark}

delicieux of all the powers that prey,--skunks, weasels, minks, raccoons, foxes, coyotes, snakes, jays, magpies, crows, and ravens; and if there be any other power of darkness, be sure it has its hand in here. Hawks and owls otherwise blameless in the bird-world, err in respect to the Meadowlark - the game is too easy. Even the noble Peregrine does not disdain this humble, albeit toothsome, quarry; and the Kestrel (Cerchneis sparverius) will stoop for a young Meadowlark when all other avian offerings are virtuously passed by.

Fecundity then is the only recourse,-this, and concealment. Not relying altogether upon its marvelous protective coloration, the lark exhibits great caution in approaching, and, if possible, in quitting its nest. In either case it sneaks along the ground for a considerable distance, threading the mazes of the grass so artfully that the human eye can follow with difficulty, or not at all. At the approach of danger a sitting bird may either steal from her nest unobserved and rise at a safe distance, or else seek to further her deception by feigning lameness, after the fashion of the Shore-birds. Or, again, she may cling to her charge in desperation, hoping against hope till the last possible moment, and taking chances of final mishap. In this way a friend of mine once discovered a brooding Meadowlark imprisoned underneath his boot-fortunately without damage, for she occupied the deep depression of a cow-track.

To further concealment the grass-lined depression in which the Meadowlark places her four or five speckled eggs is almost invariably over-arched with dried grasses. This renders the eggs practically invisible from above, and especially if the nest is placed in thick grass or rank herbage, as is customary. Touching instances of blind devotion to this 'arch' tradition were, however, afforded by a sheep-swept pasture in the North. Here the salt-grass was cropped close and the very sage was gnawed to stubs. But the Meadowlarks, true to custom, had imported long, dried grasses with which to overarch their nests. As a result, one had only to look for knobs on the landscape. By eye alone we located six of these pathetic landmarks in the course of a half-hour's stroll.

One brood is usually brought off in March or April, and another by the first of June. Although Meadowlarks are classed as altricial, i. e. having young helpless when hatched, and which require to be nurtured in the nest, the young Meadowlarks are actually very precocious, and scatter from the nest four or five days after hatching, even before they are able to fairly stand erect. This arrangement lessens the chances of wholesale destruction, but it would appear to complicate the problem from the parental standpoint. How would you, for instance, like to 


\section{The Western Meadowlark}

tend five babies, each in a separate thicket in a trackless forest, and that haunted by cougars, and lynxes, and boa-constrictors and things?

We cannot afford to be indifferent spectators to this early struggle for existence, for it is difficult to overestimate the economic value of the Meadow$1 \mathrm{a} \mathrm{rk}$. Th e Meadowlark is by preference an insect-eating bird; but in the fall, when insects are scarce, it turns to weedseed and fallen grain for sustenance. Later, when the fallsown grains begin to sprout and send up the first tender blade, the birds

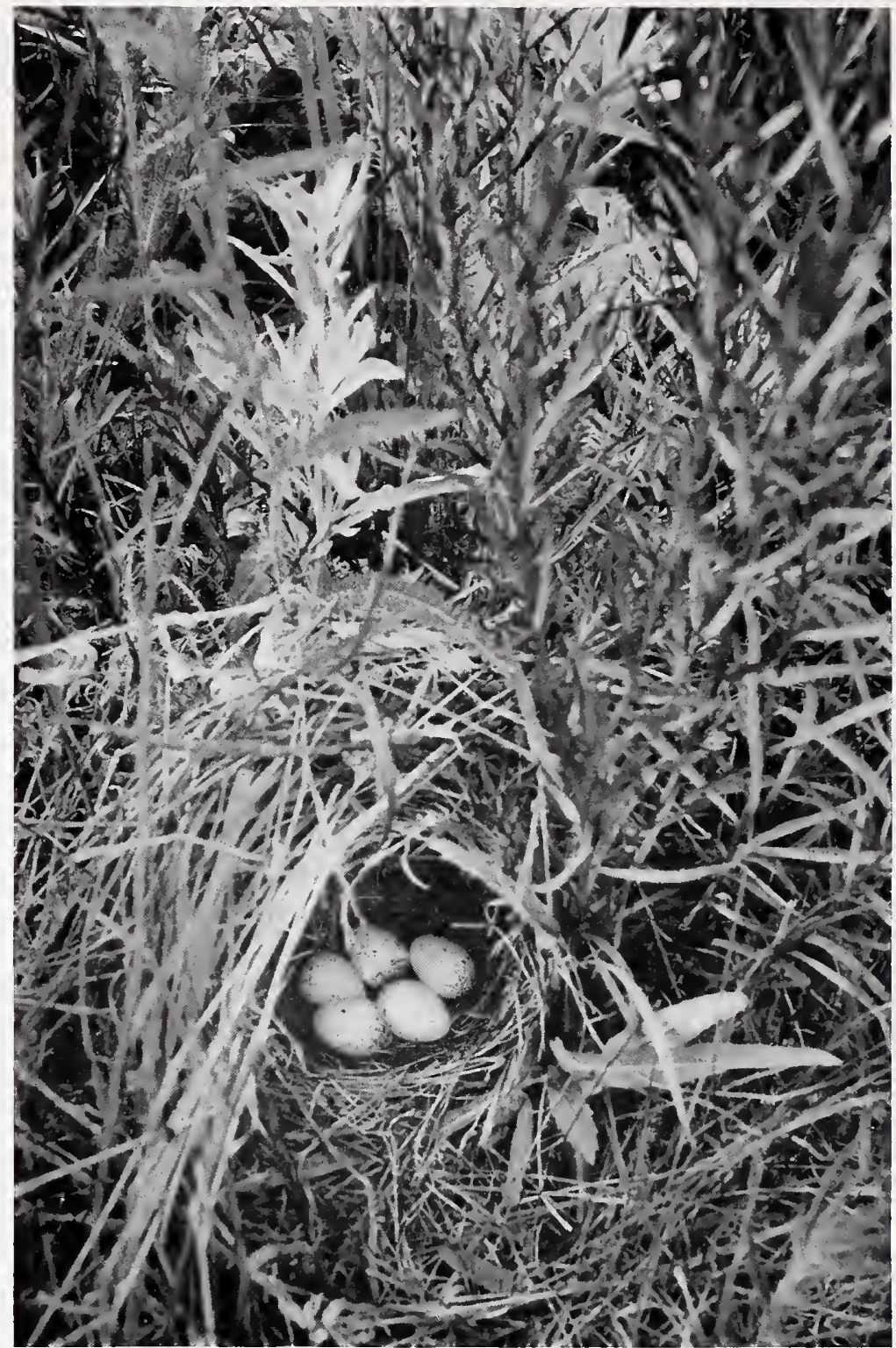

Taken in San Luis Obispo Counly

Photo by the Author

NEST AND EGGS OF WESTERN MEADOWLARK. IN YARROW sometimes in vade the fields and delve, quite cleverly, for the hidden treasure. Sprouting oats are a clear favorite, and experts estimate that this, together with a little wheat and barley, may sometimes amount to as much as one per cent of the bird's total annual fare! Of course that's naughty. But to persecute and destroy the Meadowlark on that account alone would be as silly and 


\section{The Western Meadowlark}

as criminal as it would be to shoot boys at sight because some boys occasionally steal apples. For the fact remains, incontestably proven by one of the most painstaking investigations ever conducted, 1 that the services performed by the Meadowlark as a destroyer of insects harmful to agriculture, overwhelmingly preponderate over the bird's occasional destruction of grain. The figures are interesting. Dr. Bryant estimates that a Meadowlark requires annually about six pounds of food. Of this a half pound is weed-seed, one and three-quarters pounds grain-chiefly fallen grain-and two and three-quarters pounds, insects. The grain is worth, say ten cents, or if we count the average ounce of sprouting grain consumed at fifteen times ordinary value, we will have a debit of fifteen cents per annum against the bird. But what is the minus value of predacious insects, among them the most destructive known, such as wireworms and cut-worms, which are Meadowlark's specialties? Soberly, almost anywhere from a dollar to a hundred dollars a pound, according to the value of the crops which the farmer is trying to raise. Yet, according to Dr. Bryant, it takes 193 pounds of insect food each day to feed the young Meadowlarks of the Sacramento and San Joaquin valleys alone. The imagination staggers before the sober conclusions of science regarding our indebtedness to the Meadowlark. In the face of this showing, and it does not rest on one man's testimony alone--Professor Beal has elsewhere shown that in the matter of grasshopper consumption Meadowlarks of average distribution are worth twenty-four dollars per month per township in saving the nation's hay crop--In the face of such a showing, I say, the efforts which certain individuals have persistently made in the halls of our State Legislature to remove protection from our Western Meadowlark, argue not only a spirit untouched by beauty or worth, but a low grade of intelligence.

And it goes without saying that we cannot regard this bird as lawful game. Its flesh is undoubtedly a delicacy, but so is human flesh. We exempt the horse from slaughter not because its flesh is unfit for foodit is really very sapid - but because the animal has endeared itself to our race by generations of faithful service. We place the horse in another category, that of animal friend. And the human race, the best of it, has some time since discovered compunctions about eating its friends. Make friends with this bonny bird, the Meadowlark, and you will be ashamed thenceforth to even discuss assassination. Fricassee of prima donna! Voice of morning en brochette! Bird-of-merry-cheer on toast! Faugh! And yet that sort of thing passed muster a generation ago-does yet in the darker parts of Europe!

1 A Determination of the Economic Status of the Western Meadowlark (Sturnella neglecla) in California. by Harold Child Bryant, U. of C. Pub. Zool., Vol. II., no. 14, pp. 377-510, pls. 21-24, 5 text figs., Feb. $27,1914$. 


\section{The Bobolink}

No. 22

\section{Bobolink}

A. O. U. No. 494. Dolichonyx oryzivorus (Linnæus).

Synonyms.-Skunk-Blackird. Reed-bird. Rice-bird. Meadow-Wink.

Description.-Adult male, breeding plumage: Head and below, rich glossy b'ack, - the feathers having at first a buffy edging which wears off as the season advances; a broad nuchal patch of strong buff (cream-buff to honey-yellow); scapulars, lower back, rump, and upper tail-coverts pale white; middle back gray; upper back, wings, and tail glossy to dead black, with various buffy edgings; tail-feathers sharply pointed. Bill dull black; feet brown. Adult female: Ground co!or of plumage olivebuff,- clearest below and in median crown, superciliary, and inter-scapular stripes; the remainder black and brownish fuscous. Adults in fall, and young: Like female in spring, but buffier and with less black throughout. Length of male $178-190$ (7.00$7.50)$; wing $97.5(3.84)$; tail $65(2.56)$; bill I I (.43); tarsus $27.2($ I.07). Female averages a half-inch shorter, with similar proportions.

Recognition Marks.-Towhee size; black, white, and buff plumage of breeding male. The breeding female is a shy and obscurely-colored bird, to be recognized by the amateur mainly through the attentions of the male. At other seasons both sexes and all ages may be known by the frequently uttered $d i n k$ cry. In the hand the acute tail-feathers are quite distinctive.

Nesting.- Nest: on the ground, in meadow or deserted field; a slight grass-lined depression concealed with some art, but not definitely overarched. Eggs: 5 or 6, rarely 7 ; yellowish gray (tilleul buff to pale smoke-gray) or greenish gray (light mineralgray); heavily and of ten sharply spotted or blotched with deep brown (diluting to natal brown or army brown, or veiling to vinaceous gray). Av. size, 2 I.I $\times$ I5.7 $(.83 \times .62)$. Season: About June Ist; one brood.

General Range.-North and South America; breeding in Transition zone from central latitudes of southern Canadian Provinces west to southeastern British Columbia and northeastern California, east to Cape Breton Island and New Jersey, south to about Latitude $40^{\circ}$; wintering in South America to Bolivia and Paraguay.

Distribution in California.-A breeder, perhaps irregularly, in the extreme northeastern portion of the State (Eagleville, Surprise Valley, June 30, I9I2); of casual occurrence elsewhere; four records: (See Grinnell, Pacific Coast Avifauna, No. I I, pp. IOO, IOI).

Authorities.-Littlejohn, Bull. Cooper Orn. Club, vol. i., I 899, p. 73 (at Redwood City); Breninger, Bull. Cooper Orn. Club, vol. i., I899, p. 93 (at Monterey); Fisher, W. K., Condor, vol. iv., I902, p. I I (at Mono Lake); Taylor, W. P., Condor, vol. xiii., I9I I, p. 2 I I (at San Bruno Lake); Dawson, Condor, vol. xviii., I9I6, p. 28 (at Eagleville).

I'T IS highly characteristic of California that its vast and varied empire should have provided a suitable asylum for this troubadour poet of the East; and equally characteristic, perhaps, that his presence among us should have passed almost unnoted. We are well nigh surfeited with notabilities, we Californians, surfeited and perhaps a little spoiled. Lords

$$
136
$$


and ladies have thronged our streets, and ducal parties have put up at our "best hotels." We have dined with Maharajahs, and danced with Spanish grandees. We have listened to high-brows from Boston-have even gone to hear' 'em--twice. The Russian ballet regards us as a private

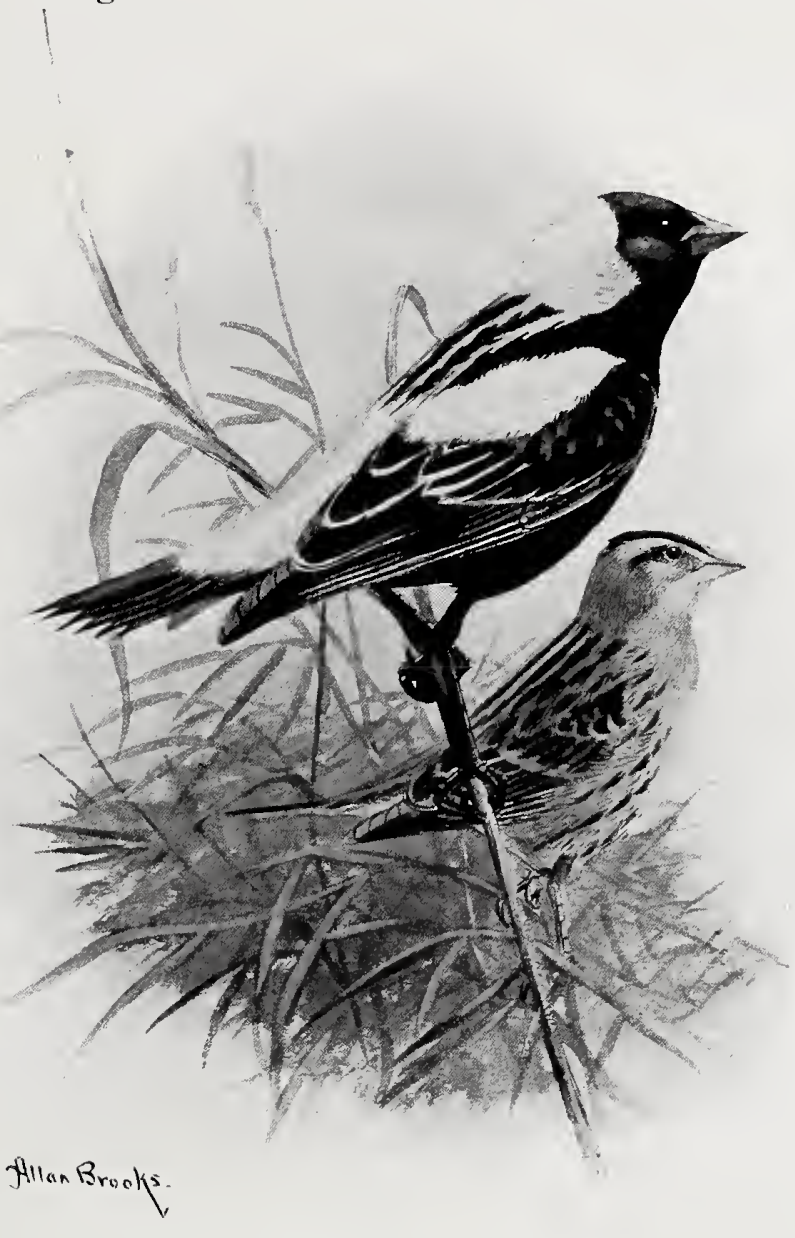

BOBOLINKS, MALE AND FEMALE

possession, and French artistes, who have never seen Dakota, visit us every year. Captains of industry from Chicago have reclaimed our goatpastures under pretense of playing golf, and social leaders from Gotham hold alternate court at Pasadena and Santa Barbara. It is all very flattering, very wonderful; but please do not expect us to get excited. They are welcome, of course, or would be if they didn't spoil the cattle ranges. But, really, a multimillionaire more or less doesn't matter, and what is a duke, anyhow? But wake up, California! the BOBOLINKS HAVE COME! Robert of Lincoln! apostle of mirth! Merriest madcap artist of spring! Symbol of divine unrest and divine--oh, divine Hope! He is here! Turn out, you Native Sons! and muster, you sons of millionaires, to do him honor! You whose fathers struck oil, or whose grandsires struck pay dirt, what will you ever strike one-half so rich as this fountain of song, this well of gladness, pure and unrestrained! Hail! blessed brother bird! And hail! tumultuous minstrel Bobolink!

It was the chief surprise of a visit paid in I9I 2 to the Surprise Valley in Modoc County to find the Bobolink common and, apparently, breeding. Although the season (June 30) would have been counted late at a lower 


\section{The Bobolink}

altitude (that of Eagleville, where the birds were seen, is $4725 \mathrm{ft}$.), the male birds were in high plumage and singing freely.

Although chiefly confined to the portion of America east of the Rockies, Bobolinks had, in all probability, discovered the well-watered region tributary to Salt Lake previous to the advent of the white man. We surmise that they reached this region by an extension of range from the north and east rather than from the south, and that they return annually by some unplotted east-andwest route. The spread of agriculture and of irrigation in Utah and southern Idaho has been attended by an increase of Bobolinks in that section, and it is altogether probable that the overflow from those favored regions is seeking out, and will find increasingly, asylum in the haygrowing sections of Washington, Oregon, and northern California. In view, therefore, of the pleasant possibility that Bobolinks may increase within our borders, I include a few paragraphs written from a frankly eastern standpoint.

$\mathrm{Next}$ after Bluebird, the coming of Bobolink marks the broadest



Taken in Modoc Counly

EAGLEVILLE AND THE SURPRISE VALLEY, LOOKING EAST WHERE THE BOBOLINKS NESTED IN IOI2 


\section{The California Evening Grosbeak}

step in the golden stair of springtime, by which we yearly attain the height of ornithological joy. His coming heralds that tidal wave of migration which begins somewhere during the last week of April, and sweeps over us till the middle of May. Without waiting for their more modest mates, the males press northward, hot-winged, to riot for a while over the dank meadows in bachelor companies, and to perfect that marvel of tumultuous song. Oh, how they sing, those Bacchanals of springtime! From fence-post or tree-top, or quivering in midair, they pour forth such an ecstacy of liquid, gurgling notes as must thrill the very clods. Such exuberance of spirit, such reckless abandon of mirth-compelling joy would cure a sick preacher on blue Monday. As the bird sings, he bows and scrapes and pirouettes till, as Wheaton says, "he resembles a French dancing master in uniform, singing, fiddling, dancing, and calling off at the same time."

But when some fine morning about a week later, a shy, plainly attired, brown lady drops from the sky with a soft dink, then it is that the passionate soul of the singer is fairly consumed by the inner fires of melody and desire. He dashes like mad after his lady love and pursues her at breakneck speed through the thickets of weeds and about fence-rows until he loses her in the grass. Then he hovers, or rather dances, in the air, over the spot where she vanished, or else retires to a fence-post hard by, to make frantic protestations of his devotion. Oh geezeler, geezeler, gilpity, onkeler, oozeler, oo, comes from that perfect throat; and somewhere between two blades of grass the lady is watching him - the sly minx-and chuckling softy to herself.

Once I heard a chorus of bachelors-or was it a musical contest?where seven birds in the top of a willow were singing with might and main. The effect of that wild melody of tinkling, palpitating, and flute-like notes, with its changeful syncopations and melodious discord, will not soon be forgotten. It was an all star team of the world's most accomplished mirth makers. (The Birds of Ohio).

No. 23

\section{California Evening Grosbeak}

A. O. U. No. 514a, part. Hesperiphona vespertina californica Grinnell.

Description.-Adult male: Forehead and superciliaries wax-yellow; feathers about base of bill, crown, and lores black; wings black, with a large white patch formed by tips of inner secondaries and tertials; upper tail-coverts and tail black; remaining plumage sooty olive-brown about head and neck, shading through olive and oliveyellow on distal scapulars, axillars, and lining of wings, lower rump, and under tailcoverts. Bill greenish horn-color and citron-yellow; feet brownish. Adult female: 


\section{The California Evening Grosbeak}

General color deep smoky brownish gray or buffy brown, darker on the head, lighter on wings, lighter, more buffy, on sides, shading to dull whitish on throat and abdomen, tinged with yellowish green on hind neck, clearing to light yellow on axillars and under wing-coverts: a small clear white patch about midway of inner primaries; another of irregular contour formed by outer edges of inner feathers of greater wing-coverts: white blotches on tips of secondaries, on tips of upper tail-coverts and inner webs of tail-feathers, in varying proportions. Length about 203.2 (8.00); av. of 6 males in M. V. Z. coll.: wing I I $2(4.41)$; tail $62(2.44)$; bill I $8.8(.74)$; depth at base I $4.6(.57)$; width at base $\mathbf{I} 3.8(.54)$; tarsus $20.8(.82)$.

Nesting. - Nest: As described by Beck, a substantial structure 35 feet up in black oak; of twigs heavily lined with moss-!ike rootlets of a dark color, and with an inside lining of light-co'ored rootlets; diameter outside I 14.3 (4.50); inside 76 (3.00). Eggs: 3 or 4 , ovate; light greenish blue, spotted and blotched sparingly with dark brown and black-distantly resembling those of a Red-winged Blackbird (A gelaius phoeniceus sp.). Av. size of three: $23.4 \times 16.2(.92 \times .64)$. Season: June I 8 (1896), July 9 (I922).

Range of Hesperiphona vespertina.-North central and western North America; breeds chiefly in the highlands or the coniferous timber from Alberta and southern British Columbia south to Chihuahua. Wanders irregularly over tributary lowlands in winter and casually east to New England.

Range of $H . \approx$ californica.- "Summer range-chiefly in Sierra Nevada of California, south at least to Yosemite National Park; but also Warner Mountains, Modoc County, and thence north at least to Bear Creek, Wheeler County, Oregon (See L. H. Miller. Condor, VI, I904, p. I04). Winters irregularly in adjacent territory south to Mount Wilson, Los Angeles County, California"-Joseph Grinnell.

Distribution in California.-As above. This, or an allied form still undescribed, occurs also in the Trinity Mountains and in the northwestern humid coast belt: near Eureka (Clay, Davis); Weaverville, Trinity County, Feb. 27, I9I I (Kellogg); near Trinidad, Humboldt County, June 22, I916 (Dawson); Tehama County, near Beegum, July 4, I9I6 (Dawson).

Authorities.-Cooper, Ornith. Calif., I870, pp. 173-176; Coues, Bull. Nutt. Orn. Club, vol. iv., I 879, pp. 65-75 (life history); Mearns, Auk, vol. vii., I 890, pp. 246-249 (part) (crit.); Beck, Nidologist, vol. iv., I896, pp. 3-4, col. pl. (nest and eggs in Calif.); Merriam, C. H., U. S. Dept. Agric., N. Amer. Fauna, no. I6, I899, pp. I22-I23 (about Mlt. Shasta); [Barlow], Condor, vol. iii., I90I, p. 88 (winter invasion of I900-I90I); Grinnell, Condor, vol. xix., I917, p. 20 (desc. of californica).

THE MAN who said, scoffingly, "What's in a name!" brought down upon himself an avalanche of criticism, or multitudinous rejoinder, whose reverberations, now angry, now eloquent, will never be done rolling. In bird-lore especially, history has embodied itself in nomenclature. Here, as in human society, the moment of introduction must of ten be taken up with a discussion of names. And while bird-names may be as diverse as Smith and Specknoodle, they are rarely so conventionalized, or so devoid of immediate significance. There is a fitness, then, in placing Hesperiphona, "Voice of the Evening Star," at the head of a group conspicuous in song, the Fringillidae. The western implications of the 


\section{The California Evening Grosbeak}

generic title were further confined by the choice of a specific name, vespertina, a term applied in 1825 by a New Yorker, one William Cooper, to an example hailing from the "far West," namely, from the wilds of Michigan! By the logic of our increasing sophistication, vespertina vespertina came to be recognized as the eastern form of IIesperiphona, and montana was used to designate the western bird. Last of all comes Grinnell, the gifted prophet of subspeciation, who restricts montana to the Rocky Mountain district and gives us californica for the authentic West. So now we have it IIesperiphona vespertina californica, West, Wester, Westest! Swayed by such considerations as these, our veteran Coues, in periods of rhapsodic appreciation, professed to see in the oliveand-gold raiment of this bizarre fowl a fitting symbol of the sunset! Moreover, the name vespertina, falling athwart a boundless ignorance, gave rise to an early tradition of vocal abilities stimulated by the evening hours, or even limited to them. This pretty story was eventually shown to be nonsense; but tradition dies hard, and "Evening Grosbeak" it will doubtless be till the end of time.

A juster reason, perhaps, for precedence among sparrows, may be found in the enormous bill which this bird boasts. A cone-shaped beak is the mark of sparrowness, and here is a proper cone-beak, indeed.

But for this primacy there are damaging limitations. The Evening Grosbeak is neither the most beautiful nor the most tuneful of the Fringillida, if he is by common consent rated the oddest. His garb is a patchwork; his song a series of shrieks; his motions eccentric; his humor phlegmatic; and his concepts beyond the ken of man. Although at times one of the most approachable of birds, he is, on the whole, an avian freak, a rebus in feathers.

Perhaps we make too much of a mystery of him, just as we rate the owl highest in wisdom for the single discretion of silence, which any dunderhead may attain. But now take this group in the park; just what are they about? They sit there stolidly in the rowan tree where all the passersby may take note of them, giving vent ever and anon to explosive yelps, but doing nothing by the hour, until an insane impulse seizes one of their number to be off to some other scene no better, be it near or far, and the rest yield shrieking consent by default of alternative idea. It is all so unreasonable, so uncanny, that it irritates us.

Evening Grosbeaks are semi-gregarious the year around, but are seen to best advantage in winter or early spring, when they flock closely and visit city parks or wooded lawns. One is oftenest attracted to their temporary quarters by the startling and disconnected noises which are flung out broadcast. It may be that the flock is absorbed in the depths of a small fir, so that one may come up near enough to analyze the sound. 


\section{The California Evening Grosbeak}

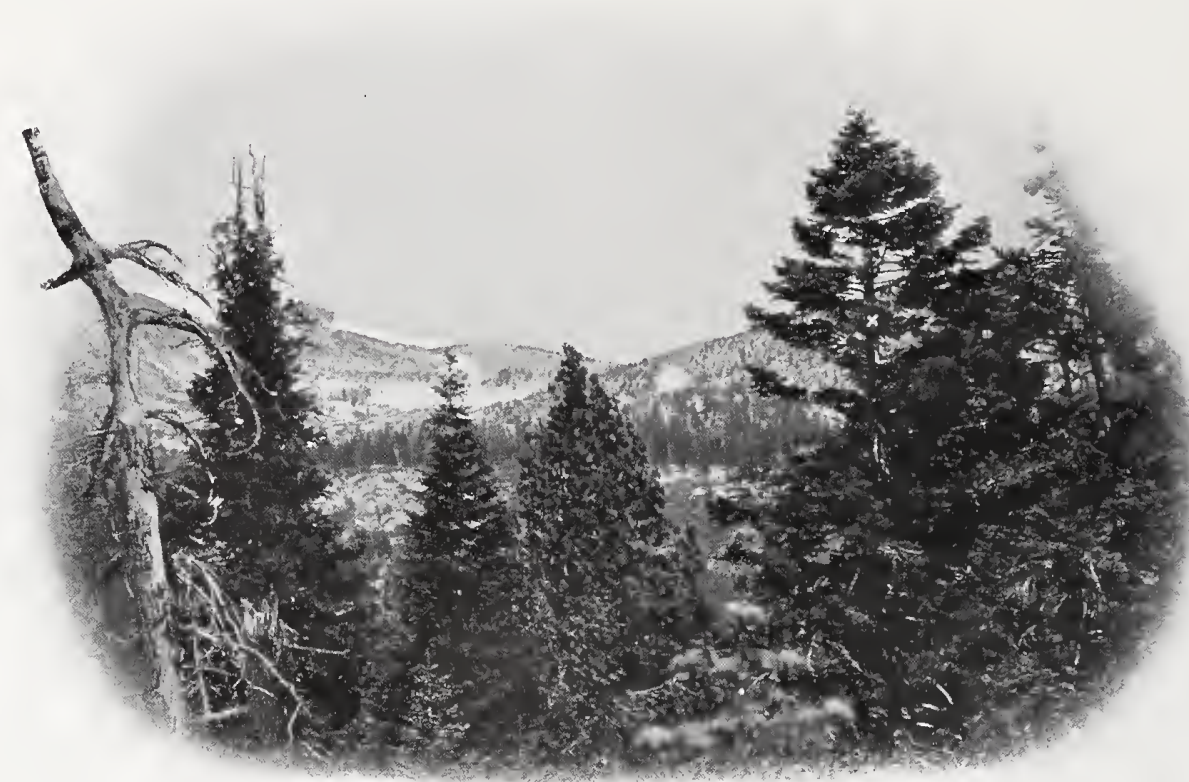

Taken in Mono County

Photo by the A uthor

NESTING HAUNT OF WESTERN EVENING GROSBEAK

$\mathrm{X}$ SHOWS LOCATION OF NEST, RI $88 / 4-22$ M. C. O.

Three sorts of notes are plainly distinguishable: a low murmuring of pure tones, quite pleasant to the ear; a harsh but subdued rattle, or alarm note, wzzzt or wzzzp, familiarly similar to that of the Crossbill; and the high-pitched shriek, which distinguishes the bird from all others, dimp. A little attention brings to light the fact that all the birds in the flock bring out this astonishing note at precisely the same pitch. Once distinguished, this note will serve again and again to draw attention to this uncanny fowl, as it passes overhead or loses itself in the bosom of some giant conifer.

If a student runs through the brief published annals of this bird, he will be surprised to see how much of its history has been written in or near the cities. The earliest California account, that of Dr. Cooper, hails from Santa Cruz. ${ }^{1}$ Another observer, a Mr. W. L. Tiffany, describes, in $\mathbf{I} 878$, the repeated appearance of the birds in the city of Minneapolis. For myself, I have seen more Evening Grosbeaks within the city limits of Seattle, Tacoma, and Spokane than in all the country besides. Just why these birds should be especially attracted to the centers of population, it is hard to say. Perhaps they love the stir and uproar of urban

${ }^{1}$ Geol. Surv. of Cal., Ornithology, p. 175 (1870).

142 


\section{The California Evening Grosbeak}

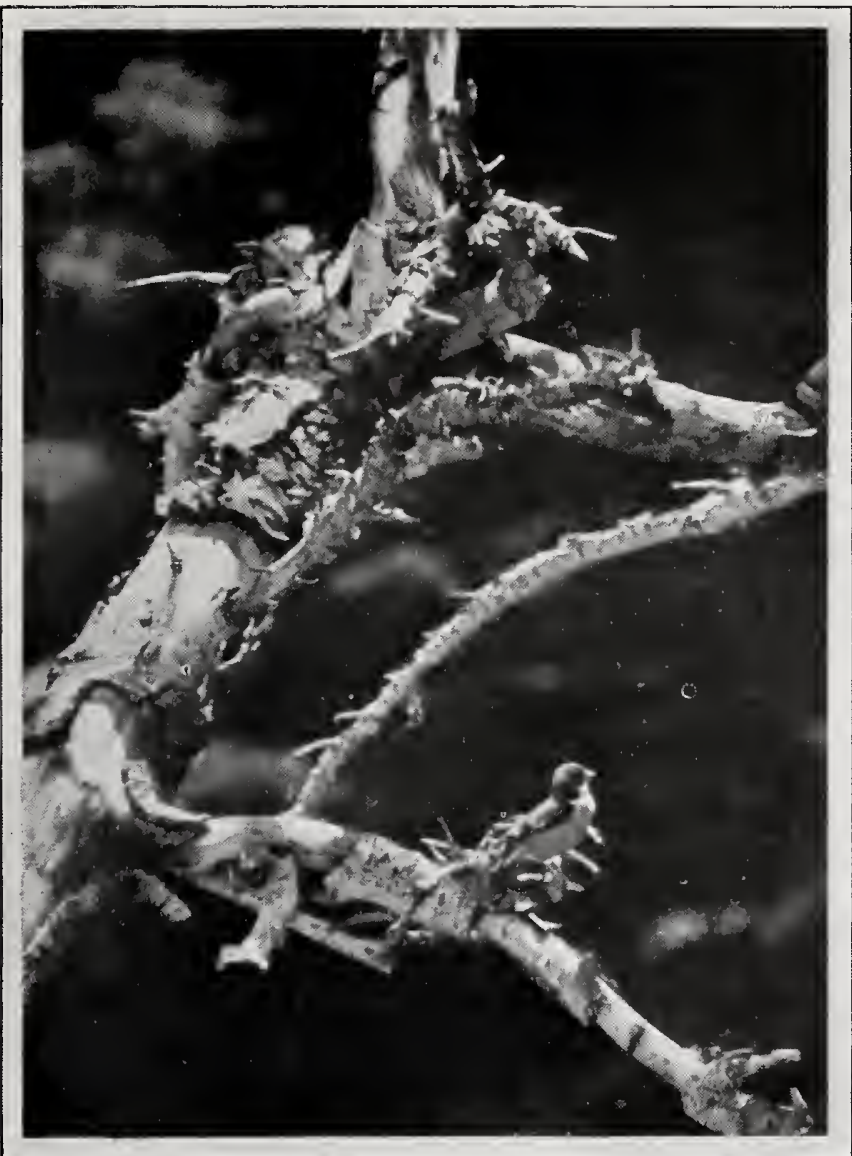

Taken in Mono County

"THE LADY IN THE GREEN BOMBAZINE DRESS"

FEMALE WESTERN EVENING GROSBEAK IN DEAD FIR TREE

life, the din which they help so valiantly to promote. At any rate, it is easy enough to see why they are more noticeable here, for their showy and patchy coloration marks them as distinguished visitors in town, whereas in the forest their colors so melt into and harmonize with their surroundings that it is difficult to follow their movements.

These Grosbeaks, or New World Hawfinches, are not to be commended as horticulturists. In winter they feed largely upon the ground, gleaning fallen seeds and fruits; and they are especially fond of the winged key of the large-leafed maple (Acer macrophyllum) and of the box elder (A. negundo californicum). They drop down to such a feast one by one from the branches above, and it is amusing to note how the loud cracking of seeds is interspersed with music. A little later the birds devote themselves to swelling buds, and here too the maple is a favorite, though ash, alder, flowering currant, and a dozen more, are not disdained. The damage done is not considerable; for the birds, viewed in the large, are not numerous enough, all told, to be taken seriously; but viewed in the concrete, the snip, snip of those mandibles in the currant bushes is no berry-growers' serenade.

It may be that the key of high C sharp, or whatever it be, staccata con moto, is the accepted love note, and that the green-liveried swain hurls declarations at his inamorata, like Samson in Handel's oratorio, the live-long year. Anyway, his exertions are redoubled in early June, and he charges about in a reckless frenzy which excites the envy of the 


\section{The California Evening Grosbeak}

oölogically minded, no less than the admiration of the ladies in gray, who are bound to believe all that is said.

The nesting of the Evening Grosbeak has been repeatedly and accurately described, ${ }^{1}$ but eggs are still very rare in collections, and they are justly rated among the most difficult of oölogical trophies. The reasons for this hark back alike to the general eccentricity of the bird, and to the seclusion of its summer haunts. The first nest of the species known to science was taken by Rollo H. Beck in Eldorado County, on the I8th of June, I 896, and at an elevation of 4700 feet. It was placed in a black oak tree, 35 feet up, and contained four fresh eggs, of a type more nearly resembling those of a Redwing (Agelaius phoeniceus sp.), than those of other, and of course unrelated, "Grossbeaks." Other nests since found, especially those in Arizona and New Mexico, have been placed in large evergreens, and often at heights from the ground and distances from the tree-trunk, sufficient to discourage any but the most hardy investigators. The bird's behavior in nesting country is erratic in the extreme, just as its psychology elsewhere is beyond analysis. One may feel perfectly certain that the bird is nesting, or intending to nest, close at hand; yet it will mope about for discouraging and unsuggestive hours, or else it will depart noisily into hopeless distances. The casual appearances of the bird at such a season suggest a detached aloofness, a total want of correlation between human thought and speculation and Hesperiphonine affairs. Thus, while in the Yosemite in June, I9I4, we saw Grosbeaks repeatedly in the very trees which overlooked Camp Curry. The voice of "the Stentor," issuing nightly, undoubtedly made the Grosbeaks quake upon their nests, but their secrets were as safe from a thousand as from a single pair of inquiring eyes.

If ever this lady in the green bombazine dress should be detected in the act of settling to a suspicious looking bunch at the end of a pine branch, she will stand by her guns valiantly; and if incubation be advanced, she will almost suffer the hand before she will quit her post. The male, meanwhile, if he is about at all, yelps in impotent rage and flits distractedly from tree to tree; but it never seems to occur to him that he might at least abstract a portion of the bird-man's ear with that potent beak.

It is important to append a caution against confusing this unique and obscure "Voice of Evening" with the more prosaic and abundant Black-headed Grosbeak, Hedymeles melanocephalus. The two species, both "Sparrows," have nothing else in common beyond the trivial name Grosbeak, a big bill, and partially overlapping ranges. They are not

1 See especially articles by Beck, Rollo H., Nidologist, Vol. IV., Sept., 1896, p. 3; Birtwell, Francis J., Auk, Vol. XVIII., Oct., 1901, pp. 388-391; Willard, Frank C., Condor, Vol. XIII., Mlarch, 1910, pp. 60-62. 


\section{The California Evening Grosbeak}

even closely related, for there are at least four mutually distinct and only distantly related groups of "grosbeaks" within the confines of the family in America alone. These are the Coccothraustea, the Hawfinches, including the "Evening" Grosbeak; the Pyrrhulce, including the Pine Grosbeaks; the Guiraca, including the Blue and the Black-headed "Grosbeak"; and the Cardinalea, including the Arizona Cardinal "Grosbeak," which all

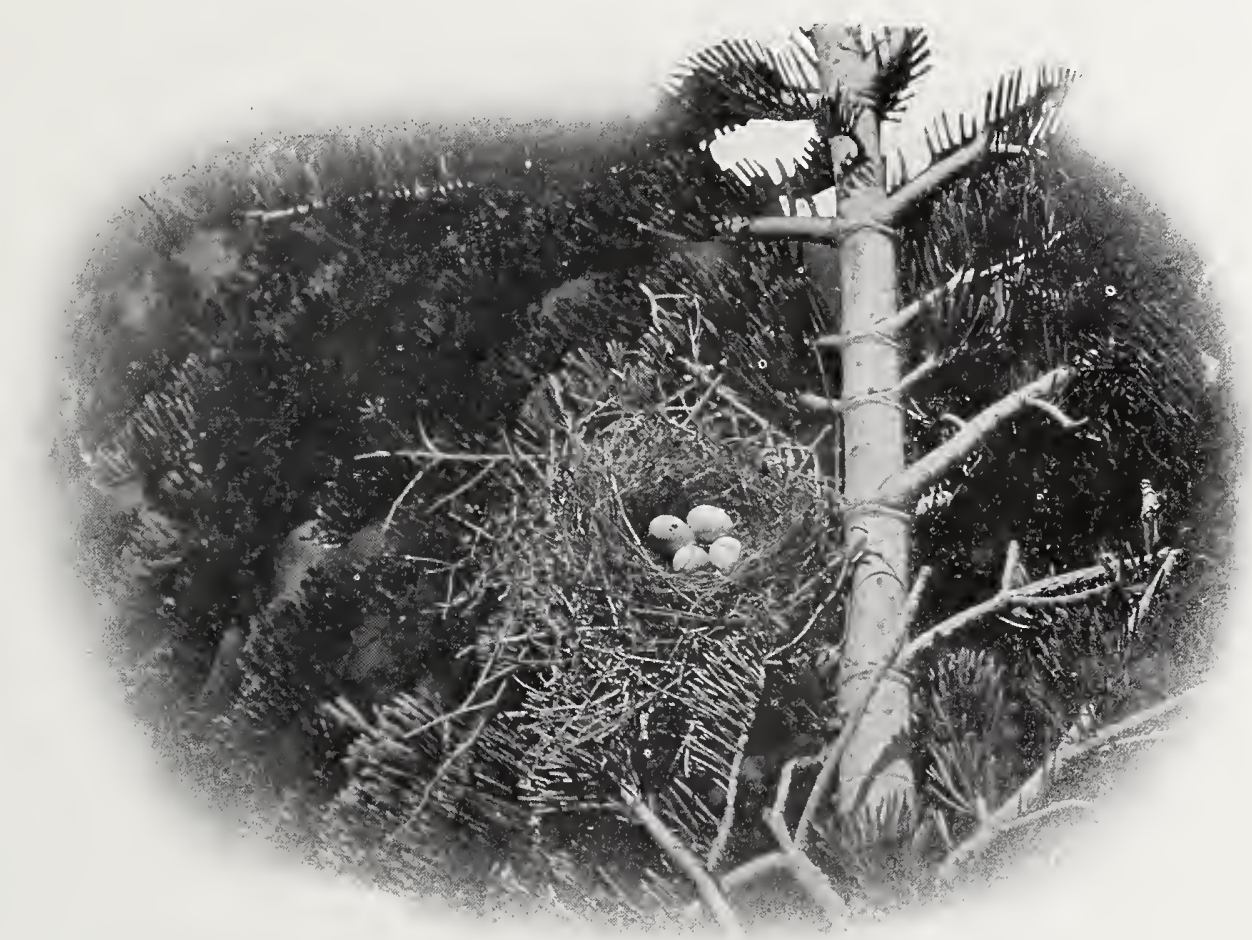

Taken in Mono County

Photo by the A whor

NEST AND EGGS OF WESTERN EVENING GROSBEAK, RI88/4-22 M. C. O., IN SITU

but attains our own borders. In view of these necessary distinctions, it is unfortunate that a confusion should have crept into the pages of so sedate an authority as the British Museum Catalogue of Birds' Eggs. The eggs described and figured (Vol. V., page I53, and Plate IX., fig. I) as those of Hesperiphona montana, the "Montana Grosbeak," taken in Alameda County, California, are unquestionably those of the familiar Pacific Black-headed Grosbeak, Hedymeles melanocephalus capitalis Baird.

The nest portrayed in the accompanying illustration was found by Robert Canterbury of the M. C. O. staff, July 9, I922. He had been directed to a likely locality, and upon hearing the "yelp" of the male bird 


\section{The Crossbills}

had started "combing" the likeliest fir tree with binoculars. At a point I 5 feet down and 9 feet out, though still 60 feet from the ground, he had detected a suspicious looking bunch, from which, upon investigation, a female Grosbeak dropped like a plummet, almost to the ground. The eggs, looking for all the world like those of a Red-winged Blackbird (Agelaius phoeniceus), were fresh, and the birds did not venture near enough to afford decent photographs, although I roosted for an hour in the tree top. Indeed, it was with a feeling akin to disgust that I saw these timorous fowls moping about like wet hens, when the romantic hopes of an oölogical lifetime were about to be realized. I could have spared the lobe of an ear, gladly, upon demand.

No. 24

\section{Red Crossbill}

\section{No. 24a American Crossbill}

A. O. U. No. 52I. Loxia curvirostra minor (Brehm).

Description.-Adult male: Tips of mandibles crossed either way; plumage dull red (duller in winter), brightest on rump; feathers of back with brownish centers; wings and tail fuscous. Shade of red very variable-English red to jasper red but never vermilion. Immature males of ten present a curiously mottled appearance with greenish yellow and red intermingled. Female: Dull olive-yellow, or better, brownish gray overlaid with yellow; the color present on head and back as broad skirtings to feathers having fuscous centers, on breast and sides more uniformly, and almost purely on rump and upper tail-coverts; throat and crissal region with least yellow or none. Immature (?) males are often indistinguishable from adult females, and it is not known whether such ever attain the characteristic red plumage. Young birds are finely streaked, dusky and buffy whitish, throughout, and everywhere more or less tinged with yellow. Adult male, length I39.7-I58.8 (5.50-6.25); wing 87.4 (3.44); tail 50 (I.97); bill I6.5 (.65); tarsus I6.5 (.65). Female very slightly smaller.

Nesting.--Not known to nest in California. "Nest: in forks or among twigs of tree, founded on a mass of twigs and bark-strips, the inside felted of finer materials, including small twigs, rootlets, grasses, hair, feathers, etc. Eggs: $3-4,0.75 \times 0.57$ [mm I9 $\mathrm{x}$ I 4.5$]$; pale greenish, spotted and dotted about larger end with dark purplish brown, with lavender shell-markings" (Coues). Season: Erratic, February to October; one brood.

Range of Loxia curvirostra.--Europe, northwestern Africa, northern Asia to the Himalayas, and northern North America, or south in mountainous districts to Guatemala.

Range of $L . c$. minor.-Northern and eastern North America, breeding in coniferous forests from northern Georgia to Nova Scotia, to Fort Anderson and to western Alaska, southward through Pacific Coast district to western Oregon (Ridgway): (hence, birds seen, but not taken, June 24, I9I6, near Trinidad, Humboldt County, Cal., may have been of this form); irregularly south in winter to South Carolina, Louisiana, Nevada, and California. 


\section{The Crossbills}

Distribution in California.-Of irregular occurrence in winter, chiefly in northwestern portion of State; has been taken at Pasadena. Possibly resident in summer in northern portion of humid coast district. Not strictly a migratory species, but highly nomadic.

Authorities.-Daggett, Bull. Cooper Orn. Club, vol. i., I899, p. 51; Grinnell, Condor, vol. xi., r909, p. ro2 (crit.); Willett, Pac. Coast Avifauna, no. 7, I912, pp. 73-74; Grinnell, Pac. Coast Avifauna, no. I I, I9I5, p. I08.

\section{No. 24b Sierra Crossbill}

A. O. U. No. 521 , part. Loxia curvirostra bendirei Ridgway.

Synonym.-Bendire's Crossbill.

Description.- "Similar to L. c. minor but decidedly larger; adult male averaging rather lighter or brighter in color, the adult female slightly lighter and grayer." (Ridgway). Also female averaging duller, less extensively yellow. Av. of 38 males, after Ridgway: wing 92.2 (.3.63); tail $52.6(2.07)$; bill $18.5(.73)$; tarsus $17.5(.69)$.

Nesting.- Nest: As described by Preston, of twigs interwoven with fine grass and pine needles, heavily lined with black moss (Alectoria fremonti) and sone feathers; diameter outside 4 to 5 inches; inside 2.50 ; depth outside 3 inches; inside 1.50 ; placed in coniferous tree, settled deeply into protecting pine needles, usually toward tip of branch, and at considerable height. Eggs: 3 or 4 , dull greenish white, spotted and marked sparingly, and chiefly at larger end, with purplish black, or else cinnamon dilution. sometimes with a flush of faint purplish or a wash of "weak chocolate." Av. size (Io spec., Preston) 2 I. $8 \times 15.2(.86 \times .60)$. Season: Not well defined; probably erratic.

Range of $L$. c. bendirei.-Central and northern mountain areas of United States, except Pacific Coast district; breeding south at least to San Bernardino Mountains in California; ranging irregularly in winter, east upon Great Plains, south to Lower California and Old Mexico.

Distribution in California.-Breeding range imperfectly made out, chiefly Sierras south to Mount Whitney, but also Mt. Pinos (in Ventura County) and San Bernardino Mts. Has been seen in summer in San Jacinto Mts., and in spring (Apr. 28, I9I I) on Santa Cruz Island, where it possibly has bred. In winter irregularly over lowlands wherever conifers of any sort offer. Was common about Santa Barbara in winter 1919-20.

Authorities.-Newberry (Loxia americana), Rept. Pac. R. R. Surv., vol. vi., pt. iv., I 857 , p. 87; Ridgway, Proc. Biol. Soc. Wash., vol. ii., I 884, pp. I0I-I07 (desc. of bendirei); Fisher, A. K., U. S. Dept. Agric., N. Amer. Fauna, no. 7, I 893, pp. 8 I-82 (record stations); Merriam, C. H., U. S. Dept. Agric., N. Amer. Fauna, no. I6, I 899, pp. I23-I24 (near Mt. Shasta; crit.); Grinnell, Condor, vol. xi., I909, p. I02 (critical); Willett, Pac. Coast Avifauna, no. 7, I9I 2, p. 74 (critical; status in so. Calif.); Grinnell and Swarth, Univ. Calif. Publ. Zool., vol. I0, I9I3, pp. 270-27 I (crit.).

THE "EARLY NUMBERS" of the Sparrow family, the Evening Grosbeaks, the Crossbills, the Pine Grosbeaks, and, to a lesser extent, the Purple Finches and the Siskins, are among the most baffling and difficult of birds. Their psychology exhibits a combination of preoccupied intentness and indifference which puts them beyond the pale of ordinary stand- 


\section{The Crossbills}

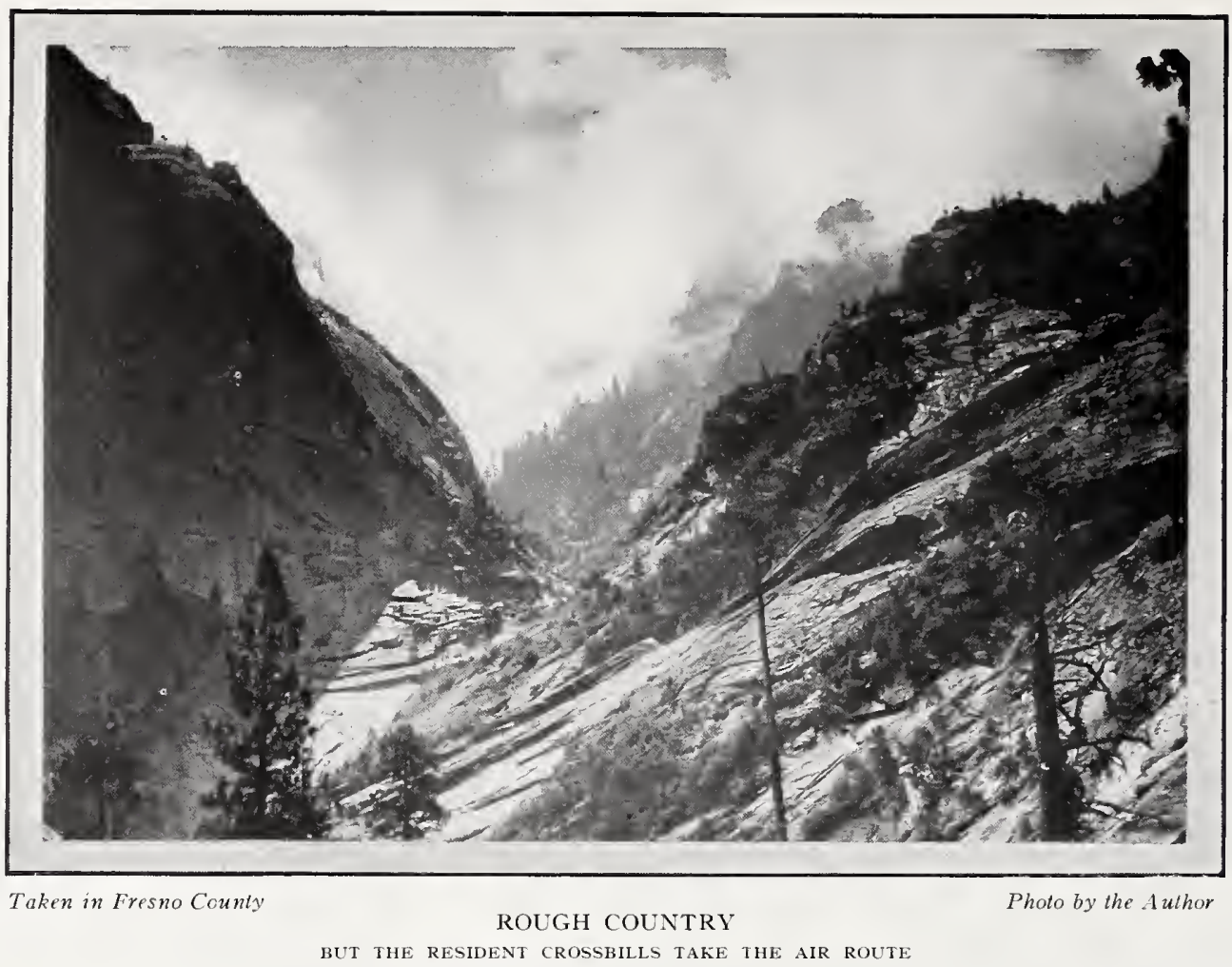

ards. They are all a bit uncanny. And of all this mad coterie, the Crossbill is perhaps the most eccentric. At a time a flock will deploy through the tree-tops of a city park and feed in dead silence, while pedestrians troop by unnoticing. At another a passing trio of birds will fill the air with sharp metallic notes which compel attention from any wayfarer. Now the birds will flee noisily at the most distant approach of a stranger. Again they will submit to the closest inspection as they crawl about the lower branches of a cone-laden sapling. For no good reason, apparently, a distant male will shout his distinct call from a tree-top. Others will chatter amiably at your feet as they glean fallen seeds, and look up with the trustfulness of petted hens. I recall how as a youngster I caught one of these birds in midair by rushing him on such an occasion. But a Crossbill in the hand is still an enigma, a strange, foreign thing, evidently not compounded of flesh and blood. For the rest, he is a wandering voice - or a set of such voices-restless, intermittent, syncopated, vagrant.

And though we shall proceed now to sober discourse of habit, song, and nesting, it will be under a haunting sense of unreality. As likely as not a bevy of "those crazy Crossbills" will interrupt our task, and we shall pause to note the fall and rise of each bird-flight as well as song 
syncopated-and we shall half shudder as the shouting mysteries in feathers lose themselves in the no less mysterious depths of distant conifers. How little of life may be snatched at in passing! We see; we hear; we do not comprehend. It is gone.

The Crossbill undoubtedly owes its peculiar mandibles to an agelong hankering for pine-seeds (using that word in the generic sense), a desire fully satisfied according to the fashion of that Providence which works so variously through Nature, and whose method we are pleased to call evolution. The bill of the bird was not meant for an organ of prehension, and Buffon, the Deist, once won a cheap applause by railing at the Almighty for a supposed oversight in this direction; but as matter of fact, its wonderful crossed mandibles enable the Crossbill to do what no other bird can, viz., to pry and cut open the scales of a fir cone, in order to extract the tiny seed with its tongue.

These birds are not entirely confined to a vegetable diet, for I once detected a group of them feeding industriously in a small elm tree which was infested with little gray insects, plant-lice, or something of the sort. The presence of these insects, in colonies, caused the edges of the leaves to shrivel and curl tightly backward into a protective roll. Close attention showed that the Crossbills were feeding exclusively upon these aphides. They first slit open a leaf-roll with their scissor-bills, then extracted the insects with their tongues, taking care, apparently, to secure most of the members of each colony before passing to the next.

Crossbills also feed to some extent upon the ground, where they pick up fallen seeds and other tidbits. An observer in Washington first called my attention to another purpose which the birds have in visiting the ground. He had noticed how at certain places, and notably where dish-water was habitually thrown, the Crossbills were wont to congregate, and, turning the head sidewise, to thrust out the tongue along the bare ground in a most puzzling manner. Suspecting at last the real state of affairs, he sprinkled the ground with salt, and upon their return the birds licked it up with great avidity. The birds do not appear to recognize the salt at first sight, but soon learn to resort to established salt-licks in open places. Others have reported similar habits in connection with certain mineral springs, where sodium chloride is sure to be one of the ingredients. When we recall that the normal food of the Crossbills is pine-seeds, this craving for nature's solvent is readily understandable.

The nesting of the Crossbill is known, but it is not well known, and it never can be perfectly known, for the reason that each pair of birds, or at least each community of birds, is a law to itself. There is, apparently, no published record of the nesting of this bird within the State of California, and that in spite of the fact that it is numerically one of the 


\section{The Crossbills}

commonest birds in the Sierras. The nearest I ever came to finding a nest was near Victoria, B.C. The exact scene was a neglected, brushy pasture, in which about a dozen lofty Douglas firs and tideland spruces, standing well apart, had escaped the woodman's axe. The date was May I8th, and a couple of Crossbills tittering among the lower branches of a nearby spruce had attracted my attention. Crossbills (of a provokingly neutral gender) were too common throughout this region to deserve notice; but here was manifestly a pair. The male was a young bird with touches of dull saffron only, while the female, though not duller, was notably smaller, and also very much busier. She selected a twig from a lower branch and made off with it through the air, closely followed by her adoring and tittering mate. The pair disappeared into the center of a giant spruce 200 feet away.

Back they soon came and I watched the female at close quarters as she tried first one and then another of the small dead twigs. The twigs were damp, however, and therefore tough. After she had tried a dozen or so, pulling and twisting and fluttering without success, she desisted and flew to the ground. Here she found exactly what she wanted, and made off again to the center of the distant spruce. By a system of approaches I presently discovered the object of her care, a growing bunch of twigs settled upon a thick, dishevelled bough at a point about eighty feet up and eight feet out.

The female never flew directly to the spot, but always lighted either above or below it, and made her way by short, watchful steps. The male, I found, did not always attend her closely, but of ten mounted guard on some neighboring tree and tittered. And now and then he varied the monotony of vigil by uttering a series of tender and endearing notes, most of which came out in short staccato phrases. Song at last! And this rare offering, this blooming of the cereus, was of the highest musical quality. Here was an artist masquerading all these years as a sphinx! $\mathrm{Ah}$ ! how love unlocks the secret treasuries of song, and puts in play the unsuspected chords. And why is love so brief? and the pursuit of pinenuts so inexorable?

The most notable of these song phrases bore a startling resemblance to the anxiety notes of the American Pipit (Anthus s. rubescens): terwil'lier, terwil'lier, terwil'lier. This phrase it is which makes you think of wrens. Indeed, if I had been in the dry country or up in the mountains, instead of at sea level, in "Humid Transition," I should have ascribed the sound, unhesitatingly, to the Rock Wren.

Thus were the foundations of the nest-to-be laid in song. And lest brethren of the oölogical fraternity (that sinister but solacing fellowship) 


\section{The Crossbills}

should pluck me by the sleeve and ask, "What happened after that?" I will add, sadly,- The next boat carried me back to Seattle.

In choice of nesting dates the Crossbill is probably the most erratic of all northern birds. Having, as it does, a regionally variable, but locally dependable, food supply, these birds nest whenever and wherever the notion seizes them-it may be in January, it may be in October. Indeed, it will not be surprising to learn that Crossbills have nested in every month of the year. The quasi-migrations, for which the Crossbills are notorious, are evidently determined by the abundance or failure of the cone crop, whether pine or fir. Now the fruiting of the conifers is, as every one knows, an exceedingly irregular matter. There is always something doing somewhere, but your evergreen has learned to defy the seasons; so, of course, the Crossbill's calendar has been turned topsy turvy. Communal life, therefore, is maintained the year around, in spite of the occasional defection of love-lorn couples; and there is nothing in the appearance of a flock of Crossbills in April to suggest that other such are dutifully nesting.

The nest of the Crossbill is said to resemble somewhat that of the California Purple Finch, but it is more compactly built, and much more heavily lined. The female exhibits a tragic devotion to duty, once confessed, and in some cases collectors have actually had to lift the bird off her eggs in order to examine them. In one classical instance, recorded by Dr. Brewer, of a nest taken early in March, the bird was not only several times forcibly removed, but she insisted upon resuming her place upon the nest as it was being carried down from the tree.

Of the distribution of our California Crossbills much yet remains to be learned. If our breeding form is bendirei, then it is safe to say that the birds have little occasion to leave the limits of the State, or even of the mountains, in winter. They are always to be found somewhere in the Sierras and in the San Bernardinos. Their occasional appearance in the lesser ranges, provided always that they are more or less pine-clad, is safely predicable, but it is not known whether they breed in such circumstances, or where. The most exceptional instance of recent times was reported from Santa Cruz Island, where Messrs. A. B. Howell and Adriaan van Rossem found them in numbers in April, I9I I, (and up to May 2nd), and where they believed them to be breeding. I saw nothing of them in April, I9I5, nor have any of our recent parties (I9I6, I9I8, I9I9, I922) observed them. 


\section{The California Pine Grosbeak}

No. 25

\section{California Pine Grosbeak}

\section{A. O. U. No. 5I5b. Pinicola enucleator californica Price.}

Synonym.-Pine Bullfinch.

Description.-Adult male: In highest plumage, foreparts, breast, back (centrally), and rump, rosy red (jasper to pompeian red); back with faintly darker centers of feathers; lower belly and under tail-coverts ashy gray (light mouse-gray) - this high plumage is the exception. In general, the rosy gives place to ashy gray in varying proportions; wings and tail ashy dusky; tips of middle and greater coverts and outer edges of exposed secondaries, white. Bill dusky; feet blackish. Adult female: Similar to male, but rosy replaced by dingy yellow (varying from olive-yellow and olivetawny to ochraceous) and chiefly confined to head, hind-neck, and upper tail-coverts (where brightest); feathers of back frequently tipped with ochraceous, and breast

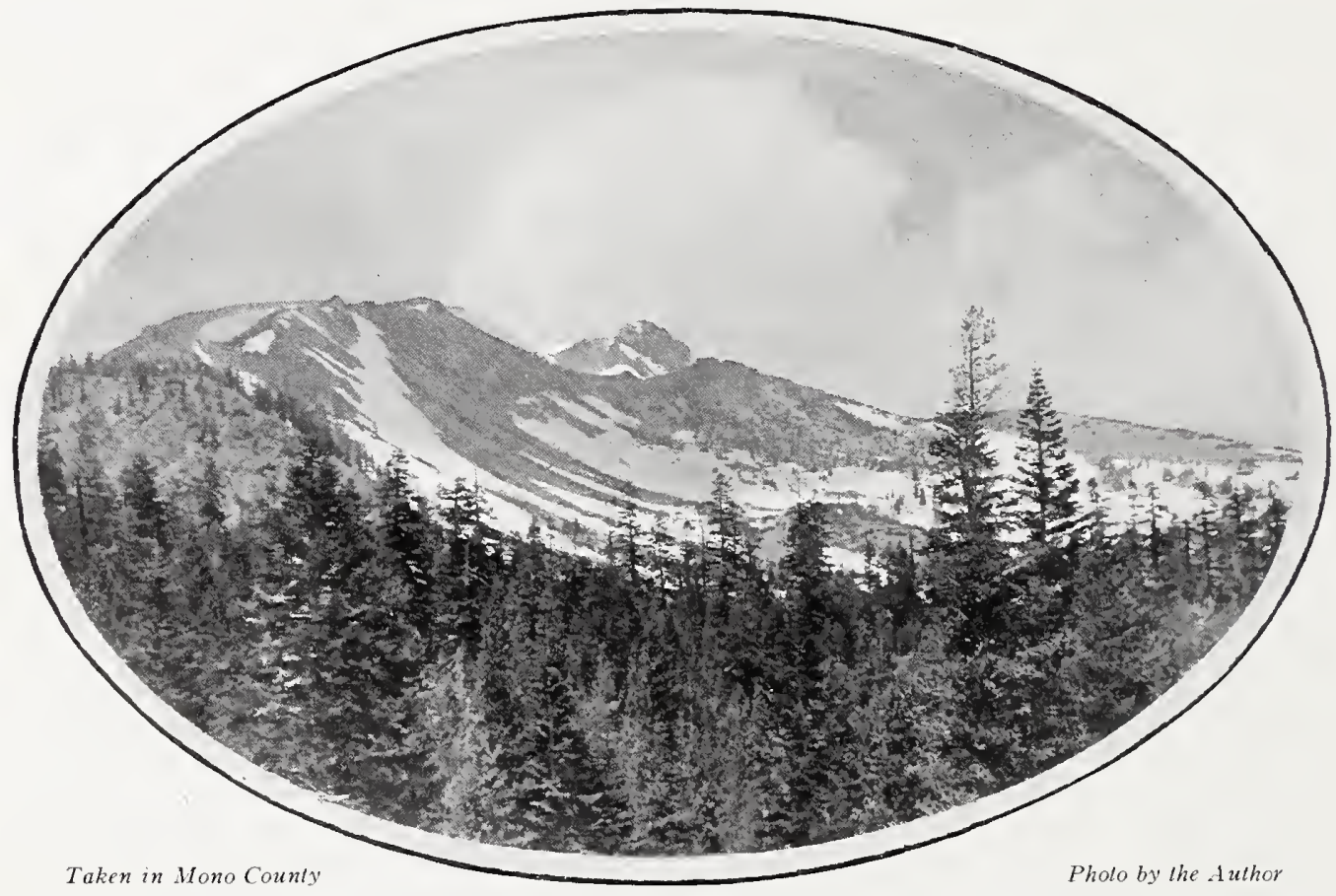

NESTING HAUNT OF CALIFORNIA PINE GROSBEAKS BIRDS SEEN HERE MARK THE SOUTHERNMOST EXTENSION OF RANGE

with an ochrey wash. Immature birds: Exactly like adult female, save that males sometimes show bricky red on head and rump. Length about 2I8.4 (8.60); wing I I 3.5 (4.46); tail Ioo (3.94); bill I $4.7(.58)$; depth at base I $0.2(.40)$; tarsus $22.3(.88)$.

Recognition Marks.- Towhee size; large, rounded, conical beak; red and gray coloration, for size, distinctive. 


\section{The California Pine Grosbeak}

Nesting, as described by Ray.-Nest: A frail platform of coniferous twigs, lined with fine, light-colored grasses, and settled carelessly upon horizontal branch of conifer, well out from trunk; height in tree I6 (type) to 35 feet. Nesting altitude 7000-8500 feet. Eggs: 3; greenish blue (rich nile blue), spotted and marked with vandyke brown or blackish, and with subdued olive-gray or dull lavender shell markings. Av. size $25.9 \times 17.3$ (1.02 $\times .68)$. Season: June; one brood.

Range of Pinicola enucleator.-Northern parts of Eurasia and North America.

Range of P. e. californica.-Local resident of the central Sierras from Plumas County south to northern Fresno County, and from elevation 6500 to timberline.

Authorities.-Cooper (Pinicola canadensis), Proc. Calif. Acad. Sci., vol. iv., I 868, p. 8; Fisher, A. K., U. S. Dept. Agric., N. Amer. Fauna, no. 7, I 893, p. 79; Price, Auk, vol. xiv., I897, pp. I82-186 (desc. of californica); Ray, Condor, vol. xiv., I9I2, Pp. I 57-I 87, I7 figs. (desc. of nesting near Pyramid Peak); Hunt, Condor, vol. xxiii., Nov. I921, pp. I87-I90 (nesting near Blairsden, Plumas County).

THE AUTHOR may as well admit, first off, that he never saw a Pine Grosbeak. He makes that humiliating confession, well knowing that his own reputation as an ornithologist will suffer accordingly, but believing that such an admission will also more accurately establish the status of the California Pine Grosbeak as a reasonably rare bird. But if he should add, in all fairness, that there are only five other mainland species of regular occurrence in California which he has not seen in life, it may serve to emphasize again the remarkably local character of the range of Pinicola enucleator californica. If one would see the California Pine Grosbeak, whether in winter or summer, he must repair to the central Sierras, and preferably to one of the six counties focussed about Lake Tahoe; although there is an old record of one seen by Mr. Nelson "on the head of the San Joaquin River, ${ }^{1 "}$ and Mr. Howell ${ }^{2}$ secured a specimen near Mammoth Pass, in Mono County, on July 3Ist, I9I4. A member of my party also encountered a pair near Twin Lakes in the throat of this pass in June, I9I9, and again in $192 \mathrm{I}$ Mr. Carriger saw a pair near the old stamp mill at Mammoth; but although I kept a sharp lookout for three seasons in this same section, no other birds were seen. The California Pine Grosbeak is unquestionably rara avis.

Our best account ${ }^{3}$ of the occurrence of this species comes from the pen of that veteran oölogist of the Sierras, Mr. Milton S. Ray, and I condense the substance of his observations, supplemented by those of W. W. Price, ${ }^{4}$ the original describer of the subspecies: The California Pine Grosbeak is of very irregular occurrence, even in the limited area where it has been known to breed. The experience of one season is only

\footnotetext{
1 North American Fauna, no. 7, May, 1893, p. 79

2 The Condor, Sept., 1915, p. 206.

3 Condor, Vol. XIV., Sept., 1912, pp. 157-187.

${ }^{4}$ Auk, Vol. XIV., April, 1897, pp. $182-186$.
} 


\section{The California Pine Grosbeak}

a slight index of another season's fortunes. The fact that they do not migrate or retire to lower levels in winter seems to be purely inferential, but there is no reason for their leaving the shelter of the hospitable pines, Pinus contorta, or the still more hospitable alpine red firs, Abies magnifica; and these trees, in their prime, mark, rather narrowly, the zone of the birds' actual occurrence.

The birds are of a decidedly plump, though not ungraceful, appearance, and the rich poppyred plumage of the male makes a bright spot in memory for one who can distinguish it from the duller and otherwise very different appearance of the Cassin Purple Finch. Not all the ma'es are thus brightly arrayed, for they breed in the fulvous-and-gray plumage of immaturity (?) as well.

These Grosbeaks

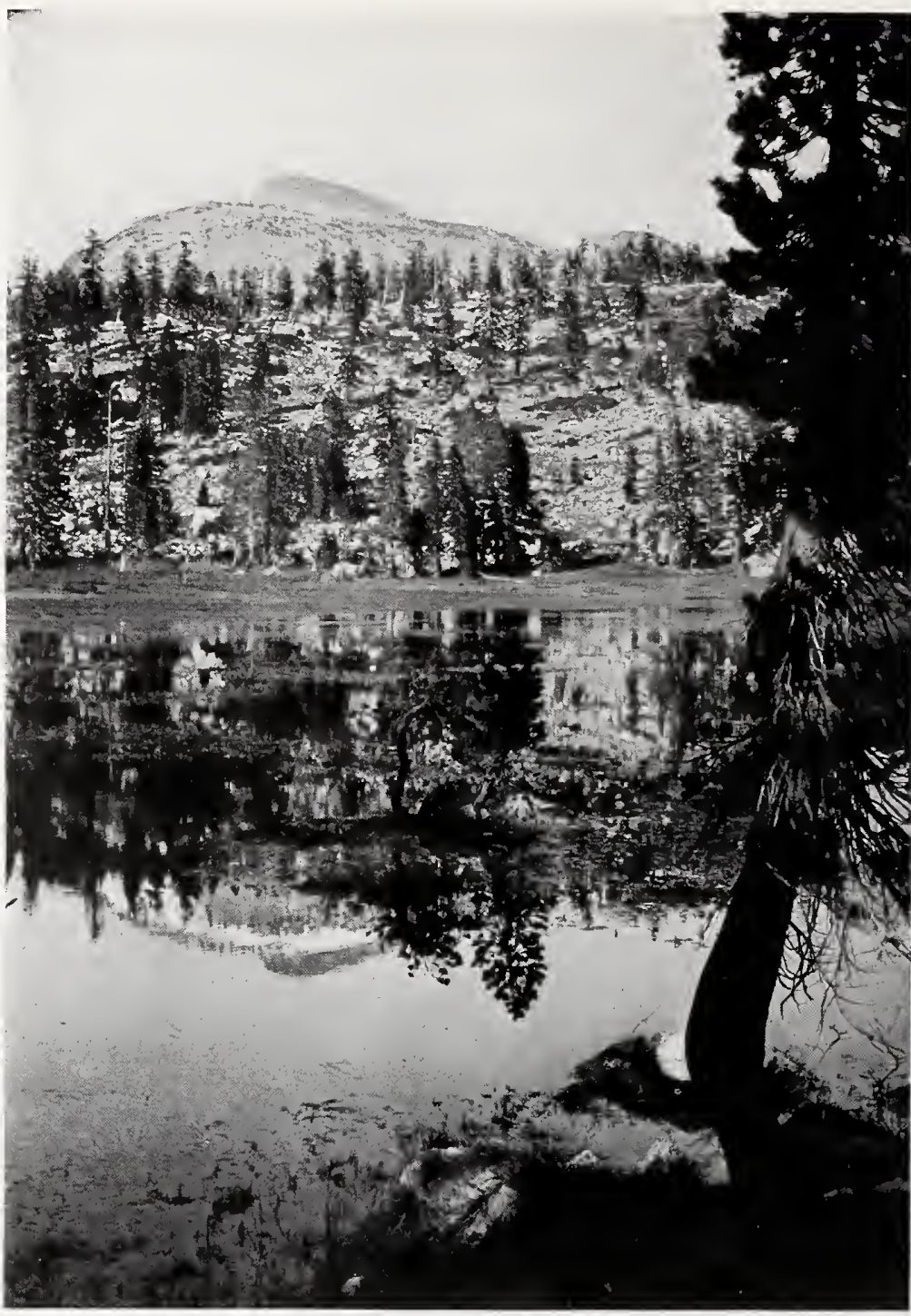

Photo by Oluf J. Heinemann

move about sedately and do not often attract the attention of casual observers. On the other hand, they are remarkably fearless, or rather, unsophisticated, alighting, as they do at times, within a few feet of the observer. They are little given to sociability with other species, and seem to live rather an independent, semi-lethargic and dream-like existence, where food is abundant and well assured. In common with other pine-cone and browse feeders, they are very fond of salt, and in 


\section{The California Pine Grosteak}

company with Cassin Purple Finches and Western Evening Grosbeaks they visit the upland salt licks where the sheep are baited.

The California Pine Grosbeak has a song which, according to Ray, deserves to rank along with that of the Dipper, the Hermit Thrush, and other major songsters. It is especially comparable to the song of the Black-headed Grosbeak, but is, if possible, still more melodious, rich, and varied. Unfortunately, the bird is not a persistent singer, and its outbursts are as rare as they are uplifting. The bird has also a melodious, two-syllabled call-note, which reminds one of the words, "All right." At the nest, or in intimate conversation with his mate, the Grosbeak indulges a series of amiable twitterings very pleasing to the ear.

The Pine Grosbeak shows its affinities very clearly in its choice of a nesting site. A rather frail platform of coarse fir twigs is heavily lined with coiled grasses, and the whole is settled loosely upon some spreading evergreen limb at any convenient distance from the ground or the tree stem. The female is a sturdy sitter, and requires to be fairly poked off if one would see the eggs. Although apparently indifferent to the presence

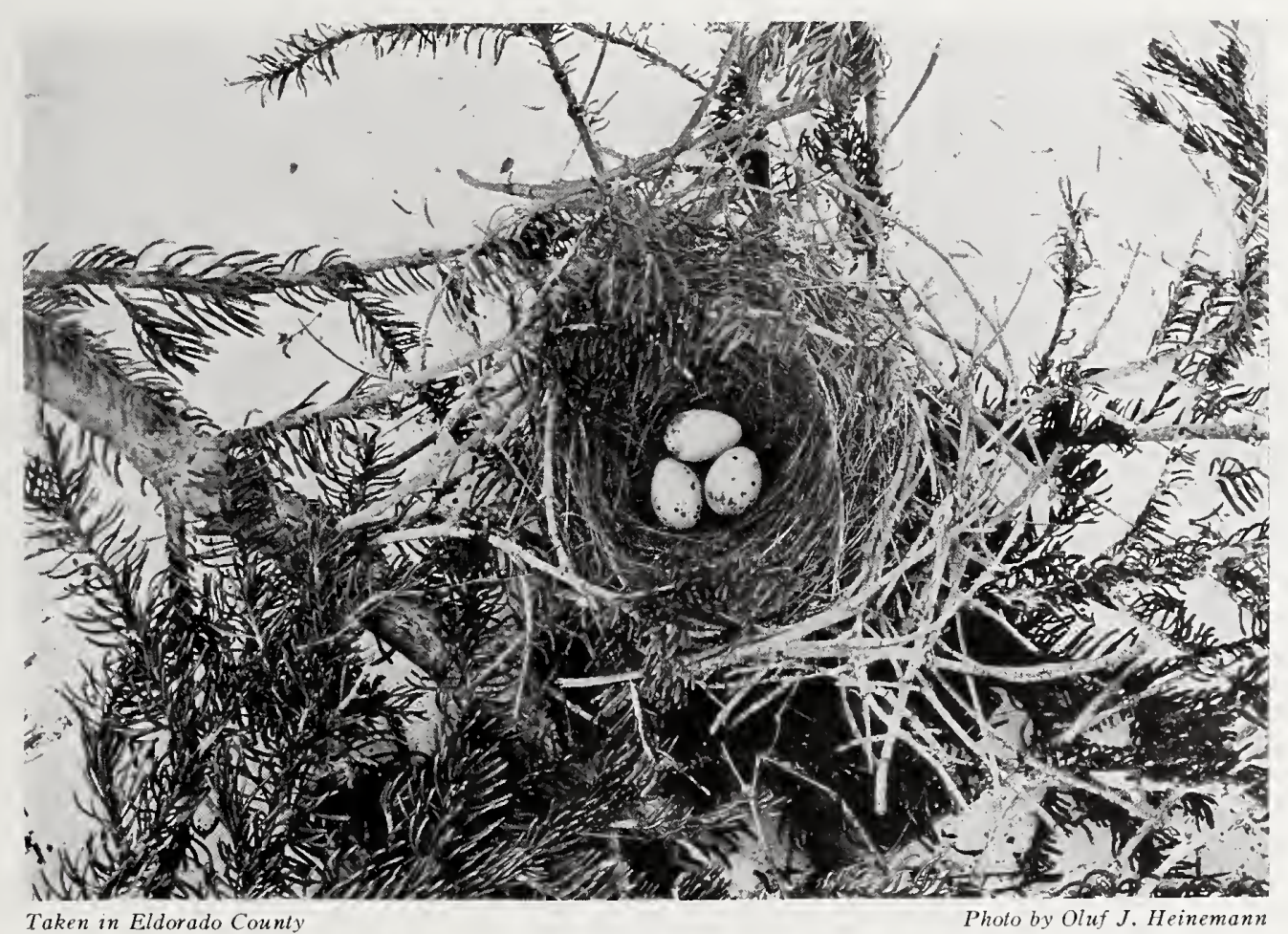

N/3 CALIFORNIA PINE GROSBEAK BACKGROUND OF SNOW I6 FEET BELOW NEST Courtesy Milton S. Ray and "The Condor" 


\section{The Dareson Leuco}

of the human stranger, the sitting female does not allow her mate to feed her upon the nest, but goes to meet him in another tree, according to approved precautions. Like the Cassin Purple Finch, she relieves the tedium of incubation by an occasional foraging expedition on her own account; and it is thus, we fear, that her business is betrayed to that inquisitive exponent of science who has laid so many of the broad foundations of our knowledge of birds. I refer, of course, to the under-rated and over-despised oölogist.

No. 26

\section{Sierra Nevada Rosy Finch}

A. O. U. No. 524, part. Leucosticte tephrocotis dawsoni Grinnell.

Synonyms.-California Leucosticte. Dawson's Rosy Finch.

Description.-Adult male in breeding plumage: General color rich brown, varied by rosy; top of head black, bordered irregularly by hoary ash, the ash including lores and superciliaries and broadening on hind-neck; lesser and middle wing-coverts (in richest examples, all exposed edges of folded wing), rump, and upper tail-coverts, flanks, and posterior under-plumage, with touches on axillars and wing-linings, rosy red (light jasper red or jasper pink, rarely jasper red), the red appearing as broad edges of feathers otherwise brown or white, and variously intermingled, especially on rump; remaining plumage rich brown (Prout's brown), blackening on throat, varied above by dark centers and paler edging, lightening posteriorly; wings and tail brownish dusky, or hoary dusky. Bill black; feet and legs brownish black. Adult female in breeding plumage: Like male but paler and duller with much less display of rosy. Bill blackish. Adults in autumn (fresh plumage): As in spring, but plumage "varied by white" (leuco-sticte), and with increase of rosy; the feathers of breast skirted by pinkish ashy in scaled effect; those of upperparts brownish-ashy-bordered; crown more extensively white; the inner greater coverts and tertials broadly edged with brownish buff; the rump and posterior underparts more broadly tipped with jasper pink. Bill yellow, darkening toward tip. Immature birds: Similar to adults in spring, but much paler; in general, buffy ashy brown; feathers of back with darker centers; wings with much buffy brown edging; rosy element much reduced, sometimes appearing only upon edges of flight-feathers. Length about I65 (6.50). Av. of adult males (Grinnell): wing I04.6 (4.I2); tail 70.4 (2.77); bill II.I (.43); depth at base $7(.27)$. Of females: wing 99.8 (3.92); tail 65.8 (2.59); bill I I (.43); depth at base 7. I (.28).

Recognition Marks.-Sparrow size; rich brown and rosy coloration; frequents high altitudes. Cheeks not gray, as distinguished from the northern form, L. t. littoralis.

Remarks. - While the characters assigned for distinction between $L$. $t$. tephrocotis and $L$. $t$. dawsoni are comparatively slight, they are supported by a wide discontinuity of range between the two forms. Theoretically, a gap of 650 miles in the established breeding ranges of two related forms, not identical, should entitle each to specific rank. It is for this reason, chiefly, that we attach weight to Dr. Grinnell's original description, as follows: "As compared with its nearest relative, Leucosticte 


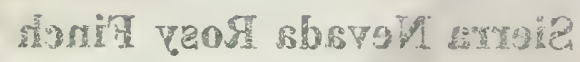

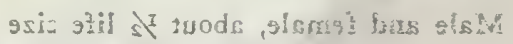

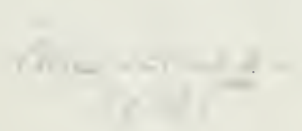




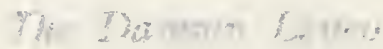

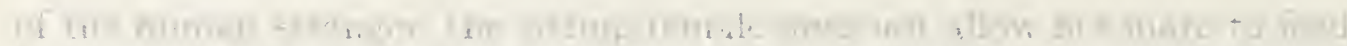

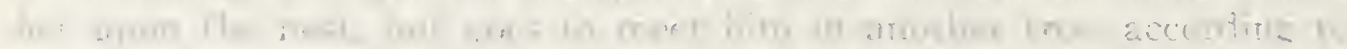

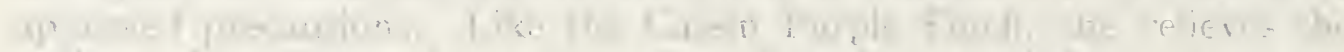

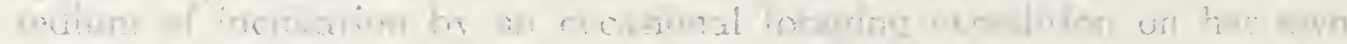

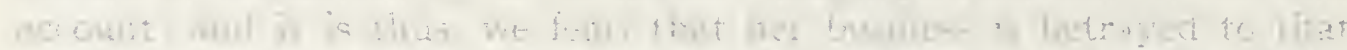

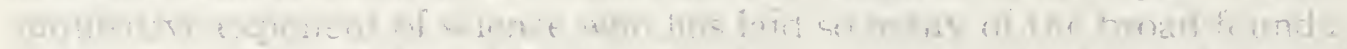

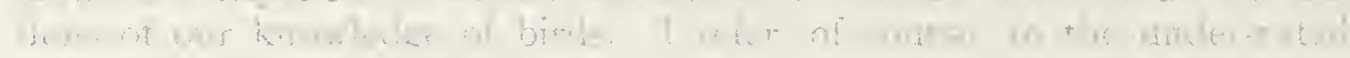

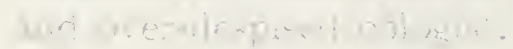

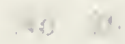

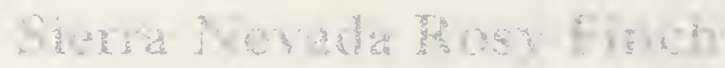

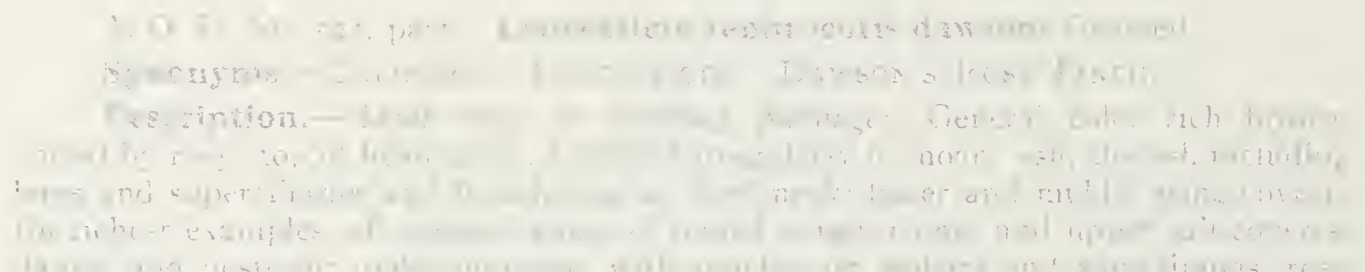

\section{Sierra Nevada Rosy Finch}

Male and female, about $x / 2$ life cize

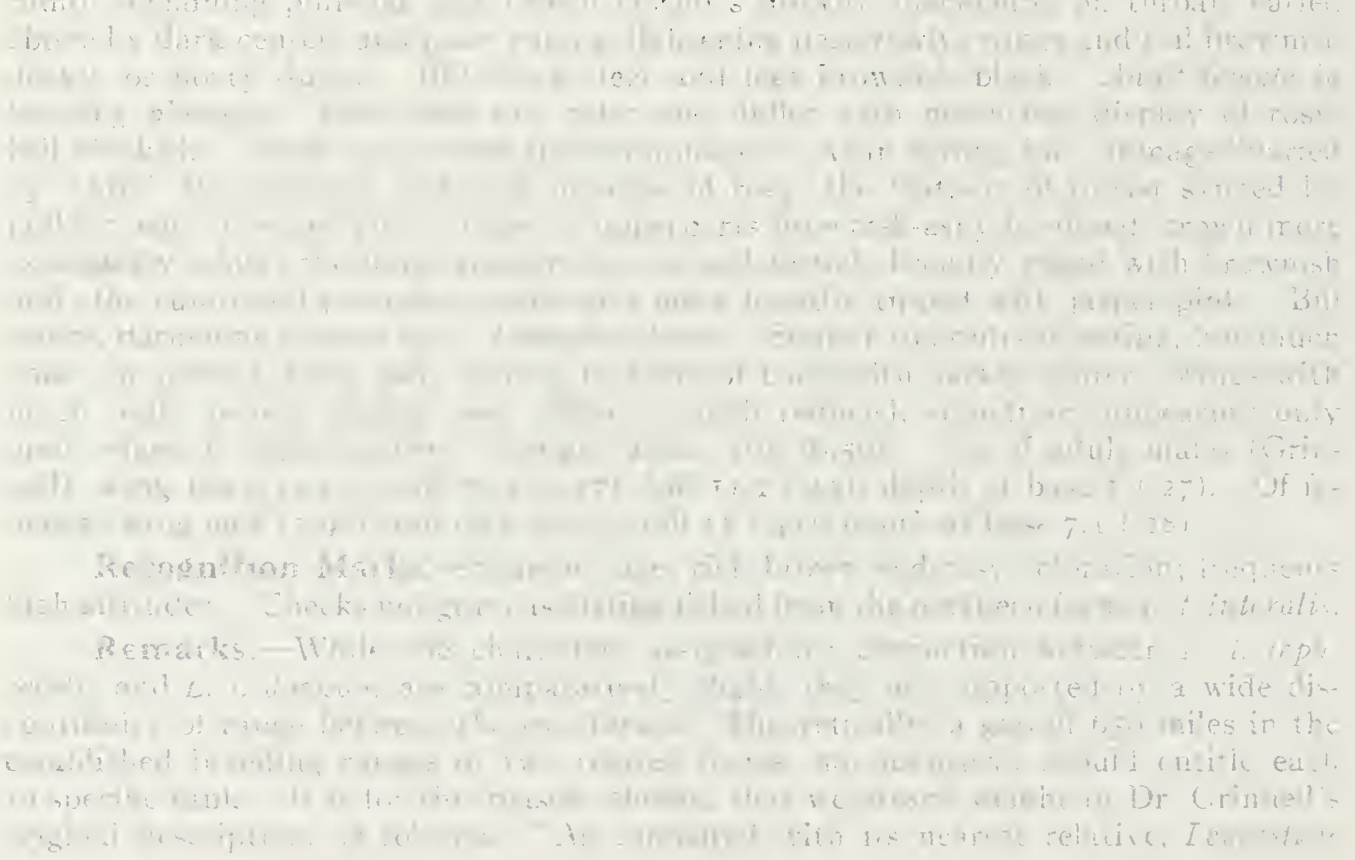




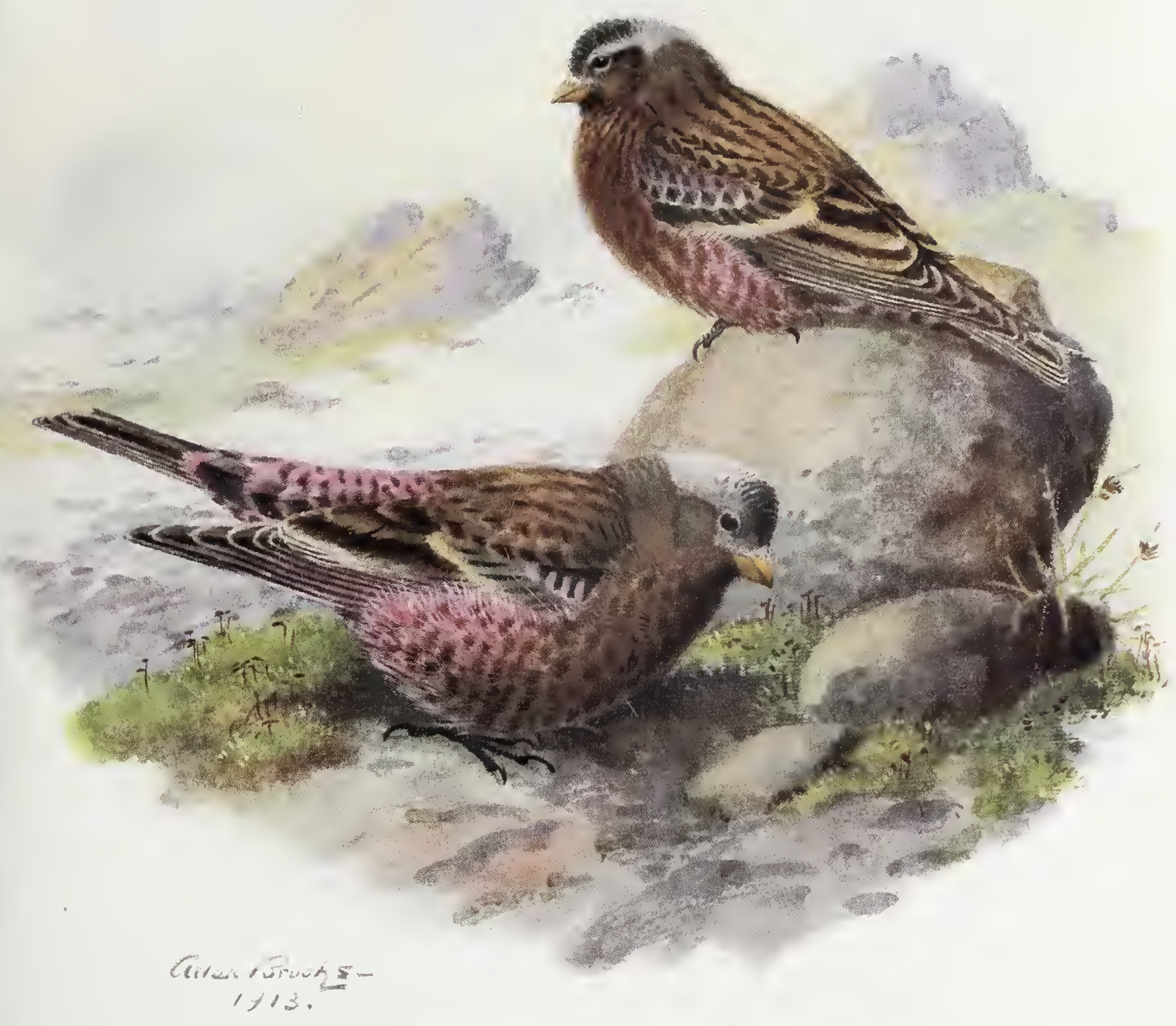





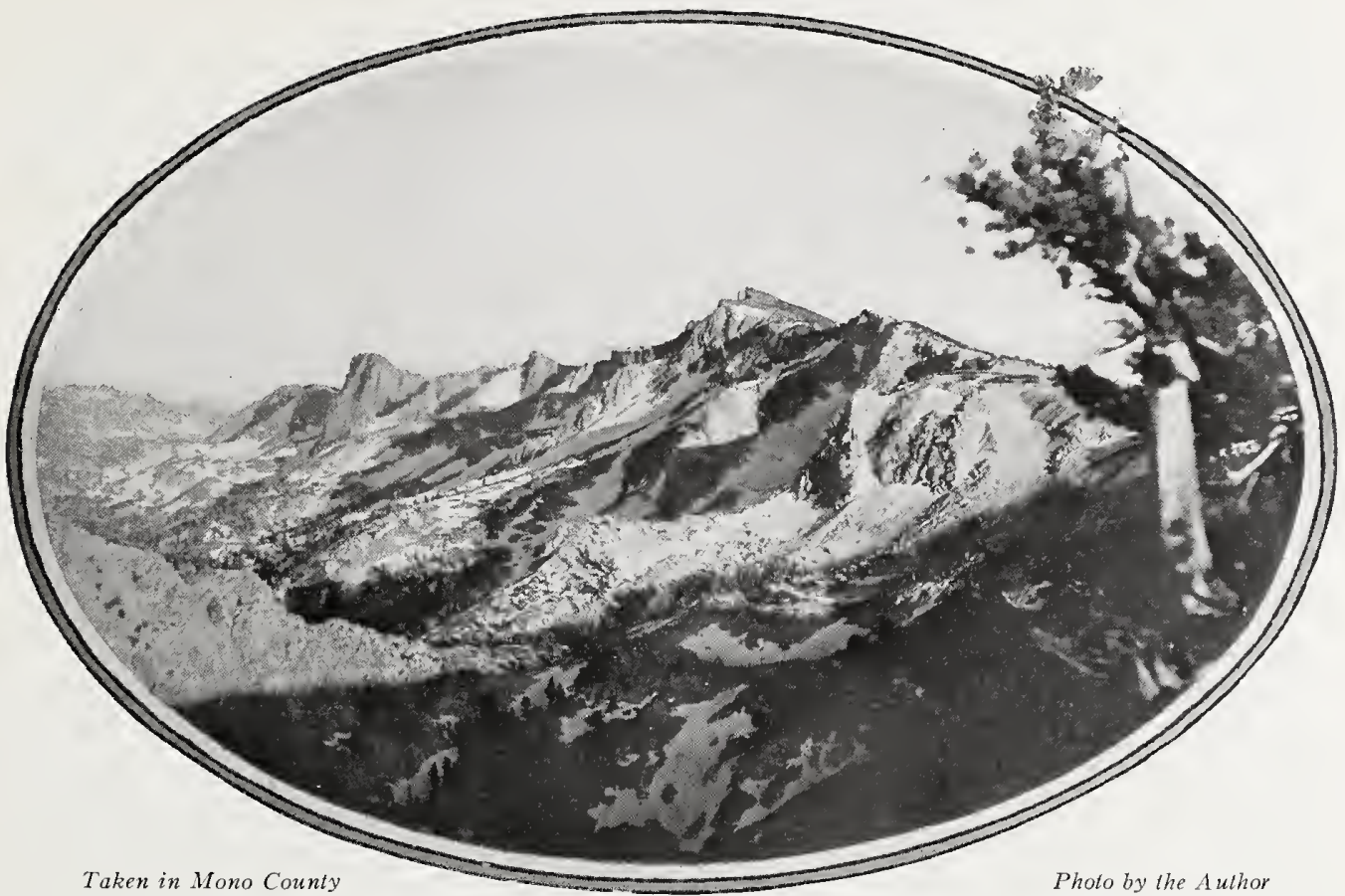

MAMMOTH CREST, A NESTING HAUNT OF THE DAWSON LEUCO

tephrocotis tephrocotis Swainson, of the northern Rocky Mountain region, in British America and western Alaska, general coloration in all plumages grayer toned, less intensely brown, size slightly less, the bill being distinctly less in bulk, and wing averaging more rounded; juvenal plumage much grayer, especially anteriorly, both above and below; breeding females less different, breeding males least different, but still perceptibly less vivid in the chestnut about the head."

Nesting.- - Nest: Placed in sheltered niche of mountain cliff or under boulder of rock-slide; a thick-walled, tidy structure, compacted of moss or dried grasses, or weathered vegetable fiber; lined indifferently with finer grass and occasional feathers;

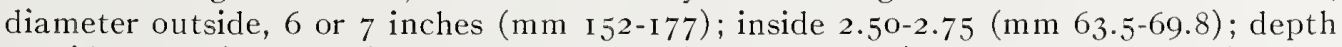
outside 3.00 (mm 76.2); inside 1.50-1.75 (mm 38.1-44.5). Eggs: 4 or 5, elongate ovate, pure white. Av. of 10 specimens: $22.5 \times 15.6(.88 \times .61)$. Season: June (cliff nesters), July (moraine nesters); one brood.

Range of Leucosticte tephrocotis. - Western North America, breeding in the higher mountains from the Alaska Peninsula south to the southern Sierras, and in winter deploying over plains east to Saskatchewan (casually to Minnesota) and south to Nevada and Colorado. Eastern limits of breeding range in the United States imperfectly made out.

Range of $L . t$. dawsoni.-At least the higher portions of the central and southern Sierras from Nevada County south to Olancha Peak; also sparingly about the higher peaks of the White Mountains; retires in winter to lower levels, chiefly easterly. Northward extension imperfectly made out. Examples seen by Vernon Bailey Aug. I7 (I 898) on Mt. Shasta (N. A. Fauna, no. I6, "Shasta Report," p. I24) are likely to have been transitional; not seen on Shasta in 1916. 


\section{The Dawson Leuco}

Authorities.-Cooper, J. G., Ornith. Calif., I870, p. I64, fig.; Fisher, A. K., N. Amer. Fauna, no. 7 , I893, pp. 82-83 (distr.; habits); Daggett, Bull. Cooper Orn. Club, vol. i., I899, p. I19; Dean, Condor, vol. vii., I905, p. I I2 (food); Ray, Condor, vol. xii., 19Io, pp. I47-16I, figs. 43-54 (discovery of nest and eggs): Grinnell, Condor, vol. xv., I9I3, pp. 76-78 (desc. of dawsoni); Dawson, Condor, vol. xvi., I9I4, p. 4I (nest).

IN ONE SENSE at least the American Leucostictes stand at the very apex of evolutionary progress. If life began, as the biologists assert, in the depths of the ocean, then it is the "Leuco" who has carried life's banner highest. Today he flaunts it from the mountain peaks, from Shasta and Whitney no less than from Blanca and Baker and Robson. If lofty association means anything for character, also, the Sierra Nevada Rosy Finch ought to be the very best of birds, for it is his privilege to spend a lifetime wrestling with the eternal snows. Be that as it may-and we, perhaps, are not able to set up the standards of bird ethics - there can be no doubt that this exalted breed of birds constitutes one of the most fascinating subjects for study which western bird-life offers. And because its ways of life have been so long remote from ordinary observation, the Leucosticte has been invested with something of the same sanctity which, in the thought of Nature's purest worshippers, clings about the vestal mountains. It seems a sort of sacrilege to bring them down, these vestal mountaineers, to ply them with questions of food and raiment and manner of life. The author knows something of these things, perhaps as much as any one, but instead of telling about them he would rather sing a pæan and draw the curtain of respect. It is one thing to know the Eleusinian mysteries, but quite another to proclaim them from the house-top. Your pardon, gentle Leucos!

A technical description of the Leucosticte's wardrobe may be found in any manual, and we pause here only to note that the rosy fringes and flushes which decorate its sober browns are a common adornment in the family Fringillida. There are, it may be, a hundred species of "rosy finches" at the very least, so that the attempted monopoly of the name "Rosy Finch" for our American Mountaineers is absurd and futile. No more fortunate is the name "Leucosticte," meaning "varied by white." The whitish edgings on this bird are few and obscure and in no wise distinctive. The name "Leucosticte" is a jaw-breaker, and the public will not stand for it. We are in a box. But since we are in it, let's make the best of it, and abbreviate our angel's name to Leuco. Never mind what it means; nobody pays any attention to Greek nowadays. It sounds distinctive, not to say expensive, and a wee bit endearing. Shall it be "Leuco," then?

158 


\section{The Dareson Leuco}

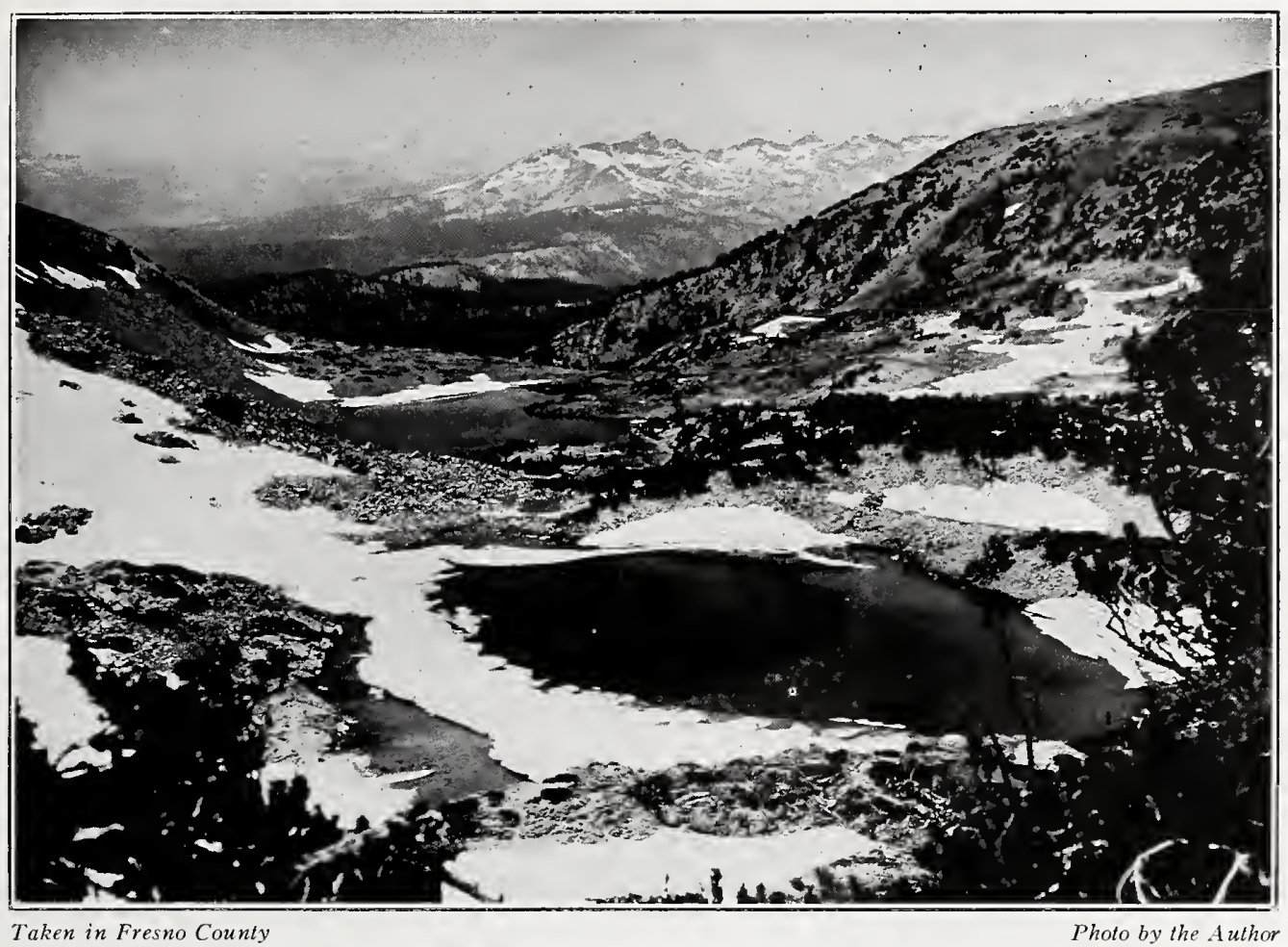

A TYPICAL FEEDING-GROUND: THE GRAND CIRQUE, LOOKING IVEST

What, now, does our divinity-eat? To all intents and purposes, snow. Watch a company of them deploy over a snowfield, hopping sedately from crest to crest of the tiny ridges, or else escalading in to the pits which the sun has made. They are pecking industriously at the surface as they go, and accumulating-well, not snow-flakes, nor yet snow-balls, but frozen insects, instead. It is marvelous what a varied diet is offered to these patient gleaners of the glaciers. The warm winds wafted up from the great interior valley bear moths and beetles, bugs and winged ants - they know not whither; and these, succumbing to the sudden cold of the Sierran heights, fall in a beneficent shower over the Leuco's table. Doubtless a few predatory insects, in a more active state, may be found. If it be asked what the predatory insects, in turn, feed upon, I point to the black "dust" which lies scattered over the surface of a June snowbank in such a uniform fashion that suspicion is aroused. These tiny black specks, a score or so to the square inch, are insects - of what order I cannot tell-insects not over a millimeter in length and perhaps a tenth of that in thickness. Thus I saw them in myriads about Mammoth Crest in 1919. What their little businesses 


\section{The Dawson Leuco}

might be, I could not conjecture; but they were quite active, and, as certainly, they were on their native heath. When one breathes upon these insects, they disappear, and they do so by diving into the depths of the snow-or, say, to a depth of three or four millimeters-down the interstices caused by the action of the sun. There's romance for you; and there are, speaking in all sobriety, about forty billion of these snow bugs to the square mile.

As the season advances and the area of the snowfields is reduced, the Leucos resort to the south slopes of the peaks, where yellow-winged locusts and deer-flies and the hardy butterflies, notably Vanessa californica, hold forth. These they pursue on the ground, or else seize in midair by dextrous leaps from below. They feed also at the lower levels over the heather beds and in the vicinity of the cirque lakes. Once I saw a company of these Leucos feasting on caddis-flies. So eager had they become that they alighted upon the stones which protruded above the water of a shallow lake, where they could seize the becoming caddis-flies as they crawled out of their chrysalis cases. Although this

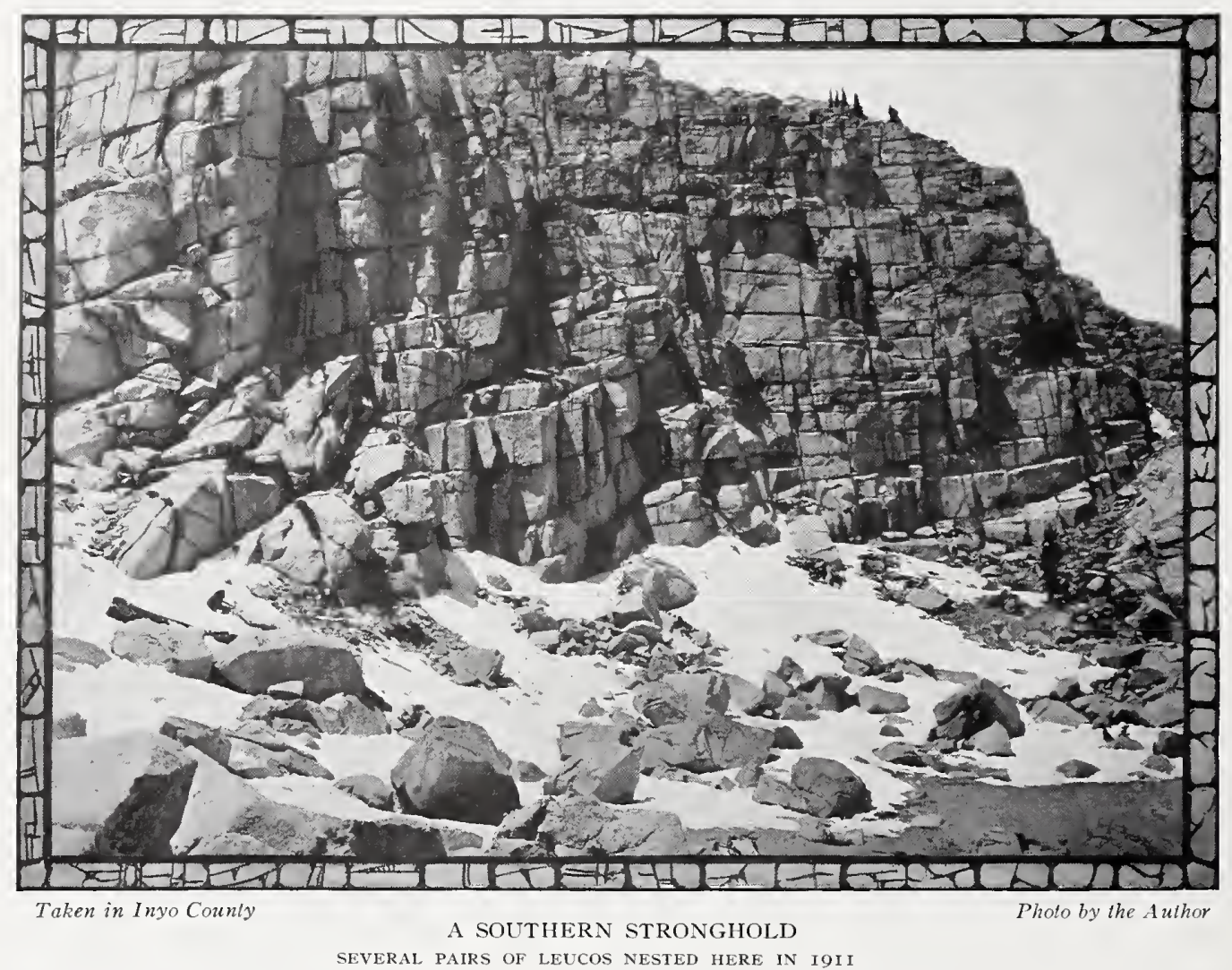

160 
was well below timber line, I never, save once, saw the Leucostictes alight in a tree, and I have an idea they feel very ill-at-ease in such a situation.

No bird, however, could be more thoroughly at home, or more matter-of-fact in its behavior, about precipices or in ice-bound couloirs. Whether in nest-hunting, mate-hunting, or in the ordinary quest for food, a Leucosticte will flit from crevice to point up the face of a twelve hundred foot escarpment as though it were a garden dike. The crannies are explored in leisurely fashion in quest of lurking bugs; and if it is mating time, the bird pauses to sing, or rather, chirp, from some eminence that would make an Alpensteiger dizzy. The "bergschrund," or chasm where the rock-wall and ice-wall part company, has no terrors for the Leuco. Once I saw a precocious infant (of $L$. $t$. hepburni) which had tumbled into one of these places some thirty feet in depth; but mama was feeding him, and he was as cheerful as a cricket, expecting, no doubt justly, to win out again after his wings were a little stronger.

Beyond the fact that the Sierran Leucos are mildly sociable at all seasons, and definitely gregarious in winter, little is known of their habits and economy, save as observed casually by campers and mountainclimbers and, more definitely, by questing oölogists. Whatever may be the popular or even Audubonian opinion of the last-named gentry, there can be no question in any honest mind that science owes much to the tireless research of the bird-egger. Granting that it is the lure of the trophy, or early possession of a something, however trifling, which the other fellow hasn't got, which impels the prodigious toils of the oölogist, it remains true that in four cases out of five it is the field oölogist who has brought back the first adequate accounts, not only of nesting, but of behavior and economy, of song and courtship, and of most that goes to make up the vital interest of a bird.

So far as the records show, it was Henry W. Carriger who, in June, I9Io, found the first occupied nest of the Leucosticte within the limits of the United States. Certainly he was the first to find a nest of the "Sierra Nevada Rosy Finch." This nest was taken on the 22nd of June by Milton S. Ray from under a boulder, one of myriads constituting the great weathered-out rock-field which covers the upper slopes of Pyramid Peak (alt. I0,020 ft.), in Eldorado County, and within I5o feet of the top of that mountain. This nest, $\mathrm{n} / 4$, now reposes in the cabinets of the Woodland Heights Museum of Analytical Oölogy. To Mr. Ray's vivid and enthusiastic description ${ }^{1}$ of the exploit there is little to be adder save the biographies of the participants.

The second set of eggs, $\mathrm{n} / \overline{5}$, now resting in the Thayer Museum, was

1 The Condor, Vol. XII., Sept., 1910, pp. 147-161. 


\section{The Dareson Leuco}

taken by H. H. Kimball, June 20, I9 I 5, at an elevation of 8900 feet. 1 I am under the impression, also, that Dr. P. B. Moody, of Sand Point, Idaho, has taken eggs of the Hepburn Leucosticte, a related subspecies, in Idaho; but if so, the accounts were obscurely published.

The lure of the Leuco has always possessed a peculiar fascination for the author since his first encounter with the bird ( $L$. t. hepburni), in I 896 on Wright's Peak, in Washington. In view of this special weakness, he craves pardon for indulging for once in a historical resumé of his own experience.

In July, I90o, a nest, which could have belonged to no other bird, was found in a peculiarly exposed situation, just below the summit of Wright's Peak (alt. about 9300). The Leuco search was the motif of a few days spent in the high Cascades in 1906, and again in 1907. On the latter occasion an old nest and a nest containing young were found.

In California in June and July, I9I I, a determined search was made along the mountains accessible from our camp at the Cottonwood Lakes; but although the birds were common at altitudes ranging from I I, ooo to I 4,00o feet, only one location was made during the season, and that one accessible only to the birds. The nest, whose existence was attested by visits of the male bird, was placed out of reach in a horizontal crevice, thirty feet over on a cliff which overlooks Army Pass, and which is sheer three hundred feet in height. By dint of going over the brink some fifty feet further west, I succeeded in worming my way, face down, along a ledge to the entrance of the crevice. It proved to be narrow, crooked, and altogether impossible-whereat I spat, reflectively, 270 feet, and wished I had never come.

On the 2 Ist of July, I9I3, while, in company with a dozen fellow members of the Sierra Club, engaged in scaling the North Palisade Peak (alt. I4,254), I came upon a nest containing five young about three days old. The nest was set well back in a cranny, which fronted a sheer drop of some two hundred feet, and it must have been within six hundred or seven hundred feet of the summit, say at an elevation of I3,600. This was, apparently, the second California record.

In June, I9I9, the field party maintained by the Museum of Comparative Öology made headquarters in the throat of Mammoth Pass in Mono County, at an elevation of 8500 feet. From this camp as a base we made several visits to the higher altitudes of the southerly-lying ranges, and spent eight nights in desultory camps made on rock ledges or rocky moraines. The following account, beginning on June I8, I9I9, summarizes our experiences and fortunes.

It looked terribly steep, that north-facing snow-cliff which led down

${ }^{1}$ John E. Thayer, in epist., Aug. 5, 1919. 
from the Mammoth Crest, but the westering sun, backed by a searching wind, urged a quick retreat to camp four miles away and 2500 feet below. The snowfield reached the very top of the ridge, choking the throat of a couloir and expanding below between massive cliffs several hundred feet high. The left-flanking cliff was dark in shadow, but the east-flanking wall was still bathed in sunlight. There might be Leucos down there; and a slide would save miles of walking. Accordingly, I let go, pike-point hard pressed against the rasping snow. The first hundred feet might have been a parachute drop. The course was narrow. Ominous ledges suddenly flashed up at the side. The startled snow, half ice, rather, flew up and engulfed my glasses. Steering had to be by instinct, and only frantic efforts kept the hurtling pilgrim right end up. But soon the pace slackened. Sun-kissed wells in the snow began to act as bumpers, and motion ceased presently, while the heart was still in a sort of panic. A Leuco spoke. Tearing off the blinded snow-glasses, I looked up-just in time to see a female Leucosticte disappear into the face of an obliquely fronting wall, and at a point a hundred feet or so up. Moments passed, and still she stayed. "A location," thought I, and backed off, slowly, across the snow, with eyes glued to the mysterious spot, until I felt the impact of the west wall, and, scarcely turning, clambered out upon a ledge. It was a cold ledge but not so cold as the penetrating snow. Sure enough, the bird has never stirred from that spot. But now comes a male sidling up to a neighboring point and giving a chirrup, whereat the hidden female darts out and joins her mate for a frolic. It is a probable location, albeit unconfirmed.

Two evenings later, fortified by the presence of my son, William Oberlin, a stripling of nineteen, I take up a station with him on the identical ledge which had witnessed the location. There is barely room on this rocky shelf for two persons to lie down; and if one rolls off, why it is only a hundred-foot slide over snow. We have brought up grub and blankets and a jag of wood. While William makes camp, although it is beastly cold, I man the binoculars and watch every bird that stirs over the snow or works across the face of the towering cliffs beyond. There are birds in plenty - for Leucos - say three or four in sight at once. Usually two or three are gleaning industriously over the face of the snowfield. The snow is in full shadow and the birds are most active at this time, partly because the glare of midday no longer blinds the eyes and makes snow work practically insufferable, even for birds, and partly, no doubt, because it is the last chance.

If there are nesting activities on, they are conducted sub rosa. There is no eagerness to display domestic secrets. These must be ferreted out. But there is lavish display of romantic interest. Males are chirping 


\section{The Dareson Leuco}

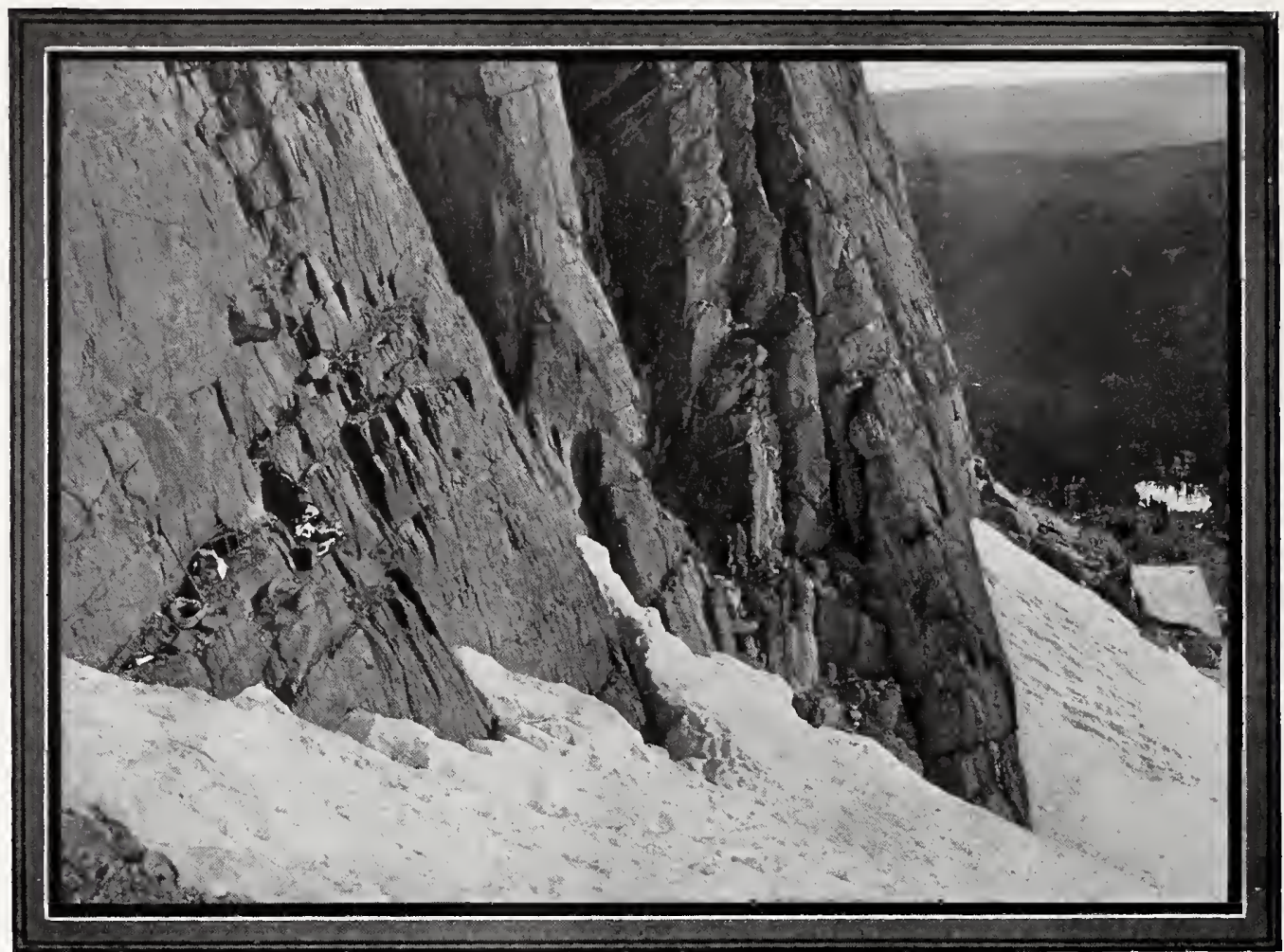

Taken in Mono County

Photo by the A uthor

" "THERE IS BARELY ROOM ON THIS ROCKY SHELF FOR TWO PERSONS TO L.IE DOWN"

loudly from vantage points; and as often as one of them discovers a female, presumably unengaged, he darts down into her neighborhood, then sidles over to her, hat in hand, so to speak, and pours forth a strident flood of amorous professions. The antics in which one of these hot-hearted bachelors engages are lush beyond description. If the lady will endure his presence at all, the male fairly perspires adoration. His wings quiver and his whole frame trembles. He turns about, slowly, in order that his enamorata may see how his every feather is engulfed; or if he pauses, he puts up a wing affectedly, as though to shield himself from the lady's overpowering glances. If the lady is cold-cold, but not impossible- in the very extremity of despair the smitten one procures a wisp of straw, seizing it by the middle, and bearing it about like a huge moustachio, the while his eloquent pleas are pouring forth. By this act, of course, he signifies that he speaks of conjugal affection. The lady must be won to a sense of responsibility. The days are long but the snows are melting. "Oh, will you? won't you? say, why don't you cast your lot with mine?"

These advances have various denouements. If the female is indeed 
smitten, as must in the nature of things sometimes happen, the couple adjourn to some cave among the rocks and carry out the purpose of love in secret. If the lady is only shy, she sidles off, or flits, and there is instant pursuit. The couple charge about like meteors amuck, and if they do not dash their brains out, it is a good sign that love is not blind. But if, as oftener happens, the lady is either previously engaged, or minded to try out the young swain's professions, she makes spiteful dabs at her admirer while he falls back in pretended and ecstatic alarm. Oftener still, the

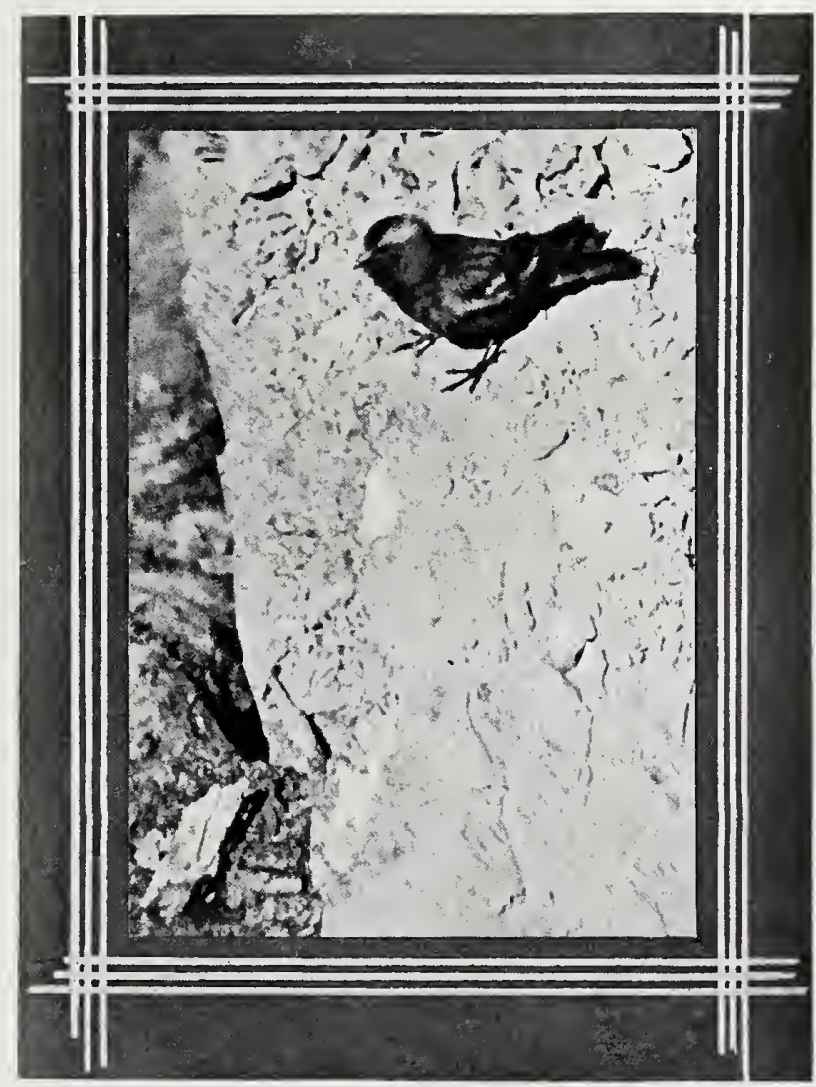

Taken in Mono County

A CIRCUMSPECT APPROACH

CLAMORING YOUNG ASSIST THE PHOTOGRAPHER'S CAUSE swain is addressing a lawfully wedded wife, for it seems to be his principle to try all doors till one of them yields. In that case, the lady tells him quickly to be off about his business, and is obeyed, or elsean avenging bolt falls out of the blue. The lawfully wedded husband, who nine times in ten is on the job, whether near or remote, falls upon that young rascal and either chases him clear out of bounds, or administers an actual drubbing. There seem to be more males than females, and it is proper form for the ladies to be always attended in public by their mates.

On this evening in question we followed the fortunes of a score of these advances and retreats, or sudden flights, but sorted out only two events of any significance: A male bird fed his mate (or young) once in a crevice only a dozen feet up on the opposite wall; and an unattended female, who fed quietly over the snow for half an hour, had such an authoritative way in "bouncing" her unwelcome admirers, that we kept our eyes focused upon her ultimate determinations. The significant moment came. When the shades of night were gathering thickly, she 


\section{The Dareson Leuco}

quietly withdrew from the field and lost herself, immediately, in a hole, one of a dozen lying at the back of a great shattered niche in the wall, from which tons of rock - a schistose granite-had recently fallen. This location, if location it was, was forty feet below location No. I, and fairly in a vertical line with it.

Fearing above all else a premature attack, we left these prospects to ripen, and visited instead the lower nest, where there was a suspicion of young. Sure enough, there were five youngsters about five days old, in a sturdy nest, which must have held its complement of eggs about June 2nd, the earliest recorded or inferential date for Leucos.

Days of tireless and all but unrewarded quest followed. Beetling cliffs began to lose something of their terrors, and if a bird disappeared midway on a six hundred foot precipice, instead of resigning in despair, as we had been inclined to do at first, we calculated soberly the chances of approach by wells or ledges, or dangling ropes. A female, traced to a hole eighty feet up on a sheer cliff, emerged presently with a white fœcal sac. No need to bother that nest, then. Another, 200 feet up and 200 feet over, seemed more feasible, and we determined to try it later. In the meantime we kept looking for confirmatory evidence regarding the early prospects. We learned that the feeding visits of a male to his mate on the nest were exceedingly infrequent. The females themselves, apparently, indulged two feeding periods, - one about eight or nine o'clock in the morning, and the other after sunset. In most instances, whether by male or female, the approach to the nest was made by leisurely stages. Significant actions were lost in the maze of casual appearances, or under a camouflage of indifference. At last, however, on the evening of the $23 \mathrm{rd}$, spying chillily from our snow-and-rock-bound ledge, we had the satisfaction of seeing the male bird visit the original location site, where he fed and departed. The next morning we caught the unattended female, she of the shattered niche, flying straight to her domicile, and disappearing. As luck would have it, we were standing at the time on the snowfield immediately below, and saw precisely which one of the twenty odd crevices she entered. It was time for action.

The writer elected, for reasons which need not be dwelt upon, to direct operations from below, while two of the party, my son, William Oberlin, and our field assistant, Robert Canterbury, equipped with ropes and pikes, made the lengthy detour and approached from above. The cliff was full five hundred feet high, but the upper portion was receding and graduated, by reason of the jointed character of the rock, into a sort of grim staircase. The "steps" themselves, however, sloped sharply, and it was no small task to get within forty feet of the nest from above. Here the boys set their pikes in a fissure and attached a I 50 -foot rope, which reached 
the bottom of the cliff, with ten feet to spare. Down this William presently descended. With a shout he greeted the appearance of the first nest, and with another shout reported that its four eggs were fresh. The nest, it seems, was set in a shallow cranny almost invisible from below, so that the eggs were only four or five inches in, and the skirts of the scanty pile reached the edge. The female had darted off when the rope was cast over, but she returned now and circled the clinging lad with anxious cries. The eggs were put hastily into a box, and the nest went into William's hat, after which he quickly descended a matter of twenty feet, where a tiny ledge afforded temporary respite. Here he managed to pack the eggs securely, to wrap the nest in tissue, and to lower them both to my waiting hands.

The next site, a little to one side, is much more difficult. A deep recess some twelve feet wide, eight feet high, and from three to six feet deep, has been formed by the recent defection of a great block of schist. The back of this cavity has been rent and shattered as by an explosion. Some of the ragged fragments are ready to tumble at a breath, and the overhang itself looks very unstable. I besought William to arrange his loops for entirely independent action; but he neglected to do so at first, with the result that when he did eventually cast them, as he was obliged. to do, they were not well placed, and one was non-functional.

It was fortunate that we had seen the exact spot at which the bird entered, and that I was able to indicate it from below. Peeping in, the boy saw the skirts of a nest set well back and quite unobtainable. The overhang was so great that William had great difficulty in keeping in touch with the situation. There wasnot sufficient projection from the cliff itself to support his weight entirely, so he struggled with the diverse purposes and functions of rope and knob. Finally, in desperation, he ascended the rope a little and pried frantically with his foot at the most obstructive rock. By alternately bearing down and toeing up he succeeded in dislodging it, and it fell, a hundred-weight crashing amid a cloud of rock-dust. When the air cleared, the boy beheld a handsome nest now scantily supported, but holding four eggs apparently fresh, "93/4-I9 Dawson's Leuco." Now to retrieve them! He first tried the use of the box. With a foot on the cliff, hugging in, and the other in the loop of the rope, and with the left arm about the rope and the hand clutching the box, he reached up with the right hand and abstracted an egg, when another supporting rock of twenty pounds weight or so let go, bringing the nest down with it. The boy frantically intercepted the nest while the rock placidly lighted on the back of his neck. He succeeded in shaking off the incubus and at the same time holding onto the nest amid the attendant smother of rock-dust. This was, it must be confessed, a rather complicated moment. There was 


\section{The Dareson Leuco}

evidently some attendant language, more or less smothered by rocks. Will says he expected to find an omelette in the nest; but he somehow managed to replace the egg which he had clutched in his right hand, and to remove the whole mass, eggs and all, to his hat. This he necessarily gripped in his teeth, and slid thirty feet, to safety, without more ado.

To his great delight, and mine, he found the eggs absolutely uninjured. Two perfect sets of Leucosticte eggs, worth, say, $\$ 400$, "exchange," retrieved on the descent of a single line! There was an exploit to be remembered with pride and gratitude!

Leaving the boys to recover from their exertions, I cleared, that same afternoon, for a distant prospect which I had named the Grand Cirque, and where an

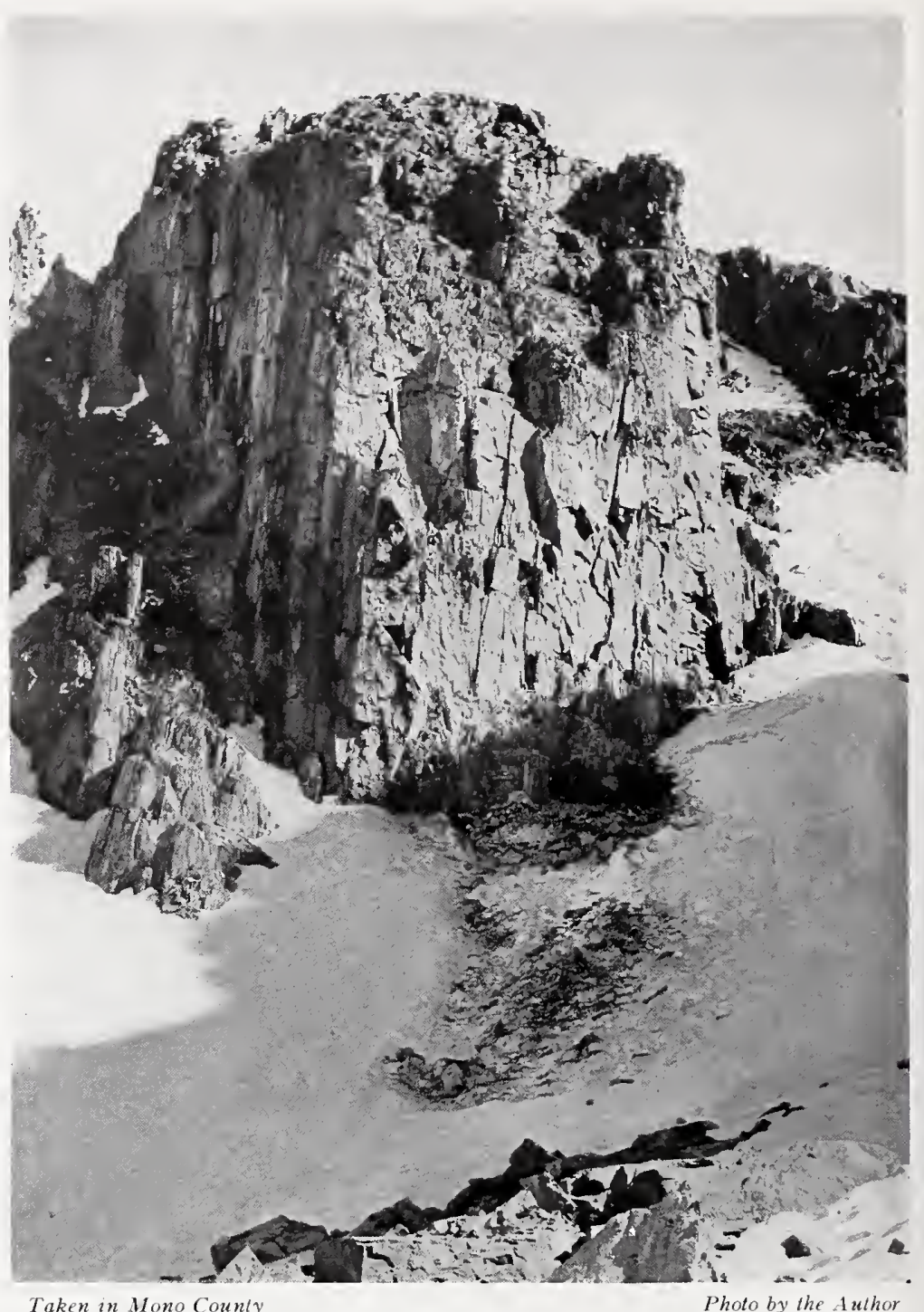

SUNRISE CLIFFS-MAMMOTH CREST

WHERE TWO SETS OF LEUCOS' EGGS WERE TAKEN WITH ONE CAST OF THE ROPE elaborate system of north-facing snowbanks protected by rugged peaks was nursing half a dozen cirque lakes, whose waters eventually found their way into the San Joaquin River. Arrived, toward evening, upon these happy hunting grounds, I first paused to make camp on the upper reaches of the central moraine. I don't mind rocks for bedding - am rather fond of them, in fact-but insist upon an approximate degree of horizontality. The bed I constructed there of schistose slabs, levelled and matched to a nicety, 
amid a chaos of boulders, fills my heart with reminiscent longing at this distant and comfortable moment. To live over again the early triumphs of cavemen is one of the sweetest privileges of the Sierras. Thus fortified by the certainty of slumber, I addressed myself for the remaining hours of daylight to the snowfields and the cliffs, and soon had the satisfaction of making a location. This was confirmed by a later, and enduring, visit of the female, at a point midway of the main cliffs, and on a wall 425 feet

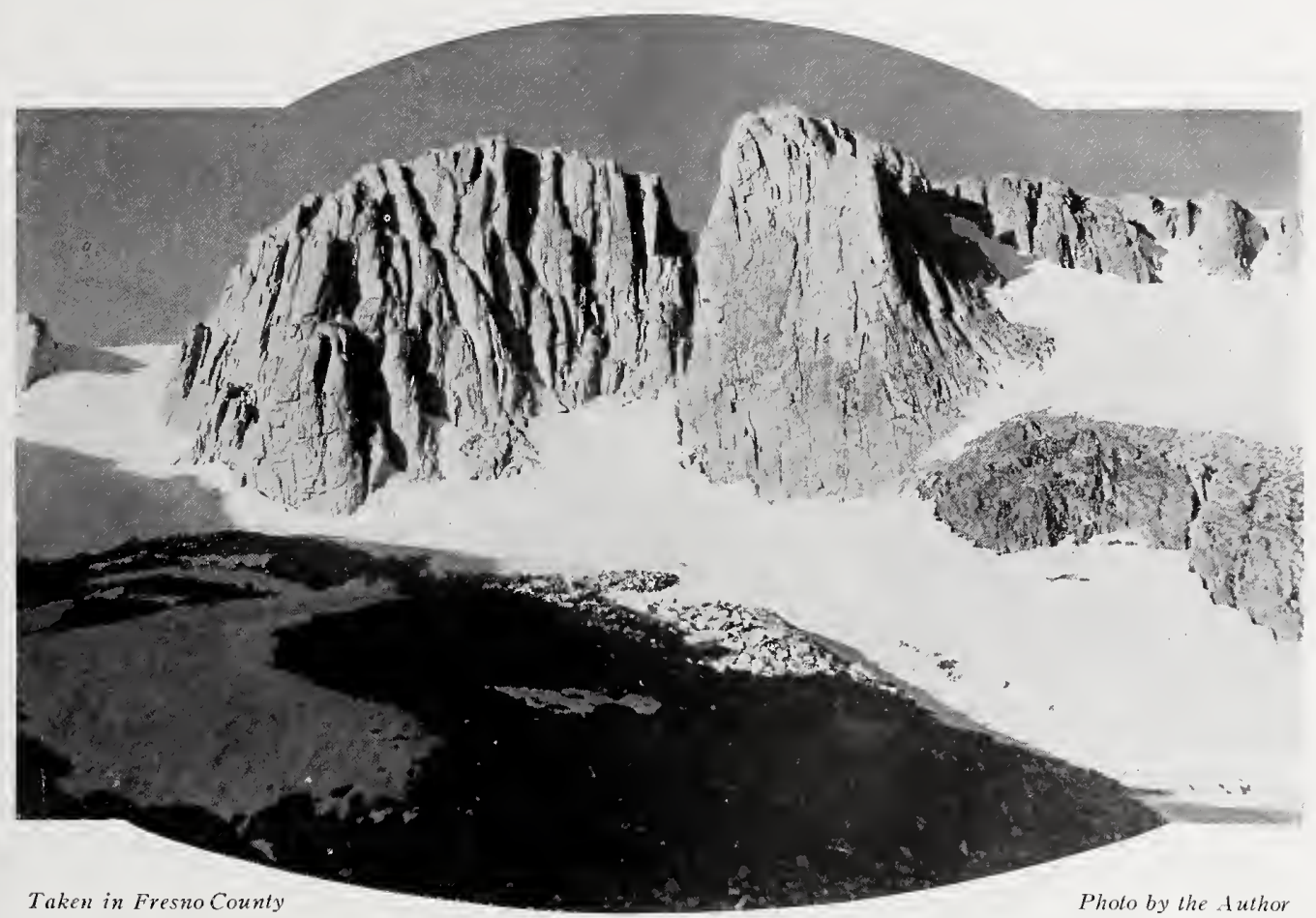

SUNRISE ON THE LEUCO CLIFFS

high. Forbidding as the prospect appeared, I saw how it might, conceivably, be reached through a succession of wells, or deep fissures, whose lowest ramifications extended to a tiny ledge which seemed to command the very niche on which the Leuco had lost herself. Repairing, accordingly, the next day to the peak (altitude I I,600) with Robert, who had joined me, we contemplated the descent. It was not alluring. It was, in fact, abominably steep, and a good bit farther than we had counted on. We stripped to the barest necessities, save rope and pikes (both a mistake, as the event proved), and prepared, with some little trepidation, to go down. The passage may be described briefly as a well, a near perpendicular ledge, and a well. The upper well was obstructed in two places by rock-masses 


\section{The Dareson Leuco}

lodged in its throat. It was easy to pass behind the uppermost of these obstructions, but the other forced us outside. There was nothing here but two blank walls. Bob felt confident, but I was dubious. Finally, I let him down with a rope to the first convenient landing, and saw him climb up again, to prove that it could be done. Still a little timorous, I had him let me down, by way of playing safe, till I got the feel of the thing (we had but one rope and had to take that down with us). The very walls here were treacherous, for their stability had never been tested save by the soft-falling snow. Block after block I flung down as we descended, so as to forestall the danger of attack from behind.

The upper reaches of the second well were occupied by a snowbank and a slithering mass of treacherous accumulation, gravel and wash, all too steep for occupation, but guarded on the outside by a ledge which we had difficulty in descending. When the ledge rose again to the proportions of a guardian wall, we were compelled to consider the well proper, a black hole at least a hundred feet deep with about a five to one grade, that is, the bottom, about one hundred feet farther down, was about twenty feet farther west. I first dropped a big boulder down, both because it was threatening to go itself and to test the depth. Out from under the

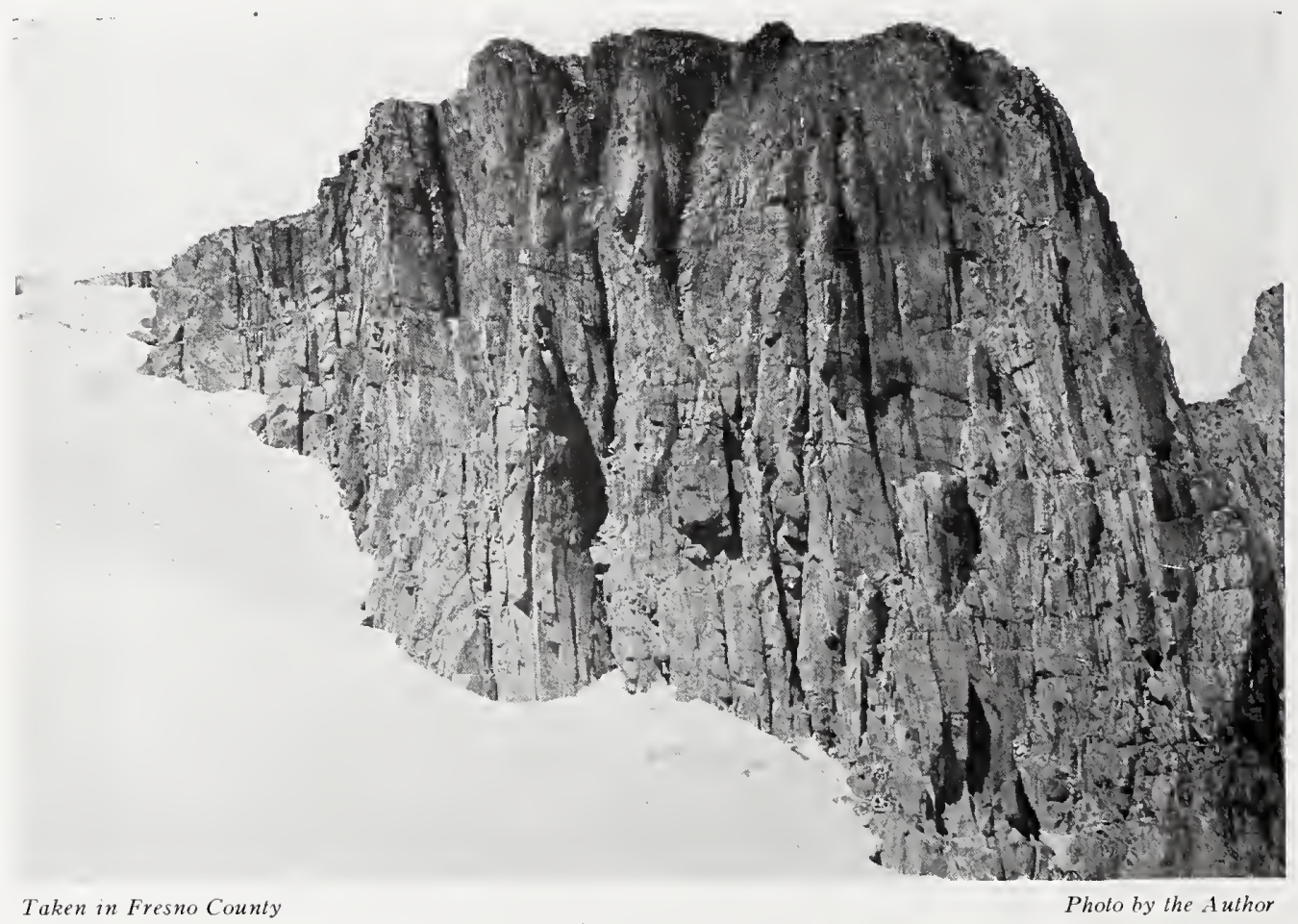

LEUCO CLIFFS-THE GRAND CIRQUE-THE GRAND MORAINE IN FOREGROUND 


\section{The Dareson Leuco}

all were savable, and the nest was an elegant and generous structure of compacted mosses, which in itself would have been worthy of preservation. The gloomy chamber in which the nest reposed was not over fourteen inches in total depth from the side wall, and the wonder is that the eggs were not scrambled.

Of the further descent and of the discovery that the nest on the outside wall contained young birds a day old, I need not speak. We found the rope was useless, because of the danger of flying rocks. We had to keep close together, so that whatever was dislodged might not acquire a dangerous momentum. We wormed our way up, therefore, as we had wormed down, viz., by bracing our backs against one wall and gluing palms and toes to the other. The round trip consumed exactly two and a half hours. Viewed dispassionately from the outside, the undertaking looks foolhardy enough. I am quite sure I would not go down the same wells to recover a fifty-dollar purse; but I am equally sure that either of us would go as far, or farther, for a set of Leuco's eggs. "94/4-I9 Sierra Leuco" now reposes in the cabinets of the Museum of Comparative Oölogy, and they are not for sale.

Well; this is not a monograph of the Leucosticte-nor a biography of the author. What follows must briefly summarize the experience of those glorious days. It is only by spending continuously the mon ths of June and July in Leuco country that one comes to realize how sharply the resident population of Leucos divides upon the question of nesting sites. The cliff-nesters find their favorite sites available in June, and they, accordingly, fall to early in the month. The moraine or rock-slide nesters expect their home sites to be buried in snow until late in June; and, subject to the variation of the seasons, nest complements may be expected in such situations at any time from the Ist to the 20 th of July. The noisy scenes of courtship, therefore, may extend from the middle of May to the middle of July; but the actual nesting is conducted so quietly, so decorously, that the inexperienced student is likely to be utterly deceived.

Theoretically, it ought to be very easy to trace a nesting female in such exposed situations as constitute the habitat of the Sierra Leuco. But, practically, one marvels when they do build. At least Leucosticte psychology has not yet been codified. Some females transport materials surreptitiously and spend days at it. Others build furiously while the fever is on, and are done. One bird, which I had traced at midday, had started her nest under a boulder on the side of the central moraine of the Grand Cirque, at a point not three feet distant from the retreating snowbank, and on a level with it. She secured her material, grass and roots, by the beakful on a young meadow some two hundred feet away; and in the half hour during which I had her under observation she averaged a trip a 


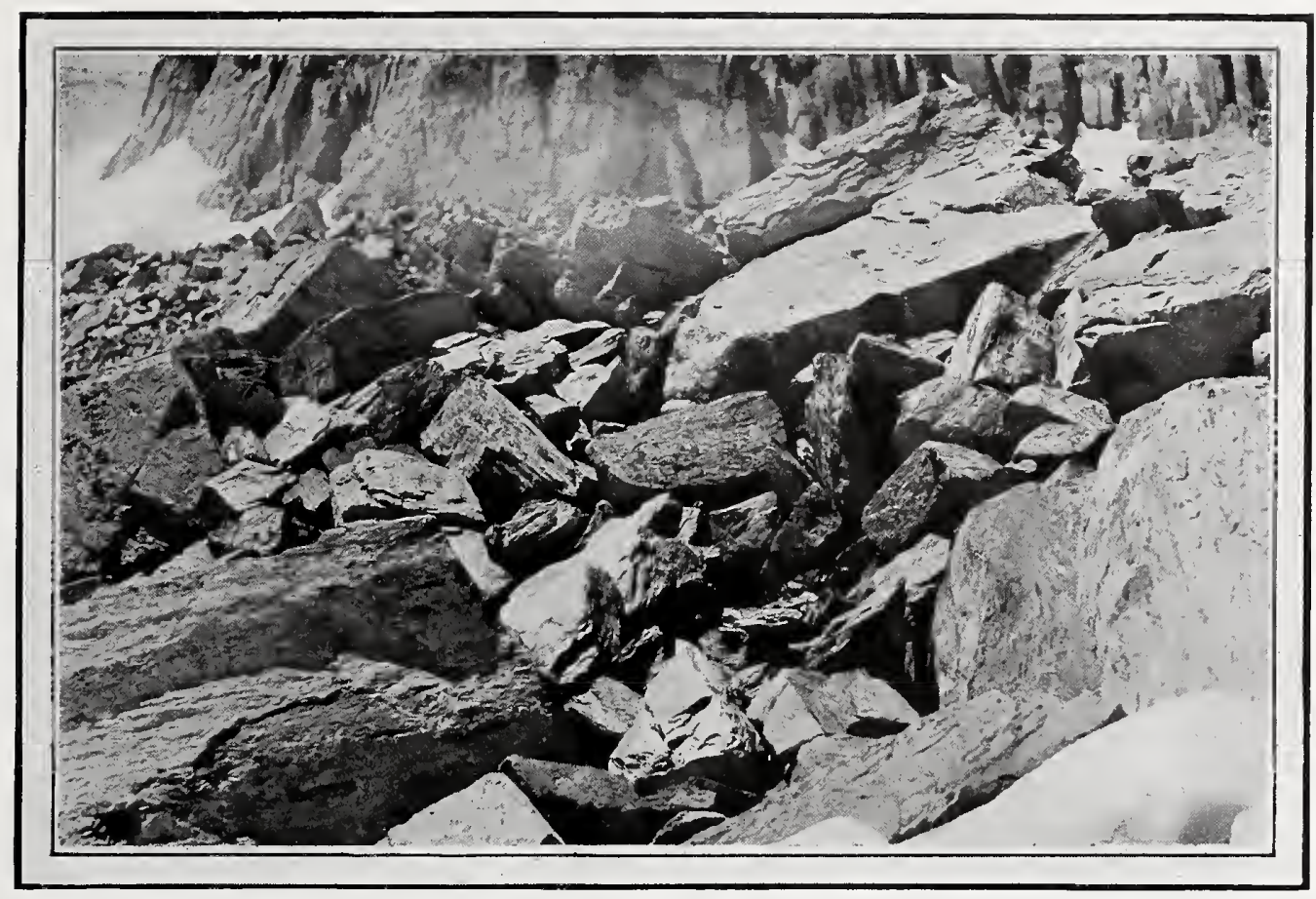

Taken in Mono County

minute. On the minute schedule she would spend about forty seconds gathering a load and fifteen or twenty seconds in arranging it; but I saw her speed up to twenty and five, respectively. The male, meanwhile, made himself useful by conducting periodical inspections, and offering advice (unheeded, no doubt), but chiefly by mounting guard and chasing off intruders. Needless to say, the birds did not resent my presence, for concealment is impossible under the pitiless glare of a Sierran noonday.

When we saw a Leucosticte seize a blob of cotton-batting which had blown off our ledge onto the snow, and bear it off in triumph toward a neighboring moraine, we thought that our oölogical fortunes were made. We dashed after her forthwith; but somewhere near the rocks an aërial scrimmage developed into a quite spirited affair, in which half a dozen Leucos and a snooping Clark Nutcracker figured. It was all over in a moment; but when the smoke of battle cleared away, we saw nothing of bird, cotton, or nest. A second theft was no more successfully traced, for the fugitive had no sooner disappeared around a sharp turn than she gave up all further interest in nest-building. A third, indeed, yielded a location; but this was a matter of sheer luck, for the bird used cotton only once, although tempting morsels were, by now, distributed all about the moraines. 


\section{The Darson Leuco}

While it is true that the nest-hunter's day is punctuated by such episodes as these, the reader should be reminded that hours of unrewarded vigil precede or follow these occasional flashes of revelation. The rigors of the evening hours, which are the best for observation, are most righteously offset by the ardors of midday, when, if one is obliged to be exposed, he feels more like a roasted marmot than a self-respecting scientist. More than once under the intolerable glare I have confessed myself "plumb leucoed," and have beaten for shelter.

The nests of the Leucos are always fully sheltered. They are set back in niches or placed under boulders, sometimes in chambers of generous proportions, and always beyond the reach of rain or snow. The birds show wisdom, too, in avoiding the established paths of falling rocks or melting snows. The Leucos themselves are fully alive to the danger of avalanches and there is an uneasy movement, or a sudden taking to wing, whenever a rock-fragment "lets go" in their neighborhood.

Some of the nests are drab-looking affairs, especially where weathered grasses are the only materials obtainable. Some, however, are wonderfully compacted of mosses, and are lined with feathers or other soft substances. An example in the M. C. O. collection

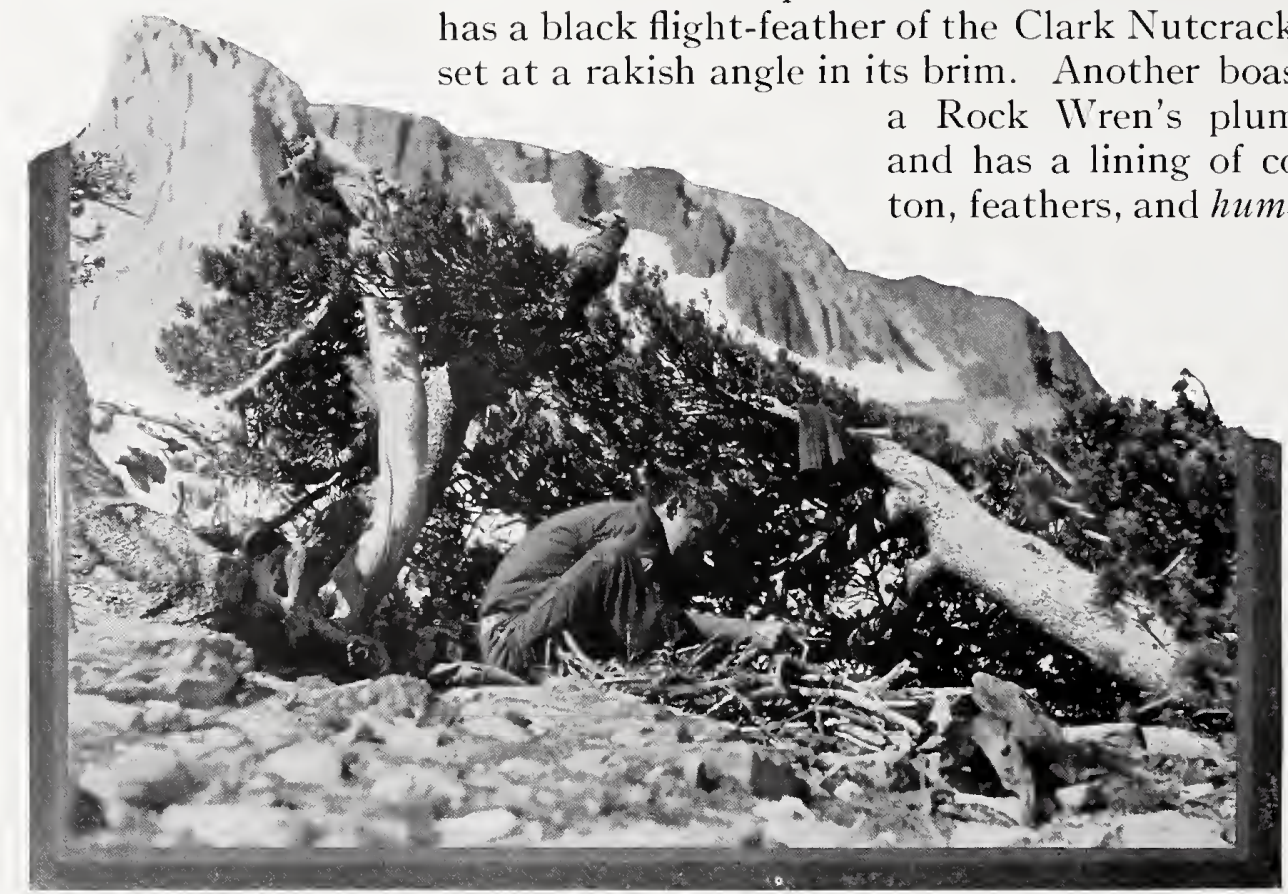

Taken in the Grand Cirque

THE OÖLOGIST IN CAMP

Photo by the A uthor

AT THESE ALTITIDES (I I,OOO FEET) THE CAMPER-OUT IS GLAD TO TAKE REFUGE BEHIND A SCREEN

of limber pine (Pinus flexilis) 


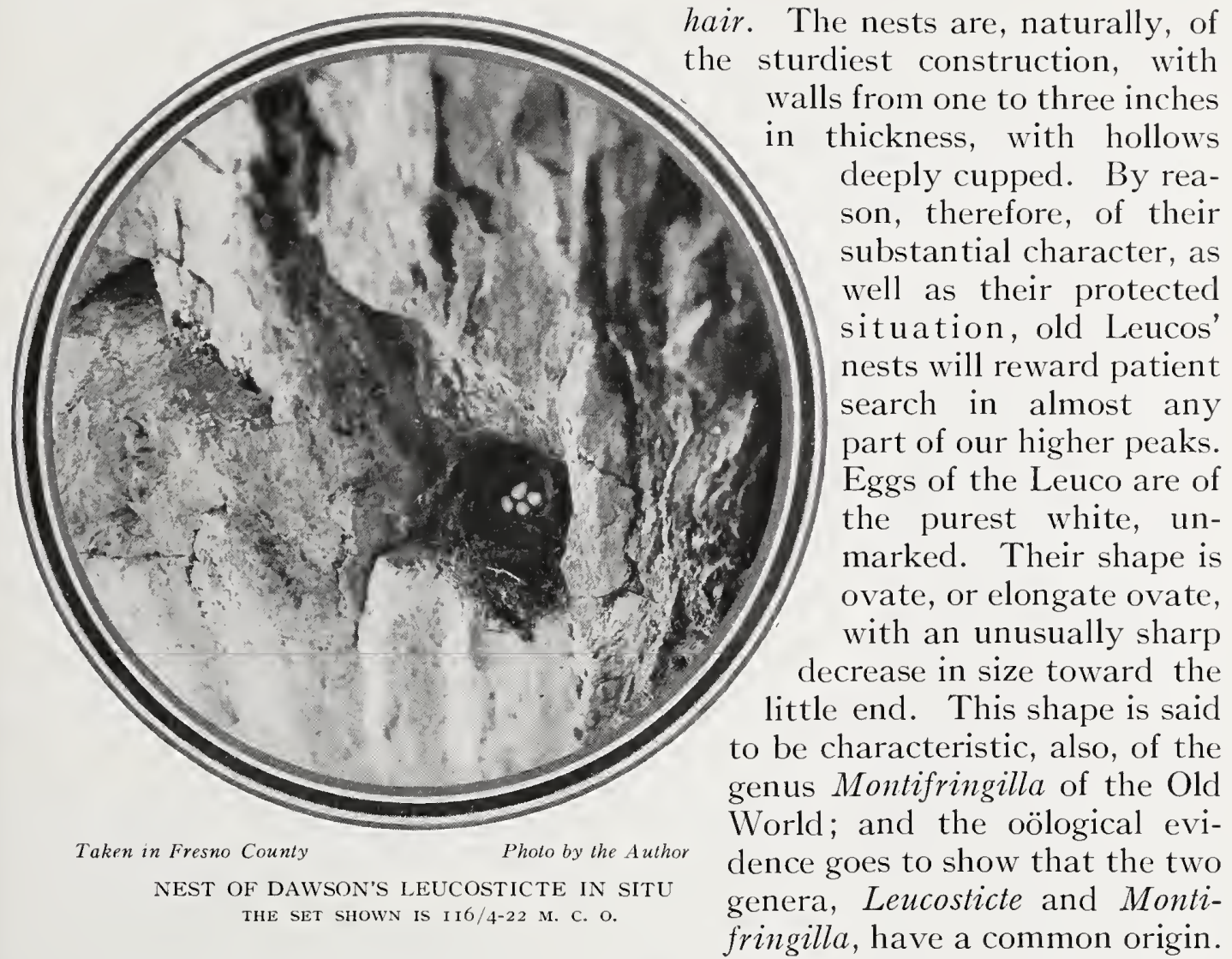

The pace of the Leuco day quickens when these white ovals part and naked babies, to the number of four or five, are born into this world of snow-glare and hunger. The parents, however, have capacious throats, or crops, and to obviate the handicap of a long haul, comparatively infrequent visits are made to the nest. I have seen parents making trips every five minutes, but ten- or fifteen-minute intervals are more usual, with half an hour, or such a matter, for older birds. Food material rarely protrudes from the parental beak, but the nature of the visit, whether parental or conjugal, may be surely determined by the presence or absence of the foecal sac, the laden diaper, without which no self-respecting parent will quit the presence of his (or her) offspring. We should hesitate to investigate this intimate matter, were it not for the cocky assurance and frank delight with which the fond parent bears off this lowly emblem. He seems to come like the bearer of good news and beams a cheerful "Family well," in response to our courteous inquiry. As a matter of fact, this arrangement for rigid sanitation is one of the most marvelous and commendable features about a well-appointed bird home. The infantile 


\section{The Dareson Leuco}

economy operates with the precision of clock-work. In goes a ration of insects, out comes the wastage of a previous feeding, all done up in sanitary white wrappings. The parent seizes the bundle and carries it two or three hundred feet away before dropping it. The nest and its vicinage are kept immaculate, and the bird's arch-enemy, the Clark Nutcracker, has no clew from careless ordure as to the presence of possible victims.

The little ones are silent for a day or so, but as their strength increases they greet the returning parent with an increasing uproar of satisfaction. The secret is out, now, for such as will hear, but it is not until the day of first flight that the outcry of the youngsters becomes incessant. Hearing that he was out, I pursued the firstborn of a certain brood with photographic intent. But the youngster was wary. He fluttered and chirped his way around the east wall, and then when I headed him off, he spread his little wings and flew clear across the amphitheater, a distance of near a hundred yards. He made a successful landing on a ledge, but afterwards he fell into the bergschrund, from which he was rescued, or coaxed, by his anxious mama. This youngster, once out, cheeped without intermission for at least eight hours. I timed him once, and he cheeped exactly ${ }_{0} 4$ times in a minute. That's 49,920 cheeps in a union day!

In complete contrast with this bantling's behavior was that of a baby sister (?) whom I found sitting quietly on a rock-slide. When I approached she said nothing, but started out bravely, and tumbled in the snow thirty feet away. Distinctly bored by this show of bad form, she presently tried again; and I'm blessed if she didn't rise on those little wings and make the west wall as valiantly as her noisy brother had done. Moreover, she sought a well and hid quietly, while the cheeper winged off for other fields-much to our relief.

The Leucosticte is not, as I had once supposed, songless. It would be fair to say, however, that he is tuneless. The "song" of the male consists only of a high-pitched ecstatic (for him) chirping, reeled off by the minute and without definite intermission. The notes vary so in "quantity," i. e., in length and inten-

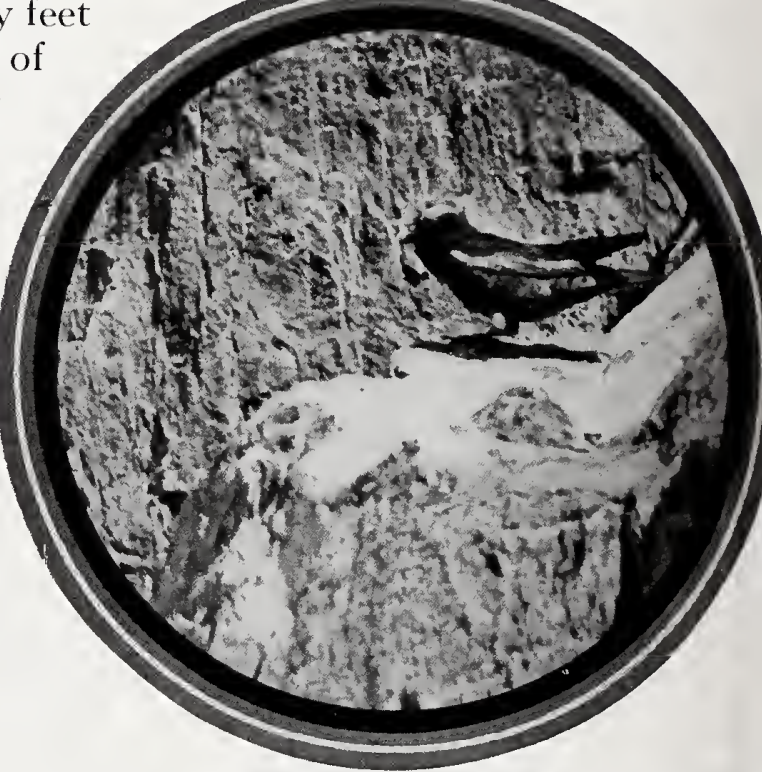

Taken in Mono County

Photo by the A uthor A FOOD-LADEN MALE ABOVE NESTING CREVICE 
sity, that an effect as of several participants is produced by each performer. Three artists at a time will produce a "din"; but the resulting effect of large numbers does not exaggerate the abundance of the birds. Most of them are silent. During the courting season the chirping choruses are kept up for an hour after the last rays of sunlight have faded from the highest peak. The din so created reminds one rather unpleasantly of a company of English Sparrows foregathering in an ancient ivy, and quite too hilarious for sleep. Again, before sunrise, there is an outburst of tuneless racket, followed very shortly by dead silence.

Akin to these strident chirps, but of very different function, are the questing notes: zee'o, zee'o; hootititeet. The first couplet, strictly speaking, constitutes the inquiry, while the hootititeet usually announces the intention to fly to another spot. The entire cycle, then, may run somewhat as follows: (alighting) zee'o, zee'o (ruffling of feathers); zee'o, $z e e^{\prime} o$ (shifting on perch); zee'o (feathers composed again--"She evidently isn't here"); hootititeet (momentary pause-flight to neighboring stand).

The Leuco also indulges much sotto voce "slushy stuff" in the near presence of his lady love. If you see a Leuco come in from a hundred yard flight, light on a stone and begin to gush softly, it's ten to one his lady is in hiding near by; and it's three to one he knows exactly where she is.

Then there are scolding notes of various degrees of intensity, emotional rather than functional expressions; and there is a mellow schthub of inquiry, mellow and low, not of ten heard during the nesting season. Also a lighter, casual note of greeting, inquiry, or appraisal, schthib, or schtlib, matter-of-fact and unemotional. Lastly, there are hovering or flight notes which are distinctly melodious and very difficult to syllabize. If the Leuco is not a singer, he is by no means destitute of expression.

These are impressions of nesting time. What the bird does with himself throughout the long Sierra winters we scarcely know. It is certain that he does not have as hard a time of it as some of his northern cousins. But for the sake of comparison I append a condensation of Mr. E. S. Cameron's account ${ }^{1}$ of the Gray-crowned Leucostictes (L. t. tephrocotis), which he encountered in winter in northern Montana.

Mr. Cameron found that these birds arrived each season about the $25^{\text {th }}$ of October, and departed about March 15 th. At Miles City during a February cold snap which registered 42 degrees below, the birds remained moping about in the cottonwoods and appeared paralyzed with cold and hunger. One which ventured into the house through an open door was captured and kindly treated, but was too far gone to recover. In milder times the Leucos are a prominent and charming feature of the prairie landscape. They feed not alone upon the ground, but also over the weeds

${ }^{1}$ The Auk, Vol. XXIV, Oct., I907, pp. 402 \& 403. 


\section{The Common Redpoll}

and grass-tops, obeying now the individual whim, or yielding to the flock impulse which sends them whirling away in erratic curves.

"Sometimes the flocks complete circles in the air, when they look like a variegated wheel of birds, or fly untiringly about the cedar thickets after the manner of Bohemian Waxwings. During snowy weather they allow an approach to within four or five yards when engrossed with grass seeds and withered dog daisies on the bare perches on the hillsides. If forced to rise they sweep around in a dense cluster and immediately return to the same spot,- their wings making a loud rustling noise. Rosy Finches are very numerous at my ranch in Dawson County; I have seen about a thousand at one time, by the water trough, distributed in the pines, and on the ground. A long stream of birds may keep flying into a draw for about a minute, and be all lost to sight in the long grass upon alighting, but the same flock perched in a small dead cedar (completely covering it) is a remarkable and charming sight."

No. 27

\section{Common Redpoll}

A. O. U. No. 528 . Acanthis linaria linaria (Linnæus).

Synonyms.-Redpoll. Lesser Redpoll. Linnet. Lintie.

Description.-Adult male: Crown carmine; throat and breast broadly rosy (eugenia red) in varying proportions according to season; frontlet, lores, and throatpatch sooty black; remaining lower parts white, flanks and crissum streaked with dusky; above variegated dusky, flaxen-brown, and whitish, the feathers having dusky centers and flaxen edgings; rump dusky and white in streaks, tinged with rosy; wings and tail dusky with flaxen or whitish edgings; two inconspicuous wing-bars formed by white tips of middle and greater coverts. Female: Similar, but without red on rump and breast, the latter suffused with buffy instead; sides heavily streaked with dusky. Immature: Like female, but without crimson crown. Length $\mathbf{I} 39.7$ (5.50) or less; wing 75 (2.95); tail 55 (2.16); bill $9(.35)$; depth at base $6(.23)$; tarsus I5 (.59.) Females average less.

Recognition Marks.- Warbler to sparrow size; crimson crown-patch in adults; no dusky spot on breast.

Nesting.-Does not breed in California. Nest: A bulky affair of twigs and grasses, heavily lined with feathers, and placed in tree or bush. Eggs: 4 to 6; pale bluish green, dotted and speckled with reddish brown or umber. Av. size I6.5 × I 2.7 $(.65 \times .50)$.

Range of Acanthis linaria.-Northern part of Northern Hemisphere, south in winter to middle temperate latitudes (A. O. U.).

Range of $A . l$. linaria.-As above, except Greenland and extreme northerly sections of North America, where replaced by rostrata and holboelli, respectively. 
Occurrence in California.-Known only from report of J. M. Willard of forty specimens taken between Nor. 30 and Dec. 2.3, i 899, near Eagle Lake in Lassen County.

Authorities.-Willard, Condor, vol. iv., I902, pp. 45-46 (only Calif. record): Grinnell, Pac. Coast Avifauna, no. II, I915, p. Io9.

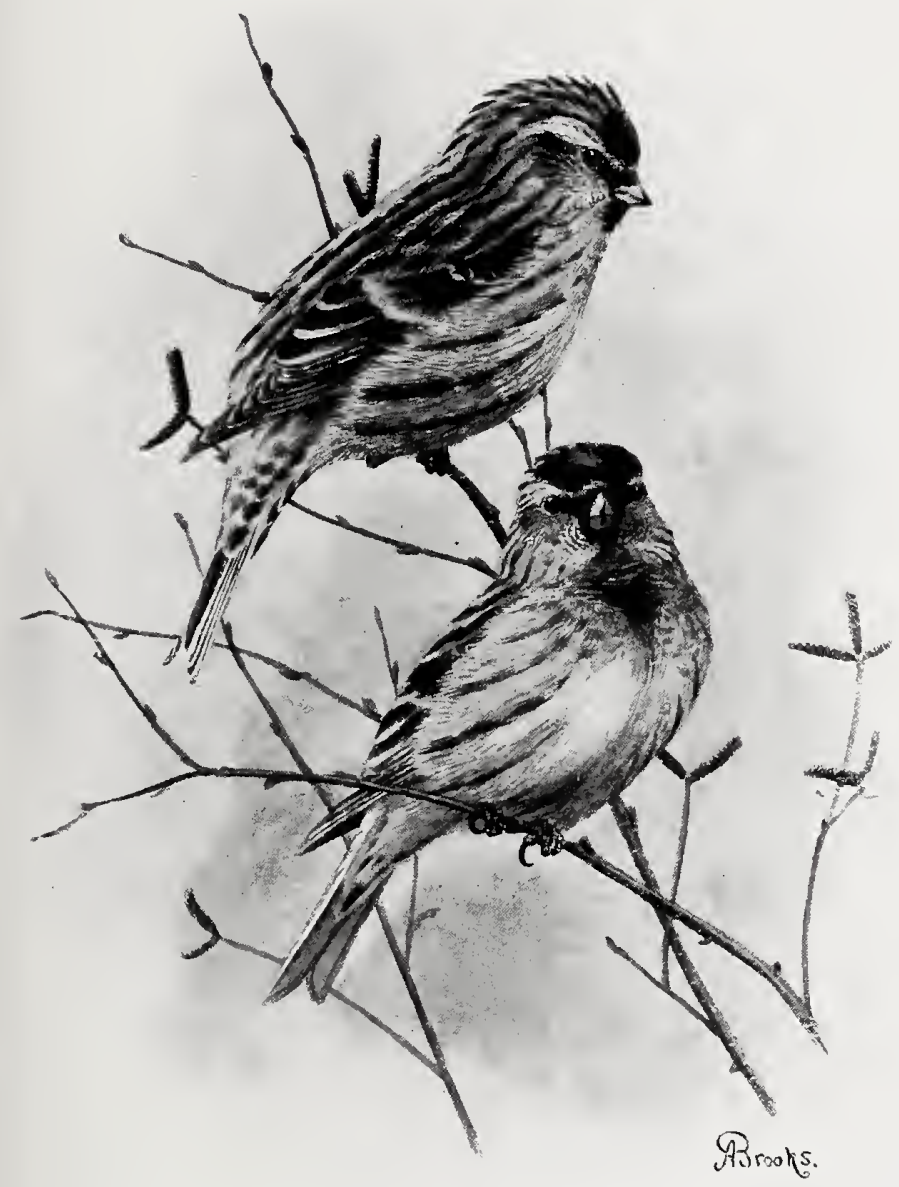

REDPOLLS IN WINTER

THE PLATEAU region of northeastern California is especially favored in the matter of northern visitors; and it is reasonable to suppose that flocks of these sturdy little Eskimos, such as sweep down annually through eastern Washington and Oregon, not infrequently reach our own borders. There is, however, only one recorded 1 instance, that by Mr. J. M. Willard, of Redpolls encountered from Nov. 30 to Dec. 23 , I 899, near Eagle Lake, in Lassen County. This observer says: "At first I found only two large flocks, but later numerous smaller ones greatly increased their number. I ran into the first of these flocks, well in a forest, a mile or so from a valley. The birds were circling about over the tree-tops, twittering noisily, much after the manner of Spinus pinus

[the Siskin], and now and then they would settle in to the upper branches of some pine, to be off again almost before the stragglers had reached it. Later the flock settled on the birches and bushes along a small stream, alighting all around me. * * * Late the same afternoon I found another flock out in the sage-brush three-quarters of a mile from 


\section{The Common Redpoll}

the edge of the forest." Specimens secured showed that these birds fed habitually upon birch buds, or upon the tenderer portions of the Artemisia.

The comparison with Spinus pinus is quite apropos; but the student is likely also to compare the Redpoll with the more familiar Willow Goldfinch. The resemblance between these two species is a striking one, both in form and appearance, as well as in habit and note. Once, however, the eyes have been assured by a near revelation of convincing red that Acanthis linaria linaria and not Astragalinus tristis salicamans is before them, the ears remark also a slight foreign accent in the sweetie call, and in the rattling flight notes.

As in so many similar cases, we are not permitted to know just what the determining causes of a southern movement are. It is known that the Redpoll can withstand the fiercest cold, even that of northern Alaska. Possibly the migration is dictated by diminishing food supply. Or perhaps it is "just for instance." That will cloak our ignorance as well as anything. And who are we that we should deny the birds the right to be whimsical or erratic, or to answer, "Oh, just because," to our impertinent questions? We got our own wanderlust from the birds, anyway.

While in the South, the Redpoll is little dependent upon the forests and not at all upon the offerings of evergreen trees. It seeks, rather, the open wind-swept plains, or the scanty shelter of willow-bordered streams. It subsists partly upon seeds as well as upon buds, or "browse." A large flock may feed for half an hour at a time in industrious silence; or else it may break out with a babel of pleasant chatter, very heartening to the listening ear. Redpoll again proves kinship with Goldfinch by eating thistle-seeds; and with Siskin by his extravagant fondness for the alder catkin. Like a Chickadee, too, he rather prefers to cling to a branch back downward, so that he can feed with head uphill. When you think of it, now, it must be easier to let food trickle downhill than to lift the head every time, or to gulp against gravity. These little rascals have their reasons.

Redpoll's manner is very confiding; and we are sure that he would not begrudge us a share of his winter viands, if we cared for them. The author is no hide-bound vegetarian, but he is gratified to record that a "simple diet of grains, fruits and nuts" makes for contentment among the birds, even at forty below zero.

As spring comes on, and the gentle hyperboreans prepare to return to their native heather, one may see the deep-dyed crimson of full regalia on crown and breast. But during the actual breeding season, we are told by a competent observer in Greenland, Holboell, that the male not only becomes exceedingly shy but loses his rosy coloring. It is hardly to be 
supposed that this loss of color is a protective measure, but rather that it is the result of the exhaustive labors incident to the season. Nature. in that forbidding clime, cannot afford to dress a busy workman in fine clothes. It is noteworthy in this connection, also, that caged Redpolls lose their rosy tints never to regain them.

\section{No. 28}

\section{Pine Siskin}

A. O. U. No. 533. Spinus pinus (Wilson).

Synonyms.-American Siskin. Pine Finch. Pine Linnet.

Description.-Adult male and female: Above brownish buffy; below creamy buff and whitish, everywhere streaked with dusky or dark olive-brown; the streakings are finer on head and foreparts, coarser on back and breast; wings fuscous, the flightfeathers light greenish yellow, or sulphur-yellow, at base, and the primaries edged with the same color; the greater coverts broadly and the middle coverts lightly tipped with buffy white; tail fuscous, all but the middle feathers sulphur-yellow at base. Bill comparatively slender, acute. Young birds closely resemble parents, but are more or less suffused with yellow throughout. Length I 20.6-I27 (4.75-5.00); wing 69.9 (2.75); tail 45.7 (I.80); bill 10.9 (.43).

Recognition Marks.-Warbler size; conspicuous general streakiness; sulphuryellow markings of wings and tail, most noticeable in flight.

Nesting. - Nest: Saddled upon horizontal limb, typically of evergreen tree, well concealed from below, usually at moderate heights; very variable in structure, flimsy to massive and ornate; composed of small twigs, weed-stems, fibers, and treemoss, with a lining of fine rootlets and horse- or cow-hair, rarely feathers. An average nest measures externally $4 \frac{1}{2}$ inches wide by $21 / 4$ deep; internally 2 inches wide by I deep. Eggs: I to 5; usually 3 or 4; pale bluish green, lightly dotted and spotted, rarely scrawled, with dull rufous and blackish, chiefly about larger end. Av. size I 7 X I $2.2(.67 \times \cdot 48)$. Season: March to September, largely governed by altitude; one brood.

General Range.- North America at large, breeding in higher latitudes, and in coniferous forests of the West, to southern boundary of United States; also sparingly in northeastern United States, and in the mountains of North Carolina; irregularly south in winter to Gulf of Mexico.

Distribution in California.--In summer nearly coextensive with that of evergreen timber; especially common in the higher mountains just below the limit of trees and through the humid coastal portion of the State; also resident in the coastal region south to San Francisco Bay. In winter occurs sporadically at lower levels, and is attracted by evergreen culture, al though not altogether dependent upon it. Casual (?) upon Santa Cruz Island (April, I9I5).

Authorities.-Heermann (Linaria pinus), Jour. Acad. Nat. Sci. Phila., ser. 2, vol. ii., I 853, p. 266; Cooper, Ornith. Calif., I870, pp. I72-I 73; Barlow and Price, Condor, vol. iii., I90I, p. I7I; Carriger and Pemberton, Condor, vol. ix., I907, pp. I 8-19, 2 figs. (nesting habits); Willett, Pac. Coast Avifauna, no. 7, I9I2, pp. 75-76 (status in s. Calif.). 


\section{The Pine Siskin}

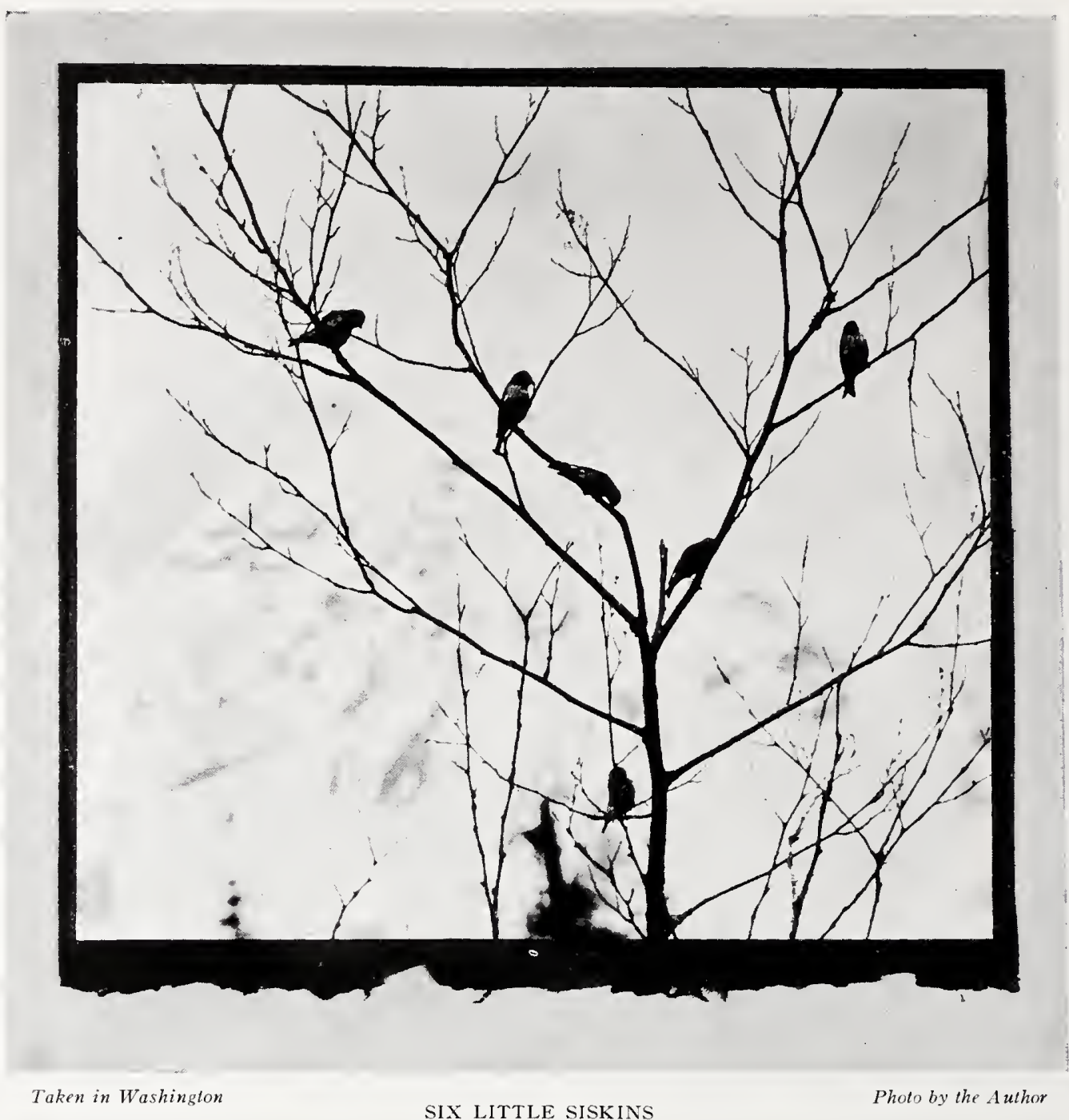

IT IS rather a sad commentary upon our childish predilection for color, that the Goldfinches of California should be so well known, while the more plainly colored Pine Siskin, who is in every way the ranking major of the Siskin-Goldfinch group, should be known only to the ornithologically elect. To be sure, Nature must have intended it so. The plumage of Spinus pinus is a triumph of obscurity. The heavy, streaky pattern, worked out in dusky olive on a buffy brown base, prepares the bird for self-effacement in any environment; while the sulphur-colored water-mark of the outspread wings barely redeems its owner from sheer oblivion. This remark applies, however, only to plumage. In behavior the Siskin is anything but a forgettable bird-person. 


\section{The Pine Siskin}

Whatever be the time of year, Siskins roam about in happy, rollicking bands, comprising from a score to several hundred individuals. They move with energy in the communal flight, while their incessant change of relative positions in flock suggests those intramolecular vibrations of matter, which the "new physicists" are telling us about. When a bird

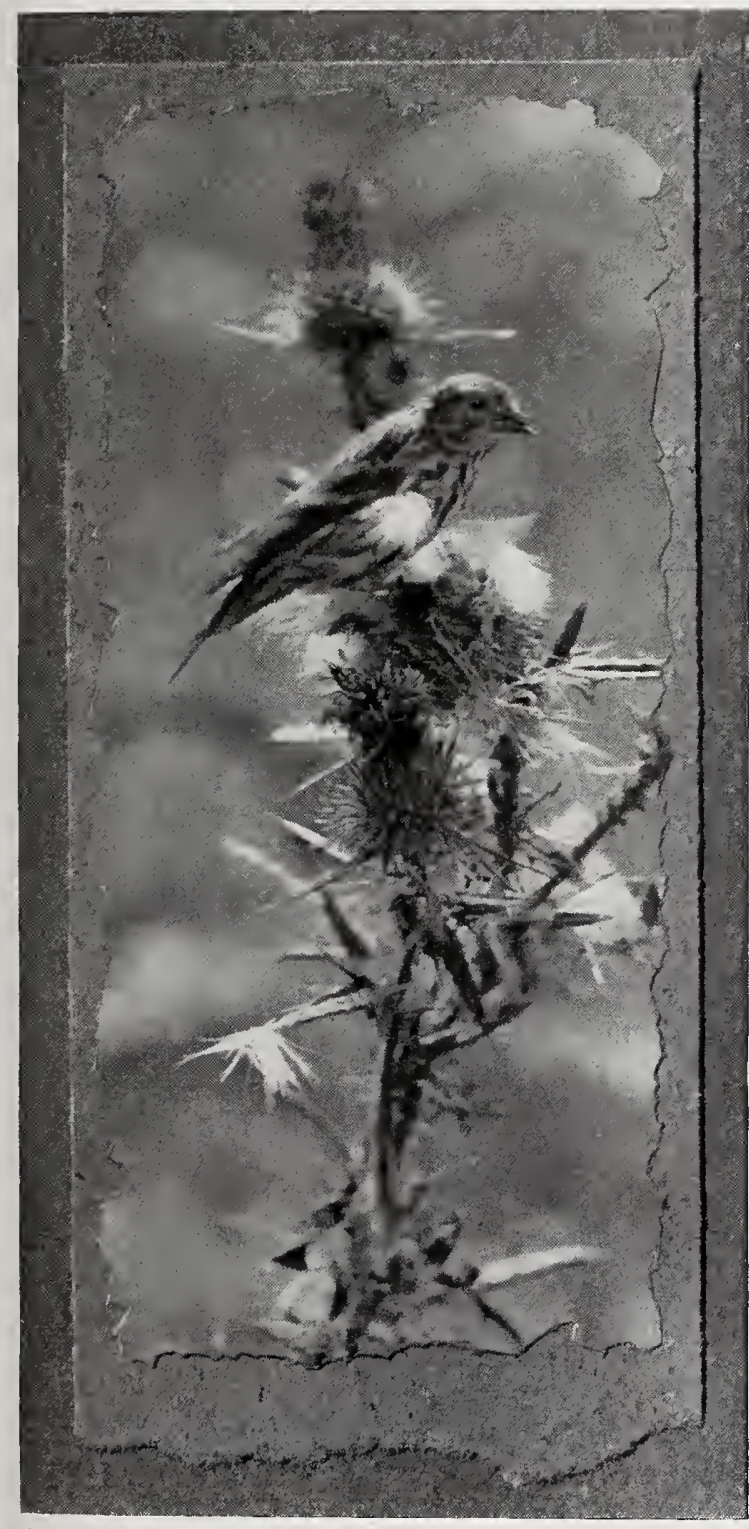

Taken in Washington

Photo by the A uthor

A THRIFTY THISTLE SISKIN

(TRY SAYING IT OUT LOUD) is sighted alone, one sees that it is the graceful, undulatory, or "looping," flight of cousin Goldfinch which the social Siskin indulges so recklessly.

Many of the notes, too, remind us of the Goldfinches. There are first those little chattering notes indulged a-wing and a-perch, when the birds are not too busy feeding. The koodayi of inquiry or greeting is the same. But there is another note quite distinctive. It is a labored, but singularly penetrating production with a peculiar vowel sound (like a German umlauted u), züm or zzeem. So much effort does the utterance of this note cost the bird, that it always occasions a display of the hidden sulphur markings of wing and tail.

Too much emphasis cannot be laid upon the value of this note as a recognition mark. A review of the pages of California literature discloses a tendency on the part of those who have observed the bird in winter in southern California, to cackle as though they had discovered an exceptional occurrence, while, as matter of fact, the peculiar züm of the Pine Siskin is one of the most familiar of notes to those who know it. It is rather the best thing about the Pine Siskin, this greeting tossed down from the upper air, as he passes on we know not what heavenly errand. Züm-it is earnest enough; it is melancholy even; yet somehow it stirs the 


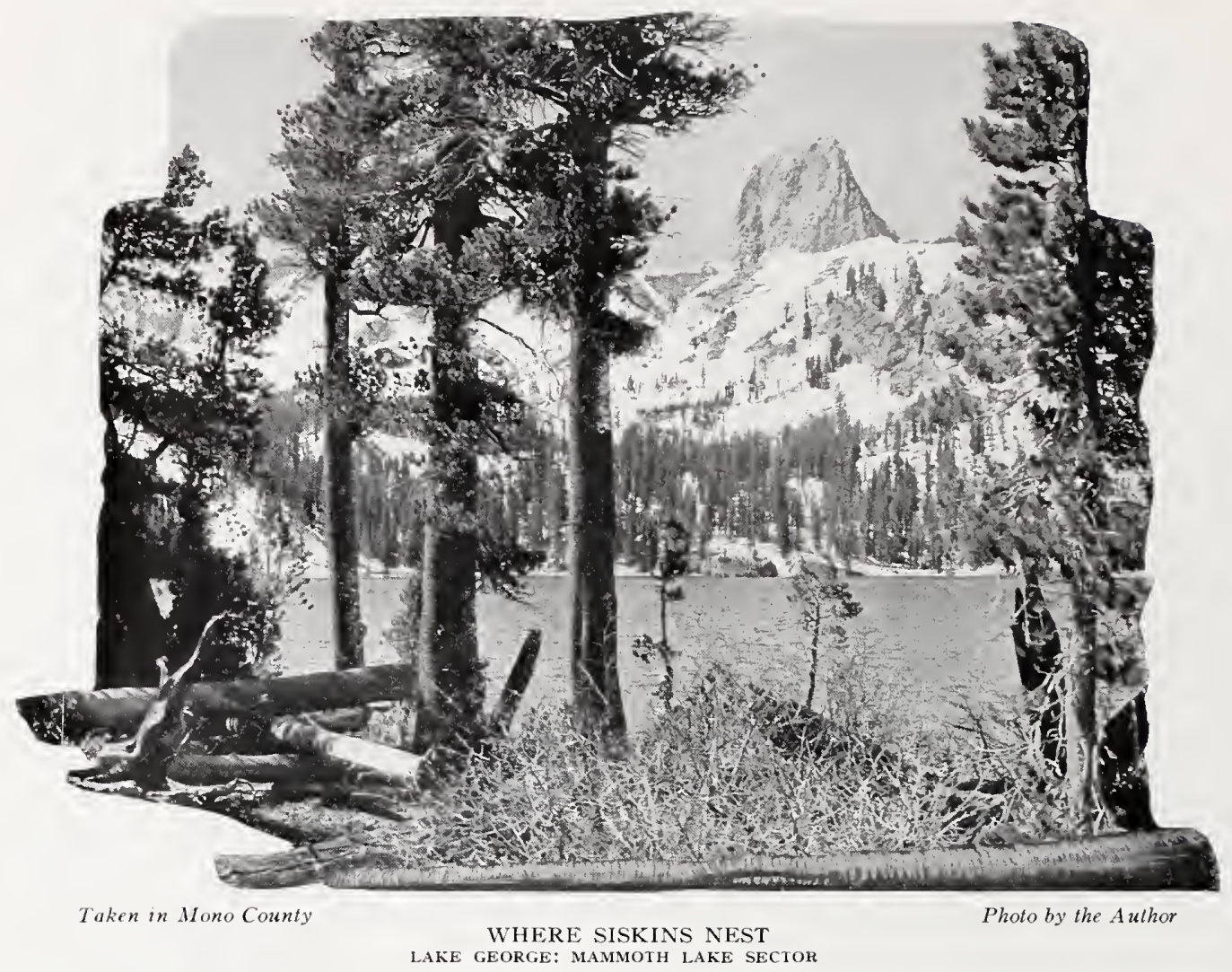

love of the wild in us. It is a call to fellowship with the simple, sincere things, a call which wakes responsive chords in an honest heart. Adios, brother!

When fired by passion the Siskin is capable, also, of extended song. This daytime serenade is vivacious, but not loud, except in occasional passages, - a sort of chattering, ecstatic warble of diverse elements. The bird has, besides its own peculiar notes, many finch-like phrases and interpolations, reminding one now of the Willow Goldfinch, and now of the California Purple Finch. The most striking phrase produced in this connection is a triple shriek of the Evening Grosbeak, subdued of course, but very effective. An ecstatic singer heard on the banks of the Eel River in Humboldt County, used the chirp of the English Sparrow instead of the shriek of the Evening Grosbeak in concluding its medley. The bird would perch on the top of a redwood sapling just over my head, and pour out a flood of mostly meaningless twaddle. One recognized it as an intended anthology, but it was too incoherent, too childish, to be identified. Then would come with startling distinctness this would-befetching vocal masterpiece, chirp chirp,- - moving one to a strange disgust.

Lest one should suppose we were exhausting the repertory of the 184 


\section{The Pine Siskin}

poking, twisting, prying, standing on their heads if need be, to dig out the dainty dole. Now and then, without any apparent reason, one detachment will suddenly desert its claim and settle upon another tree, precisely similar, a few feet away; while its place will be taken, as likely as not, by a new band, charging the tree like a volley of spent shot.

Nesting time with the Siskin extends from March to September, and the parental instinct appears in the light of an individual seizure, or decimating epidemic, rather than as an orderly taking up of life's duties. Smitten couples drop out from time to time from the communal groups, and set up temporary establishments of their own; but there is never any let-up in the social whirl on the part of those who are left; and a roistering company of care-free maids and bachelors en fete may storm the very tree in which the first lullabies are being crooned by a hapless sister. Once in a while congenial groups agree to retire together, and a single tree or a clump of neighbors may boast half-a-dozen nests; though which is which and what is whose one cannot always tell, for the same intimacy which suggested simultaneous marriage, allows an almost unseemly interest in the private affairs of a neighbor.

Once embarked upon the sea of matrimony, the female is a very determined sitter, and the male is not inattentive. In examining the nest of a sitting bird one may expect the mother to cover her eggs at a foot's remove, without so much as by-your-leave.

The nest, in our experience, is almost invariably built in an evergreen tree, usually a Douglas spruce (Pseudotsuga mucronata), a young redwood, or, in the San Francisco section a Monterey Cypress. So strong is this bird's predilection for the last-named tree as a nesting site, that it will repair to the orderly rows which bound properties in and about San Francisco. Messrs. Carriger and Pemberton report ${ }^{1}$ that of forty nests of the Pine Siskin found in San Mateo and San Francisco counties, all but one were in cypress trees, while the exception came from the very top of a fifty foot eucalyptus. Since these gentlemen have made a very close study of this species, I put the description of sites and nests in their own words:

"Nests were usually about twelve or fifteen feet from the ground, but notes show records of several forty feet up, and one fifty feet from the ground. The site chosen was almost invariably about six or eight feet from the trunk of the tree and upon the top of a good, strong, leafy limb. The nests were well built, quite compact, and slightly larger than those of the Green-backed Goldfinch whose nesting theSiskins' closely resembles. Nests were constructed of dry roots, grass and leaves from under the cypress trees, and were generally, though not always, lined with considerable hair. The nests were always of the same material and could be

${ }^{\prime}$ Condor, Vol. IX., Jan., 1907, pp. 18-19.

186 


\section{The Willow Goldfinch}

distinguished at sight from nests of the western chipping sparrow, California purple finch, and willow goldfinch, all of which birds were sometimes nesting within a few yards of one another."

The eggs are three or four, rarely five, in number, though sets of one and two are not uncommon in some seasons. They are a very pale bluish green in color, with dots, blotches, streaks, and occasional marbling, of rufous and brown, chiefly about the larger end. They vary considerably in size and shape, running from subspherical to a slender ovate. Measurements of average eggs are $.68 \times .48$ inches.

Incubation lasts about twelve days, and the young are ready to fly in as many more. The brood does not remain long in a family group but joins the roving clan as soon as possible. We suspect, therefore, that the Siskin raises but one brood in a season; and she undoubtedly heaves a sigh of relief when she may again don her evening gown, and rejoin "society."

No. 29

\section{Willow Goldfinch}

\section{A. O. U. No. 529b. Astragalinus tristis salicamans (Grinnell).}

Synonyms.-California Goldfinch. "Wild Canary." "Thistle-Bird."

Description.-Adult male in summer: General plumage clear lemon-yellow ("canary" yellow); a short crown-patch, including forehead and lores, black; wings black, the lesser and middle coverts mingled yellow and white; tips of the greater coverts and edges of secondaries white; tail black, each feather broadly tipped with white on inner web; upper tail-coverts with admixture of white; middle of belly and crissum white. Bill orange, tipped with black; irides brown; feet and legs light brown. Adult male in fall and winter: Quite different, the yellow element usually reduced to a tinge on throat, cheeks, and lesser wing-coverts; general color brownish olive (Saccardo's umber), paling on scapulars, rump, and sides, lighter (sordid buffy) on underparts centrally; upper tail-coverts varying to pure white; crown-patch partially or entirely concealed by olive; greater wing-coverts and tertials bordered by white or pale olive-brown. Bill darker. Adult female in summer: Similar to male, but without black cap and much paler and duller; upperparts dull greenish olive; underparts sordid yellow (pyrite yellow), of ten with yellow element confined to anterior portion; wings and tail fuscous. Adult female in fall and winter: Similar to adult male in fall, but without trace of crown-patch. Young birds: Closely resemble adults in fall, but are more extensively tinged with yellow below. Length of adult (sexes about equal): I 27 (5.00); wing 70 (2.75); tail 44 (1.73); bill го (.39); tarsus I3.5 (.53).

Recognition Marks. - Warbler size; black and yellow sharply contrasting; conical beak; undulating flight; "perchicopee" note; willow associations. In contradistinction from $A$. psaltria, note brighter yellow back of male, black crown-patch reduced in area and more sharply defined. The females are indistinguishable out of hand, save by association and notes.

Nesting.- Nest: A well-made cup, usually of compacted regetable fibers, finely shredded grasses, pappus of seeds, etc., settled in crotch of tree or shrub and 


\section{The Willow Goldfinch}

made fast to supporting branches throughout its entire depth; placed at moderate heights -5 to 15 feet up in willow or sapling. Eggs: 4 or 5 ; ovate; pale niagara green, unmarked. Av. of 28 eggs from Eureka (M. C. O. coll.): I $6.5 \times 9.4(.65 \times .47)$. Season: May, June, July; one brood.

Range of Astragalinus tristis.-North America from southern Canada to Lower California, Mexico, and the Gulf Coast.

Range of A.t. salicamans.-Pacific Coast district from southern British Columbia to southern California; and in winter south to central Lower California.

Distribution in California.-Common resident, of local distribution, chiefly in Upper Sonoran and humid Transition zones, west of the Sierran divide. While not found regularly east of the mountains, it shows some tendency to encroach upon the desert via the larger passes, especially in winter: Palm Springs, Jan. 25, I9I3; but also Whitewater, May 27, I9I3; Palm Springs, May 28, I9I3; and Lancaster, on edge of Mohave Desert, May I7, I919. Affects riparian willow association, but is by no means confined to it.

Authorities.-Heermann (Carduelis tristis), Jour. Acad. Nat. Sci. Phila., ser. 2, vol. ii., I853, p. 266; Grinnell, Auk, vol. xiv., I897, pp. 397-399 (desc. of salicamans): Dwight, Auk, vol. xix., I902, pp. I50-I64 (variation, plumage, molt, etc.); Tyler, Pac. Coast Avifauna, no. 9, I913, pp. 75-76 (habits at Fresno).

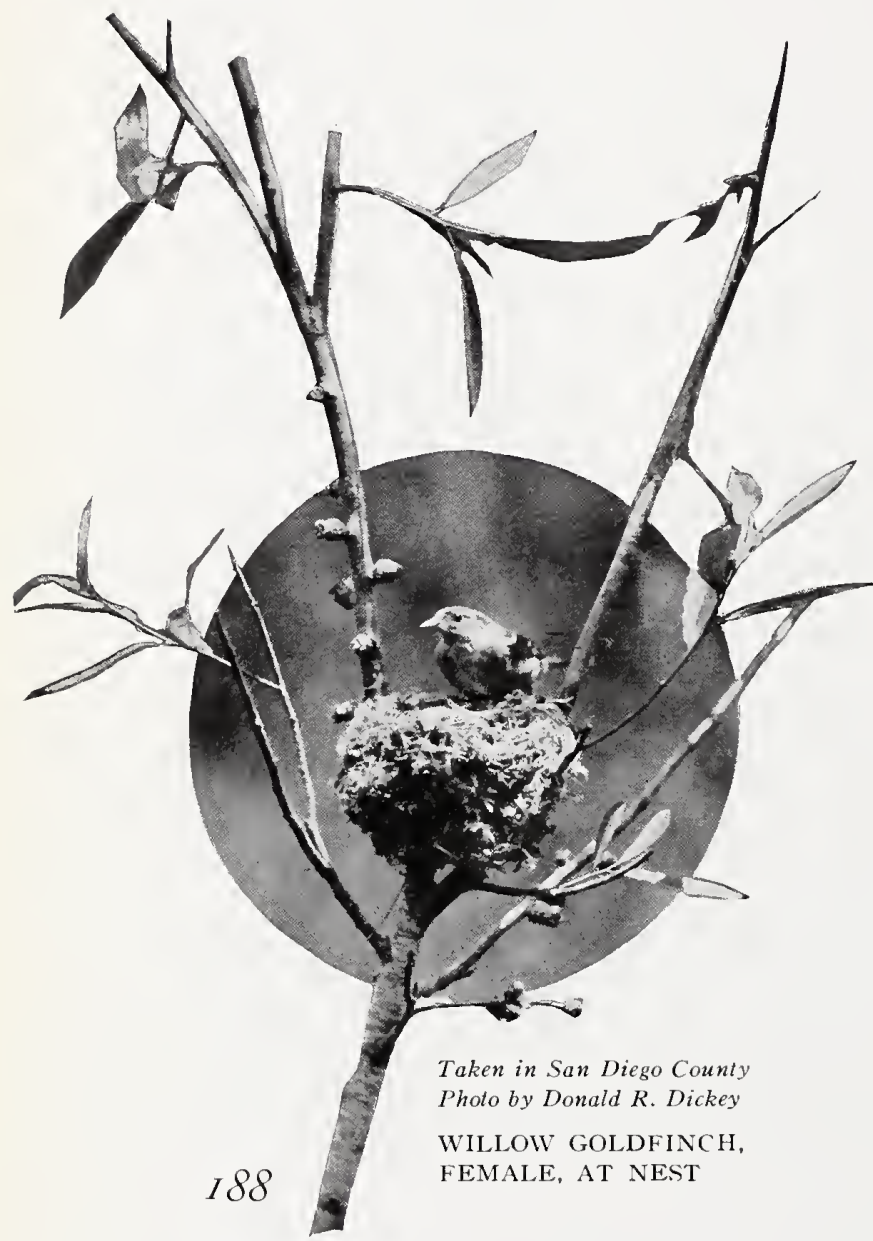

BRIGHT apostle of midsummer! Herald and poet of sunlit hours! How the drooping heads of waterless daisies lift up when they catch his cheerful salutation! Per chic' $i$ chic $^{\prime}$,-Perchic' opee, says the rollicking beak as he throws his pendant loops of flight. Perchic-ichic, perchic-and lo, the minstrel is suddenly quenched in a riot of thistledown. Or else it is a great fruiting sunflower which has engaged his attention, and he must pause upon the instant and test the ripeness of those luscious seeds. Dayick? Dayick? he questions, but the stolid ranks of little striped elves stand silent. They are not quite ready yet. Whereupon the happy minstrel remarks puchew or chu wëë oo, in a forgiving voice, and flies with an indulgent titter to another prospect.

There are those who profess to find a tinge of melancholy in the notes of the Willow Goldfinch; but 


\section{The Willow Goldfinch}

that must be because the singer offers the same sweet strains when the goldenrod is fraying, and the sered yellow leaves of willows are rattling to the ground. For the rest, Sir Goldfinch is the very apostle of good cheer. Spring or autumn, we learn to accept his passing notes as little bouquets flung down from heaven. Per chic'opee perchic' perchic'opee. Where is the heart that will not treasure such an offering!

Of course it is the Green-backed Goldfinch which furnishes the dominant element of California Goldfinchdom. Days will pass in which never a Willow Goldfinch is seen. But the birds are always somewhere about, at least west of the Sierras. If one frequents the willow bottoms, the larger "Goldies" are sure to be seen; while gardens, orchards, edges of clearings, and overgrown fencerows will get their innings. The "Willows" mix freely with their cousins, the Green-backs, but the attachment is not slavish, and a startled flock will, as a rule, separate into its specific elements. Some confusion will always linger in the student's mind until the notes of the two species-and, for that matter, of $A$. lawrence $i$ as well-are thoroughly threshed out. Both species have generic phrases and rattles, but these serve to link them rather with Cousin Siskin, or Serinus even, than with each other. The song of the Willow is often an artless and a breathless jumble of happy notes. They are ecstatic and babyish, rather than studied; and so far as I know, the Willow never plagiarizes, as do psaltria and lawrencei.

The Goldfinches are the only birds which may with any degree of propriety be called "wild canaries." The true Canary, Serinus canarius, is not, of course, a New World bird. But the phylogenetic relationship between a number of these Fringilline genera, Spinus, Acanthis, Carduelis, etc., is very close; and it is well known that the Goldfinch will cross with the Canary, although the resulting offspring is, I understand, infertile.

The nesting of the Willow Goldfinch is not usually postponed to such lengths as in the East, where tristis typicus holds forth. And that, perhaps, is because the California bird is not abjectly dependent upon the thistle for nesting material. Nesting takes place normally in May or June; but the birds occasionally prolong their efforts into July; and April nests are of record. In their later nesting the IVillow Goldfinches show some disposition to colonize. Nests are placed at moderate heights in willow trees, in ceanothus bushes at the lower levels, or even in weeds. In construction a wide range of materials is used, although a given bird may limit herself to a very narrow choice. A nest before me is a mass of willow down almost as pure as cotton; but there is structural support of grass and rootlets. Another shows no cotton, but is a close-set structure of grass, weed-stems, string, moss, catkins, dry leaves, flower-heads, and rootlets, with a lining of brownish gray pappus. 


\section{The Willow Goldfinch}

Four or five eggs of a delicate bluish green constitute a set, and the female broods for fourteen days. A like time or less is required by the babies before they reach maturity; and when they leave the nest they drone babee! babee! with weary iteration until all but their doting parents are driven frantic. The fledglings are quickly inducted into the mysteries of what to eat and how to rustle it; but they much prefer to be waited on by their parents. Most of the youngsters, as a consequence, are thoroughly"spoiled," and the assiduity displayed by an overworked female Goldfinch tending a batch of overgrown squealers reminds us, all too surely, of "home and mother."

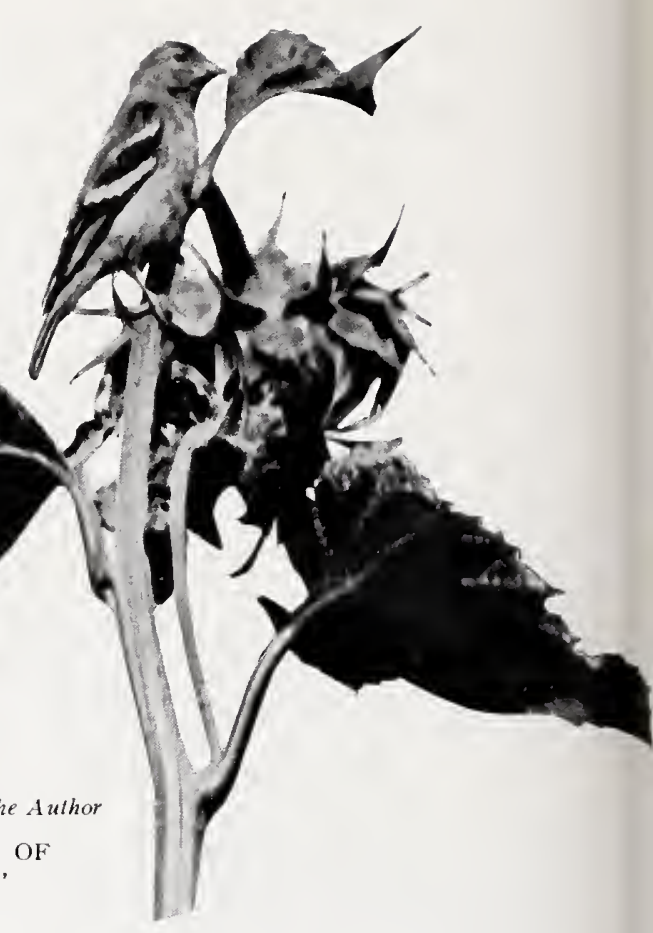

During the nesting season these birds subsist partly upon insects, chiefly bugs, flies, and caterpillars; but at other times they feed almost exclusively upon seeds. They are very fond of sunflower seeds, returning day after day till the crop is harvested. Seeds of the lettuce plant, turnip, and other garden vegetables, are levied upon freely where occasion offers; but thistle seed is a staple article; and the steady consumption of weed seeds, such as alfilaria, groundsel, and tarweed, lifts this bird into the class of highly useful species.

In the winter season Willow Goldfinches are everywhere very much less in evidence. They do not migrate, apparently, but they take on a duller plumage, and they live more quietly. Just as the impression gets about that they are gone, one stumbles upon a large company stealing about in the tops of the sycamore trees, or else sunning themselves at the edge of a ceanothus patch. If too much disturbed, they will perchic perchic opee as of yore; but it is a pale reflection of midsummer glory. 
The Green-backed Goldfinch

No. 30

\section{Green-backed Goldfinch}

\section{A. O. U. No. 530a. Astragalinus psaltria hesperophilus Oberholser.}

\section{Synonyms.-"Yellow-Bird." "Wild Canary." California Goldfinch.}

Description.-Adult male (no seasonal change): Pileum, broadly, glossy black; sides of head and upperparts olive-green, or warbler-green, clearer, more yellow, on rump, sometimes faintly streaked with darker, or blackish, on back; upper tail-coverts chiefly black; wings black; the middle and greater coverts and tertials (variably) tipped with white; both webs of inner primaries crossed about midway with white, forming a conspicuous blotch in flight; tail black, the two or three outermost pairs of feathers extensively white on inner web; underparts lemon-yellow, paling posteriorly, shading on sides. Bill horn-color; feet and legs brownish. Adult female: Like male but much paler and duller, without black. Above dull olive (citrine drab); below olive-yellow, paling posteriorly. Immature males are like adult females but brighter, with early indications of black cap. Length of adult about $127(5.00)$; wing 65.5 (2.58); tail 43 (1.69); bill $9(.35)$; tarsus $15(.59)$.

Recognition Marks. - Warbler size; black cap of male not sharply defined against olive-green of upperparts; coloration not definitely gray, and chin not black, as distinguished from A. lawrencei; the commonest yellow bird of California.

Nesting.- Nest: Placed at almost any height but usually moderate, and in almost any host,- - tree or bush or even rank weeds; live oaks and sycamores favorites; a rather careless affair of twisted grasses and weed fibers, deeply cupped, lined with fine grasses or horsehair; settled firmly into concealing bunch of leaves or branching twigs, or sometimes artfully incorporated with immediate setting. Measures 3 inches wide $(\mathrm{mm} 76.2)$ by 2 deep (50.8) outside, $\mathrm{I} 3 / 4$ inches wide $\left(\mathrm{mm}_{4} \mathrm{I} .4\right)$ by $\mathrm{I} 1 / 2$ inches deep (mm 38.I) inside. Eggs: 4 or 5, ovate, pale bluish green, unmarked. Av. of 28 spec. in M. C. O. coll.: 15.5 x II.4 (.6I x .45). Season: April to June, or occasionally in autumn; two or three broods.

Range of Astragalinus psaltria.-Southwestern United States from central northern Texas, northern Colorado, southern Idaho, and southern Oregon, south through Mexico to northern South America.

Range of $A$. p. hesperophilus.-Southwestern United States from Utah and southern Oregon south to Cape San Lucas, Sonora, and the extreme southwestern coast of Mexico; shows some altitudinal retirement in winter.

Distribution in California.-An abundant breeder below the Transition zone and locally within that zone; most abundant along the southern coasts and in the central interior; rare or wanting in the humid Northwest; apparently absent from the central region east of the Sierras, at least above the head of Owens Valley and its tributaries (White Mountains above Bishop, May 26, I919; Hilton Creek, Long Valley, June I, I919; near Mammoth Camp, June II, 1919), although reappearing in Lassen and Humboldt counties (Goose Lake, June 24, I912; Surprise Valley, June 29, 1912; Eagleville, July I2, I912); of local distribution in the deserts; of limited occurrence on some of the Santa Barbara Islands (Santa Cruz Island, April 4-19, I9I5); and casually on the Farallons. 


\section{The Green-backed Goldfinch}

Authorities.-Gambel, Jour. Acad. Nat. Sci. Phila., ser. 2. vol. i., I 847, pp. $52-53$ (habits and nesting); Atkinson, Oologist, vol. xi.. I894, pp. 240-24 I (habits); Ridgway, Bull. U. S. Nat. Mus., no. 50, pt. i., I90I, pp. I1 5-116 (crit. re arizona); Grinnell, Condor, vol. iv., 1902, pp. I15-116 (crit.); Oberholser, Proc. Biol. Soc. Wash., vol. xvi., I 903, p. II6 (desc. of hesperophilus); Beal, Biol. Surv. Bull., no. 34, 1910, pp. 73-75, pl. vi. (food): Chambers, W. L., Condor, vol. xvii., 1915, p. 166 (nesting).

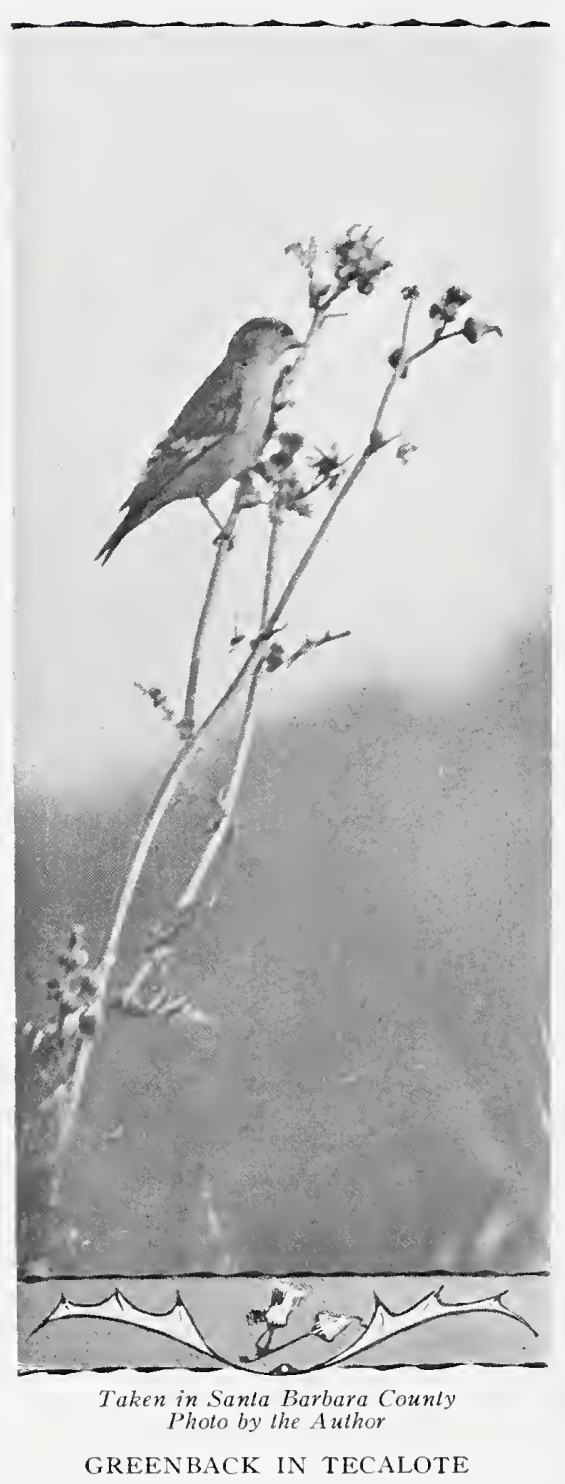

THE GREEN-BACKED Goldfinch is, after the "Linnet," possibly the most abundant numerically of the breeding birds of central and western California. That he is not also the most familiar can be due only to carelessness or inattention on the part of a too easily satisfied public. Gentle, trustful, dainty, musical, inoffensive, sociable, and abundant-these adjectives certainly entitle their subject to the fullest recognition on the part of Californians. The Green-back, too, is a bird of all seasons. It is well distributed at nesting time, insomuch that a bird-lover may scarcely cock his ears out of doors without catching the plaintive sweetness of the keyring call, near or remote. Spring or summer, little companies of them will foregather in the shade trees and raise a little hurricane of song, breathless gladness of childhood welling from a hundred childish throats. In the autumn the Goldies make common cause with the flocking Linnets, and glean from the roadside, or else straggle over the weedy meadows by the thousand. At such a time the telephone wires bear more than messages, and what they carry is of more worth, to my notion, than nine-tenths of what passes unheeded beneath the birdies' toes. There is no flock impulse or solidarity of action among goldfinches. A great company scattered over the ground will melt away somehow before the invader; but the fear-thought is absent, and there is none to cry, Beware!

The pitch and volume rather than the cadence of the Green-backs' 


\section{The Green-backed Goldfinch}

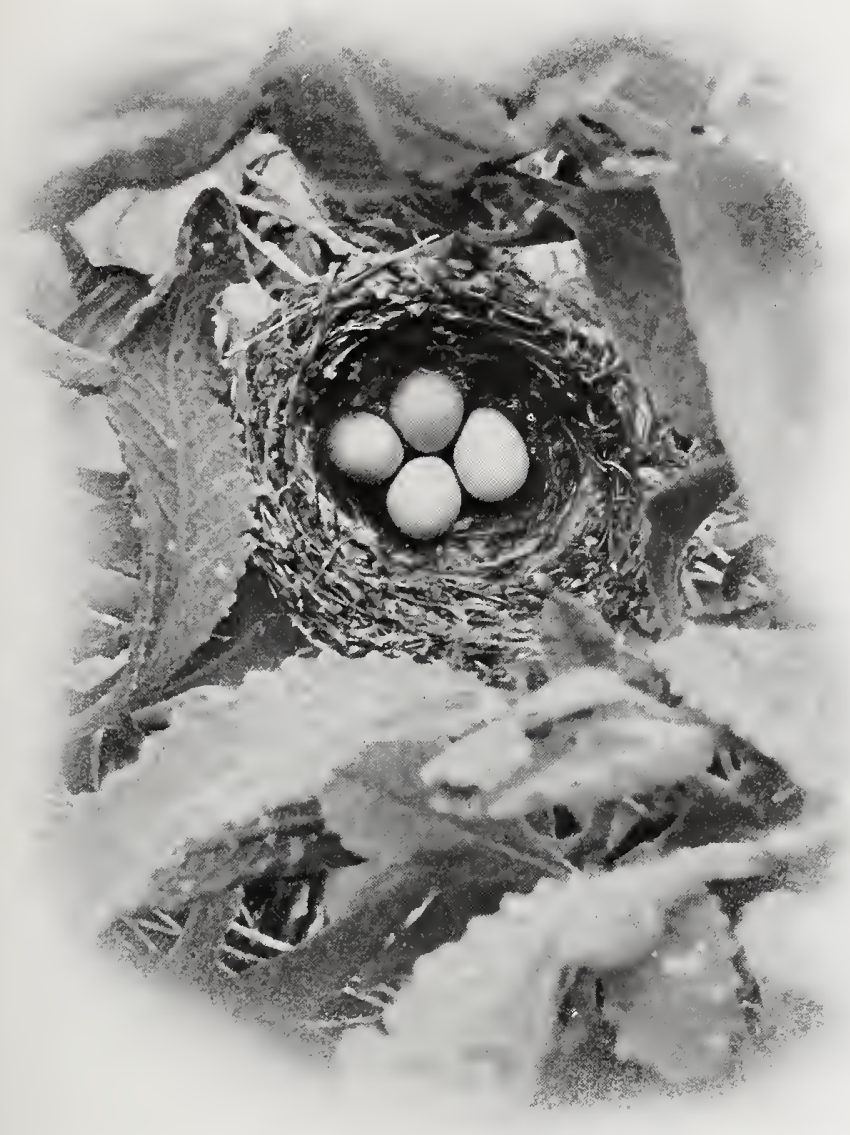

Taken in Riversidé County

Pholo by the Author

NEST AND EGGS OF GREEN-BACKED GOLDFINCH, IN YERBA SANTA notes remind some people of their caged pets (poor, tedious beasts) and so our birds get called "wild canaries." But half an ear will show that the Green-backs' calls are sweeter and subtler, with the tang of the open and the breath of active experience. There is, beside, a plaintive quality, a little hint of bitter-sweet, about the Goldfinch voice. The bird asks questions of life, Choo-i? choo-i? questions which it quietly answers in a voice of self-chiding: Chooi? cheeo! Chooi? cheeo! "Why, of course; I should have known that." As often as the business of rustling food compels the bird to shift ground-and that is pretty often-it signalizes the movement by a rattle, a musical rattle, like the titter of an excited school-girl. And when attention is seriously turned to song, the bird evinces an astonishing ability. Not only does it pour out a flood of musical chatter, sui generis, but it deftly seizes the notes of all its associates. There is no time for leisurely choice. Song of Flicker, Wren, or Pewee-everything goes, pell mell, in to the medley. Bird song is not so much imitated as appropriated. At a single sitting, with a sprig of white sage for a platform and a grasscovered hillside for a concert chamber, I have heard the following composers so clearly represented that the ears were incredulous: San Diego Wren, Western Lark Sparrow, Red-shafted Flicker, San Diego Song Sparrow, Western Wood Pewee, House Finch, Western Gnatcatcher. On this occasion another Goldfinch, probably a female, sat within six 


\section{The Green-backed Goldfinch}

inches of the singer, apparently entranced with his melody. Again and again I have seen these uprooted forests of song swept along on the flood of the Goldfinch's own passion; and I think, more than ever, that music is a spontaneous gift. Or else music is a circumambient ether. We have only to get in tune, keyed up by some exalted passion, and lo! we vibrate melodiously. At least it is so with the Goldfinch.

For the information of one of the older authorities, Dr. J. G. Cooper, we will record that nests of the Green-backed Goldfinch have recently been found. I am sure I do not know what could have befallen the good Doctor the day he wrotel by way of summary: "I have not met with their nests, nor with any description of them; but they doubtless much resemble those of C. tristis." Not met with them! Shades of Audubon! Where were your eyes? For if there is one virtue which the Green-backed Goldfinch possesses above another, it is that of propagating. Not otherwise are the swollen ranks of hesperophilus maintained. Where is the sycamore tree and where the cypress that has not sheltered the Green-back's humble cradle? Where is the weed-patch even that has not resounded to the tsui $i$ tsúi tsweetie of dainty fledglings greeting a returning parent with quivering wings, and a soft flood of thanks? Has all this good fortune been reserved for our day?

These Goldfinches not only nest "most anywhere," but they carry their labors through the seasons with relentless energy. The birds are in full sông by February, and although they do not often nest as early as March, they are all at it in April, and all busy until July. There are three published records of nests with eggs or young found in October; and one, that of John M. Niller, of Parlier, of a November nest. This last held fresh eggs on the 22nd, but in spite of the care of the parents, it was wrecked by hard rains a week later.

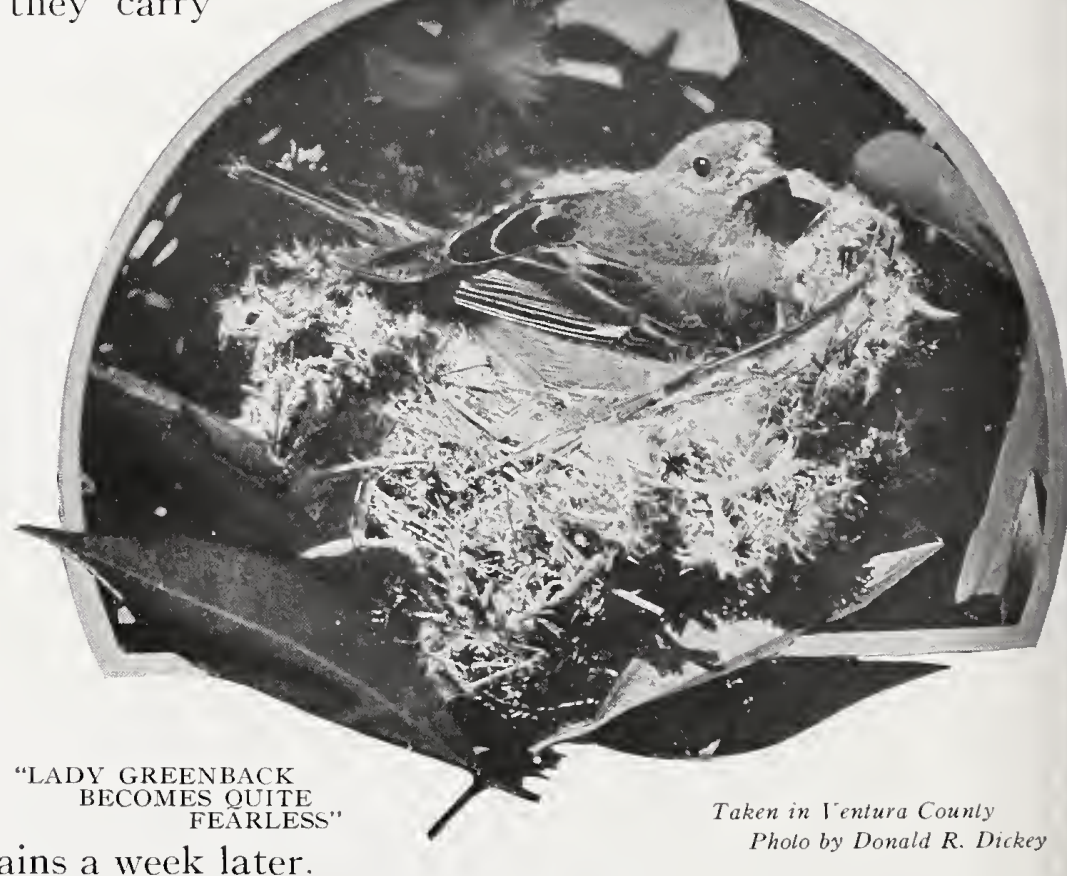

Ornithology of California Vol. I. Edited by S. F. Baird from the MS notes of J. G. Cooper, 1870. 


\section{The Green-backed Go!dfinch}

The range of choice in nesting sites for this species is very great. Sycamore trees are an early favorite, because of the shelter promised by its generous leaves. And in this connection it may be well to note that most birds, whether ground or tree nesters, see to it that their nest is in shadow through the middle of the day. The burning rays of the sun must be avoided, at least by the tender nestlings. It is this fact, and not presumed escape from observation, which is the controlling factor in most

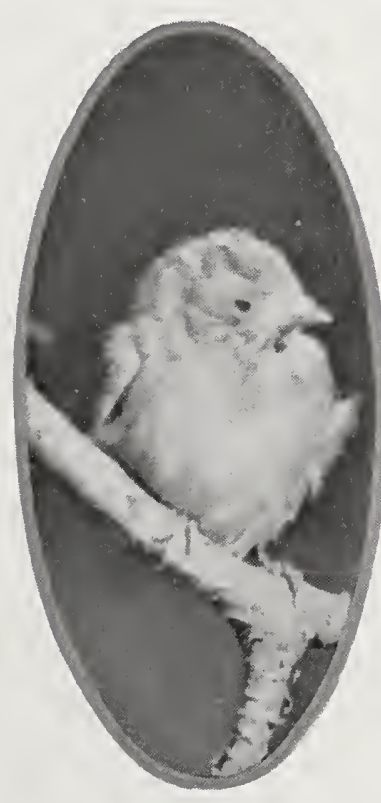

BABY GREENBACKS

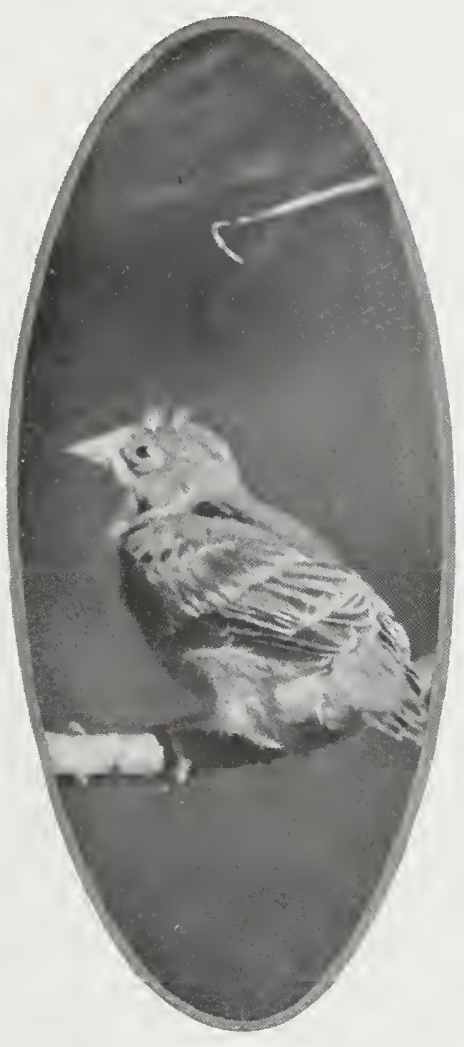

Photo by D. R. Dickey Taken in Ventura County

nest-building projects. The cypress is also a favorite with the Goldfinch, and whether the nests be placed close to the trunk of the tree, or, preferably, well out toward the tip of a branch, is determined again by the shade offered by some overshadowing twig or branch. Live oaks conceal their myriads also. In this case, the bird, securely sheltered by a bristling array of sturdy leaves, prefers the tip of a drooping branch, or at least an outside situation. When the timber gives out, the Green-backs take cheerfully to the major weed-patches, or even invade the open sage, to take pot luck with Bell Sparrows and Bush-Tits. 


\section{The Green-backed Goldfinch}

In pursuit of her supremest duty, the Lady Green-back becomes quite fearless. Not only will she sit quite close under approach, or suffer removal from the nest by hand, but she is not even deterred at nestbuilding by the presence of a stranger. Spying something suspicious in the top of a slender sapling, I once climbed up a stouter tree and bent the sapling over for inspection. Milady arrived just then with a load of cotton blankets. Although she did look mildly inquisitive, she made careful disposition of her load, and went and came as usual.

Eggs of the Green-back are described as pale green, greenish blue, or pale blue. This really means that the greener of the two elements in the color scheme fades out and leaves only a paler blue-green. But in any event, the color of these eggs in the cabinet is altogether different from the life color, for this fairy lantern is lighted from within by an orange-red bulb. This may be necessary, but we do not recommend greenish blue as a medium for the transmission of red light. Incubation lasts eleven or twelve days, and infancy as much longer. Of the period of "sweet dependency" which follows, none but a natural born kindergarten teacher is qualified to speak. But like the man running for Congress, we will own, first off, that these babies are the sweetest cherubs that ever were invented. And that is very lucky, because the dear knows that there are about thirty million of them per annum in California.

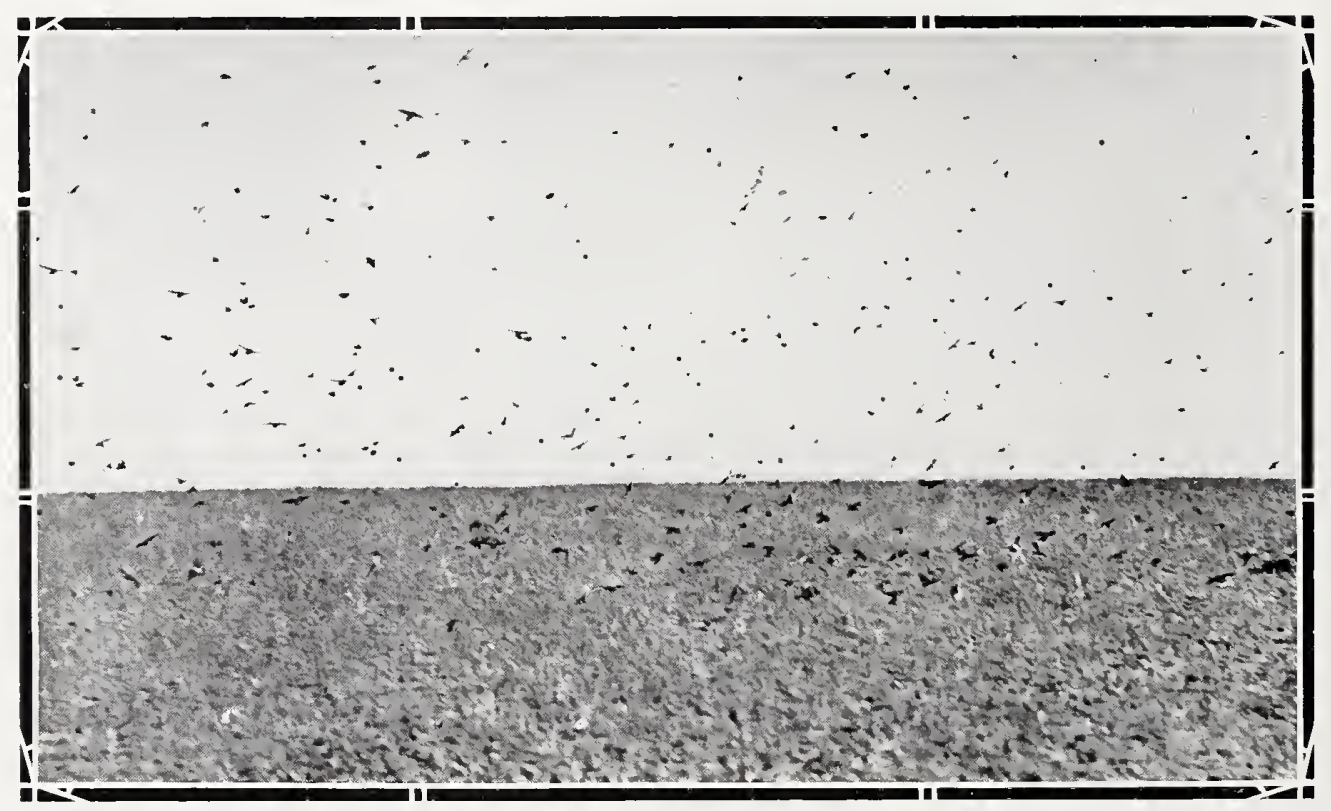

Taken in Santa Barbara Count

"HAIL THEN TO HIS INCREASING MILLIONS" A MIXED FLOCK OF GOLDFINCHES AND LINNETS 


\section{The Lawrence Goldfinch}

In view of this almost oriental fecundity, it is doubly fortunate that the economics of the Green-backed Goldfinch is above reproach. Ninetysix per cent of the bird's food consists of weed-seed. Among the various weeds which supply its wants, the Napa Thistle (Centaurea melitensis) stands supreme. It would seem to be feat enough to pluck these tiny seeds one by one, with their corrugated sides and bristling tufts, but the Goldfinch cracks each brittle shell and, aided no doubt by its tongue, extracts with consummate skill the starchy kernel. As an instrument of precision the Goldfinch bill is hard to beat. And if it were not for the gentle Goldfinch, even thirty million of him, our fields would all go to thistle seed, and we might have to eat thistles for bread. Hail, then, to his increasing millions! And if good old Doctor Cooper-peace to his ashes!- ever does take a notion to reincarnate, we will undertake to show him a Green-back's nest.

\section{No. 31}

\section{Lawrence's Goldfinch}

\section{A. O. U. No. 53 I. Astragalinus lawrencei (Cassin).}

Description.-Adult male in spring: General color neutral gray, paling on underparts posteriorly; pileum, face, and throat, narrowly, black; breast dark yellow (nearly pyrite yellow), everywhere sharply outlined against the surrounding gray; rump yellow; back touched with yellow centrally; the wings black, heavily edged with yellow; the tertials bordered with white; tail black, the three or four outermost pairs of feathers heavily blotched with subterminal white on inner web. Bill light; feet brownish. Adult male in autumn: As in spring, but back and sides of hind neck brownish olive. Adult female in spring: Like male in spring but without black on head and throat; duller. In autumn: Above brownish olive. Young birds are like adult female in autumn, but yellow element is almost or quite confined to wing, where also largely replaced by buffy brown edgings; breast faintly streaked. Length of adult about I 27 (5.0o); wing 68 (2.68); tail 48 (I.89); bill 8 (.3I); tarsus I 3 (.5 I). Female slightly smaller.

Recognition Marks. - Warbler size; black chin and throat of male distinctive; black, yellow, and gray in contrast; yellow on center of breast, in contrast with surrounding gray, fairly distinctive for female; of irregular and local occurrence.

Nesting. - Nest: A rather loosely woven cup of highly varied materials, grasses, wool, weed-stems, and feathers; placed at any height in cypress tree, or at moderate height ( 2 to 15 feet) in weeds, artemisia, elderberry bush, or small tree, as live oak. Eggs: 4 or 5, rarely 6, pure white. Av. of I 8 eggs in M. C. O. coll: 15.5 x 10.9 (.6I x .43). Season: April, May, one brood. Extreme dates: Shandon, April 8, I9I6, 5 fresh eggs; Claremont, July 5, I903, 4, inc. begun.

General Range.-California and northern Lower California; in winter east to Arizona (but chiefly at Colorado Valley points) and New Mexico (Fort Bayard,Stephens, MS.). 


\section{The Lawrence Goldfinch}

Distribution in California.-Of very local occurrence in summer west of the Sierras, perhaps chiefly in the southwestern coast districts, but also north through Great Valley to McCloud River, in Shasta County (Grinnell) and east to Weldon, Kern Co. (Grinnell), Raymond, Madera Co. (Grinnell), and Oroville, Butte Co. (July 18 , I912); breeding chiefly in Upper Sonoran life zone; perhaps casual breeder in Lower Sonoran (Indian Wells, Colorado Desert, April 27, 191 7 ). Perhaps casual on Catalina Island, but a regular breeder on Santa Cruz Island. Minters irregularly in San Diego district and east of the desert divide to the Colorado River.

Authorities.-Cassin, Proc. Acad. Nat. Sci. Phila., I850, p. 105, pl. v. (orig. desc.): Heermann, Jour. Acad. Nat. Sci. Phila., ser. 2, vol. ii., 1853, p. 266 (nest and eggs); Henshaw, Rept. Orn. Wheeler Surv., 1 876, p. 239 (meas.); Belding, Occ. Papers, Calif. Acad. Sci., 2, I890, pp. I38-139 (range); Willett, Pac. Coast Arifauna, no. 7, I912, p. 75 (status in so. Calif.); Tyler, Pac. Coast Avifauna, no. 9, 1913, pp. 76-77 (status in Fresno district).

IN STRIKING contrast with the almost infallible uniformity of distribution enjoyed by Cousin Psaltria, is the highly irregular and freakish disposition of lawrencei. Its breeding areas, though perhaps not inconstant, are exceedingly circumscribed, and its sporadic appearances in other than breeding areas give the impression of a very unstable bird. Doubtless it would be interesting to plot the breeding range of this species,

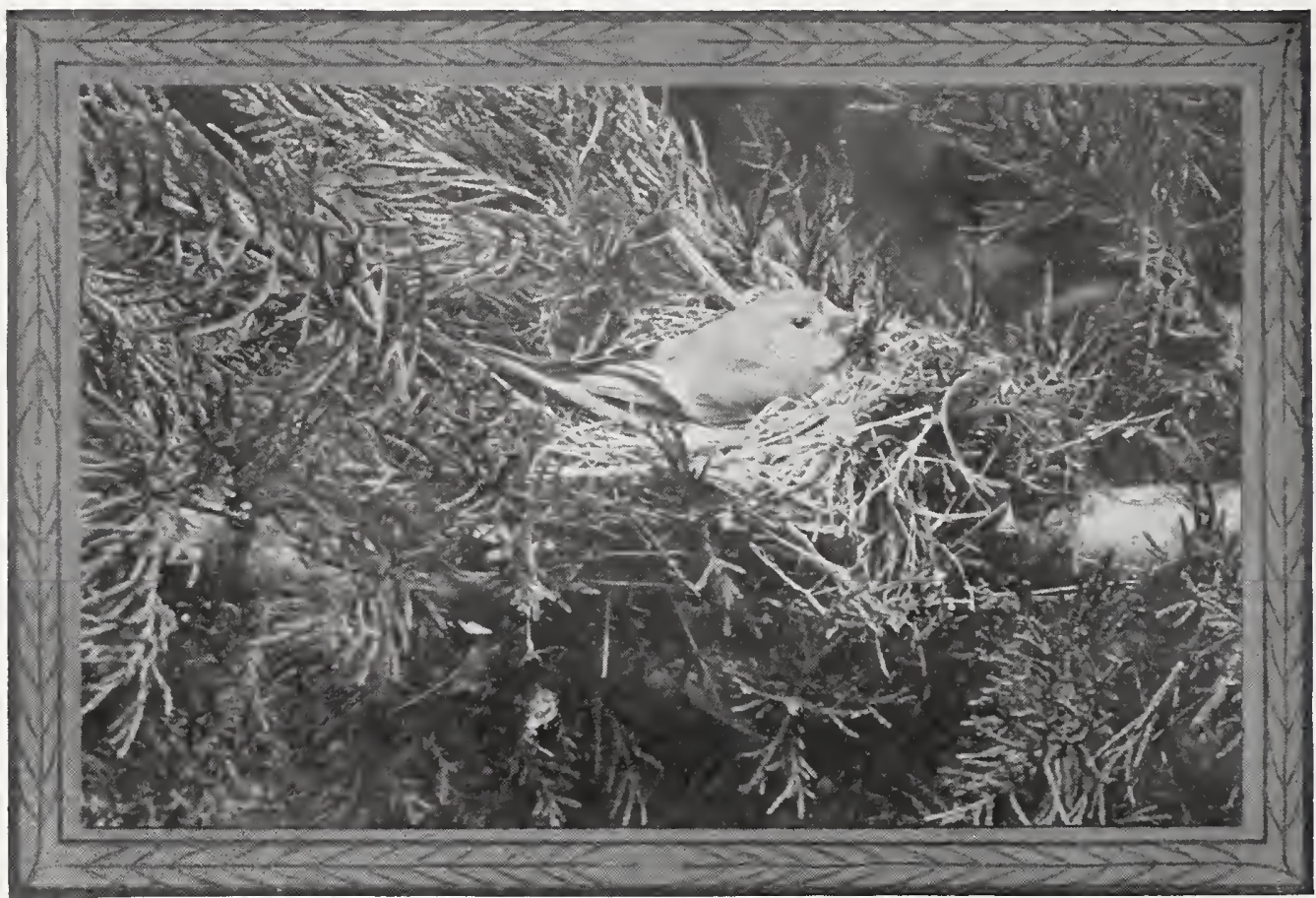

Taken in San Diego County

Photo by Donald R. Dickey

LAWRENCE GOLDFINCH IN CYPRESS TREE

198 


\section{The Lawrence Goldfinch}

and to try to find out the determining causes which move its choice. But published accounts of the bird's notes and habits are very meager; and in general, the Lawrence Goldfinch appears to have escaped both common and critical observation.

The pattern of coloration of the male lawrence $i$ is distinctive enough; that of the female much less so; but as to the more significant distinctions of habit and psychology, I can offer only notes upon the song and the nesting habits. The I.awrence Goldfinch has no proper song of his own, but renders instead a vivacious medley, which is even more varied and extended and impetuous than that of psaltria. Thus I have heard reproductions of Sparrow Hawk, Meadowlark, Lark Sparrow, Junco, Rock Wren, Audubon Warbler, Plain Tit, Robin and Bluebird. One of these roistering bodies sang for me at ten feet while I was aloft in a cottonwood tree on the banks of the San Juan Creek. The singer was surcharged with energy, and he swayed his head from side to side in the enthusiasm of utterance, - a sort of combination electric fan and Victrola, never hesitating for a moment when he changed records. Some of the minor links of his song were undoubtedly his own; but the characteristic things were shamelessly plagiarized. Among the minor notes is a pee udle, or piüudle (umlauted) note, by which a sharp ear once aroused may trace the bird forever after. While lawrencei lacks (I believe) the musical titter of psaltria, it has a sharply penetrating deew deew couplet which answers the same purpose. And there is good need to memorize these notes if you would learn more of the ways of lawrencei. For, sitting high in a budding cottonwood tree, these Lawrence Goldfinches secure about the same obliterance which their Cousin Green-back does in the sycamores. You may spy one aloft because he is singing, but you are surprised a moment later when a dozen emerge from the same branch.

Nesting, I find, is studied to the very best advantage in isolated clusters, or in hedges, of the Monterey Cypress. Here the birds colonize to some extent, and I have found as many as ten nests at once in two adjoining trees. There is no flock impulse in this matter, however, for along with uncompleted nests were others containing eggs, and others still with young. In default of cypress trees, live oaks will do, or elder clumps, or even the lowlier stations of the open sage.

April is the nesting month in the San Juan country. I have taken eggs as early as April 8th; and Mr. Truesdale, I believe, has a record for April Ist. The altitude here is about a thousand feet. In the more elevated stations of southern California, the seasons may be prolonged into June, or even July. Eggs of this species, unlike those of our other goldfinches, are pure white not even greenish white, as reported by 


\section{The Lawrence Goldfinch}

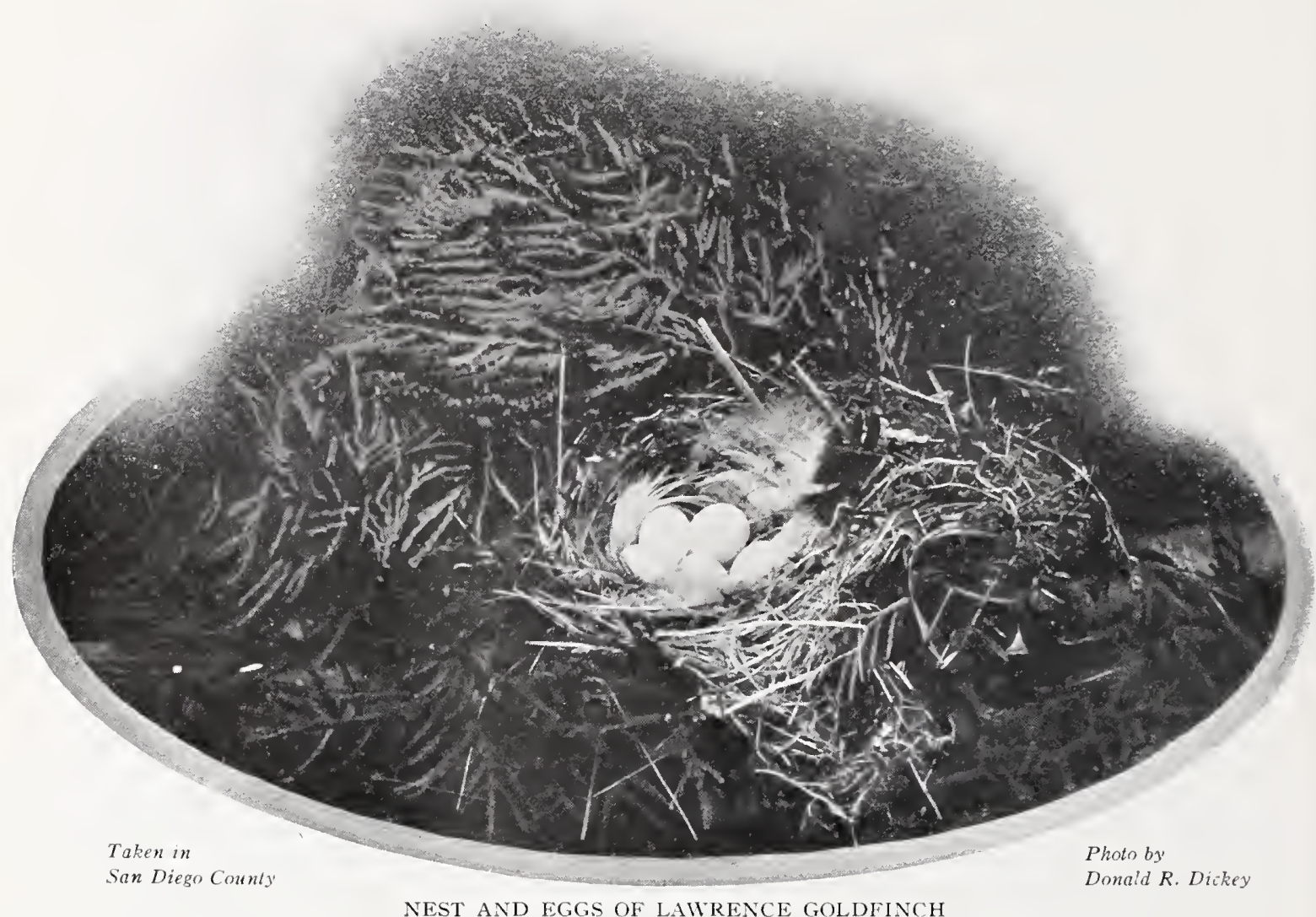

Dr. Brewer. ${ }^{1}$ They are smaller than those of either trisis or psaltria, and bulk about two-thirds that of the former. The nests are exquisite creations, highly varied in construction and sometimes quite picturesque. A dainty cup before me, an inch and a half in diameter and one in depth, is compacted of wool, flower-heads, fairy grasses, horsehair, and feathers. Another, of coarser construction, boasts several additional ingredients, but dispenses with horsehair in favor of sheer feathers for lining. A third displays a garland of protruding and highly nutant grass-heads, as chic as a Parisian bonnet. The female, naturally, disputes the intruder's claim to such a piece of handiwork; but she does not often have to be lifted from the nest.

Although irregularly resident in winter throughout its breeding range, the Lawrence Goldfinch seems to prefer the deserts of Arizona and New Mexico for a winter home. This east and west migration, having

\footnotetext{
1 Baird, Brewer \& Ridgway, Vol. I., p. 479.
} 


\section{The Cassin Purple Finch}

nothing of the economic insistence of the north to south flights, is a haphazard affair. And by the same token, the Lawrence Goldfinch seems to be a sort of haphazard bird.

No. 32

\section{Cassin's Purple Finch}

\section{A. O. U. No. 518. Carpodacus cassini Baird.}

Description.-Young (?) adult male: Crown carmine red; back and scapulars grayish red (light jasper red), mixed with brownish gray, and sharply streaked with dusky; wings and tail dusky, with more or less edging of reddish gray; remaining plumage, including rump, chiefly grayish red (jasper pink-never really" rosy"), passing into white posteriorly below; flanks and under tail-coverts sometimes sharply streaked with dusky. Bill horn-color; feet and legs light brown. Adult female, immature male, and old (?) male: Everywhere (save on wings, tail, and lower abdomen) sharply streaked with dusky, clearly, on a white ground, below; above, on a brownish gray or dull olive-buffy ground. Length of adult $152-165$ (6.00-6.50); wing 92 (3.62); tail $64\left(2.5^{2}\right)$; bill I $2.6(.49)$; tarsus $19(.75)$.

Recognition Marks.-Sparrow size; red of crown contrasting with back distinctive as compared with $C$. p. californicus; general streakiness of female (and male in more common plumage). The cast of plumage is less strongly olivaceous, and the streaking is both finer and sharper, less blended.

Nesting.- Nest: On a basis of interlaced pine twigs, rather bulky, is bedded a firm cup of interwoven grasses, rootlets, fine bark-strips, and, if possible, horsehair. The whole is usually settled in the bushy radiating tip of a pine branch, well concealed, and at any height, from ten to eighty feet. Measures outside 5 or 6 inches $(\mathrm{mm} \mathrm{I} 27$ to $\mathrm{I} 52$ ) wide, by 3 or 4 inches ( $\mathrm{mm} 76$ - IOI) deep; inside $21 / 2-3$ inches ( $\mathrm{mm} \mathrm{63-76)}$ wide, by $\mathbf{I}-\mathbf{I} 1 / 2$ in. ( $\mathrm{mm} \mathrm{25-38)}$ deep. Eggs: 4 or 5, ovate to elongate ovate; bluish green (microcline green), spotted sharply and rather sparingly with light purplish gray, or violet-gray, and black. Av. of 37 specimens in M. C. O. coll.: $20 \times 14.8(.79 \times .575)$. Season: June; one brood.

General Range.-Western North America, breeding chiefly in mountainous regions and in Upper Sonoran to Boreal zones, from southern British Columbia south to northern Lower California, central Arizona and northern New Mexico; in winter from central California and southern Arizona south over Mexican plateau to Vera Cruz, San Luis Potosi, and Valley of Mexico.

Distribution in California.- Common resident of timbered mountainous districts, chiefly on semi-arid or eastern exposures; breeding in coniferous timber from lower limit of yellow pine (Pinus ponderosa) to limit of trees. Center of abundance in east central Sierras, rare in northern coastal ranges. Has not been reported from coast ranges south of San Francisco, but possibly occurs in San Rafael Mountains of Santa Barbara County. Winter range imperfectly made out, but bird probably retires to somewhat lower levels, and is known to deploy somewhat over foothills. Has 


\section{The Cassin Purple Finch}

been taken at San Jose (C. Barlow, Condor, II., I900, p. I32) and Los Angeles (H. Swarth, Condor, III., I90I, p. 66).

Authorities.-Coues, Proc. Acad. Nat. Sci. Phila., I 866, p. 80; Cooper, J. G., Orn. Calif., I 870 , pp. I 55-156 (voice); Townsend, Proc. U. S. Nat. Mus., vol. x., I 887, p. 215 (on Mt. Shasta); Ray, Auk, vol. xx., 1903, p. I 87 (nesting at Lake Tahoe); Grinnell, Univ. Calif. Publ. Zool., 5, I908, pp. 89-90 (habits and nesting in San Bernardino Mts.).

ALTHOLGH possibly quite unknown to the stay-at-home element of our populous coastal cities, the Cassin Purple Finch is, nevertheless, among the best known and numerically most important birds of the State, for he it is who is the authentic hillsman, the multitudinous mountaineer, the genius loci of Sierra pine forests and of all timberline resorts. Roughly speaking, cassini is the dry weather bird, the Eastsider, the "arid Transition" species, while purpureus is the IVestsider, the humid Transition form. Although the ranges of the two species inosculate according to a very complex pattern traceable along the western slopes of the Sierras and the southern ranges, they do not appreciably overlap. The ranges of C. cassini and C. mexicanus, likewise, are mutually exclusive, by reason of the greater elevation of the former; whereas the ranges of purpureus and mexicanus have a wide coincidence.

It is the camper-out of the high Sierras who sees the Cassin Purple Finch at his best. The males are filling the forest with song throughout the months of June and July; and the females are pouting, or else waiting upon pouting children, throughout July and August. The word "pouting" is advisedly chosen, for of all lady birds of my experience, the female Cassin is, I believe, the least to be commended either for modesty or for its presumed opposite, that neo-feminine virtue of self-reliance. In the early days of courtship she may, indeed, be coy enough - the seasonal promptings of nature are usually of tardier appearance in the female, but once her consent is given, the female Cassin becomes either a wanton or a clinging vine-or both. No sound is commoner, therefore, in the pine forests of the upper levels than the coaxing note, oreé-eh oreé-eh, of the female Cassin Purple Finch. It is delivered as often as not with quivering wings, and unmistakably invites the attentions of the male, sometimes to the visible embarrassment of that overworked, and consequently inattentive, individual. Perhaps it is fair to call this oreeh a love note, but it is delivered with the simpering insistence of a spoiled child. Ordered favors come tardily, and the wells of spontaneity are easily troubled.

When the mating season proper is over, and there are eggs to be incubated, she teases her husband for food, oreé-eh, oreé-eh. He is doing the best he can, poor soul! but she vexes him with reminders. "Yes, yes, dear. Don't you see I'm doing the best I can? Oh, anon!" Perhaps we do the lady an injustice, but wo have seen what we have seen. 


\section{The Cassin Purple Finch}

The male Cassin, on the other hand, is a gallant suitor and a good provider. When his heart is warmed with the fresh stirrings of passion, he fills the woodland with melody. He twitters good-fellow greetings to every passerby, and he tries the summits, first of one pine tree and then of another, honoring each with a sprightly round of song. If the notes are his own, they are poured out in a quick flood, lasting, perhaps, only two seconds. They are somewhat lighter in character, less rounded and mellow than the perfect flutings of the California Purple Finch. But

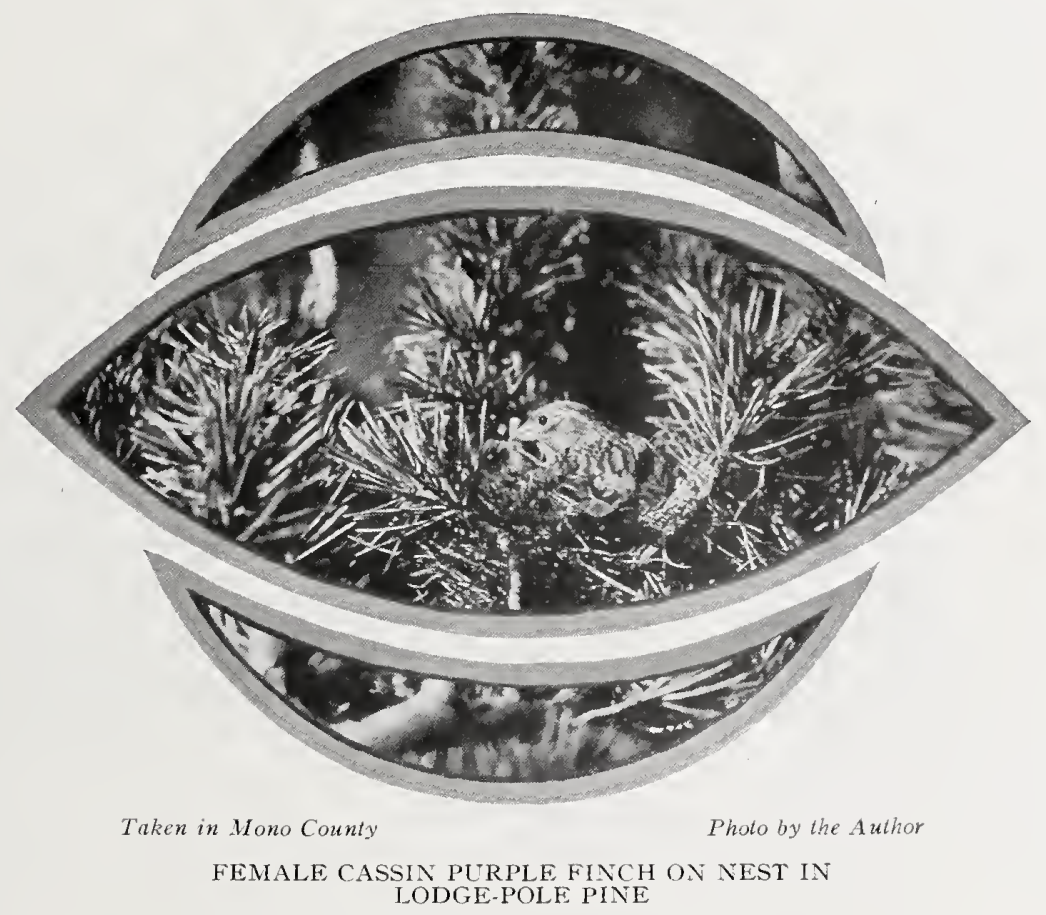

there is dash and brightness about them which is infectious. Like cousin purpureus, the Cassin helps himself freely to the common fund of woodland music. His obligation is unconscious - he is no mimic; but I have heard Western Lark Sparrow (carried up several thousand feet), Western Vesper Sparrow, Mountain Bluebird, and Western Tanager peeping out through Cassin's throat. Once, on Shasta, to our great delight, we heard the theme of the Townsend Solitaire. The exalted opening was purely Myadestine, but the quaver and jumble which followed were Carpodacine. Another medley heard in the Warner Mountains contained songs of the Sierra Junco, the Western Wood Pewee and the Western Ruby-crowned Kinglet. If a musician is known, so infallibly, by the company he keeps, we will not complain either of Cassin's morals or his art. 


\section{The Cassin Purple Finch}

He is an ardent lover, too. Once, upon hearing the note of a female Cassin Finch-she was seeking food and very intent upon the job-I gave attention and saw as pretty a sight as one could wish to see. A male in resplendent red plumage lighted on the ground beside the dull-colored female-or, more strictly speaking, he lighted at a distance of about two feet-and gave a coaxing squeak of singular intensity. Meanwhile, his crest was erected until it shone like a diadem of rubies, and he stood with outstretched wings quivering in an ecstacy of passion. The female made a spiteful run at him, whereupon he flashed away, and resumed, always at a distance of two feet. Again and again the play was repeated, the male resplendent with ardor and the female not even coy, only spiteful. Alas! for the untimed ardors. Alas! for the love that wakes too soon-or sleeps too late.

The great business of the Carpodacine life (the three species are alike in this) is nesting. This impression of the preponderating passion is heightened in the case of the Cassin Finch by the irregularity of the nesting season. Fresh eggs may be found at any time from June ist to July I5th, and that, apparently, with little reference to the "breeding level" (i. e., altitude of maximum activity for a given season) or the behavior of neighbors. Here a love-lorn couple are playing with a few sticks, pretending to build a nest - which as like as not they will presently tear down and rebuild elsewhere - while yonder a pair of birds are feverishly attending a nestful of clamoring young.

In choice of nesting sites great preference is shown for the lodgepole, or tamarack, pine (Pinus contorta). The nest is usually settled into the upper whorl of branches of a sapling, say, twenty or thirty feet high, or else placed near the tip of one of the lower branches of a full-grown tree. Having in either case the most thickly leaved pine twigs to depend upon for support, the outer structure of the nest is of the flimsiest character, usually a mere filling up of irregularities. The lining - and some nests are virtually all lining - is most carefully constructed and of highly varied materials. Horsehair is a favorite wherever obtainable, but feathers are rarely used. For the rest, fine grasses, rootlets or flower pedicels are staples; shredded bark, deer-and rabbit-hair or chance bits of cotton of rarer appearance. A pullet's nest is two and a quarter inches wide by an inch and a quarter in depth inside. A mother in Israel requires a nesting hollow three and a quarter inches wide by one and three-quarters deep. A nest taken near our Mammoth Lakes camp we call "the souvenir" because it contains, besides bits of cotton and hemp, a selection of human hair, strands from Barbarita's golden locks, orthodox raven tresses in abundance, and, I regret to add, a few threads of a compromising gray which no one of our party would own to. Quite the handsomest nest in 


\section{The Cassin Purple Finch}

the M. C. O. collection, however, is one which is lined with black horsehair picked out with bits of white cotton, and ornamented as to the brim with a few sprays of the brilliant yellow-green lichen (Evernia vulpina).

A word, perhaps, ought to be said for the nest and the bird which furnished the subject of our accompanying photogravure. I regret to say

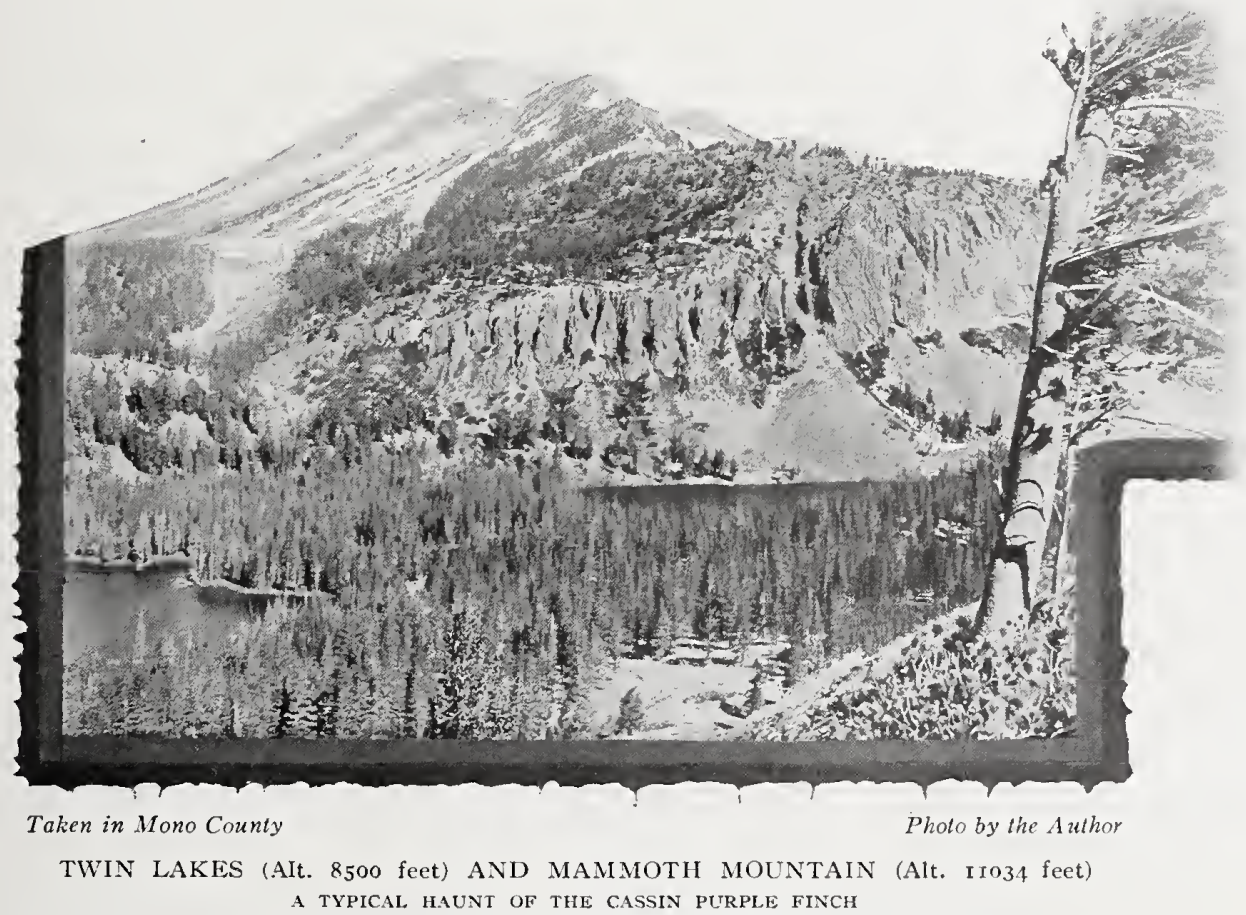

that so far as the lady is concerned it must be a somewhat disenchanting word. The nest was sighted near the top of a small Murray pine (Pinus contorta), say, 30 feet up and 4 feet out. Bird-nesting was our first business that year (I92 I), but I decreed a temporary stay of judgment in this case for photographic purposes. Arrived upon the scene and with legs firmly disposed about the main trunk, I not only found the female bird on but the male standing by, waiting, as the event proved, for a chance to feed his mate. I hauled up the camera by means of a small rope; but the light was not right, so I had to forfeit some magnificent poses. I sat within four feet while the male fed his mate, full tenderly, by regurgitation. I was much instructed to note what a lengthy and tedious process this was. While the female held her bill open, the male thrust food down her throat by means of no less than I $_{5}$ or I 8 distinct convulsive efforts, 


\section{The Cassin Purple Finch}

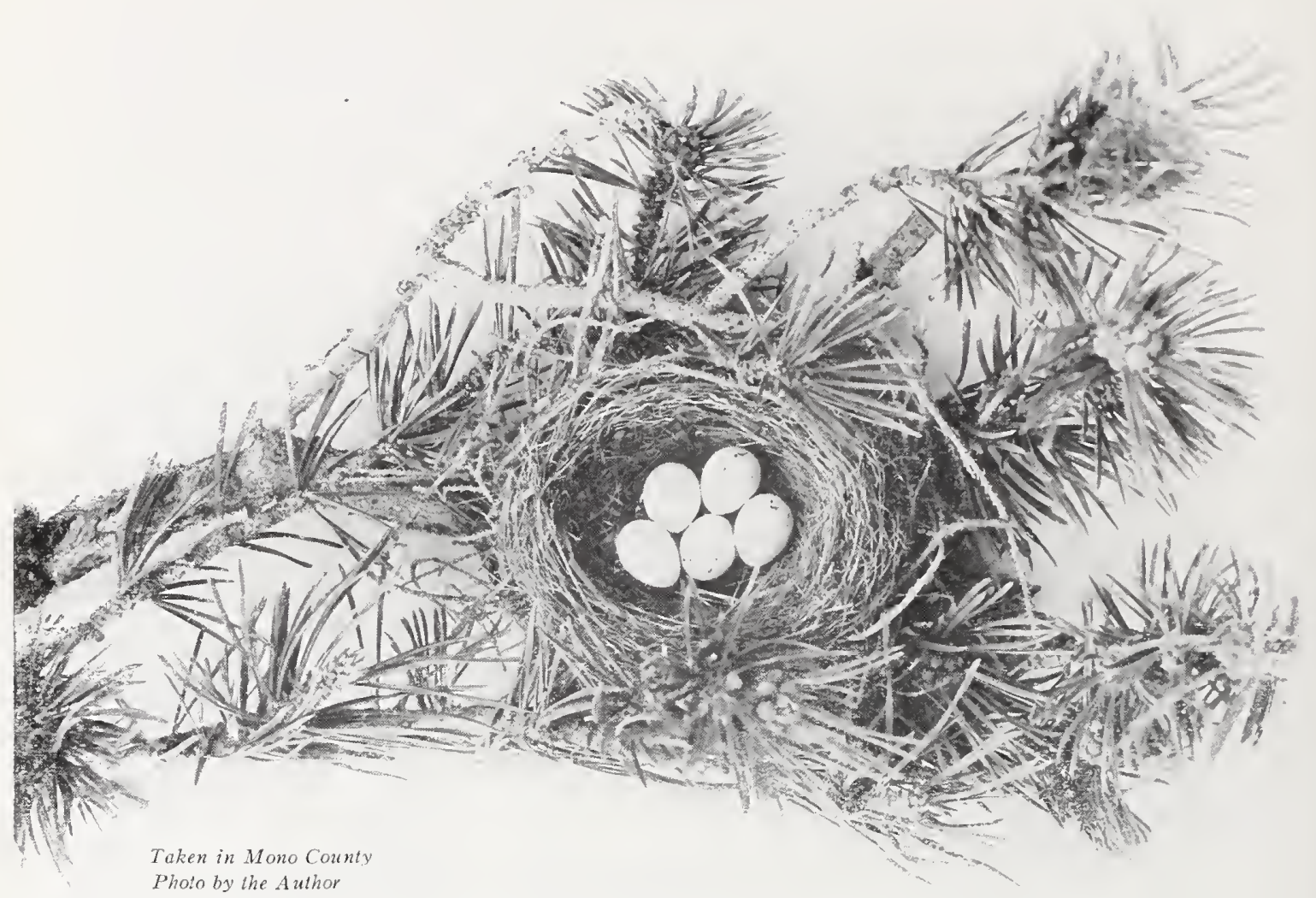

NEST AND EGGS OF CASSIN PURPLE FINCH IN MURRAY PINE (Pinus contorta) NOT IN SITU

each, apparently, successful. The female was so thoroughly stufferl that she made deglutitive efforts from time to time for as much as five minutes afterwards.

The female Cassin Finch was an ideal subject, but she was considerably shaded by closely investing branches, insomuch that my first six exposures were necessarily inadequate. But having secured "something", I ventured, for my last plates, to cut away the cover entirely, and found to my amazement that she would stand for it. At minimum range, $2 \mathrm{I} / 2$ feet, I shot down with the Graflex (Heliar lens) upon the bird, now fully exposed. Knowing that I had no more plates for the day, nor time on the morrow, I started to "collect" the nest, much against my photographic conscience and judgment. To my continued amazement the female allowed me to cut the branch at close range, and she did not quit her eggs until I had her within eight inches of my face. When with the nest branch in hand I extended it to its original position, she promptly sat again, and this time I hauled her in until she was within four inches of my 


\section{The Cassin Purple Finch}

face. This operation could undoubtedly have been repeated indefinitely, but alas! my plates were gone.

Never have I been torn by more conflicting emotions than upon this occasion, and never has the pathetic fallacy of avian domesticity been more thoroughly discredited.

When I had packed away the eggs and wrapped the nest in brown tissue paper and lowered it to the ground, the male and the female Cassin Finch searched about over the nesting site in utter bewilderment; but so far from sensing their disaster as a personal loss, they put in odd moments copulating, and once I saw the wanton female mount the male and go through the copulatory ecstacy.

In the face of such a display it is impossible to be swayed longer by anxiety or concern for domestic felicities in the bird. They are simply the agents of overmastering instincts, through which Nature accomplishes her benign purposes and achieves her infinite variety. To interfere at any point with these processes is no more a moral issue than is the wringing of a cockerel's neck when the pot waits.

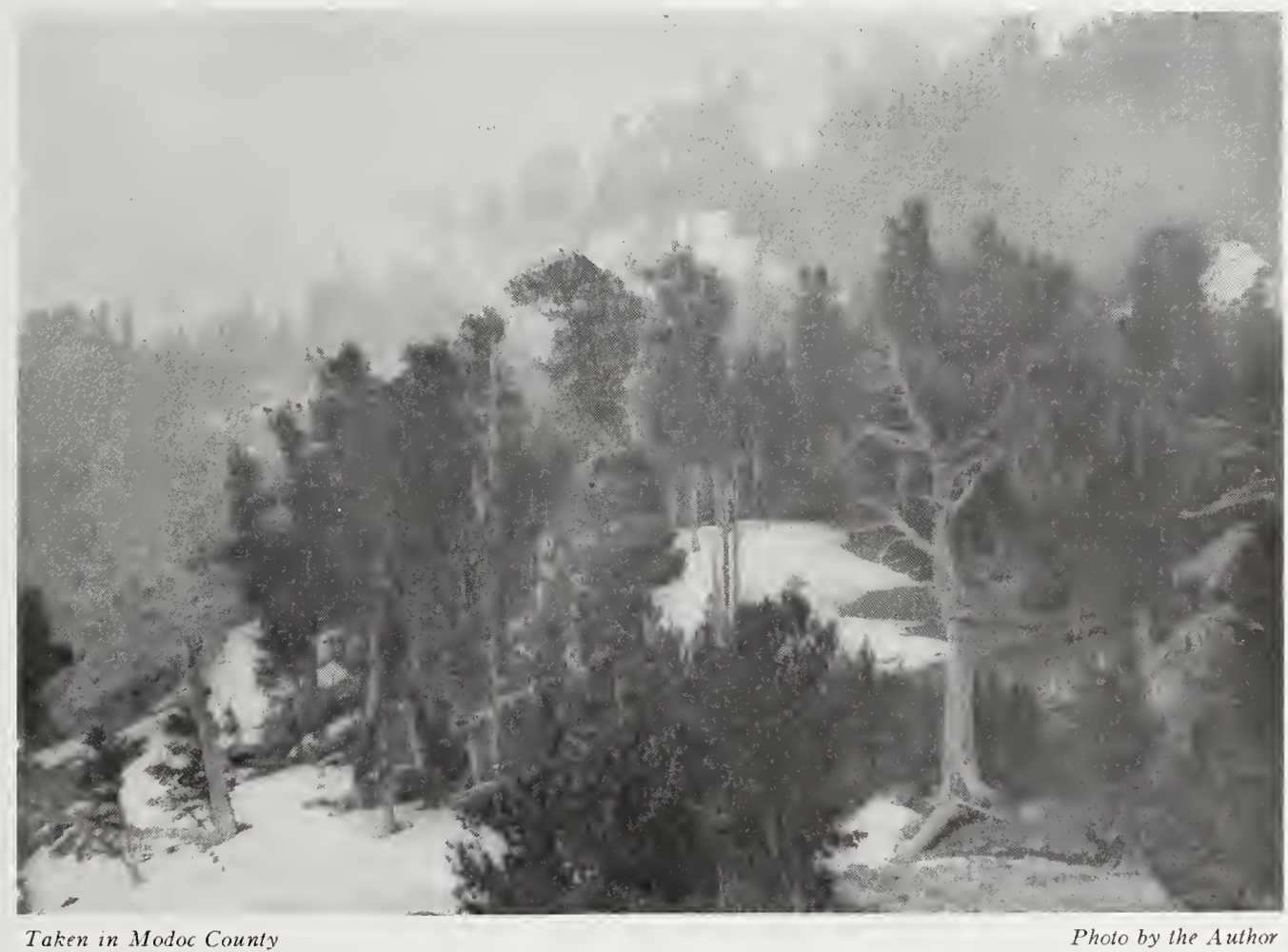

A NESTING HAUNT IN THE WARNER MOUNTAINS 


\section{California: Purple Finch}

\section{A. O. U. No. 5I7a. Carpodacus purpureus californicus Baird.}

Description.-Adult male: General body plumage dark red, or grayish red (oxblood red, vandyke red, pompeian red, occasionally vinaceous rufous), clearest on crown and upper tail-coverts, more or less mingled with dusky on back and scapulars, passing into white on crissum and under tail-coverts; wings and tail brownish dusky with reddish or bright brown edgings. Bill and feet brownish. In autumn, the color slightly duller and more blended. Adult female: Above olive dusky in streaks, with edging or gloss of brighter olivaceous; underparts whitish, everywhere, save on middle abdomen, crissum and under tail-coverts, streaked with olive dusky, finely on throat, broadly on breast and sides, shading into pattern of upperparts on sides of head, neck, and chest. Immature male, and male in ordinary (?) plumage: Exactly like female in coloration. Length about 158.7 (6.25); wing 80 (3.15); tail 60 (2.35); bill I I.9 (.47); tarsus I $8.3(.72)$.

Recognition Marks.-Sparrow size; dull rosy coloration of male (without crossed mandibles), but streaky pattern of tenest seen. Male differs from that of C. cassini in darker shade of red on crown, with less contrast. Requires careful discrimination from $C$. mexicanus frontalis, with which it sometimes associates loosely at the lower levels. Note greater extension of red, especially upon back; red usually but not always of a duller hue. In streaked plumage, more olivaceous and with somewhat coarser pattern. More sedate in bearing, but song more vivacious and better sustained.

Nesting.- Nest: A well built cup, composed externally of interlaced twigs, internally of mosses, fine grasses, string, horsehair, cotton waste, etc.; placed on horizontal or ascending branch of tree at moderate elevation ( 5 to 40 feet), and usually at considerable distance from trunk. Measures 5 inches $\left(\mathrm{mm} \mathrm{I}_{27}\right)$ wide by $3\left(\mathrm{~mm}_{7} 6\right)$

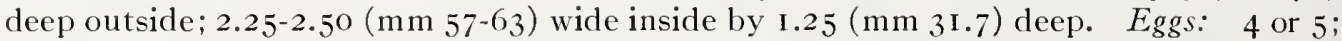
ovate to elongate ovate; light bluish green (microcline green), spotted and streaked, chiefly about the larger end, with dark olive-gray and a little black. Size rather variable; a typical set from Eureka averages $20.4 \times 14.4(.80 \times 57)$. Season: MayJune; one or two broods.

Range of Carpodacus purpureus.--North America from southern Canada south to the southern border of the United States.

Range of C. p. californicus.-Pacific Coast district, breeding from southern British Columbia and Vancouver Island south to southern California and east to the Cascade and Sierra Nevada Mountains. Although partially resident throughout its range, many of the northern birds retire in winter, so that the population in southern California is augmented, and a few pass as far south as the Santa Catalina Mountains in Arizona (Scott).

Distribution in California.-Common resident of Upper Sonoran and Transition areas west of the Sierran divide, especially coastwise, and on the lower western slopes of the Sierras and southern mountain system. C. p. californicus is a lover of cool weather and moisture, and its range is roughly complementary to that 


\section{The California Purple Finch}

of $C$. cassini. The higher residents retire irregularly to the lower slopes and adjacent valleys in winter. Casual in winter on Santa Cruz Island (Linton).

Authorities.-Gambel (Erythrospiza purpurea), Jour. Acad. Nat. Sci. Phila., ser. 2, vol. ii., I 847 , p. 53: Baird, Rept. Pac. R. R. Surv., vol. ix.. I 858, p. 4 I 3 (desc. of californicus); Cooper, W. A., Bull. Nuttall Orn. Club, vol. iii., I878, pp. 8-Io (nesting habits, nest and eggs).

TRUTH to tell, the people of California really know very little about the "California" Purple Finch. We owe the name (presumably good advertising) to an accident of discovery rather than to the character or prominence of the bird in California. The bird is not prominent at best, even in those regions - our northern sister states-where its presence is not overshadowed, as it is here, by that of the ubiquitous House Finch. The Purple Finch is rather a demure bird, quiet and inoffensive, "of the streaked streaky," and those streakings of a dull olivaceous quality which confers anything but distinction. The male, indeed, is entitled to a court dress of wine purple, but this regalia is not often seen, and we do not know to this day whether it is the badge of immaturity, or a mark of honor conferred upon old age. And even this brilliance may escape attention, for the bird's movements are not advertised by rattles or chirps, as is the case with so many of its cousins. A company of Purple Finches will feed so quietly in a blossoming fruit tree, for example, that no observer would suspect their presence, save for an occasional click of the mandibles. That the Finches do some mischief at such times is undeniable. I have seen them on a March morning, in Washington, feeding in the luxuriant bushes of the red flowering currant (Ribes sanguineum). They pluck the flowers assiduously, and either eat the fleshy part at the base, the tender ovary, or else press out the nectar just above, or both. A flower is first plucked off whole and held in the bill, while the bird appears to smack its lips several times; then the crimson corolla is allowed to drop upon the ground, which thus becomes carpeted with rejected beauty.

Like many related species, the California Finch is rather unwary, so that one may study his behavior at close range. To this fortunate trait we owe knowledge of the Purple Finch's virtues as well as of his peccadillos. Once as I was passing along my garden walk in August, several of these Finches were frightened from the gooseberry bushes. "What! eating my gooseberries too?" I frowned horribly. But one bird, presumably a young of the year, almost immediately returned to the very bush against which I was standing, and resumed his avocation, which proved to be that of gleaning caterpillars. At a distance of four feet I saw the bird search each gooseberry limb with the greatest care and devour a naked green worm about half an inch long, which my own eyes could scarcely have detected. Six or eight of these miscreants were devoured 


\section{The California Purple Finch}

before the bush was pronounced clean, whereupon the zealous deputy gardener flitted to another bush.

Because the Purple Finch is usually so unobtrusive, we are startled at the first outburst of spring song. Nothing more spontaneous could be desired; and the mellow, musical yodelling of this bird is one of the choicest things allowed us in the West. The song is midway between a trill and a carol, and has a wild quality which makes it very attractive. The notes are so limpid and penetrating that one is sometimes deceived as to the distance of the singer, supposing him to be in a neighboring copse, when, in truth, he occupies a distant fir-top. Cheedooreédooreé dooreé dooreé dooreé dooreé dooreé dreeetoreet may afford an idea of the rolling, rollicking character of the song, but is, of course, absurdly inadequate.

It is interesting to note that an experienced orchestral musician, Mr. F. N. Bassett, of San Francisco, rates the song of the Purple Finch as supreme in musical quality, only that of the Black-headed Grosbeak being, in this gentleman's opinion, at all comparable to it in respect to purity and rotundity of tone. According to this authority: "The Purple Finch pours his song forth in notes like liquid pearls, unmarred by poor tone quality or metallic accents. It is a finished performance of an unassuming, finished artist. It is not so melodious as the songs of many of our inferior singers, but the tone quality outclasses theirs." 1

A master singer among the Purple Finches once entertained us from the top of a fir tree a hundred feet high. He was in the dull plumage; that is, without red; and although he sang briskly, at intervals, we were not prepared for any unusual exhibition of vocal powers on his part. It was a long time, therefore, before we put the cry of a distant Steller Jay up to him. Our suspicions once aroused, however, we caught not only the Steller Jay cry, unmistakably, but also half a dozen others in swift and dainty succession, after the usual Purple Finch prelude. I clearly recognized notes of the Flicker, Steller Jay, Canary, Crossbill, and Bewick Wren. These imitative efforts varied in correctness of execution, and came to us with the distance of the original singer plus that of the Finch, so that the result was not a little confusing, though very delightful when explained.

During courtship this Finch will sometimes execute an aerial songdance, consisting of sundry jerks and crazy antics, interspersed with a medley of ecstatic notes; at the conclusion of which he will make a suggestive dive at his fianceé, who meanwhile has been poking fun at him. Courtship, in fact, is a strenuous matter, and though the female is docile, not to say amorous, after she is won, she knows how to exact the last farthing of tribute from the wooer. Once I saw a suitor who had quite

I"The Gull," Vol. III., no. 6, June, 1921, p. 2. 


\section{The California Linnet}

twigs of a live oak tree, at a height of thirty feet. Unfortunately, the California Jays robbed the nest, as they did another in the same grove; and so far as observation went, a small colony of these finches were practically prevented from nesting in that locality.

Nests are placed, preferably, near water, in evergreen or deciduous trees, and at heights varying from six to forty feet. They usually occur on a bough at some distance from the trunk of a supporting tree, seldom or never being found in a crotch. Composed externally of twigs, they are lined copiously with green moss, horsehair, and string; and contain four or five handsome blue-green eggs, spotted and dashed with violet and black.

Two broods are probably brought off in a season, the first about the 2oth of May and the second a month or so later. A sitting female outdoes a Siskin in her devotion to duty, and not infrequently requires to be lifted from her eggs. The male trusts everything to his wife upon these occasions, but is on hand to do his share of the work when it comes to feeding the babies.

No. 34

\section{California Linnet}

\section{A. O. U. No. 519 . Carpodacus mexicanus frontalis (Say).}

Synonyms.-California House Finch. Crimson-fronted Finch. Burion.

Description.-Adult male in highest spring plumage: Head and neck all around, throat, and breast, broadly, and rump, rich red (carmine, light carmine, or nopal red), or, rarely, tinged with orange; upper back more or less tinged with the same shade (but red never so widely diffused above as in C. purpureus californicus); remaining upperparts, wings, and tail brownish gray, or fuscous; margins of feathers vaguely paler; remaining underparts whitish, finely streaked with brownish gray (much more streaked than C. purpureus). Bill horn-color; feet and legs dark brown. In autumn, the reds duller (grayer), more blended, and more widely diffused; the intensity of red, especially, reduced on crown, where varied by darker centers to feathers (pure only on forehead); the wings with many edgings of pinkish, or brownish buffy, not present in spring. In this plumage the appearance of $C . m$. frontalis very closely approximates that of $C$. purpureus, the chief distinguishing mark being the presence of numerous and distinct dusky streaks on the posterior underparts, and their more buffy background. Adult female in spring: Above dull grayish brown, streaked with darker; below dull white, sharply and finely streaked with grayish brown or dusky; wings and tail grayish brown without distinguishing marks. Adult female in fresh fall plumage: Above, plumage more blended; wings with some marginings of lighter (buffy gray); 


\section{The California Linnet}

below, streaks broader and less distinct by reason of buffy edgings. Immature birds resemble the female parent, but are more finely streaked with dusky below, and more heavily margined by brownish buffy, especially on wing-coverts and tertials. Length about I 54.9 (6.I0): wing 78 (.3.07); tail $56(2.20)$; bill $10.4(.4 \mathrm{I})$; depth at base 9.6 $(.38)$; tarsus I $7.8(.70)$. Females have slightly shorter wing.

Recognition Marks.--Sparrow size; red and streaky plumage of male; all streaky pattern of female. In spring, males are brighter red than males of $C$. $p$. californicus; in autumn they are more thoroughly streaked below; red of back more restricted (spring), or paler (autumn). Female not certainly distinguishable from that of the Purple Finch in autumn, but upper plumage rather more blended and grayer, less olivaceous.

Nesting.- Nest: Placed in almost any conceivable situation, but chiefly about buildings or in crannies of cliffs, and in places offering more or less protection; as, Monterey cypress trees, beds of "prickly pear" (Opuntia) cactus, old birds' nests, and the like; a sturdy cup, constructed, often, with great taste from carefully selected and uniform materials; as, string, straw, grasses, etc.; or else compacted of every available sort of soft materials. Eggs: 4 or 5 , rarely 6 ; thin-shelled, very pale bluish green, or, rarely, white (quickly fading to white upon exposure), sharply and sparingly spotted, chiefly about the larger end, with dark brown, blackish, or purplish blackoccasionally immaculate. Av. of 42 California-taken specimens in the M. C. O. coll.: I $8.5 \times 13.7(.73 \times .54)$. Season: March to July; 2 or 3 broods.

Range of Carpodacus mexicanus.- Western United States from Oregon, southern Idaho, and southern Wyoming, east upon the plains to Kansas, and south throughout Lower California and to southern border of the tableland of Mexico.

Range of $C . m$. frontalis.-As above, excepting the southern half of Lower California and the southern portion of old Mexico.

Distribution in California.-Abundant resident throughout the State below Transition; numbers reduced in northwestern humid portion, and confined on deserts to vicinity of water, and somewhat dependent in great central valley upon vicinity of "culture"; breeds up to 6000 or 7000 feet, or exceptionally, to 8000 (Mammoth Camp, Mono County); passes irregularly to higher altitudes in late summer. Found also on all islands contiguous to California.

Remark.-An alleged form, clementis, originally described by Mearns (Auk, Xr., I 899, pp. 258-26I), from San Clemente Island, is here relegated to synonymy. I quite agree with Howell's conclusion (Pac. Coast Avifama, no. I2, I9I7, pp. 73-75) that we have "not a single constant character whereby clementis can be identified."

Authorities.-Audubon (Fringilla frontalis), Ornith. Biog., vol. v., I 839, pp. 230232; Gambel, Journ. Acad. Nat. Sci. Phila., ser. 2, vol. i., I 847 , pp. 53-54 (habits); Keeler, Zoe, vol. i., I 890 , pp. I $72-\mathrm{I} 76$, pl. vi. (life history); Beal, Biol. Surv. Bull., no. 30, I907, pp. I3-23, pl. ii. (food); Grinnell, Univ. Calif. Publ. Zool., vol. 7, I9I I, pp. I79-I95 (coloration); Tyler, Pac. Coast Avifauna, no. 9, I9I3, pp. 74-75 (status in Fresno district); Shepardson, Condor, vol. xvii., I9I5, pp. IOo-IoI (laying in nests of other birds).

A KINDERGARTEN teacher of our acquaintance tells of a little girl in her care who shows a precocious interest in birds. One day when the teacher was exhibiting some skins of local birds, a linnet was held up for identification. "Oh, I know what that is," cried the tot excitedly, 


\section{The California Linnet}

"that's the limit." There are farmers, at least, who will endorse this sentiment, not to mention amateur gardeners, park commissioners, and various and sundry, charged or selfcharged with the maintenance of the public weal. What tidy housewife, contemplating the litter of springtime upon her porches, has not felt, upon occasion, that the limits of hospitality have been reached? Or what suburban fruit-grower, faced with half-eaten peaches or plums, but has felt that the limits of patience have been passed? And yet, I suppose, there is not another bird in the West which is responsible for so much amiable discourse, so much friendly camaraderie, so much homely good cheer withal, as this ubiquitous "linnet." The bird is part and parcel of our California life, as much to be taken for granted as sunshine and dry weather. The linnet is the breadand-butter of the bird feast which life daily spreads before us. We may pass it over, for the nonce, in favor of more notable dainties, but it is staple. We will come back to it. For my part, I confess without shame, that I am fond of the linnets. They may

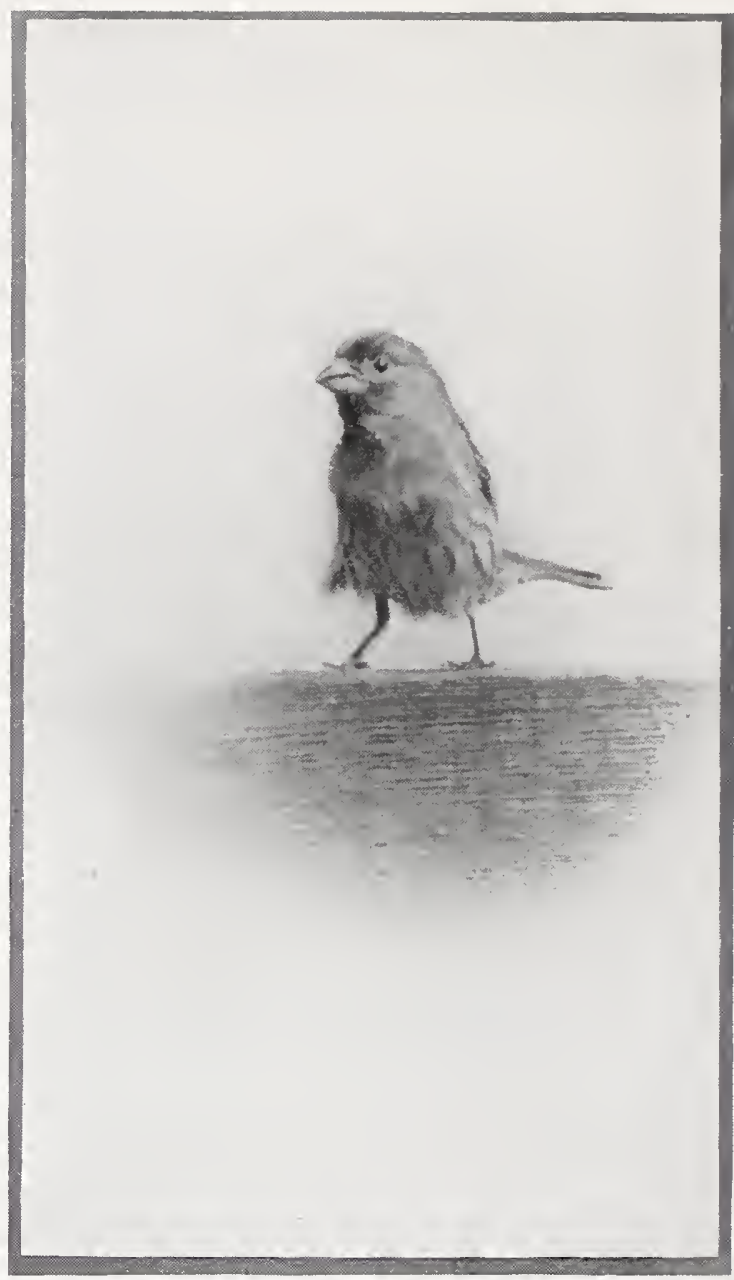

Taken on Santa Cruz Island

Photo by the Author

GOOD MORNING, SIR!

litter my porches and they may strip my vines if they like. I will take my pay in music,- that incessant, uplifting chorus of commonplace joy. It is reward enough to see the happy creatures breeding and brooding under our very noses, and lavishing upon us that flattery of confidence which they possess in common with our own children. They are not angels; and sometimes we call them dirty little brats-the birds, I mean-but the home that is not surrounded by an investing halo of linnets, I hold it to be unblest.

The House Finch is without question the most abundant bird in California. It probably outnumbers all other resident species three to one, and in some localities ten to one. It does not to any large extent 


\section{The California Linnet}

invade the chaparral nor the deserts, per se, nor does it seek to possess the mountains; and yet within its range it gives an impression of ubiquity which is very nearly supported by the facts. The bird's adaptability is marvelous. It is practically without associational restraints, and although its preference is for cultural surroundings, it makes its home in the most secluded barrancas, or haunts alike the cliffs which front the cattle range, and those which face the sea.

Of course, this associational adaptability presupposes, or depends upon, accommodation in food habits. Feeding originally upon seeds and the minor fruits, the bird's tastes quickly parallelled those of mankind. If it was barley that these gracious hombres, their hosts, planted, why then the birds would eat barley,-barley by the handful, barley by the bushel, barley by the acre, or so at least the jealous farmer claimed. Later it was fruit. If we would persist in setting out such delectable dainties as plums, and cherries, and apricots, and nectarines, why, of course, our little pensioners, the aborigines, began to help themselves. Why not? And if the damage is beginning to run up into big figures, millions, they say-again a wee exaggerated, I fear-well, I'm afraid there is going to be trouble. But let us think the problem all the way through.

Admitting that some of the witnesses are prejudiced, let us, nevertheless, hear what all of them have to say, and then let us weigh conclusions. Comes the Bird-Lover, who says: "The California Linnet is a native species of unusual attractiveness. His sprightly, varied song is pleasing to all ears, and even his minor notes, his chirpings and chipperings, have a musical and not unpleasant quality. In disposition these birds are singularly amiable. Never quarrelsome and abusive, like the English Sparrow, the Linnet gets along well with its own kind and with its immediate neighbors. Moreover, its manifest attachment to the human race has endeared it to the hearts of bird-lovers everywhere. The bird is never impudent, or blatant, or strident. It comes and goes pleasantly, trustfully, modestly. Although its association with man is fairly close, it is not known to be a filth accumulator, nor a disease car-

Taken in Teniura County Pholo by Donald R. Dickey

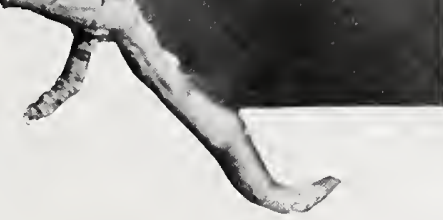

THE GRAVITY OF YOUTH rier; and the presumptions are all in favor of a helpful, happy association for mutual benefit." 


\section{The California Linnet}

Comes now the Agriculturist (call him farmer, fruit-grower, or what not) and testifies: "I have seen the birds in my barley fields. They pick up grain in the barnyard, and it stands to reason that they are damaging the crops. I'm trying to raise a little fruit, an acre or so of mixed varieties, but the linnets beat me to it every year. They bite into an apricot, and if they don't eat the whole of it, the smaller birds or the yellow-jackets finish the job. Not content with one or two peaches at a time, they pick into a dozen, and have the whole crop rotting before I

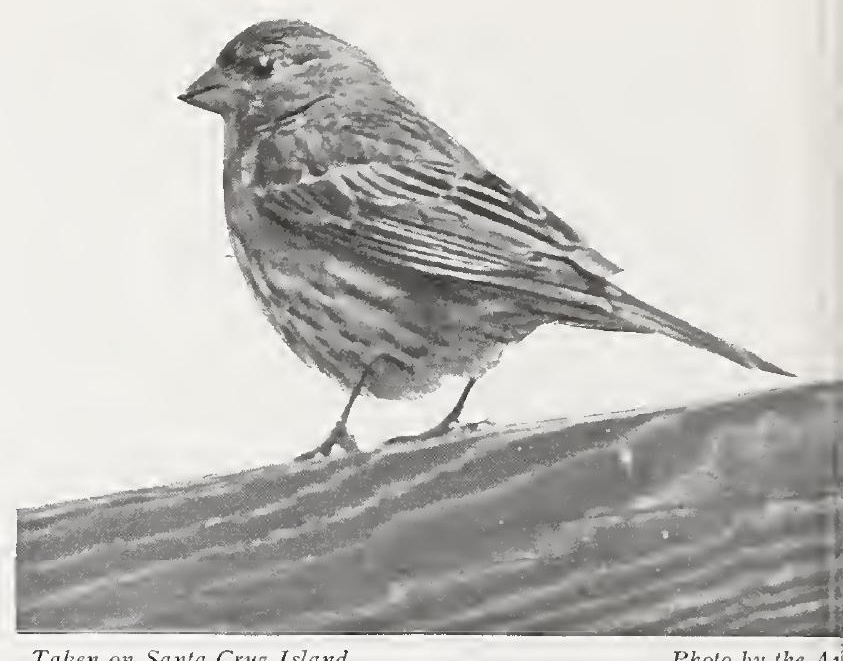

Taken on Santa Cruz Island

A NATIVE SON

know it. The only way I can head them off is to spread mosquito netting over the tree; and that's a pretty hard, not to say expensive, piece of business. I work hard enough for a living, as it is, and I'd like a little fruit once in a while to help out."

Comes now the Economist, the Government Expert, and he says: "What these gentlemen say, most of it, is true. The linnet does eat a little grain, and it does do considerable damage to fruit, especially in small, outlying orchards. It is practically impossible for a small grower to raise fruit without the use of netting, unless the numbers of linnets are either substantially reduced, or unless they are intimidated by some special means. But the alleged destruction of grain has been greatly exaggerated. The bird eats chiefly fallen grain, and this item does not arrount to above one-fourth of one per cent of the total diet for the year. In the case of fruit, the damage is not much felt by the larger growers. The birds do not flock extensively during the early fruiting season, and their depredations are chiefly confined to the edges of the orchard. The increase of fruit-growing does not appear to be a controlling factor in the abundance of the birds; although it may prove necessary in some cases to reduce their numbers and to keep them within bounds.

"On the other hand, House Finches are enormous consumers of weed seed. In the autumn they make common cause with the goldfinches, and together, in immense flocks, they purge the fields of many weeds which otherwise would increase to plague the farmer. Nature's balance depends upon the maintenance of very considerable numbers of these birds. The total or even approximate destruction of the species would probably work an enormous hardship upon agriculture." 
Needless to say, the author yields deference to the economist; but before sentence is pronounced upon even a portion, say a half or twothirds of these birds (and then only under the strictest local necessity), he would respectfully urge one very important consideration peculiar to California. We are menaced by the invasion of the English Sparrow. Having conquered the East, this blatant foreigner is not only pressing upon our borders, but he is penetrating along every line of least resistance into our most intimate midst. Resistance on our part is almost hopeless. We may shoot and trap and poison till doomsday, but by such methods we shall only partially abate the nuisance. But, fortunately for us, we have a powerful ally in the defense. It is the California Linnet. He is already on the ground, and he is thoroughly entrenched. The sparrow's place is preoccupied. It is only because the English Sparrow found an economic gap, an unfilled place in the scheme of things, that he spread through the East like an investing army. That gap does not exist here. The question with us is, shall we have Linnets or English Sparrows? For in proportion as we sacrifice our Linnets, we shall encourage the Sparrows. To my mind there can be only one answer to this question. Save in the matter of the injury done to fruit, the Linnet, compared point by point with the English Sparrow, is far and away the more desirable citizen. Tuneful, where the foreigner is strident; mildmannered and sociable, where the interloper is clannish and brutal; happy and innocent, where the gamin is surly and spiteful. One has

"THE CHOLLA CACTUS IS AN ACCUSTOMED COUCH"

Photo by the Author

Taken in Ventura County 


\section{The California Linnet}

only to review the quasi-personal qualities of these contrasted birds, to make instant choice. If we must have satellites, by all means let us have Native Sons. The Linnet is our best bulwark against the Menace.

Not the least interesting aspect of bird study is what we might call comparative genology. By this we mean a study of the vital characters which distinguish species, a study of geno-dynamic values, as distinguished from studies of structural features, habits, psychology, etc. A geno-dynamic appraisal, to be of any value, must involve a pretty thorough knowledge of the present status of a given species, its distribution, its associations, its reactions with other species, its adaptation to changing environment. It presupposes a deep knowledge of taxonomic relationships and of phylogeny-in short, the racial history of the bird. Its task, as I conceive it, is to estimate the relative value of a species, and to express that value in terms of energy and achievement, noting in each case direction of development, rate of developmental progress, degree of success or failure, mobility, adaptability, and the like.

Those whose interest has survived the preceding paragraph will

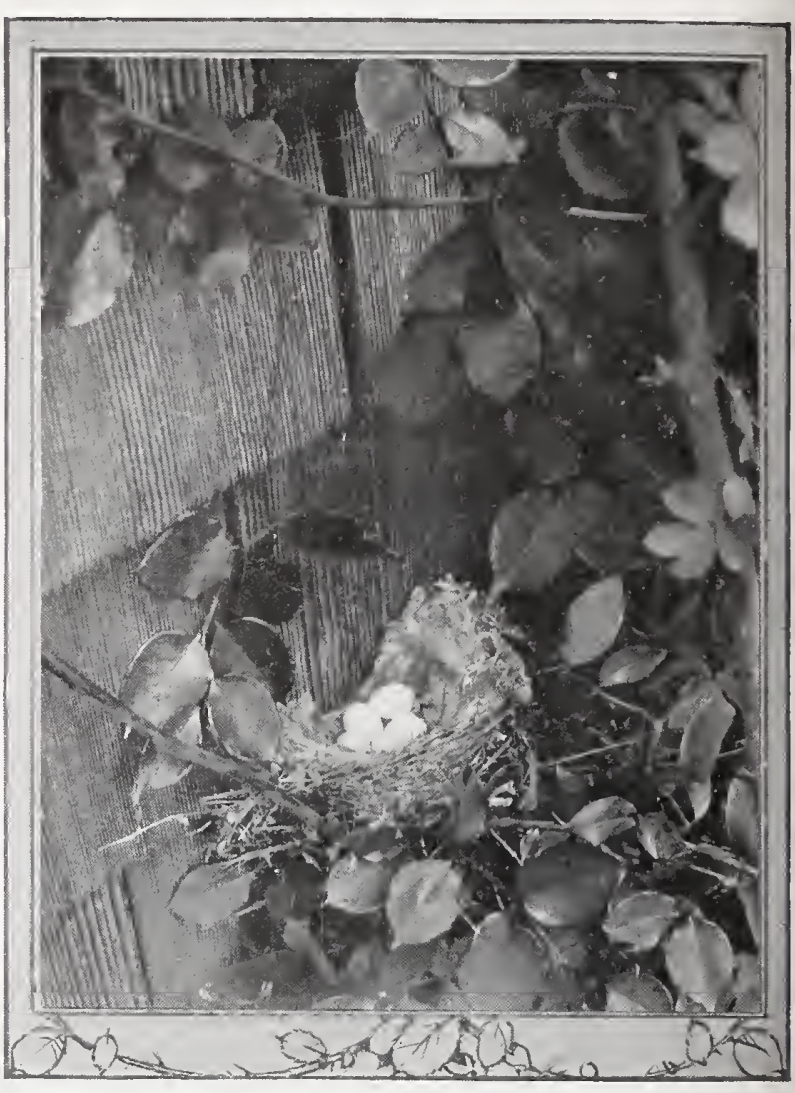

Taken in I'entura County

Phoio by D. R. Dickey

THE GARDENER'S COTTAGE

NEST AND EGGS OF CALIFORNIA I.INNET

be prepared for a geno-dynamic appraisal of the House Finch; but in expressing it we will use common terms, instead of seeking to evolve or further define a special vocabulary, such as every budding science requires.

The species Carpodacus mexicanus is of northern extraction, as evinced by its similarity to certain Asiatic forms. It was the first of its genus to flee southward before the advancing ice of the Glacial Epoch; and upon the retreat of the ice, the species quickly accommodated itself to the diverse and rapidly changing conditions of its new home, viz., the highlands of western Mexico and the lower levels of the southwestern states, instead of following the glacial retreat more closely, as did C. cassini and $C$. purpureus. We may affirm that the species mexicanus accom- 


\section{The California Linnet}

plished this adjustment by virtue of its inherent and special adaptability (however derived). This phenomenal adaptability, or tolerance of change, still remains the most prominent inheritance, or characteristic, of the species, and has made it the dominant form of the region which it occupies. This adaptability owns only one restriction, albeit an important one. The House Finch is closely dependent upon water, and is rarely found breeding at a distance above half a mile ("a few hundred yards," Dr. A. K. Fisher says1) from stream or spring. But again, adaptability, or ease of accommodation to environment, is not to be confused with plasticity, which is, rather, susceptibility to change in environment, and which reflects itself in the altered structure or appearance of the bird. Of this latter characteristic the Song Sparrow, Melospiza melodia, with its twenty subspecies in California alone, is a most conspicuous example. The House Finch, on the other hand, overrides obstacles, and is able to absorb, as it were, the shocks of change within its corporate, or specific, body, without evidence of corresponding somatic change.

One of the results of this ability is a certain tendency to vary, which exhibits itself in off-plumages and freaks, quite independently of association or environment. Thus, it is well known that partial albinism is common among House Finches. Among adult males, also, a more or less complete substitution of yellow for red is sometimes encountered. Caged birds are certain to lose their rosy tints, and to put on this mongrel yellow. That this tendency to dichromatic manifestation is more evident in insular examples is probable; and it may be that insular conditions, like confinement, for some reason fail to support the production of red pigment. As a further example of freakishness, Swarth cites a case where two young females, caught in the wild, showed distinct traces of red in their plumage.

This trait in the House Finch, which we have rather carelessly called the tendency to vary, may either be due to the species having reached the saturation point of numbers, or the limit of vitality in development. Conceivably these freakish manifestations may be evidences of phylogenetic weakness, or approaching decay, rather than promises of new departures in development. On the whole, I think the evidence of the eggs rather supports the latter view. The type is weakening. Whereas the egg is normally pale bluish green with blackish markings, sparingly applied, white shells are not rare, and some sets are entirely devoid of markings. Runts and other freak eggs are relatively numerous in this species, also.

But without pausing longer to establish the geno-dynamic status of the species, we hasten to note that in its nesting habits the California Linnet exhibits the utmost diversity of taste and the utmost degree of

1 Report Death Valley Expedition (1893), p. 80. 


\section{The California Linnet}

accommodation to varied conditions. The bird does nest about houses and outbuildings, multitudinously; but the very name House Finch is so often challenged by experiences afield, that one is sooner inclined to call it devil finch or spook finch. Does one penetrate the fastnesses of the cattle country, where the Dalton gang and the James boys used to hold forth, it is to study the mighty Eagle, or to trace the "bullet hawk" (Falco mexicanus) to its ledge. But lo, the "House" Finch has set its little tepee in a cranny beside the noble falcon; and while the falcon hurls its thunders from the blue, this tedious chit simpers and chirps as though its tiny affairs were nature's chief concern. Does one visit the cliffs at Pizmo to get the salty sting of the gales, or "to hear old Triton blow his wreathed horn," lo! the House Finch has come before. Here upon these storied cliffs, where birds of high and rare degree, Peregrines, Surf-birds, Royal Terns, pause, in passing, to greet the shore, these irreverent commoners gossip and flutter, or gather straws. Not even the occasional presence of the Whitethroated Swift, the speed demon of the upper air, daunts these hardy sansculottes. They, too, disport themselves aloft, or wing placidly across some yawning chasm which the sea has cleft, heedless alike of the buffeting wind and of the fretful seamews. House Finch, indeed! Why, there is no juniper tree where a

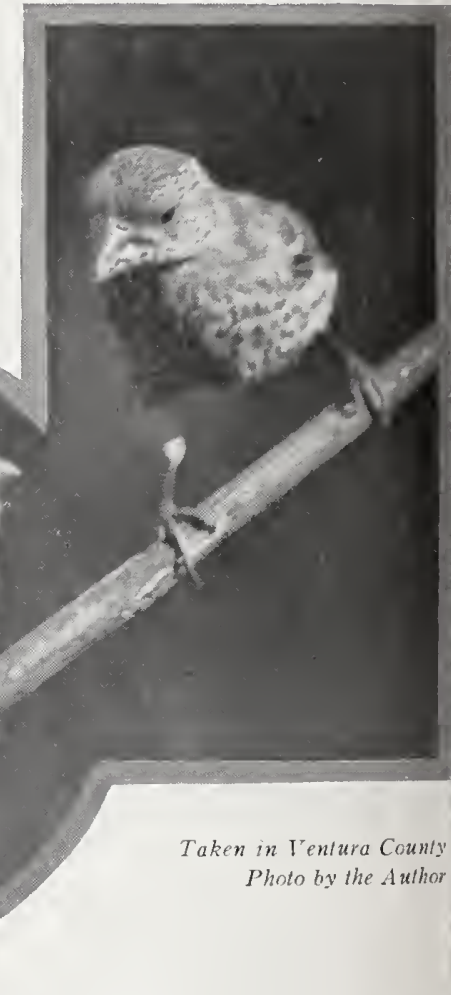

NOT VERY HUNGRY, I GUESS man may be alone with his Maker, but this bird hops in its branches and twangs his little lute!

The House Finches nest almost anywhere. If you want a playmate to engage in a state-wide game of hunt-the-thimble, confer with this bird before issuing the challenge. Nests are caught in vines, or placed on timbers, under cornices, in bird-boxes, mail-boxes, or in any cubbyhole which an outbuilding offers. Mr. E. C. Mailliard' tells of a pair which built in a garage, and which followed the fortunes of its nest while, for experiment's

${ }^{1}$ Condor, Sept., 1917 , p. 166. 
sake, this was shifted about from place to place, until it had occupied "every available spot" in the building. Eggs were laid under these trying circumstances and were hatched successfully, although the birds deserted when the man stayed around too long. The exposed ends of mission tiles are favorite places to fill with sticks. Bridges, windmills, piers, warehouses - nothing which promises shelter is overlooked. Trees of any sort and of any height are available,--cypresses, live oaks, sycamores, cottonwoods and willows, even the inhospitable eucalyptus. I have found nests in the open sage a mile from timber. The cholla cactus is an accustomed couch when not too far removed from water. On the San Jacinto River we found nests settled against the stems of the great blossom stalks of Yucca whipplei.

Choice of nesting materials is as catholic as that of nesting sites. Again the catalog comprises anything soft and available: straw, grass, weed-stems, flower-heads, string, wool, cotton, vegetable down, barkstrips, moss, horsehair, and, rarely, feathers. There is, however, real artistry among the House Finches, and often the builder makes choice of a single material, so that there is a tasteful simplicity in the finished product. A nest taken near Los Banos is composed almost exclusively of the half-developed buttons of the sycamore tree, together, of course, with their lengthened and very pliable stems. Another taken from a neighboring tree was composed of willow twigs interspersed with the seed. stalks of the shepherd's purse (Capsella bursa pastoris). Another bristles with the outstanding heads of a Briza. A specimen in the M. C. O. collection is composed almost entirely of cords plucked from old fish nets. Another taken from the porch of Mr. John Driver, in Montecito, is built of our charming gray lichen-and so through an endless catalog.

Most interesting of all is the House Finch's habit of appropriating old birds' nests. The primary thought is that of shelter; and those which afford the deepest shelter are oftenest used. Thus, we find old nests of the Bullock and Arizona Hooded Orioles great favorites. The mud bracket of the Barn Swallow is often re-rented, and the abandoned tenements of Cliff Swallows are occasionally invaded. In most cases the finch provides a new lining, one better moulded to her own form than the old structure. In the case of a pair using an old magpie's nest, the only mark of association evidenced by the nest proper was that its outer aspect upon one side curved in conformity with the larger bowl of the pie. But again, the finch's contribution may be a mere apology; and there are signs of a definite tendency toward parasitism, as betokened by this slovenly use of other birds' nests. Mr. D. I. Shepardson recordsı several instances where eggs of the House Finch were found with eggs of other birds. In one case,

${ }^{1}$ Condor, Vol. XVII., Sept., 1915, pp. 100-101. 


\section{The California Linnet}

that of a Cliff Swallow's nest containing three eggs of the owner and two of the House Finch, it is perhaps as fair to assume that the finch attempted to occupy the swallow's nest before the owner had begun laying, and was driven out upon the Cliff Swallow's assumption of duty. In another, that of an Arizona Hooded Oriole, the observer supposed that the finches had driven off the rightful owner and had established themselves. A third instance, of a Black Phoebe's nest containing five well incubated eggs of the Phoebe and one partially incubated egg of the House Finch, we may suppose either an unsuccessful attempt on the part of the House Finch to take unlawful possession, or else a more fortuity, a "dropped" egg, such as homeless females are occasionally guilty of. It is easy to see, however, that temptation lurks along this path. The habits of this very domestic bird will bear watching.

Usually the nesting of the House Finch is a matter of unceasing industry, two or three broods being raised each year. Tyler, however, found a company of birds haunting a raisin warehouse in Fresno County, which he was convinced did not breed at all during an entire season.

The young birds are little tyrants, yet as "cunning" as they are insatiable. They follow their parents about with importunate cries when we would judge them fully able to care for themselves. But mother doubtless knows best, and it certainly is a pretty sight to see a busy mother stuffing food down the throat of a tremulous hobbledehoy who looks at least half a size larger. And the youngster doesn't forget his manners, either. If he does say "Please" pretty often and pretty emphatic, he also says "Thank you" all over, with quivering wings, which to my notion are most expressive and grateful.

And when the family life of the House Finch is merged in the greater life of the flock, this charm of manner is not all forgotten. Though the songs of springtime are hushed, the keep-in-touch notes are still cheerful and friendly. And when a cloud rises, two or three thousand strong, from a wayside weed-patch to settle on the telephone wires, the heart of the passerby insensibly warms as he hears pleasant greetings and a babel of polite discussion. Surely, these are amiable bird-folk, and we may thank our lucky stars that California has bred gentlemen-commoners instead of gibbering assassins. 


\section{The English Sparrow}

No. 35

\section{English Sparrow}

Introduced. Passer domesticus (Linnæus).

Synonyms.-The Sparrow. House Sparrow. Domestic Sparrow. Street Sparrow. Gamin. Hoodlum. Mobring Sparrow.

Description.-Adult male: Pileum and occiput deep mouse-gray; rump and upper tail-coverts mouse-gray, tinged with olivaceous; back, wings, sides of neck, and supra-auricular region chestnut, varied on back and wings by black centers of feathers; tips of median coverts white, forming a conspicuous transverse bar; lores, region below eyes, chin, throat, and breast, broadly, black; cheeks and sides of throat dingy white; the remaining underparts smoky gray. Bill black; feet brownish. Immature male: Like adult, but chestnut area on sides of head and neck veiled and tipped with buffy; the black of throat and breast reduced in area and more or less veiled with white tips. Adult female: Somewhat similar to adult male, but without chestnut of upperparts and sides, and without black below; upperparts brown (between Saccardo's umber and sepia) on pileum and rump, this color shading on sides and breast into the lighter tone of remaining underparts; back, tail, and wings extensively black, edged by pale cinnamon; a dull buffy supra-auricular stripe, bordered by dusky, takes the place of the chestnut stripe of the male. Length I 39.7-I58.8 (5.50-6.25); wing $76.2(3.00)$; tail $55.9(2.20)$; bill I $2.7(.50)$. Sexes of about equal size.

Nesting. - Nest: If in a tree or other situation requiring structural consistency, a bulky sphere of grass and trash, with entrance hole on side, and heavily lined with feathers; otherwise a varied filling of hole, niche, or cranny, whether in trees or cliffs or about buildings, but always copiously lined with feathers. Eggs: 4 to 6; white; heavily sprinkled and spotted with grayish brown (hair-brown to bone-brown with drab shadings), pigment usually uniformly distributed and sometimes obliterating background; otherwise (often one egg in each clutch) more sharply defined and showing tendency to confluence in coronal wreath. Av. size 2 I.8 $\times$ I5.8 (.86 $\times$.62). Season: March to September; several broods.

General Range.-Nearly the whole of Europe (except Italy) and Siberia to Irkutsk and Dauria, south through Asia Minor, Persia, India, and Ceylon to Cochin China. Introduced into North America, New Zealand, Australia, etc.

Distribution in California.-Introduced to San Francisco about I87 I or I872; now increasing at lower and middle levels throughout the State, but still radiating from "cultural," especially railroad, centers. Introduction into southern localities much retarded by presence of California Linnet (Carpodacus mexicanus frontalis), and still more or less under control. Passer domesticus knows no barriers of temperature or humidity, and thrives alike in Del Norte County or in the Colorado desert (Mecca, Jan. 30, I9I3). It is crossing to the islands (Farallons, May 29, I9II; Santa Cruz, April 12, 1915), but is not likely to invade the upper slopes of the Sierras.

Authorities.-Barrows, U. S. Dept. Agric. Div. Orn. \& Mamm., Bull. no. I, I 889, pp. I9, 20I, 262 (history of arrival and spread in Calif.); Belding, Occ. Papers, Calif. Acad. Sci., 2, I890, pp. I68-I69; Willett, Pac. Coast Avifauna, no. 7, I912, p. 


\section{The English Sparrow}

76 (history in s. Calif.); Grimnell, Pac. Coast Arifauna, no. 1I, I9I5, Pp. III-II2 (history of spread throughout Calif.); Phillips, J. C.. Auk, vol. xxxii., I9I5, pp. 5 I-59 (crit. compar. of Old World and Amer. spec.); Grinnell, Amer. Nat., vol. liii., I9I9, pp.'. 468-473 (comment on occurrence in Death Valley).

WHAT a piece of mischief is the Sparrow! how depraved in instinct! in presence how unwelcome! in habit how unclean! in voice how repulsive! in combat how moblike and despicable! in courtship how wanton and contemptible! in increase how limitless and menacing! the pest of the farmer! the plague of the city! the bane of the bird-world! the despair of the philanthropist! the thrifty and insolent beneficiary of misguided sentiment! the lawless and defiant object of impotent hostility too late aroused! Out upon thee, thou shapeless, senseless, heartless, misbegotten tyrant! thou tedious and infinite alien! thou myriad cuckoo, who dost by thy consuming presence bereave us daily of a million dearer children! Out upon thee, and woe the day!

Without question the most deplorable event in the history of American ornithology was the introduction of the English Sparrow. The extinction of the Greak Auk, the passing of the Wild Pigeon and the Turkey, - sad as these are, they are trifles compared to the wholesale reduction of our smaller birds, which is due to the invasion of this wretched foreigner. To be sure he was invited to come, but the offense is all the more rank because it was partly human. His introduction was effected in part by people who ought to have known better, and would, doubtless, if the science of ornithology had reached its present status as long ago as the early Fifties. The maintenance and prodigious increase of the pest is still due in a measure to the imbecile sentimentality of people who build bird-houses and throw out crumbs for "the dear little birdies," and then care nothing whether honest birds or scalawags get them. Such people belong to the same class as those who drop kittens on their neighbors' door-steps, because they wouldn't have the heart to kill them themselves, you know.

The increase of this bird in the United States is, to a lover of birds, simply frightful. Their fecundity is amazing and their adaptability apparently limitless. Mr. Barrows, in a special report prepared under the direction of the Government, estimates that the increase of a single pair, if unhindered, would amount in ten years to 275,7 I $6,983,698$ birds. The number actually alive in America today must run well into the billions.

As to its range, we note that its subjugation of the East has long been accomplished, and that the occupation of the West now involves every considerable town and village. According to Professor Grinnell, to whose careful review ${ }^{1}$ I am largely indebted, the English Sparrow, having

${ }^{1}$ Pacific Coast Avifauna, no. 11, Oct., 1915, p. 111 


\section{The English Sparrow}

first been purposely introduced at San Francisco in I 87 I or I 872 , made its way by means of the transcontinental railways, and by 1886 had become thoroughly established in the San Francisco Bay region,-as also at Eureka, Stockton and Hollister. "Within a few years practically all suitable parts of California north of the 35th parallel and west of the High Sierras had been invaded." Southern California, both by reason of the insulation provided by the eastern deserts, and the previous occupation by the House Finch, was long immune. But in Igo I Howard noted the bircls at Bakersfield, and in I903 at Tehachapi, although they were not to be found that season at Mohave. Newhall, 1906 (reported by Law), appears to be the earliest date for Los Angeles County, although the birds made their appearance in Los Angeles the following year. Bradford Torrey saw them at Santa Barbara in I909. By I9I2 Pasadena and Riverside were employing a professional Sparrow-killer to keep the pest down; but San Diego was immune till November, I9I3. Howell and Huey saw the pioneers, or spies, on San Clemente on March 3oth, I9I5, and shot hopefully; while I was less successful, in that I had no gun to rebuke the first pilgrim on Santa Cruz Island, April I8, I9I5.

At the present writing, the occupation of all cities and towns is practically complete, and the birds swarm through the Imperial Valley and the infra-sea-level stations of the Colorado Desert, no less than along the upper reaches of the Sacramento and in the Surprise Valley.

The favorite means of dissemination has always been the box car, and especially the grain car. The Sparrows, being essentially grain and seed eaters, frequent the grain cars as they stand in the railroad yards, and are occasionally imprisoned in them, hopeful stowaways and "gentlemen of fortune." In this manner, also, the larger cities and railroad towns were first colonized. The sparrow follows the flag of commerce, and if he were prescient he would probably dread as much as we do the day when increasing pressure of numbers will drive him into the chaparral.

Difficult as it may seem, it is true that the English Sparrow adopts the policy of Uriah Heep upon first entering a town. With all the unctuous humility of a band of Mormon apostles, the newcomers talk softly, walk circumspectly, and either seek to escape notice altogether, or else assiduously cultivate the good opinion of their destined dupes. Thus, I resided in the town of Blaine, on the northern border of the United States, for two months (in Igo4) before running across a single member of the pioneer band of nine English Sparrows, although I was assured on good authority that the birds had been there for at least two years. A very similar experience attended early inquiries in Santa Barbara, and it was not till I9I3 that I learned precisely which palm trees in town were most likely to harbor the Englishers. 


\section{The English Sparrow}

The Sparrow, by the way, although his entrance into southern California was so belated, has found an impregnable fortress in the Washington Palm, Neowashingtonia filifera (Wendt) Sudworth. Wherever this stately savage displays his luxuriant mane, there the English Sparrow foregathers with his mates ad infinitum et ad nauseam. So far as southern California is concerned, the "problem of the English Sparrow" will be the problem of persuading the proud owners of Washington Palms to subject their favorites to tonsorial care.

If there are those who still require evidence that the English Sparrow is an undesirable alien, I beg to submit for their consideration the following specific charges, each con-

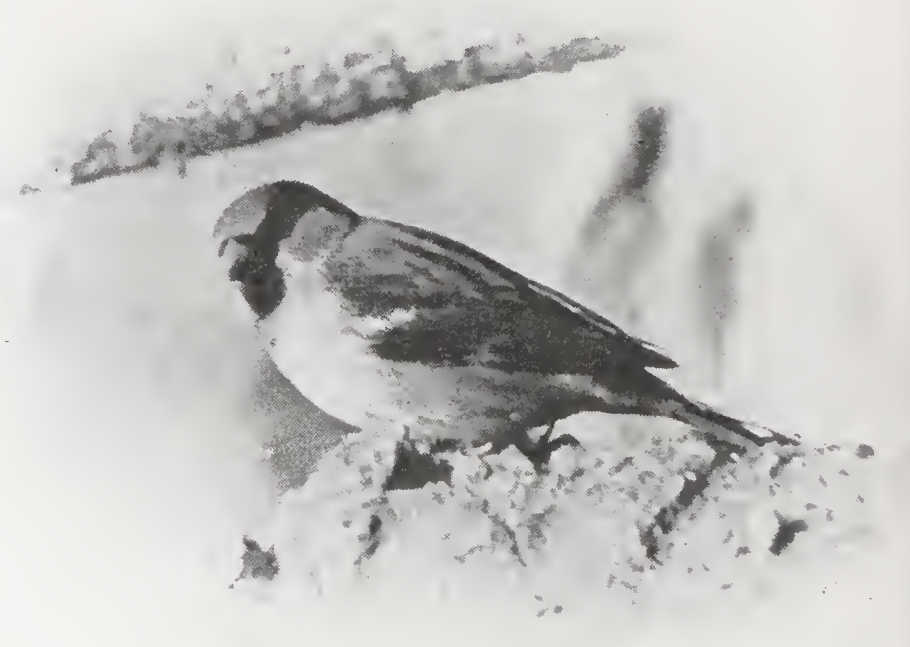

Taken in San Francisco

THE TEDIOUS ALIEN
Photo by the Author firmed by experience no less than by authority.

I. The English Sparrow destroys fruits, berries, grains, buds, garden-seeds, and tender shoots. To take up a single item: The total economic loss to the nation through the consumption of grain in the shock is enormous. A hundred million bushels would probably be a low estimate.

2. The bird destroys as many beneficial insects as it does injurious, so it can claim no exemption because of its occasional and unquestioned services as an insect destroyer.

3. It is a frequent and almost inevitable disseminator of disease, through its use of poultry litter and other trash in nest-building.

4. It harbors and disseminates chicken-lice (Dermanyssus gallince Redi), as well as bird-lice (D. avium De Geer). An able investigator, Ewing, 1 found $\mathrm{I} 8,000$ of these poultry mites in a single nest of this Sparrow. This is a fatal offense in the eyes of poultry raisers.

${ }^{1}$ Auk, Vol. XXVIII., July, 1911, p. 338 
5. The English Sparrow reduces the number of desirable native birds through destruction of their eggs and young, and through usurpation of their nesting sites.

6. It discourages and drives out desirable native species by continual annoyance and by the employment of mob tactics.

7. It defiles shrubbery, ornamental vines and trees, houses and public buildings, by its excrement; and it builds bulky, disfiguring nests out of unsightly trash.

8. The Sparrow's voice is always harsh and discordant, and its incessant racket imposes a severe tax upon the nervous energy of the nation.

9. Its unwelcome presence defiles the more remote woodland sanctuaries and mars the serenity of the everlasting hills, no less surely than it does that of the cities and the rural centers.

It requires no further testimony to show that the presence of this bird is absolutely undesirable. It is a scourge to the agriculturist, a plague to the architect, and the avowed and determined enemy of all other birds. Its nests are not only unsightly but unsanitary, and the maudlin racket of their owners unendurable. The bird is, in short, in the words of the late Dr. Coues, "a nuisance without a redeeming quality." Although we assent to this most heartily, we are obliged to confess on the part of our race to a certain amount of sneaking admiration for the Sparrow. And why, forsooth? Because he fights! We are forced to admire, at times, his bull-dog courage and tenacity of purpose, as rve do the cunning of the 


\section{The Alaska Longspur}

weasel and the nimbleness of the flea. He is vermin and must be treated as such; but, give the Devil his due, of course. What are we going to do about it? Wage unceasing warfare, as we do against rats. There will possibly be rats as long as there are men, but a bubonic plague scare operates very effectually to reduce their numbers. No doubt there will be English Sparrows in cities as long as there are brickbats, but a clear recognition of their detestable qualities should lead every sensible person to deny them victuals and shelter. Every well-ordered community should have a salaried official whose sole business it is to trap, shoot, burn, poison, and otherwise discourage this most reprehensible alien. The House Sparrow is no longer exterminable, but he may be, must be kept within bounds.

No. 36

\section{Alaska Longspur}

A. O. U. No. 536a. Calcarius lapponicus alascensis Ridgway.

Description.-Adult male in summer: Head, throat, and fore-breast black; a buffy line behind eye and sometimes over eye; a broad nuchal patch, or collar, of reddish brown (hazel); remaining upperparts light grayish brown, streaked with black and with some whitish edging; below white, heavily streaked with black on sides and flanks; tail fuscous with oblique white patches on the two outer pairs of rectrices. Bill yellow with black tip; feet and legs black. Adult male in winter: Lighter above; the black of head and chestnut of cervical collar partially overlaid with buffy or whitish edging; the black of throat and breast more or less obscured by white edging. Adult female in summer: Similar to male in summer, but no continuous black or chestnut anywhere; the black of head mostly confined to centers of feathers, - these edged with buffy; the chestnut of cervical collar only faintly indicated as edging of feathers with sharply outlined dusky centers; black of throat and chest pretty thoroughly obscured by grayish edging, but the general pattern retained; sides and flanks with a few sharp dusky streaks. Adult female in winter: Above buffy grayish brown, streaked (centrally upon feathers) with black; wing-coverts and tertials with rusty areas between the black and the buffy, and tipped with white; underparts warm buffy brownish, lightening on lower breast, abdomen and under tail-coverts; lightly streaked with black on throat, chest, and sides, sharply on sides and flanks. Immature birds resemble adult female in winter, but are more extensively brownish buffy above, the male showing also early indications of jugular black. Length of adult males about 165 $(6.50)$; wing $95.8(3.77)$; tail $63.3(2.50)$; bill II.7 (.46): tarsus $21.8(.86)$. Female smaller.

Recognition Marks.-Sparrow size; terrestrial habits: black head and breast of male. The bird may be distinguished from the Horned Lark, with which it sometimes associates, by the greater extent of its black areas, and by the chirruping or rattling cry which it makes when rising from the ground. 


\section{The Alaska Longspur}

Nesting.-Does not breed in California. Nest: In grass tussock on ground, flimsy or bulky, of grasses and moss, frequently water-soaked, and lined carefully with fine coiled grass, and occasionally feathers. Eggs: 4 to 6; light clay-color with a pale greenish tinge, variously marked,--speckled, spotted, scrawled, blotched, or entirely overlaid with light brown or chocolate brown. Av. size $20.3 \times 15.7(.80 \times .62)$. Season: First week in June; one brood.

General Range of Calcarius lapponicus.-Northern portion of Northern Hemisphere, breeding in Arctic region.

Range of $C . \quad$. alascensis.-- "The whole of Alaska, including (and breeding on) the Pribilof and Aleutian Islands. Unalaska, and the Shumagins; east to Fort Simpson, south in winter through more western parts of North America to Nevada (Carson City), eastern Oregon, Colorado, western Kansas, etc." (Ridgway).

Occurrence in California.-Two records, one by Frank Stephens, False Bay, San Diego County, Oct. 2, I909 (Condor, XII., I9Io, p. 44), and one by Henry IV. Marsden, Gunthers Island, Eureka, Oct. 2, 1909 (Condor, XII., I9Io, p. IIo).

Authorities.-As above.

IT IS a curious coincidence that the only two records of the occurrence of the Lapland Longspur in California were made on the same day, October 2, I909, and from localities so widely separated as Eureka and San Diego. In both instances, also, the birds were found near the ocean. In this respect they preserved the tradition of springtime, for in their Alaskan home the Longspurs breed down to tidewater; but their winter home is, preferably, the dry prairies of the interior. It would not be surprising, therefore, if the birds were to be found in Modoc and Lassen counties in winter; but their occurrence on the coast was purely fortuitous.

Those who have seen the prairies of Iowa or Kansas give up these birds by scores and hundreds every few rods, have been able to form some conception of their vast numbers; but it remained for the storm of March I3-I 4, I904, to reveal the real order of magnitude of their abundance. An observer detailed by the Minnesota State Natural History Survey estimates that a million and a half of these "Lapland" Longspurs perished in and about the village of Worthington alone; and he found that this destruction, though not elsewhere so intense, extended over an area of fifteen hundred square miles.

In spite of these occasional buffetings of fortune, such birds as do reach Alaska bring a mighty cheer with them to the solitudes. As Nelson says:1 "When they arrive, early in May, the ground is still largely covered with snow, with the exception of grassy spots along southern exposures and the more favorably situated portions of the tundra, and here may be found these birds in all the beauty of their elegant summer dress. The males, as if conscious of their handsome plumage, choose the tops of the only breaks in the monotonous level, which are small rounded knolls and

${ }^{1}$ Rep. Nat. Hist. Colls. in Alaska, 1887, p. 183. 


\section{The Chestnut-collared Longspur}

tussocks. The male utters its song as it flies upward from one of these knolls and when it reaches the height of ten or fifteen yards, it extends the points of its wings upwards, forming a large $\mathrm{V}$-shaped figure, and floats gently to the ground, uttering, as it slowly sinks, its liquid tones, which fall in tinkling succession upon the ear, and are perhaps the sweetest notes that one hears during the entire spring-time in these regions. It is an exquisite jingling melody, having much less power than that of the Bobolink, but with the same general character, and, though shorter, it has even more melody than the song of that well-known bird."

No. 37

\section{Chestnut-collared Longspur}

\section{A. O. U. No. 538. Calcarius ornatus (J. K. Townsend).}

Description.-Adult male in spring: Head black and white and buff; crown and sides of cervix, a post-ocular streak, and a patch on side of neck, black; throat and cheeks warm buff; enclosed areas white; breast extensively black (occasionally with dabs of chestnut, and, in early spring, more or less veiled with buffy); everywhere, including lower throat, outlined against white of remaining underparts; a sharply outlined nuchal patch, or half-collar, of chestnut; remaining upperparts blackish, edged with flaxen (light buffy brown); wings chiefly dusky with buffy brown edgings; the lesser and middle coverts black; the inner feathers of lesser coverts broadly tipped with white, the middle and greater coverts tipped with flaxen or whitish; tail extensively white, the feathers blackish-tipped, decreasingly from central pair. Bill light brown; feet and legs darker. Adult male in autumn and winter: As in spring, but lighter by reason of more extended flaxen edging; blacks almost entirely veiled by buffy tips; the nuchal chestnut reduced and veiled. Adult female: Similar to male in winter, but still lighter and duller; the black of breast almost entirely obscured by buffy tips, and chestnut collar wanting; in general, a flaxen bird, streaked with dusky above, and with some outcropping of black on breast centrally (in highest plumage the characteristic pattern of lesser wing-coverts most nearly retained). Immature birds resemble adult female, but lack wing pattern and are obscurely streaked on sides of head and throat and on chest (tail pattern of white distinctive). Length of adult male I+6-I57 (5.75$6.20)$; wing $85(3.35)$; tail $56(2.20)$; bill $\mathrm{I} 0.5(.4 \mathrm{I})$; tarsus $20(.78)$. Females average smaller.

Recognition Marks.- Warbler to sparrow size; black breast with chestnut collar of male distinctive; but female very obscurely colored,- - a dull cinnamon-buffy bird, streaked with dusky above; terrestrial and more or less gregarious habits.

Nesting.-Does not breed in California. Nest: Of grass and weed-stems, lined with fine grasses, moss and horsehair; sunk flush with surface of ground, under protection of weeds or grass-tuft. Eggs: + or 5; ovate, dull whitish as to ground, heavily but obscurely freckled, spotted, or clouded, with drab or purplish drab, and sharply but sparingly marked with brownish black. Av. size $19 \times 1+(.75 \times .55)$ (Reed). Season: June, July; two broods. 


\section{The Chestnut-collared Longspur}

General Range.-The central plains region. Breeds from southern Saskatchewan, south to central Kansas, and from the prairie portion of Montana east to western Minnesota; winters from Nebraska and Iowa to Sonora and southern portion of Mexican tableland; accidental in New England, Maryland, and California.

Range in California.-- Of accidental occurrence in Inyo County (Cow Camp, 15 miles north of Darwin, Sept. 28, 1917-an immature female taken by Joseph Grinnell).

Authority.-Grinnell, Condor, vol. xx., I918, p. 87.

THE OCCURRENCE of a single straggler taken by Grinnell in eastern Inyo County extends by a considerable distance the potential range of Calcarius ornatus. The bird is rated by Swarth ${ }^{1}$ an abundant migrant, and less commonly a winter resident in extreme eastern Arizona, "occasionally straggling further westward." The normal range of the species is the Great Plains region; and it would appear that the southward-moving hordes sweep around the southern end of the Rockies in New Mexico, and so into Arizona and Sonora, rather than risk crossing the Rocky Mountains at a point further north. This California wanderer, on the other hand, probably became involved with birds of some other species crossing the Rockies in Wyoming or northern Colorado.

Of the birds' appearance near Fort Hays, Kansas, Dr. Allen writes:"2 "They live in summer in large scattered colonies, generally many pairs being found at the same locality, while they may not be again met with in a whole day's travel. We found them very shy for so small birds, and were obliged to obtain all our specimens by shooting them on the wing at long range. They breed, of course, on the ground, constructing a rather slight but neat nest of dry grass and the stems of small plants. The eggs appear to be commonly five in number, blotched and streaked with rusty on a white ground, full sets of which were obtained the first week in June. This species has the curious habit of circling round the observer, with a buoyant, undulatory flight, generally high in the air, and usually keeping all the while well out of range, uttering, meanwhile, its rather sharp but musical call notes."

${ }^{1}$ Pac. Coast Avifauna, no. 10, 1914, p. 51.

2 In Coues' "Birds of the Northwest," 1874, pp. 122-123. 


\section{The Lark Bunting}

\section{No. 38 \\ Lark Bunting}

\section{A. O. U. No. 605. Calamospiza melanocorys Stejneger.}

Description.-Adult male in breeding plumage: Nearly uniform black, duller (browner or grayer) on back; a patch of brownish gray on flanks, occasionally crossing rump; a large white blotch on wing formed by middle and greater coverts; tertials edged with white, and tail-feathers white-blotched on tips. Bill dark horn blue above, paler below; feet brown. Adult female: Quite different; above grayish brown, finely and heavily streaked with dusky; below white, sharply streaked, especially on sides of throat, on breast and sides, with dusky; white blotch on wing much reduced and tinged more or less with buffy. Adult male in autumn: Much like adult female, but wing markings more pronounced; chin black; and feathers of underparts extensively black basally (with irruptive appearance when disturbed). Length of adult male about I $65(6.50)$; wing $88(3.46)$; tail $68(2.67)$; bill I4 (.55); depth at base II.4 (.49); tarsus $24.4(.96)$. Females average smaller.

Recognition Marks. - Sparrow size; all black of male in high plumage, with white wing blotches, distinctive. In case of females and autumnal males, the robust beak, taken in connection with white blotches on wing and tips of tail-feathers, prevents confusion in an otherwise "merely streaked" bird.

Nesting.-Does not breed in California. Nest: Of grasses, sunk flush with surface of ground. Eggs: 4 or 5; pale bluish green, immaculate, or, rarely, speckled, or marked with reddish brown. Av. size $22 \times 16(.88 \times .65)$. Season: June; one brood.

General Range.-Plains of central North America, breeding from southern Alberta, Saskatchewan, and southwestern Manitoba, south to northeastern New Mexico and northwestern Texas, east to Nebraska and western Minnesota; in winter from southern Arizona, New Mexico, and southern Texas south over the tableland of Mexico and in southern Lower California. Occurs sporadically during migrations west to California, east to Iowa; accidental in Atlantic seaboard states.

Occurrence in California.-Irregular visitor, chiefly in late winter or spring, in southern portion of State; occasionally occurs in some numbers. There are about thirteen published records of occurrence, all lying within the area defined by Santa Barbara (Mailliard), Tulare Lake (J. S. Cooper), San Diego (Holterhoff), and the Colorado River (J. Grinnell).

Authorities.-Cooper, Bull. Nutt. Orn. Club, vol. ii., I 877, p. 92 (Tulare Lake); Coues, Birds of the Northwest, I874, p. I63 (peculiarities of structure; habits; nests and eggs, etc.); Grinnell, Pac. Coast Avifauna, no. II, I9I5, p. I37 (Calif. records); Wyman, Condor, vol. xviii., I9I6, p. 203 (Los Angeles); Herron, Condor, vol. xriii., 1916, p. 205 (Cabezon); Whittle, Condor, vol. xxiv., I922, p. 74 (flight song).

DID YOU EVER hear of a bird wearing a dress suit under an ulster? Well, that is precisely what the Lark Bunting does; that is, the male Lark Bunting, during nine months of the year. The female, poor drudge, is not allowed any such finery, even for her honeymoon. She makes shift the year around with a dull habit of brownish gray, streaked with dusky 


\section{The Lark Bunting}

or relieved with whitish below. The only ornament she is allowed to wear is a creamy shoulder patch, and this must be reefed to the smallest possible dimensions, save in flight. But the male, bless you, has solved the problem of splendor-splendor plus economy. When family cares are over for the season, and it is time to think of getting ready for the annual southern trip, this crafty Beau Brummel orders a brand new black suit with white trimmings, say, epaulettes and braid. But when, after the last try-on, he comes out of the tailor shop (that is, the post-nuptial molt) late in August, he is nearly enveloped from head to foot in a flaxen "duster," suitable for travelling. The new black suit is there, you know, but since the bird can carry no bags, the tailor-made does duty for underclothes. Only with advancing springtime do the ends of the feathers wear away (aptosochromatism the ornithologists call it), and disclose to view the resplendent black of the wooer and gallant, the troubadour poet of the prairies.

The Lark Bunting, though a very self-sufficient and straight-forward mortal, is, nevertheless, a bit of a puzzle to the science. Lark he is not, for his claws are not lengthened like those of the Alaudida, nor even like those of certain other terrestrial finches. The name comes only from his habit of singing a-wing. Viewed structurally, he is, no doubt, a sparrow. The turgid beak suggests Emberiza of the Old World, so that the name "Bunting," otherwise little used in America, may be allowed to pass. The eggs which, in this species, are spotless green (niagara green), or, very rarely, maculated, link the bird to Spiza, and possibly to the lesser grosbeaks. But this black grosbeak of the prairies looks and acts more like a Bobolink. He is much the shape and size of a Bobolink; the contrast between nuptial and eclipse plumage is the same; and the flocking of winter is not altogether different.

The normal winter range of Calamospiza is Texas, Arizona, Lower California, and the Mexican table-land. Occasionally the autumnal migrants overshoot the mark and land in southern California; but oftener, apparently, the records are made in the spring by migrants which, returning from Lower California, pursue a course a little too far northward before swinging to the east. Winter flocks may be composed of both sexes in equal or very unequal proportions. They feed quietly upon the ground in the open, whether along a river bottom or over the baldest desert. The Lark Buntings are not averse to civilization, and they sometimes frequent Mexican dooryards or barnyards with much the freedom and something of the manner of blackbirds. And because they are seen lingering on into May is no sign that they are going to breed with us; for the spring winds of Manitoba blow chill and there is no hurry.

Encountered upon his native prairie, Calamospiza gives one a vivid 


\section{The Western Lark Sparrow}

assurance of his fitness. There are only two "elements" to consider, the ground and the air, and the Lark Bunting is equally at home with either. Be the wind never so fresh, the happy-hearted bird, all lark now, launches vigorously and flutters up to a height of ten or twenty feet, singing the while. Then he makes a parachute of his wings, bat-fashion, or like a concave $Y$, and, struggling with the wind, or bent on ostentatious gallantry, settles to the ground still singing. The song, which is not loud, consists of a pleasing repetition of several very different phrases. By phrases, in this instance, is meant a short succession of notes of one quality. Thus, one phrase will consist of four double notes given in the same key, wéo wéo wéo wéo. Another, perhaps immediately succeeding, will be an insect trill, like that of the Grasshopper Sparrow. The effect produced by an endless succession of these rocketing birds is very impressive; and the Lark Bunting comes in time to symbolize all that is distinctive in the life of the Great Plains.

No. 39

\section{Western Lark Sparrow}

A. O. U. No. $552 \mathrm{a}$. Chondestes grammacus strigatus (Swainson).

Synonyms.-Quall-head. Western LaRk Finch.

Description.-Adult: Head variegated, black, white, and chestnut; lateral head-stripes black in front, chestnut behind; auriculars chestnut, bounded by rictal and post-orbital black stripes; narrow loral, and broader submalar black stripes; malar, superciliary, and median stripes white, the two latter becoming buffy behind; upperparts buffish gray-brown, clearest on sides of neck, streaked by blackish brown centers of feathers on middle back and scapulars, persisting as edging on the fuscous wings and tail; tail-feathers, except middle pair, broadly (decreasingly from outermost) tipped with white; below white, purest on throat and belly, washed with grayish buff on sides and crissum, also obscurely across fore-breast, in which is situated a central black spot. Bill dark brown above, darkening toward tip, paler below; feet and legs pale brownish. Young birds lack the black and chestnut of head, and are more or less streaked below, at least across breast. Length 158.8 (6.25); wing $87(3.42)$; tail 70 (2.75); bill I $2(.47)$; tarsus $20.3(.80)$.

Recognition Marks.- Sparrow size; head variegated black, white, and chestnut; fan-shaped tail broadly tipped with white and conspicuous in flight.

Nesting.- Nest: Either on the ground, more or less concealed by protecting grass-clump or bush, or else in bush or tree at moderate heights; in the former instance a more or less careless but thick-walled saucer of dried grasses, lined with horsehair; in the latter, a sturdy deep cup built externally of twigs, weed-stems and grasses, or string and trash, and heavily lined, as before, with horsehair, or, more rarely, rootlets. Eggs: 4 or 5; ovate, or short ovate, of ten notably rounded; white, pinkish or bluish white, spotted or scrawled in zigzags, or else finely scrolled about the larger end with dark browns and purplish. Some examples are as finely scrolled as eggs of the Icterine 


\section{The Western Lark Sparrow}

orioles, and rare examples are handsomely mottled, or partially veiled, with liverbrown. Av. of 45 California-taken specimens in the M. C. O. coll.: $20.3 \times 15.7(.80$ $\mathrm{x} .62)$. Season: April 15 to June 30: one or two broods.

Range of Chondestes grammacus. - North America from the Pacific Coast east, regularly to Ohio and Tennessee, casually to the Atlantic seaboard, north to central British Columbia and Saskatchewan, south over the Mexican plateau and, in winter, through Lower California and southern Mexico to Guatemala.

Range of $C$. g. strigatus.-As above, save that eastern boundary roughly coincides with that of the Great Plains.

Distribution in California.--Resident throughout the State in the Upper Sonoran life zone, but chiefly in the interior valleys west of the Sierras; found sparingly in Lower Transition (San Jacinto Mountains, alt. 6300, June 3, I9I3; Humboldt County, June I4, I9I6), and descending casually within the upper limits of Lower Sonoran (Palm Springs, May 27, 1913; Mohave Desert, near Palmdale, May 16, I919; Indian Wells, Inyo County, May 19, I919). Seasonal redistribution imperfectly made out; local population is possibly stationary, but entire State is lightly swept by northern migrants which reinforce local populations, or deploy over deserts.

Authorities.-Heermann (Emberiza grammica), Jour. Acad. Nat. Sci. Phila., ser. 2, vol. ii., I893, p. 265; Baird, Rep. Pac. R. R. Surv., vol. ix., I 858, pp. 456-457 (crit.; meas.); Coale, Bull. Ridgway Orn. Club, vol. ii., I 887, pp. $24-25$ (crit.); Atkinson, Oologist, vol. xvii., I900, pp. 105-107 (life hist.); Judd, Biol. Surv. Bull., no. I5, I90 I, pp. 66-68 (part) (food); Tyler, Pac. Coast Avifauna, no. 9, I9 I3, pp. 79-8I.

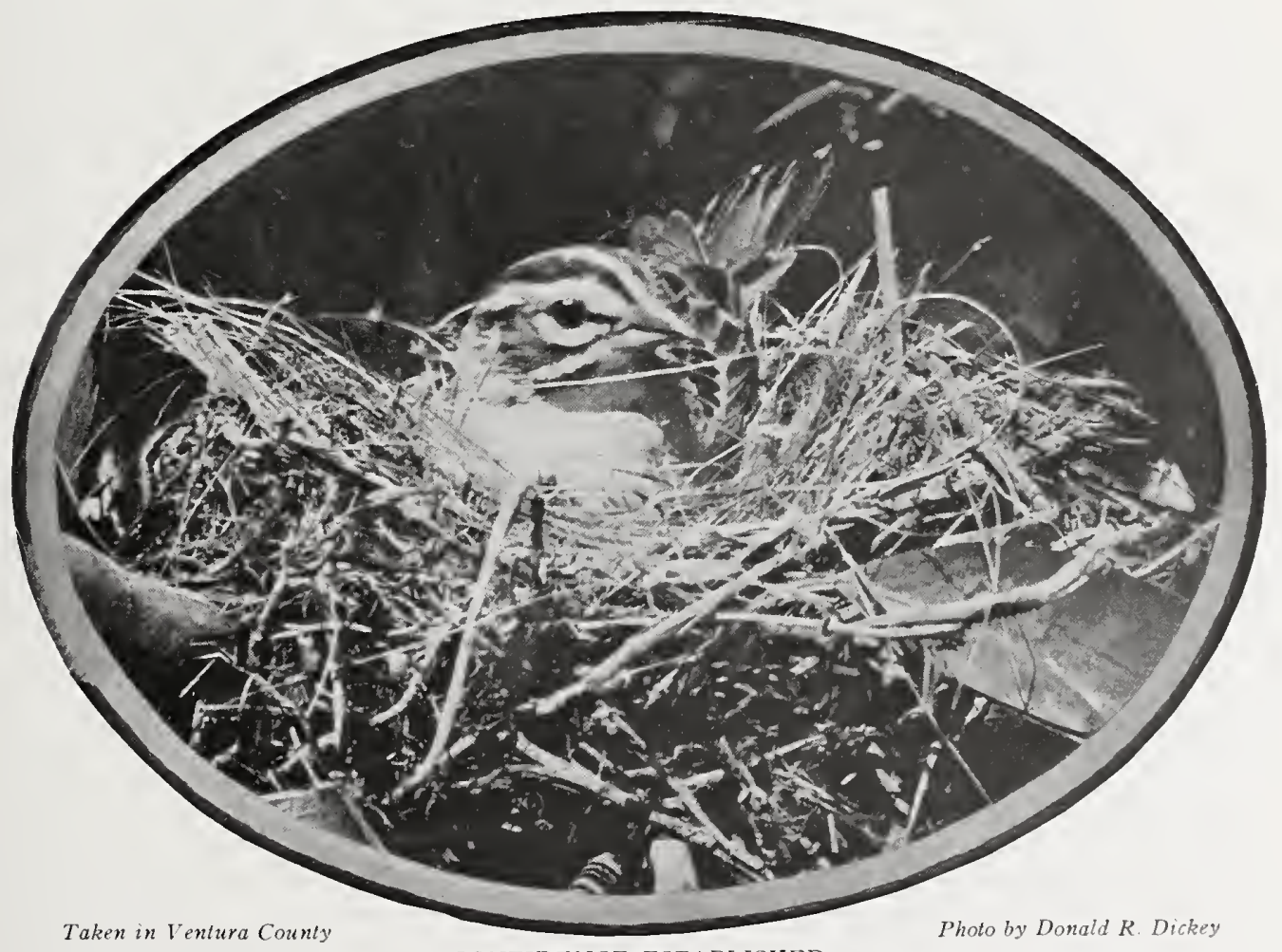




\section{The Western Lark Sparrow}

THERE is a spot near Shandon so endeared by reason of its verdure and its unspoiled simplicities, that one hesitates to draw invidious attention to it. The vaquero knew its solitudes, and the rancher clwells peacefully upon its skirts; but so far $\quad$ it has been spared the desecration of the "oil-rig," and the other engines of civilization. If you will promise not to plot "improvements," you shall join us on an afternoon in $>$ early April. It has been raining off and on for a week, but the sky is clear now, and welcome our

abandonment 'dobe hills rise of the village, and their durous eminences stretch our vision. A full third for the rains have beaten to time, and the sides of with huge amphitheaters whose sides, in turn. are the lush grasses feet with the fluted in a thousand fantastic forms. Fierce little barrancas, as sharply graven in the greensward as with the stroke of an etcher's tool, have led off the sudden torrents from the vortices of these weird funnels, but tiring presently of their impetuous burdens, they have spewed out the muddy waters in great yellow triangles over the sides of the lower slopes. But elsewhere all is green, green save for the glowing pink of owl's foot clover, 


\section{The Western Lark Sparrow}



the purple of massed lilies, or the honest blue of lupine, wave on wave. Little rounded chains of flanking hills descend with graceful sweep in cadences of green. Their sides, too, are faintly terraced with the concentric furrows of a thousand cattle trails now smothered in green. Grass is everywhere; but over it all is the pale glaucous shimmer of the younger sages, vying with the accumulated grays of last year's flower-stalks. And here and there, partially yet gracefully distributed, are spaces dotted with the larger "sages," chamisal or eruptive Rhus, with their stronger note of stippled blue-green.

A lazy country road skirts this scene of beauty; and, upon either side, its intermittent strand of fence-wire, sagging indolently, supports a gallant crowd of the merriest, sweetest sparrows to be found in the whole glad realm. No, they are not a crowd, either, for although the Western Lark Sparrows foregather here annually to pass the season of courtship, and although one may count a hundred of them in the length of a dozen panels, they are not animated to any considerable extent by flock impulses, nor does one think of them en masse.

Whether it be running nimbly along the ground, or leaping inte the air to catch a risen grasshopper, one feels in. stinctively that here is a dainty breed. The bird endears itself, moreover, because of its fondness for wayside fellowship. If you are on horseback, the Lark Sparrow, like the Horned Lark. loves to trip ahead coquettishly along the dusty road, only to yield place at last to your insistent steed

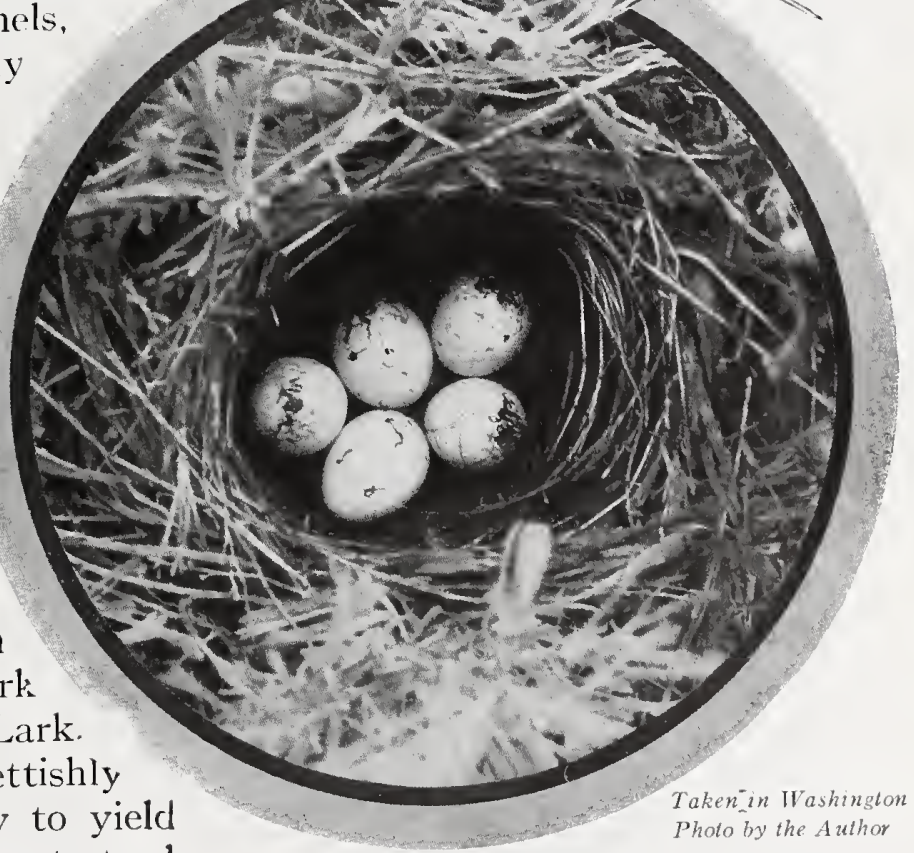

A SAGE-BUSH NEST 


\section{The Western Lark Sparrow}

with an air of gentle reproach. As it flits away, you catch a glimpse of the rounded tail held half open, with its terminal rim of white; and you know that you have met the aristocrat of the sage.

Or it may be you have caught the bird singing from a fencepost, and rather than lose his run (for poesy also has its mechanics), he will pause momentarily instead of seeking safety in flight. Then that marvelous head comes into full view. What a striped beauty he is! A finger-ring slipped over theQuail-head's head will pass twentythree patches of pure color,-black, wh i t e, chestnut and buffy, before it encounters a streaky admixture of flaxen, black, and rufoustawny on the hindhead.

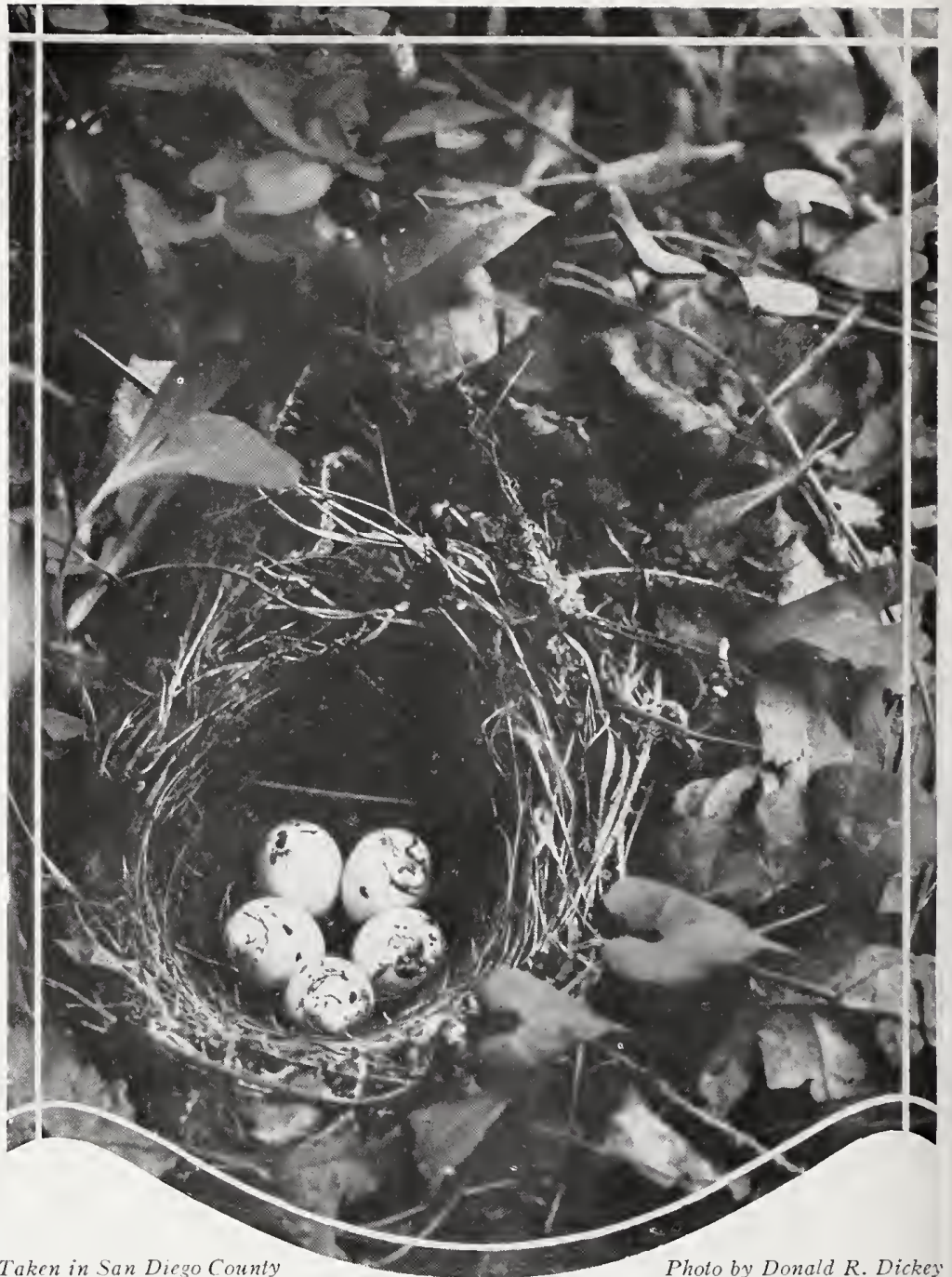

A HEAVILY MARKED TYPE: NATURAL SIZE The rest of the bird is

"sparrow-color," above, relieved only by the flashing white tips of the fanshaped tail. If you are very lucky or very well-behaved, the song will resume. And the song of the Lark Sparrow is one of Nature's sacraments.

This bird, more frequently than others, is found singing in the middle of the very hottest days in summer, and at such times his tremulous notes come to the ear like the gurgling of sweet waters. But Ridgway's description is still unsurpassed.1 "This song is composed of a series of chants, each syllable rich, loud, and clear, interspersed with emotional trills. At the beginning the song reminds one somewhat of that of the

" Birds of Illinois," Vol. I., p. 263

238 


\section{The Western Lark Sparrow}

to forego a picture of the sitting bird. To get a picture of the eggs (see page 237), I was obliged to hack away the protecting brush, having first slipped in a handkerchief to protect the nest and contents from showering debris.

In the Shandon country, where Western Lark Sparrows abound, nesting is oftenest undertaken on the ground, either with or without the protection of a bush or a lupine clump. But in the vicinity of Santa Barbara, where the bird is also not uncommon, although very irregularly distributed, the nests are oftener taken up into

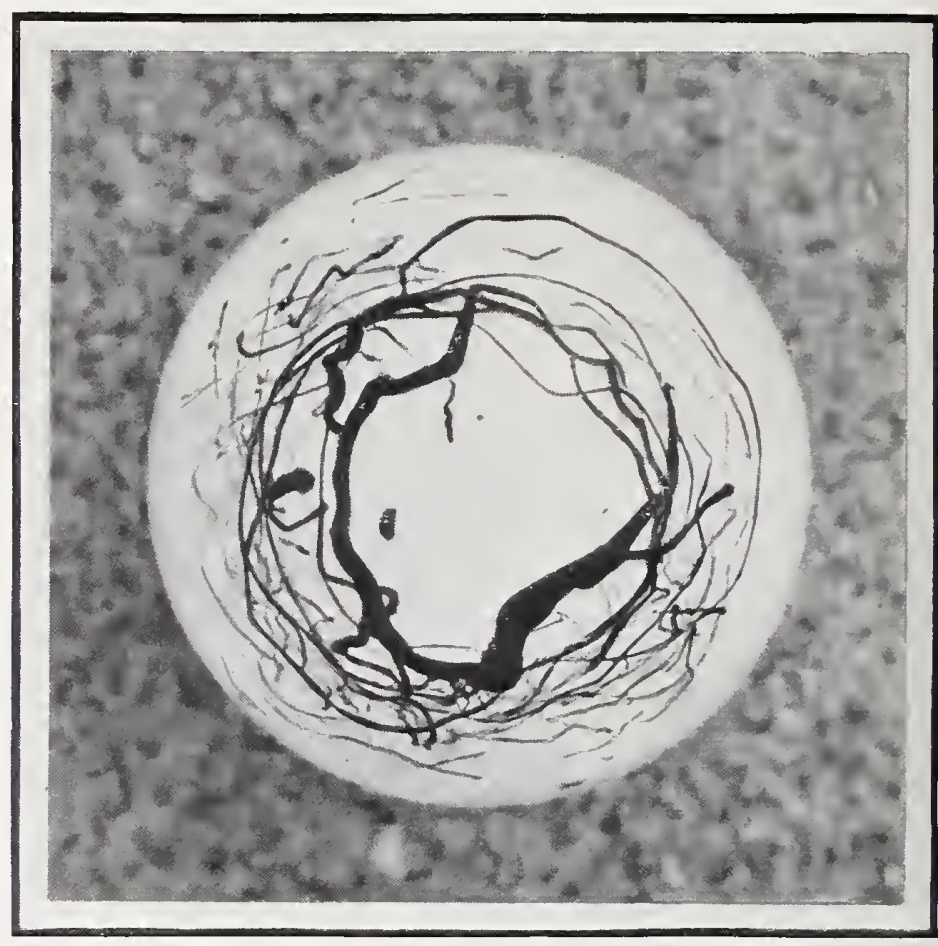

"INTRICATELY SCROLLED ABOUT THE LARGER END" TYPE FROM M. C. O. COLLECTION, $\mathrm{x} 4$

trees at moderate heights. The construction in such case is correspondingly improved. A sturdy basket of twigs, weed-stems, roots and twisted grasses, is beautifully lined with horsehair (what will the birds do when horses become extinct?). The eggs, four or five in number, white as to ground color, and purplish black or sepia as to markings, are among the most varied and easily the most interesting of the sparrow tribe-at least in California. The markings of sepia are often intricately scrolled about the larger end; and at their best the eggs are not exceeded in beauty even by those of the oriole. One specimen before me has twenty-two interwoven lines of color in the space of one-fifth of an inch. Another has discontinuous lines and flecks, like the colored lint-marks in a banknote. Indeed, I am inclined to think that the Bureau of Printing and Engraving got the idea from a Lark Sparrow's egg. Other eggs again, some few, are as plainly and sparsely marked and spotted as the egg of a Brown Towhee (Pipilo crissalis). Oriole he is not, not even remotely; but how did our Lark Sparrow hit upon the decorative scheme preempted-patented, I had almost said-by the Bullock Oriole? Here is a nut for oölogists to crack. 


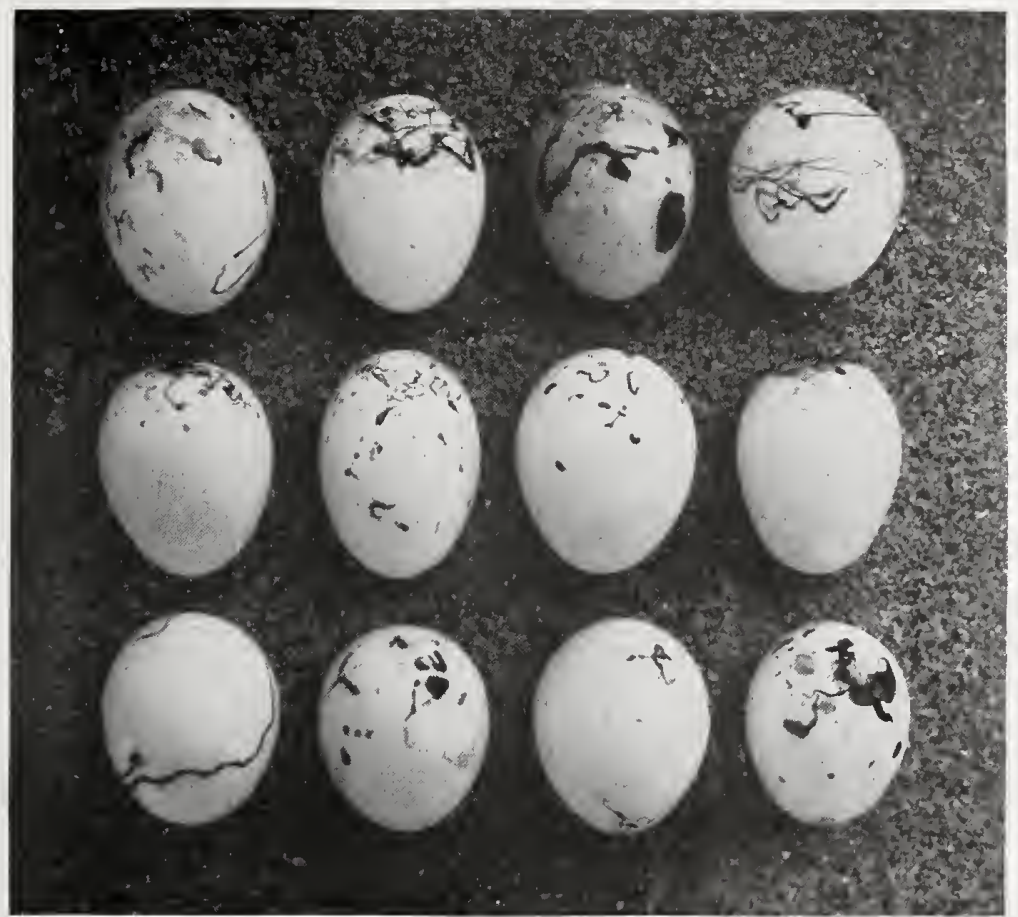

EGGS OF THE WESTERN LARK SPARROW

A SELECTED SERIES SHOWING VARIATION: FROM THE M. C. O. COI.LECTIONS

No. 40

\section{Vesper Sparrow}

No. 40a Western Vesper Sparrow.

A. O. U. No. 540a. Pocecetes gramineus confinis Baird.

Synonyms.-Western Grass Finch. Bay-winged Bunting.

Description.-Adults: General tone of upperparts grayish brown or buffy brown on the edges of the feathers, modified by the dusky centers, and warmed by delicate traces of rufous; bend of wing bay (between tawny and sayal brown), concealing dusky centers; wings and tail fuscous with pale tawny or whitish edgings,outermost pair of tail-feathers principally white, the white crossing to inner web about midway of shaft, and involving terminal portion broadly; below sordid white, sharply streaked on breast, flanks, and sides with dusky brown; the chin and throat with small arrow marks of the same color and bounded by chains of streaks; auriculars clear hair-brown, with buffy or lighter center; usually a buffy suffusion on streaked area 


\section{The Vesper Sparrows}

of breast and sides. Length of adult male I46.I-158.8 (5.75-6.25); wing 83.6 (3.29); tail $65.8(2.59)$; bill I I.2 (.44); tarsus 2 I.6 (.85). Female a little smaller.

Recognition Marks.-Sparrow size; general streaked appearance; white lateral tail-feathers conspicuous in flight; frequents fields and open sage.

Nesting.- Nest: A depression in the earth, neatly lined with grasses, rootlets and horsehair. Eggs: 4 or 5, pinkish-grayish-bluish white, speckled, spotted, and occasionally scrawled or mottled with reddish brown. Av. size $20.5 \times 15.2(.81 \times .60)$. A set of four from Mono County averages $23.4 \times 15.5(.92 \times .61)$. Season: About June Ist; one brood.

Range of Poccetes gramineus.-Temperate North America, south in winter to southern Mexico.

Range of P.g. confinis.-Western North America, breeding in Upper Sonoran, Transition, and Lower Canadian Zones, from southeastern British Columbia, Alberta, and Saskatchewan, south to central eastern California and Arizona, east to Texas and the middle of the Great Plains region; winters from southern California and central Texas to southern Mexico and Lower California.

Distribution in California.-Breeds in high mountain meadows in the southern Sierras, and in Transition to Canadian life zones east of the Sierras from the Inyo Mountains north to the Oregon border; winters in the valleys of the San Diego district, rarely to Santa Barbara, less commonly on the deserts, and in the San Joaquin Valley north to Fresno (Tyler). Limits of winter range imperfectly made out, and perhaps indeterminable as distinguished from $P$. g. affinis.

Authorities.-Heermann (Emberiza graminea), Jour. Acad. Nat. Sci. Phila., ser. 2, vol. ii., I 853 , p. 265 ; Baird, Rep. Pac. R. R. Surv., vol. ix., 1858, p. 448 (desc. of confinis); Fisher, A. K., N. Amer. Fauna, no. 7, 1893, p. 85: Grinnell, Pasadena Acad. Sci. Pub., vol. ii., 1898, p. $36 ; J u d d$, Biol. Surv. Bull., no. 15, 1901, p. $5^{8}$ (food); Tyler, Pac. Coast Avifauna, no. 9, 1913, p. 77 (winter habits in Fresno district).

A SOBER garb cannot conceal the quality of the wearer, even though Quaker gray be made to cover alike saint and sinner. Plainness of dress, therefore, is a fault to be readily forgiven, even in a bird, if it be accompanied by a voice of sweet sincerity and a manner of self-forgetfulness. In a family where a modest garb is no reproach, but a warrant to health and long life, the Vesper Sparrow is preëminent for modesty. You are not aware of his presence until he disengages himself from the engulfing grays and browns of the stalk-strewn ground or dusty roadside, and mounts a fence-post to rhyme the coming or the parting day.

The arrival of the Vesper Sparrow upon its elevated breeding grounds, in late April or early May, according to season, may mark the supreme effort of that particular warm wave; but you are quite content to await the further travail of the season while you get acquainted with this amiable new-comer. Under the compulsion of the sun the bleary fields have been trying to muster a decent green to hide the ugliness of winter's devastation. But wherefore? The air is lonely and the sage untenanted. 
The Meadowlarks, to be sure, have been romping about for several weeks and getting bolder every day; but they are roisterous fellows, drunk with air and mad with sunshine. The winter-sharpened ears wait hungrily for the poet of common day. The morning he comes a low sweet murmur of praise is heard on every side. You know it will ascend unceasingly thenceforth, and spring is different.

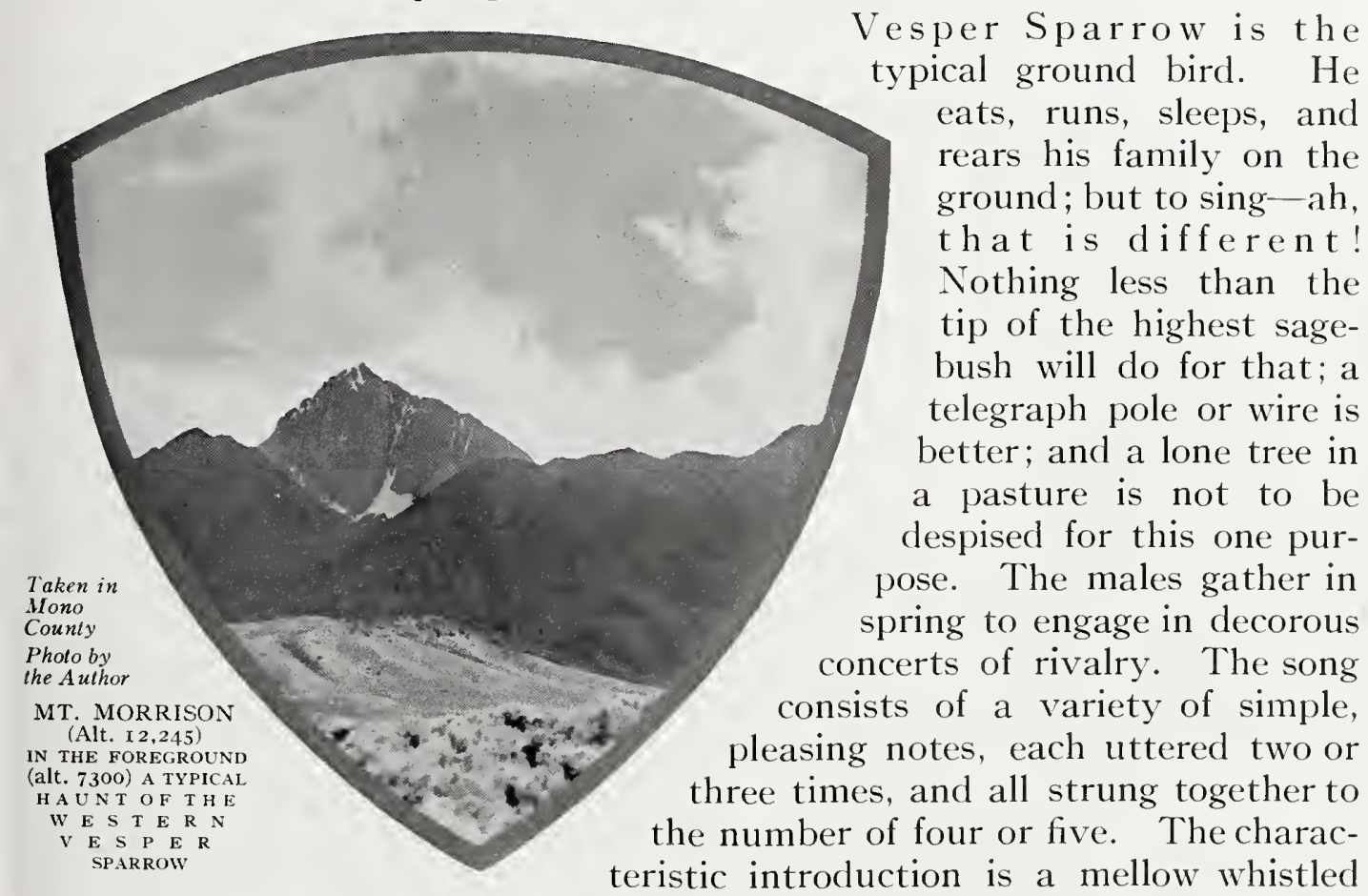

$h e-h o$, a little softer in tone than the succeeding notes. The song of the western bird has noticeably greater variety than that of the eastern. Not only is it less stereotyped in the matter of pitch and duration, but in quality and cadence it sometimes shows surprising differences. One heard in Washington, near the 49th parallel, would have passed for Brewer's on a frolic, except for the preliminary "hee-ho"s"; Heéoo heéoo heéoo buzziwuzziwuzzi wuzziwuzziwnzzi weechee weechee. And it would not be surprising if he had learned from Spizella breweri, who is a constant neighbor and a safe guide in matters of sage lore. The scolding note, a thrasher-like kissing sound, tsook, will sometimes interrupt a song if the strange listener gets too close. Early morning and late evening are the regular song periods; but the conscientious and indefatigable singer is more apt than most to interrupt the noontide stillness also.

Since this species is a bird of open country and uplands, it cares little for the vicinity of water; but it loves the dust of the country roads 


\section{The Vesper Sparrows}

as dearly as an old hen, and the daily dust-bath is a familiar sight to every traveler. While seeking its food of weed-seeds and insects, it runs busily about upon the ground, skulking and running oftener than flitting for safety. Although not especially timid, it seems to take a sort of professional pride in being able to slip about among the weed-stems unseen.

It is, of course, at the nesting time that the sneak-ability of the bird is most severely tested.

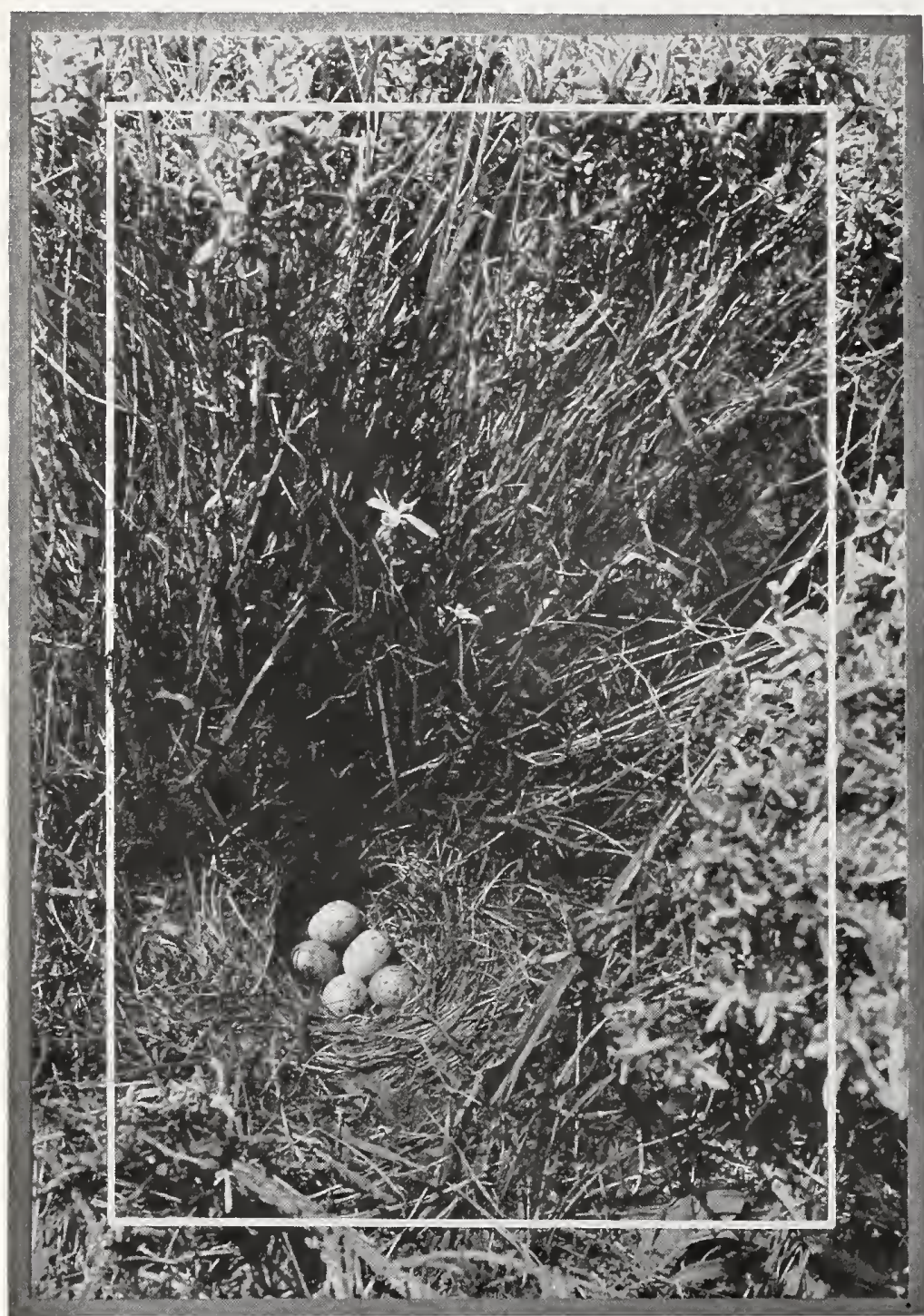

Taken in Idaho

Photo by $H, J$. Rust

NEST AND EGGS OF WESTERN VESPER SPARROW
The nest, a simple affair of coiled grasses, is usually sunk, or chambered, in the ground, so that its brim comes flush with the surface. For the rest, the brooding bird seldom seeks any other protection than that of "luck," and her own ability to elude observation when obliged to quit the nest. Her behavior at this time depends largely upon the amount of disturbance to which she is subjected. At first approach of danger she is inclined to stick to her post till the last possible moment, and then she falls lame as she flutters off. But if often frightened, she shrewdly learns to rise at a considerable distance.

In the northern states the Vesper Sparrow raises two or even three broods in a season, but inasmuch as the ranges affected by the birds in this State are rather elevated ones, it is doubtful 
if more than one brood is raised. The Western Vesper Sparrow is not by any means so common in California during the breeding season as it is in the more northern states, and its breeding range seems to be confined chiefly to the plateau region east of the Sierras, from Owens Valley north. I have found it most commonly in Long Valley in southern Mono County, where, in association with the Brewer Sparrow and the Sage Thrasher, it is one of the most characteristic birds of the dwarf-sage belt, which skirts the lowermost slopes of the mountains. It is also a familiar figure along the crests of the White Mountains; and we have an egg in the M.C. O. collection which was taken there at an elevation of Io,ooo feet.

There has been a notable shifting of this species within historic times. This change has been marked by a vigorous and successive encroachment along the northern limits of the breeding area, and, as nearly as we can make out, by a corresponding retirement from southern territory. As in so many other instances, the movement in California has been altitudinally upward, with a resultant reduction of area.

\section{No. 40b Oregon Vesper Sparrow}

\section{A. O. U. No. 540b. Poocetes gramineus affinis Miller.}

Synonyms.-Pacific Vesper Sparrow. Millér's Grass Finch.

Description.-Similar to $P$. g. confinis but smaller and coloration darker, browner above, more distinctly buffy below. Length of adult male about i46 (5.75); wing $77.2(3.04)$; tail $57.9(2.28)$; bill I0.9 (.43); tarsus $20.6(.8 \mathrm{I})$. Female a little smaller.

Nesting.- Not known to breed in California. As in preceding subspecies.

Range of $P . g$. affinis.-The Pacific Coast region; in summer from British Columbia to northwestern Oregon; in winter, California west of the Sierras to Cape San Lucas.

Distribution in California.-Winter resident and migrant west of the Sierras. Range imperfectly distinguished from preceding in winter, and doubtless overlapping it in southern portion.

Authorities.--Newberry (Zonotrichia graminea), Rept. Pac. R. R. Surv., vol. vi., pt. iv., I 857 , p. 88; Grinnell, Pasadena Acad. Sci. Pub., vol. ii., I 898, p. 36; Willard, Bull. Cooper Orn. Club, vol. i., I 899, p. 30; McGregor, Condor, vol. ii., 1900, p. 35; Grinnell, Pac. Coast Avifauna, no. II, I9I5, p. II3; Swarth, Condor, vol. xix., I917, p. I30.

THE VESPER Sparrows are a very much less conspicuous element of the Californian avifauna than of that found in the regions to the north of us. Confinis does not breed in this State, though suitable "prairies" are not lacking in Trinity or Siskiyou counties. Known only, therefore, as a winter resident and migrant, it seeks the open situations of the 


\section{The Savanna Sparrows}

coastal counties, consorts freely with local Lark Sparrows, skulks about in meadows or stubble fields, and joins in the chorus of springtime only when it is on the point of departure for the Willamette or Puget Sound.

Mr. Bowles finds that eggs may not be looked for in the vicinity of Tacoma before the first week in May, and they are not certainly found before the middle of that month. Open prairie is most frequently selected for a site, and its close-cropped mossy surface often requires considerable ingenuity of concealment on the bird's part. Ploughed ground, where undisturbed, is eagerly utilized. At other times a shallow cup is scraped at the base of a small fern, or the protection of a fallen limb is sought.

The eggs, from three to five in number, are perhaps the most handsomely, certainly the most quaintly marked of any in the sparrow family. The ground-color is grayish white; and this, in addition to sundry frecklings and cloudings of lavender, is spotted, blotched, and scrawled, with old chestnut.

The female sits closely, and sometimes will not leave the nest until removed. She seldom flies, at that, but steps off and trips along the ground for some distance. Then she walks about uneasily or pretends to feed, venturing little expression of concern. Curiously, her liege lord never appears in defense of his home, but after the young are hatched he does his fair share in feeding them.

\section{No. 41}

\section{Savanna Sparrow}

\section{No. 41 Aleutian Savanna Sparrow}

A. O. U. No. 542. Passerculus sandwichensis sandwichensis (Gmelin).

Synonyms.-Larger Savanna Sparrow. Sandwich Sparrow.

Description.-Adults: General tone of upper plumage grayish brown-the feathers blackish centrally, with much edging of grayish brown (sometimes bay), flaxen, and whitish; an ill-defined mesial crown-stripe dull buffy, or tinged anteriorly with yellowish; lateral stripes blackish, with grayish brown edging reduced; a broad superciliary stripe yellow, clearest over lore, paling posteriorly; cheeks buffy with some mingling and outcropping of dusky; underparts whitish, clearest on throat, washed with buffy on sides, heavily and sharply streaked on sides of throat, breast, sides, flanks and thighs with dusky; streaks nearly confluent on sides of throat, thus defining submalar area of whitish; streaks darkest and wedge-shaped on breast, more diffused and edged with buffy posteriorly; under tail-coverts usually but not always with concealed wedge-shaped streaks of dusky. Bill dusky or dull horn-color above, lighter below; feet palest; iris dark brown. Immature birds are brighter; the yellow, usually 


\section{The Savanna Sparrows}

less prominent in superciliary stripe, is often diffused over plumage of entire head, and, occasionally, down sides; the bend of the wing is pale yellow (or not); the sides are more strongly suffused with buffy, which usually extends across breast. Length of male about 146 (5.75); wing 77 (3.03); tail 53 (2.08); bill I2.2 (.48); depth at base $7.6(.30)$; tarsus $22.6(.89)$. Females a little smaller.

Recognition Marks.-Warbler size (but much more robust in appearance than a warbler); general streaky appearance; the striation of head, viewed from before, radiates in twelve alternating areas of black and white (or yellow); larger and lighter than the (rare) Savanna Sparrow (P.s. savanna); larger, darker and browner than the common Western Savanna Sparrow ( $P$. s. alaudinus).

Nesting.-Does not breed in California. Nest and Eggs: Much as in local breeding species.

Range of Passerculus sandwichensis.- "North America from the Arctic Coast south to Guatemala and the West Indies, breeding in the East mostly north of the United States, in the West south to the southern part of the Mexican tableland." (A. O. U. Check-List.)

Range of $P$. s. sandwichensis.--Northwest coast, breeding in Unalaska and neighboring islands, wintering eastward and southward along the coast from British Columbia to northern California.

Occurrence in California.--Occasional winter visitant to northern localities west of the Sierra divide; has been taken as far south as Merced County (Grinnell).

Authorities.-Belding, Occ. Papers, Calif. Acad. Sci., 2, I890, p. I42; Ridgway, Bull. U. S. Nat. Mus., no. 50, pt. i., I90I, p. I9I; McGregor, Condor, vol. ii., I900, p. 35; Grinnell, Pac. Coast Avifauna, no. I I, I9I5, p. II 3 .

\section{No. 41a Eastern Savanna Sparrow}

\section{A. O. U. No. 542a. Passerculus sandwichensis savanna (Wilson).}

Description.- "Similar to $P$. s. sandwichensis, but decidedly smaller (wing averaging much less than 76.20 and never more than 73.66 ), the bill much smaller both actually and relatively; coloration averaging browner, with superciliary stripe less continuously or conspicuously yellow" (Ridgway). Av. of I6 adult males (R): wing 69.3 (2.73); tail 49.3 (I.94); bill $\mathbf{I} 0.4(.4 \mathrm{I})$; depth at base $6.6(.26)$; tarsus 20.8 $(.82)$.

Range of P. s. savanna.-Eastern North America, breeding in Boreal and Transition zones, from Ungava south to northern Iowa, mountains of Pennsylvania, etc.; and wintering from southern Indiana and New Jersey south to northeastern Mexico and Cuba.

Occurrence in California.--Based on specimens taken in Humboldt and Del Norte counties, the first one Dec. 4, I9IO, by C. I. Clay, of Eureka, and identified by Dr. Joseph Grinnell; others by Messrs. Joseph Mailliard, Chester Lamb and Chase Littlejohn.

Authorities.-Clay, Condor, vol. xix., 1917, p. 68 (at Humboldt Bay); Mailliard, Condor, vol. xxiv., May, I922, p. 95 (occur. at Kneeland Prairie and Requa).

\section{No. 41b Western Savanna Sparrow}

A. O. U. No. 542b. Passerculus sandwichensis alaudinus Bonaparte.

Synonym.-Gray Savannah Sparrow. 


\section{The Savanna Sparrows}

Description.- Similar to P. s. savanna but decidedly paler and grayer; less bay or none in edging of feathers of upperparts; yellow of superciliary stripe usually paler, sometimes nearly white; bill longer and relatively weaker. Other dimensions about as in $P$. s. savanna.

Recognition Marks.-As in P. s. sandwichensis.

Nesting.-Does not breed in California. As below.

Range of $P$. s. alaudinus. - Western North America, breeding from the Arctic coast of Alaska and Mackenzie, south to the southern portion of the Mexican plateau, east to the western edge of the Great Plains; range on the west defined by that of $P$. s. nevadensis from the Great Basin region, and P. s. brooksi of the Pacific Coast district. (It is, however, incredible that in a species as plastic as P. sandwichensis the same breeding form should hold from Mackenzie to Mexico, a latitudinal range of fifty degrees!) Winters from northern California and northern Texas to Lower California, Mexico, and Guatemala.

Distribution in California.-Abundant in winter at lower levels and in open situations throughout the State, but more commonly west of the Sierras. Found also on the Santa Barbara Islands.

Authorities.-Heermann (Emberiza savanna), Jour. Acad. Nat. Sci. Phila., ser. 2, vol. ii., I 853 , p. 265 ; Bonaparte, Comptes Rendus, vol. xxxvii., I 853 , p. 918 (desc. of alaudinus); Grinnell, Condor, vol. iii., I90I, pp. 2 I-22 (crit.); Grinnell, Univ. Calif. Publ. Zool., 5, I9I0, pp. 3I I-3I6 (crit.; comp. with nevadensis); Bishop, Condor, vol. xvii., I9I5, p. I88 (crit.); Palmer, T. S., Condor, vol. xx., I9I8, p. I23 (discovery).

\section{No. 41c Nevada Savanna Sparrow}

\section{A. O. U. No. 542b, part. Passerculus sandwichensis nevadensis Grinnell.}

Synonyms.-Desert Savanna Sparrow. Pale Savanda Sparrow.

Description.- Similar to $P$. s. alaudinus but much paler throughout in all plumages; white replacing buff,- -black streaks thus more conspicuously contrasted, there being a minimum amount of hazel marginings; size slightly less.-After Grinnell. Of unquestionable validity as a subspecies.

Recognition Marks.-As in preceding-palest.

Nesting.- Nest: In pasture or grassy bottom lands, a depression in ground, lined with grasses, and sparingly with horsehair; usually under protection of a "cowblake." Eggs: 4 or 5; greenish or bluish white as to ground, spotted and marked, or else mottled and clouded, with vandyke brown or verona brown. Sometimes the entire egg is covered with a pale wash of this color. Av. of I 8 California-taken eggs in the M. C. O. coll.: I $8 \times$ I 3.5 (.7 I x .53). Season: May-June; two broods.

Range of $P$. s. nevadensis.-The Great Basin region; limits not yet defined, but probably has a considerable northerly extension in the Upper Sonoran zone, possibly to British Columbia; winters, at least southerly, to the Pacific Coast and (probably) Mexico.

Occurrence in California.-Resident in summer in watered valleys east of the Sierra divide. An isolated colony reported by Grinnell from northeastern Kern County. Winters south upon the deserts and southwest to the coast. Birds from the northern confines of nevadensis probably occur throughout the State in winter (See Bishop, Condor, XVII., Sept., I9I5, p. 186).

$$
248
$$




\section{The Savanna Sparrowes}

Authorities.-Grinnell, Univ. Calif. Pub. Zool., 5, I910, pp. 31 2-316 (orig. desc.); Bishop, Condor, vol. xrii., I915, pp. I86-I87 (crit.); Grinnell, Pac. Coast Avifauna, no. II, I9I5, pp. II3-II4 (range); Mailliard, J., Condor, vol. xxi., I9I9, p. 75.

\section{No. 41d Dwarf Savanna Sparrow}

A. O. U. No. 542 b, part. Passerculus sandwichensis brooksi Bishop.

Description.- "Nearest in size of P. s. bryanti, but with slightly longer wing and tail, slightly smaller bill, and shorter tarsus; much paler in coloring, with the dark central stripes much narrower both above and below, and the rusty paler. Smaller, but with relatively longer bill than $P$. s. alaudinus and $P$.'s. nevadensis; much paler and with less rusty in plumage of upperparts than $P$. s. alaudinus; closely resembling $P$. s. nevadensis in color, but slightly darker and more brownish above, with the supraloral stripe broader and richer, and with the auricular region, nape and sides of neck washed with buff, these differences showing best in birds of fresh winter plumage" (orig. desc.). "A of 8 males (after Bishop): wing 66.9 (2.63); tail 46.6 (1.83); bill io (.39); depth at base $5.8(.23)$; tarsus 20. I (.79).

Range of P.s. brooksi.-Described by Bishop from specimens taken at Sumas and Chilliwack, B. C., supplemented by two (male and female) taken August i9, 1909, on Humboldt Bay. Probably the coast district of British Columbia and Washington, intergrading toward Humboldt Bay with bryanti. (I cannot believe that these August specimens from Humboldt Bay were really migrants.) Also reported by Mailliard as the breeding bird of Del Norte County.

Occurrence in California.-As above.

Authorities.-Bishop, Condor, vol. xvii., I915, pp. I87-I88 (at Humboldt Bay); Mailliard, Condor, vol. xxiii., Sept., I92 I, p. I64.

SINCE nine of the eleven recognized forms of Passerculus are accredited to California, it may be in order to review the whole group briefly.

The genus Passerculus is a clearly definable and substantially homogeneous one. So nearly uniform is it that, save for the circumstance of insularity connected with $P$. princeps (and no less with $P$. rostratus sanctorum, for which, however, a specific value is not claimed), it is debatable whether there is really more than one species, viz., $P$. sandwichensis. However opinions may differ as to the existence of recognizable intergrades between $P$. s. sandwichensis and $P$. s. alaudinus, or between $P$. s. bryanti and $P$. beldingi, or between the last named and $P$. rostratus, it is certain that these coupled comparisons indicate the lines of closest and most recent relationship. The fortunes of the incipient species and subspecies have been so clearly influenced by the factors of isolation and climatic control, that it may be worth while to set the whole case before us: $P$. princeps is an insular form breeding on Sable Island, Nova Scotia, and wintering along the Atlantic Coast; $P$. $s$. sandwichensis is the robust form localized upon Unalaska and contiguous islands, but retiring in winter along the Pacific Coast; P. s. savanna, $P$. s. alaudinus, $P$. s. neradensis, and $P$. s. brooksi, all barely differen- 


\section{The Savanna Sparrows}

tiated, occupy during the breeding season the greater part of northern North America and a large but irregularly defined portion of the United States, and the elevated section of central Mexico. This range excludes the southeastern states broadly, as it does also interior southern California and Arizona. Savanna is the darker form from the northeast, breeding north to northern Ungava, and south irregularly through the northern and north central states, and retiring in winter as far as the Gulf or beyond. Alaudinus breeds throughout the northwestern quarter of North America to the north coast of Alaska, save for the portions occupied by sandwichensis and brooksi. The latter, recently defined, occupies the Pacific coastal region of Washington and British Columbia, and perhaps of Oregon. Enjoying, as it does, a perpetually mild climate, it is at least partially sedentary. Nevadensis occupies the Great Basin region, broadly, extends north indefinitely to merge with alaudinus, and south, narrowly, to the central tablelands of Mexico. These four forms, with, possibly, sandwichensis proper, should always be thought of together.

Along the coast of the Californias a sharper differentiation occurs. A form scattered over the coastal uplands from San Francisco Bay north-

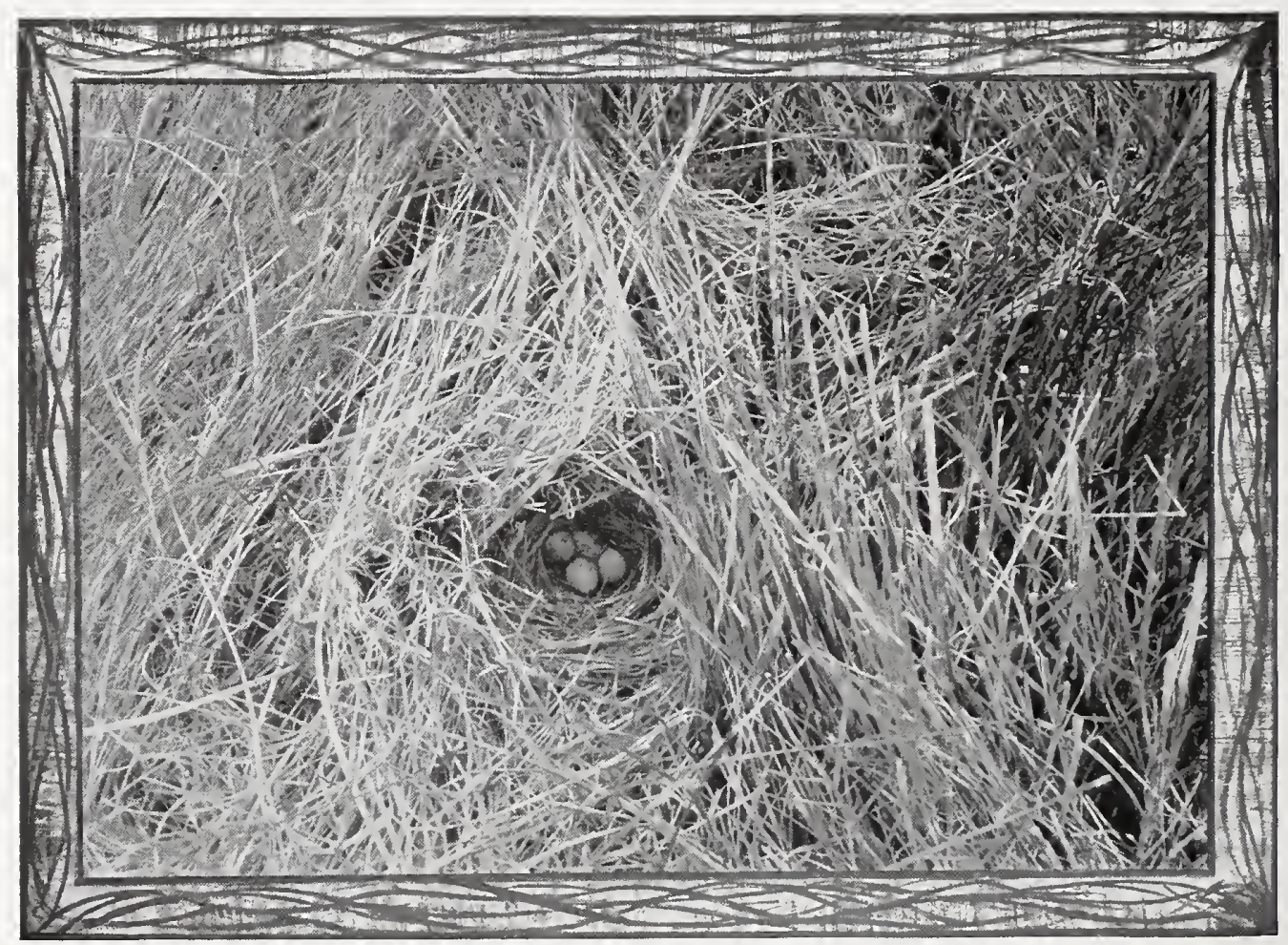

Taken in Iny, Counly

NEST AND EGGS OF NEVADA SAVANNA SPARROW

Photo by the Author

250 
ward probably deserves separate recognition, although it is not easily distinguishable in appearance from $P$. s. bryanti. This undescribed form probably retires to the southward in winter; and its occasional appearance in the San Diegan district has provoked discussion of possible relationship with beldingi. Bryanti, a darker form than alaudinus, is believed to be sedentary in the marshes bordering upon $\mathrm{San} F \mathrm{ranc}$ is co, Monterey, a nd Humboldt bays. Its occurrence further south

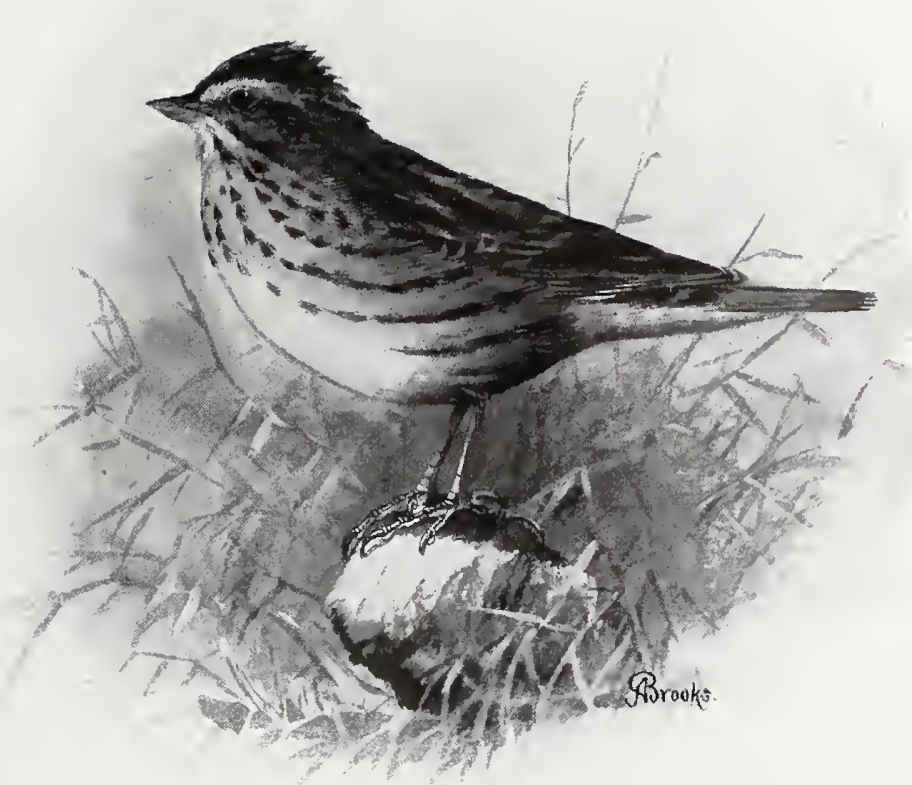

WESTERN SAVANNA SPARROU is conjectural. Belding $i$ is a well-marked form which, so far, appears to be strictly sedentary in the coastal marshes from Santa Barbara to San Diego and San Quentin Bay. Of the rostratus group, variously resident or resident-in-summer in Lower California, rostratus proper, and, possibly, $P$. r. guttatus, comes north to winter. The differentiated values of rostratus and belding $i$ are as clear-cut as those of princeps; and their tenure of the land is presumably as ancient. But as among specimens of sandwichensis, whether from Nevada, Chihuahua, Quebec, Vancouver Island, or the Klondike, there is no certain decision, save through appeal to an extended series of skins in one of the larger museums. In this group of narrow distinction and broad distribution there seems to be, in like manner, no definable difference in song and none in habit, save as enforced by local conditions. It is idle, therefore, to try to impress upon the popular attention the distinctions alleged within this group.

Not every bird can be a beauty any more than every soldier can be a colonel; and when we consider that ten times as many shot-guns are in commission in time of peace as rifles in time of war, we cannot blame a bird for rejoicing in the virtue of humility, envying neither the epaulets of General Blackbird nor even the pale chevrons of Sergeant Siskin. A Savanna Sparrow, especially the washed-out western variety, is a mere 


\section{The Savanna Sparrows}

detached bit of brown earth done up in dried grasses- a feathered commonplace which the landscape will swallow up the instant you take eyes off it. To be sure, if you can get it quite alone and very near, you see enough to admire in the twelve-radiating pattern of the head, and you may even perceive a wan tint of yellow in the superciliary region; but let the birdling drop upon the ground and sit motionless amidst the grass, or in a criss-cross litter of weed-stalks, and sooner far will you catch the gleam of the needle in the haystack.

Savanna Sparrows are birds of the meadows, of the pastures, of weedy waysides, and of open places generally. A fallow field is treasuretrove; and as for the fences, every barleycorn length of every wire or rail-top probably knows the pressure of Savanna's foot. In the warmer lowlands the birds swarm all winter long, and if the Zonotrichice did not already hold unquestioned honors in point of abundance, I would respectfully enter $P$. sandwichensis as a contestant. But as for the migrants, all you can ever get out of them is a game of hide-and-seek-or else an apprehensive $t s s$ from distant weed-tops, where the birds are taking counsel together as to what line of flight they shall next attempt.

Save for the littoral forms, $P$. s. bryanti and $P$. beldingi, which receive separate consideration, the Savanna Sparrows are not extensively resident in summer in California. They may be found regularly only in the northeastern portion of the State, and in the region east of the Sierras as far south as Owens Lake. Dr. Grinnell, however, has noted an isolated colony in northeastern Kern County, at the junction of the Kern River with its South Fork, and there is no reason why others may not be mapped out in the meadows of the Sierran foothills.

In their nesting habits these little fellows come nearer to colonizing than do any other resident members of the Sparrow family. Large tracts of land, apparently suitable, will be left untenanted, while in a nearby field of a few acres half a dozen pairs may be found nesting. They are beginning to show an interest in irrigated tracts, especially pastures, but they find alfalfa or grain fields quite too densely covered for their purposes.

To ascertain the presence of these birds, the ear-test is best, when once the song is mastered. The latter consists of a series of lisping and buzzing notes, fine only in the sense of being small, and quite unmusical, tsut, tsut, tsu wazzzztsubut. The sound instantly recalls the Western Grasshopper Sparrow (Ammodramus savannarum bimaculatus), who is an own cousin; but the preliminary and closing flourishes are a good deal longer than those of the related species, and the buzzing strain shorter.

Love-making goes by example as well as by season, so that when 
the choral fever is on they are all at it. The males will sing from the ground rather than keep silence, although they prefer a weed-top, a fence-post, or even a convenient tree. The female listens patiently, near by, or if she tries to slip away for a bit of food, the jealous lover recalls her to duty at once by an ardent chase.

The nest is settled snugly in the dead grasses of last year's ungathered crop, and is thus both concealed from above and upborne from below, and is itself carefully done in fine dead grasses.

The sitting bird does not often permit a close approach, but rises from the nest at not less than thirty feet. The precise spot is, therefore, very difficult to locate. If discovered, the bird will potter about with fine affectation of listlessness, and seems to consider that she has done her full duty in not showing the eggs.

My first nest of these rather baffling birds was found near Goose Lake on the Ioth of June, I9I2. I was traversing a big wire-grass meadow when a male Savanna crossed my bows, settled at a hundred feet by the edge of the water, and began to pick about with a preoccupation which was a shade too intense. I paused and studied him carefully until, unable longer to bear the strain of suspicion, the female burst cover at twenty feet. I did not see exactly where she rose, but I knew I had a warm scent, so I threw down my bandana (with which no proper oölogist goes unprovided) and began the search on hands and knees. A particularly good-looking "cow-flop" tempted me to look ahead of my proper and duller territory, and there, perfectly concealed by the edge of the dung cushion, which was held aloof by the stiff grass, I found a beautiful set of five dark eggs. The nest itself was merely resting upon the surface of the clamp earth, being stiffly supported all around by the wire-grass. The female chipped solicitously, but remained out of sight; while the male, whose zeal had done the mischief, sang diligently from a distance of a hundred feet.

"Nothing succeeds like success." Having found my first nest of the Nevada Savanna Sparrow, I proceeded straightway to pick out another. We were dragging the wire-grass on the shoreward side of the beach ridge for ducks' nests, when a Savanna Sparrow flushed. I didn't know within ten feet where the bird, presumably a male, rose; but I chose a spot arbitrarily and looked about. An inviting example of Minerva's handiwork lay close by, and this I seized forthwith, whereupon a bird exploded from beneath, revealing as she fled a dainty nest which contained two eggs and two young just hatched. I replaced the cow-dropping, for experiment's sake, and found that it actually and completely covered the Sparrow's nest, leaving only room for passage between the lip of the nest and the benign roof. One cannot forbear a chuckle 


\section{The Savanna Sparrows}

over this provident arrangement which Nother Nature has ordained. But, really now, a canopy of indurated fiber upborne by a hundred sturdy spears of grass-what is it but a fairy palace, if you will see it so? Nature's humblest ministries are tenderest, and the uses of life sanctify the lowliest means.

\section{No. 41e Bryant's Marsh Sparrow}

\section{A. O. U. No. 542c. Passerculus sandwichensis bryanti Ridgway.}

Description.- "Similar to P. s. savanna, but smaller and darker, with more slender bill; decidedly smaller and very much darker and browner than $P$. s. alaudinus, with black dorsal streaks very much broader, the underparts much more heavily streaked with black, and, in winter plumage, with the chest, sides, etc., strongly tinged with brownish buff" (Ridgway). Also feet and legs much darker brown. Av. of 8 California-taken males (Bishop): wing 66. I (2.60); tail 46. I (I.8I); bill I I (.43); depth at base $5.9(.23)$; tarsus $21.9(.86)$.

Recognition Marks.-Warbler size; I 2 -rayed pattern of head; heavy streaking; much darker and more heavily streaked on breast and sides than the Western Savanna Sparrow, P. s. alaudinus; lighter and less heavily streaked than P. beldingi.

Nesting.- Nest: Shows characters of foregoing or succeeding form, according 10 situation. Eggs: 4 or 5 ; indistinguishable from those of other forms. Season: A,ril-June; two broods.

Range of $P$. s. bryanti.-Common resident of California coast from Monterey worth to at least Humboldt Bay; largely but not exclusively confined to vicinity of s.lt marshes. Irregularly south in winter, at least as far as Santa Barbara.

Authorities.-Baird (Passerculus anthinus), Rept. Pac. R. R. Surv., vol. ix., 1858, p. 445; Ridgway, Proc. U. S. Nat. Mus., vol. vii., I885, p. 517 (desc. of bryanti); Wicks, Avifauna, vol. i., I 895, p. 27 (nesting); Grinnell, Pac. Coast Avifauna, no. I I, I9I5, p. II4 (range; crit.); Squires, Condor, vol. xviii., I9I6, p. 228 (on uplands); Mailliard, J. and J. W., Condor, vol. xxii., I920, pp. 63-66, 2 figs. (on hills of Marin Co.).

THE CASE of the Bryant Marsh Sparrow is still open for investigation. It is so largely a matter for expert judgment that I propose to present a brief anthology of current discussion; and pass all questions of habit with the remark that Bryant's Marsh Sparrow of the lowlands is essentially like its kinsman, $P$. belding $i$, both in its attachment to the life of the tidal marshes, especially salicornia, and in its sedentary character.

"Common resident on the tidal marshes bordering Monterey, San Francisco, Tomales and Humboldt Bays. The metropolis of this subspecies in its most typical characters is the salicornia association of San Francisco Bay and here in many places it is abundant. The Humboldt Bay representatives (specimens in Mus. Vert. Zool.) are somewhat inter- 


\section{The Savanna Sparrowes}

mediate in character towards alaudinus. Wherever this form occurs at all it is apparently permanently resident." (Grinnell, I9I5) I.

"Bryant's Marsh Sparrow (Passerculus s. bryanti) is common on the marshes around Humboldt Bay, its breeding habitat being supposedly confined to tidal marshes. Yet a male of this form was taken on May 28 (I9I6) on Kneeland prairie on top of a range at an elevation of about 2800 feet and 18 miles from salt water. It appeared to be nesting but neither nest nor mate was secured. This individual is indistinguishable from specimens taken at same date on salt marsh near Eureka except that the bill is more slender than any other obtained." (Mailliard, r9i6)².

"Joseph Mailliard's note on the Bryant Marsh Sparrow in a recent issue of The Condor suggests a solution to what has been a puzzling problem to me for some time. I have found the Bryant Marsh Sparrow breeding on the Islais Marsh, south of the Potrero district. But there are other birds apparently of this species, averaging somewhat lighter, however, found resident in the Presidio, on the Ingleside Golf Links, and high up the slopes of Twin Peaks. I have noted them many times during the breeding season at the two last named stations. Most of the books speak of this sparrow as though it were found nowhere else than on the salicornia marshes near sea level. It is my opinion that there is an upland form of Passerculus sandwichensis bryanti which verges toward $P$. s. alaudinus, and that it ranges from Humboldt County south at least to the Transition area of San Francisco County. I may add that I noted this same light-colored Bryant Marsh Sparrow last July on the uplands of western Sonoma County some miles from the sea." (Squires) 3 .

"The question is an interesting one, and there seems a great likelihood that there really are two forms nearly alike but of different habits. I have taken specimens of what I supposed was bryanti at different times and places high up on hills and ranges, but, except for the one mentioned in the notes from Humboldt Bay, have never taken any at a high elevation in the height of the breeding season, although a few were taken at dates very close to it. These latter were supposed to be wanderers or non-breeders at the time, but recent events make me doubt this conclusion.

"In our collection is a set of eggs, taken by C. A. Allen, at that time living at Nicasio, Marin County, California, the data of which are as follows: 'Western Savannah Sparrow. Black Mt., Marin Co., Calif., Apr. 29, I877. Eggs fresh. Nest on ground. Male shot. Nest on top of mountain.' This is not the exact wording of the data but is the essence of it. We did not see the parent of this set, and have always

1 Pacific Coast Avifauna, no. 11, by Joseph Grinnell (Oct. 21, 1915), p. 114

2 Joseph Mailliard in The Condor, Vol. XVII].. Sept., 1916, p. 199.

${ }^{3}$ W. A. Squires in The Condor, Vol. XVIII., Nov., 1916, p. 228. 


\section{The Belding Marsh Sparrow}

been very skeptical concerning its identification or connection with the nest, but have kept the set in abeyance all this time. It looks now as if Allen might have been pretty close to the truth, and that the bird was this possible upland form." (Mailliard)1.

No. 42

\section{Belding's Marsh Sparrow}

\section{A. O. U. No. 543. Passerculus beldingi Ridgway.}

Synonyms.-Belding's Sparrow. Southern Savanna Sparrow. San Diego Marsh SparRow.

Description.- "Similar to P. sandwichensis bryanti, but still darker in coloration, the underparts more heavily and more extensively streaked with black, the upperparts more olivaceous and more uniform; wing and tail averaging shorter, but bill larger; legs and feet darker (grayish brown)" (Ridgway). Also bill slenderer, longer, and differently proportioned. Adults (sexes alike): Above blackish brown highly varied and tempered by marginings of dull, rusty, grayish brown or olivegray; head showing obscurely the 12-rayed pattern of the genus, but central crown stripe scarcely distinguishable, and the malar and sub-malar stripes less coherent, superciliary pale yellow, and sometimes a yellow tinge spreading over crown; underparts white, or palest buffy, heavily streaked, especially on breast and sides, with brownish black, the lateral streaks sometimes bordered vaguely with rusty brown; the longest under tail-coverts narrowly and very sparingly streaked with blackish. Bill brownish, darker above, lighter below; feet and legs brown. Length of adult male about I 46 (5.75); av. of males: wing 65.4 (2.58); tail 48.3 (I.90); bill I I.5 (.45); depth at base $5.6(.22)$; tarsus 2 I.3 (.84). Females somewhat smaller.

Recognition Marks.- Warbler size; marsh-haunting habits; the darkest and most heavily streaked of the Marsh Sparrows.

Nesting.- Nest: On moist ground of tidal marsh in salicornia, well concealed, or else in protecting clump of neighboring levels; a rather bulky cup of weed-stems and grasses. Eggs: 3, or rarely, 4; greenish or bluish white, speckled and spotted or washed and clouded with verona brown. Av. of Io eggs in M. C. O. coll.: I8.5 x $14.2(.73 \times .56)$. Season: April-June, two broods.

General Range.-Common resident of the coastal marshes from San Diego north at least to Santa Barbara. Never strays far from the beach bluffs in the neighborhood of salt marshes.

Distribution in California.-As above.

Authorities.-Coues (Passerculus anthinus), Ibis, ser. 2, vol. ii., I 866, p. 268; IIenshaw, Rept. Orn. Wheeler Survey, 1876, p. 240 (meas., habits); Ridgway, Proc. U. S. Nat. Mus., vol. vii., I 885, p. 516 (desc. of beldingi); Gault, Bull. Ridgway Orn. Club, vol. ii., 1887, pp. 58-60 (nesting); Belding, Occ. Papers, Calif. Acad. Sci., 2, I890, pp. I 44-I 45 (nesting); Robertson, Bull. Cooper Orn. Club, vol. i., I899, p. 73 (nesting); Willett. Pac. Coast Avifauna, no. 7, 19I2, p. 77 (status; nesting season).

1 Joseph Mailliard in The Condor, Vol. XIX., March, 1917, p. 69. 


\section{The Belding Marsh Sparrow}

THE "SAVANNA" Sparrows, elsewhere highly migratory, have along the coasts of the Californias become largely sedentary, and are, therefore, better known as Marsh Sparrows. Most contented of all are the little dark beldingis, which inhabit the tidal marshes such as dot the coast between Santa Barbara and San Quentin Bay, L. C. We are bound to admit that the birds' requirements as to house furnishing, "garden sass," and such, are of the most modest; but "eternal sunshine" (with a judicious blending of eternal fog), a glimpse of the empurpled hills, and the wafting of gentle sea breezes, the purest on earth, make beldingi immeasurably content with his little plot of salicornia and his front parapet of sand dunes. So far as we know, therefore, the Belding Marsh Sparrow is absolutely sedentary, and each individual lives and dies in its own little pasture.

But it never occurs to anyone to pity the Belding Marsh Sparrows.

We are filled with envy, instead, as BELDING MARSH SPARROW

Photo by the Author often as we visit their haunts. Every rod's advance through the impeding succulent weeds puts up a sparrow who forthwith posts on an uppermost spray and regards you with patient indulgence; or else signals to his fellows, similarly posted, as to the next convenient rendezvous. Presently he plumps into the depths again, and pursues his business so adroitly that you will scarcely see him after. It is all so detached, so otherworldly, so utterly beyond your feeble apprehensions, that you feel like an unlettered cow permitted to stand in a clover field where fairies are at play.

The case is quite hopeless unless you are provided with binoculars, say of 8-power. It is good sport, then, to study the sleek outlines of a posted sparrow, to note the smart blackish stripes which crowd the chest and cover the flank, the touch of yellow over the eye, which relates the bird to sandwichensis, the feet darker than any other of the genus, 


\section{The Belding Marsh Sparrow}

and, most of all, the twinkling eye, which tells not of taxonomic secretsmost trifling of all-but of a merry life, rich in experience and high adventure, and not unacquainted with passion.

Belding Sparrows colonize, rather closely, at nesting time-a certain five-acre stretch at Sandyland harbors about twenty pairs in Apriland at all seasons the birds know where their fellows are. At the close of the nesting season the Sparrows deploy more widely through the more elevated weedy stretches which surround the marshes proper, or take up their station in the sand dunes, where they may welcome the return of Pipit, most indefatigable of beach-combers, or of Audubon Warbler, gayest of beach-haunting tourists. At such times, also, they invade the beaches proper, nimbly pursuing the kelpflies, or snatching salty comfits from the wet sand. The approach of a stranger, however, recalls the impropriety of such a course. There may be a little hiding and sulking behind driftwood or stranded kelp-roots, but a moment's reflection sends them bolting for cover in the beloved weeds.

Not all ears may hear the humble "chip" with which the birds keep in touch, and the song, here possibly first described, is so insect-like, that one despairs of persuading his friends to attend its trivial course. For an ear keyed high the bird says, tsit tsit tsu weezz tsit tsit, and though a mouse could put it to shame as a rocalist, the



Taken in San Diego County

Photo by Donald R. Dickey NEST AND EGGS OF BELDING MARSH SPARROW 
bird is dead in earnest, so that the difficulty experienced by the performer in squeezing out the weezz note gives the listener a spasm of sympathy. When the courting season is at its height, all the fairies (or, more properly, exactly half of them) are talking at once; and the intrusive cow steps softly so as not to miss the fun.

Nesting is on in early April, while by May ist most of the householders have brought off their broods. The birds nest indifferently in the shelter of the salicornia itself, or else they seek the protection of larger growth hard by. A discovery is made by accident, as of some bird sitting tighter than usual and flushing directly at close range. For when the colony is aroused the females appear to slip away at long range, and one may tramp about for an hour among forty pairs, all mildly disturbed and very alert, without making a single location. When flushed at close range, and knowing that she is observed, the female flutters over the tops of the plants for a great distance as though seeking to decoy. But if the nest is approached, she will not return nor evince further interest.

The nest is settled firmly upon the ground among interlaced stems or grasses, and always under adequate cover of grass or weed. One nest before me is made entirely of dried salicornia stems, lined with duck feathers. Another, deeply cupped, is composed of frayed weedstems and finely woven grasses, with a single horsehair. The eggs have the same variety of ground as those of the San Diego Song Sparrow, and are not certainly distinguishable from them in markings; but they average lighter.

No. 43

\section{Large-billed Marsh Sparrow}

\section{A. O. U. No. 544. Passerculus rostratus rostratus (Cassin).}

Description.-Adults (sexes alike): Above and on sides of hind-neck drab, streaked sparingly on back with dark brown, and sharply on pileum with blackish; wings margined with lighter brown (wood-brown or avellaneous); a short yellowish buffy superciliary; a rictal stripe and a submalar stripe of cinnamon-brown enclosing narrow malar area of white; underparts buffy white, almost immaculate on chin and throat, middle of belly and on under tail-coverts; heavily streaked across breast and on sides, each streak blackish brown, bordered broadly with cinnamon-brown. Bill brown above, paler (yellowish brown) below; feet and legs light brown. Length about I $52.4(6.00)$; av of males: wing $72(2.84)$; tail 53 (2.09); bill I3 (.52); depth at base $7.6(.30)$ : tarsus $23(.9 \mathrm{I})$. Females somewhat smaller. 


\section{The Large-billed Sparrows}

Recognition Marks.-Sparrow size; pale coloration, light grayish brown above, white streaked with brown below; beach-haunting and pier-dwelling habits.

Nesting.- Not known to breed in California. Nest and eggs still undescribed. Doubtless much as in preceding species.

Range of $P$. rostratus.- Southern California, Lower California, and the coast of Sonora.

Range of $P . r$ rostratus.-According to Oberholser, breeds at the head of the Gulf of California in Sonora and Lower California. At the close of the breeding season scatters to southward, westward, and northwestward, reaching coast of southern California and Cape San Lucas.

Distribution in California.- Resident in "winter" from August to March along the coast of southern California, from San Diego north regularly to Point Conception, casually (?) to Santa Cruz; also in the southern interior, at least at Salton Sea (Mecca, Jan. 31, 1913).

Authorities.-Cassin, Proc. Acad. Nat. Sci. Phila., I 852 , p. I84 (original description); Heermann, Journ. Acad. Nat. Sci. Phila., ser. 2, vol. ii., I 853 , p. 265 (habits in brief); Grinnell, Auk, vol. xxii., I905, pp. I6-2 I (query as to summer range; Calif. synonymy); Anthony, Auk, vol. xxiii., I906, pp. 149-I52 (regarding breeding range); Oberholser, Ohio Journal of Science, vol. xix., I9I9, pp. 344-354 (crit.; range).

\section{No. 43a San Lucas Sparrow}

A. O. U. No. 544a. Passerculus rostratus guttatus Lawrence.

Description.- Similar to $P$. $r$. rostratus, but smaller and slightly darker, especially as to streaking of underparts; sides more deeply marked with brownish buffy; bill slenderer.

General Range.- "Lower California. Breeds on Abreojos Point; winters in southern part of the Peninsula (San José del Cabo)" (A. O. U. Check-List).

Occurrence in California.-Records by Edward J. Brown, of Los Angeles, of a male taken at Anaheim Landing, Orange County, Oct. 5, I916, and eighteen skins of both sexes collected at Sunset Beach, Orange County, between Nov. I3, I9I6 and Jan. 3I, I9I7. Identified by Mr. H. C. Oberholser.

Authorities.-Brown, E. J., Auk, vol. xxxiv., I917, p. 340 (Anaheim and Sunset Beach); Grinnell, Condor, vol. xxi., I9I9, p. 4I.

CHRISTMAS bathing at Coronado or Long Beach is regularly featured by the "movies," and duly participated in by loyal Californians, desirous of impressing their eastern friends. It is great sport for the hardy and the boastful; but it is the August crowd, panting from the fervid interior stretches, which bathes because it must. And it is August which brings the Large-billed Sparrow to our shores. Seated demurely on a cushion of kelp, or scuttling nimbly about among its stranded ribbons, the bird snaps at flies and snatches up the tid-bits of the sea. So modest are its ways and so sober its colors, it is quite likely to escape the notice of careless bathers; but once espied, the bird becomes motionless, or else breaks for the shelter of the dunes. 


\section{The Large-billed Sparrows}

August is the proper seaside month, and Large-billed Sparrows are common all along our southern beaches at this season. Some few remain through the season, domiciled in the drift-wood, which is their favorite but scanty hiding place; but most of the birds settle upon our docks or piers for their winter residence. Here they subsist upon the crumbs left from fishermen's lunches, or upon the oats scattered by wasteful work-horses. The undergirding of the wharf affords them welcome shelter, to which they instantly repair in time of danger.

Contact with civilization has not yet roughened their manners, as it has in the case of the blatant English Sparrows; for they are ever dainty and demure. It is well worth while in an idle noon to entice these birds by proffer of crumbs, to see them race over the planking with

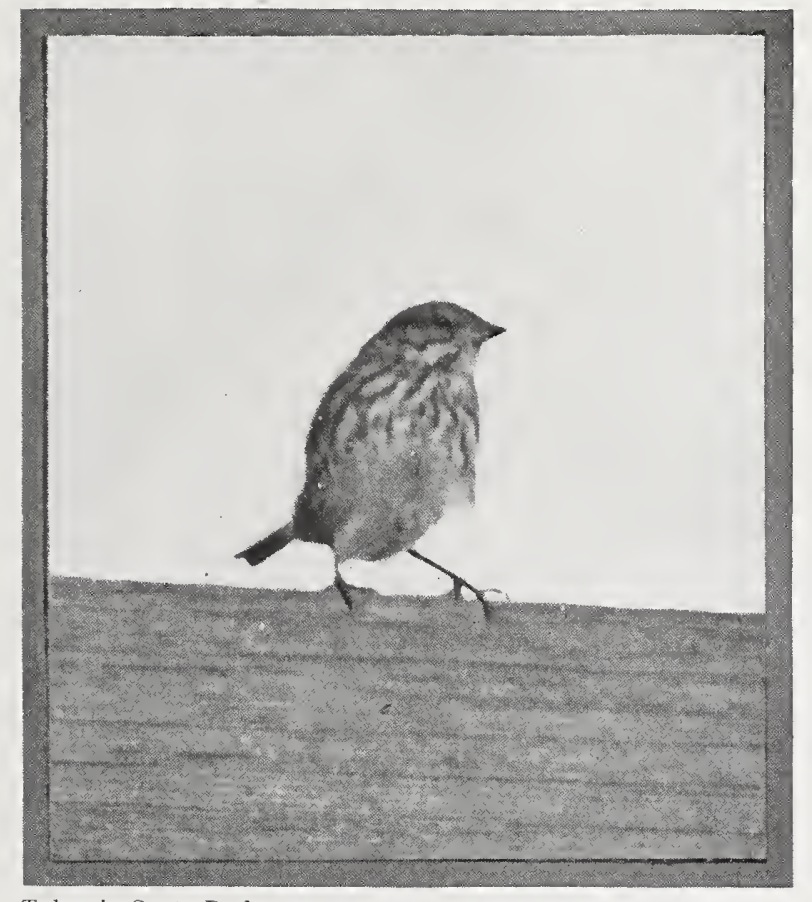

Taken in Santa Barbara THE WHARFINGER many a prudent halt, and finally accept your offering with sippling beaks (precisely as though they were drinking instead of eating) and upturned glances of gratitude.

At such times also we have heard the Passerculine song, although, coming as it did in midwinter, probably not in its fullest volume. The song, generically similar to that of $P$.s.alaudinus, is squeakier, if possible, as well as longer, and it ends in a pookish trill, both finer and lighter: Tsut tsut tsu wzzz tsut tsu wizzy weee. Having little enough of musical quality, its delivery is attended with visible effort,

as though it had to be squeezed out to the last atom.

Those who sigh at the passing of the mysteries, have at least this small comfort, that the nesting range of the Large-billed Sparrow is not yet (Sept., I915) precisely determined, and that its nest and eggs are still unknown. By dint of much public inquiry in 1905 it developed that Mr. A. W. Anthony had taken a female in breeding condition in April at Rancho San Ramon, 25 miles north of San Quentin Bay, Lower 


\section{The Large-billed Sparrows}

California; and that he had seen other such ministering to scattered young in the neighborhood of Oceanside, above San Diego. Mr. A. M. Ingersoll also believes that he once saw a nesting female near San Diego. These records probably do mark the breeding range of the species, although it may extend considerably further southward. It is surmised, also, that the Large-billed Sparrow nests on drier ground, or at least that it does not invade the salt marshes, which are the peculiar province of $P$. beldingi.

The case is an interesting one, because Large-billed Sparrows are of regular occurrence, except during the breeding season, all along our

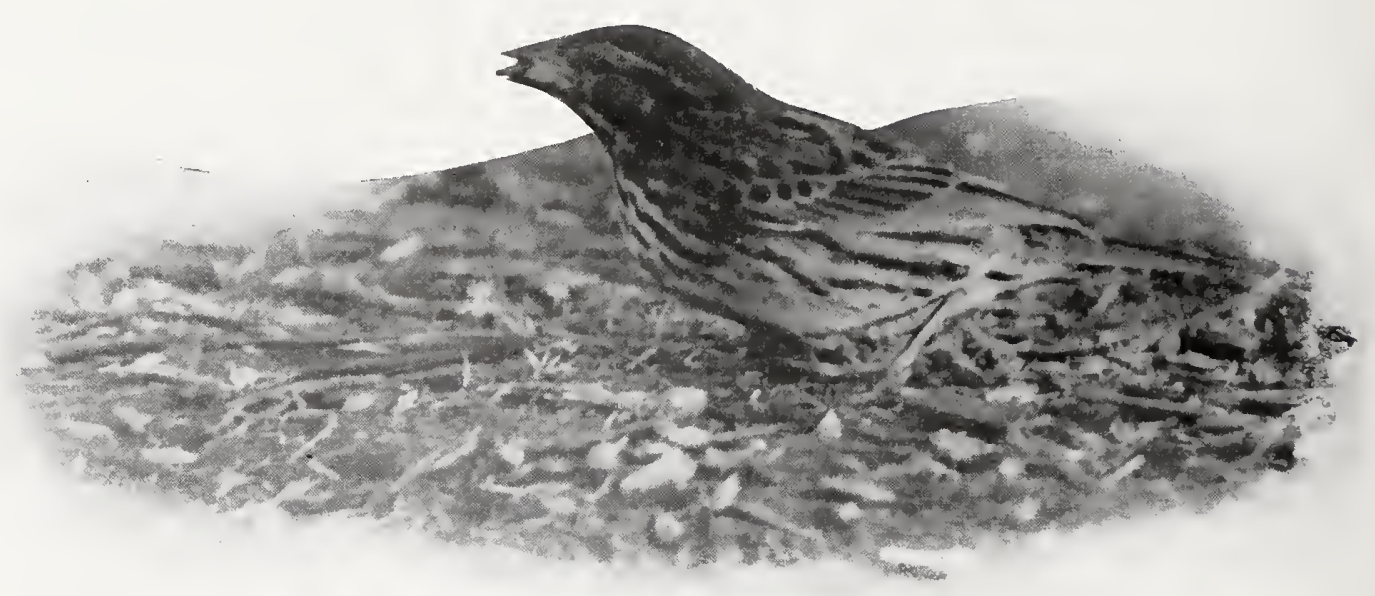

Taken in Santa Barbara

Photo by the Athor

L.ARGE-BILLED MARSH SPARROW EATING OATS

southern coasts as far north at least as Santa Barbara; and there is one record of a specimen taken at Santa Cruz, August 27, I895.

If the surmise of a southern breeding haunt proves to be correct we shall have here, as pointed out by Dr. Grinnell, 1 an example, unique among our land birds, of a northward autumnal migration with compensatory vernal return. The bird also winters along the shores of Lower California and western Mexico, in proportions not yet defined; but inasmuch as it is a strictly littoral species, never being found at rest above half a mile from salt water, it is not altogether surprising that the bird should seek to expand its range in both directions.

'Auk, Vol. XXII., Jan., 1905, p. 20 


\section{The Western Grasshopper Sparrow}

No. 44

\section{Western Grasshopper Sparrow}

\section{A. O. U. No. 546a. Ammodramus savannarum bimaculatus (Swainson).}

Description.-Adults in spring: Crown brownish black, parted by a median stripe of buffy gray; nape olive-gray, spotted with dark cinnamon; remaining upperparts black and fuscous, feathers edged with light olive-gray and tipped with cinnamon in varying proportions (a single feather, as from the greater wing-coverts, will exhibit the four colors); below cinnamon-buffy, brightest on the breast, clearing to whitish on lower breast and belly; the sides and flanks darker; an elongated spot over the eye, bend of wing, and edge of wing near alula, yellow. Bill horn-color above, yellow below; feet yellow. In winter: plumage softer and more blended by reason of increase of the cinnamon-buffy element, which now appears as additional margining of feathers above. Young birds are heavily spotted with blackish across the chest. Length of adult male I23.2-I32 (4.85-5.20); wing 62.5 (2.46); tail 46.5 (I.83); bill I0.9 (.43); tarsus $19.6(.77)$.

Recognition Marks. - Warbler size; unmarked below; bright yellow edge of wing; grasshopper notes; an obscure, close-hiding terrestrial species.

Nesting.- Nest: On the ground; a cup of coiled, dried grasses, sunk flush with surface and usually well concealed in grass or other vegetation. Eggs: + or 5; shortovate, sometimes rounded; clear white, sharply and moderately, or heavily, speckled and spotted, chiefly at larger end, with reddish brown (burnt umber to pecan brown); av. size $18.8 \times 14.2(.74 \times \cdot 56)$. Season: April to June, but chiefly May; one or two broods.

Range of A. savannarum.-United States south to West Indies, Central America, and northern South America.

Range of A. s. bimaculatus. - Western North America, breeding from southeastern British Columbia, northern Montana, and southern Minnesota, south to southern California and Texas. Winters from central California, southern Arizona, and southern Texas, to Cape San Lucas and Central America.

Distribution in California.-Partially resident or summer resident, irregularly and locally, in meadows and lowlands, or on open grassy hillsides west of the Sierras, from Sacramento and Mendocino counties (Ukiah, June I3, I9I6) south to San Diego; more widely distributed in winter.

Authorities.-Heermann (Emberiza passerina), Journ. Acad. Nat. Sci. Phila., ser. 2, vol. ii., I 853 , p. 265: Henshaw, Rept. Orn. Wheeler Surv, 1876, pp. 240-24I (nesting at Santa Barbara); Willett, Condor, vol. xii., I910, p. 204; Pac. Coast Avifauna, no. 7 , I9I2, p. 78 (nesting in so. Calif.); Tyler, Pac. Coast Avifauna, no. 9, I9I3, pp. 78-79 (habits); Dixon, Condor, vol. xviii., I916, pl. 8+ (nesting at Escondido); Pemberton, Condor, vol. xix., I9I7, pp. 24-25 (nesting in Santa Monica Mts.)

"THOSE bird-lovers who disclaim all interest in entomology will be slow in discovering this humble species, for its song is nearer like the chirring of some insect than the voice of a bird. There always comes a day in late April when the half-grown meadows and fields are suddenly found to contain from one to six pairs each of these buzzing Sparrows. 


\section{The Western Grasshopper Sparrow}

But with the possible exception of certain Warblers, there is no other bird of anything like the abundance of this one, whose very outline is so nearly unknown to all but the experienced bird-watcher. Its coloration is the plainest possible, its station lowly, and its habits secretive. Perched upon some weed-top, or standing on a fence-rail, the male sends out at regular intervals a weak hissing trill which occupies a fraction over a second in delivery. The sound is not exactly like that of any known insect, but is comparable to the clicking of a locust-or better, to the shrilling of the corydalis. Again, the opening and closing of a loud-ticking watch, especially if it be opened with a clatter and shut with a snap, is suggestive of the strange performance. Later in the season a longer effort is sometimes heard. First comes the full 'chirr,' then slow notes, three or four in number, as though the progress of the 'wheels' was somewhat impeded; after which the burr proceeds with the original or accelerated rapidity - the whole occupying three seconds. The song will carry a hundred yards for a sharp ear, or further if the ear be laid to the ground; but a fresh cold in the head will spoil the concert at thirty feet.

"Only once did I see a Grasshopper Sparrow holding forth from the top of a tall sapling in a fence-row. Surely he must have atoned for his boldness by skulking among the grass roots for two days thereafter. The birds require to be nearly stepped upon - technically 'kicked out'--before they will take wing. Some will move off in a flurried zig-zag, but others with a direct buzzing flight like a bee,- -in both cases to plump down into the weeds at no great distance." (The Birds of Ohio).

The foregoing account applies equally well to the western form of the Grasshopper Sparrow, which is merely a little paler and differently proportioned. But something remains to be said of the highly irregular distribution of the western bird in the breeding season. It is common only in the "San Diegan district," a faunal area which embraces Ventura and Santa Barbara; and even here it is very sharply localized, being found in some low-lying meadow, or again in an upland pasture, and not occurring again for a dozen miles. In the State at large one might travel a hundred miles without once encountering it. Then suddenly a colony of a dozen pairs might be found occupying a stretch of alfalfa, or a grassy hillside not too closely cropped by cattle. Besides the stations of occurrence enumerated by Grinnell, ${ }^{1}$ I have found it breeding (or at least singing) in northeastern San Luis Obispo County, and in northwestern Kern, on the coastal mesa above Santa Cruz, and at a point near Ukiah in Mendocino County.

Nesting occurs from April to June according to elevation and season.

${ }_{1}$ Distributional List, p. 115 


\section{The Western Grasshopper Sparrow}

The nests are grass-lined depressions sunk flush with the level of the ground, and usually ensconced in the shelter of some weed or importantlooking grass-tuft. The female leaves in a casual way, and whether she sneaks or flushes sharply, it takes a quick eye to mark the movement of such an obscure groundling.

Mr. J. B. Dixon reports 1 the taking of a nest near Escondido, first noted on the I3th of April, I9I5. It was

located in an extensive alkaline meadow covered with salt grass, and enjoyed the shelter of a clump of grass. The nest, which contained four eggs, was built entirely of fine dead weed-stalks, loosely pressed together, with a lining of fine dry grass and grass-seedheads, and was so frail that its removal could with difficulty be accomplished.

"When we approached the nest the female flattened out on the nest and watched us anxiously. She flushed when we were about six feet away, and after we had stood still for several seconds conversing in whispers upon the color pattern of the back, and the lack of a decided yellow streak over the eye the observers had anticipated some form of Passerculus. The bird slipped off the nest with no trace of commotion, and ran, or rather sneaked away, using

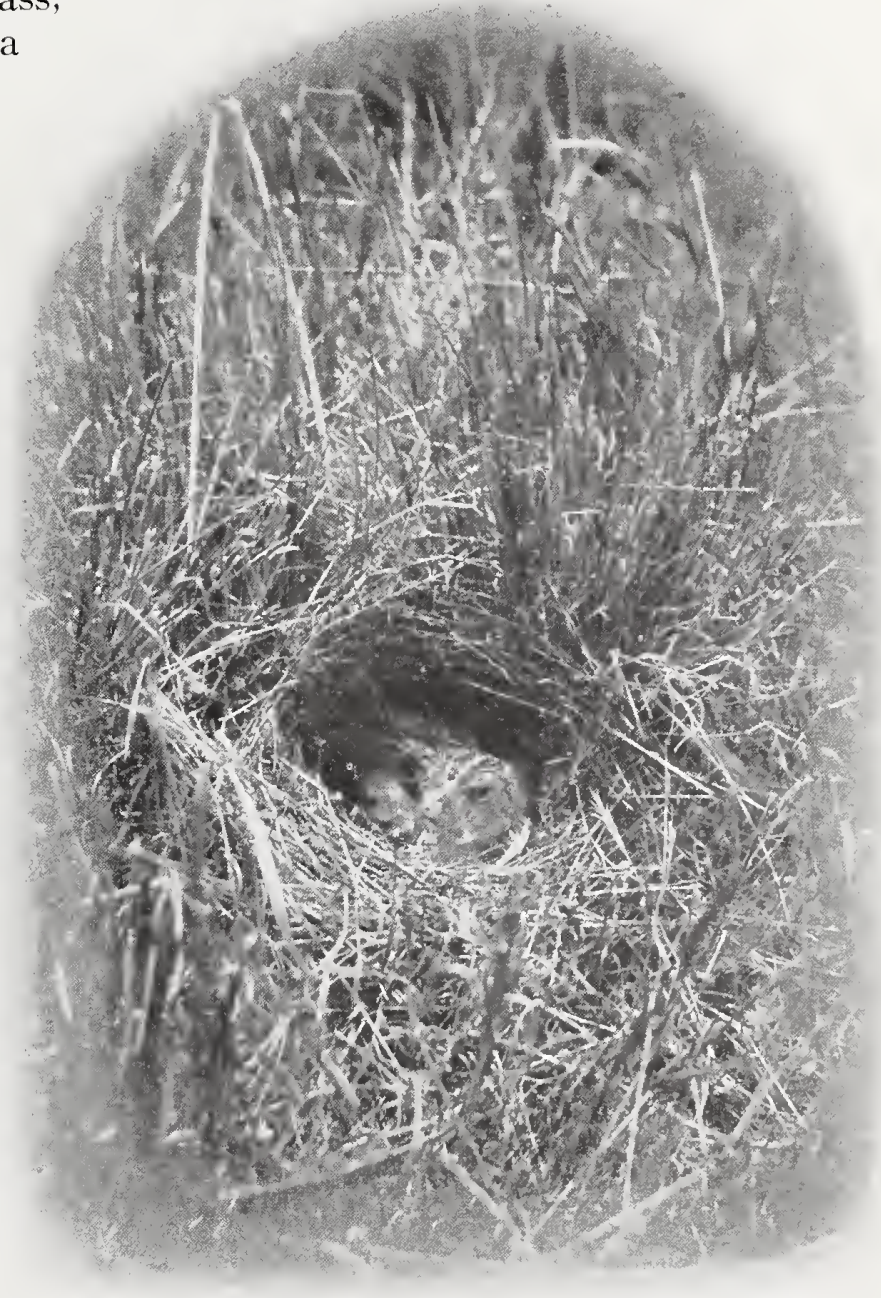

Taken in San Diego County Photo by D. R. Dickey and L. Huey WESTERN GRASSHOPPER SPARROW: (Cover Cut Away) 


\section{The Nelson Sparrow}

every available tuft of grass as a screen to hide behind. When she reached a little ridge about twenty feet away she hopped up in plain sight, and took a flying hop to another ridge a few feet farther away. To a passerby she would appear to have flushed from a point some twenty feet away from the nest. Mr. Schnack observed the bird when she left the nest several times, and he said that this was her characteristic way of leaving it. The male could be heard uttering a faint insect-like chip from some clod or ridge near by, but he was very shy and kept circling the nest at a distance."

No. 45

\section{Nelson's Sparrow}

A. O. U. No. 549. I. Ammospiza caudacuta nelsoni (Allen).

Synonym.--Nelson's Sharp-talled Sparrow.

Description.-Adult (sexes alike): Pileum narrowly black, warmed by brown edgings; a median stripe of olive-gray, broadening behind; a narrow nuchal collar, dresden brown centrally, olive-gray laterally, in highest plumage pattern of back and scapulars falling into four broad stripes of mingled black and dark brown, bordered narrowly by white and converging behind; the effect carried out by tertials having black centers and white lateral borders (in lower plumage pattern lost, but all colors represented as streaks); rump and upper tail-coverts mingled olive-gray and tawnyolive sharply streaked with black; edge of wing pale yellow, the flight-feathers with tawny olive edging (carrying out color scheme of sides); throat narrowly and belly broadly white; remaining plumage, viz., sides of head (enclosing a gray space bordered above with black), chest broadly, sides, and crissum, clay-color (grayish orangeyellow), the chest and sides obscurely streaked with dusky. Bill dark brown above, lighter below; feet and legs (drying) brownish. Length about I39.7 (5.50); wing 55 (2.I7); tail 47.5 (I.87); bill I0.4 (.4I); tarsus 20 (.79). Females average smaller.

Recognition Marks.-Warbler size; strong tawny (clay-colored) suffusion of breast, superciliary and sides; variegated pattern of upperparts, which always includes sharp white streaks on scapulars.

Nesting.-Does not breed in California. Nest: On the ground, of grasses, usually well concealed by surrounding grasses. Eggs: 5; whitish or dull greenish white, heavily speckled and spotted, or else nearly buried in reddish brown (Rood's brown to snuff brown). Av. size I9 X I3.7 (.75 x.54). Season: About June Ist.

Range of Ammospiza caudacuta.-Marshes both salt and fresh of eastern and interior North America. Winters on the Atlantic and Gulf coasts from North Carolina to Texas.

Range of A. c. nelsoni.-The interior representative, breeding from Great Slave Lake and west central Alberta southeastward to northeastern South Dakota; winters on South Atlantic and Gulf coasts; casual on the north Atlantic coast during migrations as far as Maine. Accidental in California.

Occurrence in California.-- See below. 
The Nelson Sparrow

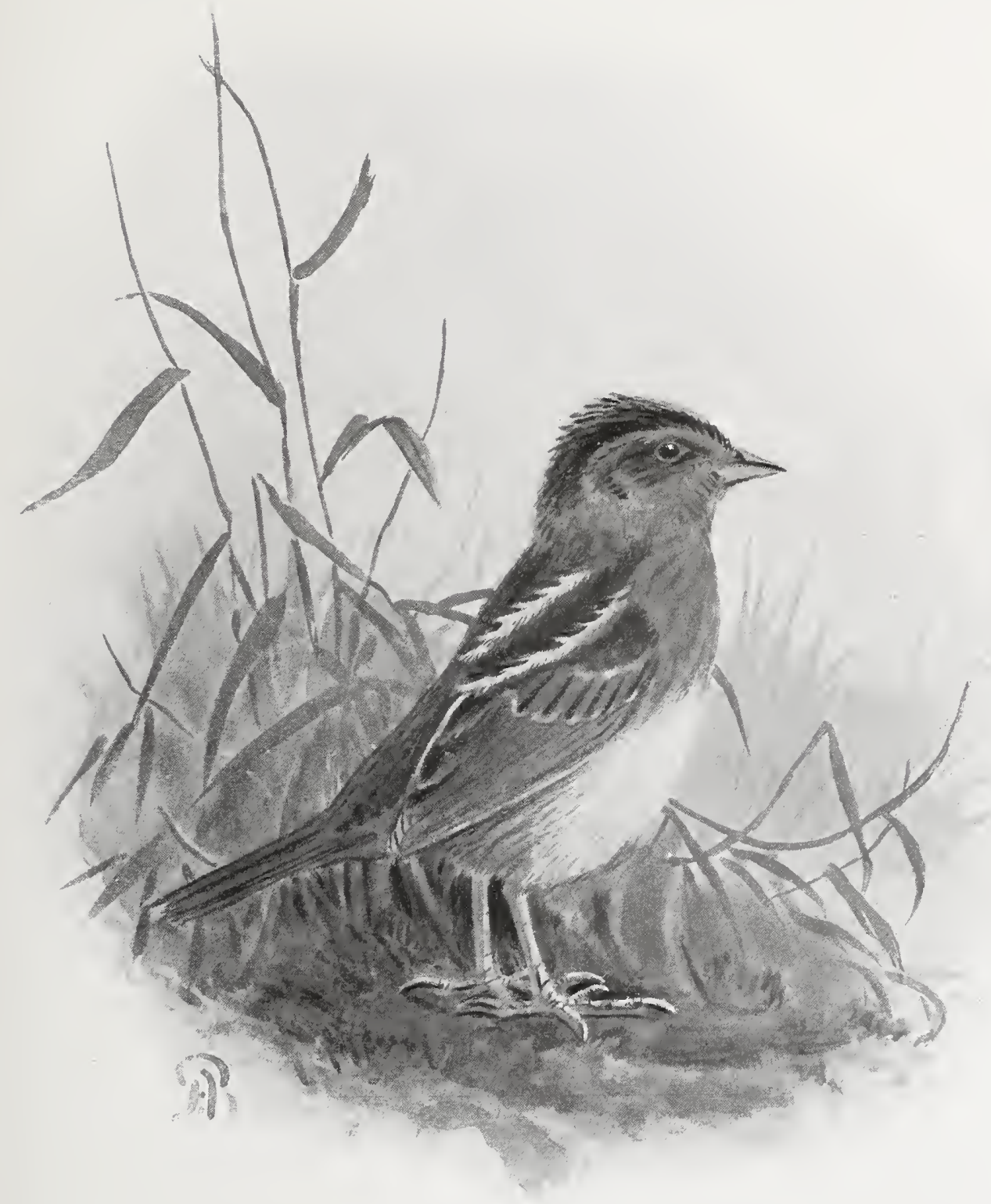

NELSON SPARROW

Authorities.-Ridgway, Proc. U. S. Nat. Mus., vol. xiv., I 89 I, p. 483 (at Milpitas; desc. of (becki); Dwight, Auk, vol. xiii., I896, pp. 27I-278, pl. iv. (monograph); Barlow, Condor, vol. ii., 1900, p. I32. 


\section{The Rufous-crowned Sparrow}

THE NELSON Sparrow lives a life of such furtive obscurity, even on its breeding grounds in the Dakotas and on the Canadian plains, that the mention of its name does not excite hope in the Californian breast. Its casual appearance in California, twice recorded, is not supported by additional evidence west of the Rocky Mountains, and we are left to suppose that both cases are really accidental, examples of those stragglers, common to many species, which attempt to go straight south in autumn instead of proceeding in a sharply southeasterly direction, as prescribed by ancient precedent. But we speak with studied restraint. Almost anything may prove to be true regarding the range of a species so obscure. The very existence of the bird was not suspected until 1875, when it was taken on the Calumet marshes, in what is now South Chicago. Almost immediately thereafter it was recorded from Racine, Wisconsin, then from Michigan, then from Kansas, and then it began to bob up on the Atlantic seaboard. The history of the progressive recognition of this ignis fatuus of the marshes, until its normal range was known to include Great Slave Lake and the Gulf States, is one of the lesser romances of ornithology.

The nesting was first described by Walter Raine ${ }^{1}$ from examples studied in Manitoba; but the first United States record was made by Eugene S. Rolfe 2 who, on June I4, 1899, found a nest containing five eggs deeply sunk in wet earth of a tiny grass island in a dismal flooded area near Devil's Lake. Mr. Rolfe's prediction that "its discovery will probably continue rare and the merest accident" has proved all too true. An acquaintance, Mr. Remington Kellogg, recently employed by the Biological Survey for explorations in the Dakotas, informs me, however, that he found several nests of the Nelson Sparrow during the course of a season's work. But having been straitly charged by "the Chief," whose youthful predilections have been quite forsworn, not to "bother with birds' eggs," these rarities were, unfortunately, lost to science.

\section{No. 46}

\section{Rufous-crowned Sparrow}

\section{A. O. U. No. 580. Aimophila ruficeps ruficeps (Cassin).}

Description.-Adult (sexes alike): Rufous and olive-gray; the olive-gray purest on sides of neck and sides of head (where appearing as broad superciliary and as malar stripe), darkening as it crosses the chest broadly, with accession of tawny element on sides and crissum; clearing, buffy whitish, on throat and belly; above and on wing-

1 Nidiologist, Vol. I.. Feb., 1894, p. 88.

2 Nidologist, Vol. VI., Oct., 1899, pp. 356-3.57. 


\section{The Rufous-crowned Sparrow}

coverts appearing as skirting, or bordering, with increase posteriorly; the rufous element (between chestnut and mars brown) nearly pure on top of head (or faintly parted by median line of olive-gray), elsewhere appearing as broad centers of feathers, on hind-neck, back, and scapulars, in decreasing ratio posteriorly; wings and tail rufousdusky, the secondaries edged with rufous, and the tail chiefly dull rufous on upper exposed surface, which is also obscurely barred with darker: edge of wing pale buffy; a post-ocular streak of rufous; a narrow line over eye, and a distinct malar stripe black. Bill dark horn-color above, lighter below; feet and legs very pale brownish. Young birds are duller and grayer above, and very finely streaked with brownish dusky below, with slight increase of the tawny element posteriorly. Length of adult male: I 46 I $53\left(5.75^{-6.00)}\right.$; wing $59(2.32)$; tail $63.5(2.50)$; bill II.4 (.448); tarsus $20(.78)$. Female doubtfully smaller.

Recognition Marks.-Small Sparrow size; rufous color nearly pure on crown and spread decreasingly over remaining upperparts, distinctive; a denizen of brushy or half-open hillsides and fallow fields near heavy cover.

Nesting. - Nest: On the ground, a rather bulky affair of weed-stems, grasses, and trash, lined with fine grasses or horsehair, and placed in shelter of bush or weed clump, usually on rocky hillside. Eggs: 4 or 5 ; short-ovate, or almost oval; pure white or pale bluish white. Av. size, $18.8 \times 15(.74 \times 59)$. Season: May to July, but chiefly May; one or two broods.

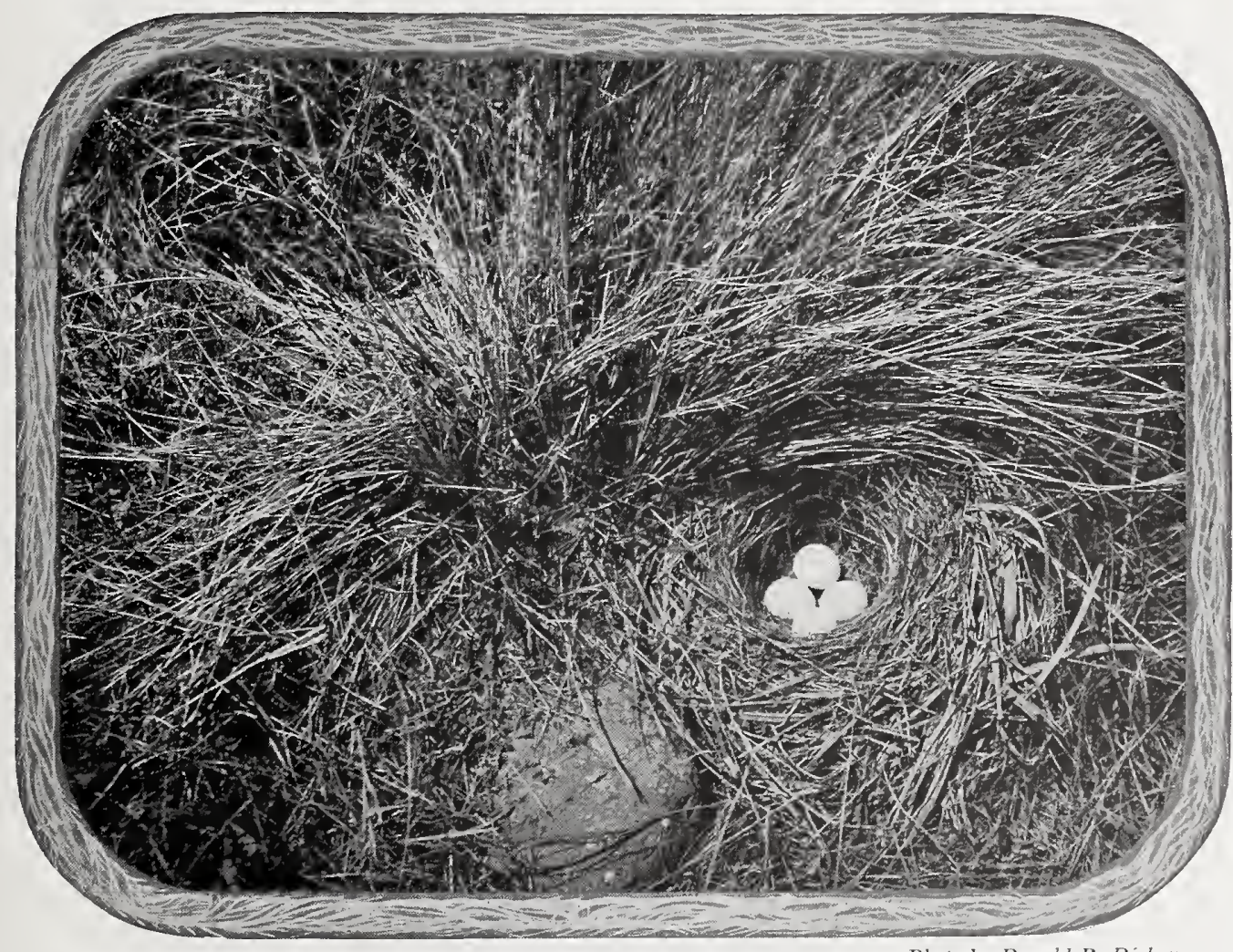

Taken in San Diego

Photo by Donald R. Dickey

NEST AND EGGS OF RUFOUS CROWNED SPARROW 


\section{The Rufous-crowned Sparrow}

Range of Aimophila ruficeps.-Southwestern United States from central California east to Oklahoma, south to Cape San Lucas and southern Mexico.

Range of A.r.ruficeps.-Resident in the Upper Sonoran life zone of California west of the Sierras from Marin and Sutter Counties south to the San Pedro Martir Mountains of Lower California.

Distribution in California.-Locally resident chiefly on open or semi-arid hillsides, as above. Common on Santa Cruz Island, and found, at least formerly, on Santa Catalina.

Authorities.-Cassin (Ammodromus ruficeps), Proc. Acad. Nat. Sci. Phila., rol. vi., I 852 , p. I 84 (orig. descr.; Cosumnes R. or Calaveras R.); Sennett, Auk, vol. v., I 888, p. 40 (synopsis of group); Barlow. Condor, vol. iv., 1902, p. 107 (monograph; habits, song, nest and eggs, etc.); Howell, Pac. Coast Avifauna, no. I2, I917, p. 80 (Santa Barbara Islands; distr., crit.); Todd, Condor, vol, xxiv., I922, p. I26 (distr., crit.).

THERE IS nothing sinister about the stealthiness of this creeping Sparrow. He is neither plotting mischief nor playing at hide-and-seek, and he seems to be so pleasantly absorbed in the interests of his little world of grass and weeds as to be quite oblivious to scrutiny or impending danger. There is something so demure, so winsome, so unaffected in his manner as he steps out into the open a dozen feet away, culls a bug and dissects it appreciatively, or else hums a half-forgotten song, that prejudice is immediately disarmed and thoughts of collector's envy dismissed. If the bird notices you at all it is only to bestow a friendly glance, after which he pursues the even tenor of a way which you are sure embraces all the beatitudes. In fine, the Rufous-crowned Sparrow must impress everyone who observes him at all as an amiable and gifted poet of content, a sort of embodiment of sunshine and solitude and homely cheer.

Few lives are so devoted to the humbler levels. Even the Savanna Sparrow will go rocketing off through the air when disturbed. But the Rufous-crown steps about through the grass-stems or tufted cover of a rocky hillside without ostentation or appearance of effort; and even when hard-pressed seems to regard flight as unprofessional, a pitiful and degrading last resort. Yet as the breeding season approaches, the Rufous-crown does not hesitate to explore the upper reaches of last year's weed-tops, or to sing from prominent stations on rock or bush.

The song of the Rufous-crown is one of the freshest, most vivacious and engaging, as well as varied, of all that may be heard upon our southern hillsides. Its vivacity is wren-like. Its minor notes, especially, a ravishing titter, tew tew, remind one now of a Bewick, and now of the Rock Wren, but they are sweeter than either. Its song has the spontaneity of a Winter Wren's, but its volume, duration, and cadence are rather those of the Lazuli Bunting. My attention was once caught by a spirited passage-at-arms and pursuit between a Lazuli Bunting and a 


\section{The Rufous-crowned Sparrow}

Brown Towhee, and I passed on, musing upon the ways of Lazulis, when a song burst forth at my elbow near the roadside. Sult sult zul eb stutz tuzzuzzu wei, said the voice, and I should have let it pass for the song of the Lazuli if curiosity had not been provoked by its nearness. There in a brush-clump not ten feet away sat a Rufous-crowned Sparrow vigorously delivering himself of the stolen (?) song. Fortunately, the Lazuli returned presently to defend his honors, and I had ample opportunity to make a critical comparison of their songs. The resemblance is, after all, superficial, due rather to the accidental characters before enumerated than to quality. The Sparrow's song is more sprightly, more varied, and of a sharper, more penetrating quality. It is rather less musical, and it lacks altogether that caressing drawl which marks the Finch's effort. A few moments later the Rufous-crown took a station well up in a eucalyptus tree and burst forth with great regularity at intervals of ten seconds, with each "performance" lasting about one and a half seconds. The song is so little stereotyped that it contains hints now of Vesper, now of Lark Sparrow (in the killy killy opening notes), now of Willow Goldfinch (for vivacity), but always, most of all, of Lazuli Bunting.

On Santa Cruz Island, where I found the birds abundant in the spring of 1915, I was deceived repeatedly by the chattering, vivacious, and

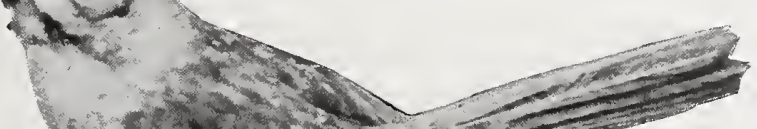
wren-like qualities of the Rufous-crown's song. Wee chee chit $i$ wit chit $i$ wit chit it, the bird said, all at a breath; and it may be that there is an average shade of difference in the insular song, but Lord forbid that the species-hunters should get after them on that

Taken in San Diego Photo by Donald R. Dickey RUFOUS-CROWNED SPARROW I will say that prickly pears are very abundant on Santa Cruz Island, and that the birds frequent the thickest patches. They are really very ungetatable, if you please.

If any one supposes that because the Rufous-crown is a fairly plentiful bird in southwestern California, the nests are common likewise, then he is entitled to another guess. The discovery of one of these obscure cradles, sunk flush with the ground on some weed-strewn hillside, is something of an exploit. Or perhaps it is fairer to say that 


\section{The Rufous-crowned Sparrow}

discovery of a Rufous-crown's nest is a fortunate accident-a bird flushed at close range, or almost stepped on-for deliberate tracing of the bird to a nest is all but impossible, owing to the exceeding wariness of the bird's approach. Mr. Pemberton has given us one of the best accounts, ${ }^{1}$ that of a set taken in Alameda County. Of the general conditions obtaining in that locality, the observer says:

"Favored localities are extremely hot, dry, unsheltered hillsides with southern and western exposures, which harbor a growth of black and gray sage, and a scattering of white oaks. Vegetable matter being from 88 to 97 per cent of their food, it is necessary that there be an undergrowth of grasses.

"Colonies are the rule, and the writer found, usually, a dozen pairs in the confines of a two or three acre hillside. The birds seldom leave the bushes for the oaks, their favorite perches being the tops of the sage. During the ante-nuptial season, the birds may be seen on their favorite perch, giving their peculiar cicada-like song, which has a wonderfully ventriloquistic power, and is very confusing when one is trying to locate the bird."

The nest was found quite by accident by a lay member of Mr. Pemberton's party on a steep, grass-covered, oak-shaded hillside. "The nest was a poor affair-simply a few dry grasses were arranged on one side and part of the bottom of an irregular hole on the edge of a bank along the side of a small gully. The eggs rested upon the earth, with a few grasses crossed between, and a small sage sheltered the nest from the sun.

"The lateness of the date, July 8, I9o8, argued well for incubated eggs, but we were glad to find these perfectly fresh. They were three in number, glossy white, with no trace of the bluish color spoken of by some writers, though slightly pink before blowing. The eggs are now in the writer's collection, and are prized the most of all the shells to be found there."

The record of the occurrence of this species upon the Marysville Buttes, in Sutter County, ${ }^{2}$ marks the northernmost extension in the West of a genus whose members are characteristic of Sonoran uplands as far south as Costa Rica. The genus Aimophila, as defined by Ridgway, ${ }^{3}$ embraces fourteen species and twenty-six "races," many but not all of them marked variously by the peculiar "red hair" which is so characteristic of our California bird. That they are of an ancient stock is evidenced by the fact that their eggs, so far as known, are either white, or pale bluish white, the bleaching of a long-drawn evolution.

1 J. R. Pemberton in The Condor, Vol. XII., July, 1910, pp. 123-125.

2 Grinnell, Distributional List, p. 123.

$\checkmark$ Birds of North and Middle America, Vol. 1., pp. 231-233. 


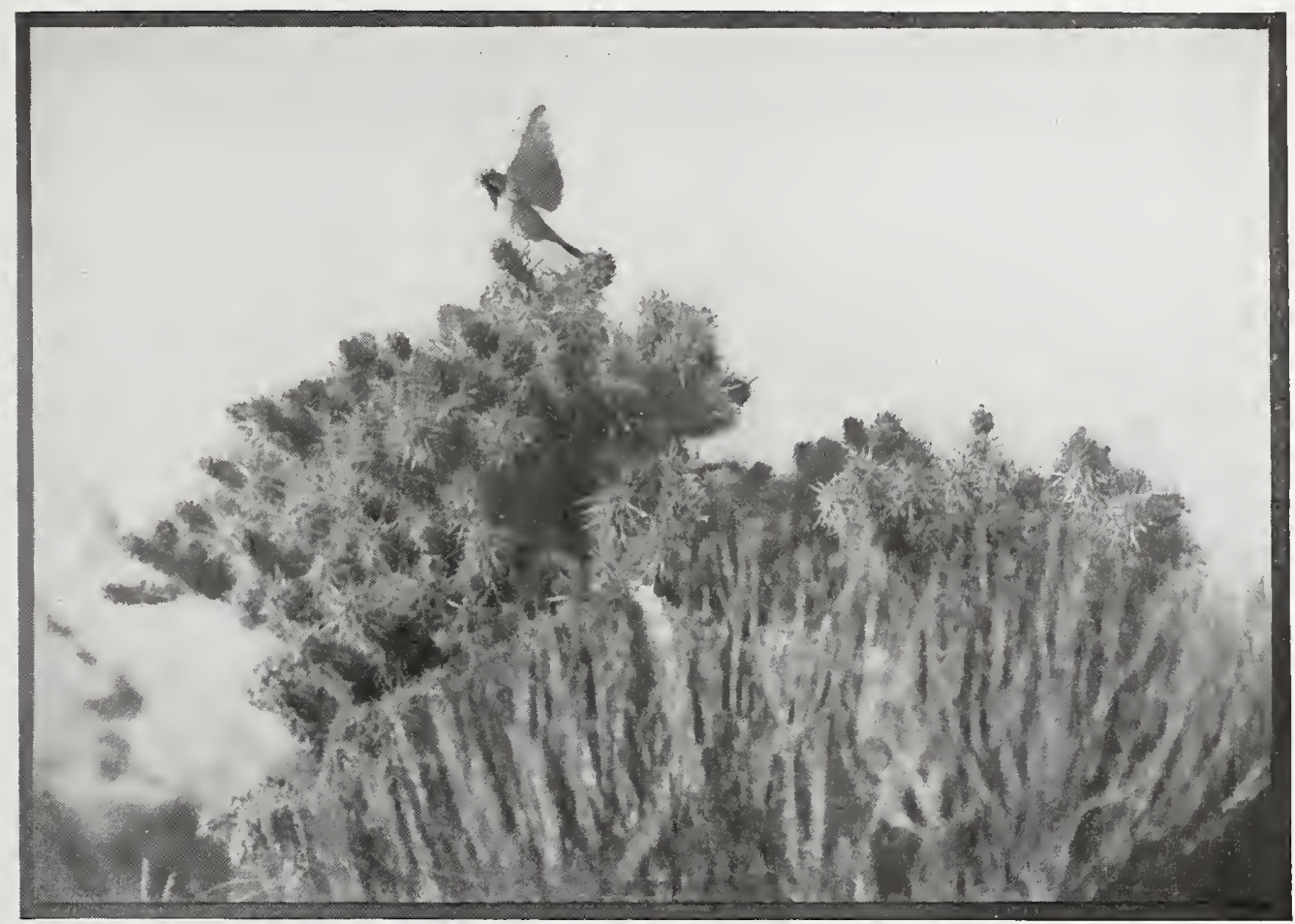

Taken in San Bernardino County

UPON THE POINT OF FLIGHT

Photo by Wright M. Pierce

No. 47

\section{Desert Sparrow}

\section{A. O. U. No. 573a. Amphispiza bilineata deserticola Ridgway.}

Description.-Adult: Crown and nuchal collar, continuous with sides of breast and upper tail-coverts, neutral gray; hindhead and remaining upperparts brownish gray, nearly fawn color on middle of back and on wings; a conspicuous white superciliary stripe bounded narrowly by black above and separated from white malar stripe (not reaching base of bill) by gray on sides of head; lores, anterior portion of malar region, chin, throat and chest centrally black, the last-named with convex posterior outline; remaining underparts white tinged with grayish on sides and flanks; tail blackish, the outer web of outermost rectrix chiefly white, the inner web with white spot on tip, second rectrix (sometimes third or even fourth) tipped with white on inner web. Bill dusky; feet and legs brownish black. Young birds: Like adults but without black pattern of head markings; chin and throat white or flecked with grayish; breast streaked with same and back faintly streaked with dusky; some buffy edging on wing. Length of adults about $135.9(5.35)$; wing $67(2.64)$; tail $64(2.52)$; bill ro (.40); tarsus I9 (.75). Females a little less. 


\section{The Desert Sparrow}

Recognition Marks.-Warbler size; grayish coloration; strong white superciliary; black throat with white trimmings distinctive.

Nesting.- Nest: Placed one or two feet up in sage-brush or other desert plant, rarely on ground; a sturdy cup of interwoven grasses and plant fibers, lined with horsehair or other fine material. Eggs: 3 to 5 ; bluish white, unmarked; av. size I 7.2 x I $3.3(.67 \times .52)$. Season: May or June; two broods.

Range of Amphispiza bilineata.-Arid plains of western United States west to Sierra Nevada Mountains, north regularly to northern Nevada, casually to Oregon (Jewett), and eastern Washington (Douglas County, May 3 I to June 6, I908), east to western Texas, and south to northern Mexico, and the whole of Lower California.

Range of $A . b$. deserticola.-As above, save as delimited by $A$. $b$. bilineata, which occupies the extreme eastern portion of specific range in Texas and northern Mexico.

Distribution in California.-Summer resident in southeastern California, especially the fringes of the deserts, north, locally, to White Mountains, Mono Lake, Susanville (June 4, I9I2), and the lower slopes of the Warner Mountains; west casually in southern portion during migration; one occurrence (possibly a breeding station) in central northern Kern County west of the divide (Sheldon).

Authorities.-Cooper (Poospiza bilineata), Orn. Calif., I87o, p. 203 (Mohave R. and Providence Mts.); Fisher, N. Am. Fauna, no. 7, I893, p. 95 (many Calif. localities; dates of nesting, etc.); Sheldon, Condor, vol. xi., I909, p. I72 (Poso Mits., Kern Co.); Willett, Pac. Coast Avifauna, no. 7, I912, p. 82 (occur. in so. Calif.); Grinnell and Swarth, Univ. Calif. Publ. Zool., vol. x., I9I3, p. 277 (San Jacinto Mts.; nest and eggs, etc.).

THE SAGE-BRUSH desert is a thing of uttermost simplicity. Viewed broadly there is nothing but soil and sage and sunshine. Shelter there is none, at least for humans. Vegetation is in one kind. One pervasive scent, that of artemisia, haunts the atmosphere. The sky itself is a simple void, for clouds have no proper place here; only the simple wind and sun (at first futile, then benign, then ardent, and then, alas! how pitiless!). Silence, the dearest simplicity of all, broods over the desert, yet before its comfort stales, the occasional offerings of some of the desert's mild children stand forth in naked, beautiful simplicity. Modest voices which would be smothered elsewhere, as in the chaos of a riverside chorus, here speak to eager ears, and bring nourishment to a heart already rested.

It was thus I heard in the cool gray of a sage-scented morning my first Desert Sparrow. I had been checking off the scattered numbers of the desert choir, Brewer Sparrow, Lark Sparrow, Sage Thrasher, and the rest, when suddenly this fresh voice of inquiry, Bleu chee tee tee, burst from within a stone's throw. The binoculars were instantly levelled and their use alternated rapidly with that of note-book and pencil as the leading features of the stranger's dress were seized upon in order of saliency: Black chin and throat with rounded extension on 


\section{The Desert Sparrow}

chest outlined against whitish of underparts, and separated from grayish dusky of cheeks by white malar stripe; lores, apparently including eye, black; brilliant white superciliary stripe; crown and back warm light brown. It was a costume of distinction, yet when the stranger's black bib was averted he was instantly lost to view in the engulfing neutrals. Later, a female, scarcely different in appearance, was glimpsed as she flitted coquettishly from bush to bush, in company with her liege lord; but the most diligent search failed to discover a nest, if such there was. Nesting was almost certainly upon the gallant's mind, for he sang at

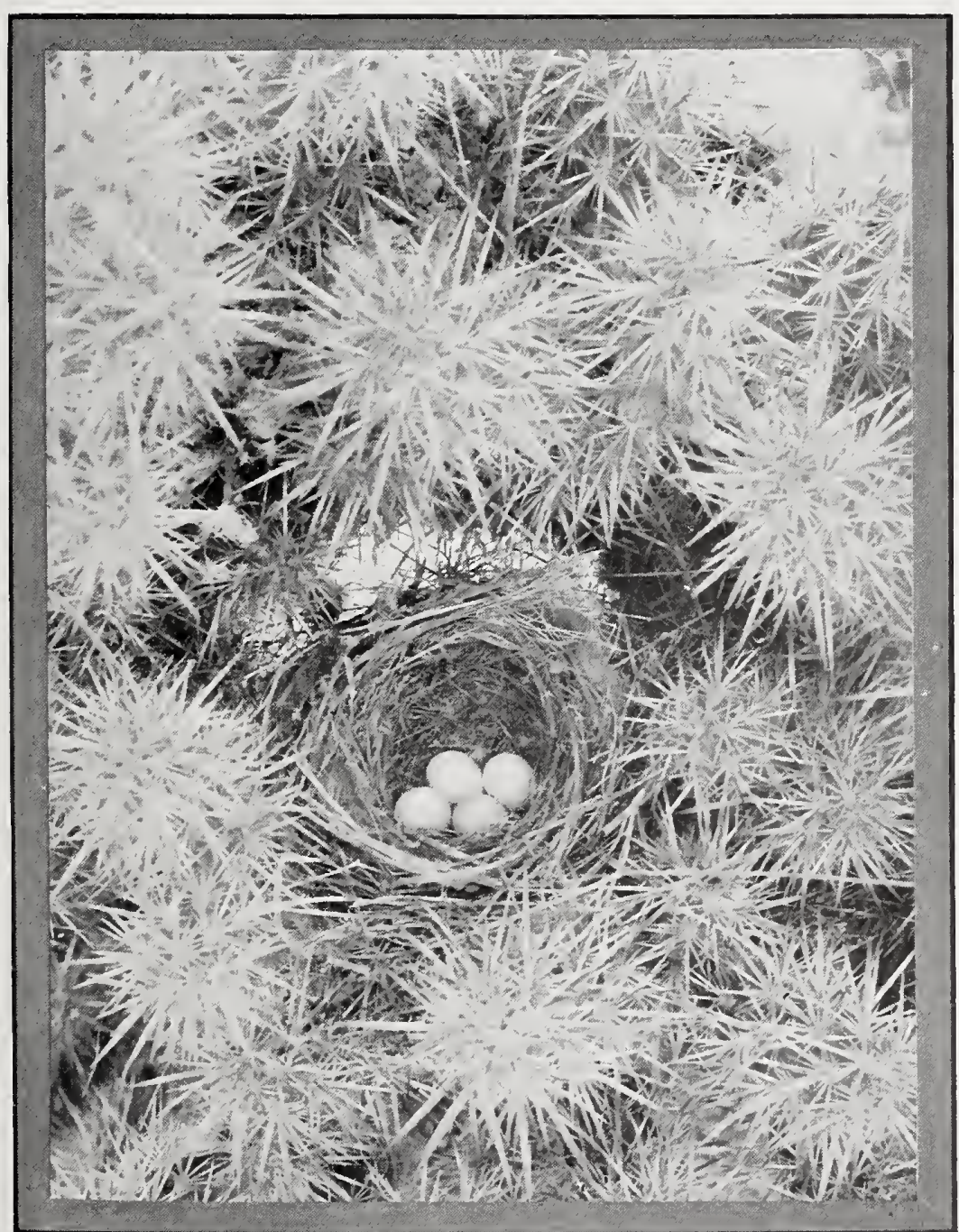

Taken in San Bernardino County

A WELL-GUARDED HOME $\mathrm{f} \mathrm{a} \mathrm{i} \mathrm{th} \mathrm{f} \mathrm{u} \mathrm{l}$ intervals. The notes of his brief but musical offering had something of the gushing and twinkling quality of a Western Lark Sparrow. A variant form, whew, whew, whit terer, began nicely, but degenerated in the last member into the metallic clinking of a Spurred Towhee. Again, the opening notes were given alone, whew whew or chew chew, as though the singer sensed danger and changed his mind. 


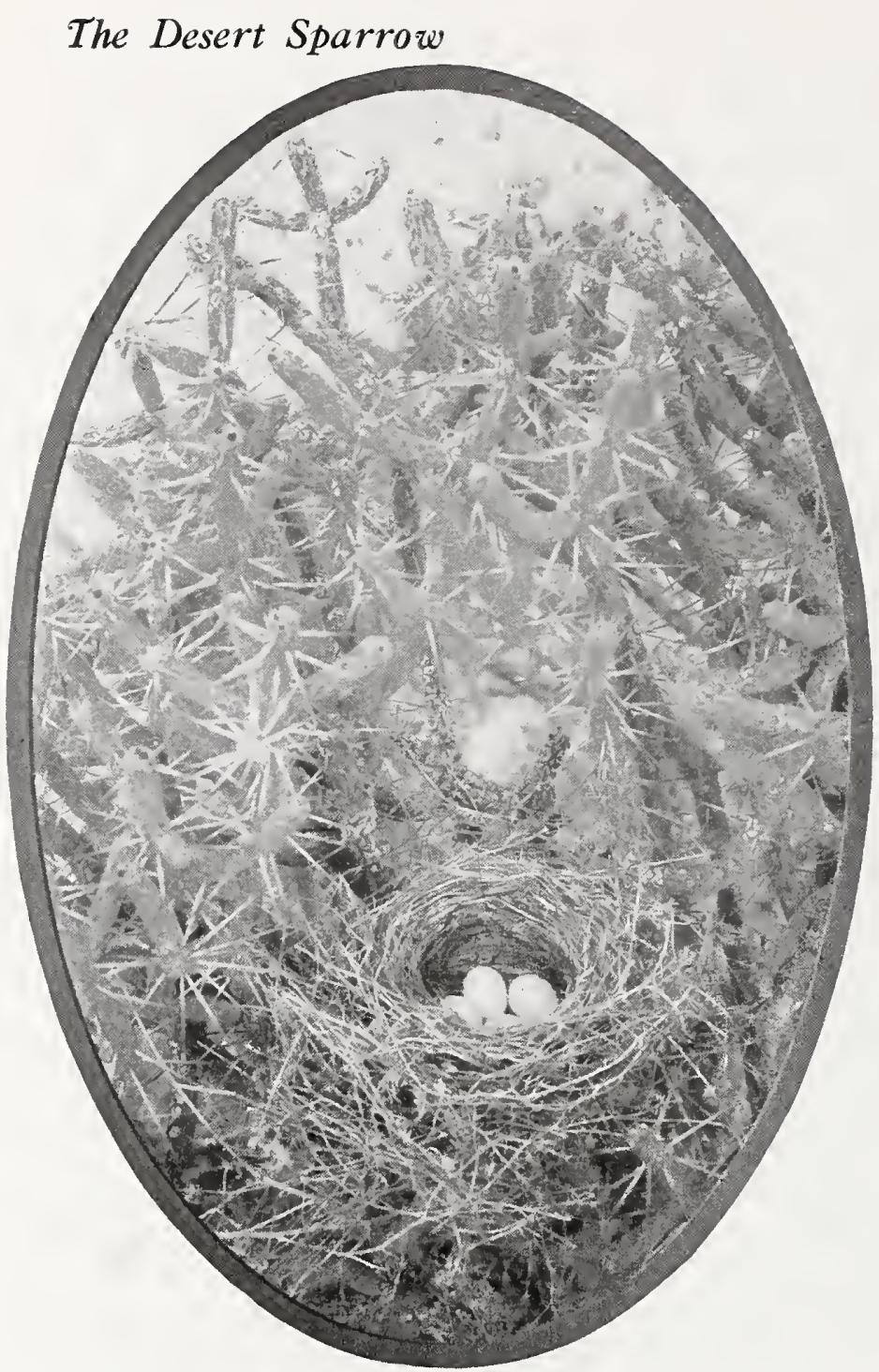

Taken in San Bernardino County NEST AND EGGS OF DESERT SPARROW IN CHOLLA CACTUS
Desert Sparrows nest twice in the season, once in March or April, and again in May or June. Their eggs are purest white; and the nests are placed a foot or so above ground in sage bushes or, upon the southern deserts, in yuccas, or chollas, or young mesquites. When surprised upon the nest, the female will drop to the ground and scamper off with tail uplifted,-- conspicuous, and intentionally so. If the decoy ruse will not work, the male tries singing. If that too fails, there is really nothing more to do but to keep out of harm's way and let happen what will. On the eastern slope of the Sierras there are great stretches of sage which harbor scarcely any other birds save Desert Sparrows. Here in late June one may see dozens of them in a brief walk, mostly family groups,--anxious, flitting mothers
who cannot sit still on a sage bush for two consecutive seconds for worriment, and pudgy little brats with short tails, who fly up valiantly, and who cannot for the brief lives of them see what mama has to worry about.

In winter the Desert Sparrows retire from their more elevated or northern ranges, and roam the southern deserts in company with their kinsmen, the Sage Sparrows. The companies are not large, not over two or three score usually, but whether at Palm Springs, at Tucson, or in western Texas, it is an unfailing pleasure to attach yourself to one of them as member at large, and watch the shifting play of the endless quest.

276 


\section{The Bell Sparrow}

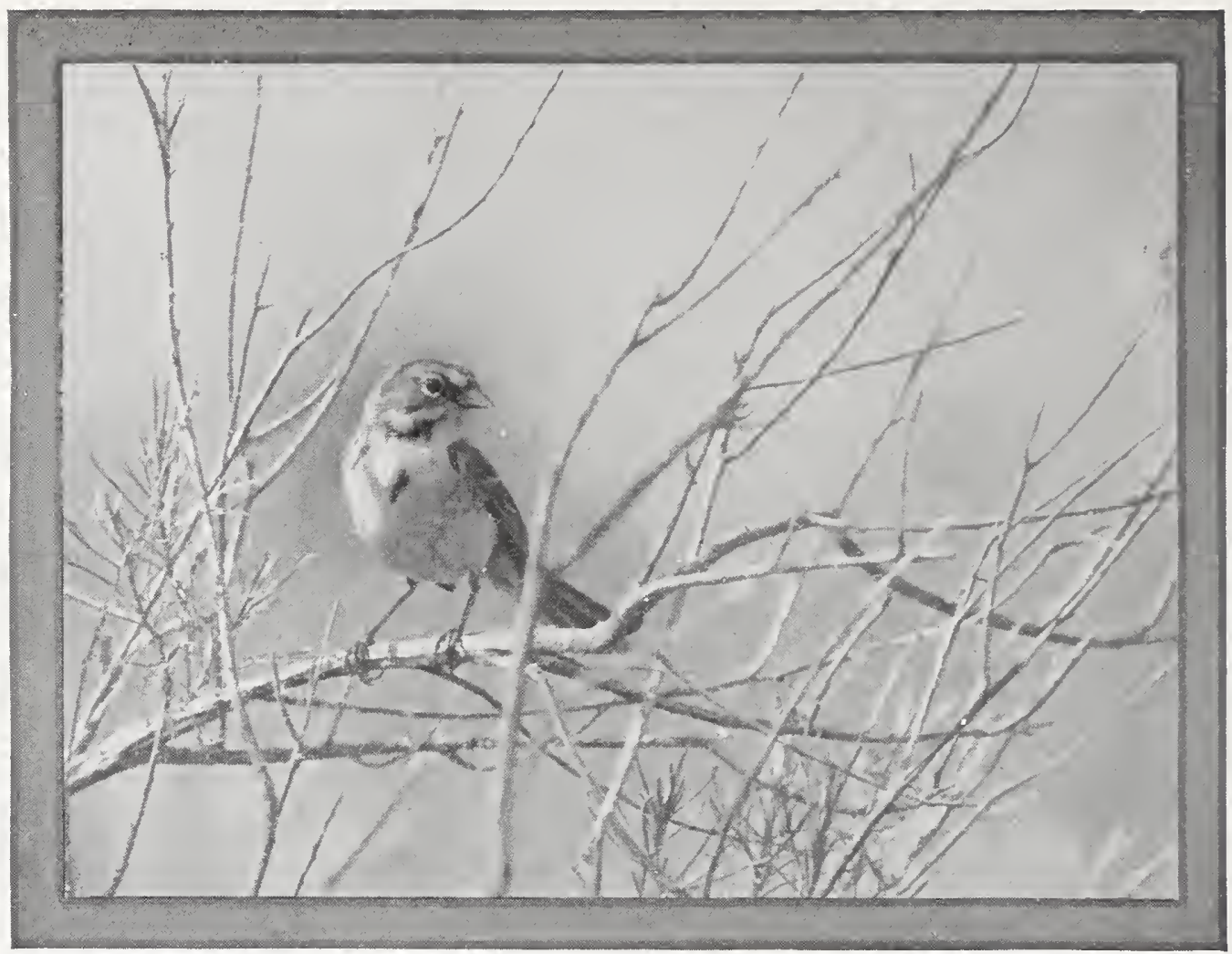

Taken in San Bernardino County

Photo by Wright $M$. Pierce

BELL SPARROW

more or less margined with wood-brown; sides, flanks, and crissum strongly tinged with vinaceous buff, all sparingly but strongly streaked with dusky; a black spot on center of breast; remaining underparts white. Bill bluish dusky above, lighter below; feet and legs dark brown. Young birds follow rather closely the pattern of parents, but are duller and are abundantly sharp-streaked with blackish on breast and sides of breast. Length of adult male about I52.4 (6.00); wing 66.8 (2.6.3); tail 66.3 (2.6I); bill 9. I (.36); tarsus $20.6(.8 \mathrm{I})$. Female slightly smaller.

Recognition Marks.-Small sparrow size; sage or low-chaparral-haunting habits; dark gray coloration above, white below, with black spot (very small) on breast, and long submalar streaks, like drooping moustachios, of black outlined against white. Much darker every way than A. nevadensis.

Nesting. - Nest: A sturdy cup composed chiefly of weed-stems and flower pedicels, and heavily lined with dried flower-heads; placed one or two feet up in sagebush or other desert shrub. Eggs: 3 or 4; pale greenish blue, or bluish white, marked lightly or heavily, sometimes mottled, with reddish brown (cameo brown, testaceous, onion-skin pink). Av. of I4 eggs in M. C. O. coll.: I $8.6 \times 14 \cdot 3(.73 \times .56)$. Season: April to June; two broods.

General Range.-Common resident in California, locally, in Upper Sonoran 278 
zone, west of the Sierras and desert divides, north to Marin, Sonoma, Solano, and Eldorado (at least formerly) counties, south to northwestern portion of Lower California; occurs on San Clemente, San Nicholas, Santa Rosa, and (probably) Santa Cruz Islands.

Distribution in California.-As above.

Authorities.-Cassin (Emberiza belli), Proc. Acad. Nat. Sci. Phila., vol. v., I850, p. I04, pl. 4 (orig. descr.; Sonoma or San Diego, Calif.); Grinnell, Auk, vol. xv., I898, p. 58 (crit.); Pierce, Condor, vol. viii., 1906, p. 152 (nesting habits); Grinnell and Swarth, Univ. Calif. Publ. Zool., vol. x., r913, p. 278 (San Jacinto M ts.; habits); Howell, Pac. Coast Avifauna, no. I2, I917, p. 79 (San Clemente, San Nicholas, and Santa Rosa Islands.).

WITH SPECIMENS in hand for comparison the casual student would suppose that Amphispiza belli and $A$. nevadensis might be included within a single species. Such, indeed, was the earlier understanding until Grinnell1 pointed out, in $\mathbf{I} 898$, that the breeding ranges of the two forms interlap without resulting intergradation. $\mathrm{Th}$ is discovery and the subsequent delimitation, still incomplete, of the breeding range of $A$. nevadensis canescens, has quite upset our earlier notions both of the relationships and distribution of $A$. belli, so that we cannot speak dogmatically at this time.

Dr. Grinnell says of the Bell Sparrow2, "Adheres closely to the cham isal (Adenostoma fasciculatum) association," yet no one of my five nests-and-eggs was taken in chamise, and only one (San Jacinto River, alt. 2200)

1 Auk, Vol. XV., Jan., 1898, p. 58.

2 Pacific Coast Ävifauna, no. 11, 1915, p. 21.

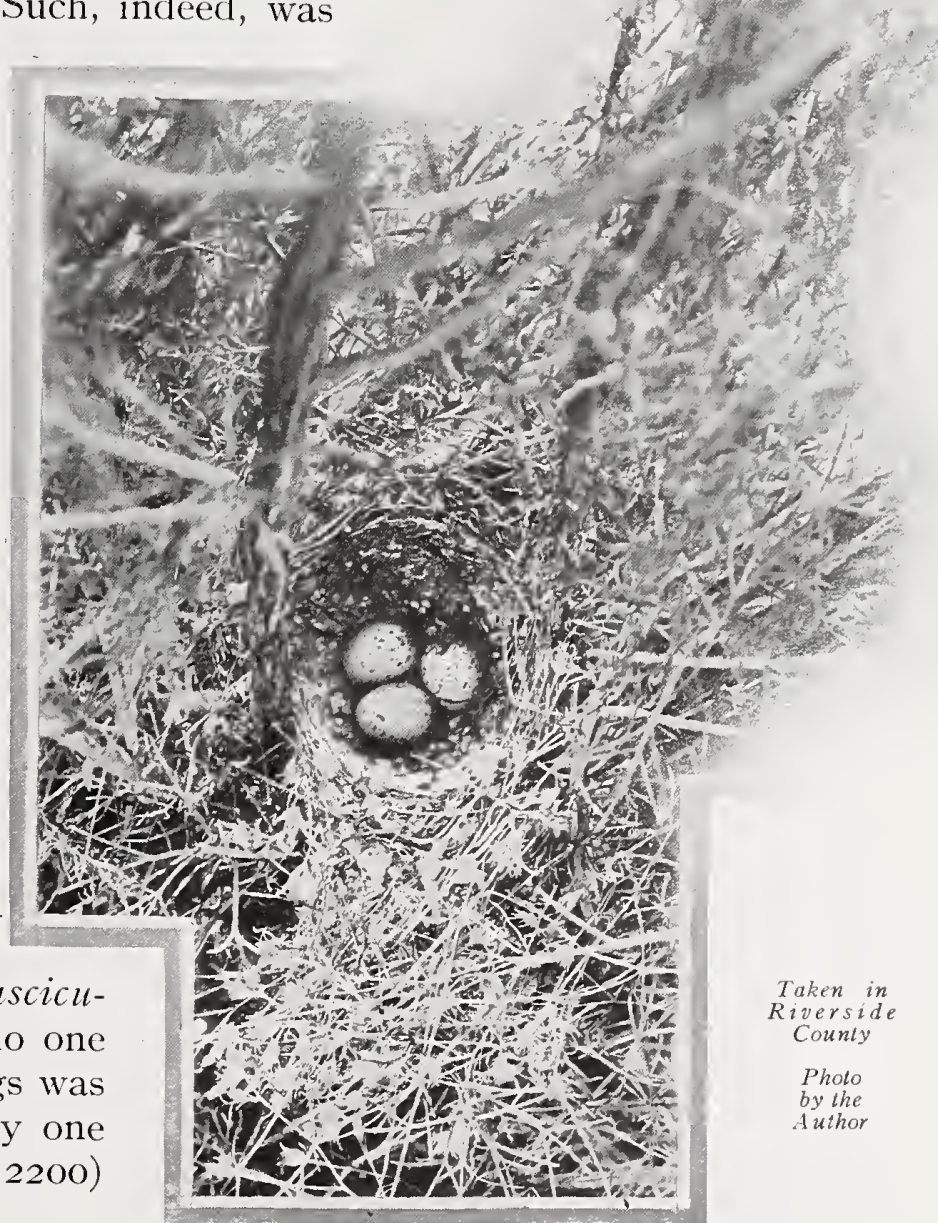

NEST A.ND EGGS OF BELL SPARROW 


\section{The Bell Sparrow}

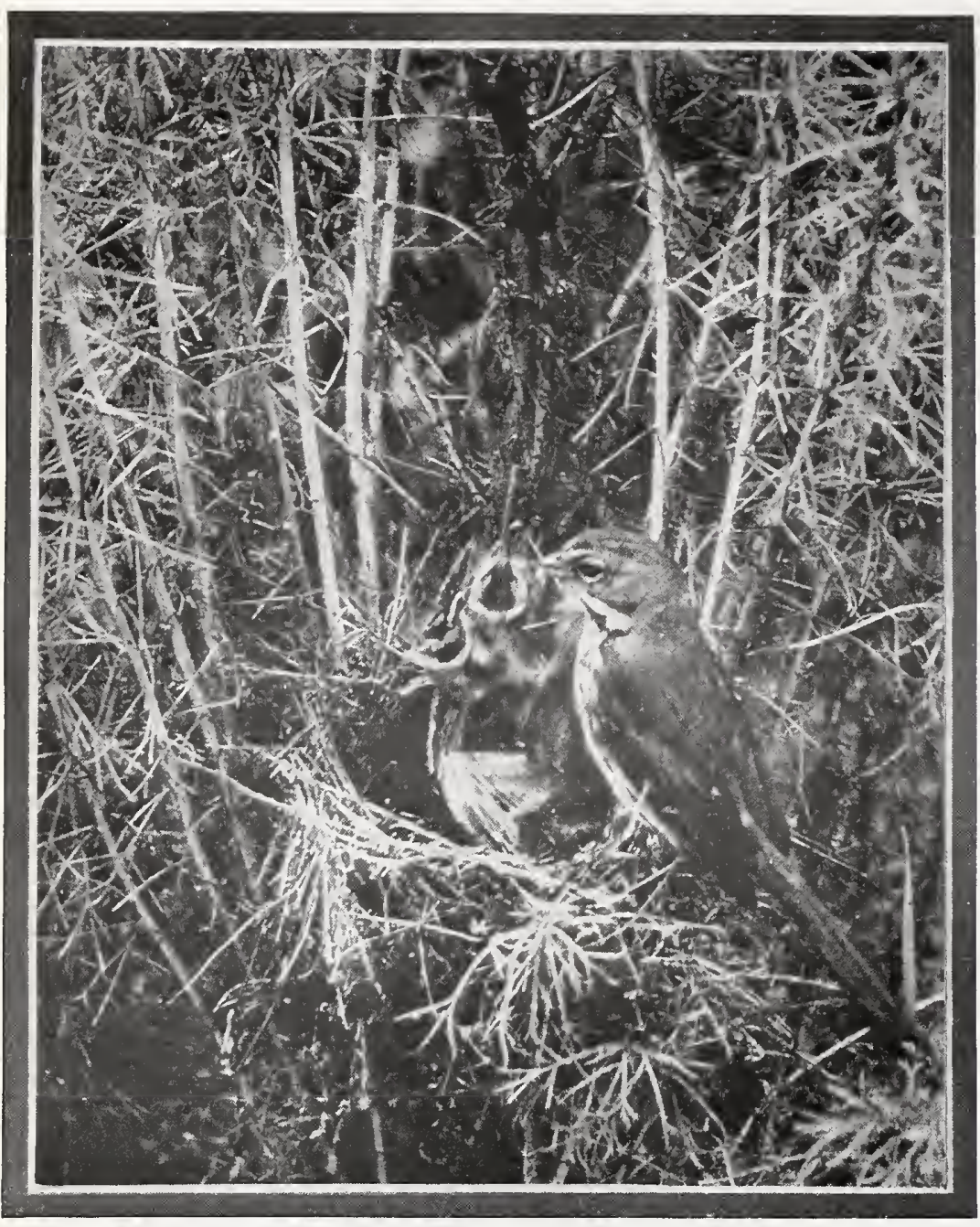

BELL SPARROW: ADULT WITH YOUNG

in the chamisal association. Two of these records were made in the pure desert association of the San Fernando Valley, opuntia bernardina, Yucca whipplei, Sambucus glauca, Rhus laurina, and the rest. Both nests were in "broom sage" (Artemisiadracunculoides), as also were two found in eastern San Luis Obispo County, April 15 , 19I4, although the latter may possibly have marked a heretofore unrecognized extension of A. n. canescens.

The remarkable situation as regards $A$. belli and $A$. nevadensis invites hypothesis. The undifferentiated members of the original species, Amphispiza preglacialis, pushing northward and westward from a distribution center in Sonora, invaded southern California and the Great Basin region. Later, becoming isolated by the Sierro-San ice barrier, the form belli evolved, while its counterpart and erstwhile brother was evicted from California by the refrigeration of the eastern slopes of the Sierras and the WhiteMountains-Inyo-Desert system. In the reoccupation of this Owens Valley country a new form, A. n. canescens, has evolved, and this form, pushing its conquest westward, has stormed the Tehachipe and the bounding barriers of the Mo ave Desert, and has spilled over variously into the Kings-Kern and San Joaquin regions. If this hypothesis be the correct one, we may expect a steady advance on the part of $A$. n. canescens, and a gradual retirement of the more strongly marked but weaker belli.

280 
Bell's Sparrow is probably not strictly sedentary, but neither is it migrant. Local breeders form winter companies and rove more or less, but how much or whither, we have no means of knowing. $\mathrm{Mr}$.

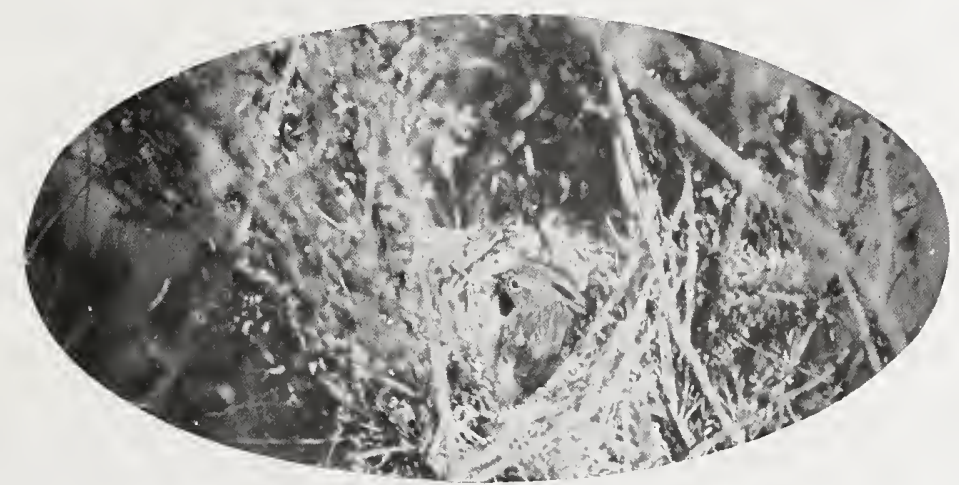

Taken in San Bernardino County

Photo by Wright M. Pierce

A HUMBLE HOME

Stephens (MS) thinks that all individuals move southward some distance in winter. Such a roving company I found in January, I9I3, upon the summit of the Santa Ynez range near Santa Barbara. What with the dark coloring and the glint of white on the edge of the lateral tail feathers, I took them for Juncoes at first, and this impression was heightened by their constant use of the tittering, or "banner" note, so characteristic of Junco hyemalis.

No. 49

\section{Nevada Sage Sparrow}

A. O. U. No. 574.4. Amphispiza nevadensis nevadensis Ridgway.

Synonyms.-Artemisia Sparrow. Sage Sparrow.

Description.--Similar to Amphispiza belli, but much lighter in every respect: the head pattern partially obliterated, and the dusky streakings of back sharper and more numerous. Adults: Head and neck above and on sides neutral gray, washed lightly with drab and touched on forehead with converging streaks of dusky; remaining upperparts drab (light brownish gray), sharply marked on back and scapulars with brownish dusky; pattern of wings as in preceding species, but all markings lighter; axillars and edge of wing pale yellowish white; the lesser coverts also sometimes tinged with yellowish; outer web and tip of outermost tail-feather white; a supraloral spot, an orbital ring, and (usually) a short median line on forehead white; sides of head slaty gray; lores dusky; underparts white, clearest on throat, where bounded and set off from white of malar area by interrupted chain of dusky streaks; occasionally with 


\section{The Sage Sparrows}

dusky spot on center of breast; washed on sides and flanks and crissum with buffy, and streaked on sides but not on crissum with dusky. Bill blackish above, lighter below; legs dark brown, toes darker; iris brown. Young: "Pileum, hind-neck, chest and sides, as well as back, streaked with dusky; otherwise essentially as in adults" (Ridgway). Underparts save on throat sometimes tinged with yellowish or buffy. Length of adult male about I52.4 (6.00); wing 80 (3.15); tail 8I (3.19); bill Io (.39); tarsus $21.5(.846)$. Females a little smaller.

Recognition Marks.--Sparrow size (barely); ashy gray or light drab plumage; white throat partially defined by dusky streaks; dusky, white and gray pattern of head.

Nesting.-As in preceding species.

Range of Amphispiza nevadensis.-Breeding in sage-brush plains of western United States from central Washington, Idaho, and Wyoming south to southern Colorado, south central California, and $(A . n$. cinerea) Lower California; wintering south from southeastern California, southern Nevada, and southern Utah to southwestern Texas and Chihuahua.

Note.-If A. n. cinerea of Lower California really occupies the isolated area assigned to it by the A. O. U. Check-List (3rd Edition), i. e., "West coast of Lower California from Santo Domingo to Ballenas Bay," it must either relate itself to A. belli and stand as $A$. belli cinerea, or else assume full specific rank as $A$ mphispiza cinerea.

Range of $A$.n. nevadensis.- As above, save as delimited by $A . n$. canescens in south central California and A. n. cinerea in Lower California.

Distribution in California.-Breeding in the Artenisia (tridentata) east of the Sierras from the Surprise Valley south to Mono Lake and in the desert ranges southwest of Owens Valley.

Authorities.-Henshaw, Rep. Orn. Spec. Wheeler's Surv., I 876, p. 243 (Kernville); Johnson, Zoe, vol. ii., I891, p. 22 (crit.); Fisher, N. Am. Fauna, no. 7, I 893 , p. 96, part (many Calif. localities); Grinnell, Auk, vol. xv., r 898, p. $5^{8}$ (crit.); Taylor, Univ. Calif. Publ. Zool., vol. vii., I912, p. 397 (Nevada; habits, nest and eggs).

\section{No. 49a California Sage Sparrow}

A. O. U. No. 574.1b. Amphispiza nevadensis canescens Grinnell.

Description.-Similar to $A$. n. nevadensis, but size slightly less and coloration somewhat darker-thus approaching $A$. belli in character. Length of wing 71 (2.8); tail $77(3.04)$.

Range of $A . n$. canescens.-Common in summer in the Upper Sonoran belt of sage-brush along the mountains encircling the south end of the San Joaquin Valley: Piute Mountains and Mt. Pinos; west rim of Owens Valley on Lone Pine Creek and near Owens Lake; vicinity of Walker's Pass; near Bakersfield and McKittrick, Kern County, and on Carrizo Plains, San Luis Obispo County; south to east slope of San Bernardino Mountains, and north to west side of Tulare Lake (Grinnell). Occurs in winter on the southeastern deserts to the Colorado River (Potholes, Feb. I1, 1913), north to Fresno County, west to San Diegan district (San Fernando Valley, etc.).

Authorities.-Fisher (Amphispiza belli nevadensis), N. Am. Fauna, no. 7, I893, p. 96, part (Calif. localities; crit.); Grinnell, Condor, vol. vii., I905, p. I 8 (orig. descr.; Mt. Pinos); Auk, vol. xxii., I905, p. 387 (Mt. Pinos; habits, crit.); Swarth, Condor, vol. xii., I9ıo, p. 108 (Riverside; crit.); ibid., Condor, vol. xiii., I9II, p. I63 (Carrizo Plain, breeding). 
THANK God for the sage-brush! It is not merely that it clothes the desert and makes its wastes less arid. No one needs to apologize for the unclad open, or to shun it as though it were an unclean thing. Only little souls do this, - those who, being used to small spaces, miss the support of crowding elbows, and are frightened into peevish complaint when asked to stand alone. To the manly spirit there is exultation in mere space. The ground were enough, the mere Expanse, with the ever-matching blue of the hopeful sky, but when to this is added the homely verdure of the untilled ground, the cup of joy is filled. One snatches at the sage as though it were the symbol of all the wild openness, and buries his nostrils in its pungent branches to compass at a whiff this realm of unpent gladness. Prosy? Monotonous? Faugh! Back to the city with you! You are not fit for the wilderness unless you love its very wormwood.

The sage has interest or not, to be sure, ac-

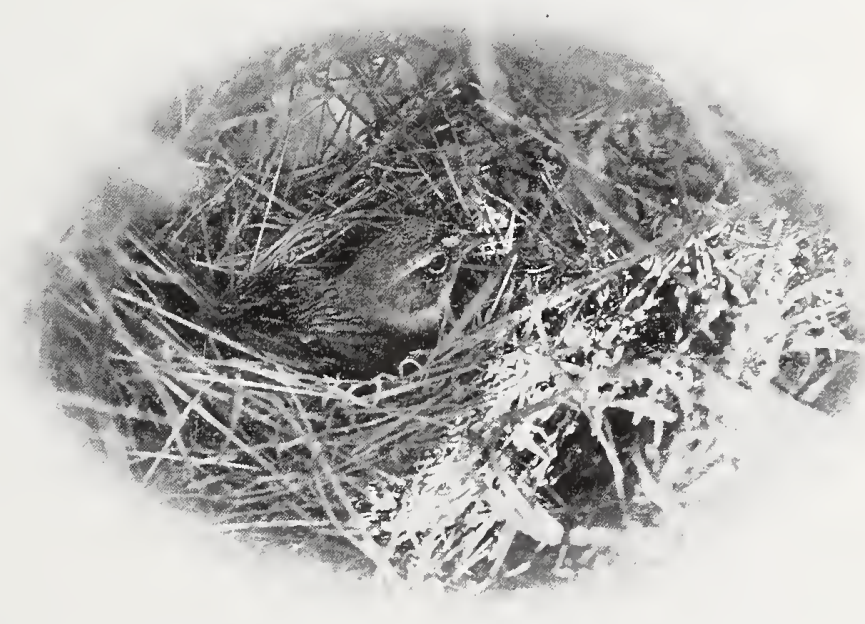

Taken in Washington
Photo by the A uthor

SAGE SPARROW ON NEST

cording to the level from which it is viewed. Regarded from the supercilious level of the man-on-horseback, it is a mere hindrance to the pursuit of the erring steer. The man a-foot has some dim perception of its beauties, but if his errand is a long one he, too, wearies of his devious course. Those who are best of all fitted to appreciate its infinite variety of gnarled branch and velvet leaf, and to revel in its small mysteries, are simple folk,- rabbits, lizards, and a few birds who have chosen it for their life portion. Of these, some look up to it as to the trees of an ancient forest and are lost in its mazes; but of those who know it from the ground up, none is more loyal than the Sage Sparrow. Whether he gathers a breakfast, strewn upon the ground, among the red, white, and blue, of stork-bill, chickweed, and fairy-mint, or whether he explores the crevices of the twisted sage itself for its store of shrinking beetles, his soul is filled with a vast content.

Here, in the springtime, he soon gets full enough for utterance, and mounts the topmost sprig of a sage bush to voice his thanks. In general 


\section{The Sage Sparrows}

character the song is a sort of subdued musical croaking, mellow and rich at close quarters, but with little carrying power. The bird throws his head well back in singing, and the tail is carried more nearly horizontal than is the case with most Sparrows. A song from a northern station ran: IIeo, chip'peway, chip'peway, chip'peway, but a more common type is Tup, tup, to weely, chup, tup. A pretentious ditty, occupying two seconds in delivery, runs Hooriedoppety, weeter wee, doodlety pootat'er,an ecstacy song, wherein the little singer seems to be intoxicated with the aroma of his favorite sage.

One may search a long time in the neighborhood of the singerwho, by the way, closes the concert abruptly when he realizes that he is likely to give his secret away--before finding the humble domicile a foot or two up in a sage bush. A nest which contained five eggs was composed externally of sage twigs set into a concealed crotch of the bush, but the bulk of it consisted of weed-bark and "hemp" of a quite uniform quality; while the lining contained tufts of wool, rabbit-fur, cow-hair, feathers, and a few coiled horse-hairs. The feathers were procured at some distant ranch, and their soft tips were gracefully upturned to further the concealment of the eggs, already well protected by their grayish green tints.

Another nest, sighted some forty paces away, contained one egg, and we had high hopes of being able to secure photographs of one of the prospects (not to mention the eggs themselves) upon our return with the camera. But a few rods further we came upon a crew of sneaking Magpies, scouring the sage with a dozen beady eyes, and passing sneering or vulgarly jocose remarks upon what they found. When we returned, therefore, a day or two later, we were not surprised to learn that the feathered marauders had preferred egg-in-the-bill to souvenir photographs.

Bird-nesting is a heartless business. Its devotees become hardened by practice, although the ends doubtless do justify the means in the case of a few serious investigators. But now and then confiding trust wins over you, and despoils you of a coveted take-especially if you are a bird-photographer. Last Sunday-May 3I, I 908, it was-I came upon a cunning home in a sage bush on the hillside just back of camp. It was empty, but manifestly awaiting the finishing touches, a few more trim feathers, to fit it for occupancy. Four days later the nest held three eggs, and the day following four, with the mother bird sitting tight. In fact, she was very loth to leave, and let me put my face within a foot or so of her before stealing off softly. This aroused the photographer in me and made the oölogist groan, for I had been this road before, and foresaw a contest of courtesy instead of oval treasures much needed by a certain museum. 


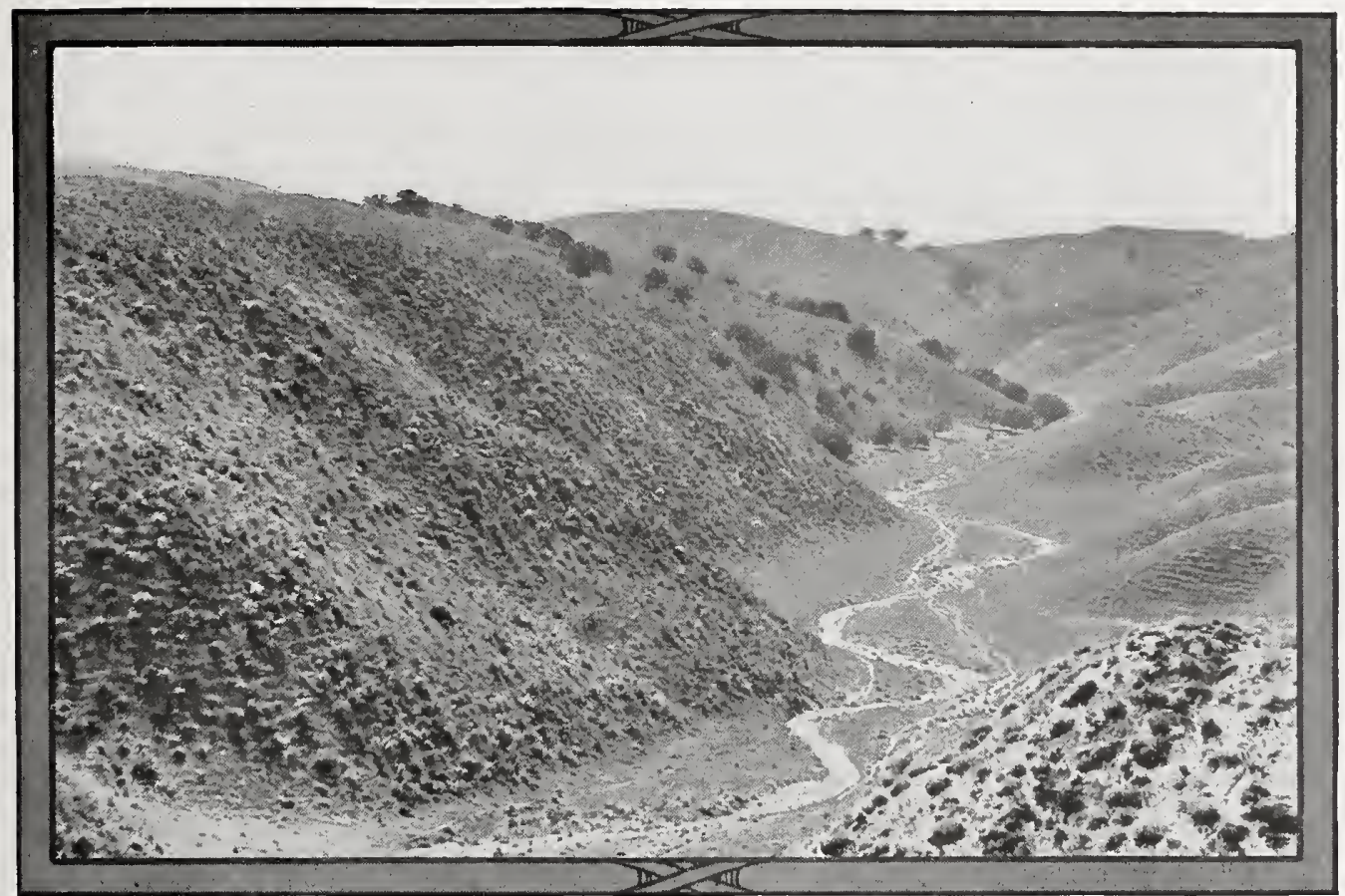

Taken in San Luis Obispo County

Photo by the A uthor

NESTING HAUNT OF THE BELL SPARROW

PERFECTLY TYPICAL ALSO OF THE SAGE SPARROW'S RANGE

Three days later I returned with the Graflex and took snap-shots at five feet. The day following I came with the Premo, straddling legs, flapping cover-cloth and all, and I made the little mother a promise. If she will sit for her portrait at the Premo limit of two feet, I will not touch her eggs. Agreed! She allows me to make all but the final adjustments without leaving her eggs. Finally, however, the strain becomes a little too great, and she slips off, but only to stand at six inches remove on the same bush. She holds her ground, too, when I snip away some twigs which obstruct the view, only craning her head and standing on tiptoe to see what I am about. Upon my retiring she immediately returns to her charge, and I am able to photograph her twice at two feet, using only the ordinary bulb. What extraordinary courage! What an overmastering power is this mother love! Here am I a hulking six-footer, backed by engines of unguessed potency, towering over a bit of a bird whose very heart is no bigger than the end of my little finger. She is free to fly, but she flies not. Her place is here, and here will she stick though the heavens fall! 


\section{The Slate-colored Junco}

Two days later I return and find the mistress absent. Secret hope, I confess, mingles with real solicitude for the absentee, for those eggs are of a particularly handsome tint of pale artemisia green, speckled and irregularly spotted, chiefly about the larger end, with lavender and purple. Who will deliver me from this temptation! Ah, here she comes again, tripping daintily from twig to twig, taking her place and resuming her task as complacently as though there were no strange passions abroad. Again and again she sits patiently while shutters click and plate-holders are flourished. We will have photographs anyhow. If she quits the eggs to stretch now and then, she never leaves the nesting bush, even while I am rearranging the tripod. The male at no time appears, although I hear him singing in the distance. He, too, trusts this very capable little person to "manage."

My little Sage Sparrow was faithful to the last. Time came to break camp, and I could not wait to see the babies hatch. But I went to say goodbye to the mother, and she let me put my face right down within a foot of hers. I was her good giant and she feared me never a whit. A flood of soft talk sprang to my lips. I could not restrain it, penitence, congratulation, and an infinite yearning. Why cannot all of life be like this-sacrifice, fidelity and uprightness! Perhaps one day we shallunderstand-each other.

No. 50

\section{Slate-colored Junco}

\section{A. O. U. No. 567. Junco hyemalis hyemalis (Linnaeus).}

Synonyms.-Eastern Junco. SNowbird.

Description.-Adult male in spring: General color slaty black (or dusky neutral gray); middle breast, belly and crissum white, abruptly contrasting with slaty of upper breast (which has a concave outline by reason of the continuation of slaty on sides), shading on sides; wings and tail deeper slaty black; the two outer pairs of rectrices wholly white, the succeeding pair extensively white, or not, centrally on distal portion of inner web. Bill pinkish white, narrowly tipped with dusky; iris dark reddish brown or purplish; legs light brown, feet darker. Adult male in fall and winter: As in spring, but upper parts lightly washed with reddish brown; the sides and sometimes the throat lightly veiled with buffy. Immature males are still more heavily veiled, with snuff-brown or light bister above, with buffy below, and with a cloudy buffy suffusion of the under whites. Adult female: Like adult male, but slaty lighter and duller, usually with slight veiling by brownish above and buffy below; the accession by brownish is correspondingly greater in autumn; and immature females are still more extensively brown. Young birds are drab above with blackish streaking, and 


\section{The Slate-colored Junco}

heavily streaked below on a dull buffy ground. Length of adult male, 152.4-105 (6.00-6.50); wing 79 (3.I I); tail 66 (2.60); bill I0.9 (.43); tarsus 2 I (.83). Females average smaller.

Recognition Marks. - Sparrow size; nearly uniform slaty coloration; concaveended outline of pectoral slate in contrast with white of underparts; does not show contrast between head and back, as compared with the Junco oreganus group. species.

Nesting.-Does not breed in California. Nest and eggs much as in succeeding

General Range.-Eastern and northern North America, breeding from the mountains of Pennsylvania and Massachusetts and the northern tier of states west to Minnesota, north to Labrador, the Arctic Coast and the valleys of the Yukon and Kowak River in Alaska; south in winter throughout the eastern states to the Gulf Coast, and casually to New Mexico, Arizona, and California.

Occurrence in California.-A casual winter visitant practically throughout the State, but chiefly on the lower mountain ranges.

Authorities.-Jeffries, Auk, vol. vi., I889, p. 22 I (Santa Barbara); Bishop, N. Am. Fauna, no. I9, I900, p. 85 (Alaska; nests and eggs, habits, etc.); Judd, U. S. Dept. Agric., Biol. Surv. Bull., no. I 5, I90 I, p. 80 (food); Willett, Pac. Coast Avifauna, no. 7, I912, p. 8I (occur. in so. Calif.); Grinnell, Pac. Coast Avifauna, no. I I, I915, p. I 9 (summary of occurrences in Calif.); Dwight, Bull. Am. Mus. Nat. Hist., vol. xxxviii., I9I 8, p. 285 , col. pls. (distr., variation, crit.).

SO FATAL is the human tendency to generalize that most of us think of the Pacific Coast of North America as a north and south line, and recall Alaska vaguely as somewhere to the north of us. Yet St. Michael, at the mouth of the Yukon, is west of Honolulu; and a Slatecolored Junco raised on the Seward Peninsula would have to travel due east at least forty degrees (and a trifle of twenty-three degrees south) in order to winter as far east as California. What wonder, then, that of the great bulk of Alaskan Snow-birds, pursuing in autumn a leisurely east by southeasterly course for the eastern states, a few should become deflected to the southward too soon! Anyhow, this happens so often that we have given up trying to keep count of the "winter occurrences" of the Slate-colored Junco.

Juncoes are highly sociable creatures, especially in winter. Other migrants afford congenial company; and the birds do not make as big a fuss over a different shade of color of the foreparts as we do. It is noticeable, therefore, that most of the northern Juncoes seen occur either singly or in small groups, in company with the California thurberi. There is nothing in behavior and little enough in appearance to distinguish the two forms; and there are, doubtless, a thousand unnoticed birds in the State to one that catches the eye of a practiced bird-man. 


\section{Oregon Junco}

A. O. U. No. 567a. Junco oreganus oreganus (Townsend).

Synonyms.--"Oregan Snow-Finch." Western Snow-bird. Oregon SnowBIRD. Townsend's Junco.

Description.-Adult male: Head and neck all around and chest (abruptly defined along convex posterior edge) sooty black; back abruptly and scapulars and edging of tertials warm reddish brown (between Prout's brown and snuff-brown); rump, upper tail-coverts, lesser wing-coverts, and tips of greater coverts, slaty gray or deep neutral gray, sometimes glossed with olivaceous; wings and tail dusky, edged with ashy; the outermost rectrix wholly and the second chiefly white, the third pair more or less white centrally near tip; sides of breast, sides, and flanks strongly washed with pinkish brown (fawn-color or vinaceous fawn); remaining underparts (below chest) white. Bill pinkish white with dusky tip; iris claret-red; feet and legs pale brown. Immature male: Like adult, but brown of upperparts redder (walnut-brown to natal brown); hindhead and nape with skirtings of the same color; the sides more strongly tinged with fawn-color; the black of chest slightly skirted with whitish. Adult female: Like adult male but black of foreparts much duller,-more grayish or slaty; the red of back slightly browner; hindhead and nape more or less veiled or mingled with color of back, thus decreasing the contrast; sides less extensively washed with pinkish brown; a slight reduction of white in tail. Immature female: Like adult female, but contrast of foreparts still further reduced; distinction between head and back obliterated by reddish brown veiling; tone of upperparts slightly more grayish (dark Rood's brown); the grayish black of throat and chest further veiled by pale vinaceous fawn. Young birds are pale reddish brown above and yellowish buffy (more sordid on chest) below everywhere, save on throat, belly and crissum finely streaked with dusky. Length of adult male about I6r.3 (6.35); wing 75 (2.95); tail $65(2.56)$; bill I I (.43); tarsus 2 I $(.83)$. Female smaller.

Recognition Marks.-Sparrow size; black of head and throat contrasting with white of breast; sides pinkish brown; white lateral tail-feathers; head black as compared with $J$. hyemalis; back reddish brown as compared with $J$. o. shufeldti.

Nesting.-Does not breed in California. Nest and eggs as in J. o. thurberi.

Range of Junco oreganus.-Pacific coastal regions of western North America, breeding from Yakutat Bay, Alaska, south to Lower California, east to west central Alberta (couesi); winters irregularly southward and eastward (couesi) or at lower levels.

Range of $J . o$ oreganus.- The northern coastal representative now breeds from Yakutat Bay, Alaska, south to the Queen Charlotte Islands, and winters irregularly southward along the coast to Santa Cruz Island, or casually east of the Sierra-Cascade divide.

Occurrence in California.-Winter visitant west of the Sierras, regularly to San Francisco Bay region, casually to Santa Cruz Island.

Authorities.-Newberry (Struthus oregonus), Rep. Pac. R. R. Surv., vol. vi., pt. iv., I 857 , p. 88, part (San Francisco); Bryant, W. E., Proc. Calif. Acad. Sci., 2nd ser., vol. i., I 888, p. 47 (Farallons); Chapman, Auk, vol. viii., I 89 I, p. I I5 (crit.); Dwight, Bull. Am. Mus. Nat. Hist., vol. xxxviii., I9I 8, p. 29I, col. pls. (distr., variation, crit.); Swarth, Univ. Calif. Publ. Zool., vol. x., I9I2, p. 59 (Vancouver Id.; habits, crit.). 
The Oregon Juncoes

No. 51a Coues's Junco

A. O. U. No. 567b. Junco oreganus couesi Dwight.

Synonyms.-Washington Junco. Hybrid Snow-bird (Coues). Rocky Mountain Junco (Coues). Shufeldt's Junco.

Description.-Adults: Similar to J. o. oreganus, but back (in males) less rufescent, more grayish (pale olive-brown to dull army-brown); in females snuffbrown; black of head and throat a little more slaty; also averaging larger. Length I 52.4-I65 (6.00-6.50): wing 80 (3.15); tail 69 (2.72); bill I I (.43); tarsus 2 I (.83).

Recognition Marks.- Sparrow size; black of head and throat contrasting with hrownish gray of back and with white of breast; grayer on back than preceding.

Range of $J$. o. couesi (as defined by A. O. U. Committee under name Junco hyemalis connectens).--Rocky Mountain region, breeding from coast of southern British Columbia, east to west central Alberta, and south to northern Oregon; wintering over entire Rocky Mountain tableland to eastern Colorado, Arizona, New Mexico, western Texas, Chihuahua and Sonora. Casual in northern Lower California.

Occurrence in California.- See general discussion below.

THE CASE of our northwestern wintering Juncoes is involved in notable confusion. All depends upon definition of the summer ranges of the three related forms, oreganus, conesi, and thurberi.

There is least question regarding oreganus, for that subspecies now breeds entirely north of the United States, probably no further south than the Queen Charlotte Islands; and its contributions to the winter population of northern California are perfectly manifest by reason of the decided rufous of their backs.

But the case of conesi is more involved. As now defined by the A. O. U. committee (Check-List, 3rd Edition, I9IO) couesi (formerly named connectens) includes not only the breeding birds of the Rocky Mountains in eastern British Columbia, but also those of Vancouver Island and Puget Sound. Either this is correct, or the Puget Sound specimens represent a northward extension of thurberi, or else they deserve recognition as a separate subspecies. In any event, these Puget Sound and southern British Columbia breeders must winter more or less in northern California; for they largely forsake their summer home, and their place is taken by oreganus. If, however, these southern winter-taken specimens of hypothetical couesi are not actually separable from thurberi, we shall have to restrict the range of couesi to the northern interior, and recognize an enormous northwestern extension of thurberi.

The situation has probably been complicated by recent rapid movements in the case of all these forms. Oreganus, at least, was the recognized breeding bird of Puget Sound no later than 1903.

We have here an indubitable instance of that northward trend of species clearly recognizable in the East, but obscured to our vision in 


\section{The Oregon Juncoes}



NEST AND EGGS OF COUES JUNCO

West by reason of varied onditions and insufficient data. The theory is that the birds are still following the retreat of the glacial ice. We know that the glacial icesheet, now confined to Green land and the high North, once covered half the continent. In our own mountains we see the vestigial traces of glaciers which were once of noble proportions. $\quad \mathrm{Ve}$ know that the s ou thward advance of the continental ice-sheet must have driven all animal life before it; and, likewise, that the territory since relinquished by the ice has been regained by the animals. What more natural than that we should witness through close observation the northward advance of those varieties of birds which are best suited to withstand cold, and the corresponding occupation of abandoned territory on the part of those next south?

Juncoes, moreover, are erratic in their migrations; and in the West, at least, tend to become non-migratory. While Oregon Juncoes are the common winter birds of Puget Sound, Coues' (or Thurber's) are not entirely absent at this season, and we may even look to see them presently hold their own throughout the year. The problem is further complicated by what we call vertical migration, by which is meant that mountain birds descend to the valleys in winter, instead of flying southward. Winter "couesi," therefore, may or may not be strictly resident at, say, Camp Lewis, near Tacoma. The summer birds of that region may be 
the ones which retire to our borders; while the wintering birds may have descended from the Olympics or from Mount Rainier.

\section{No. 51b Sierra Junco}

A. O. U. No. $5^{67}$ c. Junco oreganus thurberi Anthony.

Synonyms.-Thurber's Junco. California Snow-bird.

Description.-Adult male: Similar to $J$. o. couesi, but head, neck, and chest, blacker; i.e., of recovered intensity, practically as black as $J$. o. oreganus; sides much paler, avellaneous to vinaceous-buff. Adult females: In mature examples closely approximating the colors of adult males; black of foreparts only a shade less intense; back a little more rufescent and a shade lighter. Young birds: Like those of J.o. oreganus but lighter and grayer above, and never yellowish buffy below, palest pinkish buff instead. Length of adult male (after Ridgway): I35-15I (5.32-5.95); wing 78 (3.07); tail 65.3 (2.57); bill $10.7(.42)$; tarsus $20(.79)$. Females: wing 72.9 (2.87); tail 62.2 (2.45); bill $10.7(.42)$; tarsus $20.3(.80)$.

Recognition Marks.- Sparrow size; head, neck, and chest black; convex outline of chest contrasting with white of breast and light pinkish of sides; the commonest form.

Nesting.- Nest: On the ground, sunk flush, or not; of ten deeply recessed on side hill, or else under protection of low shrubbery; a sturdy cup with walls an inch or more in thickness, wrought externally of mosses, weed-stems, and dried grasses, and lined with fine, light-colored grasses, or horsehair where obtainable. Eggs: 3 to 5; ground-color white tinged with pinkish, greenish, or bluish, speckled or spotted, broadly or narrowly, rarely mottled or clouded with reddish brown or vinaceous. Av. size I $9.8 \times 15.2(.78 \times .60)$. Season: May-July; two broods.

Range of $J . o$. thurberi-Chiefly the mountains of California, but breeds from an undetermined area in Oregon south to the Laguna Hansen Mountains of Lower California; in winter found at lower levels, and casually east to Arizona.

Distribution in California.- $A$ summer resident of Transition and Boreal zones throughout the State, save in the Monterey section, where replaced by $J$. $o$. pinosus. An irregular breeder at intermediate levels (e. g. Santa Margarita-Swarth); and a casual breeder at lower levels (Stanford University - Snyder; Berkeley-Wythe). In winter found at all lower levels including the deserts (sparingly) and the Channel Islands.

Authorities.-Newberry (Struthus oregonus), Rep. Pac. R. R. Surv., vol. iv., I 857, p. 88, part (n. California in summer); Anthony, Zoe, vol. i, October, I890, p. 238 (Wilson's Peak; orig. desc.); Kaeding, Bull. Cooper Orn. Club, vol. i., 1899, p. 80 (Calif.; distr., habits, crit.); Grinnell, Univ. Calif. Pub. Zool., vol. v., I908, p. 95 (habits, desc. nests and eggs, etc.); Beal, U. S. Dept. Agric., Biol. Surv. Bull., no. 34, I9 10, p. 82 (food); Dwight, Bull. Am. Mus. Nat. Hist., vol. xxxviii., I918, p. 29I, col. pl. (distr., variation, crit.).

ONE'S FIRST encounter with Junco in the Southland is likely to take place on some little oak-sprinkled ridge, the coolest of that section. First one bird, then another, will quit the ground, most unexpectedly to you, and take refuge in a live oak tree. It's a game of hide-and-seek henceforth with you for "it," unless you resolutely sit down and efface 


\section{The Oregon Juncoes}

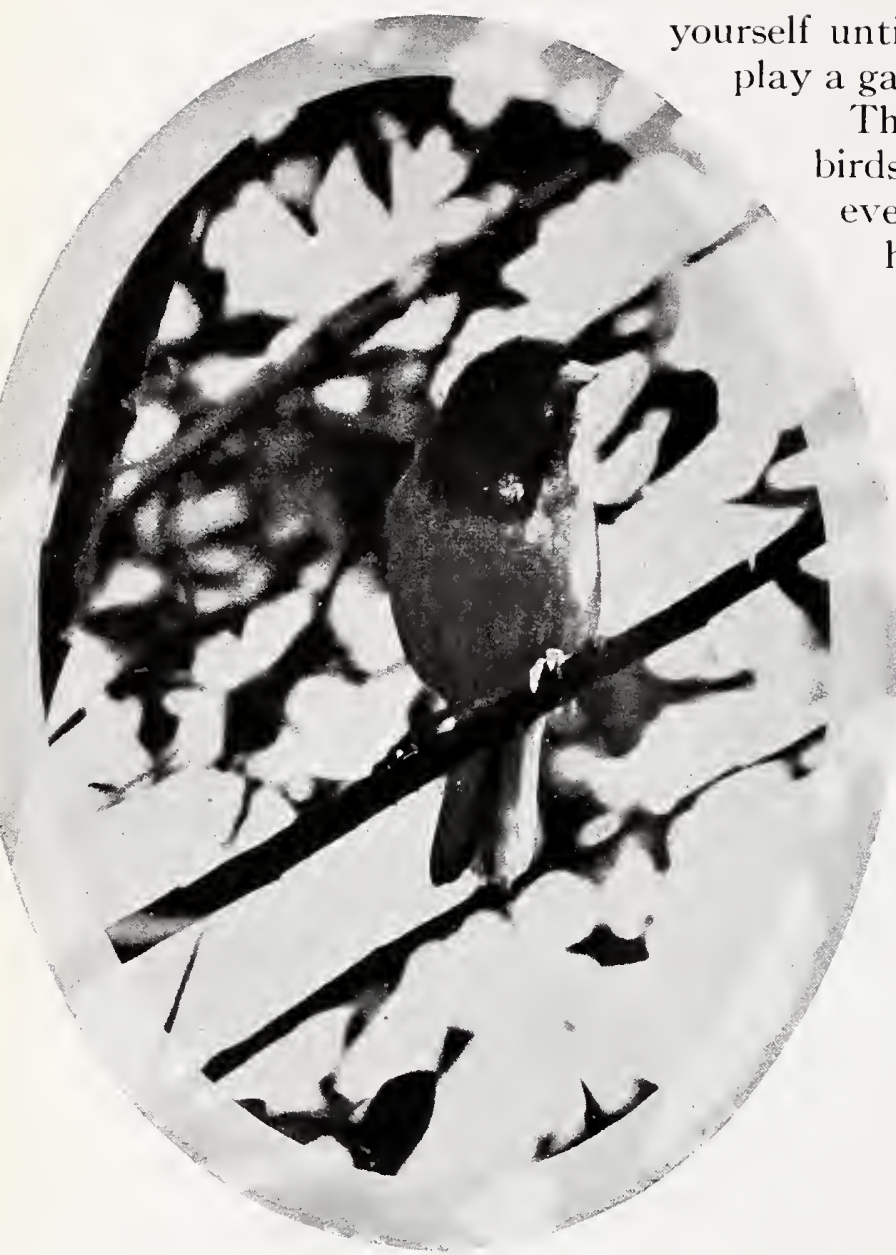

Taken in Fresno Count

SIERRA JUNCO. FEMALE

MOTHER OF THE "PHOLOPHOBIC" INFANTS

IHIS IS THE MOTHER OF THE "PHOLOPH
DESCRIBED IN THE IEXI

Photo by the A whor

uses are hard to discern. Now and then, also, a forcible kissing sound may be heard, evidently a note of repulsion instead of attraction, for it is employed in the breeding season to frighten enemies. During the progress of the concert some dashing young fellow, unable fully to express his emotion in song, runs amuck, and goes charging about through the woodsy mazes in a fine frenzywithout, however, quite spilling his brains. Others catch the excitement and the company breaks up in a mad whirl of amorous pursuit.

But before the songs are altogether sung out, or "life's great decision" made, the companies begin to climb the hillsides. Up, up they will go with the ascending season, so that Junco's year may be appropriately described as mountain climbing. Now and again a pair will pause, marriage can no longer be deferred; or else the coolness of a suitable 


\section{The Oregon Juncoes}

locality betrays them into a belief that they are high enough for happiness. So we have chance nestings at Stanford University ${ }^{1}$ or Cazadero. ${ }^{2}$ But the bulk of the species ascends until the upper Transition levels of the higher mountains are reached. A pause is made here for nesting, while the hardier individuals push on for the higher levels. Not impossibly, nesting is conducted at two levels by the same pair of birds, 6000-8000 in May, 8000-IIO00 in June or July. And when the last brood of babies is raised, the whole family goes climbing in good earnest. It is a heartening sight to one sitting on the crest of a radiating ridge, as at timberline on Shasta, to see the happy Juncoes go trouping by, brood after brood, for forage on the upper levels, or wherever the least green thing will grow.

Juncoes are rigeopathic, or cold-loving, by the same token that they are photophobic. I had a curious illustration of this in an experiment conducted at the Simpson Meadows on the Middle Fork of the King's River (alt. 6500). A nest had been found in an unusually exposed situation; viz., on the level ground with only the protection of scattered

1 W. K. Fisher, Condor, Vol. VI., 1904, p. 108.

2 Joseph Mailliard, Condor. Vol. X., 1908, p. 133.

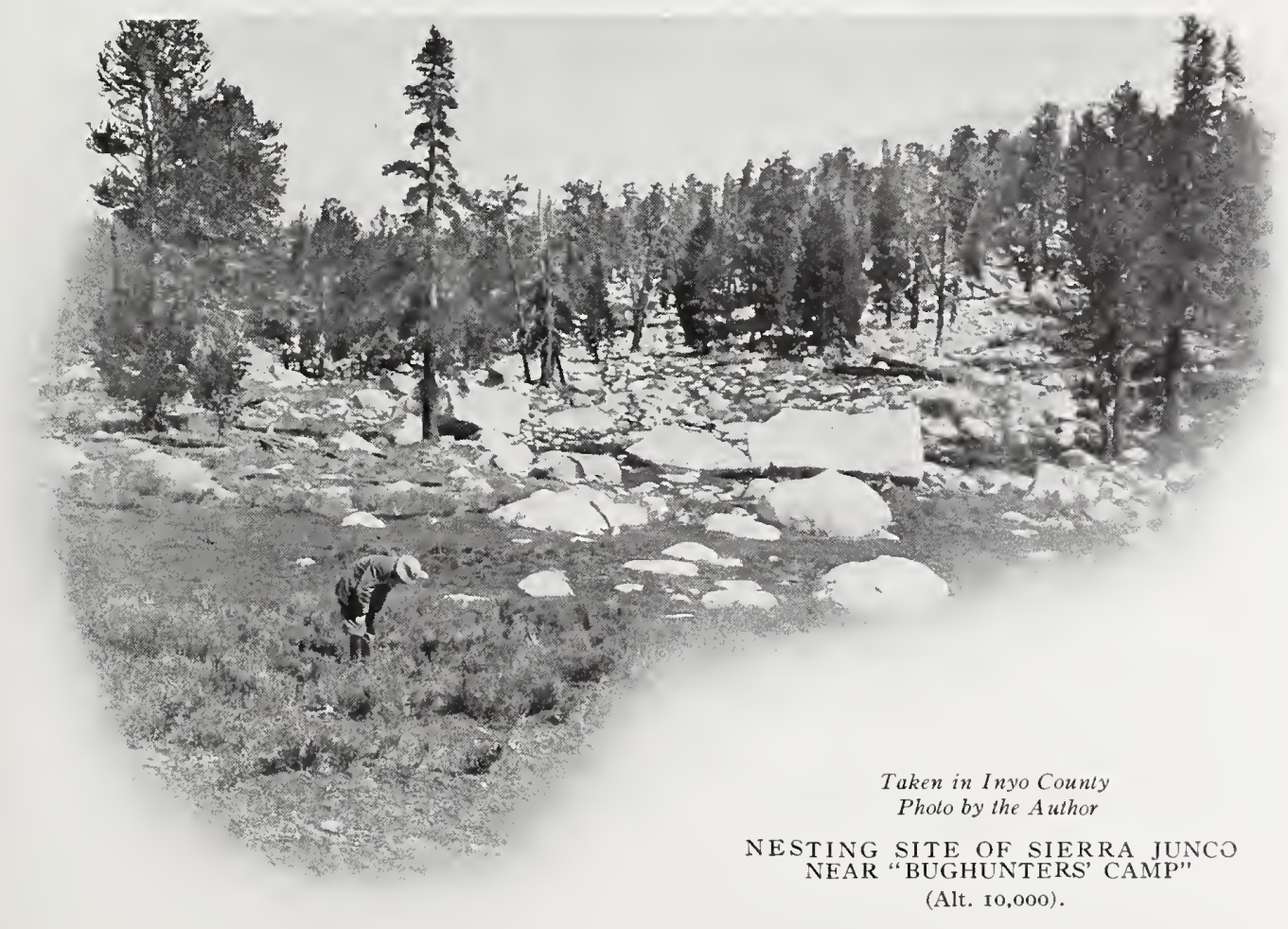




\section{The Oregon Juncoes}

herbage, instead of the customary deep shade of the forest. In order, if possible, to catch the female brooding in full light, I cut away or tied down all the surrounding foliage which would cast a shadow. The sun was warm but not to say hot. The result, however, was that the mother bird flushed at the earliest provocation, and the babies, not nearly half grown, were left momentarily to suffer. Finally, the most forward of the brood (of three) made a determined effort to better his condition, and, to my amazement, scrambled up the side of the nest and boldly over. I

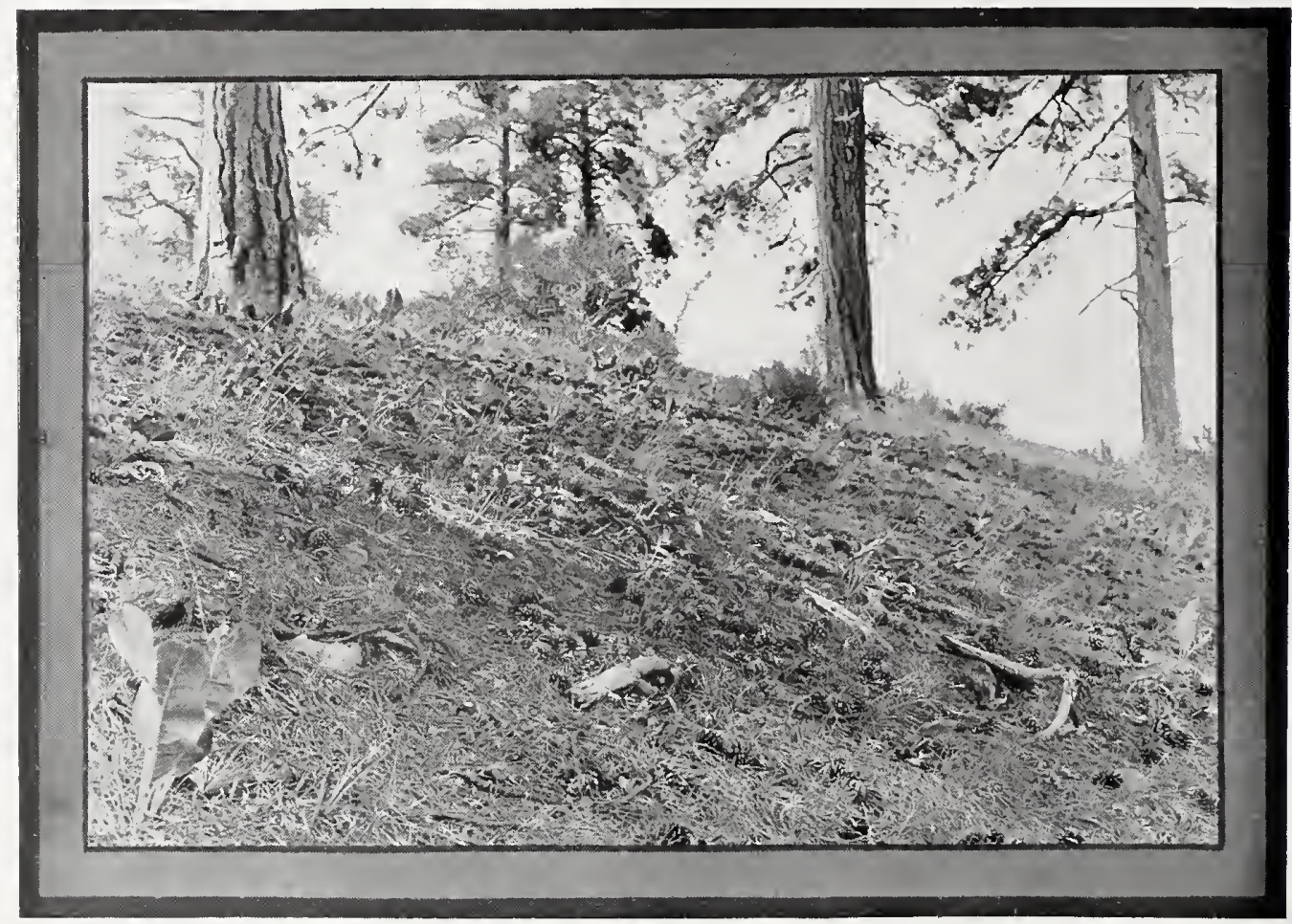

Taken in Modoc County

A NESTING SITE IN THE WARNER MOUNTAINS

Photo by the Author CONTAINS NEST SHOWN IN SUCCEEDING CUT

replaced him and stood back to photograph a possible repetition of the act. This was promptly forthcoming. The youngster scrambled up again and tumbled over the brim of the nest, and lay helplessly kicking, for it was unusually high above the ground. Of course I promptly took pity on them and provided shade. But these youngsters were still almost naked, and this precocious determination to attain shade or liberty, or both, was, I insist, most amazing.

The variety and interest of Junco's nesting habits are scarcely exceeded by those of any other bird. In general, the birds appear to be 


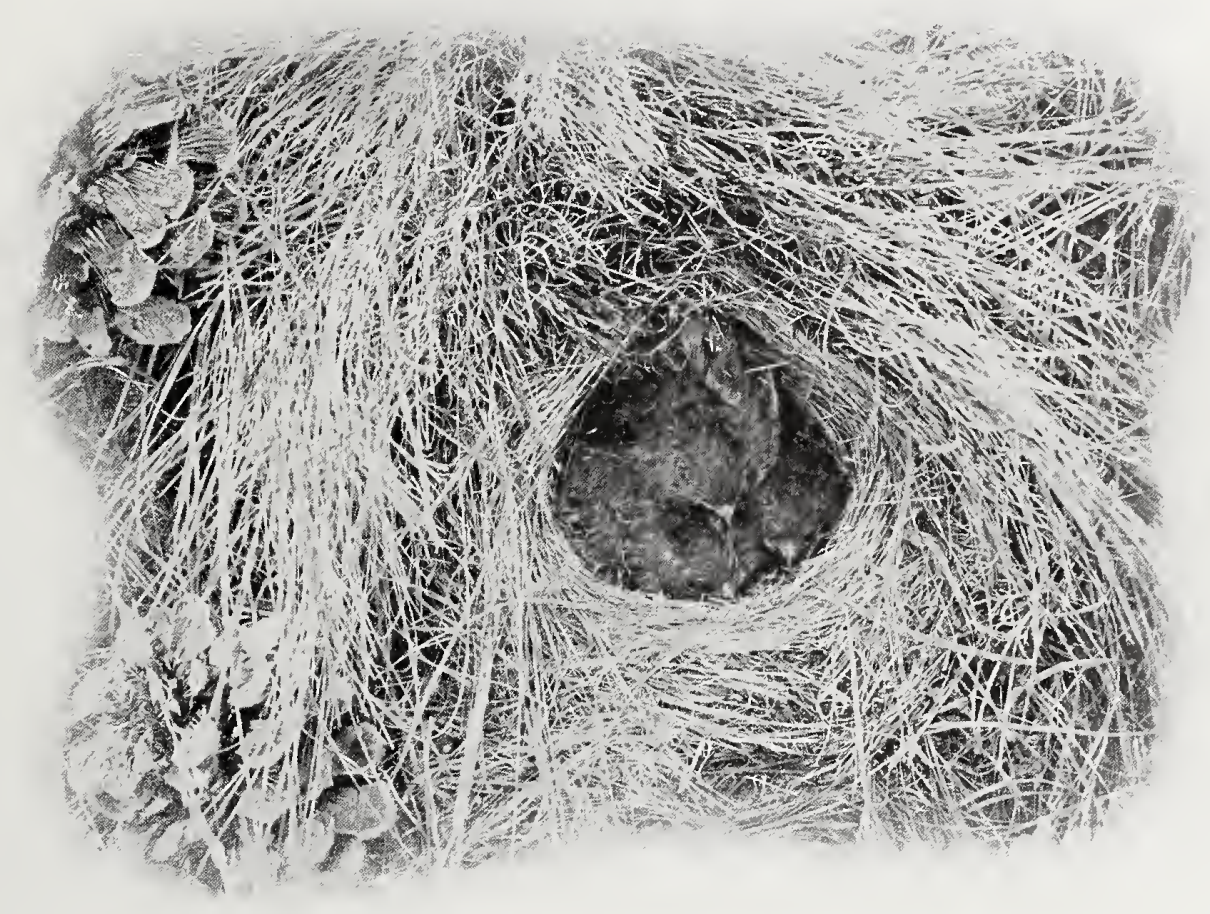

Taken in Modoc County

A FULL CRADLE

Photo by the Author

guided by some thought of seclusion or protection in their choice of nesting sites. Steep hillsides or little banks are, therefore, favorite places, for here the bird may excavate a cool grotto in the earth, and allow the drapery of the hillside,-mosses and running vines, to festoon and guard the approaches. In the foothills the upper banks of road-cuttings are frequently occupied, while in mountain meadows I have seen haystacks in whose disheveled sides the Juncoes sheltered their young. In default of suitable banks the birds will trust themselves to the density of vegetation in unmowed orchards, weed-lots, and meadows. Brush-piles afford coveted shelter, as well as small patches of mountain sage, a shaded stretch of heather, or even an accumulation of pine needles upon the ground. Once I found a bird which occupied a carefully chosen fern arbor in the midst of a collection of whitened bones, evidently the mortal remains of a defunct horse. The situation was delightfully gruesome, and, touched no doubt with vanity, the owner sat for her portrait at four feet, a la Bernhardt.

Juncoes keep very quiet during the nesting season until disturbed, 


\section{The Oregon Juncoes}

and they are very close sitters. When nearly stepped on the bird bursts off, and if there are young, crawls and tumbles along the ground within a few feet of the intruder, displaying wings and tail in a most appealing manner. The tssiks of both birds are incessantly repeated and the whole woodside is set agog with apprehension.

If one posts himself in a suspected locality not too near the nest, it is only a question of time till the solicitude of the nursing mother will

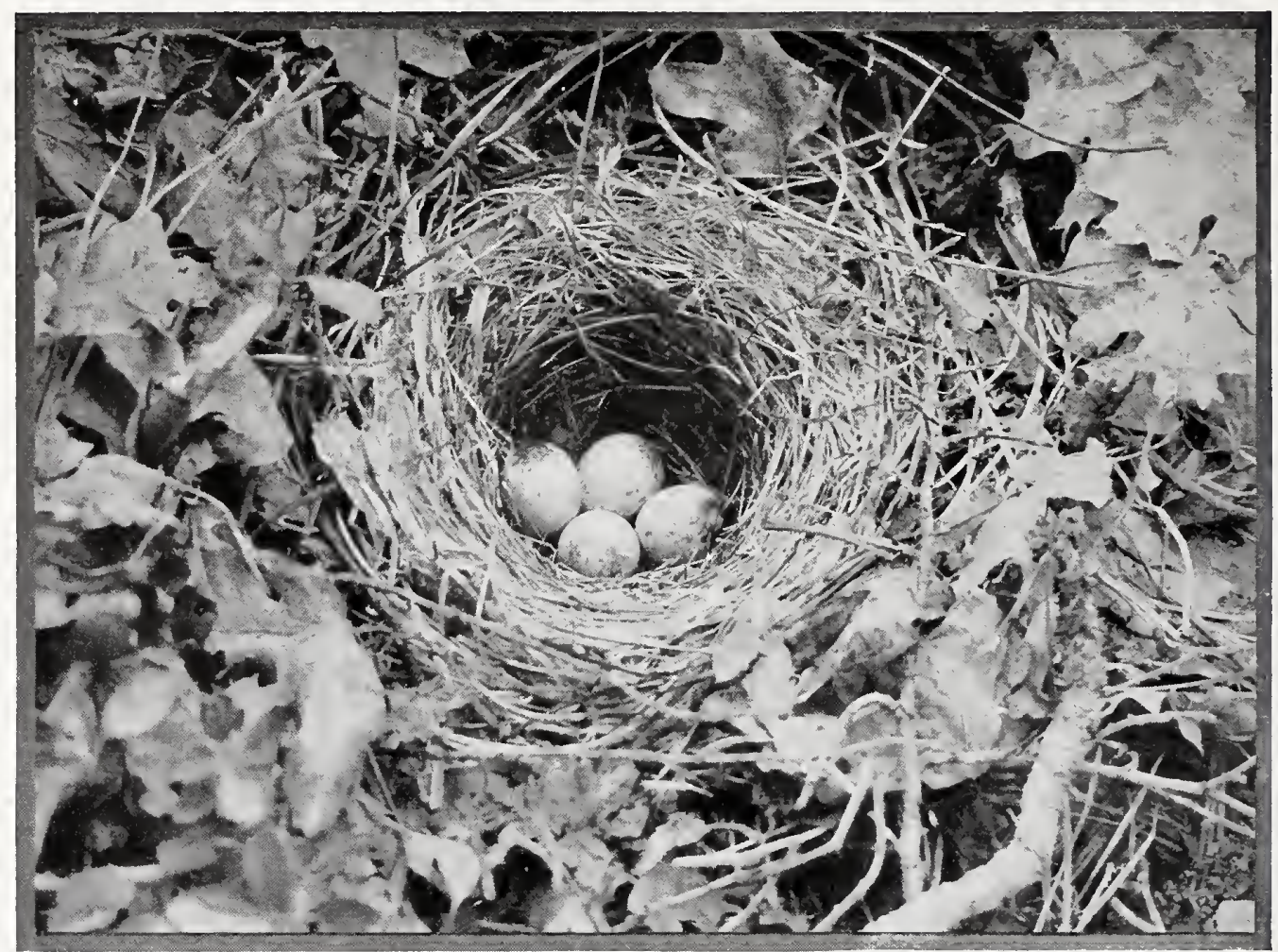

Taken in San Bernardino County

Photo by Wright $M$. Pierce

A NEST FROM THE SAN BERNARDINOS

triumph over fear. One such I traced to a charming mossy bank, overlooking a woodland pool; but on the first occasion it took the parent bird exactly half an hour to go through all the feints and preliminaries before she ventured on the final plunge. There were half-grown babies in this nest, and since we were in summer camp (at Glacier, near the foot of Mt. Baker), I resolved to make friends of this promising family with a view to portraiture.

As I sat next day watching my Juncoes, and waiting for the sun to get around and light up the vicinity of the nest, the call to dinner sounded. 296 
The mother bird, not without much misgiving and remonstrance, had just visited her babies, so I rose to go; but as I did so, caught sight of a stout garter snake, who lay watching the scene from a distance of fully twenty feet, a wicked gleam of intelligence in his eye. With quick suspicion of his purpose, I seized stones and hurled at his retreating form; but the ground was rough and he managed to escape into a large brush-pile. At table I ate hurriedly, listening the while for the faintest note of trouble. When it came, a quick outcry from both parents, instead of premonitory notes of discovery, I sprang to my feet, clutched a stick, and rushed down to the spring. Alas for us! Satan had found our Eden! The nest was emptied and the snake lay coiled over it in the act of swallowing one of the little birds. Not daring to strike, I seized him by the throat and released the baby Junco, whose rump only had disappeared into the devouring jaws. Then with the stick I made snake's-head jelly on a rock and flung the loathsome reptile away. But it was all too late. One young bird lay drowned upon the bottom of the pool, and the other (I think there were only two) soon died of fright and the laceration of the hinder parts attendant upon ophidian deglutition. It was all so horrible! the malignant plan, the stealthy approach, the sudden alarm, the wanton destruction of the fledglings, the grief of the agonized parents, the remorse of the helper who came too late! Is it any wonder that our forebears have pictured the arch-enemy as a serpent?

The Sierra Junco in California deserves to be called the Sierra Club bird. On the annual pilgrimage of its members this famous organization of mountaineers move about in a perfect halo of disturbed and protesting Juncoes. And as often as the vacationers, two hundred strong, deploy for the night over a lily-sprinkled meadow, a dozen pairs of Juncoes go sleepless, or else abandon impossible charges. At the Vidette Camp in I9I 3 the ladies showed me four cold eggs in a nest so deeply recessed in the bank of Bubb's Creek as to be entirely concealed from the vertical gaze. Buried in the ground as she was, the bird had endured the frequent proximity of the women passing to and from the creek, not three feet away, without betraying her trust, until at last one lady inadvertently emptied her half-drained drinking cup by a back-flip and sent the water square across the entrance of this hidden domicile. Thereupon its indignant mistress emerged, never to return. And of all the nests shown to the bird-man that season by the courtesies of a hundred pairs of eyes, fully three-fourths were those of Junco oreganus thurberi. 


\section{The Oregon Juncoes}

\section{No. 51c Point Pinos Junco}

A. O. U. No. 567 d. Junco oreganus pinosus Loomis.

Description.-Adults: Very similar to those of $J$. o. oreganus, and matching them fully as to rufescence of back, etc., but black of male possibly a little less intense, especially on throat and chest. Doubtfully different!-merely a sedentary stock occupying the ancient stronghold of the (sub) species oreganus, and exhibiting the two differential characters (really one) of a sedentary form, viz., the shorter wing and tail.

Nesting. - Nest and eggs much as in preceding form.

Range.-The Transitional areas of the Santa Cruz district, breeding from San Bruno (Ray) in San Mateo County south to Big Creek (Jenkins), Monterey County, irregularly east in winter at lower levels. The breeding ranges of pinosus and thurberi appear to inosculate deeply upon the northeast.

Authorities.-Vigors (Fringilla hyemalis), Zoology of Captain Beechey's Voyage, I 839, p. 20; Loomis, Auk, vol.x., I893, p. 47 (Point Pinos;orig. desc.); ibid., Auk, vol. xi., I 894, p. 265, col. pl.; Kaeding, Bull. Cooper Orn. Club, vol. i, I 899, p. 80 (distr., habits, etc.); Beal, U. S. Dept. Agric., Biol. Surv. Bull., no. 34, 1910, p. 82 (food); Dwight, Bull. Am. Mus. Nat. Hist., vol. xxxviii., I9I 8, p. 29I (distr., variation, crit.).

THE RACE pinosus, stranded upon the hills of Monterey and Santa Cruz counties, exemplifies a phenomenon which should be clearly understood by the student of western bird-life. If we are to give this tendency a name-we may call it chorophily ( $\chi \tilde{\omega} 005$, a place, a definite region, pı $\lambda \dot{o}$, I love). By this we mean that attachment to a given place or region which prevents a bird (or other animal) from forsaking its ancestral home. In the strictest sense the term might apply as well to migrants which repair to definite homes or narrow ranges both in summer and in winter. (For example, we have at Los Colibris a Dwarf Hermit Thrush who returns to us regularly in winter. The Lord knows where he nests,--perhaps on Vancouver Island - but he spends six months on our narrow acre in closer attendance than a [purely hypothetical] house cat.) But for the purposes of our discussion we will confine the term to such species or forms as are not only non-migratory, but which succeed in resisting the migratory impulse manifested by their congeneric and conspecific fellows. The Belding Sparrow, the Salt Marsh Song Sparrow, the Point Pinos Junco are such species.

The case is all the more remarkable with $J$. o. pinosus, for the related forms, J. o. thurberi, couesi, and oreganus, have shifted notably within historic times. They are invading the Northland with rapid stride. But $J$. o. pinosus has found, long since, in the coastal regions of Monterey and Santa Cruz counties, the humid coolness which the species loves. Abundant fogs and towering redwood forests are assured blessings. Wherefore, pinosus will not go questing.

There is something pathetic in this loyalty on the part of a few birds 208 


\section{The Gray-headed Junco}

belonging to a species whose other members are notorious wanderers. There must be something very attractive about the coasts of Monterey! Those whose opinions coincide with that expressed by pinosus should feel greatly flattered. No doubt they do; and we shall look to them or to some gifted member of the Santa Cruz tribe to prepare a life history of the Point Pinos Junco which shall be worth while. All that an outsider may know, so far, is that the subspecies is just appreciably different in appearance. No differences in song or nesting or winter behavior have yet been described, but such doubtless exist.

No. 52

\section{Gray-headed Junco}

\section{A. O. U. No. $570 b$. Junco caniceps (Woodhouse).}

Description.-Adult (sexes alike): Head and neck all around, chest and rump, neutral gray, darker above, lighter below, shading on breast and sides into dull white or buffy white of remaining underparts; lores and area about base of bill narrowly black; back walnut-brown; wings chiefly fuscous; the coverts gray; the outer web of scapulars tinged with brown; two outer pairs of rectrices entirely and third pair largely white. Bill pinkish in life (drying pale brown); irides brown; tarsus pale brown, feet darker. Length about 161.3 (6.35); wing 84.6 (3.33); tail 66.6 (2.62); bill 10.9 (.47); tarsus $20.6(.8 \mathrm{I})$. Females smaller.

Recognition Marks.- Sparrow size; foreparts definitely gray, and back warm reddish brown; underparts shaded without abrupt contrast.

Nesting.-Does not breed in California. Nest and eggs not certainly distinguishable from those of preceding species.

General Range.-The northernmost form of an allied group which includes $J$. phaeonotus: breeds in Utah and southern Wyoming, south to northern NewMexico; winters at lower levels to northern Mexico and casually to southern California.

Occurrence in California.--Three records: Pasadena, Oct. 26, I 894 (Grinnell); Julia, San Diego County, common, Nov. I 8 to Dec. 3, 1906 (A. P. Smith); Oak Glen, San Bernardino Mts., March 4, 1922 (A. J. van Rossem).

Authorities.-Grinnell, Pasadena Acad. Sci. Pub., no. ii., I 898, p. 38 (Pasadena, Oct. 26, 1894); Trippe, in Coues' Birds of the Northwest, 1874, p. I44 (Colorado; habits, song, etc.); A. P. Smith, Condor, vol. ix., 1907, p. 199 (Julian); Rockwell and Wetmore, Auk, vol. xxxi., 1914, p. 325, fig. (Colorado; habits, nest and eggs); Dwight, Bull. Am. Mus. Nat. Hist., vol. xxxviii., 1918, p. 299, col. pl. (distr., variation, crit.); Dickey, Condor, vol. xxiv., 1922, p. 137 (San Bernardino Mts.).

THE GRAY-HEADED JUNCO is an invader from the central Rocky Mountains and from the lesser ranges of Utah and Nevada. His mistake in wintering in California is more noticeable than that of Junco 


\section{The Western Tree Sparrow}

hyemalis; for in doing so he forsakes the traditional southeasterly trend of the autumn migrations, and turns westward. Of course we warmly applaud such effort while we speculate upon the mysterious causes which lead up to it.

The slaty gray of the foreparts in caniceps is different enough from thurberi's smart black to attract the attention of a novice, and the possibility of the stranger's presence gives zest to a review of every local flock of Juncoes in southern California.

\section{No. 53}

\section{Western Tree Sparrow}

A. O. U. No. 559a. Spizella arborea ochracea Brewster.

Description.-Adults: Pileum, a malar streak, a streak behind eye, and a small patch on side of chest, cinnamon-rufous or hazel; superciliary stripe and remaining portions of head and neck light neutral gray; throat and chest of same shade superficially but duller by virtue of concealed dusky; an ill-defined spot of dusky in center of lower chest; remaining underparts dull white, washed on sides with brownish; general color of upperparts light buffy grayish brown; much outcropping black on back, scapulars, and tertials; some rusty edging on back-feathers, scapulars, and greater wing-coverts; middle and greater wing-coverts tipped with white, forming two conspicuous bands; flight-feathers grayish dusky margined with whitish and buffy; the rectrices with narrow whitish edgings. Bill blackish above, yellow tipped with dusky below; legs brown, feet darker; iris brown. In winter the cinnamon-rufous of crown is slightly veiled, especially along median area, by ashy skirtings of feathers, and the buffy of upperparts inclines to strengthen. Length about I52.4 (6.00); wing $76(3.00)$; tail 68 (2.68); bill Io (.39); tarsus $20.8(.82)$.

Recognition Marks.-Sparrow size; resembles Western Chipping Sparrow but much larger; white wing-bars with chestnut crown distinctive.

Nesting.-Does not breed in California. Nest: On the ground or in low bushes; composed of bark-strips, grasses, moss, etc., heavily lined with feathers. Eggs: 3 to 6; pale bluish green, finely and heavily and almost uniformly marked with reddish brown (vinaceous russet). Av. size $19 \times$ I $4(.75 \times \cdot 55)$.

Range of Spizella arborea.- Northern North America, south in winter to southern border states.

Range of S. a. ochracea.-Western North America, breeding from the Anderson River west to Bering Sea, and south to mountains of central British Columbia. In winter south through the Western States east of the Cascade-Sierra divide, south to Arizona and Texas, east to eastern Kansas.

Occurrence in California.--One record: specimen taken by Captain Feilner at Fort Crook, Shasta County. Probably a rare winter visitor in northeastern portion of State.

Authorities.-Henshaw, Rep. Orn. Wheeler Surv., I879, p. 296; Townsend, Proc. U. S. Nat. Mus., x., I887, p. 2 I 8; Cooper, J. G., Orn. Calif., I87o, p. 206; Grinnell, Pac. Coast Avifauna, no. II, I9I5, p. II8. 


\section{The Western Tree Sparrow}

"THE sight of the first Tree Sparrow in the fall serves perfectly to call up a vision of impending winter. Here are the hurrying blasts, the leaden skies, the piling snow-drifts, all ready to make the beholder shiver. But here, too, in some unburied weed patch, or thicket of rose-briars, is a company of Tree Sparrows, stout-hearted and cold-defying, setting up a merry tinkling chorus, as eloquent of good cheer as a crackling Yule-log. How many times has the bird-man hastened out after some cruel cold snap, thinking, 'Surely this will settle for my birds,' only to have his fears rebuked by a troop of these hardy Norsemen revelling in some back pasture as if they had found their Valhalla on this side the icy gates. Ho! brothers! here is food in these capsules of mustard and cockle; here is wine distilled from the rose-hips; here is shelter in the weedy mazes, or under the soft blanket of the snow. What ho! Lift the light song! Pass round the cup again! Let mighty cheer prevail!" (Birds of Ohio).

The claim of the Western Tree Sparrow to a place upon the California list still rests upon the solitary specimen taken by Feilner at Fort Crook, in Shasta County, in I879. Because of the milder climate of the Pacific Coast region, these hardy birds do not come so far south in winter as do their eastern compatriots, and



WESTERN TREE SPARROW 


\section{The Western Chipping Sparrow}

they are rare even in northern Washington. At the same time, it is highly probable that northern California has enjoyed several unrecorded visitations, and a recurrence is always a lively possibility. During its Southland forays, the bird's food, consisting, as it does, of grass- and weedseed and dried berries, is found near the ground; and so, for the season, the name Tree Sparrow seems inconsistent. When persistently annoyed, however, the flock will rise to the tree-tops in straggling fashion, and there either await the withdrawal of the intruder, or else make off at a good height.

The song of the Tree Sparrow is sweet and tuneful, affording a pleasing contrast to the monotonous ditty of the Western Chipping Sparrow. Snatches of song may be heard, indeed, on almost any mild day in winter; but the spring awakening assures a more pretentious effort. A common form runs, Swee-ho, sweet, sweet, sweet, with notes of a most flattering tenderness. But we may only guess at the bird's full powers, for the home-making is in Alaska.

No. 54

\section{Western Chipping Sparrow}

\section{A. O. U. No. $560 a$. Spizella passerina arizonæe Coues.}

Synonyms.-CHIPPY. HAIR-BIRD.

Description.--Adult male in breeding plumage: Crown bright chestnut (auburn or hazel); continuation on hindhead sharply streaked with black; extreme forehead narrowly black and divided by white line; a white superciliary and a narrow black line through eye; rump neutral gray; nuchal collar (crossed centrally by black streaks) neutral gray shading on sides of head and neck and sides into dull white of underparts; back and scapulars wood-brown, or avellaneous, heavily streaked with black; wings and tail fuscous, blackening on exposed tips of tertiaries and unexposed portions of wing-coverts; lesser coverts grayish olive to fuscous; middle and greater coverts tipped with white or buffy white, forming two inconspicuous bars. Bill black in highest plumage only; otherwise brown above and much lighter to pale below; legs light brown, feet darker. Adult female in spring: Much like adult male and sometimes indistinguishable, but usually chestnut of crown largely mixed with black shaft-streaks and brownish or buffy skirtings. Yearling females in spring are scarcely chestnut on crown--merely a more intense wood-brown. In fall and winter: Hazel of crown much admixed with black and buffy; remaining plumage softer and more blended, with increase of grayish brown. Immature birds are like adults in autumn, but crown without chestnut, - exactly like back, and sides of head, including superciliary, tinged with buffy. Juvenals are like immatures, but less rufescent, more grayish or flaxen, and are heavily streaked with dusky on breast and sides. Length of adult male I 46-I 52.4 (5.75-6.00); wing 72 (2.84); tail 6I (2.4I); bill 9.6 (.38); tarsus I7 (.67). Females a little less. 


\section{The Western Chipping Sparrow}

Recognition Marks.- Warbler size; chestnut of crown and whitish superciliary distinctive; adult unmarked below. Young birds of the year heavily streaked above on a pinkish brown ground.

Nesting.-Nest: A compact or careless structure of weed-stems, grasses and (most commonly and of ten exclusively) rootlets, heavily lined with horsehair, placed at moderate heights in bushes or trees, indifferently in riparian shrubbery, orchard trees, or evergreens. Eggs: 3 to 5, commonly 4; bluish green (pale niagara green), sharply and sparingly spotted and marked, chiefly in ring about larger end, with brownish black, paling variously, according to depth below surface, to deep dull lavender or vinaceous lilac. Av. size $17 \times 12.7(.67 \times .50)$. Season: April-July; two broods.

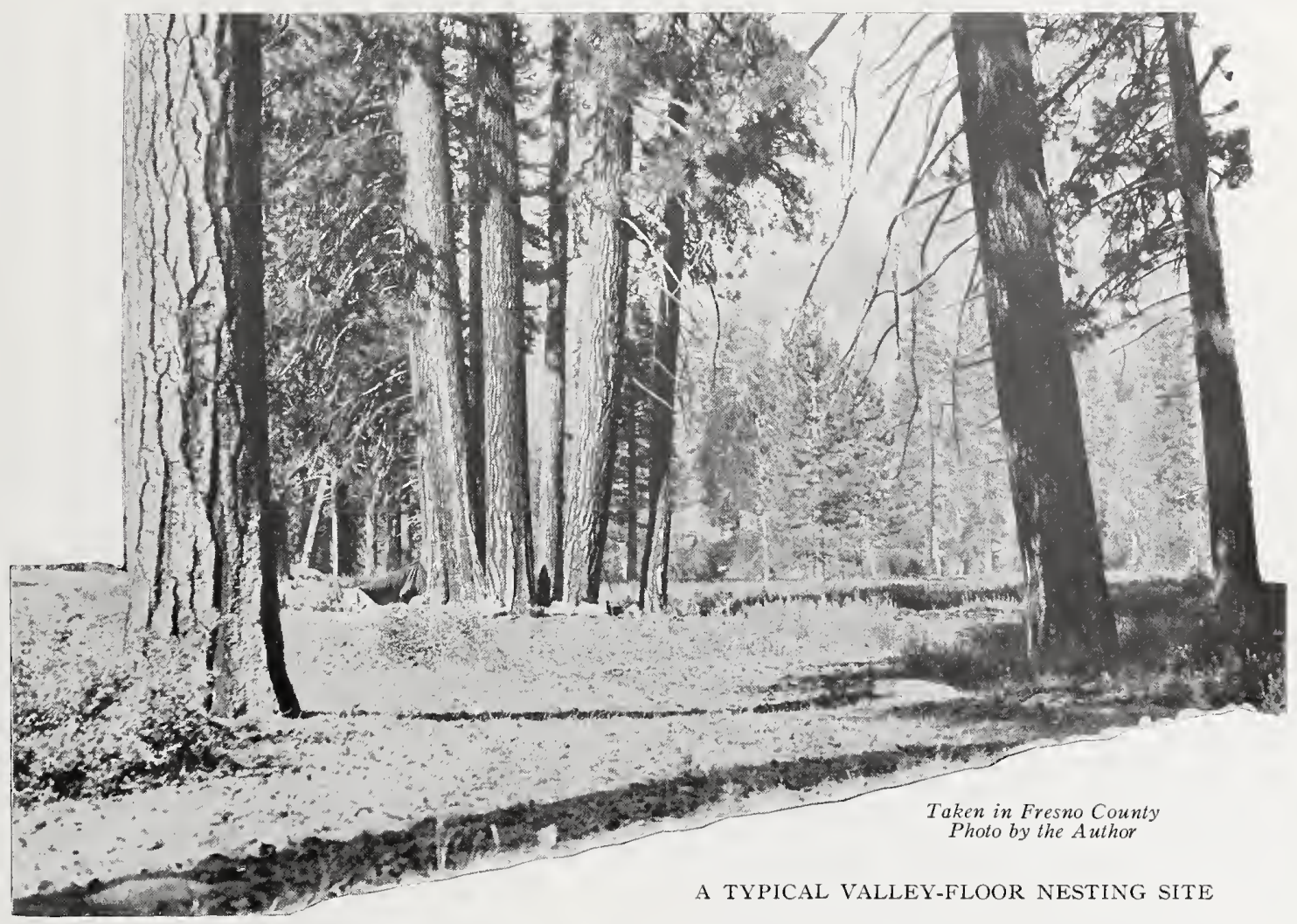

Range of Spizella passerina.-North America from southern and western Canada south to Nicaragua.

Range of $S . \not p$. arizonce.-Western North America. Breeds from the southern border of the United States, chiefly in the mountains north of the Yukon Valley and the Mackenzie (Fort Good Hope) east to eastern Colorado, western Manitoba, etc. Winters from southern California to Cape San Lucas and south over the Mexican plateau.

Distribution in California.-Breeds locally in Upper Sonoran zone west of the Sierras, and almost everywhere in Transition zones up to limit of trees in Boreal. 


\section{The Western Chipping Sparrow}

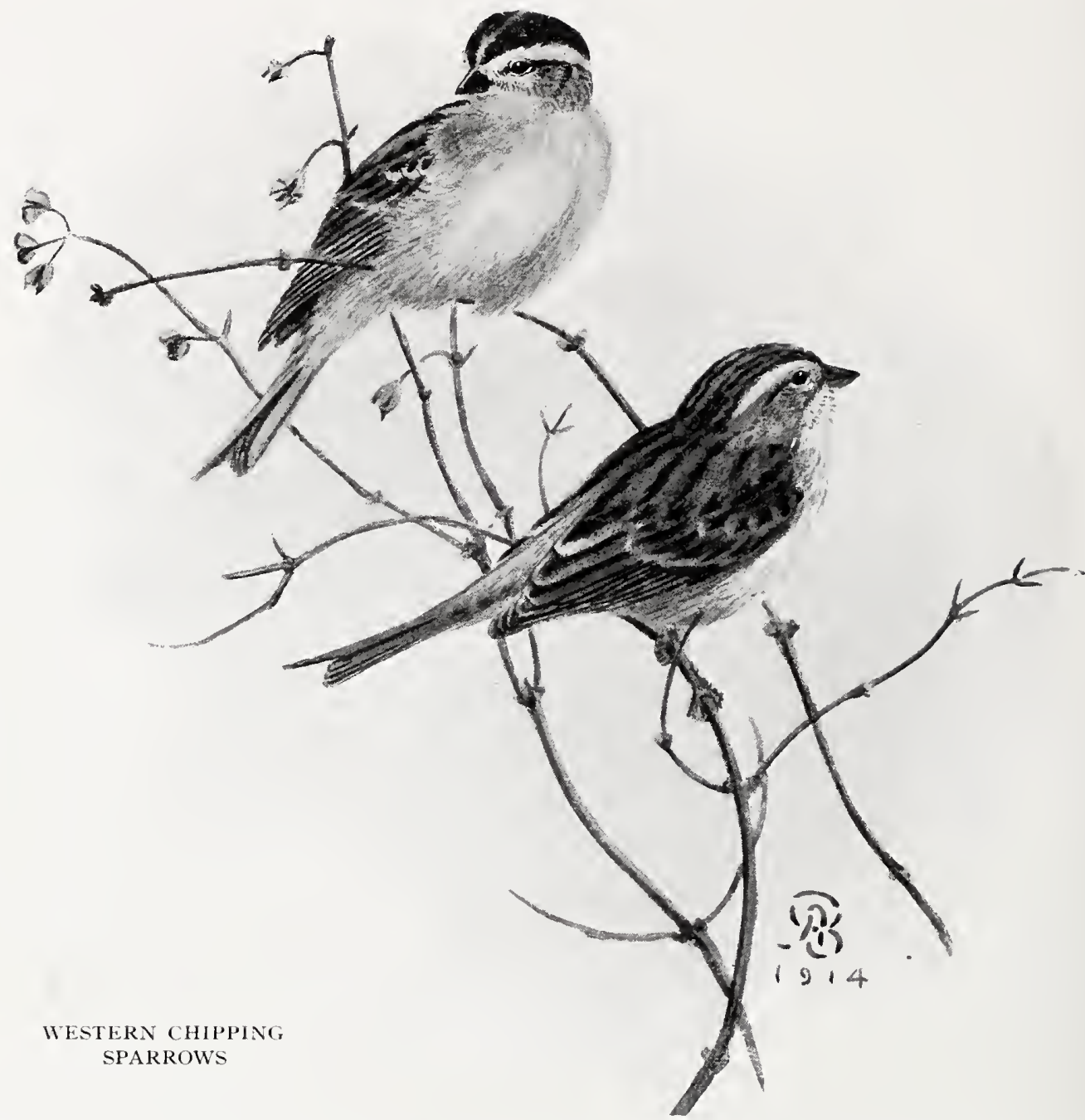

Also found attendant upon culture in valleys, even in Lower Sonoran. Occurs regularly upon the timbered islands of the Santa Barbara group. Winters sparingly in the San Diego district.

Authorities.-Heermann (Emberiza socialis), Jour. Acad. Nat. Sci. Phila., ser. 2, ii., I 853, p. 265; Cooper, J. G., Orn. Calif., I 870, pp. 207-208 (habits); Belding, Occ. Papers, Calif. Acad. Sci., 2, I 890, pp. I 55-I 56 (migration); Judd, Biol. Surv. Bull., no. I5, I901, pp. 76-78 (part) (food) ; Beal, Biol. Surv. Bull., no. 34, 1910, pp. 8o-82 (food); Howell, Pac. Coast Avifauna, no. I2, I917, p. 78 (on coastal islands).

AN OBSCURE little fellow he is to eye, a skit done in faded browns, with a chestnut crown which still does not differentiate the owner from a withered flower-cluster of wintry creosote, nor from a fallen fir cone on the flanks of Shasta. We used to call him domestica, and rejoiced to think 


\section{The Western Chipping Sparrow}

that at a given season he would make free with our lawns, or appear in the back yard to claim a share of the crumbs. Later the name socialis came into vogue, and this, too, expressed the bird's friendliness toward folks, rather than any gregarious tendency. Then the relentless law of priority inflicted the name of passerina upon us, and we have no way to record our appreciation of the bird's homely trustfulness.

The naming of birds is a highly artificial process at best, and as often misleading as instructive. Spizella, little sparrow, is excellent; passerina, sparrowlike, is a silly reduplication; while arizonce, of the desert, is rather inept as applied to the Western Chipping Sparrow in California, since the bird appears sparingly in our deserts only in the winter season. In the northern interior, say in eastern Washington, the bird is quite characteristic of the sage-brush deserts, or desert fringes; but in California the Chipping Sparrow has three principal breeding associations: culture, including parks, orchards and lawns; river fringes, especially of the upper levels; and evergreen timber. The last division requires further distinction, for this Sparrow is not a bird of the forest depths, but only of the parks and openings, - the forest borders, whether these be of second-growth redwood in the logged-off areas of Humboldt County, a yellow pine grove in the central Sierras, or the upper timbered levels lying along both sides of the Sierra crests. The Chipping Sparrow, therefore, is a bird of extreme "tolerance," for at the same time it is enduring the high temperatures (occasionally up to I Io degrees) of the lower Sonoran orchards in Los Angeles County, the chilly sea fogs of humid Transition in Del Norte County, and the nightly frosts of the I I ,ooo foot level on Mount Whitney. Yet for all this, there is no evidence of incipient change in plumage, nor

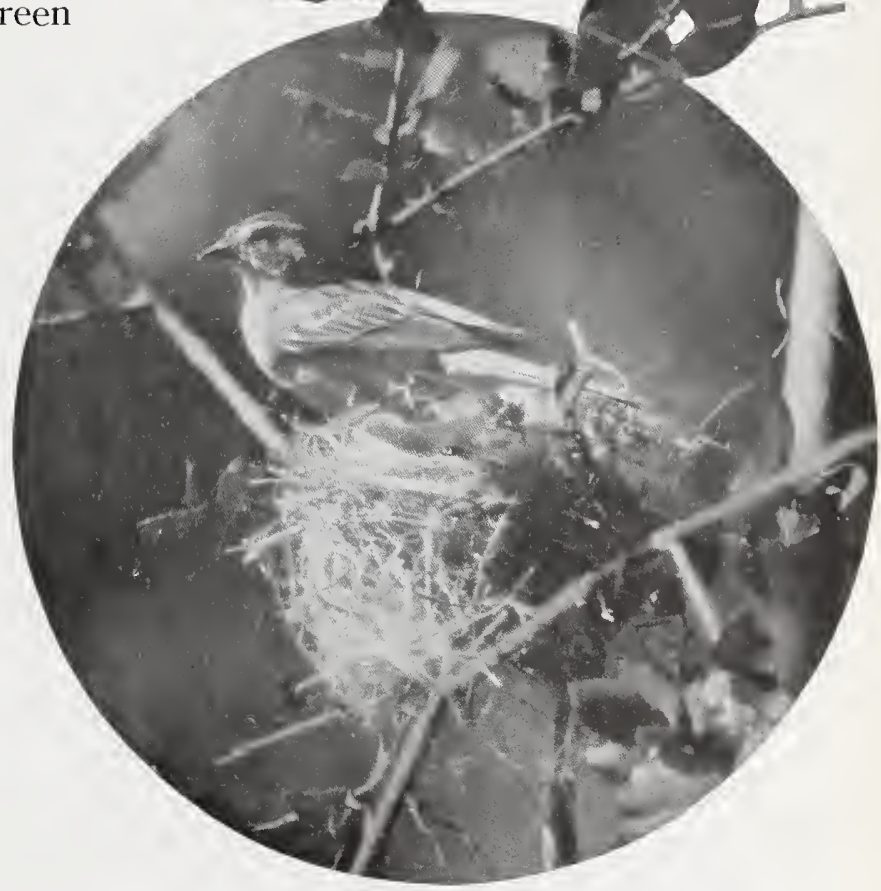

Taken in San Diego County Photo by Donald R. Dickey WESTERN CHIPPING SPARROW, NEST AND YOUNG 


\section{The Western Chipping Sparrow}

of any tendency to split up into subspecies. The alleged paling of "arizonce" is a slight character at best, and it is passing strange that the Chipping Sparrow's plumage has not become resaturated during the bird's attendance upon the humid forests which stretch from Monterey to British Columbia, nor further bleached in winter upon the burning sands of the Mohave and Colorado deserts.

Whatever the weather, Chippy returns to us about the first of April, posts himself on the tip of an evergreen branch, like a brave little Christmas candle, and proceeds to sputter, in the same part. Of all homely sounds the monotonous trill of the Western Chipping Sparrow is the most homely, - and the most easily forgivable. As music it scarcely ranks above the rattle of castanets; but the little singer pours out his soul full earnestly, and his ardor often leads him to sustained effort throughout the sultry hours when more brilliant vocalists are sulking in the shade; and for this we come to prize his homely ditty like the sound of plashing waters.

Two Chipping Sparrow songs heard in a northern locality deserve special mention. One likened itself in our ears to a tool being ground on a small emery wheel. The wheel has a rough place on its periphery which strikes against the tool with additional force and serves to mark a single revolution, but the continuous burr which underlies the accented points, or trill-crests, is satisfied by this comparison alone. The other effort, a peculiar buzz of varying intensity, carries forward the same idea of continuous sound, but the comparison changes. In this the song appears to pour from the tiny throat without effort, and its movement is as though an unseen hand controlled an electric buzz, whose activity varies with the amount of "juice" turned on : zzzzzzzzzzt, zzzzzzzzzzt, zzzzzzzzzzt, $Z Z Z Z Z$ ZZZZZT, ZZZZZZZZZZT.

In mountain camps the song of the Chipping Sparrow sometimes requires careful distinction from that of the Sierra Junco (Junco oreganus thurberi). Chippy's trill is never musical, but Junco's song occasionally emulates it in woodenness.

Chippy's nest is a frail affair at best, although it is often elaborately constructed of fine twigs, rootlets, and grasses, with a plentiful lining of horsehair. In some instances the last-named material is employed exclusively. An orchard branch or a sycamore bough is a favorite situation in the low country, a horizontal branch of fir or redwood in the wet country, and a bristling pine sapling undoubtedly has preference in the Sierras. Rose thickets are always popular, and where the bird frankly forsakes the wilds, ornamental shrubbery and vines are chosen. The nests are often so loosely related to their immediate surroundings as to give the impression of having been constructed elsewhere, and then moved bodily 


\section{The Western Chipping Sparrow}

to their present sites. Some are set as loosely as feathers upon the tips of evergreen branches, and a heavy storm in season is sure to bring down a shower of Chippies' nests.

Eggs are laid during April, May, or June, according to level. They are among the most familiar objects in Nature, and particular descrip tion of them ought to be unnecessary. But every person who knows that we are interested in birds has to stop us on the street to tell about the "cunningest little nest, you know, with four of the cutest —_." "Hold on," we say; "were the eggs blue?" "Yes." "With dots on them?" "Why, yes; how did you know?"

Incubation lasts only ten days, and two broods are usually raised in each season. Chipping Sparrows are very devoted parents and the sitting female will sometimes allow herself to be taken in the hand. The male bird is not less sedulous in the care of the young, and he sometimes exercises a fatherly oversight of the first batch of babies, while his mate is preparing for the June crop.

Taken in Mariposa County

Photo by the Author

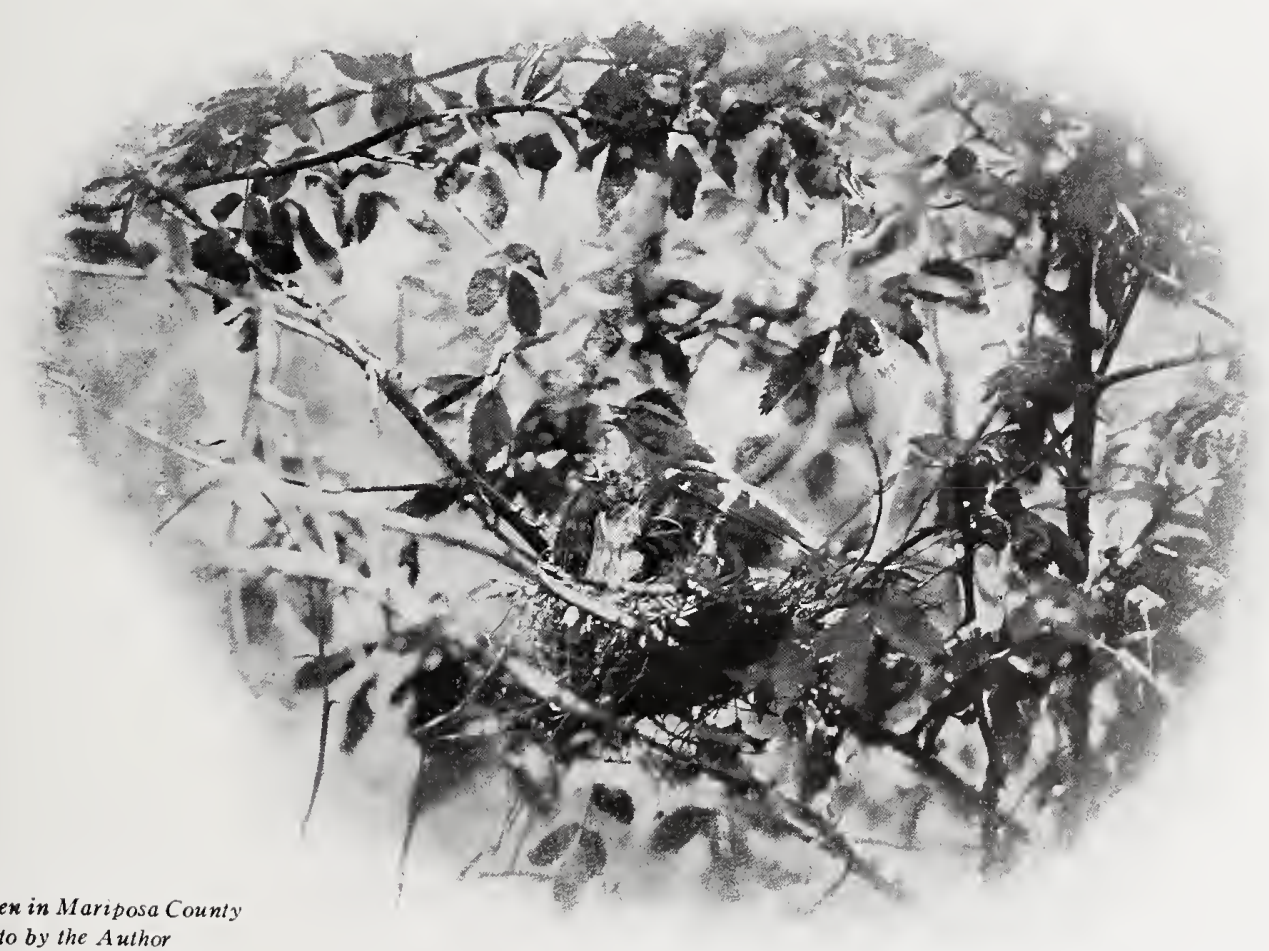

A WARM DAY IN YOSEMITE 


\section{The Western Chipping Sparrow}

The nest with young figured here was found on the I5th day of June in the Yosemite Valley. It was placed four feet up in a wild rose thicket, and not over five feet from the main traveled road. The day threatened to be an unusually warm one, and already at nine o'clock in the morning the mother bird was found standing upon the brim of the nest shielding her chicks, with outstretched wings, from the sun's rays. At ten o'clock, when we returned with the cameras, the situation was worse, heatwise, but at that I had to tear away the cover to get enough light on the nest. The mother bird returned presently, and finding the heat intolerable, fluttered and crowded until she had forced the last baby out of the nest and down the stem where there was shade. One youngster

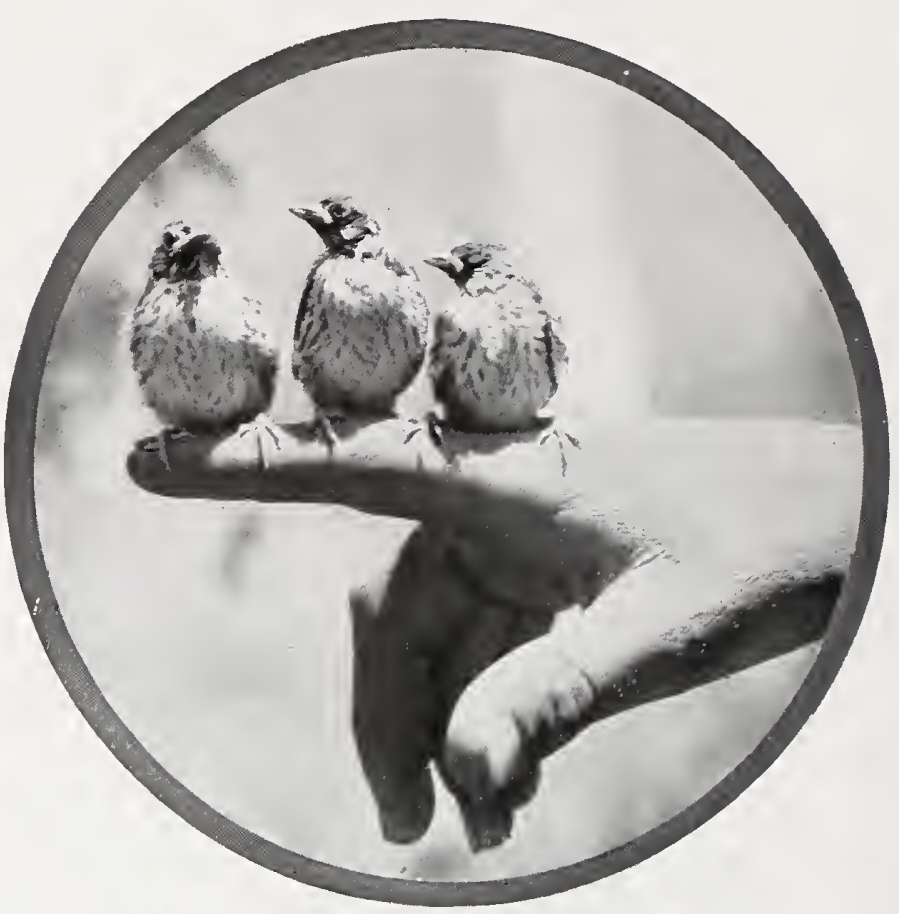

Taken in Mariposa County

Photo by the Author

"THEY WOULD NOT 'LOOK PLEASANT, PLEASE'" got the idea too thoroughly and disappeared in the depths of the bushes, but the other three we succeeded in coaxing up one by one until they would sit decently upon the hand. They would not "look pleasant, please," and were decidedly relieved when the ordeal was over and they could bolt into the shade. They simply would not stay in the nest even when the sun declined. That tie was broken. The mother bird repeatedly settled into the nest and made coaxing sounds, though whether with intention to induce a return on the part of her erring youngsters, or merely to deceive me, I could not tell. As she sat thus, the male parent lighted on the side of the nest and offered to feed, but he was promptly driven away by his mate with manifest reproaches for his stupidity. Seeing the jig was up anyway, the mother hunted up her favorite son, snuggled close, and settled down to a defiant nap. 


\section{The Black-chinned Sparrow}

No. 55

\section{Black-chinned Sparrow}

\section{A. O. U. No. 565 . Spizella a trogularis (Cabanis).}

Description.-Adult (sexes alike): Middle of back and scapulars grayish brown (sayal brown or wood-brown), heavily streaked with blackish (quite as in other Spizella); region about base of bill-the face-black, shading posteriorly, save on chin and upper throat, where abruptly defined from the neutral gray of the remaining plumage; the gray darkest above, where sometimes washed with dull brownish; shading below toward white or grayish white of middle belly and crissum; lower tail-coverts white, broadly streaked with gray; wings and tail fuscous with vague edgings of brownish gray. Bill reddish brown, darkening on tip; tarsus brown, feet dusky brownish. Immature birds lack the black of face, and the black of the adult female-never quite so strong as that of the male - is probably not attained before the second season. Young birds are faintly streaked below. Length of adult about I46 (5.75); wing 62 (2.45); tail $66(2.60)$; bill $9.3(.37)$; tarsus I $8.8(.74)$.

Recognition Marks.-Warbler size; black face against gray ground distinctive; gray of upperparts in abrupt contrast with saddle of streaky "sparrow color"; light bill; chaparral-haunting habits.

Nesting. - Nest: A compact cup of dried grasses, lined-or not-with horsehair; placed in sage or other shrub of the dwarf chaparral, of ten well concealed. Eggs: 3 or 4 ; of two types, both light bluish green (pale niagara green), the one unmarked, the other sparingly spotted and marked with dull brown and brownish black. Av. size I 6.5 x I $2.7(.65 \times .50)$. Season: May-June; one brood.

General Range.-- "Breeds in desert and coast ranges of southern California! Arizona, and southern New Mexico to northern Lower California, and south over the Mexican tableland to Hidalgo, Puebla, Mexico; Jalisco and Michoacan; winters in the southern part of its breeding range and south to Cape San Lucas" (A. O. U.).

Distribution in California.-Breeds in the chaparral of mountain sides throughout the San Diego district, northwestward at least to northeastern San Luis Obispo County (the Wreden Ranch); and on the southeastern desert ranges north at least to Silver Creek in the White Mountains (May 28, I919). Recorded casually in Monterey County (June 25, I 894, by Rollo H. Beck); and in Alameda County near Contra Costa line (May 27, I 899, by D. A. Cohen). Only one recorded occurrence in winter; San Clemente Island, Dec. 5, 1908, by C. B. Linton.

Authorities.-Gunn, Orn. and Ool., vol. x., Feb., I885, p. 30 (Colton); Coues, Proc. Acad. Nat. Sci. Phila., I866, p. 87 (Ft. Whipple, Ariz.; habits; crit.); Morcom, Bull. Ridgway Orn. Club, vol. ii., I 887 , p. 49; Fisher, N. Am. Fauna, no. 7, I 893, p. 92 (Panamint Mts., Walker Pass, Owens Valley, etc.); Willett, Pac. Coast Avifauna, no. 7, I912, p. 8I (s. Calif.; nesting dates, etc.); Grinnell and Swarth, Univ. Calif. Pub. Zool., vol. x., I9I3, p. 273 (habits, nests and eggs, song, etc.).

TSEET chweet chweet chweet trrrrr, came from the flanking chaparral high up on the hillside. Never did I name a bird with more instant confidence on the basis of its song alone, than I did this one, heard at evening as the motor labored up the lower reaches of the San Jacinto River. Its 


\section{The Black-chinned Sparrow}

quality was entirely new, but its cadence was Spizelline. We declared camp at once, and a charming spot we found, under the live oak trees at a little remove across the river. We called it Black-chin Camp, of course, although the Black-chinned Hummers were there to dispute honors with atrogularis. The night dragged all too slowly with the memory of the un-

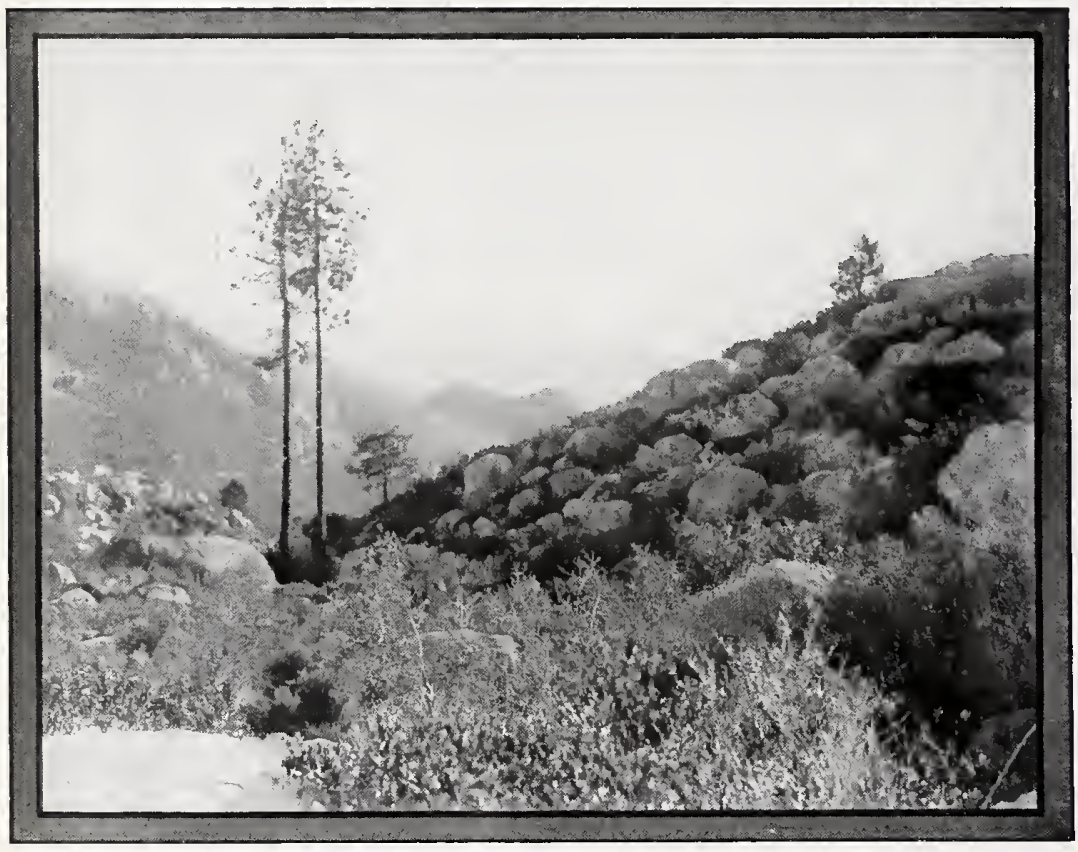

laken in Santa Barbara County

NESTING HAUNT OF THE BLACK-CHINNED SPARROW

seen singer to haunt the professional conscience, and the no less disturbing promise of early solution in the morning.

True to all the traditions of hospitality, our host called us in time for breakfast (although he would not get it for us). Shrill, vibrant, penetrating, with the incisiveness of a whip-crack, but infinitely sweeter, comes each note, accelerando, until the trill is reached. Here the singer becomes disheartened, and lets his melody peter out to an inglorious finish. Alternating irregularly with this song is another which is little more than a simple (and altogether different) trill. This phrase begins with a single inspirated note, those which follow are just distinct enough to be separated by the ear, while the terminal portion becomes rapid and diminuendo, as before. This echo song, moreover, is oftenest terminated, after the tiniest interval, by a single cheep or tsweet of characteristic quality. It is as though the singer had signed his name with a flourish to a performance which we should not otherwise have recognized.

It must have been this alternate, or echo song, of which Grinnell could say: "The general impression is of a weak song. It certainly does not carry far; on the contrary a bird may be singing close at hand and give the impression of a great distance." 1 Of the major song I can only testify that it has extraordinary carrying power, and that I have heard it distinctly (the bird being meanwhile under observation by 8-powers)

\footnotetext{
${ }^{1}$ Grinnell-Swarth, "Birds and Mammals of San Jacinto," U. of C., Publ. in Zool., Vol. 10. 1913, p. 27.5.
} 


\section{The Black-chinned Słarrow}

at a quarter of a mile. Once known, it can never be forgotten; and many a chaparral-covered hillside, which otherwise would have had no distinction, is forever impressed on memory by the quaintly sweet brank brank brank brank trrrr of this modest and all too distant singer.

The behavior of the Black-chinned Sparrow is worth recording. As a singer he performs conscientiously, and with an eye single to duty. He chooses elevated stations, a yucca stalk, the tip of the tallest chamisal, or, rarely, a tree. He is quite demure in manner, sitting pensive or turning calmly in the intervals which succeed his song. But every five or ten minutes, prudence enjoins that he shift his station, even though it be to another of equal prominence. If we approach, he will retire, singing distantly, or else conclude the concert abruptly.

Not from him shall we receive any information as to the dainty nest, placed at a height of a foot or so, in one of the thickest bushes of the hillside. And if we flush the female, sitting tight till close approach, she will disappear upon the instant, and as like as not for good. As a confirmed oölogist, I am inclined to resent this reticence, and to set it down to contumacy rather than caution. The three or four tiny bluegreen eggs, with or without spots and dots of cinnamon or sepia, are annoyingly like those of Spizella passerina. Who knows?

One would like to see the parent bird. And if there were danger of Brewer's Sparrows

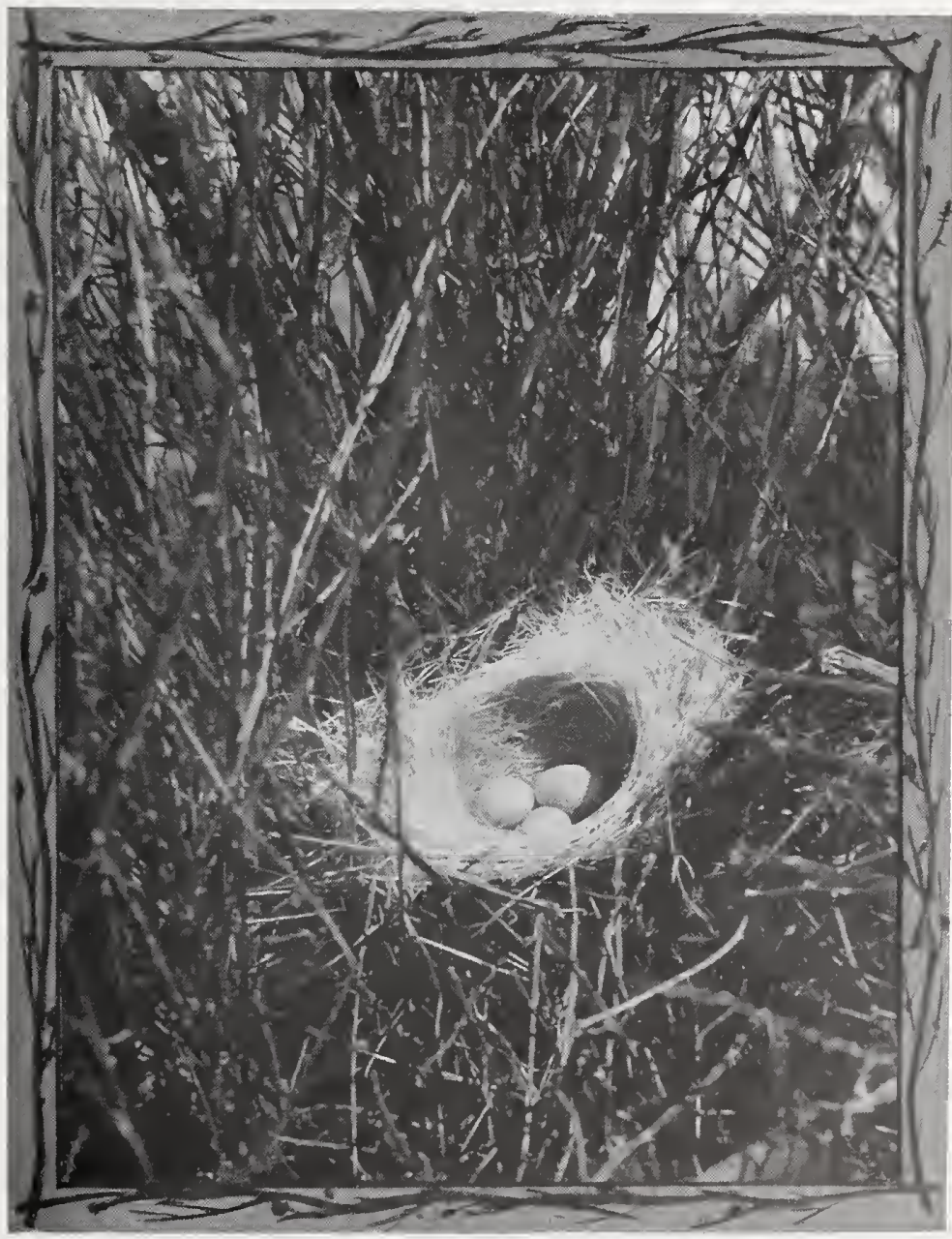

Taken in San Bernardino County

Photo by Wright M. Pierce

NEST AND EGGS OF BLACK-ĆHINNED SPARROW 


\section{The Brewer Sparrow}

being present (fortunately there is very little), the situation would be hopeless.

Like so many of the chaparral- and sage-haunting species, the Blackchinned Sparrow colonizes loosely. Here on a hillside may be found half a dozen pairs, and upon the heels of this good fortune, a silence of a dozen miles, or forty, may ensue. The time to study Black-chinned Sparrows is not when you will, but when you can.

\section{No. 56 \\ Brewer's Sparrow}

A. O. U. No. 562. Spizella breweri Cassin.

Description.-Adults: Upperparts light grayish brown, grayer-nearly light neutral gray - on nuchal collar; brightest brown on back; everywhere (save on remiges and rectrices) streaked with black or dusky, narrowly on crown, more broadly on back and scapulars, less distinctly on rump; wing-coverts and tertials varied by edgings of brownish buff; flight-feathers and rectrices dark grayish brown or dusky, with some edging of light grayish brown; a broad pale buffy superciliary stripe, scarcely contrasting with surroundings; underparts dull whitish, tinged on sides and across breast by pale buffy gray. Bill pale brown, darkening on tip and along culmen; feet pale brown; iris brown. Young birds show more of an ochraceous element upon the wings, and are heavily streaked upon the breast and sides with dusky. Length I35 (5.30). wing $62(2.44)$; tail $60.5(2.38)$; bill $9.6(.38)$; tarsus $17.3(.68)$.

Recognition Marks.-Warbler size; general streaked appearance; absence of distinguishing marks practically distinctive; sage-haunting habits.

Nesting.- Nest: A compact cup of twigs, weed-stems, and rootlets, lined, if possible, with horsehair; placed in bushes, often well concealed in sage, greasewood, or atriplex. Eggs: 3 or 4, very rarely 5; light bluish green (light niagara green to pale nile blue), spotted about the larger end (sometimes confluent in ring) with rich reddish brown (liver-brown). Av. of 26 specimens in the M. C. O. collection, I6.6 X I 2 $(.655 \times .472)$. Season: May-July, according to elevation; usually one brood.

General Range.-Sage-brush plains of the West, breeding from the southern portion of the Southwestern States north to southeastern British Columbia, and east to western Nebraska; south in winter through Lower California, and in Mexico to Jalisco.

Distribution in California.-Breeds in high Upper Sonoran and Transition zones, chiefly east of the Sierras and locally in Upper Sonoran in the great interior valley or elsewhere,--Fresno County (Tyler); Sespe (Peyton); Carrizo Plains (Swarth). Also a summer or late summer visitor and possible breeder in the Boreal zone to the limit of trees,-White Mountains at alt. 10,000, May 26 and 27, 1919; Warner Moun- 


\section{The Brewer Sparrow}

tains at alt. 8500, July 8, I9I2; Cottonwood Lakes (Inyo County) at alt. I I,00o, July Io, I9II, etc. Winters sparingly in the San Diegan district, and along the Colorado River; has occurred also in winter at Fresno (Tyler), and casually at Redwood City (Littlejohn).

Authorities.-Heermann (Emberiza pallida), Jour. Acad. Nat. Sci. Phila., ser. 2, ii., I 853 , p. 265 ; Cassin, Proc. Acad. Nat. Sci. Phila., I 856 , p. 40 (desc. of breweri); Ridgway, Orn. 4oth Parallel, I877, p. 480 (song); Grinnell, Auk, vol. xxii., I905, p. 386; Peyton, Condor, vol. xi., I909, p. 207 (nests); Tyler, Condor, vol. xii., I910, pp. I93-195 (nesting, habits, etc.).

IT IS never quite fair to say that Nature produces a creature which harmonizes perfectly with its surroundings, for the moment we yield tribute of admiration to one creature, we discover amid the same circumstances another as nearly perfect but entirely different. When we consider the Sage Sparrow, we think that Nature cannot improve much upon his soft grays by way of fitness for his desert environment; but when we come upon the Brewer Sparrow, we are ready to wager that here the dame has done her utmost to produce a bird of noncommittal appearance. Mere brown might have been conspicuous by default, but brownish, broken up by hazy streakings of other brownish or dusky - call it what you will - has given us a bird which, so far as plumage is concerned, may be said to have no mark of distinction whatever - just bird.

The Sage Sparrow fits into the gray-green massy scheme of color harmony in the artemisia, while Brewer's fits into the somber, brown-andstreaky scheme of its twigs and branches. To carry out the comparison, do not look for breweri early in the season, when the breath of the rain rises from the ground and the air is astir; he is there, of course, but disregard him. Wait, rather, until the season is advanced, when the incomparable sun of Yakima has filled the sagebrush full to overflowing, and it begins to ooze out heat in drowsy, indolent waves. Then listen: Weeeezzz, tubitubitubitubitub, the first part an inspired trill, and the remainder an exquisitely modulated expirated trill in descending cadence.

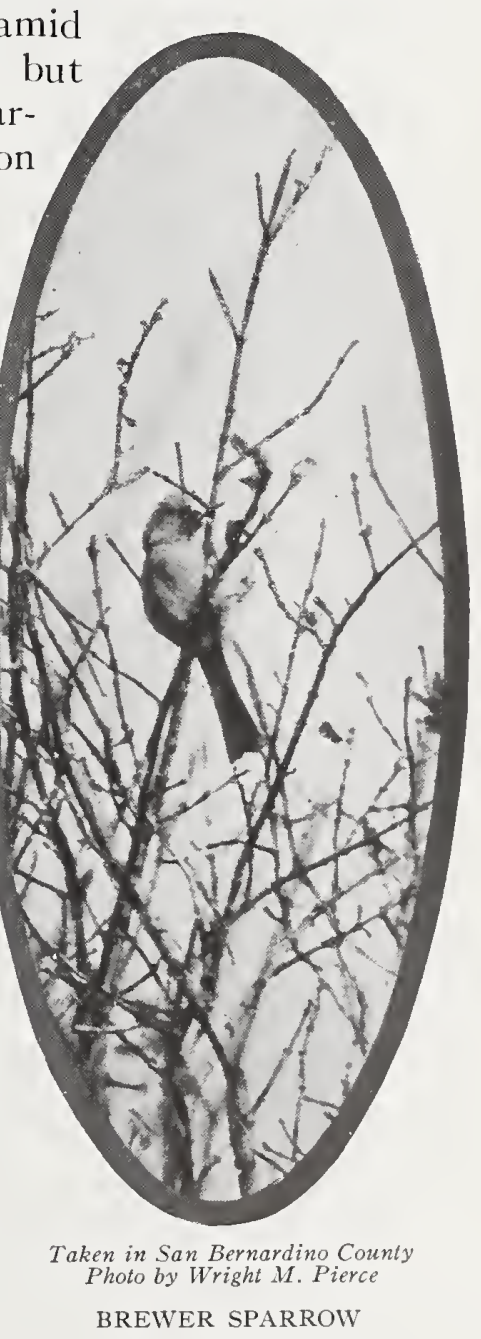

313 


\section{The Brewer Sparrow}

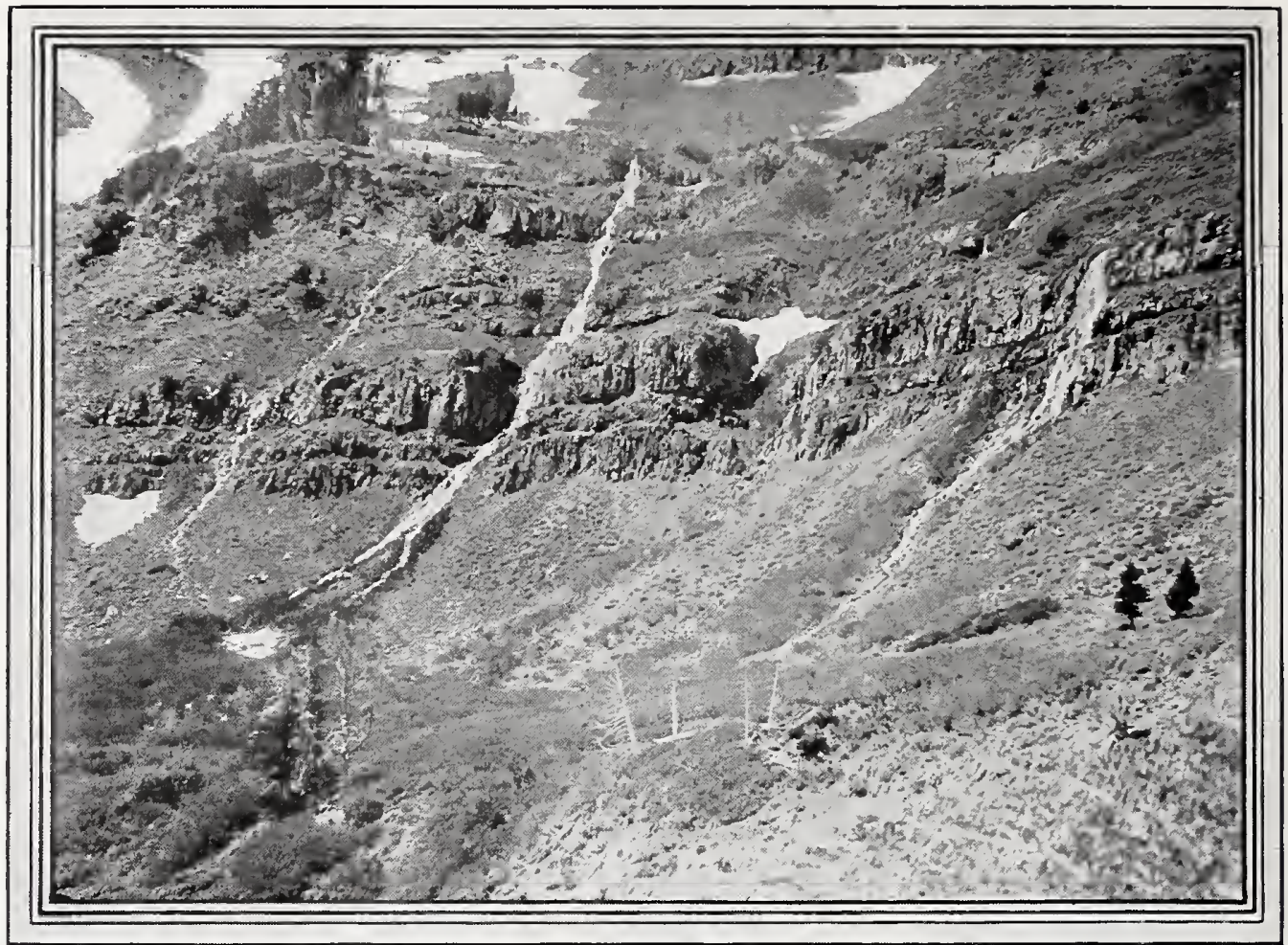

Taken in the Warner Mountains

Photo by the Author

WHERE THE BREWER SPARROW SPENDS HIS SUMMER VACATION

Instantly one conceives a great respect for this plain dot in feathers, whose very existence may have passed unnoticed before. The descending strain of the common song has, in some individuals, all the fine shading heard in certain imported canaries. Pitch is conceded by infinitesimal gradations, whereby the singer, from some heaven of fancy, brings us down gently to a topmost twig of earthly attainment. Nor does the song in other forms lack variety. In fact, a midday chorus of Brewer Sparrows is a treat which makes a tramp in the sage memorable.

The range of Brewer's Sparrow in the breeding season is nearly coextensive with that of Artemisia tridentata, the "sage" par excellence. Inasmuch as this plant has a considerable altitudinal range, the bird enjoys also a decided change of air. J. S. Appleton found Brewer Sparrows breeding at Simi (alt. 800 feet), May 2 Ist and 28th, I 899; while I took a set of four eggs on the 28th of June, I9I I, at an elevation of 8600 feet, on the east flank of the Sierras, in Inyo County. However, an occurrence at a similar level (8500) on the Warner Mountains was on July 8 th, and marked the close of the breeding season, with its attendant 


\section{The Harris Sparrow}

emancipation from lower level duties. At the Cottonwood Lakes (alt. $I I, 000)$ in Inyo County, the species made its "vacation" appearance on the Ioth day of July (I9II).

It is not impossible that the Brewer Sparrow nests twice in a season, once at a lower level, and again several thousand feet higher. The species nests in April further north, but there seem to be no breeding records for that month in California.

Neither the nest nor the eggs of Brewer's Sparrow are in themselves certainly distinguishable from those of its congener ( $S$. passerina arizonce); but its nest, in my experience, is invariably placed in a small bush, a sage-bush, at a height of not over one or two, or at most, three, feet from the ground. Records of nesting in fruit trees I distrust; but there is no doubt that Mr. Tyler did discover a unique and interesting situation near Clover, in Fresno County. ${ }^{1}$ An isolated colony of these birds found an attractive summer home in a vineyard having a south exposure. The curious fact in this connection is that the birds chose for nesting sites only such vines as were dwarfed and yellowed, whether because of the presence of some blight or through lack of soil. Mr. Tyler checked up on this phenomenon for several successive years, and came to know the afflicted specimens as "Brewer vines." When the vines in this vineyard were cured, the colony deserted in favor of another having blighted members.

No. 57

\section{Harris's Sparrow}

\section{A. O. U. No. 553. Zonotrichia querula (Nuttall).}

Description.-Adult (sexes alike): Top of head, region about base of bill, broadly, and throat black: the black continued on chest, but broken up and scattered upon center and sides of breast; hinder portion of cheeks, auricular region, and sides of neck, pale buffy brown, or rarely plain gray; nape and dab on side of neck, chiefly Prout's brown; rump and upper tail-coverts plain drab; remaining upperparts "streakedsparrow-color," i. e., drab heavily streaked with black and with marginings of lighter, more buffy, brown; wings dusky, margined with grayish or pale rusty, the middle and greater coverts tipped with white; tail dusky with narrow tips of white (in unworn plumage only); sides grayish brown or dull ochraceous, vaguely streaked with dusky; the sides of breast occasionally with admixture of rusty brown among black streaks; tibiæ dusky, under tail-coverts pale ochraceous buff; remaining underparts white. Bill light reddish brown, lightening below; feet and legs light brown (after drying, darker). Immaturity is shown by reduction of blacks, the feathers of the pileum being tipped with white, thus presenting a scaled appearance, and those of throat admixed

1 John G. Tyler in "The Condor," Vol. XII., Nov., 1910, pp. 193-195. 


\section{The Harris Sparrow}

with white. Length about I90 (7.49); wing 89 (3.5I); tail $84(3.3 \mathrm{I})$; bill $\mathrm{I} 3(.52)$; tarsus 24.4 (.96). Females somewhat smaller.

Recognition Marks.-Large Sparrow size; black of face and throat distinctive; light bill; bush-haunting habits. Will probably be found, if at all, associating with the other Zonotrichias.

Nesting.-Does not breed in California. Nest (as described by Raine): On ground at foot of tree; composed of grass and fine bark; lined with dry grass. Eggs: "Creamy white, spotted chiefly at the larger end with rusty brown and lilac" (Raine). Av. $22.4 \times 16.8(.88 \times .66)$. It is noteworthy that the account referred to above, found in Cat. Canadian Birds, by John and James M. Macoun (Ottawa, 1909, p. 510), is the only one we yet possess of the nesting of this mysterious bird.

General Range.-West central North America (the plains region north to Mackenzie), breeding from Saskatchewan north probably to the limit of trees, in migration west to central Montana, east to eastern Illinois; winters from northern Kansas and western Missouri south to southern Texas; casual in the Pacific Coast states and in Ohio.

Occurrence in California.- Three records: Hayward, Oct. 27, 1900 (Emerson); San Clemente Island, Oct. I5, I9I7 (Linton); Berkeley, bird seen repeatedly between Dec. 25, I912, and Feb. I1, I913 (A. S. Allen).

Authorities.-Emerson, Condor, vol. ii., I900, p. 145 (at Hayward); Linton, Condor, vol. x., I908, p. 84 (San Clemente Id.); Allen, A. S., Condor, vol. xvii., I9I5, p. I I6 (at Berkeley).

IT IS ground for chuckling satisfaction on the part of Californian bird-lovers that all the species and subspecies of Zonotrichia, six in number, should have registered in the Golden State. It is pure graciousness on the part of querula, for its summer home lies in British Columbia, east of the Rocky Mountain system; and to reach us it must surmount heights which are no part of its wonted scheme of things. Those few which do appear so far south and west-there are only three instances of recordhave doubtless become involved in the moving hordes of gambeli which annually sweep south regardless of obstacles.

Of the Harris Sparrow on its native heath comparatively little is yet known. It frequents the "land of little sticks," right to the edge of the Barrens, and its nests are said to be placed on the ground at the base of some small tree,-willow or birch.

An observer at one of querula's way stations, in Manitoba, notes that its spring song consists chiefly of three whistled repetitions of the same note. "The performance was disappointingly short, but the general impression gathered was, that whoever happens to hear the full song of the Hooded Sparrow will know one of the sweetest of bird melodies. During their spring visit the Blackhoods often uttered three clear whistling notes, and on one occasion a soft blue-bird-like warble was added to this." 1

1"The Birds of Manitoba," by Ernest E. Thompson; Proc. U. S. Natl. Mus., Vol. XIII. (1891), p. 598. 


\section{The Golden-crowned Sparrow}

No. 58

\section{Golden-crowned Sparrow}

\section{A. O. U. No. 557. Zonotrichia coronata (Pallas).}

Description.-Adults: A broad crown-patch pyrite yellow, changing abruptly to ashy gray on occiput; this bounded on each side by broad stripe of silky black, meeting fellow on forehead; remaining upperparts grayish brown, broadly streaked with black on back, more or less edged with dull reddish brown (wood-brown, or sayal brown) on back, wing-coverts and tertials, glossed with olive on rump and tail; middle and greater coverts tipped with white, forming conspicuous bars; chin, throat, sides of head, and breast smoky gray (light smoky gray on throat to light grayish olive on breast), with obscure vermiculations of dusky, shading into whitish of belly; sides washed with buffy brown which becomes pure on flanks and crissum. Bill blackish above, paler below; feet pale; iris brown. Immature: Without definite head-stripe; crown broadly dull olive-yellow (between citrine and olive lake), clearest on forehead, elsewhere sharply flecked with blackish in wedge-shaped marks, giving way to grayish brown or dull chestnut behind, and to blackish on sides (variably according to age?); washes of underparts strengthened. Length of adult male about $190.5(7.50)$; wing 79 (3.II); tail 76 (3); bill I2.2 (.48); depth at base 8 (.32); tarsus 24 (.95). Females a little smaller.

Recognition Marks.-Sparrow size; yellow of crown distinctive in any plumage.

Nesting.-Does not breed in California. Nest and eggs not well described, but doubtless much as in following species.

General Range.-Pacific Coast region, breeding from central British Columbia north to the Kowak River in Alaska; wintering casually from Puget Sound, and regularly from central Oregon south to northern Lower California; in migrations irregularly eastward to Alberta and Nevada, or even Colorado; accidental in Wisconsin.

Distribution in California.-Common in winter, but subject to great local variation in numbers, throughout the State but chiefly west of the Sierran divide. Occurs on the Santa Barbara Islands, and casually upon the deserts,-Yermo (Lamb); Palm Canyon, Jan. 27, 1913; a desultory lingerer in spring,-Pasadena, May 9 (Grinnell); Shandon, May I3, I9I2; Farallons, June 2, I91 I.

Authorities.-Audubon (Emberiza atricapilla), Ornith. Biography, vol. v., I 839, pp. 47-48; Mailliard, J., Condor, vol. iii., I90 I, pp. 78-79 (song); Fisher, W. K., Condor, vol. iii., I901, p. 79 (song); Beal, Biol. Surv. Bull., no. 34, 1910, pp. 78-79 (food); Bassett, Condor, vol. xxii., I920, pp. I $36-137,3$ figs. (song variations).

GOLD is, of course, the proper color for a crown, and it is a rash bird which would flaunt any other shade of yellow in the face of our determined generalization. Nevertheless, the "gold" of coronata's crown is not golden at all, but pyrite yellow, a shade produced by an admixture of about equal parts of yellow and black. And so far is coronata from being a rash bird (save for the shotgun, which is "no fair"), it will probably take the reader about three years to determine the correctness of my statement. For regal, though he be, this sparrow is very discreet in the matter 


\section{The Golden-crowned Sparrow}

of public appearances, and does not cultivate the public eye. The perennial interest, therefore, of a winter company of skulking Crown Sparrows, chiefly nuttalli and gambeli, lies in the effort to determine whether there are any Golden-crowns among them.

Zonotrichias, whether migrating or wintering. are all coquettishly retiring, and the first hint of danger sends them scuttling into the brush. If one presses up to the edge of the brush, he may hear an uncanny rustling among the leaves and branches as the birds retreat, but not a single note is uttered. Left to themselves, the birds become sociable, with many zinks, common to the genus; and if unusually merry, in the springtime, the Golden-crowns indulge a sweet preparatory hoo hee which reminds one both of the White-crowned (Z. leucophrys) and White-throated (Z.albicollis) Sparrows. We expect more, but save for modifications, prese tly to be described, these tuning up notes are all that the bird has to offer; and Mr. Grinnell, 1 in the northern breeding home of the bird, notes only their "extremely sad quavering song of two syllables."

The question of the song of this bird having been raised in the columns of the Condor, Mr. Joseph Mailliard replied in part as follows:2

"Its song, if it may be dignified by such a title, consists of three notes given in a descending scale with intervals of thirds, or to express it differently, sol, mi, do. The sound is that of a very high whistle, in fact so high that in imitating the bird it is necessary for me to make it with the tongue against the roof of the mouth, the lips apart. The notes are given very softly and yet are penetrating.

"The song is given when the bird is either on the top of a low bush or within the bush near the outside. As the two species ( $Z$. coronata and $Z$. l. gambeli) invariably flock together during their residence in this neighborhood [San Geronimo, Marin Co.], and as it is very difficult to distinguish the immature gambeli from coronata at any distance, when both kinds are banded together, especially when partly hidden by foliage, a great deal of watching was necessary to enable me to establish the identity of the songster.

"This song only seems to be given in certain states of the weather, notably before or after a rain, and is repeated again and again, of ten being taken up by other birds of the same species within call. People living in country towns often call this the rain-bird, and have asked me what bird it was that made these sounds."

The author's notes record both the two-syllabled and the threesyllabled songs, the former of tenest given with rising inflection, like that of the eastern White-throat, the latter in descending scale, notes of marvelous

] "Birds of Kotzebue Sound Region," p. 51.

2 The Condor, Vol. 1II.1May, 1901, pp. 78, 79. 


\section{The White-crowned Sparrow}

purity, save as the last is sometimes slurred through the suppressed emotions of a sigh. "Oh, dear me," the bird says; and because he really does say that, I make no apologies to Prof. W. K. Fisher, who first recorded the fact in the Condor. 1

Golden-crowns have the familiar nasal tss, the keep-in-touch note common to so many sparrows, and they have also a high-pitched chirp, or tschip, neither so metallic nor so emphatic as that of leucophrys, nor so rich as that of the Fox Sparrows.

As for the "rain-bird" tradition, one may remark that the bird hails from the rainy coasts of Alaska and is likely to feel more at home with us in wet weather. We have wet weather of our own, in Humboldt County, for example, but the reports of birds nesting in California seem to lack confirmation. I encountered a handsome male near the landing place on the Southeast Farallon, June 2, I9I I, but, seduced by the companionship of such rarities as Magnolia Warbler, Redstart, Ovenbird, Lazuli Bunting, and Sooty Fox Sparrow, he was in no wise accountable for his behavior.

\section{No. 59}

\section{White-crowned Sparrow}

\section{A. O. U. No. 554. Zonotrichia leucophrys (Forster).}

Description.-Adult male: A broad crown-stripe of pure white, bounded by lateral stripes of black, which meet in front and invade lores (but not deeply); a short superciliary, involving eyelid but cut off in front by loral black, this in turn bounded by a post-ocular stripe of black-thus making a seven-banded pattern of alternating black and white for the hindhead; nape, continuous with sides of head and neck and anterior underparts, light neutral gray, changing to white on throat and belly, and to buffy brown on sides, flanks, and crissum; coloration of remaining upperparts likewise neutral gray, heavily streaked upon back and scapulars with dark grayish brown (mars brown to vandyke brown) and some whitish, changing posteriorly to grayish drab in which the brown element gains in intensity; upper tail-coverts, therefore, buffy brown; wings and tail brownish fuscous; the flight-feathers and rectrices edged with pale grayish brown, the inner feathers of the greater coverts and the exposed outer webs of tertials edged with reddish brown (snuff-brown to Prout's brown); the middle and greater coverts tipped with white, forming two fairly conspicuous bars; axillaries and bend of wing white. Bill cinnamon brownish, darkening on tip; iris brown; tarsus pale brown; feet darker. Adult female: Much like adult male and often indistinguishable, but usually somewhat duller, the head-stripes tinged with brownish, and the whites of the head less pure; the cheeks tinged with brownish and the grays of the upperparts less pure,- more brownish. Immature birds: Somewhat like adults, but without black, and with total substitution of brownish gray for neutral

${ }^{1}$ Vol. III., 1901, p. 79. 


\section{The White-crowned Sparrow}

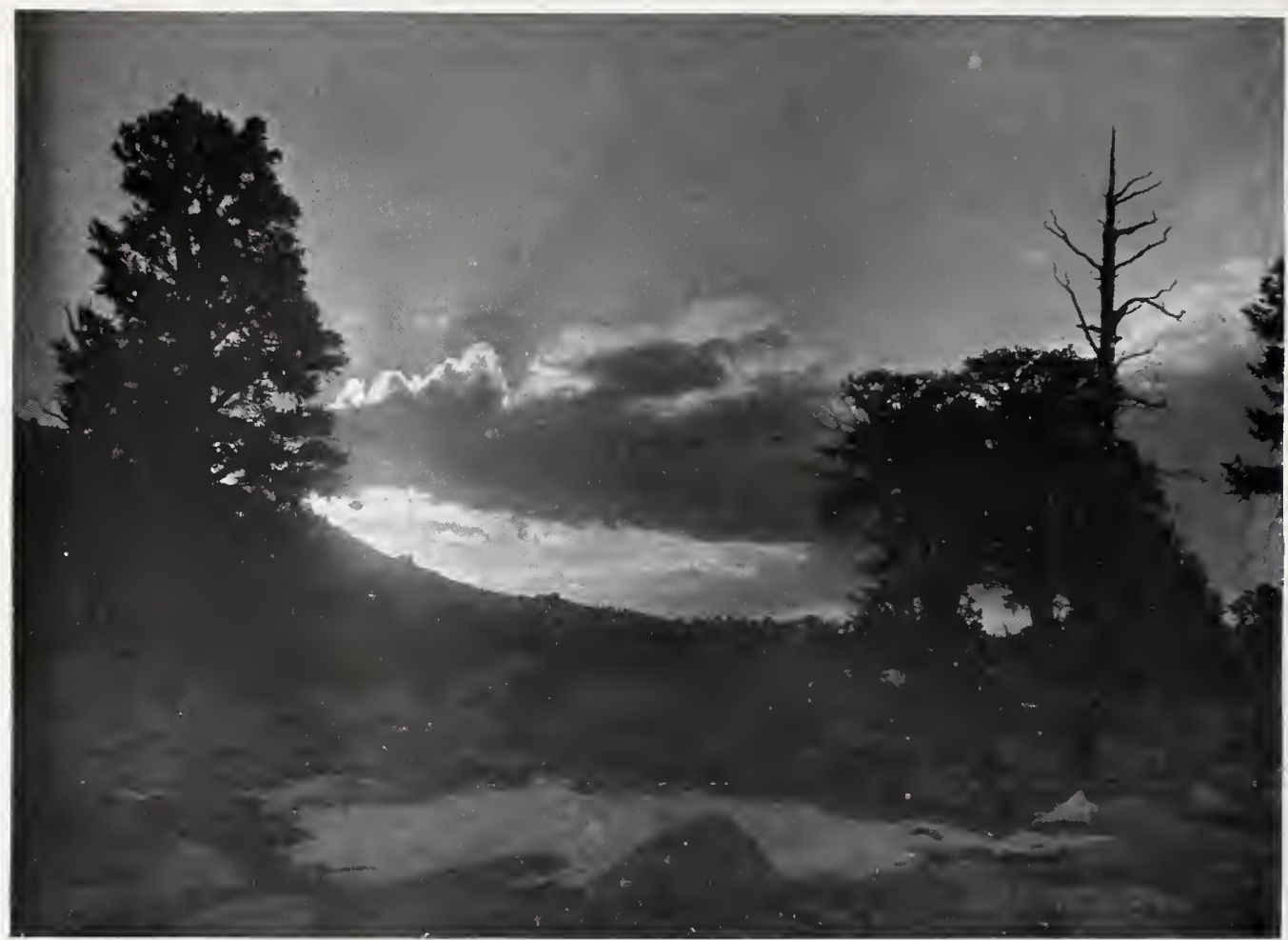

Taken at the Cottonwood Lakes, alt. II,000

Photo by the Author

SUNRISE IN THE SIERRAS

gray; lateral crown-stripes rich brown (dark mars brown or dark chestnut), the included area buffy brown; streaks of back darker; and wings with slight increase of whitish edgings. Young birds are recognizably similar to immatures, but the crownstripes are broader, grayish brown spotted with black, and the whitish underparts are sharply streaked with dusky. Length of adult male, I65-177.8 (6.50-7.00); wing 80 (3.I5); tail 75 (2.96); bill II.4 (.45); tarsus 23.4 (.92). Females average smaller.

Recognition Marks.--Sparrow size; black-and-white striping of head; white of throat not abruptly defined; lighter and grayer than Zonotrichia gambeli, but black lores absolutely distinctive.

Nesting.- Nest: A sturdy cup of grasses, weed-stems and trash, on the ground, or else a bulky mass of twigs, bark and miscellany, copiously lined with fine, dead grasses, placed at moderate heights ( $\mathrm{I}$ to 3 feet up), in bushes or thickets. Eggs: 3 to 5 ; pale bluish green (lichen green to palest niagara green), moderately or heavily sprinkled and spotted, or, rarely, mottled with brown (verona brown, or Rood's brown, or mars brown); markings show tendency to form cloud-cap or, more rarely, cumulus; ground-color sometimes practically buried under pigment. 42 Sierra-taken eggs in M. C. O. collection show limits of I 8.8-23.9 x I5.2-I 8.3 (.74-.94 by .60-.72) and average $2 \mathrm{I} .3 \times \mathrm{I} 6.5(.84 \times .65)$. Season: May 20-July 20 ; one or two broods.

General Range of the Zonotrichia leucophrys group (including Z. gambeli, now reckoned a separate species).-North America from the limit of trees south in winter to the southern border states and Mexico. Breeds in the elevated and cooler regions 


\section{The White-crowned Sparrow}

of the West from Santa Barbara County, California, north to Alaska, and in the East from Vermont to Labrador and southern Greenland.

Range of $Z$. leucophrys. - In the breeding season occupies a discontinuous range consisting of the Boreal zone in some of the highest mountains of the West, and the eastern British Provinces from the west side of Hudson Bay southeast to northern New England and northeast to Greenland; the western breeding range includes the Sierras from southern Oregon south to Tulare County, the Uintah and Wasatch ranges, the San Francisco Mountains in Arizona, and the Rocky Mountains from Wyoming south to southern New Mexico. Winters from northern Lower California, southern Kansas, and the valley of the Ohio, south to southern New Mexico.

Distribution in California.-Breeds at timberline in the Sierras from Mt. Shasta south to Surretta Meadows in Tulare County (Grinnell); also in the Warner Mountains, and irregularly at lower altitudes, e. g., valley floor of the Yosemite, alt. c. 4000 feet (June Io, I9I4), even down to Upper Sonoran zone, Paoha Island, Mono Lake (June 3, I9I9). In migrations passes chiefly west of the Sierra Nevada divide, at least north of Los Angeles County. Not found in the State in winter.

Authorities.-Newberry, Rep. Pac. R. R. Surv., vol. vi., pt. iv., I 857 , p. 87 (part); Henshaw, Rep. Orn. Wheeler Surv., I 878, p. I 85 (nesting); Belding, Occ. Papers, Calif. Acad. Sci., 2, I890, pp. I48-I49 (nesting); Condor, vol. ii., I900, p. I34 (range); Ray, Auk, vol. xx., I903, p. I88 (nest and eggs); Grinnell, Univ. Calif. Pub. Zool., I2, I9I4, pp. I67-I68; Dawson, Condor, vol. xviii., I9I6, p. 28.

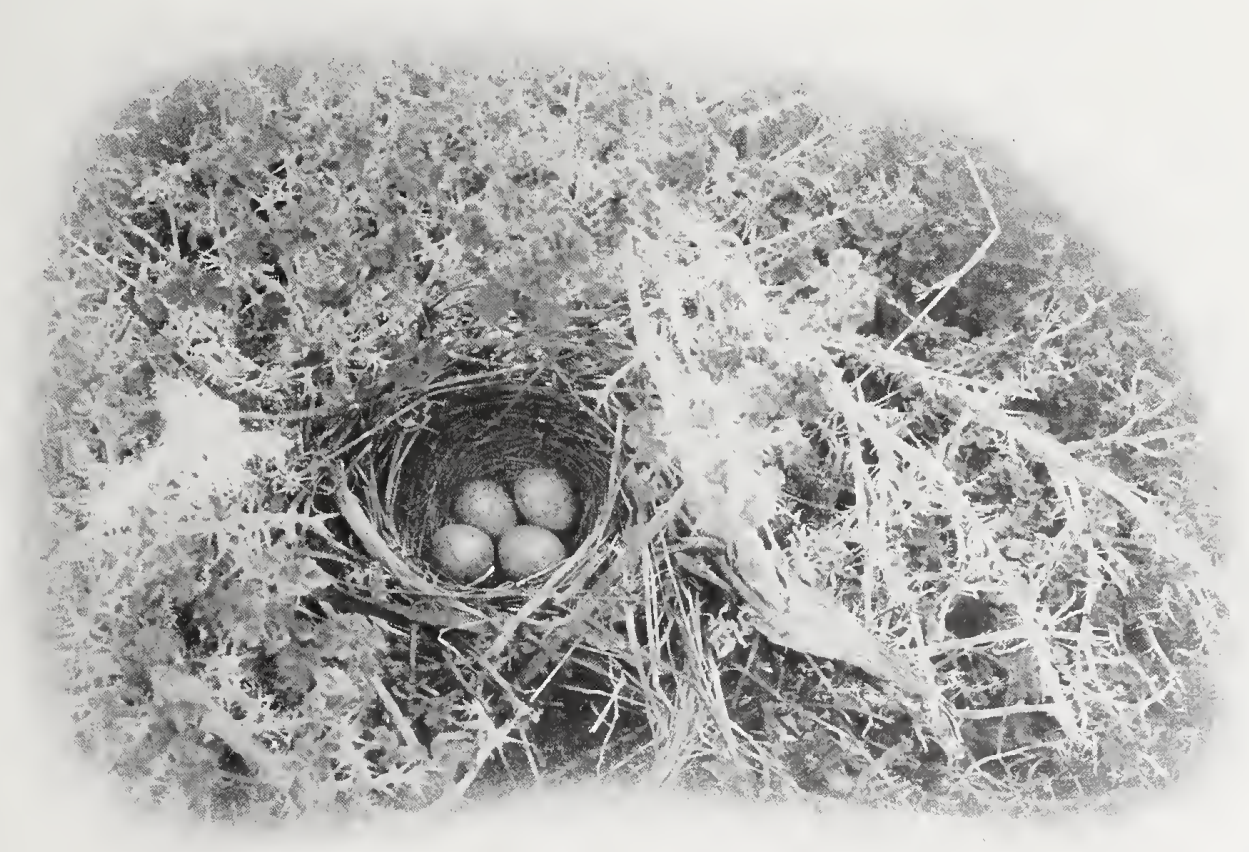

NEST AND EGGS OF WHITE-CROWNED SPARROW

A GROUND NEST AT TIMBERLINE 


\section{The White-crowned Sparrow}

PURE QUALITY pertains to the White-crowned Sparrow. He is chieftain of his gens, or clan. His central crown-stripe is purest white, and the bordering bands of black are, if possible; a little blacker, certainly a little silkier, than those which adorn the lesser members of his race. Moreover, the black invades the lores, and this mark is accepted, in this instance at least, as conclusive evidence of superiority.

Two special circumstances conspire to raise leucophrys to preëmi-

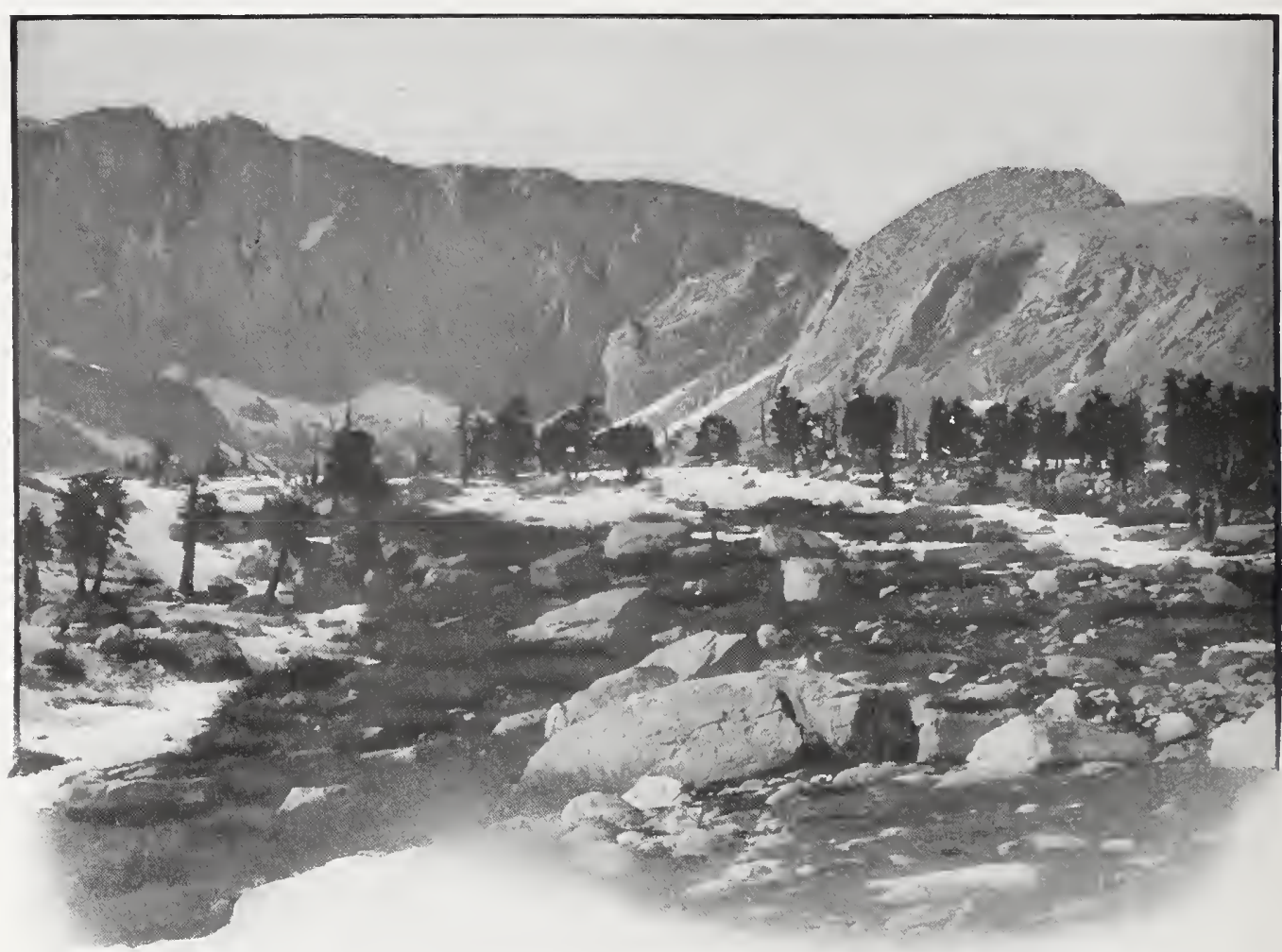

nence in our regard. In the first place, we do not see him in winter. Winter is at best a time of let-down, a time of vulgar flocking, a time of sordid scrambling for food. It is, therefore, a time of disillusionment for bird-lovers. Picture a company of our favorite film stars crowded together in a restaurant, a cafeteria perhaps, with only ten minutes in which to bolt a cup of coffee, sandwich, and a piece of pie, before the stage starts for Caesar's Camp in Francisquita Canyon, L. A.! Ah, well 


\section{The White-crowned Sparrow}

for us, no doubt, that the White-crowned Sparrow conducts his winter business in Chihuahua, beyond our troubled ken.

But the thing which endears the chieftain to us most is his choice of the high Sierras for a summer home. Here is an expression of taste which meets our unqualified approval. The birds gather dignity from the mountains, and they grace in turn the wildest fastnesses, the snow-bound meadows, and the crystal brooks of "timberline." When a bird really prefers to wrest a living from reluctant snow-drifts, to pay court to ladies beside roaring cataracts, or to sing lullabies from the vantage of stormtwisted pines, it is a sign that his heart is in the right place, and that all his actions must be $\mathrm{v}$ i e w e d indulgently. Only the Rosy Finch deserves a higher place in our regard, and he, alas! does not sing.

No matter if you have heard the ditties of gam-

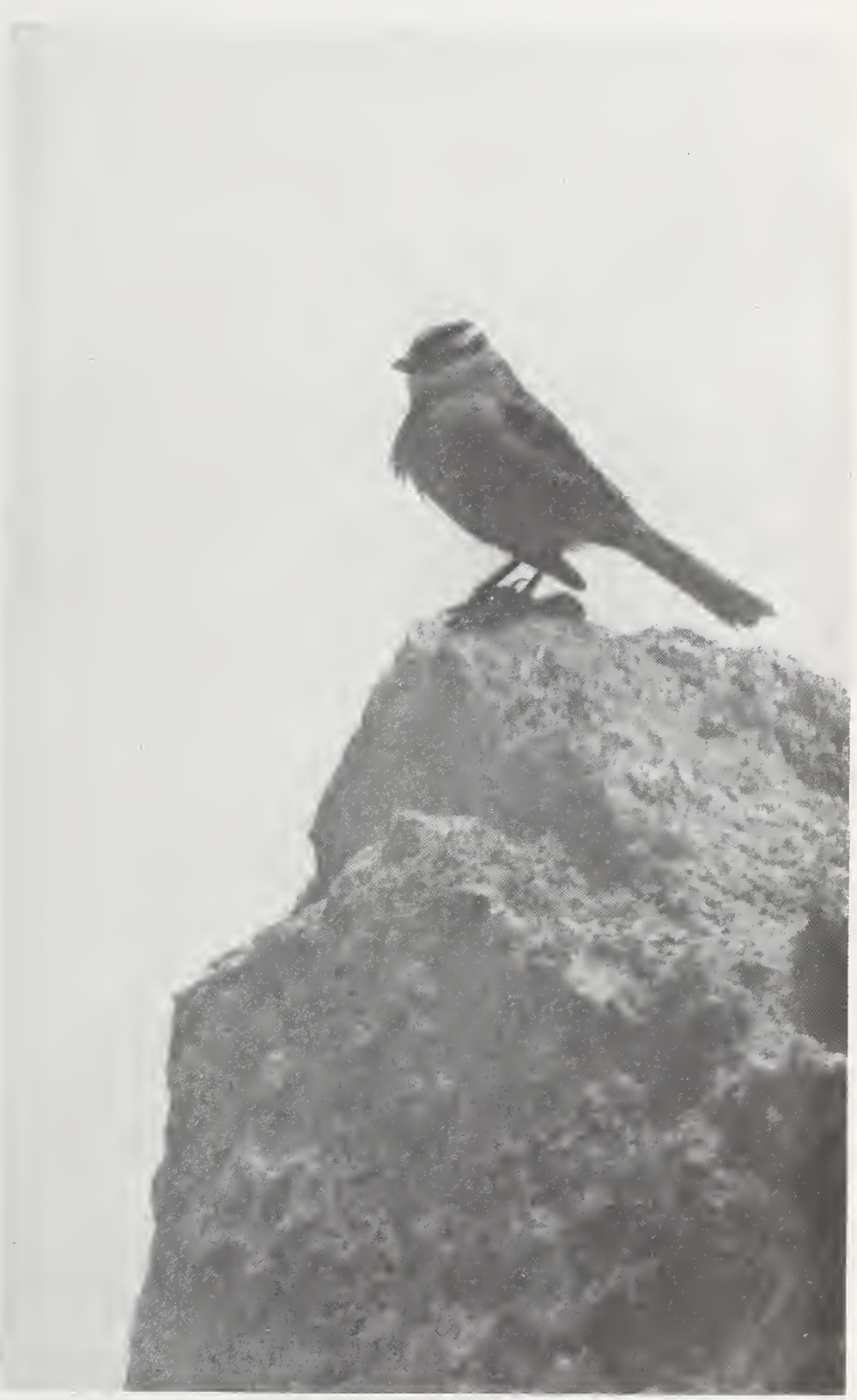

Taken in Inyo"County

Photo by the A uthor

THE CHIEFTAIN beli or nuttalli at the lower levels a thousand times, or a million times, I commend to you the sweet, courageous lay of leucophrys, sung at the I I,ooo foot level. It has in it the sprightliness of springing heather, 


\section{The White-crowned Sparrow}

the bright, compelling cheer of sunshine battling with glaciers for imprisoned waters, and a little of the wistfulness, withal, of whispering pines. The song is none so varied, and its cadences might seem prosy in the realm of Philomel. I do not know. But if I were a Lady Leucophrys, and dwelt beside a frozen mere, I should ask my lord to sing in just such satisfying tones.

An examination of the song of $Z$. leucophrys raises the question whether the characteristics of bird notes are purely hereditary; or, as

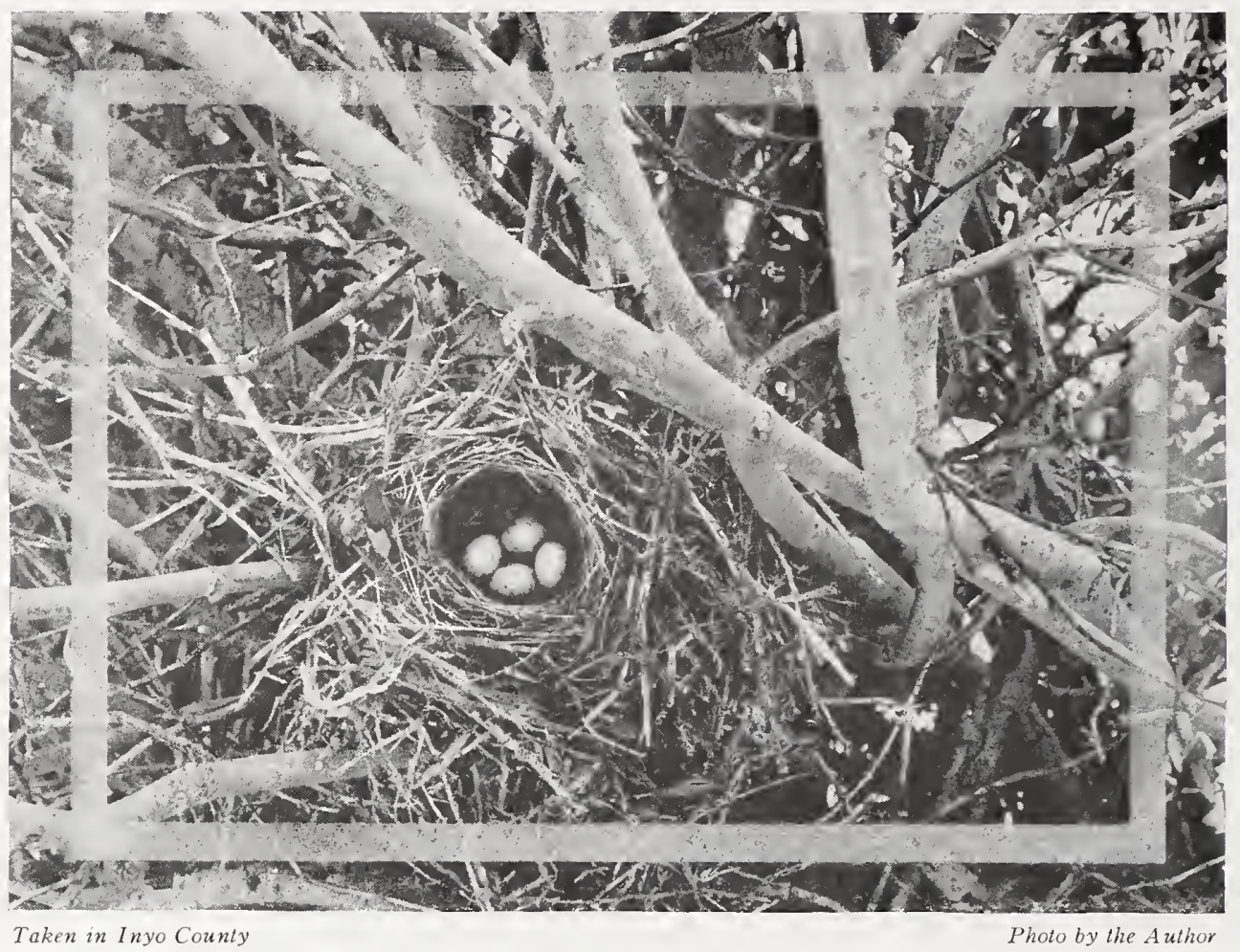

"A VERY STURDY NEST IN THE LEAFLESS BRANCHES OF THE WILLOWS"

in the case of human speech, partly cultural, that is, derived from association with others not of one's own gens. At any rate, the resemblance - I will not say dependence- of the song of leucophrys to that of the Passerella iliaca group is very suggestive. The resemblance is not slavish, but whether in phrasing or in tonal quality, there is much to hint at a blood relationship. Now and then it takes a nice discrimination to separate the two songs: Oh hee sween'tie chup ichin' from a Whitecrown's throat is like enough to the O ree rick'it loop iteer' of the Slatecolored Sparrow. 


\section{The White-crowned Starrow}

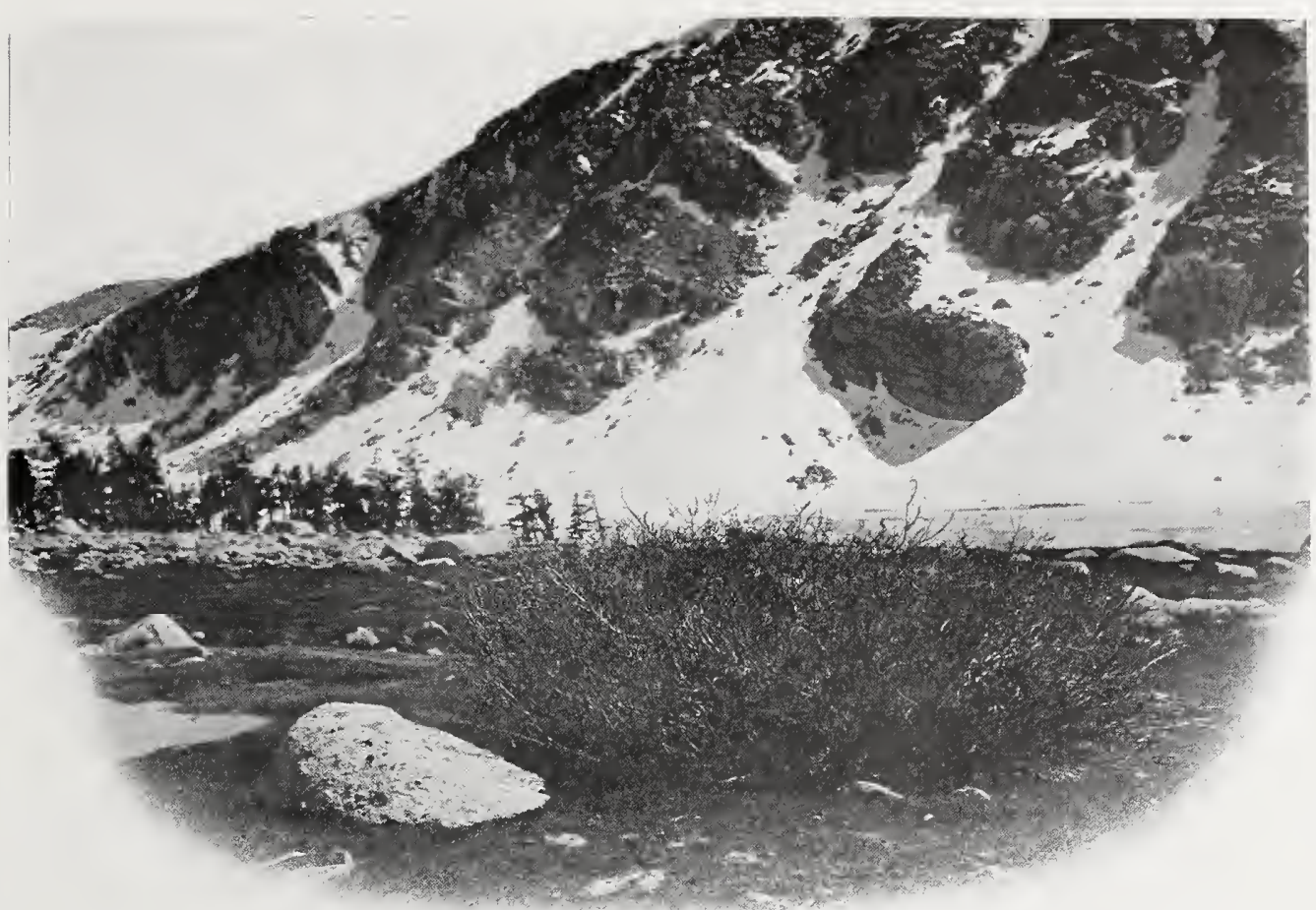

Taken in Inyu Ccunty

Photo by the Author

A DWARF WILLOW NEST1NG SITE

Or, perhaps, and I propose this with the greatest diffidence, there is a tendency toward homoplasy in song. A uniform environment reacting upon diverse organisms tends to produce like results. Compare the plumage and general appearance of the Pacific Fulmar and, say, the California Gull. They look alike, but they hail from evolutionary branches of early and vast divergence. Again, the climate of the Pacific humid coastal region, as we know, makes for general suppression of song, and especially of tonal quality. Per contra, the invigorating air of the high Sierras may exert a uniformly stimulating influence upon two sparrows so different as Zonotrichia and Passerella. Be that as it may, these two are the authoritative interpreters of the Sierran wilderness.

In nesting the White-crowned Sparrows usually crowd the season at the upper levels. There is good need for this too, for occasionally the season is so delayed by heavy snows that the osier patches are only being released in July. At such a time the birds will erect a very sturdy nest in the leafless branches of the willows, trusting to the belated bushes to provide a leafy screen before the young have hatched. So rank is this mountain growth, however, that if the season be a little more for- 


\section{The Gambel Sparrow}

ward, the birds will build openly on the tops of descending branches, in order, apparently, to escape the smother of foliage. Again, nests will be placed upon the ground in the general protection of the dwarf sage, whose density the casual footstep oftenest avoids.

A nest of these birds at timberline is worth examination, for it is a doughty castle, and a mighty resister of cold. Composed externally of stout willow twigs, bark, and grasses, the interior is lined with finest grasses, and a bit of hair, if possible. In one example before me, one taken at the Upper Cottonwood Lakes, July 3rd, I9I I, the nesting hollow, which is three inches across by two inches deep, occupies only about onetwentieth of the total bulk of the structure. The eggs are intended to be frost-proof, and are, no doubt, after incubation has begun; but I have seen nests deserted because the first-laid eggs were frozen.

The most anomalous set of our experience was taken on the floor of the Yosemite Valley, some four thousand feet below the ordinary breeding level frequented by these birds. It was as though the floor of the valley had subsided, and the birds, loth to forsake their ancestral home, had gone down with it to this unconscionable depth. But the Yosemite floor is anomalous anyway, and the White-crowns had for company other cheerful exiles, such as Hermit Thrush, Hermit Warbler, and Lincoln Sparrow.

No. 60

\section{Gambel's Sparrow}

A. O. U. No. 554a. Zonotıichia gambeli gambeli (Nuttall).

Synonyms.-Intermediate-crowned Sparrow. Intermediate Sparrow.

Description.-Similar to Z. leucophrys, but general tone of coloration darker throughout,- the posterior underparts, especially, much deeper brown; the flanks Saccardo's umber instead of wood-brown; axillars and bend of wing pale yellow; lores, broadly continuous with superciliary stripe, white. Measurements averaging a little less: Males: wing 79 (3.12); tail 7 I (2.80); bill Io.7 (.42); tarsus 22.9 (.90).

Recognition Marks.- Sparrow size; lores not black; slightly larger and general coloration lighter than in $Z$. g. nuttalli; white crown-stripe brighter. The commonest winter bird in southern and interior California.

Nesting.-Does not breed in California. Nest and eggs much as in typical form.

General Range of $Z$. g. gambeli--Breeds from mountains of northern Montana north between the codst mountains of British Columbia and Alaska and the 
interior plains to northern Mackenzie, and west to limit of trees in northwestern Alaska; winters from northern California and Utah south to Lower California and Mazatlan, Mexico; casually east during migrations to the Great Plains in Iowa, Kansas. etc.

Distribution in California.-Abundant in winter in the valleys and deserts of southern California; in lesser numbers northward to San Francisco Bay and throughout the great interior valley. Excessively common, especially east of the Sierras, during migrations. Apparently does not occur in the humid coastal region north of San Francisco Bay.

Authorities.-Gambel, Jour. Acad. Nat. Sci. Phila., ser. 2, i., I 847 , pp. 50-5I (part); Henshaw, Rep. Orn. Wheeler Surv., I 876, p. 24I ; Ridgway, Auk, vol. vii., I890, p. 96 (crit.); Beal, Biol. Surv. Bull., no. 34, I9I0, pp. 75-77 (part) (food); Tyler, Pac. Coast Avifauna, no. 9, I9I3, pp. 8I-82 (habits); Grinnell, Univ. Calif. Pub. Zool., no. I2, I9I4, pp. I68-170 (spring molt); Howell, Pac. Coast Avifauna, no. I2, I917, p. 77 (on coastal islands).

EVEN as I sharpen my pencils prepared to "do" the Crown Sparrows this crispish, bright October morning, the saucy rascals themselves are besieging my studio with song. Their tuneful cohorts occupy every point of vantage, the fence palings, the sage clumps, the lower branches of the pepper tree. I am quite beset. And how shall a bird-man write soberly of breeding ranges or interscapular areas (very necessary to an understanding of leucophrys) amidst such a clatter of whistled hee hoos and drawling recitative! I believe they are only half in earnest, the courageous pretenders! A door flung open would send them madly scurrying for cover, I warrant. A hush, a burst of wings, and thenceforth

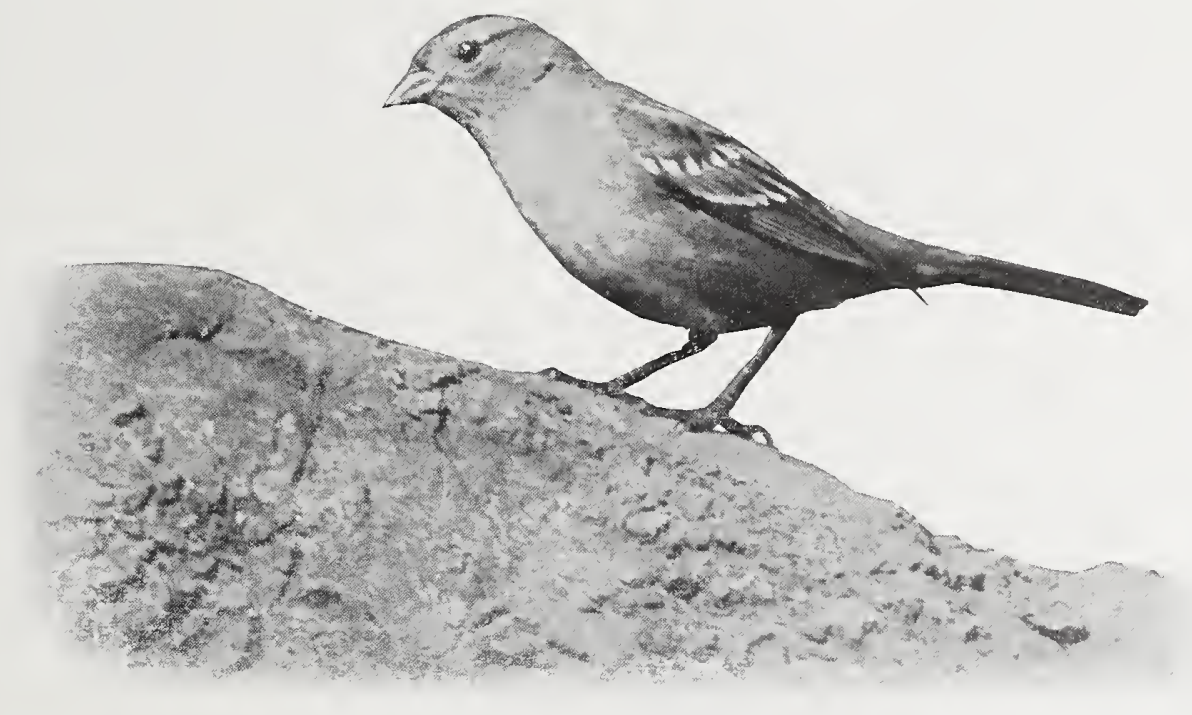




\section{The Gambel Sparrow}

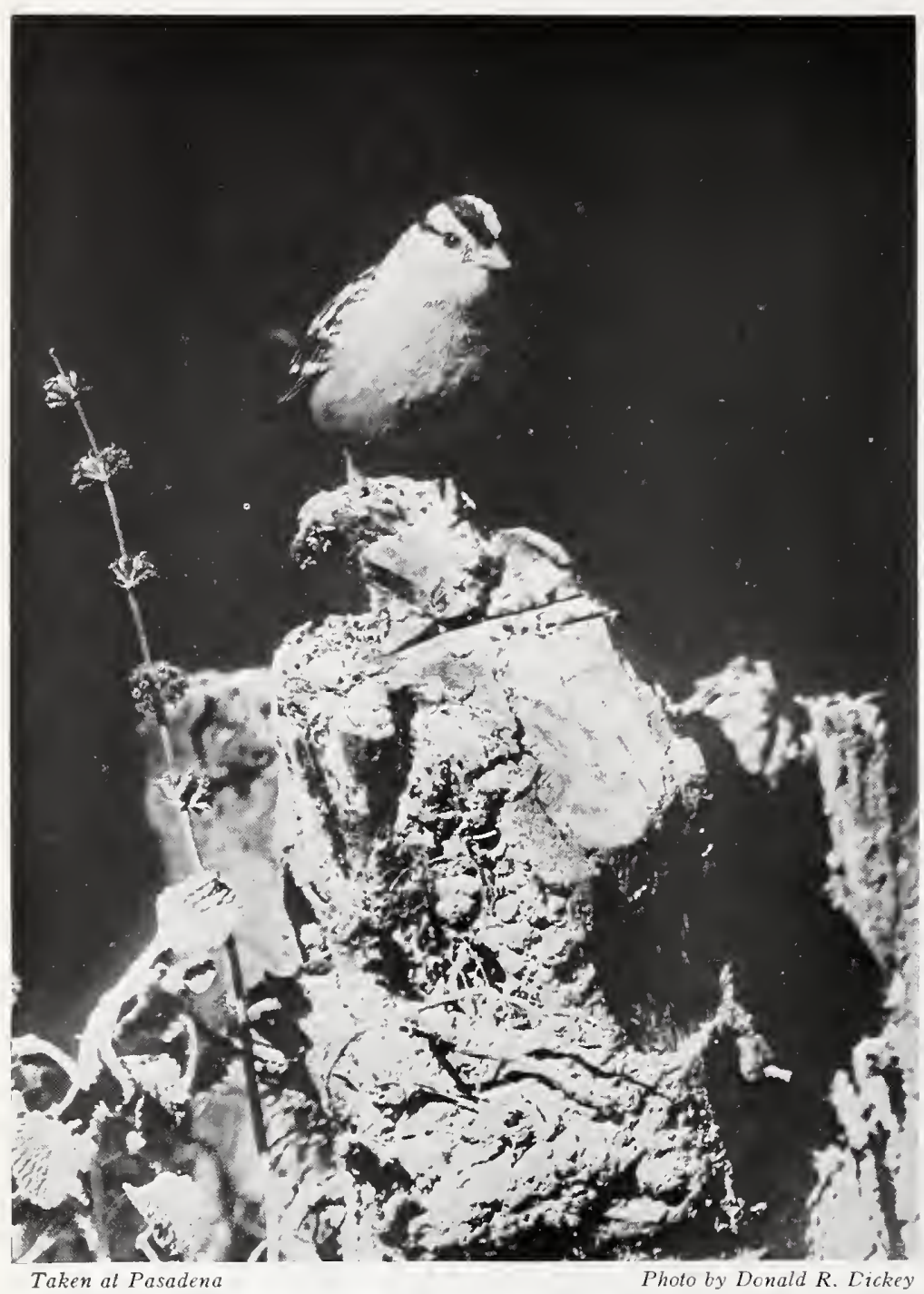

THE VANGUARD OF THE FRIENDLY HOST nothing but dzinks and titters from the skulking host. That would never do. I will surrender at discretion instead - surrender and play the part of Burns' chiel.1

Whee hee hee hee wheooo hee; wheeoo hesuddenly broken off ; IIoo hooee; wheeoo hoo che wee che wee hee; chee oo chee chee wee chee. These imitations are very stupid, of courseabout as expressive of Zonotrichian melody as a naked wire dummy is of a man. The joy of life, the tuneful modulations, the vocal slide, the clear fluting, and the languorous content, all are gone out of them. Suffice to say that the Gambel Sparrow has manifest advantage in song over his prosaic cousin nuttalli, while he fails to measure quite up to the clear resonances of leucophrys.

It is as flocking birds that we know these ubiquitous Crowners best. They feed beside the road or in the edges of fields, stealing out from cover one by one, not without misgiving dzinks, until the ground is covered with them. At a sound, at a suspicion even, the flock rises noisily and bolts for shelter. Secure in the depths of weed or bush, they wait silently until danger is past, or if it does not pass, they begin to edge away or depart by ones or twos or dozens for more distant fields. It is always provoking to the bird-student, consciously guiltless of intent to harm, to have these prosy

"The chiel's amang them takin' notes."

328 


\section{The Gambel Sparrow}

creatures, drabs now, treat him as though he were a hawk or the bearer of a blunderbuss. There are a hundred birds lurking in this copse, but as soon as one of them knows himself discovered, he dashes off like mad, or as though there were a price upon his head.

Yet these same wild savages will respond to cultivation, after a fashion. To secure the flock pictures shown herewith, we first built a shallow bathing pool of cement sunk flush with the ground, then threw out crumbs for bait. But Mrs. D. soon discovered their fondness for corn meal, and thenceforth the Crown Sparrows became regular pensioners at our door. The average daily attendance of these birds was in the thirties, but I have counted as high as 47 feeding at one time within ten feet of the kitchen door. A rank bush of achania, which at first afforded the birds dense cover, and to which they retreated under frequent alarm, soon showed such bad effects from the constant attrition of their tiny feet, that we were obliged to cut it back severely, and so destroy its immediate value as a covert. As it was, the bush was nearly

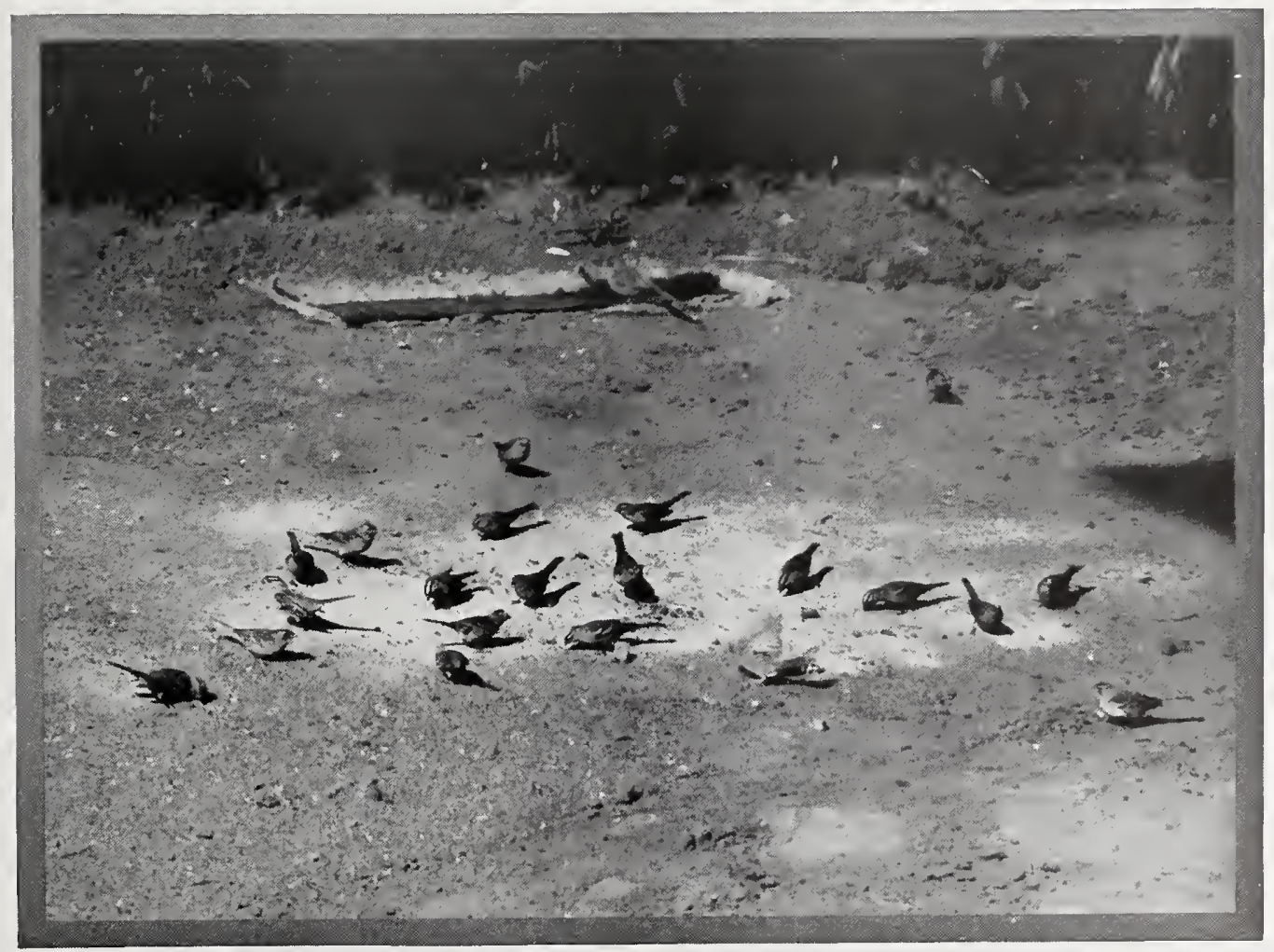

Taken at Los Colibris

Photo by the Author

FEASTING ON CORN MEAL 


\section{The Gambel Sparrow}

ruined, but the sport we had watching the antics of the sparrows amply repaid any such loss.

The first to approach the feast were the young chaps, reckless fellows, whose loss, apparently, didn't matter so much to the community. Then modest mothers ventured out, believing themselves safe where their sons could go. Finally, when security was an established fact, an old male, some chieftain, brilliant in alternating plumes of black and

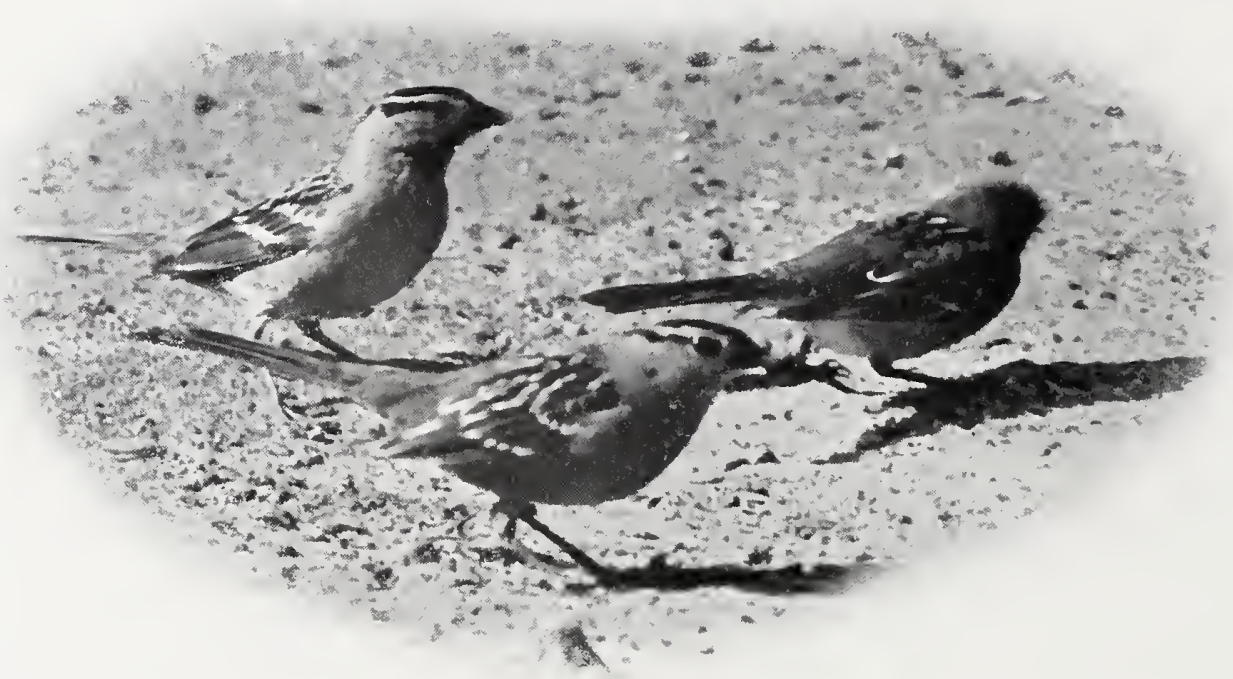

Taken at Los Colibris

STILL SUSPICIOUS

Photo by the Author

white, strutted out. Before him the sedulous gleaners gave way, or if they did not move fast enough to suit his lordship, he charged viciously at the crowd and saw it flee in dismay. Gallantry, apparently, is a thing reserved for springtime.

It would be difficult to exaggerate the abundance of Intermediate Crown Sparrows, at least in southern California. In most sections they are more abundant in winter than any other bird, and in some localities I am persuaded that they outnumber, excluding the House Finch, all other species combined. In migrations, too, they are excessively common; and although, like the White-crowned Sparrows, they are destined for a romantic setting in the breeding season, an ice-bound park in the Selkirks, or a pine-clad lake in the Yukon, they content themselves with very humble surroundings en route. At the height 
of the migrations the dullest stretch of sage-brush swarms with Crown Sparrows; and the local population of Brewer Sparrows, Desert Sparrows, and the like, must dread this annual inundation of hungry pilgrims.

\section{No. 60a Nuttall's Sparrow}

\section{A. O. U. No. 554 b. Zonotrichia gambeli nuttalli Ridgway.}

Synonyms.-Formerly called Gambel's Sparrow. White-crowned Sparrow (name properly confined to $Z$. leucophrys). Crown Sparrow.

Description.-Adults: Like preceding, but general tone of coloration somewhat darker; streaks of back and scapulars deepest brown or blackish; general groundcolor of upperparts light olive-gray; median crown-stripe narrower; white of central underparts less pure; axillars and bend of wing more strongly yellow. Bill yellowish with dark tip. Immatures: Correspondingly darker than those of Z. leucophrys; the upperparts toned with light olive-buff; the underparts somewhat tinged with yellowish. Young birds: Similar to those of $Z$. leucophrys, but much darker,- - brownish above, buffy below. Length of adult males, I $50-170$ (5.90-6.70); wing 75 (2.95); tail 72 (2.83); bill I I (.43); tarsus 23.5 (.93). Females smaller.

Recognition Marks.-Sparrow size; black-and-white striping of crown distinctive in range; darker than preceding; lores not black.

Nesting.-Nest: A well wrought, deeply-cupped mass of weed-stems, grasses, dead ferns, moss, or any vegetable waste, carefully lined with fine grasses or horsehair; placed on ground well concealed, or low in bushes. Measures outside 5-7 inches (mm I 27-178) over all, by $3 \frac{1}{2}$ or 4 (mm 88.9 or Ior.6) in depth; inside $21 / 4$ to 3 inches ( $\mathrm{mm} 57.2$ to 76 ) across, by I $1 / 2$ to 2 ( $\mathrm{mm} 38$ to 50.8 ) in depth. Eggs: 3 or 4 ; much as in Z. leucophrys, but ground-color brighter, and markings both ruddier (cameobrown to chocolate) and heavier, with more frequent appearance of mottling. Av. of 70 specimens from Humboldt County (M. C. O. Coll.) 20.7 x I6 (.8I5 x .62); extreme 18.5-22.4 by I4.7-16.5 (.73-.88 by .58-.65). Season: April-July; one or two broods.

Range of $Z$.g. nuttalli.-Breeds in the Pacific Coast district from Port Simpson, British Columbia, to Santa Barbara, California; winters occasionally on Puget Sound, but chiefly from central Oregon south to Santa Margarita Island, Lower California.

Distribution in California.-Chiefly resident along the Pacific Coast, narrowly but regularly south of the Golden Gate, presumably to Point Conception, with an isolated station at Santa Barbara (Bowles), more broadly throughout the humid Transition area north of San Francisco Bay. The western portion of the State is inundated by winter visitors, but these are either confounded with local birds or lost to notice (in the interior and the San Diegan district) in the crowd of Gambel Sparrows $(Z$.g. gambeli)-proportions in winter as compared with Gambel's quite variable.

Authorities.-Nuttall (Fringilla leucophrys), Manual Orn., ed. 2, vol. i., I840, p. 553 (part); Palmer, T.S., Auk, vol. ix., I892, p. 3 Io (range); Ridgway, Auk, vol. xvi., I 899, pp. 36-37 (renaming of nuttalli); Judd, Biol. Surv. Bull., no. I 5, I901, pp. 70-72 (food); Bolander, Condor, vol. viii., I906, pp. 73-74; Beal, Biol. Surv. Bull., no. 34, I910, pp. 75-77 (part) (food); Hubbs, Auk, vol. xxxv., I9I8, pp. 32 I-326 (range in Calif.). 


\section{The Nuttall Sparrow}

WHHEN you enter a bit of shrubbery at the edge of town in April or May, your intrusion is almost sure to be questioned by a military gentleman in a gray cloak with blackand-white trimmings. Your business may be personal, not public, but somehow you feel as if the authority of the law had been invoked, and that you would better be careful how you conduct yourself in the presence of this military person. Usually retiring, the Nuttall Sparrow courts exposure where the welfare of his family is in question, and a metallic scolding note, zink, or $d z i n k$, is made to do incessant service on such occasions. A thoroughly aroused pair, worms in beak, and crests uplifted, may voice their suspicions for half an hour from fir-tip and brush-pile, without once disclosing the whereabouts of their young.

Nuttall's Sparrow is the familiar spirit of brush-lots, fence tangles, berry patches, and half-open situations in general. He is among the

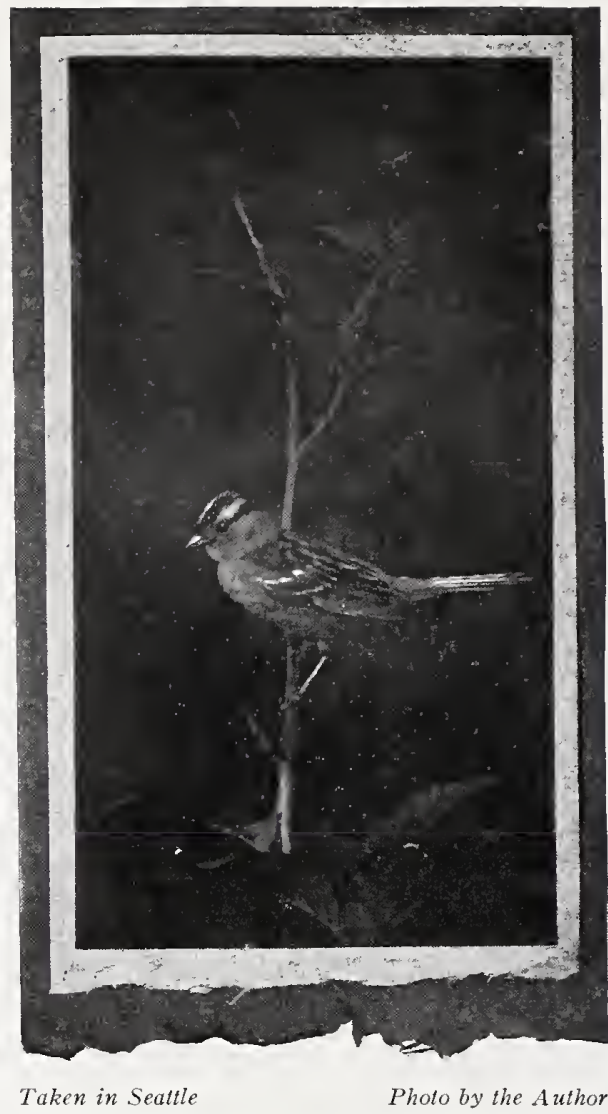

NUTTALL SPARROW, FEMALE last to quit the confines of the city before the advancing ranks of apartment houses and sky-scrapers, and he maintains stoutly any vantage ground of vacant lot, disordered hedgerow, or neglected swamplet left to him. Even Golden Gate Park boasts its breeding population of Nuttall Sparrows; and I have known them to invade Union Square in the heyday of the spring migration. With the local Song Sparrow he shares the honor of being the commonest sparrow in the northwestern coastal strip of California; and in some places, no doubt because of his less slavish attachment to water, nuttalli is more abundant than Melospiza.

As a songster this sparrow is not a conspicuous success, although he works at his trade with commendable diligence. He chooses a prominent station, such as the topmost sprig of a redwood sapling, and holds forth at regular intervals in a prosy, iterative ditty, from which the slight musical quality vanishes with distance. Hee ho, chee weé, chee weé chee weéé and 


\section{The Nuttall Sparrow}

Hee, wudge, $i$-wudge $i$-wudge $i$-weééé are vocalized examples. The preliminary hee ho is sometimes clear and sweet enough to prepare one's ear for the Vesper Sparrow's strain, but the succeeding syllables are tasteless, and the trill with which the effort concludes has a wooden quality which we may overlook in a friend, but should certainly ridicule in a stranger. No doubt the fogs and bracing breezes which characterize our western coasts

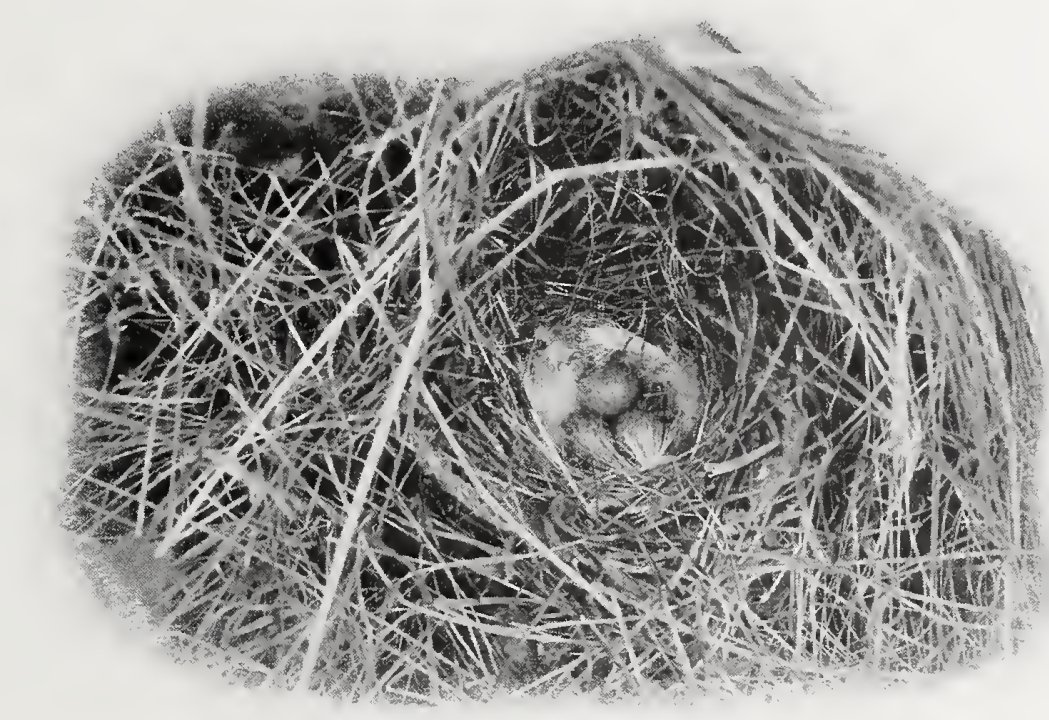

Taken in Washington

Photo by the Author

NEST AND EGGS OF NUTTALL SPARROW ON GROUND

are alike discouraging to vocal effort. At that, however, there is a noticeable improvement in quality from north to south; and I am sure that the birds of San Francisco Bay sing more sweetly than do those of Puget Sound. I hazard it as a sober guess that if our ears were infallible, we could tell within a few miles the locality from which our wintering birds hail.

Gambel and Nuttall Sparrows mingle more or less in winter, at least from San Francisco southward; and it is idle to try to separate them. They are jolly fellows in a crowd; and if to the general excitement of early springtime is added the special interest of bedtime, the noise these rascals can make is fairly deafening. There is always hilarious discussion of the merits of upper and lower berths; and when to their jostling noteswoods woods a woods - are added sharp dzinks from the grouches, the resulting babel compares favorably with Passer domesticus in Bedlam.

The local Nuttalls are nesting in late March or early April, before 


\section{The Nuttall Sparrow}

the northbound migrants have extricated themselves, or passed over their heads. First nests are likely to be placed upon or near the ground, but as the season advances the birds prefer the depths of low thickets, or saplings, or even ferns. In the southern part of the range cypress trees are effected, and one observer ${ }^{1}$ records a nest thirty-five feet up in a cypress. Of course two or three broods are raised in a season. The M. C. O. has a set of three eggs taken on the 3Ist of October (I90I) by C. I. Clay on Humboldt Bay.

The nests themselves are usually substantial and often beautiful affairs. The birds use almost any sort of material that comes to hand,bark-strips, twigs, grasses, bits of paper, rags, horsehair, and rootlets; but good taste is almost invariably exercised. A nest before me is decorated profusely with nodding grass-stems in flower, and the effect is as dainty as that of a Parisian bonnet. The eggs, three or four, rarely five in number, are of a handsome light green or bluish green shade, and are heavily dotted, spotted, blotched or clouded with reddish brown.

Young birds lack the parti-colored head-stripes of the adult, although the pattern is sketched in browns; and they are best identified by the unfailing solicitude of the parents, which attends their every movement. They are rather bumptious little creatures for all; a company of them romping about a pasture fence brings a wholesome recollection of schoolboy days, and there are girls among them, too, for my! how they giggle!

${ }^{1}$ Louis Bolander, "The Condor," Vol. VIII., May, 1906, p. 74. 
No. 61

\title{
White-throated Sparrow
}

\section{A. O. U. No. 558. Zonotrichia albicollis (Gmelin).}

\author{
Synonym.--PEABOdY BIRD.
}

Description.-Adult male: Pileum black, parted by a median stripe which is white, or with some admixture of brownish posteriorly; a broad superciliary, yellow anteriorly and white posteriorly; a post-ocular streak of black; throat white, abruptly cut off below and bounded on sides (or not) by blackish rictal streak; malar region, sides of neck, chest, and sides of breast neutral gray, darkest on sides of neck, shading posteriorly into dull brownish buffy of sides and flanks, and whitish of central underparts; remaining upperparts dull brownish gray or drab, purest on rump and upper tail-coverts; on the back highly varied by central black streaks and marginings of brownish red (snuff-brown to Prout's brown); the edge of wing yellow; the axillars white, tinged with yellow; the middle and greater coverts tipped with white, forming bars. Bill dusky above, paler below; irides brown; tarsi pale brown, feet a little darker. Adult female: Like male and not always distinguishable, but usually somewhat duller; the black of head admixed with brownish; the whites tinged with buffy; the yellow over lores paler; the cheeks darker, more brownish. Immature birds: Like dullest adult females, but still duller; the lateral crown-stripes more brown than black; the whites more deeply tinged with buffy; the supraloral yellow duller; the white of throat less pure and not sharply defined; the chest obscurely fine-barred with dusky. Length of adult male about I7I.5 (6.75); wing 75 (2.95); tail 73 (2.87); bill I I.4 (.45); tarsus $23.5(.93)$. Female a little smaller.

Recognition Marks.-Sparrow size. Yellow spot over and in front of eye; white throat sharply outlined against gray or blackish, distinctive.

Nesting.- Nest: Does not breed in California. Nest and eggs much as in Z. leucophrys; but ground-color of eggs whitish or grayish white or dull bluish white, instead of pale bluish green.

General Range.-Eastern North America, breeding from Massachusetts, the mountains of Pennsylvania, central Wisconsin and northeastern Wyoming, north to Great Bear Lake, Labrador, etc.; south in winter to Florida and northeastern Mexico. Counted a straggler in Oregon, Utah, and Colorado, but may be of regular occurrence in southern California.

Occurrence in California.-A rare but probably a regular winter visitor. Records from fourteen localities, all of them west of the Sierran divide, have been assembled by Grinnell. During the author's residence in Santa Barbara, they have been recorded three different seasons, viz.: I9I5 (in numbers), I9I8-19, and I919-20.

Authorities.-Emerson, Zoe, vol. i., I 890, p. 45 (Hayward); Bryant, W. E., ibid., p. 46 (San Francisco); McGregor, Bull. Cooper Orn. Club, vol. i., I899, p. 52 (Santa Rosa); Grinnell, Pasadena Acad. Sci. Pub., vol. ii., I 898, p. 37 (Los Angeles); Wythe, Condor, vol. xvii., I9I5, p. IOI, vol. xxiii., I92 I, p. 68 (Berkeley);Grinnell, Pac. Coast Avifauna, no. II, I9I5, pp. II7-I I8 (summary of records to I9I5). 


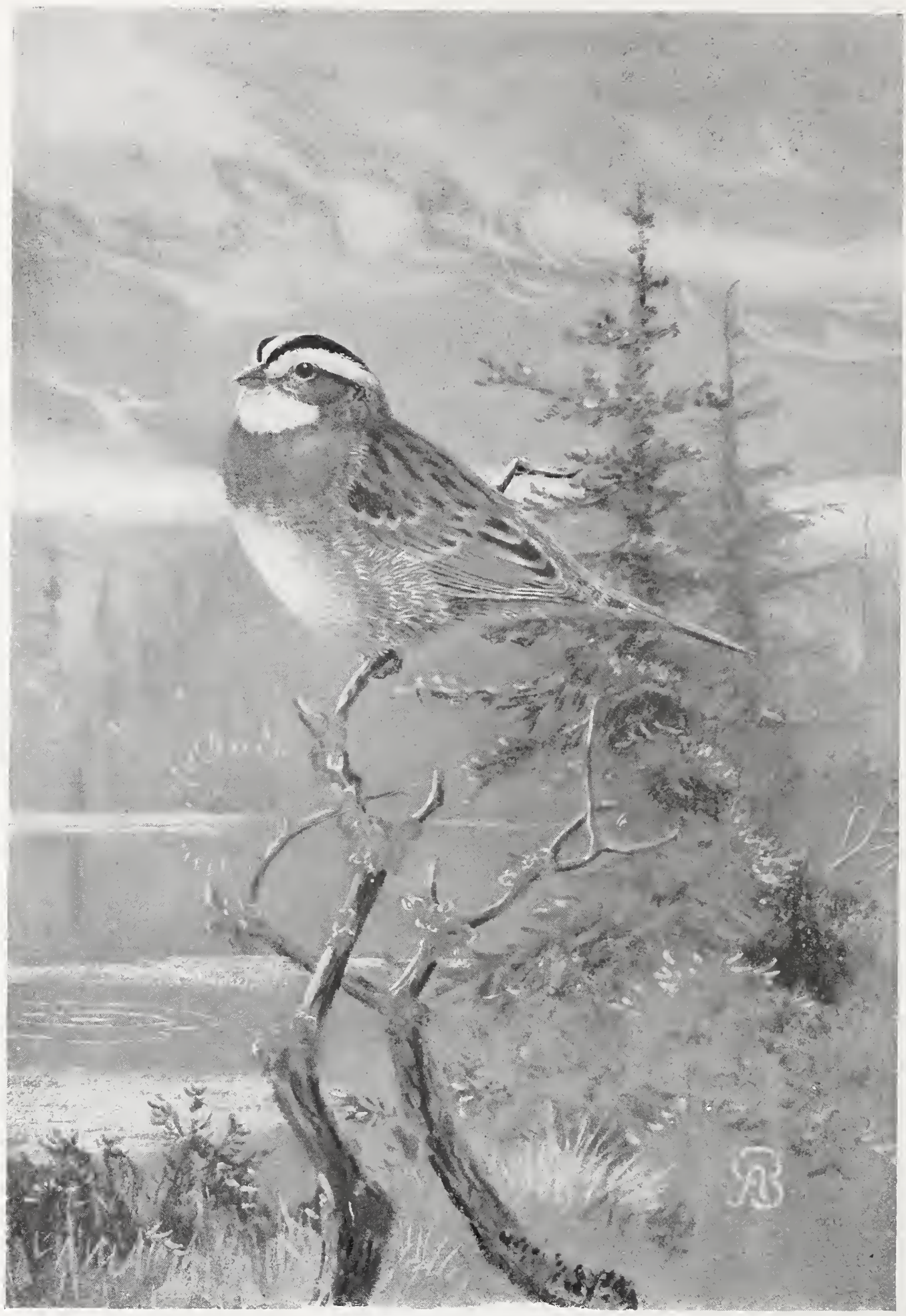


DR. GRINNELL started out to keep a record of the California occurrences of the White-throated Sparrow, but the effort has become embarrassed with success; and we no longer know whether this year's first appearance will be the steenty-steenth or the umpty-umpth. It may be a ruddier back or a flash of yellow on the lores, or the white throat itself, clearly outlined against the surrounding dingy gray, which will first attract your notice. But sometimes, if you will search diligently enough among the assembled millions of the winter Zonotrichias, you will see a White-throat. Do not be too easily satisfied about that white throat either. Remember that the white must be sharply defined, not shading off imperceptibly, as in adult leucophrys or coronata.

My own luck came so easily that I blush to record it, an adult bird feeding, on the 8th of December, I9I 5, just outside my north study window, at a distance of eight feet. They were rather common at Santa Barbara that winter, but try as I might, I could not pull off a singing match between albicollis and coronata; and I do not know to this day which of them shrills with most haunting sweetness.

In the East, where White-throat lets himself out, he is quite a famous singer. "In springtime the song proper is perfected, as we suppose, before the birds leave for the higher latitudes. It consists normally of six drawling, mournful, whistled notes, of which the last three or four have a slightly tremulous quality. The initiatory note is either much lower or a little higher than the others, which are given on one key or else descend by fractional tones. The whole may be represented as, Oh dear, dear, de-e-ear, de-e-ear, de-ear, or Hoo, he-ew, he-ew, he-e-e-ew, he-e-ew, he-e-ew. Most western writers, when consulted upon this point, dutifully repeat the tradition, said to have originated in New England, that the bird says 'Peabody, peabody, peabody,' and hence is properly called the Peabody Bird. One cannot predict what may happen further north or east, but I lift the voice of one crying in the wilderness that the bird does not utter anything remotely resembling the word Peabody while in Ohio." (Birds of Ohio.)

No. 62

\section{Song Sparrow}

EUPHONIAS and Pyrrhuloxias and Volatinias are very beautiful, no doubt, but there is a little brown-streaked bird of modest mien whose image is conjured up by the word "home," and whose homely, honest song 


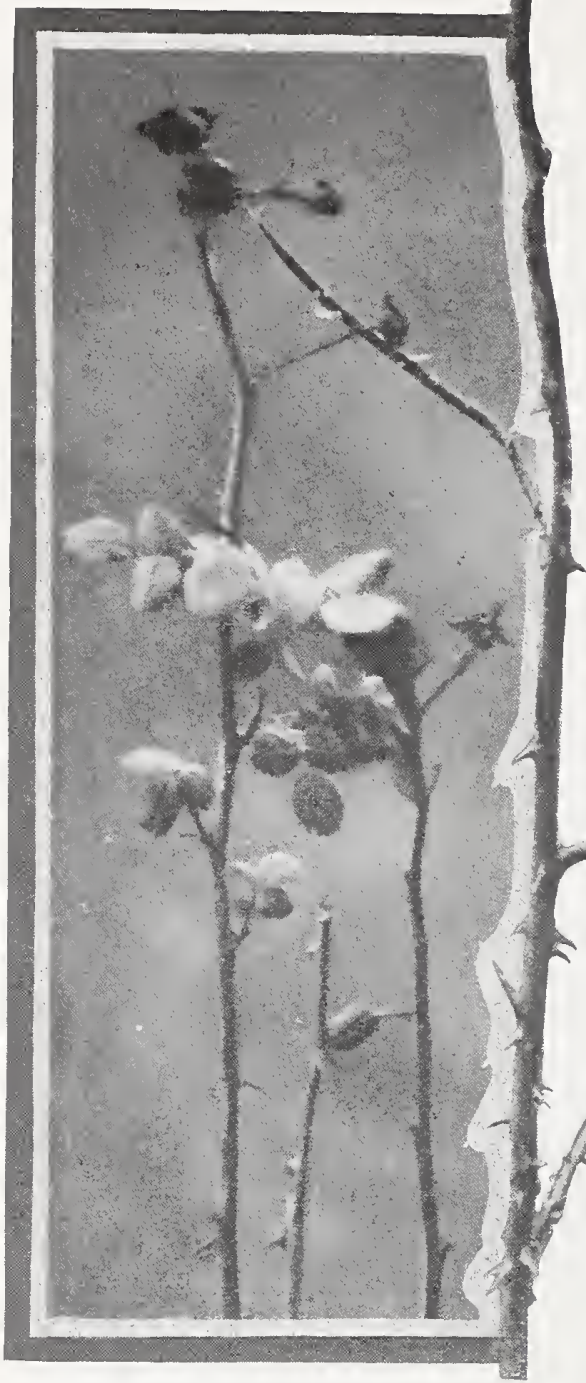

would bring glad tears to the eyes of any American wandering amid tropic delights. Disregarding for the nonce those subtle and fleeting characters of difference which oblige us in California to speak of the Song Sparrows, let us fix our attention upon the bird itself, the Song Sparrow. For where is the bird-lover whose face does not unconsciously relax, or whose heart does not turn tender

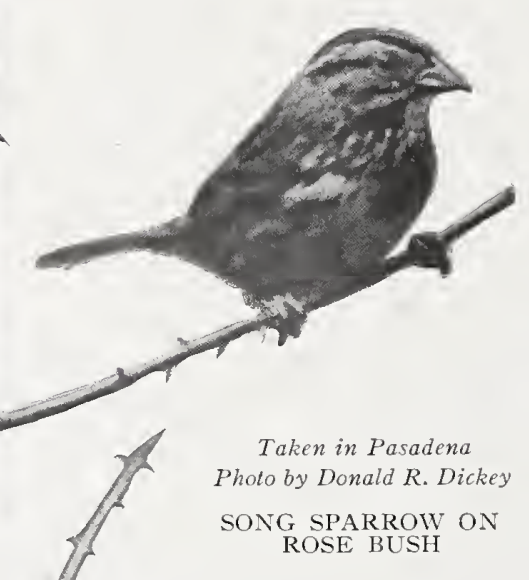
at the mere mention of this magic name, Song Sparrow! He is the poet of common day. $\mathrm{He}$ is the familiar of childhood; for knowledge of him comes at a time of life when one can poke about

without rebuke in little cool dingles, or, perchance, accompany recreant watercourses in their perilous journeys to the sea.

Familiar he surely is to most of us even though his close dependence upon water and cover prevents reckless flights in the open, after the manner of Linnets and Goldfinches, or the special consolation of brickbats affected by Passer domesticus. Although his coat is normally striped like the weedy mazes, or like the pattern of light on the cattails, which he oftenest inhabits, it bears eloquent testimony elsewhere to the power of sun or shade. On the burning beaches of the Salton Sink our Song Sparrow is bleached to the color of a pale cinder,- ash with a few streaks of ochre. In the redwood forests of Mendocino the same bird looks like a wood-brown fragment of a mouldering log, streaked or blackened by rain. Everywhere he is in harmony with nature, as if he knew her secrets and were admitted to her counsels.

Water loving, as a species, throughout their American range, the 338 


\section{The Song Sparrows}

Song Sparrows of California are even more notably attached to water. Only in the extreme Northwest, where conditions of humidity are widespread, do they suffer themselves to range above half a mile or so from some stream or swamp or saline marsh. A plot of their distribution in summer, therefore, would look like a partial blue print of our hydrographic system. Only a partial one, however, for Melospiza is unaccountably absent from considerable and well-watered areas of our State. Thus, there are no resident Sparrows in the Sacramento Valley; and they are exceedingly scarce in the western foothills of the Sierras. Even in the interior the bird exhibits a strong aquatic tendency. Not only will the bird build its nests in tussocks entirely surrounded by water, but it will itself plash about carelessly in shallow water; and it sometires seizes and devours small minnows. This hydrophilous tendency has become especially fixed in the saline marshes bordering upon San Francisco Bay. The extreme example is found in the Alameda Song Sparrow (M.m. pusillula), which scarcely deserts the salicornia barrens for a single hour, and which rears its young, as it gleans its

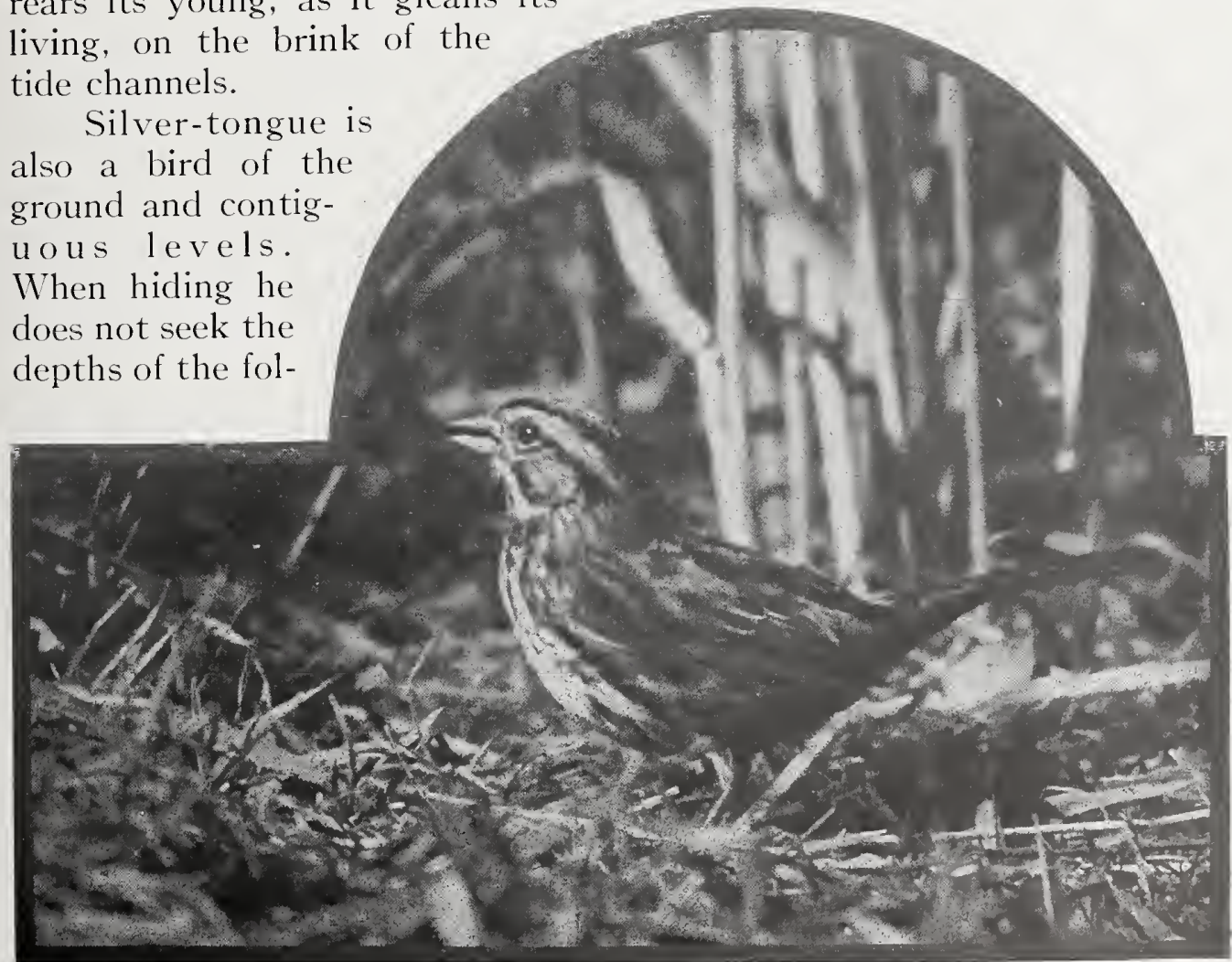

Taken in Pasadena

Photo by Donald R. Dickey "His COAT IS NORMALly STRIPED LIKE THE WEedy MAZES" 


\section{The Song Sparrows}

iage in trees, but skulks among the dead leaves on the ground, or threads his way through log heaps. If driven from one covert the bird dashes to another with an odd, jerking flight, working its tail like a pump-handle as though to assist progress. Ordinarily the bird is not fearful, although retiring in disposition. Bug-catching claims a great deal of attention, and the tules, at least, must be very grateful for the incessant purging of insect pests, especially grubs, which is contrived by this indefatigable gardener. The Song Sparrow is not above scratching for a living either. At this task

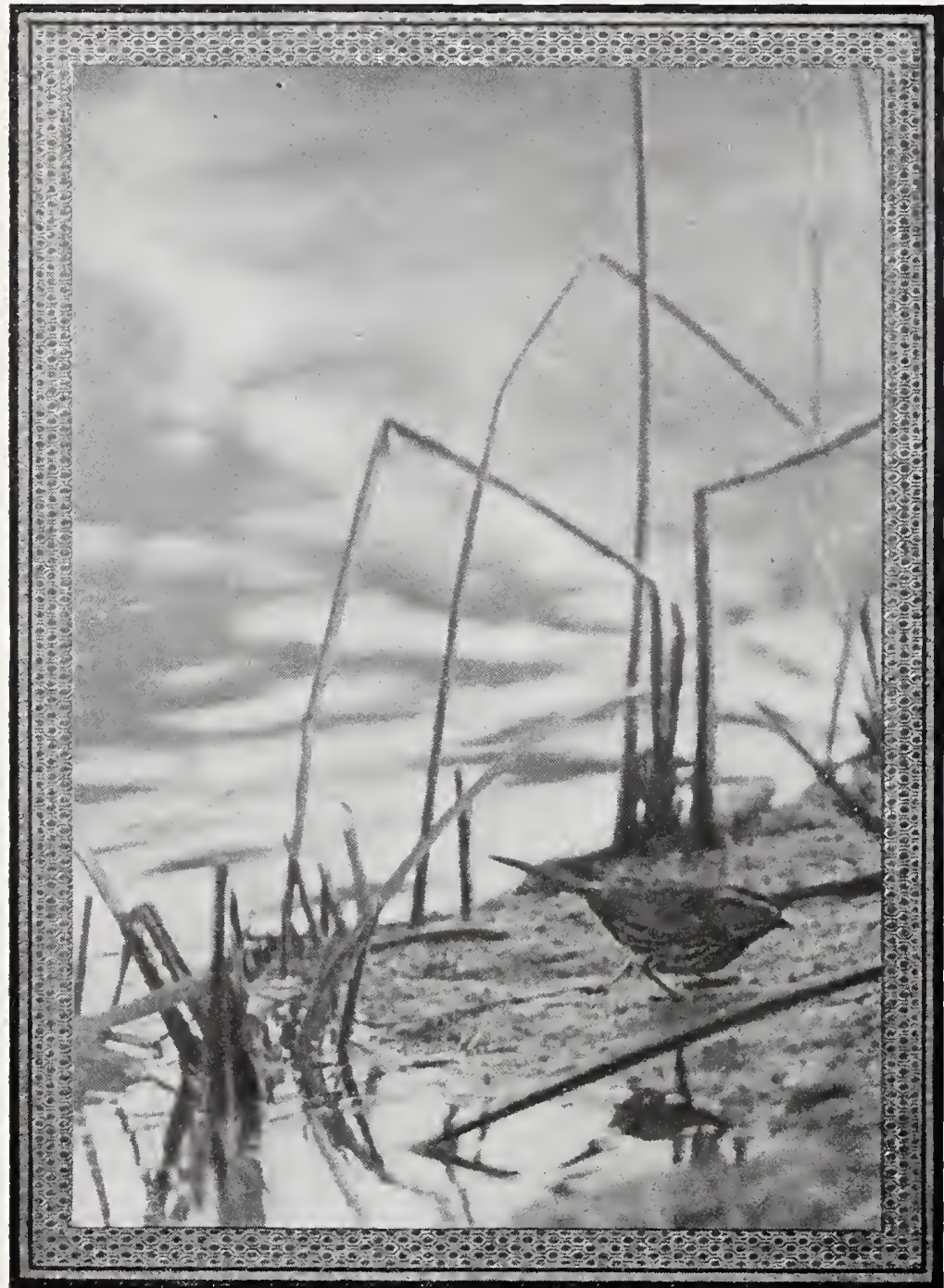

Taken in Santa Barbara County

Photo by the Author

"MEANWHILE, MANAGED TO SECURE A VERY COMFORTABLE MEAL" he kicks with both feet, after the fashion approved by Pipilo and others. He makes a business of it, too, for every once in a while a clod flies out behind as though it had been flung from a buzz-saw.

An unending succession of weed-seed goes to make up the bill-offare, and occasionally, of course, a little fallen grain. Once I sat behind a blind on the margin of a shallow lake and baited up the ducks with wheat for photographic purposes. The ducks came readily enough, but a Song Sparrow constituted herself mistress of ceremonies and interfered with my plan sadly. The Song Sparrow happened to know there was a caged monster inside that blind, whereas the larger birds merely suspected it. Every once in a while, therefore, the Sparrow came near my blind and set up a great 


\section{The Song Sparrow;}

outcry, as though I were pulling her hair or something, and the fowls scattered for their lives. Once the Sparrow flew over their heads yelling bloody murder! And that time the wheat-eaters were so scared it took them ten minutes to recover. The Sparrow, meanwhile, managed to secure a very comfortable meal. Now wasn't that clever!

It is as a songster, however, that we know this sparrow best. Silver-tongue's melody is like sunshine, bountiful and free and ever grateful. Mounting some bush or upturned root, he greets his childish listeners with "Peace, peace, peace be unto you, my children." And that is his message to all the world, "Peace and goodwill." Once on Puget Sound, we sat stormbound at the mouth of our tent, and, mindful of the unused cameras,

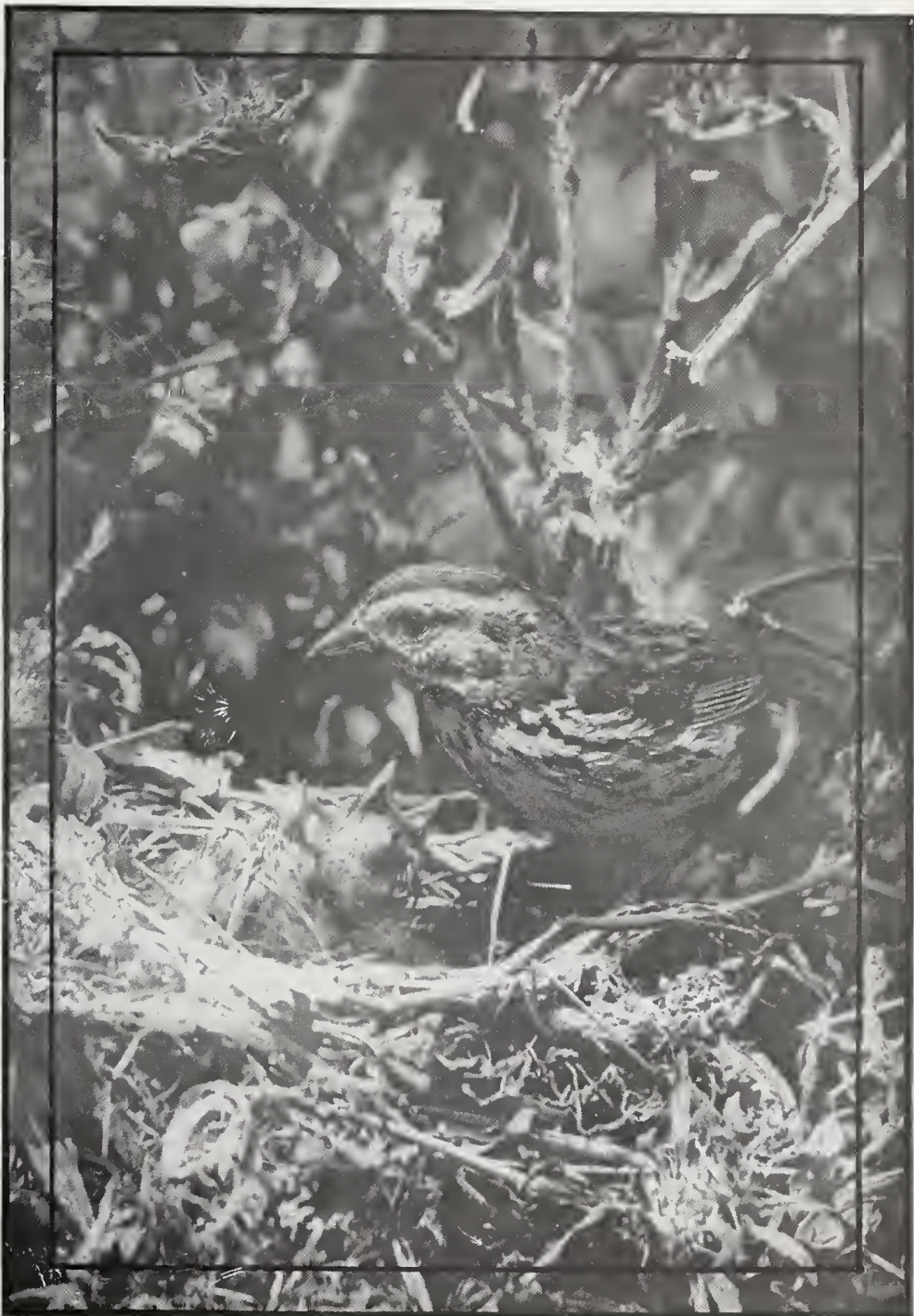

Taken in Ventura

Photo by Donald R. Dickey

SAN DIEGO SONG SPARROW, MOTHER AND BROOD grumbled at the eternal drizzle. Whereupon the local poet flitted to a favorite perch on a stump hard by, and, throwing back his head, sang, with sympathetic earnestness, "Cheer up! Cheer up! Count your many mercies now." Of course he did say exactly that, and the childish emphasis he put upon the last word set us to laughing, my partner and me, until there was no more thought of complaint. 


\section{The Song Sparrows}

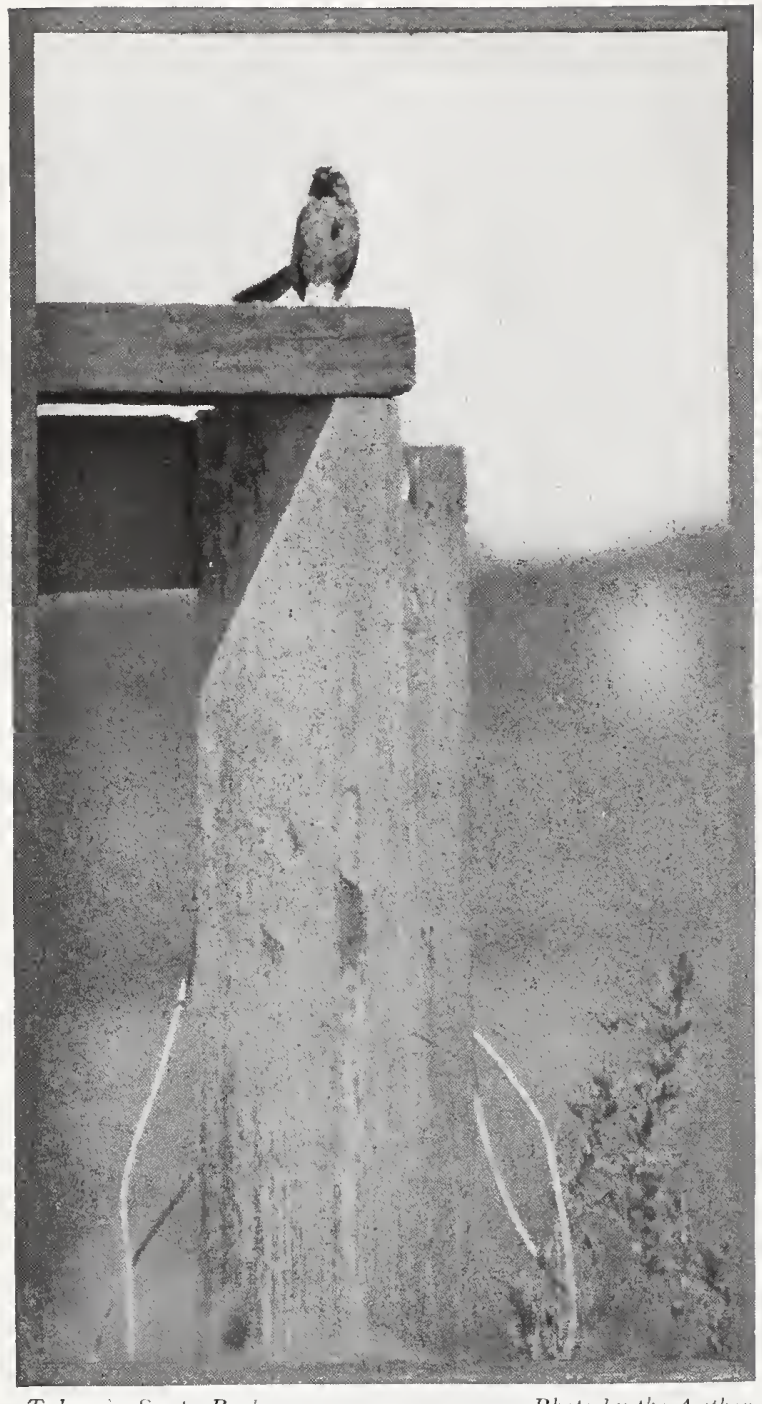

Taken in Santa Barbara

Photo by the Author

"THE FIRST TO RESPOND"

Even in winter the bravehearted bird avails himself of the slightest pretext - the passing of clouds or a rise in temperature-to mount a bush and rehearse his cheerful lay. The song is not continuous, but it is frequently repeated through periods of several minutes, and is followed by little intervals of placid contemplation.

But no matter how gentle a bird's disposition may be, there is ample use, alack! for the note of warning and distrust. When, therefore, the Song Sparrow's nesting haunts are invaded, the bird emits a chip or chirp, still musical, indeed, but very anxious. In winter, resident birds deny themselves even this characteristic cry; and, except for the occasional outbursts of full song, they are limited to a high nasal tss, which seems to serve the purpose of a flocking, or recognition, call. Song Sparrows are not really gregarious birds; nor are they even seen in close proximity save in mating time, but they like to assure themselves, nevertheless, that a dozen of their fellows are within call against a time of need.

Song Sparrows are among the very first to respond when the birdman "screeps" like a mishandled nestling, in the depths of the swamp. If he is well hidden, the reeds are soon astir with excited quest and still more excited chirps of baffled inquiry. Even when the hoax has been discovered, the incensed house-mother will scarcely forgive, but publishes her discomposure to the swamp for an hour afterwards.

Save in favored localities, such as the margins of a tule swamp, nests of the California Song Sparrows are not obtrusively common. "Back East," in a season of all around nesting, about one-fifth of the nests found would be those of the Song Sparrow. Not so in the West, for where 


\section{The Song Sparrows}

cover is scarce, the bird is also; and where cover abounds, it is likely to be so heavy as to make discovery difficult or well-nigh impossible. Nesting begins ordinarily about April first, though in the extreme South nests have been recorded in February. First nests are likely to be placed low, either upon the ground, well covered with old vines or grasses, or else in a tussock of grass in a swamp. As the season advances and cover increases, any site near water is welcomed,-brush heaps, vine tangles, dense saplings, or even trees up to twenty feet. Incubation requires only twelve days and the young are ready to fly in as many more, so that a devoted pair is able to raise two or three and sometimes four broods in a season.

At this rate we should be overrun with Song Sparrows if there were not so many agencies to hold the species in check. A young Song Sparrow is the choice morsel of everything that preys,-cats, skunks, weasels, chipmunks, foxes, Sharp-shinned Hawks, Crows, Magpies, Blue-fronted Jays, and garter snakes. How would this motley company fare were it not for the annual crop of Song Sparrows? And the wonder of it is that the brave heart holds out and sings its song of trust and love with the ruins of three nests behind it and the harvest not yet past.

Other enemies they have, no doubt, beyond our ken. On April 7 th, I9I7, an M. C. O. collector took a singing male San Diego Song Sparrow from a low stump west of Santa Barbara. Judge of our astonishment to find three ticks of the common variety firmly embedded in the flesh of the bird's head. The largest insect was swelled to the size of a currant, and the three together would eventually, I should suppose, have caused the bird's death.

\section{No. 62a Yakutat Song Sparrow}

\section{A. O. U. No. $5^{8} \mathrm{In}$. Melospiza melodia caurina Ridgway.}

Description.-Adults (sexes alike): Like the next to be described, but larger and darker, the streaks of underparts and sides of breast blackish centrally, their edgings dark grayish brown, the white of underparts sordid, tinged with gray. Bill longer and slenderer.

Nesting of Melospiza melodia.- Nest: A substantial structure of twigs, weedstems, grasses, coiled bark-strips, ferns, dead leaves, etc.; lined carefully with fine dead grass, rootlets, or horsehair; placed indifferently in bushes or on the ground, or, more rarely, in crannies, excavations in stumps, or low in trees. Eggs: 3 to 6; in California usually 3 or 4; greenish-, grayish-, or bluish-white, spotted sparingly or heavily or blotched with reddish browns-types exceedingly variable, but apparently without local significance beyond the fact that those of races from arid regions tend toward paleness, and those from humid regions toward depth and intensity of color. Av. size of species about 2 I $\times 15.5(.83 \times .6 \mathrm{I})$, but varies roughly with that 


\section{The Song Sparrows}

of parent bird. Eggs of pusillula, for example, are notably smaller than those of caurina, etc. Season: April (March, saltonis) -July; two or three broods.

General Range of Melospiza melodia.--North America from Alaska and central eastern Canada south to southern border of Mexican plateau.

Range of $M . m$. caurina.-Breeds along the coast of the St. Elias district in Alaska from Yakutat Bay to Lituya Bay (Ridgway); winters on the coasts and islands of southeastern Alaska (vicinity of Juneau: Swarth); and irregularly southward.

Occurrence in California.-Two records: Eureka, Feb. 20, I9Io, by C. I. Clay (Grinnell); and Fortuna, Humboldt County, Sept. I9, I9I5, by Huey.

Authorities.-Grinnell, Condor, vol. xii., I9I0, p. I74 (Eureka); Swarth, Univ. Calif. Pub. Zool., vol. vii., I9I I, p. 90 (Alaska; crit.); Dickey, Condor, vol. xxiv., I922, p. 65 (Fortuna, Humboldt Co.).

AT 'THE OU'TSET of our study of the particular races of Melospiza melodia we are confronted by a form which is not only strikingly different in appearance from any of our resident birds, but highly specialized in habits as well. Caurina hails from that most inhospitable coast of Alaska which borders the St. Elias Range. And because the major valleys are occupied by glaciers, and the smaller water-courses are too steep or too barren to afford suitable cover, the Yakutat Song Sparrow is confined to the narrow fringe of the sea-beaches. And because the winters here are more severe than elsewhere, caurina forsakes its summer home, displacing rufina in the northern portions of the latter's range, and straggling irregularly southward.

The extreme southern example, and the only recorded specimen for California, a female (now in the M. C. O. collection), was taken February 20, I9IO, near Eureka, in Humboldt County, by C. Irvin Clay. Mr. Clay first saw the bird on January $\mathrm{I} 7 \mathrm{th}$, and noted it on four subsequent occasions previous to capture. It haunted a certain stretch of beach, and was so devoted to it that it would return by a circuitous route as often as it was crowded out of bounds; and it took care when pursued to slip along under cover of the driftwood, guiding its course by sundry periscopic glimpses over logs, and taking to wing only when close pressed. This attachment to the beach would in itself distinguish an Alaskan visitor; but caurina is a half larger than cleonensis, the resident form, and very much darker.

\section{No. 62b Rusty Song Sparrow}

A. O. U. No. $5^{8} \mathrm{I}$ e and $58 \mathrm{If}$. Melospiza melodia rufina (Bonaparte).

Synonym.- Sooty Song Sparrow (applied to northern section of species).

Description.-Adults (sexes alike) in fresh fall plumage, and Immatures: As compared with interior races, pattern of upperparts and sides much blended, the 


\section{The Song Sparrows}

general tone of color olive-brown, reddening slightly on pileum (where sometimes separated by a faint median line of grayish), upper tail-coverts, and edgings of wings and tail; feathers of back and scapulars blackish centrally; a superciliary line (lightest in front) grayish white; cheeks varied by whitish on a brown ground; below white, clearest on chin, lower throat, and abdomen, elsewhere, especially on sides of throat, chest, and sides, heavily streaked with warm brown (Prout's brown to bister), heavily washed on sides and flanks with ochraceous buffy; tibiæ and crissum ochraceousrusty with darker centers. Bill blackish above, lighter on mandible; feet dark brownish. Juvenals somewhat resemble parents, but show more "pattern" above, with heightened contrasts of black and rusty. They are more highly, finely, and uniformly streaked below with blackish, and are tinged with yellowish buff. Length about I62.5 (6.40): wing $66(2.60)$; tail $6.5(2.56)$ : bill I $2.7(.50)$; tarsus I $7(.67)$.

Remark.-A form, M. m. morphna, has been described by Oberholser from western British Columbia and Washington. Northern specimens of rufina may average slightly larger than those resident on Puget Sound, but the color pattern is singularly uniform from Cross Sound south to the upper limits of Puget Sound. The subspecies is probably non-migratory in the southern portion of its range; so that specimens taken in California in winter hail from western Alaska; so if there is a recognizable form morphna, there is no evidence that it invades California.

Recognition Marks. - Sparrow size; heavy streaking of breast and sides fairly distinctive, save for the Fox Sparrows (Passerella iliaca group), from which it may be further distinguished by white superciliary line, smaller size, and more active behavior.

Range of $M . m$. rufina.-Breeds from the coasts and islands of southeastern Alaska south to western Washington; winters from southern British Columbia and Washington south to the humid coast belt of California.

Occurrence in California.- - Regular winter visitor in the northwestern humid coast belt, south to San Francisco Bay; casual at Riverside (Swarth) and Claremont (Pierce).

Authorities.-Audubon (Fringilla cinerea), Orn. Biog., vol. v., I 839, p. 22, pl. 390, fig. I; Grinnell, Univ. Calif. Pub. Zool., vol. v., I 909, p. 229 (Alaska; habits, nest and eggs, nomencl.); Swarth, Condor, vol. xii., I9Io, p. I08 (Riverside); Kellogg, Condor, vol. xiii., I9I I, p. I20 (Tower House, Shasta Co.; crit.); Allen, Condor, vol. xxii., I920, p. I6 (migr.); Pierce, Condor, vol. xxii., July, I920, p. I 56.

CALIFORNIA Song Sparrows are sedentary save in the territory east of the Sierras, where increased altitudes and lower temperatures enforce evacuation in winter. In like manner, upon the Pacific Coast proper a point is reached, somewhere to the north of us, where the rigors of winter institute a migratory impulse in the Song Sparrows. The reaction to this impact may be of two sorts: Either the birds, slightly discommoded, move a few miles southward and rest content; or else they may flee wildly south ward until they reach some totally different environment, and one in which they feel entirely secure. These two forms of compulsory movement do actually manifest themselves, and, probably, every gradation between. Two races of the Song Sparrow living to the 


\section{The Song Sparrows}

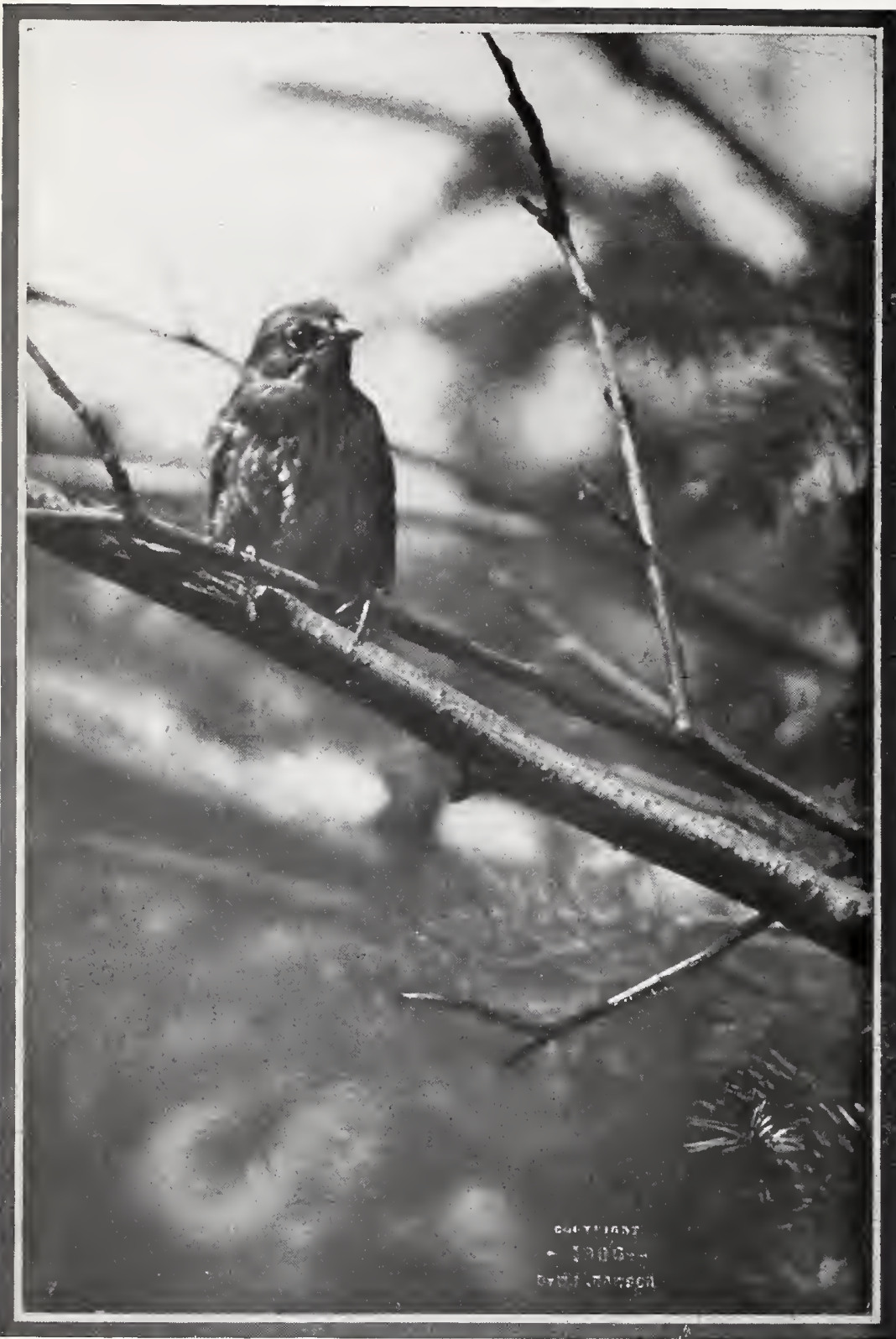

Taken in Seattle
Photo by the Author

"A BIRD OF MODEST M1EN"

north of us - viz., morph$n a$, whose range extends from the Columbia River to southernmost Alaska; and rufina, which occupies the southeastern coastal strip of Alaska north to Cross Sound -intergrade so perfectly that some authorities, Grinnell, for example, decline to separate them at all. But the final test of difference may prove to be other than somatic. The degree of participation in migration may help to determine the difference between hypothetical morphna and rufina. All we know so far is that the Song Sparrows of western Washington, morphna, are partially sedentary, perhaps wholly so in the southern portion of their range; whereas rufina forsakes the northern portions of its range,the Cross Sound and Sitka districts-outright. The probabilities are that the migratory movement of morphnarufina is, therefore, highly composite, that the southern extreme is statle, while the northern end is forced down by a telescoping motion which projects now one element and now another of the composite mass into rorthern California. The variable character of the material taken in winter in California supforts this hypothesis, while 


\section{The Song Sparrows}

it tends to obscure the operation of the saturating tendency, which increases steadily from Puget Sound to Sitka. Personally, I have no question that morphna is a valid form, and that California-taken specimens hailing, let us say, from the coast of British Columbia are referable to morphna rather than to rufina.

\section{No. 62c Oregon Song Sparrow}

A. O. U. No. $5^{81} \mathrm{p}$, part. Melospiza melodia phæa Fisher.

Description.-Similar to $M$. m. rufina, but color-pattern of upperparts less blended, more highly developed, by reason of strengthened gray edgings and of blackish centers on back and inner quills. Breeding birds from the Oregon coast show closer affinities with rufina (or morphna) than with cleonensis.

Range of $M . m$. phea.-Breeding and partially resident along the west coast of Oregon and southern Washington; irregularly southward in winter.

Occurrence in California.- A winter visitor at least in extreme northern portion of humid coast belt (W. K. Fisher), irregularly (?) southward through undefined area (San Mateo County, Nov. 25, I900, Grinnell).

Authorities.-Fisher, Condor, vol. iv., I902, p. 36 (orig. desc.; type locality, Gardiner, Ore.; spec. from Crescent City); Grinnell, Pac. Coast Avifauna, no. I I, I9I5, p. I23 (Pescadero Cr., San Mateo Co.); Brown, Auk, vol. xxxv., I918, p. 350 (Placerita Cañon, Los Angeles Co.).

\section{No. 62d Mendocino Song Sparrow}

\section{A. O. U. No. $58 \mathrm{I}$ p, part. Melospiza melodia cleonensis McGregor.}

Description.-Quite different from preceding form by reason of emerging color-pattern; nearest like $M . m$. gouldi. General tone of upperparts and sides of head and neck, as determined by edgings, tawny olive or Saccardo's umber; pileum (parted by cream-buffy middle line), wing-coverts, and edgings of tail and wings Prout's brown; feathers of back, scapulars, and inner tertials black with tawny olive edgings; a supraloral spot white, continued as grayish superciliary line; underparts basally white, clear only on middle of breast; chin and throat only slightly flecked with dusky; sides of throat, breast, and sides of breast heavily marked with rusty or tawny olive streaks having black centers; flanks and crissum heavily tinged with clay-color and streaked with dusky. Here begins to emerge the familiar Song Sparrow type. Length of adult (skins) I $37(5.40)$; wing $60(2.36)$; tail $59(2.32)$; bill I I.9 (.47); tarsus 22 (.866).

Range of $M . m$. cleonensis (Wholly within California).-Common resident chiefly of fresh-water marshes in humid coast belt from Crescent City south (at least) to Mendocino City; "casual in autumn at Olema, Marin County" (Grinnell).

Authorities.-McGregor, Bull. Cooper Orn. Club, vol. i., I 899, p. 87 (orig. desc.; Westport, Mendocino Co.); Fisher, Condor, vol. iv., I902, p. I34 (distr.; crit.); J. Mailliard, Condor, vol. xviii., I916, p. I99 (habits).

IN THIS race we begin to see the approach of "saturation," or darkening of plumage, occasioned by increasing humidity, or rather by the 


\section{The Song Sparrows}

corresponding withdrawal of sunlight. Yet the wonder is that the Mendocino-Humboldt birds are not darker, for the magnificent forests of redwood, whose trees number their rings by centuries, ${ }^{1}$ are a living witness that the region has long been one of excessive rainfall. Perhaps, after all, Melospiza melodia is not such a "plastic" form as we had supposed. At any rate, we get here a vivid conception of the enormous stretches of time at Nature's disposal, and some idea of her patience. If a thousand years (at the least) are required to alter a shade so slightly that its recognition is still debatable, how many millenniums must have elapsed since the "Sooty" Song Sparrow (M. m. rufina) began to occupy the coast of Alaska!

\section{No. 62e Marin Song Sparrow}

A. O. U. No. $58 \mathrm{Id}$, part. Melospiza melodia gouldi Baird.

Description.-Similar to $M$. m. cleonensis, but less rufescent, the black element much stronger on feathers of back, scapulars, and exposed quills, that of pileum taking form of streaks alternating with browns; the streaking of underparts also more decidedly black, often scarcely rufescent on edges.

Range (Wholly within California).--Common resident on fresh-water marshes and streams immediately to the north of San Francisco Bay, chiefly in Marin and Sonoma counties; north coastwise to Gualala, Mendocino County, interiorly to Mt. Sanhedrin, Cahto, and Ukiah, east to Vacaville and Rumsey (Yolo County) (Grinnell).

Authorities.-Baird, Pac. R. R. Rep., vol. ix., I 858, p. 479 (orig. desc.; "California”); Grinnell. Univ. Calif. Pub. Zool., vol. v., I909, p. 267 (desc.; crit.).

\section{No. 62f Samuel's Song Sparrow}

A. O. U. No. $58 \mathrm{Id}$, part. Melospiza melodia samuelis (Baird).

Description.-Similar to M. m. gouldi, but black element still further strengthened throughout, the streaking of breast, sides, etc., usually without trace of other color.

Range (Wholly within California).- "Abundant resident on salt marshes along the north side of San Francisco Bay, from Larkspur, Marin County, through Sonoma and Napa Counties to Vallejo, Solano County; also on south side of San Pablo Bay, at Selby and Pinole, Contra Costa County."-Grinnell.

Authorities.-Baird (Ammodromus samuelis), Proc. Soc. Nat. Hist., vol. vi., I 858, p. 379 (orig. desc.; Petaluma); McGregor, Bull. Cooper Orn. Club, vol. i, I 899, p. 87 (crit.); Grinnell, Condor, vol. iii., I90I, p. 92 (crit.); Beal, U. S. Dept. Agric., Biol. Surv. Bull., no. 34 , I910, p. 84, part (food).

1 "Very long-lived but greatest age undetermined. *** * A tree 20 feet in diameter and 350 feet high
showed an age of 1000 years. Another tree 20 feet in diameter was 1373 years old." - Sudworth, Forest Trees of the Pacific Slope, p. 146. 


\section{The Song Sparrows}

\section{No. 62g Suisun Song Sparrow}

A. O. U. No. 58Is. Melospiza melodia maxillaris Grinnell.

Description.-Similar to M.m. samuelis, but decidedly larger; bill much shorter, tumescent at base. Plumage shows slight reduction of blacks, and streaking of underparts shows traces of rufescent bordering. As compared with $M$. m. heermanni, maxillaris shows darker coloring with broader black markings, and base of maxilla more swollen. Measurement of type, a male: wing 63.7 (2.5I); tail 62 (2.44); bill $12.9(.5 \mathrm{I})$; depth at base $7.6(.30)$; tarsus $2 \mathrm{I} .8(.86)$.

Range (Wholly within California).- "Common resident of the marshes surrounding Suisun Bay, more particularly from the vicinity of the confluence of the Sacramento and San Joaquin Rivers west to Benicia and Port Costa where abruptly delimited."-Grinnell.

Authority.-Grinnell, Univ. Calif. Pub. Zool., vol. v., I909, p. 265 (Suisun; orig. desc.).

I HAVE never seen the Suisun Song Sparrow. I suppose I never shall. It is said to favor certain types resident a few miles up the river rather than its neighbor, samuelis, on the Sonoma shore. A closer attention to this fascinating subject of the subdivision of Song Sparrows will doubtless eventuate in a pet species for every water-hole in California; and may ultimately necessitate the establishment of a chair of Comparative Melospiziology at Berkeley. Heigh ho! I wonder if the simplehearted Song Sparrow, he of the silver tongue, suspects what a bother he is to us poor scientists!

\section{No. 62h Salt Marsh Song Sparrow}

A. O. U. No. 581l. Melospiza melodia pusillula Ridgway.

Synonym.-Alameda Song Sparrow.

Description.-Similar to $M$. m. samuelis, but slightly smaller; spotting of underparts slightly more rufescent upon the margins. Ridgway, in describing this subspecies (Birds of N.\& M.Am., vol. i., p. 370), claims the precise opposite, namely, that the markings of pusillula are less rufescent; but the abundant material in the M. V. Z. collection certainly does not sustain his contention. Immature birds are unique in displaying a yellowish suffusion of the underparts, which character is necessarily carried until the second autumn (since the species has but one annual molt). Measurements of adult males: wing 57.9 (2.28); tail 62.5 (2.46); bill II.2 (.44). Females average smaller.

Range (Wholly within California).- Resident on or near the southern portion of San Francisco Bay, from San Francisco to West Berkeley.

Authorities.-Ridgway, Auk, vol. xvi., I 899, p. 35 (orig. desc.; Alameda Co.); McGregor, Bull. Cooper Orn. Club, vol. i., I 899, p. 87 (desc.; crit.); Grinnell, Condor, vol. iii., I90I, p. 92 (habits; crit.); Cohen, Condor, vol. iii., I 90 I, p. I 85 (nesting dates).

THE RECOGNITION of a dwarf race, pusillula, from the marshes of San Francisco Bay was a clever piece of work, and the race so dis- 


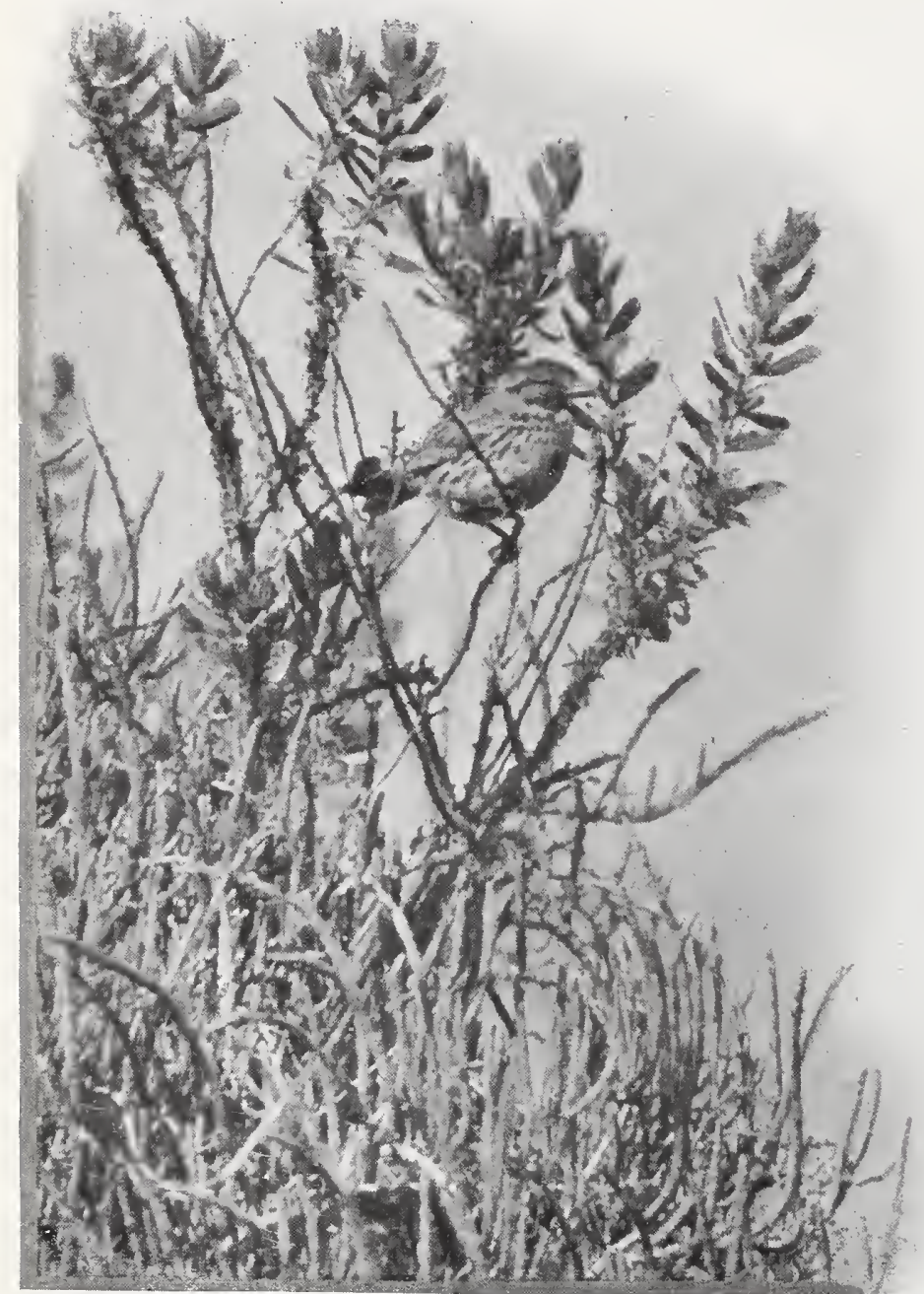

Taken in Santa Barbara
Photo by the Author

SONG SPARROW ABOVE SALICORNIA

NOT $M . m$. pusillula, but $M . m$. cooperi IN A BRACKISH MARSH, "THE ESTERO" tinguished is the more interesting because it sets at defiance one of the foremost canons of Song Sparrowdom; viz., that individuals shall increase in size northerly. Thus, the San Diego Song Sparrow, $M$. $m$. cooperi, has a wing length of $\mathrm{mm} 63$; rufina of British Columbia, $\mathrm{mm} \mathrm{68;} \mathrm{caurina} \mathrm{from}$ Yakutat Bay, mm 72; and the giant sanaka from the Aleutians, mm 85. The Aleutian Song Sparrow is, thus, more than twice as big a bird as ours in southern California. Pusillula's wing length, as given by Professor Robert Ridgway, the original describer, is only mm 58.4 .

Life with pusillula has been reduced to very simple terms. 'There' in a salt marsh, is just the same as 'here,' so where is the use of fashing one's self about quick transportation? No need; ergo, arrested wing development; that is, shorter wings.

That substantially uniform conditions have prevailed for ages in the marshes of San Francisco Bay, there can be no doubt. Today an intricate system of tidal arteries and capillaries supplies moisture to acres of salicornia, a succulent round-stemmed plant growing in rank profusion to a height of one or two feet; and each of these sodden acres harbors a legion of molluscs, nemertines and crustaceans. There is 


\section{The Song Sparrows}

nothing else to speak of - a dreary waste, of interest chiefly to Rails and Salt Marsh Song Sparrows. The latter haunt the oozy slopes of the tide-guts and snatch dainties from a salty menu, keeping a sharp eye, meanwhile, not to get their toes nipped by lurking crabs. Their bibs get pretty badly stuck up with salicornia juice and the ever generous ooze; but brackish pools are ever handy for ablution and a chance at minnows besides. Then in the springtime, because the salicornia is really impossible, the Lord sends a little green bush for a nesting site. The bush must have a Latin name, but it is unknown to the deponent. It is ordained to be a little greener and a little taller than the salicornia, and if it suits the Song Sparrow, as it certainly does, we will call it the Salt Marsh Song Sparrow Nesting Bush (or Busha pusillule for short, if our Latin friends insist). Anyhow, all one has to do during the first week in April is to visit every little green bush growing in the San Francisco marshes, and gather Salt Marsh Song Sparrows' eggs, or "information," according to the state of his development. The nests are there, and the information easy-also uniform. The eggs are, of course, indistinguishable from those of other forms; but the nests are unique, in that they are composed of plastic or sodden strands of some sort of marsh waste which, upon drying, forms a sturdy and uncommonly durable structure.

\section{No. 62i Santa Cruz Song Sparrow}

A. O. U. No. 581d, part. Melospiza melodia santæerucis Grinnell.

Description.--Most like the next to be described, but smaller. Also similar to $M . m$. pusillula, but much larger; the juvenal but not the immature (final autumnal) plumage suffused with buffy yellow; the contrast in this regard between two adjacent "races" of one species, and those existing continuously within sight of each other, gives food for reflection. Measurements of males (orig. desc.): wing 61.2 (2.4I); tail 67.5 (2.66); bill II.4 (.45). Females smaller.

Range (Wholly in California).- Resident chiefly on fresh-water marshes and along streams in the Santa Cruz district, from San Francisco south to the Sur River in Monterey County, east to include the Santa Clara valley, and north to Berkeley, south interiorly to Shandon and Santa Margarita in San Luis Obispo County (where shading into M. m. cooperi).

Authorities.-Grinnell, Condor, vol. iii., I90I, p. 92 (orig. desc.; Palo Alto); ibid., Pac. Coast Avifauna, no. II, 1915, p. I25 (range; crit.).

\section{No. 62j San Diego Song Sparrow}

A. O. U. No. $58 \mathrm{Im}$. Melospiza melodia cooperi Ridgway.

Description.-Adults (sexes alike) and Immatures: Above and on sides mingled olive-gray, olive-buff, rusty red, and black, the olive-gray element strongest anteriorly, the olive-buff posteriorly, the black element existing centrally on feathers, sharpest on pileum, broadest on back, scapulars, and exposed portions of tertials, the rusty element, as Prout's brown, bordering feathers of pileum, exposed portion of greater 


\section{The Song Sparrows}

wing-coverts, and outer edging of tertials, as dull cinnamon, on exposed edges of flightfeathers and rectrices; underparts basally white, clearest on chin, throat, and middle of breast; sides of throat, chest, sides, flanks, and posterior portions strongly tinged

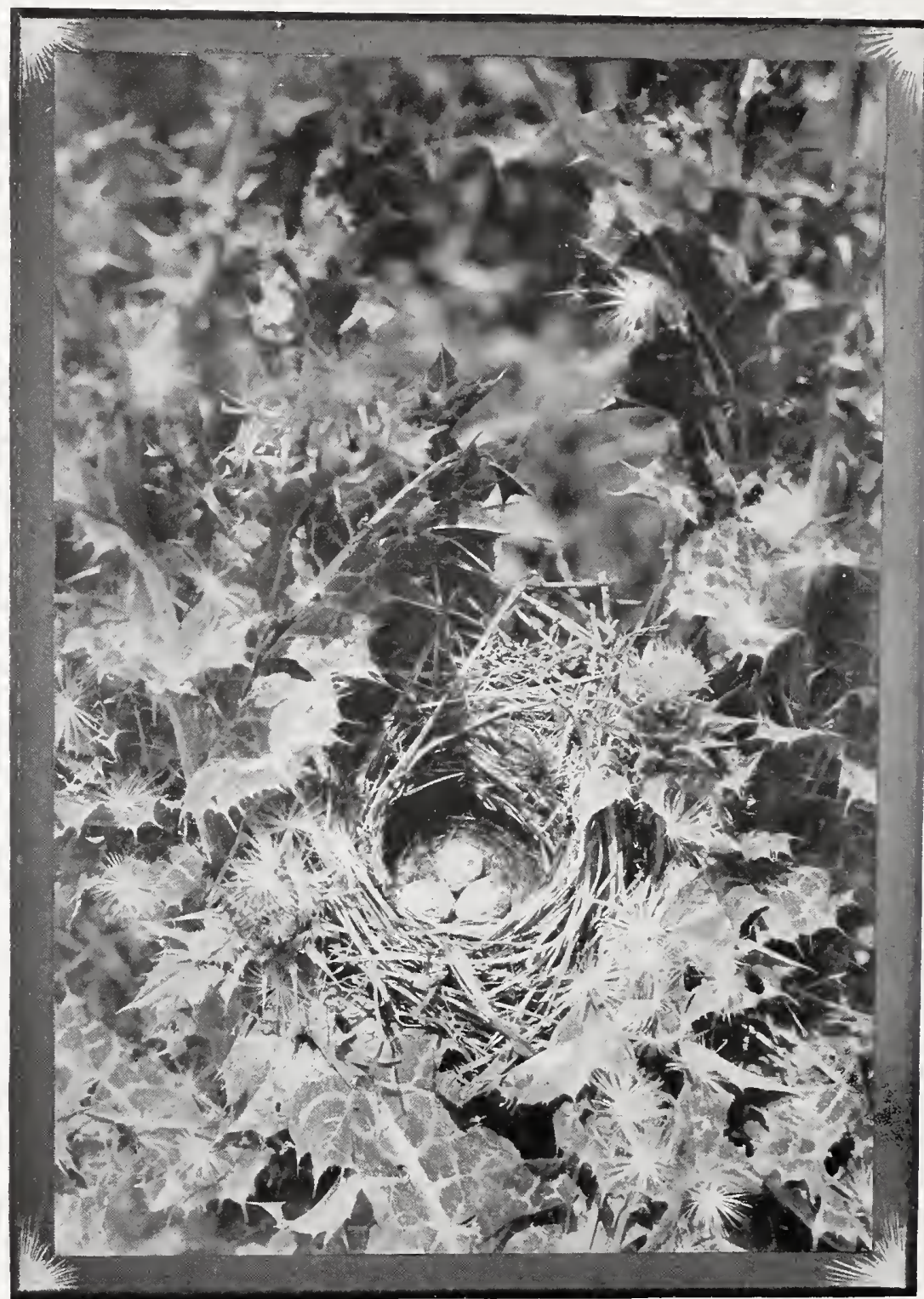

Taken in San Diego

Photo by Donald R. Dickey

NEST AND EGGS OF SAN DIEGO SONG SPARROW IN THISTLES

with buffy or pinkish buff, and heavily streaked with black or blackish, more or less tinged and bordered with rusty; pattern of head obscurely i 2-radial, by reason of crown parted by gray median line, white "eyebrows" (supraloral region, continued as gray 


\section{The Song Sparrows}

superciliary), dusky lores and cheek (the latter mingled with whitish), buffy malar stripe, blackish submaxillary stripes, and white chin. Juvenals: Somewhat like adults, but olive-gray of upperparts wanting; margining of feathers chiefly pale claycolor; underparts suffused with pale ochraceous buffy; the black streaks much narrower. Bill blackish above, lighter below; feet and tarsi light brown. Measurements, adult male (after Grinnell): wing 62.7 (2.47); tail 7I.4 (2.8I); bill II.9 (.27). Females average smaller.

Recognition Marks.- Sparrow size; the I2-radial pattern of head, with striped appearance above serves to distinguish from birds of the Passerella group. Somewhat like the Lincoln Sparrow (Melospiza lincolni), but longer and more coarsely patternedthe streaks below much broader and tending to confluence on sides of throat.

Range.--Resident in the San Diego district, broadly defined, from southern San Luis Obispo County and the Cuyama valley south to San Quentin, Lower California, east to the desert divides, and even invading both the Mohave (Victorville, Yermo) and Colorado deserts (mouth of Palm Canyon) (Grinnell and Swarth).

Authorities.-Cooper (Melospiza heermanni, part), Orn. Cal., I87o, p. 212; Fisher, N. Am. Fauna, no. 7, I893, p. Ioo; Ridgway, Auk, vol. xvi, I899, p. 35 (orig. desc.; San Diego); Myers, Condor, vol. xii., I910, p. I65 (method of feeding young); Willett, Pac. Coast Avifauna, no. 7, I912, p. 84 (distr.; nesting dates); Grinnell and Swarth, Univ. Calif. Pub. Zool., vol. x., I913, p. 279 (crit.).

\section{No. 62k San Clemente Song Sparrow}

A. O. U. No. 58ri. Melospiza melodia clementæ C. H. Townsend.

Description.-Similar to $M$. m. cooperi, but much paler; the olive-gray element of the upperparts greatly increased, the blacks reduced, and reds faded; streaks on underparts finer, the buffy suffusion much reduced, the remainder more pinkish. Size (after Ridgway): wing 64.8 (2.55); tail 64 (2.52); culmen I2.2 (.48); tarsus 2 I.8 (.86).

Range (Wholly within California).-Common resident on San Clemente Island; also apparently the resident bird of San Miguel and Santa Rosa islands.

Authorities.-Cooper (Melospiza heermanni, part), Proc. Calif. Acad. Sci., vol. iv., I870, p. 78); Townsend, Proc. U. S. Nat. Mus., vol. xiii., I890, p. I39 (San Clemente Id.; orig. desc.); Grinnell, Pasadena Acad. Sci. Pub., no. I, I897, p. I 8 (habits; song); Grinnell and Daggett, Auk, vol. xx., I903, p. 34 (crit.); Howell, Pac. Coast Avifauna, no. I2, I917, p. 8 I (distr.; syn., etc.).

\section{No. 621 Santa Barbara Island Song Sparrow}

A. O. U. No. $5^{8 \mathrm{I} h}$. Melospiza melodia graminea C. H. Townsend.

Description.-Very similar to $M$. $m$. clemente, but somewhat smaller: wing 60.2 (2.37); tail 56.I (2.2 I); culmen I $2.2(.48)$; tarsus 2 I.3 (.84).

Range (Wholly within California).- "Common resident on Santa Barbara Island; less numerous and of more local occurrence on Santa Cruz Island." -Grinnell.

Authorities.-Cooper (Melospiza heermanni, part), Proc. Calif. Acad. Sci., vol. iv., I870, p. 78; Townsend, Proc. U. S. Nat. Mus., vol. xiii., I890, p. I39 (Santa Barbara Id.; orig. desc.); Grinnell, Pasadena Acad. Sci. Pub., no. I, I897, p. 6 (nests and eggs; habits); J. Mailliard, Bull. Cooper Orn. Club, vol. i., I899, p. 44 (Santa Cruz Id.); Howell, Pac. Coast Avifauna, no. 12, I917, p. 80 (distr., syn., etc.). 


\section{The Song Sparrows}

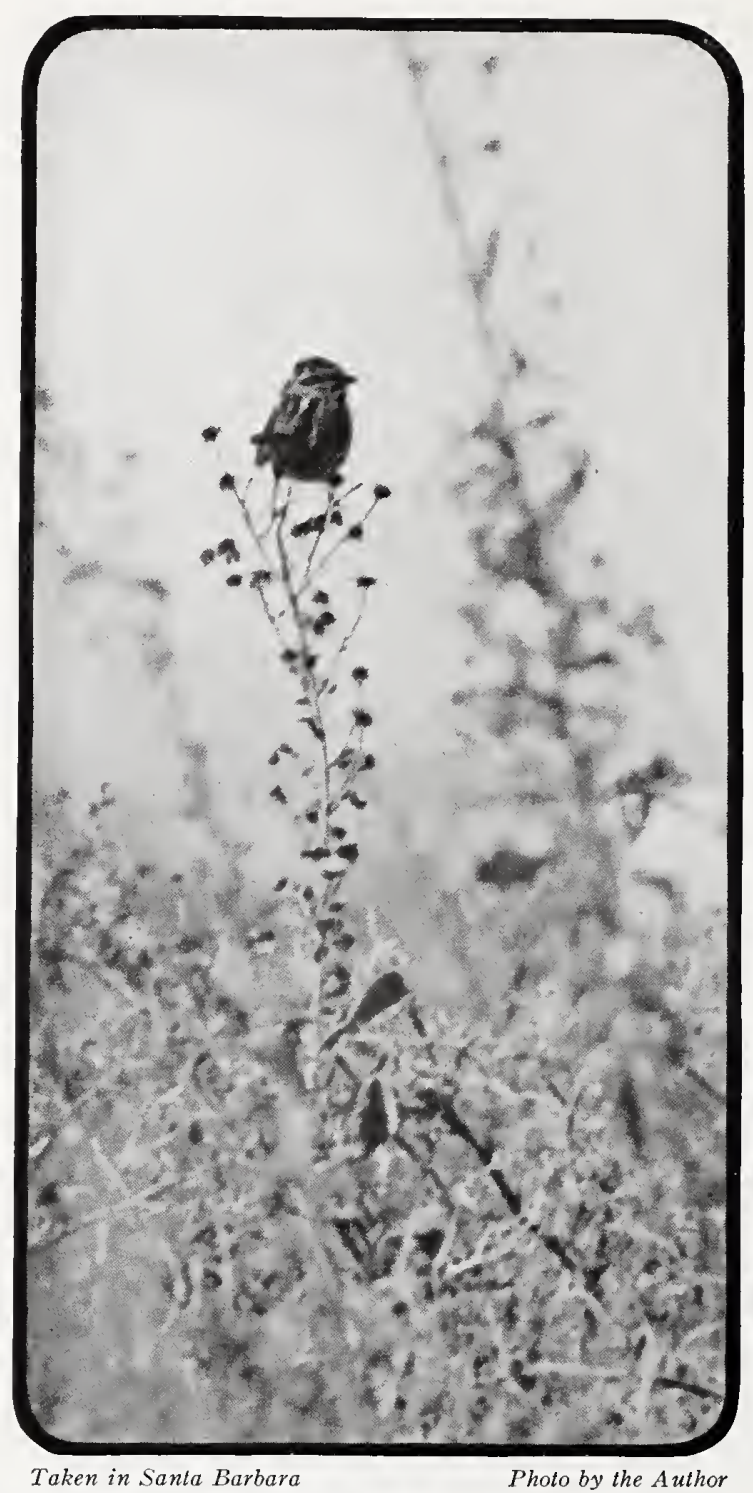

A SANTA BARBARA SONG SPARROW
IT IS NATURAL enough that these short-winged birds of comparatively limited powers of flight should have become differentiated on the islands of the Santa Barbara group. There is no apparent reason, however, why the $\mathrm{s} \mathrm{m}$ aller form, graminea, should be found on the smallest and the largest islands, Santa Barbara and Santa Cruz, widely separated as they are; or why this form should interrupt the range of clementae, which is ascribed to San Miguel and Santa Rosa as well as to San Clemente Island. The probability is that the resemblances found are adventitious, and that the stocks on San Clemente and San Miguel are of a degree of separation as ancient as that obtaining between either and its more immediate neighbors. It is a pretty problem, and we cannot pretend to be on the way toward a solution.

\section{No. 62m Heermann's Song Sparrow}

A. O. U. No. $5^{8}$ Ic. Melospiza melodia heermanni Baird.

Description.-Similar to $M . m$. cooperi, but slightly grayer, especially on sides of neck; the streaking of underparts more extensively bordered or suffused with rusty; the buffy suffusion of streaked areas reduced or wanting except posteriorly. Very slightly larger.

Range (Wholly within California).-Resident along streams and over flooded lands of the Tulare depression, from about the latitude of Fresno south to Ft. Tejon, 


\section{The Song Sparrows}

and east well into the Sierra foothills, intergrading indeterminably with mailliardi on the north; may retire partially and irregularly south in winter, but probably not to Nevada.

Authorities.-Baird, Rep. Pac. R. R. Surv., vol. ix., I858, p. 478 (Tejon Valley; orig. desc.); Grinnell, Univ. Calif. Pub. Zool., vol. v., I909, p. 266 (distr.; crit.); ibid., Condor, vol. xiii., I9I I, p. i Io (distr., habits, etc.); Beal, U. S. Dept. Agric., Biol. Surv. Bull., no. 34, I910, p. 84 (food); Swarth, Condor, vol. xiii, I9I I, pp. I6I, I63 (distr.).

HEERMANN'S Song Sparrow is characteristically, though not exclusively, a dweller in cattails. The flooded areas tributary to the San Joaquin River afford abundant cover of this special sort, and Melospiza is as much a bird of the reeds as is Agelains or Botaurus. It is always good fun to bury one's self in the heart of the reeds, then turn loose the distress notes known as "screeping," the master call of the winged wild. Song Sparrows are the first to respond. From one to a dozen will gather within a minute, peeping, prying, dashing, searching, anxious for the welfare of their little ones, or merely curious as to the source of the strange noise. And always they scold-that, at least, is safe-tswewp, squib, or tsirb. The note is as definite as a dinner bell; but no human lips can pronounce it. Frowsy females stop to upbraid the stranger, although undelivered packages of worms muffle their voices (goop, goop, is neither dignified nor intimidating); less ruffled fathers grasp a cattail firmly in both feet, and speculate intently upon the intruder's identity and intentions. The sound of infantile slaughter seems to proceed from those lips kissing a hand; but no slaughter results. Perhaps he is calling the cows-or perhaps he is not quite right in the head. It is evidently a false alarm, and we might as well go back to bug-catching. And so the little people of the green forest steal away again, disappointed or amused, according to their wont.

\section{No. 62n Mailliard's Song Sparrow}

A. O. U. No. $5^{81}$ c, part. Melospiza melodia mailliardi Grinnell.

Synonym.-Modesto Song Sparrow.

Description.-Very similar to $M$. m. heermanni, but slightly darker, comparable to $M . m$. maxillaris in this respect. Proportions of bill as in heermanni. A very "light" form which no one but a "speciation specialist" could discern.

Range (Wholly within California).-." "Common resident in the vicinity of the confluence of the Tuolumne and San Joaquin Rivers, Stanislaus County, and thence north at least to Tracy Lake, San Joaquin County."-Grinnell.

Authority.-Grinnell, Univ. Calif. Pub. Zool., vol. vii., I9I I, p. I97 (near Modesto; orig. desc.); ibid., Condor, vol. xiii., I9I I, p. I Io (distr.). 


\section{The Song Sparrows}

\section{No. 62o Merrill's Song Sparrow}

A. O. U. No. 58 Ik. Melospiza melodia merrilli Brewster.

Description.-Similar to $M$. m. fallax (next to be described), but darker and much more rufescent, intermediate toward the coastal types. Prevailing tone of upperparts grayish olive, changing to olive-gray anteriorly, the black element much subdued; the rufous element strong on pileum and wing-and-tail-skirtings; streaks of underparts heavy and broad, chiefly rusty, but with some dusky centering; flanks and crissum washed with pale clay-color.

Range of $M . m$. merrilli.- "Northwestern United States. Breeds from Fort Sherman, Idaho, west and south through Washington and Oregon east of the Cascades to Shasta County, California; winters south to Nevada, Utah, Arizona, and Sonora." -A. O. U. Committee.

Occurrence in California.- Winter visitor to northern California east of the humid coastal belt, irregularly southward over area not clearly determined. One record from Mohave Desert (Victorville, by J. Mailliard and J. Grinnell). Said to breed in Shasta County (Ridgway).

Authorities.-McGregor (Melospiza melodia ingersolli), Bull. Cooper Orn. Club, vol. i., I899, p. 35 (Battle Creek, Shasta Co.); Ridgway, Birds N. and Mid. Am., vol. i., I90I, p. 36 I (crit. com. upon Calif. spec.).

\section{No. 62p Rocky Mountain Song Sparrow}

A. O. U. No. $5^{8} \mathrm{ra}$, part; No. $5^{8 \mathrm{I}}$ b, part. Melospiza melodia fallax (Baird).

Description.- Somewhat similar to $M$. $m$. cooperi, but much lighter, more grayish, the black element much reduced, confined to centers of feathers on pileum and in jugular streak; the rufous of wing-edgings, etc., lighter; the streaks of underparts chiefly rusty; the I2-radial pattern of head usually more sharply defined.

Range of $M . m$. fallax.-The breeding range of fallax presumably bounds that of merrilli and fisherella upon the eastward, and so includes the Rocky Mountains in Idaho, Wyoming, Utah, and Montana, south to northern New Mexico; winters south to western Texas, northern Mexico, and southern California.

Occurrence in California.- - Imperfectly made out, but occurs at least sparingly in winter in southeastern and southern portions of State, probably west to Santa Barbara.

A uthorities.-Oberholser, Proc. Biol. Soc. Wash., xxiv., I9I I, p. 252 (nomencl.): Grinnell, Pac. Coast Avifauna, no. II, I9I5, p. I27 (status in Calif.); Saunders, Pac. Coast Avifauna, no. I4, I92 I, p. I29, fig. 29 (Mont.; habits, nest and eggs, etc).

\section{No. 62q Modoc Song Sparrow}

A. O. U. No. $5^{8} \mathrm{I}$ b, part. Melospiza melodia fisherella Oberholser.

Description.- Said by its describer to differ from $M$. $m$. fallax in its darker upperparts, more blackish brown streaks of under surface, heavier bill, and shorter wing. There is undoubtedly justice in this claim, especially as regards specimens from the extreme western part of the assigned range, viz., the Siskiyou district. Nevertheless, the change is so slight and so gradual that it is a pity to obscure the fact of the close relationship existing between the breeding birds of interior northern California and the Rocky Mountains by a difference in nomenclature. 


\section{The Song Sparrows}

Range of $M . m$. fisherella.--Breeds in the plateau region of northeastern California, northern Nevada, and southeastern Oregon; winters south at least to the Colorado Desert.

Distribution in California.-Breeds regularly in the Modoc region of northeastern California, west to Sisson (or wherever merrilli may be supposed to take its place), southward east of the Sierran divide through Owens Valley to Lone Pine and Ash Creek; winters commonly on the southeastern deserts and in the Colorado River valley.

Authorities.-Fisher, N. Am. Fauna, no. 7, I893, p. 99 (Owens Valley); H. C. Bryant, Condor, vol. xiii., I9II, p. 204 (food); Oberholser, Proc. Biol. Soc. Wash., vol. xxiv., I9II, p. 25 I (Honey Lake, near Milford, Calif.; orig. desc.); Mailliard, Condor, vol. xxi., I919, p. 75 (nest and eggs).

THIS LARGE, pale form from the northeastern portion of the State is typical of those northern interior varieties, merrilli, fallax, and the rest, which by reason of the more severe winters overtaking their breeding ranges, are obliged to shift southward each autumn. Their winter ranges are as yet imperfectly made out, but fisherella and fallax are likely to occur at that season almost anywhere in the southern portion of the State, and especially in the vicinity of water-holes upon the Mohave and Colorado deserts, or in the valley of the Colorado River. In such situations they are easily distinguishable from the resident saltonis by their darker plumage. Elsewhere, that is, west of the Sierro-San-San Mountain system, they are distinguishable from resident races by their large size, by their lighter, browner plumage, and more blended pattern. A hardier, darker bird, merrilli, invades the northern portion of the State in winter, but to a degree still problematical.

The Modoc Song Sparrow on his native heath differs in behavior by no appreciable quality from his less travelled fellows; but one fancies that he is more modest and reticent in his winter home.

On the I 7 th of June, I9I2, I was hunting through the willows which line the east shore of Goose Lake, in Modoc County. The east boundary of the patch was formed by a narrow-gauge railroad of recent construction. Hard by the site of an abandoned construction camp I most unexpectedly flushed a Modoc Song Sparrow from a massive paperwasp nest, which sat in a stark, naked willow about five feet up. The Sparrow's nest, of rather flimsy construction, had been sunk deeply into the fragile, papery structure on one side; and the exterior construction on that side was shielded and harmonized by a plentiful supply of scraps from a newspaper printed in modern Greek. The bird must have been moved, I think, rather by patriotism than by a taste for the classics, for an exposed paragraph mentions John Bull, Champ Clark, KANSAS (whose emphatic royalty everyone concedes), and Uncle Sam. These proper names are mercifully Anglicized (or Romanized), 


\section{The Song Sparrows}

but the next line contains reference to Tapt, who, as presidential incumbent had evidently been received into full communion by the patriotic Greeks. This exhibit of Vespa-Graeca-Melospizine architecture, together with the five eggs which it contained, now reposes in the collection of the Museum of Comparative Oölogy, and it constitutes one of her proudest trophies.

\section{No. 62r Salton Sink Song Sparrow}

A. O. U. No. 581 a, part. Melospiza melodia saltonis Grinnell.

Description.-A bleached race, retaining only the barest outlines of the familiar Song Sparrow pattern: the black element nearly suppressed, appearing only on exposed portions of tertials; general tone of upperparts smoke-gray; the rufous element both above and below lighter and brighter brown (nearest sayal brown); the whites of underparts clearer and more extended. Juvenal birds share the bleached appearance of their parents, and are very slightly streaked, of ten only upon chest and back. Measurements of type, an adult male (after Grinnell): wing 58.8 (2.315); tail 67.2 (2.646); culmen 10.5 (.4I); tarsus 20.7 (.815).

Range of $M . m$. saltonis.-Resident in Lower Sonoran zone from southern Nevada and southwestern Utah south to southeastern Arizona, southeastern California, northeastern Lower California, and Sonora.

Distribution in California.-Resident in the Colorado Valley tributary to Salton Sink, in the Imperial Valley, and along the valley of the Colorado; casual on the Mohave Desert (Oro Grande, Feb. 17, i8, 1918, by Wright M. Pierce).

Authorities.-Coues (Melospiza fallax), Proc. Acad. Nat. Sci. Phila., I866, p. 88 (Colo. Valley; s. Calif.); Cooper, Orn. Calif., I87o, p. 215 (Colo. Valley); Grinnell, Univ. Calif. Pub. Zool., vol. v., 1909, p. 268 (Mecca; orig. desc.); ibid., vol. xii., I914, p. I74 (Colo. R.; habits, crit.).

NATURE has played another of her practical jokes, and this time the victim is one of our beloved Song Sparrows. Snaring him with the lure of one of those cattail patches, which somehow manage to survive both in the Salton Sink and along the overflow lagoons of the Colorado River, she has soaked our friend with her eternal sunshine until he is bleached out almost beyond recognition. The blacks of a normal Song Sparrow's plumage have been reduced almost to the vanishing point, the browns are faded to palest tawny, and the grays are browned and blended. One is irresistibly moved to call him "Sandy"; and the discovery that this desert rat can chirp and sing and covet and wive with the lustiest provokes one, somehow, to disrespectful mirth.

Dr. Grinnell notes ${ }^{1}$ that this sparrow is characteristic of the arrowweed association in the Colorado River Valley, and that it is almost as fond of the young willows. The annual floods of this river, which occur in May and early June, defer the nesting of the sparrow accordingly;

1 "An Account of the Mammals and Birds of the Lower Colorado Valley," U. of C. Pub. in Zool., 1914. p. 17. 
and the nests, when they are built, are placed well above the mud of last year's high-water mark. In the vicinity of the Salton Sea, nesting occurs in March, and February nests in the same region are a strong probability.

Comparison of an extended series of Song Sparrows' eggs in the collections of the M. C. O. shows the eggs of $M$. m. saltonis to be brighter as to ground and decidedly lighter as to spotting than those of the eastern Song Sparrow. The difference, though unmistakable, is very much less than exists between the birds themselves; and one hesitates to affirm any bleaching action in the case of the eggs.

No. 63

\section{Lincoln's Sparrow}

A. O. U. No. 583. Melospiza lincolni lincolni (Audubon).

Synonym.--Lincoln's Song Sparrow.

Description.-Adults (sexes alike): Above grayish olive, sharply streaked with black, the streaks broadest on back and scapulars; the feathers of pileum bordered with rusty and olive-gray; exposed edgings of wings and tail pale cinnamomeous; pattern of head obscurely I 2 -rayed; below, throat and belly white, the former never quite immaculate, but with small arrow-shaped black marks; sides of head and neck and remaining underparts, including a well-defined band across chest, creamy buff, everywhere marked by elongated and sharply-defined black streaks; occasionally a dusky spot on center of breast. Bill blackish above, lighter below; feet and tarsi light brownish. Juvenals: Much like adult, but more heavily streaked and with buffy duller, more diffused. Adults measure: length about I 46. I (5.75); wing 63 (2.48); tail 53.6 (2. I I): bill $10.2(.40)$.

Recognition Marks.-Warbler size; bears general resemblance to Song Sparrow, from which it is distinguished by sharply-defined buffy chest-band, and by narrower, sharper streaks of breast and sides.

Nesting.- Nest: On the ground or in tussock of swamp, rarely low in bushes; a cup of twisted grasses, well concealed. Eggs: 4 or 5; pale bluish green, spotted and blotched, uniformly or in cloud-cap or wreath, with reddish brown (burnt umber). Av. of 5 eggs from Mono County (M. C. O.): $19.3 \times 13.97(.76 \times .55)$. Av. of 5 eggs from Salt Lake Co., Utah: I $6.5 \times 13.7(.65 \times 54)$. Season: June: one brood.

Range of Melosfiza lincolni.-North America.

Range of $M$. l. lincolni.-As above, except northwest coast district in Alaska. Breeds in Boreal zone, from limit of trees in Alaska and British Columbia south to northern Minnesota, northern New York, etc., and in the Sierra-Cascade and Rocky Mountain systems south to southern California and New Mexico; winters from southern California, Oklahoma, and the Gulf States south to Guatemala.

Distribution in California.--Breeds in mountain meadows of the Lower Boreal zone in the higher ranges throughout the State. Recorded from the San Jacintos, the San Bernardinos, the Sierras (including Shasta), the Warners, the Trini- 


\section{The Lincoln Sparrows}

ties, the Yolla Bollies, and associated ranges. Winters in southern California, north at least to the San Joaquin Valley, and on the islands.

Authorities.-Baird, Rep. Pac. R. R. Surv., vol. ix., I 858, p. 482 (Ft. Tejon, etc.); Heermann (Peucaa lincolnii), Rep. Pac. R. R. Surv., vol. x., I 859, p. 49; Judd, U. S. Dept. Agric., Biol. Surv. Bull., no. I5, I9or, p. 86 (food); Grinnell, Univ. Calif. Pub. Zool., vol. v., I908, p. 98 (habits; crit.); Pierce, Condor, vol. xviii., I916, p. 34 (San Bernardino Mts.; desc. nest and eggs.)

\section{No. 63a Forbush's Sparrow}

A. O. U. No. 583a. Melospiza lincolni gracilis (Kittlitz).

Description.-Closely resembles the foregoing form, but alleged to be darker, more broadly marked with black above and below; upper plumage more olivaceous.

Nesting.-Does not breed in California. Nest and eggs probably indistinguishable from those of preceding race.

Range of $M . l$. gracilis.-Breeds in Northwest-west coast district in Alaska from Prince William Sound south (at least) to Sitka; winters south to southern portion of Lower California.

Occurrence in California.- Winters at lower levels, commonly in the northwest humid coast district, more sparingly southwest of the Sierras, and upon the deserts to the Mexican line. Range imperfectly distinguished from that of $M$. l. lincolni.

Authorities.-McGregor (Melospiza lincolni striata), Bull. Cooper Orn. Club, I, I 899, p. 35 (Calif. localities); Grinnell, Auk, vol. xxi., I904, p. 274 (syn., meas., crit.); Oberholser, Proc. Biol. Soc. Wash., vol. xix., I906, p. 42 (nomencl.); Grinnell, Univ. Calif. Pub. Zool., vol. v., I909, p. 23I (Alaska; habits, nest, etc.).

WITH the possible exception of the Nelson Sparrow (Ammospiza c. nelsoni), Melospiza lincolni is the shyest of Californian finches,- -shyest, that is, in winter, when all but birds of the sedentary species are treading on strange ground, and feel the need of acting circumspectly. Although so inconspicuously dressed that it could well afford to rely upon its protective coloration, the winter Lincoln skulks and freezes, hides behind plant stems, or at a word dives into the depths of the thickest cover. The bird seems to possess an almost uncanny consciousness of the human eye, and it begins to evade upon the instant of recognition, as though struck by the beam of a burning-glass. Once, in the valley of the Colorado River, I caught sight of a Lincoln Sparrow in a naked mesquite tree some twenty feet away. Instead of flying, the bird became instantly motionless, "froze" to a rigidity never before witnessed in a Passerine bird. Its conduct puzzled me, so that I advanced, retreated, and circled half way around it several times, but the bird never moved a muscle, save to bat an eyelid, slowly and painfully. Altogether it behaved like a foredoomed victim whose arch enemy, the Sharp-shin (Accipiter velox), has his deadly eye upon it. And forty years of acquaintance with the Lincoln Song Sparrow in winter and on migrations will scarcely yield 
The Lincoln Sparrores

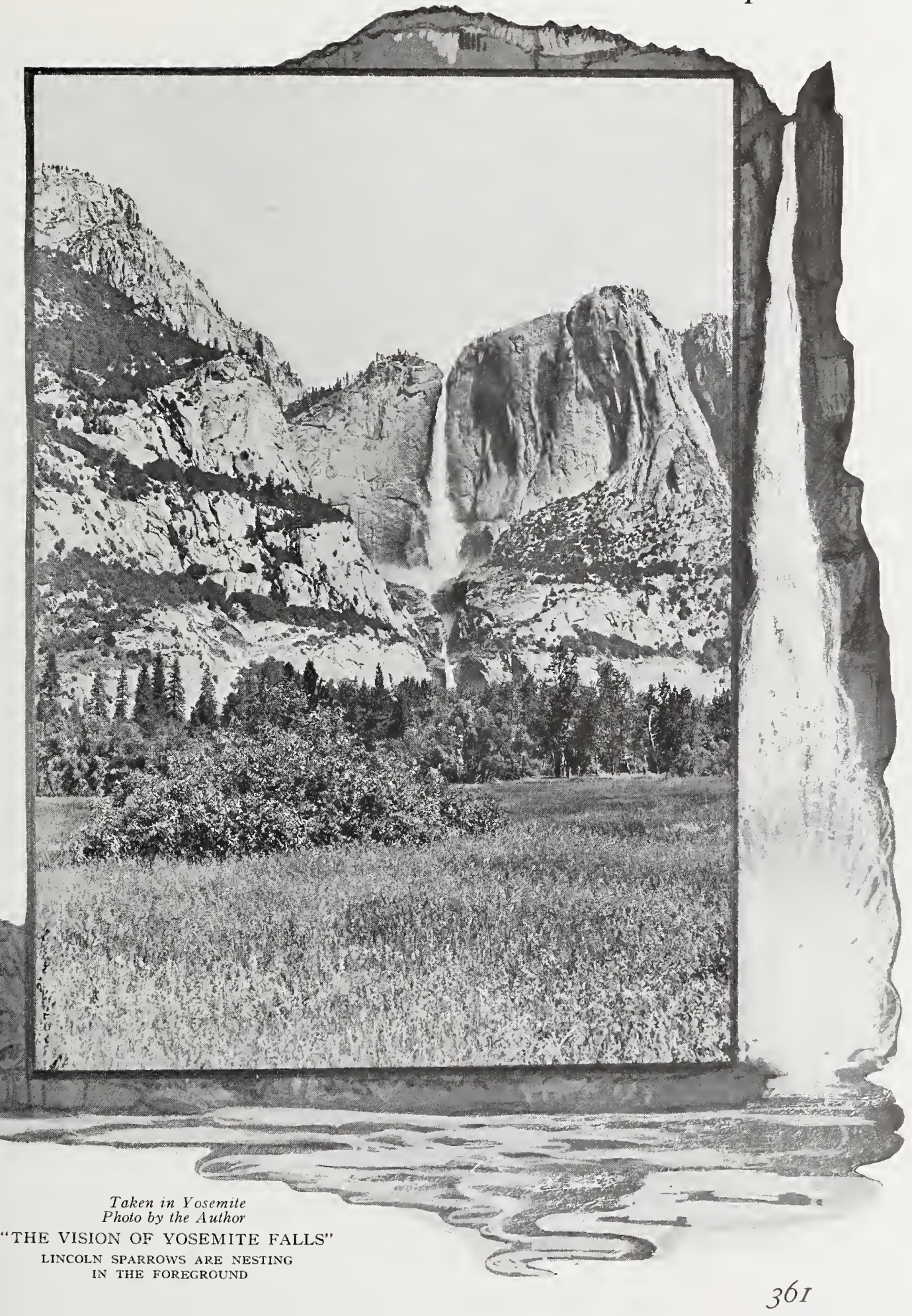




\section{The Lincoln Sparrows}

one more than fleeting glimpses, baffling disappearances, or strained moments of maddening unnaturalness.

Quite different is the story of the Lincoln Sparrow in his summer home, an emerald meadow in the Sierras, or a lush-bound cienaga in one of the southern ranges. There he bursts upon you in a torrent of music, a flood which leaves you fairly gasping. This little, slinking, bird-afraidof-his-shadow gets all at once the courage of mighty convictions, when he has the mountain to back him; and though he still skulks and evades, it is henceforth rather as a modest hero shunning the plaudits of an

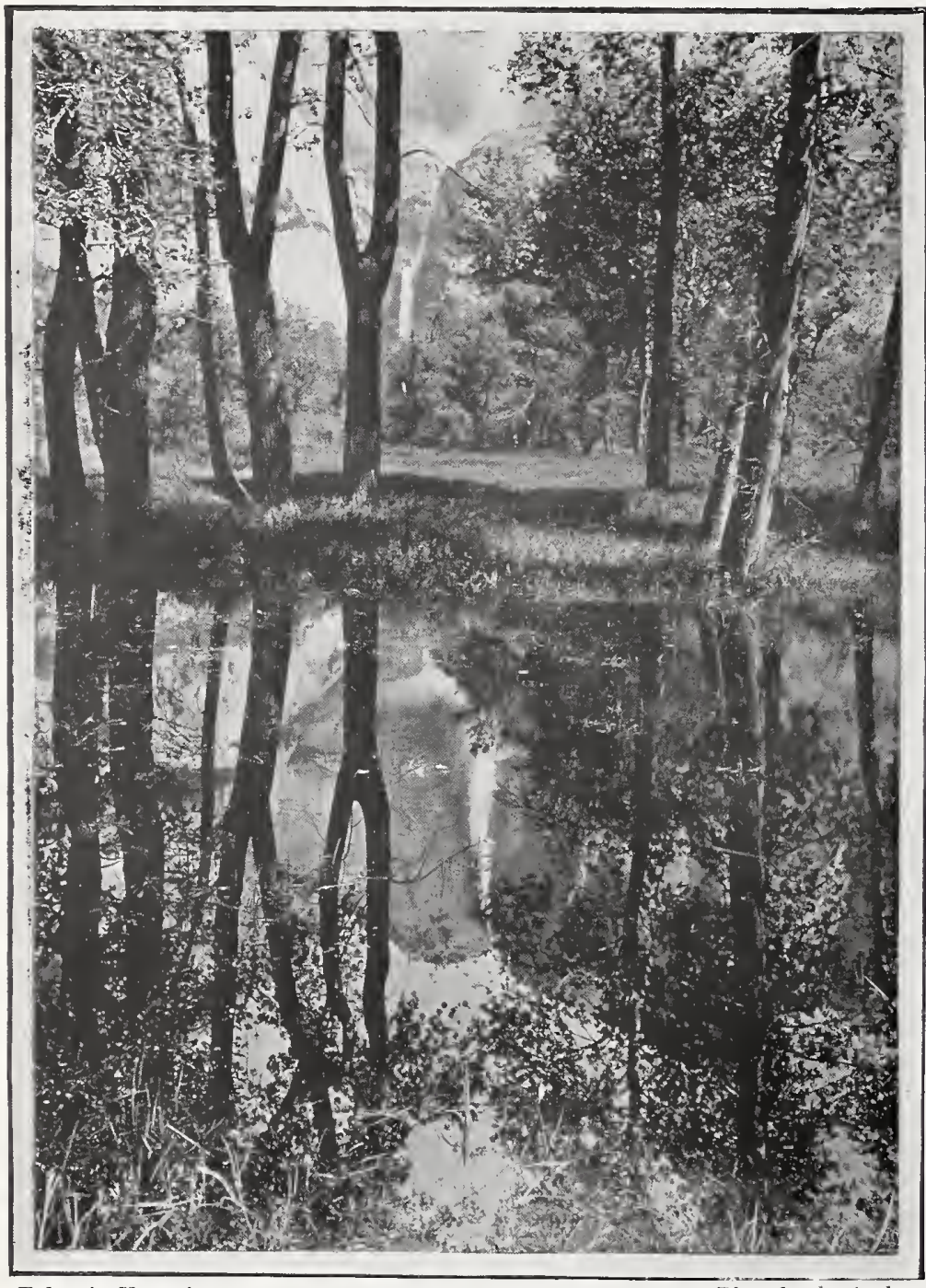

Taken in Yosemite LINCOLN'S CATHEDRAL unrestrained admiration.

The song of the Lincoln Sparrow is of a distinctly musical order, being gushing, vivacious, and wren-like in quality, rather than lisping and wooden, as are so many of our sparrow songs. Indeed, the bird shows a much stronger relationship in song to the Purple Finch than it does to its immediate congeners, the Song Sparrows. The principal strain is $\mathrm{gurgling}$, rolling, and spontaneous, and the bird has ever the trick of adding two or three inconsequential notes at the end of his ditty, quite in approved Purple Finch fashion. Linkup, tinkup perly werly willie willie weeee (dim.) says one; Riggle, jiggle, eet eet eet eer oor, another. Che willy willy willy che quill; Lee lee lee quilly willy willy, and other 


\section{The Lincoln Sparrows}

such, come with full force and freshness at a hundred yards to the listeners of the trail around Bluff Lake in the San Bernardinos, or at Camp Ahwahnee in the Yosemite. Indeed, how could any creature, however trivial, gaze upon the sublimities unfolded along the hallowed reaches of the Merced without bursting into song! Be that as it may, I shall never recall the vision of $\mathrm{Yo}_{\mathrm{O}}$ semite Falls, as seen from the road just below the village, without hearing the wild music of the Lincoln Song Sparrows sounding like a pibroch above the solemn thunders of this majesty. And if one set out to collect a photographic series of favorite haunts of the Lincoln Sparrow, he would have a muster roll of California's finest: Tahquitz Ridge, the Simpson Meadows, the Yosemite, the eastern flank of the

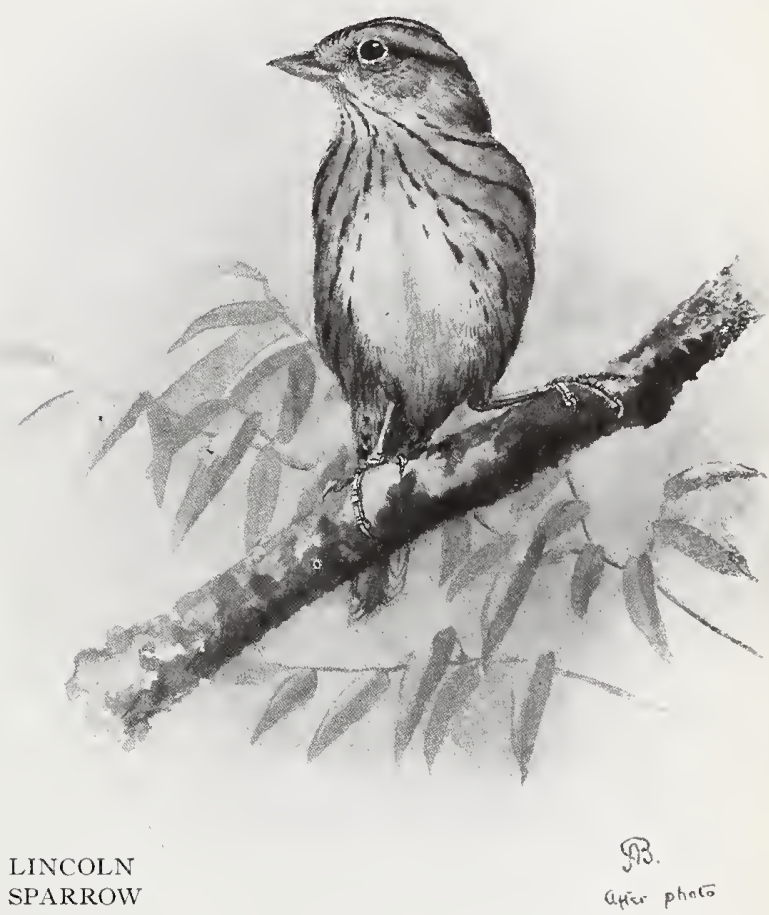
Warners, Sisson, and Mt. Shasta-these are a few of the trysting places of lincolni within the author's experience. And these are but a drop in the bucket as compared with the uncharted multitude of beauty spots which the careful taste of lincolni has honored.

Nests of the Lincoln Sparrow are hidden at the base of bush clumps or grass tussocks, in the depths of the local swamp. The female slips off as unobtrusively as a mouse, and threads the mazes in swift pedal retreat before taking to wing. The youngsters, too, according to Mr. Aretas Saunders ${ }^{1}$ move over the ground with astonishing proficiency before ever they are able to fly.

After the young have quitted the nest the solicitude of the parents becomes very manifest. The birds follow one about with soft little chips of remonstrance, and they are very jealous of avian intruders. The scolding note has nothing of the sharpness exhibited by the Song Sparrow ( $M$. melodia), nor of the asperity of the Junco, although it most resembles that of the latter in its residual quality, as in the frequency of its utterance. The bird occasionally erects its crown feathers in inquiry or excitement, as do Chipping Sparrow, White-crowned Sparrow, and others. Once, in a more northern swamp, on the flanks of Mt. Rainier, I had 


\section{The Lincoln Sparrows}

opportunity to compare lincolni and melodia (morphna) at short range. Singularly enough, the jealous Lincoln, who had just furiously evicted a Yellow Warbler from the home nesting tree, allowed the Song Sparrow to sit unchallenged at a foot's remove. Lincolni was not only the smaller bird, but it was more lightly colored, and it had a sharp-cut streakiness of plumage which does not characterize melodia. A comparison of many examples, however, showed the similarity of head pattern between the

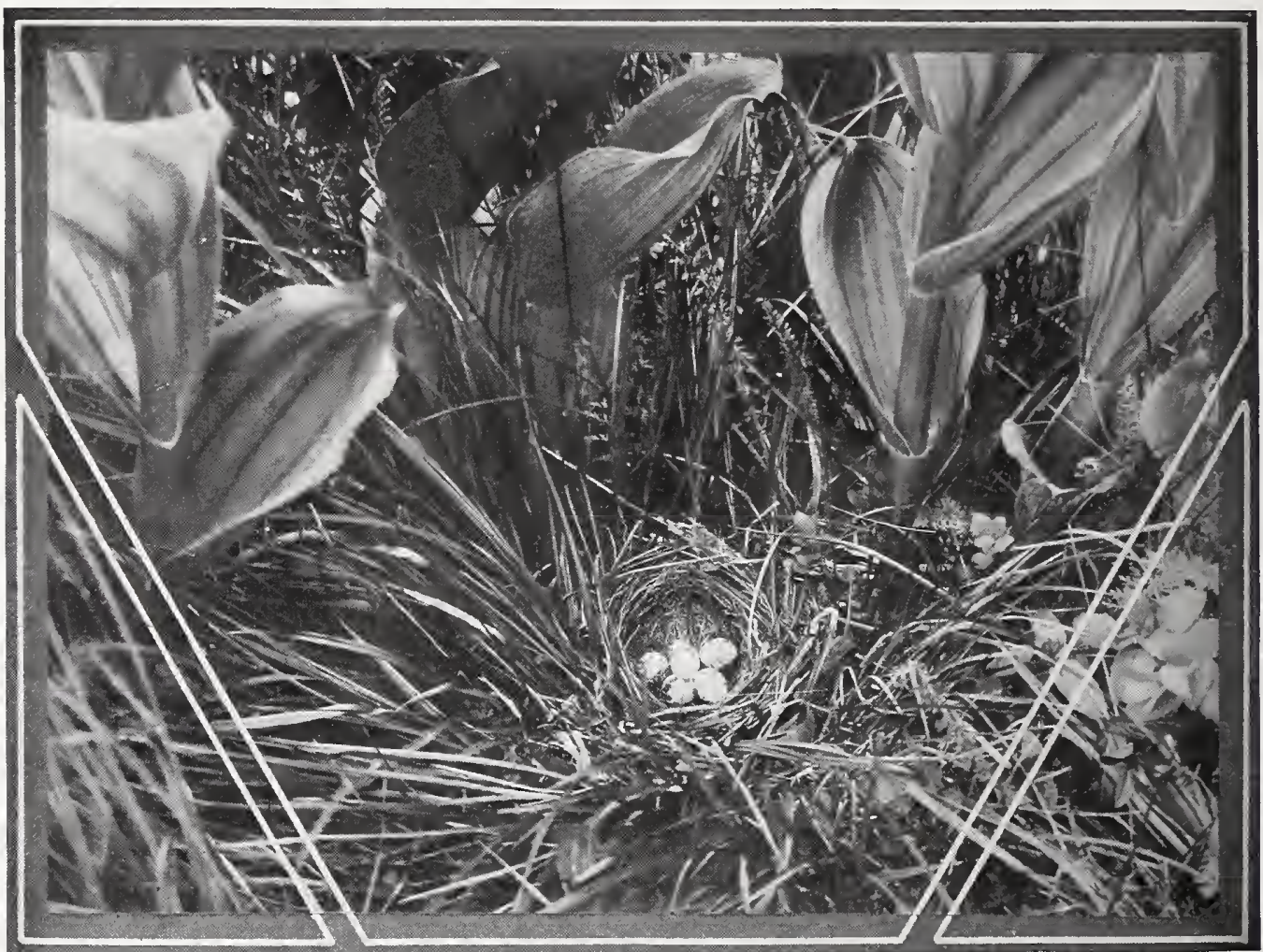

Taken in San Bernardino County

Photo by Wright M. Pierce

NEST AND EGGS OF LINCOLN SONG SPARROW

two sparrows to be very noticeable, while the buffy tinge of the Lincoln's breast would appear to be one of its least constant marks.

The claims to recognition of an alleged subspecies, $M$. l. striata Brewster, are not at all impressive. Granting the validity of the meager characters claimed, as between breeding specimens from Alaska and those of our own mountains, the attempt to distinguish winter specimens breaks down utterly; and you may report either lincolni or striata from Berkeley or San Diego, according to the state of your digestion or the prevailing fashion in eyelashes. If the latter are worn drooping this year, you pretend to see more streaks; that's all. 


\section{The Fox Sparrows}

No. 64

\section{Swamp Sparrow}

A. O. U. No. 584. Melospiza georgiana (Latham).

Synonym.-Swamp Song Sparrow.

Description.-Adults (sexes alike): Crown hazel; exposed edges of wings and tail (strongest on greater wing-coverts) hazel, paling to cinnamomeous; remaining upper plumage black, bordered by brownish buffy or olivaceous, the blacks strongest on forehead, occiput, upper back, and scapulars; the cervix invaded by gray, continuous with sides of neck and breast; a clear gray superciliary stripe bordering the bay; chin and throat and breast, centrally, white; the remaining under plumage heavily washed with brownish gray, changing to brownish buffy on flanks and crissal region. Bill dark above, lighter below; feet and tarsi light brown. Immature birds, even in the second year (?), lack the hazel crown, having black with rusty edgings instead, and are much more strongly brownish below and on sides. Adult males measure: length about I42.2 (5.60); wing 62.5 (2.46); tail 59.2 (2.33); bill II.7 (.46); tarsus 2 I.6 (.85). Females are smaller.

Recognition Marks.-Warbler size; a Song-Sparrow-like bird, unmarked below; chestnut crown of adult with swamp-loving habits distinctive.

General Range.- North America, chiefly east of the Great Plains. Breeds from west central Alberta, central Keewatin, and Newfoundland south irregularly to West Virginia, central Ohio, and northern Missouri; winters from about its southern breeding range south to the Gulf and into Mexico. Accidental in Colorado, Utah, Arizona, and now California.

Occurrence in California.-One specimen taken Nov. I, I92 I, near Keeler, Inyo County, by Mrs. May Canfield and Laurence M. Huey, now in the Dickey Collection (J I797).

Authority.-Dickey, Condor, vol. xxiv., I922, p. I36 (Keeler, Inyo Co.).

ISN'T this splendid! 'Think of coming two thousand miles from home just to be enrolled in the California Society, Ltd! Well; some of the rest of us have done as much, and they didn't shoot us for it-yet. It was rather a mistake, though-no; of course I don't mean that. I mean it was a mistake for this little bird to suppose that we needed Song Sparrows in California. Why, we already have twenty varieties on our hands; and if we needed more, Dr. Grinnell could attend to it. Birdie, I guess you got what was coming to you-" IJ I797"!

No. 65

\section{Fox Sparrow}

\section{No. 65 Fox-colored Sparrow}

A. O. U. No. 585. Passerella iliaca iliaca (Merrem).

Synonym.-Eastern Fox Sparrow.

Description.-Adult (sexes alike): In general hazel brown, mingled with slaty gray and olivaceous above, and sharply outlined against white ground upon under- 


\section{The Fox Sparrows}

parts, the rufous element clearest, cinnamon-rufous, on upper tail-coverts and tail; also nearly pure upon auriculars, sides of throat, and spotting of chest; deepening upon sides, where present in broad streaks having dusky centers, and upon back where broadly margined with olivaceous gray; wings chiefly russet, with dusky brown centering of feathers; edge of wing and extreme tips of median and greater coverts whitish; crown, cervix, and sides of neck slaty gray (light mouse-gray or olivaceous gray), tipped more or less, especially upon crown, with rufous, and showing tendency to streaking; rump olivaceous gray; underparts white, immaculate on abdomen, chin, and lower throat, crossed on upper throat with an irregular chain of rufous spots, marked boldly on chest with rufous, and across breast and of ten along sides of breast with sharp sagittate marks of dusky; a touch of white on either side of the head above the lores persisting throughout the species. Bill (drying) reddish horn-color above, lighter below; feet (drying) light brown. Specimens differ chiefly in the strength and diffusion of the olivaceous gray element of the upperparts. Length I65.I-I84.I5 (6.50-7.25); wing 88.5 (3.48); tail 7I.7 (2.82); culmen II.6 (.46); depth of bill 9.4 (.37); width at base $8.2(.32)$; tarsus $24.2(.95)$.

Recognition Marks.- Sparrow size; distinguishable from all other sparrows by the generous streaking of underparts and sides, and from all other subspecies by the brightness of its reds.

Nesting of Passerella iliaca.-Nest: A bulky structure composed externally of coarse twigs, and bark-strips, with leaves or moss, internally of fine grasses or even fur, feathers, etc.; placed low or at moderate heights in bushes, thickets, saplings, etc., or even upon the ground without attempt at concealment. Eggs: 3 or 4 in the South; 4 or 5 in the North; rounded ovate; pale niagara green or greenish gray, spotted, sometimes uniformly and heavily, or else sparingly, or blotched or cloud-capped (rarely, if ever, wreathed), with reddish brown (burnt umber or cameo-brown to deep chocolate). Av. size 22.35 x I $6.5(.88 \times .65)$. Extremes $20.3-25.4$ by 15.5-I $7.8(.80-$ I.oo by $.6 \mathrm{I}-.7 \mathrm{O})$. Season: May-July; two broods. While the material available does not justify an attempt to define subspecific distinctions in the eggs of Fox Sparrows, there is a rough correlation in size between the eggs and the parent birds, and a tendency toward brighter as well as heavier coloring in the case of the Alaskan coastal races.

Range of Passerella iliaca.-North America, but chiefly western, breeding north of the United States and in the mountains of the West; wintering south to the Gulf States and southern California.

Range of P.i.iliaca.--Breeds in the Boreal zones of Canada and northern Alaska, except the southwestern portion, from the limit of trees south to northern Manitoba and the Magdalen Islands; winters in the eastern United States from about Latitude $40^{\circ}$ south to the Gulf, and in the West casually upon the southern coast of Alaska south to California.

Occurrence in California.- - Rare or casual midwinter visitant; reported from widely scattered localities, chiefly southern.

Authorities.-Coues, Birds of the Northwest, I874, p. I6I ("Accidental in California, spec. in Mus. S. I."'); Henshaw, Bull. Nutt. Orn. Club, vol. iii., I878, p. 7 (crit.); Nelson, Rep. Nat. Hist. Coll. Alaska, I887, p. 195 (habits, song, nest and eggs, etc.); W. E. Bryant, Proc. Calif. Acad. Sci., 2nd ser., vol. ii., I889, p. 90 (Poway, San Diego Co.); Judd, U. S. Dept. Agric., Biol. Surv. Bull., no. 15, I901, p. 87 (food); Swarth, Univ. Calif. Pub. Zool., vol. xxi., I920, p. I I4, figs. (occurrence in Calif., distr., desc., crit.). 


\section{The Fox Sparrows}

\section{No. 65a Alberta Fox Sparrow}

A. O. U. No. 585 a, part. Passerella iliaca altivagans Riley.

Description.--Similar to P. i. iliaca, but darker and duller, the pattern of the upper plumage almost completely blended; hence, upper tail-coverts and exposed surfaces of folded tail and wings russet; remaining upperparts, including pileum and sides of neck, mingled olive-brown and slaty; spotting of underparts and streaking of sides broader, more copious (invading lower throat), and darker, sepia. Mandible yellow, darkening on tip. Measurements: wing 8I (3.19); tail 76 (2.99); bill Io.6 $(.42)$; depth of bill $9.4(.37)$; width $7.9(.31)$; tarsus 23.1 (.9I).

Range of $P . i$. altivagans.-Breeding in central Alberta in an ill-defined area lying between the range of iliaca upon the northeast and schistacea upon the west and south.

Occurrence in California.- " Rare winter visitant to the northeastern section of the State, casually south to Los Angeles County." - (Grinnell).

Authorities.-Riley, Proc. Biol. Soc. Wash., vol. xxiv., I9I I, p. 235 (orig. desc., type locality Moose Branch of Smoky R., Alberta; spec. from Fort Crook, Shasta Co., Calif.); Swarth, Univ. Calif. Pub. Zool., vol. xxi., 1920, p. I I9, figs. (occurrence in Calif., distr., desc., crit.).

\section{No. 65b Shumagin Fox Sparrow}

\section{A. O. U. No. 585a. Passerella iliaca unalaschcensis (Gmelin).}

Description.- Somewhat similar to $P$. i. iliaca, but much darker and pattern completely blended; spotting of underparts much heavier and darker, brown. In particular: Upperparts, including pileum, sides of neck, and sides of breast, olivebrown, becoming more rufescent, cinnamon-brown on upper tail-coverts and exposed upper surfaces of wings and tail; underparts white, heavily and broadly streaked with dark brown (Prout's brown or mummy-brown to sepia). The spots invade the chin, but are sparse upon chin, lower throat, and abdomen. Measurements: wing 83.6 (3.29); tail 76.2 (3.00); culmen I 2 (.47); depth Io (.39); width $8.7(.34)$; tarsus 25.2 (.99).

Range of $P . i$. unalaschcensis.--Breeding in the Alaska peninsula, Unalaska, and the Shumagin Islands; south in winter through western California to San Diego County.

Distribution in California.-Imperfectly determined, but occurs in winter in widely scattered localities west of the Sierras, chiefly southerly.

Authorities.-Osgood, .N. Am. Fauna, no. 24, 1904, p. 76 (crit.; unalaschcensis and iliaca regarded as specifically distinct); Swarth, Univ. Calif. Pub. Zool., vol. xxi., 1920, p. 127, figs. (occurrence in Calif., distr., desc., crit.).

\section{No. 65c Kadiak Fox Sparrow}

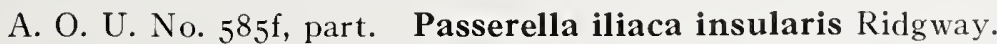

Description.- Similar to $P$. $i$. unalaschcensis, but slightly darker and more rufescent throughout, and with heavier spotting below. Size scarcely different.

Range of $P$. $i$. insularis. - Breeding range central upon Kadiak Islands (line of demarcation from sinuosa upon the north undefined); wintering south to southern California. 


\section{The Fox Sparrows}

Occurrence in California.- "Fairly common winter visitant south through the interior west of the Sierras, and chiefly east and south of the humid coast belt, to the San Diegan district and the Santa Barbara Islands."-(Grinnell).

Authorities.-Oberholser, Proc. U. S. Nat. Mus., vol. xxii., I900, p. 232 (Santa Catalina Id.); Swarth, Univ. Calif. Pub. Zool., vol. xxi., I920, p. I32, figs. (occurrence in Calif., distr., desc., crit.).

\section{No. 65d Valdez Fox Sparrow}

A. O. U. No. 585 f, part. Passerella iliaca sinuosa Grinnell.

Description.-Similar to $P$. i. insularis, but still darker (as compared with znalaschcensis) and less rufescent.

Range of $P$. i. sinuosa.-Breeding range central upon the islands and shores of Prince William Sound, Alaska; wintering south to southern California.

Occurrence in California.-Winter resident, apparently well distributed, but no records from southeastern portion of State.

Authorities.-Grinnell, Univ. Calif. Pub. Zool., vol. v., I9Io, p. 405 (orig. desc., type locality Knight Id., Prince Wm. Sd., Alaska; habits, nest and eggs, crit.; Calif. in winter); Swarth, Univ. Calif. Pub. Zool., vol. xxi., I920, p. I35, figs. (occurrence in Calif., distr., desc., crit.); Mailliard, Condor, vol. xxiii., I92I, p. I80 (migr. in Calif.).

\section{No. 65e Yakutat Fox Sparrow}



Description.-Similar to P. i. sinuosa, but still darker, although more rufescent; increase of spotting on underparts tends to coalescence on sides and flanks and across chest. Also similar to $P$. $i$. townsendi, but less rufescent; a little smaller every way.

Range of $P$. $i$. annectens. - Coast of Alaska, breeding centrally about Yakutat Bay, but also south to Cross Sound; winters south to California.

Occurrence in California.--Common winter resident, chiefly confined to the humid coast belt, but also east to Placer County (Adams) and San Diego County (Bishop).

Authorities.-Vigors, Ornithology, in the Zoology of Captain Beechey's Voyage, I 839, p. I9 (desc. of a fox sparrow [Fringilla meruloides] from Monterey that has been argued to be the same as the bird now called Passerella iliaca annectens); Grinnell, Condor, vol. iv., I902, p. 44 (crit.); Swarth, Univ. Calif. Pub. Zool., vol. xxi., 1920, p. I40, figs. (occurrence in Calif., distr., desc., crit.); Allen, Condor, vol. xxii., I920, p. I6 (return of a bird to the same winter home).

\section{No. 65f Townsend's Fox Sparrow}

A. O. U. No. $585 \mathrm{~g}$. Passerella iliaca townsendi (Audubon).

Description.-Similar to $P$. $i$. annectens, but more rufescent. Also similar to P. i. fuliginosa, but lighter and redder. In particular: Above and on sides reddish brown, bister, brightening (Prout's brown) on upper tail-coverts and exposed surfaces of wings and tail; underparts white but heavily and broadly streaked with bister, the streaking often involving the entire throat and abdomen. Smaller: wing 78.6 (3.09); tail 7 I.4 (2.8I); culmen I I.6 (.456); depth at base 9.I (.358); width $7.6(.30)$; tarsus $25(.98)$.

$$
368
$$




\section{The Fox Sparrows}

Range of P. i.townsendi.-Southeastern Alaska; breeds on the coasts and islands from Cross Sound south to Dixon entrance; winters south to Monterey, California.

Occurrence in California.-Winter resident in the northwestern humid coast strip, south to Pacific Grove.

Authorities.-Grinnell, Univ. Calif. Pub. Zool., vol. v., I909, p. 232 (Alaska; habits, nest and eggs, etc.); Willett, Auk, vol. xxxii., I9I5, p. 305 (Alaska; desc. nests, dates of nesting); Swarth, Univ. Calif. Pub. Zool., vol. xxi., I920, p. I44, figs. (occurrence in Calif., distr., desc., crit.).

\section{No. 65g Sooty Fox Sparrow}

A. O. U. No. 585 e. Passerella iliaca fuliginosa Ridgway.

Description.--Similar to $P$. i. townsendi, but plumage much darker and less rufescent; also averaging larger. In this form nearly all semblance of distinction in the streaking of the underparts has been lost. The bird is scarcely "sooty," but it is of a very dark and nearly uniform brown. Larger: wing 82 (3.23); tail 76.I (2.99); culmen II.9 (.47); depth of bill at base 10.6 (.4I7), width 8 (.3I5); tarsus 26 (1.02).

Range of $P$. i. fuliginosa.- "Northwest coast strip. Breeds on the coast of British Columbia, Vancouver Island, and northwestern Washington; winters south along the coast to San Francisco, California" (A. O. U.).

Occurrence in California.-Sparingly resident through the humid coast belt south to San Francisco.

Authority.-Swarth, Univ. Calif. Pub. Zool., vol. xxi., I920, p. I49, figs. (occurrence in Calif., distr., desc., crit.).

THE 'LIBERTY of difference' is the most fascinating aspect of bird-life, as it is one of the most engaging qualities in our fellow-men. How beings of like origin may become different under the altered circumstances of life, and the certainty that they will change under the varying impact of experience, this it is which gives zest to research and which makes bird study a reflex of life itself. The tendency to vary is one of the fundamental and familiar qualities of life. Species, genera, families, orders,-all are the result of progressively divergent movements of variation. But if the outcome in the manifold diversity of the living is agreeable to us, the beginnings of difference must exert a tenfold fascination. The detection of these beginnings is, indeed, the flattering evidence of our own progress. Just as Millet could recognize twentytwo shades of green where a layman saw only two, so the specialist in animal variation sees a world of related beauty, a realm of historical order, where the layman sees only vague confusion, or a dull array of uncomprehended names.

For practical purposes there is only one Fox Sparrow. Pages might be written about the Fox Sparrow, pages alike true of birds from Anticosti or the Yukon or Kadiak or the San Jacinto Mountains, - pages in which no sense of difference should be allowed to intrude itself upon the 


\section{The Fox Sparrows}

lay mind. Yet to the student the outstanding joy of acquaintance with the Fox Sparrow is the recognition of differences. Fox Sparrows from Kadiak Island are different from Fox Sparrows in the Warner Mountains. How? and why? Well, that would take a volume to tell; and the best half of the facts would still have to be guessed at. All we can do is to outline or summarize.

The extremes of difference manifested within the ranks of the "species" Passerella iliaca would undoubtedly be sufficient to justify separation into distinct species, provided no intermediate specimens, no "missing links," or intergrades, existed. But these do exist in unbroken perfection, and we have, instead of, say, three separable species of Fox Sparrows, a group of ten or a dozen (sixteen according to Mr. Swarth) incipient species, each exhibiting certain tendencies or directions of growth, and each entitled to some sort of distinctive recognition, yet each surrounded by an aura of intergrades, an assemblage of "transitional forms," every individual of which is just as well entitled to consideration, to recognition, to description, as are those arbitrarily chosen by us for distinctive attention. Hence, again, the species Passerella iliaca is one,

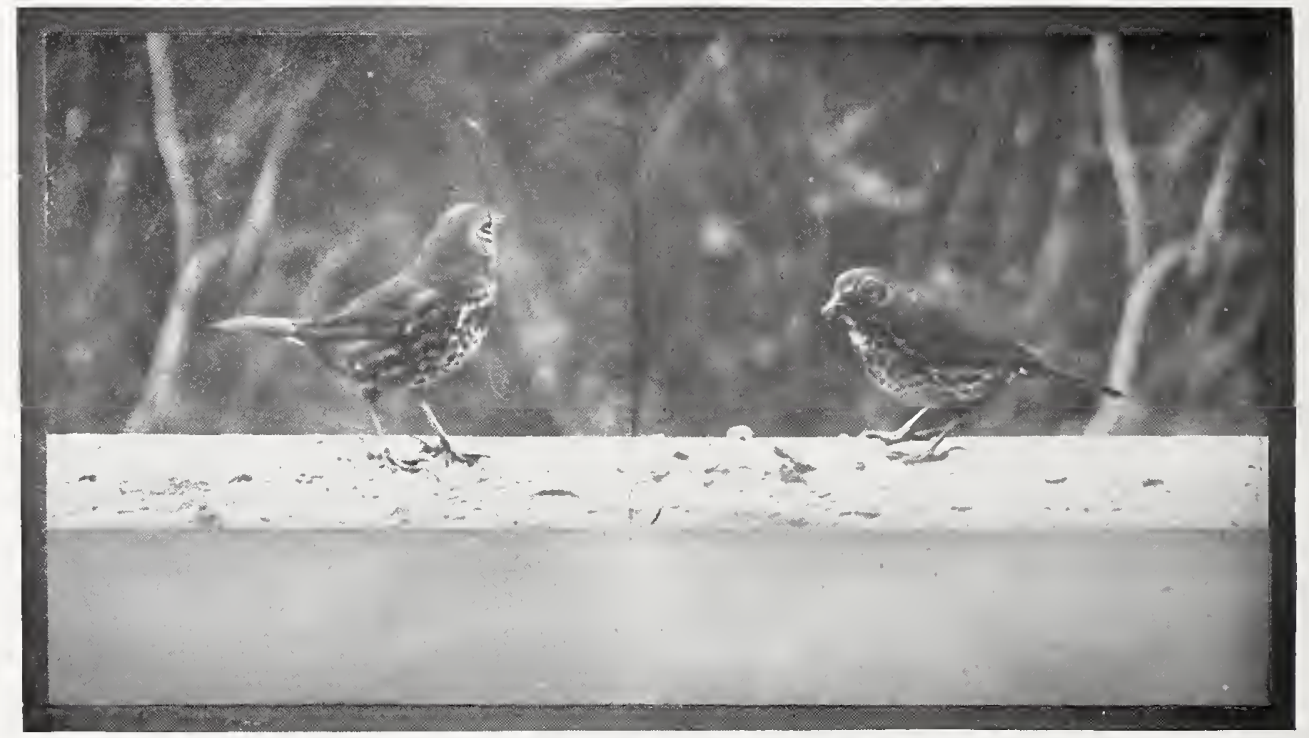

Taken in Berkeley

MRS, ALLEN'S WINTER GUESTS

Photo by Amelia S. Allen

YAKUTAT FOX SPARROW(S?). TWO PRINTS, POSSIBLY OF SAME BIRD, COMBINED

and will continue to be such unless and until the Fox Sparrow population of some intervening area drops out and so isolates a remoter group.

The exceeding complexity of the problem which confronts the student in the discussion of the monotypic genus Passerella may be summarized 


\section{The Fox Sparrows}

in the statement that all known geographical races of this highly plastic species winter, at least casually, in California. This includes (by seven exa m ples a nd m a n y intermediates) the most highly differentiated type, iliaca iliaca, normally restricted in winter to the eastern United States east of the Rocky Mountains. The problem is also of peculiar interest to the Californian, not alone because of the present hospitality enjoyed by this widely distributed species, but because of ancient tenure. The

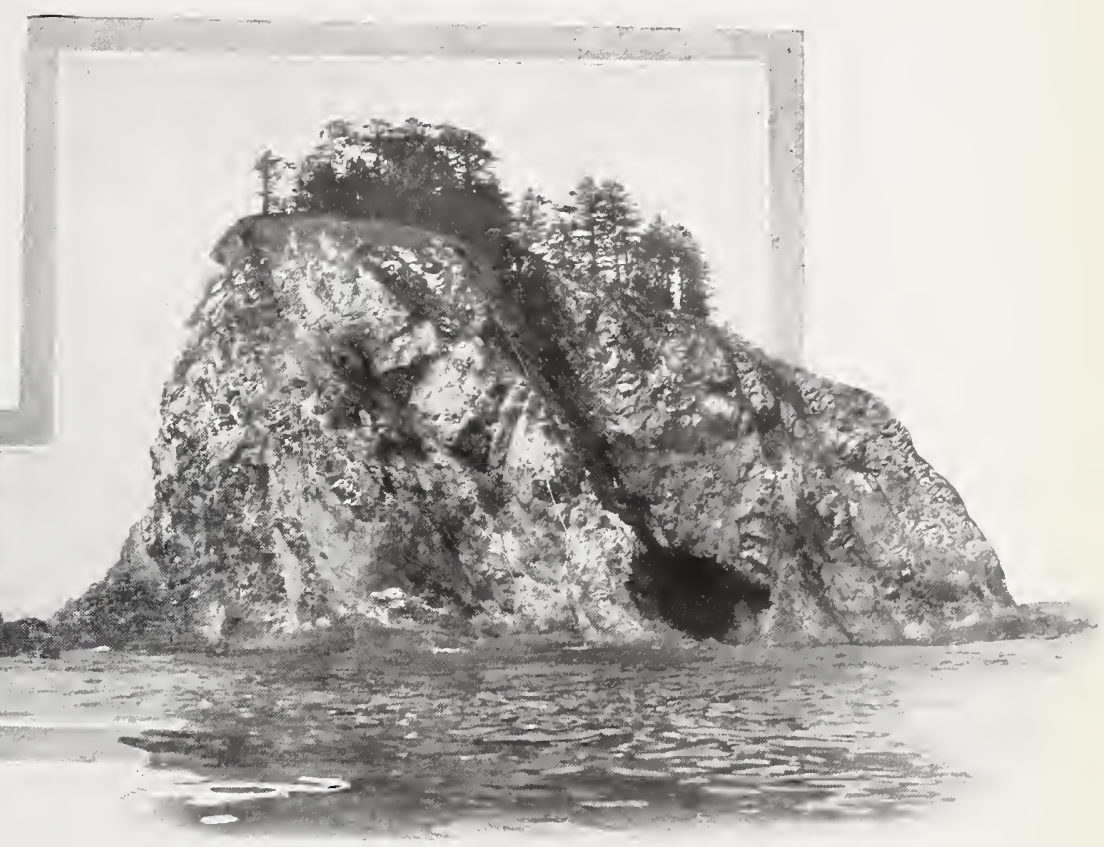

Taken in Washington

Photo by the A uthor

CARROLL ISLET: A SUMMER HOME OF THE SOOTY FOX SPARROW

Fox Sparrow not improbably originated here; or if not, it is at least certain that the species found in California its chief asylum before the oncoming of the great Ice Age. When the crisis was past, the birds pressed close upon the ice monster's retreating heels. But they did not forget California. Every winter they steal back like jolly gray ghosts, and occupy the fastnesses of riverside thickets, of young evergreens, and of hillside chaparral, in such numbers that the mind is staggered with the realization.

Let us pause a moment upon the last thought. Of the total area of California let us say that one-tenth is exactly suited to the requirements of the Fox Sparrows in winter. Upon any acre of this area one may call up, by "screeping" diligently, from one to ten birds which may be counted. Fully half the birds fail to answer, or, responding, are yet too shy to enroll themselves, their presence being indicated by distant tsooks, or movement of bushes. Very vague, of course, this method; but from it I gather that there are present on a winter's day in California anywhere from twenty million to two hundred million Fox Sparrows. We are each of us, man, woman and child, entitled to the exclusive care of, or reciprocal interest in, from five to fifty Fox Sparrows! 


\section{The Fox Sparrows}

It is one thing, however, to discover our ownership and quite another to collect our dues of opportunity for inspection, or exhibition of distinctive traits. The Fox Sparrows in winter are bafflingly modest.

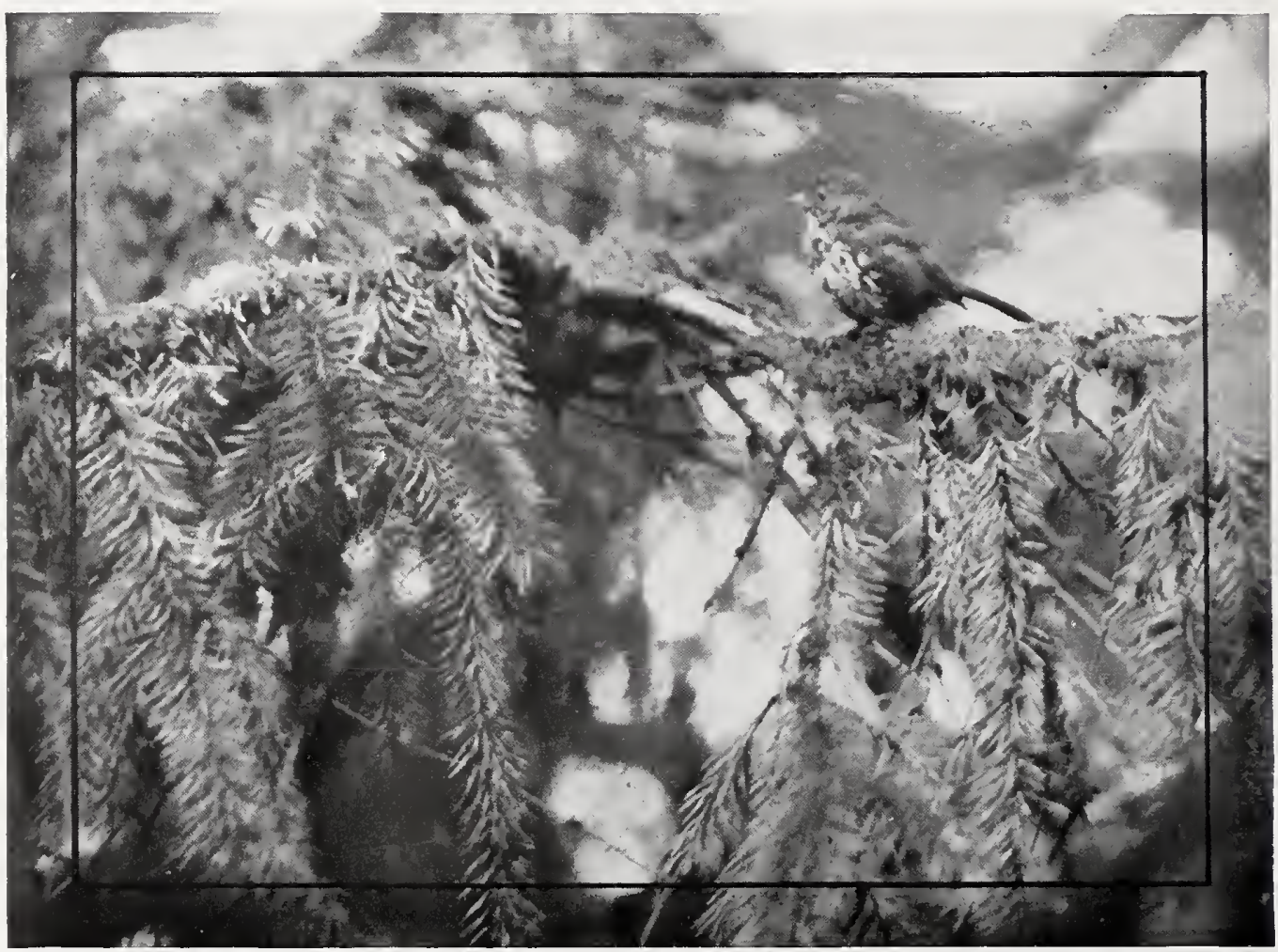

Taken on Carroll Islet

SOOTY FOX SPARROW IN SUMMER

Photo by the Author

Their colors blend so perfectly with the leaf-strewn ground and the dingy stems of the under chaparral, or else with the leaf-mold and rotting logs of the northern under forest, that search with the eyes alone is useless. Except for the circumstance of screeping (which is the birdman's trick, and "no fair" in a discussion of averages), meetings with Fox Sparrows are rare or casual. But if you are much out-of-doors the time will come, while you are footing it softly along some woodland path, that a demure brown bird will hop out in front of you and look unconcernedly for tid-bits before your very eyes. The bird is a little larger than a Song Sparrow, but you will require a second glance to note that the colors of the upperparts are smoothly blended, that the head lacks the vague stripiness of Melospiza, and that the underparts are spotted instead of streaked. Or, it may be, that you chance upon 


\section{The Fox Sparrows}

him as he is busily scratching among the fallen alder leaves. Scratching is hardly the word, though, for the bird leaps forward and executes an extravagant double kick backward, landing invariably at the edge of the cleared space. Here, without a moment's delay, he proceeds to glean busily, whereas you rather expected him to pause at the end of his stunt, like the acrobat, awaiting the conventional burst of applause. If you must needs pursue the path, he hops back into the thicket and the show is over for that day, or, perchance, for the novice, for that season.

It is by diligent screeping, however, that one may summon the Fox Sparrow population for registration and review. One chooses a humble station, partly screened, and kisses the back of the hand, in simulation of a young bird's distress cry. There is a rustle in the thicket,

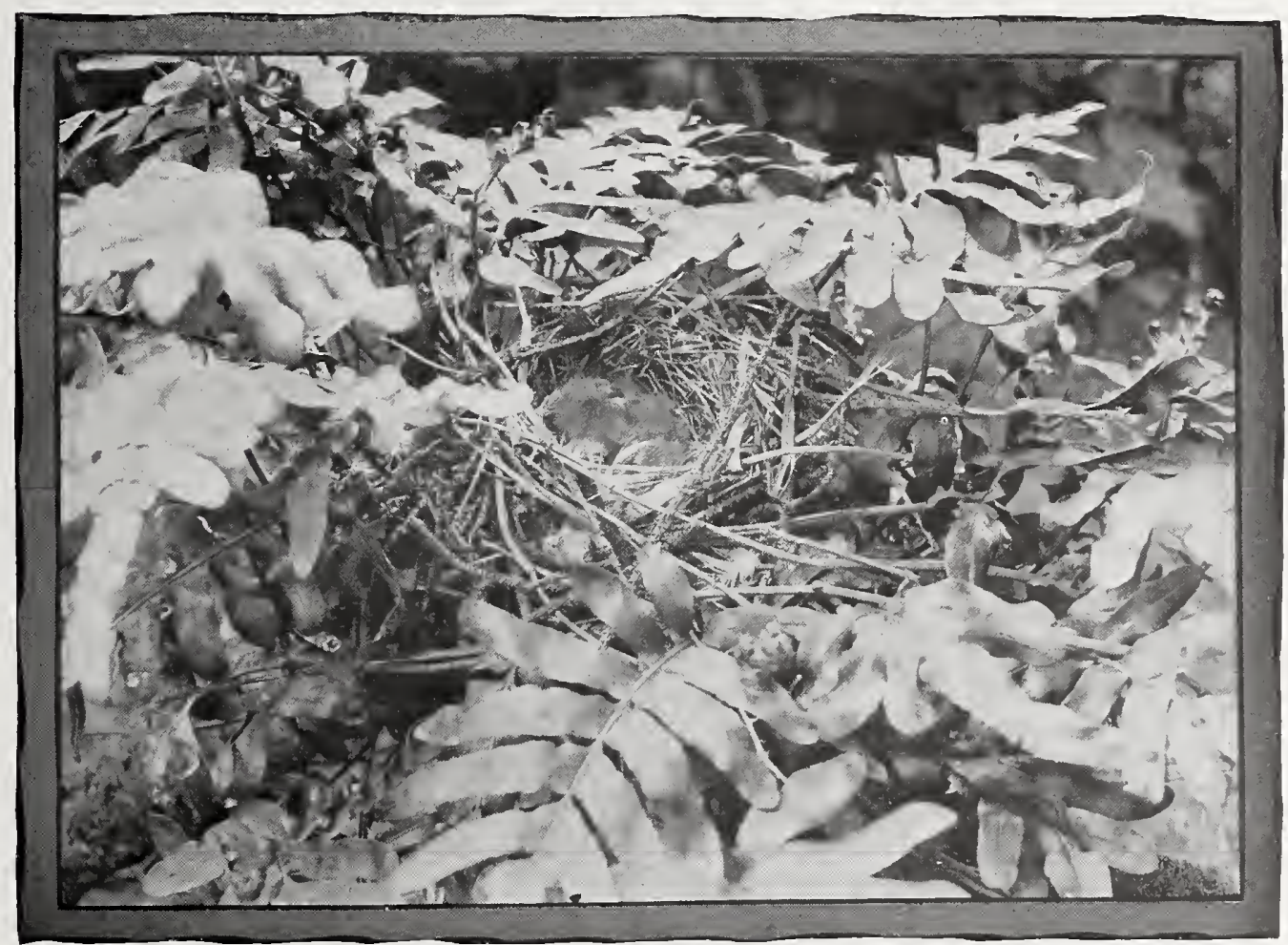

Taken on Carroll Islet

NEST, WITH YOUNG, OF SOOTY FOX SPARROW

Photo by the Author

the sound of bird-feet on branches faintly creaking, and of impinging twigs. Presently there is a faint tsook of inquiry, and a form emerges ten feet away, quiet, demure, attentive. Another and another appears 


\section{The Fox Sparrows}

at different levels and looks mild inquiry. You are inspected critically from all sides, but interest soon gives way to boredom. Napoo, says one bird with a chuckle, and prepares to move away. Frantically the bird-man renews his screeping. The birds are a trifle puzzled, but this is not the first of nature's mysteries which they have had to pass up, and almost before one knows it the curious crowd has melted away, and silence reigns again in the chaparral. It is rather humorous and rather pitiful, for, honestly, this is about all there is to it-our entertainment of a hundred million guests!

When it is remembered that our own Fox Sparrows nest only at the higher levels, 6000, 8000 , I0,000 feet, we may be pardoned for following these retreating hosts northward on some vacation trip, to British Columbia or Alaska. We shall begin to overtake them first at sea-level, on the islands of Puget Sound or along the Olympic Coast of Washington. We are tantalized, as the tent pegs are being driven on a mossy level just above the beach line, by certain sprightly songs bursting out now here and now there from the copse.

We labor under a sense of avian surveillance as we gather fuel from the beach, but the songs are too joyous and limpid to make precise connections with anything in previous experience. It is not till the cool of the evening, when we seek the spring, back in the depths of the thicket, that we come upon a fair bird-maiden slyly regaling herself upon a luscious salmon-berry, flushed to the wine-red of perfection, while three of her suitors peal invitations to separate bowers in the neighboring tangles. She flees guiltily on detection, but the secret is out; we know now where these shy wood nymphs keep themselves in summer.

The male bird is sometimes emboldened by the moment of song to venture into the tops of willows or alders, but even here he hugs the screen of leaves and is ready in a trice to dive into the more familiar element of bushes. Once under cover of the protecting salal, or among the crowding ferns, the Fox Sparrows are excelled by none in their ability to get about with a minimum of disturbance; and the longest journeys, such as are made necessary in the time of clamoring young, appear to be made by slipping and sliding through the maze of intersecting stems. The song is varied and vivacious; but, save for the opening notes, is neither very strong nor very brilliant. The opening phrase, however, Pewit, heu, comes as a tiny bugle call into which is distilled the essence of all dank hollows, of all rustling leaves, of all murmuring tides, and of all free-blowing breezes. It is the authentic voice of the little. wild. 


\section{The Fox Sparrows}

No. 65h Slate-colored Fox Sparrow

A. O. U. No. $5^{8} 5^{\mathrm{c}}$, part. Passerella iliaca schistacea Baird.

Description.--Somewhat similar to $P$.i. iliaca, but rufous spots somewhat smaller, with tail both proportionately and absolutely longer-nearly equal to wing; rufous element in plumage greatly reduced, persistent only on upper tail-coverts, wings, and tail; pattern of upper plumage entirely blended; streaking of underparts about equal in quantity, but dusky or slightly brownish instead of red. In particular: Color of upperparts brownish gray, clearest, nearly mouse-gray on crown and sides of neck, of specimens in worn (breeding) plumage; more rufescent, dull cinnamonbrown, on upper tail-coverts and exposed surfaces of wings and tail; below white, sharply streaked, especially on chest and sides, with sagittate spots of dark brown or dusky; streaks tend to confluence on sides of throat; those of the sides are prolonged and enlarged posteriorly. Bill slightly smaller and darker and feet darker than in iliaca. Measures: wing 80 (3.15); tail 77.6 (.3.05); culmen 10.9 (.43); depth of bill at base $9.5(.37)$, width $8.1(.32)$; tarsus $22.7(.89)$.

Range of $P$. $i$. schistacea.-As now defined, breeds in the Rocky Mountain district from central Colorado north into the interior of British Columbia, and west over the high Columbian plateau into Oregon and Washington; "winters south to southwestern California, Arizona, and New Mexico, and east to Kansas”' (A. O. U.).

Occurrence in California.--Scattered records of occurrence in fall and winter in interior and southern California await differentiation from those attributable to P. i. fulva.

Authorities.-Belding, Proc. U. S. Nat. Mus., vol. i., I 879, p. 4 I 8 (Murphys, Calaveras Co.); Tyler, Pac. Coast Avifauna, no. 9, I9I3, p. 85 (Fresno; occurrence, habits); Swarth, Univ. Calif. Pub. Zool., vol. xxi., I920, p. I52, figs. (occurrence in Calif., distr., desc., crit.).

IT IS an awkward expedient introducing for separate treatment a Fox Sparrow race whose physical distinctions do not entitle it to any such prominence; but the Slate-colored Fox Sparrow not only enjoys a more extended breeding range than any other form (save iliaca proper) but it establishes the perfect bridge of connection between our specialized thick-billed types, which are strictly resident in California, and the remoter coastal and interior forms. It is, therefore, an extensive neighbor of ours, though not a resident bird. The precise area of its intergradation with megarhyncha is still undetermined, but theoretically it lies along the eastern slopes of the Cascades. Like the megarhyncha type, again, schistacea is confined to high Transition, but the altitude of this zone rapidly decreases as we go northward beyond the limits of the State; so that the Slate-colored Fox Sparrow comes into contact with civilization to a degree unrealized by any other member of this group.

And a very civil bird he is, too. Seen in the half light of early morning, nothing in its pose or appearance would ever induce the student to bestow a second glance upon the evident Song Sparrow, were it not for the sweet and powerful challenge which pours from his earnest beak. 


\section{The Fox Spariows}

Oree, rickit, loopiteer, it says, with varied cadence and minor change which give evidence of no mean ability. There is something so forthright and winsome about this modest bird that the listener promptly

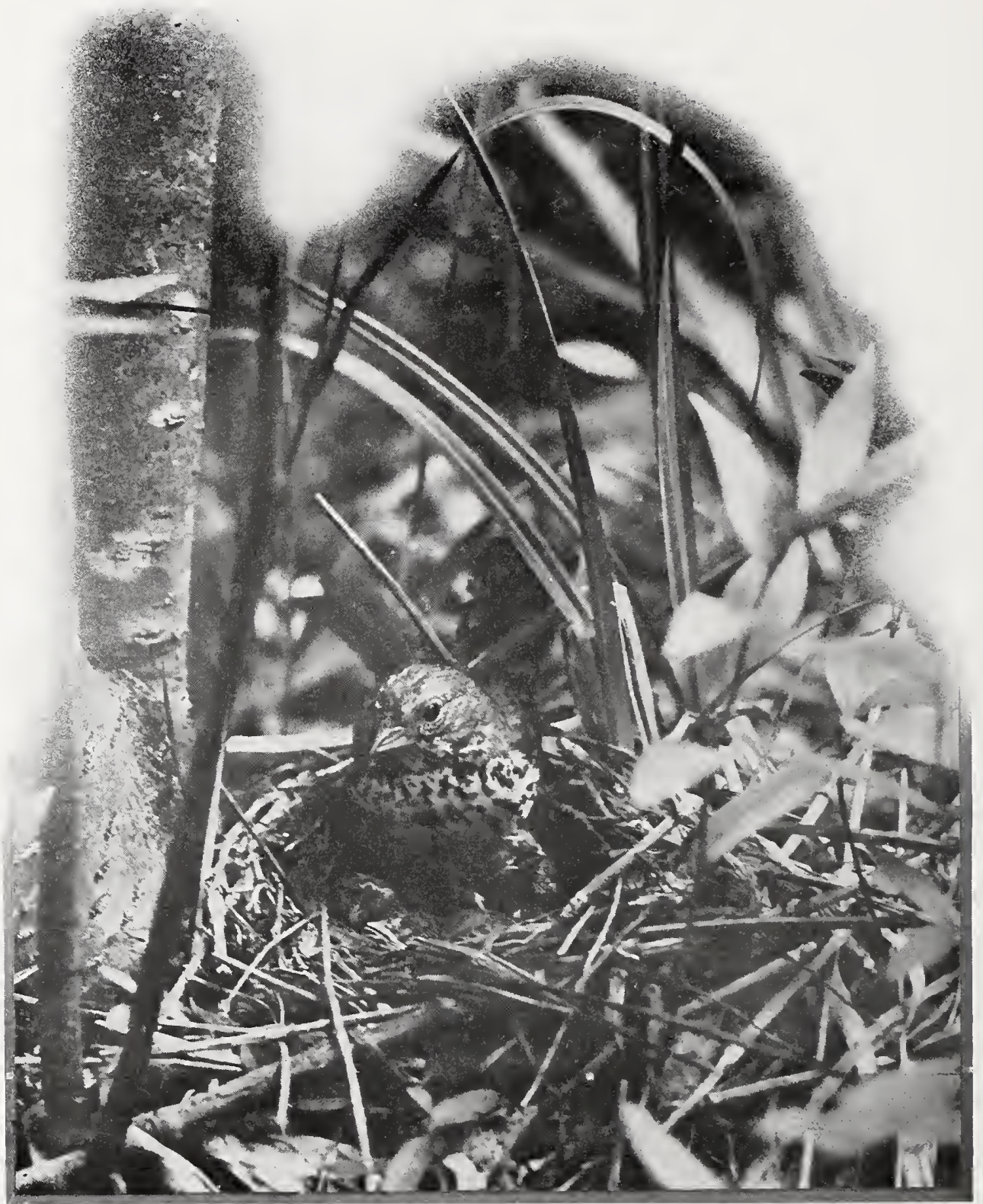

Tcken in Washington

A GENTLE MOTHER

Photo by the Author

SLATE-COLORED FOX SPARROW ABOUT TO BROOD 
surrenders "at discretion," and begins to ask eager questions of his dainty captor.

As might be expected, the home life of this Quaker poet is idyllic. In a certain aspen grove of the North a nest was located early in June; and this, rather unusually, had been placed upon the ground instead of being concealed in a bush. The nest was marked by its proximity to the base of a small tree, but it stood so high, with overflowing skirts, and without pretense of concealment, that it was plainly visible, with all its contents, two rods away.

The female was brooding, but upon our approach she slipped quietly off and left her three callow young to the tender mercies of the bird-man and his big glass eye, set at four feet, while she began searching for food upon the ground a yard or two away.

The male bird appeared once upon a bush some twenty feet away, making no hostile demonstration but beaming, rather, a hearty confidence, as who should say, "Well, I see you are getting along nicely at home; that's right, enjoy yourselves, and I'll finish up this bit of hoeing before supper."

The mother bird, meanwhile, was uttering no complaint of the strange presence, preferring instead to glean food industriously from under the carpet of green leaves. Soon she returned, hopping up daintily. Standing upon the elevated brim of her nest she carefully surveyed her brood without proffer of food, as though merely to assure herself of their welfare. I "snapped" and she retreated, not hastily, as though frightened, but quietly as matter of reasonable prudence. Again and again, during the hour I had her under fire, she returned to her brood. Each time she retired before the mild roar of the curtain shutter, never hastily or nervously, but deliberately and demurely. Thrice she fed her brood, thrusting her beak, which bore no external signs of food, deep down into the upturned gullets of the three children. Thrice she attempted to brood her babes, and very handsome and very motherly she looked, with fluffed feathers and mildly inquisitive eye; but the necessary movement following an exposure sent her away for a season.

When absent, she neither moped nor scolded, but discreetly set about scratching for food, always within a range of ten or fifteen feet of the nest. At such times she would look up trustfully and unabashed. Upon the return she never flew, and there was nothing to advise the waiting camerist of her approach, save the rustle of leaves as she came hop, hopping, until she stood upon the familiar brim.

The opportunities for picture-making were simply unlimited, save for the weakness of the leaf-diluted light. Seldom have I been stirred to such admiration as in the case of this gentle mother schistacea. So 


\section{The Fox Sparrows}

demure, so even-tempered, and so kindly a bird-person, with such a preserving air of gentle breeding, I have not often seen. It was an hour to be long remembered.

\section{No. 65i Warner Mountains Fox Sparrow}

A. O. U. No. $5^{8} 5 \mathrm{c}$, part. Passerella iliaca fulva Swarth.

Description.-Very similar to $P$. $i$. schistacea, but bill larger and differently shaped, with notable increase of basal dimensions: culmen I2.I (.476); depth of bill at base I I.I (.437), width at base $9.5(.374)$; tail longer than wing, 82.2 (3.236), as against 80 (3.I5); other dimensions about as in schistacea.

Range of $P . i$. fulva.-As at present defined is wholly included within the limits of California. Breeds in the Warner Mountains, Modoc County. Winter range not yet defined, but a specimen (M. C. O. coll.) taken at Santa Barbara, Jan. II, I9I3, is referred by Swarth to this form.

Authorities.-Swarth, Proc. Biol. Soc. Wash., vol. xxxi., I918, p. I62 (Sugar Hill, Modoc Co.; orig. desc.); Univ. Calif. Pub. Zool., vol. xxi., I920, p. I58, figs. (occurrence in Calif., distr., desc., crit.); Bendire (Passerella iliaca schistacea, part), Auk, vol. vi., I889, p. II 3 (eastern Oregon; nest and eggs, habits, etc.).

\section{No. 65j Thick-billed Fox Sparrow}

A. O. U. No. 585 c, part. Passerella iliaca megarhyncha Baird.

Description.- Similar to P. i.fulva, but browner, amounting to an olivaceous cast over upper plumage; bill much stouter, intermediate in this regard, as in brownness of plumage, between fulva and brevicauda.

Range of $P$. $i$. megarhyncha.-Breeding range undefined; may prove to be the breeding bird of the Cascade system in Oregon and Washington, or at least of the southern portion of that system. Winters commonly in the San Diegan district north at least to Fort Tejon, Kern County, and west to Santa Barbara (M. C. O. coll.).

Authorities.-Baird, Rep. Pac. R. R. Surv., vol. ix., I858, p. 490 (Passerella schistacea, part); idem, p. 925 (Passerella megarhynchus, Ft. Tejon, orig. desc.); Swarth, Univ. Calif. Pub. Zool., vol. xxi., I920, p. I6I, figs. (occurrence in Calif., distr., desc., crit.).

\section{No. 65k Yolla Bolly Fox Sparrow}

A. O. U. No. $5^{8} 5$ c, part. Passerella iliaca brevicauda Mailliard.

Description.-Similar to P. i. megarhyncha, but darker and browner with further increase of bill dimensions, comparable in this regard to P. i. stephensi, from which, however, it differs markedly in color-pattern and in shape of bill, which is constricted distally. Measurements: wing $83(3.27)$; tail 84 (3.3 I); culmen $\mathrm{I} 3.3(.52)$, depth I4. I $(.55)$, width at base I I.8 $(.465)$; tarsus $23.8(.937)$.

Range (Possibly wholly included within California).-Breeds in the northern interior and coastal ranges (the Trinities, Yolla Bollies, etc.) of California; winters from Marin County south (at least) to Santa Barbara.

Authorities.-Oberholser (Passerella iliaca stephensi), Proc. U. S. Nat. Mus., vol. xxii., I900, p. 233; J. Mailliard, Condor, vol. iv., I912, p. 63; ibid., vol. xx., I9I8, p. I38 (South Yolla Bolly Mt.; orig. desc.); ibid., vol. xxiii., I921, p. I78 (migr.); Swarth, Univ. Calif. Pub. Zool., vol. xxi., I920, p. I65, figs. (occurrence in Calif., distr., desc., crit.). 


\section{The Fox Sparrows}

\section{No. 651 White Mountains Fox Sparrow}

A. O. U. No. 585 c, part. Passerella iliaca canescens Swarth.

Description.--"From schistacea, canescens may be differentiated by its decidedly more grayish coloration. This is strikingly apparent when freshly molted birds of the two subspecies are compared, and it is also evident in the juvenal plumage. In worn midsummer birds these color differences naturally are obscured" (Swarth). A dubious candidate for nomenclatural recognition, albeit the tendency toward grayness does undoubtedly exist.

Range of $P$. i. canescens.-Breeds in the White Mountains of California (and presumably in Nevada). Winter range undefined, but specimens taken at Blythe on the Colorado River, and at Mt. Wilson, Los Angeles County, referred to this form by Swarth, the original describer.

Authorities.-Fisher (Passerella iliaca schistacea), N. Am. Fauna, no. 7, I893, p. 102 (White Mts.); Swarth, Proc. Biol. Soc. Wash., vol. xxxi., I918, p. I63 (White Mts.; orig. desc.); Univ. Calif. Pub. Zool., vol. xxi., I920, p. I69, figs. (occurrence in Calif., distr., desc., crit.).

\section{No. 65m Mono Fox Sparrow}

A. O. U. No. 585 b, part. Passerella iliaca monoensis Grinnell \& Storer.

Description.-Similar to $P$. $i$. schistacea, but slightly grayer and with much stouter bill-comparable in this regard to $P$. $i$. fulva, which is a much browner bird.

Remarks.-Monoensis is possibly the "lightest" of the recognizable forms of $P$. iliaca. Bearing in mind that a name is a mere tag, a bit of intellectual furniture attached to, or "wished on" a group of natural objects, we must constantly strive to free ourselves from the groundless notion that neighboring groups so tagged are of equal value. The Fox Sparrows found along the eastern flanks of the Sierras have somewhat smaller bills than those found further west. This tendency has been traced as far south as Kearsarge Pass, but it appears to find its strongest expression about Mono Lake. The affinities of monoensis are with mariposa, and it probably does not deserve nomenclatural distinction from it.

Range of $P$. i. monoensis (Wholly included within the State).-Breeds in high Transition in the Mono Lake region. Winter range unknown.

Authorities.-Grinnell and Storer, Condor, vol. xix., 1917, p. I65 (Mono Lake P. O.; orig. desc.); Swarth, Univ. Calif. Pub. Zool., vol. xxi., 1920, p. I 70, figs. (occurrence in Calif., distr., desc., crit.).

\section{No. 65n Yosemite Fox Sparrow}

A. O. U. No. $5^{8} 5$ b, part. Passerella iliaca mariposæ Swarth.

Description.- -Similar to $P$. $i$. monoensis, but bill slightly larger: length of bill I $2.7(.50)$; depth at base $12.4(.488)$; width $10.6(.4 \mathrm{I} 7)$. General tone of upperparts in worn (breeding) plumage brownish gray (nearest chætura drab, Ridgway); spotting of underparts dusky, not rufescent.

Range of $P$. i. maripose (Wholly included within California).-"As shown by specimens at hand, occurs in summer from the vicinity of Mount Shasta south along the Sierra Nevada, on the west slope at least as far as the Yosemite region, on the east slope to Kearsarge Pass" (Swarth). Winter range undefined, although 


\section{The Fox Sparrows}

there are examples from the San Diego district (e. g., Santa Barbara, Oct. 3I, I9I3 -M. C. O. coll.).

Authorities.-Cooper (Passerella megarhynchus, part?), Orn. Calif., I870, p. 222 (Sierra Nevada); Ingersoll, Condor, vol. xv., I9I3, p. 84 (destruction of nests and eggs); Swarth, Proc. Biol. Soc. Wash., vol. xxxi., I9I8, p. I6I (Chinquapin, Yosemite Park; orig. desc.); Univ. Calif. Pub. Zool., vol. xxi., I920, p. I73, figs. (occurrence in Calif.; distr., desc., crit.); J. Mailliard, Condor, vol. xxi., I919, p. 76 (desc. nests, habits, etc.); J. W. Mailliard, Condor, vol. xxiii., I92I, p. 73 (desc. nests, habits, etc.).

THE "SPECIATION specialists" are having a gay time just now with our Fox Sparrows. The latest authority, H. S. Swarth, of Berkeley, triumphantly announces that "the total number of recognizable subspecies of Passerella iliaca is now sixteen; and all of these occur at some season within the State." Sacre bleu! how is a plain citizen to make his way in such a maze of quiddities! And all of these alleged varieties are migratory, so that John Henry on his weekly bird-hike has sixteen guesses for every bird he sees. Verily, ornithology has ceased to be an exact science. Oh, of course the evidence is indisputable. I do not dispute it. But, also, it is quite certain that my left eye differs by definable niceties from its mate; and that the distal reticulations on the wings of a colony of flies hatched on the north side of the barn are appreciably smaller than the corresponding surfaces from a colony reared in the pigpen. Very good! tut what of it? The recognition of subspecies has become too subtle a game for the

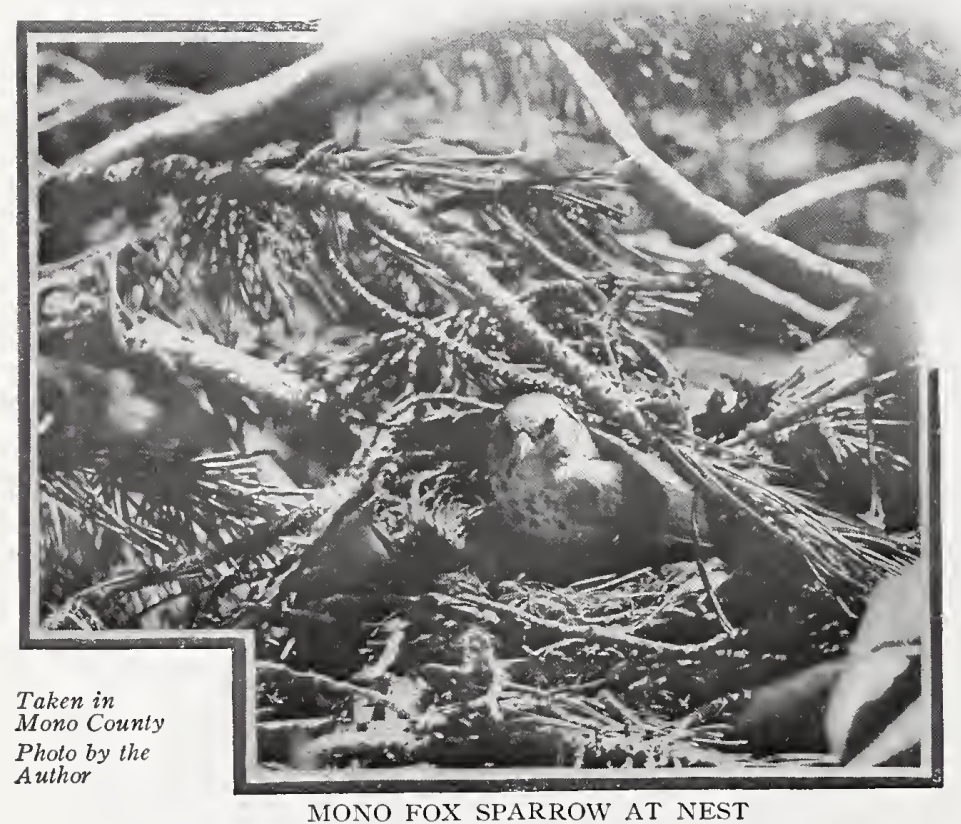

MONO FOX SPARROW AT NEST laity to follow. Let us speak of Fox Sparrows; and since we may not be sure what we have at any other season, let us speak of them in nesting time.

"Gentle, urbane, and ubiquitous" were three adjectives applied by the author's note-book to the Fox Sparrows studied near Mammoth Camp, June 7 th to July 7 th, I9I9. But though these birds were dominant in mixed pine and fir forests lying between the 8000 and 9000 foot level, they were not to be won by 


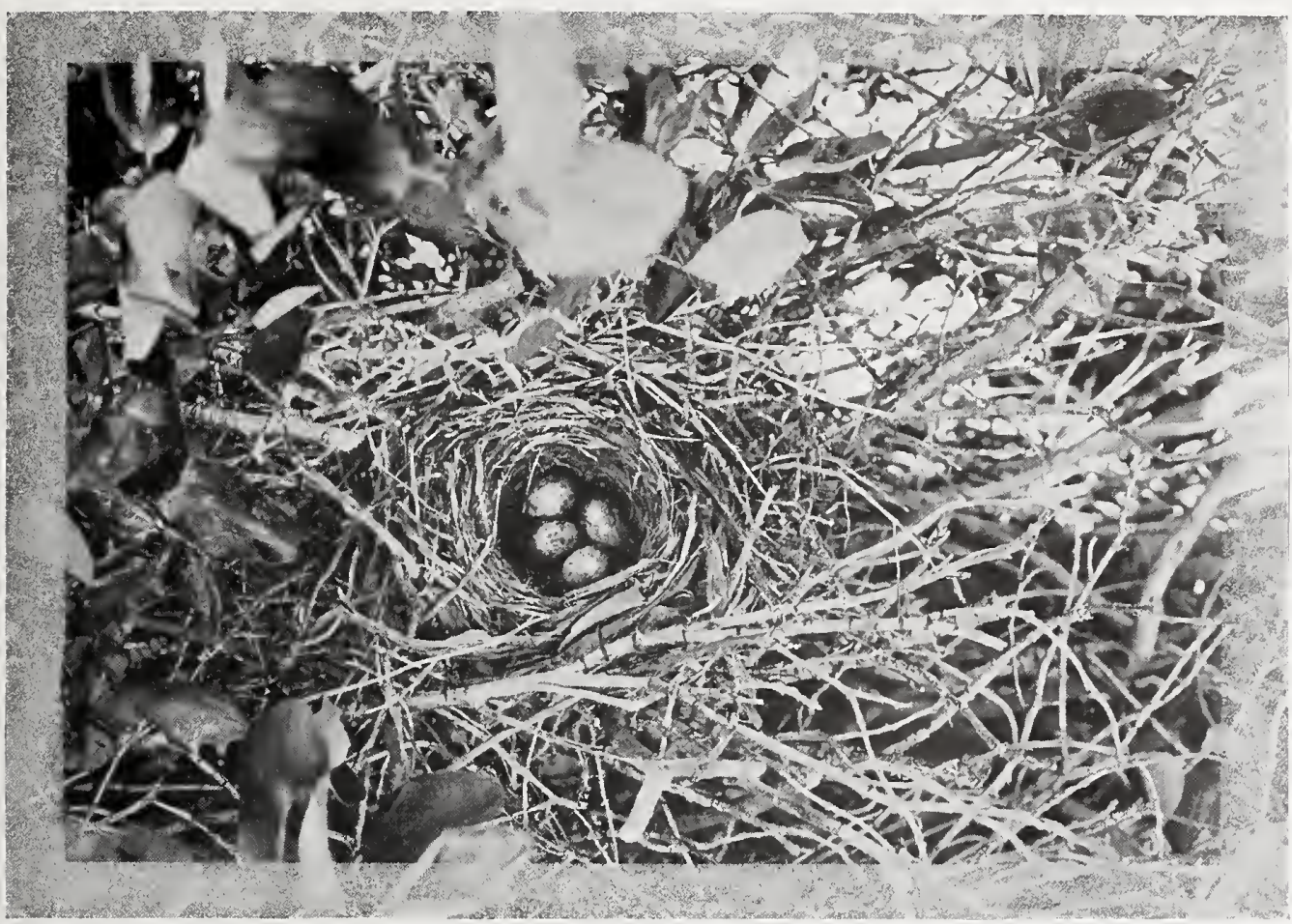

Taken in Mono County

Photo by the Author

NEST AND EGGS OF MONO FOX SPARROW, IN BUCK-THORN

pleasant words into any betrayal of nesting secrets. Our camp was pitched in a little grove of pines surrounded by abundant buck brush (Ceanothus cordatus) mingled with a hardy species of wild currant and overlooked, in turn, by scattering firs. Every morning we heard the cheery peewit wheeo and the jumble of syllables with which the male quickly checks his emotions. There were three or four pairs about. They visited our camp daily for crumbs, and we saw them gather nesting material, sometimes at our very feet. But though we searched every sapling and thrashed about in the brush for hours, we saw never a trace of a nest in that vicinity. The birds were baffling, maddening, spookish -and urbane always.

At a lower level we had better, or at least different, luck. Over a stretch which parallel creeks had rendered liable to flood, we found a virtual colony of these crafty innocents. The bottom here was overshadowed by towering firs, but also half covered by quaking asp saplings, each broken-backed from the insufferable weight of winter snows. In these twisted knots of vegetable agony, or else upon prostrate or half recumbent masses of willow stems, the "Thick-bills" (megarhyncha or 


\section{The Fox Sparrows}

monoensis or mammothensis, ad gust.) had built laborious nests. On June IIth we found ourselves between seasons, with much evidence of care for first broods and some symptoms of renewed interest in courtship and nest-building. Of two nests we did find containing young, one was placed six feet high in a dead fir sapling set in deep shadow. The owner, a confiding lady clad in deepest earth-brown raiment, came and went without the slightest regard for our presence. The other nest was lodged on a bunch of recumbent stems a foot or more above the ground. This spot was exposed to the full rays of the sun at midday, and the female divided her time between efforts to decoy the stranger with the great glass eye, and determined broodings, or shadings, of the panting young. The male, meanwhile, hopped about me with friendly curiosity, or else tried the air with song. As to any misfortune befalling the children, why that was plainly impossible-between gentlemen.

At a later time in the same season we found nine nests, building or ready for eggs - the second brood. But on the 5 th of July every nest

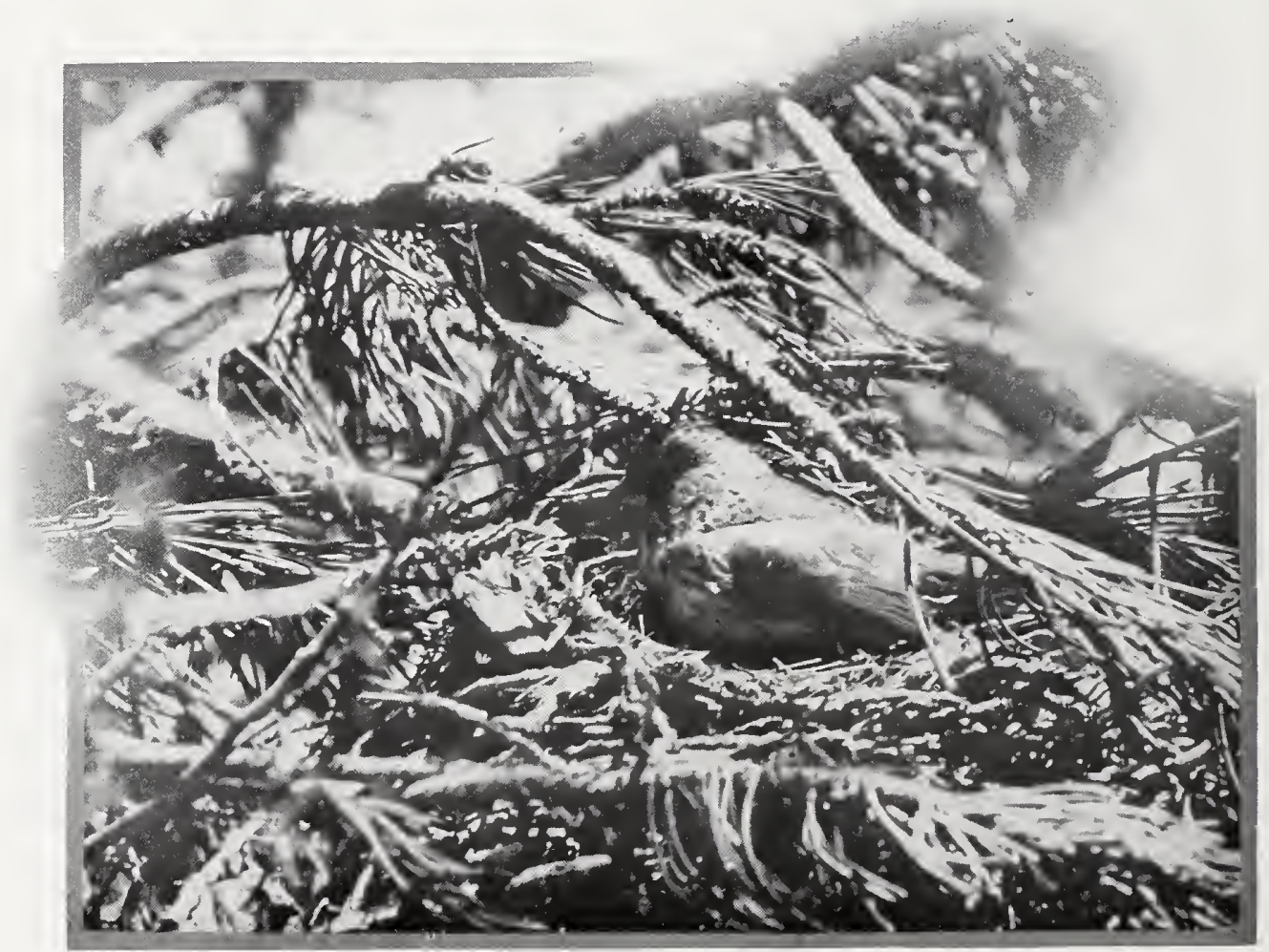

Taken in Mono County

Photo by the Author

"DETERMINED BROODINGS, OR SHADINGS, OF THE PANTING YOUNG" 


\section{The Fox Sparrows}

stood empty, save one which had a punctured egg. Nucifraga columbiana, he of the black heart and the raucous voice, had passed that way. In Nutcracker parlance, these trustful sparrows were no doubt rated "easy guys," but I wonder! Oh, if there be a Paradise for the lesser live things, I am sure that Clark's Crow will be cast into outer darkness.

Later experiences in the Mammoth section showed Yosemite (or Mono, or Mammotho, or whichever one of the sweet sixteen o' Fox Sparrows Mr. Swarth allows us here) Fox Sparrows nesting commonly in every sort of cover at the lower forest levels,- - buck brush, manzanita, pine or fir saplings, half-dead willow clumps, and especially on the knees of broken-down aspens. Threes are the usual complement of eggs, but fours mark a favorable season; and one has to be on the lookout that the set is not adulterated by the presence of an egg of the Nevada Cowbird.

The breeding ranges of the White-crowned Sparrow (Zonotrichia leucophrys) and the local Passerella overlap considerably, and at certain sections of contact between these two species, similarity of setting has wrought for uniformity of product. This has been carried so far in a certain swamp at the 80oo-foot level near Mammoth, that the nests of the two species are indistinguishable either in material, workmanship, or placing, save as identified by the proprietary actions of the birds themselves. I know of no other such instance in nature.

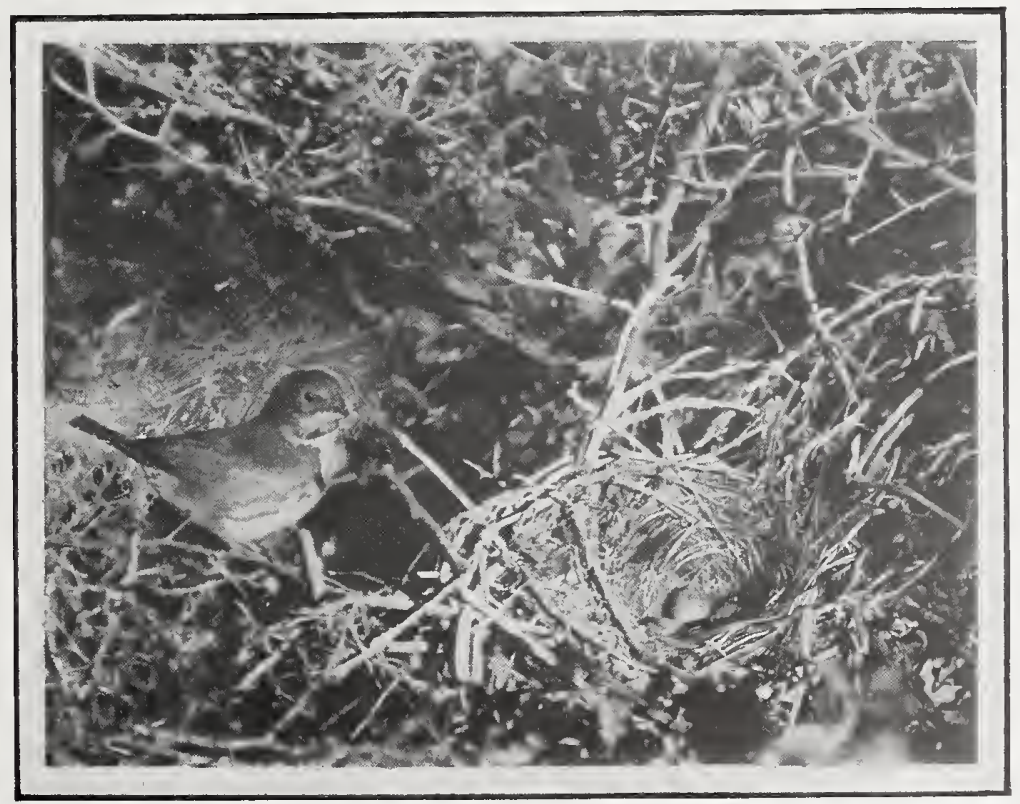

Taken in the San Bernardino Mountains

Photo by Wright $M$. Pierce

STEPHENS FOX SPARROW APPROACHING NEST IN BUCK-THORN 


\section{The Fox Sparrows}

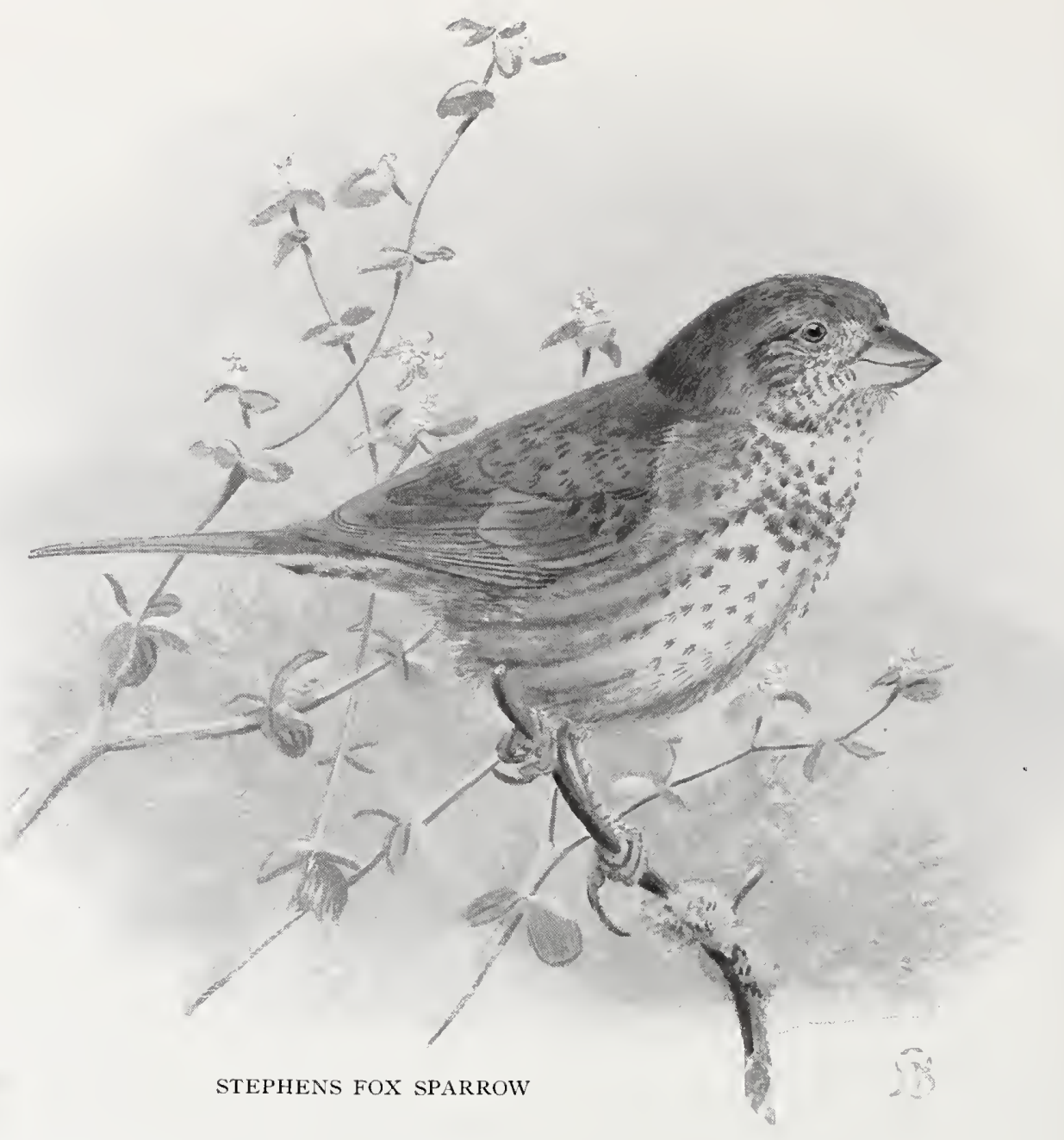

No. 65o Stephens's Fox Sparrow

A. O. U. No. 585d. Passerella iliaca stephensi Anthony.

Description.-Similar to $P$. $i$. mariposa in coloration, but size averaging slightly larger and bill at maximum of development, relatively enormous. Measures: wing $83.4(3.28)$; tail $86(3.386)$; culmen $\mathrm{I} 4.8\left(.5^{8}\right)$; depth at base $\mathrm{I} 4.3(.56)$; width I $2.2(.48)$.

Range of $P . i$. stephensi--Breeds in the higher mountains of southern California from about Latitude $36^{\circ}$ in the Sierras. Winter range unknown, presumably the mountains of Lower California.

Authorities.-Morcom (Passerella iliaca megarhyncha), Bull. Ridgway Orn. Club, no. 2, I 887 , p. 50 (San Bernardino Mts., breeding); Anthony, Auk, vol. xii., I 895, p. 348 (San Jacinto Mts.; orig. desc.); Grinnell, Auk, vol. xxii., I905, p. 388 (Mt. Pinos; habits, meas., crit.); Swarth, Univ. Calif. Pub. Zool., vol. xxi., I920, p. 176, figs. (occurrence in Calif., distr., desc., crit.); Pierce, Condor, vol. xxiii., I92I, p. 80, figs. (desc. and photos of nests and eggs). 


\section{The Fox Sparrows}

STRENGTHENING of the mandibles is one of the most familiar lines of development in sparrows, the world over. Just why it should so conspicuously affect the Californian races of the wide-spread Fox Sparrow group, we are not quite prepared to say; but it is probably because of the larger proportion which nuts and the sturdier seeds bear in their bill of fare. Development in this regard is fairly rapid, too, so that we may not learn from this character alone whether the megarhyncha and stephensi types are derived from, a northern stock, or whether they simply went on growing after their fellows emigrated to cooler northern climes. Be that as it may, it is certain that southern California has given its sparrow children harder nuts to crack and tougher twigs to weave

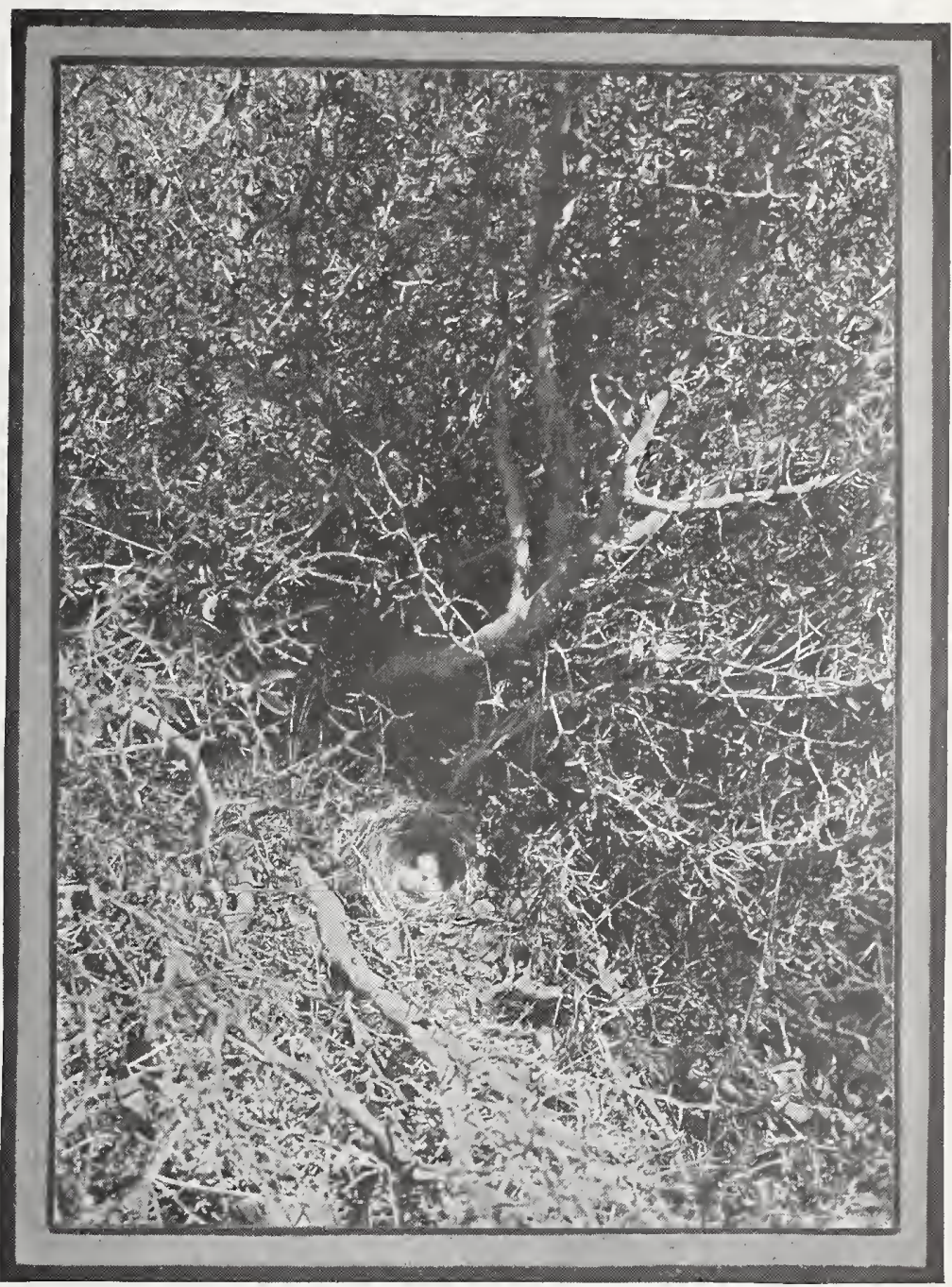

Taken in San Bernardino Mountains

Photo by Wright $M$. Pierce

NEST AND EGGS OF STEPHENS FOX SPARROW ON GROUND UNDER BUCK-THORN

into nests - and has presented them, as a consequence, with bigger bills. For $P$. $i$. stephensi, of the southern mountains, is preeminent in this regard, having a bill fifty per cent thicker than that of $P$. $i$. fulva, upon our northern border. There are those who are inconsiderate enough to hint that certain other institutions in southern California are characterized by big bills. Perhaps the proprietors of these establishments would do well to place caged examples of Stephens's Fox Sparrow in their lobbies by way of justification, and answer to grumbling guests, "Que voulez vous? C'est le climat. Voila tout." 


\section{The Green-tailed Towhee}

No. 66

\section{Green-tailed Towhee}

A. O. U. No. 592.I. Oberholseria chlorura (Audubon).

Synonyms.-Green-tailed Finch. Blanding's Finch.

Description.-Adults (sexes alike): Crown and occiput rich chestnut; forehead blackish gray, with whitish loral spot on each side; cheeks mingled gray and white; a short malar streak white, and a narrow, sharply defined sub-malar streak dark gray; remaining upperparts olive-gray, tinged more or less with bright olivegreen. Wings and tail with brighter greenish edgings (pyrite yellow to warbler green); bend of wing, axillars, and under coverts yellow; chin and throat white, sharply defined and with convex posterior outline; sides of head and neck and remaining underparts neutral gray, clearing to white on abdomen, tinged with buffy or brownish on sides, flanks, and crissum; under tail-coverts clear cream-buff. Bill blackish above, paler below; legs brown, toes darker; irides cinnamon. Immature birds are brown above, tinged with greenish and streaked with dusky, but with wings and tail much as in adult. Nestlings show greenish on wings alone, and are otherwise finely streaked above and below. Length of adult about I90.5-203 (7.50-8.00); wing 80 (3.15); tail $84(3.30)$; bill $\mathbf{I} 2.7(.50)$; tarsus $24(.94)$.

Recognition Marks.-Sparrow size; chestnut crown, white throat; greenish coloration of upperparts, especially tail and wings.

Nesting.- Nest: Low in bushes, especially sage (Artemisia tridentata), often well concealed; a bulky affair of twigs, weed-stems, pine-needles, etc.; lined with rootlets, grasses, or, rarely, horsehair. Eggs: 3 or 4; palest bluish or grayish white, finely and almost uniformly sprinkled or spotted with light reddish brown (terra cotta and testaceous to walnut-brown) and (concealed) purplish gray. Av. size $20.8 \times 15.5$ $(.82 \times .6 \mathrm{I})$. Season: May-July; two broods.

General Range.-Western United States and northern Mexico: breeding from central Oregon and south central Montana to western Texas and southern California; wintering from southern portion of its breeding range south to Cape San Lucas and Guanajuato.

Distribution in California.-Summer resident in high Transition, chiefly east of the Sierran divide, from the Warner Mountains south to the desert ranges and the San Jacinto Mountains. Also breeds, northwesterly, at least to Sissons (July I6, I9I6), and southwesterly to Mt. Pinos (Grinnell), and south centrally along the western slopes of the Sierras. Abundant during migrations easterly; and recorded variously in the northern coastal ranges. Has occurred in winter in the San Diegan district.

Authorities.-Heermann (Embernagra Blandingiana), Jour. Acad. Nat. Sci. Phila., ser. 2, ii., I 853 , p. 265); Grinnell, Univ. Calif. Pub. Zool., vol. v., I908, p. Io3 (San Bernardino Mts.; nesting habits, etc.); H. C. Bryant, Condor, vol. xiii., I9I I, pp. 203, 204 (food); Willett, Pac. Coast Avifauna, no. 7, I912, p. 87 (s. Calif.; occurrence, nesting dates, etc.); Ingersoll, Condor, vol. xv., I9I3, p. 84 (destruction of nests).

IT SEEMS absurd to call this bird a Towhee at all. To appearance it is, rather, an overgrown Warbler, or a cross, say, between a Yellow- 


\section{The Green-tailed Towhee}



Taken in the Warner Mountains

A TIMBERLINE HAUNT OF THE GREEN-TAILED TOWHEE

Photo by the Author

breasted Chat and a Chipping Sparrow. Its crown is sparrow-red; the white throat, sharply outlined against a background of gray, is typically sparrow-like; but the wings and tail, of authentic "warbler green," lead us to expect at least an Icterian vivacity, and in this, fortunately, we shall not be disappointed. Oberholseria is the familiar spirit of the high-lying sage. Active, persuasive, incessant, yet discreet withal, the presence of the Green-tailed Towhee imparts to the visitor of the Sierran slopes the same sense of mystery, of evasiveness, and of competent surveillance with which the Western Chat holds his willow bottoms or his mesquite thickets in vassal expectancy. In several trips to the Sierra Nevadas and the Warners, I have learned to recognize this bird in many roles and disguises, but it was ten years before I had penetrated the secret of his domestic economies, or had succeeded in reducing his wayward irruption to any prosaic order.

The key to Oberholseria's presence, as well as Towheeness, is primarily vocal. The commonest note heard in the upland sage or lupine association is a dainty mewing. This will be uttered, as likely as not, under inspection, mew-mewer-mew-mew whee,-a little plaintive, but friendly 


\section{The Green-tailed Towhee}

and inviting enough. Of song the bird possesses a surprising repertory. There is something dashing and wren-like about his more fam iliar ditties, and also something faintly reminiscent of the Vesper Sparrow (Pocecetes gramineus). Meay, tsit sit sit sit reminds me of orthodox Pipilo, and Ah fewgee weeee pilly willy willy will carry one right back to Pipilo erythrophthalmus - or will, that is, when one gets over the surprise of the opening notes, which in the case of two birds heard at Goose Lake were strikingly like those of the Eastern Phoebe (Sayorn is phoebe). The Green-

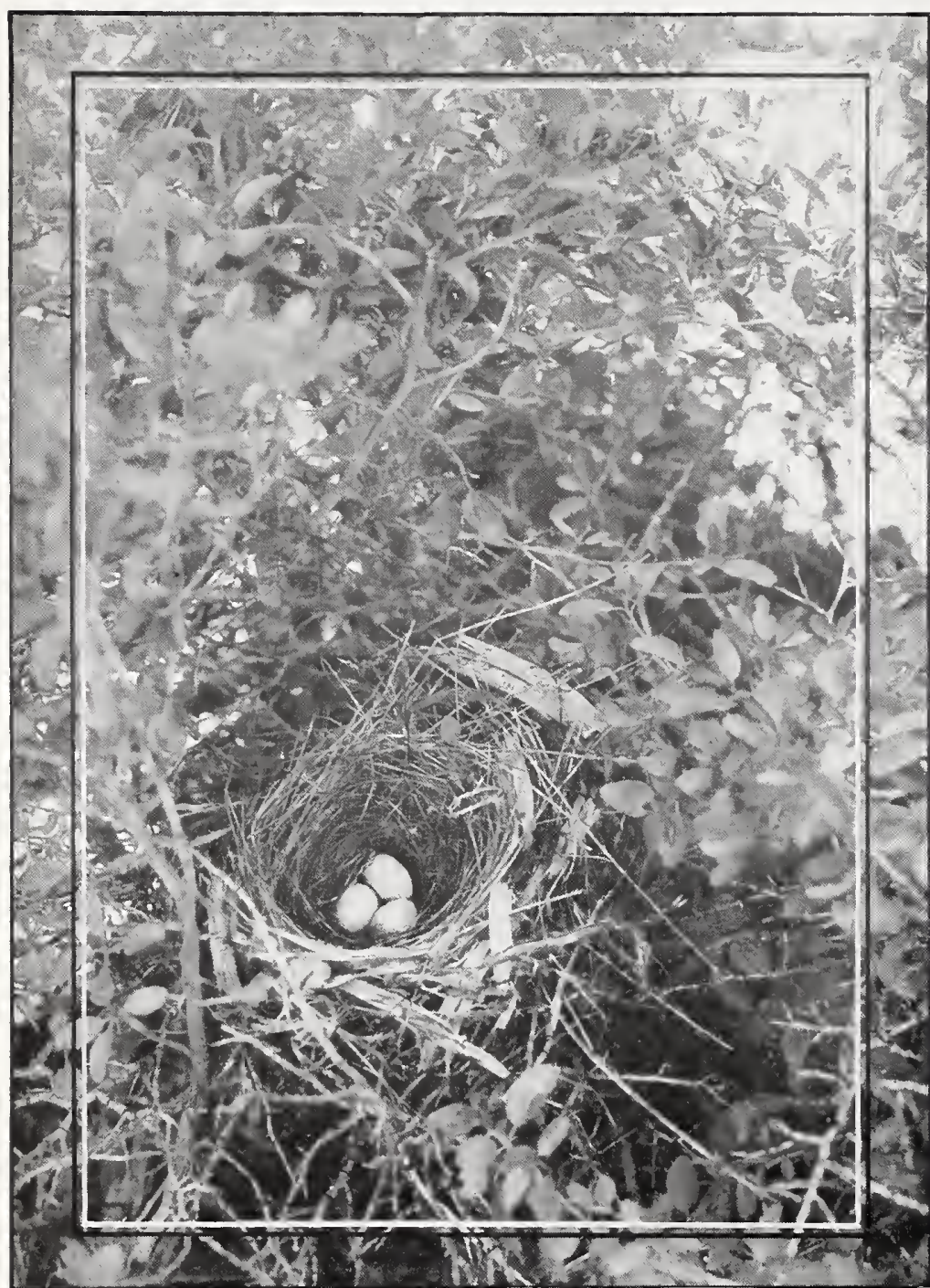

Taken in San Bernardino Mountains

NEST AND EGGS OF THE GREEN-TAILED TOWHEE tailed Towhee, I suspect, also, of being a bit of a mimic as well as a wag. One vivacious outburst from the chaparral hard by our Goose Lake camp sounded at first like a White-crowned Sparrow at his best; then it shifted to a wild medley in which I recognized not only the call of the Red-shafted Flicker, but certain phrases of the Western Lark Sparrow. Mind, I am not absolutely sure it was the Towhee, but he mewed a moment later, and he was my only suspect. In singing, the bird takes a very modest position on the side of a sage bush, and while he is not especially wary in these circumstances, it is hard to get a clear view of colors so exquisitely blended.

The secrets of this bird's nesting lie in the fact that it uniformly selects dense cover, however prosaic, the heart 388 


\section{The Green-tailed Towhee}

of a sage-bush or a greasewood clump, or, it may be, a stand of buckbrush, and that the bird almost invariably glides off upon approach, in silence and with an evasive rapidity which baffles the eye of all but the most expert. Having been shown my bird's nest in the heart of a low-lying sage (Artemisia tridentata) I retired for half an hour, then returned rapidly with senses on the alert. At six feet a something detached itself from the marked bush and scuttled away for a distance of 30 feet, all in perfectly plain view, but so almost instantaneously as to leave only a faint flare of color. After that, silence. Except for those telltale eggs I might have been persuaded that only a lizard had shot away into the desert's depths.

The nests themselves are rather insipid affairs, sturdy enough as to the bowl proper, but lacking coherence or finish as to wall construction. The closely crowding twigs of the parent bush are evidently expected to do duty for walls. Occasional nests rest upon the ground, but most of them are raised a foot or so above it. The eggs, finely dotted with prosy brown, are inconspicuous enough at best. Once, in the open sage west of Convict Creek, I flushed a Pacific Nighthawk, but not being able to find her eggs quickly, I cast about for a suitable twig to tag for a return trial. Cotton in hand I bent low and fumbled with a denuded flower-spike of a greasewood, saw another a foot away which reached a little higher, so turned and tied to it. Returning, an hour later, I hunted in vain for the Nighthawk's eggs, and finally stooped to retrieve the cotton marker. A rustle and a gleam and the Green-tail flushed from under the very twig which I had first handled. I had peered down into a nest with four eggs, unseeing, with my hand not over ten inches away.

By the time one has wrestled for six or eight seasons with this same combination of impudence, tunefulness, artfulness, and furtiveness, the Green-tailed Towhee comes to bulk large in the scheme of things. He or she is a most unforgettable bird-person.

In spite of the striking superficial differences which exist between the Green-tailed Towhee and those members of the genus Pipilo with which we in the United States happen to be acquainted, it is altogether probable that the bird should be restored to a place in a larger group. As Ridgway has pointed out ${ }^{1}$ chlorura possesses no color character not found in at least one other member of the genus Pipilo; and the very fact that this bird has these characters in common with the others would seem to designate it as the typical and central member of the genus, rather than an aberrant form. The separation, moreover, fails to take account of the striking similarity in the birds' songs; and it altogether

${ }^{1}$ Auk, Vol. VII., 1890, pp. 193-194. 


\section{The Spotted Towhees}

overlooks the emphatic testimony of the egg, although the fundamental value of such evidence has been repeatedly pointed out in these pages. Egg-wise and voice-wise, "Oberholseria" chlorura and Pipilo maculatus are much more nearly related than, say, $P$. maculatus and $P$. fuscus or crissalis. Shall we call it Pipilo chlorura?

No. 67

\section{Spotted Towhee}

\section{No. 67a San Diego Towhee}

\section{A. O. U. No. 588d. Pipilo maculatus megalonyx Baird.}

Synonyms.-Spurred Towhee. San Diego Spotted Towhee.

Description.-Adult male in spring and summer: Head and neck all around and breast glossy black, the black of remaining upperparts dulling posteriorly, especially upon rump and remiges; the scapulars heavily marked with longitudinal spots of white, included or else occupying entire outer web of feathers; median and greater wing-coverts tipped with white, with touches also on outer web of primaries midway, and on tertials near tip. Outer pair of rectrices narrowly margined and broadly tipped with white; succeeding pair less broadly tipped; third pair with included sub-apical spot; underparts centrally pure white, the sides and flanks tawny, the tips of posterior flank-feathers tawny, the anal region and under tail-coverts lighter, ochraceous; the line of demarcation from abdomen sometimes touched with black; tibiæ black, with more or less white tips; axillars whitish; wing-linings mingled blackish, white, and pale tawny. Irides red; bill black; feet and tarsi dark brown. Fall and winter specimens have feathers of upperparts slightly washed or tipped with pale tawny, especially upon rump: Female in spring: Similar to male, but duller, the black veiled with olivaceous gray, the ground-color strongest on throat and chest and persisting centrally on pileum and notæum; the white tips of scapulars, rectrices, etc., more restricted; the tibiæ dusky. Immature birds present a highly streaked appearance, not unsuggestive of a female Redwing (Agelaius phoniceus): Upperparts blackish, margined with cinnamon-buff, the ochraceous element becoming almost clear, cinnamonbrown, on head and hind-neck; the white spotting of adult much restricted; underparts mingled blackish, whitish, and cinnamon-buff, the white element strengthening on abdomen, the ochraceous prevailing on flanks and crissum; the throat, chest, and sides of breast finely streaked. The comparison of one of these juvenals with that of the Brown Towhee (P. crissalis) is highly instructive, and points clearly to a common ancestry. Length of males about 20 I.6 (8.00); av. of ro M. V. Z. specimens (after Swarth): wing 84.6 (3.33); tail 96.4 (3.795); bill 27.2 (1.07); tarsus 27.2 (1.07); hind toe and claw 2 I.3 (.84).

Recognition Marks for Pipilo maculatus.-Black, white, and tawny coloration distinctive. As compared with the easterly races of maculatus, megalony $x$ shows clearer black upon the back and restriction of white spotting.

Nesting.-Nest: Placed on the ground, or, rarely, very low in bushes, and 


\section{The Spotted Towhees}

usually sunk deeply in loose leaf-waste or trash; composed of grasses, bark-strips, dried leaves, lined with fine grasses. Eggs: 3 or 4; white or palest bluish, grayish, or pinkish, finely and heavily and of tenest uniformly sprinkled or spotted with reddish brown (cameo-brown to liver-brown). In more heavily marked specimens the color tends to coalesce in a cloud cap. Av. of 13 specimens in M. C. O. coll.: $23 \times 17.3$ (.905 x .68). Season: May, June; one or two broods.

Range of Pipilo maculatus.-Western North America from British Columbia and southern Saskatchewan to Guatemala.

Range of $P . m$. megalonyx.-Resident in the Pacific Coast district of southern California and northern Lower California, north along coast to San Luis Obispo County, east to southern Sierras (northern Kern County). Also Santa Cruz Island and (presumably) Santa Rosa.

Authorities.-Gambel (Pipilo arcticus), Jour. Acad. Nat. Sci. Phila., vol. i., I 847 , p. 54 (?) (California); Baird, Rep. Pac. R. R. Surv., vol. ix., I858, p. 51 5 (Ft. Tejon; orig. desc.); Swarth, Condor, vol. vii., I905, p. I7 I, fig., map (distr.; crit.); ibid., vol. xv., I913, p. I67, fig., map (distr.; crit.); Howell, Pac. Coast Avifauna, no. I2, I 917 , p. 85 (Santa Cruz Id.).

\section{No. 67b San Clemente Towhee}

A. O. U. No. 588c. Pipilo maculatus clementæ Grinnell.

Description.- "General size slightly greater than in megalonyx: bill and feet appreciably larger. Coloration grayer than in megalonyx; black areas in the male duller and less intense; rump and lower back more or less mixed with grayish" (Swarth).

Range of $P . m$. clemente (Wholly within California).-San Clemente and Santa Catalina islands; resident.

Authorities.-Cooper (Pipilo megalonyx), Orn. Calif., I870, p. 242, part (San Clemente and Santa Catalina Ids.); Grinnell, Auk, vol. xiv., i 897, p. 294 (San Clemente Id.; orig. desc.); Pasadena Acad. Sci. Pub., no. I, I897, p. I9 (habits, notes, etc.); Howell, Pac. Coast Avifauna, no. 12, 1917, p. 85 (distr., habits, etc.).

\section{No. 67c San Francisco Towhee}

\section{A. O. U. No. 588b. Pipilo maculatus falcifer McGregor.}

Description.-Similar to $P$. $m$. megalonyx, but averaging slightly smaller; white spotting more restricted; hind toe and claw weaker.

Range of $P . m$. falcifer.-Resident in the humid coast strip from Monterey County north to and perhaps beyond the northern boundary of California.

Authorities.- Townsend (Pipilo maculatus oregonus), Proc. U. S. Nat. Mus., vol. x., I 887 , p. 220 (Humboldt Co.); Cohen, Bull. Cooper Orn. Club, vol. i., I 899, p. 6I (nesting habits, at Alameda); McGregor, Condor, vol. ii., I90o, p. 43 (Palo Alto; orig. desc.); Beal, U. S. Dept. Agric., Biol. Surv. Bull., no. 34, 1910, p. 86, part (food in Calif.); Swarth, Condor, vol. xv., I913, p. I75, fig., map (crit., range, etc.).

\section{No. 67d Oregon Towhee}

A. O. U. No. 588b. Pipilo maculatus oregonus Bell.

Description.-Similar to $P$. $m$. megalonyx but darker every way. White spotting on scapulars, etc., much rectricted; outermost pair of rectrices not edged with white. 


\section{The Spotted Torohres}

Range of $P$. m. oregonus.- The Northwest Pacific Coast district, broadly, from Oregon to British Columbia.

Occurrence in California.-Accidental; one record: San Clemente Island, Dec. 4, I908, by C. B. Linton.

Authorities.-Linton, Condor, vol. xi., I 909, p. I 94 (San Clemente Id., one spec., Dec. 4, 1908); Swarth, Condor, vol. xv., I913, p. 172 (crit.).

\section{No. 67e Sacramento Towhee}

A. O. U. No. 588b, part. Pipilo maculatus falcinellus Swarth.

Description.-Similar to $P$. $m$. megalony' $x$, but white markings more extended; rump more olivaceous or grayer; foot weaker, with smaller hind claw.

Range of $P . m$. fllcinellus.-Resident in the great interior valley and, broadly, throughout the Sierras (south at least to southern Tulare County), eastern slopes of northern coast ranges, and thence north indefinitely beyond the northern boundary line of California.

Authorities.-Ridgway (Pibilo eryt'trophthalmus oregonus), Bull. Essex Inst., vol. vi., I874, p. I7 I (Sacramento); Barlow, Condor, vol. iii., I90I, p. I73 (habits, nests and eggs); Swarth, Condor, vol. xv., I9I3, p. I72, fig., map (orig. desc.; Marysville Buttes, type locality; distr.; crit.); Tyler, Pac. Coast Avifauna, no. 9, I9I3, p. 86 (San Joaquin Valley; habits).

\section{No. 67f Nevada Spotted Towhee}

A. O. U. No. $588 \mathrm{a}$, part. Pipilo maculatus curtatus Grinnell.

Synonyms.-Spurred Towilee. Mountain Towhee.

Description.- Similar to $P$. $m$. megalony $x$, but black of upperparts less pure grayer; white markings notably increased and carried clear across the back; tawny of sides, etc., paler and more restricted: apical white spots of 3 rd pair of rectrices more extended; hind claw notably weaker.

Range of $P$. m. curtatus.-Summer resident throughout an undefined area of the Great Basin region, including at least northern Nevada, northeastern California, and eastern Oregon; also (probably) the Upper Sonoran and arid Transition zones of eastern Washington and western Idaho north into British Columbia. Winter range undefined, but includes at least portions of the lower Colorado Valley.

Occurrence in California.-Breeds in the Warner Mountains of Modoc County; winters at Colorado River points.

Authorities.-Gi innell, Univ. Calif. Pub. Zool., vol. vii., I9I I, p. 3 Io (Colorado R.); ibid., vol. xii., I9I4, p. I77 (Colorado R.; habits; crit.); Swarth, Condor, vol. xv., I9I3, p. I67, fig., map (distr. in Calif.; crit.).

\section{No. 67 Mountain Towhee}

A. O. U. No. 588a, part. Pipilo maculatus montanus Swarth.

Synonym.-Arizona Spotted Towhee.

Description.--Sinilar to $P . m$. megalony'x, but paler every way; back and rump with admixture of gray: white markings more extended and diffuse; apical spotting of tail more extended: hind claw weaker. 
Range of $P . m$. montanus.-The southern Rocky Mountain region from Wyoming south to Tamaulipas, Mexico, and west south of the Great Basin to the desert ranges of eastern California.

Distribution in California.--Known only from the Panamint Mountains, in Inyo County, where breeding.

Authorities.-Fisher (Pipilo maculatus megalonyx), N. Am. Fauna, no. 7, 1893, p. 102, part (Panamint Mts.); Grinnell, Condor, vol. xx., 1918, p. 87 (Panamint Mts. : crit.).

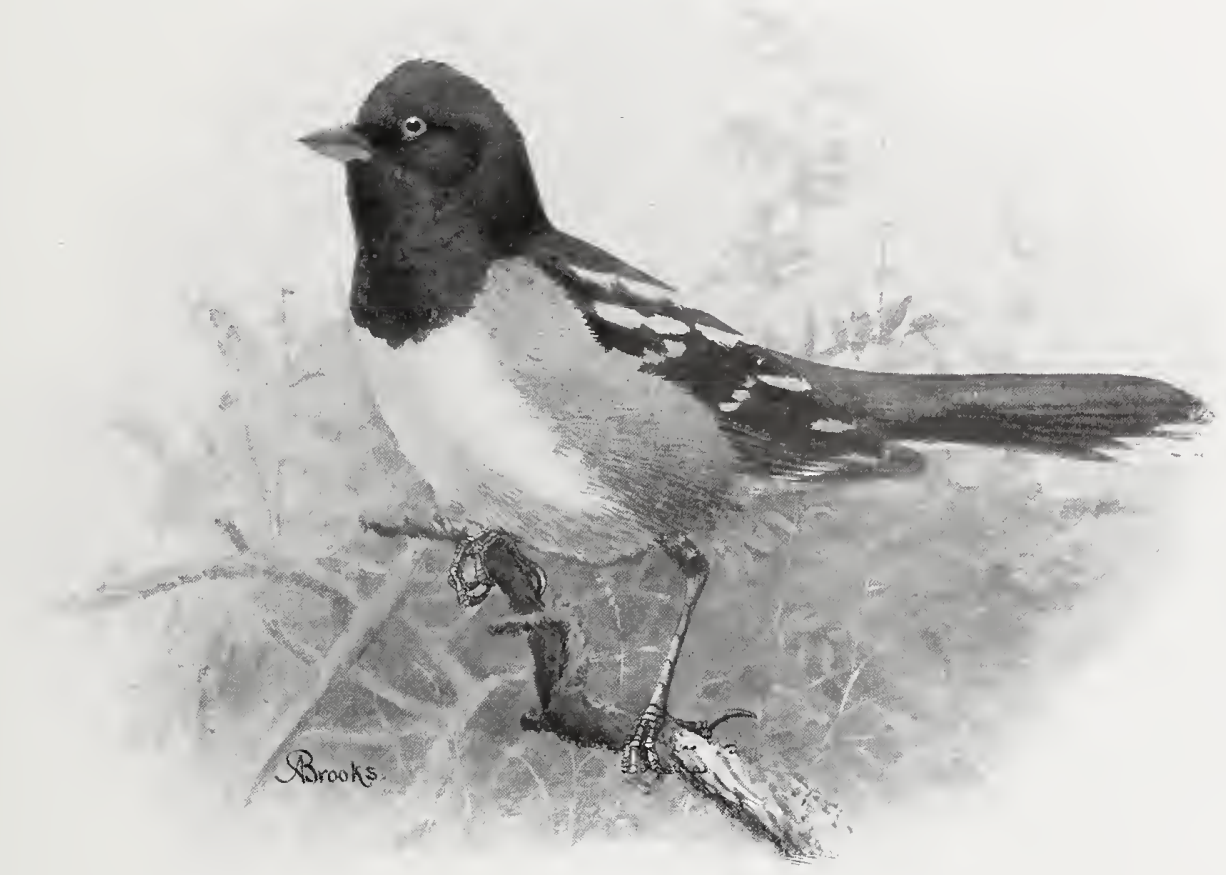

SPURRED TOWHEE, MALE

THE SPOTTED Towhee bulks large in the economy of the underworld. He is, in fact, its acknowledged prince; not, of course, in the Mephistophelian sense, but as the undoubted aristocrat among those humble folk who skulk under dark ferns, thread marvelous mazes of interlacing sticks and stalks, sort over the leafy wastage of the careless trees, and understand the foundations of things generally. To really get Master Towhee's point of view, one must be willing to creep on hands and knees among the bristling stems of mountain lilac and chamise of a southern mesa, or else go belly-wise through the rootage and castoff duffle of a northern forest. It is a wonderful world the serpent sees (albeit a mussy one), a basic, essential world, where all flesh meets 


\section{The Spotted Towhees}

is due in part, no doubt, to a certain fatherly alertness manifested on behalf of the clan. No sound or movement, whether hostile or friendly, escapes his notice. If the birdman's entrance into the local bird setting be accomplished with a becoming modesty, he presently hears a mild, questioning voice, me ay? or me ayuh? But if the man is unduly offensive, he hears instantly an indignant marié, marié, which sends the clan scattering. But when the bird-watcher glimpses the chief's costume, the secret of his ascendancy is out. Fine feathers still do make fine birds. Black-andwhite and earth red, picked out here and there with white spots, "maculations," make an impressive uniform, and one to which we all yield cheerful respect. But the marvel is how anything so spick and span can emerge from such a chaos; or how beauty can maintain itself in constant association with bugs and slugs and the innumerable horribilia of the Kingdom of Underfoot.

Truth to tell, "Beauty" emerges from concealment as rarely as possible. It is modesty again which gives the teasing fillip to our curiosity, and the elusiveness which makes itself ipso facto an object of perpetual friendly quest. Only at mating time does the Spotted Towhee throw caution to the winds. Then he mounts a sapling and drones away by the hour. The song is perhaps best described as a musical churr, a thing of slight beauty, and of interest merely for its variety and for the sprightly animation of the performer. By "variety" one uncovers the most fascinating problem in connection with the Spotted Towhee, the problem of geographical song variation. For the song of the individual Towhee is inflexible, always the same, or at least self-consistent. But as one travels from place to place in the West, he notes emphatic differences in the songs of the Spotted Towhees, and he soon comes to believe that these are locally constant, that there is in each locality a definite prevailing type, or cadence, of song, and that this is significant for geographical variation within the species.

Now the existence of races-that is, of geographical variations, as indicated by constant differences in shade of plumage, extent of white spotting, size of feet, etc.-is so well known within this species, that one has to apologize for ignoring its distinctions in a popular treatment. Suffice to say, by way of such apology, that these distinctions have been enormously over-stressed, and that no layman with an hour's instruction could hope to tell whether a given specimen of one of California's five races came from San Diego, Alturas, or Humboldt County (indeed the experts are still scrapping about it). But distinctions of song, in no wise correlated, apparently, with those of hue or claw-length, do exist, and it is a fascinating exercise for the travelled student to distinguish them. Thus, northern birds say, whéééé or tsweéé, in the dullest imagin- 


\section{The Spotted Towhees}

able kind of a way. And, in general, the song is a simple, rapid iteration, a churr. Yet in Owens Valley near Lone Pine, I heard putzé putzeé putzeé, and again from another throat a strange ventriloquial contortion, $\operatorname{hamx} \operatorname{hamx} \operatorname{ham}(a) x$. Not once in that section did I hear the familiar wheeze, or churr; and the songs were all those of foreigners. In

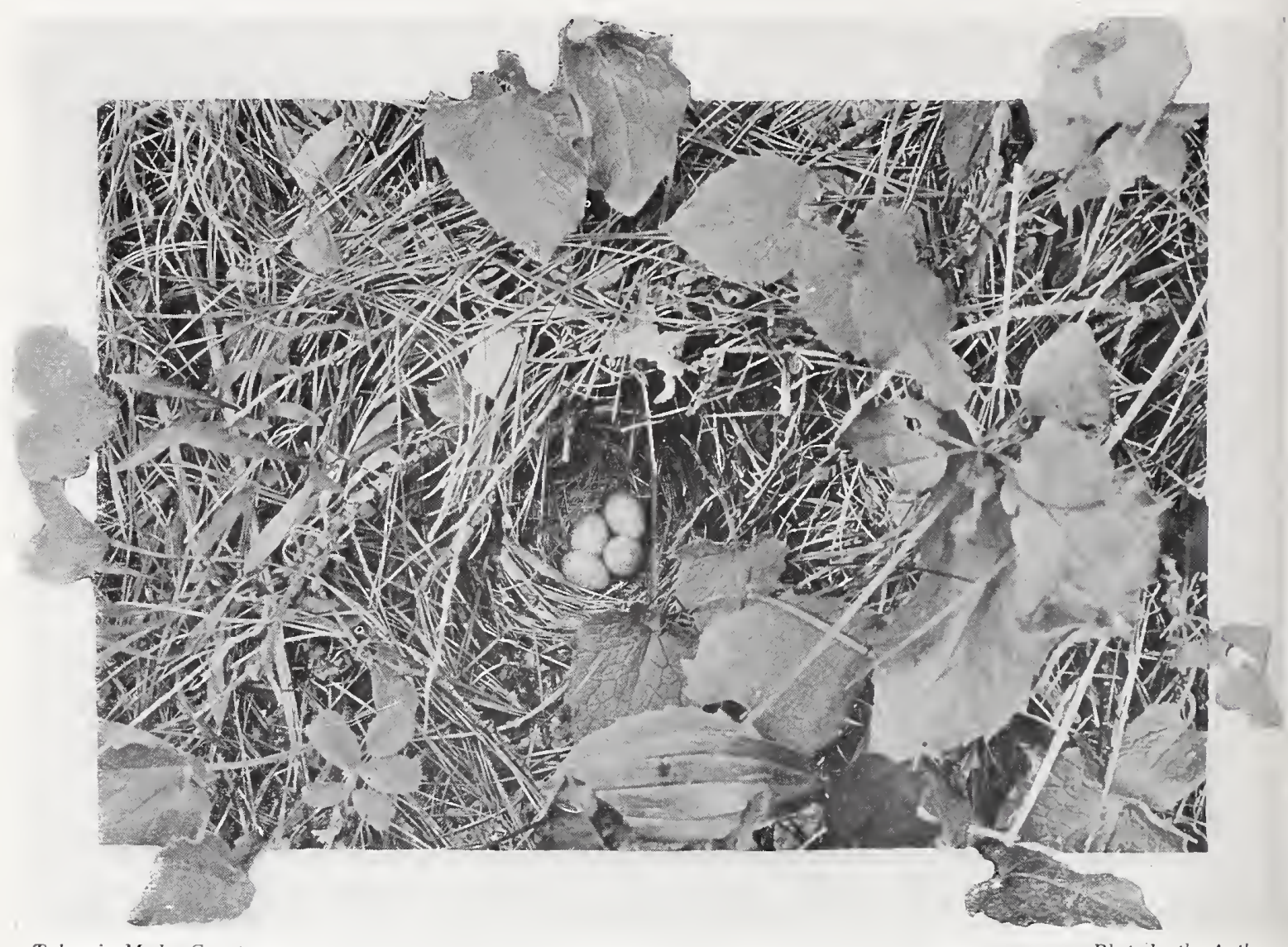

Taken in Modoc County

NEST AND EGGS OF THE NEVADA SPOTTED TOWHEE

Photo by the A uthor

the Yosemite Valley we heard a peculiar, lengthy, aspirated preface, hoorip $z^{\prime} z^{\prime} z^{\prime}$; and this came in precisely similar accents from individuals a mile apart.

The "liberty of difference" pertains, also, as certainly, to the ordinary scolding, or keep-in-touch note, marié. This varies by shades too subtle to describe; but the clear marié of Washington birds has shaded off in the case of $P$. m. montanus of southern Arizona (the Patagonia Mountains, to be explicit) to a blurred murr. Similarly the drawling meay, or meayuh of $P$. m. oregonus has become meow yaaar in Santa Cruz 
County, and unmistakable meow yeaow on Santa Cruz Island. The lastnamed note is so precisely that of the Green-tailed Towhee Oberholseria chlorura) that I reached my reluctant conclusion only after searching and repeated investigation.

Towhee's humble manner of life enables it to conduct its domestic operations by stealth. It is only by accident that one discovers the nest, deep set in the leafy covering of the ground, or flushes the close-sitting bird. On April I9th, I9I 5, on Santa Cruz Island, in a willow "bottom," well shaded, and buried in heavy grass, I caught a glimpse of a black rat shooting along the ground under a brush clump eight feet ahead. I had, fortunately, seen "black rats" before, so I checked my steps instantly, stooped and grasped firmly a dead branch which lay imbedded in the grass at my feet. Wrenching this loose, three dainty eggs were disclosed, in a sunken basket of coiled bark-strips and grasses-three eggs and a system of runways by which the brooding bird could glide off under cover for a considerable distance before emerging to view. There had not been a sound of protest at first, but when they saw the game was up, the Towhees confessed ownership vehemently enough. Sympathetic neighbors dropped in-notably, a Hutton Vireo, which sat on a twig six feet overhead and called me a bad man. But the affair was soon hushed up, and a week or so later there were, no doubt, three more treasures buried under the grass.

No. 68

\section{Abert Towhee}

A. O. U. No. 592. Pipilo aberti Baird.

Synonym.-Desert TowheE.

Description.-Adult (sexes alike): General color cinnamon-gray. Above drab, shading on sides to grayish cinnamon of underparts; red element of throat and chest more intense, nearly fawn-color, palest (avellaneous) on breast, reintensifying posteriorly; crissum mikado brown; face narrowly dull blackish, the color scattering and passing out in flecks, especially upon throat. Bill grayish brown; tarsi light brown; feet darker. Young: Like adults, but breast faintly streaked with dusky. Length about 2 I 5.9-228.6 (8.50-9.00); wing 79 (3.10); tail $88.9(3.50)$; bill I4 (.55); tarsus 26.6 (I.05). Females smaller.

Recognition Marks.-Towhee size; almost uniform drab coloration; paler above and ruddier below than Pipilo crissalis; face narrowly dusky.

Nesting.-Nest: A deep, well-made cup of twigs, grasses, weed-stems, and trash; neatly lined with fine grasses or horsehair; placed at moderate heights in bushes 


\section{The Abert Towhee}

or trees. Eggs: 3 or 4; pale bluish green (much paler than pale niagara green), marked sharply and sparingly, often curiously, and chiefly at the larger end, with black or deep brownish black, rarely with subdued shell-markings of purplish gray. The markings sometimes group into a wreath of interwoven hieroglyphics, and the eggs are at such times, or indeed at all times, roughly comparable to those of the Agelaius Redwings. Av. of 80 southern Arizonian specimens in the M. C. O. coll.: 24.2 x I 8 $(.955 \times-71)$. Extremes $21.6-26.9$ by 17 -1 8.8 (.85-1.06 by $.67-.74)$.

General Range.-Chiefly resident in Lower Sonoran zone from the Colorado Desert, southern Nevada and southwestern Utah, south through Arizona to southwestern Mexico. May wander a little farther south in winter.

Distribution in California.-Common resident in the valley of the Colorado River, Imperial Valley, and the Colorado Desert west to Whitewater and Palm Springs.

Au thorities.-Baird, Rep. Pac. R. R. Surv., vol. ix., I 858, p. 5 I6 (Fort Yuma); Cooper, Orn. Calif., I 87o, p. 244 (Colorado Valley; habits, nests and eggs); Brewster, Bull. Nutt. Orn. Club, vol. vii., I882, p. 198 (s. Ariz.; habits; desc. nests, eggs and young); Gilman, Condor, vol. v., I903, p. I2 (w. Colorado Desert; nests and eggs); Grinnell, Univ. Calif. Pub. Zool., vol. xii., I9I4, p. I77 (Colorado R.; habits, crit.).

ORNITHOLOGY, it cannot be too of ten repeated, is not an exact science. Taxonomy, the science of classification, aims at exactness, but its symbols are, after all, only records of opinion. Bird names, however diligently Latinized, are only pegs driven at irregular intervals along memory's wall, pegs upon which we may conveniently hang bundles of collective experience. These thought bundles, or observations, are called facts, and they pertain to, or are derived from, individual birds having certain points of resemblance, or certain characteristics in common. These rows of thought pegs are called family, genus, species, and subspecies, solely according to the nature and degree of resemblance between individuals which we choose to regard. And of all these ranks, or orders, or rows of pegs, the most familiar, the most useful, the best understood, and for that very reason the least accurate, is the species row. Beneath each peg of this row we paste a label called a scientific name, which must be dutifully repeated every time an individual bird is mentioned, and upon the peg itself we hang all the similarities which we may discover between two or more individuals not otherwise defined (that is, whose origin, or distribution, or actual blood relationship, is unknown to us).

I have said these name pegs are driven at irregular intervals. They should be if they expressed the facts of nature as we find them. The distance between the pegs is precisely the interesting point in any comparison of species. These distances vary enormously, but our practical realization of this fact is always being hindered or frustrated by a practical, or rather an impertinent, consideration which pertains to the mechanism of our science. The assignment of two or more names to two or more pegs tends in itself to prescribe the distance between those pegs. That distance is the space separating two names on the printed page. For economy's sake, names are printed in close succession, and for the sake of appearance they are separated by regular intervals. We tend, thus, to a uniformity of peg-spacing upon memory's wall, and so to a sense of uniform value-distances separating the species themselves. Yet nothing could be further from the facts. In truth, this artificial, constricted spacing of our 


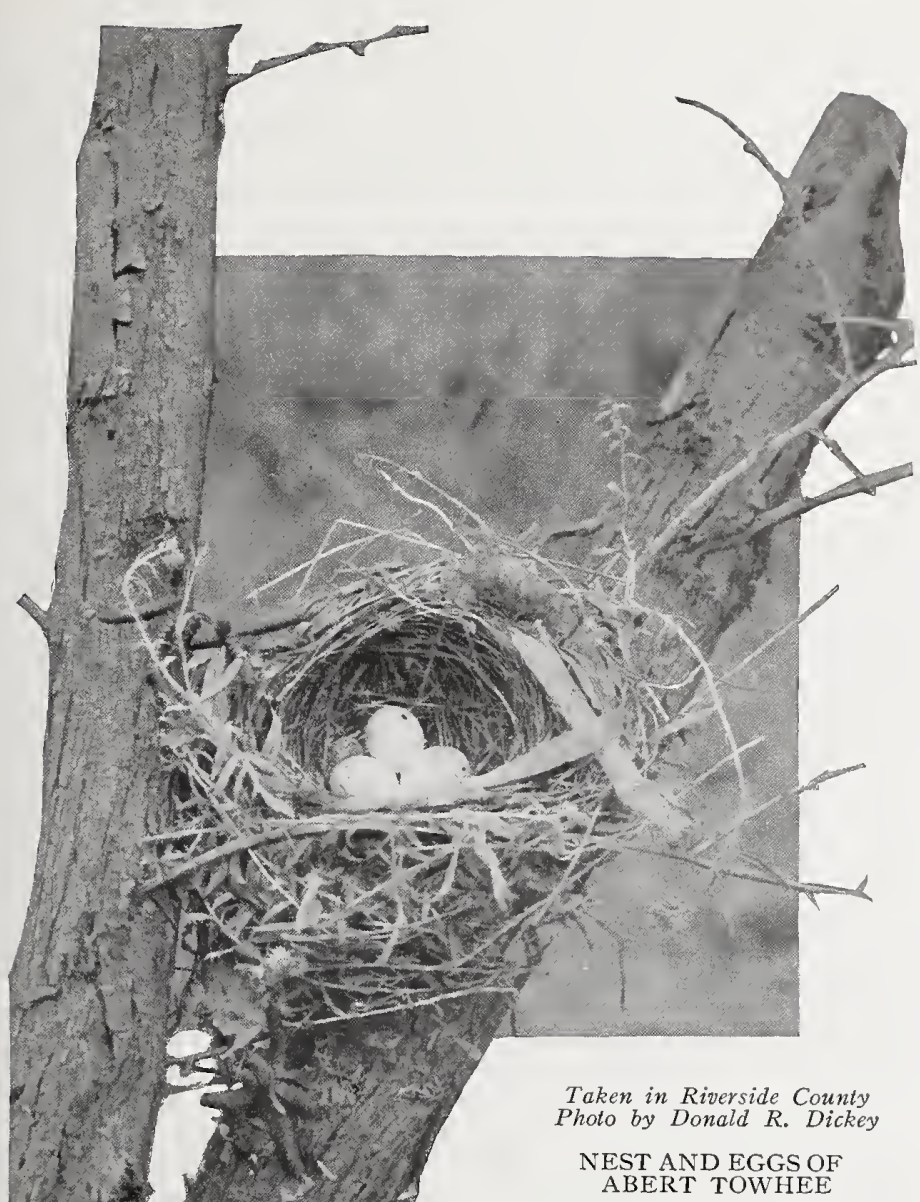

The Abert Towhee

species concepts is one of the most pernicious influences in science. We cannot avoid it altogether, but we can face it out and persistently discredit it. Thus it is that the mere assignment of names breaks up and artificially spaces out certain groups of bird species whose differences, though constant, are almost infinitesinal; and it contracts and renders inoperative the valuedistances which separate certain other species whose names, if we were consistent, could not be printed on the same page, or even in the same book.

As a practical illustration of all this I would cite the case of the genus Pipilo. Regarding for the present only those representatives of the genus which occur above the

Mexican border, and dropping for the moment sub-specific terminations, we have five species to deal with: Pipilo maculatus, P. erythrophthalmus, P. fuscus, P. aberti, and $P$. crissalis. The mere enumeration of these species names gives each one dignity and value, a place among its fellows. Whatever the facts may be, naming terms coordinates them. It gives them equal value to our human apprehension. And though we spend the rest of our lifetime specializing on the genus Pipilo, we shall never be able to shake off this initial presumption that Pipilo aberti is as distinct, as different, as important, as $P$. maculatus. Yet if we regard evolutionary distance, or what I have called value distance (for evolution proceeds in different stocks at very different rates), we shall find the three members of the Pipilo fuscus-aberti-crissalis group, the Brown Towhees, as close together as three contiguous Earths; while the members of the Pipilo maculatus group would figure as a constellation of Neptunes. In other words, a printed list of the names of members of the genus Pipilo is as inexpressive of the value distances which actually separate them, as would be a printed catalog of the names of the planets to one who had never heard of the solar system. 


\section{The Abert Towhee}

AS COMPARED with our more familiar Brown Towhee (P.crissalis), Pipilo aberti is a somewhat smaller bird, paler above, more warmly, and especially more diffusely "cinnamomeous" below. The distinctions apply, however, only to birds in the hand, for Pipilo aberti in the bush is one of the shyest of our western birds. Whether it is because of the comparative thinness of cover in his desert home, or whether it is because of an especial toothsomeness which the owls and hawks have discovered in aberti's flesh, the bird will not reveal itself to any but the most casual glance, even when its nest is threatened. Not even that mocking woodsprite, the Western Chat, knows how to be so evasive. Our knowledge of Pipilo aberti, therefore, is chiefly confined to its notes and "song," and to its nests and eggs, endlessly encountered.

The creaking note of Abert's Towhee is a good deal more of a feature of the local desert chorus than is that of $P$. crissalis in its haunts. While never varying in general character, it is susceptible of great modification of duration and intensity. It serves every purpose, therefore, from the mild overtures of amiable companionship to the fiercest challenge of rivalry, rasped out with an intensity to compel attention at a hundred yards. In any case, it seems more metallic and resonant than that of P. crissalis. The "chip" note of protest is, likewise, crissalis-like, but it is milder and more musical.

The only time an Abert Towhee would think of questioning your presence is after the discovery of its nest, three or four feet high in a bush of "all thorns," or else cunningly concealed in the thickened leafage of a decapitated stump of mesquite. The female has slipped off unseen; but if you linger for an unseemly time, the "chips" increase in frequency, and you become aware presently of an anxious pair of brown ghosts who are circling round and round you in the shrubbery. An occasional glimpse discovers the female in the lead, and the male following her about like an importunate puppy.

Although they nest twice in each season, Abert Towhees are not very prolific, both because of their many enemies, and of the fact that the set rarely exceeds three, and not always two, in number. The eggs are pale bluish green, "bird-egg green," one might say, as to ground, and the sparse spotting of purplish black suggests Icterine or Agelaiine affinities. Occasionally, the ground-color goes to pure white, and then the resemblance to a Scott Oriole's egg is irresistible.

A typical nest of this Towhee is a bulky assemblage of weed-stems, dead vines, bark-strips, green leaves; and, interiorly, coiled bark, dried grasses, and horsehair. Bark is a favorite material, and I have seen nests which contained nothing else. Occasionally, the taste inclines to green grass, and the superstructure may be composed of green, or recently 
dried, grass or leaves of a single sort. A nest which I hold in my hand is based on abundant leafage of a very prickly plant, and the lining is of macerated weed-bark. Indeed, the unfailing variety of material used by these birds gives zest to continued inspections, burglarious or otherwise, conducted in the equally unfailing absence of the owners. By their works ye shall know them.

\section{No. 69}

\section{Brown Towhee}

\section{No. 69 California Brown Towhee.}

A. O. U. No. 59I.I. Pipilo crissalis crissalis (Vigors).

Synonyms.-Brown-bird. Drab. Bush-BIrd. Backyard-BIrd.

Description.-Adult (sexes alike): Above olive-brown, shading through drab on sides and flanks and across chest; ruddier on head and neck all around, darkest (bister) on crown; throat roughly bounded by a series of dusky spots, sayal brown to ochraceous tawny, or else spotted throughout with dusky; breast paling centrally to buffy; sides and flanks increasingly tawny-tinged; crissum and lower tail-coverts abruptly pure tawny or amber-brown. Bill browner above, lighter below; tarsi light brown; feet darker. Young birds resemble parents, but show less contrast and are finely streaked with dusky on throat, breast, and sides. Length 228.6-254 (9.ooI0.00); wing 99 (3.90); tail I IO (4.33); bill I5.8 (.62); tarsus 27.7 (1.09). Female a little smaller.

Recognition Marks.-Towhee size; drab coloration; throat and crissum reddish brown. The only bird with which it could be confused even by the novice is the California Thrasher, which is larger, longer, and has a long, curved bill.

Nesting. - Nest: A bulky but well-made cup of weed-stems, grasses, and dried vegetable miscellany; carefully lined with fine grasses or horsehair; placed at moderate heights in bushes or trees. Diameter inside 76.2-88.9 (3.00-3.50); depth 38-50.8 (I.50-2.00). Eggs: 3 or 4; much as in preceding species and not distinguishable from them, although perhaps with a stronger tendency toward subdued shell-markings, and the release of the concealed red of the "black" pigment. Av. of Io eggs from Boonville (Mendocino County) : $24 \times 18.3(.95 \times .72)$. Av. of 17 eggs from Santa Barbara: 24.9 x I $8(.98 \times .7 \mathrm{I})$. Extremes: $22-26.7$ by I6.8-19 $(.87-1.05$ by $.66-.75)$. Season: April-July; two broods.

Range of Pipilo crissalis.-Pacific Coast district from southern Oregon to northern Lower California.

Range of $P$. c. crissalis (Wholly within California).-Resident in the humid coast strip, narrowly defined, from Humboldt County to northern San Luis Obispo County (Paso Robles). 
The Brown Towhees

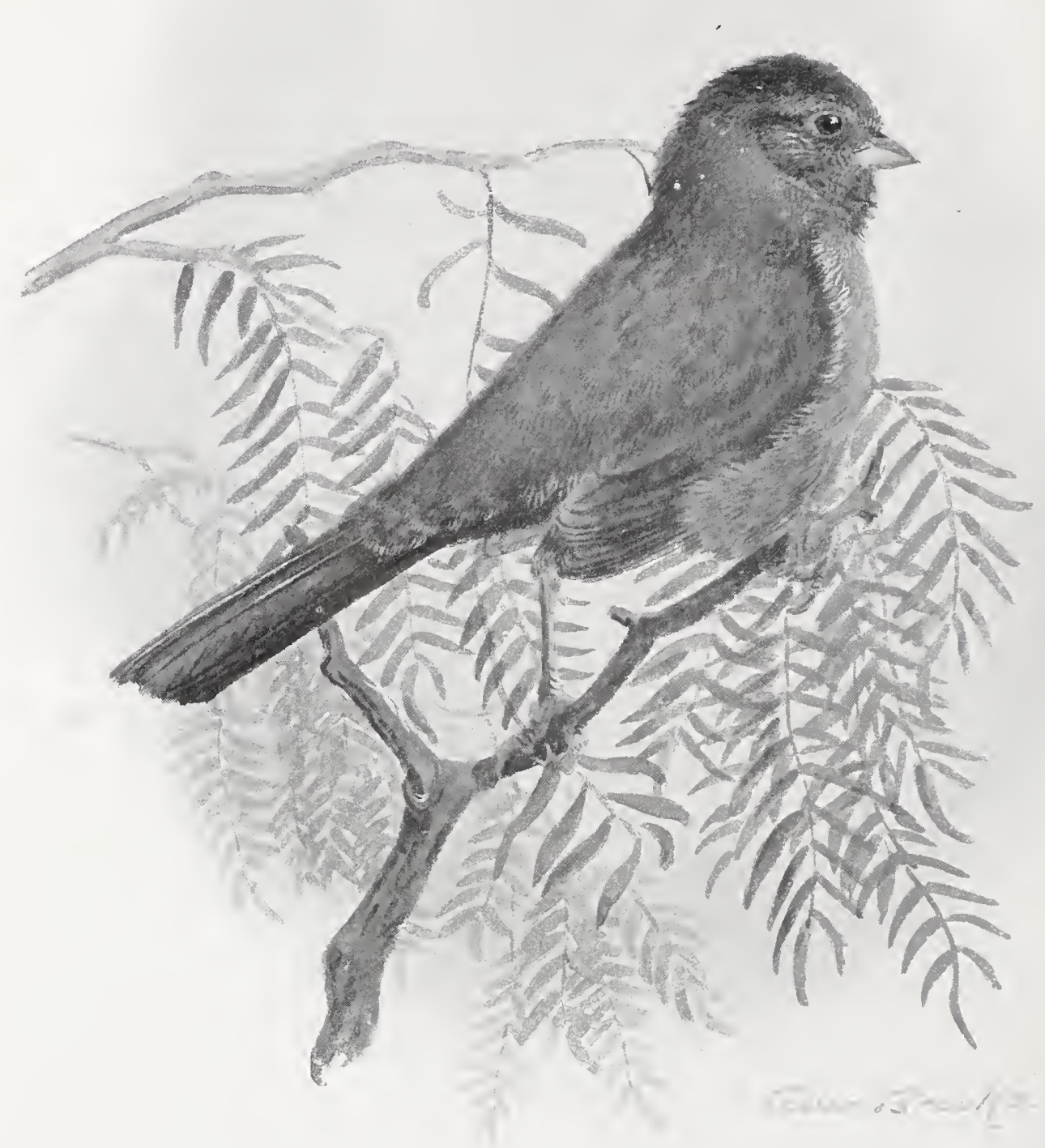

ANTHONY BROWN TOWHEE 


\section{The Brown Towhees}

Authorities.-Vigors (Fringilla crissalis), Zool. Voy. "Blossom," I 839, p. I9 (Monterey; orig. desc.); Brewster, Bull. Nutt. Orn. Club, vol. iv., i 879, p. 4I (desc. young); Beal, U. S. Dept. Agric., Biol. Surv. Bull., no. 34, 1910, p. 89, part (food); Swarth, Condor, vol. xx., I918, p. I I7, fig., map (distr., desc., crit.); Oberholser, Condor, vol. xxi., I919, p. 2 I0 (crit.); IIunt, Condor, vol. xxiv., 1922, p. I93 (song).

\section{No. 69a Northern Brown 'Towhee}

A. O. U. No. 59I.I, part. Pipilo crissalis carolæ McGregor.

Description.- "Closely related to $P$. $f$. crissalis, but distinguished by grayer and more uniform color of upper parts, much paler throat patch and slightly longer tail" (orig. desc.). Very dubious.

Range of $P . c$. carola.-Resident in Upper Sonoran zone interiorly in northern California and southwestern Oregon.

Distribution in California.-Common resident locally in Upper and Lower Sonoran zones west of the Sierras, from the Tehachipe divide north to the northern boundary. The subspecies thus occupies the western slopes of the Sierras, the great interior valley and the eastern slopes and semi-arid areas of the coast ranges, from the latitude of Tulare Lake north.

Authorities.-Heermann (Pipilo fuscus), Jour. Acad. Nat. Sci. Phila., ser. 2, ii., I 852, 267; McGregor, Bull. Cooper Orn. Club, vol. i., I899, p. I I (Battle Creek, n. Calif.; orig. desc.); Tyler, Pac. Coast Avifauna, no. 9, I913, p. 86 (Fresno; habits, nests and eggs); Swarth, Condor, vol. xx., 1918, p. I17, fig., map (distr. in Calif., desc., crit.).

\section{No. 69b Anthony's Brown Towhez}

A. O. U. No. 591.1 a. Pipilo crissalis senicula Anthony.

Description.- "Differing from crissalis in smaller size, much less rusty on lower parts, upper parts darker and lower more grayish" (orig. desc.). A very "light" form.

Range of $P$. c. senicula.- Resident in the southern Pacific Coast districts, broadly, from San Luis Obispo County, California, south to (at least) Latitude 29, Lower California. Casual east of the desert divides: Palm Springs (Gilman), Morongo Pass (Stephens). This form intergrades with crissalis on the north, but is probably distinct from carola, from which it may prove to be separated by the southern end of the Tulare basin.

Authorities.-Cooper (Pipilo fuscus), Orn. Calif., 187o, p. 245, part; Anthony, Auk, vol. xii., I 895, pp. I I I, I4 I (San Fernando, Lower Calif.; orig. desc.); Grinnell, Pasadena Acad. Sci. Pub., no. 2, I 898, p. 40 (s. Calif.; occurrence, nesting dates, etc.); Dickey, Condor, vol. xviii., I916, p. 93, figs. (habits; photos of birds, nests and eggs); Swarth, Condor, vol. xx., I918, p. I20, figs., map (distr., desc., crit.).

FAMILIAR objects, whatever their worth, come to be dear to us through association. There is, honestly, no particular reason why we should be fond of this prosy creature, save that he is always around. In appearance, the bird is a bit awkward, slovenly, and uncouth; or at least, we are obliged to see him oftenest in every-day duds, and he seems to 


\section{The Brown Towhees}

have no company manners. And for color-never was a more hopeless drab. But surely the bird must have some redeeming qualities. He sings, perhaps? Not at all; his efforts at song are a farce, a standing joke - though he is himself entirely devoid of humor. He is, to be sure, a, gleaner of crumbs and odds and ends, but so are the ants; and the bird's presence in a garden is far from being an unmixed blessing. Really, there is no reason why one should espouse the cause of this local ash-man. Yet I suppose there are few Californians who would willingly spare the homely, matter-of-fact presence of this bird under foot. Brown Towhees are just birds - the same way most of us are just folks.

Truth to tell, the sober color of our hero does match very well the universal dryness of the under scrub, during the long rest period which Californian vegetation indulges (and which dutiful Californians pretend to like). When other birds, therefore, have forsaken the mesa and have gone to higher, greener levels, the Towhee feels no need of change. He has come into his own. Trusting to his brown coat, he moves about fearlessly in the open, and is much more active than Thrasher or Wren-Tit dares to be, away from cover. Wren-Tit is, doubtless, the first bird to respond to the screeping call of the birdman, but if the Wren-Tit is not on hand, the Brown Towhee is sure to be. His name is legion, and some one of him marks the downsitting and the uprising of every human in western

or southern California.

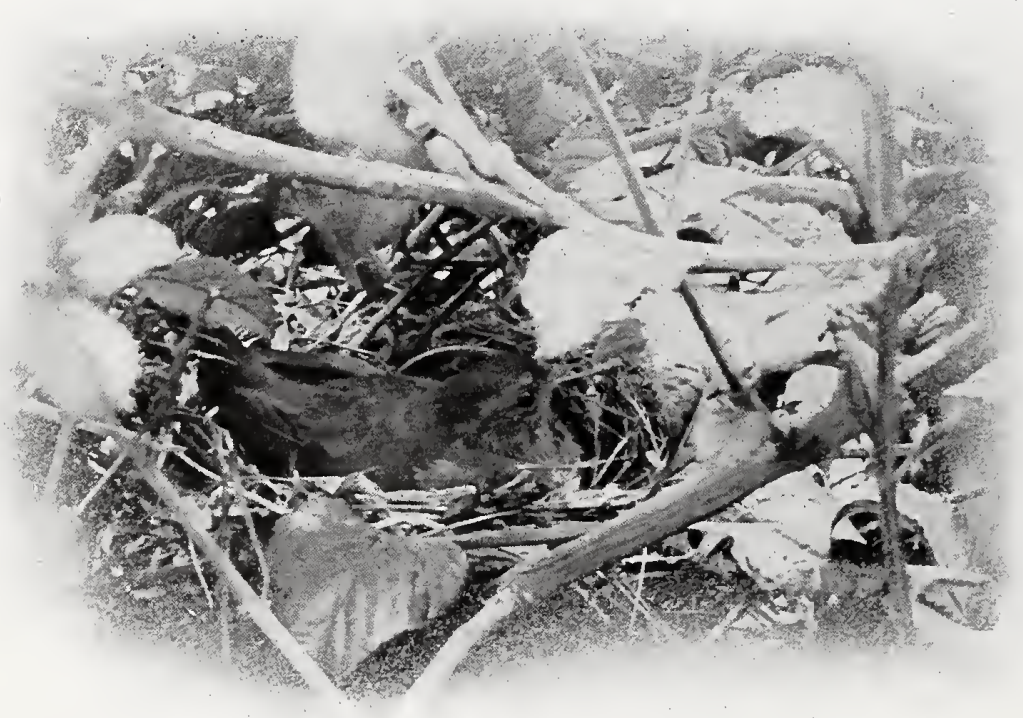

Taken at Los Colibris

FAITHFUL GRETCHEN
Photo by the Author
$\mathrm{T} h \mathrm{e}$ Brown Towhee is the typical Hans when he gets with other birds. When he is consorting w i th th e Crown Sparrows, as he often does, or tries to, he apes all their motions of f right or flight, but he does it so awkwardly and ex- 


\section{The Brown Towhees}

poses himself in such yokel fashion, according to their standards, that the crowd is jeering at him before he has re-joined it in the shelter of the bush. Save for the afflictions of the noble passion, the Towhees get along well enough with their own kind. There is likely to be amiable twittering-good-natured banter, it would seem - whenever they meet; and nothing could be more suggestive of homely joys than the sight of a wedded pair taking "the kids" out for an airing of a Sunday afternoon. The excursion, perhaps, is conducted through the garden. Bugs and worms are not overlooked. Fallen seeds are seized and bolted outright, or else shelled deftly with that curious nibbling motion which always looks babyish or affected in these large-beaked birds. Fresh herbage is sampled freely, too freely, perhaps, as we shall learn presently. Whatever the parents do the children imitate in gratefulobedience; but there are baby hours whiled in the leafy shade, when they are more prone to snatch up what father or mother has uncovered by energetic backward kicks, than to rustle (quite literally) for themselves.

The predilection of these birds for young plant growth is very marked; and there is no gainsaying the mischief they do in early spring to tender peas and lettuce. Mr. Tyler has remarked, "The Towhees are big good-natured fellows, in no way injurious to man's interests." I should like to see him argue this point (without weapons, of course) with a certain good neighbor of mine who raises "garden sass" for the market. Having had occasion to replant early peas myself, I have learned to cover the tender shoots with brush or mosquito netting for the first two weeks of their growth. The Towhee also comes in strong on the fruit harvest. Plums, apricots, early peaches, and grapes-these he will munch as innocently

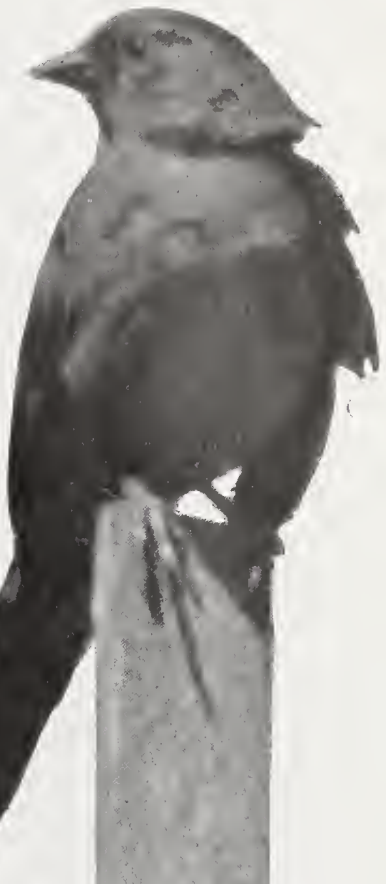
as an urchin. And why not? He was here first; and if you insist upon using his ground for growing fruit instead of bugs and weed-seed, you must expect to pay ground rent. Cheer up!

The presence and movements of the Brown Towhee are published from time to time by a metallic chip, which is quite the most familiar of vocal sounds. This chip is the ordinary keep-in-touch note, and it must also do duty for warning, for challenge, for exhortation, and other purposes which, in a sphere of action somewhat removed, necessitates the use 


\section{The Brown Torwhes}

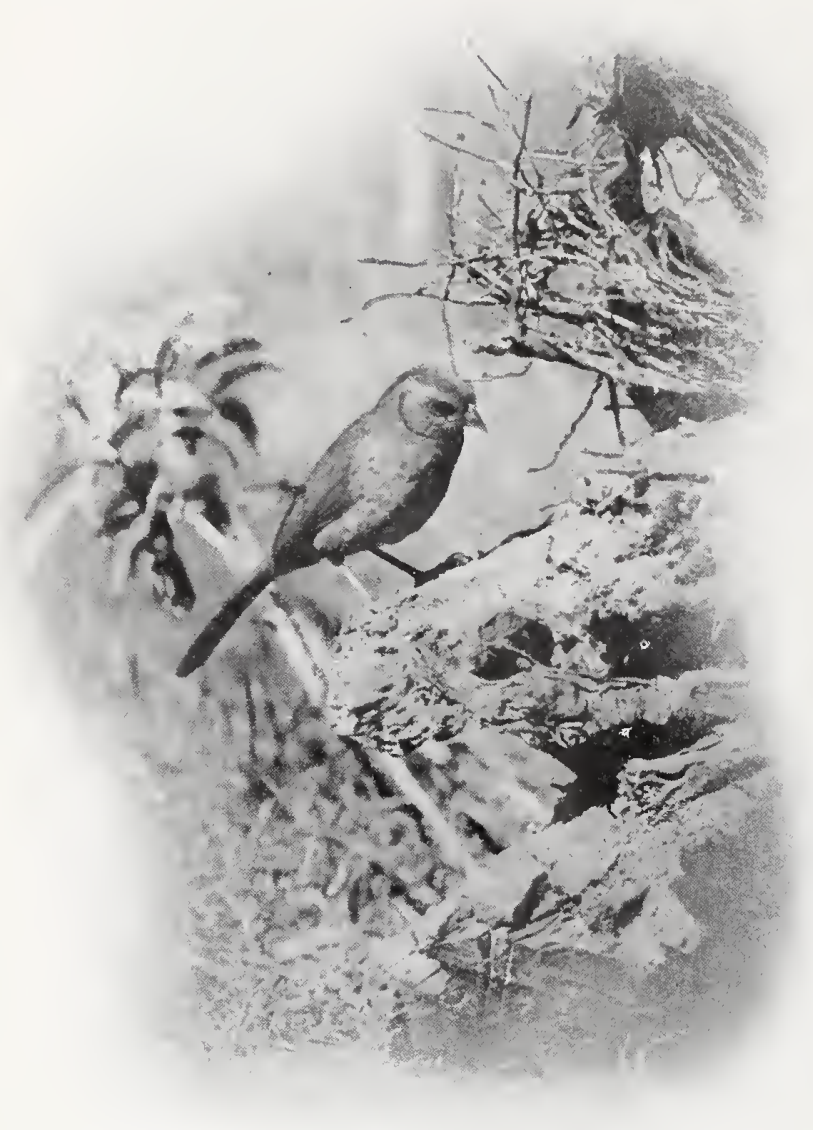

Taken in Pasadena

Pholo by Donald R. Dickey

EXAMINING THE BAIT

of 450,000 vocabulary entries. Saddest of all, this overworked note must do duty for song. For this purpose it is furbished up a bit, brightened, intensified, and aspirated, till it sounds like a sibilant squeak. The singer mounts a bush or tree-top, or the comb of a roof, and with uttermost ardor delivers himself of such sentiments as these, tsick tsick tsick tsick tsick. Listen! O ye Muses, and pause, Satyrs, in your mad gambols. Orpheus will smite the lyre again: Tsick tsick tsick tsick tsick. He is dead in earnest, too, this country Jake turned minstrel. As he concludes, his body quivers and his tail beats flail-like with his unwonted exertion. And one good lady (she of the endless regurgitations) likens this song to "the tinkle of a silver bell"!

The male bird is a masterful lover, and he will vindicate his claims against all comers. Great fights ensue, and not a few in which bodily injury is done. These encounters characterize early springtime, but there seems to be a recrudescence of hostile activities in late summer as well. Perhaps the young blades are asserting themselves. Such a fight occurred in our yard in the early morning of August 28th (I9II). Whether it was a contest between old males, or merely young fellows trying out their strength, I could not determine. At any rate, there was intermittent onset of long duration, and as often as the duellists set to, they were accompanied, or mobbed, by four others, all squeaking at once at the top of their voices. The squeaks in this case were something dynamic. They were shrieking squeaks; and six birds squeaking in concert made a fine hubbub-quite too much for that last 


\section{The Brown Towhees}

coveted hour of slumber. The feud seemed implacable; and I witnessed an attack an hour later, all to the accompaniment of admiring, or protesting, squeaks.

This pugnacity of the Brown Towhee has led to one strange length. Other birds there are who will fight their shadows in the window panesGoldfinches, Linnets and Mockingbirds; but their passion is short-lived. The Towhee adopts "shadow boxing" as a profession. It becomes a religion, a something dearer-than-meat-and-drink, an obsession. The occurrence is common enough, but the best report of it is, perhaps, that given by Mr. Donald R. Dickey, 1 whose friend, General Penney, of Nordhoff, was besieged by one of these pugilistic visitors. The trouble in this instance began in the late winter (of I9I3-I4) when the mating season had scarcely begun. "Perched on the sill, the bird would eye his reflection, and then set systematically to work to kill that supposed rival, with all the ire and intolerance of a rutting mouse. The tactics varied somewhat, but on the whole the bird firmly believed that victory lay in the frequency of his attacks, rather than in their violence, so that the blows of his beak rained on the pane with all the persistence of water dripping on a tin porch roof after an Eastern thaw. Each blow was, of course, met squarely by the shadowed beak of his opponent; each retreat was mimicked by the shadow; each unusually furious onslaught was countered in equal force. Sometimes they rested as though by mutual consent-the bird and his sparring partner-but presently some turn of the bird's

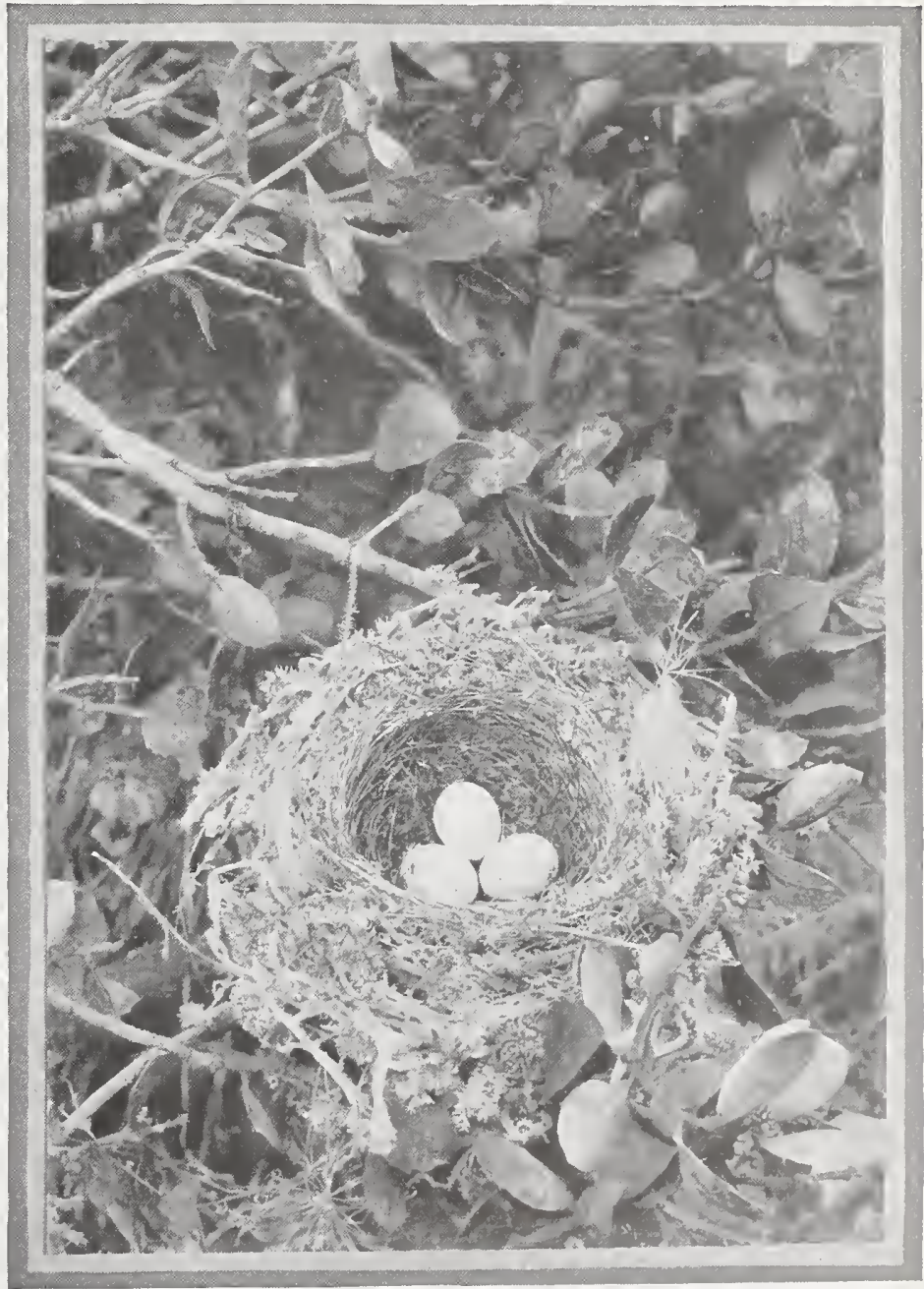

Taken in San Diego "SOME OF THEIR NESTS-ARE MODELS OF BEAUTY"

1"The Shadow Boxing of Pipilo," The Conder, Vil XVIII, 19:6. p. 9 - 


\section{The Brown Towhees}

head would find an answering challenge in the glass, and he would fly at it again. Hour after hour this continued, until the bird was completely exhausted, or until the light changed and the reflection vanished.

"This continued day after day and week after week with scarcely an interruption, and became a positive nuisance. As time went on and his attacks netted him nothing, Pipilo worked himself into greater and greater frenzy until blood specks from his beak of ten covered the lower part of the pane. The small head feathers, loosened in the fracas, would stick to these blood spots and necessitate frequent window washing, in addition to the 'damnable iteration' of his tap, tap, tapping at the pane. Nothing was done about it, however, and it continued as an almost daily performance until early summer. Then, with the close of the breeding season, the bird stopped of his own accord."

Nests of Pipilo crissalis are usually placed at moderate heights in shrubbery or trees. The birds often exhibit considerable skill in construction, and some of their nests, especially of those whose builders do not have access to the miscellaneous waste of civilization, are models of beauty. The eggs, usually three in number in the southern portion of the bird's range, four or even five northerly, are pale blue (really, pale niagara green), handsomely though sparingly marked and short-scrawled with purplish black. They resemble, thus, to a striking degree, the eggs of certain blackbirds (Agelaiince). The female, elsewhere so confiding, is singularly shy in and about the nest, and does not pose well for the photographer. The bird figured here had built in a lantana bush hard against a window. By dint, therefore, of darkening the room, her confidence was sufficiently won to permit of portraiture at long range. Nesting is the main business of life, and the Towhees take theirs quite seriously. At least two broods are raised each season, and five or six months of each year are given over to the activities attendant upon or anticipatory of chick-raising. For all this, the birds fall easy prey to prowlers, and the ranks of the species never seem to be unduly swelled, as is of ten the case, for example, with the Linnet (Carpodacus mexicanus frontalis). 


\title{
The Lazuli Bunting
}

No. 70

\section{Lazuli Bunting}

\author{
A. O. U. No. 599. Passerina amœna (Say).
}

Synonym.-LazUli Finch.

Description.-Adult male: Head and neck all around light blue (cendre blue or light cerulean blue to cerulean blue); this color carried over upperparts, but pure only on rump, elsewhere appearing as sub-skirting of feathers; middle coverts broadly and greater coverts narrowly tipped with white; wings and tail otherwise black; some skirting of ochraceous on back, scapulars, and tertials; lores black; chest ochraceous tawny, sharply defined from blue above, but shading gradually into white of remaining underparts; sides and flanks with outcropping bluish dusky. Bill black above, pale bluish below; feet brownish dusky; iris brown. Adult female: Above grayish brown or brownish buffy, the color of male recalled by dull greenish blue of crown, rump, and upper tail-coverts, and by skirtings of wing-and tail-feathers; middle and greater coverts tipped with light buffy; underparts washed with ochraceous buffy, most strongly on chest and sides, fading to whitish on belly and under tail-coverts. Young birds resemble the female but lack the greenish blue tinge, and are usually more or less streaked below on chest and sides. Length of adult male: I33.3-I39.7 (5.25-5.50); wing 73 (2.87); tail $55(2.17)$; bill Io (.40); tarsus I7 (.67). Female smaller.

Recognition Marks.-Warbler size; color pattern of male distinctive; female not so easy-in general, distinguishable by a softness and uniformity of the grayish browns, by the ochraceous of chest, and by at least some hint of greenish blue above.

Nesting.- Nest: A rather coarsely woven basket of dried grasses, especially their leafy portions; lined with finer grasses or horsehair; and lashed firmly to supporting stalks of weeds, or settled in forks of bushes, in thickets or tangles; rarely low in trees (live oaks). Eggs: 3 or 4 ; rounded ovate to elongate ovate; very pale bluish green, immaculate or, very rarely, speckled with blackish. Av. of 16 eggs in M. C. O., I $8.3 \times 13.5(.72 \times .53)$. Season: May-July; one or two broods.

General Range.-Breeds in Transition and Upper Sonoran zones throughout the western states and in the southern portion of the western provinces of Canada, east to North Dakota and Texas; winters in Lower California and in Mexico, south to the valley of Mexico.

Distribution in California.-Of general occurrence as a breeder in the Upper Sonoran and Transition zones throughout the State: apparently indifferent to moisture, but keeps to brushy margins of springs and streams in semi-arid Sonoran territory. Occurs more widely during migrations at lower levels. No winter records.

Authorities.-Heermann (Spiza amaena), Jour. Acad. Nat. Sci. Phila., ser. 2, ii., I853, p. 266; Barlow, Condor, vol. iii., I90 I, p. I74 (Fyffe; nest and eggs); Carpenter, Condor, vol. ix., 1907, p. 199 (nest and abnormal eggs); Tyler, Pac. Coast Avifauna, no. 9, I9I3, p. 89 (Fresno; habits, nesting, etc.); Howall, Pac. Coast Avifauna, no. I2, I9I 7 , p. 87 (Santa Barbara Ids.).

ONE can scarcely believe his eyes as this jewel flashes from a thicket, crosses a space of common air, and disappears again all in a trice. Either there has been some optical illusion, or Nature has grown unco careless to 


\section{The Lazuli Bunting}

fling her turquoises about in such fashion. We must investigate. Upon arrival, in late April or early May, and before the return of his dun-colored mate, the male Lazuli is quite conscious of his prominence in the landscape. He avoids notice and goes bounding away if closely pressed; but love soon makes him bold, and he will pursue the object of his affections into the very thicket where you stand. Then, while the female lurks timidly within, he mounts a spray and yields an outburst of music, piercing and earnest, if not too sweet. We see that his blue is deep azure, or turquoise, rather than that of the lapis lazuli from which he is named. The red of his breast is nearly that of the Robin's, while the pure white of the remaining underparts completes a patriotic study in red, white and blue. The female shows something of the color pattern of her mate, with the important exception that dull brown supplants the royal blue of head and back. After all, then, they are fitted for separate spheres: she to skulk and hide and escape the hostile eye in the discharge of her maternal duties; he to lose himself against the blue of heaven, as he sings reassuringly from a tree-top, or sends down notes of warning upon the approach of danger.

The song of the Lazuli Bunting is a rambling warble, not unlike that of the Indigo Bunting ( $P$. cyanea), but somewhat less energetic. Its brief course rises and falls in short cadences and ends with a hasty jumble of unfinished notes, as though the singer were out of breath. Moreover, the bird does not take his task very seriously, and he does not burden the midday air with incessant song, as does his tireless cousin.

While in camp on the southern shore of Clear Lake, in June, I916 (the year of the big freeze in that section), my attention was intrigued by an early morning singer who lisped out only a monotonous string of squeaky notes. The quality and cadence were warbler-like, but there was no such warbler called for by the books. So I followed the elusive thing through the mazes of the frost-bitten oaks for half an hour. Tsweek tsweek tsweek tsweek tsweek tsweek, was all he said, although with some variation of inflection or emphasis. When at last I had the little rascal pinned against the sky, down sun, I found not a recreant Geothlypis, but a Lazuli Bunting, a male in very low plumage, and so, presumably, a yearling.

During the year of I9I2, the year of the great warbler wave, we had Lazuli Buntings in great numbers. In the course of a fifty mile drive along the Santa Barbara coast we saw hundreds, or thousands, of them. It was not a matter of scattering individuals, either, for they appeared in squads and platoons wherever the wayside weeds gave shelter. Arrived at our own demesne, it was again Lazuli Buntings. The tall grass of a neighbor's yard seemed especially attractive to them; and once when a 


\section{The Lazuli Bunting}

struggling auto made explosive comment upon our hill, a perfect cascade of brightly plumaged birds, all males, boiled up from the ground.

The secret of Lazuli Bunting's nesting - at least in southern California-may be told all in a breath-Artemisia heterophylla! There you have it! Search the clumps of this broad-leafed sage, or "mugwort," as it grows to a height of three or four feet along the banks of streams, or upon half-shaded hillsides, and you will be astonished at the harvest of "Lazzes" it will yield. In a season's desultory nesting, that of 1920 , at Santa Barbara, I found nineteen occupied nests of the Lazuli Bunting. Of these, fourteen were in pure stands of $A$. heterophylla; two in mixed stands; two in poison oak; and one in a blackberry tangle. The nest, a rather bulky but often tidy affair, of bark-strips, hemp, and dried grasses, lined with fine grass or horsehair, is lashed to the upright clustering stems of the mugwort; or, more rarely, and in mixed cover, is supported from below by transverse stalks and vines. The female slips off quietly, often unnoticed, and the passerby would not suspect the presence of a nest; but a loitering oölogist soon elicits an anxious twisp, or twissup from the skulking bird. If he does not heed that warning, the female will presently summon her mate, and both birds will berate him soundly. Amæna means pleasant, but you could hardly expect an anxious mother to practice the amenities while a brute of a man is fingering

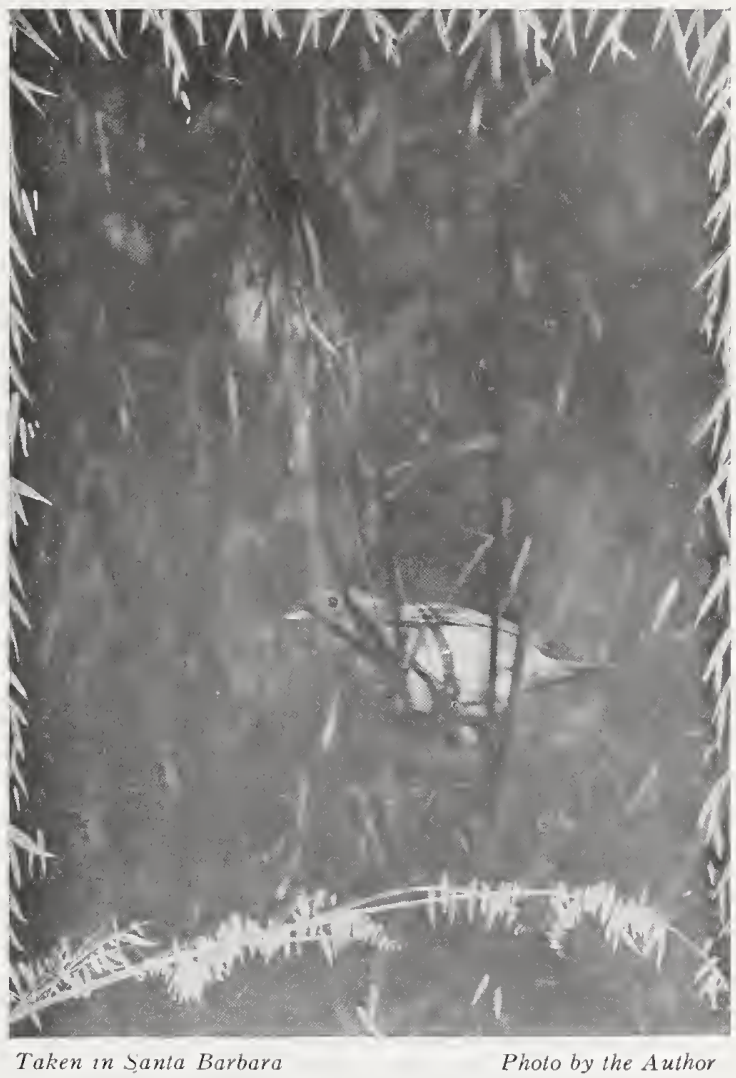

A FURTIVE INSPECTION-BY A FEMALE LAZULI BUNTING her babies-to-be and speculating upon their possible degree of freshness. The male, on the other hand, soon tires of saying unpleasant things, and will try your heart with a bit of a song instead. 


\section{Beautiful Bunting}

A. O. U. No. 60oc. Passerina versicolor pulchra Ridgway.

Synonyms.-VAried Bunting. Western Varied Bunting.

Description (of versicolor, after Ridgway).-Adult male in summer: Lores and frontlet black; chin blackish; forehead, forecrown, supra-auriculars, lower hind-neck, rump, and upper tail-coverts light purplish blue (mauve to campanula blue or flax flower blue); the malar and auricular regions and lesser wing-coverts similar but darker; hind-crown, occiput, and cervix, with a touch on either eyelid, vermilion red; back dusky purplish red, the scapulars more bluish or purplish; throat and chest maroon purplish, clearing, redder, on throat; remaining underparts dusky purple, becoming grayer on flanks; wings dusky with grayish blue and purplish edgings; tail blackish edged with dull blue. Bill black above, lighter, horn-color, below; feet and tarsi brownish black. Adult male in winter: Bright colors more or less obscured by grayish brown tips of feathers. Adult female in summer: "Above grayish brown (hair-brown), more or less strongly tinged with olive (occasionally tinged with dull light grayish blue), passing into light glaucous or bluish gray on rump and upper tailcoverts; tail bluish dusky, the rectrices edged with glaucous-bluish; middle and greater wing-coverts indistinctly tipped with paler grayish brown, and primaries and adjoining secondaries edged with pale glaucous gray or bluish; underparts dull whitish on throat, abdomen, and tips of under tail-coverts; elsewhere pale grayish brown, deepest on chest." Length (skins of adult male): I27 (5.00); wing 67 (2.64); tail 53.3 (2.10); bill $10.2(.40)$; tarsus $17.8(.70)$. Females slightly smaller.

Recognition Marks.-Warbler size; variegated plumage with contrasting blues and red distinctive for male; female much more difficult, - a grayish brown and bluish gray bird.

Remarks.-Ridgway, in his Birds of N. and M. America, Part I, I90I, p. 592, abandons the claim of a western subspecies, pulchra, which he had advanced in I 887 (Manual of N. A. Birds, p. 448), after commenting on the minor differences shown by specimens from Lower California, and the intermediate character of specimens from western Mexico. We shall either have to follow him or else define the intermediate form, which is evidently that of Arizona also.

Nesting.- Not known to breed in California. Nest and eggs much as in preceding species.

Range of Passerina versicolor.--Southern border of the United States and Mexico.

Range of P. v. pulchra.--The alleged western form found in "southern Arizona", northwestern Mexico, and discontinuously (?) in southern Lower California.

Occurrence in California.-One occurrence, as below, at Blythe, February, 1914 .

Authorities.-Daggett, Condor, vol. xvi., 1914, p. 260 (Blythe, on the Colorado R.); Grayson, Mem. Boston Soc. Nat. Hist., vol. ii., i 874, p. 276 (habits, song, etc.).

THE BEAUTIFUL Bunting is a Mexican species which upon two occasions has been caught trespassing in the States. On July I4, I884, Mr. Frank Stephens took a specimen, an adult female, at Crittenden, near 
the Santa Rita Mountains, in Arizona. And on February 8th or 9th, I9r4, Dr. J. A. Hornung, of Los Angeles, took specimens at Blyth, Riverside County, California. During the course of several days Dr. Hornung saw as many as fifteen or twenty of these birds feeding on roadside weeds bordering a cotton field. These two appearances are manifestly an insufficient basis for any hypothesis, and we can only agree with Grinnell in calling the Beautiful Bunting a casual visitant.

Mexico having been a terra horrenda for many years past, we needs must wait till the mask of the bandit is laid aside, and scientific explorers are no longer scalped or held for ransom. Would you, then, know more of the Beautiful Bunting? Then take your place among the Watchful Waiters.

No. 72

\section{Blue Grosbeak}

\section{No. 72a Arizona Blue Grosbeak}

A. O. U. No. 597a, part. Guiraca cærulea lazula (Lesson).

Synonym.-Western Blue Grosbeak.

Description.-Adult male in breeding plumage: In general, violet-blue (dark, soft blue-violet), blackening around base of bill (broadly on lores) and on back, with irruptions of black on breast, lightening (soft blue-violet) on crown and rump (where "light soft blue-violet"); the feathers of underparts and back (even in highest plumage, but in lessening degree with advance of season) irregularly tipped with cinnamonrufous on back and major edging of wing, and on chest, broadly; with white or, casually, with rufous on remaining underparts, especially abdomen and crissum. Median wing-coverts entirely russet; rectrices and remiges black, narrowly edged with blue, the four outermost rectrices narrowly white-tipped. Bill dark bluish, black above, lightening below; feet and tarsi brownish black. Adult female: Very different; chiefly brownish gray (tawny olive to buffy brown) above, paler (cinnamon-buff to pinkish buff) below; blue of male irregularly irruptive, in flecks and patches on breast and flanks, and on head, especially the cheeks; rump tinged with bluish; median and greater wing-coverts bordered with dull rufous (pinkish cinnamon), forming two inconspicuous bars; the breast and sides also sometimes faintly streaked with dusky. Young birds resemble the adult female, with increase of the ochraceous element. Length of adult male (skins): I 65 (6.50); wing 86 (3.386); tail 66 (2.60); bill I6 (.63); tarsus $20.6(.8 \mathrm{I})$. Females are a little smaller.

Recognition Marks.-Sparrow size; violet-blue of male distinctive. Female and young dull brownish with only faint outcroppings of blue,-- - best known by size and tumid beak.

Nesting of Guiraca carulea.- Nest: Placed in briar tangles, weed-clumps, thickets, or low in trees; a rather loose basket of coarse grass-blades, leaves, and vegetable trash, lined coarsely or finely with grasses and rootlets or horsehair. Eggs: 


\section{The Blue Grosbeaks}

3 or 4; pale bluish green, unmarked. Av. of 15 eggs from Arizona and California: $21.8 \times 16.5(.86 \times .65)$. Season: May-July; one or two broods.

Range of Guiraca carulea.- United States from Maryland, southern Illinois, northeastern Nebraska, central Colorado, and northern California south to Chiapas, Mexico, and in winter to Costa Rica.

Range of $G$. c. lazula.--Breeds in the western states from Nebraska and western Texas west (southerly) to the valley of the Colorado, south to Oaxaca, Mexico; winters from southern Sonora to Costa Rica.

Occurrence in California.-- "Common summer visitant in the valley of the lower Colorado River, from the Mexican line, north at least to Fort Mohave, above Needles" (Grinnell).

Autho:ities.-Morcom (Guiraca carulea), Bull. Ridgway Orn. Club, no. 2, I 887, p. 50 (Colorado R.); Grinnell, Proc. Biol. Soc. Wash., vol. xxiv., I9I I, p. I63 (crit.); ibid., Univ. Calif. Pub. Zool., vol. xii., I914, p. I80 (Colorado R.; occurrence, crit.).

\section{No. 72b California Blue Grosbeak}

A. O. U. No. 597a, part. Guiraca cærulea salicarius Grinnell.

Description.- "Similar to G. c. lazula of Arizona and Mexico in coloration and general size but bill much smaller and proportionately less tumid, that is, outlines straighter" (Grinnell, orig. desc.).

Range of G. c. salicarius.-California, except the Colorado River valley; winter range not yet distinguished.

Distribution in California.-Common, sometimes abundant in migrations in southern half of State. Breeds chiefly in Lower Sonoran zone, locally in the San Diegan district, and generally in the great interior valley north to Butte (Belding) and Tehama (Red Bluff, July 22, I916) counties; also in Owens Valley (George Creek, May 19, 1919). Not found in winter.

Authorities.-Heermann (Coccoborus coeruleus), Jour. Acad. Nat. Sci. Phila., ser. 2, ii., I853, p. 267; J. Mailliard, Bull. Cooper Orn. Club, vol. i., I 899, p. 44 (Santa Cruz Id.); Ray, Auk, vol. xxiii., I906, p. 404 (desc. nest); McAtee, U. S. Dept. Agric., Biol. Surv. Bull., no. 32, I908, p. 78, col. pl., part (food); Grinnell, Proc. Biol. Soc. Wash., vol. xxiv., I9I I, p. I63 (Colton; orig. desc.).

ONE of the major fascinations of advanced bird study is the confirmation or readjustment of relationships. It is not enough to be told by the taxonomist that a bird's relationships are such and such, because of peculiarities of structure, similarities of wing formulæ, etc. The statement may be true, but we take it under advisement as a hypothesis, and seek other evidences-evidences of song, behavior, association, and nesting habits - in confirmation or in modification of the anatomist's conclusions. While structural evidence is of the highest authority, it requires constant interpretation. Whereas the degree of change in the skeletal structure, for example, may be determined by calipers, the rate of change can never be known from physical appraisement. A knob on a bone, 


\section{The Blue Grosbeaks}

a "process," may have evolved in a century, or its development may have required a hundred thousand years. If we wish to appraise the actual or significant degree of difference between one species and another, we must weigh a multitude of outside, or non-somatic, factors. Very little may happen to a bone or an artery or a muscle in a millenium, but a great deal may happen to a species in that length of time. For this reason, therefore, the pronouncements of anatomists, however rigid and authoritative within their realm, are never complete. They are true, but they are only part of the truth.

Take, for example, the case of the Blue Grosbeak (Guiraca carulea). Its beak is "gross" enough. Its anatomical characters, so far as they have been determined, may ally it closely with the genus Hedymeles. I do not know. But in its associational habits, in its behavior, in its song, and, above all, in its nesting, the Blue Grosbeak much more closely resembles the Blue Buntings (Genus Cyanospiza or Passerina). There are, to be sure, distant resemblances between Guiraca and IIedymeles. Guiraca belongs between IIedymeles and Passerina; but if we called him Great Blue Bunting instead of "Grosbeak," we should come nearer to expressing the facts.

The Blue Grosbeak is never exactly prominent save during migrations, and then only, as it were, casually. Not knowing precisely the lie of the land through which he is passing, the bird is at less pains to conceal himself, and moves about rather sluggishly - along fences or telephone wires or other exposed places. But when his summer station is found-a willow-lined stream, a brushy patch adjoining a swamp, or even a moist fallow field - discretion is backed by knowledge of leafy mazes, and escape is easy. Like the Lazuli Bunting, however, the Blue Grosbeak chooses a rather prominent station for song - a tall weed, a wayside fence-post, or a tree-top. The song is sprightly and exuberant, but not well sustained. It is a musical outburst with, sometimes, a wild, fresh quality, but it oftener trails off into a jumble, like the remoter lispings of Passerina. Exceptional singers do recall the rounder, mellower notes of Hedymeles; and the offerings are so varied, so individual, that one cannot dogmatize. Some, not altogether amiss, have compared this song to the burbling of the House Finch. There should be no mistaking of qualities, but the gushing fashion of utterance is similar enough. The Grosbeak, however, is not an indefatigable singer, and too much or too close an attention to his efforts will send him charging behind the leafy screen.

The lady Grosbeak is not much in evidence at singing time. Presumably the suitor knows her approximate whereabouts in the shrubbery; but let her once show her head, and he is after her like a Kansas cyclone. It is a wonder, surely, that more lovers are not dashed to pieces in their 


\section{The Blue Grosbeaks}

headlong flights through hedgerows and briars. Or, perhaps, it is all a solemn farce. The lady does not want to get away. She only wants to be appreciated.

According to Mr. John G. Tyler, of Fresno, who has probably had a wider experience of this species than any other observer in the State, the Blue Grosbeaks are closely dependent upon the presence of water during the nesting period. "Along many of the canals and ditches in the valley grow patches of a plant the name of which I do not recall, but which greatly resembles in appearance and manner of growth the Chrysanthemum. It would probably be no exaggeration to state that seven of every ten grosbeaks' nests are built in the clumps of this plant, being fastened to two or three upright shoots, in much the same manner that a blackbird attaches its basket-like nest to a bunch of tules." If there are not enough of these favored plants to go around, the Grosbeaks invade the willows, or even the neighboring orchards. Nests in the weeds are, of necessity, only three or four feet above the ground, but orchard nests run ten or a dozen feet in height, and a twenty-foot elevation is of record.

The deeply cupped basket of the Western Blue Grosbeak is both a more artistic and a more substantial affair than that of Hedymeles. Externally, it is composed of weed-stems, grasses, and dried leaves; internally, of grasses, rootlets, and, above all, horsehair. Mr. Tyler says, "I have yet to find a nest that did not have either a piece of paper, or a dry paperlike leaf woven into the framework somewhere." A nest in the M. C. O. collection has a piece of cast-off snake-skin which evidently satisfies this same requirement.

The eggs, which are of the palest possible "blue" (light niagara green), unmarked, establish beyond controversy the Passerine connection. Indeed, they may be distinguished from eggs of our Lazuli Bunting only by their larger size and somewhat stouter proportions.

Nesting is in May or June (May 18 to June 23 is the Fresno record), and in an incredibly short time thereafter, by the Ioth of August at the outside, the birds are on the move for the South.

Since their stay with us is so brief, and after we have been comfortably assured that these Grosbeaks do not molest fruit, we are not greatly concerned with their food habits. It is interesting to know, however, that more than other birds with "gross" beaks this species is highly insectivorous. Fully two-thirds of its diet is comprised of animal matter, among which the grasshopper figures prominently. After bugs, come weed-seed and grain. Family groups assemble at the close of the season in larger flocks, and since the duller plumages of the female and young predominate, the old South notices a considerable resemblance between them and Rice-birds (Dolichonyx oryzivorus). Like the lordly Bobolink in 
disguise, these birds (or at least the eastern form) are said to inflict some damage upon the unharvested rice of Louisiana. If so, this is only another case where governmental compensation, rather than personal revenge, ought to be sought. For the Blue Grosbeak, whether carulea, lazula, or salicarius, is unquestionably a useful bird.

\section{No. 73}

\section{Rose-breasted Grosbeak}

\section{A. O. U. No. 595. Hedymeles ludovicianus (Linnæus).}

Description.-Adult male in spring and summer: Head and neck all around and upperparts sooty black; the rump white with some black tips of feathers, the upper tail-coverts black with white tips; median coverts and tips of greater white; a large white patch on primaries basally; inner secondaries and tertials tipped with white; three outer pairs of rectrices extensively white on the inner webs distally; chest broadly and breast centrally red (between spectrum red and jasper red); axillars and lining of wings pink (geranium pink to light jasper red); remaining underparts white. Bill light horn-color; feet and tarsi brownish gray. Adult male in winter: Quite different; wings and tail as in summer, but black of head and neck and back replaced by brown, more or less streaked with black; pattern of head broken by dull buffy superciliaries, malar stripes, and median crown-stripe; underparts dull brownish white, paling posteriorly; chest more or less suffused with pink, and chest, sides and flanks streaked with dusky (Ridgway). Adult female in spring and summer: Above and on cheeks brownish dusky, varied, especially on back and scapulars by brownish or ochraceous edging; an irregularly defined superciliary stripe white; a still more obscure median stripe white or buffy white; two narrow white bars on wings formed by white tips of median coverts and tips of greater coverts continued by outcropping white of distal portion of white primary-patch; beneath sordid brownish white, tinged with ochraceous on sides of throat and chest, and more or less on sides and flanks; underparts also sharpstreaked with dusky, save on chin and throat centrally, and on abdomen and crissum; sharply and briefly on sides of throat and sides, more heavily and grossly on sides; axillars and lining of wings light orange-yellow. Length (sexes about equal): 196.85$215.9\left(7.75^{-8.50)}\right.$; wing 101.6 (4.00); tail 76 (3.00); bill I6.7 (.658); tarsus 22.5 (.886).

Recognition Marks.-Towhee size; black and white of male with red breast distinctive. Female very different, brownish dusky above, brownish white (heavily streaked with dusky on chest and sides) below. Requires careful distinction from female of $H$. melanocephalus, from which it differs chiefly in the broader streaking of the underparts, and of course diagnostically in the orange (in place of yellow) of axillars and wing-linings.

Nesting.- Nest: A frail saucer of interlaced grasses, fibers, or rootlets, placed at moderate heights in bushes, saplings, or orchard trees. Eggs: 3 to 5, usually 4; much like those of succeeding species, and not certainly distinguishable from them, though averaging darker. 


\section{The Rose-breasted Grosbeak}

General Range.-Chiefly eastern North America, breeding north to Nova Scotia and Ontario, Manitoba, and west to eastern Kansas or, rarely, eastern Colorado and Alberta (Lesser Slave Lake-Spreadborough) and "sporadically" in northern California; south in winter over the Bahamas and throughout Mexico and Central America to Ecuador.

Occurrence in California.-Taken in California, evidently breeding (see account below), in Humboldt County. Also immature male taken Sept. Io, I897, by M. F. Gilman, at Palm Springs.

Authorities.-McLain, Auk, vol. xv., I898, p. I90 (Myer's, Humboldt Co.). Grinnell, Pac. Coast Avifauna, no. 3, I902, p. 59 (Palm Springs); McAtee, U. S. Dept, Agric., Biol. Surv. Bull., no. 32, I908, p. 33, col. pl. (food); Fry, U. S. Dept. Interior General Information Regarding Sequoia and General Grant National Parks, Season of I9I2, p. I4; Cooke, U. S. Dept. Agric. Bull., no. I85, I9I5, pp. 24, 30, map (migration route and distribution); Gilbert, Condor, vol. xviii., I916, p. 8I ; Allen, Auk, vol. xxxiii., I9I6, p. 53 (nesting habits, in Mass.).

NO MORE remarkable instance of the sporadic, or rather, eruptive, occurrence of a species is on record than that furnished by the Rosebreasted Grosbeak, which was encountered in numbers on July Ist, I897, by a party of Stanford students in charge of Professor C. H. Gilbert. The birds were quartered somewhere on the Nyer Ranch, in Humboldt County, and they were being shot because of their persistent depredations in the orchard. From the meager accounts given ${ }^{1}$ we infer that the birds must have bred in the vicinity. Inasmuch as there is no other record of the breeding of this species west of the Great Plains States, we must suppose that a detachment of migrant Grosbeaks faring northward from Colombia in the spring of I897 was deflected sharply to the westward, and finding itself at last in suitable, though unfamiliar, territory, it made the best of circumstances, both nest-wise and cherry-wise.

There is only one other specific record of the occurrence of this species in the State, Palm Springs, Riverside County, September Io, I897, by M. F. Gilman; and it is significant that this was made during the same year as the great experiment recorded above. Quite possibly, then, this bird was a returning member of the Humboldt County colony feeling its way southward.

Of course lightning sometimes strikes twice in the same place, but until it does, and so that we may become acquainted with the bird at first hand, we will content ourselves with a paragraph from the author's "Birds of Ohio."

"During migrations this Grosbeak often keeps to the highest treetops, where his bright colors almost escape notice amidst the newly

${ }^{1}$ Auk, Vol. XV., April, I898, p. I90, and Condor, Vol. XVIII., March ,1916, p. 81 .

418 


\section{The Black-headed Grosbeaks}

bursting verdure; but he is most at home in second-growth thickets and swampy tangles. In either case, he sings freely, a rich, rolling, continuous warble, which is among the finest of woodland notes. The song is most nearly comparable to that of the Scarlet Tanager, but it is to be distinguished by its rounder quality, and the entire absence of phrasing. When singing to his mate, the bird sometimes stands on tiptoe with excitement, and makes the thickets vibrate with long-drawn melody. Sometimes, especially if you are known to be watching near, the music is interrupted by the harsh nasal thkimp or kimp of distrust and warning."

No. 74

\section{Black-headed Grosbeak}

A. O. U. No. 596, part. Hedymeles melanocephalus melanocephalus (Swainson).

\section{Synonym.-Rocky Mountain Black-headed Grosbeak.}

Description.-Adult male in summer: Head above and on sides, and narrowly across chin, glossy black, area of black occasionally invaded by a supra-auricular stripe of orange-tawny; a cervical ring, sides of neck, throat, breast, and sides, rump, and interrupted stripes connecting rump and cervix, orange-tawny (antique brown), paling on flanks posteriorly to buckthorn brown; a touch or wash of the lighter shade also on crissum, which is otherwise white; abdomen narrowly white, middle of breast, axillars, and lining of wings pure lemon-yellow; remaining upperparts black, interrupted, as aforesaid, on back by tawny, and on wings by broad white tips of median coverts, narrower white tips of greater coverts and secondaries; basal portion of remiges, nearly half on primaries, white; the 6 th, 7 th, and 8 th primaries (reckoned from within) sharply edged with white on the distal portion; rectrices black, the two outer pairs broadly tipped and the 3 rd pair touched with white on inner web; tibiæ black tipped with white. Bill dark horn-color, lightening below; feet dark brown. Adult female: Very different; pattern of male preserved only in yellow of axillars and wing-linings, with touches of yellow on breast; in general, above blackish, streaked with white; below fulvous, streaked sharply and narrowly with blackish; pileum blackish, separated by a coronal stripe of white sharply flecked by black; lores and superciliary broadly white; back black, broadly edged with whitish or fulvous; white spotting of wings much restricted; the spots on tail lacking; underparts chiefly whitish, clearest on chin, throat (or else on sides of throat only), and abdomen; elsewhere more or less suffused with pale ochraceous, most intensely on breast, and sharply streaked with dusky. Immature birds resemble the adult female, but the ochraceous element is stronger both above and below, and the lesser wing-coverts are extensively edged with yellow. Length of adult males about 201.6 (7.94); wing IOO (3.94); tail 80 (3.15); bill, length I $7.5(.69)$, depth at base I 5 (.59); tarsus 24 (.945). Females scarcely smaller.

Recognition Marks. - The rich orange-tawny throat and underparts of male, with black head and mingled black and white and tawny of remaining upperparts, distinctive: the yellow of the wing-linings is especially rewarding as well as distinctive. 


\section{The Black-headed Grosbeaks}

The black-and-white striped head with heavy conical beak (and convex culmen) of female unmistakable.

Nesting.-As in next form.

Range of Hedymeles melanocephalus.-Western North America from the plateau of Mexico north, in summer, to eastern Kansas, southeastern Dakota, Montana, and British Columbia; breeds throughout its range.

Range of $H . m$. melanocephalus.-Restricted to the portion lying east of the Sierra-Cascade Mountain system.

Range in California.-At least the Colorado River valley during migrations; presumably the breeding bird in mountain ranges east of the Sierras (Grinnell).

Authorities.-Grinnell, Univ. Calif. Pub. Zool., vol. xii., 1914, p. I 79 (Colorado R.; occurrence; crit.); Swarth, Pac. Coast Avifauna, no. 4, 1904, p. 44 (Ariz.; habits, migr., molt, etc.): Oberholser, Auk, vol. xxxvi., 1919, p. 412 (nomencl.; crit.).

\section{No. 74a Pacific Black-headed Grosbeak}

A. O. U. No. 596, part. Hedymeles melanocephalus capitalis (Baird).

Description.--Similar to $H$. m. melanocephalus, but bill averages smaller; black of crown more liable to invasion of tawny from behind, especially in post-ocular stripe, and occasionally developing a median crown-stripe.

Remark. - There is no doubt that coastal specimens exhibit this ochraceous invasion of the cephalic areas more frequently than do Rocky Mountain specimens; but the latter do show individual examples of the same tendency, and the grounds of separation are probably invalid.

Nesting.- Nest: Externally a bulky and of tenest airy assemblage of interlaced twigs or dishevelled weed-stems, or sometimes a generous mass of leaf-bearing twigs plucked green; internally a rather careful hollow of interwoven rootlets, or else a choice of finer strands of the materials already used outside - some nests are composed of a single material rigidly selected; placed at moderate heights in the larger bushes, saplings, or small trees, chiefly those of the riparian association. Eggs: 3 or 4; bluish green (pale to light niagara green), spotted sparingly or profusely, but always sharply, sometimes uniformly, but oftener chiefly about larger end (sometimes in wreath or cloud-cap) with brownish olive, buffy olive, or sepia. Av. of 27 eggs (of both races): $24.1 \times 17.5(.95 \times .69)$. Season: May-June; one brood.

Range of $I . m$. capitalis. - The Pacific Coast district of western North America, broadly; probably includes eastern slopes of Sierra-Cascade system.

Distribution in California.-Common breeder in Upper Sonoran and Transition zones practically throughout the State. Association preferably riparian or in deciduous timber (but found alike in humid Transition and in arid Upper Sonoran. Casual in winter in the San Diegan district (Santa Barbara, Dec. 25, 1915, following).

Authorities.- Heermann (Coccoborus melanocephalus), Jour. Acad. Nat. Sci. Phila., ser. 2, ii., 1853, p. 267 ; Baird, Rep. Pac. R. R. Surv., vol. ix., I858, p. 498; Shufeldt, Auk, vol. v., ı 888, p. 438 (osteology); F. A. Merriam, Auk, vol, xiii., I896, p. I20 (song, flight); McAtee, U. S. Dept. Agric., Biol. Surv. Bull., no. 32, 1908, p. 60, col. pl. (food); Beal, U. S. Dept. Agric., Biol. Surv. Bull., no. 34, 1910, p. 93 (food);

BIX, and again, bix. It is our own bird that speaks from the shrubbery on an August day, and by this alone we know that the minstrel of 
The Black-headed Grosbeaks

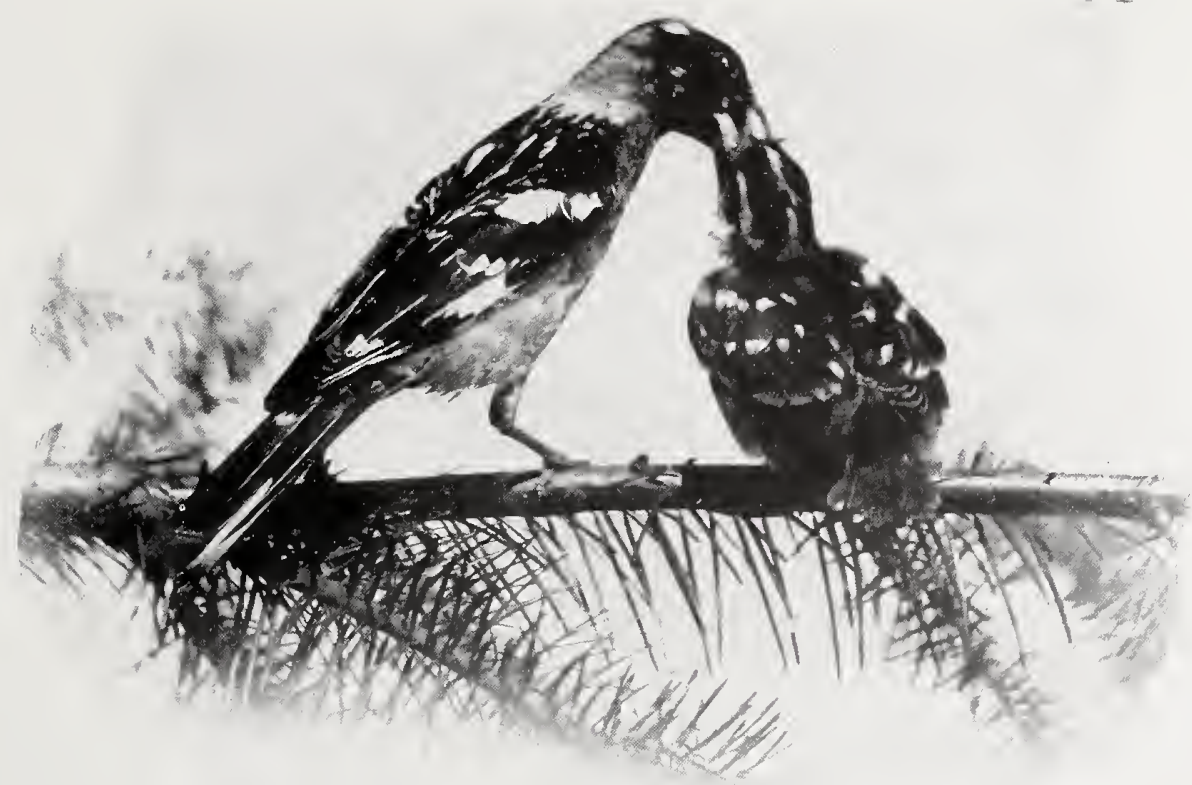

Taken in Oregon

Photo by Finley of Bohlman

KEEPING A DINNER ENGAGEMENT

springtime is with us still. How he gladdened those fresh hours! And how he sang on, cheerful, melodious, content, until June had silenced other singers of the lower levels. The Black-headed Grosbeak is a bird beloved of Californians. Gentle, modest, unassuming, he moves about with quiet dignity which proclaims his worth; and when he does consent to be interviewed, the reporter is sure to wax enthusiastic over his somewhat bizarre beauty. For my part, I never hear those first mellow flutings of springtime without being seized with a wild desire to see the singer, and to quench the thirst of long abstinence by a satisf ying vision of black and white and ochraceous tawny. As a sporting proposition, too, I always insist upon getting under the bird, so as to catch the flash of yellow which his wings disclose in flight. Strange, is it not? that the most brilliant color in his mottled costume, yellow of spectrum purity, should lie concealed under the singer's armpits! The female, too, boasts (or, rather, she never boasts) yellow axillaries. Otherwise, her costume is the palest possible replica of her lord's. Her blacks have become blackish, or that nondescript color known to naturalists as "fuscous." Ochraceous tawny has become cinnamon-buff, or pinkish buff. She parts her hair, somewhat anxiously, in the middle; and her sides are plentifully streaked with blackish, to break up the pattern and to deceive the eye. Only her 


\section{The Black-headed Grosbeaks}

spouse could possibly deem her beautiful, and he, as every one knows, is blinded by springtide's passion. Her only virtue, so far as I can see, is to say bix quite dutifully-also quite emphatically-and so keep up the Grosbeak tradition.

The glory of the Black-headed Grosbeak is his song-not often a brilliant or wonderful song, but always a jovial, rolling, or eumoirous song. Sometimes it is a little argumentative, as though the singer, having taken a brief for optimism, had encountered a skeptic. Sometimes the singer's heart is so full that he carries his song about with him while he works. Bug-catching is a very necessary occupation, so he follows it dutifully, but song breaks out after every third or fourth bug, and it follows him about as he threads the mazes of willow and alder or mountain birch. At such times, too, his progress is further punctuated by bixes, all harmless, apparently, but delivered with such energy that a camper caught at close quarters starts to his feet.

The song of the Black-headed Grosbeak is frequently compared to that of the Western Robin. Chance phrases caught at a distance are sometimes indistinguishable. But the Grosbeak's song lacks at all times the incisiveness of the Robin's carol. Its notes are softer, rounder, mellower, and a little weaker. The bird himself is not so brusque. Heard at close quarters there are grace notes and little embellishments which exceed the Robin's art. Once, at the foot of Mt. Shasta, I listened to a perfectly wonderful song of the Black-headed Grosbeak. He must have been within thirty feet of me, behind a screen of manzanita brush, so that I got the modulations and finer passages. But the singer was, undoubtedly, a bird of ten thousand, for his voice was fine and exquisitely flexible, so that he executed the most brilliant trills and appogiaturas. Although I am loth to institute such a comparison, I am bound to confess that much of his music was like that of a highly trained canary, for it was brilliant, crystalline, exquisitely modulated, and highly varied. This bird was not at all above giving the hearty, homely, rolling song of his species, but he graced it anew with every repetition, as became a highly accomplished artist. The concerto was all too brief, for the Grosbeak is rather a restless spirit; but his memorable effort taught me an altogether new respect for his species. And, after all, doesn't a bird species, like the human race, deserve to be judged by its best examples?

The happiness which fills the Grosbeak's breast carries into the nesting season. He is so proud to have Mrs. G. honor him with her company, that he is willing to help build the nest, or at least to pretend to-singing is always more important on such occasions-and he is willing, more than willing, to take his turn at sitting upon those precious eggs. This means that he is a model husband and father. The glory of paternity 
fills his being. The wonder of life amazes him. The graciousness of Mrs. G. is extraordinary. The eggs which she has deposited in the family basket are nothing less than superb. So this doting, marveling, and altogether amiable idealist sings as he works, sings as he contemplates his offspring-to-be, the imprisoned mysteries within those walls of freckled blue; and as he feels the warm, round wonders pressing against his breast, he breaks ever and again into joyous song.

Truth to tell, the singing of the male Grosbeak is the surest guide to the nest, carelessly placed, midway, in bush or sapling. And if the male is disturbed at his task, or if he hears the anxious cry of his mate, this gentle bird has no recourse, again, but song. How does he do it, pour out those tender, trustful notes of ecstacy, while the enemy is threatening his dearest treasures? And yet, believe me, it is the most disarming procedure imaginable. One may overpower a snarling wild-cat. The bombastic objurgations of a Long-eared Owl make nest-robbing a sacred duty,

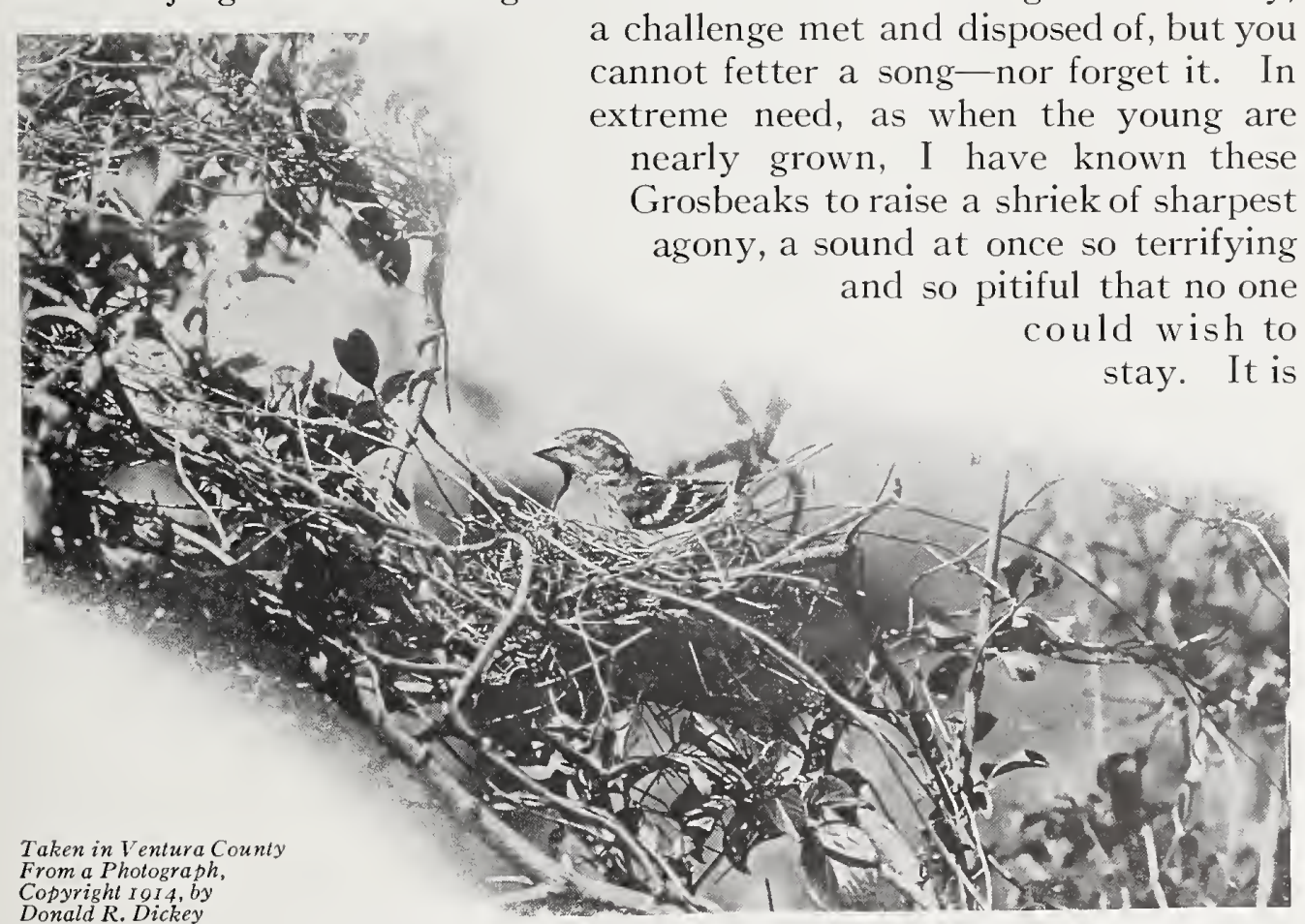

A MODEL SUBJECT-FEMALE GROSBEAK ON NEST

the master cry of distress, and at the sound of it all the lesser songsters of the woods come pell-mell to the rescue.

The nest of the Black-headed Grosbeak is of singularly light and open construction, evidencing, as we suppose, the habit of the tropics, 


\section{The Black-headed Grosbeaks}

where ventilation, rather than conservation of heat, is the object sought. Some nests are so thin that the eggs may be counted from below. As a usual thing the nest is composed almost entirely of coiled rootlets, with, at best, a little chevaux de frise of plant-stems. One nest in the M. C. O. collection is composed entirely of slender blackish twigs cunningly interlaced, a very durable, if also airy, structure. A pair of Grosbeaks nesting on the Salinas River near San Ardo hit upon an ingenious plan for keeping cool. Instead of the usual lace-work construction, they. heaped up a mass of green willow leaves, plucking for the purpose the terminal twigs of the youngest trees, and wedging them to a height of nine inches in a convenient crotch. In the top of this mass, kept cool by reason of evaporating moisture, they set the conventional rootlined cup. We have also a nest from Arizona where the same idea has been followed out less boldly, - a root cup surrounded by a two-inch stratum of green leaves of the narrow-leafed willow.

Like many another species, the Black-

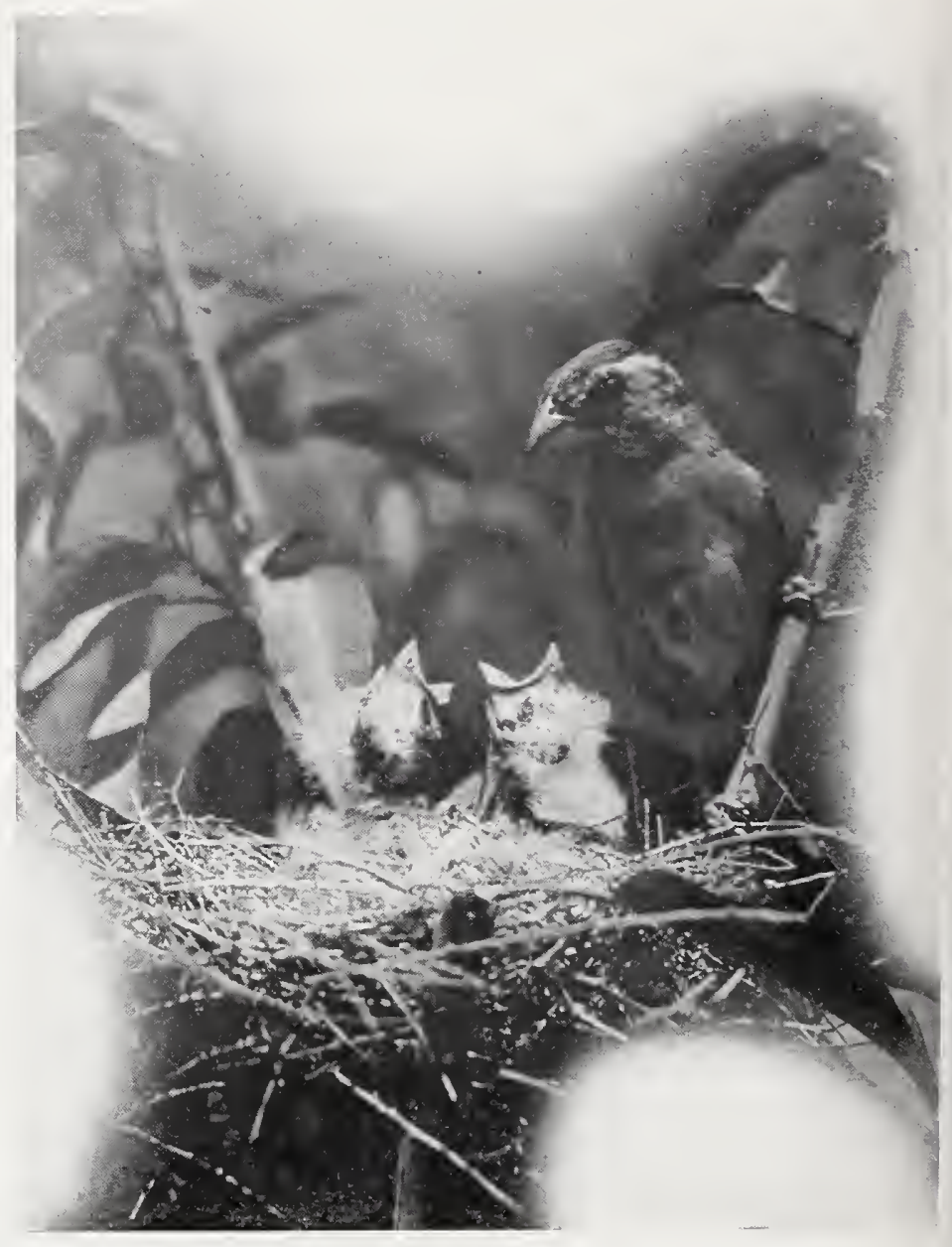

Taken in Ventura County
Photo by Donald R. Dickey

TAKING ORDERS headed Grosbeak displays a strong local attachment, and will return year after year to a given copse or tangle, or even to the very bush. The nests, although so light, are sturdy enough, and the occupation of former years is evidenced by contemporary cabins in successive stages of disrepair.

A Grosbeak family makes a pretty group at, or just before, nestleaving time. Few birds show more clearly the essential values and 


\section{The Black-headed Grosbeaks}

sexual differences of parenthood. The mother is timid as well as tender, indefatigable, indeed, in household ministrations, but a little pensive withal, a clinging vine. The father is a hustler as well as an idealist. He manages to bring in great loads of food every ten or fifteen minutes, and the youngsters thrive amazingly. Nor does this model parent allow increasing cares to weigh down his spirits. Even with his "market basket" laden to the brim, he shouts a cheerful snatch of song to herald his approach; and the children greet his return with clamorous applause. Lucky children of "Big Bill"! he has a big heart, as well as a big beak.

If we must descend to inquire as to the economic standing of our large-billed friend, we shall find that he has a large and cultivated appetite. We will admit with a smile that he is very fond of fruit in season, especially cherries and figs. Well, then, feed him; he deserves the fat of the land. Give him the best, and present the bill to the community. The community ought to be made to pay, for the Grosbeak is a community guest, and he is one of our chief benefactors. And I speak not alone of song, but of benefits far more substantial. Hear what W. L. McAtee, ${ }^{1}$ the Government expert, has to say about it:

"Aside from the fact that ravages by the Grosbeak may be prevented or greatly reduced without destroying the birds, it is evident that their general services to agriculture are so valuable that their destruction is not to be considered. It is to be noted: First, that the animal food of the Blackhead, consisting almost wholly of injurious insects, is practically twice the bulk of the vegetable, or more than four times that portion which is pilfered from man. Second, that the bird could not possibly select insects more prejudicial to the interests of western horticulture than the ones forming its natural food. These include the codling moth, cankerworms, flower-beetles, and such scale insects as the frosted, apricot and black olive scales. Finally, these formidable fruit destroyers alone, not to mention 20 per cent of other injurious insects, compose two-fifths of the entire amount of the Black-headed Grosbeak's food from April to September, or at least three times as much by actual bulk as the fruit consumed. In other words, for every quart of fruit eaten, more than three pints of black olive scales and more than a quart of flower-beetles, besides a generous sprinkling of codling moth pupæ and cankerworms fall prey to this Grosbeak."

A peck of cherries is worth, say, two dollars to the producer. Set that against the debit side of the bird's account. Granting that he could do it at all, how much of a man's time would it take, without injury or sacrifice of tree stock, to collect half a bushel of black olive scales? Say

'Food Habits of the Grosbeaks, Bureau of Biological Survey Bulletin, No. 32, 1908, p. 76. 


\section{The Black-headed Grosbeaks}

two weeks? At three dollars per day? Thirty-six dollars! Put that on the credit side of the Grosbeak's account. But the man couldn't do it; and there is in that half bushel of pests potential destruction of a hundred olive trees, or at least one season's crop, say a hundred bushels, worth four dollars a bushel. Total saved to the community four hundred dollars, less two dollars for board! Johnny, get your gun! There's a bird eating a cherry!

\section{For Younger Readers}

HANDSOME is that handsome does, they tell us, and this bird is handsome any way you take him. He has a good heart as well as good clothes, but I guess we'll look at his clothes first. It takes a good deal of time to look at a heart, or to find out "handsome does." Or, no! the very first thing we do when we meet a new friend is to look at his face, isn't it? And a Grosbeak's face is almost all bill. Grosbeak is the same as gross beak, and that means big bill. Suppose we call him Big Bill. Big Bill has a black-and-white suit, on top at least; but he is buried in front in a great big orange apron (golden brown, somebody called it), which ties behind in two places. And under the arms (wings are the same as arms, you know) there's a big patch of yellow that you can't see except when the bird is flying. And when Mother Nature was trying to hide the yellow under his arms, she spilt some of the color down the front of his apron. Now that's what I call a pretty complete description. Mrs. Grosbeak looks a good deal the same, only she's been many times through the wash, and most of the color has soaked out - all except the yellow patch under her wings, and that didn't soak out because she kept her wings tight shut when she was in the wash.

Mr. and Mrs. Grosbeak spend the winter down south somewhere, in Mexico, I guess; but they come back to California in the springtime, when the bugs are ripe; and then Mr. Grosbeak spends half his time catching bugs and the other half singing. My! how sweetly he sings! round, rich, rolling notes that make you so glad you're here, and so glad he came, and so glad-oh, for just everything. I can't tell you how he sings, of course. You must hear him the very first chance you get. 


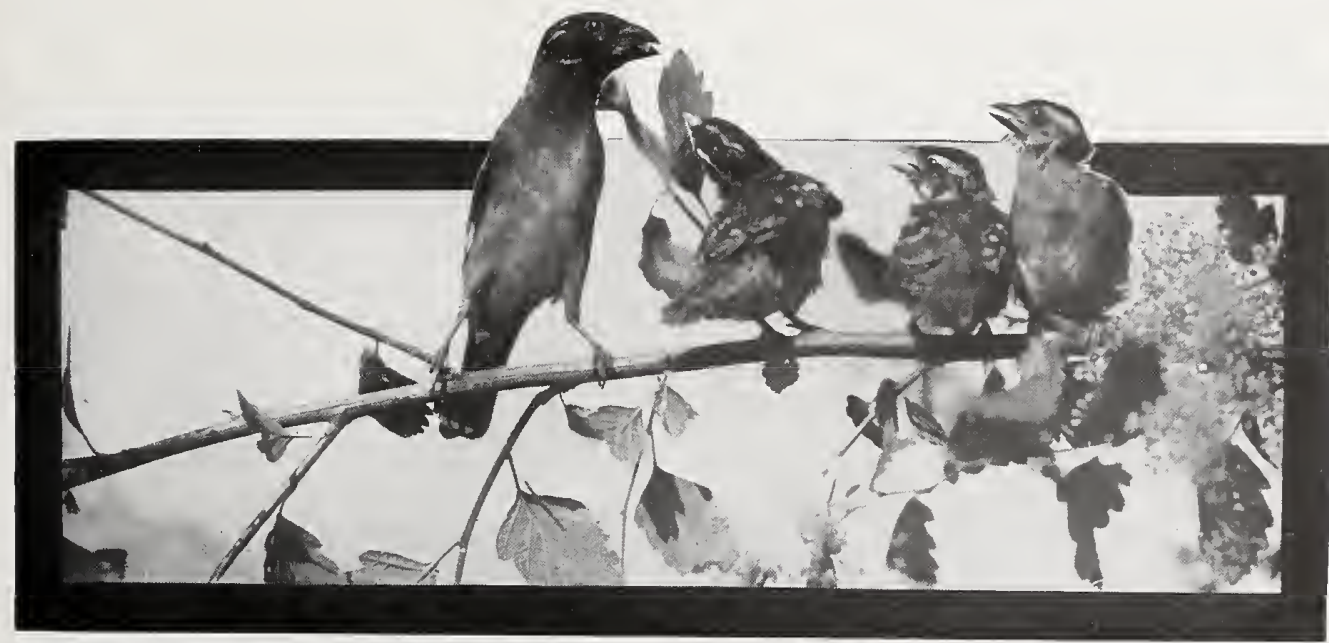

Big Bill is one of the very few people who ever succeeded in working and playing at the same time. At least, singing is a sort of play, I suppose. And bug-catching, believe me, is real work. Why, this bird catches the bad beetles that want to spoil our rose bushes, and he eats those funny little black things that get on the bark of your fruit trees and stick so tight-black olive scales, we call them. And if it wasn't for the busy bird, the scale insects would suck all the juice out of our trees, so that they couldn't make fruit any more. So he's at it early and late, and every little while he stops to sing. And when the Grosbeak sings, we stop and listen. We just can't help it. It sounds like a Robin sometimes, only we know that the Robins have gone north, so it can't be a Robin.

But that isn't all about the "handsome does." This jolly bird and his washed-out mate make a nest somewhere in the bushes. They make it out of little roots, and the walls of the nest are sometimes so thin that you can count the eggs from below, one, two, three-or maybe four. And as likely as not, it is the father bird who is sitting on the eggs to keep them warm. And he is so happy, oh, so happy, that he just can't help singing even when he is sitting on the nest and ought, I suppose, to keep very still. He is thinking about the dear little babies that are coming by and by out of those speckled blue eggs. He loves children, so he just can't help singing. 


\section{The Summer Tanagers}

And by and by those eggs do break open, and out roll some squirming, naked babies, bird babies, one, two, three or maybe four. And their little eyes aren't open yet; but they can open their mouths, oh, so wide. Big Bill's little babies have big bills, too; and Big Bill and Mrs. Big Bill have to hurry and hurry and hurry to fill them. But no matter how much of a hurry Big Bill is in, he never loses his temper. When he goes away to hunt food, he says a little goodby song, and when he comes back with his bill chock full of bugs, he shouts a merry "Hello, I'm coming!" Nobody knows how he can do it with his mouth chock full, but he does, and you'd hardly know the difference. And how the children shout when they hear him coming! They're not very well mannered, I fear, for they shout, "Me, too; I'm hungry, Daddy!" But everybody is good-natured about it. And by-and-by they learn to say, "It's sister's turn first," or "I have enough; give little Bill some."

And, if you'll believe it, I never saw a cross Grosbeak baby; nor ever once saw little Bill slap sister. Betty. Of course I don't know why, but I think it is because Big Bill is so gentle and so happyhearted and so handsome.

\section{No. 75}

\section{Summer Tanager}

\section{A. O. U. No. 6Io. Piranga rubra rubra (Linnæus).}

Synonym.-Summer Red-Bird.

Description.-Adult male (no seasonal changes): Dull red, darker above (madder brown), lighter below (jasper red); wing-quills dusky on exposed ends and unexposed inner webs. Bill and feet light brown. Adult female (no seasonal changes): "Above plain yellowish olive-green, more yellowish on pileum, lower rump, and upper tail-coverts, the back and scapulars sometimes tinged with grayish; primaries grayish brown with light yellowish olive-green edgings; lores pale yellowish gray; an indistinct orbital ring of light dull yellow; underparts dull yellow (wax-yellow or dull maizeyellow); the under tail-coverts purer yellow (chrome-yellow); bill and feet as in adult male" (Ridgway). Immature male: Much like adult female, but somewhat more richly colored; above more ochraceous; the pileum, edges of primaries, upper tailcoverts, and tail, tinged with dull orange or orange ochraceous. First year male (?) 


\section{The Summer Tanagers}

in spring (possibly also second year male): The yellows clearing and the reds of adult plumage appearing in scattered patches. Immature female: Like adult female but slightly duller. Length of adult male about I90.5 (7.50); wing 95 (3.74); tail 72 (2.84); bill I7.5 (.69); tarsus I9 (.75). Females average slightly less.

Recognition Marks.-See next form.

Nesting.-Does not breed in California. Nest: A rather frail structure of twigs and interlaced weed-stems; lined with grasses; and placed at moderate heights in bushes or trees, often settled well out toward end of horizontal branch. Eggs: 4; pale bluish green ("egg" green, i. e., pale to light niagara green), finely and sparingly or boldly and heavily spotted with brown (bister or Saccardo's umber to tawny olive). Av. size 24.1 x $16.8(.95 \times$.66). Season: Early June; one brood.

Range of Piranga rubra.- Southern United States and northern Mexico; south in winter to the Antilles and northern South America.

Range of $P$. rubra rubra.-Breeds in the eastern states north to about Latitude 40 ; casually north to provinces of southern Canada; in winter, south to the Antilles, eastern Mexico, etc., to Guiana and eastern Peru.

Occurrence in California.--Two records, both by Loye Holmes Miller: March I0, I919. Arroyo Seco, between Los Angeles and Pasadena; ib., ib., Aug. 29, I919.

Authorities.-Miller, Condor, vol. xxi., I919, p. I29 (Los Angeles); ibid., vol. xxii., 1920, p. 78 (Los Angeles).

Remarks.-The reported occurrence of any subspecies a thousand miles out of its usual range, and near that assigned to another subspecies, always lays a heavy burden of proof upon the expert. But the records given us by Professor Miller of the occurrence of Piranga rubra rubra near Los Angeles deserve special consideration. The record station, Arroyo Seco, between Los Angeles and Pasadena, is more than 200 miles west of the regular range of $P$. $r$. cooperi. That a single observer, working at one station, should have caught both the spring and the fall movement (March io and August 29, I919) of an exotic form, is indicative of a definite movement, however aberrant. It is quite conceivable that a wandering party of Summer Tanagers, deflected by early storms, but urged on by the northing instinct, should have bred at some central point in California in the summer of 1919 , much as did a party of Rosebreasted Grosbeaks (Hedymeles ludovicianus) in Humboldt County in the summer of 1897.

\section{No. 75a Cooper's Tanager}

A. O. U. No. 6ioa. Piranga rubra cooperi Ridgway.

Synonym.-Western Summer Tanager.

Description.-Similar to P. r. rubra, but decidedly larger; male lighter red, female grayer above and duller below. Adult male: Above pompeian red (a little brighter); below bright jasper red. Occasionally older (?) birds are much paler. Female: Above buffy citrine (olive-yellow), lightening to old gold on pileum, rump, skirtings of primaries, and tail; below olive-ochre, clearing centrally and on lower tail-coverts to wax-yellow. Length $196.8-203.2(7.75-8.00)$; av. of $\mathrm{Io}$ adult males from Colorado River valley, M. V. Z. coll: wing I00.7 (3.97); tail 78.6 (3.09); bill $20.4(.80)$; tarsus $20.9(.82)$.

Recognition Marks.-Sparrow to towhee size; all-red coloration of male distinctive (save as regards the accidental $P . r, r u b r a$ ). Female requires discrimination from that of $P$. ludoviciana. Its yellows incline toward orange instead of greenish, and it lacks the whitish wing-bars of ludoviciana. 


\section{The Summer Tanagers}

Nesting. - Nest: Placed 15 to 20 feet up in willow or mesquite tree of riparian associations; a careless affair of coarse grasses, weed-stems, and rootlets or trash, saddled on horizontal limb. Eggs: 4 ; as in P. r. rubra, but markings perhaps averaging smaller; not so clear-cut as in P. ludoviciana. Av. of 8 eggs in M. C. O. coll: 22.9 X I7 (.90 x .67). Season: June; one brood.

Range of P. r. cooperi.-Breeds in Southwestern States and in northern Mexico from southern Nevada and northeastern New Mexico, south to Nuevo Leon and Durango; winters in Mexico south to Morelos and Colima; accidental (?) in Colorado.

Distribution in California.-Breeds in the Colorado River valley. Of casual occurrence in the San Diegan district; (Santa Barbara, "spring" of I 885 , Streator; San Clemente Island, Oct. II, I907, Linton).

Authorities.-Cooper, Orn. Calif., 1870, p. 142; Baird, Brewer, and Ridgway, Hist. N. Am. Birds, vol. iii., I874, p. 508 (Ariz.; desc. nest and eggs); Brewster, Bull. Nutt. Orn. Club, vol. vii., I 882, p. 147 (Ariz.; meas., etc.); ibid., Auk, vol. ii., I885, p. I98 (Ariz.; desc. young, etc.); Grinnell, Univ. Calif. Pub. Zool., vol. xii., I9I4, p. I 82 (Colorado R.; habits, etc.). Streator, Orn. and Oöl., vi., I 886, p. 52 ; Stephens, Condor, vol. v., I903, p. I04; Linton, Condor, vol. v., I 908 , p. 85.

THE WESTERN Summer Redbird occurs regularly in summer along the valley of the lower Colorado. One surmises that it may have occurred also in that oldtime mesquite forest of the Salton Sink, now drowned out by the latest eruption of "New" River. For all it is so brilliant in color, every feather being wholly red, or at least tinged with red, the male cooperi is not easily seen in its spring setting of complementary greens. Besides, the bird is very deliberate in movement, adding, perhaps, to the natural languor of the Southland a consciousness that hawks and others are wont to penalize pernicious activity. Be that as it may, the male makes a virtue of indiligence, and is gratefully content to be just beautiful. The female, however, in spite of the fact that nature has done her utmost for her in the way of dull yellows and melting olive-greens, is unwilling to take any chances, and so she slips away adroitly upon the faintest suspicion of approach.

The case of the young male, who is "bechwixt and bechune," is a challenge to attention. Beginning life with the modest garb of his mother, he spends two or three years in the laborious acquisition, by bits and patches, of the proper masculine vermilion. As a consequence, for several seasons he looks like a flying crazy-quilt; and one wonders how he manages to survive the merciless "ragging" of the ladies.

The Cooper Tanager has a full, rounded song of familiar Tanagrine quality, although it lacks something of the acid sharpness and burred r's which characterize $P$. ludoviciana. It may be not inaptly compared with the vocal effort of the Black-headed Grosbeak, or, on occasion, to the disconnected phrasing of the Red-eyed Vireo. These Tanagers make frequent use, also, of a mildly sturdy call-note, chick itew, or kit it it tew. This 
may be a mere keep-in-touch call between the birds themselves; or it may express a strong suspicion that strangers are about; or it may voice vigorous disapproval, as when the nest is threatened. Whatever be the import of the note, its utterance is the only act in any wise approaching violence of which these leisurely and always genteel Southerners can possibly be guilty.

The sight of a male Cooper Tanager lighting on the ground to glean a recreant bug is not to be forgotten. It is a vision of ravishing redness, and one's first impulse is to admonish the vision for its rashness. But even royalty feels hunger and thirst at times. One day in Arizona the writer spent an hour watching a little water-hole where a tired river had died within sight of a disappointed mesquite forest. Its approaches were marked by the imprint of a thousand tiny feet, but cover there was none, only dunnest dust. Among the doughty visitors came this symphony in red, a superb old male Cooper Tanager. I could scarcely believe my luck, but the bird approached demurely, according to his wont, and selecting a root which projected conveniently from the margin of the pool, proceeded to assuage his thirst. And as he drank, or rather, sipped, chick-a-biddy fashion, he was utterly unconscious either of my frank admiration or of lurking dangers. Bélieve me, what with image and reflection, that portion of the pool wherein Piranga drank was illuminated for a season! Oh, to have had an autochrome plate!

No. 76

\section{Western Tanager}

\section{A. O. U. No. 607. Piranga ludoviciana (Wilson).}

Synonyms.-Lovisiana Tanager. Crimson-headed Tanager.

Description.-Adult male in spring and summer: Head all around and throat, broadly, bright red (nopal red), the color most intense on forehead and crown, shading posteriorly; back, wings, and tail black, the feathers of back often slightly margined with yellow; the tips of greater coverts pale yellow or yellowish white; the posterior portion of lesser wing-coverts, the middle coverts, hind-neck, rump, upper tail-coverts, and all remaining underparts rich yellow. Bill wax-yellow, browning on culmen; iris brown; feet and legs bluish gray. Adult male in autumn: As in spring, but red wanting, or indicated by faint tinge, the yellow of occiput and hind-neck veiled by olive greenish or dusky tips; the tertials tipped with pale yellow, and the rectrices with white. Adult female: Somewhat like male, but much duller, without red, or sometimes tinged with reddish about face; above olive-gray; changing on head, rump, and upper tail-coverts to pyrite yellow; below olive-yellow, clearing on middle of breast and under tail-coverts to strontian yellow. Immature males resemble the adult female and only gradually acquire the clearer, brighter plumage of maturity. 


\section{The Western Tanager}

Immature female: Like adult female, but duller; little contrast above; more extensively olivaceous below. Length I77.8 (7.00); wing 95 (3.75); tail 7I (2.80); bill I 5 (.59); tarsus $20.5(.80)$.

Recognition Marks.-Sparrow size; sedate ways; pittic note. Black and yellow with crimson head of male distinctive; dull olive of female not likely to be confused when size is discriminated (but see under $P$. rubra cooperi). The female Tanager bears a strong superficial resemblance to the juvenal plumage of the Scott Oriole (Icterus parisorum), although its yellows are brighter and its beak stouter; but they are associationally different.

Nesting.- Nest: A rather thin-walled and often careless structure, usually scantily provided with external furniture of interlaced twigs or weed-stems, or long pine needles; lining of interwoven rootlets, or more rarely of grasses, and occasionally supplemented by horsehair; settled into investing foliage of horizontal branch of pine or fir tree, usually near tip, or more rarely, at moderate heights in deciduous shrub. Eggs: 4, or rarely, 5; light bluish green (light niagara green), spotted sharply and rather sparingly, often minutely, with dark grayish olive, or fuscous (shading to drab). Av. of 3I California-taken eggs in M. C. O. coll: $22.9 \times 16.5$ (.90 x .65); extremes: I 9.8-25.9 by I 5.2-I 7 (.78-1.02 by .60-.67). Season: June; one brood.

General Range.-Western North America, breeding from high Upper Sonoran to Boreal zones, and from southwestern Mackenzie, northern British Columbia, and southwestern South Dakota, south to western Texas and southern California; wintering from central Mexico south through the highlands of Guatemala; of casual occurrence during migrations in the eastern states and as far as Maine.

Distribution in California.-A common migrant practically throughout the State, locally and sporadically abundant; breeds chiefly in Transition zones from the San Jacinto Mountains north along both slopes of the Sierran ridge, and in associated mountains, including the inner coast ranges of northern California; also locally throughout the Coast Range system south to Santa Barbara (Bowles, I9ro; also Dawson, I915). The Western Tanager is a spring loiterer and the following records, although interesting, do not necessarily indicate local breeding: Farallon Ids., June I, I9I I; Lathrop, San Joaquin County, May 26, I9I2; Ben Lomond, Santa Cruz County, May I8, I914; Los Banos, Merced County, May 30, I914; The Pinnacles, San Benito County, May I 7 , I9I6.

Authorities.-Heermann, Jour. Acad. Nat. Sci. Phila., ser. 2, ii., I853, p. 267 (Calif.); Emerson, vol. v., I903, p. 64 (Haywards; unusual migratory "wave"); Beal, U. S. Dept. Agric., Biol. Surv. Bull., no. 30, 1907, p. 23 (food); Grinnell, Univ. Calif. Pub. Zool., vol. v., I908, p. I05 (San Bernardino Mts.; nest and eggs, etc.); Cooke, U. S. Dept. Agric. Bull., no. I85, I91 5, p. 23, figs. 9, Io, maps (distr. and migr.).

RED, yellow and black-can anyone imagine a more dashing color combination! and the colors are all guaranteed pure-prime, or "spectrum" yellow for the collar, rump, epaulets, and underparts; spectrum red for the forehead, crown, and as much of the remainder of the head as the age of the wearer entitles him to; black, also of the purest, albeit not glossy, and picked off appropriately on wings and tail with white, and on the back with yellowish edgings. It is a costume for a king!

Of course the young birds are not entitled to all this finery. The 
merest suggestion of red upon the forehead is enough to distinguish a growing son from his mother; and nesting males two or three seasons old may be poorly furnished as to the head. On the other hand, old males sometimes become so drunk with redness that it begins to ooze out upon the feathers of breast, rump, and crissum.

Seen in the hand, this vivid costume would seem to assure a very conspicuous bird, but afield it is not so. Seen against the changing green of willows, pines, or fir trees, these brilliant colors are lost to any but the most attentive eye. A resplendent male does not hesitate to stand quietly upon the end of a branch and survey you until his curiosity is fully satisfied. This quiet attitude of genteel curiosity seems to be character-

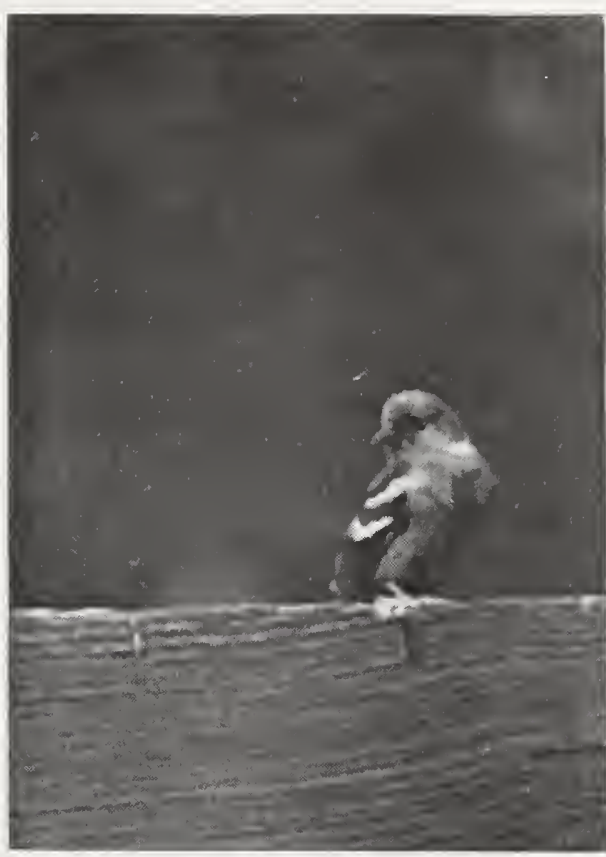

Taken in Santa Barbara County Photo by the Author

"A QUiET ATtitude OF . GENTEEL CURIOSITY" istic of all Tanagers. Apart from its psychological bearings, sedateness would seem to play an effective part in modifying the attractions of bright plumage.

In the spring migrations the male birds precede the dull-colored females by several days, and the movement is likely to be deflected, or retarded, by weather conditions, so that at a time a whole countryside may be aroused to the splendor of these avian visitors. Such a Tanager wave we well remember at Santa Barbara in late April and early May of the year I9I2. The birds "fairly swarmed," so says the note-book, along the fences or through the mustard patches which lined the lesser indentations of the sea-cliffs. Without exaggeration I think I may say that one could have seen a hundred adult males in the course of an afternoon's drive.

It is to be feared that these congested movements affect the fruit grower to some extent. The beauties are hungry, and berries are very much appreciated, thank you. A lady in Montecito, noting the predilection of the birds for fruit, had a wheel-like arrangement placed on top of a stake driven in her lawn. Upon the end of each spoke half an orange, freshly cut, was made secure. The Tanager saw and appreciated; and the lady had the satisfaction of seeing as many as twelve Tanagers feeding on 


\section{The Western Tanager}

the wheel at one time. Think of it! Never was a more distinguished array of beauty at a single function-not in Montecito even.

The historic flight of 1896 , reported by Mr. W. Otto Emerson, ${ }^{1}$ was, perhaps, the most memorable on record. Practically the entire State was invaded, and in certain fruit-growing sections the Tanager-wave assumed the proportions of a scourge. In a single cherry orchard near Haywards Mr. Emerson estimates that during the last two weeks of May not less than 600 Tanagers were killed, and that the number might have been as high as a thousand. At Pasadena Mr. H. A. Gaylord reported their maxi-

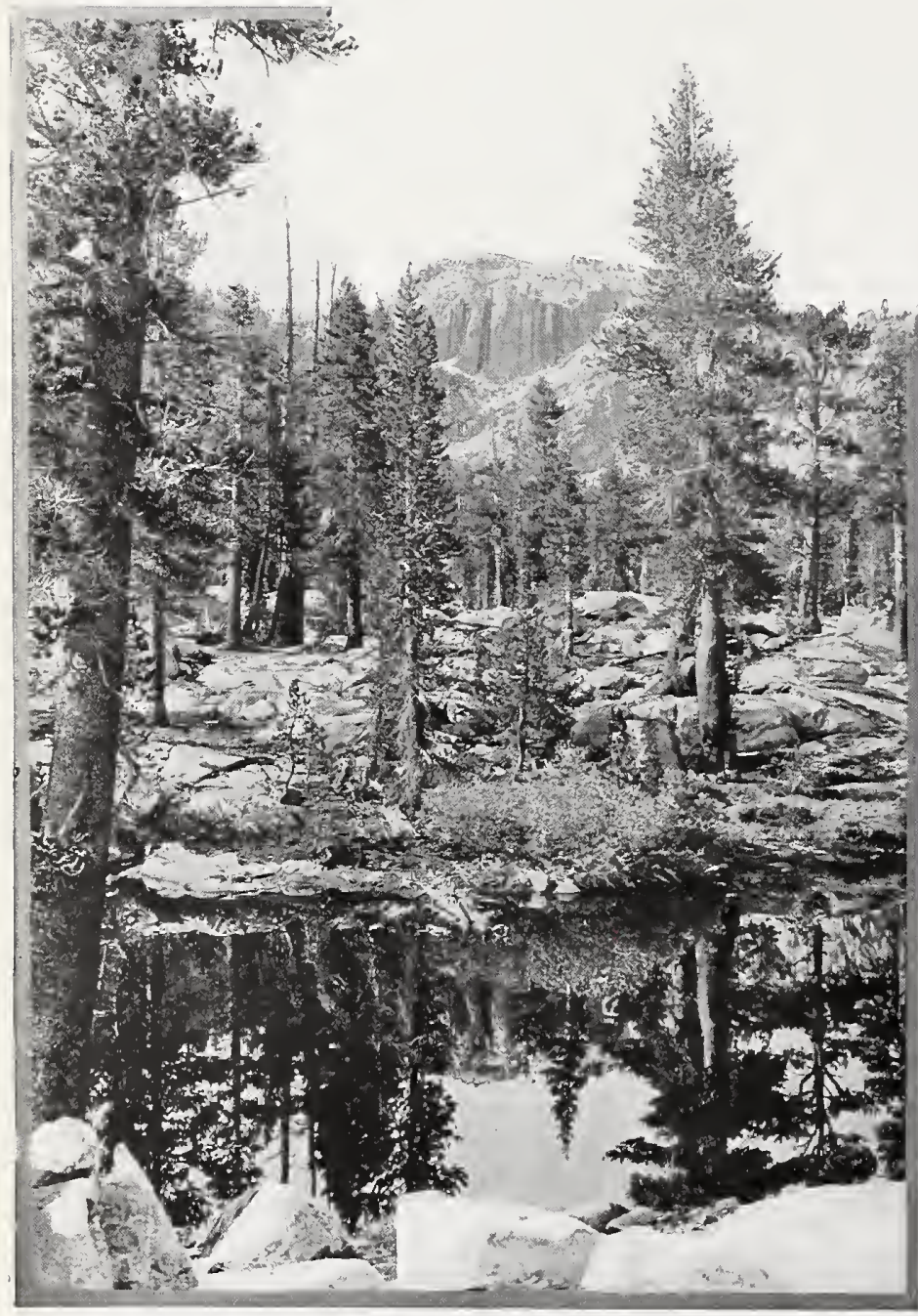

Taken in Fresno County

Photo by the A uthor mum abundance as occurring from May 6 th to 16 th, and adds: "The damage done to cherries in one orchard was so great that the sale of the fruit which was left did not balance the bills paid out for poison and ammunition. The Tanagers lay all over the orchard, and were, so to speak, 'corded up' by hundreds under the trees." One must conclude that the travel of the entire Tanager population of western North America was routed by way of California that season. It is only fair to add that the depredations committed by these birds in ordinary seasons are quite negligible.

While chiefly silent during the migrations, the arrival of the birds upon their chosen summer sites is betokened by the frequent utterance of a pettish pit'ic or pit'itic. The full-voiced song grows with the season, but at its best it is little more than an étude in $R$. "It is remotely comparable to that of the Robin, but it is more stereotyped in form, briefer, and uttered at

A SIERRAN HAUNT OF THE WESTERN TANAGER

${ }^{1}$ Condor, Vol. V., May, 1903, pp. 64-66.

434 


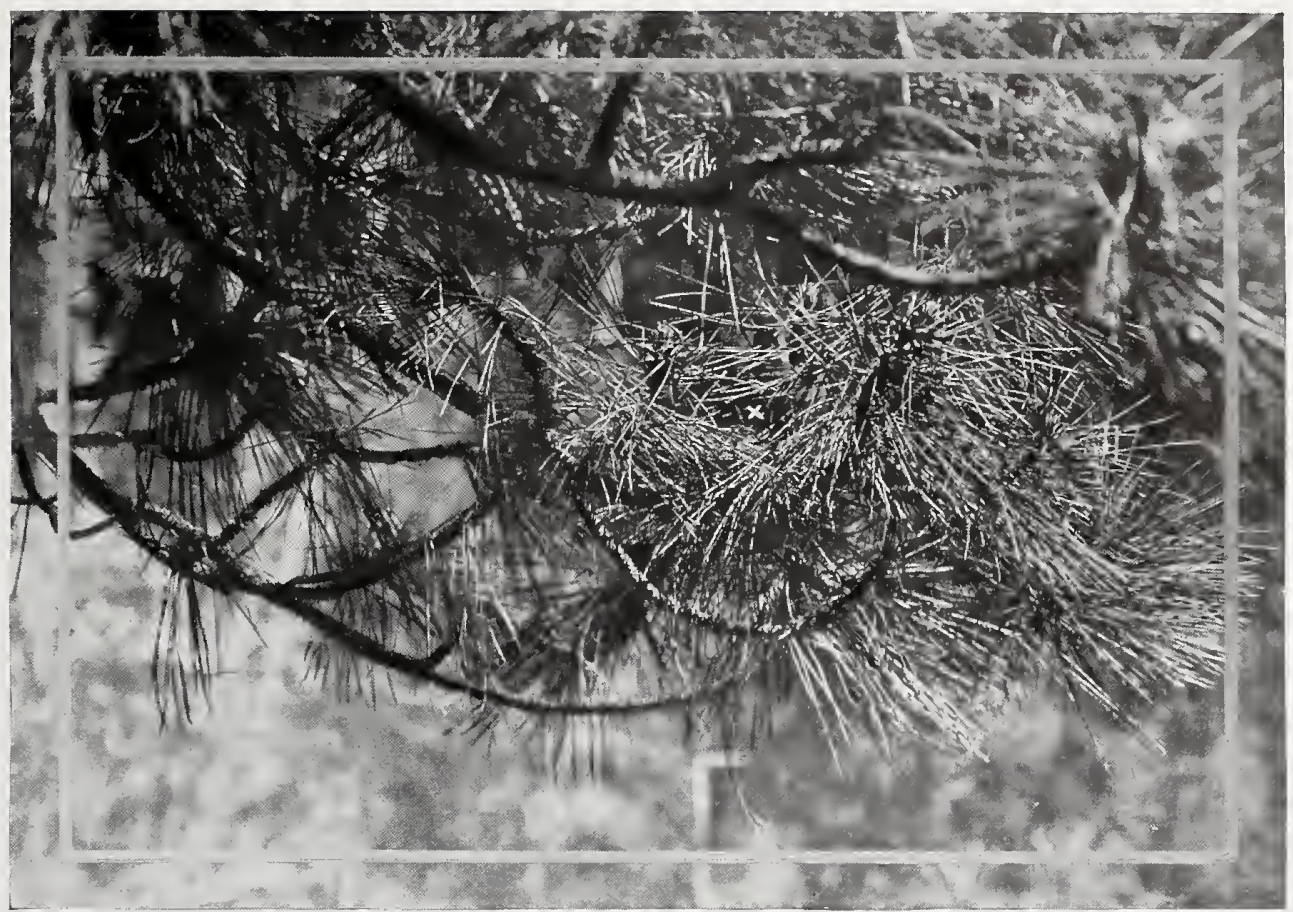

Taken in Modoc County

NEST IN YELLOW PINE

Photo by the Author

A FEMALE TANAGER MAY BE DIMIX DISCERNED BENEATH THE X MARK

intervals rather than continuously sustained. The notes are sharpedged, and rich in r's, while the movement of the whole, though deliberate, is varied, and the tone cheerful." 1 I can detect no constant difference between the song of the Western Tanager and that of the Scarlet Tanager ( $P$. erythromelas), save that that of the former is oftener prefaced with the call note, thus: Piteric whew, we soor a-ary e-erie witooer. This song, however, is less frequently heard than that of the Scarlet Tanager, East. Its perfect rendition, moreover, argues the near presence of a demure little lady in olive, a person who looks like nobody in particular to our undiscriminating gaze, but who exerts a strange fascination over our brilliant squire. Young males of the second summer sing hopefully, but they are less often successful in love than their ruddier rivals.

It behooves the Tanager maiden to be exacting in her choice, for all the help she will get out of him at best will be sympathy and song. When it comes to real work, like nest building, she must do it. He will graciously advise as to the situation, some horizontal branch of fir or pine, from six to fifty feet high, and from three to twenty feet out. He will even accompany

'Applied to P. erythromelas in "The Birds of Ohio," p. Iog, and exactly applicable here. 


\section{The Western Tanager}

her on her laborious trips after nesting material, cooing amiable nothings, and oozing approval at every joint,--but help her?-nevaire!

The nest is quite a substantial affair though rather roughly put together, of fir twigs, rootlets, and moss, with a more or less heavy lining of horse- or cow-hair, and other soft substances. The four eggs of bluish green, dotted and spotted with lavender and dark greenish slate, appear especially handsome from above, when viewed against the dark brown nest. But, as everybody knows, the red fir (Pseudotsuga taxifolia) is a tree of moods and tenses. You may dangle with impunity from the very tips of the branches of some fir trees, while a step from the trunk is fatal in others of the same general appearance. The Tanagers are quite as apt to patronize the brittle kind.

In California nesting dates are everywhere complicated with questions of altitude. The nest with three eggs taken by Mr. Ralph Arnold on the 5 th of May, I 895 , seems to be the earliest record, and a truly remarkable one, seeing that the migrant birds have scarcely cleared by that time,

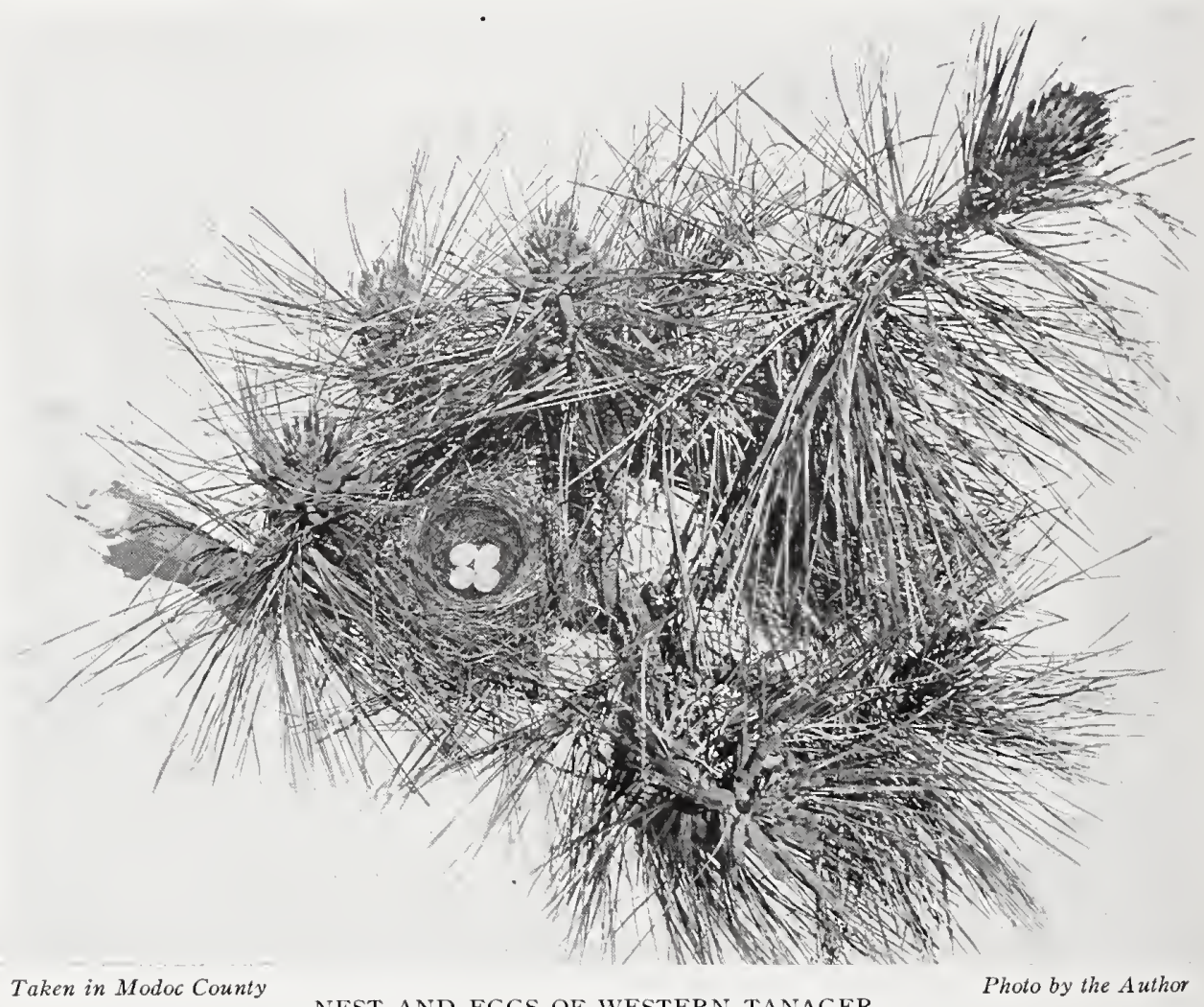

THE SITUATION OF THE NEST IS SHOWN IN THE PRECEDING CUT 


\section{The Black-and-rohite Warbler}

and many linger in more northerly localities till near the first of June. On the other hand, I took a set of four fresh eggs from a mountain mahogany bush in the IVarners (alt. $7800 \mathrm{ft}$.) on the I2th of July, I9I2. William Oberlin Dawson found an incomplete set of two eggs in Los Canoes Canyon, near Santa Barbara, on the 9th of June, I9I5; but the Jays, Aphelocoma californica, cleaned it out before we could get back to it. This record is remarkable chiefly for having been made well within the bounds of Upper Sonoran territory.

What the birds do with themselves after the nesting season is over is a subject that has not been enough inquired into. The birds will not take us with them on their leisurely mountain rambles, and our feeble trail of inquiry all too frequently ends with the deserted nest. But I'll confess I was surprised to find the Tanagers at Simpson Meadows, on the Middle Fork of the Kings River, in July, assiduously haunting the vicinity of the river itself. What they found I do not know-insects of one certain brand, perhaps; but I do know that they hawked and fluttered back and forth across the raging torrent even more assiduously than the Solitaires (Myadestes townsendi). The Tanagers combined the roles of Flycatcher and Ouzel, for they would alight unhesitatingly upon the rocks which cut the foaming water, even when they had to cling tightly to resist the accompanying rush of air. Again, in the Tehipite Canyon, I saw a flycatching Tanager who courted the hollow of the roaring torrent where his only rivals were a IVood Pewee and a Spotted Sandpiper,- - the latter, it must be confessed, seemingly as much out of character beside the merciless stream as himself.

No. 77

\section{Black-and-white Warbler}

A. O. U. No. 636. Mniotilta varia (Linnæus).

Synonyms.- Tree-creeping Warbler. Black-And-white Creeper.

Description.-Adult male: Chiefly black and white in streaks and stripes; two lustrous black stripes separated by broad median white stripe on head and prolonged to cervix; eye-ring and superciliary stripe white; malar stripes, broadly, and usually extreme chin white; throat, narrowly, black, or broadly with some admixture of white; exposed tips of primaries and tertiaries and primary coverts dusky rather than black; median and greater coverts tipped with white, broadly, and forming two conspicuous stripes; rectrices chiefly dusky with bluish ashy skirtings on outer web; the two outer pairs of feathers white-blotched near tip of inner web, and all narrowly edged with white; upper tail-coverts broadly black; axillars, lining of wings, and belly white; remaining plumage streaked black and white, broadly and sharply on breast, sides, and flanks, narrowly on sides of neck, less sharply defined on back. Bill black; 


\section{The Black-and-white Warbler}

feet horn-color with yellowish claws (in life). Adult male in fall and winter: Black of throat reduced or wanting; streaking of chest and sides of neck less sharply defined. Immature male: Like adult male, but throat white and chest more narrowly streaked. Adult female: Similar to adult male, but smaller and duller, the streakings of underparts wanting or obsolescent, except on sides and flanks, where much reduced; the whites chiefly tinged by buffy brownish, especially in malar region and on flanks. Mandible light-colored, becoming dusky on tip. Young: Like adult female, but lateral head-stripes ill-defined; buffy suffusion more prominent everywhere; sides unstreaked. Length of male I I 4.3-I39.7 (4.50-5.50); wing 68.6 (2.70); tail 48 (I.89); bill II.4 (.45); tarsus I7 (.67). Length of female II 3.5 (4.47); wing 66 (2.60); tail 46.5 (I.83); bill II $.4(.45)$; tarsus I6.8 (.66).

Recognition Marks.-Medium Warbler size; black and white in streaks and stripes. Requires careful distinction from Black-throated Gray Warbler (Dendroica nigrescens), which it superficially resembles, especially from a side view. Note absence of supraloral yellow spot, and the presence of distinctive stripes on crown, and the black-and-white-streaked back. Tree-creeping habits also distinctive.

Nesting.- Not known to breed in California. Nest: On the ground, usually sheltered by stump, log, or projecting stone; of leaves, bark-strips, and grasses, with a lining of fine rootlets and hairs. Eggs: 4 or 5; white or creamy white, speckled and spotted with chestnut or umber, chiefly in wreath about the larger end. Av. size I $7 \times$ I $4(.67 \times .55)$. Season: c.June Ist; one brood.

General Range.- North America, chiefly east of the Rocky Mountains, and northern South America. Breeds from northern portions of the Gulf States north to northern Ontario and central Keewatin, and west, perhaps casually, to Colorado and Wyoming; winters from Florida and the West Indies south to Venezuela and Ecuador; casual on the Pacific Coast and in Bermuda.

Occurrence in California.-Casual during migrations and in winter (Carpinteria, Jan. 9, I920, by Dr. H. C. Henderson)-about a dozen records. McGee Creek, Mono County, June 9, I92 I, by H. IV. Carriger and IV. Leon Dawson, appears to be the latest spring occurrence.

Authorities.-W. E. Bryant, Proc. Calif. Acad. Sci., 2nd ser., i., I 888, p. 48 (Farallon Ids., May 28, I887, one spec.); Cooke, U. S. Dept. Agric., Biol. Surv. Bull., no. I8, I904, p. I8 (distr. and migr.); U. S. Dept. Agric. Bull., no. I85, I9I5, p. 25, figs. I5, I6, maps (distr. and migr.); Chapman, Warblers of North America, I907, p. 38, col. pl. (life hist., biog. ref., etc.); Grinnell, Pac. Coast Avifauna, no. I I, I9I5, p. I44, ibid., Condor, vol. xxiv., I922, p. I 85 (Calif. occurrences).

Note.-The following works are especially recommended as source books in the study of the American Wood Warblers. Because of their general pertinence, detailed references are omitted henceforth from the "Authorities": Distribution and Migration of North American Warblers, by Wells W. Cooke, U. S. Dept. of Agric., Div. of Biol. Survey, Bulletin no. I8, Washington, 1904, pp. I-I42. The Warblers of North America, by Frank M. Chapman, New York, D. Appleton \& Co., I907, pp. I.-ix and I-306.

THE NORTH American Wood Warblers fall naturally into two distributional groups, the eastern and the western. So marked is this division, and so important to an understanding of conditions in California, that we may be pardoned if we attempt at the outset a brief reconstruction of Mniotiltine history. Spreading from some center in the South, 


\section{The Black-and-white Warbler}

where this family was already highly differentiated, a varied cohort invaded the timbered territory east of the Mississippi, found congenial conditions, and spread rapidly northward. Encountering, presumably, the ice barrier in the Laurentian Highlands, this eastern division found relief in a northeasterly direction, flowed across the timbered stretches of Ontario, Manitoba, and Saskatchewan, and reached at last the eastern Rockies of British Columbia, and the limit of trees in Mackenzie, Yukon Territory, and Alaska.

A similar but smaller cohort, starting perhaps at the same time, invaded the mountains of the West, proceeding slowly northward by way of the Rocky Mountains, the Sierra-Cascades, and the continuous forests of the Pacific slope. This western army of invasion has also reached the limit of trees in Alaska, but it is represented there by only two forms,forms whose conspecific analogues of the eastern stream had long since reached the limit of trees in Mackenzie. The eastern stream, also, has three exclusive types already on the ground.

In the early days an effective barrier existed between the eastern and western divisions of the Mniotiltine army in the treeless plains west of the Mississippi. This barrier still exists, but it is disregarded by such eastern species as, having found a home in the British Northwest, now cut "cross-lots" in going to and from their winter quarters, instead of returning by the Mackenzie-Ontario-Atlantic route originally traversed. It is worthy of remark, however, that the great majority of such northern residents still return by the old route. In a similar way, we may suppose that the western pioneers were originally separated by the Great Basin; but having passed beyond it, and becoming now reunited in the North, they have learned to traverse it unfearingly in their annual flights.

Disregarding for the present the recent or the non-aggressive types, eight in number, such as Vermivora lucice and Peucedramus olivaceus, which are confined to our southern latitudes, there are in the West only eleven species. Of these, five, presumably the oldest, that is, the first to enter this territory, are peculiar to the West. But of these, in turn, one, and that the dominant warbler of the West, D. auduboni, while specifically distinct, is yet so closely related to the dominant bird of the North (eastern division), D. coronata, that it forms a connecting link with the second grand ethnological division of western warblers, viz., those which are subspecifically related to eastern forms. For instance, the Yellow Warbler (D. estiva subsp.), aggressive, dominant, has penetrated Alaska both by way of the East and of the West; but in the days of separation, slight differentiations have arisen within the species, not only between the eastern and western birds, but in the West itself as between the more aggressive northern birds and the more indolent south-keeping birds. 


\section{The Tennessee Warbler}

With these rough generalizations in mind by way of guidance, it must be remembered always that neither warblers nor any other birds ever actually invaded a country en masse, and that each species, therefore, has a perfectly independent history of its own. And it goes without saying that the history of the species is simply the combined record of individual birds, birds which, precisely in so far as they are individual, make history.

A few individuals, a score perhaps, of the species Mniotilta varia have gone far toward making Mniotiltine history, in that they have allowed themselves to be taken within the limits of California. These occurrences serve to remind us that those eastern species which, in their agelong northwesterly gropings, have reached, or nearly reached, the eastern base of the Rocky Mountains, are likely to send down scouts, pioneers, accidentals, waifs - call them what you will-in search of a nearer passage to Panama than that afforded by the ancestral route. So far as the individual is concerned, these aberrations may represent any one of several happy (or unhappy) accidents: local associations with western migrants upon the breeding grounds; the failure of the migratory instinct; the superiority of the general sense of direction over the urge of the ancestral memory; - - however it may come to pass, the economical purposes of nature will be subserved, and we shall see more and more of these northwestern-reared "eastern" birds taking the short cut to Mexico, precisely as their remote ancestors did across the, till then, forbidden "Great Plains."

There have been, I believe, increasingly frequent repetitions of Black-and-white Warbler records of late, so that it is, perhaps, not too much to say that this species has become the commonest of the so-called "accidentals." We may look forward with some degree of confidence to seeing it establish itself as a regular migrant.

No. 78

\section{Tennessee Warbler}

\section{A. O. U. No. 647. Vermivora peregrina (Wilson).}

Description.-Adult male in spring and summer: Pileum and hind-neck, broadly, bluish ash (deep grayish olive), faintly glanced with warbler green; remaining upperparts bright warbler green; flight-feathers and tail dusky, the primaries narrowly edged with whitish, a whitish blotch (or not) on tip of inner web of outermost pair of rectrices; an obscure superciliary line whitish; a line through eye olive-gray; underparts, shading on sides of head and neck, dull white, more or less tinged with yellowish; flanks clearer yellow. Bill and feet horn-color. Adult male in fall and winter: Upper- 


\section{The Tennessee Warbler}

parts entirely overlaid with warbler green; underparts sordid yellow (pyrite yellow), shading on sides. Adult female: Similar to adult male, but duller, more sordid, below. In fall and winter correspondingly deeper-toned throughout, sometimes actually dusky on belly. Length of adult male (skins) about II2 (4.4I); wing 65 (2.56); tail 42 ( 1.65$)$; bill 9.6 (.38); tarsus I6.8 (.66). Females average a little smaller.

Recognition Marks.- "Warbler" size; a difficult "warbler green" nondescript. May be distinguished with certainty from the $V$. celata type in spring only, when the gray crown, whitish underparts, and whitish superciliary stripe may be noted. In fall, note the more sordid, less yellow, underparts, and the usual presence of a superciliary line, now yellowish. Smaller than V. celata.

Nesting.-Does not breed in California. Nest: Low in bushes, or on the ground sunk in moss or crowding vegetation at base of small tree; of weed-fibers, grass, etc., lined with hair. Eggs: 4 to 7 , usually 6; white, speckled and wreathed with dull reddish brown and vinaceous gray. A typical set averages I6.3 x II.9 (.64 x .47). Season: June; one brood.

General Range.-Eastern and northern North America. Breeds in Canadian zone from upper Yukon valley and southern Mackenzie south to southern British Columbia, and east to the Atlantic Coast, including northern New York and New England; winters from Oaxaca to Colombia and Venezuela; migrates chiefly through the Mississippi and eastward with diminishing frequency to the Atlantic seaboard; rare in Cuba and Florida; accidental in California. Grinnell.

Occurrence in California.-One record: Pasadena, Sept. 27, 1897, by Joseph

Authorities.-Grinnell, Pasadena Acad. Sci. Pub., no. 2, I 898, p. 45 (Pasadena, Sept. 27, I 897 ; one spec.) ; Norris, Auk, vol. xix., I902, p. 88 (desc. habits, nest and eggs; British Columbia).

ALTHOUGH RATED only "accidental in California" on the basis of a single specimen taken by Mr. Grinnell at Pasadena (Sept. 27th, I 897), we cannot help wondering whether the fault has not been rather one of non-recognition on our part than non-occurrence. The Tennessee Warbler breeds in the central mountains of British Columbia; and while it is undoubtedly true that the bulk of the migrants in quitting the Columbian Rockies and the Upper Yukon Valley take a sharp southeasterly course to rejoin their fellows from Keewatin and Ungava, it would be passing strange if there were not a certain proportion deflected by the western route. The bird is of that non-committal type with which our thickets are already so well provided; and since it is also somewhat secretive in habit, it might easily pass unnoticed among the throngs of our western migrants.

Wilson first found this bird on the banks of the Cumberland in Tennessee, and promptly named it after their common hostess. Both Wilson and Audubon regarded it as extremely rare, the former having seen but two specimens, and the latter three. Inasmuch as it is now considered one of the common migrants of the Mississippi Valley, one scarcely knows 


\section{The Orange-crowned Warblers}

whether to indulge a chuckle at the expense of those early heroes, or to concede that the bird has enormously increased.

\section{No. 79}

\section{Orange-crowned Warbler}

\section{A. O. U. No. 646. Vermivora celata celata (Say).}

Description.-Adult male: Above warbler green over grayish olive,-brighter, clearer yellow, on rump and upper tail-coverts; duller, more grayish, on crown and hindneck; a crown-patch of "orange" (sudan brown) feathers more or less concealed by olive tips; wings and tail fuscous with greenish skirtings, the outermost primaries edged with white; eyelids whitish or yellowish, separated both anteriorly and posteriorly by wedges of dusky; underparts yellow, of ten with streaky irruptions of pale olive-gray (the resultant blend nearly pyrite yellow); the yellow clearest on axillaries, wing-linings, and under tail-coverts; dullest and grayest on throat and sides of neck. Bill and feet horn-color. In fall and winter, plumage "softer"; crown-patch concealed or wanting. Adult female: Similar to male, but possibly duller, with crownpatch restricted or wanting. Young, first plumage: "Above dull olive, or grayish olive, becoming more olive greenish or russet olive on rump and upper tail-coverts; middle and greater wing-coverts tipped, more or less distinctly, with pale olive or dull buffy; throat, chest, sides of breast, sides, and flanks pale brownish gray, tinged with dull buffy, especially on chest; abdomen white; otherwise like adults, but without trace of tawny-ochraceous on crown" (Ridgway). Length of adult male (skins) about I I7 (4.61); wing 6I.4 (2.42); tail 49.2 (1.94); bill 9.8 (.386); tarsus 17.7 (.70).

Recognition Marks. - Warbler size; warbler green above, yellow below; blended pattern of color difficult to distinguish from the rare Tennessee Warbler $(V$. peregrini). Larger and much duller yellow than the Pileolated Warblers (Wilsonia pileolata group); duller, more olivaceous, than the Dendroica astiva group. Orange crown-patch, of course, distinctive of species. Duller than V.c.lutescens; lighter than V. c. sordida.

Nesting.-Does not breed in California. For description see under $V . c$. lutescens.

Range of Vermivora celata.-North America, breeding in the mountainous states of the West and in British America; wintering in southern United States, south to Guatemala.

Range of $V . c$. celata.-Breeding in Canada centrally and northwesterly and in Alaska to the limit of trees. Apparently rare as a breeder anywhere east of the longitude of Hudson Bay; migrates chiefly through the Mississippi Valley and eastward in diminishing numbers to the Atlantic seaboard; winters in the South Atlantic and Gulf States, the southwestern states and in Mexico.

Occurrence in California.- Not common winter resident in southern California; many records; migrant elsewhere.

Authorities.-Swarth (Helminthophila celata), Condor, vol. iii., I901, pp. I7, I45 (Los Angeles); Coues, Birds Col. Val., I878, p. 226 (desc., nest, eggs, etc.); Oberholser, Auk, vol. xxii., I905, p. 242 (distr., desc., crit.); Grinnell, Univ. Calif. Pub. Zool., vol. xii., I9I4, p. 194 (Colorado Valley). 


\section{The Orange-crowned Warblers}

\section{No. 79a Luteoline Warbler}

A. O. U. No. 646a, part. Vermivora celata orestera Oberholser.

Note.-In his original description of this form (Auk, xxii., July, 1905, pp. 243-245), Oberholser did not assign a vernacular name, and I propose the more distinctive term Luteoline (from the Latin luteolus, yellowish), in place of the cumbrous "Rocky Mountain Orange-crowned Warbler" used by Grinnell and others. The name has not only the advantage of accuracy, but of family resemblance to the related form, V.c.lutescens. The word lutescens, by the way, although understood to mean "becoming yellow," is probably derived from lutum, mud, luteus, muddy, instead of lutum, or luteum, yellow weed. Hence, lutescens means" becoming muddy," a term rather more applicable to sordida than to the Lutescent Warbler. But, anyway, all the celatas are muddy yellow, and the names will stick on either count.

Description.-Described by Oberholser as an intermediate type, larger and more yellow than $V$. c. celata, duller, less yellow, and also larger than $V$. c. lutescens. Measurements of males (Oberholser): wing 63.5 (2.50); tail 50.5 (1.99); bill I 0.2 (.40); tarsus $\mathrm{I} 8.3(.72)$.

Nesting.--Much as in next form.

Range of $V . c$. orestera.-The Rocky Mountain and intra-mountain areas, breeding from New Mexico and Arizona (Mt. Graham) west to eastern California, and north to the mountains of eastern British Columbia and western Alberta; probably passes entirely south of the United States in winter.

Distribution in California.-Definitely recorded in summer only from the Panamint and Argus Ranges, and the White Mountains of eastern California. Other east-side birds are apparently intergrades between orestera and lutescens.

Authorities.-Oberholser, Auk, vol. xxii., I905, p. 243 (orig. desc.; specimens from the Argus Range, Panamint Mts., and Olancha Peak); Grinnell, Pac. Coast Avifauna, no. I I, I915, p. I46, in text (status in Calif.); ibid., Condor, vol. xxi., I919, p. 42 .

IMMIGRANT children sometimes arrive at Ellis Island with their names and destinations pinned conspicuously upon their breasts. It is not altogether otherwise with our migrant birds, for by closely examining their marks of identification we may tell where they hail from and whither they are bound. The subtle differences between $V$. celata and $V$. celata lutescens may not interest the general public, but by these marks we know that the Orange-crowned Warblers, which are found in winter in southern California, and especially in the Colorado River Valley, hail from Alberta and Alaska, east of the Rockies; whereas our own Lutescents, as common as grass throughout the State in summer, absent themselves altogether in winter.

No. 79b Lutescent Warbler

A. O. U. No. 646a. Vermivora celata lutescens (Ridgway).

Description.--Similar to $V$. c. celata, but brighter and more yellow throughout; upperparts bright warbler green; underparts between pyrite yellow and lemon yellow. Young said to be considerably different,--more olive greenish; abdomen yellow, not white. Length: wing $59.8(2.35)$ : tail 47 (1.85): bill $9.9(.39)$; tarsus $17.6(.70)$. 


\section{The Orange-crowned Warblers}

Nesting. - Nest: On the ground, usually on partially shaded hillside, and often recessed in bank; of weeds, moss, and woodland waste, lined with dried grasses and horsehair. Eggs: 4 or 5; white, heavily speckled, chiefly about larger end, with dull reddish brown. Av. size: $15.8 \times 11.9(.62 \times .47)$; index, 76. Season: April -June; two broods.

Range of $V . c$. lutescens.-Summer resident in the Pacific Coast district of North America, broadly defined, and occasionally spilling over upon the eastern slopes of the main ranges in Oregon, Washington, etc.; breeding from the mountains of southern California north (at least) to the Kenai Peninsula; south in winter beyond the border of the United States to Guatemala.

Distribution in California.- Early spring migrant and summer resident west of the Sierran divide; breeding in semi-wooded areas of the Upper Sonoran and Transition zones; also common east of the Sierras northerly, where inclining toward orestera; apparently passes entirely beyond the State in winter.

Authorities.-Gambel (Vermivora celata), Proc. Acad. Nat. Sci. Phila., iii., I 847 , p. I55, part (Calif.); Finley, Condor, vol. vi., I904, p. I3 I, figs. (nesting habits, nests and eggs; photos of adults, young and nest); Oberholser, Auk, vol. xxii., 1905, p. 245 (distr., desc., meas., crit.); Beal, U. S. Dept. Agric., Biol. Surv. Bull., no. 3o, 1907, p. 5 I part (food).

THE NAME "Warbler" as applied to the American family Mniotiltide is rather a misnomer. Originally applied to the Old World Sylviida,

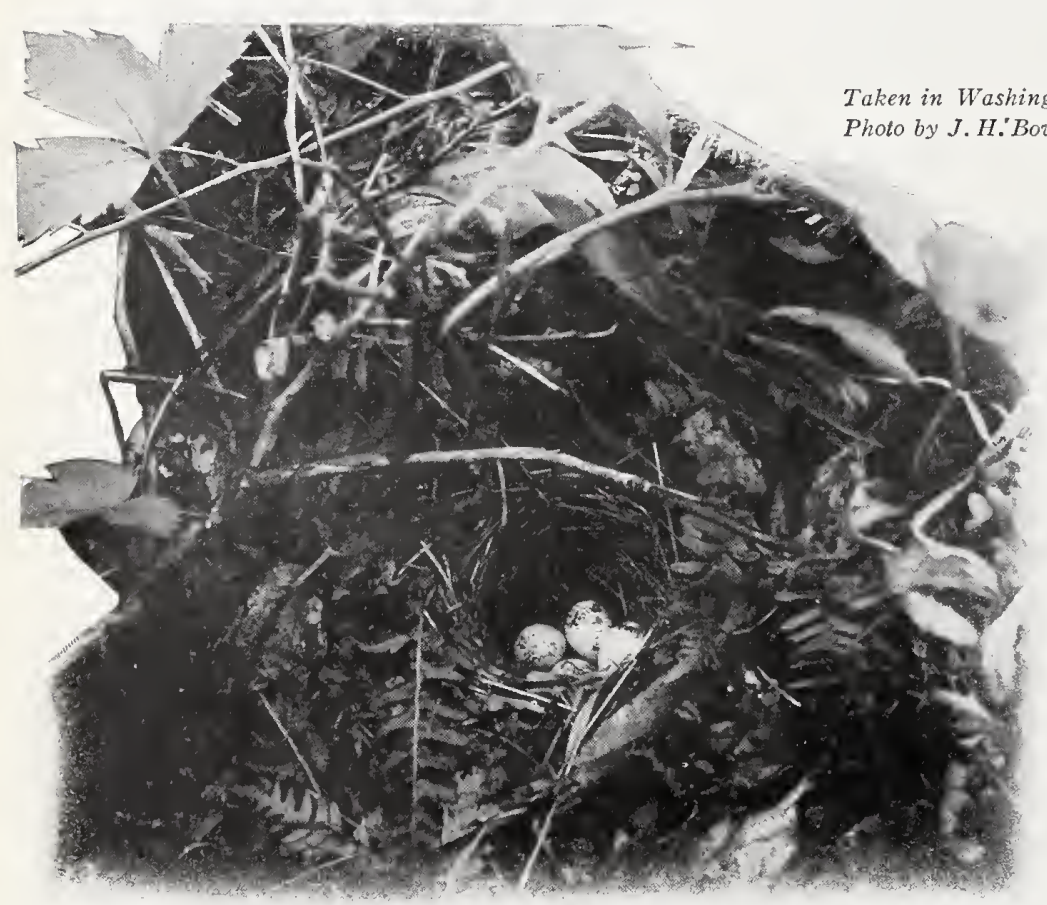

NEST AND EGGS OF LUTESCENT WARBLER the word becomes intelligible with us only by us ing the prefix "Wood." Of the sixteen genera of American Wood Warblers now recognized by our A.O. U. Committee, only two, Seiurus (the VaterThrushes) and Icteria (the Chat), are conspicuous in song. The rest all have characteristic utterances, technically called songs, but they seldom achieve the dignity or suggested sweetness of "warblers." These "songs" are, rather, in every case, a conventionalized phrase, a crystallized and stereo- 


\section{The Orange-crowned Warblers}

typed publication of presence, declaration of love, and allpurpose medium. These phrases, or song-cries, are specifically characteristic in form, quality, and emphasis, but they are so tiny, and so high removed from the human plane, that their successful identification offers the severest test of the discrimination and the enthusiasm of the bird-student. Quaint, queer, bizarre, rather than tuneful, these tiny offerings, nevertheless, afford the keenest delight to the critical ear of the seasoned amateur.

The song of the Lutescent Warbler appears to have been very largely overlooked, but it was not the bird's fault. While waiting for his tardy mate, he has been rehearsing diligently from the taller bushes of the thicket, or else from some higher vantage point of poplar, sycamore or ceanothus. The burden is intended for fairy ears, but he that hath ears to hear let him hear a curious vowel scale, an inspirated rattle or trill, which descends and ends in a simple twitter of several notes. The trill, brief as it is, has three qualities of change which make it quite unique. At the opening the notes are full and slow, but in the instant necessary to the entire recital the pace accelerates, the pitch rises slightly, and the component notes decrease in volume, or size. At the climax the tension breaks unexpectedly in the gentle, musical cadence of the concluding phrases, whose notes much resemble certain THIS LITTLE DEAR, WHOM THE SCIENTISTS CALL Eutamias of the Yellow Warbler's. The opening trill carries to a considerable distance, but the sweetness of the closing warble is lost to any but near listeners. The whole may be rendered graphically somewhat as follows: O-o-a-a-i-i-é-é-é-é-é-é wichy, wichy, wichy.

In the brush and under alarm these birds utter a brusque, metallic scolding note, which is perfectly distinctive locally, although it much resembles that of the Oporornis group East. By this mark alone may the mere yellowish female be certainly discerned.

Yellow appears to be the prevailing color among our western Wood 


\section{The Orange-crowned Warblers}

The latter, you understand, is quite the subtlest and most baffling form of revenge which a bird may compass in the case of an oölogist anxious to identify his find.

\section{No. 79c Dusky Warbler}

A. O. U. No. 646b. Vermivora celata sordida (C. H. Townsend).

Description.-Similar to V. celata lutescens, but decidedly darker; upperparts olive-green; underparts warbler green, or lightening to pyrite yellow on belly and under tail-coverts. Also bill and feet larger. Av. of ro males in M. V. Z. colls: Length I 20.4 (4.74); wing 59.9 (2.36); tail 53.3 (2.10); bill I I.3 (.445); tarsus I 8.5 (.73).

Recognition Marks.-See those of species. Easily distinguishable afield by dusky coloration.

Nesting.-Much as in preceding form, save that nests are occasionally placed well up in trees. A set in the M. C. O. coll. averages $15.9 \times 13.3(.625 \times .525)$; index 84 .

Range of $V$. c . sordida.-Spring and early summer resident upon the Santa Barbara Islands, off the coast of southern California, Los Coronados and Todos Santos Islands of Lower California, and a few adjacent portions of the mainland; spending the remainder of the year chiefly (but not exclusively) upon the neighboring mainland.

Distribution in California.-- Partially resident and common spring and summer resident upon all the islands of the Santa Barbara group, except San Nicholas; found breeding also upon Pt. Loma and at Coronado Beach; winters chiefly upon the mainland coastwise, or to the summits of the neighboring ranges; has wandered north in winter as far as Palo Alto (Grinnell), Haywards (Emerson), and Berkeley (Grinnell).

Authorities.-Gambel (Vermivora celata), Jour. Acad. Nat. Sci. Phila., ser. 2, i., I 847 , p. 37 (Santa Catalina Id.; song); Oberholser, Auk, vol. xxii., 1905, p. 245 (desc.; crit.); Willett, Pac. Coast Avifauna, no. 7, I912, p. 95 (occurrence in s. Calif.); Grinnell, Pac. Coast Avifauna, no. II, I915, p. I46 (status in Calif.); Howell, Pac. Coast Avifauna, no. 12, 1917, p. 90 (distr., habits, nest and eggs, etc.).

IF IVE CALL the Lutescent Warbler "yellow," we must call the Dusky Warbler "green," and this we hasten to do, because green is Nature's color. But green must not be understood in too harsh a sense. There is just enough of redeeming yellow in birdikin's plumage to represent the play of sunlight on oak-leaves or on grass; while as for the "dusky" element, no one who has ever tried to trace the movements of a self-conscious female Dusky Warbler over a shaded hillside will ever doubt its efficacy as an extinguisher. Never was a fairy in a wishingcap more difficult to follow.

For those who know the Channel Islands, the Dusky Warbler best embodies those rioting greens of springtime which make these charmed spots live in memory; and of all island sounds it is the cheerful, varied, all-prevailing trill of the Dusky Warbler which first suggests itself to recollection. Every hillside which boasts a modicum of shade is alive 


\section{The Orange-crowned Warblers}

with them; and because of their unceasing efforts in song one gets a rather better impression of the abundance of bird life on the Channel Islands than the facts strictly warrant. Sordida is, of course, a localized race of the $V$. celata type. That it should be a "saturated" form, following the analogy of the Island Horned Lark, Otocoris alpestris insularis, seems a little surprising, even to those who know island conditions best. To be sure, moisture is abundant and fogs fairly prevalent in season; but

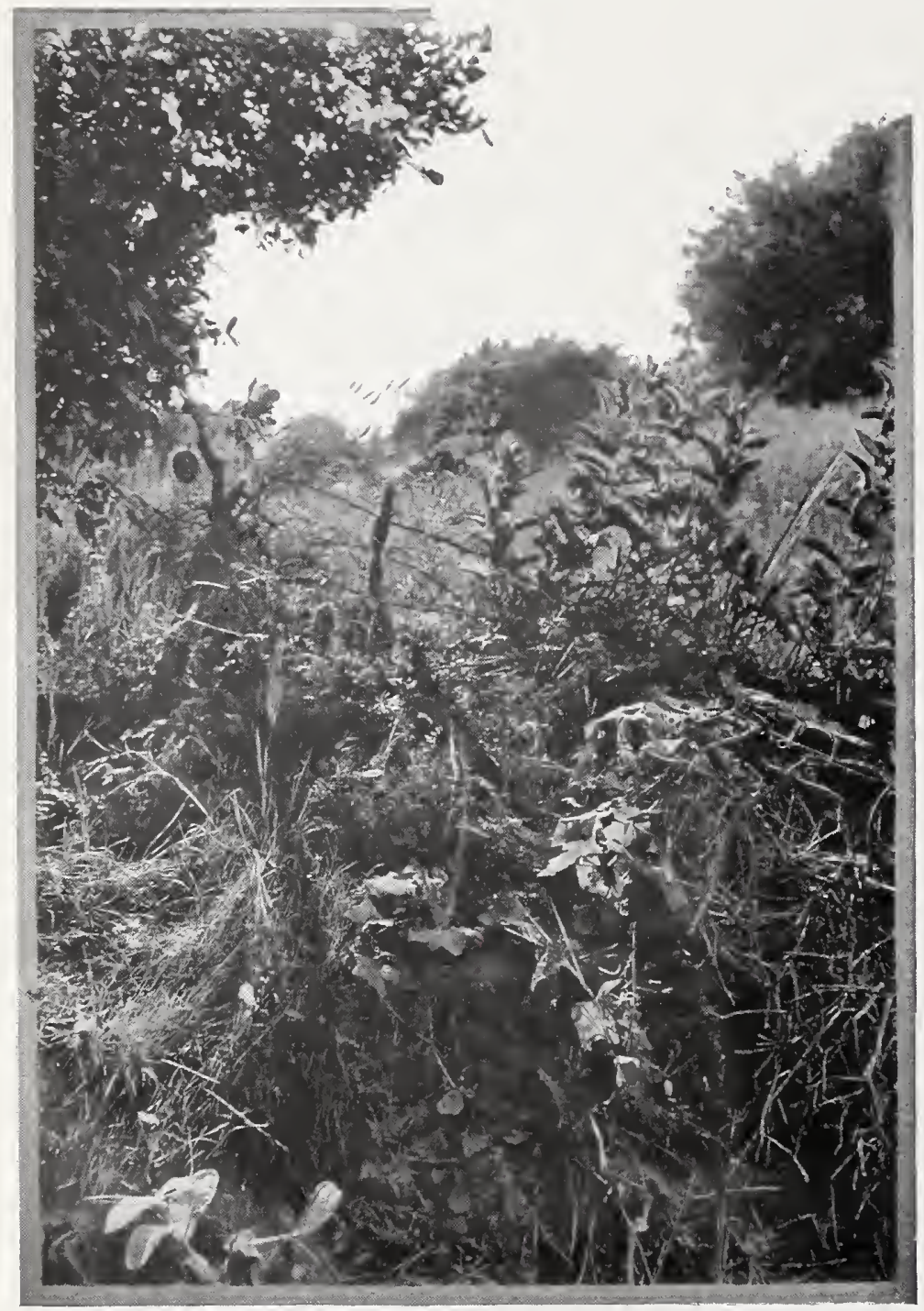

Taken on Santa Cruz Island

Photo by the Author

A NESTING HAUNT OF THE, DUSKY WARBLER so, too, are bright days and open places, insomuch that the Islands are rated "Upper Sonoran."

Perhaps it is only imagination on the writer's part, and perhaps it is lack of immediate competition in song; but I have fancied that the vocal efforts of $V$. c. sordida are more varied than are those of the mainland type; and this, although the changing pitch and the ventriloquial quality which characterize the northern bird are less conspicuous. The trill in sordida is rapid and slightly accelerated; but the notes are more open and uniform. The units, too, are so distinct as to simulate the Wilsonia pileolata type of song; and they sometimes require careful discrimination. The rendition of a "song" occupies only a fraction over a second, but a good deal can happen in an avian sec448 


\section{The Orange-crowned Warblers}

ond. Anyhow, these momentary offerings are the very life of Santa Cruz and Santa Catalina,-and of all the other saints whose good fortune it is to be entirely surrounded by water.

Anybody can find a bird's nest by accident- - a cow might-but the achievement of discovering a Dusky Warbler's nest always flatters the hunter's vanity. The bird has risen silently from the ground, and less visibly than a fluttering leaf. When twenty or thirty feet removed,

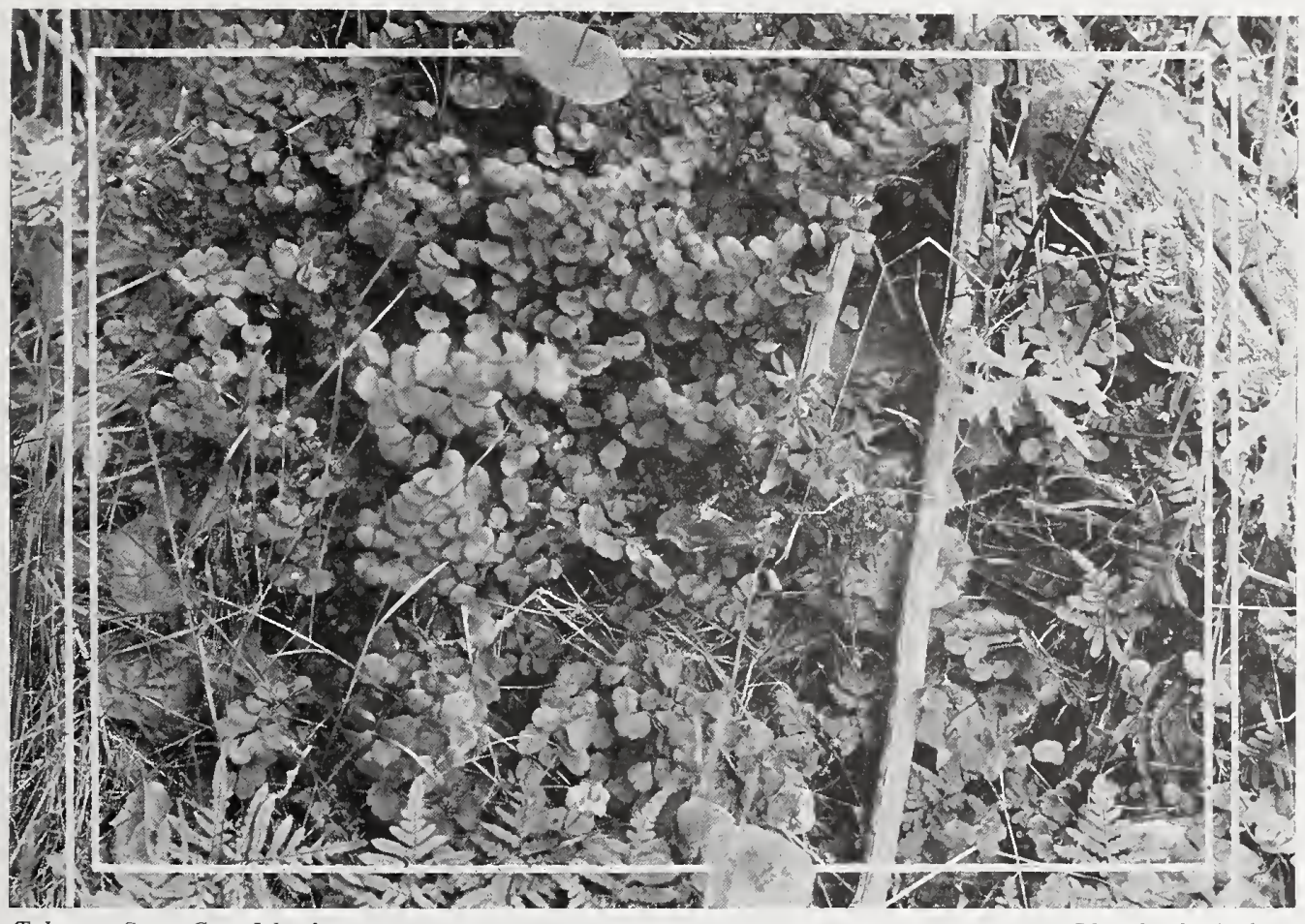

Taken on Santa Cruz Island

A NESTING SITE OF THE DUSKY WARBLER

Photo by the Author

THERE IS A NEST WITH FOUR EGGS SOMEWHERE ON THE GROUND BEFORE YOU, BUT NOT EVEN THE PHOTOGRAPHER REMEMBERS THE EXACT LOCATION

a sharp "chip" breaks out, and by this token alone can you follow the earlier movements of excited revolutions in the treetops. Presently, the bird, long cramped on the nest, bethinks herself of her toilet, pauses to stretch and preen and ruffle, never omitting dutiful chips the while. Then, if you are well "frozen" and not by accident too near the nest, the bird begins a slow and, to you, a very painful return. A crackling twig, a waving hand, a suspicion even, sends her off to begin all over again. Maddening pauses ensue. Will the creature never move? Yes; a little nearer, a little lower. Presently you suspect the particular bush she has her eye upon. Long she hesitates to pass from tree to bush. 


\section{The Orange-crowned Warblers}

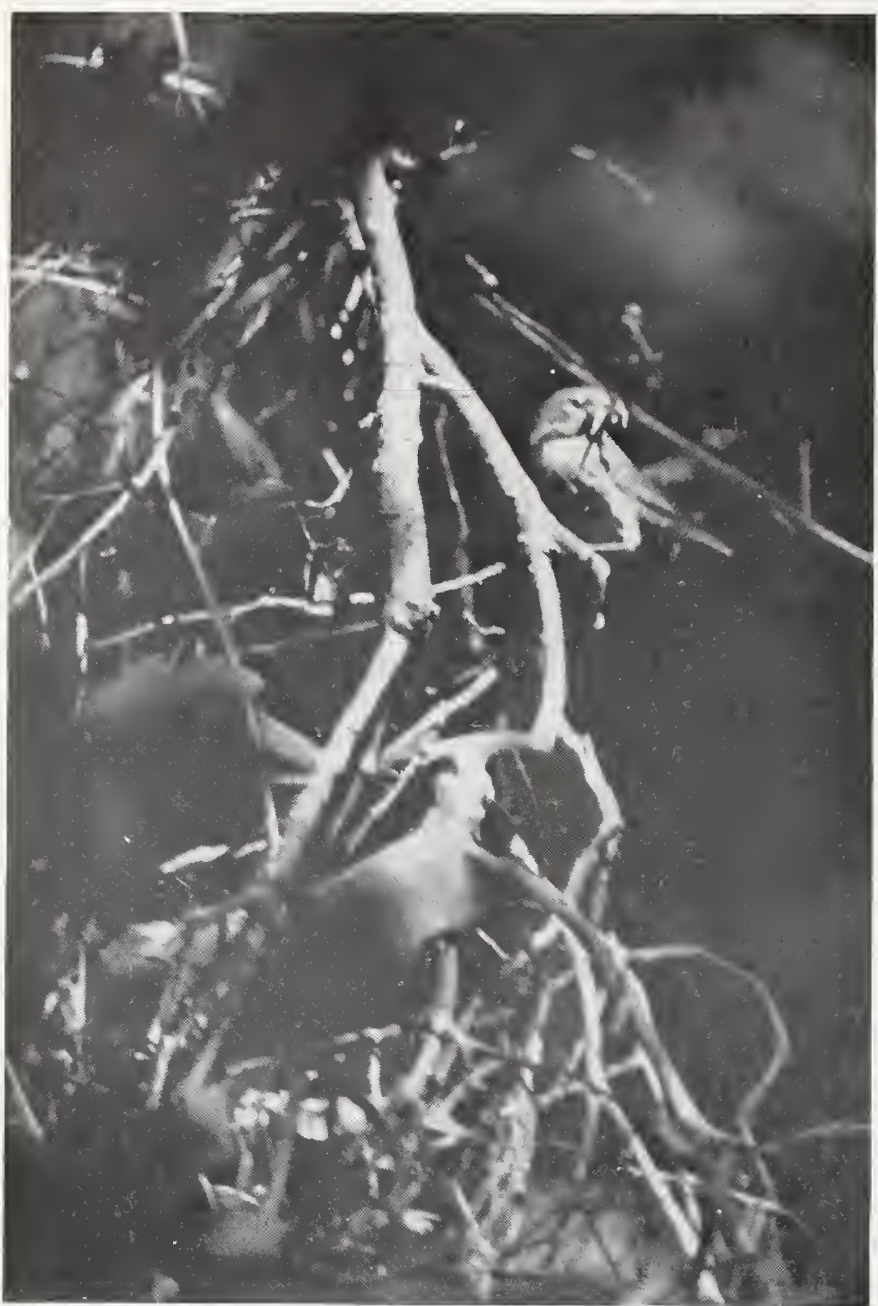

Taken on Santa Cruz Island
Photo by the Author

A WAYSIDE STATION

Half a dozen times she feints, maybe. Finally the fatal plunge is taken. Down, down the bush she crawls, reluctant. Then, level with the grass-tops, she darts to a spot on the ground-and there is silence. But keep your eye on that particular spot, or you will scarcely note the flit of exit, once you are in motion. The whole game has been a mutual agony of apprehension; and whether your heart goes pit-a-pat or not when the authentic location is made, depends upon your "sporting blood." The owner of the nest here shown feinted five times after reaching the bush, and though her exit was marked, the nest itself was absolutely invisible at a foot's remove, by reason of investing foliage.

The reason of our comparative failure in the spring of I9I5 to find nests of the Dusky Warbler, was revealed several seasons later by Mr. M. C. Badger, of Santa Paula, who reported that he had found them nesting in trees. With this friendly tip, succeeding expeditions sent out by the Museum of Comparative Oölogy have been more successful. The Dusky Warbler, evidently to escape the persecutions alike of sheep and of foxes, have taken to nesting in the live oak trees almost exclusively, and very wonderful nests they make, too, especially those which are nearly buried in oak blossoms.

For some reason the Dusky Warbler tires of island life and brings her brood to the mainland shores in late July or early August, there to remain until the following February or March. We do not know the precise extent of this winter range, nor do we know the precise length of 
the island stay (some birds stay there all the time). I venture the guess that some Dusky Warblers, which have been successful with the early nesting, come ashore as early as late April (we have found nests with young on Santa Cruz as early as April 6th). What becomes of these early, dark rémigrés we do not know, for undoubtedly the only breeders of the Santa Barbara mainland are of the lutescens type.

The winter residence of this species is probably quite as definitely localized as is that of the breeding season. I have watched birds month after month at Los Colibris which I felt reasonably sure must be the same. This is shaky "science," but the author offers no apologies for the lack of shot-gun testimony. One may take toll of the migrant hosts on occasion - some are bound to fall by the wayside anyhow - and there will be no vacancies to reproach us; but resident birds become in so far forth personalized, that we hesitate to disarrange the established order of things. The shot-gun is all too rude a questioner. The bird himself could tell us if we would only learn his language.

No. 80

\section{Calaveras Warbler}

A. O. U. No. 645a. Vermivora ruficapilla gutturalis (Ridgway).

Description.-Adult male: Head above and on sides, broadly, neutral gray; a broad crown-patch of chestnut veiled anteriorly by gray tips of feathers; eye-ring white; remaining upperparts warbler green, clearing and brightening on rump and upper tail-coverts; abdomen narrowly white; remaining underparts bright yellow (lemon-chrome). Bill and feet horn-color. Adult female: Like male, but somewhat duller; gray of head less pure, glossed with olivaceous; chestnut of crown reduced or wanting; flanks and thighs tinged with buffy (sordid chamois). Immature: Like adults, but without crown-patch; head and neck on sides deep grayish olive, shading on back into warbler green, and on sides into olive ochraceous and sordid buff; yellow of underparts clearing on breast and crissum, elsewhere shading into buffy and ochraceous. Av. of Io males in Museum of Vertebrate Zoölogy: length (skins) I09.4 (4.3I); wing 59.4 (2.34); tail 57.8 (2.275); bill 10.8 (.425); tarsus I7.I (.67). Females average smaller.

Recognition Marks.--Smaller; bright yellow of throat (and underparts) contrasting with gray of head distinctive.

Nesting. - Nest: Usually sunk well into ground or moss at base of bushclump or rank herbage; well made of fine bark-strips and grasses, lined with finer grasses, horsehair and, occasionally, feathers; outside, 3 in. wide by $2 \mathrm{in}$. deep; inside I3/4 wide by $1 / 2$ deep. Eggs: 3 to 5 , usually 4 ; dull white as to ground color, but showing two distinct ty pes of markings: one heavily sprinkled with fine dots of reddish brown, nearly uniform in distribution, or gathered more thickly about larger end; the other sparingly dotted, and with large blotches or "flowers" of the same pigment. Av. size $16.3 \times 12.5(.64 \times 49)$. Season: May $20-J u l y 20$, according to altitude; two broods. 


\section{The Calaveras Warbler}

Range of Vermivora ruficapilla.-- North America, breeding north to the Great Slave Lake, wintering south to Guatemala.

Range of $V . r$ gutturalis.-Pacific Coast region, breeding in Transition zone from southern British Columbia and Idaho south to central California, wintering south to Cape San Lucas and Mexico, and occurring eastward during migrations to southeastern Texas.

Range in California.-Common summer resident in Transition zone from the Greenhorn Mountains in Kern County (Grinnell), north on the west slopes of the Sierras to Shasta, in the Warner Mountains and in the coastal ranges south at least to Mt. Sanhedrin. Also common migrant interiorly, and coastwise west at least to Santa Barbara.

Authorities.-Baird (Helminthophaga ruficapilla), Rep. Pac. R. R. Surv., ix., I 858, p. 923 (Ft. Tejon); Osgood, Nidologist, vol. iii., I 896, p. I 40 (Sierra Nevada; nest and eggs); Barlow, Condor, vol. iii., I901, p. 175, fig. (Sierra Nevada; occurrence, habits, nest and eggs); McAtee, Auk, vol. xxx., I9I3, p. I55 (Angeles Nat. Forest; killed by poison placed in sapsucker holes).

THERE is something distinct and well-bred about this demure exquisite, and the day which discovers one of them searching the willow tops, with genteel aloofness, is sure to be underscored in the note-book. The marks of the spring male are as unmistakable as they are regal; a bright yellow breast and throat contrasting with the ashy of cheeks and head, the latter shade relieved by a white eye-ring, and surmounted by a chestnut crown-patch. If you stumble upon a company of them at play among the thorn bushes, you are seized as likely as not with a sense of low birth, and feel like retiring in confusion lest you offend royalty.

These gentle despots are bound for the mountains, and since their realms are not prepared for them till late May or early June, they have ample leisure to discuss the fare of wayside stations. Entering the State from the southeast about the middle of March, the early migrants probably follow the Colorado River, or else tarry for a few days in its friendly woods, before setting out across the desert, whether for the Santa Rosa and San Bernardino Mountains or for the Sierra foothills. The main migratory stream in its northward progress keeps to the Sierras, insomuch that records from the coast ranges are rare. In the great wave which inundated the Santa Barbara coast, however, in the spring of I9I2, Calaveras Warblers were a constant element; and I have a specimen taken on the Santa Ynez Range, April 29th, I9I3.

As the season advances the Calaveras Warblers take up quarters on brushy mountain sides, or in the deciduous skirts of fierce mountain torrents. Here, while the female skurries about through the buck brush or "mountain misery" in search of a suitable nesting site, the male mounts a pine tree and occupies himself with song. If you are spying on this sacred function, the bird first peers down at you uneasily, then throws 


\section{The Calaveras Warbler}

his head back and sings with great animation: choopy, choopy, choopy, churr (tr). The trill is composed of a dozen or so of large notes which the ear can easily distinguish, but which, because of the vivacious utterance, one cannot quite count. The song has something of the sharp, wiry quality of the Yellow Warbler's. A male heard at Kanawyers was actually confusing by reason of the quality; tsewick, tsewick, tsewick, tse, tse, tse, or $i t^{\prime}$ sick, $i t^{\prime}$ sick, $i t^{\prime}$ sick, it'se keee. This bird moved about restlessly in a tall fir tree as he sang, and he had to deliver himself of this message, or challenge, or declaration of love, once every twenty seconds.

While the female is sitting upon a neatly turned nest, sunk flush with the ground at the base of some small sapling or bush clump, the

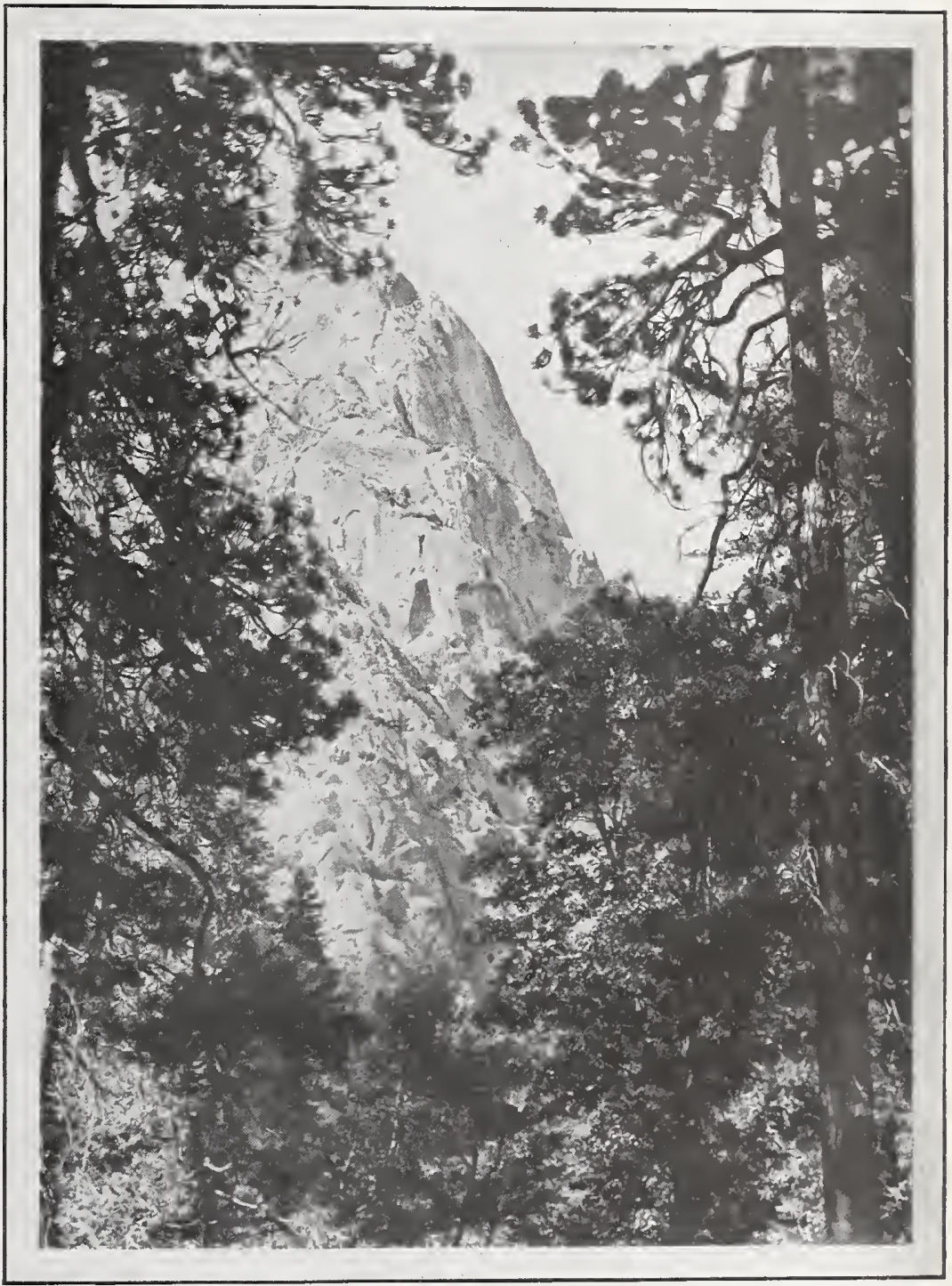

Taken in Fresno County

ARE BIRDS AWARE?

male takes good care not to be seen in the immediate neighborhood. His voice is so penetrating that it may distill a sufficient consolation for the brooding mate from any one of a dozen stations a hundred yards away. The finding of a nest, therefore, is a matter of accident rather than attention; or, if you insist upon inspecting the whole hillside on hands and knees, you must be prepared to count a nest of the Calaveras Warbler's close associates, the Tolmie Warbler, the Spurred Towhee, or the Sierra Junco, a sufficient reward. 


\section{The Calaveras Warbler}

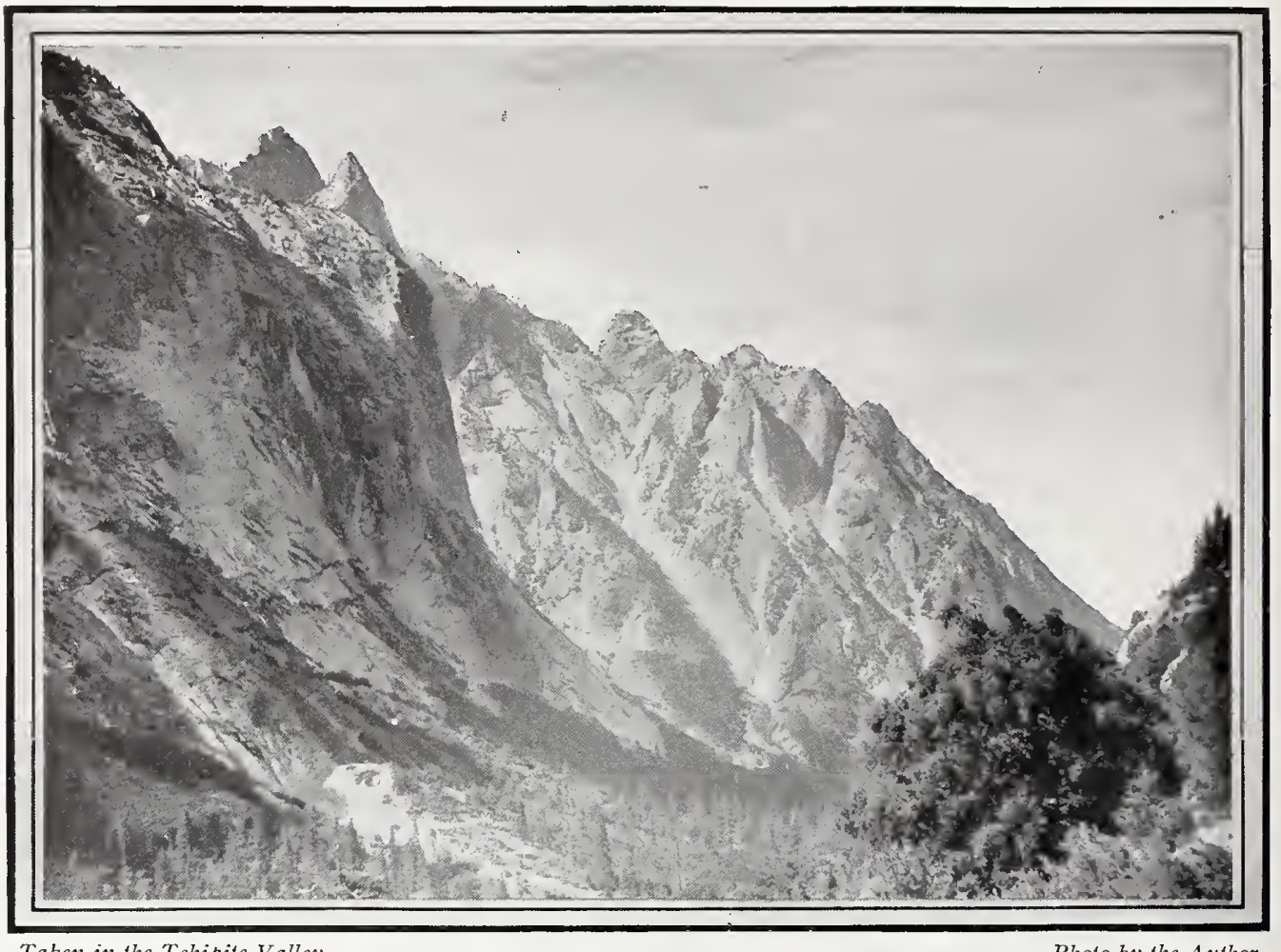

A SUMMER HOME OF THE CALAVERAS WARBLER

The female Calaveras sits very tight, but when once dislodged she instantly disappears; and she returns, if at all, only after the lapse of a tedious interval. Even then she approaches with the greatest caution, ready to dart away again at the first movement of the intruder. In this connection, according to Mr. Bowles, the male has a very curious and amusing habit. If he sees his mate after she leaves the nest, instead of joining her and consoling her in her misfortune, he promptly gives chase in the most furious fashion, driving her from bush to bush as though she had wilfully deserted their treasures.

As near as we can determine the Calaveras IVarbler nests but once in a season in California. Five eggs make the usual set complement, and deposition occurs from May 20 to June 20 , according to altitude. Ceanothus cordulatus, snow-bush, is a favorite cover, according to Mr. Chester Barlow, in the middle Sierras; and $C$. velutinus further north. A favorite lining is soap-root fiber wherever this is obtainable, but dried grasses, horsehair, and feathers are welcome elsewhere. Nests are still rare in collections, and are likely to remain so while California chaparral offers such ample asylum to the birds.

\section{4}


The Lucy Warbler

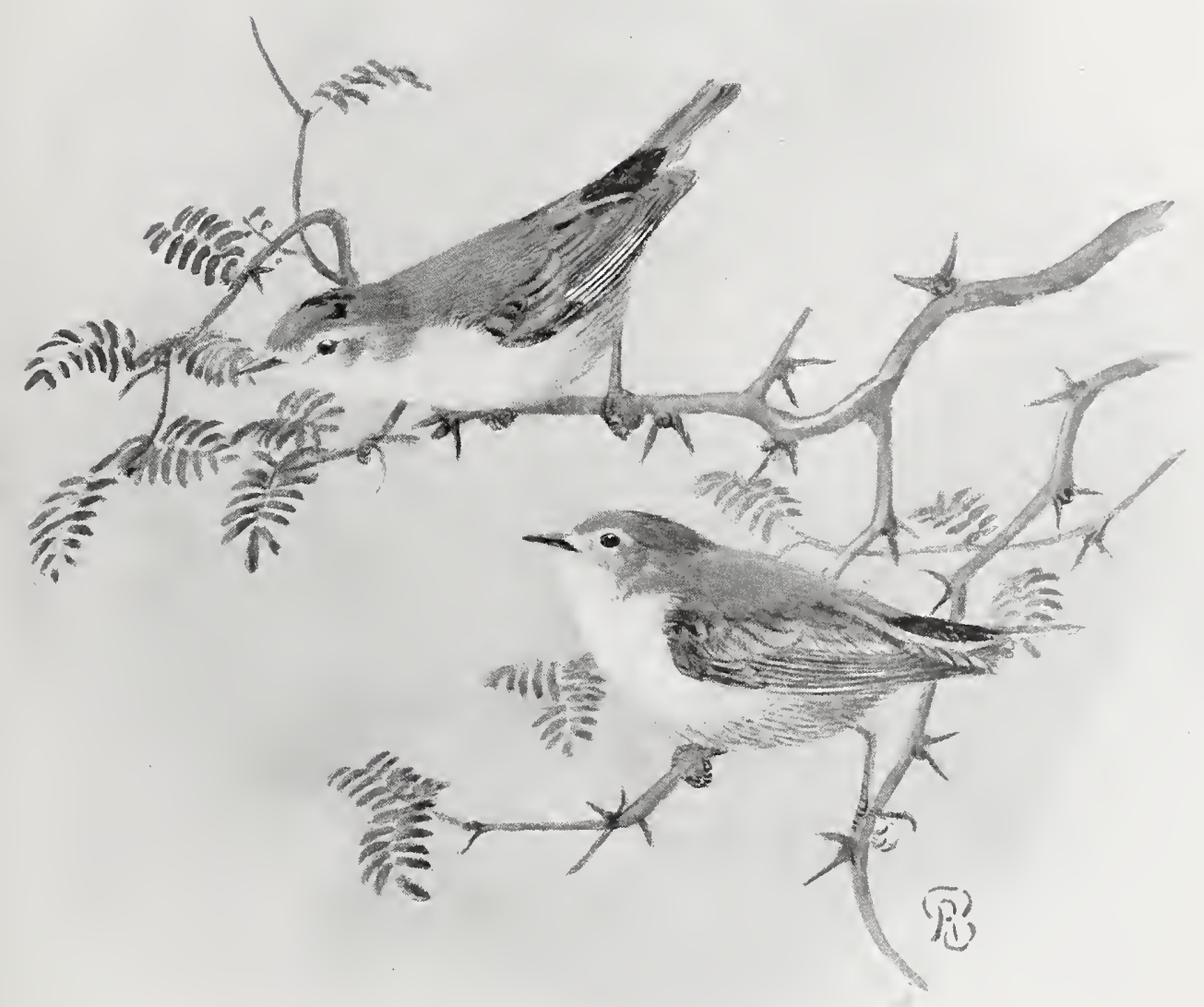

LUCY WARBLERS

No. 81

\section{Lucy's Warbler}

A. O. U. No. 643. Vermivora luciæ (J. G. Cooper).

Description.-Adult male in spring and summer: Crown and upper tailcoverts chestnut, that of crown often more or less concealed by gray tips; remaining upperparts light neutral gray, shading on sides into dull white of underparts; lower 


\section{The Lucy Warbler}

cheeks, lores, and a short superciliary, white. Bill and feet dark horn-color. Adult male in fall and winter: Like male in spring, but upperparts overcast with brownish, and underparts, save on belly, overcast with brownish buff; the chestnut of crownpatch nearly concealed by broad tips of brownish gray feathers. Adult female: Like male but chestnut of crown reduced in area, and more or less concealed by gray tips of feathers. Young, first plumage: Like adults, but of a clearer white below; chestnut of crown lacking, that of upper tail-coverts changed to buffy ochraceous, middle and greater wing-coverts tipped with buffy, forming two noticeable bars. Av. of io males in M. V.Z. colls: Length (skins) I03.4 (4.07); wing 56.6 (2.23); tail 4I.8 (1.646); bill 8.5 (.33); tarsus I6. I (.63). Females a little smaller.

Recognition Marks.-Smallest warbler size; gray coloration with chestnut patches distinctive.

Nesting.- Nest: An unpretentious cup of fine grass, lined or not with horsehair, or, more rarely, with cowhair; placed at moderate heights in crevices or holes, or behind bark-scale of mesquite trees. Eggs: 4 or 5, 6 of record; white, sharply and sparingly speckled, chiefly about the larger end, or else wreathed with chestnut and violet-gray. Av. size I $5.24 \times 12.2(.60 \times .48)$. Season: Colorado River, April; Tucson, May; one brood.

General Range.-Southwestern United States and Mexico. Breeds in Lower Sonoran zone in southeastern California, extreme southwestern Utah, and Arizona; winters in western Mexico south to Jalisco.

Range in California.--Breeds in the mesquite belt of the Colorado River, and occurs sparingly upon the Colorado Desert: Chemehuevis Valley, March io, I9I0, by Joseph Grinnell; Mecca, March 29, I9I I, by A. van Rossem.

Authorities.- van Rossem, Condor, vol. xiii., I9I I, p. I37 (Mecca); Brewster, Bull. Nutt. Orn. Club, vol. vii., I 882, p. 82 (Ariz.; habits, desc. young, nest and eggs, etc.); Gilman, Condor, vol. xi., I909, p. I66 (Ariz.; nesting habits); Grinnell, Univ. Calif. Pub. Zool., vol. xii., I9I4, p. I9I (Colo. Valley).

IT IS NOT surprising that some of the ornithological fathers should have overlooked this elusive and obscurely colored species. The bird, nevertheless, abounds in those sharply limited areas of California which support mesquite trees (Prosopis juliflora glandulosa) of a sufficient size. Our own Dr. Cooper discovered and described the species from a bird taken at Fort Mojave in the spring of I $86 \mathrm{I}$; and as he described it he made graceful dedication forthwith to Miss Lucy Baird, whose father, Spencer F. Baird, Secretary of the Smithsonian Institution, had shown such conspicuous interest in western ornithology. But Fort Mojave was on the Arizona side of the Colorado River. This left the occurrence of the species in California in a presumptive state; and its status was never fully established until Grinnell,1 reporting in I9I 4 upon the expedition sent out by the Museum of Vertebrate Zoology in I9IO, declared it to be of common occurrence, and breeding along the California side of the Colorado River. Yet to a more recent observer, Mr. Adriaan van

1"An Account of the Mammals and Birds of the Lower Colorado Valley," by Joseph Grinnell, p. I9I fg. Published March 20, 1914. 
Rossem, fell the honor of first published record, for he took a specimen, a female, at Mecca on the 29th of March, I9I I, and reported in the Condor for July of the same year. According to Grinnell's recent Distributional List, 1 Frank Stephens took an adult male Lucy Warbler at Silsby in the Imperial Valley on the 8th of April, I909. This was probably the first specimen ever taken in California, for the Stephens MS before me (doubtless written just previous to the above record) says, "I do not know of any actual captures of this species in California."

Having settled the "honor to whom honors," it is time to admit that the joke is on us, and that the Lucy Warbler, who was undoubtedly here all the time, has for years been laughing quietly at our expense. The long-established presence of the Warbler is at least as certain as that of the mesquite tree. Gilman is right in saying that this bird ought to have been called the Mesquite Warbler, for rarely has a bird become so devoted to a single association. That the relation between tree and bird is an ancient one is evidenced by the gray tone of the bird's plumage, which assimilates so remarkably with the feathery, sky-mixed glaucous of the mesquite leaves. Albeit an active creature and zealous in song, the Lucy Warbler becomes almost invisible in its habitual setting, and the difficulty of detection is heightened by the bird's instinctive wariness. Again and again I have known a bird which had seemed quite engrossed in song to fall silent at the stir of a footstep a hundred yards away.

The Lucy Warbler is a loud and industrious singer, but the song has a curious generic quality very difficult to describe. It is Warbler song, rather than the song of the Lucy Warbler. It is, perhaps, most like that of the Pileolated Warbler (Wilsonia pileolata) in quality. After that, it reminds one of the Yellow Warbler's song, having the same viva-

1"A Distributional List of the Birds of California," p. I45. Published Oct. 21, I9I5.

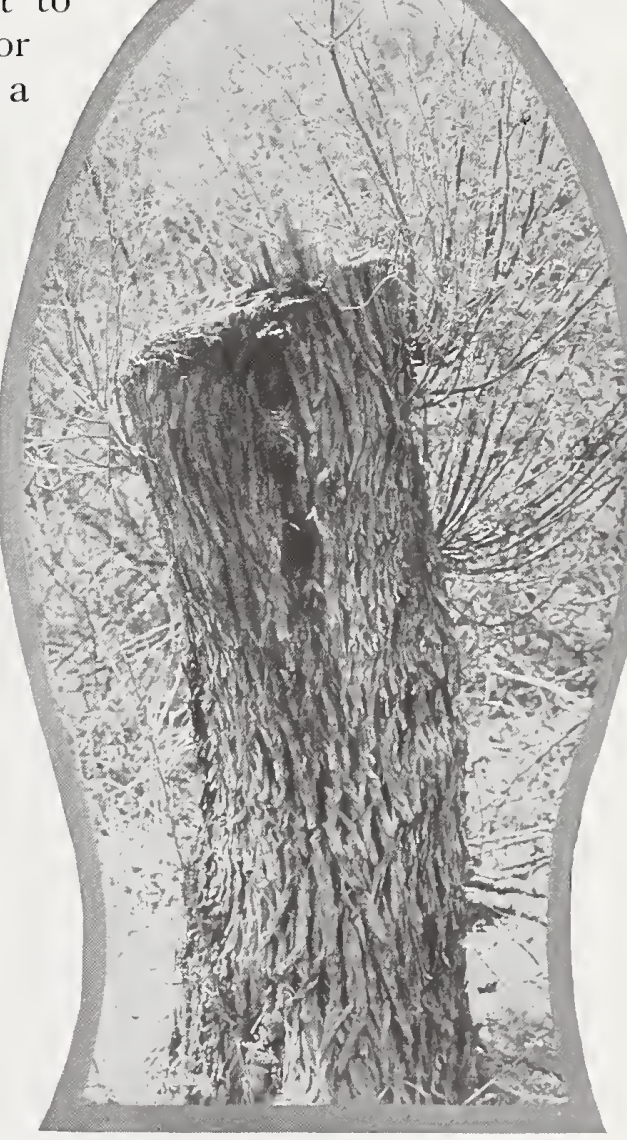

Taken in Arizona

Photo by the Author A NESTING SITE OF THE LUCY WARBLER A NEST IS SUNK INTO A RECESS NEAR THE TOP OF THIS STUMP 


\section{The Lucy Warbler}

cious cadence, but not being so sharply piercing. Again its breathless, haphazard quality suggests one of the Buntings; and I once followed its tantalizing seductions for half an hour under the delusion that I was on the track of the coveted Beautiful Bunting (Passerina versicolor pulchra).

The Lucy Warbler has also an emphatic, vibrant chup note,-an alarm which one hears a hundred times, to once that he catches sight of the gray wood sprite himself.

These birds take mighty good care not to be caught on or near their nests; and in an experience of some forty nestings, I do not remember to have flushed a parent bird above twice. Even after the nest is discovered, rifled even, the wary midgets seldom venture nearer than a neighboring tree, and then they are content to voice their displeasure in futile chups at long range.

The reason for the bird's attachment to mesquite becomes evident at nesting time. The wounded or rent trunk and the shaggy bark of this tree offer abundant hidey holes from which the warbler may select a nesting site. Back of a sprung bark scale, or deep in some cranny, and at heights varying from 18 inches to 25 feet, the warbler hides a dainty cup fabricated of bark-shreds, frayed weed-stems, seed-pods, and fine dried grasses. The lining is of macerated bark-pulp, cow-hair, or feathers; and the birds are so careful to secrete their treasure that only rarely does a telltale bit of grass protrude. Unoccupied holes of the Cactus Woodpecker make acceptable sites if shallow enough; and old Verdin nests, especially the smaller "cock nests," are often made use of for the protection they afford. Once our party found a set of the Lucy Warbler eggs accompanied by one of the Dwarf Cowbird, in a re-lined nest of the House Finch. Dwarf Cowbirds are prominent in the formidable host of enemies which this tiny bird must face. Sometimes the warblers are able to entrench themselves behind apertures so narrow that the Cowbird cannot get in; and once we saw the Cowbird's foundling resting unharmed, but also harmless, upon the "doorstep," not less than two inches distant from the warbler's eggs. Another nest, more exposed, contained three eggs of the arch enemy, and had been deserted by the troubled owners. The Gila Woodpecker is an especially persistent enemy. Accustomed as he is to poking and prying, he seems to take a fiendish delight in discovering and devouring as many Lucy Warblers' eggs as possible. We caught several of these villains red-handed, and we found reason to believe that more than half of the nests in a certain section had been wrecked by them. Add to these the depredations of lizards, snakes, and, possibly, rats, and the wonder is that these tiny gray waifs are able to reproduce at all.

While much of the history of the Lucy Warbler is still shrouded in

$$
458
$$




\section{The Virginia Warbler}

mystery, and much of its range remains to be worked out, we feel sure from the Mecca record that the species once occupied in numbers the mesquite forest of Coachella Valley, whose pathetic bones now bleach on the salty borders of the Salton Sea. For the rest, it is narrowly confined to the banks of the Colorado River, and as the mesquite is much sought after for fire-wood, the bird may at no distant date disappear from our borders altogether.

No. 82

\section{Virginia's Warbler}

\section{A. O. U. No. 644. Vermivora virginiæ (Baird).}

Description.-Adult male in spring and summer: Crown-patch chestnut, largely and irregularly, sometimes almost totally, concealed by gray feather tips; rump and upper tail-coverts yellow (lemon-chrome); remaining upperparts and sides of head and neck and chest neutral gray; chest and under tail-coverts clear yellow (lemon-chrome), the color vaguely continued mesially on throat, or else glossed lightly over entire throat, or else wanting; belly and sides dull ochraceous buffy, shading on breast centrally to buffy white; eye-ring white. Bill blackish above, lighter below; feet and tarsi brownish black. Adult male in fall and winter: Like spring male but duller; the chestnut of crown entirely concealed by broad gray tips; the yellow of chest duller; the upperparts washed with brownish. Adult female: Like male, but duller; chestnut of crown restricted and usually entirely concealed; the yellow of chest more restricted; and the underparts grayer, less brownish. Young, first plumage: Like adults, but median and greater wing-coverts tipped with dull buffy, forming two bars; underparts chiefly pale brownish gray, whitening centrally on breast and belly; no yellow on chest. Av. of 9 males in the collections of H. S. Swarth: Length (skins) I I I.I (4.38); wing 62.I (2.45); tail 47.7 (1.88); bill Io (39.4); tarsus I 7.7 (.70).

Recognition Marks.-Gray upperparts distinguish from all but $V$. lucia. Yellow areas of chest and tail-coverts distinguish from $V$. lucia, which in many other respects it closely resembles.

Nesting.-Breeding in California presumptive, but not of record. Nest: A slight structure, composed of fine dried grasses or occasionally moss; placed on ground, of ten a hillside, sunk flush, and nestled under cover of grass, weeds, or bush. Eggs: 4 or 5; white, finely sprinkled, chiefly at the larger end, with vinaceous brown. Av. of 9 eggs in M. C. O. coll., I 5.I x I I.6 (.59x.46). Season: May, June; one brood.

General Range.-Southern Rocky Mountain region, west to eastern California. Breeds in timbered areas of Transition zone from Nevada, Utah, and northern Colorado, south to southern Arizona (Huachuca Mountains-2 sets in M. C. O. Coll.); winters in Mexico south to Latitude I 8 north.

Range in California.-Transition areas of the White Mountains. Based on a single specimen, a juvenal taken by Halsted G. White, on Cottonwood Creek, east flank of White Mountains, in Mono County, August I, I9I 7 .

Authorities.-Grinnell, Condor, vol. xx., 1918, p. 193 (White Mts.); Swarth, Pac. Coast Avifauna, no. 4, I904, p. 50 (Ariz.; habits, migr., desc. nest, molt, etc.). 


\section{The Yellow Warblers}

THE TAKING of a juvenal example of the Virginia Warbler by Mr. Halsted G. White, of the staff of the Museum of Vertebrate Zoology, while at work in the White Mountains, justifies the pleasant presumption that this shy and dainty species may be found as a regular breeder upon our timbered desert ranges.

Virginia resembles "Lucy" ( V. lucia) so closely that one suspects the change of color on the rump and the added touch of yellow on the breast to be mere devices, like different colored hair ribbon, whereby Mother Nature may herself distinguish her twin daughters. Virginice is a bird of the mountains, never allowing herself to be seen, according to Howard, 1 below the 5000 foot level. Here she haunts the thickets of ceanothus and cercocarpus, or else the underbrush among the pines. The slightest suspicion of danger causes the little sprite to dash into the brush, whence issues thereafter only a shifting and elusive, though perfectly characteristic, chip. The male Virginia (we ought, perhaps, to call him Virginius) is indefatigable in song. He sings at his work, which, of course, is bug-catching. And when his appetite is satisfied, he mounts a neighboring treetop and makes a business of entertaining his lady love. The song is highly variable, but resembles more or less that of the Lucy Warbler, common forms being, according to Minot: Ché-we-ché-we-ché-we-ché-we, wit-a-wit'-wit'-wit', and che-wé-che-wé, ché-aché-a-ché.

The nest is placed upon the ground, among the pine needles or in the shelter of nodding grasses, so cleverly concealed at times that search must be made on hands and knees, even when the location is known within a foot or so. The greatest circumspection is observed by the birds, both in approaching and in leaving their nests; for where the eyes of humans are dull, the eyes of snakes are glittering sharp, and the eyes of jays are backed by a cunning which is almost second sight.

\section{No. 83}

\section{Yellow Warbler}

No. 83a Sonora Yellow Warbler

A. O. U. No. 652a. Dendroica æstiva sonorana Brewster.

Description.-Adult male: Similar to that of $D$. a. brewsteri, but brighter, clearer yellow (less olivaceous) above; the forehead more strongly or extensively tinged with mars yellow; the upper back obscurely streaked with chestnut or dull chestnut; the chestnut streaking of underparts much reduced, the streaks narrower or obsolete.

1Bull. Cooper Orn. Club (Condor), Vol. I., July 1899, pp. 63, 64. 
Adult female: Similar to that of $D$. a. brewsteri, but slightly paler. Both sexes slightly larger than in $D$. a. brewsteri.

Nesting.-See under D. a. brewsteri.

Range of Dendroica astiva.- North and South America. Breeds from northern Mexico north to limit of trees; winters from Mexico to Brazil and Peru.

Range of $D$. a. sonorana.-Breeds in Lower Sonoran (or Lower Austral) zone of the southwestern states from western Texas to southeastern California, and in northern Mexico (Sonora, Chihuahua); south in winter through Mexico to Nicaragua.

Occurrence in California.-Abundant summer resident in the Colorado River Valley; probably also the Imperial Valley and Colorado Desert.

Authorities.-Grinnell, Univ. Calif. Pub. Zool., vol. xii., r9r4, p. I95 (Colo. Valley; occurrence, desc., meas., etc.); ibid., Pac. Coast Avifauna, no. I I, r9 I5, p. I46 (status in Calif.); Howard, Bull. Cooper Orn. Club, vol. i., I 899, p. 39 (desc. nests; Ariz.).

\section{No. 83b California Yellow Warbler}

A. O. U. No. 652c. Dendroica astiva brewsteri Grinnell.

Description.-Adult male: General color of upperparts yellow with an olivegreenish cast (between pyrite yellow and warbler green); clearing and brightening on forehead, where feathers sometimes touched mesially with orange (mars yellow); flightfeathers fuscous with yellow edgings on outer webs; rectrices fuscous centrally on exposed upper surfaces, with yellow edgings on outer webs; inner webs almost entirely clear yellow; underparts (shading on sides of head and neck) clear bright yellow (lemonchrome), streaked sharply across chest, on sides of breast, and sides, with chestnut. Bill blackish with pale tomia; feet and legs pale brownish. Adult female: Similar to male, but more uniform in color and slightly duller; clear pale yellow below without chestnut; sometimes slightly paler above (not darker as in D. a. aestiva). Young (nestling): Chiefly brownish gray above; below brownish gray on chest and sides; whitish on belly, broadly; lining of wings, inner webs of tail-feathers, and edgings of quills and tail-feathers, yellow; middle and greater wing-coverts tipped with buffy. Av. of Io adult males in the Museum of Vertebrate Zoölogy: Length (skins) I I 5 (4.53); wing 6I.5 (2.42); tail 49.5 (1.95); bill $9.6(.38)$; tarsus $18.6(.73)$.

Recognition Marks.-Medium size; golden yellow coloration; chestnut streaks on breast of male distinctive. The best distributed of the breeding warblers, but found chiefly in deciduous timber near water.

Nesting.- Nest: A compact cup of woven "hemp" (gray weed-bark), and fine grasses; lined heavily with plant-down, grasses, and, occasionally, horsehair; fastened to upright branches of willow or other tree or bush. Eggs: 4 or 5; white, bluish-, greenish-, grayish-, or, rarely, creamy-white, speckled or marked with largish spots of dark brown (clove-brown to buffy brown), reddish brown (mikado brown to bister), and vinaceous gray, or rarely, black. Av. of 22 California-taken specimens in the M. C. O. colls., I6.5 x I $2.2(.65 \times .48)$. Season: May I 5 to June I 5 ; one brood.

Range of $D$. a. brewsteri.-Summer resident and migrant in the Pacific Coast states, but perhaps typical only west of the Sierra-Cascades. Winter range undefined.

Distribution in California.-Breeds in riparian associations of Upper Sonoran and Transition zones, practically throughout the State. Common migrant everywhere. Relations to $D$. a. astiva upon the east not exactly definable, but breeding birds from the region east of the Sierras appear to belong to this race. Curiously absent, even during migrations, from the Santa Barbara Islands. 


\section{The Yellow Warblers}

Authorities.-Heermann (Sylvicola estiva), Jour. Acad. Nat. Sci. Phila., ser. 2, ii., I 853, p. 262 (Calif.); Grinnell, Condor, vol. v., I903, p. 7 I (orig. desc.; type from Palo Alto); Beal, U. S. Dept. Agric., Biol. Surv. Bull., no. 30, 1907, p. 47 (food); Ingersoll, Condor, vol.xv., I9I3, p. 84 (destruction of nests and eggs); Tyler, Pac. Coast Avifauna, no. 9, 1913, p. 99 (Fresno; habits; nests and eggs).

\section{No. 83c Alaska Yellow Warbler}

A. O. U. No. 652b. Dendroica æstiva rubiginosa (Pallas).

Description.--Similar to D. a. brewsteri, but slightly larger and somewhat darker, more olivaceous above; yellow of forehead less clear.

Nesting.-Much as in preceding race. Does not breed in California.

Range of D. a. rubiginosa.-Breeds in the northwest coast district of North America, broadly defined, from Alaska (entire) south to Vancouver Island.

Occurrence in California.-Common late spring (May) and autumnal migrant, practically throughout the State, but probably more abundant west of the Sierras.

Authorities.-Oberholser, Auk, vol. xiv., I 897, p. 76 (syn.; desc.; crit.; Mountain Spring, San Diego Co.); Grinnell, Pac. Coast Avifauna, no. I I, 1915, p. 147 (status in Calif.); Swarth, Univ. Calif. Pub. Zool., vol. xxiv., 1922, p. 287, in text (desc., distr.).

TAKE a willow catkin bursting with powdered gold and nestling against a cluster of its own vivid leaves, and you will have the model after which the Yellow Warbler was painted. The bird was made for the tree-perhaps in a sense he was made by it-and this associational bond is a very strong one. Roughly speaking, the Summer Warbler breeds wherever willows are found, and this means that his summer home in California is nearly confined to the Upper Sonoran faunal zone and to the vicinity of water, whether running or stagnant. Transition tongues of alder and cottonwoods, mingled with willow, sometimes tempt the birds into the upper reaches of some mountain valley, but here more than ever he is dependent upon water.

The original Warbler, we guess, was yellow. At least the color predominates throughout the group, and this warbler, yellow in excelsis, is at once the most widely distributed and most abundant of the Mniotiltida. Ignoring for the nonce the trifling subspecific variationswhich variations, of course, testify to the long-established dominance of the species-we find Yellow Warblers breeding from ocean to ocean, and from Sonora in Mexico to the limit of trees in Alaska. In well settled districts, moreover, the bird no longer depends upon the exclusive shelter of willows, but frequents wayside thickets and swarms through orchards and gardens, and in town takes possession of shrubbery in lawn or park. Thus, it is demonstrating its fitness to survive, while it is forcing upon public attention consideration of at least one species of that vast host of Wood Warblers whose variety and charm are known only to the initiated. 


\section{The Yellow Warblers}

And that bovine object, the public, when it does condescend to notice anything so tiny as a Wood Warbler, dubs this bird a "Wild Canary"- and is done. Wild Canary, forsooth! Why, if I had my way, anyone who insulted one of these woodland exquisites by such an epithet should be sentenced to hard laborreading bird-books for thirty days, or else tethered solitary beside some brook whose mossy banks rang vocal with a hundred strains of woodland music-music such as never came from cagewired throats. The name as applied to one of our Goldfinches might be barely tolerated, for the Canary (Serinus canarius) is a Finch (Family Fringillida), but in the case of the Warbler, it is quite inappropriate, since the bird has nothing in common with the canary except littleness and yellowness. Its bill is longer and slimmer, for it feeds exclusively on insects, instead of seeds, and its pure yellow and olive-green plumage knows no admixture, save for the tasty but inconspicuous chestnut stripes on the breast of the adult male.

The Yellow Warbler, while frequenting wooded streams, is, nevertheless, a bird of sunshine. It does not keep to the depths of the larger trees, but hunts over the thickets and saplings, with occasional bold excursions to outlying rose briars or even to the sage. As it moves about, to thread some willow clump with sunshine- that we speak not of such prosaic matters as bug-catching-it pauses momentarily for song.

The song is sunny, too, and while not elaborate, makes substantial contribution to the good cheer of spring. Heard in the boskage it sounds absurdly as if some wag were shaking an Attic salt-cellar on a great green salad. The notes are almost piercing, and sound better, perhaps, 


\section{The Yellow Warblers}

from across the river than they do in the same tree. Individual variation in song is considerable, but the high pitch and vigor of delivery are distinctive. Certain common types may be syllabized as follows: Sweet, sweet, sweet, sweetie; tsee, tsee, tsit-a-wee, tsee; wee-chee, chee, chee wee-i-u; $t s u, t s u, t s u, t s u, t s e e e w . \quad F r o m$ its arrival some time in April, until near the close of its nesting season in July, the bird may be found singing throughout the sunlit hours.

The migrations of this bird in Californ: : have not been closely studied. April Ist at Los Angeies is our éc rliest record, but "some time in April" is as near as we dare to come to generalization. Nesters in Transition areas are doubtless detained at lower levels until May. Late April migrants are probably bound for Washington; $D$. a. rubiginosa may dawdle within our borders till early June, to the scandal of honest mothers of families. Occasionally, no doubt, typical eastern



Taken in Oregon

Photo by Finley \& Bohlman

A CONTENTED BABY

birds occur as stragglers, but the grounds of difference as between astiva and a. brewsteri are already so slight that you never could prove the occurrence of astiva.

The nest of the Yellow Warbler is found in suitable territory at any height, in alders, willows, apple trees, or even fir saplings, but without doubt the most acceptable site is that afforded by dense thickets of the wild rose (Rosa californica), wherever found. Unlike its habit in the northern and eastern portions of its range, Yellow Warblers appear to raise but one brood in a season in California. Dates for fresh eggs vary from May 5 th to June 26 th, but it goes without saying that later dates concern higher elevations, or else second trials. The cradle of this bird is of exquisite fabrication. The tough inner bark of certain weeds--called indiscriminately "hemp"- - together with grasses and other fibrous materials in various proportions, is woven into a compact cup around, or settled into,

$$
464
$$


some stout horizontal or ascending fork of bush or tree. As a result the bushes are full of Warblers' nests, two or more seasons old. A fleecy lining, or mat, of plantdown is a more or less conspicuous feature of every nest. Upon this as a background, a scanty horsehair lining may exhibit every one of its strands; or again, as in the case of a nest taken on the Chelan River (in Washington), the eggs themselves may be thrown into high relief by a coiled black mattress. In colder sections feathers are employed as an auxiliary lining. I have one taken at Goose Lake after a June snow-storm where white chicken f e a thers figure prominently.

The male Yellow is very domestic in his tastes, insomuch that, quite unlike other Warblers, he will often ven-

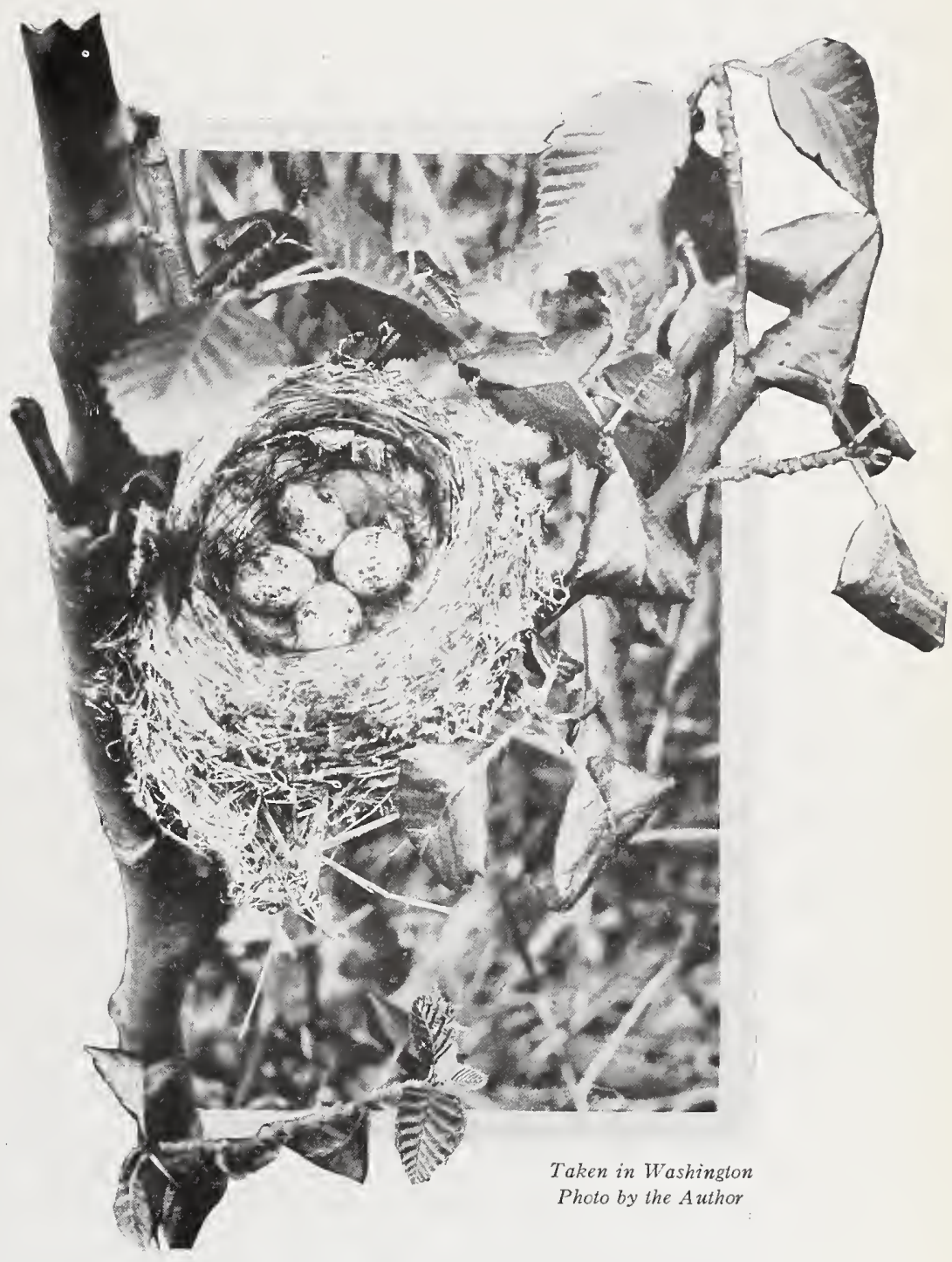

NEST AND EGGS OF CALIFORNIA YELLOW WARBLER ture to sing from the very bush in which his mate is sitting. Unless well accustomed to the presence of humans, the female will not sit patiently under the threat of close approach. She slips off quickly, and her vigorous complaints serve to summon her husband, when both flit about close to the intruder, and scold roundly in fierce, accusing notes, which yet have a baby lisp about them. 


\section{Magnolia Warbler}

\section{A. O. U. No. 657. Dendroica magnolia (Wilson).}

Description.-Adult male in breeding plumage: Crown and nape bluish gray (nearly clear Payne's gray); upper back and sides of cervix, continuous with broad facial band, involving eye and meeting fellow on forehead, black, faintly lustrous; a white superciliary half-stripe separating black and gray, and continuous with white upper eyelid; lower eyelid also white; rump yellow, shading as an overlay upon lower back; some yellow or olivaceous skirtings also on scapulars; upper tail-coverts abruptly black; quills and rectrices with narrow edgings of bluish gray; a large irregular blotch of white formed by tips of middle, with tips and outer edges of greater wing-coverts; tailfeathers, except middle pair, with square white blotches, involving middle third of inner webs; lining of wings and lower tail-coverts and middle of belly, narrowly, white; remaining underparts yellow (orange-chrome to pyrite yellow), clear on throat and upper abdomen, heavily and broadly streaked with black on jugulum, sides of breast, and sides, the streaks tending to become confluent in two or three large stripes on sides of breast, and to form a large black patch on chest. Bill blackish; feet dark brown. Adult male in autumn: Similar to spring male, but black of head almost entirely replaced by gray or olive-gray; supra-auricular stripe of white wanting; back washed with warbler green, and black persisting only as central spots on scapulars; wing-blotches reduced and divided by black so that two narrow white wing-bars appear; black striping of underparts much reduced and often wanting on chest. Adult female in spring: Like adult male but duller; back washed with warbler green; black of back present, if at all, as irruptive spots; black of face usually much reduced; white wing-blotch also reduced in area; yellow of underparts paler and duller, the black striping much reduced, or, rarely, wanting. Immature birds suffer still further reduction of black, which persists only as stripes on lower flanks and across abdomen; chest crossed by dull band of olive-gray. Length of adult males (skins): II3.6 (4.47); wing 60. I (2.37); tail 48.7 (1.92); bill $9(.36)$; tarsus I7.8 (70). Females slightly smaller.

Recognition Marks.-Small warbler size; below rich yellow, heavily streaked with black, distinctive in spring, save in comparison with $D$. townsendi, from which magnolia is further distinguished by its yellow throat (instead of black), blue-gray crown (instead of black), white line above and behind eye (in place of yellow), black back (instead of warbler green), and by its greater posterior extension of yellow below. Square white spots on central third of tail-feathers distinctive in any plumage.

Nesting.-Does not breed in California. Nest: Of twigs, grass, and rootlets; lined, or not, with hair; placed at any height in coniferous trees. Eggs: 3 to 5; white, spotted and blotched, often wreathed or capped with chocolate (cameo brown to blackish brown of the same hue) and vinaceous. Av. size, I6.5 $\times 12.2(.65 \times .48)$.

General Range.-Eastern North America. Breeds in Canadian and Upper Transition zones from southwestern Mackenzie, northern Quebec and Newfoundland, south to Alberta, northern Minnesota, Michigan, New York, and New England, and in the mountains south to Virginia. Winters from southern Mexico to Panama and rarely in the Antilles. In migrations west to the Rocky Mountains, and casually to the Pacific Coast.

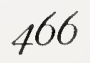




\section{The Magnolia Warbler}

Occurrence in California.-A straggler during migrations. Four records: Santa Barbara Island, May I5, I 897 (Grinnell); Los Angeles, Oct. 21, I 897 (H.S. Swarth); Los Angeles, Oct. 5, I90I (Swarth); two taken on the Farallon Islands, May 29 and June 2, I9II, by the author.

Authority.-Grinnell (Dendroica maculosa), Pasadena Acad. Sci. Pub., no. I, I 897 , p. 7 ; ibid., no. 2, I 898 , p. 45 ; Swarth, Condor, vol. iii., I90 I, p. I45; Dawson, Condor, vol, xiii., I9I I, p. I 82.

INASMUCH as there are four records of the appearance of this warbler in California, it may be reckoned casual, or even "rare migrant," rather than accidental; and we may hope to welcome it again. Indeed, all the evidence would go to show that there is every year a certain small percentage of eastern species which comes up or goes down the wrong side of the Rockies, in the attempt to pass to and from the breeding grounds in Alaska and Yukon Territory. These may be regarded either as wanderers blown out of their course by adverse winds, or as adventurers, unconscious pioneers, scouting out new flylines for their respective species. The presence of an occasional foreigner among our regular migrants may also be accounted for by pleasant entanglements formed in the Southland, Mexico, or Panama. Yet it is also noticeable that these waifs do go in bands of associated eastern species, detached fragments of that brilliant army of invasion which, billions strong, annually sweeps the East in a resistless, joyous tide. We do not, of course, detect a thousandth part of the strangers among us, for they pass unheeded through the wastes of chap-

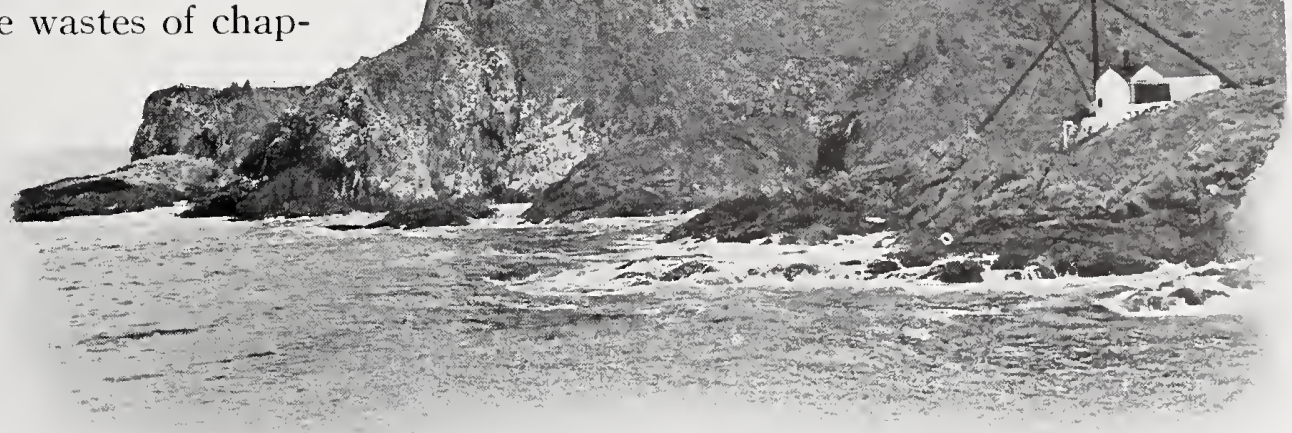




\section{The Black-throated Blue Warbler}

arral or pine or fir. It is only when some fugitive battalion storms a barren outpost, like San Clemente or the Farallons, that we realize what is going on annually around us. Five of the nine first records of accidental eastern Mniotiltine species have thus been made on the Farallons or some other offshore island along our coast, and three of the remainder were made on the mainland shore.

It was in such a stranded flock that I observed several handsome Magnolias on the S. E. Farallon, May 28-June 3, I9II. They were quite the daintiest as well as the most conspicuous members of that sad company, all destined, we feared, to be lost at sea. Most of the warblers kept rather closely to the shelter of a small grove of cypresses which surrounded the steam siren, or else deployed upon the grounds adjacent. But one of these jewels, a stunning male, yet all bewildered and subdued, was encountered on the steep trail leading out of the Raven cave on the "West end"; and here, where his only companions were "shag flies" and sea fowl, he maintained himself for several days.

No. 85

\section{Black-throated Blue Warbler}

\section{A. O. U. No. 654. Dendroica carulescens carulescens (Gmelin).}

Description.-Adult male in spring: Above deep green-blue gray, faintly marked on pileum and back with mesial spots of black; extreme forehead, sides of head, broadly, involving eye, entire throat, continuous with sides of head and sides, broadly, black, faintly lustrous; remaining underparts pure white, abruptly defined from black of throat; wings and tail black; basal half of primaries, except outermost, chiefly white, forming a conspicuous and sharply defined blotch on exposed wing; inner edges of tertials sharply bordered by white; the three outermost pairs of rectrices marked on the inner webs with broad subterminal blotches of white, the two succeeding pairs narrowly edged with white near tip of inner webs. Bill black; feet and legs brownish. Adult male in autumn: Exactly like male in spring, except mandible brownish instead of black. Immature male: Like adult male but somewhat duller; the blacks of throat and sides tipped with bluish or olivaceous; the blue of upperparts faintly glossed with olivaceous; the whites of underparts, especially on flanks and crissum, faintly washed with buffy; the flight-feathers dusky instead of black. Adult female in spring: Entirely different from adult male, save in white wing-blotch, which is reduced in area; white spotting of tail faintly indicated by blotch on inner web of outer feathers only; above and on sides of head deep grayish olive (or gray washed with warbler green); forehead of ten with increase of bluish green; underparts deep olive-buff, shading on sides into color of upperparts; lower eyelid and a narrow superciliary of dull white or pale olive buffy. Bill dark brown. Adult female in fall: Scarcely different. Upperparts, perhaps brighter, more greenish; cheeks more distinctly plain dark olive. Immature female: Exactly similar to adult female, save that white wing-blotch still further 


\section{The Alaska Myrtle Warbler}

reduced or wanting. Length of adult males (skins): I I 4.3 (4.50); wing 65.2 (2.57); tail 5I.I (2.0I); bill 9.4 (.37); tarsus I $8.7(.74)$. Females very slightly smaller.

Recognition Marks.-Medium warbler size; black throat and sides abruptly contrasting with white of breast and belly, distinctive for male. Female an obscure olivaceous bird, best known by white blotch near edge of wing.

Nesting.-Does not breed in California. Nest: Of bark-strips, twigs and grasses; lined with fine rootlets and horsehair; placed in low bushes near ground. Eggs: 4 or 5 ; dull white, spotted with dull reddish brown and vinaceous gray. Av. size, I6.5 X $12.7(.65 \times .50)$.

General Range.-Eastern North America. Breeds in northern portion of United States from Minnesota to Rhode Island, and centrally in Ontario and Quebec; winters in the West Indies and casually west to Central America and Colombia; in migrations casually west to the eastern base of the Rocky Mountains.

Occurrence in California.-Accidental; one record: Farallons, Nov. I7, I 886.

Authority.-W. E. Bryant, Proc. Calif. Acad. Sci., 2nd ser., i., I888, p. 48 (Farallon Ids., Nov. I7, I886, one spec.).

A SOLITARY example of this strictly eastern species was taken by W. E. Bryant on the Farallon Islands in November, I 886 . The specimen was destroyed in the great San Francisco fire.

No. 86

\section{Alaska Myrtle Warbler}

A. O. U. No. 655, part. Dendroica coronata hooveri McGregor.

Synonyms.-Hoover's Warbler. Western Myrtle Warbler.

Description.-Adult male in spring: Crown (centrally), rump (narrowly), and a large spot on each side of the breast, pure yellow (lemon yellow); the tint of the crown-patch slightly "richer" (lemon-chrome); general color of upperparts blue-gray (deep green-blue gray), heavily streaked with black (or else black with heavy edgings of blue-gray), the black streaks narrow on pileum, and broad on notæum and scapulars; wings black, the tips of the greater and middle coverts white, forming two conspicuous bars; the lesser wing-coverts and outer edges of flight-feathers brownish, and often more or less brownish gray across middle portion of back; tail black with white blotches on inner webs of outer tail-feathers, successively decreasing in area, and vanishing on the $4^{\text {th }}$ or $5^{\text {th }}$ pair; cheeks and lores black; a dab of white above lores; another on lower eyelid; and a white streak over auriculars; throat pure white; breast and sides black, with much admixture of white present as edging, the black thus roughly defining the yellow, and persisting on sides and flanks as streaks; remaining underparts, including lining of wing, white. Bill black; iris brown; feet and legs dark brown. Adult male in autumn and winter: "Very different from the summer plumage; above grayish brown, with black streaks concealed except on back and scapulars, where much less conspicuous than in summer plumage; yellow crown-patch concealed by brown tips to the feathers; sides of head brown, like pileum, varied by the same white markings as in summer plumage, but these less distinct; chin, throat, and chest brownish white or 


\section{The Alaska Myrtle Warbler}

pale buffy brown, the last more or less streaked with black; lateral yellow pectoral patches less distinct than in summer, usually tinged with brownish and flecked with dusky; black sublateral pectoral patches broken by broad white margins to feathers; wings and tail as in summer, but white bands across former more or less brownish" (Ridgway). Immature male: Like adult male in autumn, but buffy element more strongly represented, and black of chest and sides less strongly developed (?). Adult female in spring and summer: Like male in summer, but smaller and duller; brownish gray largely displacing the bluish gray of upperparts; the yellow areas (except that of rump) more restricted, both by encroachment and by blackish streaks on tips; the black of breast and sides reduced by broadening of white edgings; sides of head brownish black or brownish gray. Adult female in autumn and winter and immature: Like male in winter but upperparts more decidedly brown; the black streaks much sof ter or wanting; the lateral yellow patches saffron-tinged, or wanting; the coronal patch entirely overlaid with brown tips. Length of adult males: I29 (5.08); wing 74.I (2.92); tail 56.2 (2.2 I); bill Io (.39); tarsus I9.6 (.77). Length of adult females: I30 (5. I 2 ); wing 70.5 (2.775); tail 56.I (2.2 I); bill 9.2 (.36); tarsus I 8.7 (.736)-(After Ridgway under D. coronata). Five adult males, northern-taken, in the M. V. Z. colls. average: wing 75.7 (2.98); tail $59.5(2.34)$; and apparently sustain the contention that Alaskan birds are to be distinguished by slightly greater lengths of wing and tail.

Remarks.-The very characteristics, viz., longer wing and tail, alleged to distinguish hooveri from coronata, mark the form as the acme of the northwestern migratory trend which carried (and still carries) coronata from its winter home in the Antilles north and west (via the edge of the Mackenzo-Laurentian ice sheet) to extreme Alaska. Hoover $i$ is, therefore, the extreme of the most vigorous coronata stock; and the greatly lessened annual flights which those who winter in California indulge, must eventually operate to reduce, and so render indistinguishable, the very character upon which its differentiation is now based (for length of wing is a well-recognized function of exertion).

Recognition Marks.-Large warbler size. Much like D. auduboni, from which distinguished chiefly by white throat of adult birds; tchip note much softer. Females in autumn and winter and immature males are marked by at least a trace of yellow on the sides of the throat; while immature females of the two species may be absolutely indistinguishable out of hand (save by note). Yellow rump always a distinctive mark of this and the succeeding species.

Nesting.-Does not breed in California. Nest and eggs, probably indistinguishable from those of $D$. coronata, described as follows: Nest of weed-stalks, twigs, vegetable fibers, and grasses, lined with fine grasses and feathers; and placed five or ten feet up on horizontal branch of coniferous tree. Eggs: 3 to 5; dull white, speckled and spotted or blotched, chiefly about larger end, with snuff-brown, buffy brown, and vinaceous gray. Av. size, I $7.3 \times 12.7(.68 \times .50)$.

Range of $D$. coronata. - North America, except (?) the Rocky Mountain and intramountain states. Breeds from the mountains of the northeastern states, northern Michigan, etc., nearly throughout Canada north to the limit of trees and in Alaska. Winters in the eastern states, sparingly from the latitude of Kansas and New Jersey, increasingly south through the Antilles and to Mexico and Panama; in the Pacific States south to southern California; also in Arizona,-four records (Swarth).

Range of D. c. hooveri.-Presumably the western portions of the range of D. coronata, in Alaska, south in winter to California.

Distribution in California.- Not uncommon winter resident and migrant in 


\section{The Alaska Myrtle Warbler}

west central California, south to the Islands and Los Angeles, and east to the western slopes of the Sierras; casually to the Colorado River (Potholes, Feb. I I, I9I3). Whether, indeed, spring occurrences represent merely the return movement of our own winter residents, or whether the race also winters farther south, has not been determined.

Authorities.-Cooper (Dendroica coronata), Proc. Calif. Acad. Sci., vol. vi., I 875, p. I93 (Oakland and Haywards); McGregor, Bull. Cooper Orn. Club, I, I 899, p. 32 (orig. desc.; type from Palo Alto); Willett, Pac. Coast Avifauna, no. 7, 1912, p. 96 (occurrence in s. Calif.); Allen, Condor, vol. xvi., 1914, p. 37 (Berkeley, winter).

D. CORONATA is the dominant warbler of the East and North, just as its counterpart, D. auduboni, is of the West. By virtue of its aggressiveness and hardihood, it has long been entrenched in Alaska, and has even been known to overshoot the mark into eastern Siberia. Of this northwestern contingent a certain proportion has deserted the old Mississippi Valley flyline, and now comes south along the Pacific Coast to winter. The winter range, therefore, of this western contingent is widely separated from that of the main body, and there is thus a valid reason for separation of a subspecies, hooveri, even though the physical differences assigned may be of the slightest. It may even prove true that the two forms interpenetrate so thoroughly on their Alaskan breeding grounds that hooveri will have to be defined as that portion of the coronata host which winters in Washington, Oregon, and California.

There is little in the appearance and less in the behavior of these sojourners in the Southland to distinguish them from D. auduboni, which everywhere outnumbers them a hundred to one. The chance has a sporting interest in central and northern California, but those of us who, living south of the Tehachipi, have levelled the binoculars a thousand times in vain, have come to feel that the odds are against us. Although broadly scattered and diluted in winter, members of this species are likely to be found in groups, or pockets, and it is possible that they concentrate still more closely during migration. At any rate, friends both in Seattle and Tacoma have given me circumstantial accounts of flocks containing hundreds, all white-throats.

Mr. Ralph Hoffmann, recently come to sojourn in Santa Barbara, has called our attention to the fact that $D$. coronata has a softer, more languid chip note than that of D. auduboni. This friendly tip proves to be a touch-stone to recognition. The ear test is often better than the eye test, especially when one is casting up averages. Perhaps, after all, the odds against the Alaska Myrtle are only fifty to one. 


\section{Audubon's Warbler}

A. O. U. No. 656 . Dendroica auduboni auduboni (Townsend).

Description.-Adult male: Similar to D. coronata hooveri, but throat rich yellow (lemon-chrome); black cheeks reduced by encroachment of bluish gray over auriculars; no white above and behind eye; white on middle and greater wing-coverts much increased, sometimes involving most of the exposed surface of the greater coverts; tail with white subterminal blotches on inner webs of four or five outer feathers; black of breast and sides much purer, less white. Adult female: Similar to adult male, but duller (differences closely corresponding to those in $D$. coronata); the white of wingpatch nearly obsolete; the yellow of throat paler and of ten, especially on chin, more or less displaced by white. (Young females, even of the second summer, are sometimes absolutely without yellow on throat, but the more abundant white on rectrices is distinctive, as compared with $D$. coronata hooveri.) Seasonal changes follow very closely those of $D$. coronata, but yellow of throat is retained in winter, save in young females and (rarely) in young males. Young, first plumage: Above, bluish and brownish gray, heavily streaked with dusky; the streaks finer on pileum and rump; the borderings whiter on rump (no yellow), and browner on wings; underparts white, heavily and finely streaked with dusky; white blotches on tail, as in adult. Av. of Io adult males in M. V. Z. colls.: length (skins) I32 (5.20); wing 76.5 (3.0I); tail 60.4 (2.38); bill 10.2 (.40); tarsus I $8.8(.74)$. Av. of Io adult females: length (skins) I 30.4 (5.I35); wing 72.7 (2.86); tail $56(2.2 \mathrm{I})$; bill $9.8(.386)$; tarsus $\mathrm{I} 8.4(.72)$.

Recognition Marks. - Warbler size; five spots of yellow; extensive white blotching of tail. Yellow rump distinctive in any (except first) plumage, save as compared with $D$. coronata, from which it is further distinguished (usually) by yellow or yellowish of throat. (If this character fails, the more extensive white on tail will always hold.)

Nesting.- Nest: A well-built bulky structure of fir twigs (or pine needles), weed-stems, rootlets, etc.; heavily lined with horsehair and feathers; placed usually on branch of conifer from four to fifty feet up, sometimes in small tree close against trunk; measures 4 inches in width outside, by $23 / 4$ in depth; inside 2 by $1 \frac{1}{2}$. Eggs: 3 to 5, usually 4; dull greenish white, sparingly dotted with blackish, or handsomely wreathed, spotted, and blotched with reddish brown-black and vinaceous gray. Av. size I $8 \times 13.7$ (.7 I x .54). Season: May-June; one brood, or rarely two.

General Range.-Western North America, breeding in the north from central British Columbia to southwestern Saskatchewan and the Black Hills, and in the south from the mountains of southern California east to southeastern New Mexico; winters from California and the valley of the Rio Grande south to Guatemala.

Distribution in California.-A common breeder of the mountainous sections in both Boreal and Transition zones; found from the Santa Rosa and San Jacinto Mountains north along the Sierran ridge to Shasta; east upon the White and Warner ranges; in the northwest in the Trinities, south to northern Lake and Mendocino counties, and locally in Sonoma County ( $\mathrm{J}$. Mailliard). Abundant in winter at the lower levels practically throughout the State.

Authorities.-Gambel (Sylvicola auduboni), Proc. Acad. Nat. Sci. Phila., iii., I 847 , p. I 55 (Calif.) ; Beal, U. S. Dept. Agric., Biol. Surv. Bull., no. 30, I 907, p. 43 (food); Grinnell, Univ. Calif. Pub. Zool., vol. v., I908, p. 27 (mortality); ibid., p. II 2 (San Bernardino Mts.; habits, nest and eggs, molt, etc.). 


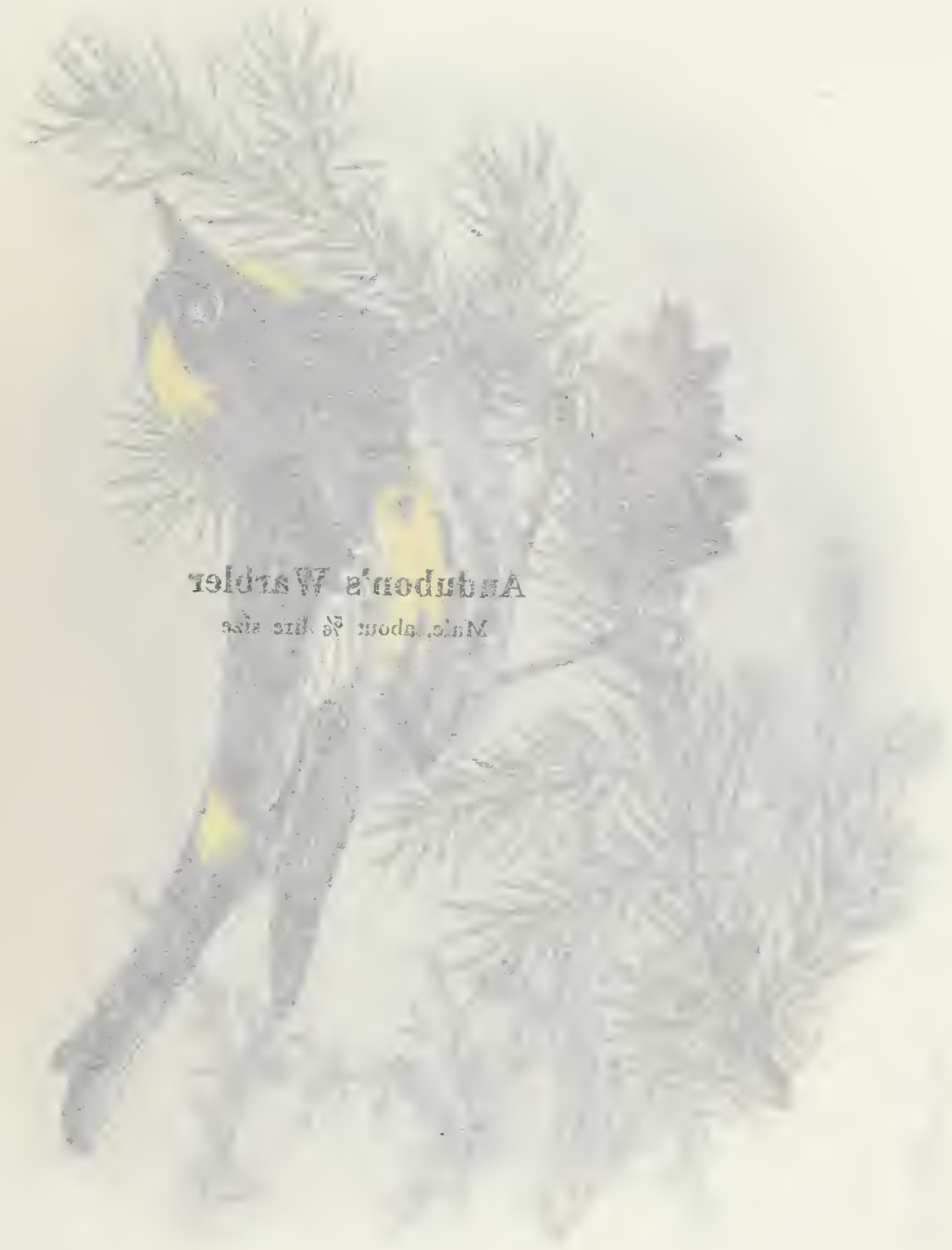




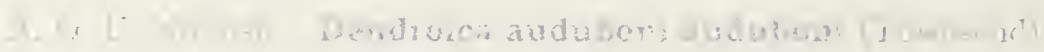

I.

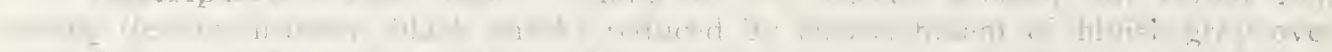

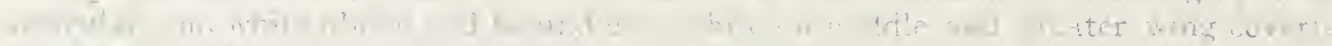

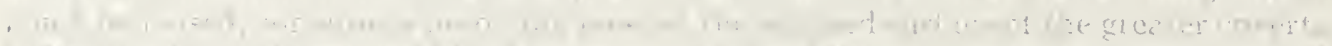

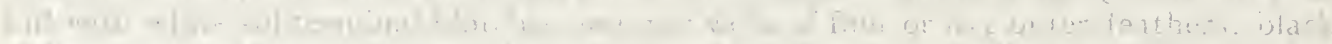

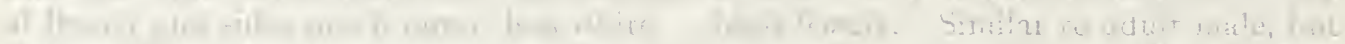

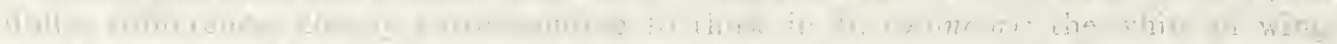

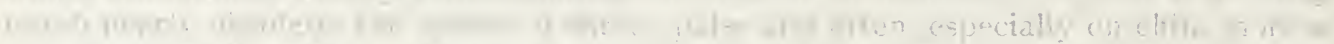

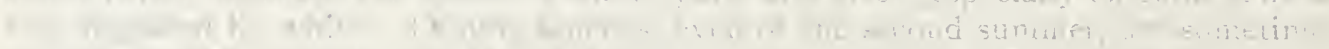

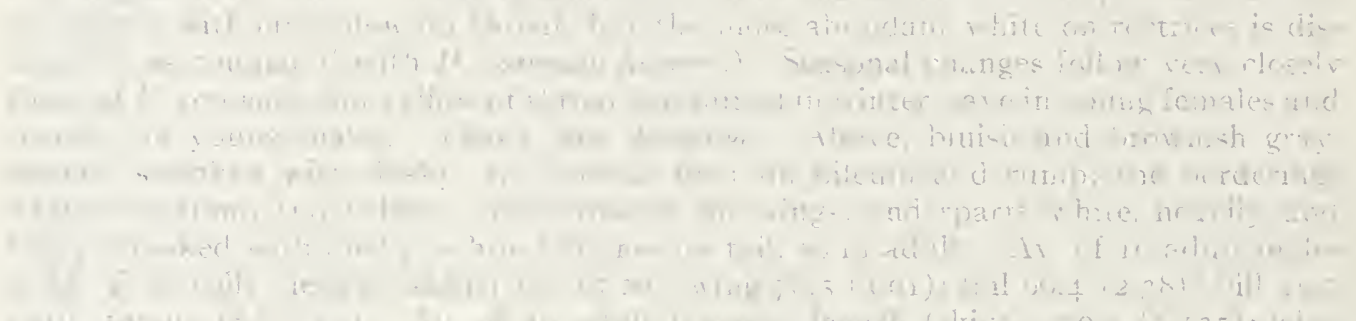
Audubon's Warbler

I. ree mates 11 : Male, about $\%$ life size

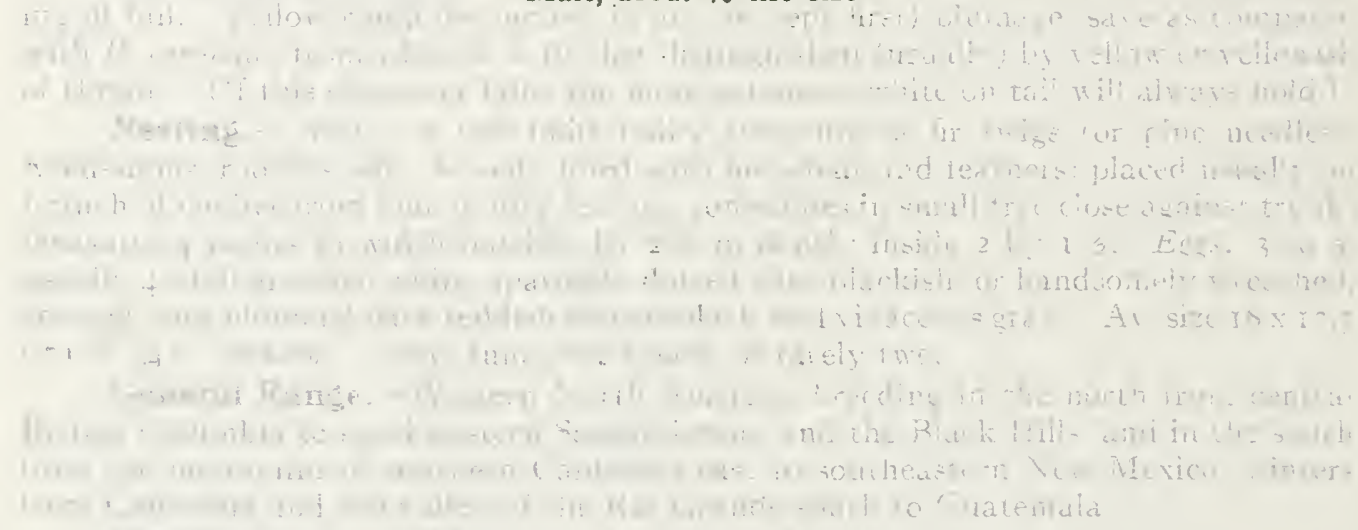

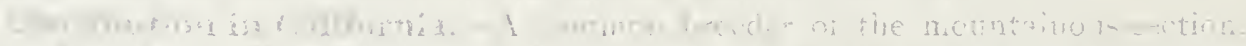

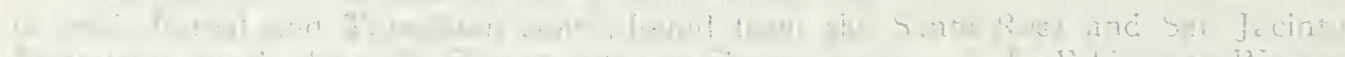

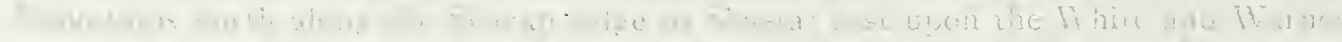

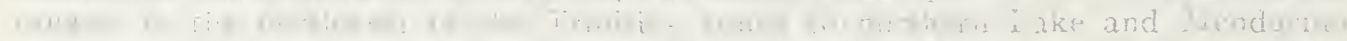

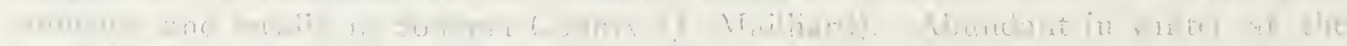

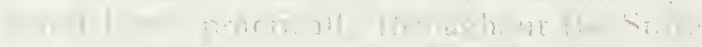

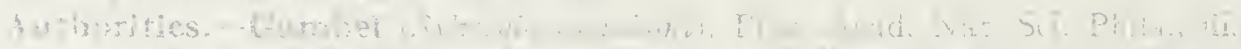

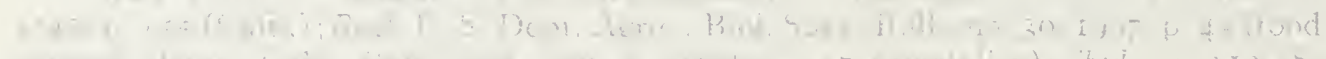

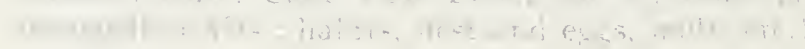




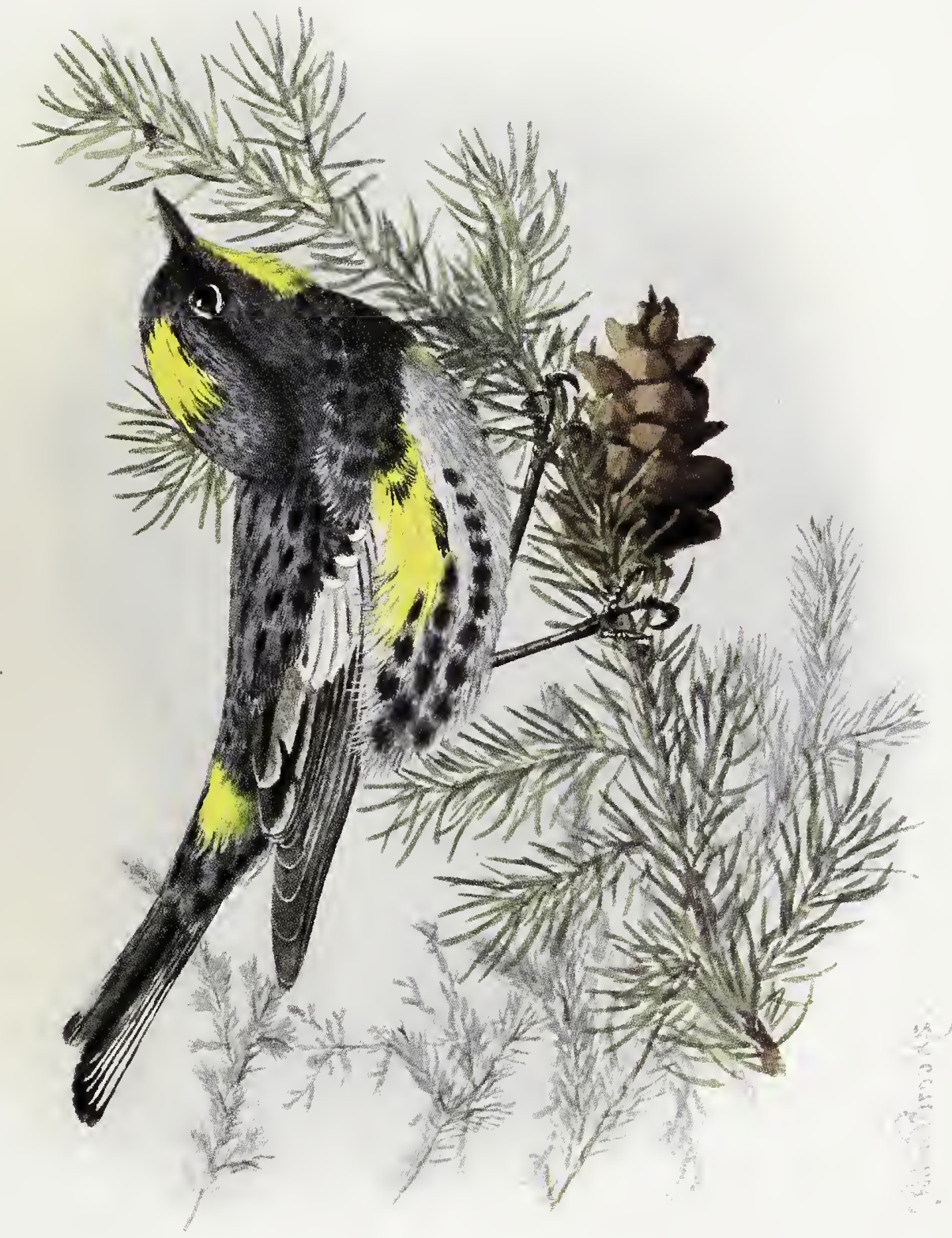





\section{The Audubon Warbler}

AS ONE CONSIDERS the Thrushes, Wrens, and Sparrows of our north temperate clime, he is apt to grumble a little at the niggardliness of Mother Nature in the matter of providing party clothes. The dark mood is instantly dispelled, however, at the sight of this vision of loveliness. Black, white, and gray-blue make

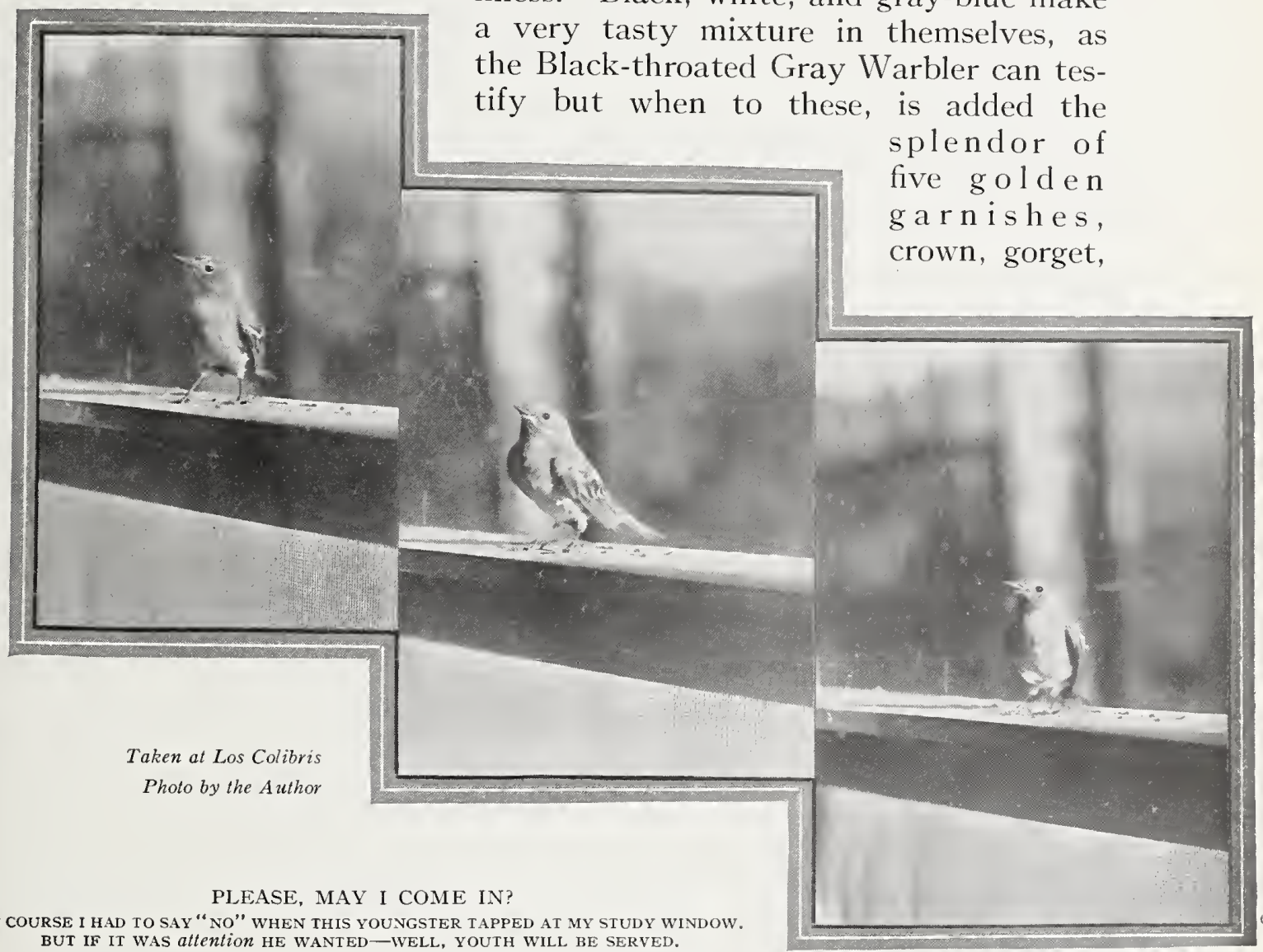
BUT IF IT WAS attention HE WANTED - WELL, YOUTH WILL BE SERVED.

epaulets, and culet, you have a costume which Pan must notice. And for all he is so bedecked, auduboni is neither proud nor vain,- - properly modest and companionable withal.

Audubon Warbler is par excellence the warbler of the West. Cheerful, aggressive, capable, the bird symbolizes, as we would fain believe, the best in western tradition. For your true Westerner needs no artificial aids. Pride of family, education, circumstance, these are flung aside in that fundamental democracy which faces nature unafraid and wrests from her the prizes which she is obliged to bestow upon the resolute. And how splendid an example the bird sets! Without tools or furnishings, 


\section{The Audubon Warbler}

without connections or backing, without so much as a hand-bag in which to keep a few cherished belongings, this brave young argonaut faces the world. This world is full of winged assassins, feline prowlers, serpents, storms, glaciers, fogs, droughts, and a thousand nameless terrors. "Ho ho! Who cares!" says Sir Audubon. "The world is mine. Not a tree, but I shall explore it; not a canyon, but I shall quaff water from its depths; not a mountain, but I shall mock at its glaciers; not a tempest, but I shall know how to escape its fury. Ho, Ho!" And so this tiny warbler, penniless and homeless, threads mazes which no surveyor has ever chained, scales heights which no aneroid has ever measured, sleeps in a hundred and forty different beds, from the lowly weed to the fir tree's loftiest pinnacle, lunches at ten thousand counters, and comes back to us winter by winter, artless, unspoiled, cheerful, and courageous. Oh, who would not be such a bird!

One is tempted to declare that the Audubon Warbler is the commonest bird in California, in midwinter. Doubtless this would be an exaggeration, for there are Gambel Sparrows, not to mention House Finches, to consider; but it is certain that these warblers are more in evidence on a winter day in the interior valley and south of the Tehachipi than are the presumably more abundant birds skulking in the chaparral. It is nothing, for example, to see two hundred Audubons in the course of a morning's tramp. When they are as thick as this, they string out along the telephone wires, or deploy over the ground of open fields. Their movements are always desultory and individually independent, so that they remind one at times of irresolute Pipits. Best of all, we see them in numbers on the sand dunes and over the beaches. Having known Sir Audubon as a dweller at timberline, I am not even yet reconciled to seeing him perched on a stranded kelp root and snapping at flies. For the rest, every wayside hedge claims him; and as for the eucalyptus trees, they are surely made on purpose to house Audubons.

Of course the winter plumage is duller. Only the pale yellow of the rump, and the palest possible yellow of the throat remain to distinguish the Audubonity of the younger males, and of the females both young and old. In young females even the yellow tinge of the throat is so dubious as to be indecisive as against $D$. coronata; but coronatas (hooveri) are so rare that we do better not to worry about them until a genuine white-throated male heaves into sight. Our friends, whether $D$. auduboni or $D$. coronata, are better distinguished, and always distinguished from all other warblers, by the quality and frequency of their keep-in-touch note. Chip or tchip doesn't convey much intelligence on paper, and its peculiar quality is indescribable (save for its manifest content of good cheer), but one who has mastered that quality has 


\section{The Audubon Warbler}

found the keynote to a life-long acquaintanceship with one of the dearest and bravest of birds.

Audubon's Warbler as a songster deserves some notice. His song,

to be sure, is brief and

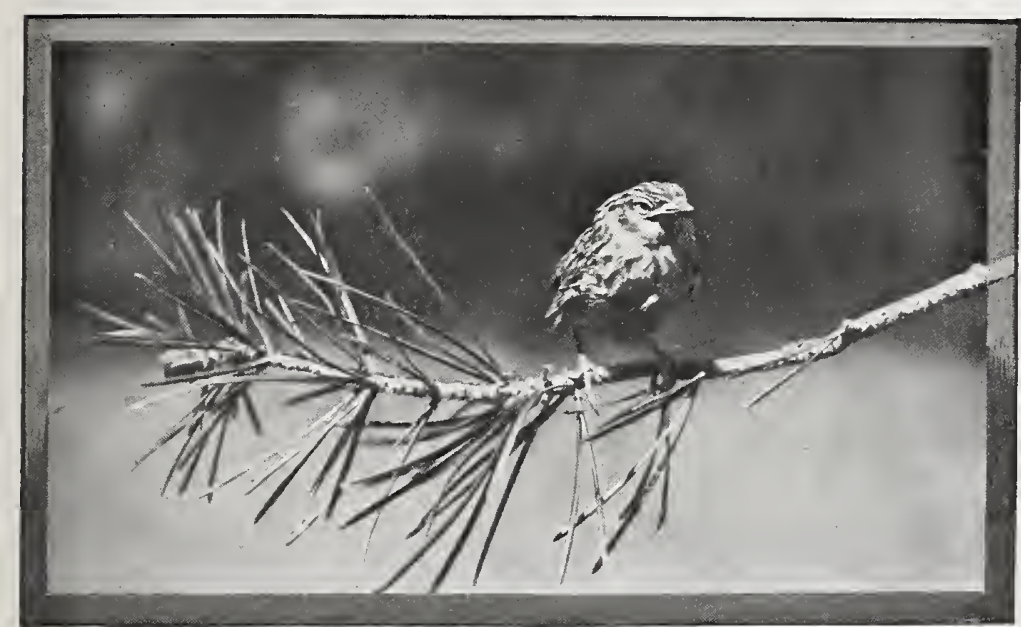

Taken in San Bernardino County
Photo by L. Huey \&o D. R. Dickey

A DISCOURAGED BABY-AUDUBON WARBLER its theme nearly invariable, as is the case with most warblers; but there is about it a joyous, racy quality, which flicks the admiration and calls time on Spring. The singer posts in a high fir tree, that all may hear, and the notes pour out rapidly, crowding close upon each other, till the whole company is lost in a cloud of spray at the end of the ditty. At close quarters, the "filling" is exquisite, but if one is a little way removed, where he catches only the crests of the sound waves, it is natural to call the effort a trill. At a good distance it is even comparable to the pure, monotonous tinkling of Junco.

I once heard these two dissimilar birds in a song contest. The Warbler stood upon a favorite perch of his, a spindling, solitary fir some hundred feet in height, while the Junco held a station even higher on the tip of another fir a block away. Here they had it back and forth, with honors surprisingly even, until both were tired, whereupon (and not till then) a Spotted Towhee ventured to bring forth his prosy rattle. It was like Sambo and his "bones" after an opera.

The range of Audubon's Warbler in summer is nearly coincident with that of evergreen timber, if we except the digger pine (Pinus sabiniana) on one hand, and the desert juniper (Juniperus utahensis) on the other. It does not, however, frequent all the more open pine woods of the north central Sierras, nor does it occur in the redwood or associated forests of the northwestern coast. Although the conditions which obtain in Humboldt and Del Norte counties are very similar to those which extend into Alaska as the "humid coast belt," the Audubon does not appear to breed with us anywhere near sea level, as it does in Washington; nor is it found below strict "Transition" upon the eastern slopes of the Sierras. But given its altitudinal requirements, the bird 


\section{The Audubon Warbler}

is equally at home in the village park. in the loftiest fir trees, or in the dwarfed pines of timberline. Under such diversity of conditions, the bird's habits must differ widely; and, indeed, it is difficult to generalize with reference to its nesting.

In any case, the absorbing duty of springtime is nesting, and to this art the Audubons give themselves with becoming ardor. The female does the work while the male cheers her on with song, and not infrequently trails about after her, useless but sympathetic. Into a certain tidy grove in the North the bird-man strayed one crisp morning in April. The fir trees stood about like decorous candle-sticks, but the place hummed with Western Golden-crowned Kinglets and clattered with Juncoes and Audubons. One Audubon, a female, advertised her business to all comers. I saw her on the ground wrestling with a large, white chicken-feather, and sputtering excitedly between tussles. The

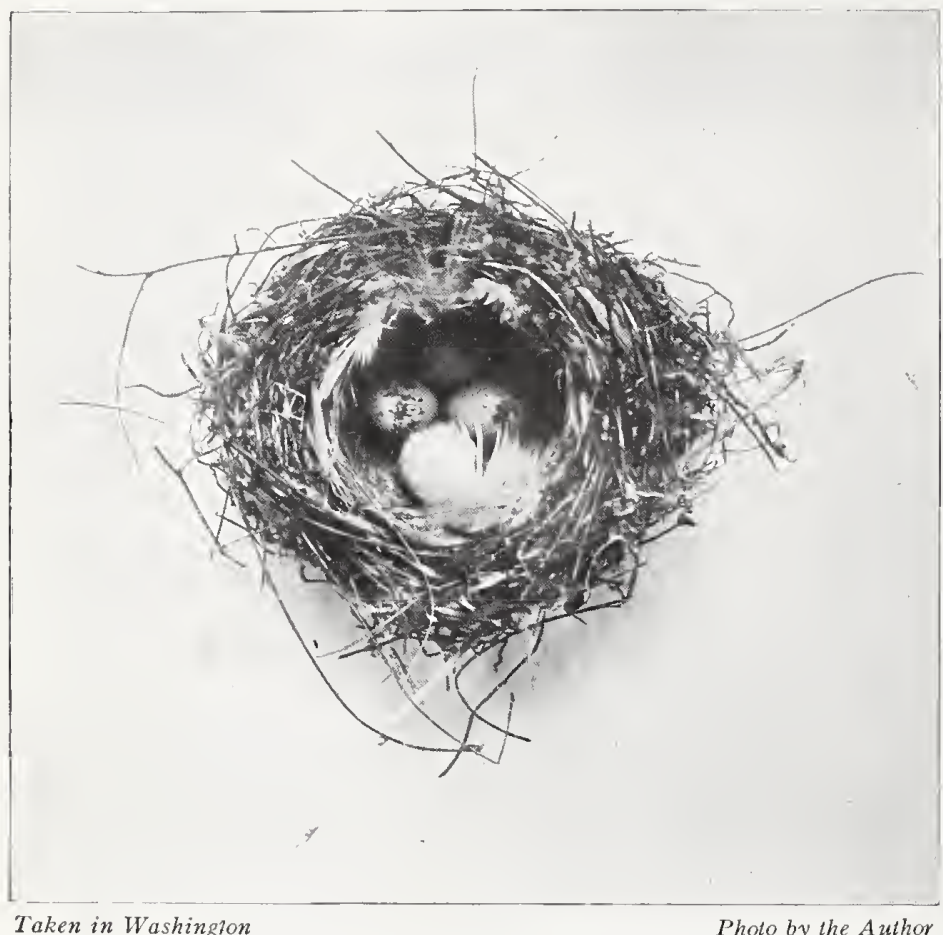

NEST AND EGGS OF AUDUBON WARBLER feather was evidently too big or too stiff or too wet for her proper taste; but finally she flew away with it across the grove, chipping triumphantly. And since there were other feathers and since she repeated her precise course three times, the bird-man had little trouble in tracing her to her nest some fifteen rods away and forty feet up in an ascending fir branch.

When the nest was presumed to be ripe, I ascended. It was found settled into the foliage and steadied by diverging twigs at a point some six or seven feet out

along the limb. None of the branches in the vicinity were individually safe, but by dint of standing on one, sitting on another, and clinging to a third, I made an equitable distribution of avoirdupois and grasped the treasure. Perhaps in justice the supporting branches should have

$$
476
$$




\section{The Audubon Warbler}

broken just here, but how could you enjoy the rare beauty of this handsome structure unless we brought it to you?

The nest is deeply cup-shaped, with a brim slightly turned in, composed externally of fir twigs, weed-tops, flower-pedicels, rootlets, catkins, etc., while the interior is heavily lined with feathers, which in turn are bound and held in place by an innermost lining of horsehairs. One feather was left to curl daintily over the edge, and so partially conceal the eggs,-four speckled beauties.

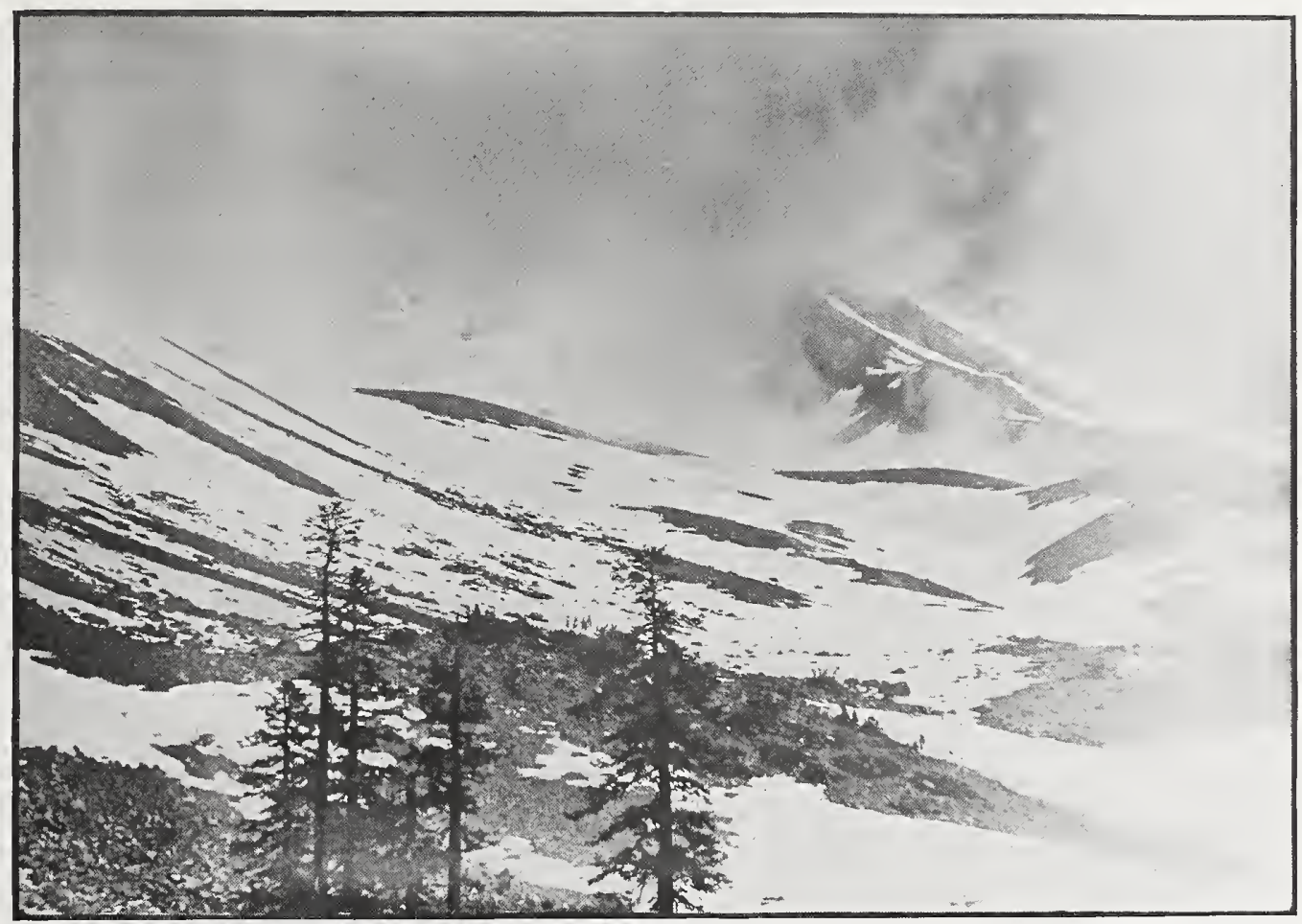

Taken in Siskiyou County

A TIMBERLINE HAUNT ON SHASTA

Photo by the A uthor

These warblers are connoisseurs in feathers, and if one could have all their nests submitted to him, he would be able to make a rough assignment of locality as between northern and southern birds, according as feathers of Plumed Quail, Oregon Ruffed Grouse, or Washington Ptarmigan were used. The most absurd nest I ever saw was one which had a lining exclusively composed of Plymouth Rock chicken-feathers. The effect was like that of a party dress made of bed-ticking.

Though evergreens are the commonest host trees, in which nests are placed at any height from four to eighty feet, the bird is not above using 


\section{The Audubon Warbler}

the shelter of deciduous trees as well. A nest which we attempted to photograph in a northern city was placed in the lowermost available crotch of an elm tree, one of a row of shade trees in front of a fashionable residence, and not ten feet up. The composition of the nest was so unusual-strings and white horsehair-that we decided we "needed" it in our business. But the situation was very prominent, under review of we knew not how many lorgnettes. Moreover, we did not know the state of local sentiment, nor did we care to provoke discussion. Accordingly, we provided ourselves (my astute partner, J. H. Bowles, was particeps criminis in this affair) with a convenient nest of Western Chipping Sparrow containing three well incubated eggs, to supply to the inquisitive eyes the place of the Audubon $\mathrm{n} / 4$, to be abstracted. When we had photographed the nest in situ, therefore, with due and discouraging solemnity, we quietly substituted Western Chipping Sparrow $\mathrm{n} / 3$, pressing the new nest firmly down into place, so that the prevailing winds would not disturb it. Judge of our amusement and satisfaction when, upon strolling by half an hour later, we saw the female Audubon sitting upon her foster eggs. We had not expected so complete a success. To be sure, the bird appeared a little discontented, as though chiding herself for folly in providing such a shallow nest. The next day, also, found the victim of our little deception still in charge, so we retired, quoting the comfortable proverb, as good for birds as for humans, "What you don't know doesn't hurt you."

Few warblers express such a frank concern for the welfare of their domicile as do these lordly Audubons. When the young are grown, the parents throw discretion to the winds and advance within a foot or so of the intruder, prostrating themselves along the branches, or spreading their tails and wings in frantic efforts to arouse a distracting cupidity. The young are gentle, well-behaved little creatures, whom no one could possibly wish to harm. When the nest is quitted, they follow their parents dutifully through the treetops; or if the season is early, the male takes charge of his brood while his mate prepares another nest. When the season is ended, the family party works slowly over the mountainside above timberline. Such parties I met in July at Io,ooo feet on Shasta, where the only other birds one might expect were Thurber Juncoes, or, perhaps, the heavenly Rosy Finch. 


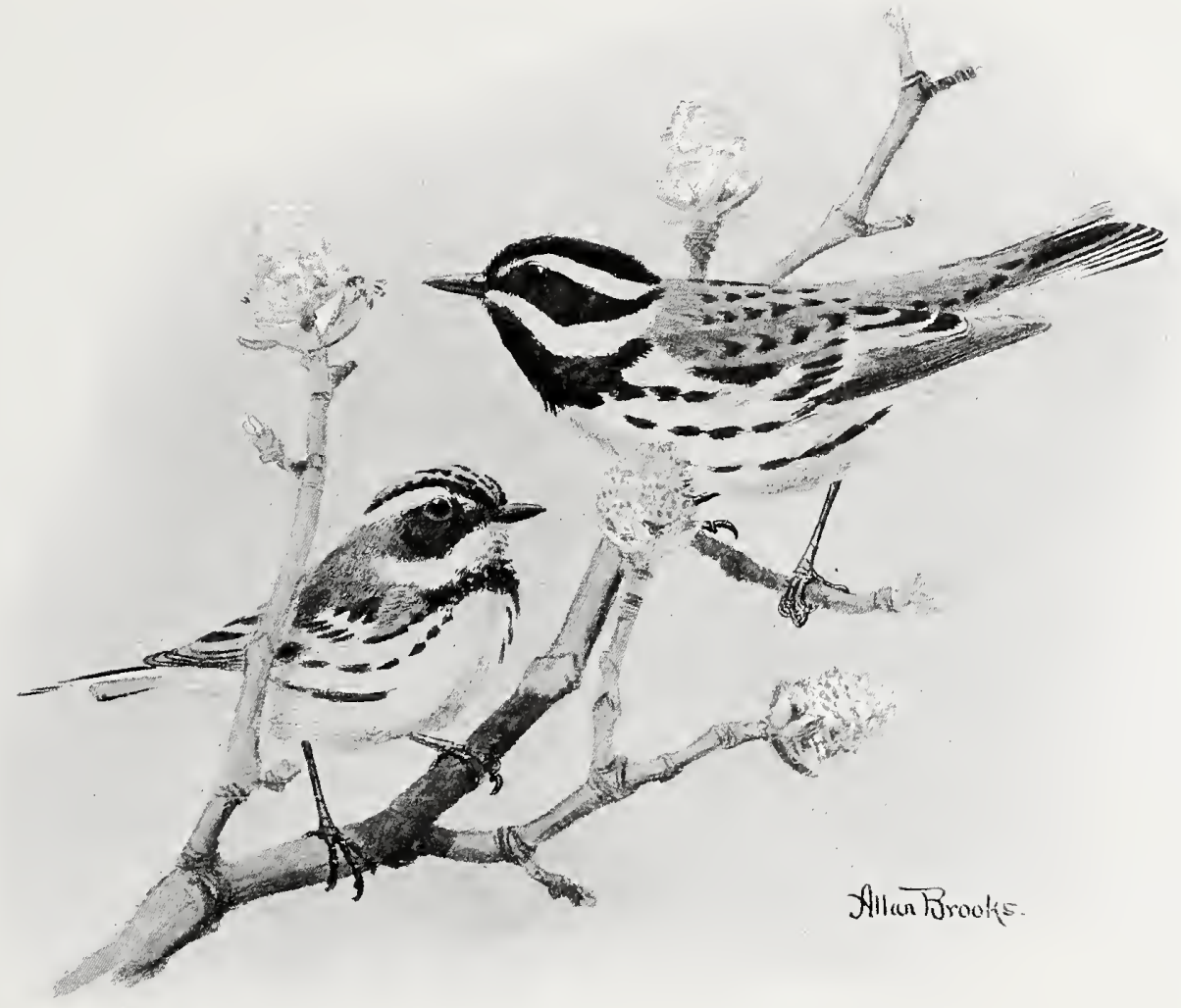

BLACK-THROATED GRAY WARBLERS

No. 88

\section{Black-throated Gray Warbler}

\section{A. O. U. No. 665. Dendroica nigrescens (Townsend).}

Description.-Adult male in spring and summer: A supraloral spot of rich yellow (lemon-chrome); remaining plumage black, white, and warbler gray; head, throat, and chest black, interrupted by supra-auricular stripe of white, and by a malar stripe of white, broadening on side of neck; remaining upperparts chiefly blue-gray or "warbler gray" (dark green-blue gray), marked with black in inverted wedge-shaped spots on back, scapulars, and upper tail-coverts; wings black or dusky, edged narrowly with bluish ash or white, the quills broadly margined with white on the inner webs, the middle and greater coverts tipped with white, forming two conspicuous bands: rectrices black, the two outermost pairs narrowly edged with white, and all the feathers, except the middle pair, marked with white on the inner webs in sharply decreasing order, from nearly totally in the outermost to mere subterminal marginings on the $4^{\text {th }}$ and $5^{\text {th }}$ pairs; remaining underparts white, the sides sharply and heavily streaked with black. Bill black; iris brown; legs and feet blackish. Adult male in fall and winter: Much as 


\section{The Black-throated Gray Warbler}

in spring, but gray of upperparts washed with brownish, the black streaking much reduced in area, and the gray more or less intrusive on pileum. Immature male: Much like fall adult but more heavily washed with brownish above, and almost without black streaks; the pileum more extensively gray; the black of cheeks partly veiled by gray, and the black of throat partially veiled by white tips of feathers. Adult female in spring and summer: Much like male in summer and sometimes almost as brightly colored, but usually duller throughout; the upperparts more extensively gray, the color invading and nearly covering pileum, where sharply streaked with black; the black streaks of back and upper tail-coverts fewer and narrower; the black of throat more or less veiled with white tips, and the stripes of sides reduced in width. In autumn: Plumage softer, the black streaks of upperparts obsolete or wanting. Immature female: Like adult female in autumn, but upperparts uniform brownish gray (mouse-gray), cheeks a little darker; white of underparts tinged with pale buffy. Av. length of 9 males (afield): I 28.77 (5.07). Ten specimens in U.S. N. M. measure: wing $62.2(2.45)$; tail 50.5 (I.99); bill 9.2 (.36); tarsus 17.7 (.70). Eight females average: wing 59.I (2.33); tail 48.9 (1.925); bill 9.I (.358); tarsus I7.3 (.68).

Recognition Marks.-Black and white and "warbler gray" coloration. Yellow spot above lores distinctive, but otherwise requires careful discrimination afield from Black-and-white Warbler (Mniotilta varia), q. v.

Nesting.-Nest: A deep cup-shaped structure, often rather loosely built, of dead grasses, silky plant-fibers, moss, etc.; placed low in crotch of bush or sapling or else on horizontal limb of conifer, 25 to 50 feet from ground; measures externally 3 inches $(\mathrm{mm} 76.2)$ wide by $2(\mathrm{~mm} 50.8)$ deep; internally $\mathrm{I} 3 / 4(\mathrm{~mm} 44.5)$ wide by I $(25.4)$ deep. Eggs: 4, rarely 5; creamy white, marked chiefly about the larger end with spots and small blotches of varying shades of brown, lavender, and black. Av. size 2 I X I 6 $(.83 \times .63)$. Season: Last week in May and first week in June; one brood.

General Range.-Western United States north to Colorado, northern Utah, and Washington, and southern British Columbia west to the Cascades; breeding south to northern Lower California, Arizona, and northern New Mexico; "winters in southern Lower California, and in Mexico from Durango to Michoacan, Vera Cruz, and Oaxaca" (A. O. U. Com.).

Range in California.--Breeds in Lower Transition and high Upper Sonoran zones practically throughout the State, save in the extreme coastal portion of the humid district; less common on the coastal ranges. Well distributed during migrations. Usually appears at Santa Barbara about April 29th; earliest Santa Barbara record for spring migrations March 29, I9I9. Earliest Pasadena record March 23, I 895, by Joseph Grinnell; latest fall records: Los Angeles, Oct. 30, I899, by H. S. Swarth; Berkeley, Nov. I, I89 (?), by F. O. Johnson.

Authorities.-Heermann (Sylvicola nigrescens), Jour. Acad. Nat. Sci. Phila., ser. 2, ii., I 853,262 (Calif.); Townsend, Proc. U. S. Nat. Mus., vol. x., I887, p. 223 (n. Calif.; discovery of nest and eggs); Barlow, Condor, vol. iii., I90I, p. I77, fig. (Sierra Nevada; habits, nests and eggs).

THE BLACK-THROATED Gray Warbler is not a mermaid, nor yet a merman, but I shall never forget how one sang to me as I stood "silent upon a peak in Darien," nor how he plunged presently into the nearest billow of an ocean of fog, which on a June morning had engulfed southern California. Oh, the witchery of that June morning in the San 


\section{The Black-throated Gray Warbler}

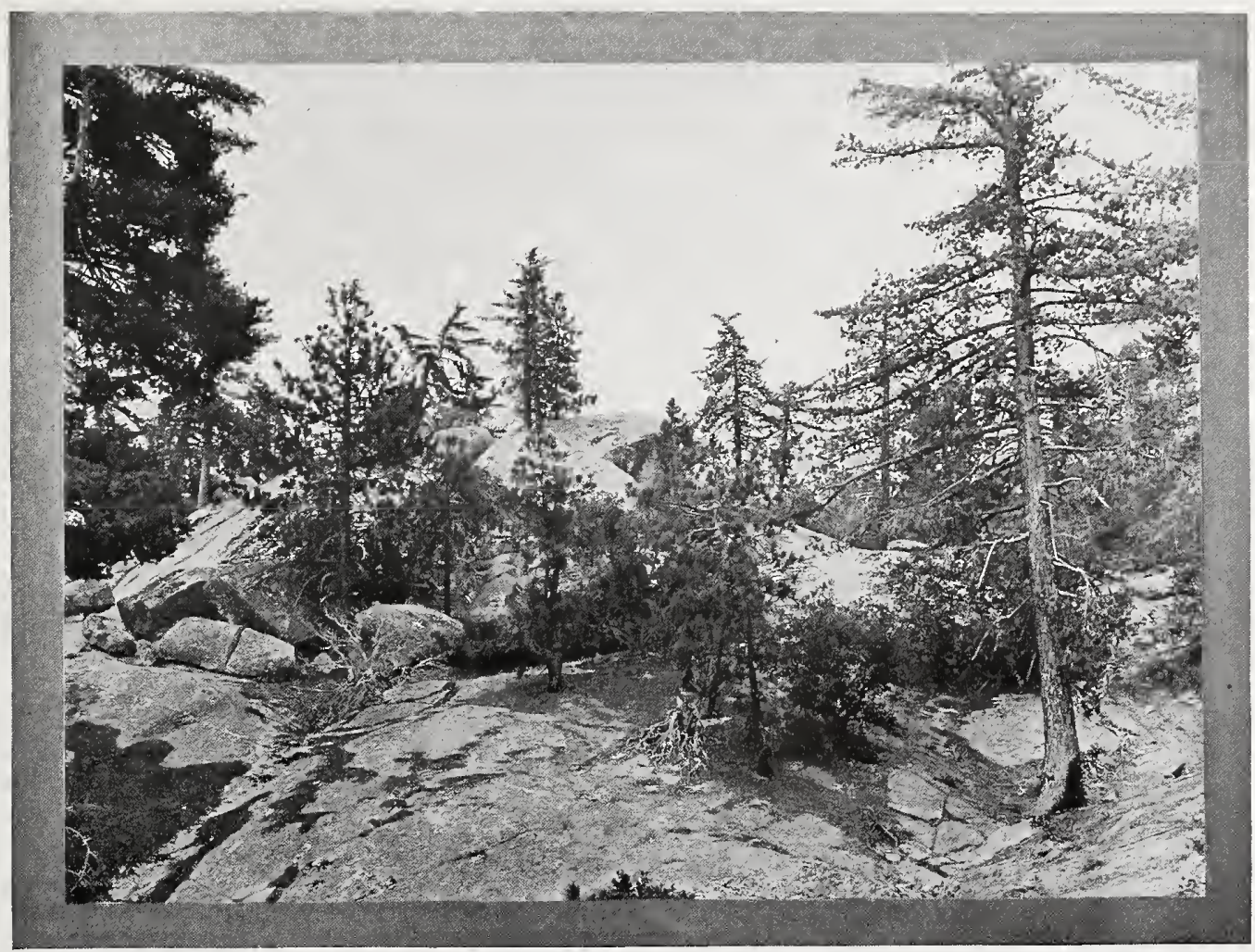

Taken in Riverside County

Photo by the Author

AT THE 6300 FOOT LEVEL-SAN JACINTO MOUNTAINS

Jacinto Mountains! and oh, the solitude of that all-obliterating sea! To be sure, the "shore" where I stood was 6300 feet above sea-level; but it was as if the elder world had reasserted itself. Our continent-to-be comprises only mountain ridges. The Hemet Range to the south juts into our ocean like a promontory, while the distant Santa Ana Range (beyond Elsinore) lies as an island, as perfectly defined as Santa Cruz. Riverside, Pomona, Pasadena, Los Angeles, those troublers of the future, they are indistinguishable ooze at the bottom of this ocean of grayness. The sun, coming up from behind, smiles to see the prank which Mother Nature has played, and all the surface of this pseudo-sea quivers with delight,- - weird doings, which only the bird and I witness; for presently he emerges from his morning dip and resumes his drowsy song of solitude. His perch is authentic mountain laurel (for all we are at the seaside), and the bird, unmindful of the morning's frolic, voices his quaint happiness in woods woods woodsy, tones whose somnolent effect belies the earnestness of the singer.

These notes are evidently the charm before which the spell breaks. 


\section{The Black-throated Gray Warbler}

Reefs of trees disclose themselves beneath the retreating billows. Distant shoals of "culture" emerge. The ocean is sucked up by old Sol's impetuous beams. Sullen wraiths of mist are chased off the landscape hilariously. Day is at hand. And day discloses the soberest chap, nigrescens, all tricked out in black and white and Quaker gray. There is a bird called the Black-and-white Warbler, and it has been known to visit California. By way of distinction, I propose a new name for

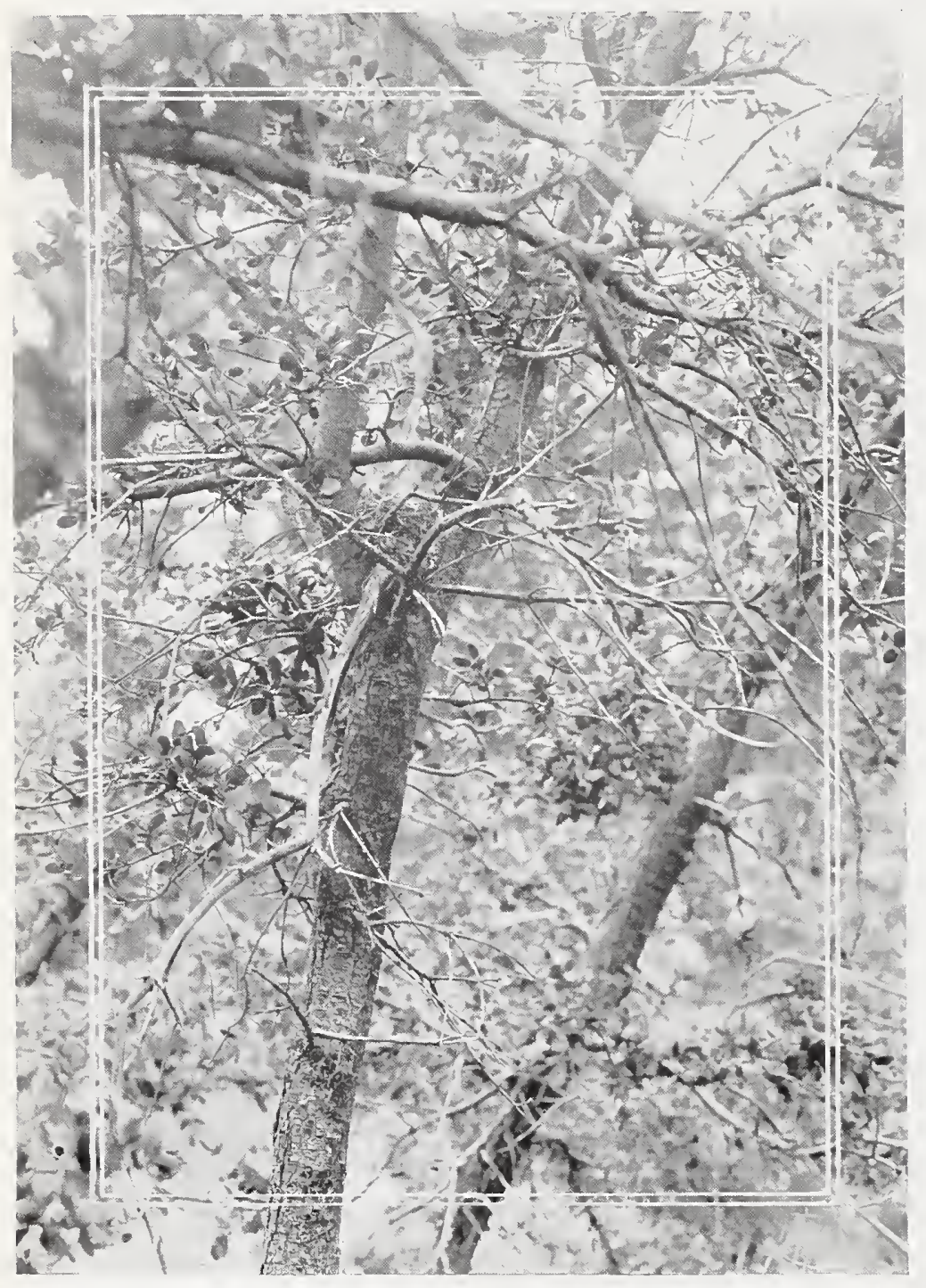

Taken in San Jacinto Mountains

Photo by the Author our native son, viz., Black-and-white-andRussian-gray-with-justa-saucy-dot-of-yellowin - front - of - the - eye Warbler. That'll fix him. Or at least he will come to mind if you call him that.

Th e Black-throated Gray Warbler is singularly deliberate in movement. He does not fear exposure, but neither does he court attention by fidgeting. Besides, what's the hurry anyhow? We've got all day to it. There is time for a bug, and time for a song, and time, mayhap, for a tender passage with a dear little lady, not so black and not so white and not so saucy with her yellow.

However inconspicuous the migrations in a given locality - and they are usually inconspicuous in California - the Black-throated Gray Warbler is an assured factor in the spring bird movement. Travelling, 


\section{The Black-throated Gray Warbler}

as all warblers do, by night, this natty little voyageur will descend wherever daybreak overtakes him; and I have seen him spend a merry day in late April on the sand dunes, breathing the incense of sand verbenas, or venturing out upon the beach after seductive flies.

The normal breeding range of this warbler, however, is in Upper Sonoran or lower Transition zones, wherever mixed cover is available. Although fond enough of ceanothus and manzanita and scrub oak, in which the nests are often placed, pure cultures of these chaparral plants are not usually patronized by these birds unless they are overlooked by scattering trees from which the male may sing. This requirement of mixed cover, therefore, rules out alike the treeless chaparral of the lower levels and the upper Sierran forests, where the snows of winter restrain the undergrowth.

The song of the Black-throated Gray is rather unpretentious, although varied and highly individual. Mrs. Bailey has called itı "a simple warbler lay, zee-ee-zee-ee, ze, ze, ze, with the quiet woodsy quality of virens and caerulescens, so soothing to the ear." "Woodsy" is excellent, unescapable, but in view of increasing experience I can hardly admit that the song is so simple as Mrs. Bailey's characterization suggests. While the droning woodsy quality is usually the clew to identification, even where Hermits and Audubons and Lutescents and Calaverases and Tolmies are singing at the same time, the Black-throated Gray's variations will keep the student on the alert. Typical songs are: Heo flidgity; heo flidgity; and twidge widge widge widgyleêootee. A Yosemite male sang Tip $i$ dwee, tip $i$ dwee, tid wee tipple. There is character, especially in the last turn, which occasionally suggests the lilt of the Hermit, as, heo flidgity cho mêo; or the explosiveness of an Empidonax, as, Hoo cool kuhmeéako kuhweé ack. Light, rambling, inconsequential ditties I have heard which utterly lacked the woodsy quality, Churee churee kee, churee churee. And again, a lilting song dropped by a young male who was feeding patiently among the catkins of a tall, fresh-budding alder, had some of the airy qualities of the Kinglet's notes, Deo déopli, $d u d u d u$, deo déo pli, deo déo pli, deo déo pli,-really a mere fairy sibilation, too fine for mortal ears to analyze.

In nesting, the Black-throated Grays are decidedly shy and secretive. The female, who of course does all the work, may be traced at building time, but she takes better pains than most not to be caught on the nest. Once in the San Jacinto Mountains, at an altitude of about 6700 feet, an excited lady nigrescens burst out indignantly, as I was rounding a point of rocks with a few scrub live oaks about. I hove to while the little Quaker sputtered, and then I watched her make an interminable

${ }^{1}$ Handbook of Birds of Western United States, p. 4 I 9 


\section{The Townsend Warbler}

toilet while she sat in a dead manzanita of ashen gray hue. This making of the toilet is the master sign of an incubating female. Cramped as she has been by long hours on watch, she immediately falls to preening her feathers, when danger, not too threatening, has obliged her to quit her post. The mate, in this instance, appeared also, and "chipped" both sharply and vigorously. But his interest flagged presently and he made off, pouting, while the madame, always chipping, proceeded to preen her feathers for the sixth time. It was a desperately tedious process for the onlooker, but at last the call of the nest became irresistible. The female roused herself, circled about noisily to throw me off the scent, and then fell silent in the depths of a little live oak patch. I moved toward it watchfully, but or ever I reached the edge the scolding notes burst out afresh. This time I used my eyes, and presently made out a dull gray nest snugly ensconced in the dull gray fork of an oak sapling about eight feet up. The nest is deeply cupped, composed externally of frayed weed-bark, bleached in some instances to whiteness. The lining is of finest grasses interspersed with deer-hair, and the brim is turned with a copious use of feathers, among which I recognize the bronzy sheen of the Roadrunner's.

Another nest, taken by Mr. C. W. Bowles in Oregon, is set in a multiple fork of manzanita at a low height. The walls contain every sort of woodsy loot,--flower-stems, frayed grasses, catkins, spider-cases, and sheer trash. The lining is of gray feathers exclusively, while the brim bristles with an array of Mountain Quail feathers. The four eggs are white, speckled and spotted, chiefly about the larger end with light russet vinaceous.

Although so fond of nesting at the lower levels, this warbler does not scruple to nest also at any height in fir or pine trees; and in such fashion it carries out the genius of the genus Dendroica, which is singularly unfettered in its habits and choices.

No. 89

\section{Townsend's Warbler}

\section{A. O. U. No. 668. Dendroica townsendi (Townsend).}

Description.-Adult male: Pileum, hind-neck, lores and auriculars, chin, throat, and upper chest, black; supraloral region, continuous with broad superciliary, a spot under eye, and a malar stripe (broadening behind, and nearly meeting end of superciliary on side of neck), yellow; breast yellow, heavily streaked on sides with black, 


\section{The Townsend Warbler}

the black streaks thickening and merging with black of chest in front, scattering on flanks, and reappearing on under tail-coverts; upper sides and flanks and remaining underparts, posteriorly, white as to ground; back, scapulars and rump yellowish olivegreen (warbler green), sharply streaked with black, shading into black of head on hindneck; longer upper tail-coverts abruptly bluish gray; wings and tail blackish with some edgings of light gray; two white wing-bars formed by tips of middle and greater coverts; three outer pairs of tail-feathers blotched with white on inner webs in descending ratio. Bill black with paler tomia; feet and legs brown; iris brown. Adult male in fall and winter: Scarcely different; the black areas only suggestively veiled, that of the throat by scanty yellow tips, that of the pileum by warbler green. [Note: This characterization is based on four California-taken specimens in the Museum of Vertebrate Zoölogy, and bearing dates of Nov. 25, Dec. 3I, Jan. 6, and Jan. 22, respectively. The description given under this head by Ridgway (Birds of N.\& M. America, Bull. 50, U. S. N. M., Pt. ii., p. 560) and others applies only to first year males.] Adult female: Much like adult male, but black areas somewhat restricted and much reduced in intensity; black spottings of back nearly obsolete; pileum chiefly warbler green, upon which black appears mesially as streaks; cheek-patch olive-green; throat chiefly yellow; the black of chest greatly reduced, appearing only as irruptive patches and streaks. Immature male: Similar to adult female, but blacks everywhere a little more prominent, less veiled. Length about I27 (5.00). Av. of Io adult males in M. V. Z. colls: wing 66.5 (2.62); tail 53.4 (2.10); bill 9.5 (.37); tarsus 19.3 (.76). Av. of Io adult females: wing 63.3 (2.49); tail 50.4 (I.98); bill $9.5(.37)$; tarsus I $8.4(.72)$.

Recognition Marks.-Warbler size; black on crown, cheeks, and throat of adult male. Female and young exhibit same pattern with blacks reduced, or changed to olive-green. Note breast yellow in contrast with Dendroica virens. Crown black or olive-green, and superciliary yellow, in contrast with D. magnolia (which is warbler blue on top of head).

Remark.-Mr. Swarth has called my attention to the close resemblance in color pattern between Dendroica townsendi and D. nigrescens. If with townsendi as a base, one should substitute warbler blue for warbler green, and white for yellow (with the retention of a single spot over the lores), he would have an almost exact replica of D. nigrescens. Not impossibly there is a real phylogenetic hint here.

Nesting. - Not known to breed in California. Nest: Of coarse and fine weedstems and grasses, lined with fine grasses, flower-stems or horsehair; settled rather loosely upon horizontal pine or fir branch at any height, or nestled near trunk in top of evergreen sapling. Eggs: 4 or 5; white, speckled and spotted, chiefly about larger end, with reddish brown and dark brown. Av. size, $15.2 \times 12.7(.60 \times .50)$ (Reed).

General Range.-Western North America. Breeds from Prince William Sound and the Upper Yukon, south to Washington and western Montana; winters regularly from central California to Guatemala, and sparingly north to Puget Sound. Migration includes western Texas and several of the Rocky Mountain states.

Distribution in California.-A winter resident in west central California; of regular occurrence from Marin County south to Santa Barbara; more sparingly throughout the San Diego district, including the Santa Barbara Islands. Also a common migrant through southern and interior California. Dr. Grinnell's surmise (Condor, vol. vii., I905, pp. 52-53) that we have here two geographical races is probably a valid one. According to this authority, the winter resident birds have shorter wings, and hail from the northwest coast district; the longer-winged migrants which pass in numbers in late April and up to mid-May, have spent the winter in the remoter South, 


\section{The Townsend Warbler}

and are bound for the northern interior, eastern British Columbia, to the Yukon territory.

Authorities.-Baird, Rep. Pac. R. R. Surv., vol. ix., 1858, p. 269 (Santa Clara); Grinnell, Condor, vol. vii., I905, p. 52 (status in Calif.); Beal, U. S. Dept. Agric., Biol. Surv. Bull., no. 30, 1907, p. 46 (food).

VERBAL description of this woodland exquisite is superfluous with Brook's excellent plate at hand;1 but one may be allowed to testify to the thrill of pleasure which its appearance invariably creates. It is impossible, moreover, for any color "process" to do justice to the luster of the shining black in toronsendi's panoply, or to the purity of the lemon chrome with which it alternates. This is, in fact, a very dream of a bird, and I count it rather the handsomest of our western species.

Californians are no grumblers, and we have learned, I guess, to "count our blessings" as well as to forget our woes. IVe are quick to resent, therefore, the frequent criticism of the back-Easter as to the variety and abundance of our birds. We point with pride to the fact that our State boasts 580 varieties, at least one hundred more than any other state in the Union (except Texas, that whale of a state which Oberholser has gone over with a fine-toothed comb and a magnifying glass, looking for subspecies); and we explain patiently that the reason why we do not witness billows of migration in spring is because our birds are not starved out in winter, and so do not have to go south to live off Mexico. But strictly among ourselves, we shall have to confess that we are beaten on the Warblers. The Yankee has us here, and he will not forbear to rub it in. Out of 56 species (not counting subspecies) of the Mniotiltidae, New England claims 34 as resident or migrant, of which 29 breed; and even prosy old Ohio sees 36 of these lisping fairies, as against I3 (regulars) for California. We are justified, you see, in paying double honor to western warblers.

Until very recently the authorities persisted in ascribing to Townsend's Warbler a summer home in California, but an expectant search of all our mountains has failed to discover a single breeding bird, and we are fain to conclude that townsendi, like coronata (hooveri) alone, passes entirely beyond our border. On the other hand, the occurrence of this species as a resident in winter has been persistently ignored, or at least underestimated. It is likely to occur at lower levels throughout the State wherever moderate temperatures prevail and suitable cover offers. Always modest and unobtrusive, townsendi becomes more retiring in the winter and hunts quietly through the live oaks, or visits the ragged

${ }^{1}$ Regrettably omitted in the smaller format. 


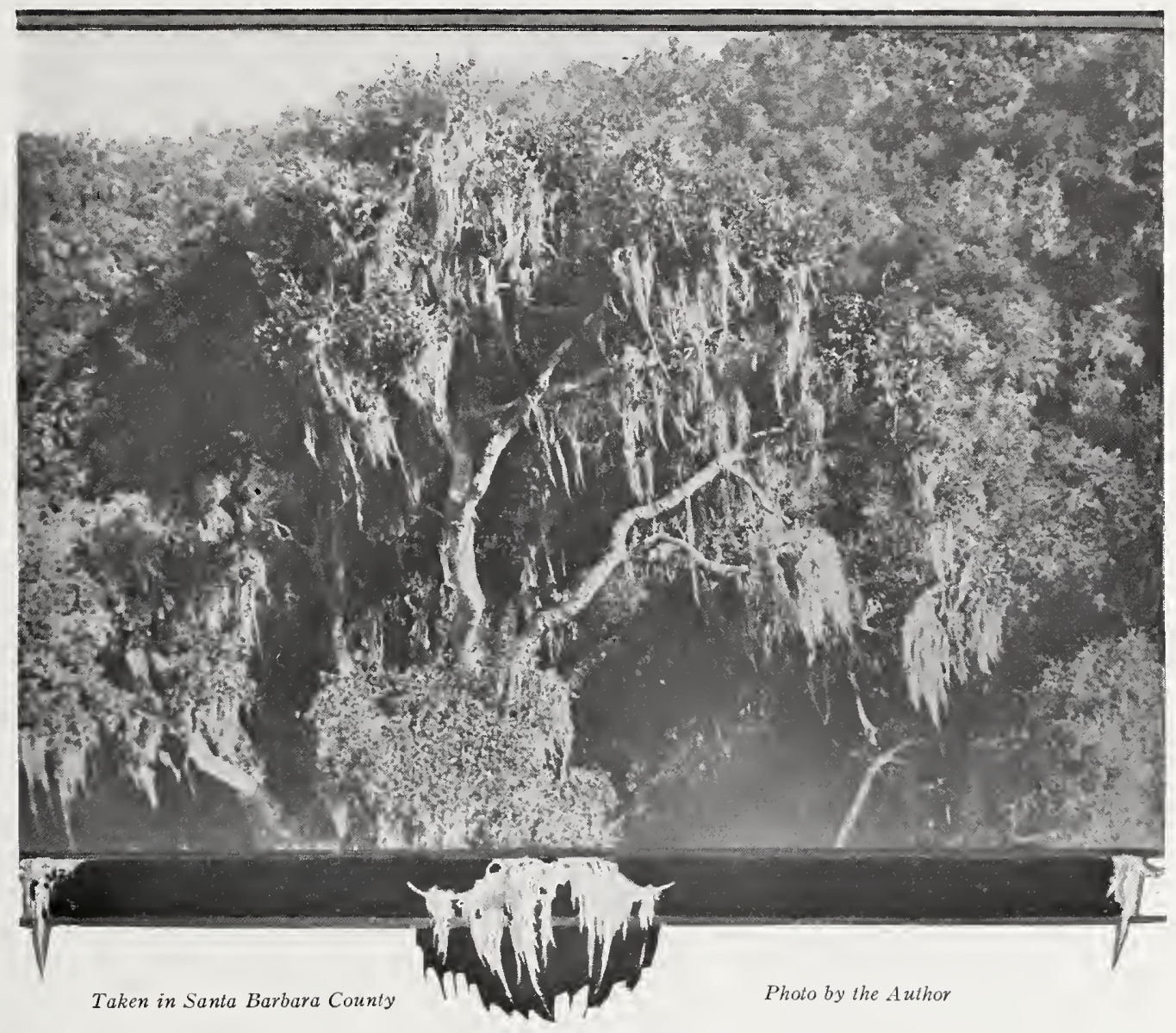

THE BEARDED OAKS OF HOPE RANCH

A WiNTER STATION OF THE TOWNSEND WARBLER

ranks of unfallen leaves on the willow and sycamore trees. Its rarely uttered tsip or tsiip, although a little sharper and more clean-cut than Audubon's note, passes so easily for that of the more abundant bird that townsendi habitually escapes notice the season through.

During the spring migrations, which occur in late April or full May, townsendi attracts more attention. It is driven to lower levels in its search for aphides or worms, and in a land where all is sunshine and teeming life it does not so fear exposure. A bird sighted in the North during the last week in May haunted a pine and a balm tree at the foot of a lake, singing constantly. The song ran, dzwee, dzwee, dzwee, dzwee, dzweetsee, the first four notes drowsy and drawling, the fourth prolonged, and the remainder somewhat furry and squeaky. The bird hunted patiently through the long needles of the pine, under what would seem 


\section{The Black-throated Green Warbler}

to an observer great difficulties. Once he espied an especially desirable tidbit on the under side of a needle-beset branch. The bird leaned over and peered beneath, until he quite lost his balance and turned a somersault in the air. But he returned to the charge again and again, now creeping cautiously around to the under side, now clinging to the pine needles themselves and again fluttering bravely in the midst, until he succeeded in exhausting the little pocket of provender, whatever it was.

The song of the townsendi I find to be more variable both in quality and cadence than that of any other western member of its group. It sometimes reminds one of the lisping squeak of Dendroica virens, an own cousin in the East. Sometimes it will have the drowsy obstructed quality of our own Black-throated Grays. If I had not known that I was bestriding the Forth-Sixth Parallel of longitude, and had not seen the Townsendine mandibles keeping time at fifteen feet, I should have ascribed a certain song, Swuss swuss swuss tsuss tsss, to the Blackburnian Warbler (D. blackburnia) of the East. Again, near Victoria, B. C., I have listened to a high-pitched clear-cut song which had in it something of the light quality and crispness of the Fox Sparrow's notes, although not, of course, so "large" a sound: Heo teo teeoo teeoo chee chee wee chu. But it is in competition with the Hermit Warbler that our hero becomes most alluring and most confusing. Lilly lilly lilly leêoolee, says the Hermit; and if you are a quarter of a mile away, you catch only the exquisite lilt at the end. Oozi woozi leê oo lee, says the Townsend; and if you hear him, too, at a distance, you do not know which bird has spoken,- - Shibboleth or sibboleth? A very pretty wreath of bay awaits the birdologist who will satisfy us on this little point of Mniotiltine philology.

No. 90

\section{Black-throated Green Warbler}

\section{A. O. U. No. 667. Dendroica virens (Gmelin).}

Description.-Adult male in spring: Above bright warbler green (yellow with a dash of black in it), changing on sides of head and neck to pure yellow, where also interrupted by postocular streak, or patch, of olive-green; longer upper tail-coverts chiefly ashy gray, or with a greenish gloss; two prominent white bars on wing formed by tips of middle and greater coverts; three outermost pairs of tail-feathers chiefly white on inner webs, the fourth pair broadly edged with white on inner web near tip; chin, throat, chest, and sides of breast, black, continued narrowly, posteriorly, until breaking into streaks; the black usually very slightly veiled by whitish tips; remaining underparts palest yellow, or palest buffy white, clearing to pure white on under tail-coverts; the flanks touched with yellow. Bill and feet dark brown. In autumn: Scarcely 


\section{The Black-throated Green Warbler}

different - the blacks only slightly veiled by whitish tips (these tips, irregularly, persist until April). Adult female in spring: Similar to adult male in spring, but black of lower parts much reduced, displaced by yellow on chin and upper throat, and veiled elsewhere by whitish or buffy edgings. In autumn: Blacks still further veiled by buffy edgings; the upper throat dull yellow or buffy and marked obscurely with olivaceous irruptions on sides. Immature male: Much like female in autumn, but blacks a little stronger everywhere, and appearing under yellow veiling of upper throat. Length about I 27 (5.00). Av. of 9 males: wing 63.8 (2.5 I); tail 47.8 (I.88); bill 9.9 (.39); tarsus 17.3 (.68). Av. of 7 females: wing 60 (2.36); tail 46 (I.8I); bill 9.7 (.38); tarsus $17.3(.68)$.

Recognition Marks.--Small warbler size. Warbler green without spots above; black of throat contrasting with yellow of cheeks and white of underparts.

Nesting.-Does not breed in California. Nest: Of twigs, bark-strips, grass, moss, and feathers; settled loosely into needles on upper side of horizontal branch of coniferous tree, Io to 50 feet up. Eggs: 4 ; white, with creamy or buffy tints, speckled and spotted with vinaceous gray and chocolate, usually gathered in loose wreath about larger end. Av. size I $6 \times 12.5(.63 \times .49)$.

General Range.- North America, breeding in Transition and Lower Canadian zones, in the states and provinces lying each side of the 49th Parallel, and from Alberta east to Newfoundland; south in the Alleghany Mountains to Georgia; wintering in Mexico and south to Panama.

Occurrence in Galifornia.- Accidental during migrations; one record: adult female taken on the Farallon Islands, May 29, I9I I.

Authorities.-Dawson, Condor, vol. xiii., I9I I, p. I68 (Farallon Ids., May 29, I9II, one spec.; June I, I9II, one seen).

ON THE evening of May 29, I9II, the author, in company with John F. Rowley, secured, at all too close range, a female of this characteristic eastern species. It had settled momentarily upon the ground in front of the head light-keeper's house on the S. E. Farallon. Unfortunately most of the bird's head was carried away by a bunched charge of shot, but "the remains," deftly prepared by Mr. Rowley, are now in the Academy collections in San Francisco to attest the validity of this first and only record. Another specimen, also a female, was seen in company with such other migrants as Redstart, Magnolia Warbler, etc., on the afternoon of June Ist; but no attempt was made to secure it. As significant of the fine shades of distinction necessary in identifying these warblers, I was amused (?) to find that an assistant curator at the Academy had filed this specimen away as D. townsendi. Dr. Grinnell, however, confirms our original diagnosis. 


\section{Hermit Warbler}

A. O. U. No. 669. Dendroica occidentalis (Townsend).

Synonym.-Western Warbler.

Description.-Adult male in breeding plumage: Forehead, crown and sides of head and neck, broadly, rich lemon-yellow, sharply defined below by black of chin, throat and upper chest, less sharply above by black of occiput or hind-neck; this in turn shading through mingled olive and black into gray of remaining upperparts; upper plumage more or less tinged with olive-green and streaked more or less broadly with black; wings and tail black with grayish edgings; middle and greater coverts tipped with white forming two conspicuous wing-bars,-outermost pair of tail-feathers chiefly white on both webs, next pair white on terminal half of inner web, and third pair marked with longitudinal spot near tip; black of chest with convex posterior outline sharply defined from white of remaining underparts. Bill blackish; legs and feet dark brown; iris brown. Adult male in fall and winter: Yellow of crown veiled by olive-green, sooty olive or blackish; black of throat veiled by whitish tips; black streaking of upperparts less conspicuous. Adult female in spring: Like male but much duller; the black of throat and chest wanting, or else heavily veiled,- upon the throat with yellow, upon the breast with sordid buffy; the yellow of head duller, pale yellow: the feathers of crown generously tipped with sooty olive or blackish; the black of cervix wanting; remaining upperparts dull bluish gray, glossed with olive-green; black streaks obsolete; remaining underparts sordid white or dull buffy. Immature birds resemble the adult female, but the olive-green element in the upper plumage much strengthened, nearly pure warbler green on cervix; the pileum chiefly olivegreen with mesial streaks of black; the black also more or less present in broad wedgeshaped streaks on back (most abundant in males ?); underparts more strongly buffy, with throat often buffy-white rather than yellow. Length about I30.8 (5.15). Av. of Io adult males in M. V. Z. colls.: wing 67 (2.64); tail 50.8 (2.00); bill 9.8 (.39); tarsus r $8.9(.74)$. Av. of 5 adult females: wing 63.3 (2.49); tail 49 (1.93); bill $9.6(.38)$; tarsus I $7.8(.70)$.

Recognition Marks.-Warbler size; yellow mask of male outlined against black of throat and hind-neck distinctive. Female and young more difficult, but essential yellowness of head contrasting with gray and sordid white usually suggestive.

Nesting. - Nest: Saddled on horizontal branch of fir tree at considerable height; a compact structure of fir-twigs, mosses, and vegetable down; lined with fine grass and horselıair; measures outside 4 inches wide by $23 / 4$ deep; inside, 2 wide by $11 / 4$ deep. Eggs: 4 or 5; dull white, heavily spotted and blotched with shades of reddish brown and vinacalous gray. Av. size, $17 \times 13.2\left(.67 \times .5^{2}\right)$. Season: c. June 1 st; one brood.

General Range.-Pacific Coast district and Sierra-Cascade system with its outliers, north to British Columbia; Nevada and Arizona in migrations; Mexico and Guatemala in winter.

Distribution in California.--Fairly common breeder in the Transition zone of the Sierras from Mt. Whitney north to Shasta; doubtfully a breeder in the San Bernardino Mountains; common migrant through southern California and on both sides of the Sierras; less common or sporadic spring migrant through west central 


\section{The Hermit Warbler}

California. Has been twice taken in winter in west central California: Pacific Grove and San Geronimo (Mailliard-Grinnell).

Authorities.-Baird, Rep. Pac. R. R. Surv., vol. ix., I858, p. 268 (Petaluma); Brewster, Auk, vol. iv., I 887, p. I66 (discovery of nest and eggs, at Blue Canon); Barlow, Auk, vol. xvi., I 899, p. I 56 (Eldorado Co., nesting habits, desc. nest and eggs); ibid., Condor, vol. iii., I90I, p. I79 (Sierra Nevada; habits, song, etc.).

FIRST impressions are unescapable; and the author hopes he may be pardoned, for once, in introducing verbatim et literatim a record written in the State of Washington, because it is, after all, strictly applicable to much of the Hermit Warbler's setting in California.

"There is a piece of woodland south of Tacoma which we call the Hermit Woods, because here on any May day may be heard the voice of this exalted Warbler. The proper hour in which to approach this forest is early morning, before the winds have begun to stir in its dim aisles, and while the hush of its nightly peace is upon everything-save the birds. The soft moss muffles the footsteps, so that the devotee may move about unheralded from shrine to shrine, as he pays silent homage

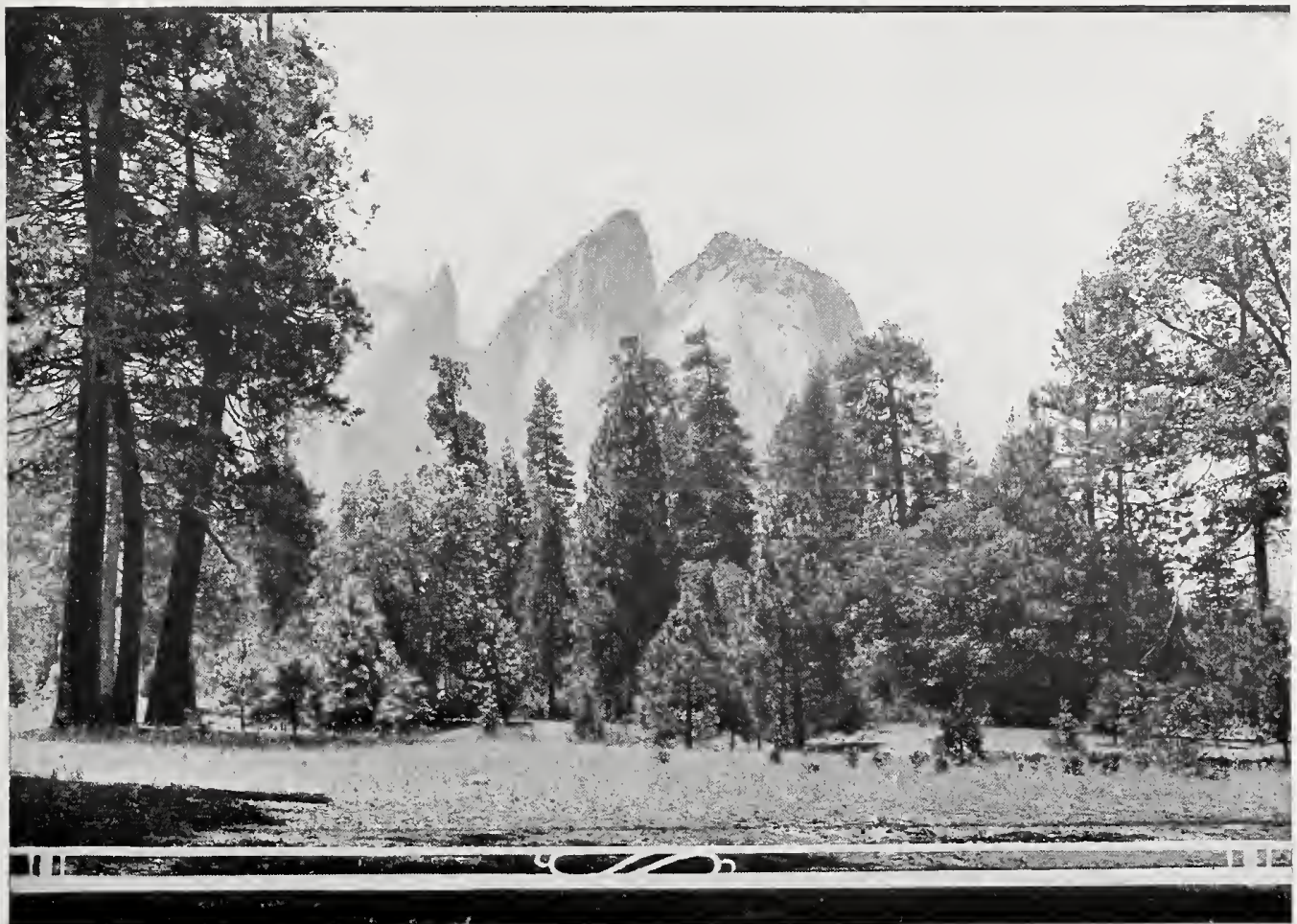

Taken in Yosemite Valley

Photo by the A uthor THE CATHEDRAL IN WHICH THE HERMIT SINGS 


\section{The Hermit Warbler}

to each, in turn, of those morning stars of song, the Wood Warblers. There is Audubon with his hastening melody of gladness. There is Black-throated Gray with his still drowsy sonnet of sweet content. Then there is Hermit hidden aloft in the shapeless greenery of the underdawn,- his note is sweetest, gladdest, most seraphic of them all, Lilly, lilly, lilly, leê o leet. It is almost sacrilege to give it form-besides it is so hopeless. The preparatory notes are like the tinkle of crystal bells and when our attention is focused, lo! the wonder happens,the exquisite lilt of the closing phrase, leê-oleet.

"In broad daylight it is the same. The singers remain in the treetops and tease the imagination with thoughts of a domestic life lived upon a higher plane than that of earth, an exalted state where all is beatific and serene. And try you never so hard, with glasses of a high power, it is a good hour's work to obtain a satisfactory sight of one of the uplifted creatures.

"In despair, one day, I determined to penetrate this supramundane region where the Hermit is at home, and selected for the purpose a well branched tree in the center of the forest and some hundred and fifty feet in height. The tree was, fortunately, of the tougher sort, and permitted ascent to a point where the stem might be grasped with the finger and thumb of one hand. It was a treat to see the forest as a bird does. The surface viewed from above was surprisingly uneven. Here and there strong young trees, green and full of sap, rose to the level of mine, but the majority were lower, and some appeared like green rosettes set in a well of green. Others still, rugged and uneven as to limb, towered above my station by fifty or seventy-five feet. My first discovery upon reaching the top was that the bulk of the bird chorus now sounded from below. But a few singing Hermits did occupy stations more lofty than mine. One I marked down-rather, up - fifty feet above and a hundred yards away. He sang away like a contented eremite from a single twig, and I was reverently constructing his high biography and trying to pick out his domicile from the neighboring branches, when flash! he pitched headlong two hundred feet and was seen no more."

In marked contrast with this lofty conduct, is the behavior of the Hermit Warbler during migrations. In common with most other species of Mniotiltida, the Hermits will not scruple at such times to descend upon fences or wayside willows, or even upon the ground. We had them in I9I2-the year of the great warbler wave-fairly swarming over the Santa Barbara coast up till May Ioth. On the 27th of April we found them, together with ten other varieties of warblers, at a single observation post near the city. Elsewhere and ordinarily, the appearance of the bird at all, anywhere outside of its Sierran breeding range, is 
deemed worthy of record.

The nesting of the Hermit Warbler has always possessed a peculiar fascination for Californian ornithologists. And at that I am bound to record, as I did ten years ago, "the nest of this species is still rare." Most of the Californian records gather about the classical locality of Fyffe in Eldorado County, where the first fully identified set known to science was taken by Rollo H. Beck, on June Io, I 896.1 The Beck set, n/4, was placed well out on a sloping limb of yellow pine at a height of forty feet, and a regional elevation of 3500 .

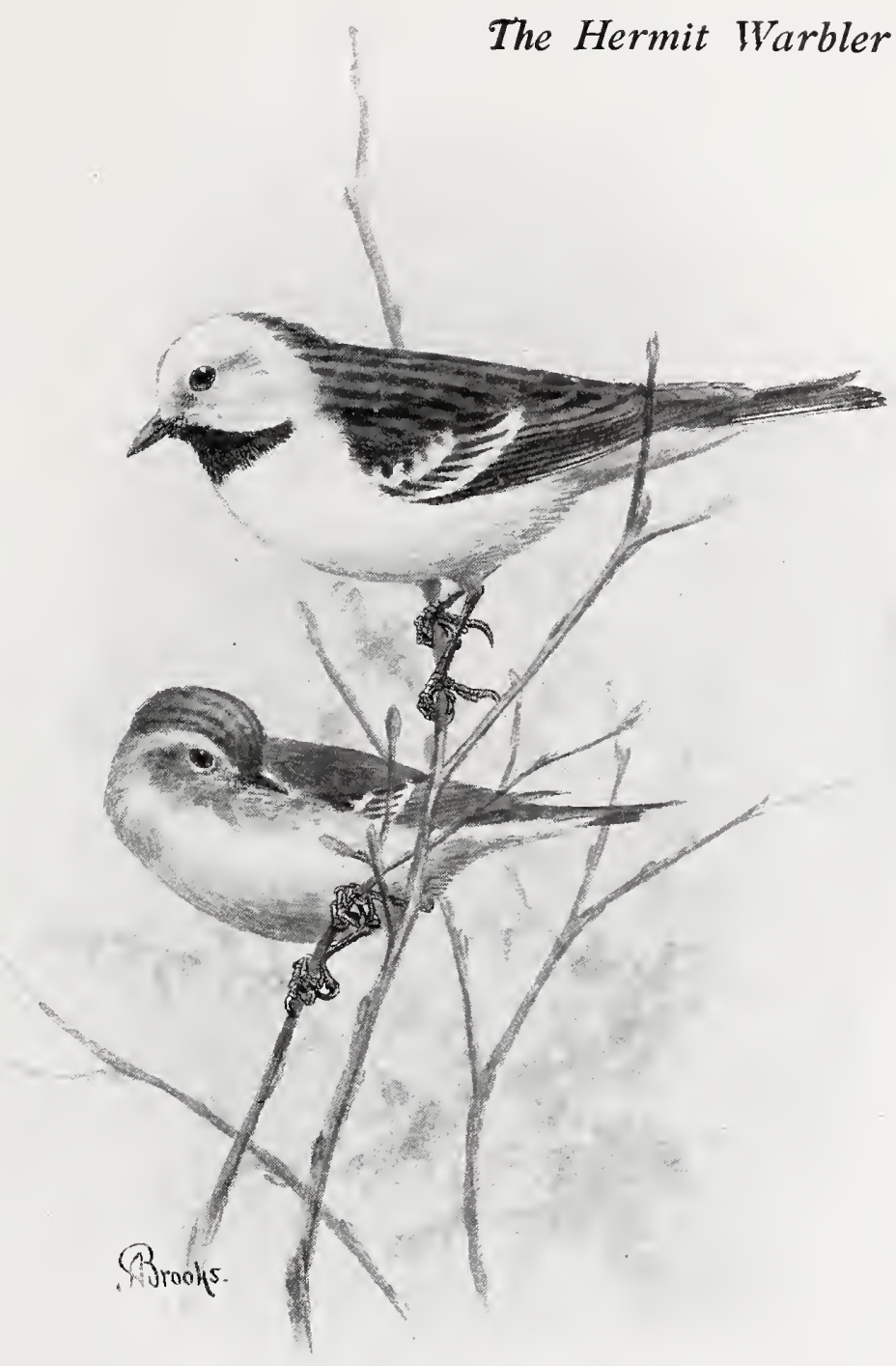

The following year, on June IIth, Mr. F. M. Nutting 2 found a nest containing young, which was placed only $\mathrm{I} 2$ feet up in a small cedar. Chester Barlow took the second set, also of four eggs, in the same locality on June I4th, I898.3 This was placed at a height of 45 feet in a yellow pine, but good photographs were secured and published. 4 The third set, $\mathrm{n} / 4$, June 8 , I 899, fell to the lot of our veteran oölogist, Henry W. Carriger, then in his twenties. This might have been deemed an easy find, since it was placed only $2 \mathrm{r} / 2$ feet up in a tiny cedar; but a Hermit Warbler

1The Nidologist, March, 1897, p. 79.

'The Auk, Vol. XVI., April, I899, p. 157.

IIb., p. I58.

${ }^{4}$ The Condor, Vol. II., March, I90o, pp. 44 and 45. 


\section{The Hermit Warbler}

is never easy; and if it was in this instance, Mr. Carriger has justified his reputation by picking Hermits' nests out of tree-tops, where the laity see only irresolvable greenery. In March, I9I4, Mr. Milton S. Ray reported a set taken May I4, I9I3 (near Fyffe, of course), as the "first to be found containing five eggs." Unfortunately, a northern collector, Mr. J. H. Bowles, had already taken three sets of five, the first of which, taken June I I, I905, had been twice published.1

Although by no means confined to Fyffe, the breeding range of the Hermit Warbler is, without doubt, very restricted. The bird is absent from vast stretches which would seem to be perfectly suited to its needs; and, in general, we may hazard the guess that the species, in obedience

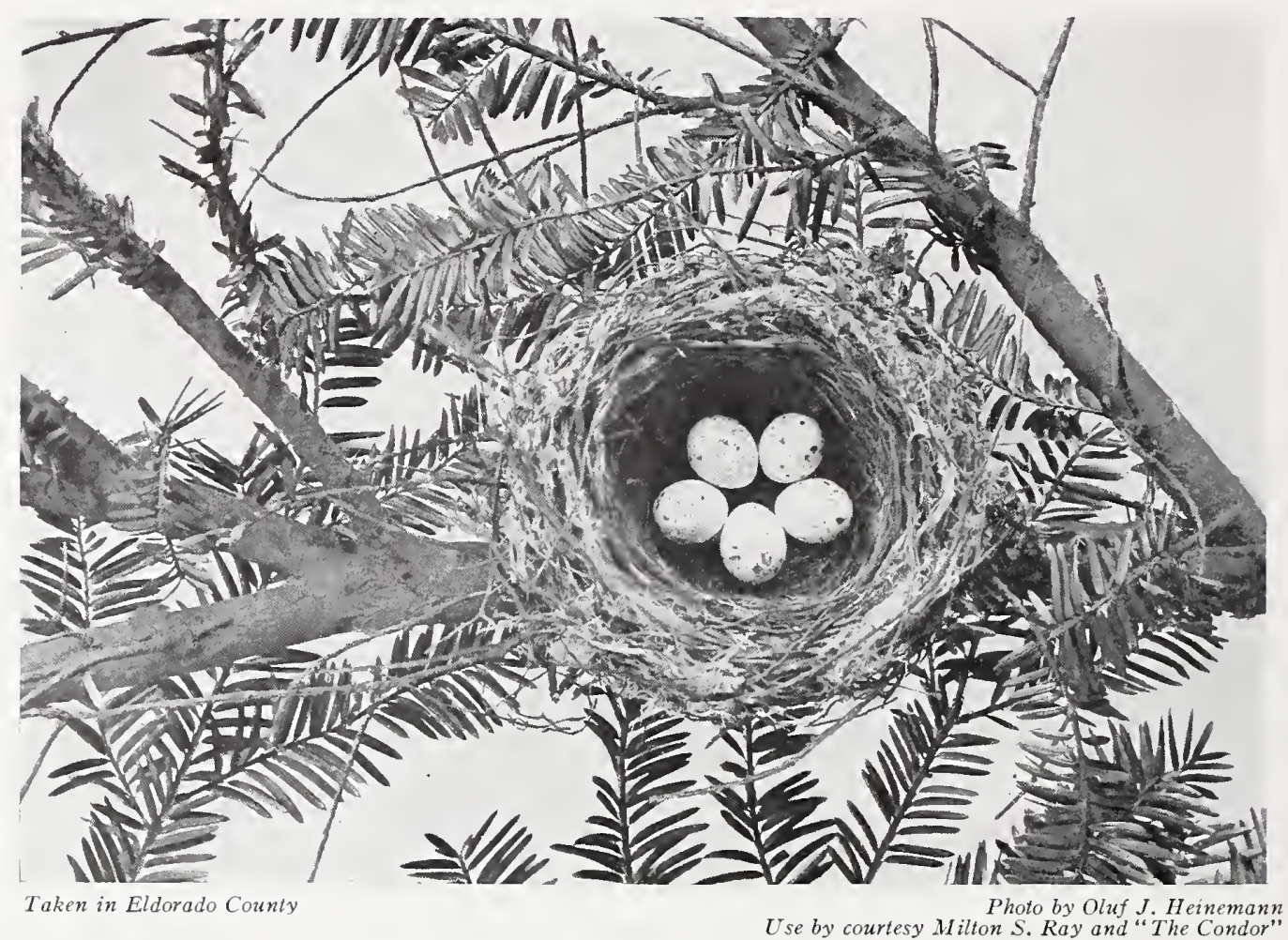

NEST AND EGGS OF HERMIT WARBLER

to that strange hyperborizing instinct which the retreating ice left as its peculiar legacy, is gradually deserting California for more northern climes. The occasional occurrence of the bird in winter, as along the Monterey coast, may be cited in support of this "northward trend."

"Vide Condor, Vol. VIII., March, 1906, p. 4I, and "The Birds of Washington," p. I96 (I909). 


\section{The Chestnut-sided Warbler}

Since it requires a rather discriminating ear to note the bird in passing, or to pick it out in its breeding haunts, I record here a few variant song forms which I have clearly traced to the Hermit Warbler: Zeegle, zeegle, zeegle, zeet, fuzzy and low like that of $D$. nigrescens - this was heard in Washington and is recognized by $\mathrm{C}$. W. Bowles as being the type form of southern Oregon songs; dzee, dzeé, tzibid-zeedzeé, dzee dzeé in a sort of sing-song rollick; dzudzudzudzudzeêo zeêo zeet-first syllables very rapid, musical; nasal turn to accented notes very like the "ping" note of the Creeper song, and occupying much the same position save that it is repeated; days, days, days, days zeêt-the first notes lisping, with slight accelerando, and the nasal ringing quality reserved for the last. Of the song of the Fyffe birds Mr. Barlow has written:1 "Though not loud it would penetrate through the woods quite a distance, and very much resembled $t$ sit, $t$ sit, $t$ sit, tsit, chee chee chee, the first four syllables being uttered with a gradual and uniform speed, ending quickly with the chee chee chee. It was quite distinct from any other of the warbler songs, and whenever it was heard the little musician was usually traced to some pine tree where he would be found hopping nervously about."

No. 92

\section{Chestnut-sided Warbler}

\section{A. O. U. No. 659. Dendroica pensylvanica (Linnæus).}

Description.-Adult male in spring: Extreme forehead and supraloral region white; upper forehead and crown olive-yellow (pyrite yellow); malar region, lores, and superciliaries black, the last-named produced and meeting fellow across occiput, broadly, where also streaked with white and yellow; auriculars and hind-neck (crossing cervix obscurely) white; remaining upperparts in general black centrally on feathers, with bright olive-yellow (oil-yellow) or dull warbler blue edgings, the yellow sometimes confined to middle of back; broad wing-bars, sometimes confluent, of white and sulphur; chin, throat, and underparts white, relieved on sides by a broad stripe of chestnut, continuous from malar black patch to flanks, where, and on lower sides, breaking irregularly. Bill blackish; feet and legs dark brown. Adult female in spring: Much like male and of ten indistinguishable, but usually duller, with restriction of chestnut on sides posteriorly; white of forehead displaced by yellow, and the yellow of crown duller (wax-yellow). Adult male in autumn: Quite different from adult in spring plumage; of the more prominent characters only the chestnut remains, and that confined to the posterior portion of the sides. Above plain warbler green (olive-yellow), purest on forehead and crown, elsewhere streaked with black; eye-ring white; extreme forehead, lores, sides of head, and breast, dull neutral gray, changing variously to dull white on throat and abdomen; flanks touched with yellow. Bill lighter. Adult female in autumn: Like male in autumn but chestnut still more restricted; the black streaks of

${ }^{1}$ Auk, Vol. XVI., April, 1899, p. 159. 


\section{The Palm Warbler}

upperparts chiefly confined to rump and upper tail-coverts. Immature male: Like adult female in autumn. Immature female: Like adult female in autumn without chestnut on sides or black streaking above. Length about I27 (5.00). Av. of 7 males: wing $63(2.48)$; tail $50(\mathbf{I} .97)$; bill $9.6(.38)$; tarsus I $7.8(.70)$. Av. of 7 females: wing $59.3(2.33)$; tail 46.7 ( (.84); bill 9.5 (.37); tarsus I $7.6(.69)$.

Recognition Marks. - Warbler size; chestnut sides and white underparts in adult; sordid gray on sides of head and neck contrasting with warbler green of crown in immature; yellow wing-bars.

Nesting.--Does not breed in California. Nest: Of coiled bark-strips, grasses and plant-down; lined with hair; placed 2 to Io feet high in bush or sapling. Eggs: 4 or 5 ; white or creamy white, speckled with rufous or chestnut, chiefly near larger end. Av. size, $16.5 \times 12.7(.65 \times .50)$.

General Range.-Eastern North America. Breeds in Transition zone from central Saskatchewan, Ontario, and Newfoundland, south to eastern Nebraska, northern Ohio, etc., and Rhode Island, and along the Alleghanies to Tennessee and South Carolina. Also casually (?) to southern Missouri and the valley of the Wabash. Winters from Guatemala to Panama. Casual, in Florida and the Bahamas.

Occurrence in California.--One record: Sherwood, Mendocino County, September $2 \mathrm{I}, \mathrm{I} 908$.

Authority.-Marsden, Condor, vol. xi., 1909, p. 64 (Sherwood, Mendocino Co., Sept. 2 I, I908, one spec.).

INSTINCT is less fallible than reason, but it is not infallible. The migrating instinct successfully guides uncountable legions of frail creatures across abysses of distance from which all but the most hardy of human travellers would shrink. Yet now and then we are called upon to witness its failure, and to record some straggler utterly separated from his kind. A waif Chestnut-sided Warbler, a juvenal male, was picked up in Mendocino County, Sept. 2I, I908, a thousand miles west of any known breeding station of the species.

If we had not such abundant treasure of our own, we should surely covet the possession of this dainty midget which so abundantly gladdens the brushy hillsides of little old New England.

No. 93

\section{Palm Warbler}

A. O. U. No. 672. Dendroica palmarum palmarum (Gmelin).

Synonyms.-Red-poll Warbler. Wagtail Warbler.

Description.-Adult (sexes alike): Forehead and crown chestnut; extreme forehead dusky, divided by short yellow line; a yellow superciliary line; cheeks much like back, rump and upper tail-coverts, olive-yellow; remaining upperparts olive-brown, chiefly in broad mesial streaks, edged obscurely with lighter, and glanced with yellow; wings and tail dusky with obscure grayish and greenish yellow edgings, the former 


\section{The Tolmie Warbler}

without conspicuous bars; subterminal white spots, usual to the genus, on two outer pairs of rectrices; underparts yellow, clearest on chin, throat, and lower tail-coverts, dingy on belly; elsewhere sharply and finely streaked with chestnut or olive-dusky; the sides washed with brownish. Adult in autumn and immature: Crown much obscured by brownish tips; superciliary line whitish or buffy; below dingy white, or buffy with faint yellowish tinge; breast and sides obscurely streaked with olive-dusky; lower tail-coverts, only, clear yellow. Length of males, II4.3-I39.7 (4.50-5.50); wing 65 (2.56); tail 50 ( I.97); bill ro (.39); tarsus $20(.79)$. Females average a little smaller.

Recognition Marks.-Medium size; chestnut crown distinctive in high plumage. Keeps to fence-rows, hedges, and wayside bushes during migrations; "bobs" nervously and wags tail.

Nesting.-Does not breed in California. Nest: On the ground, in low places or edges of swamps; a compact structure of grasses, bark-strips, and mosses; variously lined. Eggs: 4; creamy white, spotted and blotched with reddish browns and vinaceous gray. Av. size, $17.8 \times 13.2(.70 \times .52)$.

General Range.-Breeds in the northern interior of North America from northern Minnesota to southern Mackenzie and central Keewatin; winters from southern Florida and the Bahamas to the Greater Antilles and Yucatan; during migrations on the Atlantic slope; accidental in Colorado, Montana and California.

Occurrence in California.-One record, that of an immature male taken at Pacific Grove, Oct. 9, I 896.

Authority.-Emerson, Osprey, vol. ii., I 898, p. 92 (Pacific Grove, October 9, I 896 , one spec.).

IN LATE October, I 896, Mr. W. Otto Emerson, the veteran ornithologist and collector of Hayward, took the record specimen of $D$. palmarum, a young male, near Pacific Grove. He took it at first for a Pipit (Anthus s. rubescens), which it somewhat resembles, both by reason of its hunting much upon the ground, and its habit of teetering the body and jetting the tail. The Palm Warbler is unique among the Dendroicans in the last-named respect, but it may be speedily distinguished from Anthus by the tell-tale white blotches on the rectrices. Inasmuch as the bird breeds as far west as southwestern Mackenzie, and there are other western records, a sharp lookout should be kept for a possible repetition of this "accident."

\section{No. 94}

\section{Tolmie's Warbler}

A. O. U. No. 680. Oporornis tolmiei (J. K. Townsend).

Synonym.-Macgillivray's Warbler.

Description.-Adult male in spring and summer: Foreparts in general, including head and neck all around and chest, blackish slate or slate-gray; extreme forehead and lores jet black; feathers of lower chest slate-black narrowly fringed with ashy gray; extreme chin usually white; a sharp touch of white on upper eyelid behind 


\section{The Tolmie Warbler}

and a longer one on lower lid; remaining plumage bright greenish yellow to olive-green, clearest yellow, canary to olive-yellow, on breast and remaining underparts, centrally, and on bend of wing, shading through yellowish olive-green on sides to olive-green of upperparts; outer primary edged with white on outer web. Bill dusky brown above, paler below; feet and legs light brown; iris brown. Adult male in fall and winter: Similar, but feathers of hind-neck and crown tipped with dull brown; ashy skirtings of throat and chest more extensive, sometimes nearly concealing the black. Adult female in spring: Like male but slate of hood replaced by dull brownish gray (deep mouse-gray to deep neutral gray) above, and by pale brownish gray (smoke-gray) on chin, throat, and chest. Adult female in autumn: As in spring, but brown of head more intense. Immature male and female: Like adult female in autumn, and not certainly distinguishable, although males incline toward slaty on breast, and females are of a buffier brown. Length of adult male (female smaller) about I 39.7 (5.50); av. of Io adult males in coll. of Mus. Vert. Zool., wing 58.6 (2.3I); tail 52.7 (2.07); bill I0.4 (.4I); tarsus 20.5 (.8I). Av. of Io females, wing 56.6 (2.23); tail 52. I (2.05); bill I0.2 (.40); tarsus $19.3(.76)$.

Recognition Marks.-Warbler size; slaty hood of male distinctive; contrast of color between chest and breast apparent in any plumage. A frequenter of thickets. With a sharp tsick or chuck note of alarm.

Nesting.- Nest: A cup of coarse twisted grasses; lined with fine grasses and (if possible) black horsehair; placed low in bushes, sometimes practically on the ground. Eggs: 3 to 5, usually 4i dull white, handsomely spotted and blotched, or self-toned, chiefly at larger end in wreath or cap, with blackish brown or chocolate and underlying vinaceous gray. Av. size, $17.8 \times 13.7(.70 \times .54)$. Season: June; one brood.

General Range.-Western North America, breeding from central British Columbia, central Alberta, southern Saskatchewan, and southwestern South Dakota, south to central California, central Arizona, and northern New Mexico. Wintering from Lower California and Mexico south to Colombia; casual a few degrees easterly during migrations.

Distribution in California.- Summer resident, locally common in Transitional areas, south along the Sierras to the latitude of Independence (Kenawyer's, south fork of the Kings River, July 8, I9I3), and along the desert ranges to Grapevine Mountain (A. K. Fisher); in the Coast ranges south to San Francisco Bay, and even, sparingly, to Los Gatos, Santa Clara County (Van Denburgh); also a common migrant throughout the State. One winter record, apparently of a derelict: Los Angeles, Dec. I7, I914 (Wyman).

Authorities.-Heermann (Trichas tolmiei), Jour. Acad. Nat. Sci. Phila., ser. 2, ii., I853, p. 263 (Calif.); Coues, Birds Colo. Vall., I878, p. 3 I2 (syn., habits, etc.); Wythe, Condor, vol. xviii., I9I6, p. I23 (desc. habits, nest, eggs, young birds, etc.).

BRUSHY hillsides not too remote from water, or dense shrubbery partially shaded by trees, afford ideal cover for this handsome warbler and his all but invisible spouse. Mere chaparral will not do either, for the bird loves moisture, and a certain tang in the atmosphere, found in California in the humid coastal counties and on the middle levels of the northern Sierras. Variety, also, is his delight; and after temperature, variety in cover seems to be the bird's requirement; and a great confusion of shrubs, willow, alder, ceanothus, chokecherry, service-berry, 


\section{The Tolmie Warbler}

chinquapin, or mountain mahogany suits him best. Here he may hide, a most persistent skulker, wary, suspicious, active, and very competent. Yet even he, when he thinks no one is looking, emerges from his shrubbery depths, selects a topmost twig and breaks out in song,- - a song which is neither diffident nor uncertain. Sheep sheep sheep shear shear sheep, he announces in a brisk, business-like tone, totally devoid of musical quality. And when you have heard him once, or, say, a hundred times, you have learned all that may be

known of the Tolmie Warbler-out of cover. Those who know the Dickcissel of the middle West will at once be struck with the close similarity of its song, although it must be admitted that the Warbler's is lighter in quality and less wooden. A close study of these efforts discloses some variation, both in the number of the syllables and in the number and distribution of the r's; thus, Sheep, sheep, shear, shear, sheep; Sheep, sheep, shear, shear, sheep, sheep; and, a shade more emphatic, Jick jick, jick, jick, shear, sheep. A Lake County performer sounded forth eight times per minute in songs of a second and a quarter's duration: crik, crik, crik, crik, ree'tie; while the members

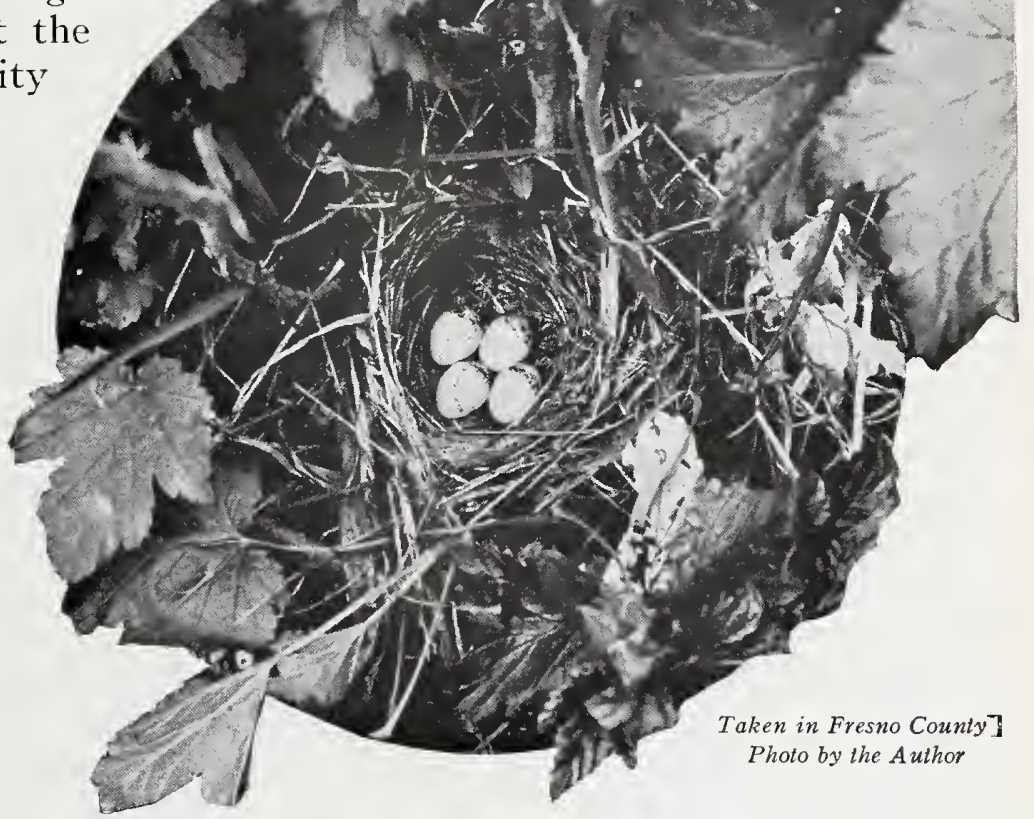

NEST AND EGGS OF THE TOLMIE WARBLER of a colony near Sisson invariably said, Creek, creek, creek, bizhup', bizhup'.

For all we see so little of the Tolmie Warbler, the converse is by no means true. That is to say, the bird does see a great deal of us if we frequent the thickets. Whenever there is anything doing in his vicinity, the Warbler promptly and silently threads the intervening mazes, takes observations of the disturber from every angle, and retires with, at most, a disapproving chuck. In the fall of the year discipline 


\section{The Tolmie Warbler}

is somewhat relaxed, and a little judicious screeping in the shrubbery will call up platoons of these inquisitive Warblers.

Owing partly to the caution of the sitting female, and more to the density of its cover, the nest of the Tolmie Warbler is not often found. When approached, the bird glides away silently from her nest, and begins feeding ostentatiously in the neighboring bushes. This of itself is enough to arouse suspicion in an instructed mind, for the exhibition is plainly gratuitous. But the brush keeps the secret well, or, if it is forced, we find a bulky, loose-built affair or coarse dead grasses and rootlets, lined with black rootlets or horsehair, and placed either in an upright fork of a bush, or built around the ascending stems of rank herbage at a few inches, or at most two or three feet, from the ground. Eggs, usually four or five in number, are deposited about the first week in June at the mile high level, and Tolmie babies swarm in July and August, quite beyond the expectation of our oölogical fore-season.

The finding of a Tolmie Warbler's nest is almost always a happy accident. It is, therefore, such nests as have happened to be placed near trails or mountain camps which get found and reported. Thus, Mr. Mailliard reports' ${ }^{1}$ a nest with five eggs taken May 7 th near San Geronimo, from a tangle of blackberry vines in a railroad right-of-way, whose boundary fence he was following. Miss Margaret Wythe found a nest with four eggs in the Yosemite Valley within three feet of the camp trail, and noted that incubation consumed eleven days, with the birds away in eight and nine days thereafter. The nest given in the illustration was shown me by the ladies of the Sierra Club on the I8th day of July on the Simpson Meadows (in eastern Fresno County).

A word of explanation regarding the change of name from Macgillivray to Tolmie is in order. J. K. Townsend discovered the bird and really published it first, saying," "I dedicate the species to my friend, W. T. Tolmie, Esq., of Fort Vancouver." Audubon, being entrusted with Townsend's specimens, but disregarding the owner's prior rights, published the bird independently, and tardily, as it happened, as Sylvia macgillivrayi, by which specific name it was long known to ornithologists. Macgillivray was a Scotch naturalist who never saw America, but Tolmie was at that time a surgeon and later a factor of "the Honorable the Hudson Bay Company," and he clearly deserves remembrance at our hands for the friendly hospitality and coöperation which he invariably extended to men of science.

\footnotetext{
${ }^{1}$ Condor, Vol. XI., March, I909, p. 66.
${ }_{20}$ Narrative," April, I839, p. 343.
} 


\section{The Oven-bird}

No. 95

\section{Oven-bird}

A. O. U. No. 674. Seiurus aurocapillus (Linnæus).

Synonyms.-Golden-Crowned Accentor. Golden-Crowned Thrush.

Description.-Adult (female very slightly duller): Above buffy olive; top of head with two blackish lateral stripes, the enclosed area ochraceous-orange ("golden" only by courtesy), slightly veiled by olive-buffy tips of feathers; sides of head washed with color of back; lores, obscurely, and ring about eye, whitish; below white, broadly and sharply spotted on breast, sides of breast, and sides, with blackish; a narrow black malar stripe; axillars and under wing-coverts pale sulphur; flanks pale olive-buffy, shaded by darker; extreme flanks, possibly of immature birds, sometimes tinged with yellow. Bill horn-color above, pale below; feet and legs light brownish. The species exhibits little change with age, sex, or season, but plumage is brighter, fresher, in the fall. Length (sexes equal), I39.7-165.I (5.50-6.50); wing 72.5 (2.85); tail 52 (2.05); bill I I.5 (.45); tarsus I $3.2(.52)$.

Recognition Marks. -Small sparrow size; general thrush-like appearance; head-stripes with included "golden" crown distinctive.

Nesting.-Does not breed in California. Nest: On the ground in deep woods; a slight depression lined and completely overarched with leaves, grasses, bark-strips, and trash, and with entrance at side. Eggs: 4 or 5, rarely 6; white, or creamy white, speckled and spotted lightly and uniformly, or heavily and with tendency toward wreathing or cloud-capping, with dull reddish brown (sometimes as dull as benzo brown) and brownish drab. Av. size, $20.3 \times 15.2(.80 \times .60)$.

General Range.-Eastern and northern North America; breeds from southwestern Mackenzie (casually in the lower Yukon Valley), northern Ontario and Newfoundland, south to central Alberta, Colorado, southern Missouri and Virginia, and in the mountains of South Carolina and Georgia; winters from central Florida and the Louisiana coast south through the West Indies to Colombia.

Occurrence in California.-One record of two birds on the Farallons; one of them taken, May 28, I9I I. Also the first clearly authenticated mainland record by Richard Hunt as below.

Authorities.-Bonaparte, Compte Rendu, I 854, p. 385 ("California"); Dawson, Condor, vol. xiii., I9I I, p. I67 (Farallon Ids., May 29, I9I I, two seen); Hunt, Condor, vol. xxii., I920, p. I9I (Lavic, Mohave Desert, May I 8, I920, one spec.).

THE LIST of "casual" warblers in California is already very large, and it seems probable that most, if not all, of such eastern warblers as breed above the northern tier of states, will eventually be recorded as wanderers into our domain.

This familiar spirit of every eastern woodland was one, or rather two, of a band of waifs which came to the Farallon Islands on the morning of May 26th, I9I I. One bird, an adult male in prime feather, was caught in an empty room of a light-keeper's house, and is now in the California Academy collection. Another, first seen a few minutes later 


\section{The Louisiana Water-Thrush}

outside the house, was frequently sighted in the general vicinity of the keepers' quarters during the remaining five days of our stay.

\section{No. 96}

\section{Louisiana Water-Thrush}

\section{A. O. U. No. 676. Seiurus motacilla (Vieillot).}

Description.-Adult (sexes alike): Above dark olive-brown, darker on crown, more olivaceous on upper tail-coverts; a dark stripe through eye of color of back; a whitish superciliary line extended to cervix; a malar stripe of white, and a submaxillary stripe of olive-brown; underparts white shading to color of back, on sides changing to pale dull buffy posteriorly, sharply spotted on breast and sides with color of back. Bill dark horn-color above, lighter below; feet light (flesh-colored in life?). Fall birds are of fresher appearance, darker, less olivaceous (chætura drab) above. Length I46. II62.6 (5.75-6.40); wing 8I (3.19); tail 52 (2.05); bill I3.2 (.52); tarsus $13.5(.53)$.

Recognition Marks.-Small sparrow size; thrush-like pattern of plumage; white superciliary distinctive, as compared with $S$. aurocapillus or $S$. noveboracensis notabilis; throat unspotted, as distinguished from $S . n$. notabilis; larger.

Nesting.-Does not breed in California. Nest: On mossy bank or among roots of upturned tree; of sodden leaves and twigs; lined with fine grasses and rootlets. Eggs: 4 to 6, 7 of record; white, sprinkled and spotted, lightly or heavily, uniformly, or, more rarely, in wreath or cloud-cap, with reddish brown (vinaceous russet to natal brown) and vinaceous gray. Av. size, $19.3 \times 15.8(.76 \times .62)$.

General Range.- "Eastern United States to South America. Breeds mainly in Carolinian zone, from southeastern Nebraska, southeastern Minnesota, and the southern parts of Michigan, Ontario, New York, and New England south to northeastern Texas, northern Georgia, and central South Carolina; winters from northern Mexico to Colombia, and Greater Antilles, Antigua, and the Bahamas; accidental in California" (A. O. U. Check-List, 3rd Ed.).

Occurrence in California.-Accidental, one record: Mecca, Aug. I7, I908, by Loye Holmes Miller.

Authority.-Miller, Condor, vol. x., 1908, p. 236.

THE CIRCUMSTANCES attending the capture of a unique specimen of this species, at Mecca near Salton Sea, hint strongly at an artificial agency of transportation. Mr. Miller had first noted the bird on August I th (I908), as it hopped about the trucks and platforms of tank cars on the railroad siding; and it flushed repeatedly without quitting the little oasis caused by the overflow of the railroad water-tank. He shot it the same day from one of the timbers of the tank. On the whole it would appear that the restless little Water-Thrush, one of a great company, migratory through eastern Texas, had become entrapped in a freight car of the Southern Pacific system. Or it might have flitted 


\section{The Alaska Water-Thrush}

in through an open window of a passenger coach and been held prisoner until its impulsive captor had relented and turned it loose a thousand miles from home.

No. 97

\section{Alaska Water-Thrush}

\section{A. O. U. No. 675a. Seiurus noveboracensis notabilis Ridgway.}

Synonym.-Grinnell's Water-Thrush.

Description.-Adult: Somewhat similar to Seiurus motacilla, but smaller; the throat spotted, and the whites everywhere tinged with dull sulphury yellow (much duller than in $S$. $n$. noveboracensis): Above dark olive-brown, a little darker on crown and more olivaceous on rump; below white, tinged with sulphur, increasing in strength posteriorly, shading on sides into color of back, elsewhere, save on middle of belly, spotted or streaked with olive-brown, the spots finest on throat and cheeks, thickest on breast, and most elongated on sides; axillars and under wing-coverts pale olivebrown, or whitish tinged and spotted with olive-brown; a yellowish or pale buffy superciliary line. Feet and legs as in S. motacilla. Length I39.7-I52.4 (5.50-6.00); wing 76.5 (3.0I); tail 53.4 (2.10); bill I 3.4 (.53); tarsus 2 I.7 (.85).

Recognition Marks.- Large warbler size, but more suggestive of small sparrow; nearly uniform olive-brown above, streaky below; superciliary yellowish and not so prominent as in $S$. n. notabilis; underparts tinged with yellowish; throat spotted (definitive as compared with $S$. motacilla).

Nesting.-Does not breed in California. Nest (of S. n. noveboracensis): On the ground or in roots of upturned tree; of moss and leaves; lined with fine rootlets and tendrils. Eggs: 4 or 5; white or creamy white, speckled and spotted with reddish browns and vinaceous gray. Av. size, $19.8 \times 15.2(.78 \times .60)$.

Range of Seiurus noveboracensis.-North America, breeding from northwestern Nebraska! (A. O. U.), and in the Alleghany Mountains from West Virginia north to the limit of trees; south in winter to northern South America.

Range of $S$. n. notabilis.-Western North America and northern South America; breeds from southern British Columbia, central Montana, northwestern Nebraska, northern Minnesota, and northwestern Michigan north to the limit of trees in extreme western Alaska. Migrates chiefly east of the Rocky Mountains, through and over the Mississippi Valley, striking the Atlantic Coast from South Carolina southward; winters from the Bahamas, Cuba, and Mexico south to northern South America.

Occurrence in California.-Casual during the fall migrations; several records: Santa Cruz, Sept. 25, I885 (two examples), by A. M. Ingersoll; San Diego, Sept. I I, I 887 (Keeler); Cactus Flat, desert side of San Bernardino Mountains, Aug. I6, I905, by J. Grinnell; National City, San Diego County, Sept. 29, I906, by C. B. Linton; Marin County, Aug. I3, i916, by Harold E. Hansen.

Authorities.-Belding, Land Birds Pac. Dist., I890, p. 2 I6 (Santa Cruz, Sept. 25, I885, two spec.); Keeler, Zoe, vol. I, I89 I, p. 37 ; Grinnell, Univ. Calif. Pub. Zool., vol. v., I908, p. II 5. Linton, Condor, vol. ix., I907, p. 60. 


\section{The Yellowthroats}

GRINNELL counts the records of this bird's occurrence like pearls on a string, and chuckles each time a jewel is added. Alas! for the author that he has no pearl to add! But how will a gem from Arizona do? (the seventh, Mr. Swarth tells me, from that State).

It was May 8th, I9I7. I was seated on the bluff bank of the Santa Cruz "River" (save the mark! it was a piddling trickle at this season) in the heart of the famous mesquite forest south of Tucson. The boastful notes of the White-winged Doves still filled the air, but the sun was getting well up, and most of the other birds had fallen silent. It was time to heave to and play the waiting game. Noting a stir, presently, in the recesses of a great root, which lay thirty feet below me in the edge of the streamlet, I languidly applied the glasses. It was well I did so, for out stepped as jaunty a dancer as ever confronted the Theatre Français. Daintily he teetered and daintily progressed across the area of green scum which bordered the runlet. He picked his way and he picked his food with equal fastidiousness; and though his streaked suit is of the most conventional fashion, I was struck by the note of haunting yellowness which Brooks has hit off so well in his painting. It was as though the bird carried a sort of yellow aureole which yet scarcely tinged his garments. Nothing could have exceeded the trim jauntiness or the well-bred demureness of this titled, ogled, multitudinously coveted fowl; and I could easily imagine that he was stopping to admire himself as he paused beside a clear pool of water. A Vermilion Flycatcher, surely some charmer himself, for he was a splendid male, hopped about the neighboring roots in friendly fashion, and the gentleman from Alaska seemed nothing loth to join fellowship. Er-that's all. The bird flew.

\section{No. 98}

\section{Yellowthroat}

No. 98a Western Yellowthroat

A. O. U. No.68Ia. Geothlypis trichas occidentalis Brewster.

Description.-Adult male in spring and summer: Above grayish olive-green (buffy olive to olive-citrine), brighter (less gray) on upper tail-coverts and tail, changing abruptly to brownish olive (Saccardo's olive) on cervix and crown; an obliquely descending facial mask of black, involving forehead, lores, space about eyes, cheeks, and (more narrowly) sides of neck; along the posterior margin of this mask a narrow band, or fillet, of white, abruptly contrasting anteriorly, shading posteriorly; chin, throat, breast, bend of wing, and under tail-coverts, rich yellow (lemon-chrome); sides of breast and sides heavily shaded with olive-gray (buff-citrine to dark olive-buffy), the color shading and lightening as it crosses lower breast and belly. Bill blackish above, dark horn-color below; feet and legs pale brownish. Adult male in autumn: Much as in 


\section{The Yellowthroats}

spring, but darker and browner above, the brown intensified on crown, and nearly obliterating the white fillet; the black of forehead veiled by buffy or brownish tips. Immature male: Like adult male in autumn, but pileum entirely brown; the white fillet wanting, and the black facial mask only faintly outlined under brown skirtings; the yellow of breast less extended posteriorly, and more or less clouded by an orange-buff element. Adult female in spring and summer: Subsimilar to adult male, but without facial mask or white fillet; head above and on sides brownish olive, most intense on crown, lightening vaguely about eyes; the yellow of underparts much restricted and duller, clearest on throat and in pectoral irruptions, chest and under tail-coverts inclining to dull orange (old gold); breast buffy or creamy (colonial buff to naples yellow). Adult female in autumn: Duller; the yellow element of underparts almost entirely subdued by olive-gray; throat and belly cream-buff. Immature female: Much like adult female in autumn, but showing a little more yellow, especially on under tailcoverts. Young birds are olive-brown above and olive-buffy below, clearing toward warbler green on wing-edgings and on tail, and lightening toward creamy on belly. Length of adults (female a little smaller) about I27 (5.00). Av. of 7 adult males from Humboldt County, Nevada (M. V. Z. colls.) : wing 55.8 (2.20); tail 53 (2.09); bill Io.8 (.43); tarsus $20.4(.80)$.

Recognition Marks.-Warbler size; black mask and white fillet of male distinctive. The female is a much more difficult bird to recognize-perhaps best known by peculiar sordid olive-brownish-yellow shade of underparts. The pale orbital area also assists, but one must live with these birds to know them infallibly.

Nesting.-Nest: Of coarse coiled grasses, or, more rarely, leaves of Typha angustifolia; lined with fine grasses or horsehair; placed at moderate heights in cattails, tules, weeds, or grass-clumps, or, more rarely, in bushes or even trees. Eggs: 3 or 4, rarely 5 ; white, marked with a few bold strokes or scrawls of blackish, and dotted and spotted, sparingly, chiefly about the larger end, with deep vinaceous gray. Av. size, I6.8 x I3 $3(.66 \times 5$. I $)$. Season: May-June; one brood.

Range of Geothlypis trichas.-North America, south in winter to Central America and the West Indies.

Range of G.t.occidentalis.-Western North America west of the Great Plains, breeding from southeastern Alaska east to southern Saskatchewan, south to south central California and western Texas; south in winter to Lower California and Mexico.

Distribution in California.-Common migrant throughout the State; remains to breed in the vicinity of fresh-water marshes (occurring below the Boreal zone) from western central California (except the San Francisco Bay region) and the Death Valley region north to the Oregon line. Status in winter undetermined, but possibly the number of Yellowthroats found in California at that season increases.

Authorities.-Gambel (Trichas marylandica), Proc. Acad. Nat. Sci. Phila., vol. iii., I 847 , p. I 55 (California; subsp. uncertain); Johnson, Condor, vol. vi., I904, p. 129 (Clear Lake; habits; desc. nests and eggs); Beal, U. S. Dept. Agric., Biol. Surv. Bull., no. 30, I907, p. 49 (food); Swarth, Univ. Calif. Pub. Zool., vol. x., I9I2, p. 7 I (crit.; occurrence in California).

\section{No. 98b Tule Yellowthroat}

A. O. U. No. 68Ia, part. Geothlypis trichas scirpicola Grinnell.

Description.--Like G. t. occidentalis, but somewhat darker and richer coloration, especially in the yellows, which incline toward orange; also slightly larger (?) throughout. 


\section{The Yellowthroats}

Nesting.-As in preceding race.

General Range.- Southern California and southern Arizona (presumably, also, northern Sonora and Chihuahua).

Distribution in California.- "Common resident on fresh water marshes of the Pacific lowlands of the San Diegan district; San Diego, Orange and Los Angeles Counties northwest to Santa Barbara, and valley of the South Fork of the Kern River, Kern County; also along the lower Colorado River from Riverside Mountain to the Mexican line"-Grinnell (omitting parentheses).

Authorities.-Grinnell, Condor, vol. iii., I90I, p. 65 (orig. desc.; type from El Monte); ibid., Univ. Calif. Pub. Zool., vol. xii., I9I2, p. 202 (crit.; desc., etc.).

\section{No. 98c Salt Marsh Yellowthroat}

A. O. U. No. 68Ie. Geothlypis trichas sinuosa Grinnell.

Description.-Like $G$. $t$. scirpicola, but slightly darker throughout, with reduction of the white fillet; averages somewhat less in size than $G$. $t$. occidentalis, especially

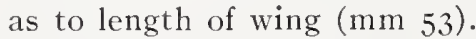

Nesting.-As in preceding form.

Distribution (Wholly contained within California).- Resident in the freshwater and brackish marshes immediately tributary to San Francisco Bay.

Authorities.-Grinnell, Condor, vol. iii., I90I, p. 65 (orig. desc.; type from Palo Alto); Pac. Coast Avifauna, no. I I, I9I5, p. I5I (status in Calif.); Ray, Condor, vol. xviii., I9I6, p. 225 (nesting); Schussler, Condor, vol. xx., I9I8, p. 62 (nesting, song, etc.); van Rossem, Condor, vol. xxiv., July, I922, p. I34 (occurrence at Anaheim Bay, Orange Co., in winter).

Remarks.-Although the atmosphere of San Francisco Bay is undeniably bracing, its effect upon such forms of animal life as have chosen this region for a permanent residence appears to be restraining rather than stimulating. Thus, the local races of certain birds, as, Melospiza melodia pusillula and Geothlypis trichas sinuosa are slightly dwarfed in size. The trouble is caused rather by reduced activity than by unfavorable environment; for, as Coues says, "Migration holds species true; localization lets them slip."

A critical study of the two local or sedentary forms, G. $t$. scirpicola and $G$. $t$. sinuosa, will scarcely discover any points of difference from the migrant occidentalis, save those trifling ones of plumage, tone, and wing measurements. But the fault is manifestly our own. Our methods of observation are too crude and our facilities for comparison are too limited. It is impossible but that these separate races which have endured so differently should reflect that diverse experience in modification of song, of feeding habits, of courting and breeding cycles, - in short, in an altered psychology. But all this is too subtle for our detection-so far.

"CATTAIL Yellowthroat" would be a more appropriate name, if only we had the courage to apply it, because for every pond or swamp in the Southland which can boast the presence of the giant bulrushes (Scirpus lacustris occidentalis and S. californicus), which alone are properly called tules, there are a dozen where only cattails (Typha latifolia or 
The Yellowthroats

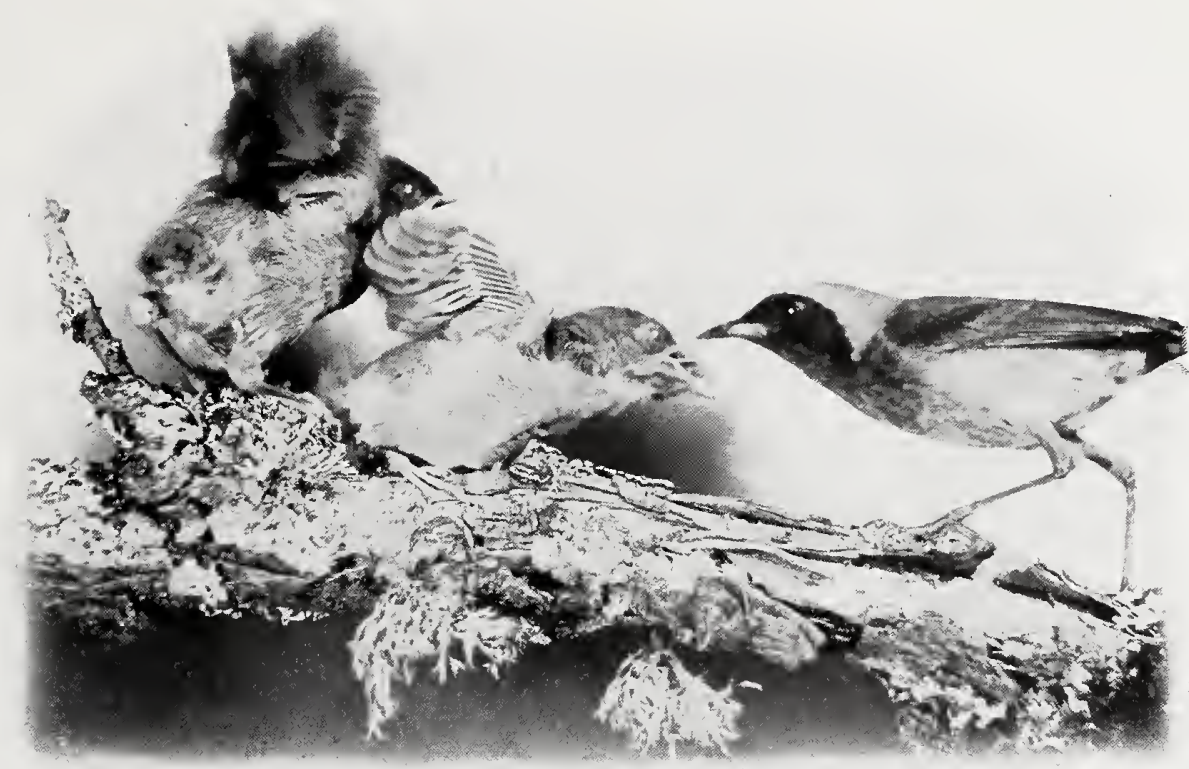

Taken in Oregon

Photo by H. T. Bohlman and W. L. Finley

AN ENTHUSIASTIC RECEPTION

T. angustifolia) dwell. And for every cattail patch there is a pair of Yellowthroats-more, if there is room.

Given a cattail or tule patch as an assured base of operations, Geothlypis will roam about adventurously enough. Rank grass, coarse herbage, stunted bushes - these and the promise of insects will lure him away several hundred yards, but always he sings, "My heart's in the cattails." Yellowthroat is a restless, active, little body, and he is among the first to come forward when you enter the swamp. His method is hide-and-seek and the game would all be his, if he did not reveal his presence from time to time by a harsh accusing note, a sort of Polish, consonantal explosion, wzschthub,--a sound not unlike that made by a guitar string when struck above the stop. If you attempt to follow the bird, the game ends in disappointment. But if the observer pauses, curiosity gets the better of the bird, and he is soon seen peering out from a neighboring bush, roguery only half hidden by his highwayman's mask.

The female, having no mask, keeps to the background, but she is not less interested than her mate in the progress of events. When the scout returns to report, there is often a curious outbreak of discussion, in which the husband, as like as not, finds it necessary to defend his opinion with a perfect torrent of wzschthubs. 


\section{The Yellowthroats}

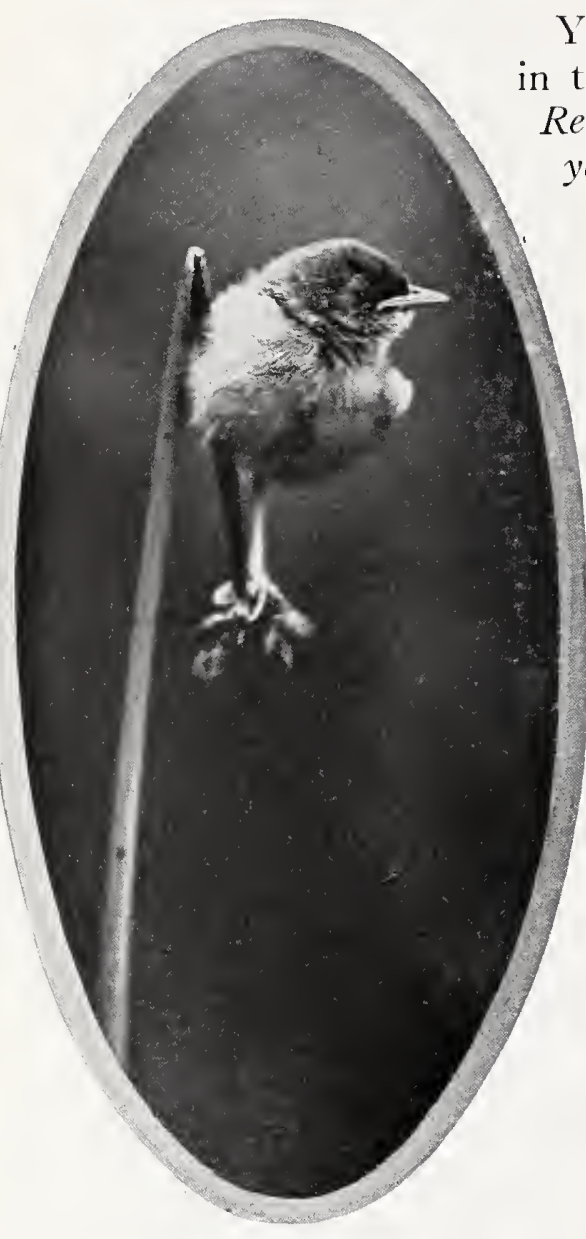

Taken in San Diego Counly Photo by Donald R. Dickey

AN OBLIGING POSE

YOUNG TULE YELLOWTHROAT ON BROKEN TULE STEM

edge of a northern pond, reminded me of the Kentucky Warbler (Oporornis formosus); while another, less ambitious, lisped, O-tis twiss' pe,o-tis twiss' pe. Returning to the typical rhythm, one indignant swain near Los
Yellowthroat's song is one of the few explicit things the swamp. Mounting a weed-stalk, he rubs out, Rees'iwitte rees'iwitte, rit, or I beseech you, I beseech you, I beseech. Rhythm is the chief characteristic of this song, and although a given bird appears to be confined to a single type, the variety of "feet" offered by a swamp is most entertaining. Chit'ooreet chit'ooreet chu', heard on the.

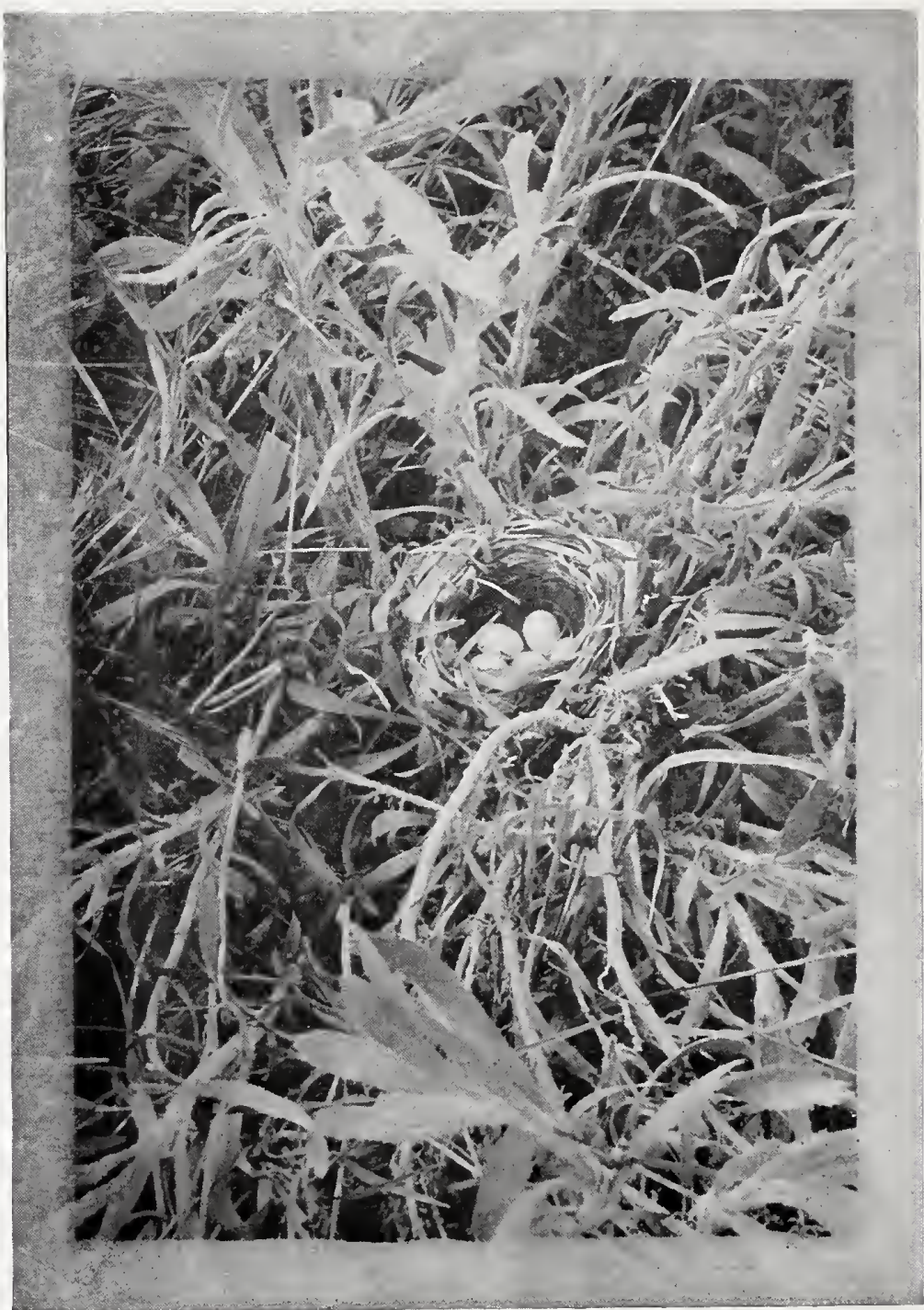

Taken in San Diego County

Photo by Donald R. Dickey

NEST AND EGGS OF THE TULE YELLOWTHROAT 
Angeles, shouted, Greas'y wittles, greas'y wittles, grit! 'The lady who must have been responsible for this outburst had neglected to Hooverize.

But by far the most remarkable song in my experience came from a locality in eastern Washington. We had just been listening to the unwonted notes of a Desert Sparrow (Amphispiza bilineata deserticola) some hundreds of miles out of its usual range, and were not unprepared for shocks, when Hoo hee, chink $i$ woo chu tip fell upon the ear. What! a Slate-colored Sparrow here in the sage-brush! Or is it, maybe, a Vesper, grown precise? Again and again came the measured accents, clear, strong, and sweet. Not till I had seen the mandibles of a Western Yellowthroat, and that repeatedly, moving in perfect rhythm to the music, could I believe so small a bird the author of this song. For fifteen minutes the Warbler brought forth this alien strain, Hee-o chiti wo, chu tip, or Hee oo chitiwew chu tipew, without once lapsing into ordinary dialect. Wherever did he get it?

Nests of the Yellowthroats are the commonplace of all swampy localities-commonplace, yet never without interest, because of their varied architecture and their diverse setting. A nest may be sunk firmly into a damp tussock of grass barely clear of the ground or water, or it may be lashed firmly to the stalks of an investing clump of cattails, or it may be deftly hidden under a canopy of weed-tops a hundred yards from water. The nest may be composed chiefly of brittle weathered leaves of grass or sedge, so incoherent as to be scarcely removable, or else it may be settled into a veritable fortress of coiled cattail leaves, sturdy and dependable. The lining, too, may be of coiled grasses almost as light in color as the speckled white eggs which they support, or it may be of black horsehair, throwing the jewels into prized relief.

While fully two-thirds of all Yellowthroat nests are placed within a stone's throw of water and at levels not over three feet, an observer in Lake County has given us a remarkable account ${ }^{1}$ of the effect of the heavy rains of I903-4 upon the nesting at Clear Lake. The Yellowthroats almost forswore nesting in the tules altogether, and sought shelter both by elevation and by retreat from the water's edge. Of sixty nests examined between May I4th and July 12th, I904, only five were held to be typical. One pair of birds revamped a blackbird's nest for occupation. Another placed its nest hard against the side of a dwelling house under cover of a protecting vine. Some, in the r panic, went as much as three hundred yards from water; and of the tree-nesters the record pair built in a eucalyptus tree at a height of nearly twenty-three feet above the ground.

1A. W. Johnson in "The Condor," Vol. VI., Sept., I90.4, pp. I29-I3I. 


\section{Western Chat}

\section{A. O. U. No. 683a. Icteria virens longicauda Lawrence.}

Synonym.--Long-Talled Chat.

Description.-Adult male: Upperparts deep mouse-gray, usually lightly glossed with olive-green; wings and tail brownish fuscous on exposed inner webs; a broad line above lores and eye, a short maxillary stripe, extreme chin, and eye-ring, white; enclosed area blackish mouse-gray, shading on cheeks into color of upperparts; chin, throat, and breast, broadly, axillars and wing-linings, rich yellow, the color abruptly defined on middle of breast from pure white of remaining underparts; flanks shaded with brownish gray. Bill black; feet blackish. Male in autumn: As in summer, with slight increase of olive-green above, and a suffusion of brownish across crissum. Bill dark brown above, lighter below. Adult female: Like male in autumn but somewhat duller; upperparts olive-brown rather than mouse-gray; pattern of head less distinct; sides of breast tinged with olive-yellow; flanks more broadly olive-buffy. Immature birds closely resemble the parents. Young birds are chiefly brownish olive above, and white or smoky white below, with patchy irruptions of yellow. Length I 7I.5-I 84.2 (6.75-7.25); av, of 23 males (Ridgway): wing 79.I (3.II); tail 81.4 (3.20); bill I $4.5(.57)$; tarsus 26.5 (I.04). Females a little smaller.

Recognition Marks.-Strictly "Sparrow" size; but because of bright color having nearly size value of Towhee,- the largest of the warblers. Bright yellow breast with contrasting white below, distinctive for size.

Nesting.- Nest: A bulky and often careless structure of coiled or interlaced plant-stems and grasses, lined with finer grass or weed-bark or horsehair; set rather carelessly in thick bush or small tree; averages 6 or 7 inches wide by 4 deep outside; 3 to $3 \frac{1}{2}$ wide and $I \frac{1}{2}$ to 2 deep inside. Eggs: 3 or 4 ; white with a slight gloss, finely sprinkled or boldly spotted, uniformly or with wreathed confluence, with reddish brown (vinaceous russet to deep vinaceous brown) and vinaceous gray. Av. of 20 eggs in M. C. O. Coll.: $21.3 \times 16.3(.84 \times .64)$. Season: First week in June; one brood.

Range of Icteria virens.--United States and Mexico, south in winter to Central America.

Range of $I$. v. longicauda.-Western United States and Mexico; breeding from southern British Columbia, Montana, and North Dakota, south to Jalisco and Mexico; winters on the tableland and west coast of Mexico from Chihuahua to Oaxaca.

Distribution in California.-Common migrant at lower levels practically throughout the State, summer resident of riparian associations in Lower and Upper Sonoran and Lower Transition zones, on both sides of the Sierras, and practically throughout the State, save as locally irregular or restricted.

Authorities.-Gambel (Icteria viridis), Proc. Acad. Nat. Sci. Phila., vol. iii., I 847 , p. 157 (Calif.); Lawrence (Icteria longicauda), Ann. Lyc. Nat. Hist. N. Y., vol. vi., I 853 , p. 4 (orig. desc.; from "California"); Coues, Birds Col. Val., i 878, p. 3 I6 (structural characters, habits, song, etc.); Grinnell, Condor, vol. xiv., I9I2, p. I06 (song).

STRUC'TURALLY allied to the Wood Warblers, the Chat has yet such a temperamental affinity with the Catbird, that it is difficult, for me 


\section{The Western Chat}

at least, to dissociate the two birds in thought. Both love the thickets; both excel in song; both plague their neighbors by mimicry; and both alike are dearly provoking bundles of contradictions. The Chat is, perhaps, the greater buffoon, as he is certainly the more handsomely dressed of the two. Beyond this we must consider him on his own merits.

Ten to one you know him, if at all, only as a voice, a tricksy bushwhacker of song, an elusive mystery of the thicket; or you have unconsciously ascribed his productions to half a dozen mythical birds at once. But look more closely. It is well worth the quest to be able to resolve this genius of roguery. Be assured he knows you well enough, by sight, for he does not poke and pry and spy for nothing, in the intervals of song. He has still the proverbial curiosity of woman. Seat yourself in the thicket, and when you hear the mellow, saucy Kook, with its whistled vowel, bounded by consonants barely thought of, imitate it. You will have the bird up in arms at once. Kwook, returns the bird, starting toward you. Repeat it, and you have won. The bird scents a rival and he will leave no stem unclasped but he finds him. As the bird alternately squints and stares from the brush, note the rich warbler olive of his upperparts, the gorgeous yellow of the throat and breast, the white brow-stripe and the malar dash, offset by black and darker olive. It is a warbler in color-pattern, a Yellow-throat done larger, but waggish, furtive, impudent, and resourceful beyond any other of his kind.

The full song of the Chat is usually delivered from some elevation, a solitary tree rearing itself above dense cover. The music almost defies analysis, for it is full of surprises, vocal somersaults, and whimsy turns. Its cadence is ragtime, and its richest phrases are punctuated by flippant jests and droll parentheses. Even in the tree-top the singer clings closely to the protecting greenery, whence he pitches headlong into the thicket at the slightest intimation of approach.

The love song of the Chat, the so-called "dropping song," is one of the choicest of avian comedies, for it is acted as well as sung. The performer flings himself into mid-air, flutters upward for an instant with head upraised and legs abjectly dangling, then slowly sinks on hovering wing, with tail swinging up and down like a mad pump-handle,-Punch, as Cupid, smitten with the mortal sickness. And all this while the zany pours out a flood of tumultuous and heart-rending song. He manages to recover as he nears the brush, and his fianceé evidently approves this sort of buffoonery.

The Chat is a skilled mimic. I have traced the notes of such diverse species as Bullock Oriole, Slender-billed Nuthatch, and Magpie to his door. Once, down on the Rio Grande, we rapped on a vine-covered cottonwood stump to dislodge a Flicker that had been shrieking Klyak at us for some 


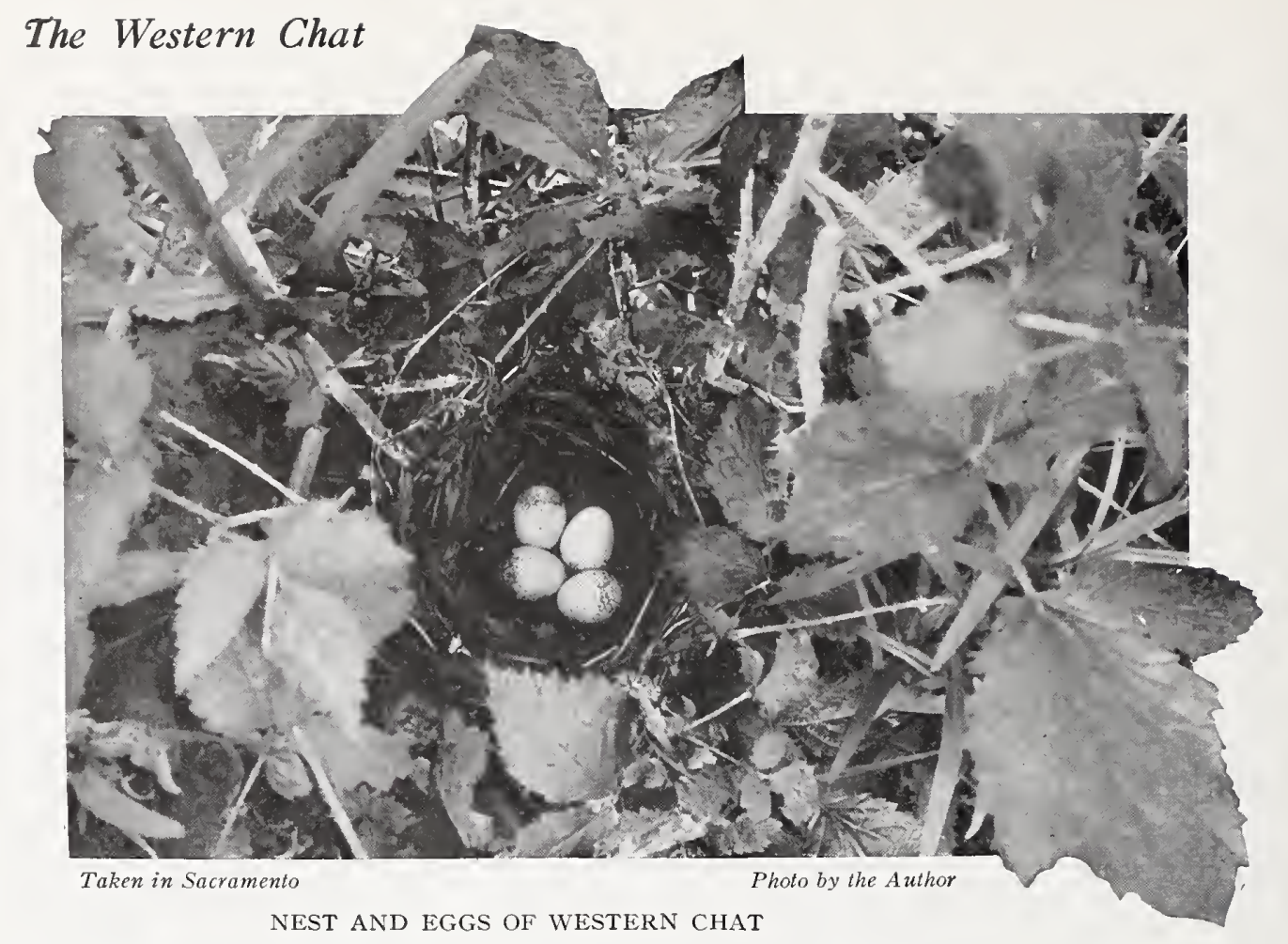

minutes past, and we flushed a snickering Chat, instead.

It is perhaps as a singer of the night that one finds the versatile Chat most impressive. The bird has no compunction about awakening a tired ornithologist; and the prudent camper will, therefore, measure his hours so as to allow for several nocturnal interruptions. It is that incurable malady of the heart again! Chaucer might have said of our hero as he did of the knight:

"So hote he loved that by the nightertale

He slep na more than doth the nightingale."

Be that as it may, the Western Chat will assail the midnight with guttural reproaches, explosive cackles, cat-calls and shrieks until the would-be sleeper is fairly frenzied. Then the bird will pour on a sudden ointment of sound in tones of richest ravishment. The mollified sleeper sinks to rest again amidst a silence palpable.

Skilled minstrel though he is, the Western Chat, like the eastern bird, has small taste for architecture. A careless mass of dead leaves and coarse grasses is assembled in a bush at a height of three or four feet; and a lining of finer grasses, when present at all, is so distinct as to permit of removal without injury to the bulk of the structure. From three to five eggs are laid, and so jealously guarded that the birds are said to destroy the eggs once visited by man. So cautious are the Chats that even after 


\section{The Wilson Warblers}

the young have hatched out, they take care not to be seen in the vicinity of their nest, but a low, anxious chuck sometimes escapes from the harassed mother in a neighboring thicket.

No. 100

\section{Wilson's Warbler}

No. 100a Alaska Pileolated Warbler

A. O. U. No. 685a. Wilsonia pusilla pileolata (Pallas).

Description.-Adult male: Above bright olive-green (warbler green); forehead, sides of head, and underparts bright yellow, shading on sides into color of back; crown or "cap" lustrous black; wings and tail fuscous, edged with olive-green and without peculiar marks. Bill dark above, light below; feet light brown. Adult female: Similar, but the black cap sometimes wanting-dark olive veiled by warbler green tips instead. Immature: Like respective sex of parents, but black of cap sometimes variously, or even completely, veiled by olive-green. Both sexes in autumn suffer some veiling of black crown by olive-green tips. Length about I20.6 (4.75); wing $56(2.20)$ tail 50 (I.97); bill $8.5(.33)$; tarsus I $8.8(.74)$.

Recognition Marks.-Least-pygmy size; black cap of male distinctive; recognizable in any plumage by small size and greenish yellow coloration. Brighter than $W$. p. pusilla; not so bright as $W$. p. chryseola.

Nesting.--Does not breed in California. Nest and eggs much as in next form.

Range of Wilsonia pusilla.-North America, breeding chiefly north of the United States, save in the Rocky Mountain region and in the Pacific Coast states; winters in Mexico and Central America.

Range of $W . p$. pileolata.-Western North America, breeding in Boreal zones from northern Alaska, south upon the Pacific slopes to Queen Charlotte Island, and upon the east side of the Sierra-Cascade system through eastern Oregon and eastern California and along the Rocky Mountains to northern New Mexico and western Texas; wintering from north central Mexico to Panama.

Distribution in California.-Fairly common migrant through southern California, especially east of the desert divide. Also breeds in the mountain ranges east of the Sierras and for an undetermined distance northward. Possibly the line of demarcation between pileolata and chryseola should be arbitrarily set at the Sierran divide.

Authority.-Grinnell, Pac. Coast Avifauna, no. II, I9I5, p. I52.

THE PERVADING yellowness of this little bush-ranger will hardly serve to distinguish it from the equally common Lutescent Warbler, unless you are able to catch sight of its tiny silken crown-patch of black,the "little cap" which gives the bird its Latin-sounding name. With 


\section{The Wilson Warblers}

chryseola it is the smallest of our warblers, and during migrations it is one of the commonest, especially east of the Sierras. Pileolata appears in the lowlands of the San Diegan district and upon the great deserts by the middle of April; but its northern movement is quite leisurely, and loiterers may be encountered anywhere up to June Ist, and even later in the northern portion of the State. Grinnell surmises that this race breeds in Modoc County, but I failed to find a single example in the Warner Mountains between June 7 and July 12 ; so pending discovery of an actual nest, I must beg to consider the question open.

Partly because of his unseasonable dalliance, this tiny golden fragment becomes one of the most conspicuous of migrants in certain sections. Life is a great adventure anyway, and the migratory flight, undertaken before family cares have become a factor in the bird's life, is a rollicking, care-free quest. The Pileolated Warblers, therefore, range higher in the trees during migration than is their midsummer wont. At the lower levels they swarm over the mesquite of the desert oases, or the willow trees of the river bottoms; and the pines know their coming as well as do the huckleberry thickets, which will ultimately swallow them up in the far north. As they go, they "work" their passage most conscientiously, for as Coues says:1 "They peer into the crevices of the bark, scrutinize each leaf, and explore the very heart of the buds, to detect, drag forth and destroy those tiny creatures, singly insignificant, collectively a scourge, which prey upon the hopes of the fruit-grower, and which, if undisturbed, would bring his care to nought."

\section{No. 100b Golden Warbler}

A. O. U. No. 685b. Wilsonia pusilla chryseola Ridgway.

Synonym.-Golden Pileolated Warbler (properly so-called, but the bird, because of its local abundance, deserves the shorter name. Moreover, although "golden" is the commonest color among the Warblers, the name has not been pre-empted).

Description.- "Similar to W. p. pileolata, but slightly smaller and much more brightly colored; olive-green of upperparts much more yellowish, almost olive-yellow in extreme examples; yellow of forehead and superciliary region (especially the former) inclining more or less to orange; yellow of underparts purer, more intense" (Ridgway). Length of adult males (skins) I I0.5 (4.35); wing 55.4 (2.I8); tail 49. I (I.93); bill 8.3 (.327); tarsus I $8.2(.72)$.

Recognition Marks. - As in preceding; brighter.

Nesting.-Nest: A firmly knit, but bulky and often almost spherical mass of felted grasses and mosses, lined with finest grasses, rootlets, moss, or finely shredded bark or hair; set carelessly among ferns, or in low bushes or briary tangles. A splendid moss-ball from Eureka measures 6 inches in width by 5 in depth outside, while the

'Birds of the Colorado_Valley, p.'20I. 


\section{The Wilson Warblers}

dainty cup sunk into the top measures only $\mathrm{I} 5 / 8$ inches in width by $\mathrm{I} 1 / 8$ in depth $(\mathrm{mm}$ $4 \mathbf{I} .3 \times$ 28.6). Another only half as large is composed almost entirely of fine barkstrips. Eggs: 3 or 4; white (or, rarely, with a pale vinaceous buffy suffusion derived from the applied pigment), spotted and dotted generously or sparingly with reddish brown (cameo-brown or walnut-brown) with the usual tendency toward the formation of wreaths and cloud-caps. Av. of 40 eggs in the M. C. O. Coll.: $16.3 \times 12.2(.64 \times$ .48). Season: April and June; two broods, possibly at different levels.

Range of W. p. chryseola.-Summer resident in the Pacific Coast district from southern British Columbia to southern California; winters in Lower California, Sonora, and Chihuahua; occurs during migrations on the east side of the Sierro-Cascade divide and in Arizona.

Distribution in California.-Common migrant, less common east of the Sierran divide; summer resident, chiefly in semi-riparian associations in Lower Sonoran and Canadian zones, from the crest of the Sierras to the Pacific, and from the Oregon line south to the San Bernardino Mountains, - or even central western San Diego County. Note: Grinnell's surmise (Pac. Coast Avifauna, no. I I, p. I52) that the Transition zone is taboo to this bird as a breeder can be only suggestively considered. I have encountered the species during the breeding season at the following points, all well within Transition: Ben Lomond (Santa Cruz County), Cazadero Redwoods (Mendocino County), Eureka and Trinidad (Humboldt County). In fact, W. p. chryseola is one of the commonest breeding species of the coastal section of Humboldt County, indubitable Transition.

Authorities.-Gambel (Sylvania pusilla), Jour. Acad. Nat. Sci. Phila., ser. 2, i., I 847 , p. 38, part (Calif.); Barlow, Nidiologist, vol. i., I 893, p. 44 (nesting habits); Ridgway, U. S. Nat. Mus., Bull. no. 50, part 2, I902, p. 7 I4 (orig. desc.; type locality Red Bluff, Calif,, according to A. O. U. Check-List, I9Io, p. 325); Beal, U. S. Dept. Agric., Biol. Surv. Bull., no. 30, I907, p. 5I (food).

THIS DAINTY little warbler is perhaps the most characteristic, as it is one of the best distributed of all the Mniotiltidce in California. Ranging, as it does, practically from sea-level to timberline in the high Sierras, it nevertheless avoids most of the middle levels of the drier Transition areas. Just why the bird should "skip from thar to thar" is not quite clear until one begins to realize its fondness for dull weather and relatively low temperatures. In this respect the Canadian-Boreal Zone of the Sierras resembles somewhat that portion of the coastal area whose temperatures are regulated by "high fog" or rains; and in these two regions the Golden Warbler dwells. Most grateful of all, perhaps, is the semihumid coastal area of Santa Cruz County, and the frankly humid stretches of Humboldt and Del Norte counties. The Golden Warbler is certainly one of the most abundant birds in the last-named section, and its golden flittings not only dominate the fern levels but extend upward into the mossy arms of the evergreens. A brilliant dress does not appear to endanger the life of this little despot, for he is quite too insignificant for notice among the Knights of Claw and Jaw, and so he flashes in and out, scolds, sings, and meditates, by turns, without molestation.

Nor is there any lack of interest in the life of this golden midget. Have 


\section{The Wilson Warblers}

you never wished that you were tiny-oh, teeny-with beady black eyes, that you might explore the mysteries of a moss forest? that elderberries might look to you like great blue pippins? and madrone berries like luscious fiery pumpkins? that you might pluck a thousand sapid meats at first hand where now you know only a few "staples," disguised by the meretricious arts of cookery? That you might-Ah, here I have you!that you might pantingly pursue a golden maiden down dim forest aisles, over plunging billows of spiræa blossoms, past corridors of giant swordfern, into-Oh, where is that maddening creature? She's given me the slip again! Never mind; I'll pause and sing: oooooéééééééé ooooo.

Truth to tell, the song just recorded is one of the rarest,- - a perfectly modulated swell of sharp staccato notes of little resonance, but greater power and intensity. The ordinary song is a series of monosyllables, uttered with increasing emphasis, chip chip CHIP cHIP CIIIP CHIP. The singer is very much in earnest, and compels attention in spite of his utter lack of musical ability. Late in August, the 26th it was, I provoked a Black-cap by screeping, until he sang merely to relieve his feelings, chip CHIP CHIP CHIP chip chip chip, the precise type of the Pileolated Warbler, $W$. p. pileolata proper. The only other variant in my collection is tsew

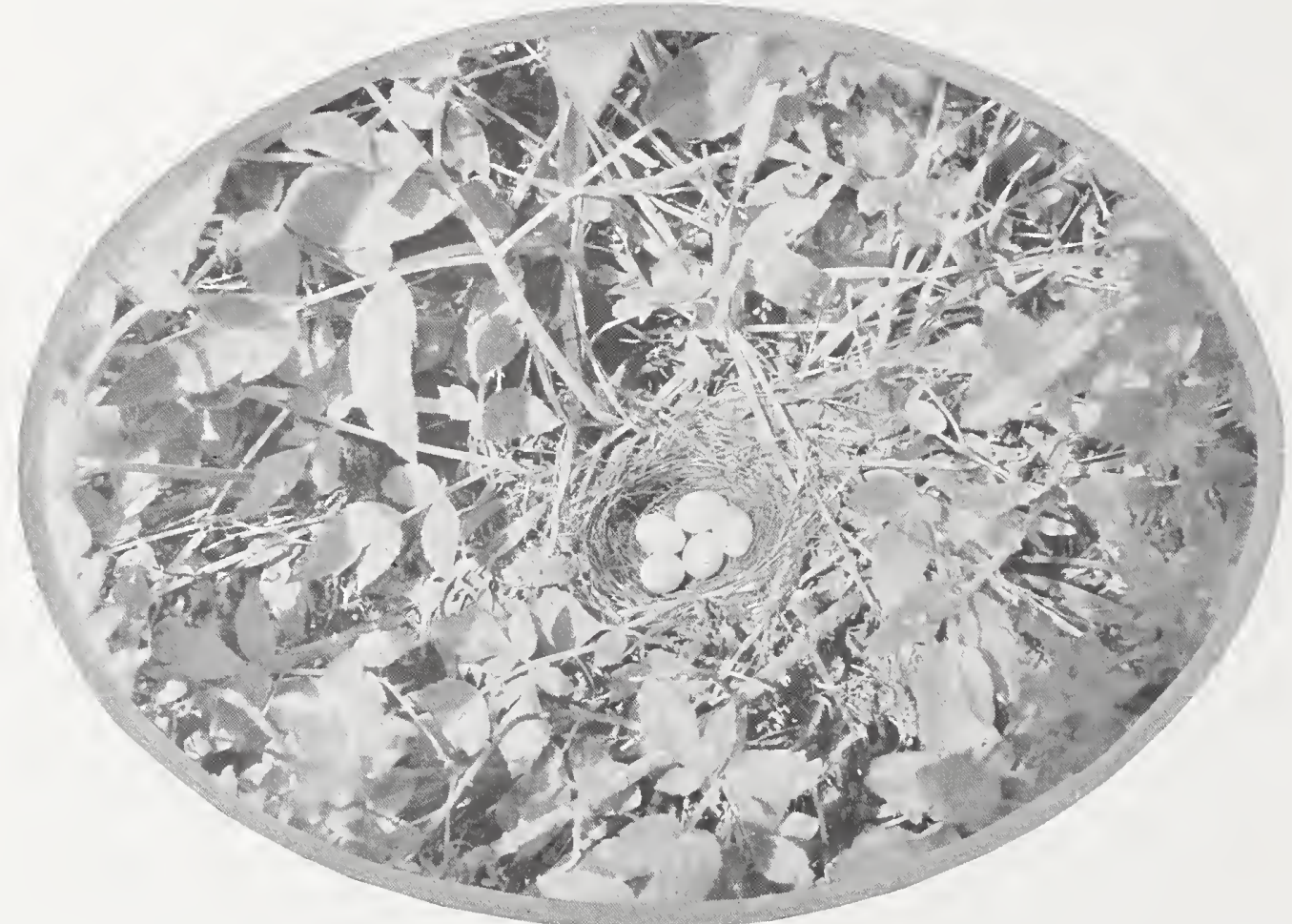

Taken in Mono County

516

NEST AND EGGS OF GOLDEN WARBLER

Photo by the Author 


\section{The Wilson Warblers}

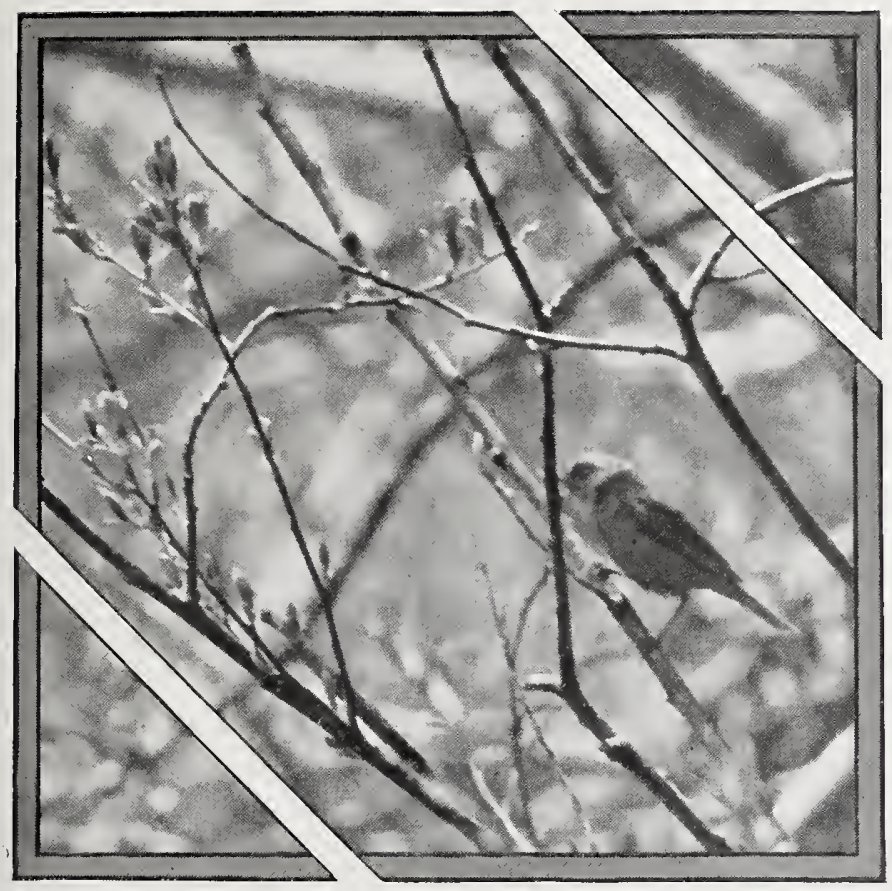

Taken in Mono County

A GLIMPSE OF A GOLDEN WARBLER

tsew tsew tsee tsee tsee whhhack$i t y$, - the last note, somewhat whimsically represented here, being an intense guttural trill very difficult to characterize.

In the Monterey section this bird nests abundantly throughout the brush-covered areas tributary to streams; and it is especially partial to the shelter of blackberry vines. Mr. O. P. Silliman, of Salinas, who probably has had more experience with the Golden Pileolated Warbler than any other living collector, tells me that as a lad he has taken as many as ten sets in a single morning "on the way to school" near the Pajaro River. He found them nesting in late or middle April, and again in later May. A nest before me from this section is made of materials culled from river drift,- dirt-incrusted twigs, rootlets, and macerated bark, together with the wastage of trees,-leaf skeletons, catkins, and the like. The lining is of fine rootlets, skeletonized leaves, and a few strands of horsehair. This structure represents an enormous amount of labor; but it is quite outdone by an exquisite moss-ball from Humboldt County, which was collected by John M. Davis, of Eureka. This was placed two feet high in a cluster of ferns, and consists of little else than most exquisitely compacted moss, with walls over an inch in thickness. I cut through one side of this nest with a razor, intending to count its component strands, but I was appalled by the task presented and promptly sewed it up again. This birdie assuredly has more time than a busy bird-man. And it is a satisfaction to know that when one home is requisitioned in the name of science, another as exquisite is prepared within a week or ten days.

Such birds as are impelled to nest along the willow-lined streams of the San Diegan district appear to adjourn to the higher levels for the summer session. Whether, indeed, any pair of birds of any species does nest twice in the same season at different levels, is an open question. All 


\section{The American Redstart}

indications certainly point that way, but we shall never know for sure until leg-banded specimens are traced.

No. 101

\section{American Redstart}

\section{A. O. U. No. 687. Setophaga ruticilla (Linnæus).}

Description.-Adult male: Head and neck all around, breast and upperparts, glossy black, shading on wings and tail into glossless brownish black; a large patch on sides of breast, sides, axillars, lining of wings, basal half of secondaries, and basal portion of primaries upon outer edge, coalescing in a conspicuous patch, and basal two-thirds of tail (except central pair of rectrices) reddish orange, the color purest and deepest (mikado orange) on breast-patches and axillars, elsewhere paler (capucine orange); lower breast, belly and crissum sordid whitish or grayish, more or less tinged with orange; under tail-coverts broadly tipped with dusky. Bill blackish; feet dark brown. Adult female: Quite different: the orange patches of male replaced by dull yellowwax-yellow on breast spots; amber-yellow, straw-yellow, or barium-yellow elsewhere; head above, shading on sides, deep mouse-gray; remaining upperparts olive or yellowish olive; remaining underparts white or dull buffy white. Immature male: Like adult female. This plumage is usually held through the first spring, and is then distinguished from that of adult female by some irruption of black on breast, by a lesser exposure of yellow on wing, and sometimes by increase of yellow on breast. Immature female: Much like adult female, but yellow patch of wing reduced in area of exposure or entirely covered. Length of adult I 27 -I 46 . I (5.00-5.75); wing 65.8 (2.59); tail 55.I (2.17); bill 9.I (.36); tarsus I 8 (.7I). Females average smaller.

Recognition Marks.-Medium warbler size; black with salmon-red and salmon patches of male; similar pattern and duller colors of female and young; tail usually half open and prominently displayed, whether in sport or in ordinary flight.

Nesting.- Not known to breed in California, but possibly does so. Nest: in the fork of a sapling, from five to fifteen feet up, of hemp and other vegetable fibers, fine bark, and grasses, lined with fine grasses, plant-down and horsehair. Eggs: 4 or 5; greenish-, bluish-, or grayish-white, dotted and spotted, chiefly about larger end, with cinnamon-rufous or olive-brown. Av. size $17.3 \times 13(.68 \times .5 \mathrm{I})$. Season: June; one brood.

General Range.-Temperate North America in general, regularly north to Nova Scotia, the Mackenzie River (Fort Simpson), etc., west to southern Alaska, British Columbia, eastern Washington, Utah, etc., casual in eastern Oregon, northern California, and in the southeastern states; breeding from the middle portion of the United States northward; south in winter throughout West Indies, Mexico and Central America to northern South America.

Occurrence in California.-A little-known visitor, casual or rare; four published records as follows: Haywards, a male (taken), June 20, I88I, by W. O. Emerson; Marysville Buttes, male (seen), June 6, I884, by Lyman Belding; Pasadena, female (found dead), Dec. 27, I905, by P. I. Osburn; Farallon Islands, a 2nd year 


\section{The American Redstart}

male (seen), June I, I9I I, by W. L. Dawson. To these I may add a rather regretably unsatisfactory glimpse of a bird, also a young male, obtained in northern Mendocino County, June I4, 1916, when in company with A. G. Vrooman.

Authorities.-Emerson, Zoe, vol. I, I 890, p. 45 (Haywards, June 20, I880, one spec.); Belding, Land Birds Pac. Dist., I 890, p. 222 (Marysville Buttes, June 6, I884, one spec.); Osburn, Condor, vol. xi., 1909, p. 102 (Pasadena, Dec. 27, I905, one spec.); Dawson, Condor, vol. xiii., I9II, p. I82 (Farallon Ids., June I, I9I I, one spec.).

THE REDSTART is the presiding genius of eastern woodland and grove, and because he is only casual with us we are going to depart from our usual custom and snatch a glance at an eastern page." "He is a bit of a tyrant among the birds, and among his own kind is exceedingly sensitive upon the subject of metes and bounds. As for the insect world, he rules it with a rod of iron. See hin as he moves about through a file of slender poplars. He flits restlessly from branch to branch, now peering up at the under surface of a leaf, now darting into the air to secure a heedless midge and closing upon it with an emphatic snap, now spreading the tail in pardonable vanity or from sheer exuberance of spirits; but ever and anon pausing just long enough to squeeze out a half-scolding song. The paler-colored female, contrary to the usual wont, is not less active nor less noticeable than the male, except as she is restrained for a season by the duties of incubation. She is even believed to sing a little on her own account, not because her mate does not sing enough for two, but because she-well, for the same reason that a woman whistles, -and good luck to her!

"During the mating season great rivalries spring up, and males will chase each other about in most bewildering mazes, like a pair of great fire-flies, and with no better weapons-fighting fire with fire. When the nesting site is chosen the male is very jealous of intruders, and bustles up in a threatening fashion, which quite overawes most birds of guileless intent.

"Redstart's song is sometimes little better than an emphatescent squeak. At other times his emotion fades after the utterance of two or three notes, and the last one dies out. A more pretentious effort is represented by Mr. Chapman as 'Ching, ching, chee; ser-wee, swee, sweee-e-e.' Many variations from these types may be noted, and I once mistook the attempt of a colorless young stripling of one summer for that of a Pileolated Warbler."

The ancestral home of the Redstart was Mexico, but this species seems to have reached its northwestern range, in Utah, Idaho, and eastern Washington, by overflowing from the saturated East through the Rocky Mountains. Doubtless the western residents now find

1"The Birds of Ohio," p. I96. 


\section{The Western Martin}

their way up and down on the "left hand side" of the Rockies, but the three or four stragglers taken in California appear to have been members of lost companies of easterners, rather than scouts of a new migration route. Thus, a second year male, observed on the Farallons, June Ist, I9II, was associated with Magnolia Warbler, Black-throated Green Warbler, Ovenbird and other waifs.

No. 102

\section{Western Martin}

A. O. U. No.6ria. Progne subis hesperia Brewster.

Description.- Adult male: Rich violet bluish black, glossy and metallic (never "purple"); wings and tail dead black. Adult female: Somewhat similar to male, but upperparts chiefly sooty gray, the blue-black element present in variable amount as broad plating of feather-tips, notably on crown, scapulars, wing-coverts and upper tail-coverts; some indication of paler collar across nape; breast, broadly, lighter sooty gray, with darker mesial streaks and much whitish edging; forehead, sides of neck, and throat sooty gray, still more overspread with whitish; belly and crissum dull white; the lower breast white with sharp mesial streaks of sooty gray. Bill black, stout, and broad at base, decurved near tip; nostrils exposed, circular, opening upward; feet moderately stout. Young males resemble adult female, but are somewhat darker, the steely blue appearing at first in patches. Length I 84.2-2 I 5.9 $\left(7.25^{-8.50)}\right.$; av. of 8 specimens: wing I 46.I (5.75); tail 73 (2.87); bill I I.7 (.46); tarsus I5 (.59). Females average smaller.

Recognition Marks.- Towhee size; the largest of the swallows; blue-black, or blue-black and sooty gray coloration.

Nesting.- Nest: Of leaves, grass, and trash, sometimes lined with fine green leaves; in some cavity, as old woodpecker holes, etc., or in crannies about buildings. Eggs: 4 or 5, rarely 6; elongate ovate; pure, glossy white, unmarked. Av. size 24.9 $\mathrm{x} 18.5(.98 \times \mathrm{.73})$. Season: First week in June; one brood.

Range of Progne subis.- North and South America, breeding from the southern British Provinces to Mexico, and wintering in Brazil.

Range of $P$. s. hesperia.-Summer resident in the Pacific Coast district, broadly, from British Columbia to Cape San Lucas; winter range undefined.

Distribution in California.-Fairly common migrant throughout the State; summer resident of very local distribution, in sections offering nesting facilities; hence, practically confined to timbered areas, save as found (increasingly?) in cities and towns.

Authorities.-Bonaparte (Progne purpurea), Compte Rendu, xxxviii., I 854 , p. 650 (Calif.); Barlow, Condor, vol. iii., I90I, p. I74 (Placerville and Slippery Ford, breeding); Willett, Pac. Coast Avifauna, no. 7, I912, p. 89 (status in s. Calif.).

THOSE to whom the Purple Martin (Progne subis) of the East is one of the most familiar objects of springtime, are surprised to note the scarcity, one might almost say rarity, of this species in the West. While 


\section{The Western Martin}

it is of necessity "fairly common" ${ }_{1}$ where it is found at all, being a sociable bird, one who has traversed the State counts up with dismay the "record stations," and concludes that it is quite the rarest of the swallows-in aggregate, I should say not above one ten-thousandth of the total formed by our seven species.

Curiously enough, our Martin is chiefly found in its native fastnesses, - a pine tree riddled and deserted by Lewis Woodpeckers affording it shelter on the banks of Eagle Lake; a doughty oak back in the hills beyond Paso Robles; or both pines and oaks together on the lower ridges of the San Jacinto range. In such situations the birds seem to be quite dependent for their lodgings upon the services of the larger woodpeckers; and it may be a scarcity of these necessary accommodations, or perhaps an unwillingness on the part of the woodpeckers to rent them, which has kept the species down.

April Ist is the earliest date I have for the arrival of the Martins in California, and a week later is nearer the average; but Mr. Belding has a record of March Ist (I879) for Stockton, and half a dozen others for the first week in March. Their movements depend largely upon the weather; and even if they have come back early, they are willing to mope indoors when the weather is chilly or disagreeable. The Martins feed exclusively on insects, and are thus at the mercy of a backward season. Not only flies and gnats are consumed, but moths, wasps, grasshoppers, dragon-flies, and some of the larger predatory beetles as well.

The birds mate soon after arrival; and for a home, if in town, they select some crevice or hidey-hole about a building. A cavity left by a missing brick is sufficient, or a station on the eave-plate of a warehouse. Old nests are renovated, and new materials are brought in,---straw, string, and trash for the bulk of the nest, and abundant feathers for lining. Sometimes the birds exhibit whimsical tastes. Mr. S. F. Rathbun, of Seattle, found a nest which was composed entirely of wood shavings mixed with string and fragments of the woven sheath which covers electric light wires. The haunts of men are in no wise shunned, and there is no reason why houses should not be provided for the Martins, as is the custom in the older East. Even the Indian sagamores of the Five Nations used to hang out gourds for their feathered friends; and if our western aborigines, the Diggers and the Piutes, were less thoughtful, we shall have to work a little harder, that is all. Architects not yet overawed by fear of the English Sparrow sometimes exhibit a commendable negligence and leave recesses which please the eye as well as the birds. Thus, an observer in Pasadena' ${ }^{2}$ noted the successive occupation by Martins of the eaves of the Maryland Hotel until they

I "Fairly common summer resident, locally" -Willett: "Birds of the Pacific Slope of Southern California," p. 89. 2 A son of Geo. Priestly. See "Condor," Vol. XI., p. 208. Also" The Oologist," Vol. XXXII., No. 9 , p. I53. 


\section{The Western Martin}

numbered thirty pairs. Likewise the birds, a dozen of them now, which haunt the ample cornices of the new Federal Building in Santa Barbara, are a source of never-ending delight to the public.

The nest is not often occupied till June, when the birds may be most certain of finding food for their offspring; and the rearing of a single brood is a season's work. Five eggs is almost invariably the number laid; and they are of a pure white color, the shell being very little glossed and of a coarser grain than is the case with eggs of the other swallows.

Martins are very sociable birds, and a voluble flow of small talk is kept up by them during the nesting season. The song, if such it may be called, is a succession of pleasant warblings and gurglings, interspersed with harsh rubbing and creaking notes. A particularly mellow coo, coo, coo occurs from time to time, and any of the notes seem to require considerable effort on the part of the performer.

Our information regarding the Western Martin is, truth to tell, still quite inadequate. In dealing with any western analogue of a species so well known in the East as is the Purple Martin, we are under constant temptation to transfer impressions or to neglect opportunities for local study. Thus, it may be presumed that the Western Martin is somewhat pugnacious, that it defends the colony courageously by driving predatory birds out of bounds, that it contends with bluebirds and wrens and woodpeckers and other swallows for possession of nesting holes; but of all this the notes are silent, and there is never a line in print.

Just for honesty's sake, the author will share with his readers verbatim et literatim the only field notes entered in his files for a period of five years:

Western Martin.

San Luis Obispo County, April 5, IOI2.

Half a dozen pairs of them hanging about the top of a giant oak back in the hills on the Sacramento Ranch. The upper limbs were perforated with holes, and there was much voluble discussion of nestbuilding to be heard. An idyllic spot and a grateful revelation of the primitive taste of this all too sophisticated bird.

Lassen County, June 4, I9I2.

A pair of these blessed birds have made their home in a hollow limb of a great pine tree standing in the middle of the road overlooking Honey Lake, and their amiable gurglings and twitterings are a comfort to the wayfarer.

Shandon Country, Valley of the San Juan, April I7, IgI4.

Cooka picka pooka pooka coo, gurgles a Western Martin as he passes up-stream in the eye of a beautiful morning. What a happy, amiable body he is, the Martin! And how much more in keeping with a blithe spirit is this noble wilderness than are the sordid haunts of men! 
The Cliff Swallows

\section{No. 103 \\ Cliff Swallow}

A. O. U. No.612. Petrochelidon albifrons albifrons (Rafinesque).

Synonyms.--Eave Swallow. Republican Swallow.

Description.-Adult: A prominent whitish crescent on forehead; crown, back, and an obscure patch on chest steel-blue; throat and sides of head deep chestnut, the color sometimes meeting fellow across nape; breast, sides, and a cervical collar browngray; belly white or whitish; wings and tail blackish; rump pale tawny, or pinkish cinnamon,- the color reaching around on flanks; under tail-coverts dusky, edged with whitish. In young birds the frontlet is obscure or wanting; the plumage dull brown above; and the throat blackish with white specks. Bill and feet weak, the former suddenly compressed near tip. Length I27-152.4 (5.00-6.00); wing II0.5 (4.35); tail 50.8 (2.00); bill from nostril $5.6(.22)$.

Recognition Marks.--"Warbler size," but comparison inappropriate-better say "Swallow size"; white forehead and rufous rump. Found in colonies.

Nesting.-In colonies with nests often in contact. Nest: An inverted stackshaped, or declined retort-shaped structure of mud; lined scantily, or well, with grass, and depending from the walls of cliffs, sides of barns under the eaves, concrete bridges, and the like. Eggs: 4 or 5; white, or, rarely, suffused with pale buffy (cartridge buff to pale pinkish cinnamon), spotted sharply and sparingly, or occasionally broadly, with tendency to confluence, with reddish brown (chocolate to warm sepia and verona brown) and deep vinaceous gray. Av. size 20.8 x $14(.82 \times 55)$. Season: April -July; two broods.

Range of Petrochelidon albifrons.--North and Middle America, migrating to South America in winter.

Range of $P$. a. albifrons.-North America. Breeds in the United States, except Florida and the Rio Grande Valley, and from the western portion of Mexico north to the Arctic Circle (or less easterly). Winter home undescribed, but undoubtedly in South America.

Distribution in California.-Abundant migrant throughout the State; also a common breeder in favorable sections anywhere below the Boreal zone, but somewhat localized-a general preference for open country instead of timber. Nests on the protected seacoasts, but is curiously absent from the islands. Occurs sparingly in winter in the Imperial Valley (van Rossem).

Authorities.-Gambel (Hirundo fulva), Jour. Acad. Nat. Sci. Phila., vol. ii., I 847, p. 3 I (Calif.); Coues, Birds Col. Val., i 878, p. 426 (syn., desc., hist. of discovery, habits, etc.; see also p. 364); Beal, U. S. Dept. Agric., Biol. Surv. Bull., no. 30, I907, p. 28 (food); Grinnell, Univ. Calif. Pub. Zool., vol. v., I908, p. 106, pls. I8, I9 (San Bernardino Mts.; nests built upon a pine tree); Cooke, U. S. Dept. Agric., Bull. no. I 85 , 1915, pp. I9, 26, fig. 6, map (migr. route).

\section{No. 103a Northern Cliff Swallow}

A. O. U. No. 6I2, part. Petrochelidon albifrons hypopolia Oberholser.

Description.--Similar to Petrochelidon albifrons albifrons from eastern United States (and California), but larger; frontal band paler, more whitish; breast more grayish (less ochraceous). Length of male: wing I I2.I (4.4 I); tail 50.7 (2.00); bill 7.2 (.284); tarsus I $2.3(.49)$. Female: I I0.2 (4.34); tail 50.7 (2.00); bill 7 (.27); tarsus I 3 (.5 I). 


\section{The Cliff Swallows}

General Range.-Breeds in northwestern North America north to Mackenzie and central Alaska; west to central British Columbia; south to Montana; and east to Alberta and Mackenzie. Migrates through Wyoming and California. Winters probably in South America.

Occurrence in California.--One record: Laguna Station, San Diego County, May $4, \mathbf{I} 894$.

Authority.-Oberholser (Petrochelidon albifrons hypopolia), Canadian FieldNaturalist, vol. xxxiii., Nov. I9I9, p. 95 (orig. desc.; type locality, Ft. Norman, Mackenzie; one spec. listed from Calif.).

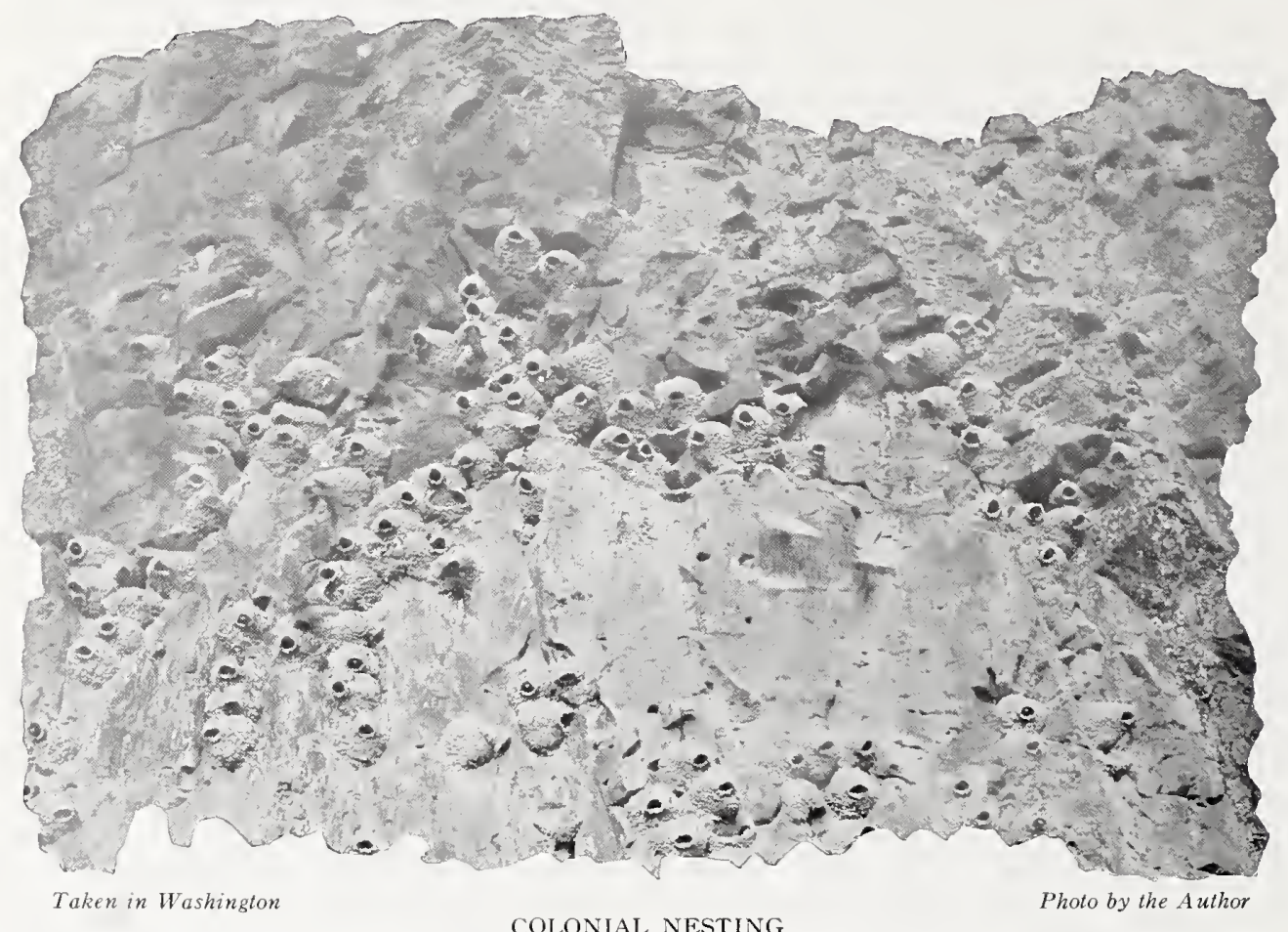

DOUBTLESS the Lord-to paraphrase Lincoln's aphorism-must love the Cliff Swallows, else he would not have made so many of them. Common they unquestionably are; yet I do not know that they are altogether lovable. Common they are, too, not alone in the sense of abundance, but also in that of familiarity. They harry our pastures, they swarm about our horse-ponds, they appropriate the eaves of our barns, and they even invade our porches and house-gables, if un rebuked. But they are not exactly friendly, as are the Barn Swallows; or dainty and fastidious, as are the Violet-greens. There is something, also, a little detached about their ways. Their colonies are self-sufficient, like those of ants. They dwell, a people apart, like the Jews, who 
do not even ask the fellowship which we would gladly accord them. Perhaps it is for the same reason, viz., that their fathers were bred in - the wilderness, where all things are hostile, and that the race has acquired the habit of being repulsed.

But there! every person, even a bird-person, deserves to be judged for what he is, and not for what he is not. Also, doubtless, the Lord loves the Cliff Swallow.

One only special cause of resentment does the author cherish against this bird, and that, admittedly, not a moral fault. In certain sections, as for example, the flower-clad slopes of eastern San Luis Obispo County, Cliff Swallows are so abundant as actually to distract and weary the attention. In their quest for flying insects they race tirelessly

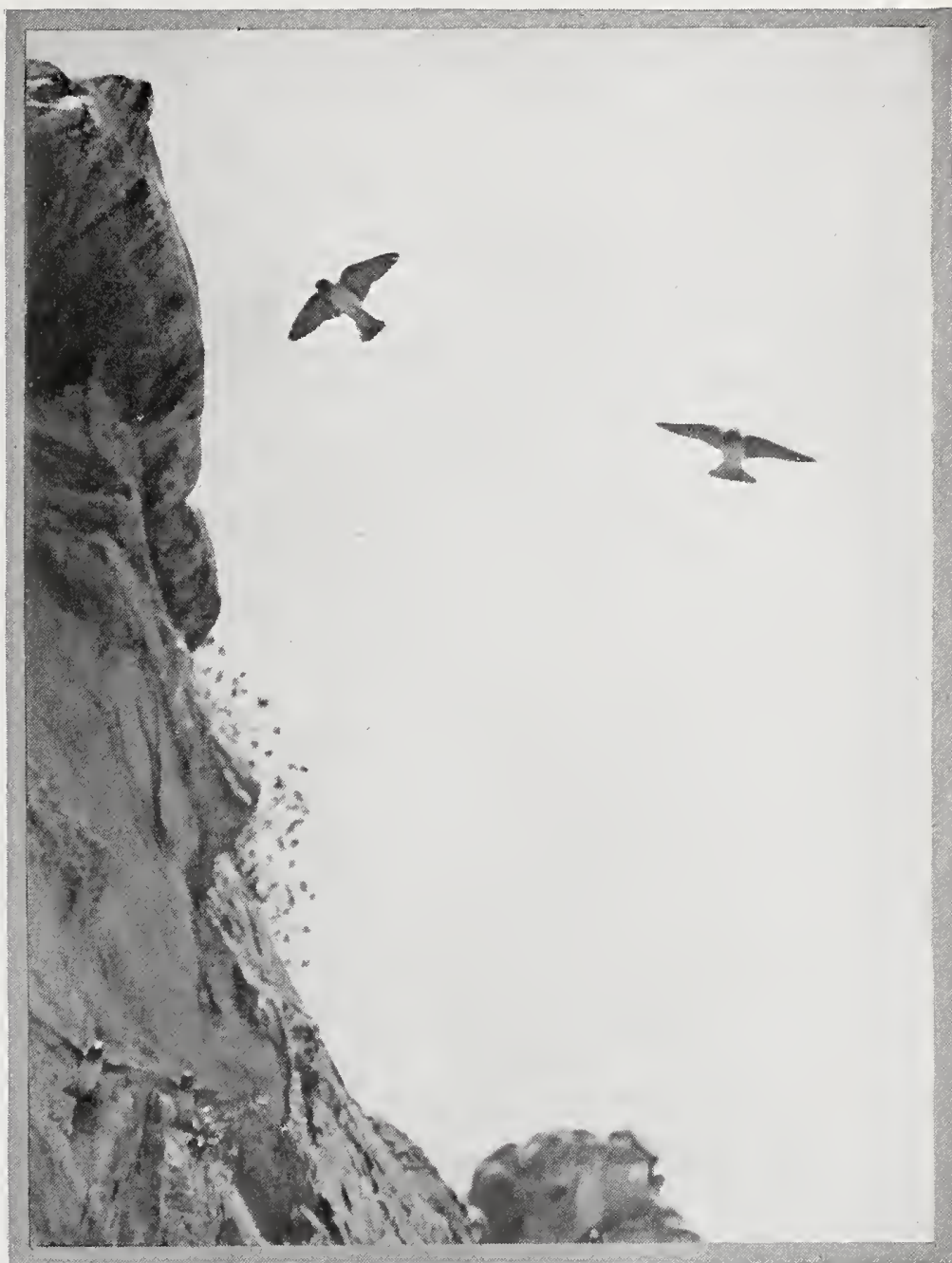

Taken in Santa Barbara County

Photo by the Author

CLIFF SWALLOWS A-WING

to and fro across the landscape, weaving a magic tapestry of search until it would seem that not a cubic inch of atmosphere remains without its invisible thread of flight. The Swallows appear friendly enough, but upon such occasions it is our coin and not our fellowship they are after. For as man or beast moves about in the luscious grasses, swarms of insects arise, and these the avaricious eye of the Swallow eagerly notes. Bird-study-of anything but the Cliff Swallow-is difficult in such distracting circumstances.

But all resentment vanishes when one sees a colony of these sturdy 


\section{The Cliff Swallows}

"republicans," nesting in the wild along the solemn bastions of some river-fronting, lake-fronting, or even sea-fronting, cliff. The particular nesting site may be a matter of a season's use, populous this year and abandoned the next; but somewhere along this frowning face of granite or sandstone or basalt, Swallows were nesting before Fra Junipero Serra came to California with the touch of civilization. Soon after the sculptor, Ice, unveiled that masterpiece, Yosemite, these fly-catching cohorts must have swept into California to establish themselves forevermore.

Evidence of this age-long occupation of the cliffs is furnished not only by the muddy cicatrices left by fallen nests, but, wherever the wall juts out or overhangs, so as to shield a place below from the action of the elements, by beds of guano and coprolitic stalagmites, which cling to the uneven surface of the rock. Judged by the same testimony, certain of the larger blow-holes, or lava-bubbles, as well as under-cut arches of dobe, must be used at night as lodging places, at least out of the nesting season.

The well-known bottle- or retort-shaped nests of the Cliff Swallow

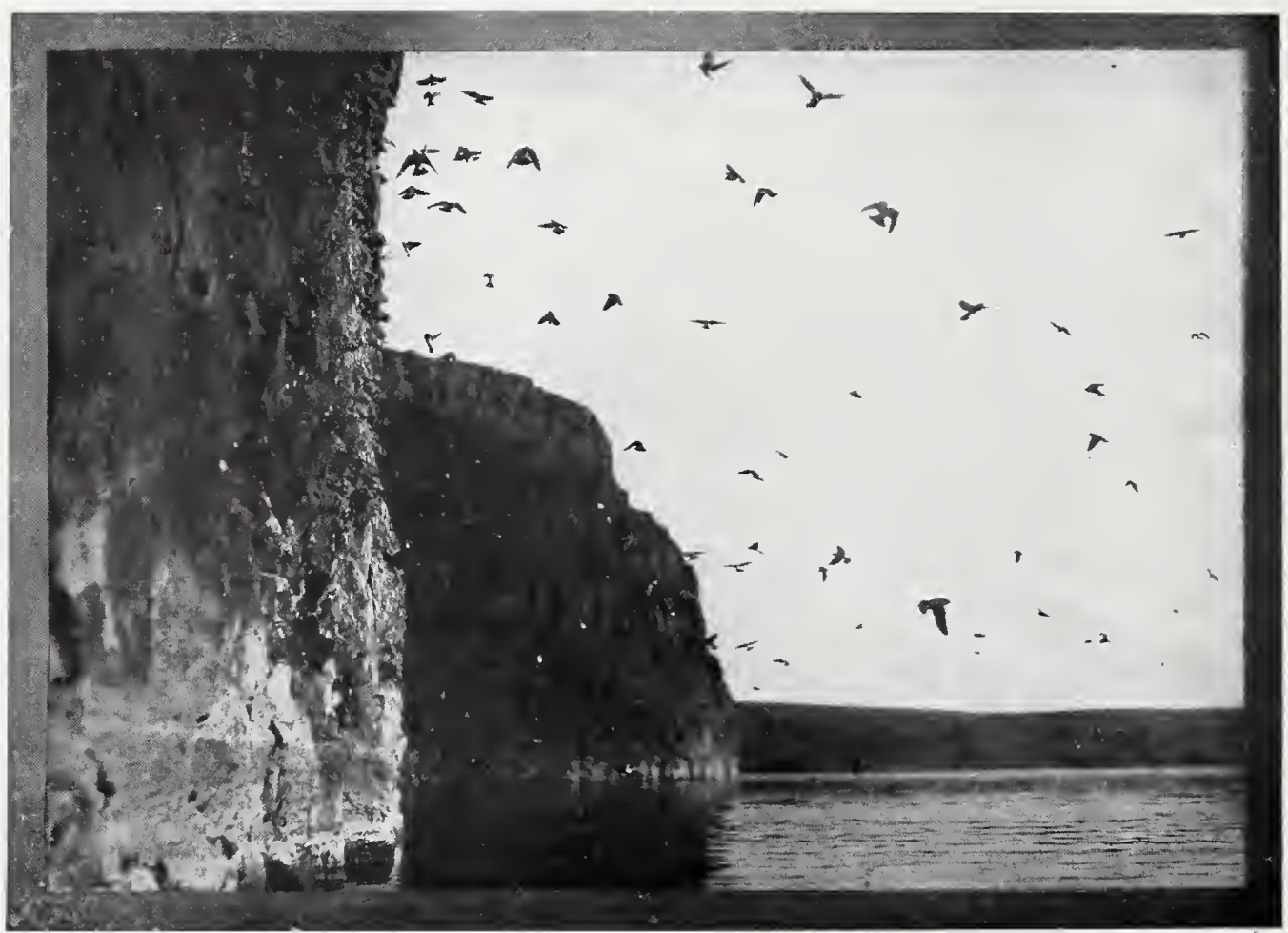

Taken in Washington 


\section{The Cliff Swallows}

are composed of pellets of mud deposited in successive beakfuls by the industrious birds. It is always interesting to see a twittering company of these little masons gathering by the water's edge and moulding their mortar to the required consistency. Every wing is a-flutter, and so seething is the commotion that no camera can do justice to the scene. Not less interesting is it to watch them lay the foundations upon some smooth rock facet. Their tiny beaks must serve for hods and trowels, and because the first course of mud masonry is the most particular, they alternately cling and flutter, as with many prods and fairy thumps they force the putty-like material to lay hold of the indifferent wall.

There is usually much passing to and fro in the case of these cliffdwellers, and we can never hope to steal upon them unawares. When one approaches from below, an alarm is sounded, and anxious heads, wearing a white frown, are first thrust out at the mouths of the bottles, and then the air becomes filled with flying swallows, charging about the

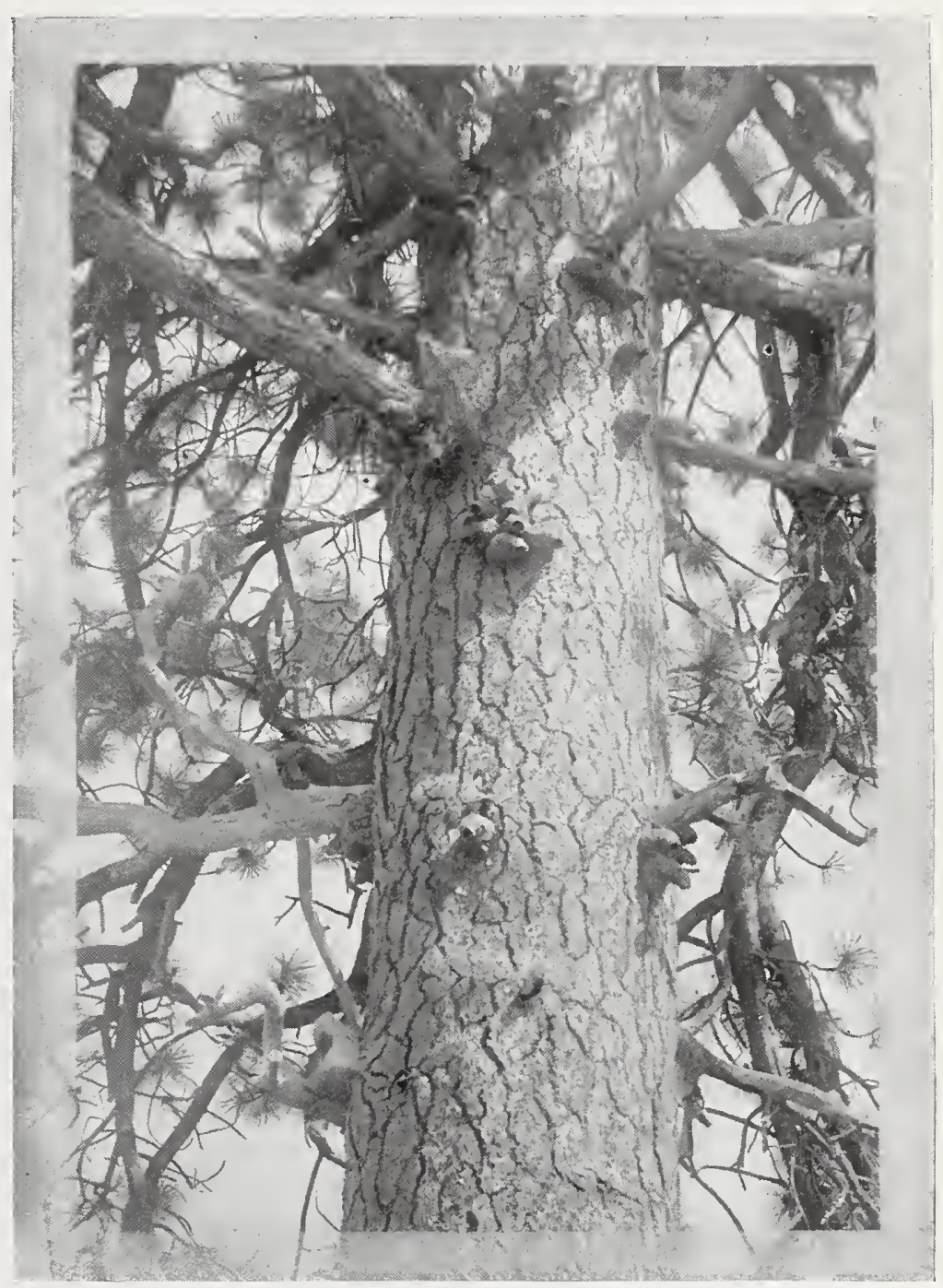

Taken in the San Bernardino Mountains
Photo by Wright M. Pierce

AN UNUSUAL NESTING SITE-YELLOW PINE AT BEAR LAKE head of the intruder in bewildering mazes, and raising a babble of strange frangible cries, as though a thousand sets of toy dishes were being broken. If the newcomer appears harmless, the birds return to their eggs by ones 


\section{The Cliff Swallowes}

and twos and dozens, until most of the company are disposed again. At such a moment it is great sport to set up a sudden shout. There is an instant hush, electric, ominous, while every little Injun of 'em is making for the door of his wigwam. Then they dislodge themselves from the cliff like an avalanche of missiles, a silent down-sweeping cloud; but immediately they gain assurance in the open, and bedlam begins all over again.

Once, in a wild, separate Paradise, in Kern County, we took lodgings for a night in a sandstone cave

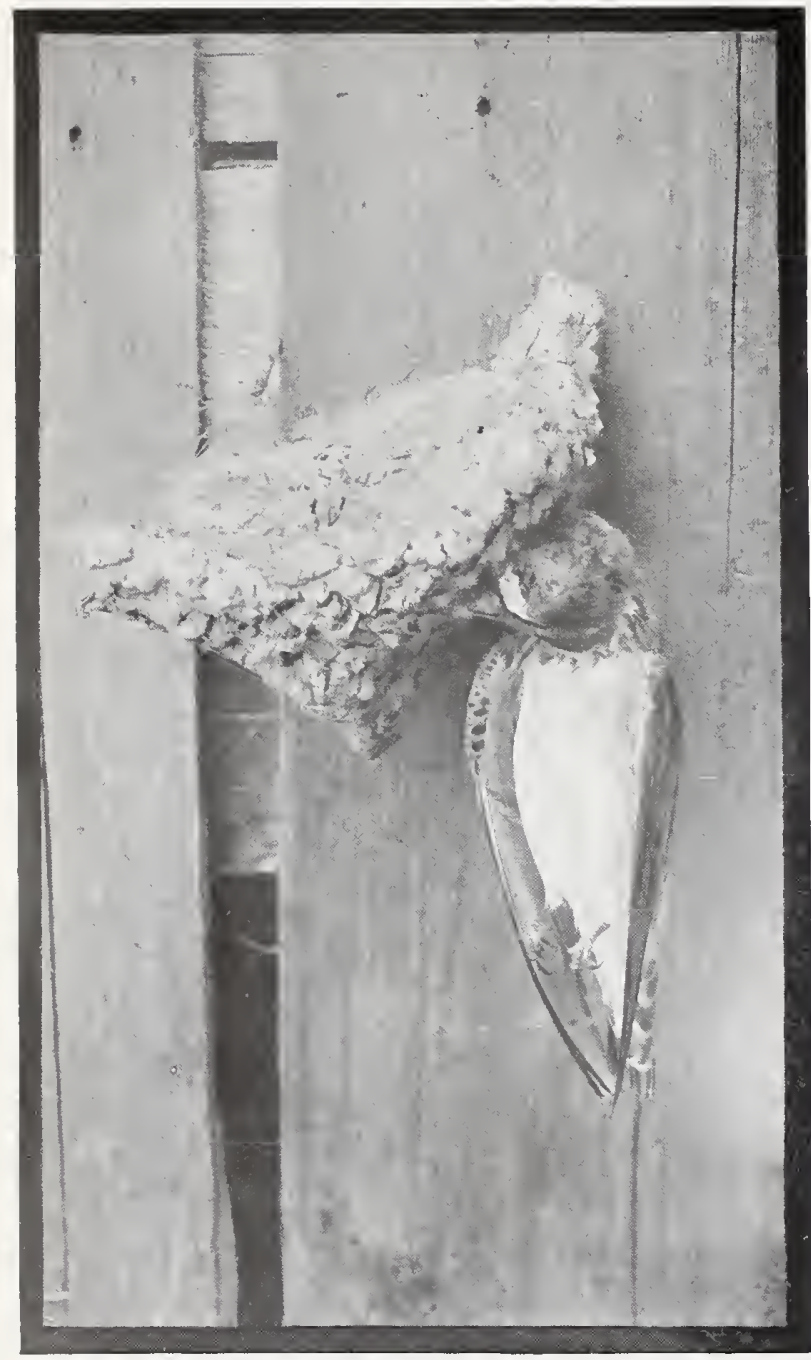

Taken in San Bernardino County

Photo by Wright M. Pierce

A FAMILIAR TRAGEDY

BUT BIRDS CANNOT RESIST THE TEMPTATION TO USE HORSEHAIR 528 which happened to shelter at its upper and outer rim a small colony of Cliff Swallows. There were ten pairs of them within ten feet of our sleeping heads. And they were more or less upon our minds all night long, as we, no doubt, were upon theirs, for every once in a while some restless bird would make an excursion out into the darkness to settle his nerves. Towards morning I observed a new nest-note, a sort of croaking protest made by a bird when jostled (or so one would judge). Probably Mrs. Swallow was reminding her sleepy spouse that it was time to get up and seize the early bug; while he, poor soul, recalling his disturbed slumbers, grunted disapproval.

During the morning which followed we learned to distinguish the chirp in several qualities or emphases, the dimp, or china-smashing note of extreme alarm, and the creaking song. This song exhibits, in outline only, the characteristics of the more able Western Martin's, especially when it is uttered from the mouth of the nest, as the Martin is so fond of doing.

Both Grinnell ${ }^{1}$ and Willett ${ }^{2}$ have recorded how the Cliff Swallows of

\footnotetext{
1The Biota of the San Bernardino Mountains, p. Io6. ${ }^{2}$ Birds of the Pac. Slope So. Cal., p. 90.
} 
Bear Valley, hard put to it for nesting sites in an otherwise delectable country, attached their retorts to the sides and under surfaces of great pine trees. On the beach cliffs near Santa Barbara I have found them, not intermingling freely with the Bank Swallows, but sponging more or less upon the latter for nesting sites. The entrance to a Bank Swallow's burrow, whether new or old, is plugged up by a mud wall of conventional appearance, and this mud facing has the customary entrance hole of the Cliff Swallow; but behind the wall there is nothing but the lens-shaped chamber in the sand, as fashioned by the Bank Swallow. This was the usual style of composite nest; but one found by my son William presented a still more curious set of conditions. The mud plug, built some six inches inside the entrance, admitted to an empty chamber, while back of this was a similar partition, which, in turn, guarded a well-lined nest with three fresh eggs (June 28, 19I3).

Cliff Swallows have won a bad name as tenants, because their quarters are likely to be infested with bed-bugs, not, as it appears, 1 the unwelcome troubler of human dreams, Acanthia (formerly Cimex) lectuaria, but a related species, Acanthia hirundinis. It is not at all probable that this related bug would prey upon mankind, but the suggested association is an unpleasant one. Certainly the birds must suffer tortures from their insect persecutors, for I have seen whole colonies deserted, eggs and all, on this account.

No. 104

\section{Rough-winged Swallow}

\section{A. O. U. No. 617. Stelgidopteryx serripennis (Audubon).}

Description.-Adult: Upperparts warm brownish gray, or snuff-brown; breast and sides a paler tint of the same color, shading insensibly on borders; throat still paler, sooty gray (whitish in winter); wings fuscous. Young birds exhibit some rusty edging of the feathers above, especially on the wings; and lack the peculiar, recurved hooks on the edge of the outer primary. Size a little larger than the next. Length I27-I 46. I (5.00-5.75); wing I09.2 (4.30); tail 47 (I.85); bill from nostril 5.3 (.2I).

Recognition Marks.-Medium swallow size; throat not definitely white (nearest so in winter); warmish brown coloration, and brownish suffusion below fading to white on belly. It is easy to distinguish between this and the succeeding species if a little care is taken to note the general pattern of underparts.

1Mr. Edward R. Warren of Colorado Springs, Colo., has given this matter special study. See his excellent article in The Condor, Vol. XV., Jan., 1913, pp. I4-I6. 


\section{The Rough-winged Swallow}

Nesting.- Nest: In crevice of cliffs at end of tunnels of earth, or sand-banks, or in crannies of bridges, etc.; of leaves, weed-stems, grasses, feathers, and the like; bulky or compact according to situation. Eggs: 4 to 8 ; white. Av. size 18.8 x I3 $(.74 \times$.5I). Season: May, June, according to altitude; one brood.

General Range.-United States at large, and southern portions of Canada; breeding north to Connecticut, southern Ontario, southern Minnesota, British Columbia, etc.; south to southern border, and in Mexico south to Jalisco. Winters from central Mexico to Costa Rica.

Distribution in California.-Of general occurrence during migrations; locally common as a breeder, chiefly in the Lower and Upper Sonoran zones. Less common in the humid coastal regions. Has occurred in winter, but probably only as an early migrant: San Diego, Jan. 27 (J. G. Cooper); Potholes, Feb. 8, 1912.

Authorities.-Heermann, Jour. Acad. Nat. Sci. Phila., ser. 2, ii., I853, p. 26 I (Calif.); Cooper, Orn. Calif. I870, p. I Io (San Diego, Nov. and Jan.); Coues, Birds Col. Val., I 878 , p. 438 (syn., habits, desc., etc.; see also p. 364); Tyler, Pac. Coast Avifauna, no. 9, I9I3, p. 93 (San Joaquin Valley, nesting habits); Grinnell, Univ. Calif. Pub. Zool., vol. xii., I9I4, p. I86 (Colo. Valley; nesting habits, etc.).

IT NOT infrequently happens that some oversight, or want of discrimination, on the part of early observers condemns a species to long obscurity or unending misapprehension. The Bank Swallow was at once recognized by the pioneer naturalists of America as being identical with the well-known European bird, but it was not till i 838 that Audubon distinguished its superficially similar but structurally different relative, the Rough-wing. Dr. Cooper, ${ }^{1}$ writing in 1870 under the caption "Bank Swallow," says: "This species . . . seems rather less common on this coast than the next [i. e., the Rough-wing] and resembles that so closely that they cannot be distinguished without examination of specimens. Their habits being exactly alike, I will describe those of both under one heading." And this the good doctor proceeds to do, under the caption of Rough-winged Swallow, to the great confusion of all succeeding literature.

Of course the two species are perfectly, if not easily, distinguishable a-wing; and of course their habits do show marked differences. It may be easier, however, to take the Bank Swallow as a basis, and to say that our subject differs from that species by thus and so.

In the first place it has those curious little hooklets on the edge of the wing (especially on the outer edge of the first primary)-nobody knows what they are for. They surely cannot be of service in enabling the bird to cling to perpendicular surfaces, for they are bent forward, and the bird is not known to cling head-downward. It is easy to see how the bird might brace its wings against the sides of its nesting tunnel

${ }^{1}$ Ornithology of Calif., Vol. I., Land Birds, p. I Io. 


\section{The Rough-winged Swallow}

to prevent forcible abduction, but no one knows of a possible enemy which might be circumvented in this way.

Again, the Rough-winged Swallow has a steadier, rather more labored flight than that of its foil. Its aerial course is more dignified, leisurely, less impulsive and erratic. In nesting, although it may include the range of the Sand Martin, or even nest side by side with it, it has a wider latitude for choice and is not hampered by local tradition. If it burrows in a bank it is quite as likely to dig near the bottom as the top. Crevices in masonry, in dobe walls, or stone quarries, crannies and abutments of bridges, or even (it is said, although I am very skeptical) holes in trees, are utilized. Unlike the Bank Swallows, the Roughwings do not colonize to any great extent, but are rather solitary. Favorable conditions may attract several pairs to a given spot, as a gravel pit, but when together they are little given to community functions. In open country, where the cover is scarce but the food supply attractive, I have found them nesting along irrigating ditches with banks not over two feet high. Conditions for nesting sites are very favorable in California, by reason of the steep-walled barrancas which abound along the

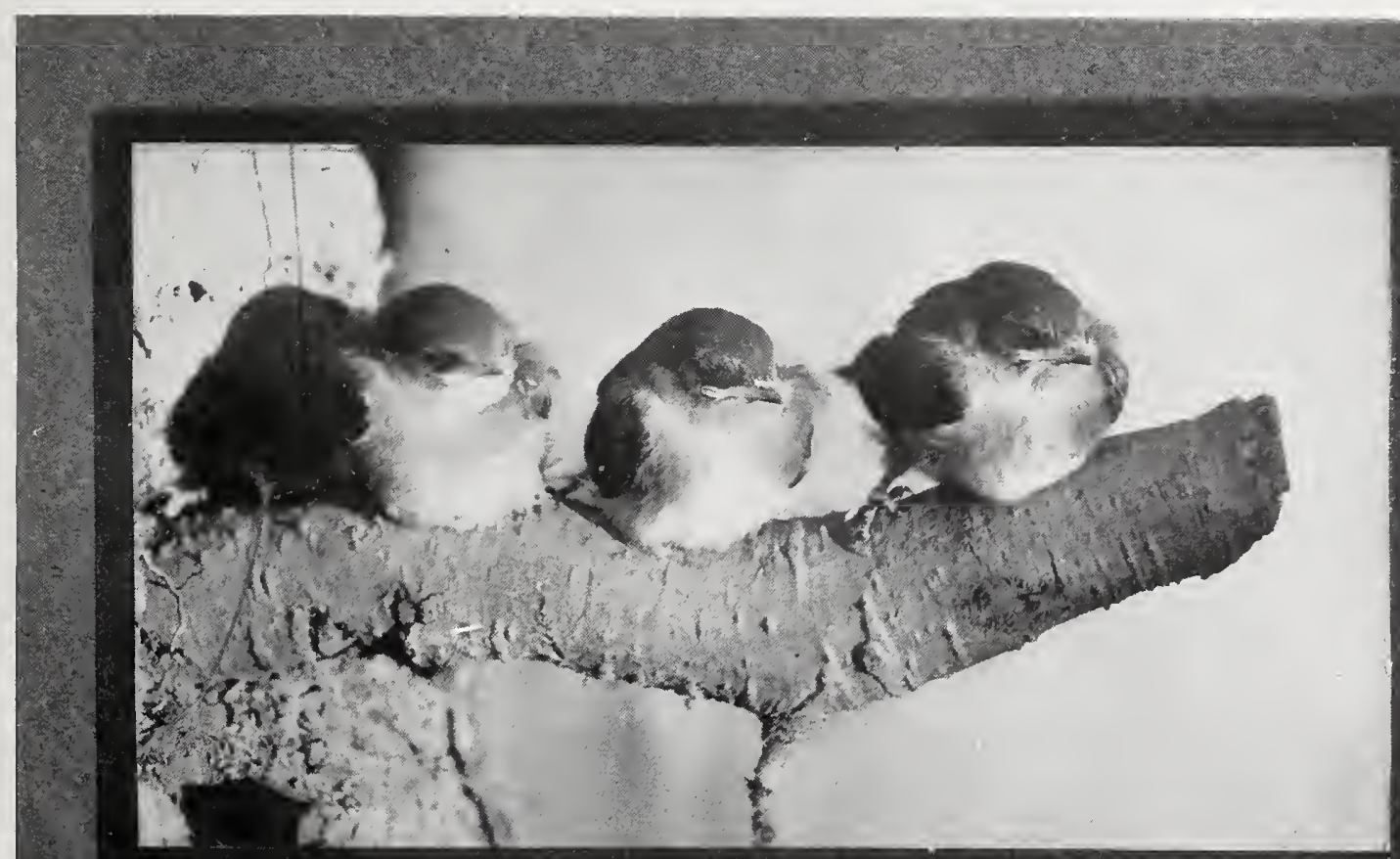




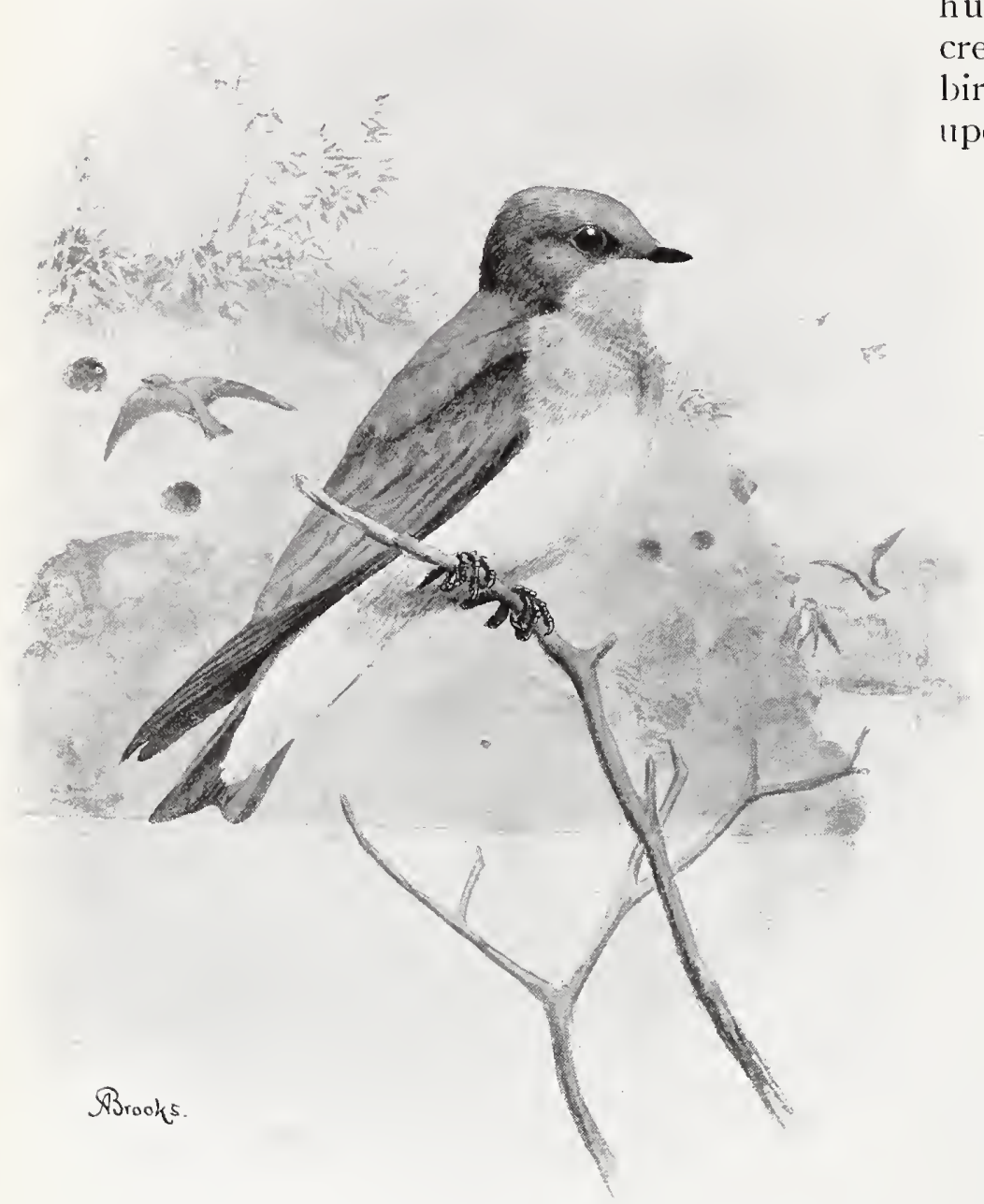

ROUGH-WINGED SWALLOWS

lower levels of the treeless foothills. Yet not over a hundredth of these "dry creeks" are utilized, for the birds are rather dependent upon the proximity of water.

The nesting holes vary widely in their consistency. While the birds are quite capable of excavating for themselves, they prefer some natural lead, - an old Kingfisher's burrow, a hole left by a rotten root or a fallen stone, or something of the sort. One I found near Santa Barbara nesting under a concrete culvert in a small rectangular stormdrain too small to admit the arm. When excavated by the bird, the entrance is quite certain to be round and overlarge, as distinguished from the lens-shaped opening of the Bank Swallow's tunnel. Nesting materials are everything or nothing, but loose, open-wrought cushions of dried grasses are the rule, where the birds have room enough Some nests are excessively large, quite beyond all possible need, as though. the birds had not forgotten some ancient tree-nesting habit.

These Swallows are fairly common throughout the indicated areas of Upper and Lower Sonoran belts, and are evidently on the increase. Dr. Grinnell found them well established in the Colorado River Valley; and they have been noted, as well, in some of the Upper Sonoran "islands" in the upper part of the State. But after all is said, the Rough-wings are a humble folk; and it would require an ardent specialist to ferret out and illuminate all their modest doings. 


\section{The Bank Swallow}

No. 105

\section{Bank Swallow}

A. O. U. No. 6I6. Riparia riparia (Linnæus).

Synonym.-SAND MARTIN.

Description.-Adult: Upperparts plain brownish gray; wings fuscous; throat and belly white; a brownish gray band across the breast; a tiny tuft of feathers above the hind toe. There is some variation in the extent of the pectoral band; it is sometimes produced indistinctly backward, and sometimes even interrupted. Length I27-I33.3 (5.00-5.25); wing I00.3 (3.95); tail 5O (I.97); bill from nostril 5.I (.20).

Recognition Marks.--Smallest of the Swallows; throat white; brownish gray pectoral band on white ground.

Nesting.- Nest: At end of tunnel in bank, two or three feet in; a frail mat of straws and grasses, or, occasionally, feathers. Eggs: 4 to 6 ( 7 of record); pure white. Av. size I $7.8 \times 12.5(.70 \times .49)$. Season: May-June; one brood.

General Range.-Northern Hemisphere. In America south to West Indies, Central America, and South America; breeding in the East about the latitude of Virginia; and in the West from the southern border states north ward to the limit of trees, winters in Brazil and (at least) Peru.

Distribution in California.-A common migrant, practically throughout the State; rather rare as a breeder. Known colonies as follows: Alvord (A. K. Fisher); Placerville (Emerson); Paicines (J. \& J. W. Mailliard); Oceanside (N. K. Carpenter); near Long Beach (J. Grinnell); Port Los Angeles (Shepardson); Whittier (Willett); Santa Barbara (Author); San Ardo (Author); Santa Cruz (Skirm).

Authorities.-Gambel (Cotyle riparia), Proc. Acad. Nat. Sci. Phila., iii., I 846, p. I I I (Calif.); Coues, Birds Col. Val., I878, p. 435 (syn., desc., etc.; see also p. 364); Judd, U. S. Dept. Agric., Biol. Surv. Bull., no. I7, I902, p. 46, pl. ix., fig. 2 (food); Shepardson, Condor, vol. xi., I909, p. I74 (breeding colonies in s. Calif.).

THOSE who know, conceive a regard for this plain-colored bird which is quite out of keeping with its humble garb and its confessedly prosy ways. The fact is, we have no other bird, so nearly cosmopolitan, and we of the West, who are being eternally reminded of our newness, and who are, indeed, upon the alert for some new shade of color upon the feather of a bird for each added degree of longitude, take comfort in the fact that here at least is an unchangeable type, a visible link between Port Los Angeles and Florence on the Arno. Birds of precisely this feather are summering on the Lena, or else hawking at flies on the sunny Guadalquivir, or tunneling the sacred banks of the Jordan; and the flattery is not lost upon us of such as still prefer Weaver Creek and the San Benito.

The life of a Swallow is so largely spent a-wing, that our interest in it centers, even more than in the case of other birds, upon the time when it is bound to earth by family ties. We are scarcely conscious 


\section{The Bank Swallow}

of the presence of the Bank Swallow until one day we see a great company of them fluttering about a sand-bank which overlooks the river, all busily engaged in digging the tunnels which are to shelter their young for that season. These birds are regularly gregarious, and a nesting colony frequently numbers hundreds.

The birds usually select a spot well up within a foot or two of the top of a nearly perpendicular bank of soil or sand, and dig a straight, round tunnel three or four feet long. If, however, the soil contains stones, a greater length and many turns may be required to reach a safe spot for the slight enlargement where the nest proper is placed. The bird appears to loosen the earth with its closed beak, swaying from side to side the while; and, of course, fallen dirt or sand is carried out in the mouth.

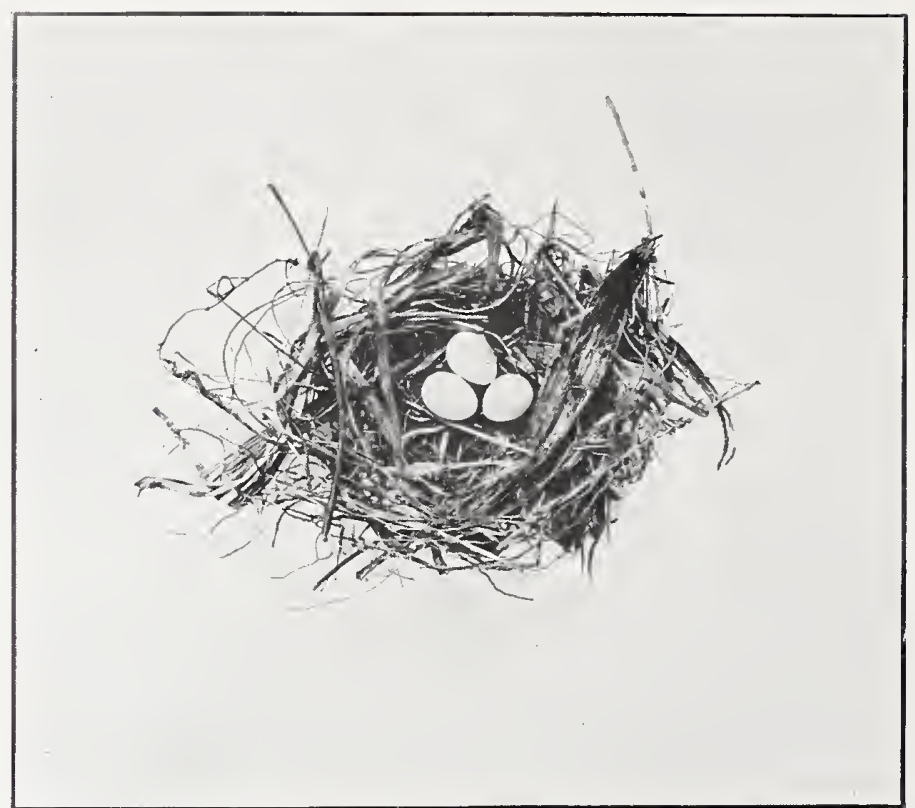

Taken near Santa Barbara

Photo by the A uthor

Sometimes the little miner finds a lens-shaped tunnel more convenient, and I have seen them as much as seven inches in width and only two in height. While the members of a colony, especially if it be a small one, usually occupy a straggling, horizontal line of holes, their burrows are not infrequently to be seen in loose tiers, so that the bank presents a honey-combed appearance.

Communal life seems a pleasant thing to these Swallows, and there is usually a considerable stir of activity about the quarters. A good deal of social twittering also attends the unending gyrations. The wonder is that the rapidly moving parts of this aerial kaleidoscope never collide, and that the cases of turning up at the wrong number are either so few or so amicably adjusted. The nesting season is, however, beset with dangers. Weasels and their ilk sometimes find entrance to the nesting burrows, and they are an easy prey to underbred small boys as well. The undermining of the nesting cliff by the swirling river sometimes 


\section{The Bank Swallow}

precipitates an entire colony-at least its real and personal propertyto destruction.

June is the nesting month, and this whether the colony elects to breed on a Santa Barbara sea-cliff (where March would do just as well) or within the Arctic Circle (where it is June or nothing). June seems to be a sort of sacrament which keeps this widely dispersed species bound together. How diverse are the conditions under which these stouthearted gypsies will consent to live, may be realized from two record stations of the West: Alford in Inyo County, where the mercury owns a friendly acquaintance with IIO; and the Kowak River in Alaska, where, as Grinnell testifies, their nesting burrows do not exceed twelve inches, because the ground beyond that is frozen.

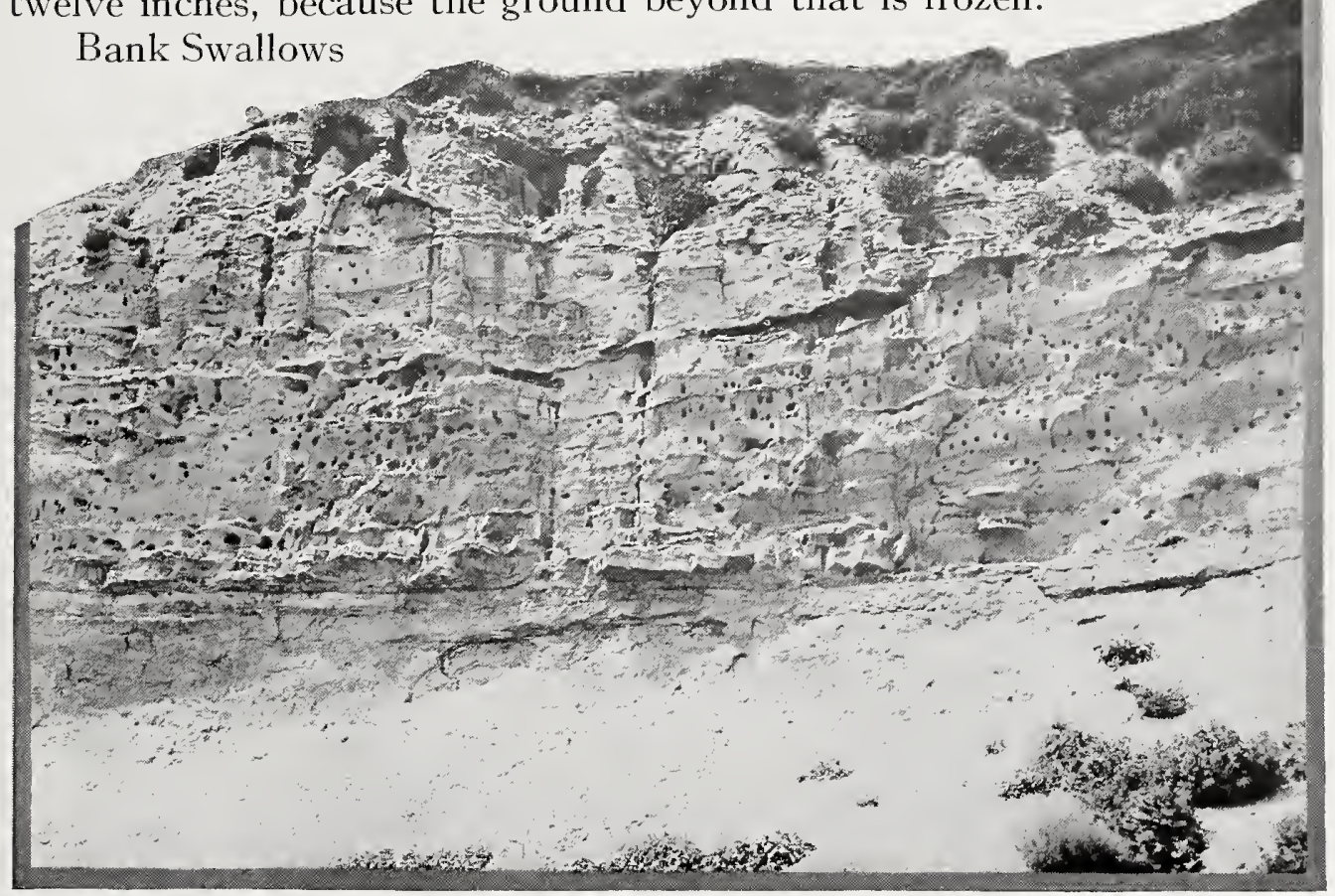

Taken near Santa Barbara

A NESTING CLIFF

Photo by the Author

are the least musical of the Swallow kind,--unless, perhaps, we except the Rough-winged species, which is naturally associated in mind with this. They have, nevertheless, a characteristic twitter, an unmelodious sound, like the rubbing together of two pebbles. An odd effect is produced when the excited birds are describing remonstrant parabolas at an intruder's head. The heightened pitch in the tones of the rapidly approaching bird, followed instantly by the lower tone of full retreat, is enough to startle a slumbering conscience in one who meditates mischief on a Swallow's home. 


\section{The Bank Swallow}

No. 106

\section{Barn Swallow}

A. O. U. No. 613. Hirundo rustica erythrogaster Boddaert.

Synonyms.-American Barn Swallow. Fork-talled Swallow.

Description.-Adult: Above lustrous steel-blue; in front an imperfect (interrupted) pectoral collar of the same hue; forehead chestnut; lores black; throat and breast rufous; remaining underparts, including lining of wings, more or less tinged with the same, according to age and season; wings and tail blackish, with purplish or greenish reflections; tail deeply forked, the outer pair of feathers being from one to two inches longer, and the rest graduated; white blotches on inner webs (except on middle pair) follow the bifurcation. Immature: Forehead and throat paler; duller or brownish above; lateral tail-feathers not so long. Length of adult 177.8 (7.00) wing I20.6 (4.75); tail 76.2-I I 4.3 (3.00-4.50); bill from nostril 6.I (.24).

Recognition Marks.-Aerial habits; rufous of throat and underparts; forked tail; nest usually inside the barn.

Nesting.- Nest: A neat bracket or half-bowl of mud; luxuriously lined with grass and feathers; and cemented to a beam of barn or bridge. In the IVest still nests occasionally in original haunts, viz., cliffs, caves, and crannied sea-walls. Eggs: 3 to 6 ; ovate or elongate ovate; white, or, rarely, pinkish white, spotted sharply and sparingly and rather uniformly with reddish brown of several shades and vinaceous gray. Av. of 23 southern-taken eggs: 18.8 x I3.2 (.74 x .52). Season: May, June; one or two broods.

General Range.- North America, breeding from northwestern Alaska, southern Manitoba and southern Ungava, south to North Carolina, northern Arkansas, and southwestern Texas, thence throughout the southwestern states, and in Mexico south to Jalisco and Tepic. Winters from southern Mexico to Brazil, Argentina, and central Chile.

Distribution in California.--An abundant migrant practically throughout the State; remains to breed in favorable sections west of the Sierras, more sparingly and locally east of the Sierras and in southern California. Most abundant in the Tulare-Merced section and in the vicinity of San Francisco Bay. Found interruptedly along the sea-coast and commonly upon the islands. Occurs sparingly in winter in the Imperial Valley (van Rossem).

Authorities.-Heermann (Hirundo rufa), Jour. Acad. Nat. Sci. Phila., ser. 2, ii., I 853, p. 26I (Calif.); Coues, Birds Col. Val., i 878, p. 407 (syn., habits, etc.; see also p. 364); Beal, U. S. Dept. Agric., Biol. Surv. Bull., no. 30, I907, p. 30 (food); van Rossem, Condor, vol. xiii., I9I I, p. I33 (Imperial Valley in winter); Tyler, Pac. Coast Avifauna, no. 9, I9I3, p. 9I (Fresno; occurrence, habits, nesting).

ONE hardly knows what quality to admire most in this boyhood's and life-long friend, the Barn Swallow. All the dear associations of life at the old farm come thronging up at sight of him. You think of him somehow as a part of the sacred past; yet here he is today as young and as fresh as ever, bubbling over with springtime laughter, ready for a frolic over the bee-haunted meadows, or willing to settle down on 


\section{The Barn Swallow}

the nearest fence-wire and recount to you with sparkling eyes and eloquent gesture the adventures of that glorious trip up from Mexico.

Perhaps it is his childlike enthusiasm which stirs us. He has come many a league this morning, yet he dashes in through the open doors and shouts like a boisterous schoolboy, "Here we are, you dear old barn; ar'n't we glad to get back again!" Then it's out to see the horse-pond; and down the lane where the cattle go, with a dip under the bridge and a few turns over the orchard-a new purpose, or none, every secondlife one full measure of abounding joy!

Or is it the apotheosis of motion which takes the eye? See them as they cast a magic spell over the glowing green of the young alfalfa, winding about in the dizzy patterns of a heavenly ballet, or vaulting at a thought to snatch an insect from the sky. Back again, in again, out again, away, anywhere, everywhere, with two-miles-a-minute speed and effortless grace.

But it is the sweet confidingness

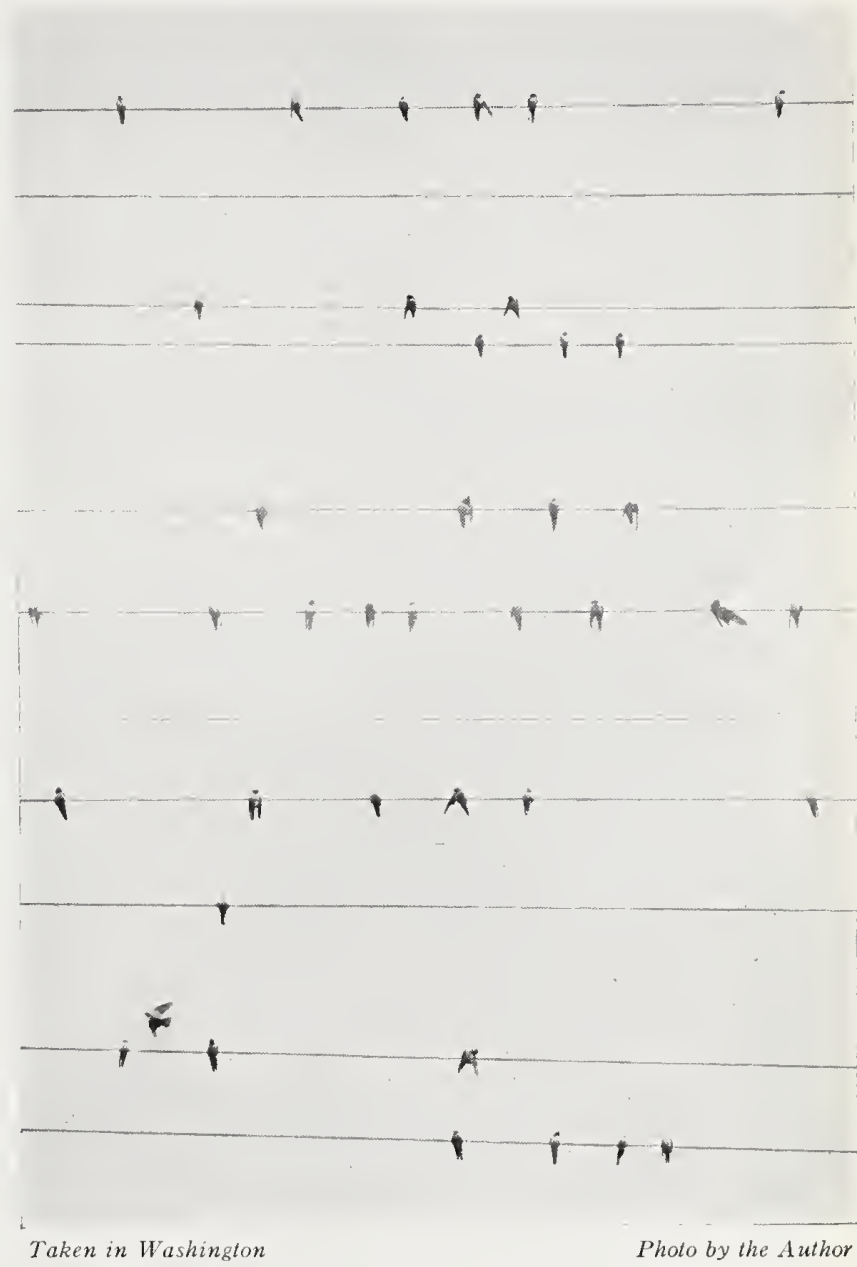

BARN SWALLOWS ON TELEGRAPH WIRES of this dainty Swallow which wins us. With all the face of Nature before him he yet prefers the vicinage of men, and comes out of his hilly fastnesses as soon as we provide him shelter. We all like to be trusted, whether we deserve it or not. And if we don't deserve it-well, we will, that's all.

Truth to tell, the transition of the Barn Swallow from a state of nature to one of human dependence has been less conspicuous and less perfect in California than it has further north. With us the bird is still to be found nesting, sparingly, in little caves or rock-pockets in wild ravines, or, still more commonly, in sea-washed caverns. On the Santa Barbara Islands, especially, Barn Swallows are a familiar feature of shore life; and they show no disposition to forsake their haunts nor to avail 


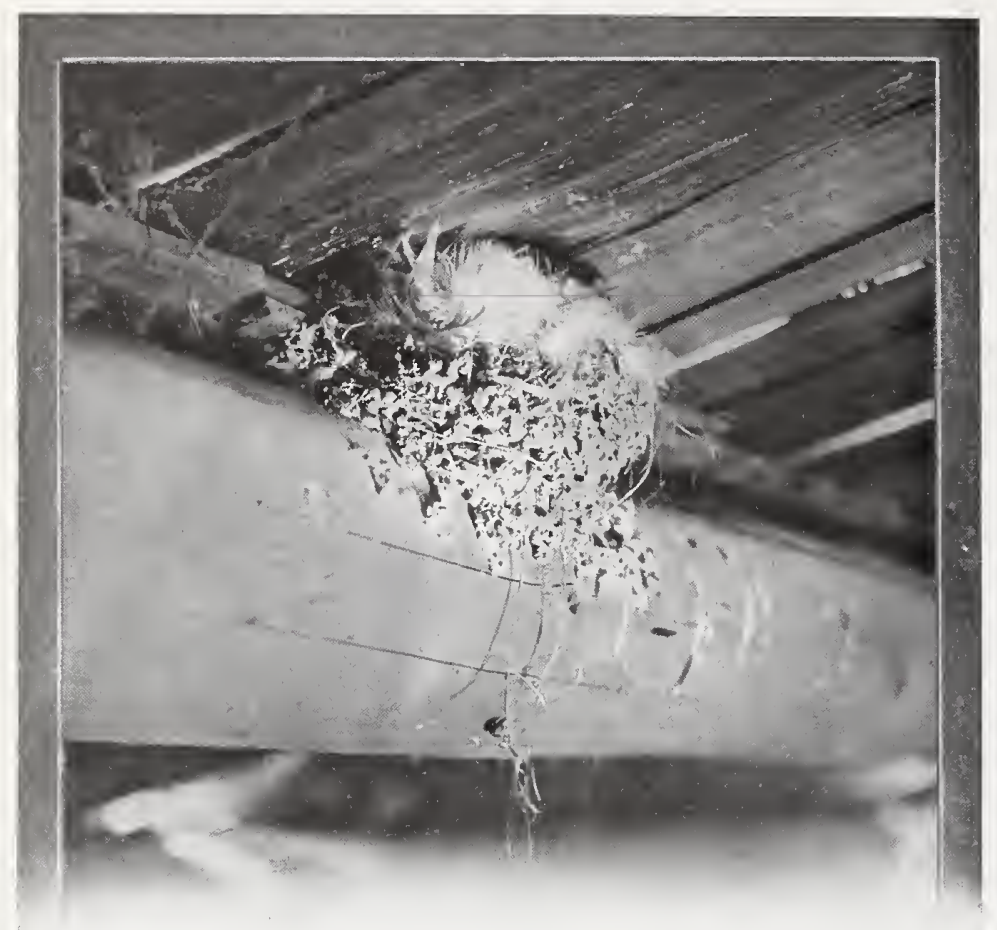

Taken in Washington NEST OF BARN SWALLOW themselves of the shelter offered by ranch buildings. By way of contrast, I recall a town in western Washington, Hoquiam, where a pair of these swallows had placed their nest under the porch roof of a tailor shop on one of the main streets. This nest held young birds nearly ready to fly on the zoth of August, I9Io, and is perhaps one of the latest records known.

A via media has been f o und i n California, however, for the Barn Swallow has enthusiastically accepted the wooden bridge as his portion. In the San Francisco Bay region,

and especially in the San Joaquin Valley, where the country is intersected by a network of drainage or irrigating canals, these birds abound. Almost every bridge from the least to the greatest is utilized. The smaller one will harbor a pair or two, while the greater may boast a hundred. In nesting, thus, over running water, the birds secure a certain immunity from predatory animals, and they are near their work, for insects abound over these canals. Two broods are reared each season, one in April or May, and another in June or July. At the time of flood water, in early June, there are anxious days for the nesting swallows. I have seen them much agitated on such occasions, as though knowing that danger impended; but a heroic mother will not fail to visit her brood, even though the stringers of the bridge clear the flood by no more than three or four inches.

The nest of the Barn Swallow is quadrispherical, or bracket-shaped, with an open top; and it usually depends for its position upon the adhesiveness of the mud used in construction. Dr. Brewer says of them: "The nests are constructed of distinct layers of mud, from ten to twelve in number, and each separated by strata of fine dry grasses. These 


\section{The Tree Swallow}

layers are each made up of small pellets of mud, that have been worked over by the birds and placed one by one in juxtaposition until each layer is complete." The mud walls, thus composed, are usually an inch in thickness, and the cavity left is first lined with fine soft grasses, then provided with abundant feathers, among which the speckled eggs lie buried and almost invisible.

Bringing off the brood is an event which may well arrest the attention of the human household. There is much stir of excitement about the barn. The anxious parents rush to and fro shouting tisic, tisic, now in encouragement, now in caution, while baby number one launches for the nearest beam. The pace is set, and babies number two to four follow hotly after, now lighting safely, now landing in the hay-mow, or compromising on a plow-handle. Upon the last-named the agonized parents urge another effort, for Tabby may appear at any moment. He tries, therefore, for old Nellie's back, to the mild astonishment of that placid mare, who presently shakes him off. Number five tumbles outright and requires to be replaced by hand, if you will be so kind. And so the tragicomedy wears on, duplicating human years in half as many days, until at last we see our Swallows among their twittering fellows strung like notes of music on the far-flung staff of Western Union.

If birds really mean anything more to us than so many Japanese kites flown without strings, we may surely join with Dr. Brewer in his whole-souled appreciation of these friendly Swallows: "Innocent and blameless in their lives, there is no evil blended with the many benefits they confer on man. They are his ever constant benefactor and friend, and are never known even indirectly to do an injury. For their daily food and for that of their offspring, they destroy the insects that annoy his cattle, injure his fruit trees, sting his fruit, or molest his person. Social, affectionate and kind in their intercourse with each other; faithful and devoted in the discharge of their conjugal and parental duties; exemplary, watchful, and tender alike to their own family and to all their race; sympathizing and benevolent when their fellows are in any trouble,- - these lovely and beautiful birds are bright examples to all, in their blameless and useful lives."

No. 107

\section{Tree Swallow}

A. O. U. No. 6I4. Iridoprocne bicolor (Vieillot).

Synonym.-White-BELLIEd SWaLlow.

Description.-Adult male: Above, lustrous steel-blue or steel-green; below, pure white; the axillaries, sides, and lining of wings dusky; lores black; wings and tail 


\section{The Tree Srallow}

black, showing some bluish or greenish luster; tail slightly forked. Female: Similar to male, but duller. Immature: Upperparts mouse-gray instead of metallic; below whitish. Length about I 52.4 (6.0o); wing I I6.I (4.57); tail 55.6 (2.I9); bill from nostril $6.4(.25)$.

Recognition Marks.--Aerial habits; steel-blue or greenish above; pure white below; a little larger than the next species.

Nesting.-Nest: In holes in trees, preferably "drowned" trees, or those surrounded by water; a heavy lining of soft materials, especially feathers. Eggs: 4 to 6; pure white-a pinkish white before removal of contents. Av. size I9. I x I3.7 $(.75 \times .54)$. Season: May-July; one or two broods.

General Range.- North America. Breeds from Virginia, Kansas, and southern California, north nearly to the limit of trees. Winters from central California, southern Texas, and the Gulf States, south to Cuba, and through Mexico to Guatemala.

Distribution in California.-Common migrant throughout the State. Breeds widely but very locally, notably upon the lakes east and west of the Sierras up to (at least) 9000 feet, and in the Sacramento-San Joaquin Valley; but also in the coastal valleys even at sea-level and down to San Diego County. Winters sparingly and irregularly in the lowlands of west central and southern California; also upon the Colorado Desert (Indian Wells, Jan. 30, I9I3; Mecca, Feb 3, I9I3).

Authorities.-Gambel (Chelidon bicolor), Proc. Acad. Nat. Sci. Phila., iii., I846, p. IIo (Santa Barbara); Coues, Birds Col. Val., i 878, p. 4I3 (syn., habits, early hist., etc.; see also p. 364); Ray, Auk, vol. xx., I903, p. I 90 (Sierra Nevada; desc. nest); Willett, Pac. Coast Avifauna, no. 7, I912, p. 90 (status in s. Calif.); Tyler, Pac. Coast Avifauna, no. 9, I913, p. 92 (Fresno; occurrence, habits, nesting).

THE SWALLOW is the symbol of summer, and by this token we know that we are in the land of perpetual summer, for does not the Tree Swallow "winter" with us? The "Merry Christmas" of the Tree Swallow is, I think, the sweetest greeting the season offers in the Southland. For these birds symbolize purity, liberty, daintiness, and all of gladness that the heart holds dear. In their immaculate garb of dark blue and white, they seem like crystallizations of heaven and its templed clouds, truth and beauty blended, winged fancies, tender tokens of constancy, fragile, yet potent, perennial pledges of the eternal Becoming of Nature.

The Tree Swallow is a lover of water, though doubtless for economic - or shall we say gastronomic? - rather than esthetic reasons. Ponds and lakes are the surest source of supply for insect food, not alone because of the variety and luxuriance of plant life which their borders afford, but because of the comparatively warm atmospheric areas which persist over their surfaces when the weather is turning cold. Swallows are very much attracted, therefore, to favorite watering places; and whatever their wanderings between whiles, they report back every hour or so to headquarters. It is over such places that the migrant species linger longest in the autumn, and it is here that the hardiest of the returning hosts join the Tree Swallows in early spring. This close dependence upon water gave rise to the 


\section{The Tree Swallow}

early belief that swallows hibernated by plunging beneath the waves, burying themselves in the mud of the bottom to await the return of spring. So stubborn was this conviction, and so circumstantial were the reports upon which it was based, that the tradition remains as one of the most curious examples of pseudo-science and human gullibility in the annals of all history. Even so recent a writer as Dr. Elliott Coues, cleverest exponent of American ornithology, treated the evidence with respect, and refused to express an adverse judgment.

The Tree Swallow remains faithful to its winter love, and nests by preference along streams or in dead trees whose roots are protected by standing water. The stretches of submerged forests made by the back water of mountain reservoirs are sure to be used as nesting sites. The piling of abandoned wharves, as at Lake Tahoe, is deemed exactly fit. The birds are not themselves able to make excavations in the wood, but they have no difficulty in possessing themselves of the results of other birds' labors. Old holes will do, if not too old, but I once knew a pair of these swallows to drive away a pair of Flickers from a brandnew nesting hole, and to occupy it themselves.

Even more startling was a situation we found on the banks of the Pajaro River, in Santa Cruz County, May 20,

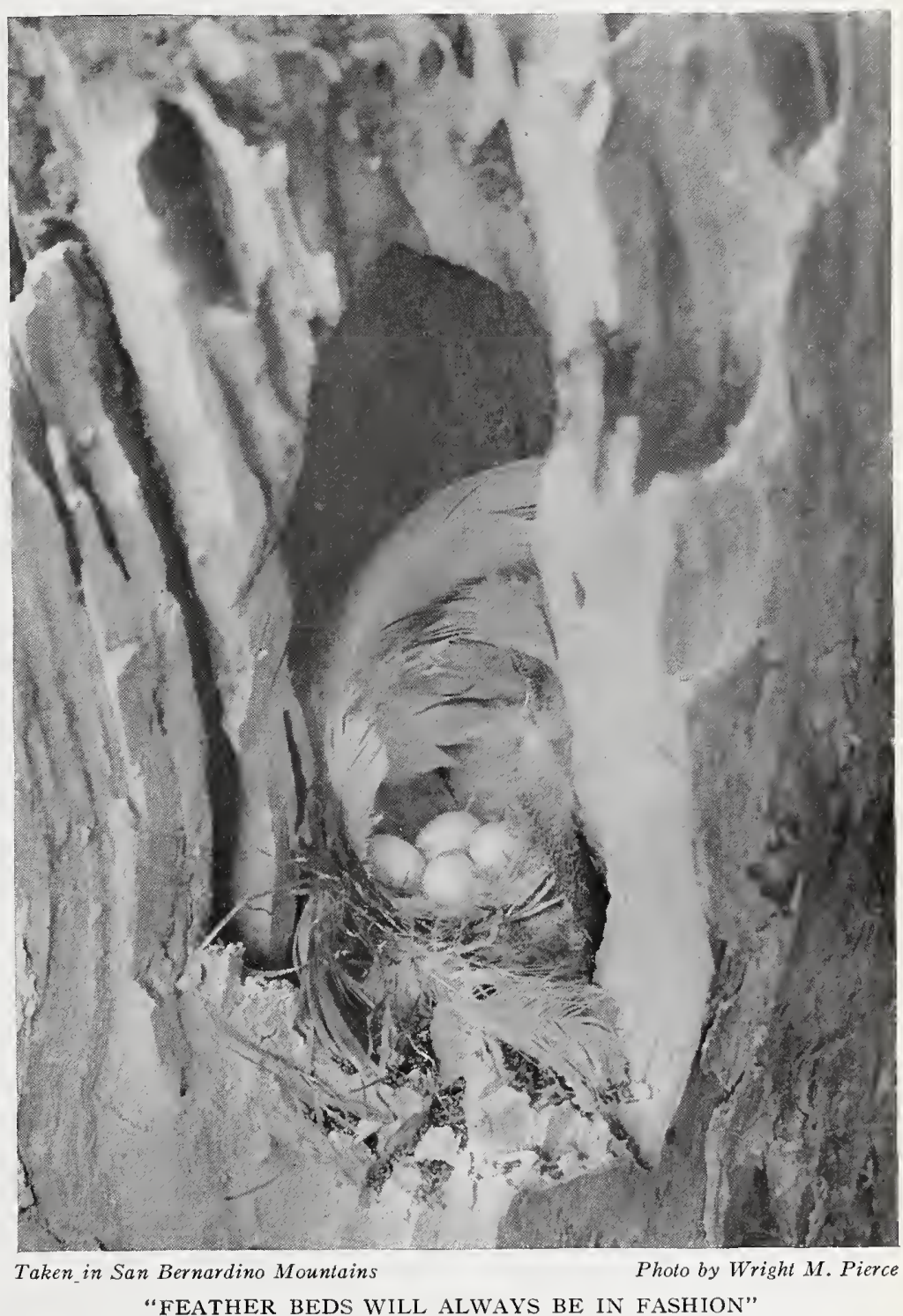




\section{The Tree Swallow}

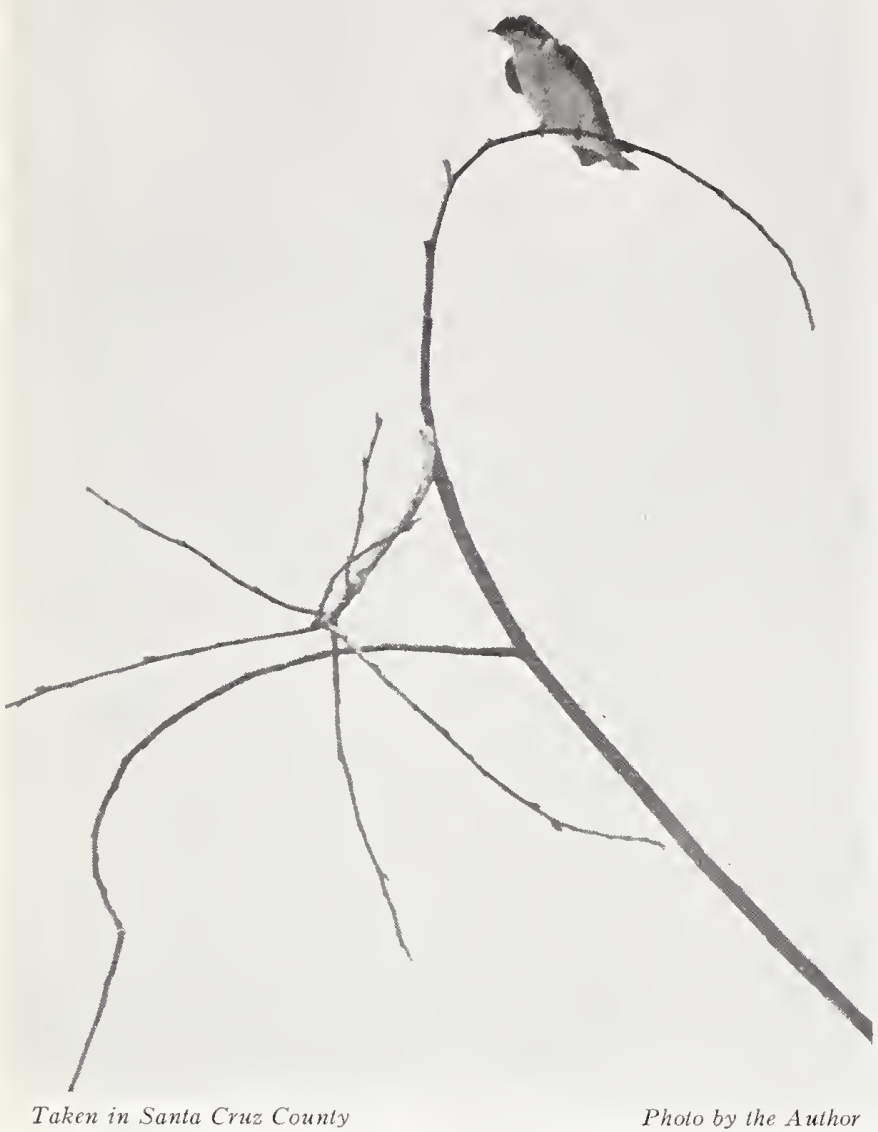

AN AIRY PERCH

I9I4. The swallows were visiting a hole about five feet up in a willow tree, and the female was caught on the nest, though events proved she was only building. At the bottom of the hole, beneath a massive cushion of chicken-feathers, lay the desiccated body of a Willow IVoodpecker, brooding in death upon five discolored eggs. We recoil in selfrighteous horror over such an exhibition of callousness. But what do we better? Certain monastic orders play at pyramid building with the bones of their departed friars. Cemetery picnics are things not unknown, and many an amour has braved the voiceless protests of the dead. The tragedy of the Woodpecker was doubtless that of the previous year. To Mistress Swallow, house-hunting, this devoted mother perishing at her post was only a bundle of feathers, a seasonable legacy for a new home.

Feather beds will always be in fashion in Swallowdom. As a ribbon to a maid or a bonnet to a dowager, so is a feather to a Tree Swallow. It is one seduction she cannot resist. As a result, the sign of the feather protrudes from the nest, and the youngsters are brought up in a swaddled ease which bodes ill for future usefulness. (Yet we recall that the redoubtable Prussian sleeps between two feather-beds!) If the home is disturbed, both parents are very solicitous; and should a feather from the nest be tossed into the air, one of them will catch it and fly about awaiting a chance to replace it. Or if there are other swallows about, some neighbor will snatch it first and make off with it to add to her own collection.

In the West, Tree Swallows are beginning to avail themselves of artificial nesting sites, as they have for years in the East. In fact, there is no reason why we should hesitate to recognize the changing order of things, and we may well bestir ourselves to make the birds at home. Bird-boxes are evidently the order of the new day; wherefore, let us build 


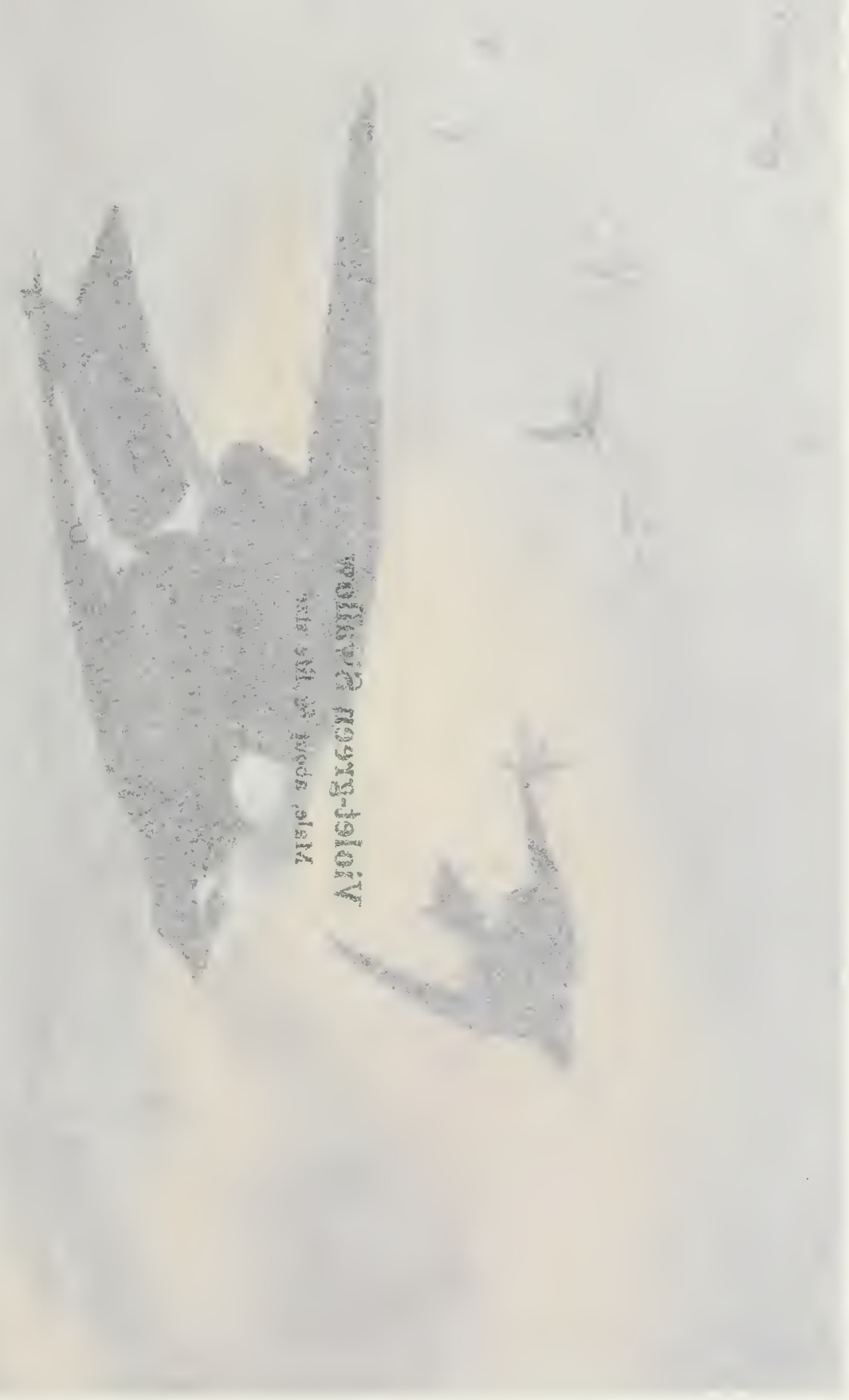





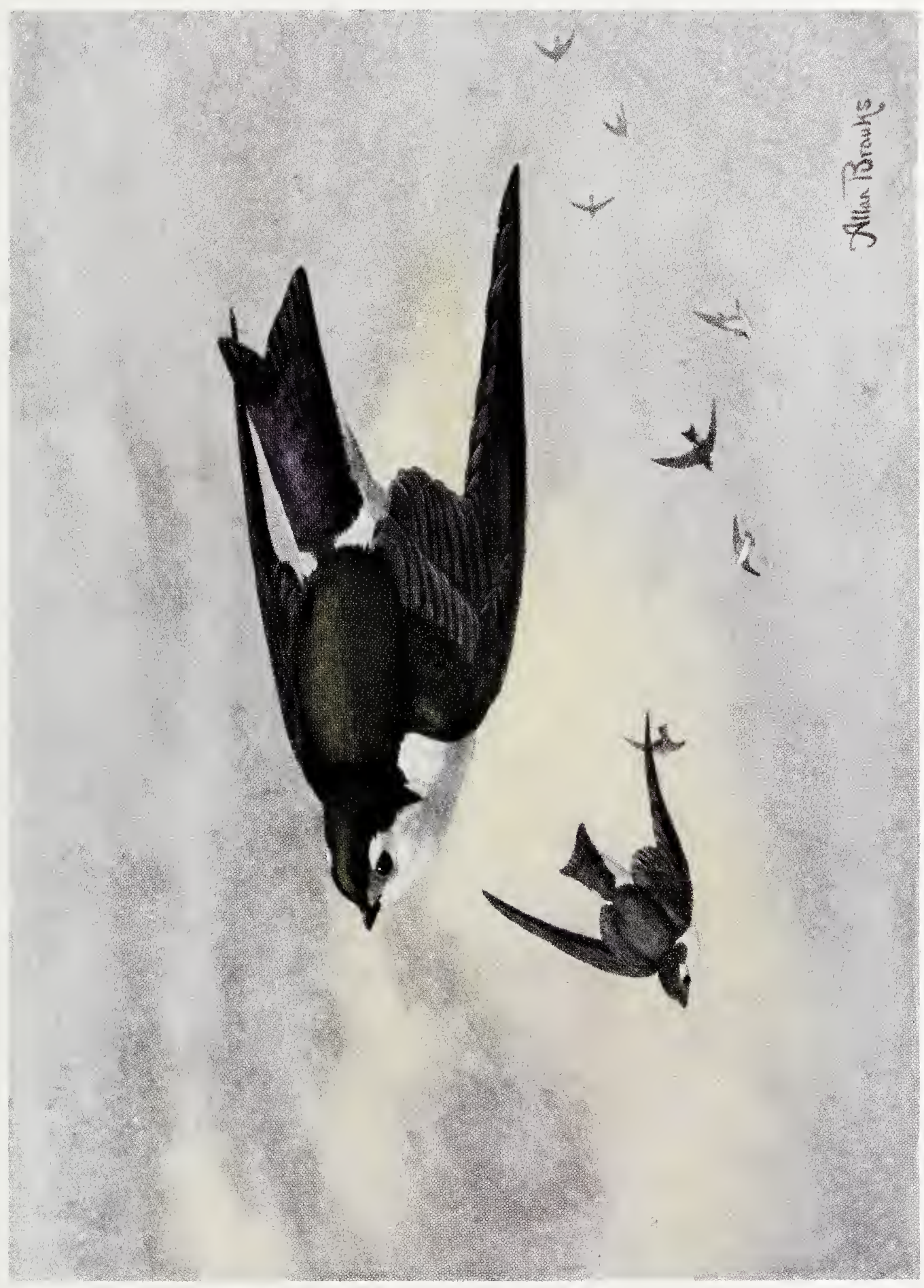





\section{The Northern Violet-green Swallow}

bird-boxes. No more welcome tenants can be lured from the wilds than birds of this and the succeeding species. Besides the fascination of their endless wing-play, one comes to love as a thing apart their amiable creakings and twitterings. At the height of the nesting season, both Tree and Violet-green Swallows will dedicate the first hour of the morning twilight to song; and they will sail about slowly in the darkness uttering continuous notes for minutes at a stretch. The rhythm (but not the sentiment) may be embodied as follows: Sweetie kickup, sweetie kickup, sweetie sweetie kickup, sweetie kickup kickup, etc. It is very difficult to distinguish between the notes of the two species, but those of the smaller bird, T. thalassina, are perhaps of a lighter character and more often musical.

No. 108

\section{Violet-grreen Swallow}

A. O. U. No. 6I5. Tachycineta thalassina lepida Mearns.

Synonym.-Northern Violet-Green Swallow.

Description.-Adult male: Upperparts, including pileum, hind-neck, back, upper portion of rump, scapulars, and lesser wing-coverts, rich, velvety bronze-green, occasionally tinged with purple; crown usually more or less contrasting with color of back, greenish-brown, or olive-green, rather than bronze-green, and more strongly tinged with purple; a narrow cervical collar, lower rump, and upper tail-coverts velvety violet-purple, or with more or less admixture of green; wings (except lesser coverts) and tail blackish, glossed with violet or purple; lores grayish; underparts, continuous with cheeks and area over and behind eye, and with conspicuous flank-patch, nearly meeting fellow across rump, pure white; under wing-coverts pale gray, whitening on edge of wing. Bill black; feet brownish black; iris brown. Adult female: Like male, but usually much duller; bronze-green of upperparts reduced to greenish brown, or brown with faint greenish reflections; the cheeks brown with white skirtings. Young birds are plain mouse-gray above, white or pale sooty gray below, and their inner secondaries are tipped with grayish. Length I I4.3-I39.7 (4.50-5.50); wing I I 2 (4.4I); tail 45 (1.77); bill $5.2(.20)$.

Recognition Marks.--Smaller; green and violet above, white below; whitecheeked and white-rumped (apparently), as distinguished from the Tree Swallow.

Nesting.- Nest: Of dried grasses, with or without feathers; placed in cranny or crevice of cliff (especially in vapor holes of volcanic formations), or in o'd woodpecker holes-latterly and less commonly in bird-boxes, or in cranny of building. Eggs: 4 to 6; pure white. Av. size $18.3 \times \mathbf{I} 2.2(.72 \times .48)$. Season: May or June, according to altitude; one brood.

General Range.-Western North America, breeding from western Nebraska to the Pacific, and from central Lower California and northern Durango north to 


\section{The Northern Violet-green Swallow}

central Alaska and Yukon; wintering sparingly in southern California and in Mexico, south to Guatemala and Costa Rica.

Distribution in California.--Abundant migrant throughout the State. Breeds in the mountains and throughout the State at Transitional levels; also well down into Upper Sonoran zone in the coastal valleys, and upon the southern coastal rangesaltitudinal breeding range from sea-level to about 10,000 (Granite Basin, eastern Fresno Co., July I3, I9I3). Winters sparingly in the Imperial Valley and casually in the San Diegan district, north to Santa Barbara (Dec. 19-24, I914; Dec. 24, I918). However, most February records and some in January are of returning migrants. Accidental (?) on the Farallons (June Ist, I9I I).

Authorities.-Audubon (Hirundo thalassina, Synop. Birds N. Am., I 839, p. 36 ("California"); Ridgway, Orn. 4oth Parallel, I 877, p. 443 (Nevada; habits; nesting in rocks); Coues, Birds Col. Val., I878, p. 419 (syn., habits, desc., etc.; see also p. 364); Mearns, Proc. Biol. Soc. Wash., vol. xv., I902, p. 3 I (Tachycineta lepida, orig. desc.; type locality Campbell's Ranch, Laguna Mts., San Diego Co.); Beal, U. S. Dept. Agric., Biol. Surv. Bull., no. 30, 1907, p. 32 (food).

IF WE lavished any superlatives on the Tree Swallow-and our memory misgives us that we did-we regret it now. Not but that the Tree Swallow is strictly deserving-oh, a very deserving bird-but we needed all our superlatives for present use, and one hates to repeat. What shall we do for the Violet-green Swallows? Simply this: we will call them children of heaven.

To appear to the best advantage, this child of heaven should be seen on a typical California day, burning bright, when the livid green of back and crown may reflect the ardent glances of the sun with a delicate golden sheen. The violet of upper tail-coverts and rump comes to view only in changing flashes; but one catches such visions as a beggar flung coins, and adds image to image until he has a full concept of this rainbow hue. At such a time, if one is clambering about the skirting of some rugged precipice in Yosemite, he feels as if the dwellers of Olympus had come down in appropriate guise to inquire his earth-born business. Not, however, that these lovely creatures are either meddlesome or shrewish. Even when the nest is threatened by the strange presence, the birds seem unable to form any conception of harm, and pursue their way in sunny disregard. Especially pleasing to the eye is the pure white of the bird's underparts, rising high on flanks and cheeks, and sharply contrasting with the pattern of violet and green, in such fashion that, if Nature had invited us to "remold it nearer to the heart's desire," we must have declined the task.

Before the advent of the white man in California these birds nested, altogether, as they still do largely, in deserted woodpecker holes and in natural cavities in trees, or in the fastnesses of rocky cliffs. In the lastnamed situations they utilize the rocky clefts and inaccessible crannies, 


\section{The Northern Violet-green Swallow}

and are especially fond of the smaller vapor holes which characterize the basaltic formations. Favorable circumstances may attract a considerable colony, to the number of a hundred pairs or more, but even so it is not easy to find a getatable nest. If one is able to reach the actual nesting site, the mouth of the ancient gas-vent, which the birds have chosen for a home, may prove too small to admit the hand.

Though the near presence of water is not a fundamental requirement of this bird, I have found nests about some of the lesser sea-walls; and a mountain stream is more to the bird's taste than an insipid lake

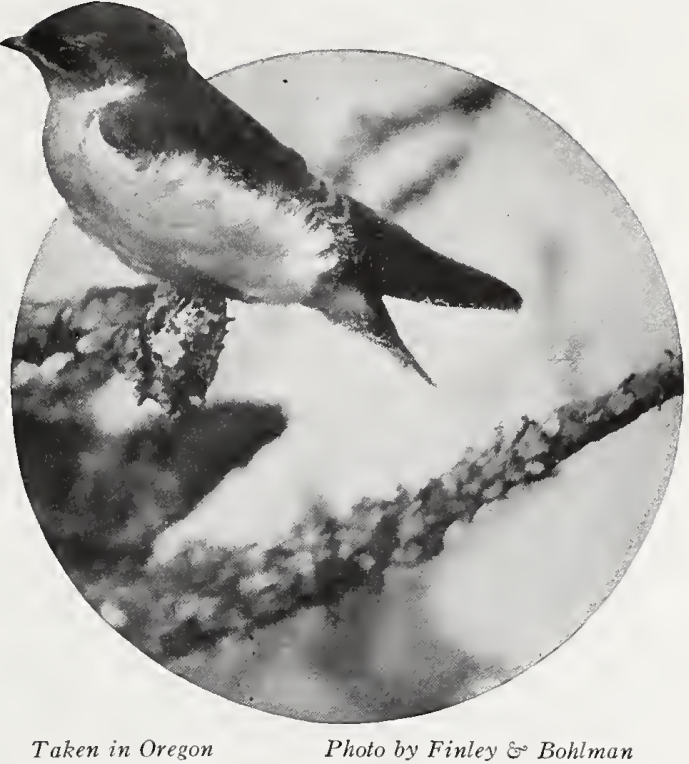

YOUNG VIOLET-GREEN SWALLOW or a brackish pool.

The Violet-green Swallows seem to be on excellent terms with those reckless meteors, the White-throated Swifts; and while they will not follow them into some of their Lower Sonoran fastnesses, they are likely to share with them the austere hospitality of the wildest granite walls, Tehipite Dome or El Capitan. In a charmed spot I know near Santa Barbara, an epitome of romance which is yet but a doll's house compared with Sentinel Rock or the desert-frowning bastions of San Jacinto, the following birds rear their young in perfect peace within the space of a stone's cast: Western Red-tailed Hawk, Pacific Horned Owl, Cliff Swallow, White-throated Swift, and Violet-green Swallow.

But throughout the State these children of heaven are exhibiting a most commendable willingness to dwell among the children of men. We are not yet half alive to our privileges, but there are authentic records of Violet-greens nesting in the heart of the city, while such towns as happen to be near their ancient fastnesses are likely to be blessed in triple measure. It is a pretty sight on a sunny April day to see Violet-green Swallows fluttering about a suburban cottage, inspecting knot-holes or recessed gables, or, in default of such conveniences, daintily voicing their disappointment at such neglect on the part of careless humans.

Although not formerly so fastidious-I have found cliff nests composed entirely of dried grass - these birds have become connoisseurs in upholstery of feathers, and their unglossed white eggs, five or six in number, are invariably smothered in purloined down, until we begin to 


\section{The Bohemian Waxwing}

suspect that our fowls rather than our features have favored our adoption.

In these birds and in the Barn Swallows, the well known twittering and creaking notes of Swallows most nearly approach the dignity of song. Indeed, Mr. Rathbun contends that the song heard at close quarters is a really creditable affair, varied, vivacious, and musical.

The Violet-greens are less hardy and venturesome than the Tree Swallows, although they do winter sparingly as far north as the Imperial Valley. In the spring migrations the pioneers enter the State from the South about the middle of February, but the species is nowhere common before the middle of March. Last year's nesting site becomes at once the spring rendezvous for the returned birds, and to see them twittering about in the upper branches of a dead tree riddled by woodpecker holes, or to see a Swallow enter a hole with a feather in its beak, you would imagine them to be early nesters; but these are only happy anticipations. Egglaying never occurs before late May, and middle June is a more nearly average date.

As the nesting season draws to a close, the Violet-green Swallow yields in fullest measure to the social instinct, and the young are mustered in great happy companies. Whether instruction is meted out on such occasions, we do not know; but evidently good fellowship promotes good manners. Even the hobble-de-hoy stage is believed to be less acute and painful in the case of these heavenly children.

No. 109

\section{Bohemian Waxwing}

A. O. U. No. 6I8. Bombycilla garrula pallidiceps Reichenow.

Synonyms.-Northern Waxwing. Greater Waxwing.

Description.-Adults: A conspicuous crest; body plumage soft, grayish brown or drab, shading by insensible degrees between the several parts; back darker passing into bright russet on forehead and crown, and through dark ash of rump and upper tail-coverts into black of tail; tips of tail-feathers abruptly yellow (wax-yellow); breast with a vinaceous cast, passing into light russet of cheeks; a narrow frontal line passing through eye, and a short throat-patch velvety black; belly narrowly and centrally yellowish white; under tail-coverts deep cinnamon-rufous (russet); wing blackish ash, and tips of the primary coverts and tips of the secondaries on outer webs, white; tips of primaries on outer webs bright yellow (lemon chrome to wax-yellow), whitening outwardly; the shafts of the secondaries produced into peculiar flattened red "sealing wax" tips. Bill and feet black. Length 203.2 (8.00); wing I I4 (4.49); tail 63 (2.48); bill I I.4 (.45). 


\section{The Bohemian Waxwing}

Recognition Marks.-Towhee size; grayish brown coloration. As distinguished from the much more common Cedar-bird: belly not noticeably yellow; white wing-bars; under tail-coverts cinnamon.

Nesting.-Does not breed in California. Much like that of next species. Eggs: Larger. Av. size $24.9 \times 17.5(.98 \times .69)$.

Range of Bombycilla garrula.-Boreal zones of Northern Hemisphere.

Range of B. g. pallidiceps.-North America, breeds west of Hudson Bay nearly to the limit of trees, and south to southern British Columbia, Alberta, and northern Idaho; winters east to Nova Scotia and south regularly through the northern tier of states, and occasionally to California, Colorado, southern Illinois, Pennsylvania, Connecticut, etc.

Occurrence in California.--Of irregular occurrence in winter; sporadically abundant. There were especially notable invasions in I882, in I9II, and in. I9I9, - the last named extending clear to San Diego County.

Authorities.-W. E. Bryant (Ampelis garrulus), Zoe, vol. iv., I893, p. 226 (Susanville, February, I892); Maillard and Grinnell, Condor, vol. viii., I895, p. 77 (Victorville, Mohave Desert); Pierce, Condor, vol. xxii., I920, p. I Io (Claremont); Stephens, Condor, vol. xxii., I920, p. I59 (Vallecito, San Diego Co.); Coues, Birds Col. Val., I878, pp. 45I, 459 (desc., hist., bibliog., syn., etc.); Oberholser, Auk, vol. xxxiv., I9I7, p. 330 (syst. rev.); Swarth, Univ. Calif. Pub. Zool., vol. xxiv., I922, p. 266, col. pl., figs., map (habits, desc. nests and eggs, plumage changes, etc.).

IT WAS not a very happy inspiration which dubbed this bird "Bohemian"; 1 for however accurate the term in its prime literary sense of "wandering," it does violence to the character of the Northern Waxwings in all other respects. These are very decorous Gypsies. Though they be nomads, their manners have suffered no breach thereby; and irregularity of conduct is a thing not to be thought of in their polished circles. Nothing could exceed the refined elegance of these "gentlemen in feathers" who occasionally cross our northern borders in winter. Demure, gentle, courteous to a fault, and guileless to the danger point, and beyond, these lovely creatures exceed in beauty, if possible, their more familiar cousin, the Cedarbird. They move about in flocks, sometimes to the number of hundreds, and as the rigors of winter come on they search the orchard and berry-patch for ungarnered fruit, or divide with hungry Robins the largess of rowan trees. Much time is spent in amiable converse, but it is not at all fair to call them "chatterers," or garrulus, ${ }^{2}$ as though they were monkeys. Dignity is of the very essence of their being, and, as fond as they are of good living, they would starve rather than do anything rude or unseemly.

1"Bohemian, the French appellation of Gypsies, involves an error similar to ours; they were taken at first by the common people of France to be the expelled Hussites of Bohemia, and hence this name" (Trench).

2Originally named Lanius garrulus by Linnæus in 1758 . 


\section{The Bohemian Waxwing}

An observer in Utah ${ }^{1}$ relates how an ill-mannered Robin, jealous of the good behavior of a company of these visitors, in an apple tree, set about to abuse them. "He would bluster and scream out his denunciations till

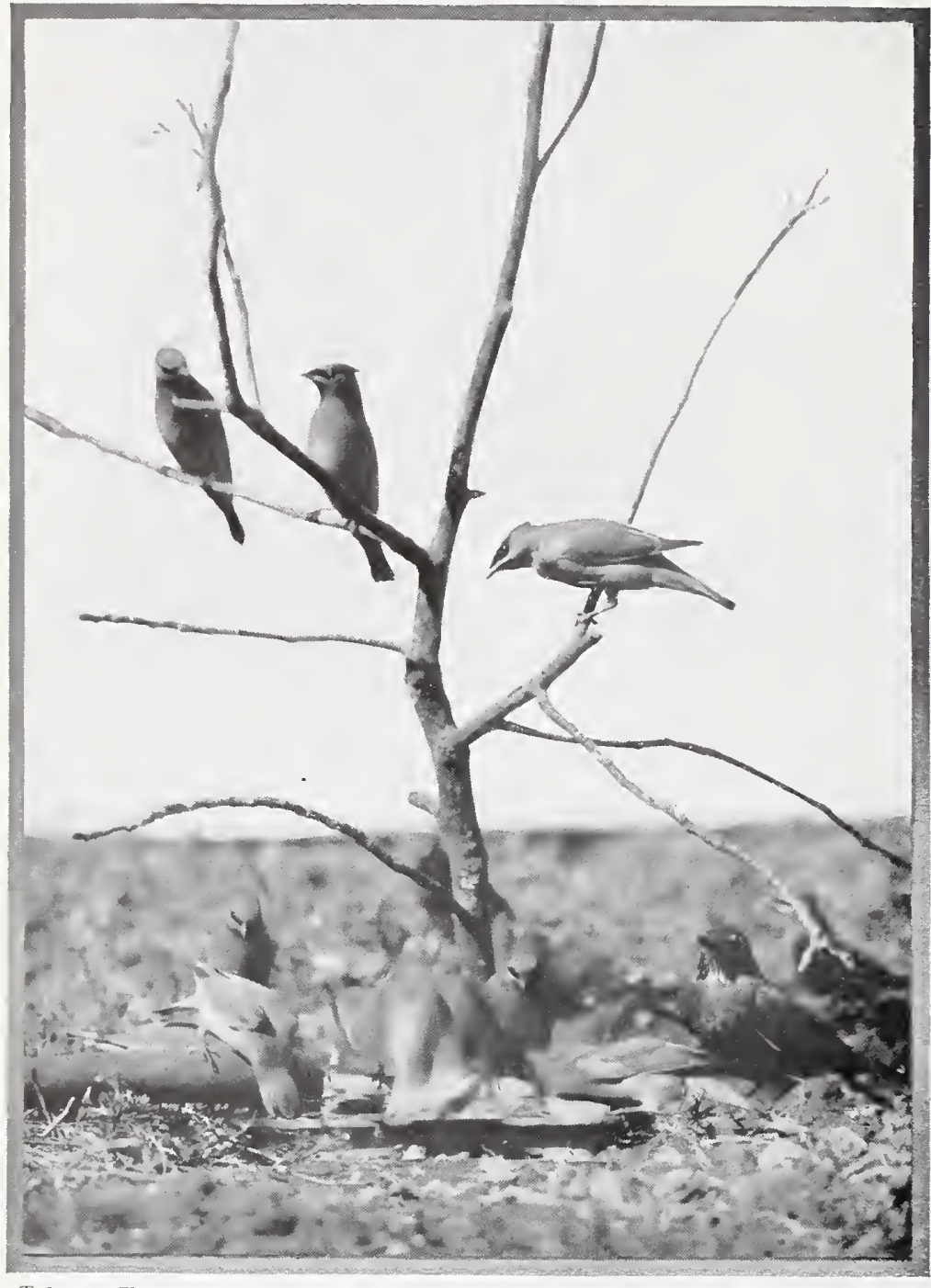

Taken at Claremont he seemed unable longer to restrain himself, when, to all appearances, absolutely beside himself with rage because the objects of his wrath paid no attention to his railings, he did the catapult act-hurling himself straight at the intruders. Several of the IVaxwings, in order to avoid an actual collision, left the places where they were feeding, and alighting on twigs near by, paused for a moment, as if to observe the antics of the furious Robin, when they would resume their feeding. Their indifference to the loud bullying protests of the Robin, and their persistence in remaining on the premises after he had ordered them off, so exasperated Mr. Redbreast that with screams of defiance he dashed from group to group without stopping to alight, until, exhausted quite as much by the heat of anger as by the unusual exertions he was making, he was glad to drop to a branch and pant for breath" - while the Waxwings continued to ignore the churl, as gentlemen should.

There was a notable invasion of this species in the winter of $\mathbf{I} 892$

${ }^{1}$ Rev. S. H. Goodwin in "The Condor," Vol. VII., July, I905, p. 100. 


\section{The Bohemian Waxwing}

and again in I9I I, with record stations for the latter at Dutch Flat, Galt, Tower House, and Helena. Of the last-named Miss Kellogg says: "At Helena the birds came into the orchard in the afternoon to feed and roost for the night in the trees. They seemed especially fond of the rotten apples left on the trees or fallen on the ground, and they showed so little fear that it was possible to approach within a few feet of them, and when one got too close they would only fly up into the trees near by. They kept up an incessant soft twittering noise, and for several days we had excellent opportunities for observing them at close range."

Most notable of all was the invasion of I9I9-I920, for during that winter the species established the record of furthest south, not only for California but for America as well. Swarth saw two birds at Danby, some 50 miles west of Needles, Dec. 2 I, I9I9. A little earlier, Dec. I8th, he had observed others at El Tovar in the brush of the Grand Canyon of the Colorado, in Arizona. Wright M. Pierce found Bohemian Waxwings in considerable numbers in January and February, 1920, at Claremont, in eastern Los Angeles County. He estimated their number at I 50, and noted that they consorted freely with the Cedarbirds and that they fed, like their congeners, almost exclusively upon pepper berries. Lastly, Stephens, on the 29th day of March, I920, found two dead and badly decomposed Bohemian Waxwings on the camping ground at Vallecito, eastern San Diego County. Some fool with a gun had shot them and left them to rot. Thus in all probability Bombycilla garrula passed to the southern extremity of our border during the winter of I9I9-20.

There are also records of two wanderers taken on the Mohave Desert, Dec. 3I, I90I, and Dec. I3, I9Io; so it is altogether probable that the bird is of more frequent occurrence than our meager records would bear witness. The species is essentially sporadic, both in winter and in summer. Indeed, its breeding range was shrouded in mystery for nearly a century after the bird had been recognized by science; and it was not until the year I 856 that Mr. H. Wolley (founder of Oötheca Wolleyana) discovered the first nests, in Lapland.

For many years the single eggs taken by Kennicott at Fort Yukon on July 4, I86I, remained unique in America; but latterly we are learning that it also nests much further south. Mr. Brooks took four sets, one from a Murray pine and three from Douglas firs, at I58-Mile House, B. C., in June, I90I.1 Dr. C. S. Moody² reports the taking of a set of five eggs at Sandpoint, Idaho, July 5, I904. On June 26, I904, Robert G. Bee, of Provo City, found a nest near Sunnyside, Utah. ${ }^{3}$ With such examples before us it is not impossible that the species may one day be

${ }^{1}$ The Auk, Vol. XX., July, I903, p. 283.

2"Pacific Sportsman," Vol. 2, June, 1905, p. 270.

${ }^{3}$ The Condor, Vol. VII., July, August, I 905 , p. Ioo. 


\section{The Cedar Waxwing}

found breeding in this State. It is not to be supposed, however, that the Bohemian Waxwing is a regular breeder at any of the stations listed above. The Waxwings of both species are a law unto themselves, and their comings and goings and nestings (usually in small colonies) are subject to what we call caprice.

No. 110

\section{Cedar Waxwing}

\section{A. O. U. No. 6r9. Bombycilla cedrorum Vieillot.} WAXWING.

Synonyms.-Cedar-bird. Cherry-bird. Carolina Waxwing. Lesser

Description.-Adults: A conspicuous crest; extreme forehead, lores, and line through eye velvety black; chin blackish, fading rapidly into the rich grayish brown (snuff-brown to buffy brown) of remaining foreparts and head; a narrow whitish line bordering the black on the forehead and the blackish of the chin; back darker, shading through ash of rump to blackish ash of tail; tail-feathers abruptly tipped with gamboge yellow; belly sordid yellow; under tail-coverts white; wings slaty gray, primaries narrowly edged with whitish; secondaries and inner quills without abrupt white markings, but obscurely whitish and grayish along exposed inner webs, and bearing tips of red "sealing wax"; the tail-feathers are occasionally found with the same curious, horny appendages. Bill black; feet plumbeous. Sexes alike, but considerable individual variation in number and size of waxen tips. A very common "imperfect" plumage lacks the waxen tips altogether, and such lack is usually, though not always, correlated with an emphatic narrowing of the yellow terminal band of the tail. Young: Darker and duller,-olive-brown above and on breast and sides; throat pale to whitish and dark areas of underparts much broken up by whitish streaking; without waxen tips. Length I52.4-I77.8 (6.00-7.00); wing 94 (3.70); tail 55 (2.17); bill I0.2 (.40).

Recognition Marks.-Sparrow size; soft grayish brown plumage; crest; red sealing wax tips on secondaries; belly yellow; wings without white bars or spots, as distinguished from preceding species.

Nesting.- Nest: (Desc. of California-taken specimens in M. C. O. coll.) Of twigs, fern-stems, grass, moss, string, hair, and especially gray "moss" (lichen) of the usnea type; placed 5 to 20 feet up in young fir or mountain lilac (Ceanothus). Eggs: 4 to 6, usually 4 or 5; dull bluish gray (pale smoke-gray, light mineral gray, or pale court gray, to pale olive-gray), spotted sharply and sparingly with purplish black Av. size $22.6 \times 15.5(.89 \times .61)$. Season: Nidsummer; one brood. Eureka dates fall between June 30 and August 4 .

General Range.-North America. Breeds chiefly in Transition and Canadian zones, from central British Columbia, southern Keewatin, northwestern Quebec, etc., south to northwestern California, northern New Mexico, northern Arkansas, and 


\section{The Cedar Waxwing}

North Carolina. Winters irregularly from about 49th Parallel south to Cuba and Panama.

Distribution in California.-Fairly common but erratic winter visitor, 1ocally abundant in Upper and Lower Sonoran zones, chiefly west of the Sierras. Three known occurrences east of the Sierras and desert divides: Lone Pine (A. K. Fisher); Victorville (Mailliard \& Grinnell); and Palm Springs, Jan. 29, I9I3 (Author). Also recorded casually from some of the islands: San Clemente (Grinnell); Santa Cruz, April II, I9I5 (Author); Farallons, May 30, I9I I (Author). The migrations are desultory and the species lingers into May or even June; but the only established breeding point for the species in California is Eureka, Humboldt County.

Authorities.-Baird (Ampelis cedrorum), Rep. Pac. R. R. Surv., vol. ix., I858, p. 3 I 8 (San Francisco, winter); Coues, Birds Col. Val., I 878, pp. 45I, 470 (bibliog., syn., desc., habits, etc.); Beal, U. S. Dept. Agric., Farmers' Bull. no. 54 (revised), I 904, p. 38 (food); Davis, Condor, vol. xvi., I9I4, p. I 82 (Eureka, nesting); Howell, Pac. Coast Avifauna, no. 12, I917, p. 88 (San Clemente and Santa Cruz Ids.).

OU'T OF THE pepper-tree comes a chorus of excited squeaks. The passerby pauses to see what the commotion may be, and finds the tree

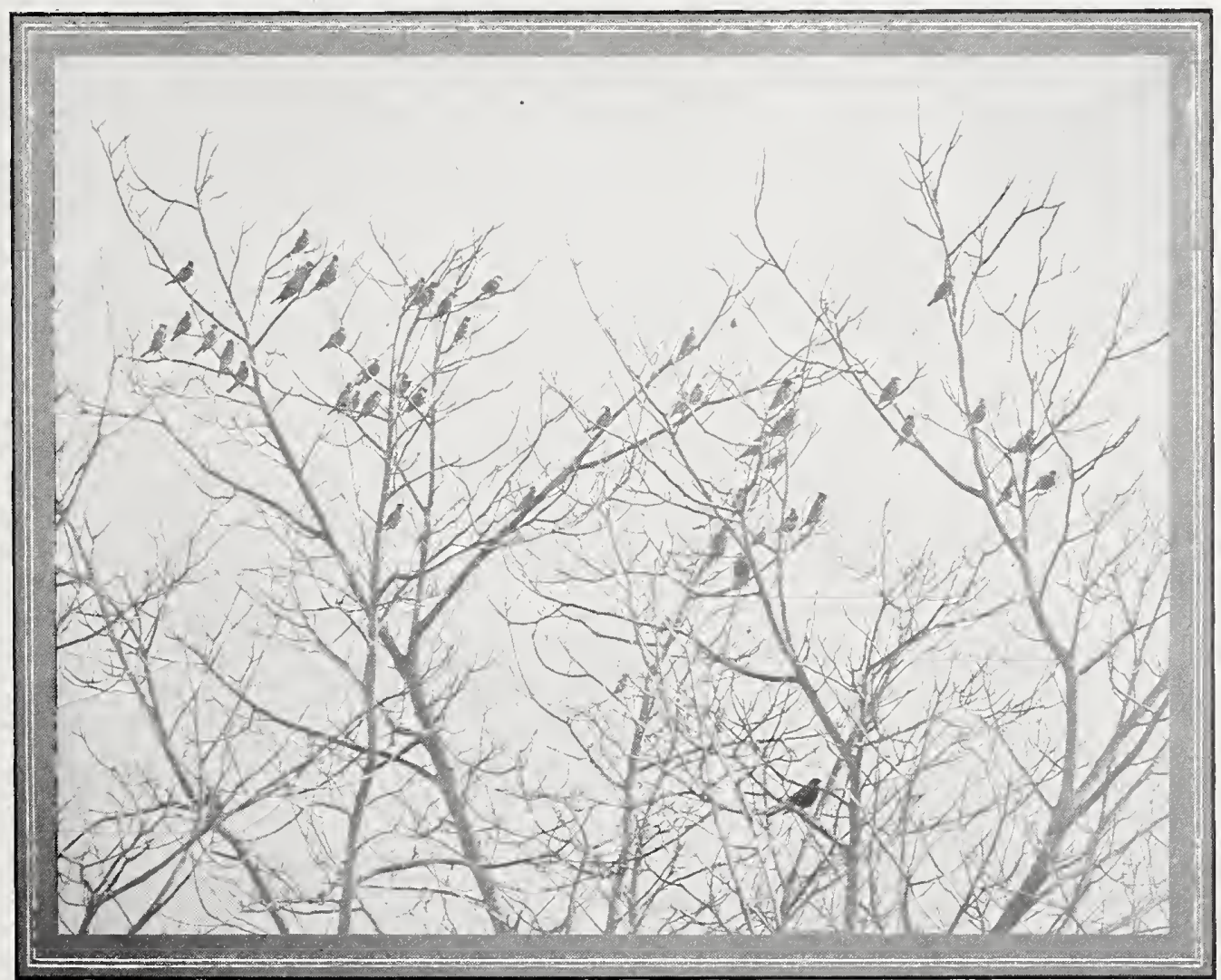

Taken in Claremont

CEDAR AND BOHEMIAN WAXWINGS IN WINTER

Photo by Wright M. Pierce 


\section{The Cedar Waxwing}

alive with birds, - birds of a ravishing beauty, albeit engaged in a scramble for food as unseemly as that of an American pie-eating contest. You would suppose that a bird so beautiful would behave with becoming decorum, or at least pause for admiration. But no, it is gobble, gobble, gobble, and the red berries disappear almost faster than one can count. At a squeak, a little louder than the rest, perhaps, though we cannot tell it, the whole company bursts out of the sheltering greenery, effects an instant and graceful squadron formation, and either retires, squeaking, to a conspicuous outpost, such as a leafless sycamore tree, or else plumps unquenched into some other green fountain of peppery consolation.

Thus the normal Bombycilline day divides itself into frequent periods of disgraceful gluttony, alternating with periods of dignified retirement. Needless to say, the latter period is concerned chiefly with digestion; but when we know how little these greedy beauties really get out of their food, we may pardon their apparent voracity. As Dr. Grinnell' has pointed out, it is only the viscid coating of the kernel of a pepper berry which has an agreeable flavor and furnishes nourishment, so that the papery hulls and the peppery centers require to be disgorged. This operation appears to involve momentary distress, and is accomplished by two or three coughs and a sidewise jerk of the head, which disposes of several kernels at once. Aside from these exspuitive interruptions, the sight of a snug company of Cedarbirds lined up on a telegraph wire, or bunched in a treetop, is pleasing in the extreme. The soft body-plumage of melting browns and saffrons and Quaker drabs, set off by the abrupt black "trimmings" of the head, the military crest, and the erect soldierly pose of the figure, give one a somewhat awed impression.

And that squeak! The Cedarbird, being so singularly endowed with the gift of beauty, is denied the gift of song. He is, in fact, the most nearly voiceless of any of the American Oscines, his sole note being a highpitched, sibilant squeak. Indeed, so high-pitched is this extraordinary note, that many people, and they trained bird-men, cannot hear it at all, even when the Waxwings are squeaking all about them. Cedarbirds are especially noisy when scrambling for food but the self-same squeaks issue from a motionless company in the treetop; and the bird seems to have settled upon this note because it requires least effort. Discussion is liveliest just before flight, and the squeaking continues while the birds are a-wing.

The food of the Cedarbirds is 87 per cent vegetable. Insects, especially noxious beetles, are levied upon moderately the year around, and are fed to the young almost exclusively in August. Wild fruits and berries are, however, the staple diet, and of these, because their "caloric"

${ }^{1} \mathrm{Auk}$, Vol. XIV., July, I897, p. 318. 


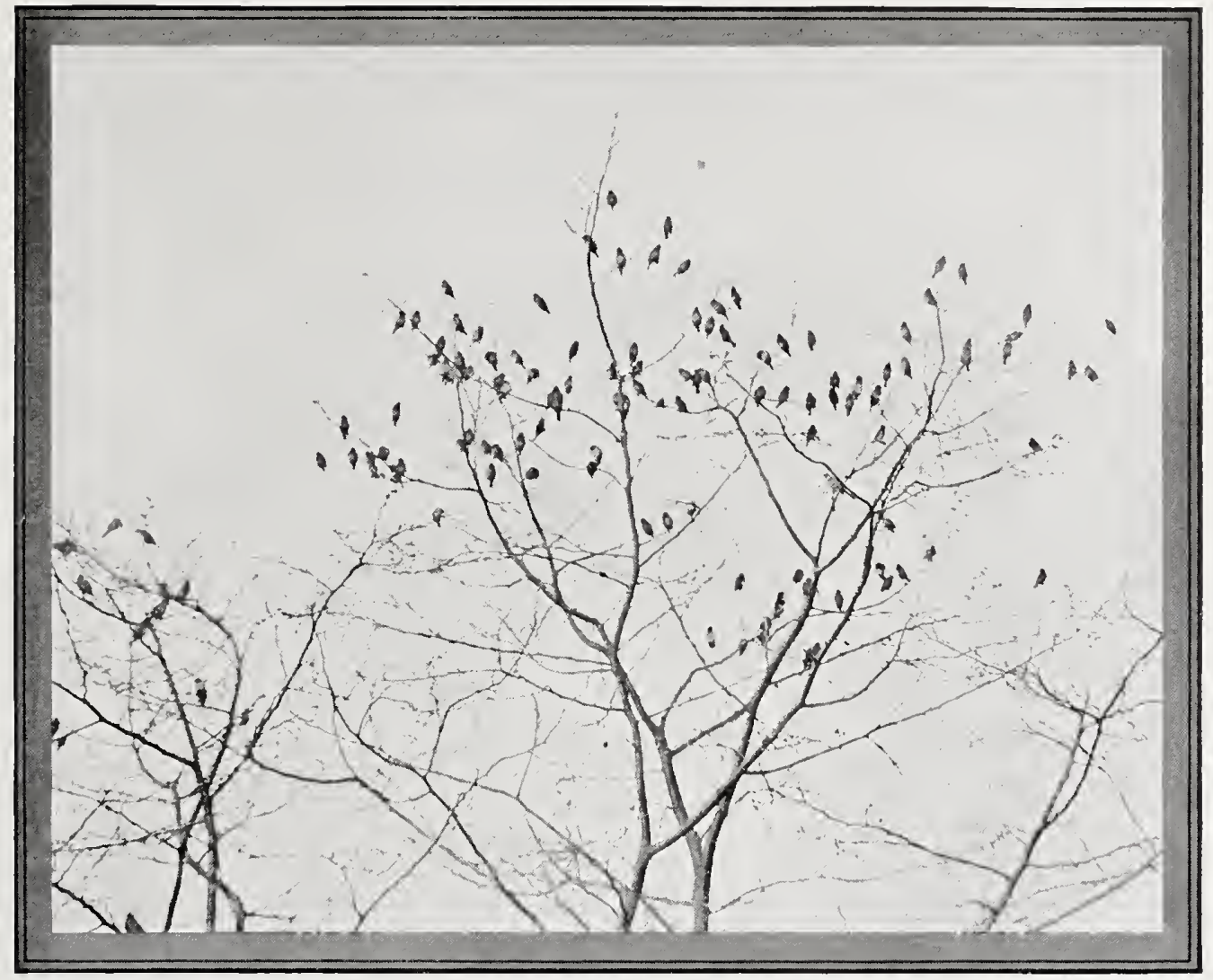

Taken at Los Colibris

CEDAR WAXWINGS EN FLOCK

Photo by the Author

value is low, enormous quantities must be consumed. Cherries come in for a share of attention, enough to merit for this Waxwing the name of Cherrybird in the northern states; but it may be asserted emphatically that by reason of its absence from the State during the cherry season, the bird does no harm in California. Mr. John G. Tyler, of Fresno, reports1 a winter company of Waxwings which formed the habit of eating raisins, resorting daily for this purpose to the culm piles of "Raisin Row." On the neighboring buildings they would remain "motionless for an hour at a time, perched with almost military precision along the edge of the roof, suddenly to become an animated mass of hissing, excited birds that greedily scratched and tore through the piles of stems in search of the few raisins that still adhered thereto." In this frantic search a few were over-lucky, for Mr. Tyler knows of several birds which choked to death trying to swallow raisins too big to go down.

'C. O. C. Pacific Coast Avifauna, No. 9, p. 94. 


\section{The Phainopepla}

Cedarbirds are the gypsies of the feathered kind. They rove about in companies numbering from a dozen or a score to several hundred, nesting for the most part much further north, and wintering irregularly throughout the State. There seems to be a sharp accession of numbers into southern California from the first of February on, and these newcomers clean up whatever pepper-berries the thrushes have left. If conditions are favorable, the Waxwings may linger well into May. There are sporadic records of summer birds, even as far south as the San Jacinto range, ${ }^{1}$ but the only authentic account of the bird's nesting within the State comes from Humboldt County.

The dilatory habits of Waxwings are well shown in their nesting, which they put off until late June or July, for no apparent reason. In constructing the nest the birds use anything soft and pliable which happens to catch the eye. Some specimens are composed entirely of the green hanging mosses, while others are a complicated mixture of twigs, leaves, rootlets, fibers, grasses, rags, string, paper, and what not. The nest may be placed at any moderate height up to fifty feet, and a great variety of trees are used, although orchard trees are favorites. The birds are half gregarious, even in the nesting season, so that a small orchard may contain a dozen nests, while another as good, a little way removed, has none.

The female sits closely upon her eggs, not infrequently remaining until forcibly removed. Once off, however, she makes away without complaint, and pays no further attention to the incident until the intruder has departed.

No. 111

\section{Phainopepla}

A. O. U. No.620. Phainopepla nitens (Swainson).

Description.-Adult male: Conspicuously crested. General plumage shining black, with violet and steely reflections; the inner webs of primaries extensively pure white centrally, save on outer edges, thus forming a regularly interrupted (latticed) patch, conspicuous in flight. Bill and feet black; iris bright red. Adult female: Nearly uniform mouse-gray, deeper (deep mouse-gray) on back, browner (hairbrown) on belly; crest chiefly slaty or dusky mesially; wings and tail dusky to blackish; the wing-coverts and remiges with much narrow white or grayish margining, the conspicuous primary patch of male faintly echoed by pale gray; crissum margined and varied by white. Young birds are much like their mothers, and the males take on color

\footnotetext{
${ }_{1}$ Grinnell-Swarth: Birds and Mammals of San Jacinto, 1913, p. 288.
} 
in patches. Length $177.8-203.2$ (7.00-8.00); wing 95 (3.74); tail 96 ( 3.78$)$; bill II (.43); tarsus 18 (.7 I). Females average somewhat smaller.

Recognition Marks.-Sparrow size; slender proportions and erectile crest; shining black with latticed white wing-patch of male; nearly uniform mouse-gray of female.

Nesting. - Nest: A rather shallow cup of soft vegetable materials of almost every conceivable sort, bound together with cobwebs, and without special lining; placed in fork of tree-mesquite, elderberry, sycamore, or live oak-often at considerable elevations. A typical example is $21 / 2$ inches wide across the bowl, and one inch deep, with walls $3 / 4$ of an inch in thickness. Eggs: 2, occasionally 3, 4 of record; ground-color light yellowish gray (yellowish glaucous) fading to pale mineral gray or grayish white, usually broadly belted at the larger end with dull violet (light Varley's gray), which fades entirely out, speckled sharply and with practical uniformity (or, rarely, with tendency to wreath formation), with dull olive-black or olive-brown and violet-gray. Av. of 32 eggs ( 15 sets) in the M. C. O. coll., $22.1 \times 15.8(.87 \times 62)$. Season: Varies with local conditions: March-April on the deserts; May-July, but chiefly June, elsewhere.

General Range.- The southwestern states and Mexico, breeding from central California, southern Utah, and southwestern Texas, south to Cape San Lucas, Vera Cruz, Puebla, and the valley of Mexico. Winters from the Mohave Desert southward, or casually farther north in west central California.

Distribution in California.-Abundant winter resident and fairly common summer resident in suitable sections of the deserts, Mohave and Colorado, north to Owens and Panamint valleys; common summer resident in the San Diegan district and north,- -west of the Sierras along the western ridge to Alameda County (Pemberton); in the interior valley, to Chico and Marysville (Belding); and along the western foothills of the Sierras to Butte County, or even (at least formerly) Shasta County (Townsend). Rare in winter in the San Diegan district, but found at sheltered stations along the western coastal ranges to Paicines (J. Mailliard). Reported in summer from Catalina Island (Bryant).

Authorities.-Heermann (Ptilogonys nitens), Jour. Acad. Nat. Sci. Phila., ser. 2, ii., I 853 , p. 262 (s. Calif.); Coues, Birds Col. Val., I 878, p. 45 (general account: syn., desc., habits, hist., etc.); Evermann, Auk, vol. iii., I886, p. I83 (habits; desc. nest and eggs); Fisher, N. Am. Fauna, no. 7, I893, p. II 3 (occurrence in Calif.; food, nest and eggs, etc.); Merriam, F. A., Auk, vol. xiii., I896, p. 38 (nesting habits; song).

CERTAIN baffling contradictions, and many elusive qualities besides, mark this wayward son of the desert. Handsome he is, indeed; and they have given him a high-sounding Grecian title in appreciation of his magnificence. Yet is he ever the soul of modesty, and the sudden consciousness of a spying eye will scatter all his show of finery, and send him dashing into the bush with "peps" of disgust. Shy he is to a fault, insomuch that the other side of a bush has always the preference both in approach and in escape. The waste places are his proper home; yet he will conduct his small affairs in a crowded suburb, and he will set his nest in a spreading oak tree which overshadows a human habitation. Curiosity will tempt him to answer a cat-call from the depths of a mes- 


\section{The Phainopepla}

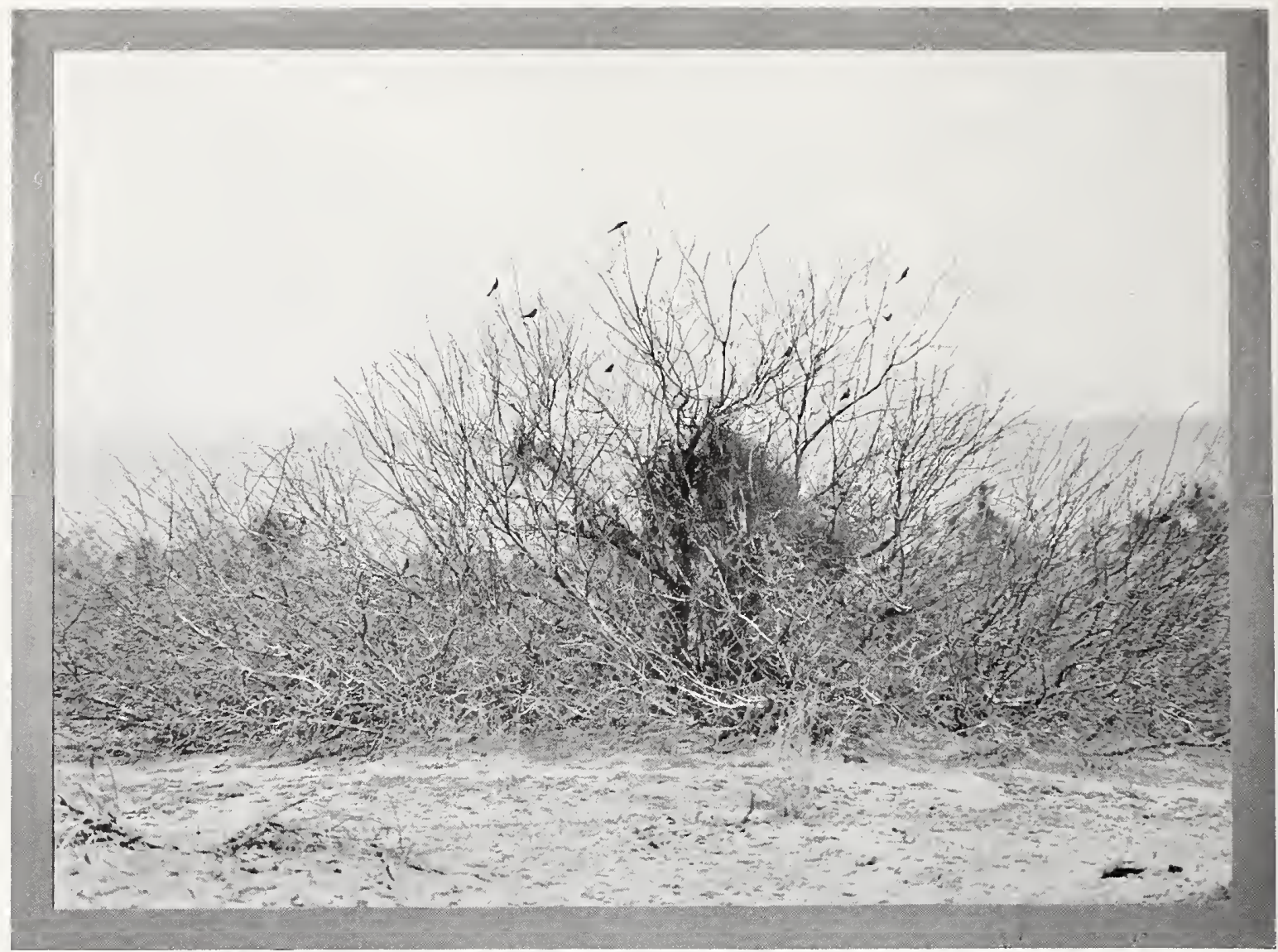

Taken at Palm Springs

SONS OF THE DESERT

Photo by the Author

"PEPS" IN WINTER

quite-a cat-call, mayhap, with a gun behind it-while caution will drive him forth at a hundred yards and keep him a skulking wraith in the offing while the home-trees are being searched. Gallantry struggles in his breast with spiteful tyranny, daintiness with gourmandizing greed, dignity with buffoonery, courage with cowardice, and last but not least, diligence and devotion alternate in his purpose with the most shocking caprice.

To speak soberly, therefore, of the Phainopepla, one's first impression is of a shining black beauty, graceful and active, enlivened by a mobile crest, a fiery red eye, a snowy mantle (in interrupted pattern, shown only in flight), and a bird possessed, withal, of a voice which promises all sorts of good things. But this favorable first impression pales with familiarity, and one admits after long acquaintance that the Phainopepla is, without doubt, a little queer, his voice a little disappointing, his 


\section{The Phainopepla}

psychology not quite understandable, and his manners hopelessly alien.

Having said so much, we have perhaps said too much. Any prisoner at the bar is entitled to the services of an attorney, and any bird sitting at the bar of our poor human judgment is entitled to sympathetic consideration. He is entitled, moreover, to be judged by a jury of his peers; and if we would deal exact justice, or even approximate justice, to the Phainopepla, we must doubtless become birds ourselves for the nonce. Here is a motion, then, for a new trial.

Pep pep - it is a musical, half-plaintive, haunting note which first apprises us of the arrival of the "shining flycatchers" from their winter home in the desert. The males arrive first, but are followed in four or five days by the modest gray females, who, likewise, call pep pep, or perp perp, in solicitude, or resentment of human attention. The male is discreet, but a well-screened observer may sometimes catch one in a transport of ecstacy. He leaps into the air, turns a somersault, returns to the perch with quivering wings, swaps ends violently, displays the crest to the utmost, and produces all the while a flood of jumbled, weak notes intended for song. In soberer moments one catches

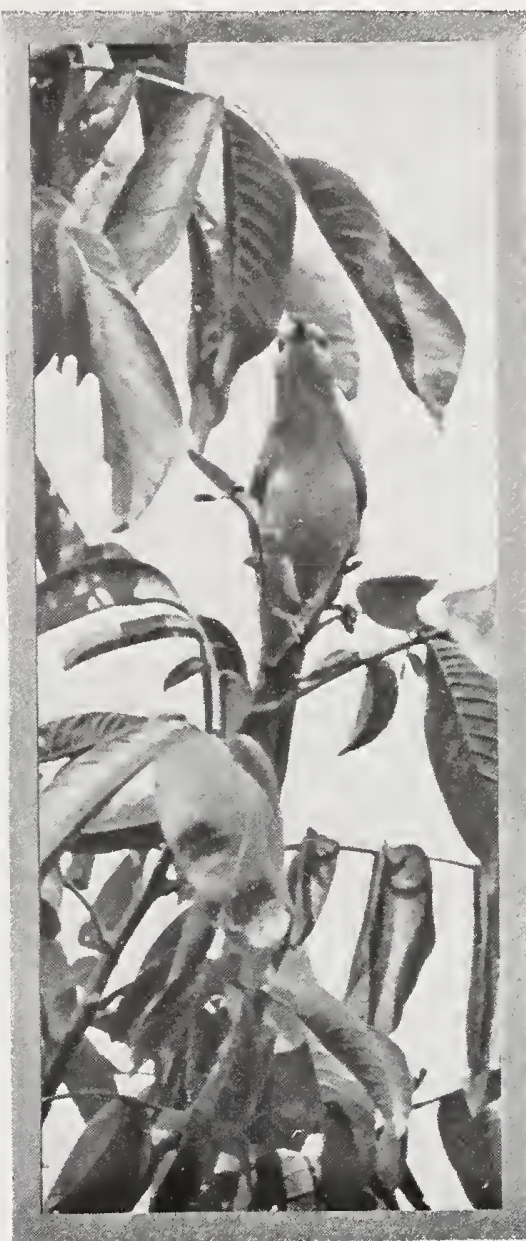

Taken at Los Colibris Photo by the Author AN UNOBTRUSIVE OBSERVER A FEMALE PHAINOPEPLA TAKING NOTES constricted phrases of a yodeling character: ahcuhcheziweerp, cleerp, zweep, and, most characteristically, "wheedle ah" (Mrs. Bailey). These vocal efforts are casual and disconnected, and they never by any possibility attain the dignity "of a superb song, powerful and finely modulated," as alleged by Coues in his single encounter with the bird in Arizona. Besides the song and call notes, one hears a scrat or kuteerp, which betoken apprehension, or distress, or at least disagreement of opinion at home.

All these vocal expressions are subdued, as though the performer had stuck a mute in the throat of his little cornet, and had never been able to remove it again. 


\section{The Phainopepla}

The Western Mockingbird not only plagiarizes the Phainopepla's notes most outrageously, but it seems to take a special delight in persecuting these timorous little mortals. Once, in winter, I heard the round perp-note of a Phainopepla sounding from a clump of mistletoe, in a tall cottonwood at Potholes. He had scarcely uttered his note three times when he was set upon and ousted by some enemy which I could not plainly see. Suspecting a Sharp-shin, I raised my gun and fired at the first show of form. I had intended to lay out the miscreant with a charge of 8's; but the wrong hammer struck, and from out the harmless shower of "dust" emerged a well-rebuked Mockingbird.

The flight of the Phainopepla, though oftenest direct, is both languid and ostentatious, so that one catches distinct views of the white blotch (the $\pi \dot{\varepsilon} \pi \lambda_{0}$ ) on the wing of the male, or the corresponding pale area on

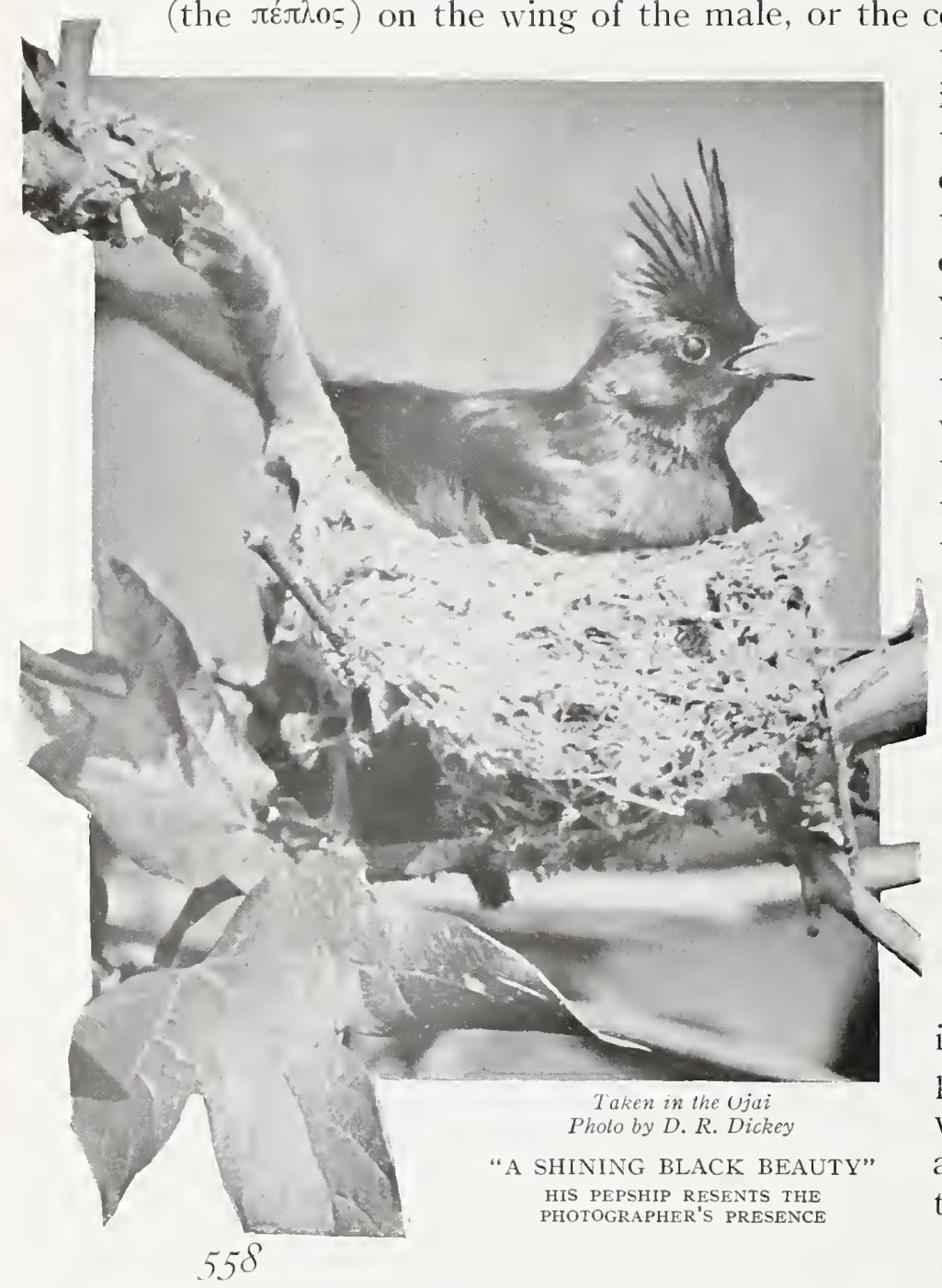
that of the female. In going any considerable distance, the birds rise to several times the height of the tallest vegetation, so as to obtain an unobstructerl view; and upon reaching the intended destination, they dive abruptly down, with much display of putting on brakes by means of the ample tail. Now and then some smart Aleck will play drunk, and go reeling about hither and thither in the air in the most eccentric fashion. But on other occasions apparent eccentricity of flight may be explained by the presence of $\mathrm{my}$ riads of insects. The Phaino will launch out on fluttering wings, and instead of returning to its perch after each capture, will maintain itself in midair for several minutes at a time, attacking each insect 


\section{The Phainopepla}

from below, and not deigning to retreat until twenty or thirty captures have been registered.

Insects form, undoubtedly, an important element of the food supply of the Phainopepla in summer; but as in the case of the Cedar Waxwings, their distant cousins, berries constitute their chief food at all times of the year. The staple winter diet is the mistletoe berry (of that variety which grows chiefly on the mesquite tree). In spring and summer, or irregularly in winter, the birds subsist chiefly on the berries of the pepper tree; but their diet also includes berries of the juniper tree, night-shade, manzanita, and, indeed, any small edible berry which grows in profusion. Like the Cedar Waxwing, again, the Phainopepla has the habit of disgorging the indigestible kernel of the pepper-berry; and it is evident that it must consume enormous quantities of this food in order to derive a sufficient sustenance from the thin, viscid inner surface of the berry, which alone is wholesome.

In building a nest the male Phainopepla takes the initiative and does at least nine-tenths of the work. Indeed, he seems to be jealous of any attention to this drudgery on the part of the female, and will even drive her away if she meddles over much. Visits of inspection are, however, permitted, and the virtuous architect is not insusceptible to words of praise. "Architect" is, perhaps, an over-pretentious word; for a Pep's nest is a mere aggregation of soft substances, such as, by reason of a general stickiness, will under pressure assume some sort of coherence. Twigs there may be, but these are used for filler rather than as structural support. Sage-leaves, string, catkins, dried flowers, lichens, bits of wool, cobwebs, soft shredded bark, - anything which will lend itself to a soft gray or greenish gray ensemble, is acceptable. The nest is settled into branching twigs or forks, whether upright, horizontal, or declining; or occasionally it may be balanced upon the shaft of a bare branch. Bunches of mistletoe in mesquite trees are the almost invariable hosts of the early spring desert nestings. In the interior return-nesting, elderberry trees (Sambucus glauca) are prime favorites, with live oaks a close second. After these come pepper trees and sycamores, with rare chances for almost anything else. My son has found nests in the mountain lilac (Ceanothus spinosus) here at Santa Barbara.

Nests are placed at any height from five to sixty feet, though fifteen would be a near average for those which are placed in mesquite and elders. The builder reserves the right to change his mind as to location at any stage of construction; so you may waken to find a nest which you had supposed about done, being carried off piecemeal into a neighboring tree. Similarly, the architect is never quite satisfied with the finish, and a particularly seductive catkin goes into the outside in spite of the clamor of hungry babies. 


\section{The Phainopepla}

A Phainopepla's egg is quite unlike anything else. Speckled eggs there are in abundance, but none others in America are so uniformly speckled,-fly-specked as it were- as these. An average egg plotted and computed with considerable care, was estimated to have upwards of ten thousand spots on it. The markings, while of a nearly uniform size, vary greatly in depth; and so run from palest lavender-gray to black; or, more rarely, from lavender through a yellowish olive series to sepia. The ground-color, too, has a high individual variation, being either white, pale greenish, greenish gray, or, more commonly, purplish gray. Now and then specimens are found which are strongly suffused with purplish in irregular areas. The number of eggs is usually two, but sometimes three; and, according to Mr. Morcom, threes predominate in certain favorable seasons.

The male bird shares the duties of incubation (or does Y 15 considerably more than half of it), although he does not

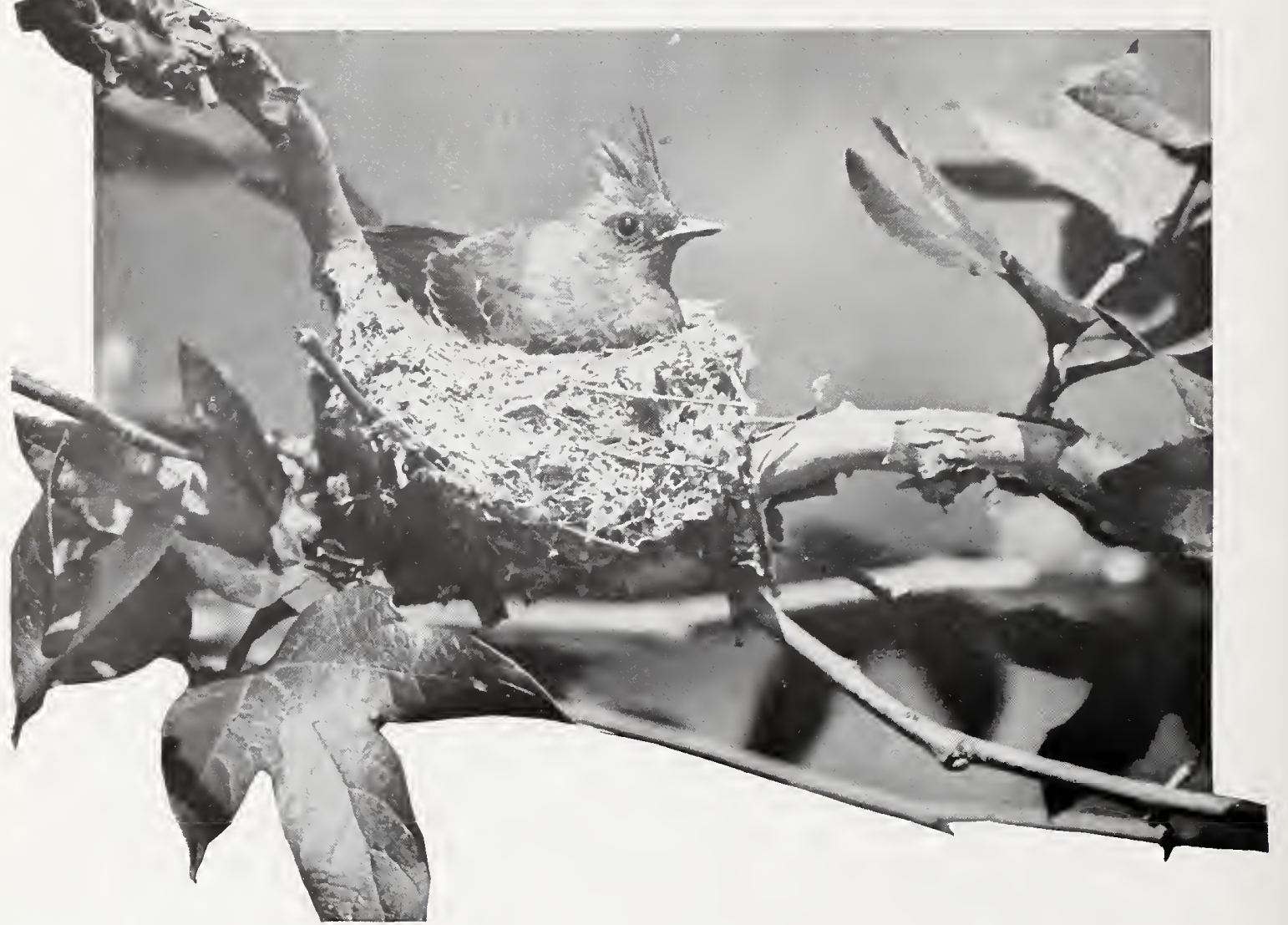

Taken in the Ojai 


\section{The Phainopepla}

monopolize it, as in the case of nest-building. There is frequent change of shifts at the nest, so that the birds are likely to betray their secret to an attentive observer at any hour of the day.

The young are hatched upon the fourteenth day after the deposition of the last egg; and they would look much like blackberries a little underripe, if their appearance were not relieved by generous tufts of long white down. The edges of the mouth are bright yellow, but the lining proper is flesh-colored. The parents do not feed by regurgitation; but berries are carefully crushed and perhaps invested with parental mucous before being fed. The fledglings look a good deal like their mother when they are ready to fly. According to Mrs. Harriet Williams Myers, who has made a careful study of this species, the birds first leave the nest in about nineteen days. They do not, however, leave it for keeps, as most birds do, but will make it headquarters for a day or so, as though loth to sever home ties. The parental solicitude is expressed by many flutterings to and fro, or by elongation of the form with maximum erection of the crest. The bird sways to and fro, or shifts position with an exaggerated swinging or flirting of the tail, and utters often and

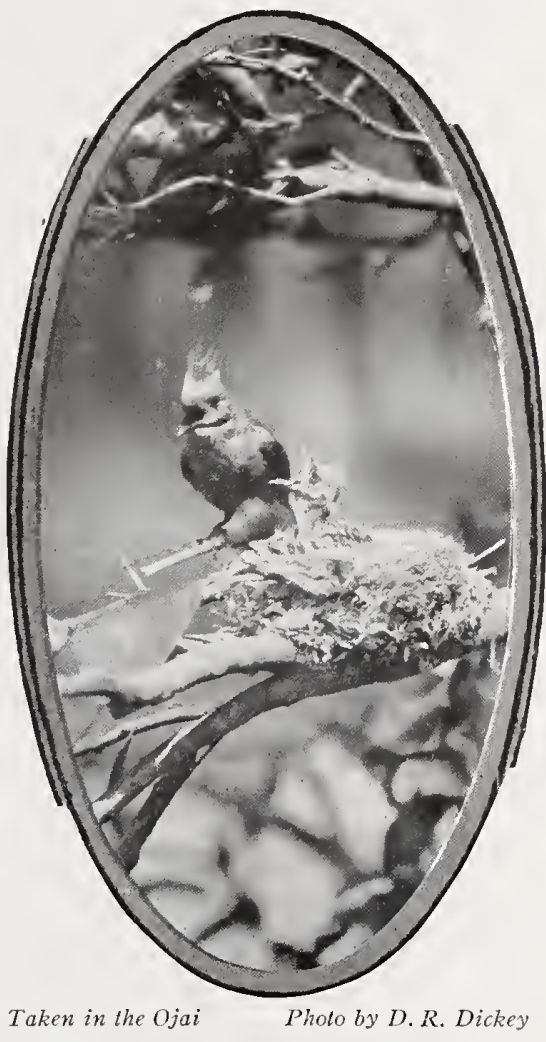

VOICES OF HUNGER AND PROTEST earnestly that sonorous mew, which is its only means of vocal relief.

But not all Phainopepla parents are so solicitous; and I suppose the instance which I am about to narrate is largely responsible for my deepseated distrust of the species. The birds in question had made a nest at a moderate elevation in a live oak tree which overshadows our front porch. (They were quite as welcome to nest elsewhere if they feared intrusion.) We discreetly noted three eggs, and were careful to make only gentle advances, and to consider the seclusion prized by sitting birds. At a time when the babies were about one-third grown, we arranged a little photographic sitting, but took care, in view of the parental hesitations, not to touch or to molest the little birds in any way. The parents, who were both visible on a distant telephone wire, showed considerable agitation, but they would not venture within eighty feet of the scene. We retired seasonably and completely, but the old birds never came back. The next day it rained, and the little ones died of exposure and starvation. Although sensible of my own culpability in connection with this 


\section{The Phainopepla}

tragedy, I cannot escape a sense of deep resentment toward such unfeeling and cowardly parents. It was monstrous! Such conduct brings us to realize anew that the intelligence of birds is a very imperfect and undeveloped thing at best. Birds are moved rather by deep, unconscious promptings, which we in our ignorance have dubbed instincts. These instincts, however they may have arisen, have to do only with the usual, the regular, the ordained. A chance variation, an accident of difference too slight for human detection, may throw the whole mechanism out of gear. We are brought face to face, then, with the irrational, and it plagues us. But the mother instinct! It is that which we have counted upon as being infallible. Failure here outrages us. Pity we may, and forgive, but no longer trust.

But the eccentricity of the Phainopepla is best exemplified in its distribution. Here it is easily first cousin to the Cedar Waxwing (as the taxonomists aver). The Waxwing is a nomad, and acknowledges no tyranny, not even that of the season. Similarly, the Phainopepla society, if it ever had any coherence, has been disrupted by individual or partisan caprice. Now the birds appear in a given section in considerable numbers, now they are scarce, and now they absent themselves altogether. Why this difference, we cannot altogether tell, though we surmise it may be largely due to variation in food supply. All fruit-eating birds are more or less at the mercy of changing seasons. This question of migration and distribution is, however, so interesting in case of the Phainopepla that we will endeavor to re-state it in detail. The Phainopepla winters chiefly in Lower Sonoran areas, from the Mojave and Colorado deserts south to Cape San Lucas and the Valley of Mexico. Within our limits the bird is chiefly confined in winter to the mesquite-bearing areas of the deserts and the lower Colorado River Valley. But where the food supply warrants it, scattering individuals, or little groups, may winter as far north as Mt. Hamilton, in Santa Clara County. Joseph Mailliard found them common one winter at Paicines, in San Benito County, and I have seen them at San Ardo, on the lower Salinas River.

The desert-wintering birds remain to breed in late February, and in March; and then in April migrate to the cooler sections of the State, west and north. Whether these desert-nesting birds breed again when they arrive at their summer home, we do not know; but it is more probable that they remain as a non-breeding element in the local summer population. The bulk of the birds, coming from places and directions unknown, irregularly invade the western portions of southern and central California about the middle of April, with fresh accession of numbers up to June Ist. They abound in the San Fernando and neighboring valleys, clinging, rather fatuously, to the dwindling desert washes, although they appear to be 


\section{The Red-eyed Vireo}

relatively less common in San Diego County. The Coast Range is shot full of visiting Peps, at least as far north as Alameda County, where they have been known to breed. In the great interior valley they are only occasionally found in the lower portion, as at Fresno (Tyler), Tracy (Grinnell), and Marysville; but they abound throughout the Upper Sonoran and Lower Transition belt of the western Sierran foothills, and have been taken as far north as Chico. Throughout this extensive, irregular area, nesting may be undertaken at any time from middle or early May up to late June; but it is probable that only one brood per pair is raised.

The movements and distribution of this species are, thus, very complicated, and we shall never know the whole truth about it until a thorough-going system of trapping and banding (the placing of aluminum bands bearing registered numbers upon the legs of fledglings) is carried out.

No. 112

\section{Red-eyed Vireo}

\section{A. O. U. No. 624. Vireosylva olivacea Linnæus.}

Description.-Adult: Crown grayish slate (deep mouse-gray), bordered on either side by blackish; a broad white line above the eye, and a dusky line through the eye; remaining upperparts light grayish olive-green (the olive-green element present as a gloss or overlay over dark gray,-in its pure aspect courge green or mignonette green); wings and tail dusky with narrow olive-green edgings; below dull white, with a slight greenish yellow tinge on lining of wings, sides, flanks, and crissum; first and fourth, and second and third primaries about equal, the latter pair forming the tip of wing. Bill blackish at base above, thence dusky or horn-color; pale below; feet leaden blue; iris red. Little difference with age, sex, or season, save that young and fall birds are brighter colored. Length I39.7-I58.8 (5.50-6.25); wing 80 (3.I5); tail 53.5 (2.I I); bill I2.5 (.49); tarsus I 8 (.70).

Recognition Marks.-Warbler size; largest; white superciliary line contrasting with blackish and slate of crown; red eye. Note smoother, and utterance a little more rapid than in L. s. cassini.

Nesting.-Does not breed in California. Nest: A semi-pensile basket or pouch of bark-strips, "hemp," and vegetable fibers; lined with coarse coiled bark-strips or grasses, and fastened by the edges to forking twigs near end of horizontal branch; five to twenty feet up. Eggs: 3 or 4; white, flecked very sparingly, and chiefly near the larger end with dark brown (bone-brown to natal brown) or blackish. Av. size $19.8 \times 14.2(.78 \times .56)$. 


\section{The Red-eyed Vireo}

General Range.-North and South America. Breeds from central British Columbia, southern Mackenzie, northern Ontario, etc., south to southeastern Washington, eastern Wyoming, eastern Colorado, western Texas, northern Cohuila, and central Florida; migrates through Yucatan, eastern Mexico, and Central America, to Colombia and Ecuador, and east to southern Brazil. Accidental in California, Nevada, Greenland, and England.

Occurrence in California.-One record: San Diego, Oct. 6, I9I4, adult male taken by Laurence M. Huey.

Authorities.-Huey, Condor, vol. xvii., I9I5, p. 58 (San Diego, Oct. 6, 1914, one spec.); Coues, Birds Col. Val., I878, p. 495 (syn., desc., habits, song, nest and eggs, food); Cooke, U. S. Dept. Agric., Bull. no. I 85 , I915, p. 36, figs. I8, I9, maps (distr. and migr. route).

IN ALL probability the single example of this species taken by Mr. Lawrence M. Huey on the 6th of October, I9I4, at San Diego, was not an "accidental" nor a wanderer, but a duly accredited representative of a small migratory movement which has been going on through our borders for several years. That the Red-eye, familiarly known throughout the East, is also steadily increasing in numbers in the Pacific Northwest, we know full well. Our veteran ornithologist, the late Lyman Belding, of Stockton, told me that the first appearance of this species west of the Rocky Mountains was noted in Washington by his friend, Dr. J. W. Williams, of Walla Walla, and that he took specimens on June 4 and 24, I885. The first published record for the Coast is that of Chapman (I890)1, who took birds at Ducks, and Ashcroft, British Columbia. These birds have now become common throughout northern and eastern Washington, and were found breeding near Seattle as far back as I908. It is altogether probable, therefore, that the species has become a regular if still rare migrant through California; and it is not impossible that its breeding range may gradually extend southward along the flanks of the Sierra-Cascade Range, as it has along the Rockies.

Although undoubtedly a recent immigrant, the Red-eye may have been confused at first with the better-known Cassin Vireo; and we shall never know the precise manner of its entrance into the West. In habit the two species are not unlike, and their ordinary notes do not advertise differences, even to the mildly observant. Those of the Red-eye are, however, higher in pitch, less mellow and soft in quality, and are rendered with more sprightliness of manner. Its soliloquizing notes are often uttered-always in single phrases of from two to four syllables eachwhile the bird is busily hunting, and serve to mark an overflow of good spirits rather than a studied attempt at song. His best efforts are given to the entertaining of his gentle spouse when she is brooding upon the

${ }^{1}$ Bull. Am. Mus. Nat. Hist., N. Y., Vol. III., p. I49.

$$
564
$$




\section{The Yellow-green Vireo}

nest. A bird to which I once listened at midday, in Ohio, had chosen for his station the topmost bare twig of a beech tree a hundred feet from the ground, and from this elevated position he poured out his soul at the rate of some fifty phrases per minute, and without intermission during the half hour he was under observation.

Since the chances that this bird may eventually be found breeding in northern California are not altogether remote, I append a word concerning the breeding habits of the Red-eye, which, save for the distance from the ground and the precise materials composing the nest, will apply almost equally to any of our vireos:1

"So thoroughly possessed does our little hero become with the spirit of poesy, that when he takes a turn upon the nest he indulges, all unmindful of the danger, in frequent outbursts of song. Both birds are closely attached to the home, about which center their fears and their hopes; and well they may be, for it is a beautiful structure in itself. The nest is a semipensile cup, bound firmly by its edges to a small fork near the end of some horizontal branch of tree or bush, and usually at a height not exceeding five or ten feet. It is composed largely of fibers from weed-stalks, and fine strips of cedar or clematis bark, which also forms what little lining there is. A curious characteristic of the entire Vireo family is the attention paid to the outside instead of the inside of the nest. The outside is carefully adorned with lichens, old rags, pieces of wasp nests, or bits of newspaper, with no idea of furthering concealment, for the result is often very conspicuous. The walls are not over a third of an inch thick, but are so strong that they not infrequently weather the storms of three or four seasons."

No. 113

\section{Yellow-green Vireo}

\section{A. O. U. No. 625. Vireosylva flavoviridis Cassin.}

Description.-Adult: Somewhat similar to $V$. olivacea, but sides and flanks more extensively and uniformly olive-yellow; under tail-coverts deeper, sulphuryellow; without distinct dusky post-ocular area; top of head and hind-neck plain mouse-gray, the former bordered indistinctly, or not, with dusky; remaining upperparts bright olive-green; an ill-defined superciliary of pale gray; lores dull gray; auriculars light olive-green; chin, throat, median line of chest and breast, and belly, white; the contiguous portions of sides and flanks olive-yellow, shading into olive-green of upperparts; under tail-coverts, wing-linings, and axillars clear sulphur-yellow. Bill and feet much as in V. olivacea; iris red or brownish red (compiled from Ridgway). Length about I52.4 (6.00); wing 78 (3.07); tail 55 (2.17); bill I 4.4 (.57); tarsus I $8.4(.72)$.

"From "The Birds of Washington." 


\section{The Western Warbling Vireo}

Recognition Marks.-Warbler size; much like foregoing species, but color pattern of head duller, with less contrast; general color tone brighter yellow.

Nesting.-Does not breed in California. Nest and eggs said to be indistinguishable from those of $V$. olivacea.

General Range.-Mexico, from the states of Tamaulipas, Nuevo Leon, and Sinaloa, south to Peru.

Occurrence in California.-One record: Riverside, Sept. 29, I887, by IV. IV. Price.

Authorities.-Price, Auk, vol. v., I886, p. 2 Io (Riverside, Oct. I, I887); Cherrie, Auk, vol. vii., I890, p. 329 (Costa Rica; habits, desc. nest and eggs).

THE OCCURRENCE of an example of this species near Riverside in $\mathbf{I} 887$ seems to have been entirely an accident; that is, an appearance without known cause or probability of recurrence. The bird looks most nearly like the still rare Red-eyed Vireo; and report of its alleged recognition afield, if based on anything short of specimens in hand, would not carry conviction to the scientist.

\section{No. 114}

\section{Western Warbling Vireo}

\section{A. O. U. No. 627a. Vireosylva gilva swainsoni (Baird).}

Description.-Adult: Above dull mouse-gray, pure on crown, elsewhere glossed with dull olivaceous; the olive-green element clearest on rump and edgings of remiges; wings and tail otherwise plain grayish brown ("fuscous"); extreme forehead paler; lores and space about eye chiefly (and variously) whitish, save immediately in front of eye, where dusky, and behind eye, where connecting with color of upperparts; chin, throat, and underparts, centrally, white,- the chest and belly faintly glossed with olive-yellow; the crissum and axillars definitely pale yellow, shading into color of upperparts through olive-yellow of sides and flanks, and olive-buffy of sides of neck and breast; "first" (outermost) primary spurious-only about a third as long as the others; the point of wing formed by third, fourth and fifth primaries (old style reckoning); the second shorter than the sixth. Bill horn-color above, paler below; feet and legs bluish dusky; iris brown. Young birds are brighter with access of yellow; bright olive-green above (save on crown), and bright olive-yellow below (save on throat). Length I27-I39.7 (5.00-5.50); wing 67 (2.64); tail 49.3 (I.94); bill Io $(.39)$; tarsus $17.5(.69)$.

Recognition Marks.-Warbler size; without wing-bars; general absence of positive characteristics. A difficult, nondescript bird, best known by notes and associations, but also by plain shading, olive-gray and whitish coloring, and by imperfect whitish (broad) ring about eye.

Nesting.- Nest: A semi-pensile pouch of bark-strips, grasses, vegetable fibers, and other available soft substances; sometimes ornamented with moss, catkins, etc.; and lined carefully with fine grasses or horsehair, or, rarely, plant-down; hung usually from fork of small limb, at any height. Eggs: 3 or 4; white, very sparingly and sharply 


\section{The Western Warbling Vireo}

dotted or spotted or very rarely blotched, chiefly at larger end, with dark brown or brownish black. Av. of 20 California-taken eggs, I $8.3 \times 13.2(.72 \times .52)$. Season: May-June, according to altitude; one brood.

Range of Vireosylva gilva.-Temperate North America, south in winter to Guatemala.

Range of $V . g$. swainsoni.-Western North America, breeding from southern British Columbia, southwestern Mackenzie and northeastern Alberta, south to Lower California, Sonora, and western Texas, to the eastern border of the Rocky Mountain states; south in winter to Guatemala.

Distribution in California.-Summer resident from uppermost Transition zone down to wooded and watered portions of uppermost Lower Sonoran zone, practically throughout the State. Found only in or near deciduous trees of riparian association. More broadly distributed and abundant during migrations.

Migrations.-Spring arrival: Pasadena, March 23, I 895 (Grinnell); Gaviota pass, April I, I912; Santa Barbara, March 29, I9I3; March 28, I914; March 20, I915; March I3, I916; March I8, I920. Autumn, last seen: Los Angeles, October 4, I90I.

Authorities.-Heermann (Vireo gilvus), Jour. Acad. Nat. Sci. Phila., ser. 2, ii., I 853 , p. 269 (Calif.); Baird (Vireo swainsonii), Rep. Pac. R. R. Surv., vol. ix., I 858, p. 336, in text (orig. desc.; type from Petaluma); Coues, Birds Col. Val., i 878, p. 50 I (syn., desc., habits, nests and eggs, food, etc.); Beal, U. S. Dept. Agric., Biol. Surv. Bull., no. 30, I907, p. 39 (food); Rust, Condor, vol. xxii., I920, p. 85, figs. (nesting habits); Grinnell, Univ. Calif. Pub. Zool., vol. v., I908, p. I08 (San Bernardino Mts.).

IS THERE a moment in springtime more delicious than that in which the greeting of the returning Vireo falls upon the ear! Fresh as apples and as sweet as apple blossoms comes that dear, homely song from the willows. How the heart feeds upon it! We tell another bead on life's jewelled rosary; and, somehow, I think that bead is emerald. The old-fashioned n a m e "Greenlet," as applied to the Vireos, was a misnomer, if a description of plumage was intended; but if it was intended to memorialize the bird's fondness for greenery, nothing could have been more apt. The Warbling Vireo's surroundings must be not only green, but freshly green, for it frequents only deciduous trees in groves and riverside copses.

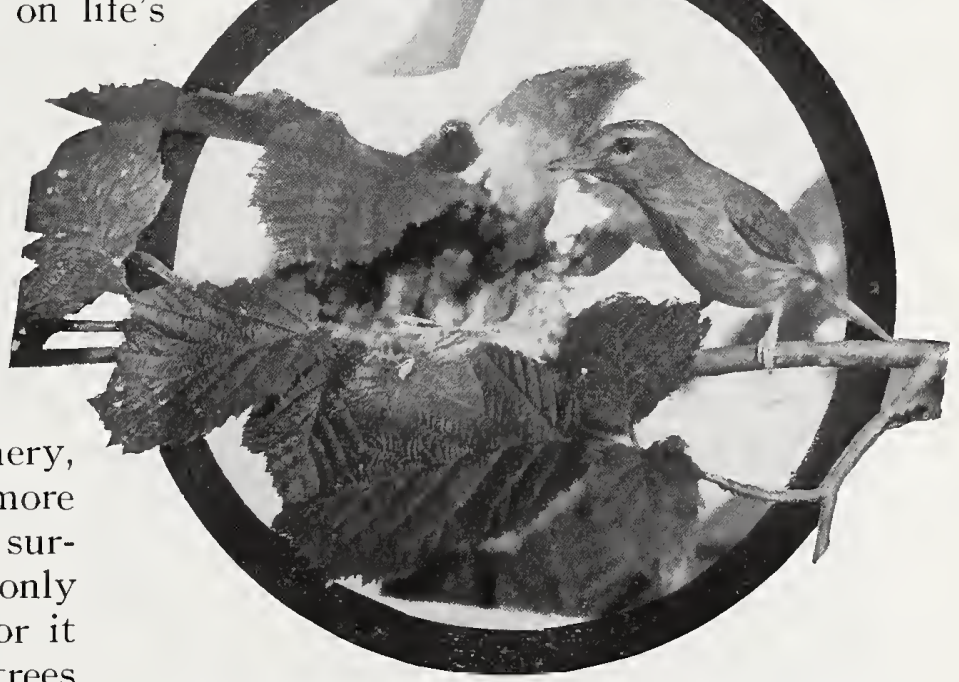

Taken_in Oregon

Photo by Dickey

WESTERN WARBLING VIREO AT NEST 


\section{The Western Warbling Vireo}

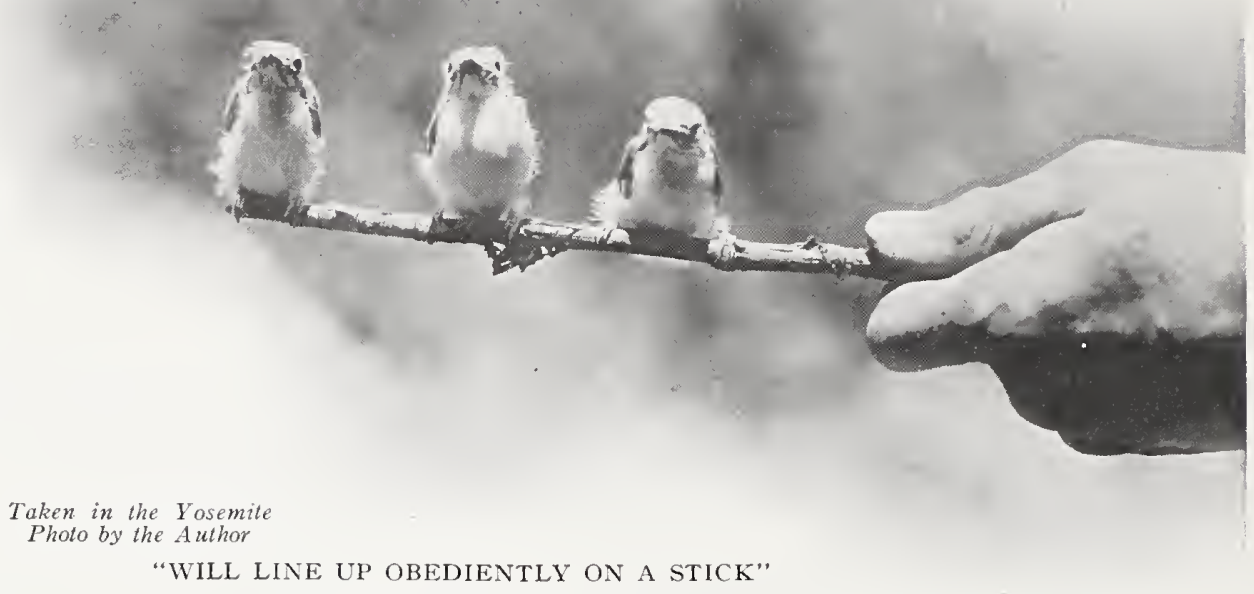

It is not an abundant bird, therefore, in California, although equally distributed, whether in the willows and cottonweeds which gather about some lonesome spring in the cattle country, or among the crowded alders and maples of the turbid McCloud. Moreover, the bird is not so frequently found about parks and shade trees as in the East, although it looks with strong favor upon the advent of orchards. And the orchardist may welcome him with open arms, for there is not among all his tenants a more indefatigable gleaner of bugs and worms.

Because he is clad in Quaker gray there is little need for the Vireo to show himself as he sings, and he remains for the most part concealed in the dense foliage, a vocal embodiment of the living green. Unlike the disconnected fragments which the Cassin furnishes, the song of this bird is gushing and continuous, a rapid excursion over pleasant hills and valleys. Continuous, that is, unless the bright-eyed singer happens to spy a worm in medias res, in which event the song is instantly suspended, to be resumed a moment later when the wriggling tid-bit has been dispatched. The notes are flute-like, tender, and melodious, having, as Chapman says, "a singular alto undertone." All hours of the day are recognized as appropriate to melody, and the song period lasts from the time of the bird's arrival, early in May, until its departure in September, with only a brief hiatus in July.

In sharp contrast with the beautiful canzonettes which the bird showers down from the treetops, come the harsh, wren-like scolding notes, which it often delivers when searching through the bushes, and especially if it comes across a lurking cat. 


\section{The Western Warbling Vireo}

The Warbling Vireo's cradle is swung midway from the fork of some nearly horizontal branch in the depths of a shady tree. In height it may vary from fifteen to twenty-five feet above the ground; but I once found one in a peach tree without a shadow of protection, and within reach from the ground. The structure is a dainty basket of interwoven grasses, mosses, flower-stems, and the like. It is not, however, so durable as that of some other Vireos, since much of its thickness is due to an ornamental thatching of grass, bark-strips, green usnea moss, and cottonwood down, which dissolves before winter is over. The female is a close sitter, sticking to her post even though nearly paralyzed with fear. The male is usually in close attendance, and knows no way of discouraging the inquisitive bird-man save by singing with redoubled energy. He takes his turn at the eggs when his wife needs a bit of an airing, and even, it is said, carries his song with him to the nest.

Baby vireos are among the most engaging objects in Nature's crèche. If not too much discouraged by parental counsels, they will sit confidently upon a finger, or line up obediently on a horizontal stick. If the birdies only knew when to be trustful! Nothing so moves one's heart to tender-

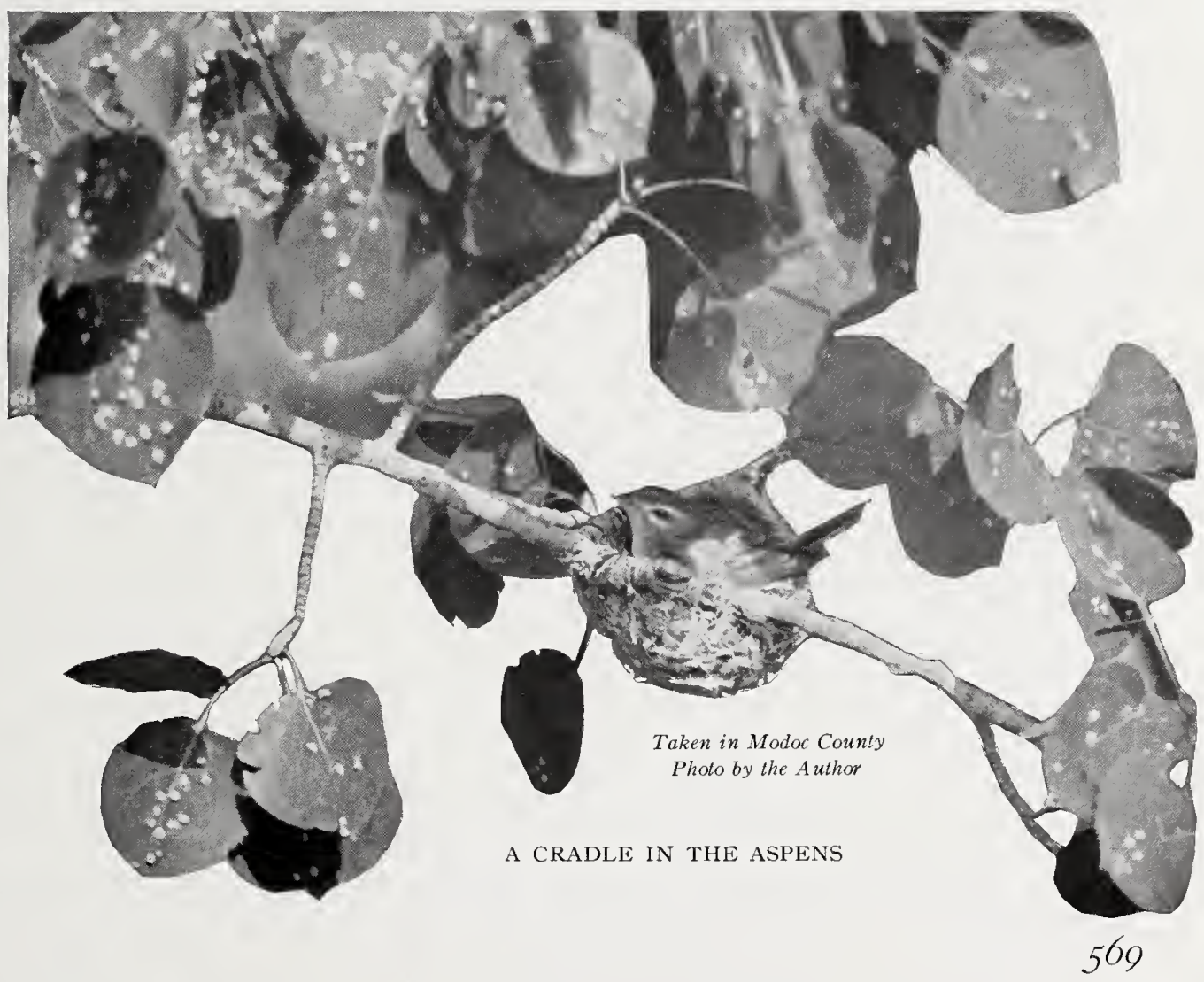




\section{The Solitary Vireos}

ness and pity as does the cuddling confidence of a baby bird. You would not harm the tiny creature for the world. On the other hand, nothing is more irritating - at times fairly maddening - than the frantic efforts of some bantling to escape at all hazards. No delicacy of overture, no titilation, no proffered finger-hold will appease him. You are an ogre and he will escape, if it be with but a single feather. Suggestion is a powerful influence, even though it come from a bird, and it takes a real saint to live down an ogre reputation.

\section{No. 115}

\section{Solitary Vireo}

No. 115a Cassin's Vireo

A. O. U. No. 629a. Lanivireo solitarius cassini (Xantus).

Synonyms.-Cassin's Solitary Vireo. Western Blue-headed Vireo.

Description.-Adult male: Top and sides of head deep mouse-gray, the pileum glossed with olivaceous; a supraloral stripe and conspicuous narrow eye-ring, white, the latter interrupted by bluish dusky of lower lore; remaining upperparts mousegray, increasingly tinged posteriorly with bright olive-green; wings and tail dusky with edgings of greenish yellow; the edge of the wing, the tips of middle and greater coverts (forming two conspicuous transverse bars), the edges of the tertials and extreme tips of the secondaries, the rectrices upon extreme inner edges and tips, and the outermost pair of rectrices on the outer edge, white or yellowish white; chin, throat, breast, and belly (centrally), and the under tail-coverts, pure white; the sides of breast shading into color of upperparts; the sides and flanks mingled olivaceous and pure greenish yellow; the crissum, especially on sides, axillars, and lining of wing, light greenish yellow. Bill black; feet deep plumbeous; iris brown. Adult female: Like male, but somewhat duller in color, the gray of head more brownish. Immature: Color of head, scarcely different from that of remaining upperparts, dull olive-brown; supraloral space, orbital ring, and underparts strongly tinged with brownish buffy. Length about I39.7 (5.50); wing 72.2 (2.84); tail 52.2 (2.06); bill Io (.39); tarsus I9 (.75).

Recognition Marks.-Warbler size; slaty gray head, contrasting with olivaceous back; narrow white eye-ring distinctive; voice has more of an edge than that of $V$. olivacea; whitish wing-bars and varied tertials as compared with $V$. g. swainsoni; more olivaceous than L. s. plumbeus.

Nesting.-Nest: A semi-pensile basket of woven bark-strips, grasses, and vegetable fibers, variously ornamented externally with white flower-petals, spidercases, bits of paper, and the like; lashed to fork of horizontal or descending bough of sapling (oak, maple, fir, etc.) at a height of from 5 to 30 feet; bulkier and of looser construction than that of most other vireos; measures $21 / 4$ inches across by $1 \frac{1}{2}$ inches deep inside; walls often $3 / 4$ of an inch in thickness. Eggs: 3 to 5 , usually 4 ; white or creamy white, sparingly marked with spots, which vary from rich red-brown to almost black; but unmarked eggs are of record. Av. size $19 \times 13.9(.75 \times .55)$. Season: May-July, according to elevation; one brood.

Range of Lanivireo solitarius.-North America, breeding from Great Slave 


\section{The Solitary Vireos}

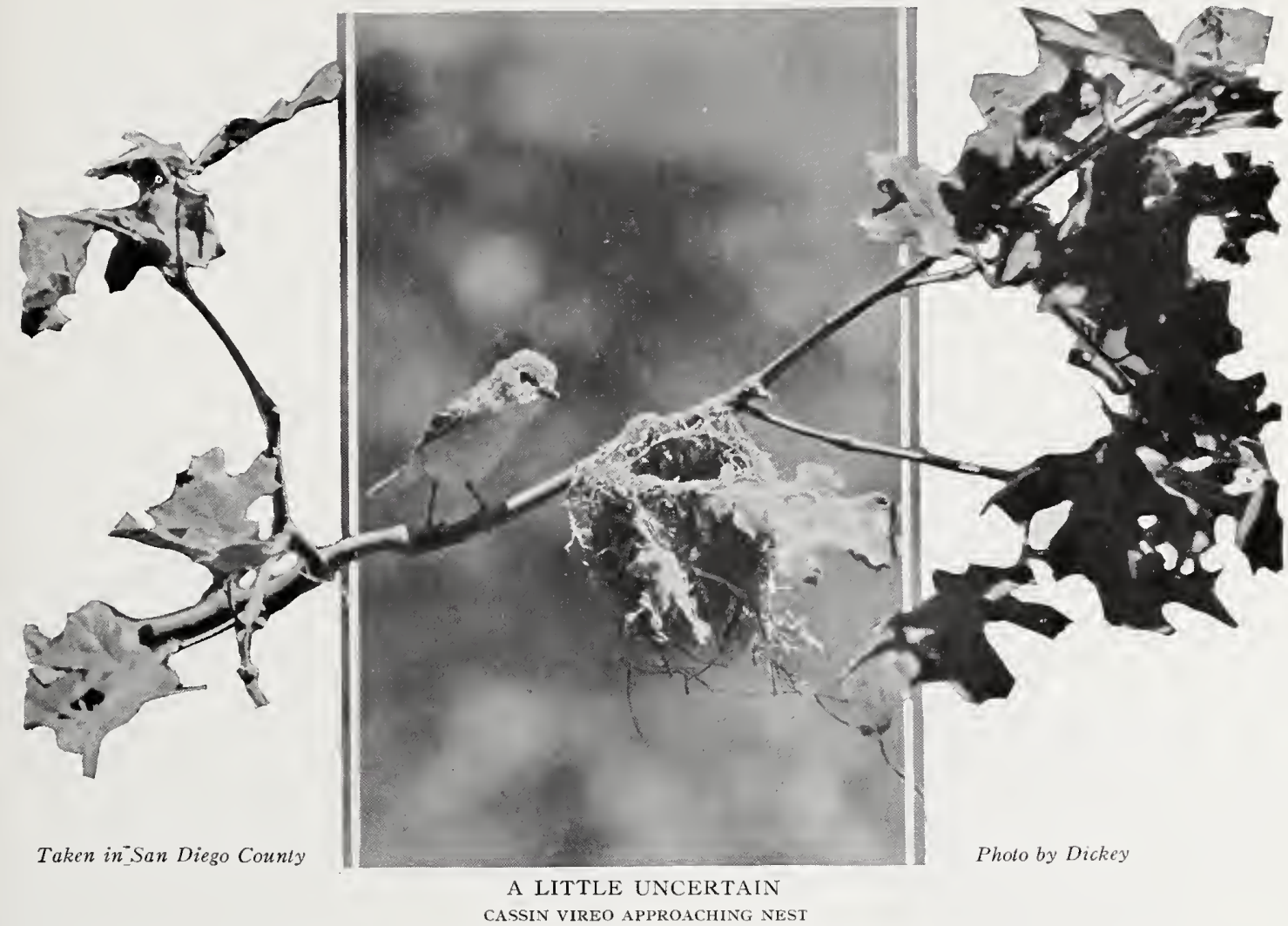

Lake and Cape Breton Island south to Lower California and the mountains of Mexico; wintering from the Gulf States and Mexico south to Guatemala.

Range of $L$. s. cassini.-The Pacific district, broadly defined; breeding in Transition zone from central British Columbia, southwestern Alberta, and western Montana south through California and western Nevada to the San Pedro Martir Mountains; migrating through the Great Basin states to a winter home in Mexico.

Distribution in California.-Common during migrations, practically throughout the State; remaining to breed only in the Transition zone and that chiefly in the Sierras and cognate ranges. Not common as a breeder in west central California nor in the humid coast strip.

Authorities.-Gambel (Vireo solitarius), Proc. Acad. Nat. Sci. Phila., iii., I 847 , I58 (Calif.); Xantus (Vireo cassinii), Proc. Acad. Nat. Sci. Phila., I858, p. I I 7 (orig. desc.; type locality Ft. Tejon); Barlow, Condor, vol. iii., I9or, p. 775 (Sierra Nevada; desc. nests, etc.); Beal, U. S. Dept. Agric., Biol. Surv. Bull., no. 30, 1907, p. 4o (food); Grinnell, Univ. Calif. Pub. Zool., vol. v., I908, p. iog (San Bernardino Mts.; occurrence, desc. nest and eggs, etc.).

No. 115b Plumbeous Vireo

A. O. U. No. 629b. Lanivireo solitarius plumbeus (Coues).

Description.-Adult: Like L. s. cassini, but the olivaceous and greenish yellow elements much reduced; scapulars entirely gray; the rump gray, tinged with olivaceous; 


\section{The Solitary Vireos}

the marginings of wings and tail broader and more purely white; the sides faintly tinged with yellow; also somewhat larger. Wing 80 (3.I5); tail $5^{8}$ (2.28); bill II.2 (.44); tarsus $19.8(.78)$.

Recognition Marks.-As in foregoing-grayer.

Nesting.-Quite as in preceding form.

Range of L. s. plumbeus.--Breeding in Rocky Mountain and intra-mountain districts from northern Nevada, northeastern Wyoming, etc., south through Arizona and southwestern Texas to Chihuahua and the mountains of Vera Cruz; wintering south to Oaxaca and Colima; accidental in California.

Occurrence in California.-One record: an adult female taken near Fort Tejon, Aug. I, I 875 , by H. W. Henshaw.

Authorities.-Henshaw (Vireo solitarius var. plumbeus), Rep. Orn. Spec. Wheeler's Surv., 1876, p. 236 (Ft. Tejon, Aug. I, I 875, one spec.); Scott, Auk, vol. v., I 888, p. 32 (Ariz.; occurrence, habits); Mearns, Auk, vol. vii., I 890, p. 260 (Ariz.; habits, song, etc.).

NOTHING so endears a bird to a human admirer as a frank exhibition of confidence. Overtures of friendship on the bird's part may traverse all rules of caution and previous procedure, but henceforth there is a new relation established between them, bird and man, and the man, at least, is bound to live up to it. At the oncoming of a smart shower the bird-man once put into a fir-covered nook for shelter, and had not been there two minutes before a pair of Cassin Vireos entered for the same reason. They were not in the least disturbed by the man's presence, but cheerfully accepted him as part of Things as They Are. Therefore, they proceeded to preen their dampened feathers at distances of four or five feet, while the bird-man sat with bated breath and glowing eyes. The birds roamed freely about the nook and once, I think he made a grimace behind the bird-man's back; for when they came around in front again, I judged she was saying, "Ar'n't you the wag!" while he tittered in droll recollection.

These Vireos roam the half-open woods at all levels, like happy school children; and their childish curiosity is as little to be resented. If one hears a bird singing in the distance, he need only sit down and wait. Curiosity will get the better of the bird, and under pretense of chasing bugs it will edge over, singing carelessly now and then, by way of covering the inquisitive intent. At close range the song is stifled, and you feel for the ensuing moments as you do when you have overtaken and passed a bevy of ladies on a lonesome street, all hands and feet with a most atrocious swagger. Inspection done, the bird suddenly resumes the discarded melody, and you no longer have to "look pleasant."

Like most Vireos, Cassin sings as he works; and, as he works a good deal of the time, albeit in leisurely fashion, he sings in tiny phrases, separated by unembarrassed intervals of silence, a sort of soliloquizing 


\section{The Solitary Vireos}

commentary on life, very pleasant to the ear,-Weé ee-tsiweéoo-tsoo psooipetewer-ptir-sewtrs-piti-wee-sueeé-pisooor. But our schoolboy does not fully express himself in music so staid and delicate. He has at command a rasping, nerve-grating war-cry, possibly intended by Nature as a defense against cats, but also used, on occasion, when the bird is in particularly fine spirits. The note in question, which I call the nutmeg-grater note, may perhaps be more fitly likened to the violent shaking of a pepper box,-a rattling, rubbing, shaking note, of three or more vibrations, ending in a little vocal flourish.

This startling vocalization proves to be the master call of the woods. When it is sounded, other birds leave their nests and hasten to the scene of conflict. At a time when a Cassin Vireo's nest was threatened, I have seen Blackthroated Gray, Hermit and Lutescent Warblers, Creepers, Western

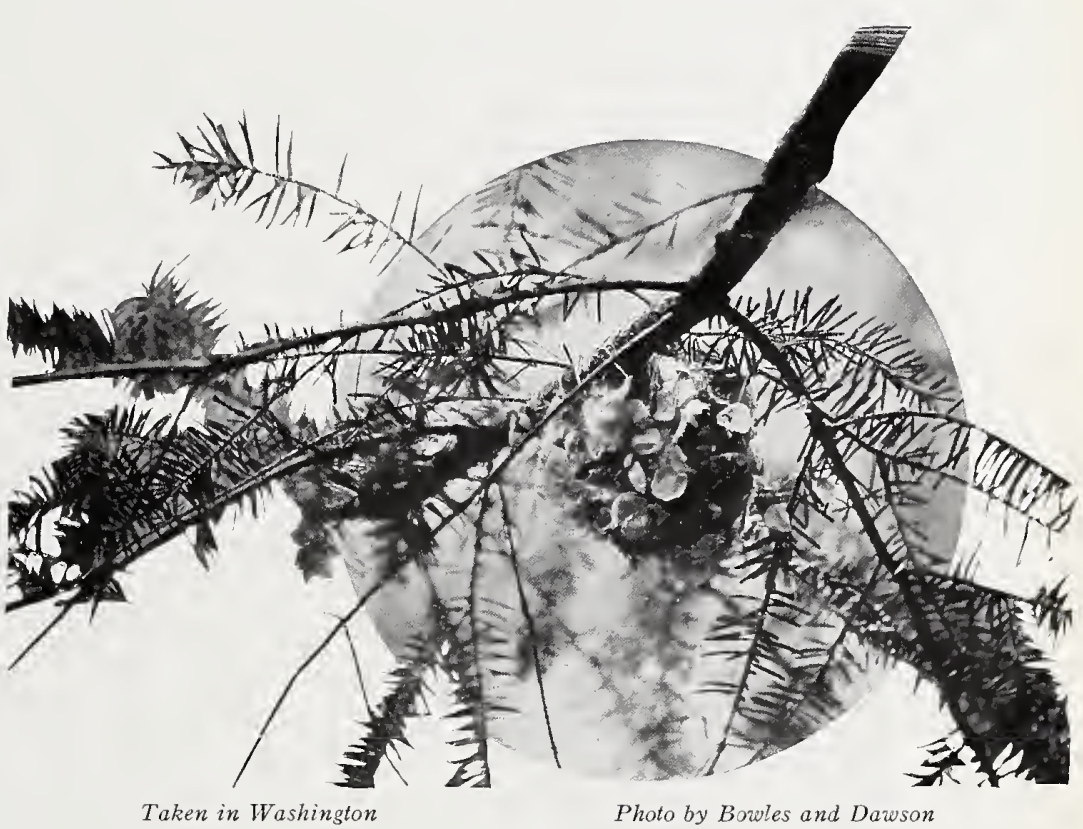

A DECORATED NEST Flycatchers, Pine Siskins, Juncoes, and Western Winter Wrens among those present. The parent birds resent all such intrusion upon their privacy, and they divide their time between scolding and driving fiercely at the invading neighbors. At such a time, also, I have seen the female keep up an incessant delivery of the nutmeg-grater notes, in spite of a beakful of worms. The male's most characteristic utterance on this occasion was a low, buzzing, or purring sound, having not above one-fourth the volume of his mate's cry. For the rest, he gave a thin, interrogatory squeak, - a roguish sound, obviously not intended as humor-and outbursts of song. Curiously enough, the bird sang during his most passionate anxiety; and although he broke off now and again to dash at my head, the notes themselves could express naught but pure serenity.

These Vireos swing a bulky basket from the lower or middle heights of oak trees, fir trees, alders, or saplings of various sorts. Usually no dependence is placed in cover, save that the ornamented nest cor- 


\section{The Solitary Vireos}

responds roughly with its general surroundings of leaf, moss and lichen. In sheltered places, the texture of the nest is so well preserved that it may require close inspection the second season to distinguish it from a new nest. One such I examined, green with growing moss, and stark at the lowermost branch-tip of an unleafed cornel sapling, and I could not have determined its age save for a tiny weed-shoot germinating from the bottom of the cup. Exterior decoration is the specialty of the $V$. solitarius group, whether it be solitarius proper of the East, or $V$. s. cassini or V. s. plumbeus of the West. White spider-egg cases in profusion are the acknowledged acme of elegance, but in default of these the bird will use cherry petals, catkins, or bits of paper.

Mr. J. H. Bowles says further of their nesting habits: "Both birds assist in the duties of incubation, the male singing most assiduously while on the nest, and usually singing close to his mate while she is sitting. His turn at sitting seems to come between nine o'clock in the morning and noon, and the nest is not hard to find if his song can be traced. The bird student must work quietly, however, as the song

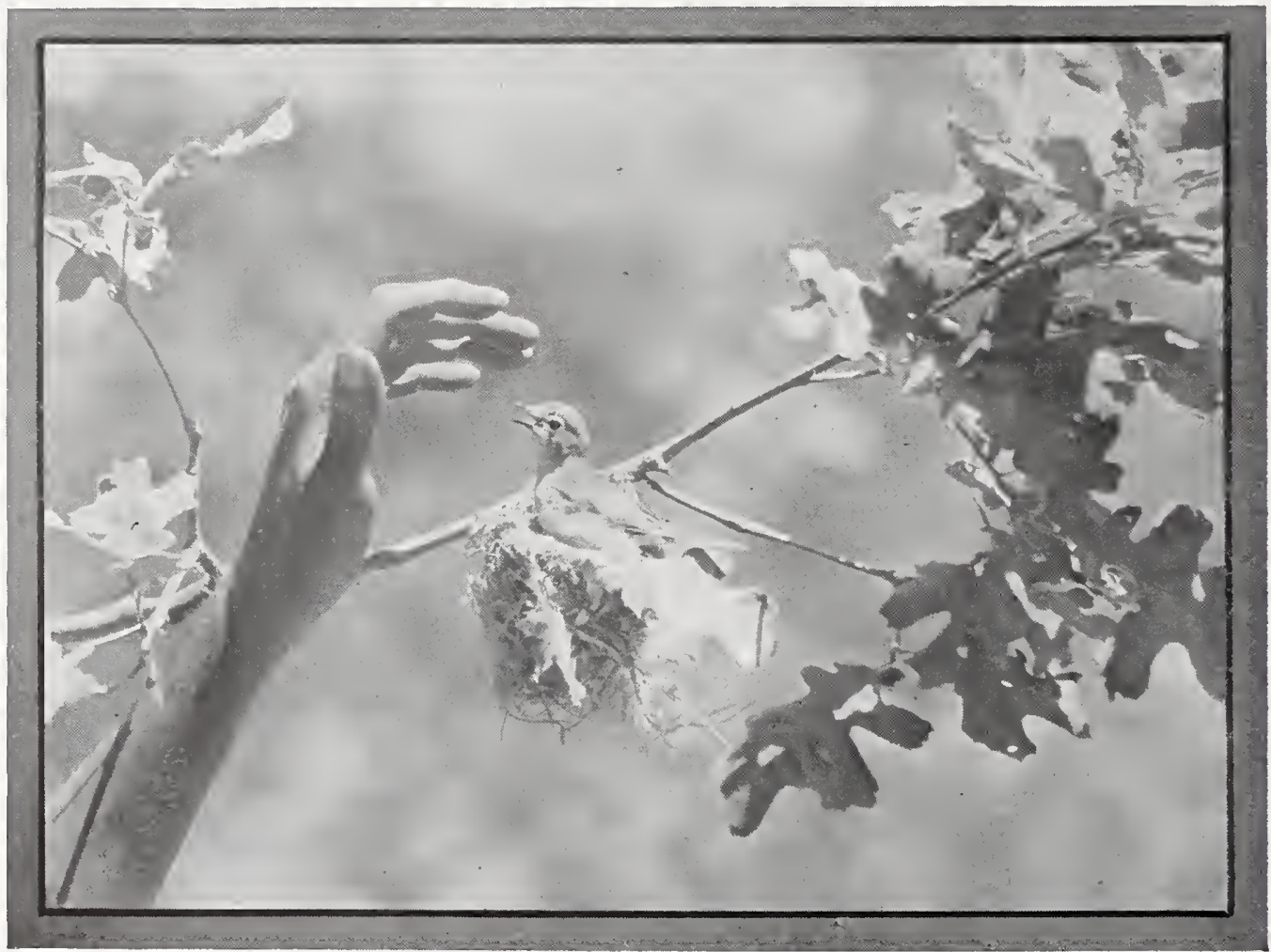

Taken in San Diego County

Photo by Dickey 
The Solitary Vireos

at once ceases should any unusual noise occur. They are most courageous while on the nest, seldom leaving until removed by hand, when both birds remain within a few feet of the intruder, scolding vigorously.

Of this courageous confidence on the part of sitting birds we have abundant testimony. While it is characteristic of the species, there are wide individual departures. Of a pair I had under close observation for three weeks in Modoc County, the fe-

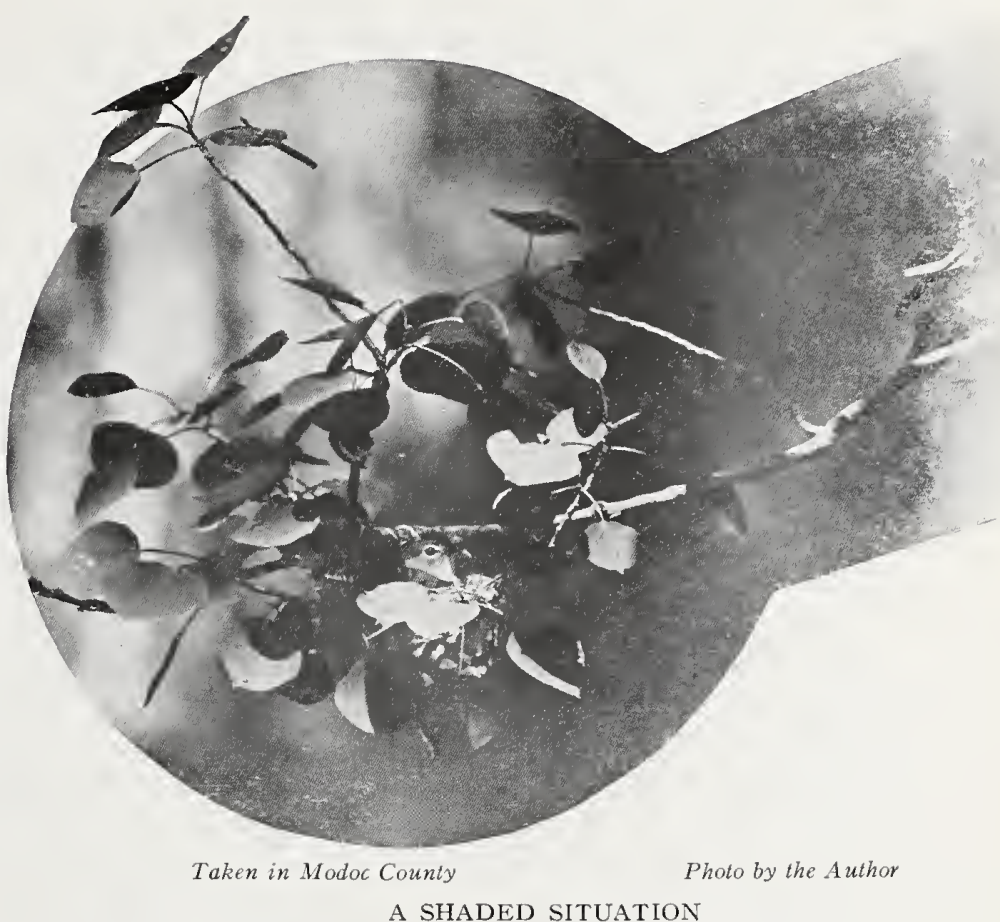
male would submit to being lifted from the nest, while the male would fly at three or four feet. The male, moreover, was greatly disturbed over what he considered my undue familiarity with his mate.

$\mathrm{B}$ ird psychology is sometimes a very disappointing thing. Psychological experimentation, likewise, is often inconclusive, because of our lack of insight into many of its operating causes. After two weeks' study of the nest, shown indifferently on this page, having nursed the brood through two storms and otherwise proven myself a good fellow, and having, as I supposed, made a decided hit with the mistress of the manse, I sought to secure better photographs than the shaded situation allowed. So, finding the female Cassin astride of her three ungainly youngsters, I first stroked her gently, then insistently pressed her foot until she clambered up on the edge of the nest to be rid of annoyance. Presently she flew for food, and after her return I cut the nest branch and lashed it to another sapling in the sunlight 25 feet away, then retired to await results. Neither bird made the faintest move to follow or to seek the young in a new location. Both, however, moped in the old home tree, or took turns examining the severed branch. The only sound made was an occasional low chuckle, much as a farmer who has mislaid his specs might ejaculate, "Sho," in deprecation of his carelessness. 


\section{The Hutton Vireo}

Finding that the Vireos were making no progress, I returned the branch with the nest and lashed it into place. The female made prompt acknowledgment of the restored status, but was rather more curious as to the new fastenings than solicitous as to the welfare of the young. Only after the lapse of some minutes did she visit the young, and then for sanitary purposes. Next, I again removed the nest, very slowly this time, holding the branch aloft so that my movements might be followed. The male dashed at me repeatedly, snapping the mandibles when nearest my head, and alternating this cavalier treatment with snatches of song. When I had proceeded six feet, he desisted and paid no further attention to me. Again I lashed the branch to the new situation, and this time met only frigid indifference. Neither bird appeared at the old site, nor was any outcry made. Again, in despair, I lashed the branch in the old situation. Neither bird attended my efforts. The male thereafter spent his entire time preening his feathers, at a point thirty feet away, while the female absented herself outright. Finally, after about fifteen minutes, the mother bird returned bearing a large white moth. She offered this to each youngster in turn, but it was disdainfully refused. Then she ate it herself and proceeded to brood. The male made no move to rustle food, but sang a little, or else gave the greater note of disquiet - all rather inconsequential, it seemed to me, considering the very unusual experience which they had been called upon to undergo. Thus do our idols disappoint us, and thus does the commonplace thrust its dull shoulder across life's gleaming horizon.

No. 116

\section{Hutton's Vireo}

A. O. U. No. 632 and 632 c. Vireo huttoni huttoni Cassin.

Synonyms.-Dusky Vireo. CoAst Vireo. Includes northern form, previously recognized as ANTHONY's ViREO.

Description.-Adults: Above dull olive (olive on head and cervix, olivecitrine on back and scapulars); wings and tail dusky, edged chiefly with pale olivegreen; two prominent wing-bars of pale olive-yellow (barium yellow to reed-yellow) or whitish, formed by tips of middle and greater coverts; tertials broadly edged with pale olive-yellow on outer, and with palest olive-yellow on inner webs; outer web of outermost rectrix whitish; underparts dingy olive-yellow (marguerite yellow), and more or less washed, chiefly on breast and sides, with olive-buffy; lores pale; an orbital ring of pale olive-yellow, interrupted midway of upper lid by spot of dusky. Bill 


\section{The Hutton Vireo}

horn-color above, pale below. Young: Like adult, but olive of upperparts grayer, especially paler and grayer on sides of head and neck; underparts paler. Length IOI.6-I20.6 (4.00-4.75); wing 6o (2.36); tail 48.5 (1.9I); bill 8.8 (.35); tarsus I9 (.75).

Remarks. - The characters alleged for $V$. $h$. obscurus Anthony, viz., darker coloration and more definite olivaceous, seem not to be supported by the evidence, and the form V.h. huttoni exists in unbroken uniformity from San Diego County, Cal., to Vancouver Island, B. C.

Recognition Marks.-Pygmy to warbler size; dingy coloration; whitish wingbars serve to distinguish bird from Vireosylva g. swainsoni, but throw it into confusion in summer with the Western Flycatcher (Empidonax difficilis), which it otherwise closely resembles, and in winter with the Sitkan Kinglet (Corthylio c.grinnelli). From the Flycatcher it may be distinguished by its shorter, narrower and yet thicker bill, and by its more restrained yellowness; from the Kinglet by its greater size and much stouter bill, more prominent wing-bars, and rather less prominent eye-ring; and from both by its demure ways.

Nesting.- Nest: Chiefly of moss (gray usnea lichen); carefully lined with fine grasses and occasionally horsehair; suspended from forked branch at any height in tree, preferably live oak. Eggs: 3 or 4 ; white, speckled lightly, chiefly at larger end, with reddish brown or brownish black. Av. of 23 California-taken specimens in M. C. O. colls: I 8 x I $3.2(.7$ I x .52). Season: March-July, but chiefly May and June; two broods. Extreme dates: Pasadena, March 7, I896, 3 eggs, fresh (Grinnell); Pasadena, July I5, I 894, 4 eggs, fresh (Gaylord).

Range of Vireo huttoni.-Western United States and Mexico.

Range of $V . h$. huttoni.-Resident in the Pacific Coast district from southern British Columbia and Vancouver Island to San Diego County, California.

Distribution in California.-Common resident in timbered portions of Upper Sonoran zone and (northerly) of the Transition zone west of the Sierran divide. Casual (?) on the desert side: Victorville, Dec. 28, I904 (J. Mailliard \& J. Grinnell); Palm Springs, Jan. 25, I9I3 (Author). Found on Catalina Island; common on Santa Cruz Island.

Authorities.-Cassin, Proc. Acad. Nat. Sci. Phila., v., I851, p. I50; vi., pl. Io, fig. I (orig. desc.; type locality Monterey); W. A. Cooper, Bull. Nutt. Orn. Club, vol. iii., I878, p. 68 (Santa Cruz; breeding habits, nest and eggs); Grinnell, Condor, vol. v., I903, p. 157 (Vireo mailliardorum described, from Santa Cruz Id.); ibid., vol. xi., I909, p. 66 (crit., discussing $V$. h. oberholseri); ibid., vol. xxiv., I922, p. 32 (crit., $V . h$. huttoni considered as the only recognizable subspecies of Vireo huttoni in California and northward).

CHU WEEM - - . - - chuweem - . - chuwêem, rings across the quiet woodland on a sunny winter's day. The sound does not, at first, suggest a Vireo to the uninitiated; but it does command attention, and it demands explanation forthwith. When you have traced it to a small, yellowish, demure-looking bird who languidly pursues his task of bug-hunting over the smaller branches of a live-oak, you will begin to suspect the truth; and if you are at all expert in eastern Vireonine lore, and if you are so fortunate as to hear the bird at close quarters, you will detect in 


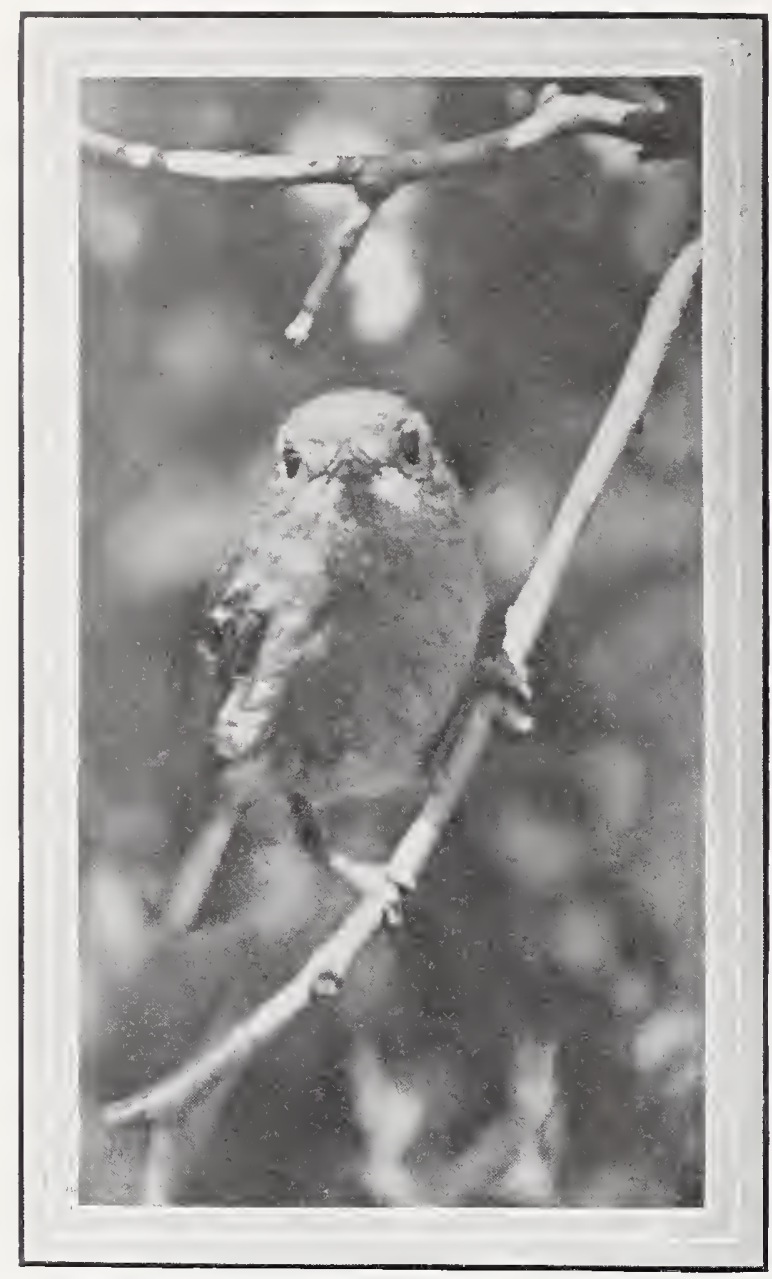

Taken in Santa Barbara

"LOOKS HIM EARNESTLY IN THE EYE'

MALE IYUTTON VIREO NEAR NEST the notes a certain edge, or timbre, which proclaims the bird's affinities.

Hutton's Vireo is leisurely, almost sluggish, in all his movements. He never hurries. Why should he? He is at home. It is California, to be sure; but it has always been California. The sun shines. Tomorrow will be like today. Or maybe it will rain. No matter. Chu wêem -..chu wêm. Besides, it is not necessary to get excited over a bug-hunt. What's one bug more or less? It's all in the day's work. Chu wêm.

In winter the Hutton Vireo associates tolerantly with our lesser guests,-Dusky Warblers, or perhaps a Townsend in the South, Chickadees in the North, and Kinglets everywhere. When moving about silently, it bears a striking resemblance to the Ruby-crowned Kinglet. It is, of course, slightly larger and much more deliberate, lacking especially the wing-flirt of the little king. The region about the eye is more broadly whitish, and the wing-bars concede a difference, upon inspection, but the resemblance is so close as altogether to deceive the unwary.

As spring approaches, the bird separates itself from its late companions and begins to explore the budding alders or sycamores. As the season advances the bird plants itself in some thicket and complains by the hour in strange, monotonous, unvireonine notes. The songs vary endlessly in different individuals, but have this in common, that they are a deliberate, unvarying succession of double notes, usually, but not always, of a slightly nasal character. Chu-wêem - . - chu-wêem - . . - chu-wêem - ad lib., is the common type; Pu-cheéa ñ


poo-êêp $p^{t}$ and jüree $\hat{e}^{t}-j u ̈ r e \hat{e}^{t}-j u ̈ r e \hat{e}^{t}$, are types lacking the nasal quality. On several occasions I have heard the notes pronounced quite rapidly, 578 


\section{The Hutton Vireo}

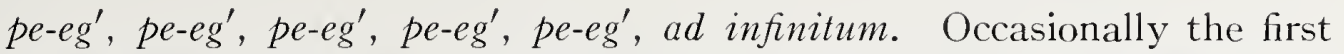
syllable is accented; as, (pe)cheé-oo or cheé-oo, cheé-oo. A bird in San Roqui Canyon gave us from 63 to 66 peegs per minute under repeated tests, whereupon Son William suggested that he ought to be called the Clockbird. When disturbed, this bird dropped his pitch and brought out a full, rich $k a z u m$, for a dozen times or so-after which he fell silent.

Before he has found a mate huttoni roams about with some degree of restlessness, shifting his burden of song from place to place with a view to effect, and uttering now and then coaxing little requests which are certainly meant to win the heart of the lady in hiding. This squeaking note is sometimes raised to the dignity of song, at which times it is not unlike the whining of a dog, a most extraordinary sound to come from so tiny a throat. And if one mentions a chirp, or chuck, like that of a Red-wing Blackbird on a small scale, we have most of the representative efforts of this eccentric genius.

The female also has her perturbations. According to Miss Jennie V. Getty, "The female is exceedingly sensitive. Her peevish ank ank ank from the thickets may mean one of several things: namely, she may be hunting a home-site, building, incu-



THE LADY IS QUITE SURE SHE WILL GET THE BUG bating, or feeding young in the trees. She reminds one of an adolescent school-girl, who screams upon any and all occasions for the mere pleasure of being actively protected. At her cry of alarm the male is almost certain to appear. Sometimes he sings to quiet and reassure her. Again he comes almost

¿ Condor, Vol. XIV., p. 75. The report concerns "Vireo huttoni obscurus" since determined to be synonymous with $V$. huttoni. 


\section{The Hutton Vireo}

to the bird-lover, looks him earnestly in the eye, as though he would determine the intruder's mission there."

Lives there a man with soul so dead that it is not ravished by the sight of a Vireo's nest? I will admit, if you like, that an appreciation of birds' eggs is the survival of the monkey in us, but an appreciation of the consummate elegance of a Hutton Vireo's nest is only the tribute which one artist soul must pay to another. Hutton Vireo is Artium Magister. An example before me is a three-quarter sphere composed of sycamore

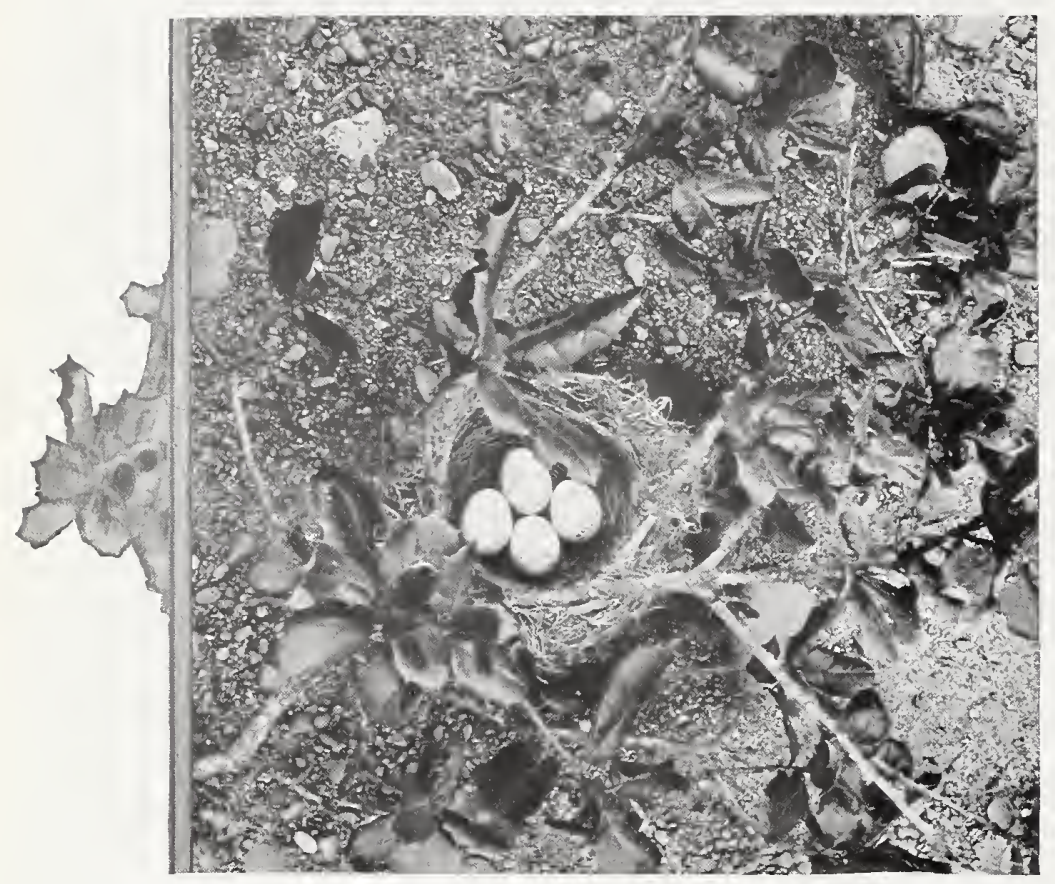

Taken near Santa Barbara
Photo by the Author

NEST AND EGGS OF HUTTON VIREO NOT IN SITU down, and the familiar gray-green usnea (a lichen, of course, but we all call it "moss") lashed together with cobwebs. The edges are made fast to forking twigs of live oak, and are exquisitely rounded, while a convenient twig below supports the bottom of the nest in graceful security. The nesting hollow, almost as deep as it is wide, is daintily lined with the finest of dried grasses. Its dimensions are three inches in width by two and three-quarters in depth, outside; and two and threeeighths in width by one and three-quarters in depth inside.

Another nest, in a bay tree, lacks the supporting twig below, and is of a rather bolder, more open construction. Conspicuous cinctures of vegetable fiber lash, or undergird, the entire structure, externally; while in the open meshes of the dried usnea are embedded decorating fragments of paper-a linen envelope, I should judge-torn to convenient shreds. The effect of the whole is as striking as that of any Red-eye or Solitary.

The eggs, normally four in number, are pure ovate as to shape, pure dull white as to color, and are coarsely though sparingly sprinkled about the larger end with deep sepia or purplish black. As to the why of this color-pattern, which, with variations as to shading and abundance runs 580 


\section{The Hutton Vireo}

consistently through the entire family of Vireos, science makes no conjecture. It simply and delightfully is.

That the birds themselves have the highest opinion of their treasures, universal opinion attests. Finding a nest near Pasadena placed some fifteen feet up in a dead willow sapling, and utterly devoid of local cover, save the general umbrage of taller trees, we speculated in bewilderment as to its affiliations. The nest itself, an elegant creation of willow-down, was so placed that we could reach and control the limb it was swung to from an adjacent live tree. But it was so out of character, and the Least Vireos of the neighborhood were so abundant, that we determined to capture the owner, if possible, and establish her identity. Mr. A. B. Howell accepted this disagreeable role, and approached the sitting bird by slow degrees until he could pounce upon her. Seizing the bird successfully by the bill, and with some necessary severity, he lifted her from the nest. We examined the wing, saw that the third primary was decidedly shorter than the fourth, and let the bird go. While I still held the limb in my hand, the

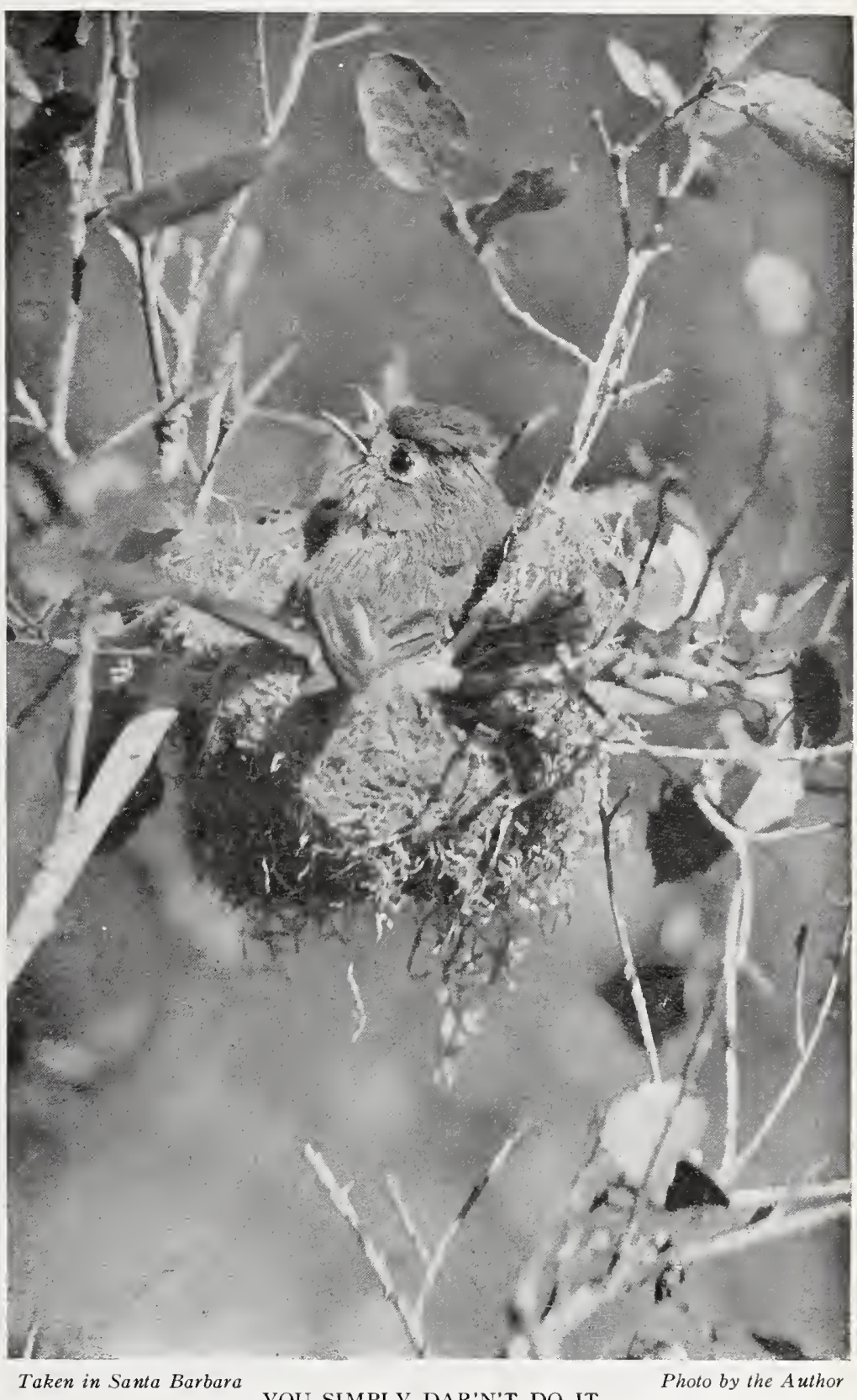

YOU SIMPLY DAR'N'T DO IT 


\section{The Hutton Vireo}

bird returned and settled with an air of quiet determination to her eggs. William put his finger up to her bill, and she pecked at it with a few dainty dabs. I put first my nose and then my lips to her beak, but she did not show any further spite. Finally, I photographed her in various positions, and Howell lifted her gently and without constraint, from her eggs, while I photographed the group. Soon after the final release, the male bird approached the scene, and visited the nest. The female quitted it for a few moments while he inspected its contents critically,-and to his evident satisfaction, for she immediately returned and resumed her duties.

This species being at the time unrepresented in Oötheca Dawsoniana, we cherished feelings of conscious virtue over our forbearance; but our hopes of better luck next time were dashed when Mr. J. H. Bowles, then resident at Santa Barbara, said that of the four nests he had taken he had been obliged, in each instance, to lift the bird from the nest. In one case he had been obliged to cut away a large willow branch, and the foliage was so heavy and so one-sided that the branch had turned over in his hands, insomuch that the Vireo's nest, which hung near the tip, was nearly upset, lacking only an eighth turn, that is, a quarter of a half, of

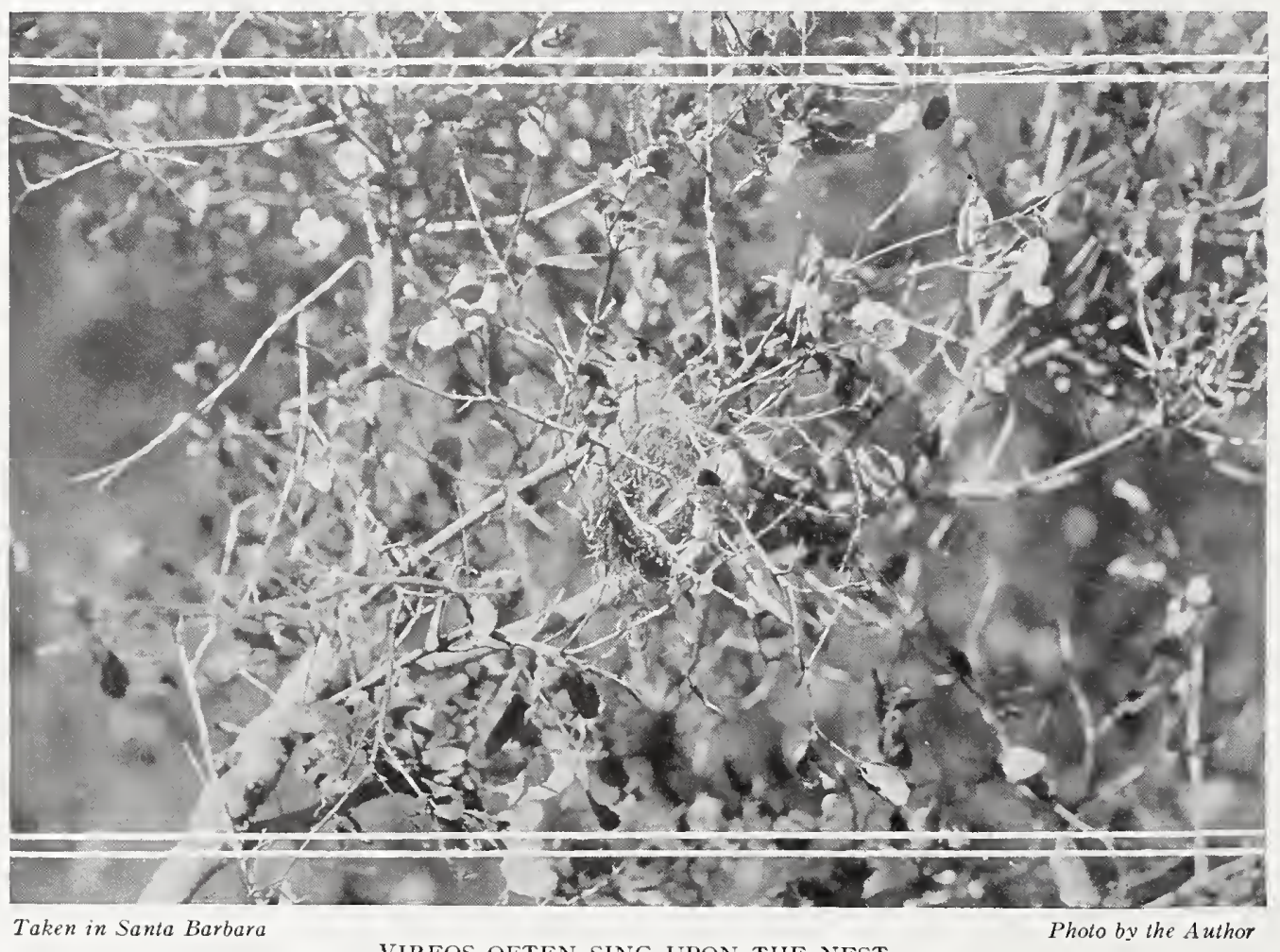

VIREOS OFTEN SING UPON THE NEST 


\section{The Gray Vireo}

being upside down. But the bird clung to the nest, and it was her presence alone which saved the eggs! Even when the branch was hauled in, she required to be removed by hand. A large experience with this bird, unfolding with the years, shows it to be, without exception, the most confiding species within our borders. Only a few of the Hummers, Calliope, Costa, Anna perhaps, are at all comparable in this respect.

\section{No. 117}

\section{Gray Vireo}

\section{A. O. U. No. 634. Vireo vicinior Coues.}

Description.-Adult: Upperparts plain mouse-gray, scapulars and lower back very slightly glossed with olivaceous; wing and tail nearly uniform grayish dusky, with some paler edgings; edge of wing white; outer margins of tertials grayish white; underparts dull white, the sides slightly tinged with pale greenish yellow; cheeks like back; lores dull grayish white; an inconspicuous whitish eye-ring. Bill (drying) bluish dusky; feet and legs leaden black; iris brown. Young birds are much like adults, but slightly browner above and purer white below; the edgings of wings and tail tinged with olivaceous. Length I27-139.7 (5.00-5.50); wing $65\left(2.5^{6}\right)$; tail 58 (2.28); bill $9.6(.38)$; tarsus I9. I (.75).

Recognition Marks.-Warbler size; definite gray coloration distinctive (the slight olivaceous tinge will escape notice afield); a haunter of chaparral.

Nesting.- Nest: Semi-pensile; of weathered leaves, grasses, strips of weedbark, etc.; of rather loose construction without special lining; placed at moderate heights in bush of chaparral. Eggs: 3, rarely 4; white, finely and sparingly flecked with dark brown or blackish. Av. size I 7 x I2.5 (.67 x .49). Season: c. May 2o; one brood. Riverside, Apr. 26, I 889 (F. Stephens); Cajon Pass, June 4, I886 (F. Stephens).

General Range.-The Southwestern States and Mexico. Southern California, southern Nevada, the Grand Canyon of the Colorado, and southeastern Colorado south to Lower California, Sonora and Durango.

Distribution in California.-Resident in summer in Upper Sonoran chaparral of mountain ranges in southern California - of local distribution: Campo (Stephens); Cajon Pass (Morcom, Stephens); Riverside (Stephens); San Jacinto and Santa Rosa Mountains (Grinnell \& Swarth). Also Bodfish, Kern Co., June I6, I9I I (Grinnell).

Migrations.-Spring arrival: Campo, March 24, I876 (Stephens); Mecca, March 26, I9I I (van Rossem).

Authorities.-Stephens, Bull. Nutt. Orn. Club, vol. iii., I878, p. 42 (Campo, San Diego Co.); Morcom, Bull. Ridgway Orn. Club, no. 2, I887, p. 5I (Cajon Pass); Grinnell and Swarth, Univ. Calif. Pub. Zool., vol. x., 1913, p. 291, pl. Io, fig. 2 (San Jacinto Mts.; occurrence, habits, song, nest and eggs, etc.);Grinnell, Condor, vol. xxiv., I922, p. 2 I I (distr. in Calif., song, appearance, etc.). 


\section{The Gray Vireo}

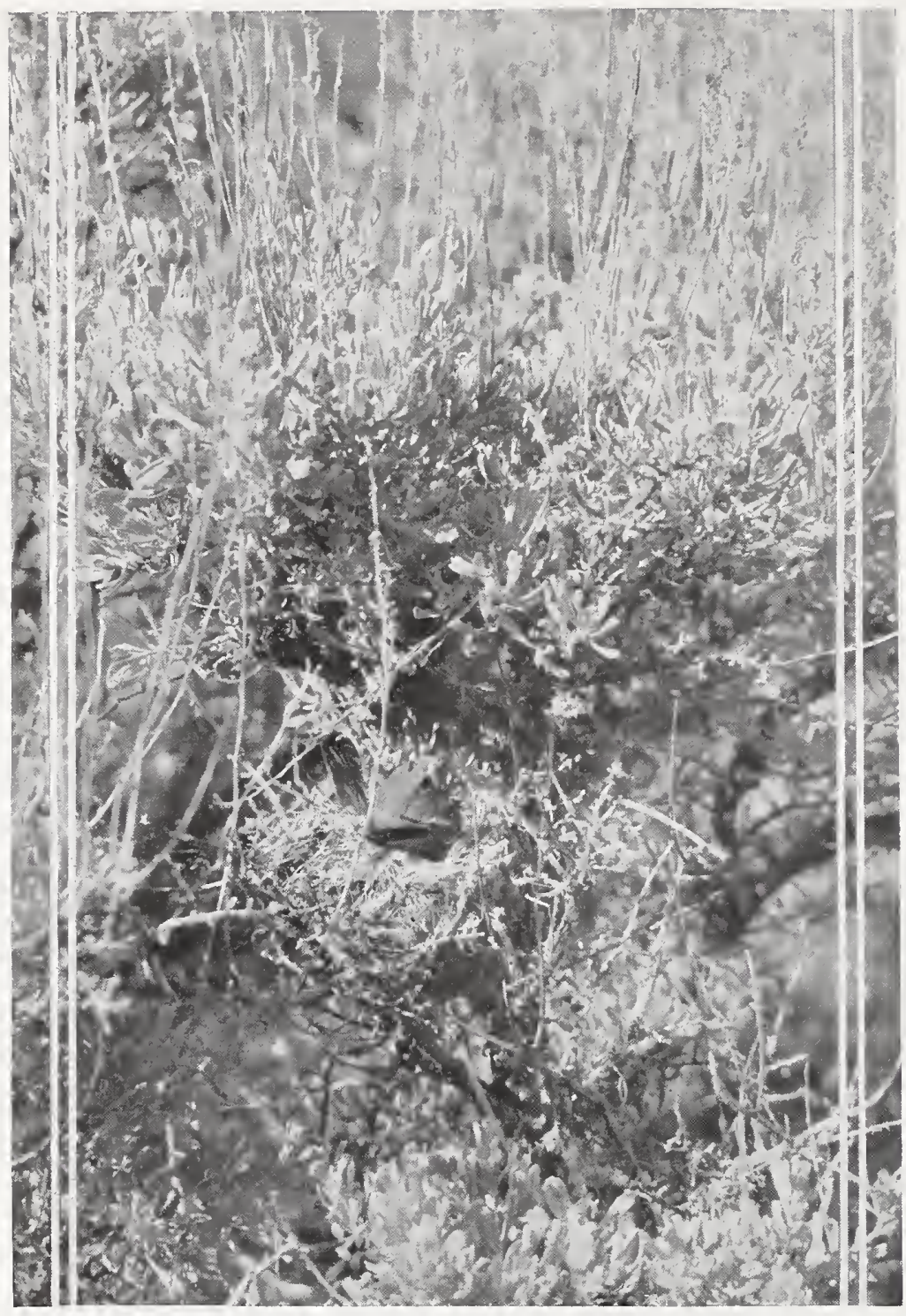

Taken in San Bernardino County

Photo by Pierce

GRAY VIREO AND NEST

THe "host TReE" is the homely SAGE, Artemisia tridentato
A VOICE, a flitting shape, an association, and an attachment: these be the brief annals of the Gray Vireo. To speak of the association first, and in the words of Grinnell and Swarth:1 "The distribution of Vireo vicinior is capable of more exact definition than is usually the case with birds. It is, namely: The Adenostoma minor association, of the chaparral major association, of the $\mathrm{S}$ a $\mathrm{n}$ D i e ga $\mathrm{n}$ faunal division, of the Upper Sonoran zone." That is to say, the Gray Vireo keeps pretty close to the chamise on the lower middle slopes of our southern mountains. It is, therefore, a "dry forager," and its habits contrast sharply with those of our other vireos, which we naturally associate with purling brooks and bosky dells. But so devoted is the Gray Vireo to his prosaic haunts that he rarely appears above the chap-

${ }^{1} \mathrm{An}$ account of the Birds and Mammals of the San Jacinto Area of Southern California: U. of C. Press, Oct. 3 I 1913, p. 291.

584 


\section{The Gray Vireo}

arral tops, and seldom tarries within range of vision at those middle levels which are his chosen home. It is from such depths, therefore, that his song emerges, a surprising and delightful contribution which vindicates all the bird's vireonine claims.

According to the authorities above cited, "the song of the Gray Vireo is loud and full-toned in volume and quality. In these respects it reminds the hearer strongly of the Cassin Vireo, yet with the twang and less deliberate utterance of a Western Tanager. In measure, and in the suggestion of rising and falling inflection, it recalls the Least Vireo." I noted this resemblance to Cassin's song in I9I3; but the phrases seemed to me to come more rapidly, vivaciously, and energetically. They were a good deal more varied in character, and showed broader powers. Now and again the singer would rise to a rhythmic medley, a sort of rhapsody, wherein the diverse elements were connected by a musical ku-ching, - a clashing of tiny cymbals after each phrase.

The song will rarely betray the singer alone, for he easily contrives to slip away from his pursuer; but it will, alas! sometimes betray the "attachment." For how could one ever expect to "meet up" with these elusive sprites, these flitting genii of the interminable chamise, except that they are obliged to pin their faith to some one spot? Some certain one of ten thousand stalks must serve to support the annual cradle. "Weary, stale, flat, and unprofitable," the situation seems to us; but the birds not only make the best of it, but they seem to draw from the endless store of common things high inspiration for song and for life. Moreover, when the nest is found, the birds prove to be very much attached. The first-known nest, secured by W. E. D. Scott in I 885 , proved to have no eggs; yet Mr. Scott had been obliged to displace the sitting bird with his finger in order to ascertain the fact. This habit of resting in the nest, or of trying it out for a few days previous to laying, is characteristic of many birds, but notably of the vireos; yet scarcely any other will submit to be handled under such circumstances.

The nest of the Gray Vireo is placed at about three feet above the ground, and conforms to the usual vireonine type,- a semi-pensile basket, made fast by the edges; yet by reason of the density of its cover, it is likely to be partially supported by underlying twigs, or even to be settled down into them. The materials, too, which compose this basket are simpler than usual in character, with less attempt at ornament. Two nests found by Messrs. Grinnell and Swarth had on the very outside unbroken, tridentate, gray leaves of the sage-brush-a rather pathetic commentary on the meager resources of the pioneers. 


\section{The Least Vireos}

\section{No. 118}

\section{Least Vireo}

\section{No. 118a California Least Vireo}

A. O. U. No. 633a, part. Vireo belli pusillus Coues.

Description.-Adult: Upperparts plain mouse-gray, shading on sides of head, neck, and breast, the pileum faintly varied by brownish gray; back, scapulars, and rump, faintly, sometimes very faintly, glossed with olivaceous; underparts white, the breast sometimes lightly tinged with palest grayish olive; sides lightly washed, or not, with pale greenish yellow; axillars pale sulphur-yellow; a pale whitish supraloral area; lores, narrowly, dusky; eyelids, narrowly, especially below, black, then white; the major feathers of wings and tail with paler edgings; the greater coverts definitely tipped with pale grayish white. Bill horn-colored above, pale or flesh-colored below; feet and legs bluish dusky; iris brown. Length about I20.6 (4.75); wing 55.3 (2.I8); tail $5 \mathrm{I}$ (2.0I); bill 9.5 (.37); tarsus I9 (.75).

Recognition Marks.-Pygmy size; plain gray above, white below; slight tinge of olivaceous, especially on sides; song of "breathless jumbled notes."

Nesting.- Nest: A semi-pensile basket lashed by edges to fork of horizontal or descending branch of tree, at lower levels -2 to 5 feet above ground; composed of bark-strips, dry leaves, and grasses; lined with fine grasses or, rarely, felted with plant-down. Eggs: 3 or 4, rarely 5; white, speckled and spotted sparingly, and chiefly at larger end, with reddish brown or brownish black. Av. size, as in next form. Season: May-June; one brood. Extreme dates given by Willett, on authority of H. Robertson, Los Angeles, Apr. I, I900, 3 newly hatched young; Los Angeles, June 30, I898, 3 eggs. Mexico.

Range of Vireo belli.-Western United States east to the Mississippi Valley, and

Range of $V . b$. pusillus. - Central and southern California and northern Lower California, and east possibly to southwestern Nevada; breeding south to San Pedro Martir Mountains and San Fernando, Lower California; south in winter to Cape San Lucas and probably the west coast of Mexico.

Distribution in California.-Summer resident in riparian associations of the Lower Sonoran zone, breeding north in the central valley to Marysville (Belding), and in the coastal counties, north at least to southern Monterey County (San Ardo, May I4, I9I6, eggs taken); recorded east of the Sierras north to Bishop Creek (A. K. Fisher). Status of bird's breeding in desert counties east of the main divide undeterminedmay be $V . b$. arizonce.

Authorities.-Coues (Vireo pusillus), Proc. Acad. Nat. Sci. Phila., I866, p. 76, part (orig. desc.; type locality Cape San Lucas, Lower Calif.; also ascribed to "Southern California"); McAtee, U. S. Dept. Agric., Yearbook, I906, p. I94 (feeding on scale insects); Grinnell, Condor, vol. xiv., I9I2, p. Io6 (song); Tyler, Pac. Coast Avifauna, no. 9, I9I3, p. 98 (Fresno; habits, song, nest and eggs, etc.); W. C. Hanna, Condor, vol. xx., I9I8, p. 2 I I (San Bernardino Valley; descr. of nests occupied by Cowbirds).

\section{No. 118b Arizona Least Vireo}

A. O. U. No. 633 a (part). Vireo belli arizonæ Ridgway. 


\section{The Least Vireos}

Description.--Similiar to $V$. belli pusillus, but browner gray above, with decided increase of olivaceous; underparts less purely white, more strongly tinged with oliveyellow on breast, and with olivaceous on sides.

Nesting.-Quite as in preceding form, save for narrower choice of nesting treeschiefly confined to mesquite. Av, size of 34 eggs in the M. C. O. colls: I6.5 X I 2.2 $(.65 \times 48)$. Season: In the Colorado Valley, April.

Range of $V . b$. arizonce.- Southeastern California and southern Arizona east to western Texas and south through the Mexican states of Chihuahua, Sonora, and Sinaloa.

Distribution in California.-A common breeder in the Colorado River valley; possibly entitled to recognition throughout the southeastern desert area.

Authorities.-Cooper (Vireo bellii), Proc. Calif. Acad. Sci., I86I, p. I22 (s. e. Calif.); Brewster, Bull. Nutt. Orn. Club, vol. vii., I 882, p. I44 (s. Ariz.; descr. nest, meas., etc.); Auk, vol. ii., I885, p. 197 (descr. young); Morcom, Bull. Ridgway Orn. Club, no. 2, I887, p. 5I, part (Fort Yuma, breeding); Grinnell, Univ. Calif. Pub. Zool., vol. xii., I9I4, p. I 89 (Colo. Valley; habits, desc. nest and eggs).

UNLESS one is already acquainted with the vivacious White-eyed Vireo of the East, or, better, with Vireo belli of the Middle West, he is likely to be somewhat mystified at first in his efforts to place this little stranger. At least, he will hardly be helped by any recollection of sedate Cassin or drawling Hutton. The Least Vireo hunts from the lower levels, from the ground up to a height of six or eight feet. He is very partial to the willow association, but includes alders and sycamores and whatever else may grow in the near vicinity of water. Those who know the bird as a familiar spirit of the irrigating ditches,

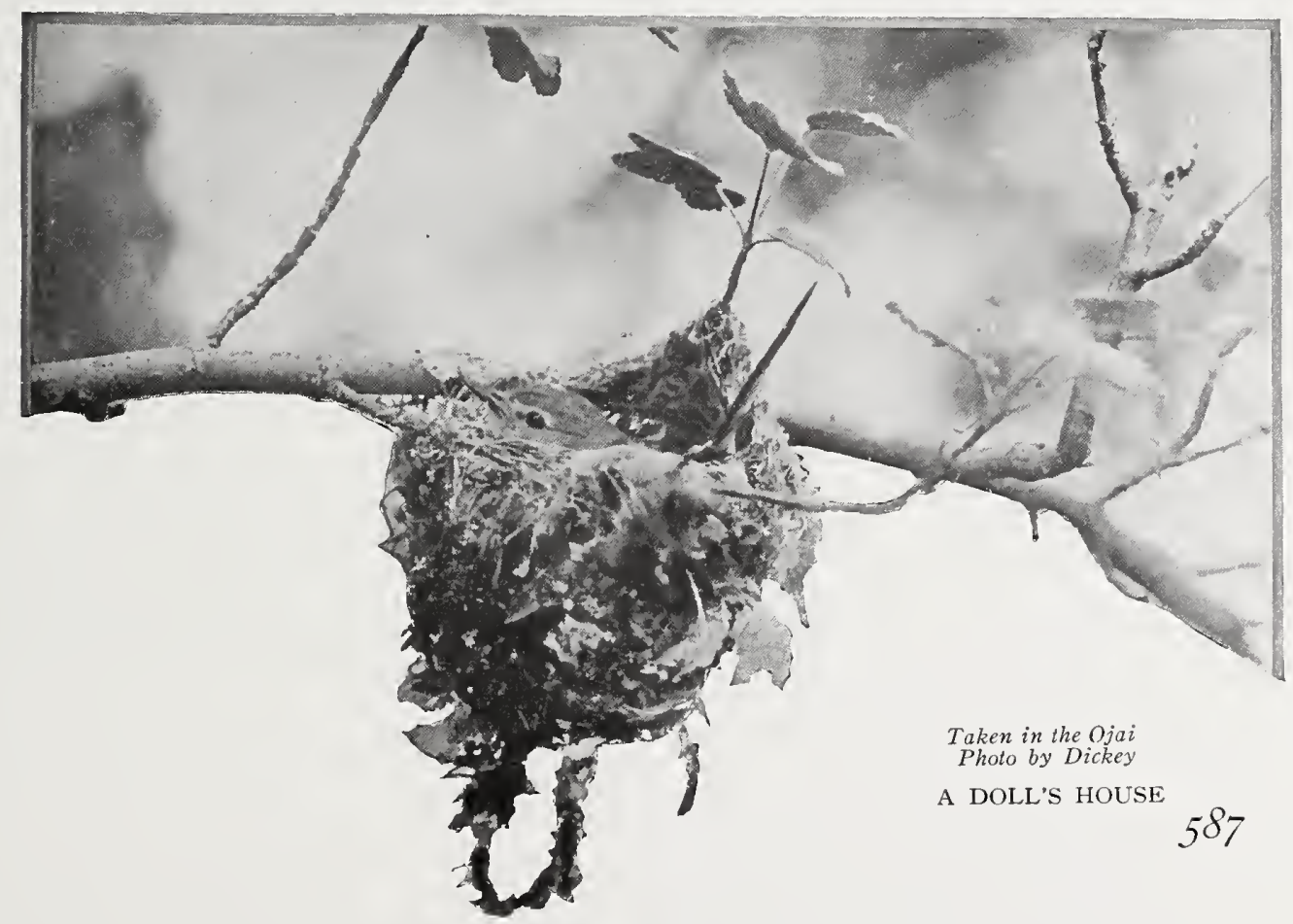




\section{The Least Vireos}

such as intersect the Fresno district, or who have found him to be the inevitable concomitant of willow trees on the banks of the Colorado, can scarcely conceive of the Least Vireo apart from running water. Yet I have seen the bird, in mid-May, in the cactus and chaparral belt near Claremont, as much at home, apparently, as was the Western Gnatcatcher.

There is, for me, a whimsically childish quality in both the voice and behavior of the Least Vireo. The bird is as agile and restless as a four-year-old; while his "song," a gushing outburst of childish confidences, an incoherent medley which you will not take seriously the first time, you will be obliged to hear again and again. Whether you intend to or not, you will soon find yourself puzzling over his bright gibberish, and trying to make out what the youngster is driving at. Hooly doopity doolity todaw'it, evidently means nothing at all, unless it happens to be the Chinese for "I wish you a happy New Year." A merry elfin over on the San Jacinto kept telling us I'm surely happy to meet' yer. He'd possibly got wind of our coming, for he insisted, I'm surely happy to meet yêu. This same youngster haunted certain thickets near camp, and took a lively interest in our domestic affairs, - an

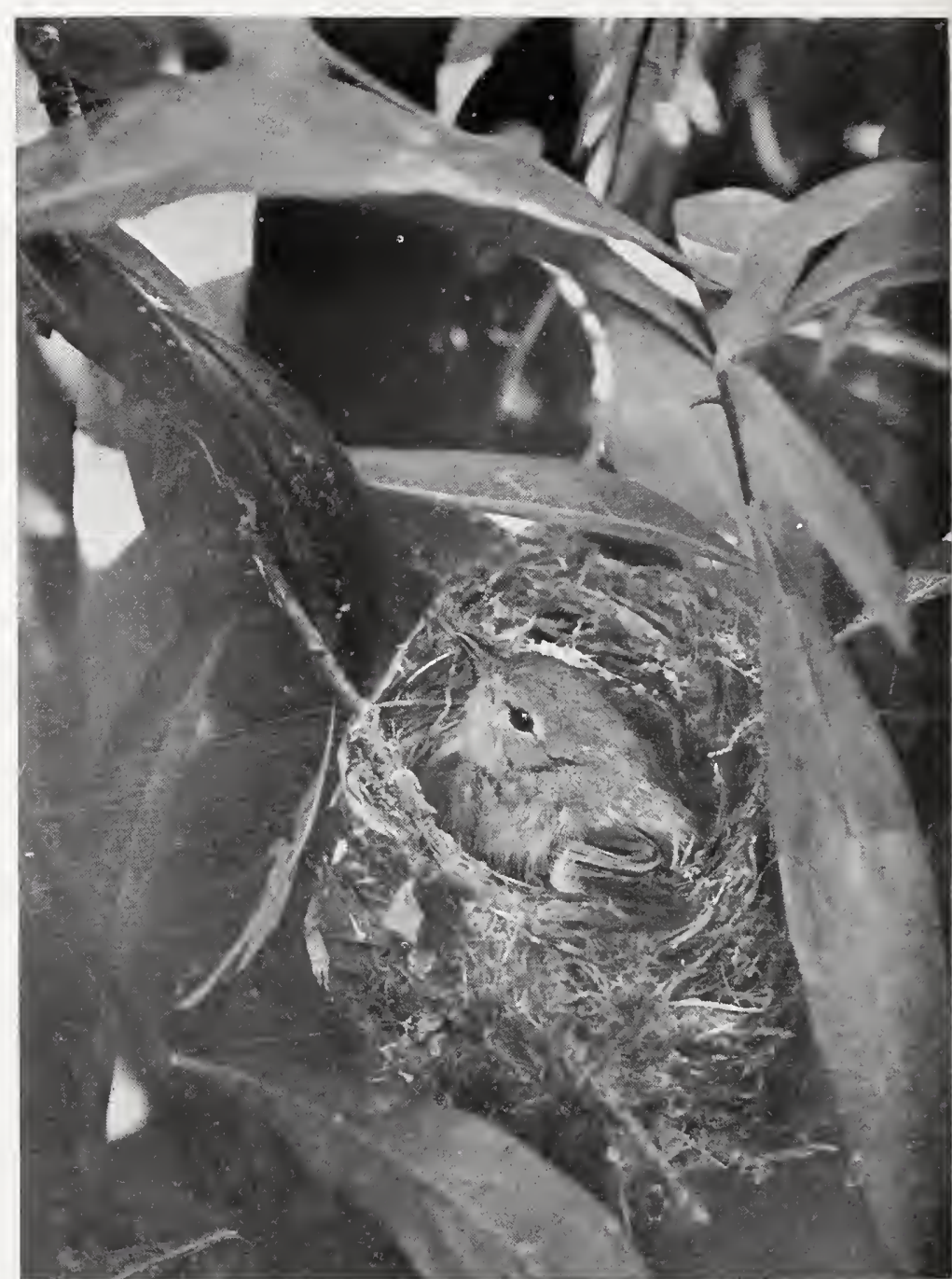

Taken in Monterey County

Photo by the Author

A CONTENTED LITTLE HOUSEW1FE CALIFORNIA LEAST VIREO ON NEST 588 


\section{The Northwestern Shrike}

interest which we warmly, but vainly, endeavored to reciprocate. (It was absurd to think that this flibbertigibbet should be wedded; but if not, wherefore this hurried recitative they call his "song"?) Anyhow, if his observations were directed at us, they showed a certain lack of discrimination, for his stock remark was, I sh'd think that'd be worth a great deal. Capital! when a White-throated Swift's egg was being held up for William's inspection! But it was to laugh that the same remark was made when the cook was ruefully inspecting a mess of sour beans. Out of the mouth of babes and sucklings!

The bird's song, when it is not innocently (or cunningly?) misleading, will take you straight to the nest, the little hempen basket, swung this time from the tip of a descending branch, at a height of not over two or three feet from the ground. Nests twelve feet off the earth are of record, but those only one foot up are less rare. Quite frequently, also, nests are placed like those of Flycatchers, over a running stream. There is, perhaps, a general disposition to place the basket, however humble, in the open, a disposition that, according to Dr. Grinnell, results in a considerable loss when the nests line cow-paths, as they do in the Colorado River bottom. On the other hand, I once saw a nest on the upper Salinas River in shade so dense that one could not see to read on a bright afternoon. In this case, we may suppose that the birds had been overtaken by an unforeseen rankness of the surrounding growth.

No. 119

\section{Northwestern Shrike}

A. O. U. No. $62 \mathrm{I}$, part. Lanius borealis invictus Grinnell.

Synonyms.-Great Northern Shrike. Butcher-bird.

Description.-Adult: Upperparts clear bluish gray, lightest-almost whiteon upper tail-coverts and tips of lowermost scapulars; extreme forehead and line over eye (increasing behind) whitish; wings and tail black, the former with conspicuous white spot at base of primaries, and with narrow white tips (increasing inwardly) on the inner primaries and the secondaries, the latter with large white terminal blotches on outer feathers, decreasing in size in wardly; a black band through eye, including auriculars; below grayish white, the feathers of the breast and sides narrowly tipped with dusky, producing a uniform fine vermiculation which is always present. Bill blackish, lightening at base of lower mandible; feet black. Young birds are more heavily vermiculated below, and are heavily washed all over with dull rusty brown. The plumage of adult is sometimes overcast above with a faint olivaceous tinge. Length 235-273. I (9.25-I0.75); wing II 4.3 (4.50); tail I IO (4.33); bill 17.7 (.70); tarsus 27.3 (I.07).

Recognition Marks.- Robin size; gray and black coloring; sharply hooked bill; breast vermiculated with dusky as distinguished from next species. 


\section{The Northwestern Shrike}

Nesting.-Does not breed in California. Nest: A well-constructed bowl of sticks, thorn-twigs, grasses, and trash, heavily lined with plant-down and feathers; in bushes and low trees. Eggs: 3 to 7 ; dull white or greenish gray, thickly dotted and spotted with olive-green, brown, or vinaceous gray. Av. size, $27.2 \times 19.8$ (I.07 X.78).

Range of Lanius borealis.-Northern North America; south in winter to the middle and southern portions of the United States. Breeds north of the United States, except sparingly in New England.

Range of $L . b$. invictus. - Alaska south in winter, sparingly, to Pacific Coast states. Eastern delimitations of range imperfectly made out.

Occurrence in California.-Rare midwinter visitor in northern Californiahalf a dozen records.

Authorities.-Gambel (Lanius septentrionalis), Proc. Acad. Nat. Sci. Phila., vol. iii., I 847 , p. 20 I (Calif.); Feilner, Ann. Rep. Smiths. Inst., I 865, pp. 422, 425 (Shasta and Siskiyou counties); Coues, Birds Col. Val., i 878, pp. 535, 558 (syn., habits, hist., nomencl., etc.); Belding, Land Birds Pac. Dist., I 890, p. I97 (Nicasio and Marysville); Judd, U. S. Dept. Agric., Biol. Surv. Bull., no. 9, I898, p. I5 (food); Grinnell, Pac. Coast Avifauna, no. I, I900, p. 54 (orig. desc.; type locality Kowak River, Alaska; meas., habits, etc.).

FLITTING like a gray ghost in the wake of the cheerful hosts of Juncoes and Redpolls, comes this butcher of the North in search of his accustomed prey. If it is his first visit south he posts himself upon the tip of a tree and rasps out an inquiry of the man with the gun. Those that survive these indiscretions are thereafter faintly descried in the distance, either in the act of diving from some anxious summit, or else winging swiftly over the inequalities of the ground.

All times are killing time for this bloodthirsty fellow, and even in winter he "jerks" the meat not necessary for present consumption-be it chilly-footed mouse or palpitating Sparrow-upon some convenient thorn or splinter. In spring, the north-bound bird is somewhat more amiable, being better fed, and he pauses from time to time during the advance to sing a strange medley, which at a little remove sounds like a big electric buzz. This is meant for a love song, and is doubtless so accepted by the proper critics, but its rendition sometimes produces about the same effect upon a troop of finches which a cougar's serenade does upon a cowering deer.

Experts try to make out that this creature is beneficial, "on the whole," because of the insects he devours, but I have seen too much good red blood on this butcher's beak myself. My gun is loaded!

Fortunately, owing to the retarding influence of the milder climate of the Pacific Northwest, this bloodthirsty species does not often appear below our northern boundary. But when he does so, it is not to be supposed that there is always a birdman with a gun right at hand, so the five or six scattered records which have been preserved hint at hundreds which might have been made. 


\title{
The White-rumped Shrikes
}

\author{
No. 120
}

\section{White-rumped Shrike}

\section{No. 120a White-rumped Shrike}

\section{A. O. U. 622a. Lanius ludovicianus excubitorides Swainson.}

Description.-Adult male: Dark bluish gray above, changing abruptly to white on upper tail-coverts; scapulars chiefly white; wings chiefly black, the edges white, a small white patch at base of primaries, and the inner quills narrowly tipped with white; tail black, the outer pair of feathers chiefly white, the succeeding broadly tipped with white in descending ratio until color disappears in two central pairs; below white, slightly soiled, or buffy-tinted, on breast and sides, but everywhere strongly contrasting with upperparts; a narrow frontal line, nasal tufts, lores, and ear-coverts, black-continuous and passing mostly below eye. Bill and feet black. Adult female: Similar to adult male, but somewhat duller; the gray of upperparts faintly washed with olivaceous; the buffy of underparts deeper, more sordid, with some showing of darker vermiculation. Immature males of the second year are also glossed with olivaceous and retain vermiculation below. Young of the year: Colors of adult, less strongly contrasted; lower parts washed with brownish; loral bar obscure; more or less vermiculated with dusky all over (in younger birds), or upon the underparts alone (save throat and crissum, which are immaculate); ends of wing-quills, coverts, and tail-feathers often with ochraceous or rusty markings. Length of adult male about 2 I5.9 (8.50); wing I00.6 (3.96); tail 99 (3.90); bill I 5.3 (.60); tarsus 28 (I.10).

Recognition Marks.-Towhee size or larger; dark gray above; whitish below; longitudinal black patch of head; wings black and white; breast of adult unmarked, as distinguished from both $L$. borealis invictus and L. $l$. gambeli.

Nesting.- Nest: A bulky but well-built structure of sticks, thorn-twigs, sagebark, dried leaves, etc.; heavily lined with wool, hair, and feathers; placed at moderate heights in bushes or trees. Eggs: 5 to 7 ; dull grayish or greenish white, thickly speckled and spotted with grayish olive or buffy brown. Av. size, $24.6 \times 18.5(.97 \times .73)$. Season: April, June; two broods.

Range of Lanius ludovicianus.- North America from southern Canadian provinces south to southern Mexico.

Range of l. l. excubitorides.-Western North America from the Great Plains westward, except Pacific Coast district, and from Manitoba and the plains of Saskatchewan south over the tablelands of Mexico; south in winter over the whole of Mexico, intergrading with $L . l$. migrans in region of the Great Lakes.

Distribution in California.-Common resident east of the desert and Sierran divides-exact area of intergradation with succeeding form indeterminable, but lies west of the Sierras.

Authorities.-Baird (Collyrio excubitorides), Rep. Pac. R. R. Surv., vol. ix., I 858, p. 327, part (spec. listed from Fort Yuma); Coues, Birds Col. Val., I 878, pp. 535, 56I (syn., habits, hist., nomencl., etc.); Judd, U. S. Dept. Agric., Biol. Surv. Bull., no. 9, I898, p. 20, part (food); Swarth, Pac. Coast Avifauna, no. 4, I904, p. 48 (s. Ariz.; habits, nesting dates, molt); Grinnell, Univ. Calif. Pub. Zool., vol. xii., I9I4, p. I 88 (Colo. Valley; crit.; habits, etc.). 


\section{The White-rumped Shrikes}

\section{No. 120b California Shrike}

A. O. U. No. 622b. Lanius ludovicianus gambeli Ridgway.

Description.-Similar to L. l. excubitorides, but slightly darker, duller gray above; underparts more sordid, tinged with brownish, or with more or less distinct transverse vermiculation of pale brownish gray on chest and sides of breast (even in adult male); averaging slightly smaller. A "light" form, not always readily distinguishable from the westernmost members of excubitorides.

Recognition Marks.-As in preceding-duller.

Nesting.- As in L. l. excubitorides.

Range of L. l. gambeli.-Pacific Coast district from southwestern British Columbia to northern Lower California; south in winter to Cape San Lucas and western Mexico.

Distribution in California.-Common resident, locally abundant west of the Sierran divide. The differentiating factor of this very "light" race is the humidity of the coastal airs; hence the race is found in its purity only in the northwestern humid coastal strip south to Monterey. Elsewhere, and especially in the heated interior valley, gambeli approaches, or "intergrades with," excubitorides.

Authorities.-Vigors (Lanius ludovicianus), Zoology of Beechey's Voyage, I 839, p. I7; Ridgway, Man. N. Am. Birds, I887, p. 467 (orig. desc.); Atkinson, Condor, vol. iii., I90 I, p. 9 (Santa Clara County; nesting habits); Strong, Am. Nat., vol. xxxv., I90I, p. 27 I, figs. (crit.); Tyler, Pac. Coast Avifauna, no. 9, 1913, p. 95 (San Joaquin Valley).

Remark.-Inasmuch as the characters which distinguish these two subspecies, excubitorides and gambeli, are so slight, and the area of their intergradation so broad and undefined, they are treated below as practically synonymous. There is no recognized difference in notes or habits, and in nesting only such as would be dictated by the more arid character of the range of excubitorides.

OPEN or half-open country is the basic requirement of this audacious and familiar little Butcher-bird. Bird-of-prey he is for all economic purposes, but he is no prowler, nor yet is he a hoverer, wearing out his wings with incessant flight. He is, rather, the fearless watcher, and he must have for his purpose some practical, elevated station where he may mount his marvelous field glasses; for his eyes are scarcely less in their keenness than in their length of focal range. Telephone poles suit him to a $\mathrm{T}$, and so devoted is the bird to this marshalled soldiery of civilization, that one wonders how he ever fared before the advent of telephone poles. It is on their account, doubtless, that the traveller gets such a strong impression of the Shrike's abundance; for telephone poles and roads are ever close friends.

Professor Beal has noted that the California Shrike dances close attendance upon the Kestrel, who is, likewise, fond of telephone poles, or wires; and Professor Beal thinks that although the lesser bird does not dare to disturb the Hawk, he is, nevertheless, jealous of his presence within the domain of his insect preserves, and means to keep close tab on his consumption of victuals. Be that as it may, their methods have nothing in common beyond use of the telephone service. From a 


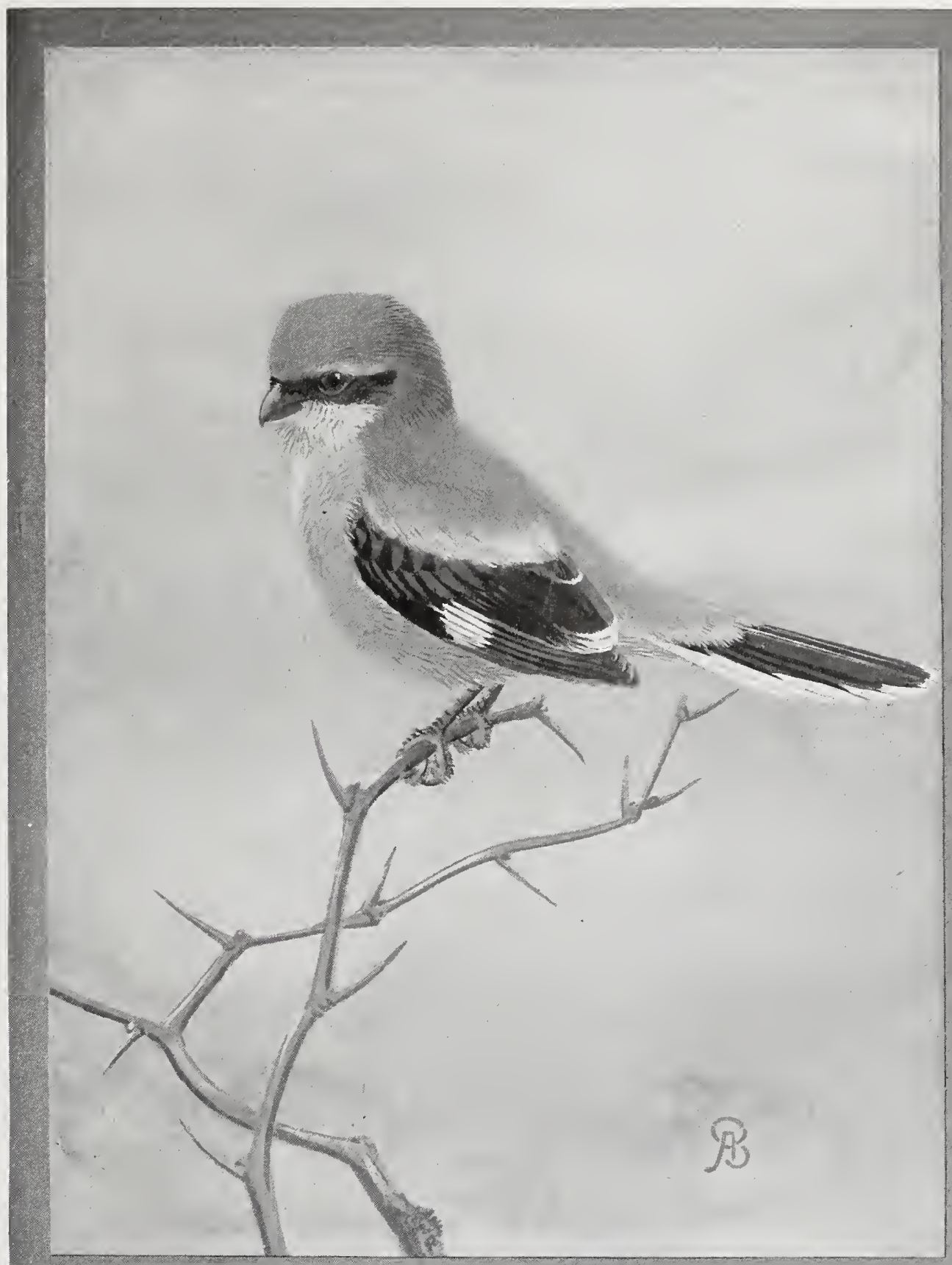

CALIFORNIA SHRIKE 


\section{The White-rumped Shrikes}

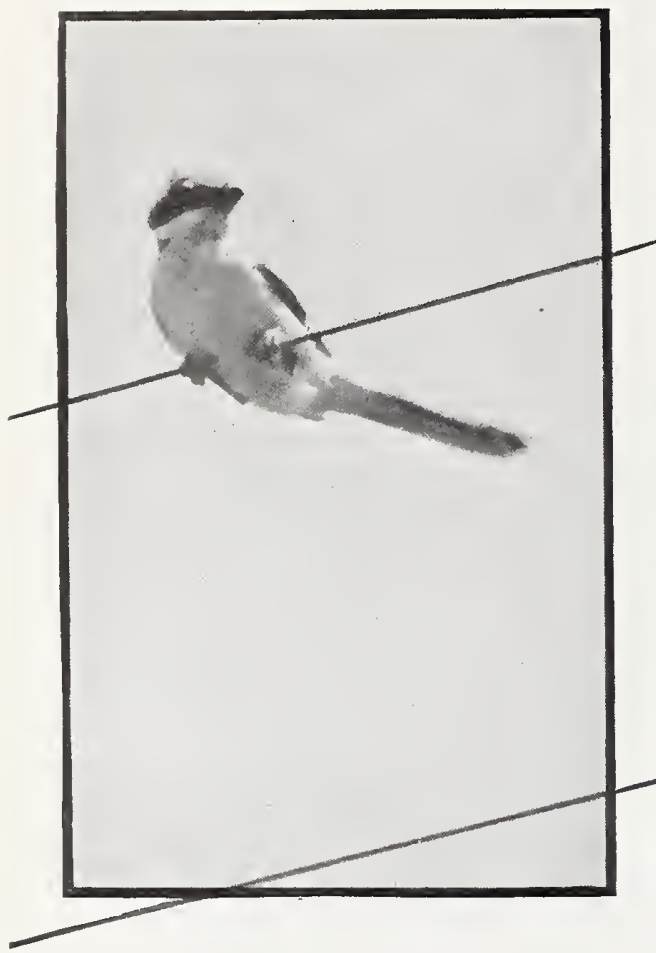

Taken in Merced County Photo by the Author AN ANXIOUS FATHER

commanding station, if it be no better than a weed-top, this Shrike searches the ground with his eye until he detects a suspicious movement of insect, mouse, or bird. The bird can spot a cricket at sixty feet, Tyler says, and I think that is well within the mark. Then he darts toward his quarry, settles, and strikes with his beak, or else skirmishes nimbly in mid-air if the creature seeks to elude him. From a successful foray the Shrike returns to devour at leisure; but if the victim is large or ungainly, he must have help from a sharp crotch, or a splinter, or the barb of a fencewire even, to hold it; for here again he is no hawk, and does not know how to clutch with his feet.

In flight, the Shrike moves either by successive plunges and noisy ascensions, or else pitches down from his perch and wings rapidly over the surface of the vegetation. He does not exhibit much local attachment, but rather roves restlessly from post to post, so as not to wear out his welcome with the crickets. All the Shrike's operations are direct and business-like; and if he pauses a moment to look over his shoulder as you whirl by in your automobile, you get an impression of a very alert bird-person,- no loafer, but a Twentieth Century brother in feathers.

The nervous energy which characterizes the California Shrike has got him into trouble with the ladies. He has to be doing something, so when his appetite is satisfied, he just goes right on killing-for the fun of it. He doesn't waste the game, exactly-at least he doesn't mean to-for having killed a mouse or a grasshopper, he hunts up a splinter or a thorn, and neatly impales his victim upon it. He might be hungry some time, you know. That the bird does occasionally return to feast upon this stored-up provender is pretty clearly known; but at the best his killings are far in excess of his needs.

Insects, according to Professor Beal, form more than eighty per cent of the bird's food. These include a few useful ground beetles; but the consumption of pests-moths, caterpillars, stink-bugs, crickets, and, above all, grasshoppers-is so enormous that we count him among the most useful of birds, and are even prepared to forgive him for occasional inroads upon the bird-world. 


\section{The White-rumped Shrikes}

There is less excuse for this lesser butcher to turn upon his fellows than for his greater kinsman from the North (L. borealis invictus), because insect food is plentiful in California the year around. Nevertheless, it is notable that most published instances of his defection have occurred in the winter months. Tyler has seen them capture House Finches and Goldfinches, but regards the Western Vesper Sparrow (Poxcetes gramineus confinis) as a more frequent victim than either. Mr. Charles H. Richardson saw a California Shrike overtake and kill a Goldencrowned Sparrow (Zonotrichia coronata), near Pasadena, and on examination of the victim he found that its neck had been cut and the vertebræ broken. ${ }^{2}$ The date was Feb. 6th; so that even in this mild climate some provocation of hunger may be urged in extenuation of this dreadful act. Mrs. Stephens thus summarizes her experience with these birds in San Diego:3 "For the last two or three years a pair of California shrikes (Lanius l. gambeli) have inhabited the eucalyptus trees growing in our yard. In the yard are also two large century plants. The thorns on these century plants are favorite shambles of the shrikes. Some of the food items observed sticking on the thorns are: Lizards of several species including 'horned toads' (Phrynosoma), scorpions, centipedes, Jerusalem crickets, beetles, young quail, adult and young horned

\footnotetext{
${ }^{1}$ Birds of the Fresno District, by John G. Tyler (1913), p. 96.

${ }^{2}$ Condor, Vol. X., p. 92. ${ }^{3}$ Mrs. Kate Sted
dor, Vol. 8, p. 130.
}

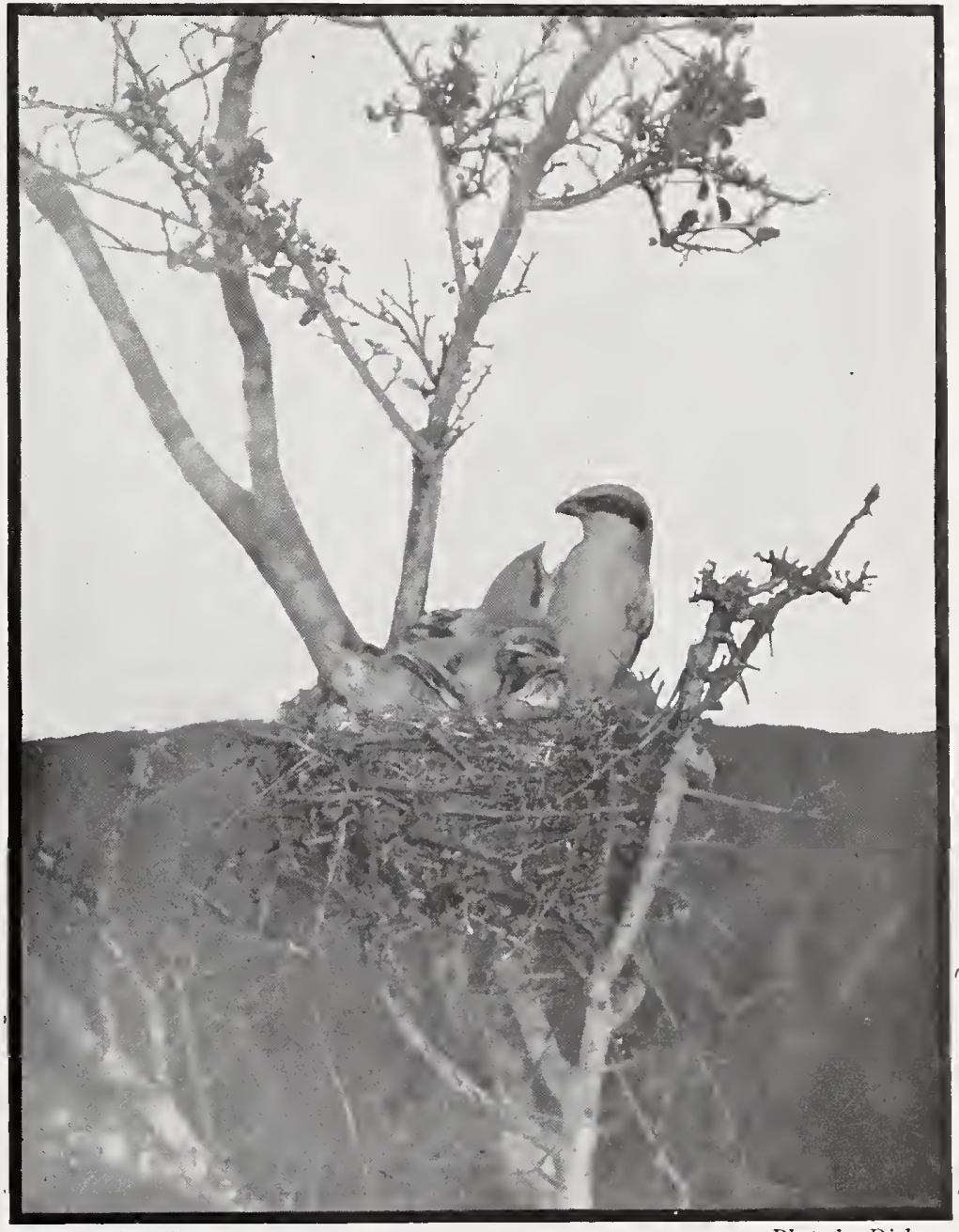

CALIFORNIA SHRIKE AND YOUNG
Photo by Dickey 


\section{The White-rumped Shrikes}

larks, a meadow mouse, and young pocket rats. The heads of the mice and rats were eaten first; but the heads of the horned toads were usually allowed to remain on the thorns. The shrikes do not appear to care for the lizards as they are usually allowed to remain and dry on the thorns. I have broods of young chickens running about the place, including one brood without a mother. None of these have been molested by the shrikes."

The Shrike possesses to

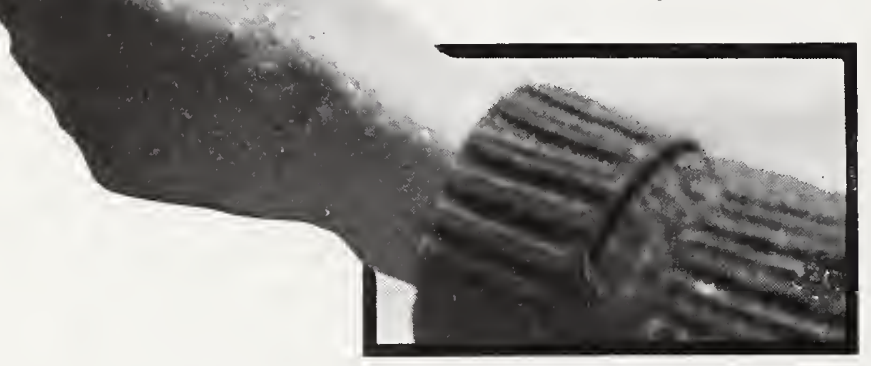

A CONFIDING CHILD perfection the power of disgorging indigestible portions of its quarry. Whether it be the elytra of beetles or the bones and hair of a mouse, after an hour or so of digestive attention, during which time the nutritive materials have all been

extracted, up comes a compacted pellet of waste- a cough and a sneeze and the trouble is over for that time. The Shrike has, therefore, no need to "Fletcherize," for he possesses an ironclad guarantee against dyspepsia. "Tummy aches" are presumably a thing unknown in the Shrike nursery, and babies have never to be warned against the unhappy consequences of greed. If a stink-bug or a Calosoma beetle proves recalcitrant before digestive amenities, he has only to unswallow the offending morsel, and the incident is closed without prejudice.

Every one has heard the harsh churning or buzzing notes of the Shrike, but few know him as a songster. Those who have not heard the White-rumped Shrike sing, have missed a treat. He begins with a series of rasping sounds, which are probably intended to produce the same receptive condition in his audience which Ole Bull secured by awkwardly breaking one string after another on his violin till only one was left. There, however, the resemblance ceases, for where the virtuoso could extract a melody of marvelous variety and sweetness from his single string, the bird produces the sole note of a struck anvil. This pours forth in successive three-syllabled phrases like the metallic and reiterative clink of a freely-falling hammer. The chief difference which appears between this love song and the ordinary call of warning or excitement is that in the latter case the less tender passions have weighted the clanging anvil with scrap iron and destroyed its resonance. Heard at close quarters, as when the observer is tampering with a nest, these scolding notes are exceedingly offensive, even terrifying; yet I 


\section{The White-rumped Shrikes}

have never heard in the interior such a supreme of venom as the Island Shrike (L. l. anthonyi) is able to inject into its exorcism.

The California Shrikes are prolific and attentive breeders. In a large portion of their range first broods are brought off in early April, and another toward the end of May. Middle March records for fresh eggs are common; and there is one, by H. J. Lelande, ${ }^{1}$ near Pasadena, for February I4.

The nests are placed at moderate heights in small trees or bushes, or even, in extreme cases, on the ground. A sage bush or a clump of

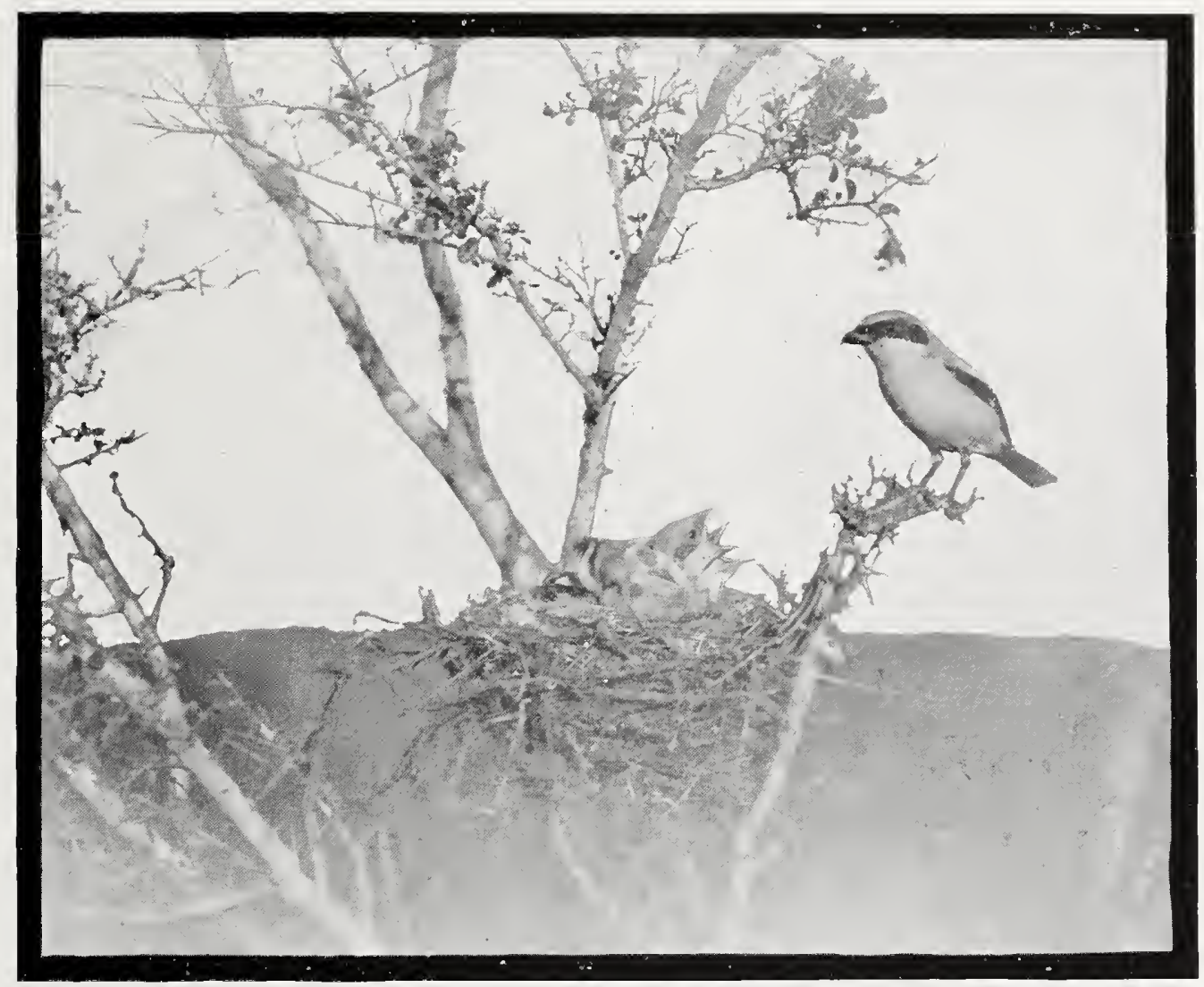

Taken in San Diego

ALERT

Photo by Dickey

greasewood is a very acceptable support in certain regions, while isolated clumps of willow or cottonwood, in regions otherwise treeless, are almost sure to harbor a pair of Shrikes.

The Shrike, being of a stock well intrenched in the North, is a builder of handsome and substantial nests. An example before me,

${ }^{1}$ Grinnell, Pub. 2, Pasadena Acad. Sci., I898, p. 43. 


\section{The White-rumped Shrikes}

taken from the heart of a clump of mistletoe in an oak tree near Shandon, has a generous foundation of criss-crossed twigs, chiefly oak. Within this is a matrix, or cup, of interwoven grasses and rootlets, compactly felted with fine vegetable substances of a dozen sorts,- - frayed stems, flower-heads, pappus, inner bark of weeds teased to a silky fineness, and a few, a very few, feathers. The inner walls are at no point less than an inch in thickness and, I scarcely doubt, would hold water. The cup is three inches across by two and a half inches deep, while the nest measures externally some four and a half inches by ten.

Another nest from the same section is made almost entirely of the macerated and frayed-out fibers of cottonwood bark, with a scanty lining of fine, black wool, obtained, apparently, from some old garment, or perhaps a felt hat. Its hollow is two and three-quarters inches deep by quite three and a half wide.

The eggs, from five to seven in number, are pale bluish gray, or dull grayish white, as to ground, with a generous and nearly uniform spotting of yellowish brown and cold gray-brown.

The parent birds are singularly indifferent, as a rule, to the welfare of a nest containing eggs alone. The female sits close, but once flushed, stands clinking in the distance, or else absents herself entirely. When the young are hatched, however, the old birds are sure to put up a spirited and deafening defense. The babies themselves are most engaging little fellows. Their confidence is easily won, and they are said to make excellent pets.

\section{No. 120c Island Shrike}

A. O. U. No.622c. Lanius ludovicianus anthonyi Mearns.

Description.-Similar to L. l. gambeli, but gray of upperparts much darker (deep neutral gray); rump light bluish gray (not white); white of scapulars duller, or else invaded by light bluish gray; the white patch at base of primaries much reduced; and white of tail less extensive; the underparts darker-definitely dingy brownish gray, but not exhibiting so strong a tendency toward vermiculation. Size about as in gambeli.

Nesting.-As in excubitorides. Av. of $36 \mathrm{eggs}$ in M. C. O. colls: $24.4 \times 18(.96 \times$ $.71)$. Season: April.

Range (Wholly contained within California).--Resident on the timbered members of the Santa Barbara Island group; hence, found on Santa Cruz, Santa Rosa, Santa Catalina, San Clemente, and even Anacapa; but not on San Miguel or San Nicolas.

Authorities.-Henshaw (Collurio ludovicianus var. excubitorides), Rep. Wheeler Surv., I876, App. Hs, p. 237, in text (Santa Cruz Id., crit.); Mearns, Auk, vol. xv., I898, p. 26I (orig. desc.; Santa Cruz Id.); Howell, Pac. Coast Avifauna. no. I2, I9I7, p. 88, part (Santa Cruz Id.; syn., habits, etc.). 


\section{The White-rumped Shrikes}

THIS slightly darker form appears to be well established on the Santa Barbara Islands, where it is supposed to be strictly resident. It was originally described from Santa Cruz Island; but its numbers there have possibly suffered from the limelight of "scientific" scrutiny ensuing. One party, in 1907, took off sixteen "skins"; whereas I did not see half that many birds in an eighteen-day visit in the spring of I9I5. For some unaccountable (?) reason, these Island Shrikes are universally characterized as "very shy." Dr. Mearns says:1 "In the daytime they never permitted us to come within range of them." Dr. Joseph Grinnell says² of one defiant fellow who persisted in singing in his neighborhood: "The rustle of the tent door or the click of a gun lock, however, was sufficient to send him up over the ridge, not to appear again for hours." And Mr. Rollo H. Beck, who, nevertheless, managed to secure a modicum of ten birds, testifies:3 "They were the wildest land birds I ever saw, by far."

Island Shrikes are early breeders. The first brood is brought off in March and a second by the first of May. It is my conviction that the matured birds, at least of Santa Cruz and Santa Rosa Islands, in order to escape the ensuing drought, repair to the mainland. At any rate, along the Santa Barbara coast, where L. l. gambeli is at best a rare breeder, there is a sudden accession, or irruption, of Shrikes in July. For the ensuing two months they are greatly in evidence, not so much for their numbers, which are moderate, as for their excessive and unique noisiness. An entry in the notebook, under date of August I I, I9I I, faithfully records first impressions: "A series of violent, explosive, and altogether offensive notes has been traced definitely to the local Shrikes. I have heard the rudiments of the same sounds before from eastern birds, but these local sounds are from three to seven times harsher. Your Santa Barbara Shrike [sic] is a very pirate, and he bursts out, with no apparent provocation at all, into a perfect torrent of abuse-excoriation is the word which most accurately describes it: Scrat, scrat, scrat, scrat, scrat, scrat, scrat, scrat, with somewhat diminishing intensity. The outburst lasts for several seconds, and consists of a nearly uniform series of harsh, rasping notes of an intensity and repulsiveness calculated to shatter the nerves of a cat. However, I am not even sure that this bird is displeased, for the malediction is uttered oftener in solitude than elsewhere, and is delivered from fence-post or telephone wire without any apparent regard to audience. It seems to mark rather an overflow of good spirits, such as we might expect from an otherwise unoccupied devil. This evening in going across country to a farmer neighbor's, I heard not one but half

\footnotetext{
1 Auk, Vol. XV., July, I898, p. 263.

2 Pub. I., Pasadena Acad. Sci., Aug., I 897, pp. I9, 20.

3 So quoted by Dr. Edgar Mearns, Auk, Vol. XV., p. 26 .
} 


\section{The White-rumped Shrikes}

a dozen of these birds in various places, having no apparent relation to each other, unless, indeed, they be offspring of one vicious pair."

Now this note, common at this season all along the Santa Barbara coast, I never heard elsewhere until we arrived at Santa Cruz Island in April, I9I5. Scrat, scrat, scrat, cried the first bird we met in Prisoners' Harbor, and he might have been the very bird we had listened to in August, as he shouted from a fence-post overlooking Neighbor Johnson's bean-field. And all the shrikes of Santa Cruz Island scratted us in the same tones.

I am thus explicit regarding the testimony on this point because certain friends who, at my instigation (people in glass houses always throw stones), have collected August Shrikes at Santa Barbara, report that they can detect no difference between them and the mainland form, L. l. gambeli. Perhaps the plumage characters assigned (with some show of justice) to $L$. l. anthonyi bleach out and become unrecognizable in late summer. Perhaps the ear-test is, on occasion, more trustworthy than the eye-test. Perhaps there are here differences worthy of recognition as between gambeli and anthonyi, but differences which inhere in psychology rather than in shades of pigment or length of toenails. A distinction in notes or song may be as valid (and I hold that it is) for purposes of subspecific discrimination, or "race". determination, as length of bill or breadth of wing-bars. Anyhow, we are very sure that there is a difference here; and we are pleased to find that Dr. Mearns bears us out, for he says, ${ }^{1}$ speaking of his experiences on Santa Cruz Island: "At night when we went out to shoot bats, Shrikes would dash about us uttering loud harsh screams, different from the voices of any Shrikes I have heard elsewhere."

A nest of the Island Shrike, found six feet up in an acacia tree at Prisoners' Harbor, was empty on the 4th of April (I9I5), but on the evening of the 8th it held one egg of a large, light-colored type. On the afternoon of the I I th, three days later, it held six eggs, which we took, together with the nest. This was throwing them in pretty fast, and reminded us of the "two eggs a day and three on Sunday" record of the model hen of childhood's tradition. However, two eggs of this set were strikingly large and light-colored, and three were of a small, dark type; while the sixth, which might have belonged to either, so far as its mediating appearance was concerned, probably should be credited to the "large, light" account. On the Igth, eight days later, we found a more hastily constructed nest in a pollard willow, near the site of the first, and undoubtedly the product of the same birds, though it was still empty. Two days later, at five p. m., this new discovery held three eggs, and on the following

${ }^{1}$ Auk, Vol. XV., July, I898, p. 263.

\section{0}




\section{The Plain Titmice}

morning (viz., April 22) at nine o'clock, it held five eggs. Close examination showed two types, two light and three dark, precisely those of the set previously taken. Casting about for explanation, we found three birds scolding us. This was a polygamous household, rare, indeed, among Passerine birds. Whether the evil doctrine of Joseph Smith has penetrated to this remote isle, or whether the Shrikes of Santa Cruz have

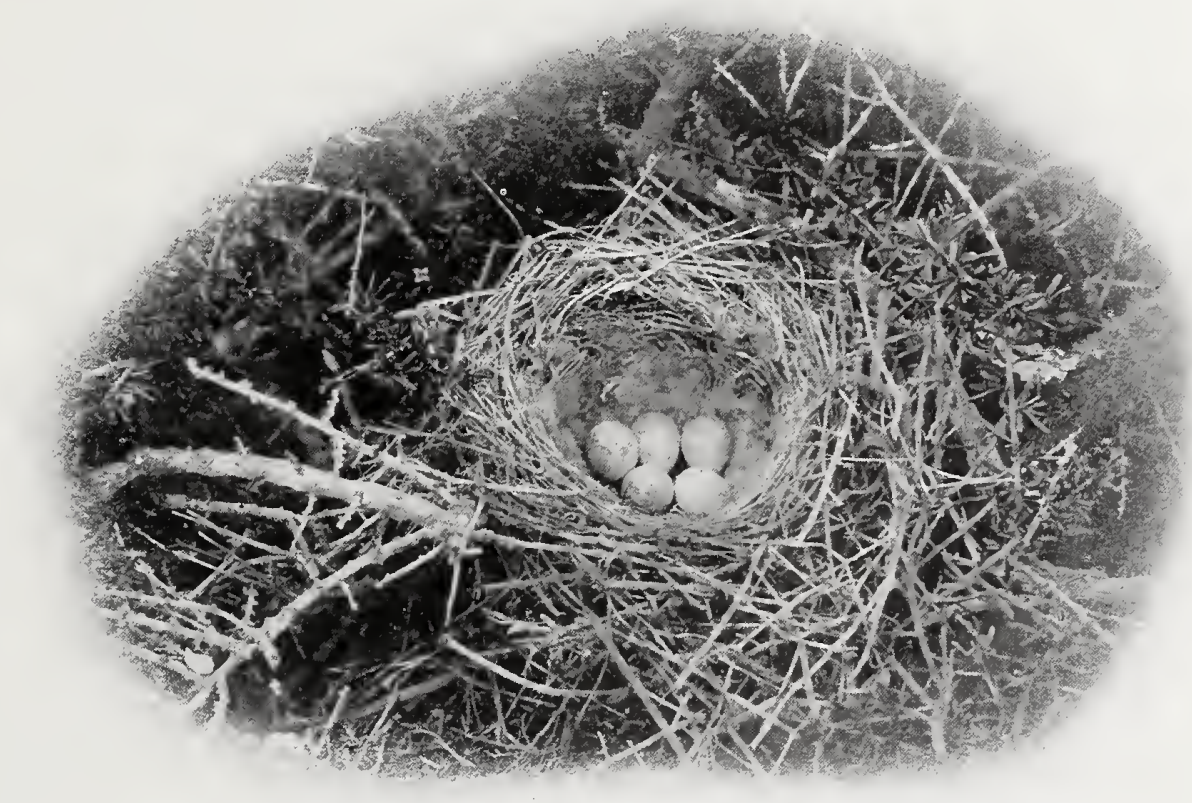

Taken on San Clemente Island

Photo by D. R. Dickey

NEST AND EGGS OF ISLAND SHRIKE

been reduced, through persecution, to the pitiable condition described in Scripture when seven women take hold on one man, we are unable to say. Unfortunately, the whistle of the departing steamer "Santa Cruz" cut investigation short, and we nearly broke the eggs in our mad scramble to get aboard. Why, yes; they belonged to us, the confiscated product of palpable malefactors.

No. 121

\section{Plain Titmouse}

A. O. U. No. 733, part. Bæolophus inornatus inornatus (Gambel).

Description.-Adults (sexes alike) and immature: Crested; upperparts plain hair-brown with olivaceous reflections on rump and on wing-edgings, shading on sides 


\section{The Plain Titmice}

into dull grayish white or pale brownish gray, the brownish element strengthening posteriorly. Bill grayish horn-color with paler tomia; feet and tarsi bluish gray. Young birds are buffier, especially posteriorly. Males average: length (skins) I27 (5.00); wing 68.7 (2.70); tail 57 (2.24); bill I I.3 (.44); tarsus 2 I.I (.83).

Recognition Marks.-Warbler size; "plain" gray coloration distinctive.

Nesting.-Nest: A deep cushion of rabbit-fur or other soft substances, placed in natural or "worked" cavity in tree or in adobe cliff; also variously in artificial nestingboxes. Eggs: 5 to 7 ; plain white or spotted sparingly or variously, sometimes wreathed with yellowish brown. Av. size $18.5 \times 12.95(.73 \times .51)$. Season: MarchJune; two broods.

Range of Baolophus inornatus.-Resident chiefly in the Upper Sonoran zone of the United States from the northern border of Lower California and Mexico north to Colorado, Utah, Nevada, and northern California.

Range of $B$. $i$. inornatus (Wholly within California).-Common resident, chiefly in the oak association of the Upper Sonoran zone west of the Sierra divide and north of the Tehachipe, north to Mendocino and Siskiyou counties.

Au ihorities.-Gambel (Parus inornatus), Proc. Acad. Nat. Sci. Phila., vol. ii., I 845, p. 265 (orig. desc.; Monterey); Adams, Osprey, vol. ii., I898, p. 81 (habits, eggs, etc.); Beal, U. S. Dept. Agric., Biol. Surv. Bull., no. 30, 1907, p. 68, pl. v., part (food).

\section{No. 121a San Diego Titmouse}

A. O. U. No. 733, part. Bæolophus inornatus murinus Ridgway.

Description.- Similar to $B$. $i$. inornatus, but said to be slightly larger; tone of upperparts a trifle lighter; the gray of underparts slightly darker. An intergrade between inornatus and griseus whose recognition in nomenclature is of doubtful wisdom.

Range of $B . i$. murinus (Almost wholly within California).- Resident in the San Diego district, from the northern border of Lower California north to Ventura and Santa Barbara counties, east to the desert divide.

Authorities.--Baird (Iophothanes inornatus), Rep. Pac. R. R. Surv., vol. ix., I858, p. 386, part (Ft. Tejon); Willett, Pac. Coast Avifauna, no. 7, I9I2, p. I04 (s. Calif.; occurrence, nesting dates).

\section{No. 121b Gray Titmouse}

A. O. U. No. 733a. Baolophus inornatus griseus (Ridgway).

Description.-Similar to $B$. i. inornatus, but decidedly grayer, less olivaceous above, nearer light grayish olive and smoke-gray; slightly longer.

Range of B. $i$.griseus.- That of the species, save for California, west of the Sierran and desert divides.

Range in California.- Sparingly resident in the Upper Sonoran zone of the desert ranges, east of the Sierras. Northern limit "the eastern slope of the Sierra Nevada ... at the head of Owens River" and Benton. Mono County (A. K.Fisher).

Authorities.-Fisher (Parus inornatus griseus), N. Am. Fauna, no. 7, 1893, p. I38 (Panamint Mts., etc.); Stephens, Condor, vol. v., I903, p. I05 (Providence Mts.); Coues, Birds Col. Val., I878, p. I I4, part (Ariz.; syn., desc., etc.). 


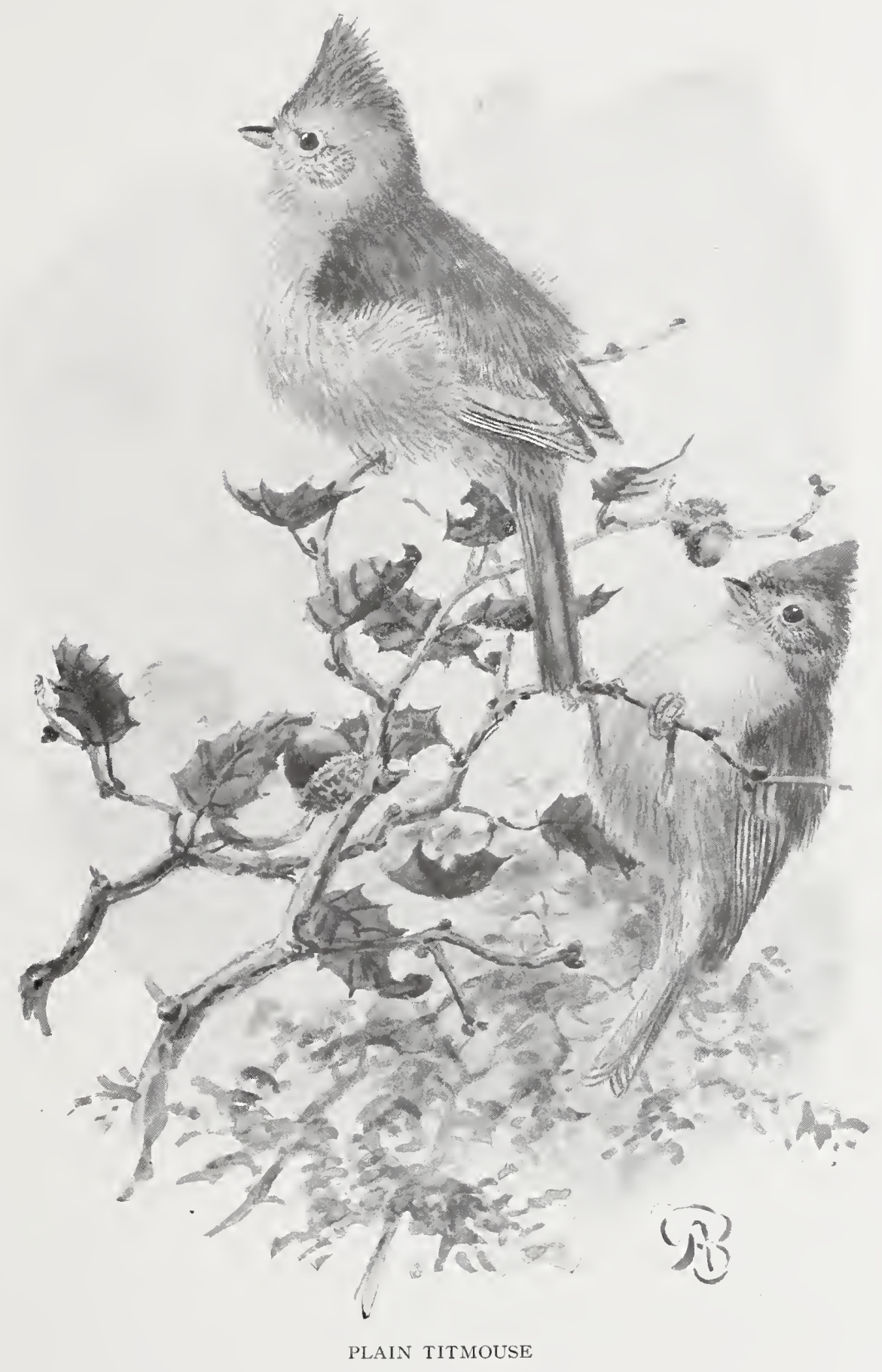

603 


\section{The Plain Titmice}

SSIC-RAP sssicrap comes from the depths of an oak tree on an April day, and unless one is used to this accusing expletive, he is apt to start up like a guilty cat, before he recovers his aplomb and decides to face his accuser. The bird is only trying your nerves, and if they stand the ordeal, he will utter a tsay tsay tsay of reassurance, and fall to hammering on the bark in a quite abstracted way. If the bird's mate is not sitting on the eggs, she is in close company with her lord, and you will hear scraps of conversation in sibilant squeaks and merry day days, which win the ear and delight the heart. 'The Plain Tit's repertory of song is highly varied, like that of the eastern Tufted Titmouse (B. bicolor). Many of the notes bear a close resemblance to those of the eastern birds, but the two most characteristic cries of bicolor, the cheéyv, cheévy, cheévy, and the clearer

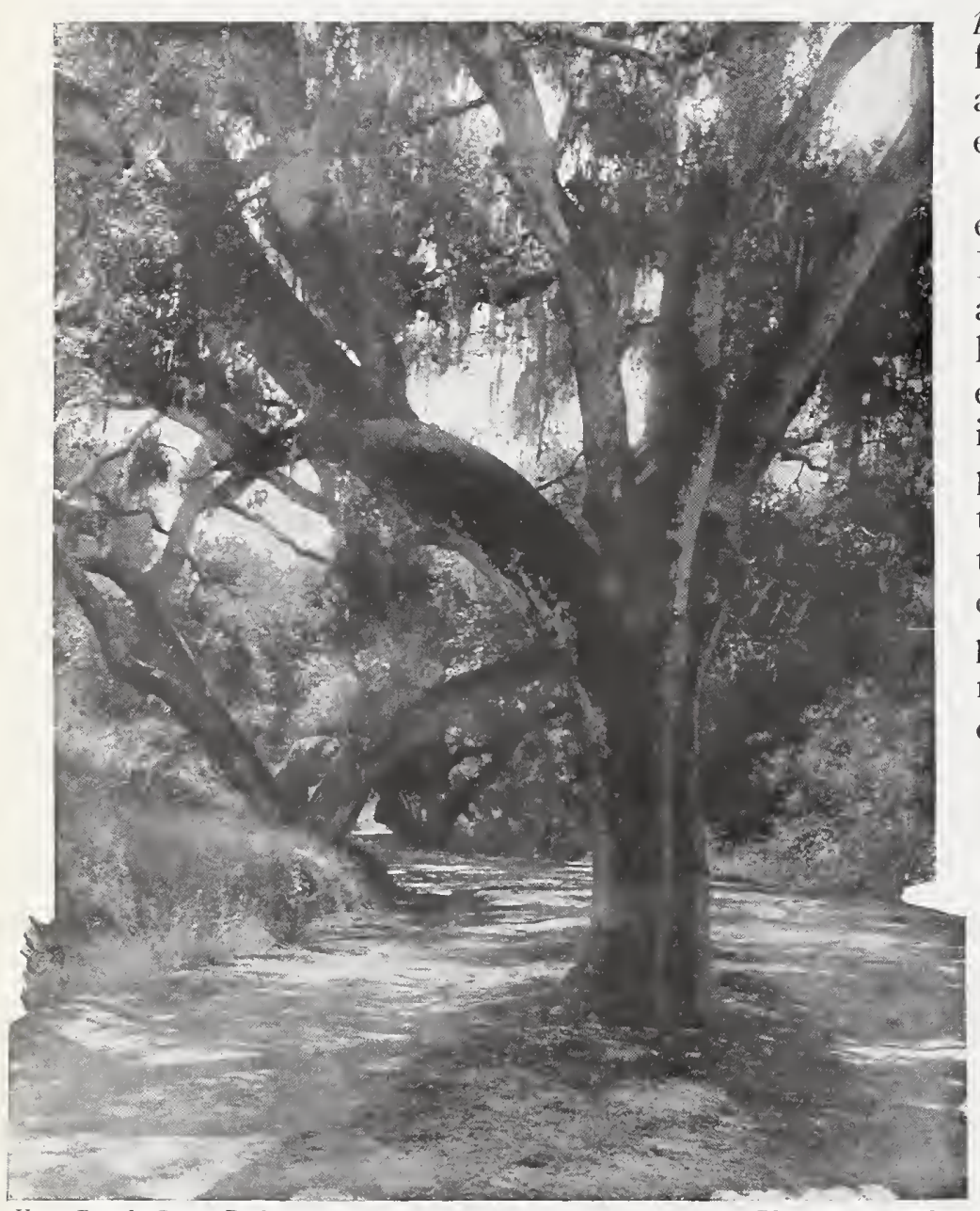

Hope Ranch, Santa Barbara
Photo by the Author

SUCH SHADES AS TITMICE LOVE péto, péto, péto, are rarely heard from inornatus; and the utterances of the latter are both less emphatic and less distinct.

It takes an experienced ear to recognize all of Master Plain's achievements; and after one has familiarized himself with generic lines of effort, there remain charming individual variations and surprises which assure a sustained interest on the part of the student. It's dollars to doughnuts that this very plain bird will give you momentary visions of rare exotics-Troupials and golden

Tanagers, and what notbefore you acquire the habit of attributing all strange noises to B. inornatus. What should I do, for instance, upon catching the golden crests of a mellow bassoon in the acacia tree across the road? Why, rush to the house for the binoculars and hard after, of course. At near approach

604 


\section{The Plain Titmice}

it sounded like di di di tipoong, di di di tipoong, the $d i$ notes very wooden and prosaic, the concluding member suddenly and richly musical. An escaped cage-bird from Brazil, at least! No; a "plain" Titmouse!

West of the Sierras the range of the Plain Titmouse is nearly coextensive with that of oak trees (with the exception of the tan-bark oak, which would take it in to the redwood country, where it is almost never found). From the oak trees as a base, the bird occasionally ventures up into the pines in the Sierran foothills-even nests there; and excursions in to the chaparral, of almost any distance, are matters of course. The eastern form of the species, B. inornatus griseus, scarcely different to appearance, even under scrutiny, inhabits the pinyons and junipers of the northeastern desert ranges. And this griseus, although it appears at suitable submountainous stations all the way to New Mexico, does not occur in the valley of the Colorado, even where it is well timbered. Wherever found, a crested Titmouse is lively and officious, a sort of major domo of the woods, before whom every invader must give account. $\mathrm{He}$ is, perhaps, at times a bit too inquisitive. Once when the author was offering a morning orison from a wayside camp near Los Olivos, thanking God, if I remember correctly, for the rare beauty of that country - a billowy sea of green embossed with jade oaks - a clear voice in the foliage overhead suddenly shouted péto péto péto. I do not know whether this was an inopportune demand for passports, or whether the little fellow was really meaning to join our worship. Whatever he wanted, the good Lord no doubt heard his petitions as well as ours.

Plain Titmice enjoy a mixed diet. Insects of many kinds reward the relentless scrutiny of twig and trunk; and because we find among them a sensible proportion of the black olive-scale, a notorious pest, we count Tom Tit among our most valuable horticultural allies. Vegetable food 


\section{The Plain Titmice}

forms a larger proportion of this bird's fare -57 per cent, Professor Beal says - than in that of any other Titmouse. Fruit is sampled in season, but eaten chiefly out of season, that is, in late autumn and winter, when other forage fails. Weed-seeds, leaf-galls, and poison oak seeds make up a quarter of the half, but the staple article of diet is the acorn. This is oftenest secured from the ground, but the bird takes it up into the tree and opens it with many a yeoman blow, holding it tight in a crack of the

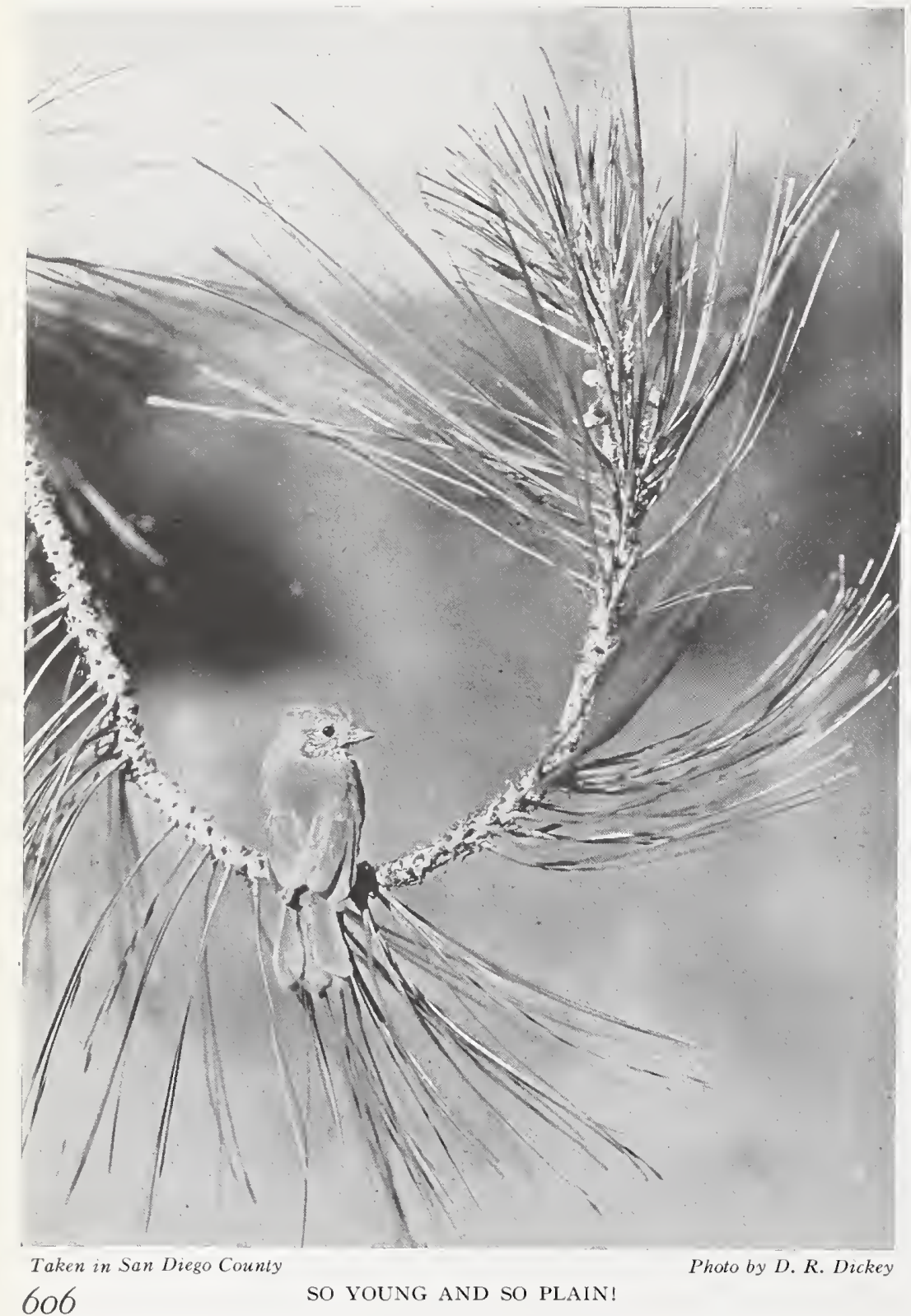
bark the while.

Early authorities asserted that the Plain Titmouse used only hollows already providedold woodpecker holes and the like-for its nest. This is quite a mistake, although it is true that the birds will gratefully a c c e p t a "start," whether from woodpecker, wind crevice, or incipient decay. Two of the nests I have found (and not rifled) were excavated in the heart wood of live limbs of the blue oak (Quercus douglasi), not less than ten inches in diameter. A five-inch wall of oak affords good protection even from humans; but resolute collectors report that pure white or fairly spotted eggs, to the number of five or six, are to be found within upon a luxurious cushion of fur.

I once traced a Plain Titmouse to a hole about twenty feet up in one of those cliffs of mingled gravel and "dobe" which line the 
banks of the San Jacinto River. We judged there were young-on May 23rd, I9I3-but the situation was so remarkable as to demand investigation. We found a neat, round aperture in the earth, which must have been barely large enough to admit the bird, being, in fact, so snug that it showed two separate "scores" for the feet. This opened rapidly into an ample chamber with extensive inner recesses, - a monument of toil. The nest proper, a great bed of rabbit-fur, was placed about one foot from the entrance, and it contained, or tried to contain, six full grown young. Because we had been obliged to enlarge the opening, I pushed all the little fellows back along the passage for safety's sake - all but one (there is always a smart Aleck in every brood), who insisted upon scrambling out over my arm and making a break for liberty. He got an awful tumble for his pains, but we rescued him, a sadder, etc.

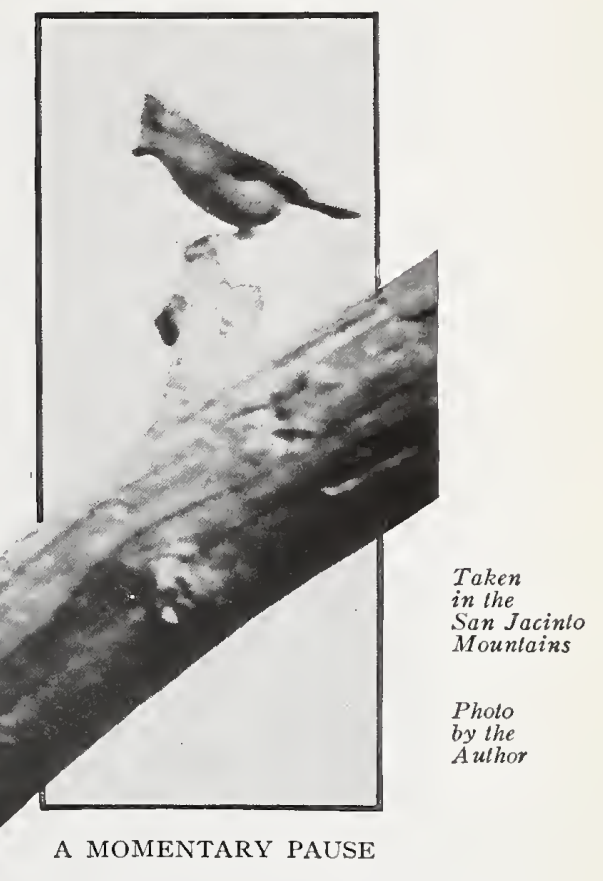

No. 122

\section{Oregon Chickadee}

\section{A. O. U. No. 735b. Penthestes atricapillus occidentalis (Baird).}

\section{Synonym.-Western Black-Capped Chickadee.}

Description.-Adult: Top of head (including eye) and nape shining black; throat and chest dead black with whitish skirting posteriorly; a white band on side of head and neck, increasing in width behind; "back varying from deep mouse-gray to very slight buffy slate-gray in spring and summer to deep hair-brown to light olive in fall and winter plumage"; wings and tail dusky, more or less edged, especially on outer webs of tertials, with ashy or whitish; breast and belly white, centrally; sides and flanks pale buffy in spring, strong brownish buff or pale wood-brown in fall plumage. Bill and feet blackish. Length I I 4.3-I $33.3(4.50-5.25)$; wing $62(2.44)$; tail $56(2.20)$; bill .95 (.37); tarsus I6.8 (.66).

Recognition Marks. - Warbler size; black of crown not broken by white, i. e., no white stripe over eye, as distinguished from $P$. gambeli; back gray as distinguished from P. rufescens.

Nesting.- Nest: a heavy mat of moss, grasses, and plant-down, lined with 


\section{The Oregon Chickadee}

rabbits' fur, wool, hair, or feathers, in made hole or natural cavity of stump or tree, usually not over ten feet from the ground, and near water. Eggs: 5-8, white, marked sparingly with reddish brown, in small spots, tending to gather about larger end. Av. size, I $4.7 \times$ I $1.9(.58 \times .47)$. Season: April I5-May I5; one brood.

Range of Penthestes atricapillus. - North America from limit of trees south to about the middle of the United States.

Range of $P$. a. occidentalis.-Transition zone of northwest coast district from British Columbia to extreme northern California.

Occurrence in California.-Breeds sparingly in Siskiyou County. One definite record, four specimens: Scott River, June Io and I3, I9I I, by Miss A. M. Alexander and Miss L. Kellogg.

Authorities.-Grinnell, Pac. Coast Arifauna, no. II, 19I5, p. I63 (near Callahan, Siskiyou Co., June); Belding, Condor, vol. vii., 1905, p. 82 (crit.; early records in Calif.).

THERE is only one record of the occurrence of this black-capped Chickadee of the North within our borders; but as that was a breeding record, we may suppose that the species is of regular occurrence in that ornithologically neglected region, western Siskiyou County. The Oregon Chickadee does not greatly differ in habit from our more familiar Chestnut-backed species; but it has a predilection for water, and its nests should be looked for in some low, swampy woods, or in deciduous timber lining some stream, rather than in the uplands and evergreens frequented by $P$.rufescens and $P$. gambeli. Any appreciation of the "Oregon" Chickadee drawn from Californian material would be so inadequate that I venture some conclusions drawn from northern studies, and only regret that we lack excuse for more extended consideration of a most engaging bird.

Chickadees are friendly little folk (and this remark applies, irrespective of species), so that wherever they go, except in the busy nesting season, they form the nucleus of a merry band, Western Golden-crowned Kinglets, Sitkan Kinglets, Creepers, Juncoes, Towhees maybe, and a Bewick Wren or two to guard the terrestrial passage, and to furnish sport for the federated fairies. The Chickadees are undisputed leaders, though their name be legion. While they remain aloft, we may mistake their dainty squeakings and minikin ways for those of Kinglets, but if we can only determine what direction the flock is pursuing, we may count on the vanguard's being composed of these sprightly, saucy little Black-caps.

Chickadee refuses to look down for long upon the world; or, indeed, to look at any one thing from any one direction for more than two consecutive twelfths of a second. "Any old side up without care," is the label he bears; and so with anything he meets, be it a pine-cone, an alder catkin, or a bug-bearing branchlet, top-side, bottomside, inside, outside, all is right side to the nimble Chickadee. Faith! their little brains must have 


\section{The Oregon Chickadee}

special guy-ropes and stays, else they would have been spilled long ago, the way their owners frisk about. Blindman's buff, hide-and-seek, and tag are merry games enough when played out on one plane, but when staged in three dimensions, with a labyrinth of interlacing branches for hazard, only the blithe bird whose praises we sing could possibly master their intricacies.

But Chickadee is as confiding and as confidence-inviting as he is capable. It is precisely because you babble all your secrets to him at the first breath that the whole wood-side comes to him for news. With the fatuity of utter trust he will interrogate the fiercest looking stranger; and the sound of the "sweetee" call is the signal for all birds to be alert. At the repetition of it the leaves begin to rustle, the moss to sigh, and the log-heaps to give up their hidden store of sleepy Wrens, bashful Sparrows, and frowning Towhees. Juncoes simper and Kinglets squeak over the strange discovery; the Steller Jay takes notice and sidles over to spy upon the performance; while the distant-faring Crow swerves from his course and bends an inquiring eye toward the mystery. Dee-dee-dee says the Black-cap. A hundred beady eyes are bent upon you, trying to resolve your domino of corduroy or khaki. Caw says the Crow in com-

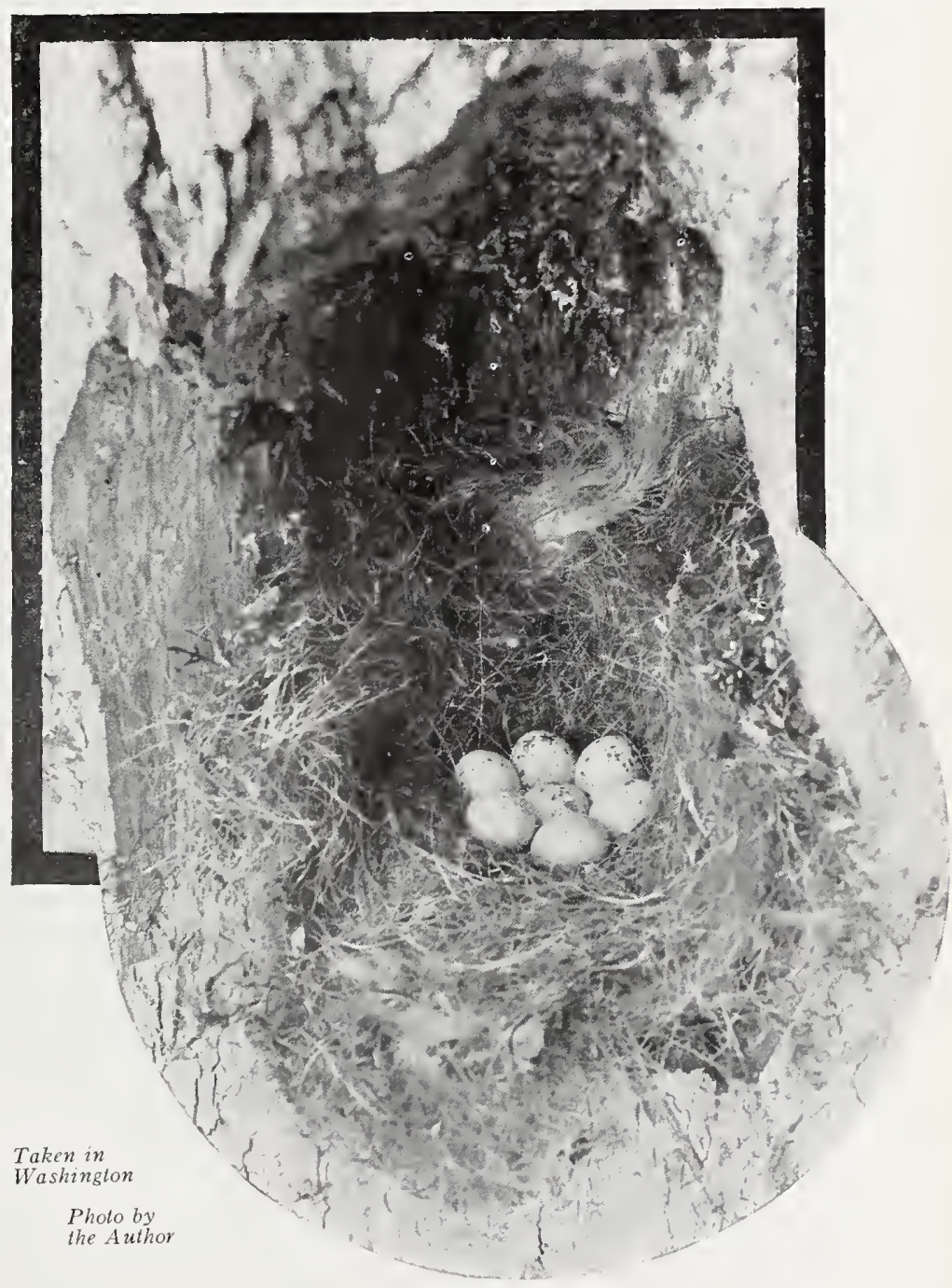

NEST AND EGGS OF OREGON CHICKADEE THE FRONT WALL OF THE CONTAINING STUMP HAS BEEN REMOVED 


\section{The Oregon Chickadee}

prehension, and you know that the game is up,- - up for all but the Chickadee. He will stay and talk with you as long as you may endure to pucker your lips to his fairy lispings.

It is no exaggeration to say that the "Swee-tee" note of the Chickadee, passably imitated, is the quickest summons in the bird-world. It is the open sesame to all woodland secrets. One drawback, however, attends its use: you cannot compass it when the air is chilly and the lips thick. Now the eastern bird ( $P$. atricapillus) has a clear, high-pitched call-note, Swee-tee, or Swee-tee tee as the type of this of the western bird are

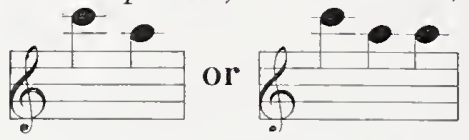
which must be taken genus and the calls best understood by reference to this norm. In the song of occidentalis the first note of the



Taken in Oregon LADEN WITH DAINTIES type, "high C," is oftenest repeated three or four times, and has a double character impossible to represent on paper; while the whole ends, or not, with the lower note of atricapillus. These notes may be called the deo deo deo day series. In rare instances they become a ravishing trill on high $\mathrm{C}$, beyond imitation or analysis. For the rest, Chickadee's notes divide themselves in to squeaks, vocal notes, and whistles of such a variety that Chickadee's friends have always a sufficient excuse to stop midway of prosy labors and listen to the latest news from fairyland. 


\section{The Mountain Chickadees}

No. 123

\section{Mountain Chickadee}

\section{No. 123a Short-tailed Chickadee}

A. O. U. No. 738 , part. Penthestes gambeli abbreviatus Grinnell.

Description.-Adults in spring and summer: Somewhat as in $P$. atricapillus occidentalis. Head and throat similar, but black interrupted by strong white superciliary stripe, nearly or quite meeting fellow on forehead; upperparts plain deep olivegray, or mouse-gray; wings and tail deeper gray, with some pale grayish edging; sides of head, below the black trans-ocular stripe, and neck, white; underparts (except throat) dull white, more or less washed on sides, flanks, and under tail-coverts with pale olive-gray. Adults in fall and winter: Upperparts washed with buffy (cartridge buff); brownish on sides; some white edging on forehead; and superciliary stripe broader. Young birds are duller as to black of head and neck, and have a less distinct superciliary. Length I 27 -I $39.7(5.00-5.50)$; wing $70(2.75)$; tail $60(2.35)$; bill $10.2(.40)$; tarsus I 8 (.70).

Recognition Marks. - Warbler size; much like Oregon Chickadee, but white superciliary distinctive; range higher (on the average) than that of other species.

Nesting. - Nest: A thick mass of rabbit-fur placed in cavity of tree whether natural or artificial, but chiefly in holes excavated by parent birds. Eggs: 5 to 8; usually plain white, but sometimes faintly or even sharply marked with reddish brown. Av. size, I6.5 X I I.9 (.65 x.47). Season: May-June, according to altitude; one brood.

Range of Penthestes gambeli.-Mountains of western North America from British Columbia (centrally) and east-central Montana south to northern Lower California and western Texas.

Range of $P . g$. abbreviatus.-The Sierra Nevada and northern coast ranges in California north into Oregon and, presumably, east into northern Nevada. Intergrades with baileya in the extreme southern Sierras, and with inyoensis in the Mono Lake region, and thence along the eastern flank of the Sierras.

Authorities.-Gambel (Parus montanus), Proc. Acad. Nat. Sci. Phila., vol. iii., I 847 , p. I 55 ("California"; subspecies uncertain); Belding, Bull, Nutt. Orn. Club, vol. iii., I878, p. I02 (breeding habits); Proc. U. S. Nat. Mus., vol. i., I879, p. 400 (Big Trees; desc. nest and eggs) Barlow, Condor, vol. iii., I90I, p. I 83 (Sierra Nevada; desc. nest and eggs); Grinnell, Univ. Calif. Pub. Zool., vol. xvii., I9I8, p. 510 (orig. desc.; Siskiyou Mts.).

\section{No. 123b Bailey's Chickadee}

A. O. U. No. 738a. Penthestes gambeli baileyæ Grinnell.

Synonym.-Mrs. Bailey's Mountain Chickadee.

Description.-Similar to $P$. g. abbreviatus, but darker, "smoke-gray" on sides and flanks, "mouse-gray" on back. Bill a little larger.

Range of $P$. g. baileya.-The mountain ranges of southern California northwest to the Santa Lucia Mountains in Monterey County, south, presumably, to northern Lower California; intergrading with $P . g$. abbreviatus in the southern Sierras.

Authorities.-Baird (Parus montanus), Rep. Pac. R. R. Surv., vol. ix., I858, p. 394, part (Ft. Tejon); Grinnell, Condor, vol. x., I908, p. 29 (orig. desc.; type 


\section{The Mountain Chickadees}

locality, Mt. Wilson, Los Angeles Co.); Univ. Calif. Pub. Zool., vol, v., I908, p. I24 (San Bernardino Mts.).

No. 123c Inyo Mountain Chickadee

A. O. U. No. 738, part. Penthestes gambeli inyoensis Grinnell.

Description.-Similiar to $P$. g. abbreviatus, but paler, in worn plumage more ashy; tail averaging a little longer.

Range of $P . g$. inyoensis.- "The higher mountains of eastern California lying east and southeast of Owens Valley, from the vicinity of Mono Craters and the White Mountains, in Mono County, south to the Panamint Mountains, in Inyo County" (Grinnell).

Authorities.-Fisher (Parus gambeli), N. Am. Fauna, no. 7 , I893, p. I39, part (Panamint Mts., etc.; desc. nest); Grinnell, Univ. Calif. Pub. Zool., vol. xvii., I9I8, p. 509 (orig. desc.; type locality, Jackass Spring, Panamint Mts.).

IT MAY BE only the partiality of a fellow mountaineer, but somehow I have fancied that we have in the Mountain Chickadee the sweetest and most winsome of his clan. That white line above the eyebrow adds a little distinction to the mountaineer, but we will not ground our hopes on so slight a claim. Is it, then, that in sweet confidingness it

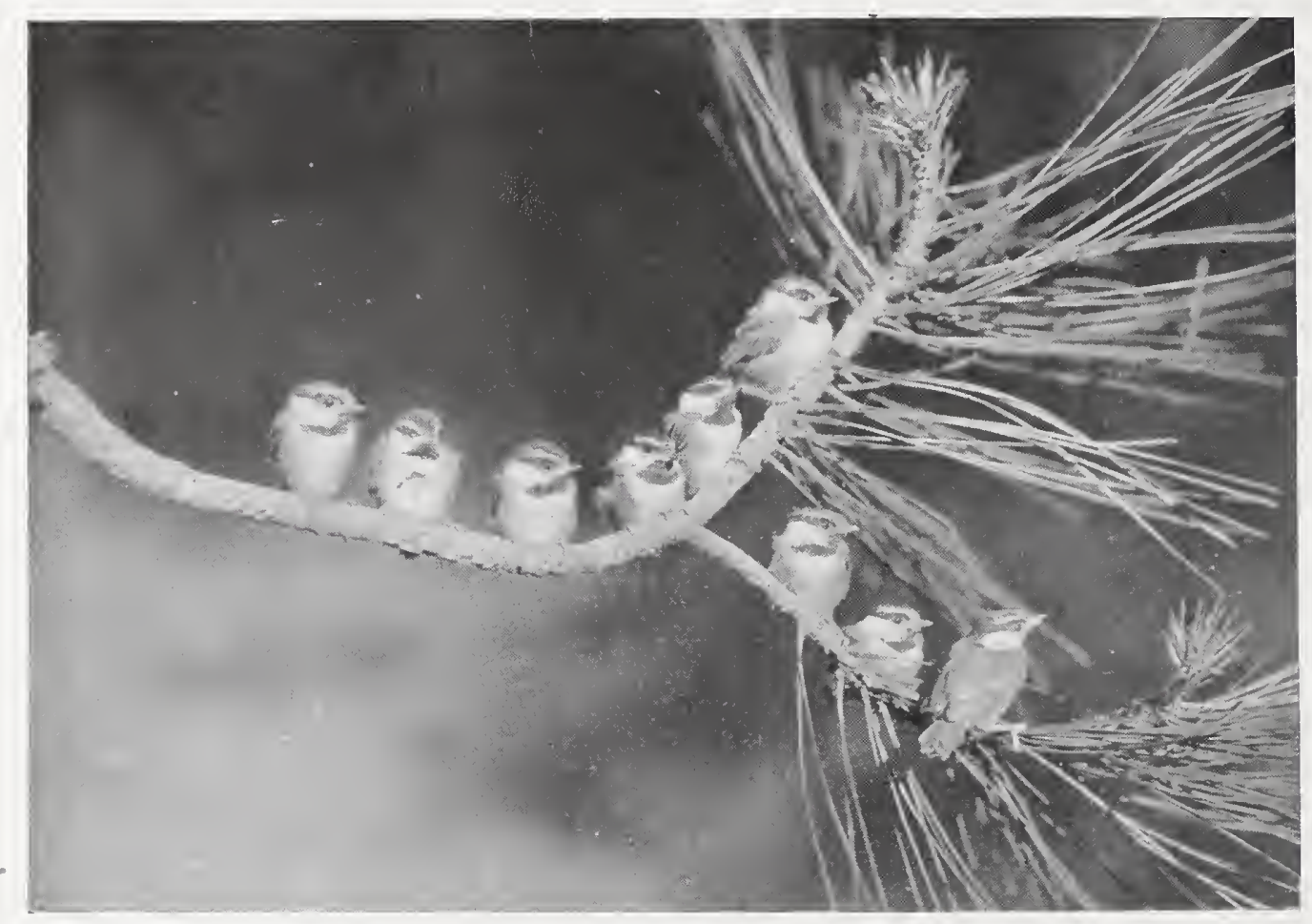

Taken in San Diego County

SWEET BABIES!

Photo by Dickey

612 


\section{The Mountain Chickadees}

outdoes its eastern cousin, Black-cap, justly renowned? or is it, rather, that it loves the high, thin air of the Sierras, and fears not the groans of dying glaciers, nor the outbursts of unseasonable atmospheric wrath? This, undoubtedly; for it takes the touch of adversity, well met, to bring out the admirable traits of bird character, as well as human.

For myself, I have fallen in love with these brave midgets a dozen times over, and I hold my heart ever ready to cast at the feet of the next beady-eyed charmer who hops into view on a pine bough and lisps her name, "Sweet Baby."

Mountain Chickadees fear isolation as little as they fear cold; and although they move about in family troupes in autumn, and do not despise the wintry fellowship of juncoes and kinglets, they are not dependent, like Chestnut-backs ( $P$. rufescens), on the near presence of their kin. With the world before them, they enjoy plenty of "searoom," and nest anywhere, from two to three thousand feet-in California; a thousand will do in Washington-to the limit of trees. It

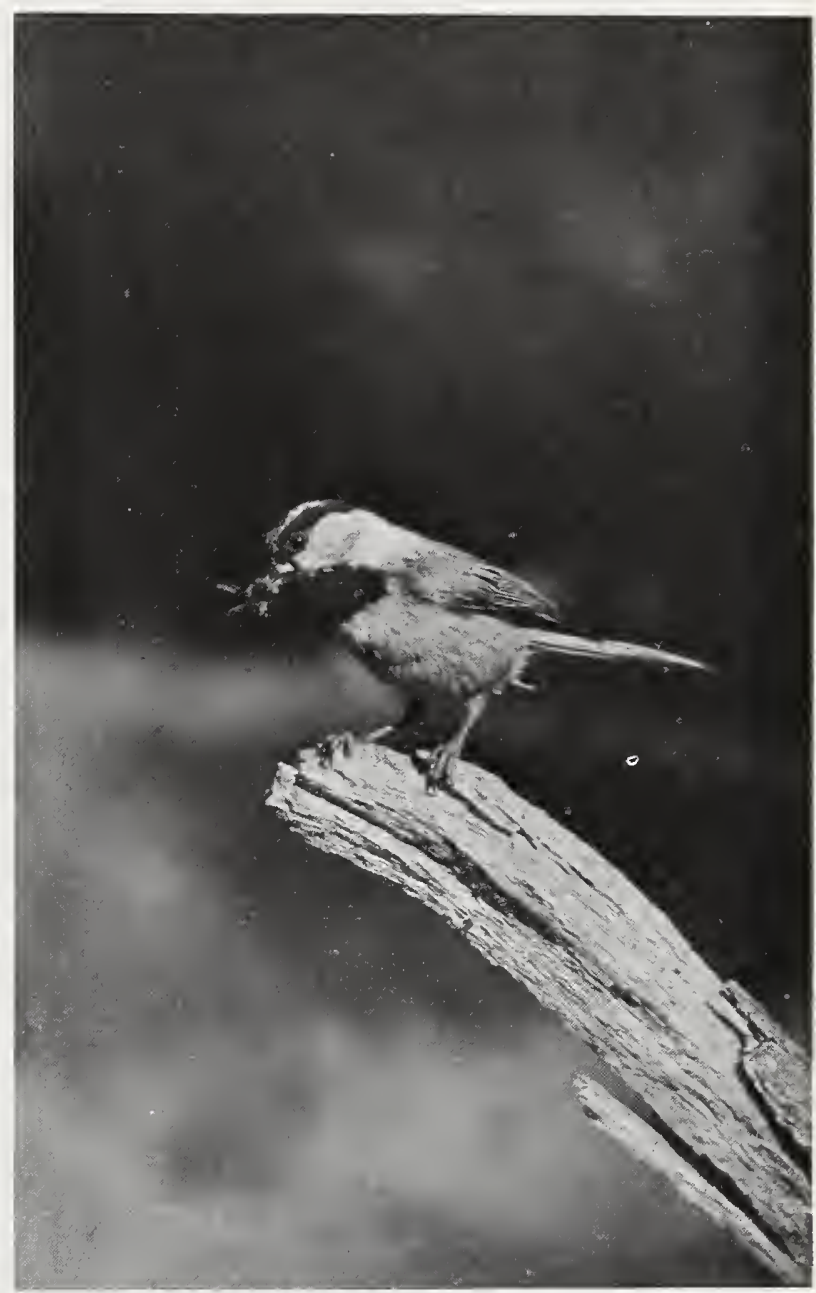

Taken in San Diego County

Photo by Dickey

A BEADY-EYED CHARMER

should be added, also, that they prefer open timber, especially pine, and varied cover; hence, they experience little temptation to invade the woodland fastnesses which are consecrate to Chestnut-backs.

Family life is the keynote to appreciation of the Penthestine character, and while the writer cannot profess always to have deserved the confidence reposed in him, memory adverts to half a dozen scenes of Penthestine home-life, and conscience is untroubled by reproaches which were more like fairy blessings.

The first occasion was the finding of a nest three feet up in a wild cherry stub. This contained fresh eggs on the I8th of May. Their color had been pure white, but they were much soiled through contact 


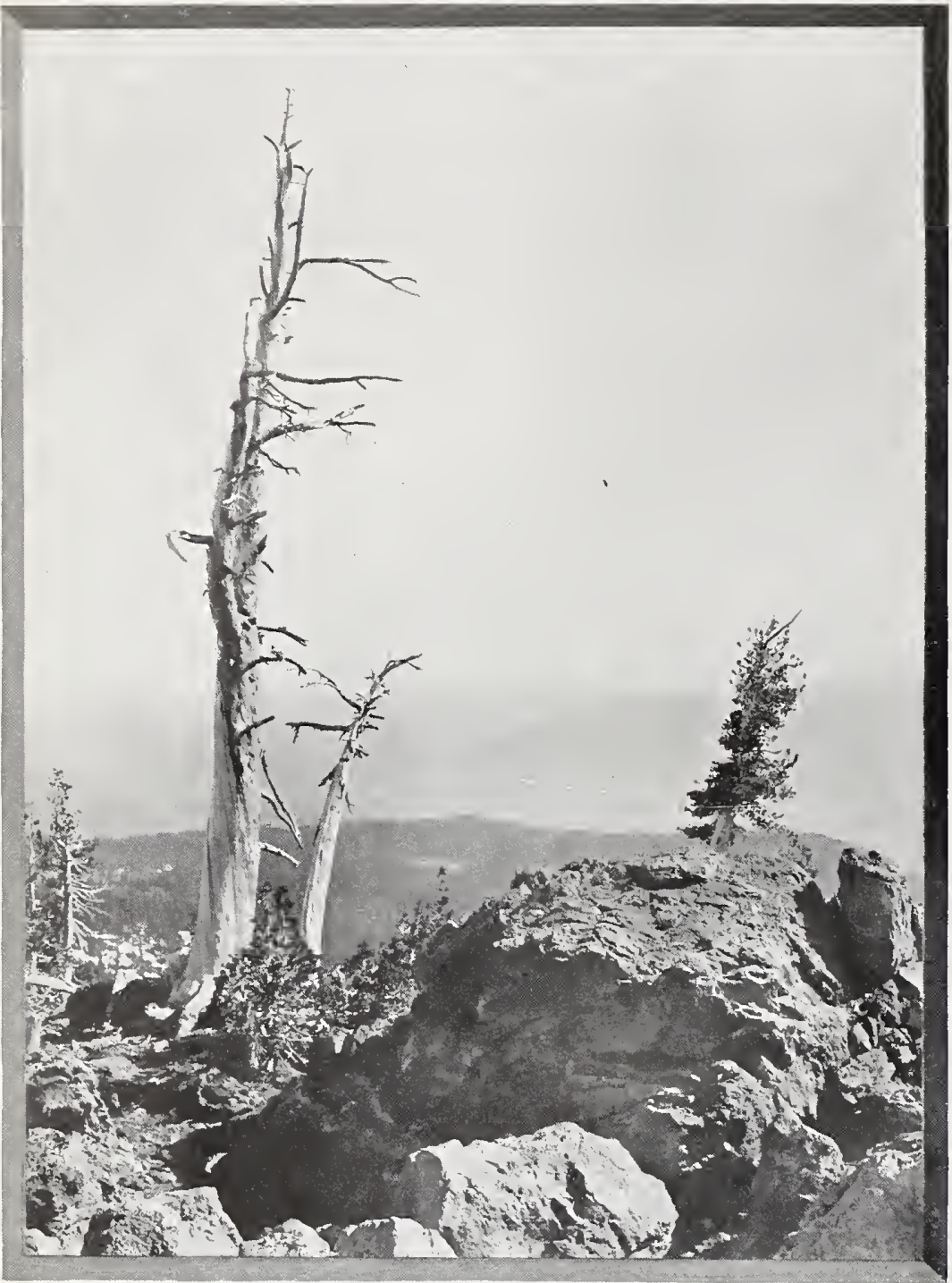

Taken on Mt. Shasta
Photo by the A uthor

FELLOW MOUNTAINEERS

with the miscellaneous stuff which made up the lining of the cavity: moss, cow-hair, rabbits' wool, wild ducks' down, hawks' casts, etc. The birds were not especially solicitous, although once the female flew almost into my face as I was preparing the eggs for the cabinet (alma mater's). And then she sat quietly for several minutes on a twig not above a foot from my eyes.

On the well-kept grounds of a northern magnate I came upon a nestful of these Chickadees, which the thoughtfulness, or possibly the inat $\mathrm{tent}$ ion of a gardener had spared. The nest was two feet up in a stump, concealed by a clump of secondgrowth maples, picturesquely nestled at the base of a volcanic knob. Upon first discovery the parent birds both appeared with bills full of larva, and scolded daintily. Finally, after several feints, one entered the nesting hole and fed, with our eyes not two feet removed. Photography was impossible because of the subdued light, but it was an unfailing source of interest to see the busy parents hurrying to and fro and bringing incredible quantities of provisions in the shape of moths' eggs, spiders, wood-boring grubs, and winged creatures of a hundred sorts. Let us hope the gardener knew what he was about in sheltering these unpaid assistants. Why, when it 


\section{The Mountain Chickadees}

comes to horticulture, three pairs of Chickadees are equal to one Scotchman any day.

The young were fully fledged, and the irrepressible of the flock (there is always an irrepressible) spent a good deal of time at the entrance shifting upon his toes, and wishing he dared venture out. The old birds fed incessantly, usually alighting upon the bark at one side of the

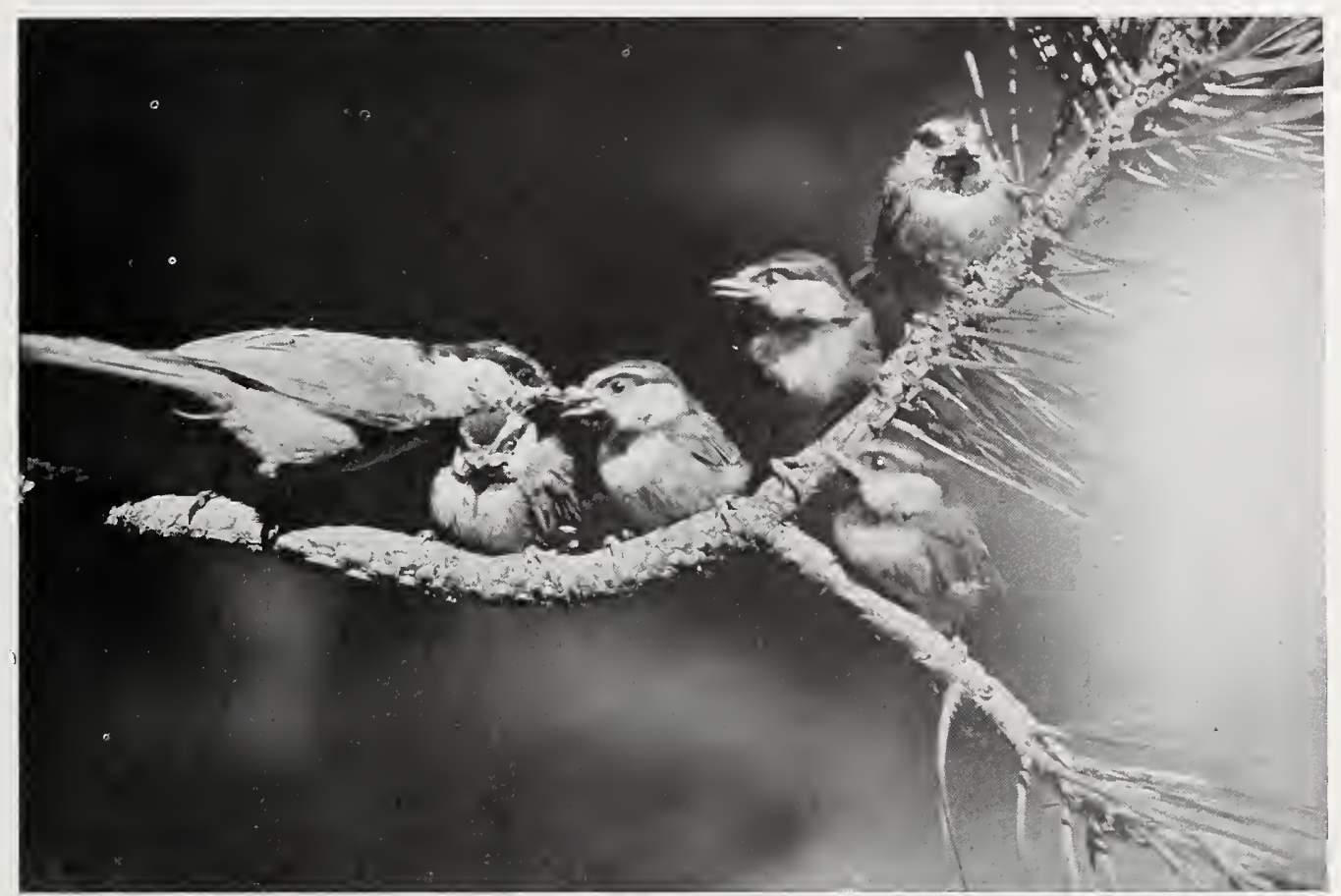

Taken in San Diego County

EXACT JUSTICE

Photo by Dickey

A MOTHER BIRD ALWAYS APPEARS TO KNOW EXACTLY WHOSE TURN IT IS

hole and debating for a moment before plunging into the wooden cavern, whence issued a chorus of childish entreaties.

The next morning our Chickadees had all flown, and upon breaking into the abandoned home we found a nest chamber some six inches in diameter, with its original warm lining mingled with fallen. punk and trodden into an indistinguishable mass by the restless feet of the chick Chickadees. A special feature of the interior construction was a knot, which had persisted as a hard core when the surrounding punk had been removed. This had evidently been no end of amusement to the young birds and of service to the parents as well, for its surface was polished by the friction of many Penthestine toes.

The pair figured next (indifferently well) had a home in the upturned 


\section{The Mountain Chickadees}

root of a pine tree overlooking the Cottonwood Lakes in Inyo County, at an elevation of over $\mathrm{I}, \mathrm{I}, \mathrm{OOO}$ feet. The first stage of photographic preparation involved sawing off the end of the root where the Mountain Chickadees held forth, so as almost to expose the babies. The old birds were considerably disconcerted at first, and they were especially afraid to trust the heavy felted material, chiefly marmot fur, of their own providing, which lapped over the edge of the sawed-off stump. They seemed to fear being smothered in its abundance, for as often as they lighted in it, they sprang out in great alarm. After many efforts I had the good fortune to catch both parents at the nest for three consecutive exposures, though the roar of the shutter never failed to frighten them. The last exposure was made while both were standing crowded in the cavity, and they jumped as if shot. This circumstance of their being caught together in a narrow place seemed to impress them, for when a few moments later they found themselves in the same position, they bethought them of their recent experience and jumped so suddenly (although the camera did not go off at that time) that they looked like fragments of an exploding bomb.

After these experiences it was a relief to find, in the Warner Mountains, a nest with four white eggs, from which the

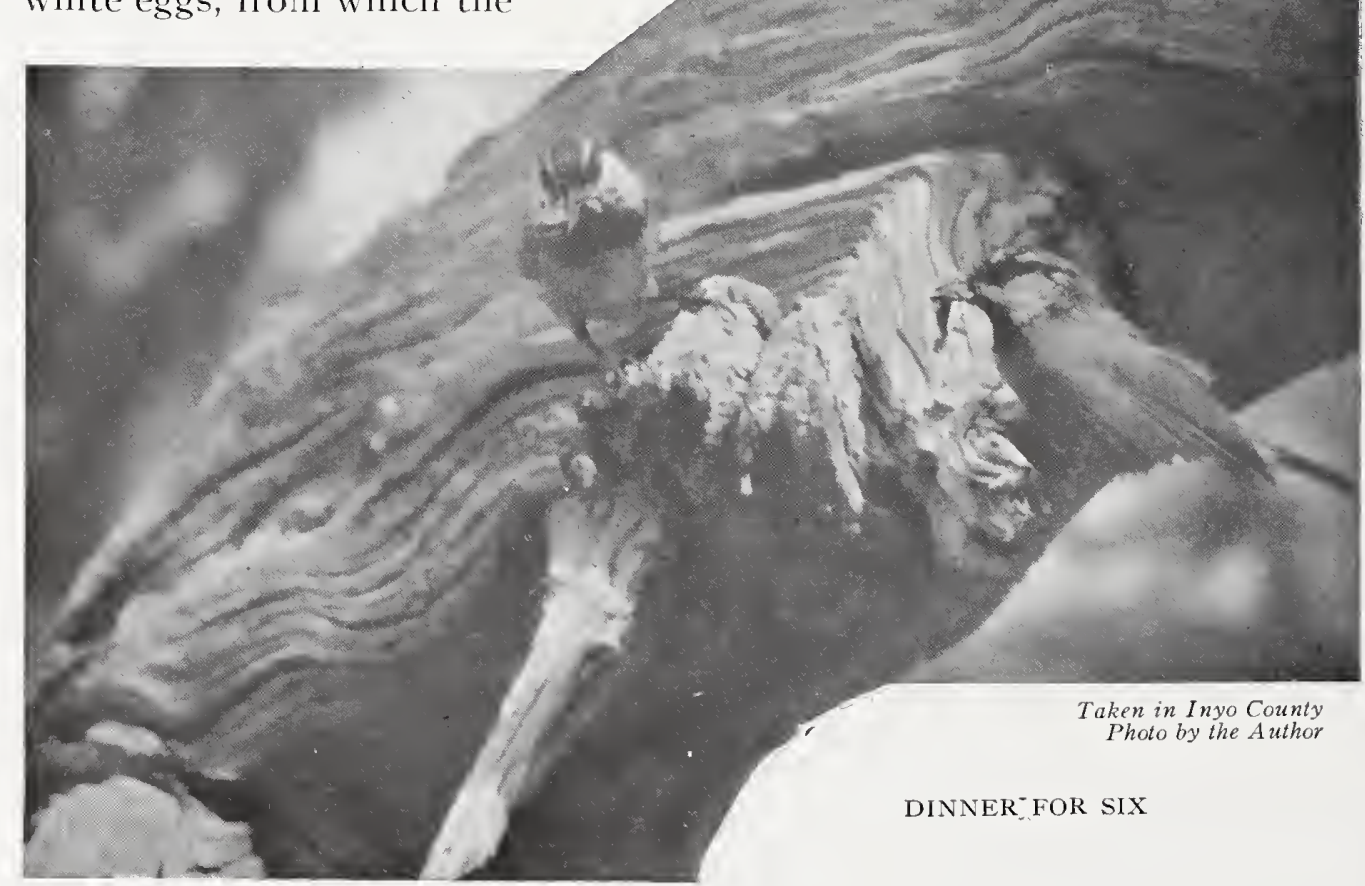




\section{The Mountain Chickadees}

owner was absent. She with her mate had "gone a-hunting," and true to the old nursery rhyme, she had left the Baby Buntings (in ovo) wrapped in a piece of rabbit skin. The nest, which was a great mass of rabbit fur, occupied an old cavity made by a Batchelder Woodpecker in a pine stub, at a height of four feet from the ground. The set was, of course, incomplete, so pending its completion, the eggs had been left by the mistress soundly covered up under a blanket of rabbit fur at least an inch in thickness.

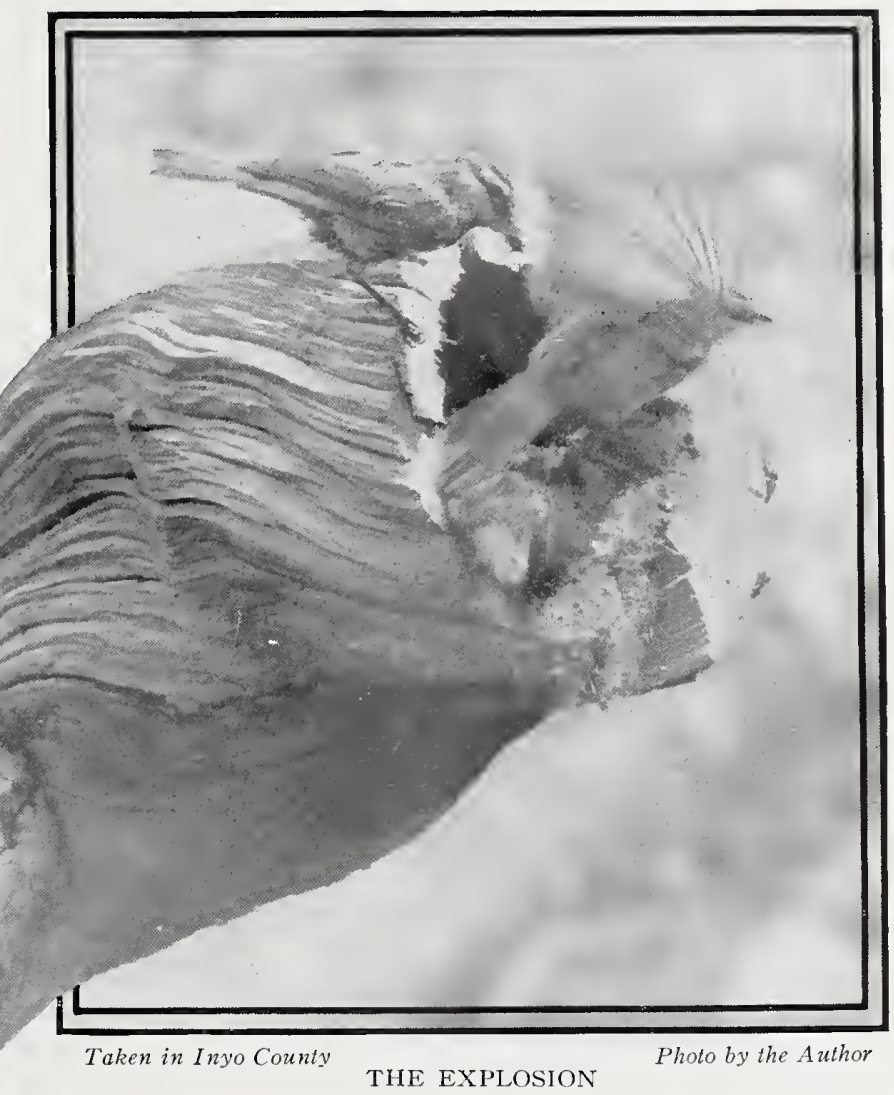

The notes of the Mountain Chickadee closely resemble those of the more familiar Black-cap ( $P$. atricapillus), and our knowledge of such distinction as undoubtedly does exist, is still incomplete. The Swee-tee call may be either of two notes (see under Oregon Chickadee) or three, Swee-tee-tee, or both notes may be doubled. Dr. Grinnell says explicitly of the Mountain Chickadees which he heard in the San Bernardino Mountains, that their "clearly whistled song" was of four notes, the first two pitched higher than the others. Now the song phrase of the birds heard, not once nor a hundred times only, in the San Jacinto Mountains, in the season of 1913 , was of quite a different order: hoo hee hee, or The tones were really ravishing sweet, of a quality which put them on a par with the product of the most gifted of mountain songsters. Half a dozen times during a stay 


\section{The Chestnut-backed Chickadees}

of a fortnight I started to my feet thinking I heard the song of the Sierra Hermit Thrush-only to find that it was a nearer Chickadee who had stolen his voice and accent. This type of song was constant, so far as observation went, and may possibly serve to distinguish a separate race of Mountain Chickadee in the San Jacintos.

No. 124

\section{Chestnut-backed Chickadee}

A. O. U. No. 74I. Penthestes rufescens rufescens (J. K. Townsend).

Synonym.-Chestnut-sided Chickadee.

Description.-Adults: Crown and nape dull sepia brown, becoming sooty toward lateral border-black before and behind eye, separated from sooty black throat-patch by large white area, broadening posteriorly on sides of neck; back, scapulars, rump, and sides of body bright chestnut (nearer auburn); lesser wing-coverts grayish brown; upper tail-coverts hair-brown or more or less tinged with chestnut; wings and tail deeper grayish brown, edged with paler gray; remaining upperparts (centrally) white; under tail-coverts washed with brownish. Bill black; feet brownish dusky; iris brown. The brown of crown and hind-neck deepens in winter. Young birds are duller in coloration, especially as to the chestnut of back and sides. Length about I20.6 (4.75); wing 60 (2.35); tail 48.3 (I.90); bill 9.5 (.37); tarsus I6.5 (.65).

Recognition Marks.-Pygmy size; chestnut of back and sides distinctiveotherwise not easily distinguished in the treetops from $P$. a. occidentalis. Frequents thicker timber, and usually drier situations.

Nesting.- Nest: In hole in dead stub, usually some natural cavity enlarged, and customarily at moderate heights, I0-20 feet; a couch of fine bark-shreds, green moss, etc.; heavily felted with squirrel-, rabbit-, or cow-hair, and other soft substances. Eggs: In California 5 or 6;9 of record in the North; pure white as to ground, and sparingly sprinkled with reddish brown dots (sayal brown to snuff-brown), chiefly about larger end. Av. of 47 eggs from Eureka, I5.2x II.7 (.60x.46). Season: April 25 -June I5 (according to altitude); one brood.

Range of Penthestes rufescens.-Pacific Coast district of North America from Prince William Sound, Alaska, south to Monterey County, California.

Range of P. r. rufescens.--The Pacific Coast district from southeastern Alaska, south to Sonoma County, California; east (centrally) to western Montana.

Distribution in California.-Common resident in Canadian and Transition zones of the northwest humid coastal region, east regularly to the Siskiyou Mountains, casually to west base of Mt. Shasta, south on coast to Freestone, in Sonoma County, and interiorly to Mount Saint Helena.

Authorities.-Audubon (Parus rufescens), Birds of America, vol. ii., I84I, p. I58 (Upper California); Fisher, Condor, vol. iv., I902, p. I35 (redwood belt of Humboldt and Del Norte counties); Grinnell, Auk, vol. xxi., 1904, p. 364, 3 maps (origin, distr., etc.); Beal, U. S. Dept. Agric., Biol. Surv. Bull. no. 30, 1907, p. 70 (food); Bowles, Condor, vol. xi., I909, p. 55 (nesting habits, etc.; in Washington). 


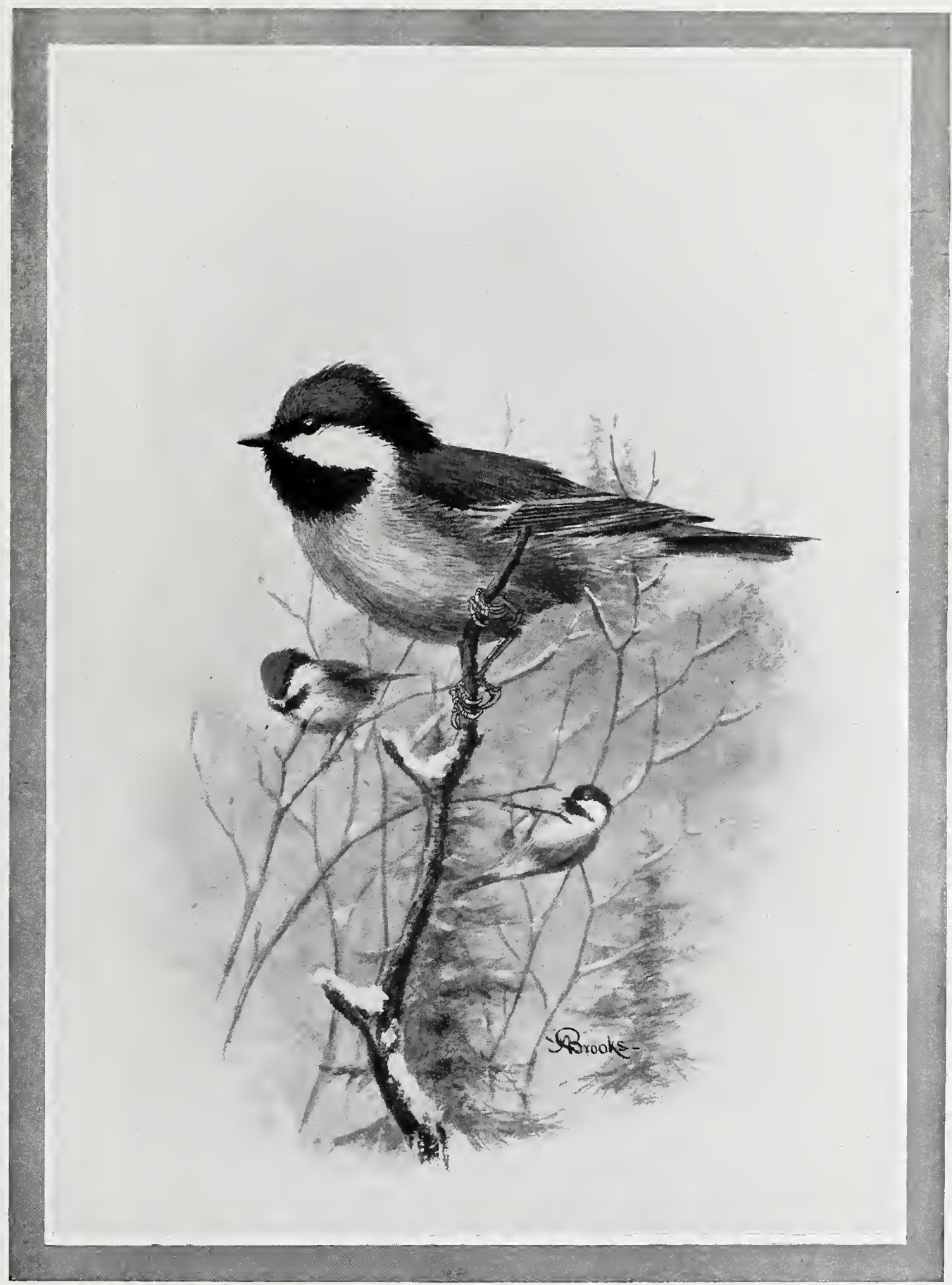

CHESTNUT-BACKED CHICKADEE 


\section{The Chestnut-backed Chickadees}

No. 124a Marin Chickadee

A. O. U. No. 74Ia. Penthestes rufescens neglectus (Ridgway).

Synonym.-California Chickadee.

Description.--Like P. r. rufescens, but chestnut duller and paler, that of sides and flanks much reduced in area, and admixed with dull mouse-gray.

Range of $P . r$.neglectus (Wholly included in California).- "Common resident of humid Transition in Marin County, from Nicasio west to Point Reyes" (Grinnell).

Authorities.-Brewster (Parus rufescens), Bull. Nutt. Orn. Club, vol. iii., I878, p. 20 (Nicasio; desc. young); Ridgway (Parus rufescens neglectus), Proc. U. S. Nat. Mus., vol. i., I 879 , p. 486 (orig. desc.; type locality Nicasio, Marin Co.); J. Mailliard, Condor, vol. x., I908, p. I8 I (distr. of P.r. rufescens and P. r. neglectus).

\section{No. 124b Santa Cruz Chickadee}

A. O. U. No. 74I b. Penthestes rufescens barlowi (Grinnell).

Synonym.-Barlow's ChickadeE.

Description.-Like $P$. r. neglectus, but chestnut of sides and flanks entirely wanting, or, if present, only as rusty or pinkish tinge over light mouse-gray.

Range of $P$. $r$. barlowi (Wholly included within California).- "Common resident of Transition in the coast district south of Golden Gate and San Francisco Bay, from Presidio to Little Sur River, Monterey County" (Grinnell). Ranges a little way into interior in autumn and occurs, thus, as far north as Berkeley.

Authorities.-Nuttall (Parus rufescens), Man. Orn. U. S. and Can., vol. i., I 840, p. 268, part (Upper California); Grinnell, Condor, vol. ii., I900, p. I27 (orig. desc.; Stevens Creek Canon, Santa Clara Co.); ibid., Pac. Coast Avifauna, no. I I, I 9 I 5 , p. I64 (dist.); Ray, Condor, vol. xviii., I9ı6, p. 226 (desc. nests and eggs).

THE PLEASANT traditions which have grown up about the name Chickadee in the East, applying as they do to Penthestes atricapillus and its scarcely different kinsman, $P$. carolinensis, have operated to discourage independent study of this roughly related but wholly distinct species, P. rufescens. The public curiosity being already measurably satisfied as to Chickadees, we have been allowed to suppose that the Chestnut-backed Chickadee was about the same sort of a bird, while careless writers have described $P$. rufescens in terms boldly borrowed from $P$. atricapillus. There is, however, a more creditable excuse for our continued ignorance. The associational range of the Chestnut-back is the heavy conifer forest of the West, notably, in California, the Redwood belt; and the bird's days are largely passed in wooded depths beyond the reach of common observation. The birds pay less attention to the human presence than do the eastern Black-caps, because they have felt no such need of a wintry dole of suet or chopped nuts to tide them over hard weather; nor has our presence been forced upon them through destruction of their forest fastnesses. It is possibly true, also, that the somber forests of the humid belt have had a restraining effect upon the spirits of our coastal Chickadee, so that he is neither quite so lively nor so noisy as his giddy eastern 


\section{The Chestnut-backed Chickadees}

cousin. But having said so much, we have perhaps said too much in apology of Penthestes rufescens, for he is one of our darlings, one of the daintiest and most alluring of the dwellers in the redwoods.

What busy little midgets these are as they go trooping through the treetops intent on plunder! The forest spaces are vast, so they muster a whole regiment for service, in order that they may always have some of their own kind within hail. And what a merry war they wage on beetle and nit, as they scrutinize every crevice of bark and bract! The bird eats insects at all times of year, but his staple diet is formed by the eggs and larvæ of insects. These are found tucked away in woody crannies, or else grouped on the under surface of smaller limbs and peristent leaves, as of oak or madrone.

On this account the Chickadee must frequently hang head downward; and this he does very gracefully, using his tail to balance with, much as a boy uses his legs in hanging from a "turning pole," swinging to and fro as though he thoroughly enjoyed it.

As nearly as we have made out, to date, the commoner notes of the Chestnut-backed Chickadee closely simulate those of the Oregon. The sweetee call is either indistinguishable or a mere shade smaller. The sneezing note becomes more distinct as kechézawick; and "Chickadee" becomes kissadee, the latter given so caressingly that you want to pinch the little darling. The Chestnut-backed Chickadee has a really truly song, but it is anything rather than musical. When the emotion of springtime is no longer controllable, the minikin swain mounts a fir limb and raps out a series of notes as monotonous as those of a Chipping Sparrow. The trial is shorter and the movement less rapid, so that the half dozen notes of a uniform character have more individual distinctness than, say, in the case of the Sparrow: Chick chick chick chick chick chick. Another performer may give each note a double character, so that the whole may sound like the snipping of a barber's shears: Chulip chulip chulip chulip chulip.

The best account of the nesting habits of the Chestnut-backed Chickadee has come to us from the pen of J. H. Bowles, ${ }^{1}$ and I draw largely upon his experience to supplement my own in reaching more exact conclusions. Chestnut-backs nest often in loose colonies; that is, a certain stretch of half-open woods containing forty acres may have a dozen nests, while it might be a mile to the next "village." Nesting is at lower levels of the forest, from two to ten feet, and in drier situations; though I have found nests as high as eighty feet in a fir stub; and in two instances in a dead tree wholly surrounded by water.

In beginning a nesting cavity this bird almost always avails itself

1"Notes on Parus rufescens in Western Washington," by J. H. Bowles, Condor, Vol. XI., Mar., 1909, p. 55. 


\section{The Chestnut-backed Chickadees}

of some natural advantage; as, a place from which a bit of wood has been torn away, or a hole made by a grub of one of the Cerambycid beetles. On this account, and because opportunities or prospects are legion, the nest is rather difficult to find. Dr. Brewer, writing in 1874 , thirty-seven years after the discovery of the bird by Townsend, had to say: "Their eggs are not as yet known."

Whatever the nature of the wood encountered, the Chickadee is prepared to take pot luck. It will sometimes chisel out a cavity in hard wood with all the industry of a woodpecker, or it will revel, instead, in the punk of some rotting branch. Or, again, with no labor at all, it will enter a hollow chamber by means of some knot-hole. But, as if to atone, it will in the last-named instance immediately set to work to fill up the hollow, if not chock full, at least to a becoming level. I have a nest wonderfully composed of moss, fur, and feathers, which is six inches across the top (and as level as a board), yet the nest cup proper occupies a space not over an inch and a half in diameter, in this relatively broad expanse. Mr. Milton S. Ray ${ }^{1}$ records two instances where Santa Cruz Chickadees $(P . r$. barlowi) occupied natural cavities in eucalyptus trees.

Every furred creature of the woods and some of the pastures may be asked to contribute to the furnishing of a Chickadee's home. But however luxurious the upholstery inside, the foundation is the ancestral green moss. Eggs to the number of seven, or even nine, are snugly bestowed in the inner cavity; and these, because they have so much of external protection, are of the frailest, white as to ground-color, and sparingly dotted with pale rufous. Incubation begins with the first egg laid; and the female is lavishly supplied with food by her attentive mate. If, however, she wishes to excuse herself for a bit of exercise or a bath in a woodland pool, she has only to pull the fur coverlet snugly over her treasures, and they are safe against chilling for a very considerable time.

"The female is very brave in defense of her eggs, and frequently cannot be made to leave the nest until it is broken open. In looking into a nesting hole that is occupied by the bird, I have never been able to overcome being badly startled by the sudden flutter of wings and the fierce cat-like hiss with which she dashes at the face of the intruder when he applies an eye to the entrance of their home. When she is forced to vacate, her complaints always bring up her mate, and then both birds hop about within two or three feet of the student, of whom they seem to lose all fear in anxiety over their treasures. Their only

${ }^{1}$ Condor, Vol. XIII., p. 211.

622 


\section{The Verdin}

note of complaint is a weak, squeaking peep, not in the least what one would expect from a true chickadee" (Bowles).

Young Chickadees are such cunning little creatures that the temptation to fondle them is sometimes irresistible. The parents may have very decided views as to the propriety of such action, or they may regard you as some benevolent giant, whose ways are above suspicion. Not infrequently, if the young are kindly treated, the parent bird will venture upon the hand or shoulder to pursue its necessary offices.

\section{No. 125 \\ Verdin}

A. O. U. No. 746. Auriparus flaviceps flaviceps (Sundevall).

Description.-Adult male: Whole head yellow, the yellow of ten extending to chest (and, rarely, down middle line of breast), clearest (lemon chrome) on throat, more olivaceous (citrine) on auriculars and crown, especially laterally and posteriorly (forehead in highest plumage touched with chestnut); space just before eye dusky; lesser wing-coverts bright chestnut (burnt sienna); remaining upperparts plain drab, the rump sometimes faintly glossed with yellow; remaining underparts pale smoky gray or buffy gray. Bill dusky horn-color; feet and legs bluish dusky; iris brown. Adult female: Like male, but slightly paler. Young birds lack the yellow of head and chestnut of wing, but are extensively washed above with yellowish; paler, nearly white, below. Length IOI.6-I I 4.3 (4.00-4.50); wing 53 (2.09); tail 47 (I.85); bill 8.5 (.33); tarsus 15.4 (.6I).

Recognition Marks.-Pygmy size; yellow head contrasting with drab body; bright chestnut patch on wing; quite distinctive in range.

Nesting.- Nest: A ball of interlaced twigs, usually thorny; 6 or 7 inches in diameter; placed at moderate heights in desert shrubs, without attempt at concealment. Entrance is effected by small, round, overarched hole in side, and interior is lined with soft substances, chiefly felted plant-downs. Eggs: 4 or 5; pale bluish green, finely wreathed or capped and sparingly sprinkled with reddish brown (sayal brown or mikado brown). Av. size, $14.5 \times 10.7(.57 \times .42)$. Season: April Ist-June Ioth. Mexico.

Range of Auriparus flaviceps.-Desert areas of southwestern United States and

Range of $A . f$. flaviceps.- "Sonoran deserts of southwestern United States and Mexico from southern California, southern Nevada, southwestern Utah, southeastern New Mexico, and southern Texas south to northern Lower California, northern Sonora, Durango, Coahuila, and Tamaulipas" (A. O. U. Check-List).

Distribution in California.- - Resident in Lower Sonoran areas of the deserts of southeastern portion of State, north to Resting Springs, Inyo County, west to Victorville and Whitewater. Most abundant in Colorado River valley and in Imperial Valley.

Au thorities.-Sundevall (Aegithalus flaviceps), Efv. K. Vet-Akad. Förk. Stockholm, vii., 1850 , p. I29 (orig. desc.; "Sitka or California"); Coues, Birds Col. Val., I 878, p. I29 (syn., structural peculiarities, habits, etc.); Sennett, Bull. U. S. Geol. and Geog. Surv. Terr., vol. v., no. 3, I879, p. 378 (Texas; nesting habits, crit., meas., etc.); Oberholser, Auk, vol. xiv., I897, p. 390 (crit. study of the genus Auriparus); Gilman, Condor, vol. iv., I902, p. 88 (San Gorgonio Pass; desc. nests, eggs, habits, etc.). 


\section{The Verdin}

THE DESERT is the final testing ground of character. To despise its austere beauties, to wince before its hardships, to shudder at its solitudes, is to mark one's self ignoble. And there are ignoble souls, else would the desert be over-populated.

Aye, it is a cruel place, the desert! Cruel, that is, to the body. It denies food to the hungry stomach, and withholds water from the parched lips. The hot sands burn the toiling feet, and there is no living thing which the hand may touch without being pricked or stung or lacerated or enmeshed. If one would shout there is no man to hear, and if one would run there is no whither. A cruel, cruel place is the desert, the abode of all discomfort. But who wants to be comfortable? Not the noble soul; for to be comfortable is to be oblivious, to be unaware of livingness, to be in so far forth unalive. No one can be exactly comfortable in the desert; so when he is goaded and scorched and stung into a sufficient alertness, the noble soul knows that he is alive, and, living, he rejoices. Rejoicing, he rejoices with all that is alive, and chiefly with the living things of the desert.

And so we love (only the noble have read thus far),- we love the bristling cholla cactus, which in its eagerness to impart its delicious pain seems to fairly leap at the passerby. We love, too, the giant cactus, the majestic sahuaro, defending its soft flesh with shiny rows of enduring spines. We love the thorny mesquite, and the zizyphus, "all thorns," which hides the hardy Thrasher in its depths. And we love, oh, how we love the bland cat's claw, which welcomes mildly but will not let the guest depart. We love the green-barked Parkinsonia, "palo verde," which being denied, ever and anon, by a merciless sun, the use of leaves, breathes pluckily through its skin instead, and which when the sky relents a little, flings back unresentful gratias of splendid golden blossoms. Oh, we love them all, but most of all we love the tiny fearless Gnatcatcher and the tiny golden Verdins, the Verdins who cruise about in this parched sea of terrors with never a luffing sail. Surely here is intrepid nobility, or else magic, outright, that a golden-visaged atom should brave these myriad frowns of nature and pronounce them good, should move happily from thorn to thorn and stop ever and anon to proclaim his boundless satisfaction. It was in the desert that Samson found honey in a lion's carcass, and it is in such another desert that Samson's little brother passes a honeyed existence.

The Verdin is without doubt the least restricted in its local ranging of all the desert birds. It is at home alike in the depths of the mesquite forest or in the monotonous mazes of atriplex, which border the shores of the Salton sea, alike in the unending leagues of creosote, or in the varied flora of the "washes," such as sweep down from the Chocolate Moun- 


\section{The Verdin}

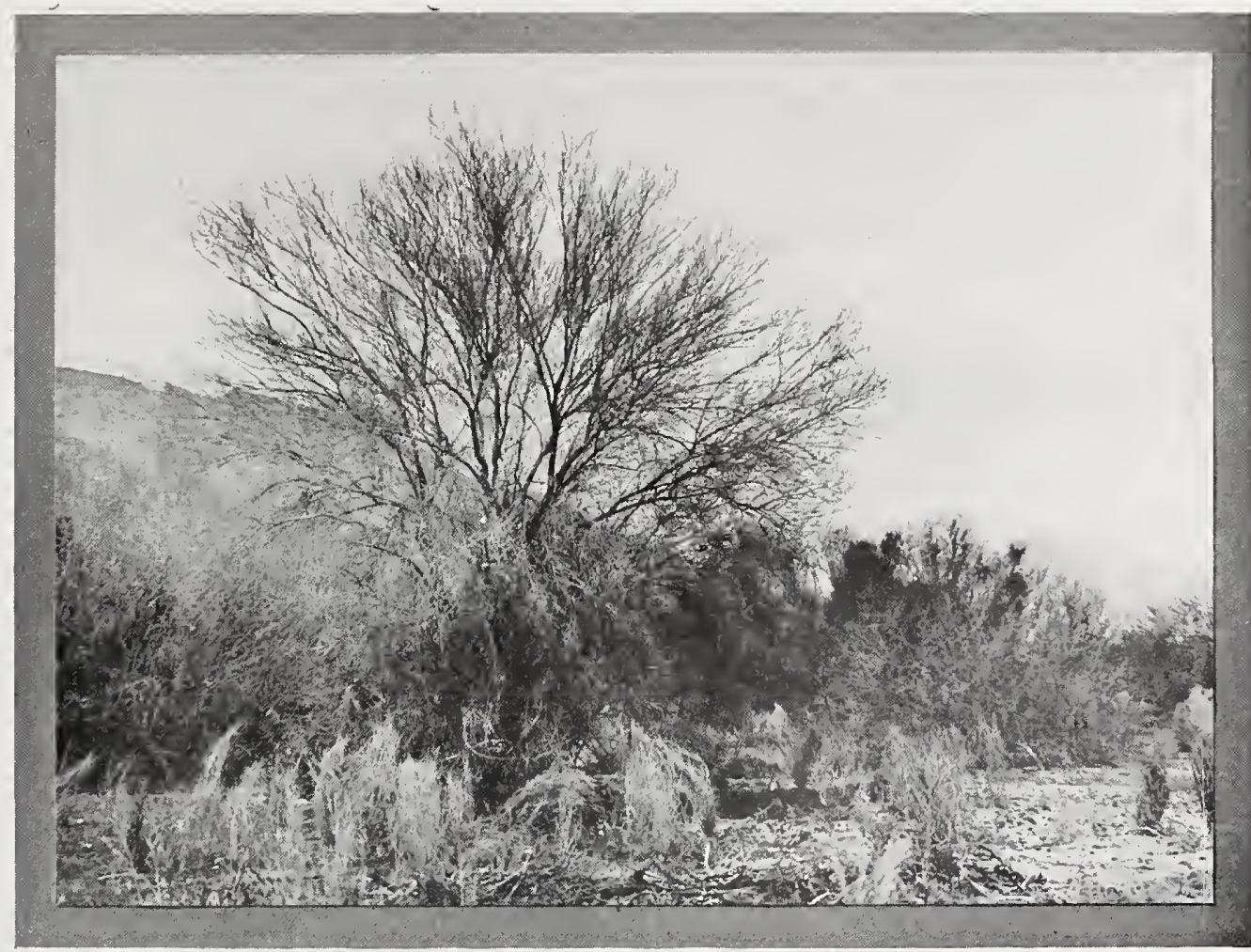

Taken near Palm Springs

A PALO VERDE

Photo by the Author

(GREEN TREE), WHICH "BREATHES THROUGH ITS SKIN"

tains; and so the very first sound one listens for upon revisiting the desert is always the pensive shthilp of a passing, or it may be an approaching, Verdin.

Truth to tell, there is something a little plaintive and melancholy about the authentic voice of the desert. The birds seem happy enough, and they must be so, else they would not tarry; but their notes confess something of the pathos of unending sands. My note book contains a dozen efforts at syllabification of one of Verdin's call-notes, but there is still an elusive tang about it which defies record. Tseelp; tslit; chsthilp; chilp; tschink; and even ching; are among the attempts, but they are alike unavailing. It is doubtful if the Verdin has a song, in the proper sense of the word; but I have heard tew tew tew teep, like the peeping of a young turkey, a pathetic sort of would-be song, followed or interspersed with the more familiar silp notes. Again, I have heard chu'it chu'it chu'it, which set me involuntarily looking for titmice; and a sweet che'wit, a chickadee-like challenge which was very sweet indeed. 


\section{The Verdin}

Verdins are not gregarious, like Bush-tits; but also they are never solitary, for they roam the desert in pairs, or, in small family groups, or in loose association. It is here that the remarkable penetrative, or carrying power, of the silp note serves the Verdin in good stead, for it allows mated birds to hunt, say, a hundred yards apart, without actually losing each other.

Once, in the Colorado River bottom, I heard a sudden piteous outcry, a miniature uproar, jeeb, jeeb, jeeb, jeeb, from an unsuspected number of Verdins at once. The notes were specifically new, but generically similar to the universal Sharp-shin alarm of the smaller birds. Sure enough, there was a Sharp-shin (Accipiter velox), the slinking devil! hiding in a Lycium bush and glowering wickedly over the recollection of a missed stroke.

The strong local attachments of the Verdins are evidenced by the successive ages of their nests, placed as likely as not in a single tree. These interesting objects are monumental, as well in size and prominence as in durability. Save when bedded in the heart of a mistletoe (Phoradendron californicum), the sturdy globular nests of the Verdin are as prominent as so many tin cans would be if lodged at random in all but leafless branches. These structures owe their comparative immunity from attack to their very rugged walls of interlaced twigs, whether mesquite or cat's claw, or, better yet, of "all thorns," and to the tiny hole in one side, just large enough to admit the tiny owner. The ingenuity as well as sheer physical strength shown by the birds in the construction of these fortresses almost taxes comprehension. I have before me a nest built in a hackberry, and composed externally of bristling thorn twigs, each six or eight inches long, and so adroitly enmeshed that no single twig may now be removed without virtually wrecking the entire structure.

During incubation the birds are rather careful not to be seen in the vicinity of the nest, and the female does not quit her charge without being rudely disturbed. On May I4, I9I7, I sighted a likely looking domicile four feet up in the midst of one of those terrible "allthorn" bushes. I was thrusting in an exploratory finger when a struggling and very irate female forced a passage out, and ruffled with indignation, sat at four feet demanding what right I had to enter a lady's boudoir. My! but she was beautiful, and imperious, with every jewel of color flashing a double radiance-or so it seemed to excited fancy. The bad man apologized, of course, and proceeded to cut down the nest and to invert it very carefully - for this is the only way one can possibly determine the contents of a Verdin's nest without ruining it. Four opalescent gems rolled out slowly, one after another, upon the "floor" of the inverted porch roof, or cowl, which normally protects the entrance. To return the 


\section{The Verdin}

eggs in reverse fashion and to reinstate the nest in some other thorny tangle equally secure was but the work of a moment. The birds both attended closely, as the male came up at the first sign of disturbance, and they exhausted the Verdinian vocabulary from tslit down,-all, it must be confessed, quite daintily and inoffensively.

Not less remarkable than these fortified nurseries are the structures

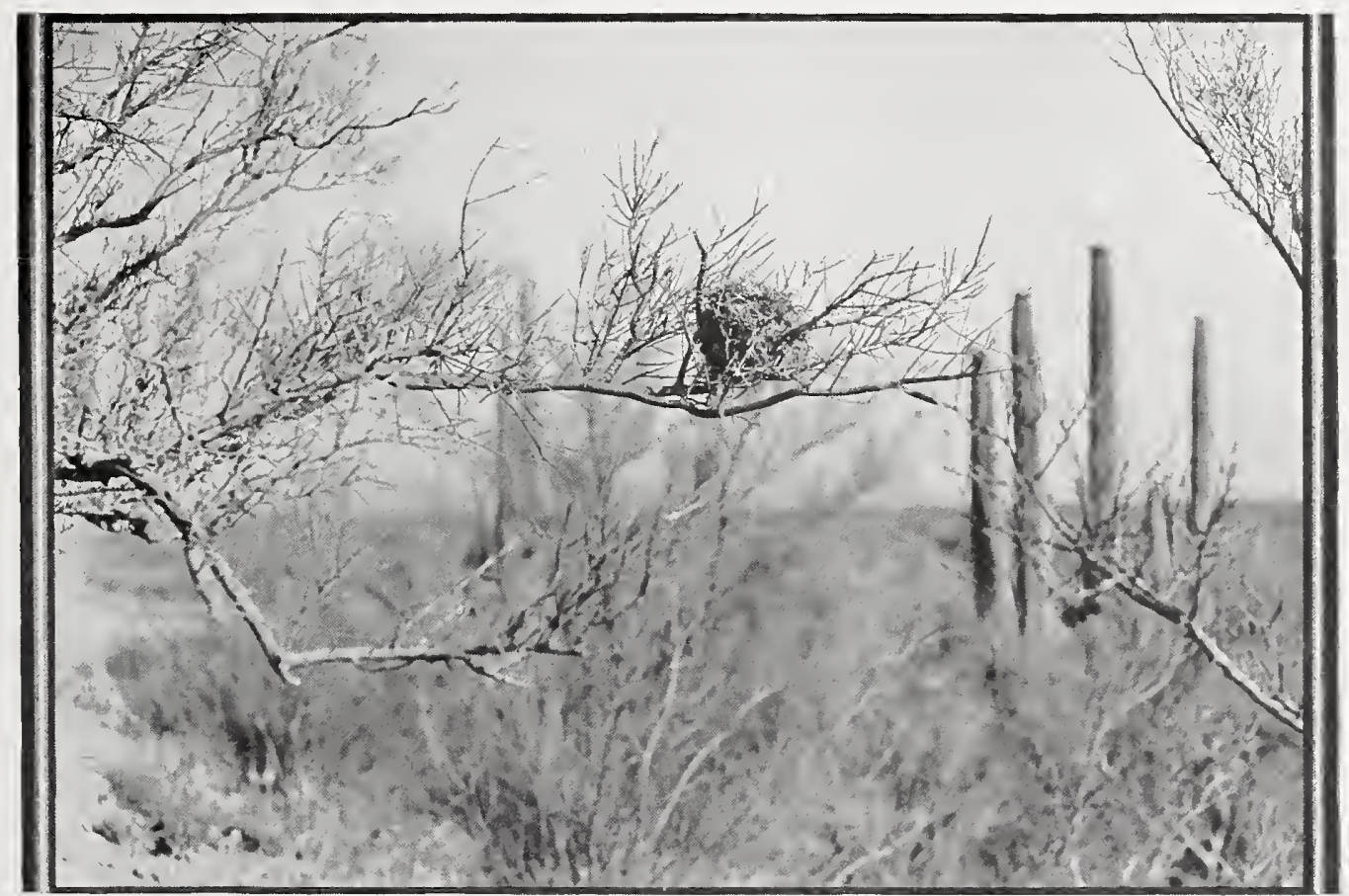

Taken in Arizona

NEST OF VERDIN (OCCUPIED) IN PALO VERDE

Photo by the A uthor

which the birds erect as roosts or winter lodges. According to Mr. M. French Gilman, ${ }^{1}$ who has made a special study of these birds upon the Colorado desert, these lodges are built in the fall or early winter and are of two types.

"The nests of male and female differ a little, the former being less elaborate, smaller, with not so much lining in it. The female winter nest differs but little from the breeding nest and I am inclined to believe in some cases is used as such, possibly by inexperienced or lazy birds."

Two male lodges in the M. C. O. are each only three inches in length over all, with openings at either end, and about two and a half inches of

${ }^{1}$ Condor, Vol. IV., No. 3, July, 1902, p. 88. 


\section{The Bush-Tits}

clear space inside - not room enough to turn around in, but just sufficient protection from the pounce of an Elf Owl.

From the circumstance that the nests, both winter and breeding, are found miles from water, it is inferred that these hardened devotees of desolation are quite independent of that supposedly necessary element. Literal bug juice may be presumed to supply all the needs of these simplehearted citizens of "dry territory."

No. 126

\section{Bush-Tit}

\section{No. 126 Coast Bush-Tit}

A. O. U. No. 743. Psaltriparus minimus minimus (J. K. Townsend).

Synonyms.--Least Bush-Tit. Pacific Bush-Tit.

Description.-Adult in fresh fall plumage: Pileum, broadly, olive-brown, shading through drab on sides of head and sides to light drab of underparts; back and remaining upperparts, in abrupt contrast to pileum, hair-brown or mouse-gray; the remiges and rectrices fuscous, with some paler or ashy edging. Bill and feet dark brown; iris light yellow. Adult in worn (spring and summer) plumage: Pileum lighter (buffy) brown; back grayer; underparts lighter, almost whitish centrally. Young birds are much like adults in spring, but plumage somewhat mottled in appearance, and wing-coverts and rectrices varied by lighter brown. Length about ior.6 (4.00); wing 47.5 ( 1.87$)$; tail 52 (2.05); bill 6.9 (.27); tarsus I 5.8 (.62).

Recognition Marks.-Pygmy size; grayish and drab coloration, contrasting with warm brownish cap; darker and browner than next.

Nesting.- Nest: A pendulous pouch 8 or 9 inches in length and 3 or 4 inches in diameter at the widest point, with small entrance hole in side near top; an exquisite fabrication of mosses, plant-down, and other soft vegetable substances, bound together by cobwebs and ornamented externally with lichens, etc.; lined with plant-down and feathers; placed at moderate heights in bushes, rarely from io to 20 feet up in trees. Eggs: 5 to 8, usually 7 ; dull white. Av. size $13.2 \times 10.2(.52 \times .40)$. Season: April $-J u l y$; two or more broods.

Range of Psaltriparus minimus.-The Pacific Coast district from southern British Columbia to Cape San Lucas, east centrally to the interior of Oregon and in northern California to the Nevada line.

Range of P.m.minimus.-The Pacific Coast strip, narrowly, from southern British Columbia to northern Lower California.

Distribution in California.- Resident in the coastal districts, more broadly in the northern and southern portions of its range; thus, east to Tower House, Shasta County, and Victorville on the Mohave Desert; inosculating with $P$. m. californicus along its eastern border and throughout the northern two-thirds of its range. Found also on Santa Cruz Island.

Authorities.-Nuttall (Parus minimus), Man. Orn. U. S. and Can., vol. I. 628 
I 840, p. 269 (Santa Barbara); Grinnell, Condor, vol. v., I903, p. 85 (call notes); Finley, Condor, vol. vii., I905, p. 9I, figs. (habits); Swarth, Auk, vol. xxxi., I9I4, p. 5Io, map (crit.; distr., changes of plumage, etc.); R. C. Miller, Condor, vol. xxiii., I92I, p. I2 I, map (flock behavior).

\section{No. 126a California Bush-Tit}

A. O. U. No. 743a. Psaltriparus minimus californicus Ridgway.

Synonym.-Interior Bush-Tit.

Description.- Similar to $P$. m. minimus, but paler and grayer, especially whiter below, with less of contrast between fresh and worn plumage; pileum buffy brown; back, etc., mouse-gray; throat and breast pallid mouse-gray or whitish; belly drab-gray; sides vinaceous buff; the skirtings of wings and tail, especially the remiges, bluish ash.

Range of $P$. m. californicus.-Upper Sonoran and Transition zones, interiorly, from northeastern Oregon south to the southern end of the Sierras.

Distribution in California.--Resident in the valley and on the slopes of the San Joaquin-Sacramento trough, broadly; and in northern California east of the humid Pacific coastal strip and east to the Nevada line. Range curves around the southern end of the Sierras to (at least) the latitude of Lone Pine.

Authorities.-Heermann (Psaltria minima), Jour. Acad. Nat. Sci. Phila., ser. 2, ii., I 853 , p. 264, part; Ridgway, Proc. Biol. Soc. Wash., vol. ii., I 884, p. 89 (orig. desc.; type locality, Baird, Shasta Co.); Beal, U. S. Dept. Agric., Biol. Surv. Bull., no. 30, I907, p. 74, pl. (food); Tyler, Pac. Coast Avifauna, no. 9, I9I3, p. Io6 (Fresno; habits, occurrence, etc.); Swarth, Auk, vol. xxxi., I9I4, p. 5I6, map (crit.; distr., changes of plumage, etc.).

HOP O' MY THUMB is one of the six most characteristic examples of California bird-life. Whether as a member of the bug-hunters' brigade, or as a very domestic person devoted to architecture, his ways are engaging and his achievements memorable. Of his movements en troupe Dr. Joseph Grinnell, dean of western ornithologists, has given, perhaps, the best account: 1

"During three-fourths of the year the California bush-tits forage about in flocks. These bands may consist of as many as thirty individuals, but generally there are from fifteen to twenty. Although we call them flocks, they are not such in the sense that blackbirds or linnets form flocks; for the bush-tits never bunch together and mount high in air to take a prolonged flight. But they form a loitering company, scattered among several scrub-oaks or brush-clumps. There may be a general onward movement, for if a person locates himself in the midst of the restless drove, in a few minutes they will have almost all gone off in some particular direction. A few stragglers sometimes forget themselves, and suddenly feeling lost, fly helter-skelter after the main company with excited calls. Evidently there are some, perhaps two or three adults, 


\section{The Bush-Tits}

who take the initiative, and involuntarily direct the movements of the younger or more timid individuals which follow along after. During such slowly moving excursions, each individual is rapidly gleaning through the foliage, assuming all possible attitudes in its search for tiny insects among leaves and twigs. The attention of each is on himself as a usual thing, but each is continually uttering a faint but characteristic simple location-note, a note of all's-well which indicates safety and also the whereabouts of the main body to stragglers, and each individual to any other."

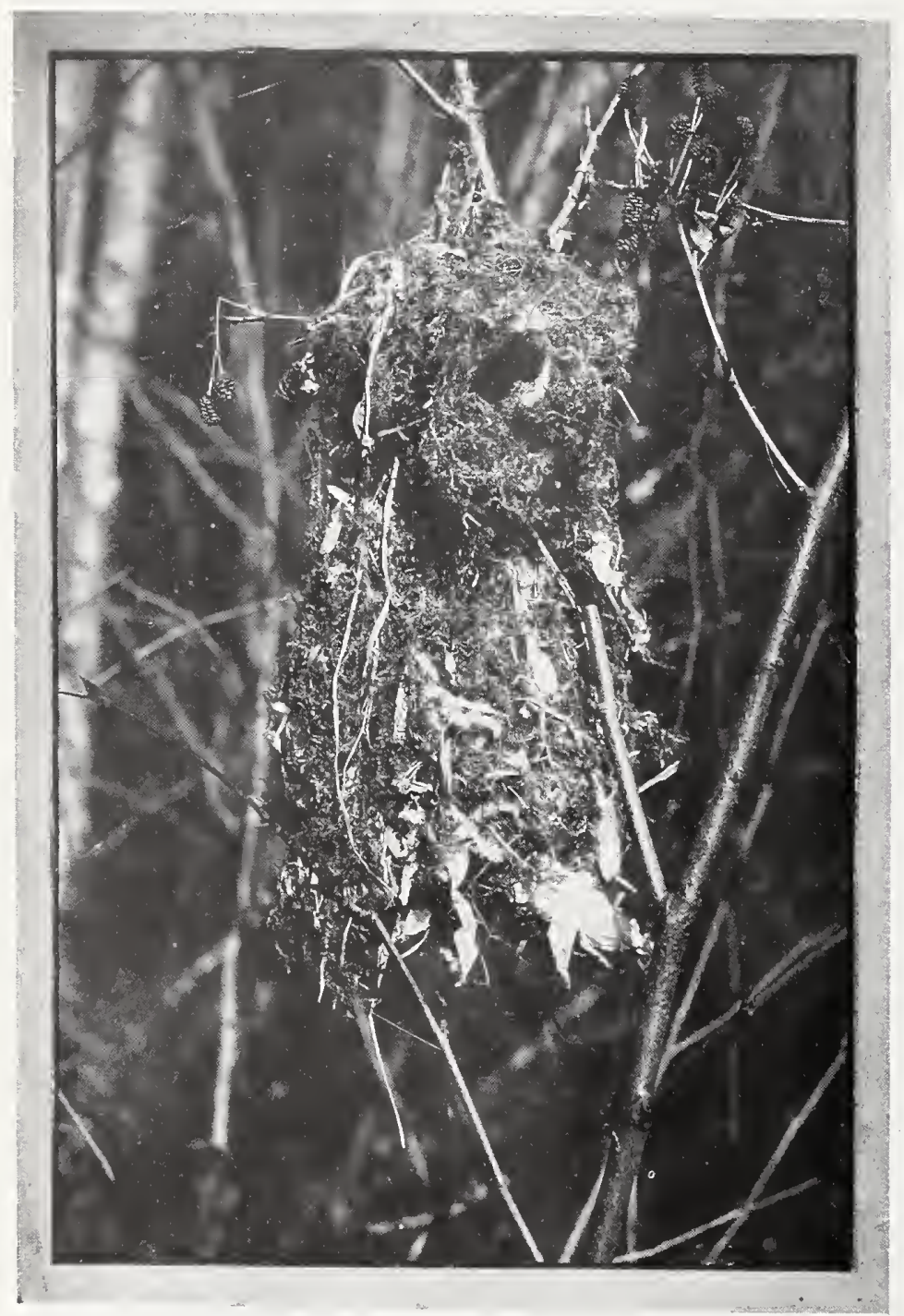

Taken in Washington NEST OF BUSH-TIT, IN SITU
Photo by the Author

The question of the number of Bush-Tits which may occur in a winter troupe perhaps deserves further attention. While twenty may be a fair average, I recall having seen very much larger troupes near Santa Barbara. One day while working along a southsloping oak- and chaparral-covered hillside beyond the Riviera I saw what I judged might be a hundred birds cross a certain opening. Then as the route halted, the discharge tree, or positive pole of the Psaltriparine battery, was seen to be still "full" of BushTits. Presently some fairy recall was sounded, whereupon seventyseven birds, by actual count, returned across the open.

Those who have followed the fortunes of these little gleaners with any degree of care must have heard at some time or other the confusion- 
chorus which attends the presence, or immanence, of a Sharp-shinned Hawk or other smaller depredator. Upon the first suspicion of danger every birdling becomes motionless, and sets up a sharp chittering note of distress which grips the heart of any human witness, a piteous outcry of helpless minimity. And yet this distress note, which seems to be the outcome of sheer ter-

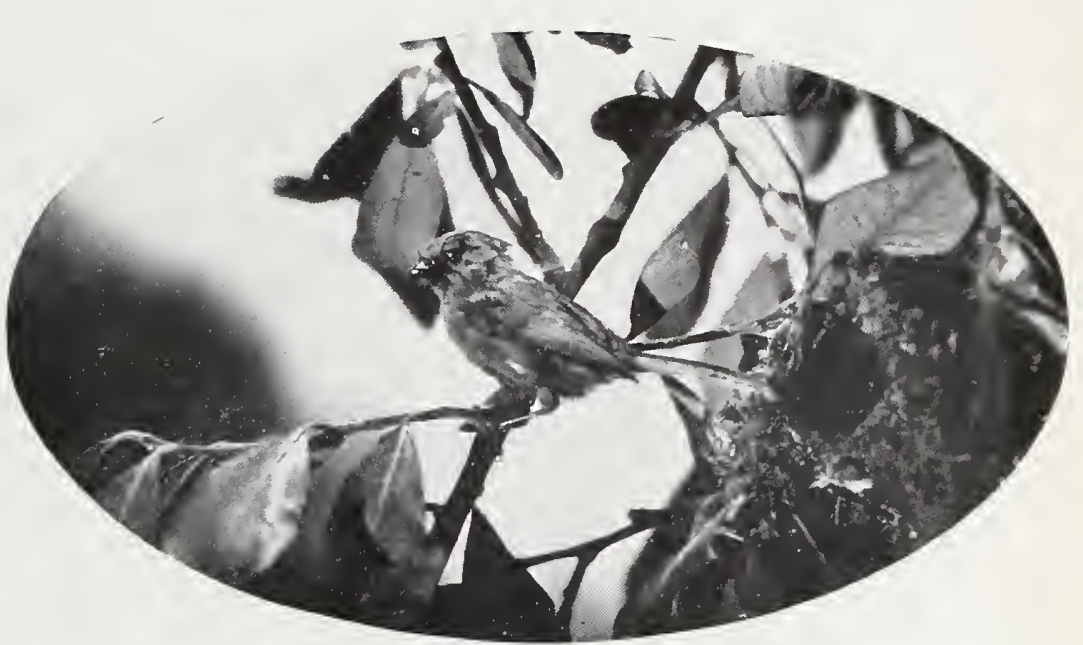

Taken in Oregon ror, not only serves to apprise all members of the troupe of the danger, but it seems to actually distract the enemy. Where everything is vocal nothing is localized, and ten to one the baffled marauder goes off in a huff.

Apart from their pleadings, our sympathies are all with the little fellows, and they would be even if we regarded only self-interest, for it is probably impossible to exaggerate the usefulness of these little titmice in the preservation of some of our most important fruit crops. Says Mr. Beal:1 "Examination of the stomachs of a number of California Bush-Tits (Psaltriparus minimus) revealed the presence in considerable numbers of the black scale (Lecanium olea), which infests the olive. This insect has been a serious pest to the olive trees on the Pacific Coast, and any bird that will destroy it should certainly be encouraged by western fruit growers. The usefulness of titmice depends largely upon the small size of the birds. In dealing with pests of any kind, the more minute they are the less the probability that man can by his own unaided efforts succeed in exterminating them. . . . The eggs of insects, especially those of such small species as plant lice, are often so minute as to escape the closest search of man; but the more microscopic eyes of these small birds detect them even in crevices of buds or bark." And that they do not despise these, to us, insignificant sources of nourishment is abundantly attested.

Although among the most useful of citizens, it is as artists, architects, and decorators that the Bush-Tits are best known to fame. Nestbuilding is a passion with these dun-colored atoms. In the exercise of this function they seem to express all the pent-up longings of an obstructed

1"How Birds Affect the Orchard," by F. E. L. Beal, Reprint from Year Book of Dept. of Agr. for I90o, p. 296. 


\section{The Bush-Tits}

race. A beautiful home is more than meat or drink to them. For its construction they are ready to forswear the delights of foreign travel, and to its embellishment they devote every surplus energy, even after the babies have come. Your Bush-Tit is no songster. A prosy keep-intouch-note, $t$ sit or shlit, and an excited chitter, crééée, are all he can achieve from year's end to year's end; but, by the same token, he is an esthete when it comes to choice of harmonious settings, to selection of materials, and linings and draperies and laces withal.

Nest-building begins universally some time in March, and this irrespective of whether the setting is a live oak with its perennial cover, or a spiræa bush just struggling into leaf, or a bleak grayness of dead branches with no cover at all. Indeed, when one regards the openness of some of the situations chosen, it is a marvel that the nests should ever escape notice. But however exposed the nest may be, the materials used in its construction are likely to be harmonious in color, if not in texture, with their surroundings. Besides, it is really astonishing how many accidental collections of leaves, sprays of mistletoe, withered pannicles of spiræa, hanging bunches of moss, and what not, simulate, and so abet the escape of an object so boldly shaped as a Bush-Tit's nest.

In the northern or coastal portion of this bird's range the pendent pouch is likely to be composed chiefly of mosses, but in the south other vegetable fibers must do duty; and always, everywhere, cobwebs are the webbing of the most diverse woof. Dead leaves already beplastered with spider webs are dragged in entire. The lining of the nest is composed variously, sometimes of felted plant downs exclusively, but often of felt mingled with wool, fur, or feathers.

Egg-laying may begin as soon as the nest is decently framed, or again, it may be deferred for a week or ten days after the structure is practically complete. But, however that may be, the birds never rest from their artistic labors. A Bush-Tit's nest is like the Jamestown Fair, never finished. The nest must be ornamented with lichens, petals, spider-egg cases, bits of tissue paper,--in short, whatever takes the fancy of the birds in the course of their restless forays. Acacia blossoms are an undying favorite in the Southland. The interior furnishings, likewise, must be continually augmented. If the bottom of the nest was only an inch thick at the outset, it is built up from within until it attains a thickness of two or three inches. Even though the eggs be near hatching, the thrifty housewife, as she returns from an airing, must needs lug in a beakful of feathers, which it would have been a shame to waste, you know. Besides this, the male bird has two or three shanties under construction in the neighborhood, upon which he can profitably put in those tedious hours between three a. m. and sunset.

632 
The mother Tit lays six or eight pearly white eggs, and these the Coast and California Jays count quite the daintiest item on their bill of fare. Hence, of all the Bush-Tits' nests one sees in a season, fully half of them have been slit open and rifled by these heartless freebooters. It is possible that this interference accounts for the "second nests" found in May and June; but I am inclined to believe that many Bush-Tits raise second broods even where the first have been successful. In one instance, at least, I knew of a second set of eggs being deposited (May 8), in a nest which had held young in March. Thereto, perhaps, agrees a phenomenon which several of us believe we have observed, viz., a late brood of youngsters being supplied with food by more than two adults. Either unoccupied aunts and old maid cousins turn to and help the embarrassed couple with their clamoring family, or else, as is more likely, the children of the first brood are doing their duty by their younger brothers and sisters.

One who has approached a "loaded" Bush-Tit's nest at flying time will never forget the infantile eruption which follows a rude touch upon the nest. Like fire balls from a Roman candle, but with notably less reluctance, the youngsters emerge in swift succession. One flies east and one flies west, while fourteen at least - or so it seems to excited fancyare left to flutter wildly over the Cuckoo's nest.

\section{For Younger Readers}

BUSH-TITS are bird children who never grew up. That would be very sad if they were really truly children, but you see most bird people grow up so very, very fast that half the time there ar'n't any bird babies. And so bird-life would be very dull, in the fall and winter, say, if it were not for these happy-hearted children in feathers who are forever young.

To see a flock of these merry mites trouping over the bushes you would think they were playing an endless game of tag. It does look that way, for they always keep hopping and dodging about, and if one bird flits to a nearby tree, why another one takes after him, and another and another. By and by some little birdie, who wasn't paying attention just then, looks up to find himself all alone, and when he does, he is scared and he hops up on the tip top branches and shouts, creeee, meaning "Where are you?" And at that the last bird who flew across to the other tree shouts back, $t$ sit - tsit-tsit, meaning 


\section{The Bush-Tits}

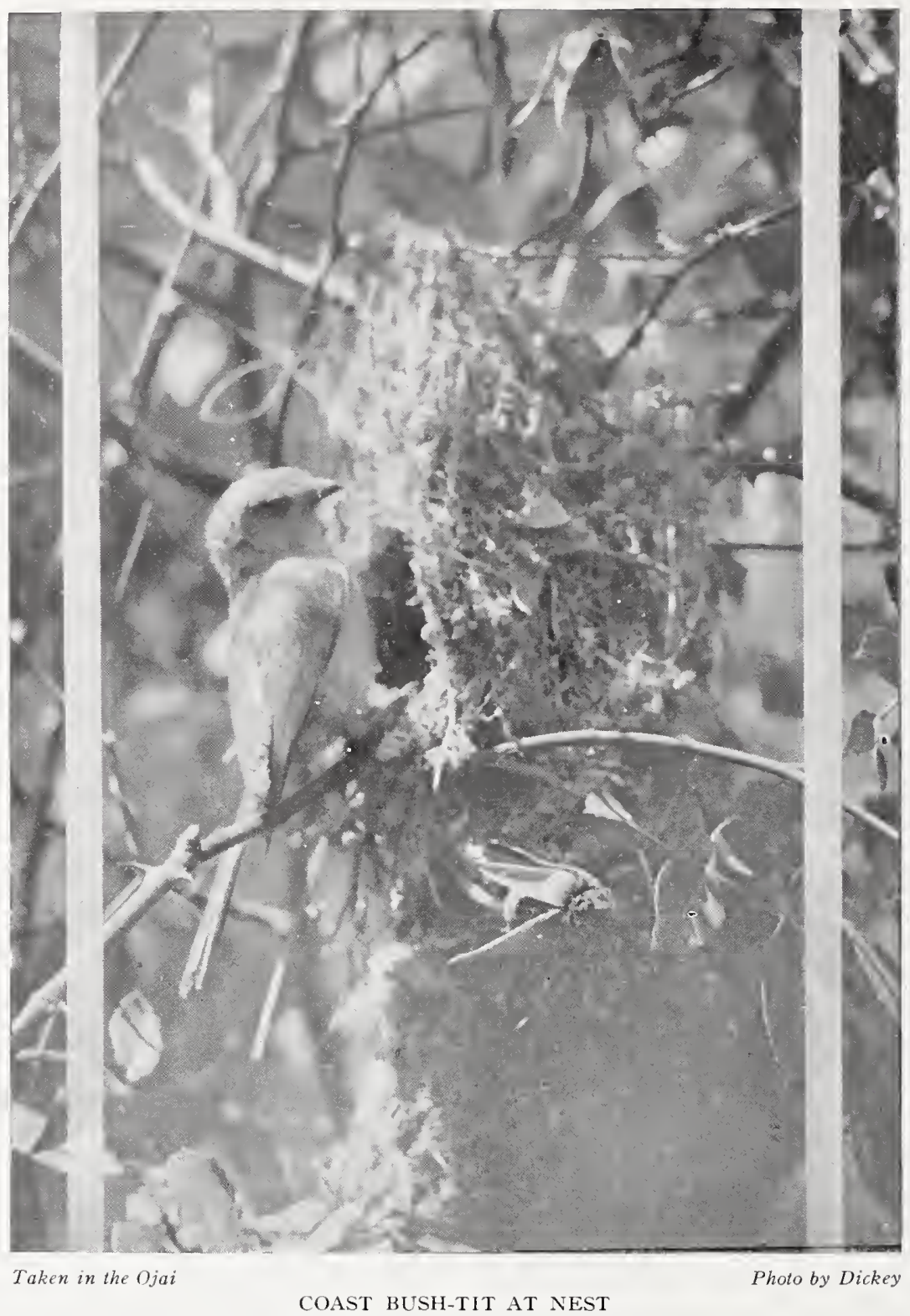

Here we are. Hurry up! But the Bush-Tits are not really playing tag; they're only hunting. And they find it a most interesting game. Little beetles hiding under shreds of bark, bugs that look as big as rabbits (to them), and funny little insects, called scales, that look as big as oysters to a Bush-Tit, and taste quite as good, I am sure. 634 
Best of all, perhaps, are the shining rows of eggs they find. Now a moth's egg isn't as big as a hen's egg, even to a Bush-'Tit, but if you were to find forty dozen Hummingbirds' eggs all in one spot, I guess you'd think you were in for a square meal. So the Bush-Tits have merry hunting and high living.

The best part of it all is that these little Bush-Tits are the gardener's best friends; and that means, of course, that the birds are our best friends too. If it wer'n't for these birds, and others like them, I don't know what we'd do for something to eat. 'The gardener can catch the rats and the gophers and the squirrels, and he can chase away the rabbits, but he never could see to catch the sneaking little bugs, and he couldn't find the moths' eggs, not even forty dozen at once; and if he didn't, or if somebody didn't, the eggs would hatch out worms, and the worms would eat our peaches and our apples and our cabbage and our corn, until we wouldn't have much of anything left. So who says that the merry little Bush-'Tit with his tiny, beady eyes and his great big appetite isn't our best friend?

But if you think that's all a Bush-Tit is good for, just to eat bugs and moth eggs, you'll have to guess again. 'The Bush-Tit is an architect. What? Yes, an architect. 'That's a person who builds houses, you know. And the Bush-'Tits build the most beautiful bird houses. No, I don't mean houses made for birds, I mean houses made by birds - the most beautiful bird houses that there are in the world, I guess. 'To be sure, they look like pockets, these Tit-houses, like fat, round pockets, hung up by the tops in trees, and with, oh, such a tiny, round hole in the side to get in at. 'The hole is big enough for the bird to get in, and it wasn't meant for prying fingers, nor yet for the Jays' snooping beaks. But if we could look into one of these pocket-houses, we'd find six or eight tiny white eggs, like pearls; and we'd find them resting on a cushion of the softest downcotton and flower blossoms and spider webs, and anything else that is soft.

And this pocket-house is as beautiful outside as it is inside, for the birds never tire of bringing in any thing that pleases their fancya white spider cocoon, an acacia blossom, or a moth's wing-and hanging it up outside for an ornament. Why, some of these beauty- 


\section{The Lead-colored Bush-Tit}

lovers get so interested in a new blossom or bit of moss, even when the babies are crying for food, that they will forget what they went after, seize the blossom and hurry home with it. I could imagine a hungry Bush-'Tit baby saying, "But where's my dinner?" And I could imagine the Bush-Tit mamma saying, "Well, now, dear child, it's too bad that mamma forgot you were hungry. But look at the perfectly be-eautiful moth-wing I brought to you. See; I'll hang it up where we can all see, and we'll forget that we haven't had anything to eat. Anyhow, that'll stay your stomach until I can get back with some real victuals."

But Mr. and Mrs. Bush-Tit are pretty good providers, after all, and the babies grow and they grow until they fill the nest chock up. Then by and by they get restless and tired of taking turns peeping out of the little round hole. The biggest one makes up his mind to strike out for himself, whereupon his brothers and sisters follow so fast that a Bush-Tit's nest giving up its young reminds you of nothing else in the world so much as a Roman candle sputtering and spitting out balls of colored light. And every one of those youngsters will hunt bugs and build nests and lug in useless pretties to hang on the walls to the end of the chapter.

No. 127

\section{Lead-colored Bush-Tit}

\section{A. O. U. No. 744. Psaltriparus plumbeus Baird.}

Synonym.-Plumbeous Bush-Tit.

Description.- Somewhat similar to $P$. minimus, but pileum of the same color as back. Adult: Above neutral gray, tending to drab (especially on forehead in worn plumage); wings and tail hair-brown to fuscous, with edgings of bluish gray (gull gray); sides of head drab (darkening on eyelids and lores in fresh plumage); chin, sides of throat, and sides light drab; remaining underparts drab-gray, palingwhitish - on throat and chest. Bill and feet blackish; iris pale yellow. Young: Much like adult, but sides of head less brownish, more like crown; and texture of plumage looser. Length about II 4.3 (4.50); wing 5 I (2.0I); tail 56 (2.20); bill 7 (.275); tarsus I $6(.63)$. 


\section{The Lead-colored Bush-Tit}

Recognition Marks.-Pygmy size; nearly uniform gray coloration-crown not contrasting with back, as in $P$. minimus.

Nesting.-Much as in preceding species, but nest a little shorter, 7 or 8 inches long, and more compactly built; sage leaves and dismembered hummingbirds' nests are favorite materials, together with blossoms, catkins, cobwebs, etc. Eggs: av. I $3 \times 10.2(.51 \times .40)$.

General Range.-Resident in Upper Sonoran and Transition zones of the arid interior from eastern Oregon and western Wyoming south to Sonora and western Texas, and from southeastern California east to central Colorado.

Distribution in California.-Resident in the Upper Sonoran zone in the east central desert ranges, and sparingly along the eastern slope of the Sierras from Carroll Creek north (at least) to Bridgeport (Aug. 2, I918).

Authorities.-Cooper (Psaltriparus plumbeus), Orn. Calif., i870, p. 49 ("to Sierra Nevada, Cal. (?) Gruber"); Coues, Birds Col. Val., I878, p. I25 (syn., desc., habits, etc.); Bendire, Proc. U. S. Nat. Mus., vol. x., I888, p. 557 (habits; food; desc. nest and eggs; Ariz.); Swarth, Auk, vol. xxx., I9I3, p. 399 (crit.; discussion of Psaltriparus plumbeus, P. m. lloydi, and $P$. santarita); Auk, vol. xxxi., I9I4, p. 520, map (crit.; distr., changes of p'umage, etc.).

While the Lead-colored Bush-Tit is lighter, grayer, and more uniform in color than examples of $P$. minimus, the degree of relationship existing between minimus and plumbeus is admittedly a closer one than can be accurately expressed in current nomenclature. ${ }^{1}$ It is enough, perhaps, to understand this relationship on its own merits without forcing our knowledge into taxonomic moulds, whether new or old. Plumbeus is the bird of the central Southwest, and so of the central-southern, semiarid ranges of eastern California. Along the eastern slopes of the Sierras, in Inyo and Mono counties, plumbeus overlaps the range of $P$. minimus californicus, and probably interbreeds with it. ${ }^{2}$ We may conceive the two forms as having recently diverged (speaking phylogenetically-the process was really a very slow one, for Psaltriparus is a comparatively implastic type) from a common southern stock. From new differentiation centers, in Arizona and western California, respectively, and separated by a long interval, the two evolving forms have recently flowed toward each other (speaking distributively) until they now meet and hybridize along a narrow line, still undefined, in eastern California.

ALTHOUGH undeniably different in color-tone from our more familiar California Bush-Tits, the lighter, grayer bird from the desert ranges does not appear to differ from its darker relative either in voice or action. Without pausing, then, to give it separate appreciation, I copy briefly some excellent notes furnished me by Mr. Frank C. Willard, lately of Tombstone, Arizona. In the Huachuca Mountains, near the recognized center of distribution for this species, Mr. Willard finds the Lead-colored Bush-Tits nesting chiefly in the oak trees, junipers, grape-vines, and firs, though occasionally in pine trees, and that up to a height of forty

\footnotetext{
1 See Swarth in "The Auk," Vol. XXXI., Oct., I914, pp. 522-524.

Ib., p. 22 I and following.
} 


\section{The White-breasted Nuthatches}

feet. The nest is composed typically of interlaced oak blossoms, felted with down from the oak leaves, and lined copiously with feathers. Both sexes assist in nest-building, and the mated birds hunt together for suitable material, to a distance of several hundred yards. The birds display considerable anxiety whenever the nest is approached, and are very likely to betray the presence of an otherwise inconspicuous home. Unlike other titmice, however, the female is seldom caught at her task of incubation.

As is the case with northern members of this genus, even $P . m$. saturatus of Puget Sound, plumbeus starts building in March or early April, and in many assured instances nests again in late May, June, or even July. A special accommodation to southern climate may be noted in the custom which the birds observe of breaking a hole through the fabric of the nest-wall, at a level with the floor, as soon as their babies are half-way grown. That this is actually for ventilation only is assured by the fact that the parents continue to go and come by the established entrance overhead. One cannot help wondering whether these birds close the window at night.

No. 128

\section{White-breasted Nuthatch}

\section{No. 128a Slen ter-billed Nuthatch}

\section{A. O. U. No. 727a. Sitta carolinensis aculeata Cassin.}

Description.-Adult male: Top of head, nape, and upper boundary of back shining black, with a slight greenish reflection; remaining upperparts ashy blue (clear green-blue-gray to clear Payne's gray); outer wing-quills fuscous, the second and three or four succeeding primaries narrowly touched with white on outer web in retreating order; inner quills and coverts edged narrowly with blue-gray or whitish; tailfeathers, except upper pair, black, the outer pairs squarely blotched with white in subterminal to terminal order; sides of head, and neck well up including eye, and underparts, white with a faint bluish tinge; distinctly marked, or washed more or less, on flanks and crissum with rusty brown. Bill stout, subulate, the under mandible slightly recurved, blackish plumbeous above, lighter at base of lower mandible; feet dark brown; iris brown. Adult female: Similar to male, but black of head and back more or less veiled by color of back. Length I39.7-I 54.9 (5.50-6. Io); wing 87 (3.43); tail 46 (I.8I); bill $19.5(.77)$; tarsus I $8.2(.72)$.

Recognition Marks.- Warbler to sparrow size; tree-creeping habits; black and ashy blue above; white below. 


\section{The White-breasted Nuthatches}

Nesting.- Nest: A deserted woodpecker hole, or newly made cavity in stump or tree, usually at a considerable height from ground; and lined with leaves, feathers, or hair; of ten rabbit-fur is used exclusively. Eggs: 5 to 8, sometimes 9 or even Io; white, thickly speckled and spotted with reddish brown (mikado brown, pecan-brown). Av. size 18.3 x $13.5(.72 \times 53)$. Season: April, May; one brood.

Range of Sitta carolinensis.-Temperate North America south, in the mountains, to Coahuila and Lower California.

Range of S. c. aculenta.-Pacific Coast States and British Columbia (to Ashcroft); in the northern portion of its range east to the Cascades. Non-migratory.

Distribution in California.- Resident in Transition and Boreal zones, practically throughout the State, save in the humid northwestern coast strip, and in the desert ranges (where replaced by $S$. c. tenuissima); also breeding locally in the oak-belt of the Upper Sonoran zone. Wanders to lower levels and casually to the deserts in winter.

Authorities.-Gambel (Sitta carolinensis), Proc. Acad. Nat. Sci. Phila., ser. 3, iii., I 846, p. I I 2, part (Calif.); Feilner, Ann. Rep. Smith. Inst. for I 864 (I 865), p. 425 (Fort Crook; habits); Carriger, Bull. Nutt. Orn. Club, vol. I, I899, p. 83 (nesting habits); Beal, U. S. Dept. Agric., Biol. Surv. Bull., no. 30, 1907, p. 68 (general nature of food); Grinnell, Univ. Calif. Pub. Zool. vol. v., I908, p. I23 (San Bernardino Mts.; nests, etc.).

QUOOK-quook-quo-ew-ew-ew-ew, goes the California Screech Owl in broad daylight. There is an instant hush on the oak-clad hillsidea hush followed by an excited murmur of inquiry among the scattered members of a winter bird-troop. If you happen to be the Screech Owl, seated motionless at the base of some large tree and half obscured in its shadows, perhaps the first intimation you will have that the search party is on your trail will be the click, click, click, of tiny claws on the treebole above your head, followed by a quank of interrogation, almost comical for its mixture of baffled anxiety and dawning suspicion of the truth. He is an inquisitive fellow, this Nuthatch, for, you see, prying is his business; but he is brave, as well. The chances are that he will venture down within a foot or two of your face before he flutters off with a loud outcry of alarm. When excited, as when regarding a suspicious object, he has an odd fashion of rapidly right-and-left facing on a horizontal bough,- - swapping ends, as Jones puts it - as though to try both eyes on you and lose no time between.

Nuthatch is the acknowledged acrobat of the woods-not that he acts for display; it is all business with him. A tree is a complete gymnasium in itself, and the bird is master of it all. In all positions, any side up, this bird is there, fearless, confident; in fact, he rather prefers traveling head downward, especially on the main trunk route. He pries under bark-scales and lichens, peers into crevices, and explores cavities in his search for tiny insects, larvæ, and insects' eggs, especially the last-named. 


\section{The White-breasted Nuthatches}

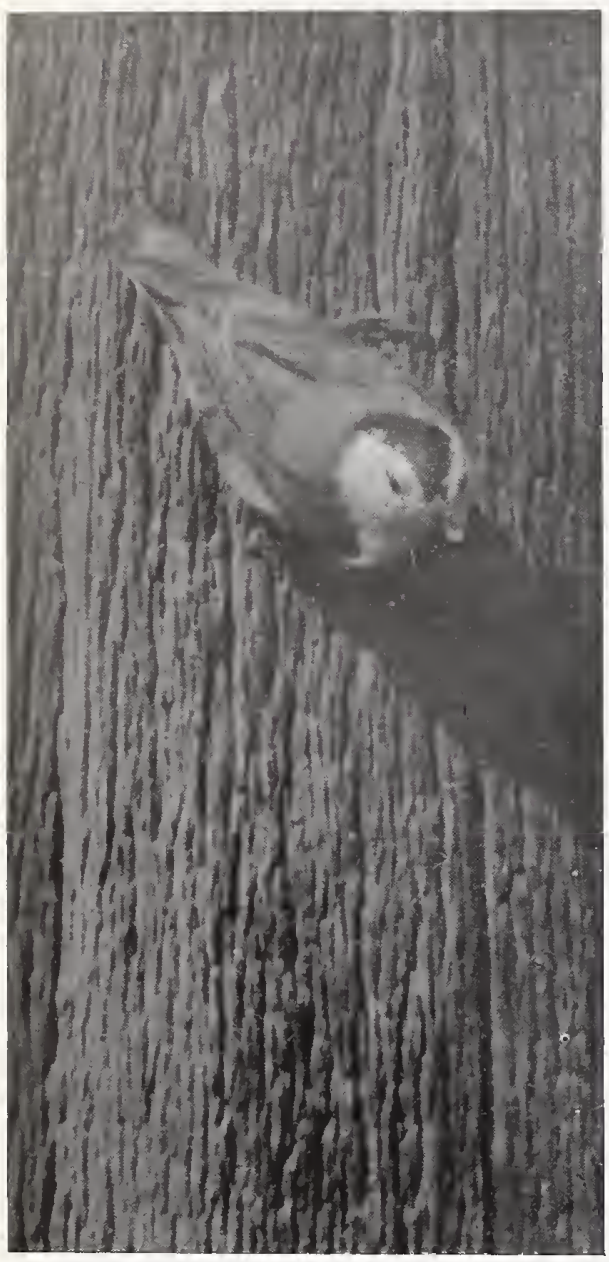

Taken in Inyo County A HESITANT APPROACH

The value of the service which this bird and his associates perform for the horticulturist is very considerable. There should be as heavy a penalty imposed upon one who wantonly kills a Nuthatch or a Chickadee, as upon one who enters an enclosure and cuts down an orchard or a shade tree.

The Nuthatch has a variety of notes, all distinguished by a peculiar nasal quality. When hunting with the troop he gives an occasional softly resonant tut or tut-tut, as if to remind his fellows that all's well. The halloo note is more decided, tin, pronounced á la francaise. By means of this note and by using it in combination, they seem to be able to carry on quite an animated conversation, calling across from tree to tree. During the mating season, and often at other times, they have an even more decided and distinctive note, quonk, quonk, quonk, or ho-onk, ho-onk, in moderate pitch, and with deliberation. They have also a sort of trumpeting song, but this is rarely heard in the West; and, indeed, all the notes of the Slender-billed Nuthatch have a softened and subdued character as compared with those of the eastern bird, typical S. carolinensis.

In selecting a nesting site the Slender-billed Nuthatch of tenest chooses an opening prepared by other species, - a rotting knot-hole, a weather crack, or a woodpecker's food prospect, giving access to some capacious interior. The hollow may be laboriously remodelled; and this Nuthatch does, on occasion, excavate a nest de novo; but the very general avoidance of unnecessary labor on the part of the western bird has probably given rise to its special character, viz., a relatively slenderer and weaker bill. Both sexes share the labor of excavation, and when the cavity is somewhat deepened, one bird removes the chips while the other delves. Like all the hole-nesting species of this family, but unlike the woodpeckers, the nuthatches provide for their home an abundant lining of moss, fur, feathers, and the like. This precaution would not be necessary so far as warmth is concerned, in the lower portions of its range, even though it appears to nest in March; but elsewhere the bird crowds the season, and in the mountains is quite indifferent to lingering snows.

$$
640
$$




\section{The White-breasted Nuthatches}

The male is a devoted father, feeding the female incessantly during incubation, and sharing with her in the care of the large family, long after many birds have forgotten their young. The young birds early learn to creep up to the mouth of the nesting hole to receive food when their turn comes; and they are said to crawl about the parental tree for some days before they attempt flight.

While the Slenderbilled Nuthatch is mildly indifferent to the presence of man on ordinary occasions, it becomes exceedingly wary at nesting time. The mother of the birdlings here shown nearly wore out our patience with her eternal suspicions. She was not long in making the first attempt, but she "swapped ends" an incredible number of times before she actually dived into the nesting crevice; and she was out in a trice, having had time merely to jab her burden down the

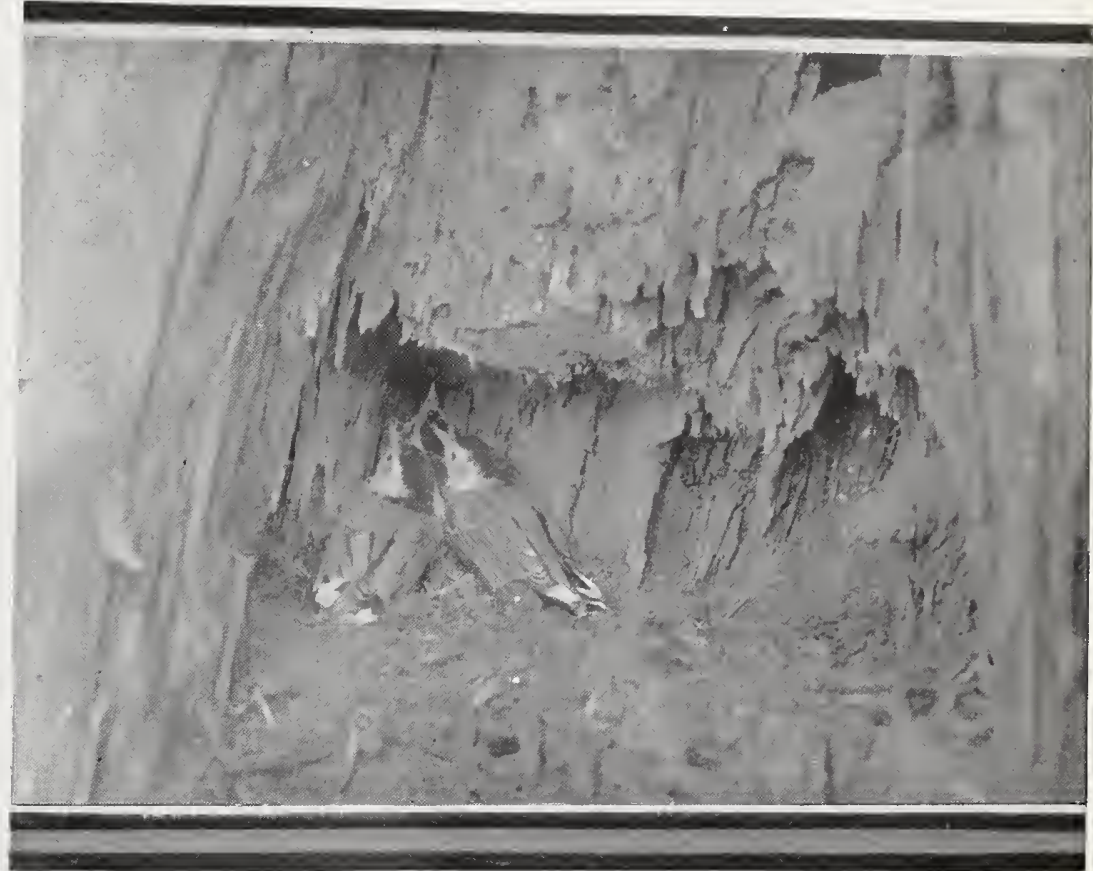

Taken in Inyo County

Photo by the Author

YOUNG OF SLENDER-BILLED NUTHATCH IN NESTING CAVITY nearest throat. Once outside, she hesitated not a little, as knowing full well that she had another duty to perform. But she concluded it was less important, after all, and went off without removing an excrement. Four successive times she did this, judging that digestion was more to the present need than sanitation. The fifth time she went into the hole resolutely, as having made up her mind that duty must be done whether or no, and as resolutely she returned to bear off an enormous foecal envelope with its contents. I snapped her at this, and she never forgave me for the indignity. Only once again in two hours did she attempt sanitary work. Although we were twenty-five feet away, this Nuthatch flinched as often as she heard the shutter roar, and it invariably set her back a minute or so in her progress. Once she deserted outright, and she must have eaten the food intended for her babies, for she was a long time gone. 


\section{The White-breasted Nuthatches}

In this case the husband and father, usually so devoted, did not put in an appearance; and the entire care of this lusty brood devolved, for the time being at least, upon the tired mother. Her intervals of feeding were very irregular-whether due altogether to the fortunes of the chase or an occasional effort to "smoke me out," I could not tell. Once she was gone fifteen minutes, and again a half hour. She did tire us out this time, and I believe she was tricking us, for she returned promptly, upon our withdrawal, from some unseen vantage point.

Trickery is quite within the bird's range of intelligence. Mr. Frank C. Willard tells of a clever pair which did him out of a coveted set of eggs:1 "May i 8, I9I0. I heard a pair of these birds talking to each other, and began to trail them. One soon secured some bit of food and started up the steep mountainside, with me in hot pursuit. I soon lost sight of it, but discovered the mate close by with some grass or bark or something of that character in its beak. It dived into a cavity of a small oak, and shortly reappeared without its nesting material. After a few minutes calling it was joined by the other one of the pair, and both were soon busy carrying nesting material into the oak. I quietly withdrew to return ten days later. There were no birds about so I examined the cavity, and was chagrinned to find only the few bits of grass and fur I had seen them carry in. Some time later I found the real nest with its family of large young in an oak some distance further up the mountainside."

The Slender-billed Nuthatch does not, with minor local exceptions, appear to be a common bird anywhere in its range. Certainly it is not one-fourth as abundant as is carolinensis in the East. "Rare but regular," would probably best characterize its appearance at lower levels. Not being harrassed by the rigors of winter, it has not shown that disposition to make friends (at the price of a bit of suet) which is making the eastern bird famous. It does, however, fall back somewhat before the Sierran snows; and it invades in winter certain lowland sections, which are promptly deserted in early spring. Even so, it enjoys a most extraordinary breeding range, from sea level (irregularly) up to the limit of trees in the Sierra Nevada.

\section{No. 128b Inyo Slender-billed Nuthatch}

\section{A. O. U. No. 727 d, part. Sitta carolinensis tenuissima Grinnell.}

Description.- "Similar to S. c. aculeata from west-central California, but bill much longer and slenderer, size larger, back of a darker tone of gray, and flanks paler; similar to $S$. c. nelsoni from southern Arizona, but bill much slenderer, and sides, and lower surface generally, whiter." Av. of 7 males: wing 89.5 (3.52); tail 49 (I.93); length of bill $20.5(.8 \mathbf{I})$. Depth at base 3.8 (.15).

${ }^{1}$ Condor, Vol. XIV., I9I2, p. 214 . The incident refers to $S . c$. nelsoni, a scarcely distinguishable form. 


\section{The Red-breasted Nuthatch}

Range of S. c.tenuissima.-At least the Panamint and White Mountains of California; probably also the western rim of the Great Basin north to eastern Oregon.

Authorities.-Fisher (Sitta carolinensis aculeata), N. Am. Fauna, no. 7, I893, p. I36, part (Panamint Mts.); Grinnell, Condor, vol. xx., I9I8, p. 88, fig. (orig. desc.; type locality, Panamint Mts.; meas., etc.).

THIS interesting subspecies, described by Grinnell from the White Mountains, which occupy the eastern border of Inyo and Mono counties, would not deserve special mention here save for a circumstance connected with its nesting. The slenderer and, therefore, weaker bill of this form requires accounting for. I think it may be due to this fact, that at the upper levels, say I0,000 alt., where the bird nests, it is usually able to avail itself of natural cavities, instead of being required to make with its beak a laborious excavation for the nest. The bird's bill, therefore, became debilitated through lack of exercise. At least the three nests we examined, May 26-28, I9I9, were natural cavities in the lodge-pole pine (Pinus contorta), although one of them had been partially enlarged by the birds.

The male Nuthatch is indefatigable in his devotion to his sitting mate; and when we wished to spy upon domestic secrets, we had only to watch diligently the comings and goings of male birds until the nest location was made. The notable paucity of bird life at this level was of assistance also, in that it simplified the quest.

\section{No. 129}

\section{Red-breasted Nuthatch}

\section{A. O. U. No. 728. Sitta canadensis Linnæus.}

\section{Synonyms.-Red-Bellied Nuthatch. Canadian Nuthatch.}

Description.-Adult male: Crown and nape shining black; white superciliary lines meeting on extreme forehead; a black band through eye; remaining upperparts grayish blue; wings fuscous, unmarked; tail-feathers, except upper pair, black; the outer pairs subterminally blotched with white in retreating order; chin, and sides of head, and neck below the black, pure white; remaining underparts rusty, or ochraceoustawny. Bill short, subulate, plumbeous-black; feet dark brown. Adult female: Similar, but crown like the back with only traces of black beneath; lateral head-stripe blackish; usually paler rusty below. Immature male: Like adult male, but paler below and black of head not glossy. Young female: Like adult, but duller. Length IoI.6-I20.6 (4.00-4.75); wing 66.3 (2.6I); tail $36.3(\mathrm{I} .43)$; bill I $4.4(.57)$; tarsus 16 (.63).

Recognition Marks.-Pygmy size; black and grayish blue above; rusty below; tree-creeping habits.

Nesting. - Nest: Of grasses, feathers, etc., in a hole of tree or stub, excavated by the bird, usually at lower levels. Eggs: 4 to 6; white or creamy white, speckled 


\section{The Red-breasted Nuthatch}

and spotted with reddish brown. Av. size $16 \times 12.2(.63 \times 48)$. Season: First week in May; one brood.

General Range.-North America at large, breeding from northern New England, northern New York, and northern Michigan northward, and southward in the Alleghanies, Rocky Mountains, and Sierra Nevada; also on Guadalupe Island, Lower California, and Santa Cruz Island, California; in winter south to about the southern border of the United States.

Distribution in California.-Summer resident of the Canadian zone in the Sierras and other ranges, as, the Warners, Trinities, San Jacintos, and sparingly in the

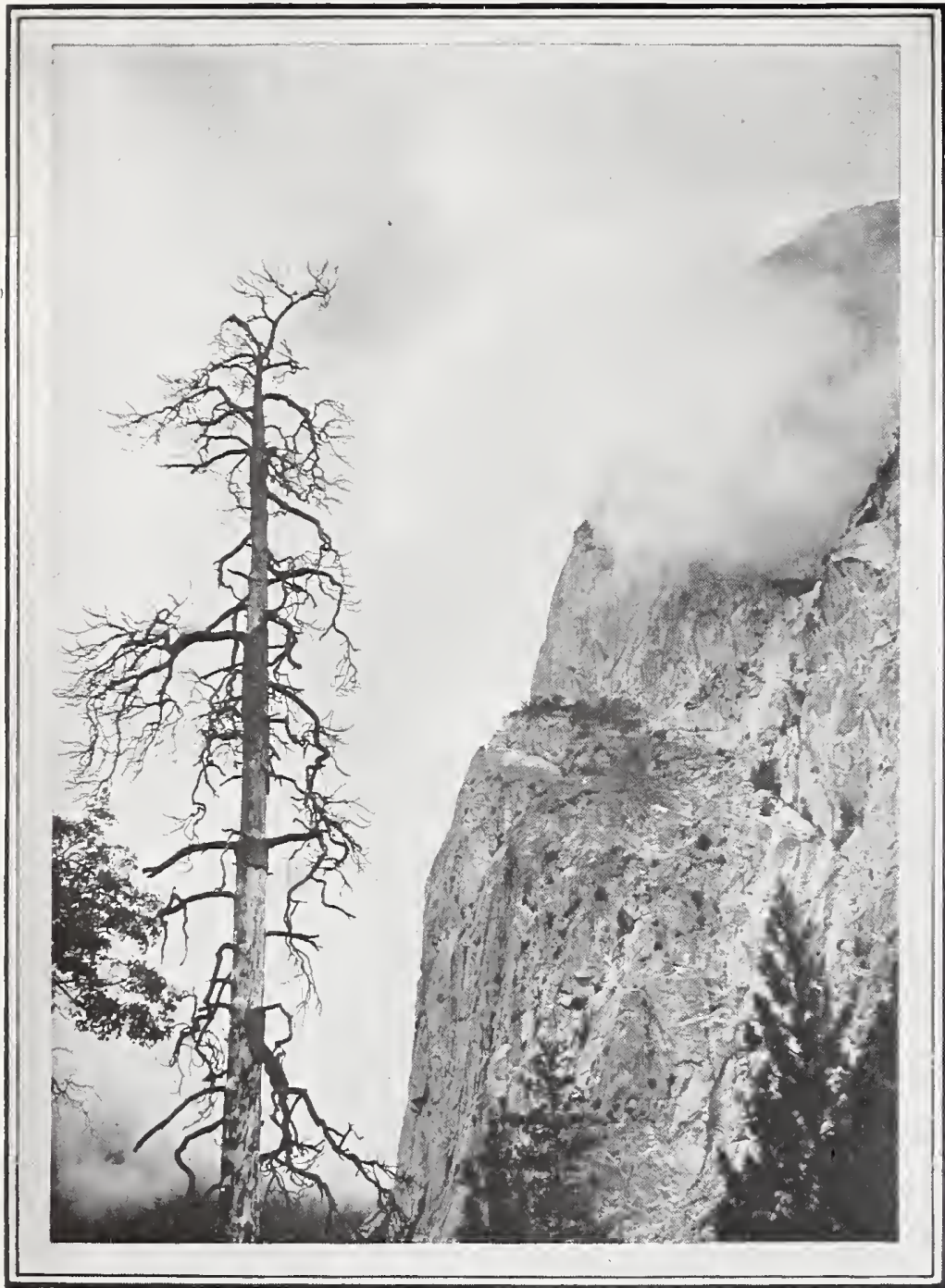

Taken in Fresno County

A NUTHATCH MAY LOOK AT A KING

Photo by the Author

AND DOUBTLESS MANY NUTHATCHES HAVE USED THIS OLD TREE TO OBTAIN A CLOSE-UP OF TEHIPITE DOME humid coast belt south at least to Cazadero in Sonoma County. Perhapsirregularly resident on Santa Cruz Island. Winters irregularly, sometimes abundantly, in wooded valleys at lower levels, practically throughout the State, or even at the edges of the desert. Casual upon the Farallon Islands (Bryant, and May 24, I9II, Author).

\section{Authorities.-Gambel,} Proc. Acad. Nat. Sci. Phila., vol. iii., I 846, p. I I 2 (Calif.); Coues, Birds Col. Val., I 878 , p. I36 (syn., desc., habits, etc.); Averill, Auk, vol. v., I 888 , p. I I 8 (feeding habits); Beal, U. S. Dept. Agric., Yearbook, I 900, p. 296 (food; relation to orchards); Howell, Pac. Coast Avifauna, no. I2, I9I7, p. 99 (Santa Cruz Id., probably breeding).

THERE is nothing big about the Redbreasted Nuthatch save his voice. If undisturbed, birdikins pursues the even tenor of his ways, like any other winged bug-hunter; but once provoke his curiosity or arouse suspicion, and he publishes forthwith a broadside of sen- 


\section{The Red-breasted Nuthatch}

sational editorial matter which no thoughtful reader of the woods can overlook. The full war-dance song of the Red-breasted Nuthatch, executed, for instance, when he hears the false notes of the California Screech Owl, is something like this:

Nyăă nyăă ny ăă

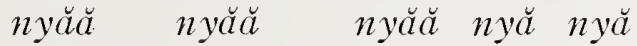

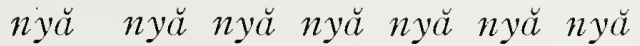
$n y \breve{a} n y \breve{a} n y \breve{a}$ and so on, in an incoherent strain of wild excitement, until he runs clean out of breath and quits, exhausted. The early notes of this orgic rhapsody are interrogative and penetrating; the succeeding notes are a sort of trumpeting challenge for the intruder to show himself; failing which, the irate creeper drops into a lower, non-resonant series, of doubtful meaning and more doubtful morals. But the bird is not always angry, and the nasal call sounding on migration has a friendly quality about it which brings one hastening out-of-doors to greet the traveler again.

When Dr. Cooper could write:1 "I have not myself met with the bird in California," it is perhaps not to be wondered at that our ideas of its relative distribution are still somewhat hazy, and accounts of its precise nesting habits in California lacking. It is a boreal-breeding, migratory species, and occurs in summer sparingly in the higher ranges of southern California, regularly throughout the timbered Sierras, and irregularly throughout the mountainous timbered districts of the northwestern counties. The occurrence of birds in the mountains of Santa Cruz Island as late as May 2nd (I9II), ${ }^{2}$ I do not regard as conclusive evidence of breeding, as this species is very irregular in its migratory movements; and those individuals which do not purpose nesting until

1 Ornithology of California, I870, p. 55.

2 Vide Howell in "Condor," XIII., I9I I, p. 2 Io. 


\section{The Pygmy Nuthatches}

June in the high Sierras linger late in the Southland. For instance, I saw a migrant Red-breast on the Farallons on the 24th of May of that same year (I9II).

Canadian Nuthatches nest at any height, and their lack of consideration in this respect accounts for much of our relative ignorance. I located a nest, in Seattle, in a nearly limbless live fir tree, at a height of I 20 feet. Obligations to a growing family forbade attention to details. On the other hand, a nest taken near Tacoma on the 8th of June, I 906, was found at a height of only seven feet, in a small fir stump. It would be unsafe to suggest that the cost of living in these rival towns had anything to do with the birds' choices: I only know that Tacoma nests adorn many collections. The wood of the last-named nesting stub was very rotten, and the eggs rested only four inches below the entrance. The nest-lining, in this instance, was a heavy mat an inch in thickness, and was composed of vegetable matter-wood fiber, soft grasses, etc.-without hair of any sort, as would surely have been the case with that of a Chestnut-backed Chickadee, for which it was at first taken.

The Nuthatches appear to leave their eggs during the warmer hours of the day, and one must await the return of the truant owners if he would be sure of identification. One mark, but not infallible, is the presence of pitch, smeared all around, and especially below, the nesting hole. The use of this is not quite certain, but Mr. Bowles's hazard is a good one; viz., that it serves to ward off the ants, which are often a pest to holenesting birds. These ants not only annoy the sitting bird, who is presumably able to defend herself, but they sometimes destroy unguarded eggs, or young birds.

No. 130

\section{Pygmy Nuthatch}

A. O. U. No. 730. Sitta pygmæa pygmæa Vigors.

Synonym.-California Nuthatch (early name).

Description.-Adults: Crown, nape, and sides of head to below eye, deep grayish olive; a buffy white spot on hind-neck (nearly concealed in fresh plumage); lores and region behind eye (bounding the olive) blackish; remaining upperparts grayish blue (dark green-blue-gray to clear Payne's gray), browning (brownish slate) on flight-feathers, etc., becoming black on rectrices (except central pair); longer primaries usually with some edging of white; central pair of tail-feathers with elongated basal white spot; two outer pairs crossed obliquely with white, and the three outer tipped with slate; underparts sordid white, smoky brown, or even pale ferruginous, clearest (nearly white) on chin and cheeks; sides, flanks, and crissum washed with color of back. Bill plumbeous, lightening below; feet plumbeous; iris black. Young: Like adults, but crown and hind-neck nearly color of back; sides and flanks washed 
with brownish. Length IOI.6 (4.00) or less; wing 65 (2.56); tail 34 (I.34); bill I 4.2 $(.56)$; tarsus $15(.59)$.

Recognition Marks.-Pygmy size; top of head olive-gray, contrasting with plumbeous of back; gregarious habits.

Nesting. - Nest: A hole in dead stub or dead top of pine tree, excavated by birds, smeared about entrance with pitch, and lined with soft substances, - grass, hair, and feathers. Eggs: 5 to 8; pure white, flecked more or less heavily with reddish brown. Av. size I 5.8 x I I.4 (.62 x .45). Season: May I-20; one brood.

Range of S. pygmea.-Western North America from southern British Columbia south, in the mountains, to Lower California and Mexico.

\section{California.}

Range of $S$. p. pygmaa.-As above, except southern California and Lower

Distribution in California.-Locally distributed in high Upper Sonoran or Transitional areas, chiefly in the Sierra Mountains, and in northern ranges from Shasta to the Warners, and in the vicinity of Monterey (the type locality). Found also sparingly elsewhere in the southern humid coastal district north to Mendocino County. A slight movement, or none, to lower levels in winter.

Authorities.-Vigors (Sitta pygmaa), Zool. Voy. "Blossom," I 839, p. 25, pl. 4, fig. 2 (orig. desc.; type locality, Monterey); Feilner, Ann. Rep. Smith. Inst. for I 864 ( I 865), p. 426 (n. Calif., habits); Coues, Birds Col. Val., I878, p. I39 (syn., desc., hist., habits, etc.); Fisher, N. Am. Fauna, no. 7 , I893, p. 137 (localities in Calif.); Beal, U. S. Dept. Agric., Biol. Surv. Bull., no. 30, 1907, p. 67 (food).

\section{No. 130a White-naped Nuthatch}

A. O. U. No. 730a. Sitta pygmæa leuconucha Anthony.

Description.- "Similar to S. p. pygmaa, but larger, especially the bill; color of pileum and hind-neck grayer, the latter with the buffy or pale buff spot decidedly larger; gray of back, etc., less bluish, and underparts less strongly buffy" (Ridgway). Adult male: wing 66.8 (2.63); tail 36.7 (1.45); bill I6.3 (.64); tarsus I6 (.63).

Range of $S$. p. leuconucha.-Resident in Transition and Lower Canadian zones in the mountain ranges of southern California, south to the San Pedro Martir Mountains, Lower California.

Authorities.-Cooper, Am. Nat., vol. viii., I874, p. 17 (Cuyamaca Mts., San Diego Co.); Grinnell, Univ. Calif. Pub. Zool., vol. v., I908, p. I 23 (San Bernardino Mts.; habits, desc. nest and eggs, etc.); Grinnell and Swarth, Univ. Calif. Pub. Zool., vol. x., I9I3, p. 3 Io (San Jacinto Mts.; occurrence; crit.).

AS FOR THE Pygmy, the pine tree is his home. It is not quite proper, however, to speak of this Nuthatch in the singular. Lilliputians must hunt in troops and make up in numbers what they lack in strength. Pygmy Nuthatches are not merely sociable; they are almost gregarious. Where a company of Kinglets would be content to straggle through a dozen trees, a pack of Pygmies prefers to assemble in one. Yet there is no flock impulse here, as with Siskins. Each little elf is his own master, and a company of them is more like a crowd of merry schoolboys than anything else. It's "come on, fellers," when one of the boys tires of a given tree, and sets out for another. The rest follow at leisure but 


\section{The Pygmy Nuthatches}

are soon reassembled, and there is much jolly chatter with some goodnatured scuffling, as the confederated mischiefs swarm over the new field of opportunity.



Taken in the San Jacinto Mountains

Photo by the Author

"THE PINE TREE IS HIS HOME"

Nuthatches are not methodical, like Creepers, in their search for insects; they are haphazard and happy. The branches are more attractive to them than the tree bole, and the dead top of the tree is most alluring of all. The Pygmies are never too busy to talk. The more they find the more excited their chatter grows, pretty lispings and chirpings quite too dainty for our dull ears. It makes us sigh to watch their happiness, and we go off muttering, "We, too, were young."

Again, it shocks us when we find these youngsters in knickerbockers and braids paired off for nesting time. Tut, tut! children, so eager to taste life's heavier joys? A nest is chiselled out with infinite labor on the part of these tiny beaks, in the dead portion of some pine tree. The cavity is from four to twelve inches in depth, with an entrance a trifle over an inch in diameter. The owners share the taste of the Chickadees, and prepare an elaborate layette of soft vegetable fibers, fur, hair, and feathers, in which the eggs are sometimes quite smothered. 
The parents are as proud as peacocks, and well they may be, of their six or eight oval treasures, crystal white, with rufous frecklings, lavish or scant. When the babies are hatched, the mother goes in and out fearlessly under your very nose; and you feel such an interest in the little family that you pluck instinctively--but alas! with what futilityat the fastenings of your purse.

Those of our readers who are not interested in collecting, or who profess disdain for its quasi cruelties, are admonished to pause here; for we cannot forbear to recite the circumstances attending the taking of two sets of eggs now in the Museum of Comparative Oology: No. 56/6-I3, White-naped Nuthatch, May 25, I913, San Jacinto Mountains; elevation 4000 feet; discovered by tracing male bird to nesting hole 45 feet up in lone yellow pine, where he made frequent trips to feed his mate. The nesting cavity, approached by an entrance hole $\mathrm{I} / 2$ inches in $\mathrm{di}$ ameter, had evidently been carved out by the birds; but it was very irregular in shape, the sides being deeply fluted by intrusive pillars of harder wood. The interstices and pockets so fashioned had been carefully calked with fur and feathers of the same general character as that of the material used in the remainder of the nest. On the face of this lateral padding, had been arranged an elaborate system of draperies, consisting chiefly of the wing quills of the California Woodpecker (Balanosphyra formicivorus bairdi). The

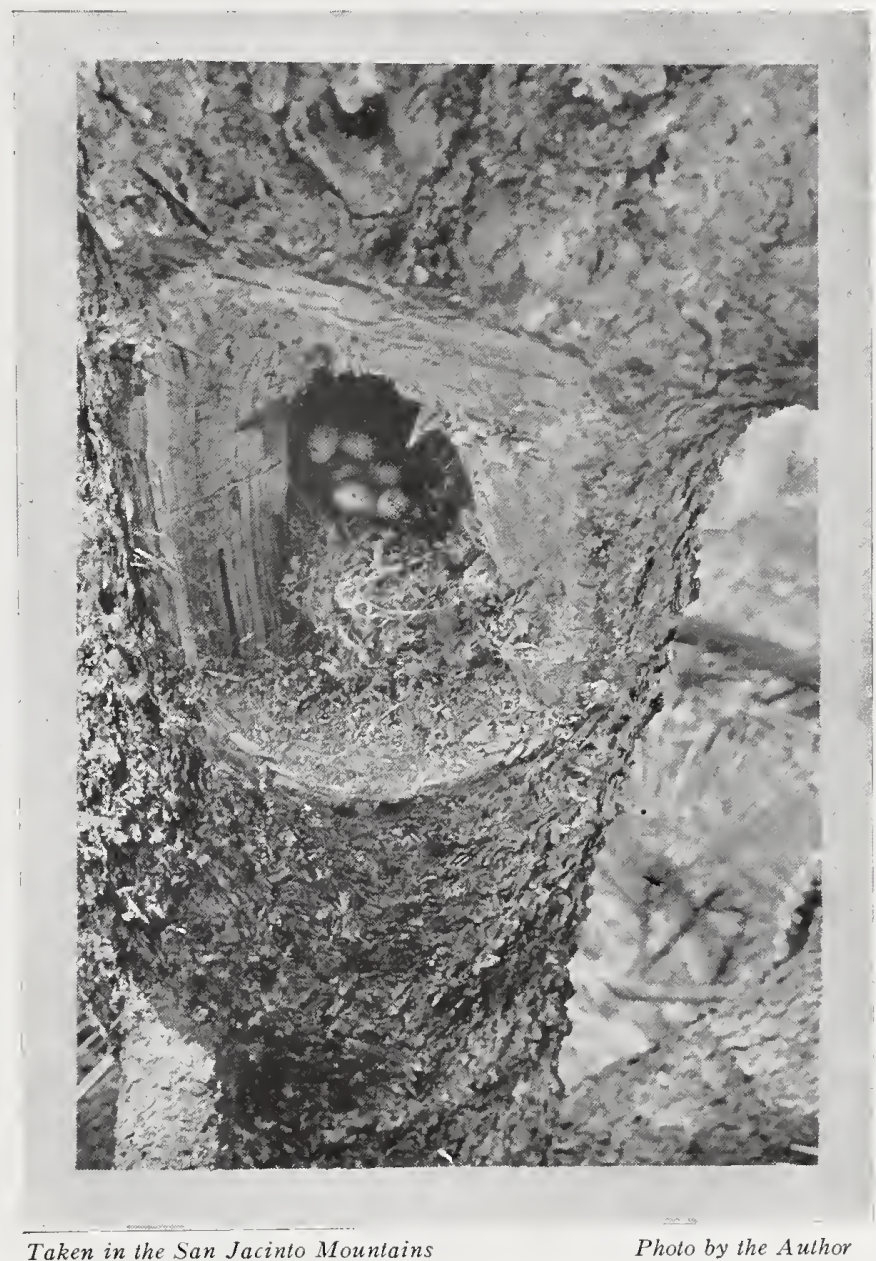

No. $56 / 6-13,1 \mathrm{~N}$ SITU 


\section{The Pygmy Nuthatches}

hollow was thus a feather-lined shaft, with the nest proper built up half way from the bottom.

The second set, taken on the 2nd of June, I9I3, at an elevation of 6000 feet in the San Jacinto Mountains, came from a naked stub of black oak. An inquiring rap on the trunk had brought the excited mistress from a hole 15 feet up. But she returned almost immediately and no amount of disturbance at the foot of the stub would induce her to feint or loaf around for photographic purposes. I suspected young and so dug in with proper precautions for restoring the front wall if necessary, but found instead only an empty cavity six inches deep. Upbraiding myself for a dub, I descended in a daze, wondering how an excavating bird could have been so fearless and so persistent. Once on the ground

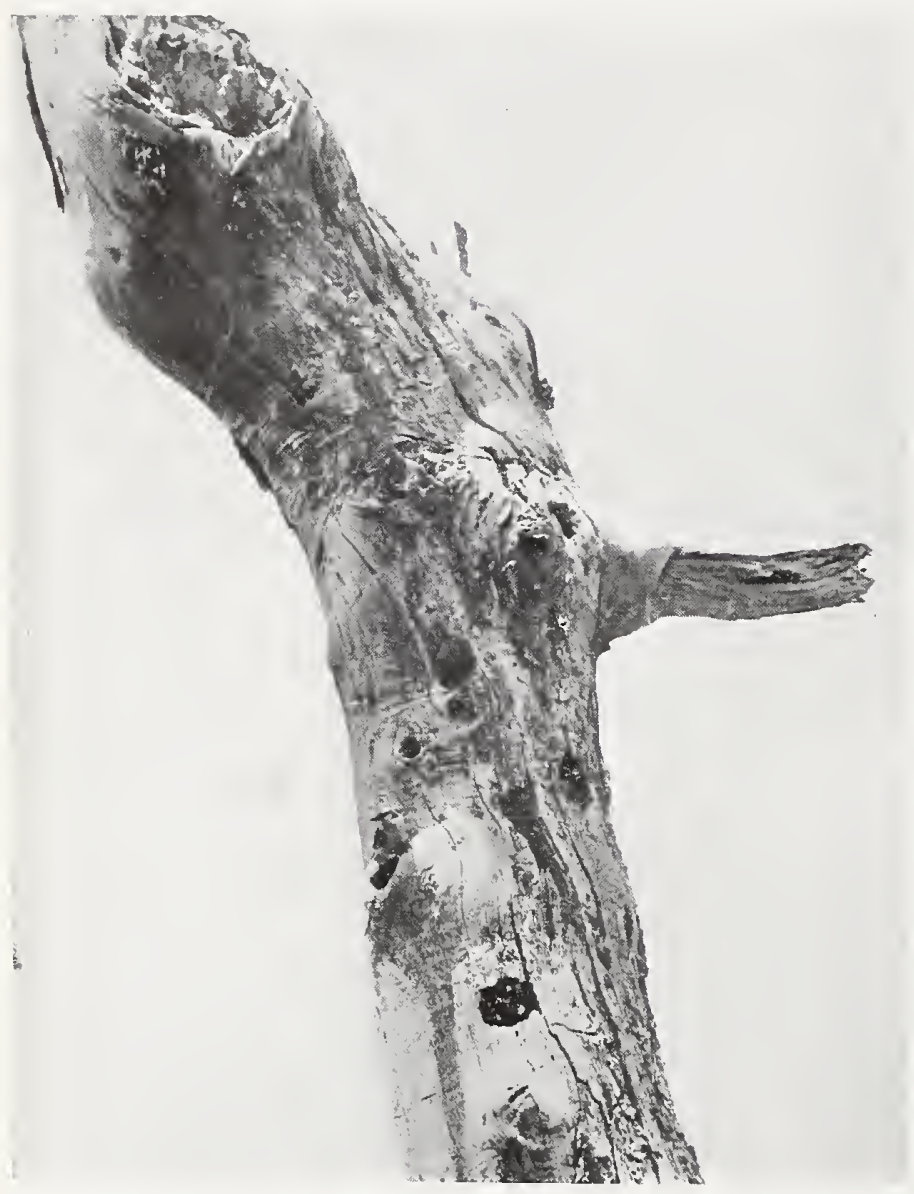

Taken in the San Jacinto Mountains

"A NAKED STUB OF BLACK OAK"

THE FEMALE NUTHATCh MAY BE SEEN JUSt ABOVE THE ENTRANCE hole again, however, I saw the back of the cavity, which in my strained position in the tree I had not seen. Midway there was another entrance to an inner chamber. William, my assistant, went up and developed it, reporting first two eggs, then four, then six. Inasmuch as the position was very straining, he retired and left me to finish. As soon as I put my fingers under the nest to lift it a deluge of eggs poured out. The nest was so thin that the bottom fell out when it was touched. Fortunately, a detaining chip poised on edge prevented the oval cascade from rushing down into the hollow of the tree which now yawned below. I worked my handkerchief in to reinforce the chip, and managed to lift the fallen eggs one by one, four of them, unbroken. It was a delicate task, for my sartorius muscles, by which alone I retained my hold on 


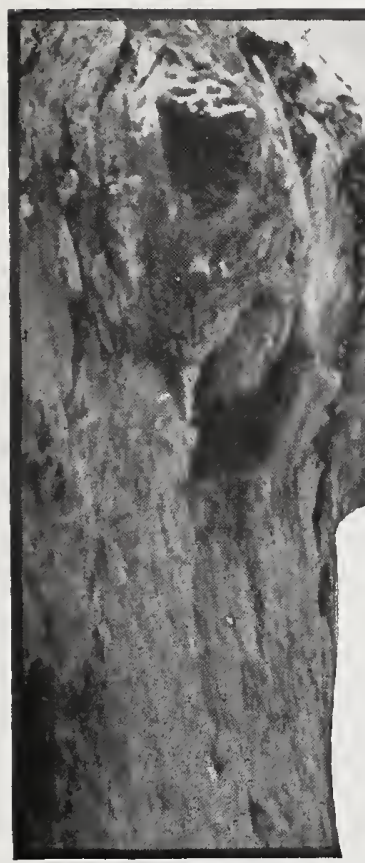

the smooth tree-trunk, were quaking like cowards. One by one the eggs went into the open hat, and then I felt inside,-one, two, three, four more. Taken in the San Jacinto Mis.

Photo by the Author Most bounA TENDER PASSAGE tiful! And fresh at that.

As soon as I descended, the late proprietress began an elaborate tour of investigation. She inspected the nest cavity; she seized bits of nest lining, carried them out to the light and sifted them to bits. She entered neighboring holes and tested other cavities; but chiefly she returned ever and again to the home cavity to peck and peck and peck. Time after time she came back, and chip after chip she removed as though in hopes to discover some secret panel through which her treasures had disappeared. The male bird paid little attention to the catastrophe and did not appear to understand its gravity at all. Once he came to feed his mate, in the regular way of business, and she came out to meet him on a neighboring branch, receiving his present with quivering wings and tender twitterings, as though nothing had gone wrong. But immediately thereafter the male disappeared and the female returned to her fruitless quest.

A sympathetic Hummer, however, showed a morbid interest in her neighbor's mishap. Several times she fluttered inquiringly in front of the ruined house, and once she followed the male off, like an excited gossip demanding the news. But Sitta pygmaa answered never a word. He had sighted another bug.

No. 131

\section{Brown Creeper}

No. 131a Sierra Creeper

A. O. U. No. $726 \mathrm{~d}$. Certhia familiaris zelotes Osgood.

Synonym.-California Creeper (Ridgway). 


\section{The Brown Creepers}

Description.-Adults: Above brownish black, varied by rusty brown, broadly and loosely streaked with ashy white; more finely and narrowly streaked on crown; rump bright reddish brown (argus brown to russet); wing-quills crossed by two pale ochraccous buffy bars, one on both webs near base (white on inner web), the other on outer webs alone; greater coverts, secondaries, and tertials tipped with whitish or grayish buff; tail graduated, fuscous with pale brown shafts; a narrow superciliary stripe dull whitish or brownish gray; underparts white, pure on throat, becoming sordid posteriorly, tinged on sides and flanks with dull brownish gray; crissum ochraceous buff. Bill slender, decurved, brownish black above, paler below; feet and legs brown; iris dark brown. Length of adult male about 139.7 (5.50); wing 63.5 (2.50); tail 60.8 (2.39); bill I6 (.63); tarsus I $5(.59)$. Female a little smaller.

Recognition Marks. - Warbler size; singularly variegated in modest colors above; the only brown creeper in its range. Blacker above and whiter below than the next form.

Nesting.- Nest: Of twigs, bark-strips, moss, plant-down, etc.; crowded behind a warping scale of bark, whether of cedar, pine, or fir. Eggs: Usually 5 or 6 , sometimes 7 or 8 ; white or creamy white, speckled and spotted with cinnamon-brown or hazel, chiefly in wreath about larger end. Av. size I5.5x I I.4 (.6Ix.45). Season: Mlay-June; one brood. Africa.

Range of Certhia familiaris.-The greater part of Northern Hemisphere, except

Range of C.f.zelotes.-The Cascade-Sierra Mountain system, broadly, in Oregon and California, and south to the Cuyamaca Mountains, retiring regularly to adjacent lowlands in winter.

Distribution in California.-Common resident in Canadian and Transition zones throughout the Sierra Nevada and associated ranges, south to the southern border of the State; also west along the inner northern coastal ranges, and in the pine belt of the San Rafael group. Winters irregularly and sparingly at the lower levels, e. g., Santa Barbara and the Mohave Desert.

Authorities.-Woodhouse (Certhia familiaris), in Sitgreaves' Rep. Expl. Zuni and Colorado Rivers, I853, p. 66, part (Calif.); Barlow, Condor, vol. ii., I900, p. 59 (Eldorado Co., breeding; desc. nest and eggs); Osgood, Auk, vol. xviii, I9oI, p. I82 (orig. desc.; Battle Creek, Tehama Co.); Grinnell. Univ. Calif. Pub. Zool., vol. v., I908, p. I20 (San Bernardino Mts.; desc. nest and eggs, habits, etc.).

\section{No. 131b California Creeper}

A. O. U. No. 726c. Certhia familiaris occidentalis Ridgway.

Synonym.-Tawny Creeper.

Description.- "Similar to C. f. zelotes, but browner and more suffused with buffy above; wing markings more pronouncedly buff; underparts more buffy" (Ridgway); also rusty of rump averaging brighter (light amber-brown). Length of male: wing 6I.9 (2.44); tail 6I.2 (2.4I); bill I 5.2 (.60); tarsus I 5.5 (.6I).

Nesting.- Nest: As in preceding; placed behind sprung bark scale, preferably of fir or redwood, and usually at moderate heights- 3 to 20 feet up (one record of 6o). Inner diameter of one nest $13 / 4$ inches, depth $21 / 2$. Eggs: 5 or 6 ; as in C.f. zelotes. Season: May-June; two broods.

Range of $C$. $f$. occidentalis.- The Northwest Pacific coastal strip, broadly in the north, to Sitka, Alaska, narrowly in the south to Monterey County, California.

$$
652
$$




\section{The Brown Creepers}

Distribution in California.-Resident in the northwest humid coastal strip south to Big Creek, Monterey County; occurs in winter in the San Francisco Bay region and doubtless elsewhere at lower levels.

Authorities.-Cooper (Certhia mexicana), Orn. Calif., r87o, p. 58, part (Coast Ranges, south to Santa Cruz); Ridgway, Proc. U. S. Nat. Mus., vol. v., I 882, p. 257 , part (orig. desc.; distr. in Calif.); Grinnell, Condor, vol. iv., I902, p. I 26 (Monterey Co.; habits); Beal, U. S. Dept. Agric., Biol. Surv. Bull., no. 30, I907, p. 66 (food); Pemberton and Carriger, Condor, vol. xvii., I9I5, p. 199 (Monterey Co., nesting).

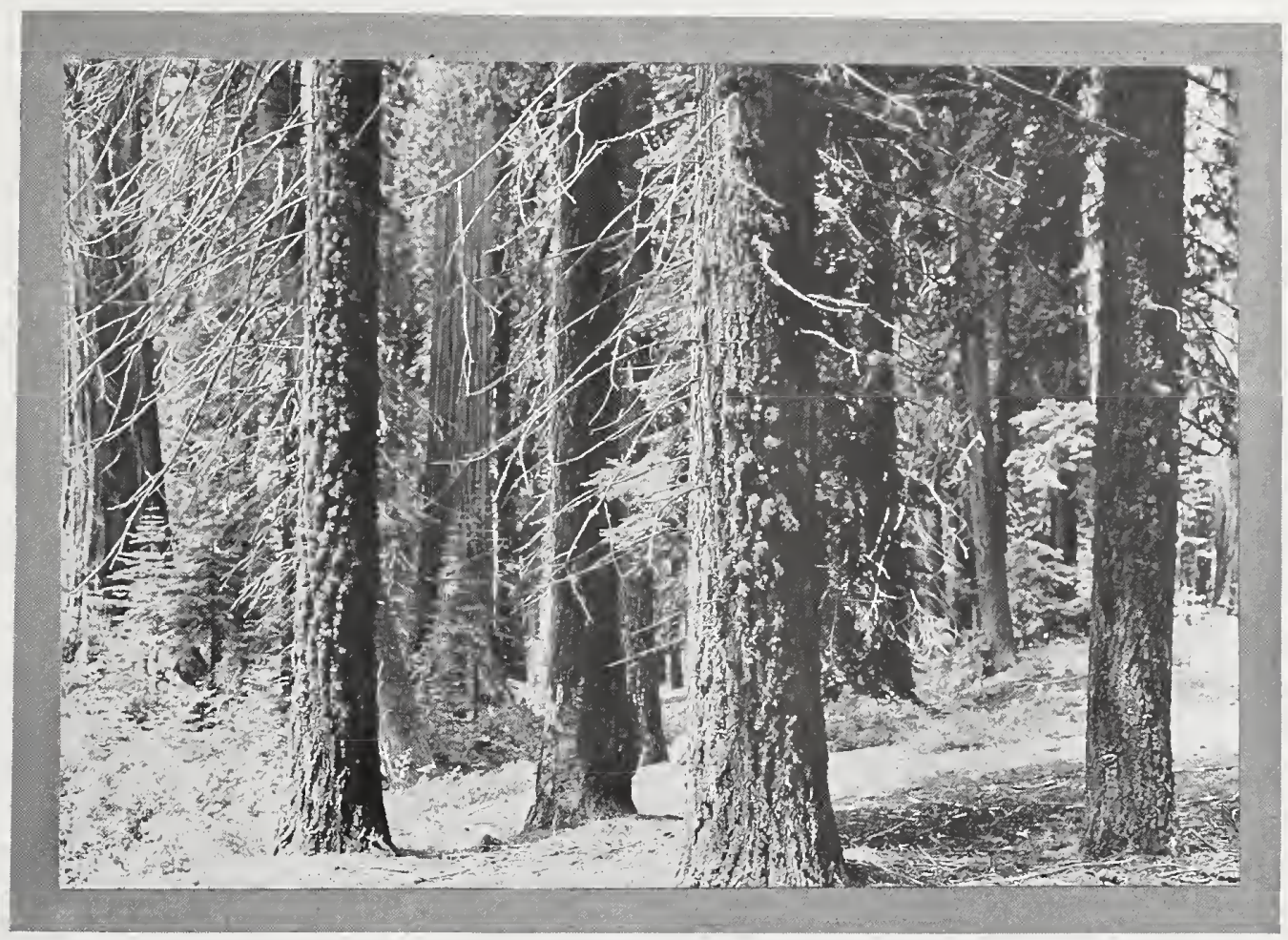

Taken in Fresno Couniy

Photo by the A uthor

TO ONE who loves birds with an all-inclusive passion-such as the undecided bachelor is wont to confess for the fair sex-the temptation to use superlatives upon each successive species, as it is brought under review, is very strong. But here, perhaps, we may be pardoned for relaxing our attention, or, it may be, for being caught in the act of stifling a little yawn. Certhia is a prosy drab, and all the beauty she possesses is in the eyes of her little hubby-dear, devoted creature.

This clerkling (hubby, of course, I mean) was brought into the world behind a bit of bark. His first steps, or creeps, were taken along the bark of the home tree. When the little wings got stronger and when 


\section{The Brown Creepers}

the little claws had carried him up to the top of tree Number One, he fluttered and spilled through the air until he pulled up somehow, with

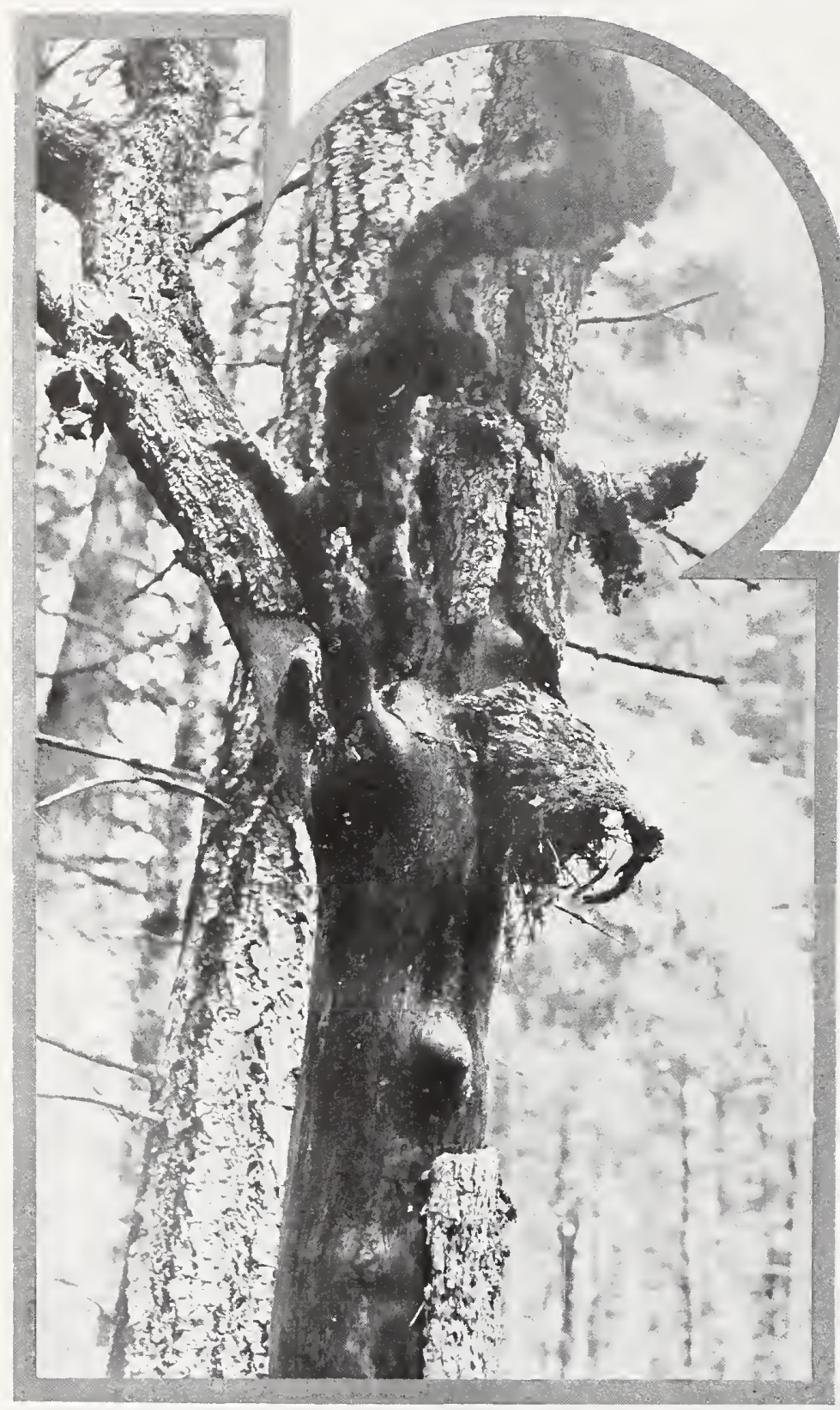

Taken in Washington

Photo by the A uthor

NEST OF CALIFORNIA CREEPER IN DEAD OAK TREE THE NEST APPEARS UNDER THE BARK-SCALE AT THE RIGHT, AND THE MARVEL IS HOW
IT MAINTAINS ITS POSITION heart beating fiercely, at the base and on the bark of tree Number Two. Since then he has climbed an almost infinity of trees (but I dare say he has kept count). Summers and winters have gone over his head, but never a waking hour in which he has not climbed and tumbled in this worse than Sysiphæan task of gleaning nits and eggs and grubs from the never-ending bark. Why, it gets upon the nerves! I pray you think, has not this animate brown spot traveled more relative miles of ridgy brown bark in his wee lifetime than ever mariner on billowy sea! Work, work, work! With the industry of an Oriental he seeks to shame the rollicking caprice of Chickadee, and to be a "living example" to such spendthrifts as Goldikins, the Kinglet.

But wait! I am not sure. Could anyone live in these majestic forests, could anyone breathe this incense of perpetual balsam, could 
The Brown Creepers

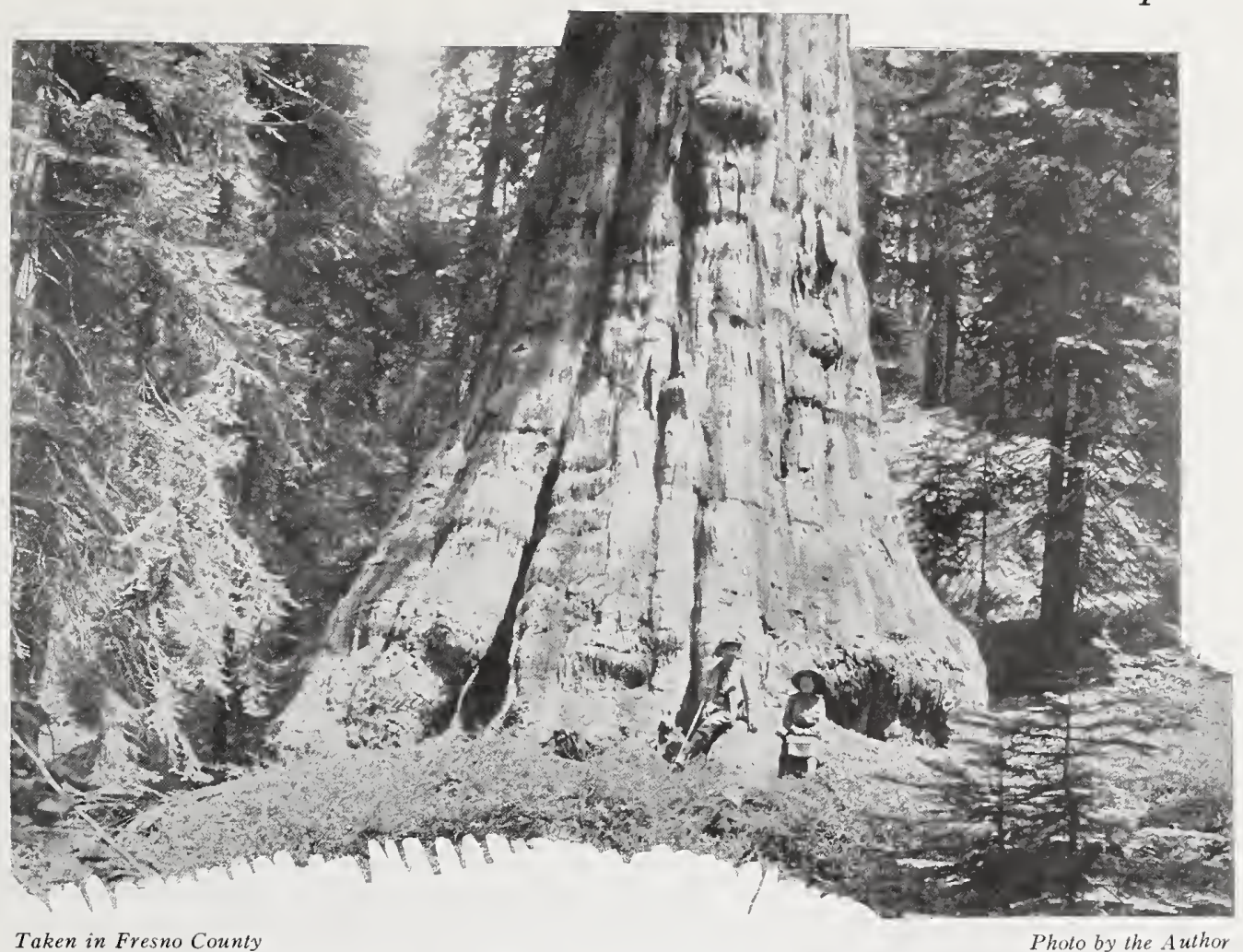

Taken in Fresno County

Photo by the A uthor

THE GIANT TREE OF THE MCKINLEY GROVE, PARTIALLY DESTROYED BY FIRE

anyone mount triumphantly these aspiring tree-boles, way, way up into the blue, without growing the soul of a poet? Hark! Tew, tewy, tewy, pi $\tilde{n} g$, tewy, - an angel ditty lisped in the tree-tops where the tender green fir-fronds melt into the sky-some Warbler, I guess; the Hermit, perhaps,

rounding out his unsaid devotions. And again, kee kus wit it tee swee

like a garland of song caught up at either end and made fast to the ether. No! Would you believe it! It is our prosy clerkling! He has turned fay, and goes caroling about his task as blithely as a bejeweled artiste with nothing to do. Love? Yes; love of the woods, for it is the middle of September.

All of which leads me to apologize for the rude epithets previously used; for one who can sing belongs to the immortals; and never again will we judge a brother harshly, for who knows the vaulting heart of the seeming plodder!

The ordinary, working note of the Tawny Creeper is a faint tsip, and this is varied from time to time by a longer double note, tsue tsee (of a resonant quality which cannot be made to appear in the transcript). 


\section{The Brown Creepers}

This latter it is which one can never quite certainly distinguish from that of the Western Golden-crowned Kinglet. The full song is, indeed, very sweet and dainty, with a bit of a plaintive quality, which serves to distinguish it from the utterances of the Wood Warblers, once you are accustomed.

A knowledge of the Creeper's nesting habits would be quite unattainable were the bird to choose the tree-tops; but with characteristic humility it seeks the lower levels at the nesting season, so that one need not look much above his head in searching for its nest. The dainty charm of the Creeper's nest, as well as its cunning seclusion, gives zest to a search which in the case of several veteran nidologists has been almost a passion. If the Creeper had not told us, we should scarcely be aware of the tendency of bark, especially in the case of dead trees, to warp and curl away from the parental stem. But the Creeper found this out early in the game, so behind the sprung bark scale his nest is neatly and often invisibly ensconced. Showing, as it does in California, a strong preference for evergreen trees, the bird uses only such other deciduous host-trees as happen to be closely associated with firs or pines. Its commoner preference is for the incense cedar (Libocedrus decurrens) in the Sierras, or for the Redwood (Sequoia sempervirens) in the coastal region. In both these trees great vertical strips of bark are likely to become detached at the lower end and to warp up slowly from the bottom. In such case the Creepers avail themselves of the certain shelter from rain which is provided by the uppermost angle of attachment, even though the yawning space below has to be bridged or floored, by twigs and barkfragments laboriously braced. For the felted mass of the nest proper the bird requires little besides the fine shredded bark, as soft as satin, of cedar or redwood. But if the host-tree happens to be a fir or maple scorched by a quick running fire and so yielding a bent plate or two, the excess space of the cavity chosen is first filled up with sticks, barkstrips, moss, cotton and every other sort of woodsy loot. As the top is approached, only materials of exquisite fineness are chosen, and into the upper stratum of the crescent-shaped cushion so formed (its outlines being determined by the curve of the tree trunk, and the sharper curve of the springing bark scale) a deep cup is sunk,- the nesting hollow proper.

Bark scales of exactly suitable dimensions are not always to be had; and the very charm of Creeper nests lies in their great variety, and in the pluckily skillful adaptiveness displayed in their construction. Here is a nest which enjoys a three inch fairway between trunk and bark-room to burn! while here is another so scanted, one and a quarter inches, that the wood must serve for sidewalls in the inner cavity, while

$$
656
$$


the bird herself is obliged to sit lengthwise of the crescent. In a nest which the author took on Sugar Hill, in Modoc County, the entrance crevice was only five-eighths of an inch across!

So great is the scarcity of suitable nesting sites in country otherwise desirable for the birds, that an ingenious friend of mine has hit upon the scheme of putting out an extensive line of decoys. In the depths of the woods he nails up curling bark strips, as inconspicuously as possible, against sound tree boles. And from a line of, say, thirtyfive or forty traps he gathers an annual vintage of five or six sets of Creepers' eggs. It is only fair to add that the birds profit in the long run by this arrangement for they are allowed to raise second broods undisturbed throughout an area which offers no other shelter.

No. 132

\section{Marsh Wren}

\section{No. 132a Tule Wren}

A. O. U. No. 725a. Telmatodytes palustris paludicola (Baird).

Synonyms.-Marsh Wren (locally). Western Marsh Wren (now restricted to T.p.plesius). California Marsh Wren (inappropriate). Pacific Marsh Wren.

Description.-Adult: Similar to $T$. p. plesius, but smaller and with coloration decidedly darker. Length about I 20.6 (4.75); wing 50 (1.97); tail 44 ( 1.73 ); bill $\mathrm{I} 3.2$ $(.52)$; tarsus $20(.78)$.

Recognition Marks.-Pygmy size; brownish coloration; reed-haunting habits and sputtering notes distinctive.

Nesting.- Nest: Shaped like a cocoanut, of reeds and grasses, lined with plantdown, and with entrance in side; placed two or three feet high in reeds; rarely, high in bushes of swamp. Eggs: 5 or 6, ground-color grayish brown, but so heavily dotted and clouded with varying shades of brown as to be frequently obscured. Av. size I6 x I2.2 $(.63 \times$.48). Season: Last week in March to July; two broods.

Range of Telmatodytes palustris.--United States and southern Canada, wintering south into Mexico.

Range of T. p. paludicola.-Pacific Coast strip, breeding from British Columbia to the San Diegan district, wintering from Puget Sound south to Cape San Lucas and northwestern Sonora.

Distribution in California.- "Resident locally in marshy tracts. In northern California, the region west of the Coast ranges; south of San Francisco Bay, along the coast, in the Santa Cruz and San Diegan regions, probably to the Mexican boundary line" (Swarth).

Authorities.-Gambel (Troglodytes palustris), Proc. Acad. Nat. Sci. Phila., vol. iii., I 846, p. I I 3 (Calif.); Coues, Birds of the Northwest, I874, p. 34, part (syn.; life hist.) ; Beal, U. S. Dept. Agric., Biol. Surv. Bull., no. 30, 1907, p. 62 (food); Ray, Condor, vol. xviii., 1916, p. 226 (San Francisco; nesting dates); Swarth, Auk, vol. xxxiv., I917, p. 308, map (syst.; desc.; range in Calif., etc.). 


\section{The Marsh Wrens}

NEXT AFTER the frogs, the Tule Mrens are the noisiest choristers of all sunlit February swamps. One hesitates to call the medley of clicking, buzzing, and sputtering which welters in the reeds, music; but if one succeeds in catching sight of a Tule IVren, holding on for dear life to a cat-tail stem, and vibrating like a drill-chuck with the effort of his impassioned utterance, he feels sure that music is at least intended.

Wrens are ever busybodies, and if they could not sing or chatter, or at least scold, they surely would explode. It is a marvel, too, that they find so much to interest them in mere reeds, now green, now brown, set above a foot or so of stagnant water. But, bless you! Do not waste your sympathies upon them. They have neighbors-Red-wings, Yellow-throats, and the like-and is it not the gossips of the little village who are most exercised over their neighbors' affairs?

The name "Tule" which we have applied to our Pacific Coast bird must not be taken to imply any divergence in general habits from the Marsh Mrens of the remoter interior. They are Marsh Wrens all, and they avail themselves of whatever cover offers,-tules (Scirpus lacustris occidentalis) on Tulare Lake, cat-tails in the intersecting channels of the Monterey Gun Club, salicornia (S. ambigua) in the San Francisco Bay region and in all coastal marshes where the supply of cat-tails is inadequate. In autumn the Tule Wrens leave the sheltered precincts of the ponds, and go roaming about through dry weed patches and adjacent chaparral. Here they are as noisy and as elusive as ever, and are in nowise awed by their less usual surroundings. There is, doubtless, some invasion from the north and consequent crowding in winter. The swamps of Los Angeles County certainly contain (or fail to contain) more birds in winter than in summer; but whether our local birds stand by their guns in winter, we shall never know until we have put into force some comprehensive passport system.

Nesting is a less urgent matter in the South, and Willett's record of "six, slightly incubated," April 15, I904, seems to be the earliest record for southern California. We used to find them in March at Tacoma, and full sets were the rule by the first week in April. It is possible, however, that, as in so many other cases of California birds, this species, long familiarized to observation in the East, has not been closely studied in our State. Our students have been ever on the lookout for novelties, and it is a curious fact that Condors and Solitaires are better known to California ornithologists than Jenny Wrens and Titmicemihi conscius sum culpa.

The eggs of Marsh Wrens, usually five or six in number, are so overlaid with tiny dots as to appear of an almost uniform wood-brown (wood-brown, army brown or verona brown to natal brown, scarcely

$$
058
$$


"mahogany" or "chocolate"),- -very dark, except occasionally in the case of the last-laid egg. These eggs are not only among the handsomest known, but they form another exception to the "rule" that eggs laid in holes are white. We may scarcely suppose that the hole-nesting habit is one recently acquired, and yet I once found at Los Baños a Tule Wren's nest whose contents, four eggs, were entirely exposed, as in a blackbird's nest. The sitting bird must subject her eggs to frequent turning in the nest, for they become highly polished during incubation.

\section{No. 132b Western Marsh Wren}

A. O. U. No. $725 \mathrm{c}$. Telmatodytes palustris plesius (Oberholser).

Synonym.-Interior Marsh IVren.

Description.-Adult: Crown blackish; forehead warm brown (brussels brown), centrally,--color sometimes spreading superficially over entire crown; hind-neck and scapulars a lighter shade of brown; rump bright brown (sudan brown); a triangular patch on back blackish, with prominent white stripes and some admixture of brown; wings and tail fuscous or blackish on inner webs, brown with black bars on exposed surfaces; upper and under tail-coverts usually more or less distinctly barred with dusky; sides of head whitish before, plain brown or punctate behind; a white superciliary line; underparts white, tinged with ochraceous buff across breast, and with pale cinnamonbrown on sides, flanks, and crissum. Bill blackish brown above, paler brown below; feet and legs brownish. Length II4.3-I46 (4.50-5.75); av. of Io males: wing 54 (2.12); tail 46.4 (I.82); bill I4.2 (.56); tarsus 20. I (.79).

Recognition Marks.-Warbler size; brown and black pattern of back with white stripes distinctive; white superciliary stripe and long bill distinctive in haunts. Strictly confined to bulrushes and long grass of marshes. Lighter and larger than T. p. paludicola.

Nesting.- Nest: A ball of reeds and grasses, chinked and lined with cattail-down, with entrance in side, and suspended in growing cattails, bulrushes, or bushes. Eggs: 5 to 7 ; so heavily speckled with snuff-brown or bister as to appear almost uniform brown. Av. size I6 x I2.2 (.63 x .48). Season: May-July; two broods.

Range of T. p. plesius.-The Great Basin region, broadly; breeding in Upper Sonoran zone from central British Columbia south to northeastern California and Mexico; wintering from California and central Texas south to the Tropic of Cancer.

Authorities.-Cooper (Cistothorus palustris), Orn. Calif., I 870 , p. 75, part (Lake Tahoe); Grinnell, Condor, vol. v., I903, p. I33 (occurrence in s. Calif.); Swarth, Auk, vol. xxxiv., I9I7, p. 308, map (syst.; desc.; range in Calif., etc.).

\section{No. 132c Suisun Marsh Wren}

A. O. U. No. 725a, part. Telmatodytes palustris æstuarinus Swarth.

Synonyms.-San Joaquin Marsh Wren. Swarth's Marsh Wren.

Description.--Like T. p. paludicola, but larger and somewhat darker; like T. p. plesius in size, but much darker.

Range of T. p. astuarinus (Wholly confined to California).-Breeds in the 


\section{The Marsh Wrens}

estuary region of the Sacramento River and in the San Joaquin Valley; winters irregularly south to the San Diego district.

Authorities.-Heermann (Troglodytes palustris), Jour. Acad. Nat. Sci. Phila., ser. 2, ii., I853, p. 263 (Sacramento Valley); Swarth, Auk, vol. xxxiv., 1917, p. 308, map (orig. desc.; type locality, Grizzly Id., Solano Co.).

"TO THE COOTS and Rails belong the ooze-infesting morsels of the swamp; but all the little crawling things which venture into the upper story of the waving cat-tail forest belong to the Marsh Wren. Somewhat less cautious than the waterfowl, he is the presiding genius of flowing acres, which often have no other interest for the ornithologist. There are only two occasions when the Marsh Wren voluntarily leaves the shelter of the cat-tails or of the closely related marshables. One of these is when he is driven South by the migrating instinct. Then he may be seen skulking about the borders of the streams, sheltering in the weeds or clambering about the drift. The other time is in the spring, when the male shoots up into the air a few feet above the reeds, like a ball from a Roman candle, and sputters all the way, only to drop back, extinguished, into the reeds again. This is a part of the tactics of his courting season, when, if ever, a body may be allowed a little liberty. For the rest, he clings sidewise to the cat-tail stems or sprawls in midair, reaching, rather than flying from one stem to another. His tail is cocked up and his head thrown back, so that, on those few occasions when he is seen, he does not get credit for being as large as he really is" (The Birds of Ohio).

Since his sphere of activity is so limited, we may proceed at once to the main interest, that of nest-building. And this is precisely as the Marsh Wren would have it, else why does he spend the livelong day making extra nests, which are of no possible use to anyone, save as examples of Telmatodytine architecture? It is possible that the female is coquettish, and requires these many mansions as evidence that the ardent swain will be able to support her becomingly after marriage. Or, it may be, that the suitor delights to afford his lady love a wide range of choice in the matter of homes, and seeks thus to drive her to the inevitable conclusion that there is only one home-maker for her. However this may be, it is certain that one sometimes finds a considerable group of nest-balls, each of apparent suitability, before any are occupied.

On the other hand, the male continues his harmless activities long after his mate has selected one of his early efforts and deposited her eggs; so that the oölogist may have to sample a dozen "cock's nests," or decoys, before the right one is found. Some empty nests may be perfectly finished, but others are apt to lack the soft lining; while still 
others, not having received the close-pressed interstitial filling, will be sodden from the last rains.

The Marsh Wren's nest is a compact ball of vegetable materials, lashed midway of cat-tails or bulrushes, living or dead, and having a neat entrance-hole in one side. A considerable variety of materials is used in construction, but in any given nest only one textile substance

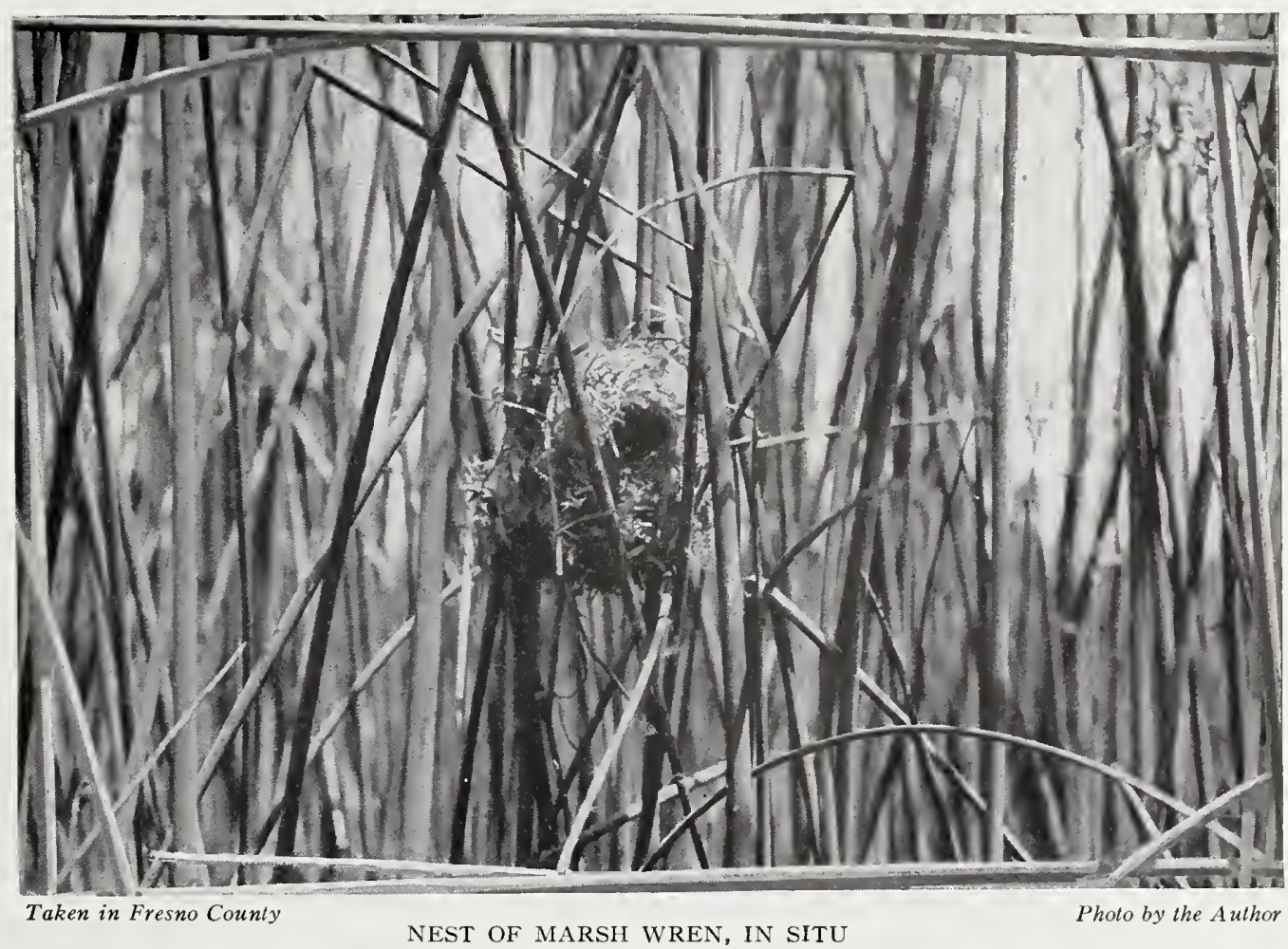

will preponderate. Dead cat-tail leaves may be employed, in which case the numerous loopholes will be filled with matted down from the same plant. Fine dry grasses may be utilized, and these so closely woven as practically to exclude the rain. In shallow lakes where rankly growing bulrushes predominate in the nesting areas, spirogyra is the material most largely used. This, the familiar, scum-like plant which masses under water in quiet places, is plucked out by the venturesome birds in great wet hanks and plastered about the nest until the required thickness is attained. While wet, the substance matches its surroundings admirably, but as it dries out it shrinks considerably and fades to a sickly light green, or greenish gray, which advertises itself among the obstinately green bulrushes. Where this fashion prevails, one finds it 


\section{The Cactus Wren}

possible to pick out immediately the oldest member of the group, and it is more than likely to prove the occupied nest.

The nest-linings are of the softest cat-tail down, feathers of wild fowl, or dried spirogyra teased to a point of enduring fluffiness. It appears, also, that the Wrens often cover their eggs upon leaving the nest. Thus, in one we found on the $17^{\text {th }}$ of May, which contained seven eggs, the eggs were completely buried under a loose blanket of soft vegetable fibers. The nest was by no means deserted, for the eggs were warm and the mother bird very solicitous, insomuch that she repeatedly ventured within a foot of $\mathrm{my}$ hand while I was engaged with the nest.

The Marsh Wrens regard themselves as the rightful owners of the reedy fastnesses which they occupy, and are evidently jealous of avian, as well as human, intruders. In one instance a Wren had constructed a sham nest hard against a completed structure of the Yellow-headed Blackbird, and to the evident retirement of its owner. Another had built squarely on top of a handsome Blackbird nest of the current season's construction, and with a spiteful purpose all too evident.

While there is no other conspicuous distinction in habit between $T . p$. plesius and T. p. paludicola, it is worthy of note that the interior birds, breeding at high levels east of the Sierras, are obliged to retire in winter to the meager fastnesses of our southeastern deserts, and the more ample overflowed margins of the Colorado River and "New" River. Many, however, spill over at this season into the San Diego district, where they mingle with the resident form, paludicola, and there is a suspicion that the resident stock of the Great Valley (San JoaquinSacramento) is slightly diluted in winter.

\section{No. 133 \\ Cactus Wren}

A. O. U. No. 7I3. Heleodytes brunneicapillus couesi (Sharpe).

Description.-Adult: Pileum and nape warm brown (argus brown to Prout's brown), the former with dusky mesial streaks; back and scapulars, broadly, pale grayish brown, highly varied by mesial white in streaks and stripes, and submesial dusky; flight-feathers (and in a lesser degree their coverts) dusky, spotted with white and brownish on outer webs, and broadly with white on inner webs (the spots forming bars on closed wing); tail (upper aspect) blackish, finely and irregularly barred with pale grayish brown; concealed webs of lateral rectrices chiefly black, the outermost pair black-and-white-barred throughout; the remaining pairs with at least a subterminal band of white; a prominent superciliary, continued to bill, white; post-ocular area clear brown; cheeks mingled brown and white; underparts basally white, immaculate on chin and upper throat, tinged with pale cinnamon on belly and crissum; the sides of 


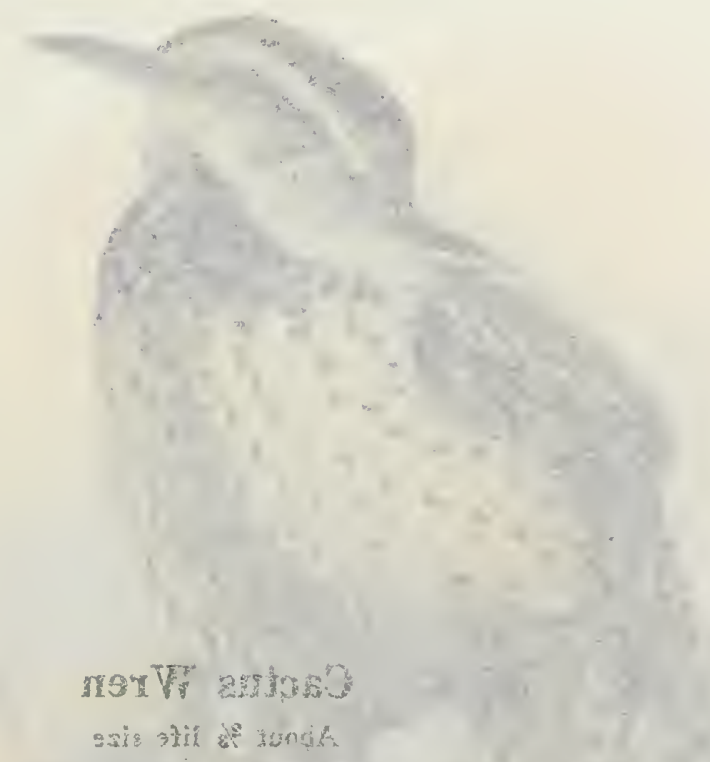

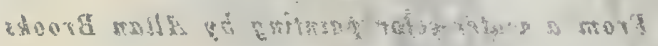




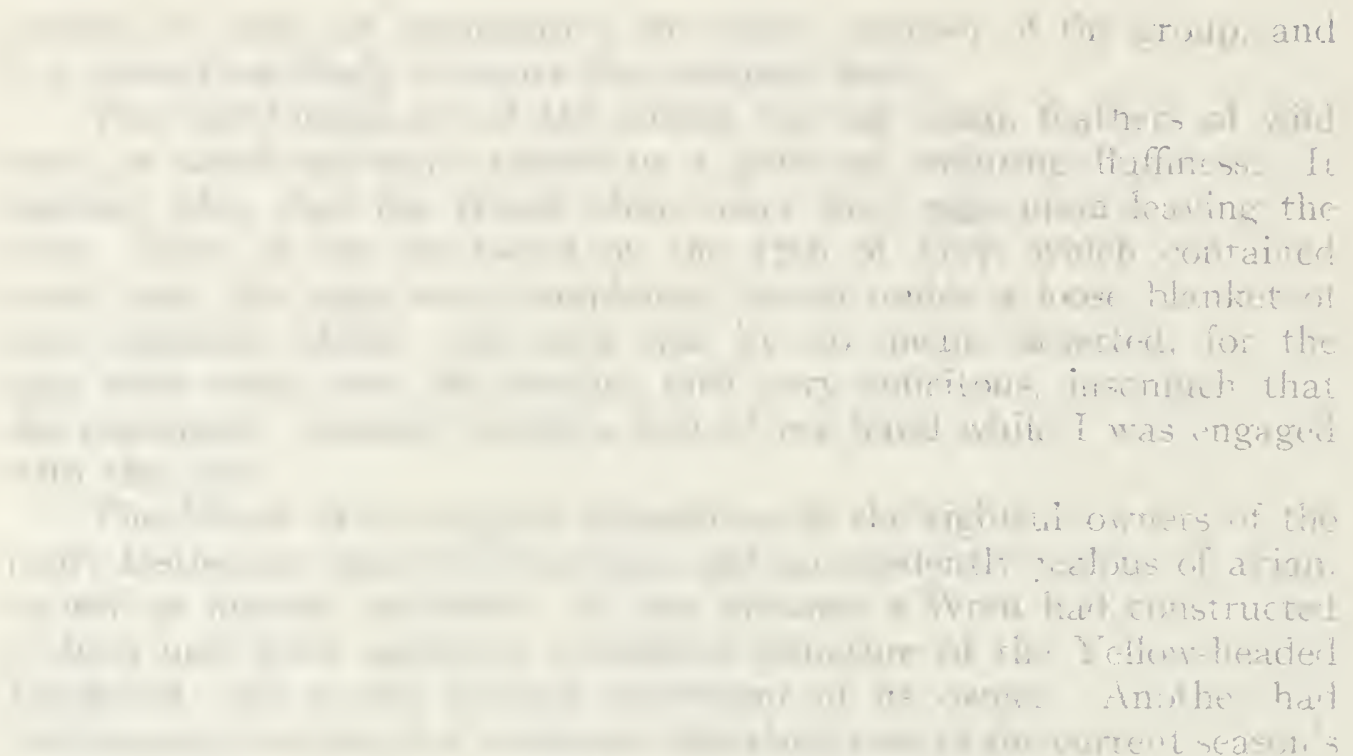

Cactus Wren

About $2 / 3$ life size

From a water-color painting by Allan Brooks

wh hit hetreets 


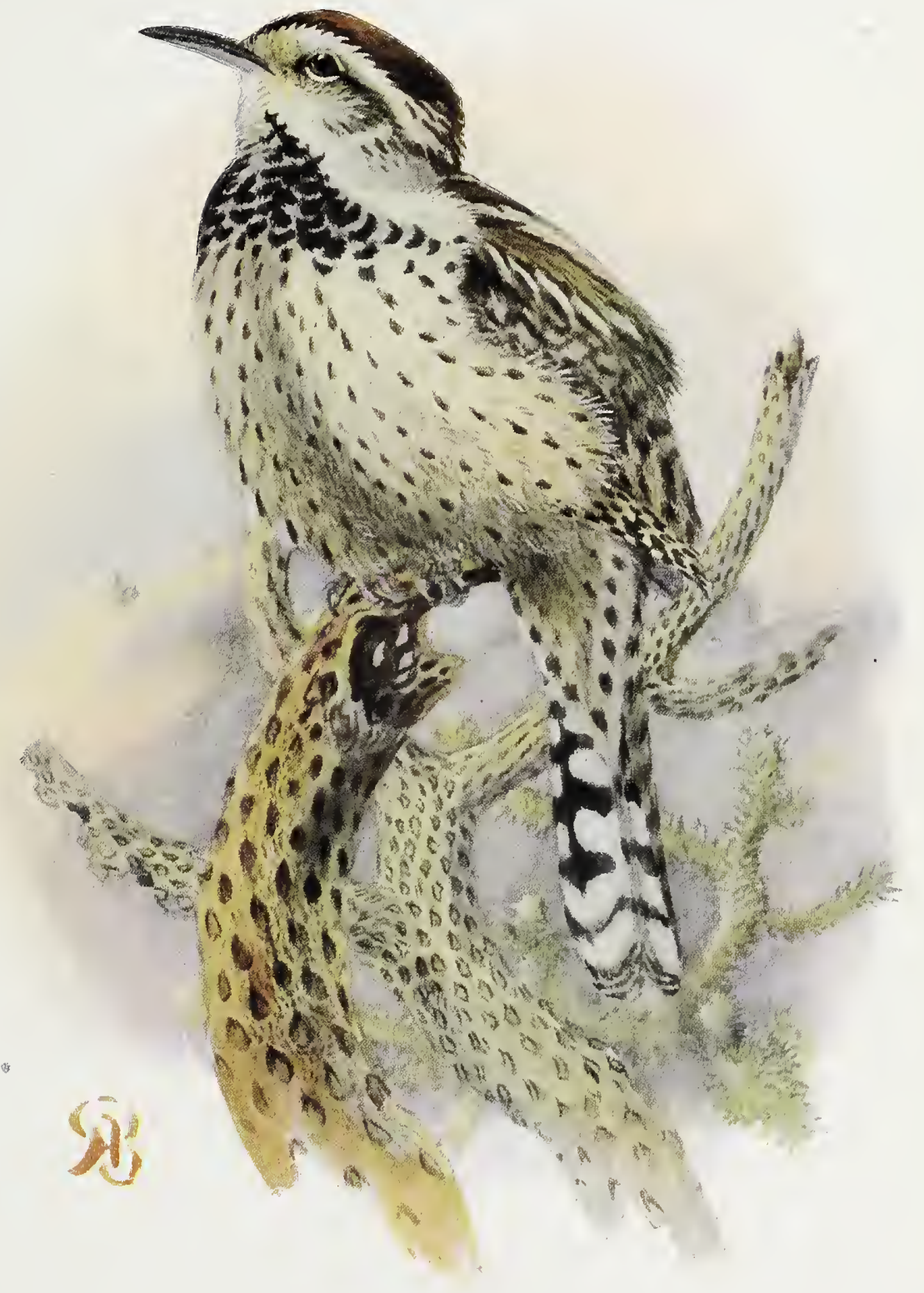





\section{The Cactus Wren}

throat, lower throat, and chest heavily spotted with black, - the spots nearly or quite confluent in high plumage; at other times, perhaps in less mature specimens, $V$-shaped or various; breast, sides of belly, sides, and crissum sharply and rather finely spotted with black - the spots rounded, rhomboidal, elongate, or various. Maxilla dusky horn-color; mandible and feet light horn; irides red. Young birds are more sparingly spotted below, especially on chest. Length about 203.2 (8.00); average of 29 males: wing 86.7 (3.4I); tail 80.7 (3.18); bill 23.3 (.92); tarsus 28.3 (I.I I). Females average somewhat smaller.

Recognition Marks.-Towhee size-largest of American wrens; highly varied (white-striped) upperparts and heavily black-spotted underparts, unmistakable.

Nesting.- Nest: A cylindrical mass of dried grasses, heavily lined with feathers; placed horizontally, with entrance at one end, and well-shaded above; in top of cholla cactus, yucca, or at base of sahuaro branch, or, more rarely, in mesquite, or other desert shrub. Cylinder about a foot long and 6 inches thick; entrance not large enough to admit hand without forcing. Eggs: 4 or 5, rarely 6 ( 7 of record); pale pinkish cinnamon to pinkish cinnamon, finely, heavily, and uniformly sprinkled or spotted with deeper cinnamon-sometimes faintly wreathed or capped. A rare type shows a white ground upon which the pigment is sharply outlined in largish spots. Av. of 203 eggs in the M. C. O. colls: 23.5 x I7 (.925 x .67). Index 72.4. Range I9.6-26.4 by I5-1 8 (.77-1.04 by .59-.7I). Season: March, April-June two broods.

Range of Heleodytes brunneicapillus.- -Southwestern United States, Mexico, and Lower California.

Range of $H . b$. conesi.-Lower Sonoran deserts of southern California, southern Nevada, and Utah, Arizona, New Mexico, and western Texas, with northern Lower California and the northern states of Mexico.

Distribution in California.-Common resident of the Lower Sonoran portions of the southeastern deserts, north to southern end of Owens Valley; also locally resident in the San Diego district north to Simi and, formerly, Santa Paula; found by Grinnell at Weldon. Local range nearly coincident with that of the Opuntia cacti (especially O. fulgida), and the tree yuccas (Yucca arborescens (Torr.), and Y. mohavensis Sargent).

Authorities.-Baird (Campylorhynchus brunneicapillus), Rep. Pac. R. R. Surv., vol. ix., I 858, p. 355 (Los Angeles, Fort Yuma, etc.); Heermann, Rep. Pac. R. R. Surv., vol. x., pt. iv., I 859, p. 4 I (Mohave Desert; habits; desc., nest); Swarth, Condor, vol. vi., I904, p. I7 (distr.; crit.); Beal, U. S. Dept. Agric., Biol. Surv. Bull., no. 30, I 907 , p. 64, pl. (food); Woods, Condor, vol. xxiii., I92 I, p. 47, figs. (nesting in s. Calif.; photos);Grinnell, Condor, vol. xxiii., I92 I, p. I69 (crit.; H.b.bryanti not found in Calif.).

BRUNNEICAPILLUS is the northern outpost of a vigorous genus which in Mexico and South America boasts twenty-seven species. Of these the South American members are known as Marsh Wrens, but the Middle American branch of the genus affects the driest situations, and their northern range is almost exactly delimited by the occurrence of the larger species of Opuntia cactus and the tree yuccas (Yucca arborescens and $Y$. mohavensis).

Fully conscious of his larger size and of the envy which it may incite, our giant wren is the most wary and secretive of the Troglodytine race. WTe are welcome to study his architecture, since there is no help for it, but his person is sacred from all eyes. 


\section{The Cactus Wren}

We have no choice, then, but to begin our studies with an investigation of those great globular, or foot-ball-shaped, masses of grass and fine weeds which we shall find imbedded in almost any cactus patch, or upborne by some taller stem of cholla, in fine scorn of concealment. The mistress will inevitably have slipped away - the conspicuous position of the nest guarantees that; but if incubation is well along, or young are in the basket, an anxious head will presently be thrust up from a concealed vantage point in a neighboring thicket. A glance, and down

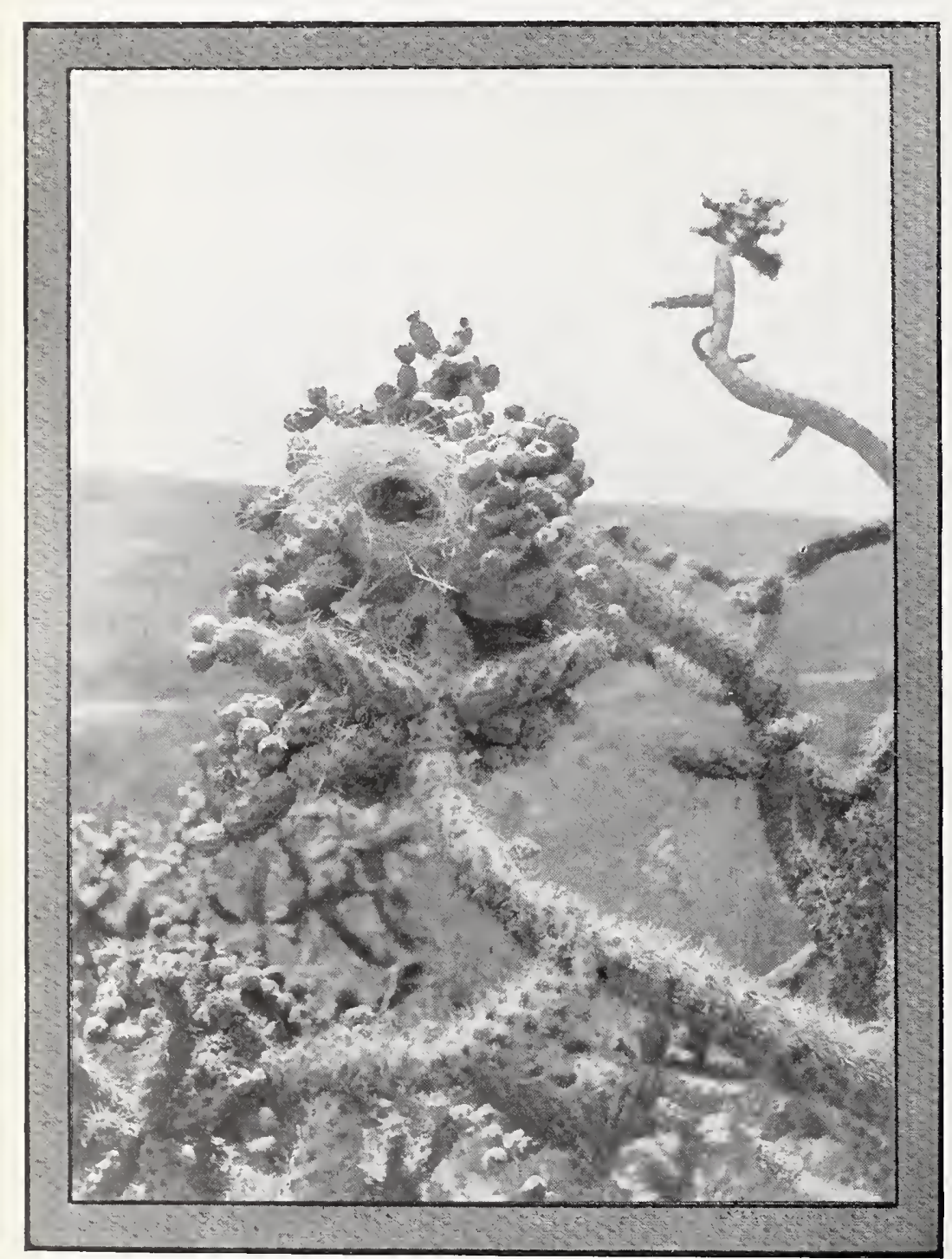

Taken near San Diego

NEST OF CACTUS WREN IN "CHOLLA" CACTUS 664 again. Or if the bird is descried on top of a cholla in the distance, it is in a strained, alert attitude. The male parent voices his anxiety by song, the very same with which he charmed his mate, for he has never felt the urge of harsher passions. Soft and low it comes, a rich yodelling alto of uniform tone-uniform, that is, save for the light crescendo with which the series opens, and the fading murmur of its closing note. Adroit use of the pedals is the performer's one claim to distinction, for $\mathrm{h}$ e c a n b reat h e amoroso con expressione (soft pedal), or else fetch out a clashing, metallic fortissimo. In extreme cases I have known the bird to enter the very bush in which the nest was placed and plead most eloquently.

$\mathrm{Ah}$, the nest! it is a wonderful affair, as big 


\section{The Cactus Wren}

as a peck measure, sometimes a perfect sphere, but oftener an ellipsoid, resting on one side and with an entrance in one end. Whoever he was that first called it "purse-shaped" had either too much imagination or none at all. Is a foot-ball purse-shaped? Yet every compiler in recent literature has dutifully repeated this epithet and will, I suppose, to the end of time. Purseshaped it certainly is not, for it is neither pendent, nor widemouthed, nor open at the topnor even flat, as most of our purses are-only hollow. But one might well wish for a purse or even a treasure-chest of such a size.

The nesting ball, whatever

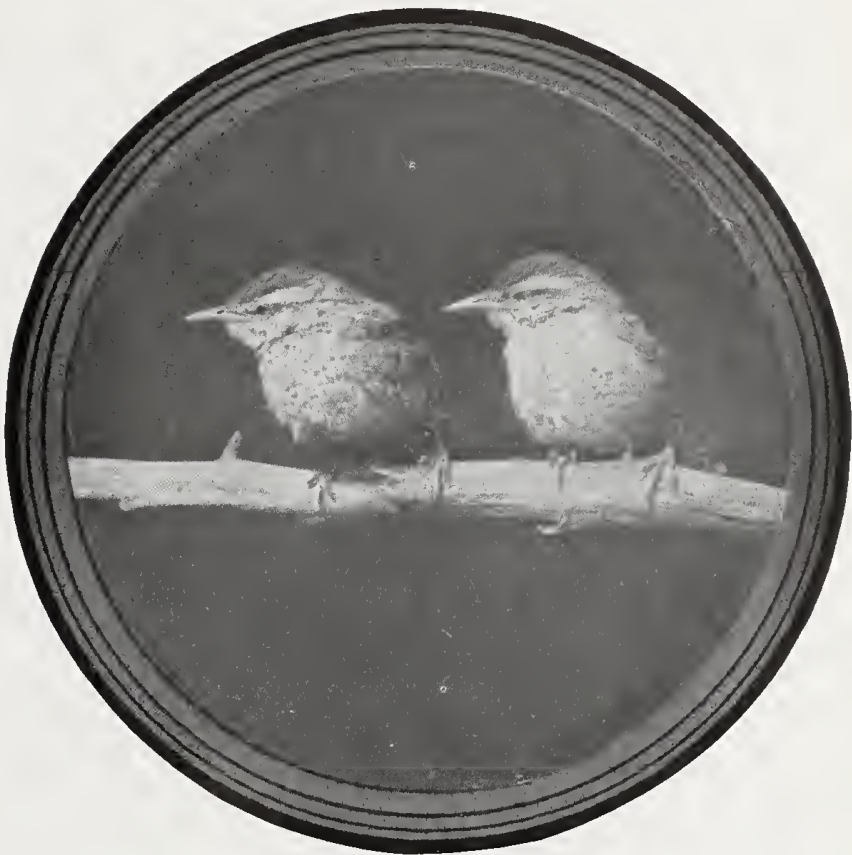

Taken near San Diego Photo by Dickey

YOUNG CACTUS WRENS its shape, is composed externally of fine twigs, chiefly those of the artemisia (A. dracunculoides, etc.), dried flower pedicels, and stiff grasses, all of which, being unyielding in character, impart a bristly, dishevelled appearance to the outside, especially in that portion surrounding the entrance hole, which is purposely left "out of focus." The body of the structure is made of finer, more tractable materials,-grasses, rootlets, dried flower-heads, bark-strips, etc., artfully coiled; while the capacious hollow is heavily lined with the shredded inner bark of weeds, spider cocoons, and feathers, wherever the last-named are obtainable. The eggs, four or five in number, are quite the handsomest of the wren kind, pale ochraceous salmon as to ground-color, but so finely dotted with orangecinnamon, mikado brown, or russet, as often to appear of a uniform vinaceous cinnamon. There is a tendency toward annulation of color about the larger end, and this ring is notably near the apex, sometimes including it.

The stock host of this bird in the desert patches of the San Diego-Ventura district and on the margin of the Colorado Desert is the cholla cactus, Opuntia bernardina, and its related forms. On the margin of the Mohave Desert the Joshua trees, or tree yuccas, are largely resorted to. Elsewhere in the desert valleys, mesquites, palo verdes, indigo bushes, canotias and cat's claw (Acacia greggi) are resorted to freely, as well as any other 


\section{The Cactus Wren}

sort of support which promises to scratch the enemy sufficiently. In the San Fernando Valley I found one nest in a gooseberry bush (Ribes hesperium). Mr. Frank S. Daggett found a nest in an apricot tree, and another one, still more remarkable, on the cross arm of a power-line pole, near Azusa, at a height of thirty feet.
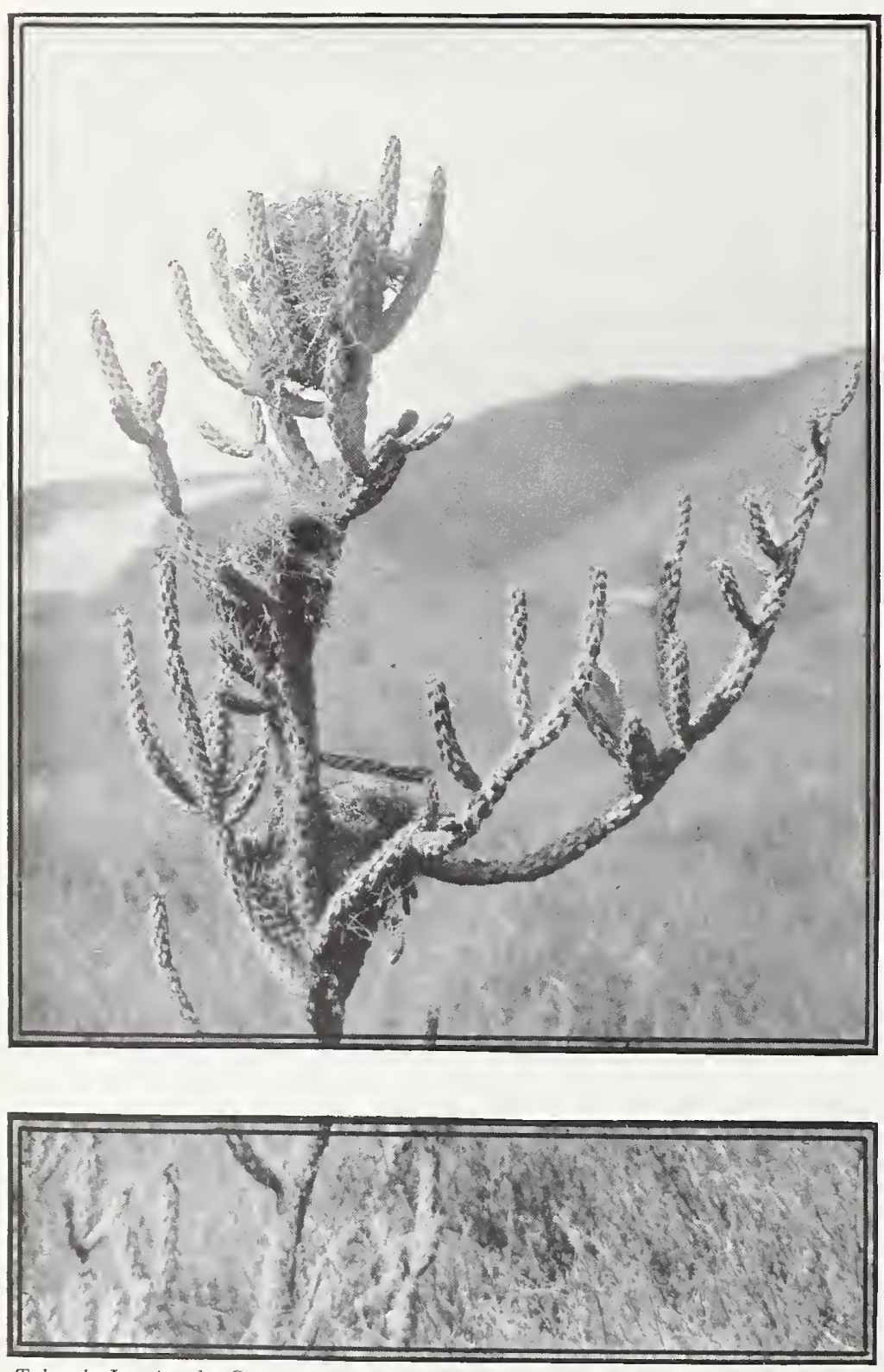

Taken in Los Angeles County

A THREE-STORY FLAT

Cactus Wrens tend to colonize in loose association of from ten to twenty pairs. Their individual attachments to locality are, moreover, very strong, and a practiced eye can identify the nests of several successive years in one immediate neighborhood. The older nests are gray and discolored, while "this year's nests" may include the one in occupation, the one recently quitted by the first brood of the season, and a cock-nest or two in good repair. The males, quite certainly, use these extra nests as roosts during the breeding season, and it is probable that some of them are in commission the year around.

The remaining wonder is how these birds, be they never so agile, can make their way about through the cruel cactus spines with impunity. They do not achieve immunity by instinct, for I have seen young birds lacerate 


\section{The Bewick Wrens}

themselves cruelly in first attempts. Yet they took their punishment uncomplainingly, or exhibited but the mildest surprise that their world should be so beset. Theirs is a hard life, inexplicable, save as we cast the blame upon the "lure of the desert," which claims many victims, and those most willing, among human kind.

All proper desert areas west of San Gorgonio Pass are being threatened sharply by the human invasion. Those joyous bits of desert "washes" which the canyons of the San Gabriel Mountains shoot down like arrows into the heart of the plains, have become so cluttered up with bungalows and chicken coops that one is ashamed to be caught prowling around. The last nest I found, near Roscoe, was stuffed with "Plymouth Rock" chicken-feathers. Recognizing the futility of further effort the birdman adjourned next door and had a drink of ice cream soda-"All ices received fresh from the city daily."

The Cactus Wren has receded from many parts of the San DiegoVentura section already, and is in danger of being altogether cut off. It is a pity, for he not only brought us the authentic breath of the wilderness, but so long as his home was untouched he waged unceasing warfare on spiders, wasps, beetles, and grasshoppers, while from the neighboring olive-yard he culled the dreaded scale insect.

No. 134

\section{Bewick's Wren}

No. 134a Desert Wren

A. O. U. No. 7 19b, part. Thryomanes bewicki eremophilus Oberholser.

Synonyms.-Baird's Wren (part). Desert Bewick Wren.

Description.- Similar to the next form, but larger and much paler above and below. Length of males (skins) I29 (5.08); wing 58 (2.28); tail 53 (2.087); bill 14.8 $(.58)$; tarsus $18.4(.72)$.

Nesting of Thryomanes bewicki in California.-Nest: Indescribably varied in construction; in general, any available sof tor pliable material to fill any available hole or cranny; basally of sticks, twigs, weed-stems, grasses, bark, or moss; lining of fine grasses, hair, fur, or feathers; placed in old woodpecker holes, in crannies about buildings, in trash-piles, or, not infrequently, in crannies and crevices of 'dobe cliffs, or barranca walls. Eggs: 3 to 6, usually 5; white, sprinkled rather sparingly with reddish brown; sometimes handsomely wreathed. Av. size I6 x $12.2(.63 \times$.48). Season: April-June; two broods.

Range of Thryomanes bewicki.-The United States, southerly, and Mexico.

Range of $T$. b. eremophilus.- Southern Great Basin region, broadly, and Mexico south to Zacatecas.

Distribution in California.-Breeds in the desert ranges and higher valleys (Lone Pine, June 16, I9 I ; George Creek, May 19, 1919) southeast of the Sierra Nevada; retires to the adjacent valleys and the southern deserts in winter. 


\section{The Bewick Wrens}

Authorities.-A. K. Fisher (Thryothorus bewickii bairdi), U. S. Dept. Agric., N. Am. Fauna, no. 7, I893, p. I34 (localities in s. e. Calif.); Oberholser, Proc. U. S. Nat. Mus., vol. xxi., I 898 , p. 427 (monogr.; orig. desc.; spec. listed from Death Valley, White Mts., etc.);Grinnell, Condor, vol. vi., I904, p. 44 (Palm Springs, winter);Grinnell, Univ. Calif. Pub. Zool., vol. xii., I9I4, p. 209 (Lower Colorado Valley, winter; habits; crit.); Swarth, Proc. Calif. Acad. Sci., 4th ser., vol. vi., no. 4, I9I6, p. 8o, map (monogr.: distr. in Calif.).

\section{No. 134b San Diego Wren}

A. O. U. No. 7Igd. Thryomanes bewicki charienturus Oberholser.

Description.-Adult (sexes alike) and Immature: Upperparts and auriculars, shading on sides of neck, warm brown (mummy brown); the exposed surfaces, greater coverts, tertials, upper tail-coverts, and rectrices finely barred with black or blackish; a sharply defined superciliary, white; underparts ashy gray, clearing almost to white on chin and throat, darkening to pale neutral gray on sides; distal portions of prolonged flank-feathers touched with brownish; under tail-coverts barred with black. Bill blackish above, lighter below; feet brownish. Juvenals are much like adult, but lighter above, and more or less spotted by dusky below. Av. length of adult males (skins): I 20 (4.72); wing 52.7 (2.07); tail $52.8(2.08)$; bill I4 (.55); tarsus I9 (.75). Females average smaller.

Recognition Marks.-Midget to warbler size; warm brown above, whitish to gray below; white superciliary line distinctive, especially as contrasted with House Wren (Troglodytes aëdon).

Range of $T . b$. charienturus.--Southern California, chiefly west of the desert divide, south to about Latitude $28^{\circ}$, Lower California.

Distribution in California.-Common resident, chiefly in the Upper Sonoran zone of the San Diego district north, at least, to Santa Barbara and Mount Pinos; wandering down to adjacent portions of the Mohave and Colorado deserts in winter.

Authorities.-Baird (Thriothorus bewickii), Rep. Pac. R. R. Surv., vol. ix., I 858 , p. 363, part (Ft. Tejon); Oberholser, Proc. U. S. Nat. Mus., vol. xxi., I 898, p. 435 (monogr.; orig. desc.; spec. listed from s. Calif. localities); Grinnell and Swarth, Univ. Calif. Pub. Zool., vol. x., I913, p. 307 (San Jacinto Mts.); Swarth, Proc. Calif. Acad. Sci., 4th ser., vol. vi., no. 4, I9I6, p. 74, map (monogr.; distr. in Calif.).

\section{No. 134c Catalina Island Wren}

\section{A. O. U. No. 7 I9d, part. Thryomanes bewicki catalinæ Grinnell.}

Description.-Similar to T. b. charienturus, but "averaging darker dorsally (more sepia and not so umber brown), and with heavier bill and conspicuously and constantly larger feet" (Grinnell).

Range of $T . b$. catalina.-Common resident on Santa Catalina Island.

Authorities.-Oberholser (Thryomanes bewickii charienturus), Proc. U. S. Nat. Mus., vol. xxi., I 898, p. 435, part (monogr.; comment upon spec. from Catalina Id.); Richardson, Condor, vol. x., I908, p. 68;Grinnell, Univ. Calif. Pub. Zool., vol. v., I9 Io, p. 308 (orig. desc.; Avalon, Catalina Id.); Howell, Pac. Coast Avifauna, no. I2, I9I7, p. 97 , part (syn.; distr.; habits; crit.).

668 


\section{The Bewick Wrens}

\section{No. 134d San Clemente Wren}

A. O. U. No. 7I9.I. Thryomanes bewicki leucophrys (Anthony).

Description.-Similar to $T$. $b$. charienturus, but averaging paler and duller throughout, with reduction of black barring (especially on under tail-coverts) and increase of white in superciliary.

Range of $T . b$. leucophrys.-Common resident on San Clemente Island.

Authorities.-Cooper (Thryothorus bewickii), Proc. Calif. Acad. Sci., vol. iv., I87o, p. 78, part; Anthony, Auk, vol. xii., I895, p. 5 I (orig. desc. of Thryothorus leucophrys; San Clemente Id.).

\section{No. 134e Santa Cruz Island Wren}

A. O. U. No. 7I9d, part. Thryomanes bewicki nesophilus Oberholser.

Description.-Similar to $T$. b. charienturus, but flanks much more strongly tinged with brownish. Islands.

Range of T. b. nesophilus.-Common resident on Santa Cruz and Santa Rosa

Authorities.-C. H. Townsend (Thryothorus bewickii bairdi), Proc. U. S. Nat. Mus., vol. xiii., I 890, p. I4I (Santa Cruz Id.);Oberholser, Proc. U. S. Nat. Mus., vol. xxi., I 898, p. 442 (orig. desc.; Santa Cruz Id.); J. Mailliard, Bull. Cooper Orn. Club, vol. i., I899, p. 42 (habits); Howell and van Rossem, Condor, vol. xv., I9I3, p. 92 (nest).

\section{No. 134f San Joaquin Wren}

A. O. U. No. 7Igd, part. Thryomanes bewicki drymœcus Oberholser.

Description.--Similar to T. b. charienturus, but "upperparts decidedly browner," "tail shorter" [about one millimeter], "bill longer" [.9 and $.8 \mathrm{~mm}$ respectively in male and female], and "feet smaller" [Heaven only knows how much].

Range of $T . b$. drymecus (Wholly contained within California).- Resident in the Upper Sonoran zone of the great interior valley, broadly defined-involves the inner coast ranges, possibly to the sea in San Luis Obispo and northern Santa Barbara counties, west as far as Helena in Trinity County, north to Baird in Shasta County, northeast to the Warner Mountains (Grinnell), east well into the Sierran foothills (Kenawyer's south fork of Kings River, July 9, I913), south to the Tejon Mountains.

Authorities.-Heermann (Troglodytes Bewickii), Jour. Acad. Nat. Sci. Phila., ser. 2, ii., I 853 , p. 263 (Calif.); Oberholser, Proc. U. S. Nat. Mus., vol. xxi., I898, p. 437 (monogr.; orig. desc.; type locality, Baird, Shasta Co.) ; Barlow, Condor, vol. iii., I90I, p. I82 (Fyffe; song); Swarth, Proc. Calif. Acad. Sci., 4th ser., vol. vi., no. 4, I9I6, p. 68, map (monogr.; distr.; etc.).

No. $134 \mathrm{~g}$ Vigors's Wren

A. O. U. No. 719a, part. Thryomanes bewicki spilurus (Vigors).

Description.- Similar to T. $b$. charienturus, but decidedly browner (darker than drymocus even) and slightly smaller.

Range of $T$. b. spilurus (Wholly contained within California).- "Common resident of the Upper Sonoran chaparral association in the humid coast belt, from northern Monterey County north up to the Golden Gate; east around the south arm of San Francisco Bay at least to Berkeley" (Grinnell). 


\section{The Bervick Wrens}

Authorities.-Vigors (Troglodytes spilurus), Zool. Voyage "Blossom," I 839, p. I 8, pl. iv., fig. I (orig. desc.; Monterey or San Francisco); Oberholser, Proc. U. S. Nat. Mus., vol. xxi., I 898, p. 438 (monogr.); Beal, U. S. Dept. Agric., Biol. Surv. Bull., no. 30, I907, p. 57, part (food); Allen, Condor, vol. xvii., 191 5, pp. 82-84 (Berkeley; nesting); Swarth, Proc. Calif. Acad. Sci., 4th ser., vol. vi., no. 4, I9I6, p. 67, map (monogr.; distr.; crit.).

\section{No. $134 \mathrm{~h}$ Nicasio Wren}

A. O. U. No. 7 I9a, part. Thryomanes bewicki marinensis Grinnell.

Description.- Similar to T. b. spilurus, but dorsal coloration brighter brown, of a vandyke tone, and flanks and light intervals on crissum strongly washed with vandyke brown" (Grinnell).

Range of $T$. b. marinensis (Wholly contained within California).-Resident in the humid coastal strip from San Francisco Bay north through Marin, Sonoma, and Mendocino counties, at least to the Eel River in Humboldt County (Elinor, June i 5, I916).

Authorities.-Oberholser (Thryomanes bewickii spilurus), Proc. U. S. Nat. Mus., vol. xxi., I 898 , p. 438, part (monogr.; comment upon spec. from Marin Co.); Grinnell, Univ. Calif. Pub. Zool., vol. v., I910, p. 307 (orig. desc.; Nicasio, Marin Co.).

A CAREFUL LIST of the dozen most prominent birds of California must make early mention of the Bewick Wren. "Prominent" is not exactly the word to use, either, if it suggests large size or brilliant plumage or bold behavior. The Bewick Wren has none of these marks, - but he is one of the dozen most abundant, best distributed, most versatile, most adaptable, and most characteristic birds of the West. Dominant is, perhaps, a better epithet, though "prominent" is recognized as suitable by one who has mastered the intricacies and varieties of the Thryomanian song.

That our hero's tenure of Californian soil is of long standing is evidenced by the several varieties which are now recognized within our borders - each reflecting, if we had skill to read the evidence, some reaction of local environment-and by the fact that the species enjoys a great altitudinal range, viz., from sea level up to 8000 or 9000 feet. These minute differences, whether of relative length of bill and wing or barring of tail, it is not worth our while to follow out in this connection; nor is it often worth while to trace these shades of physical change anyway, unless it can be clearly shown that they are accompanied by contrasting behavior characters, or by constant differences in song. This our present knowledge of the several races of the Bewick Wren does not permit us to do, and we feel justified in treating them practically as one.

But as compared with the Bewick Wren of the East, one hastens to say that the western races bulk larger in the scheme of things, and have acquired a greater versatility in song. For to the characteristic

$$
670
$$




\section{The Berwick Wrens}

ditty of bewicki proper, sprightly as it is, spilurus and nesophilus and their clan have introduced so many trills and flourishes that the original motif has been almost lost to sight. Calophonus (having a beautiful voice) Oberholser calls a variety found still further north, but the name is descriptive of all western forms; and so important an element is the song of the Bewick in the western chorus that there are many sections where it bulks larger than that of any other species.

The Bewick Wren freely invades the haunts of men; it even disputes much territory claimed by the House Wren (Troglodytes aëdon parkmani) but timberslashings, rocky hillsides, sunny arroyos, and the chaparral are more to its taste. Thus, the Canon Wren, the Rock Wren, the House Wren, the Winter Wren, and the WrenTit are brought into active competition with it; and while each in turn goes to places where the Bewick Wren will not follow, it is the Bewick Wren which dominates the general situation. Whether in chaparral or log-heap or cactus bed, therefore, the Bewick Wren knows his ground. And he lets you see exactly as much of himself as he intends and no more. If there is any unusual appearance or noise which gives promise of mischief afoot, then the Bewick Wren is the first to respond. Flitting, gliding, tittering,

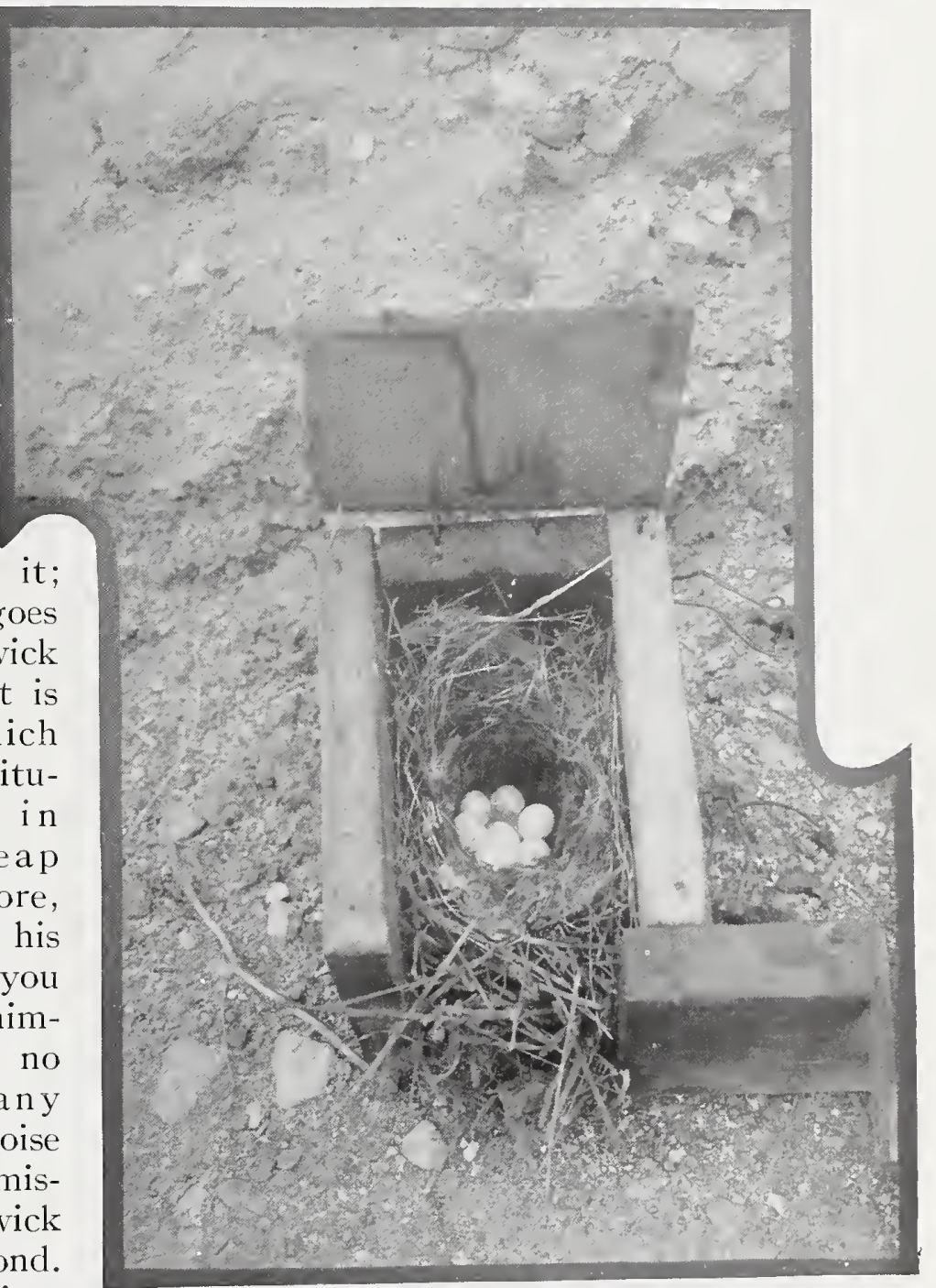

Taken in Los Angeles County Photo by Wright $M$. Pierce NEST OF SAN DIEGO WREN IN DECOY BOX 


\section{The Bewick Wrens}

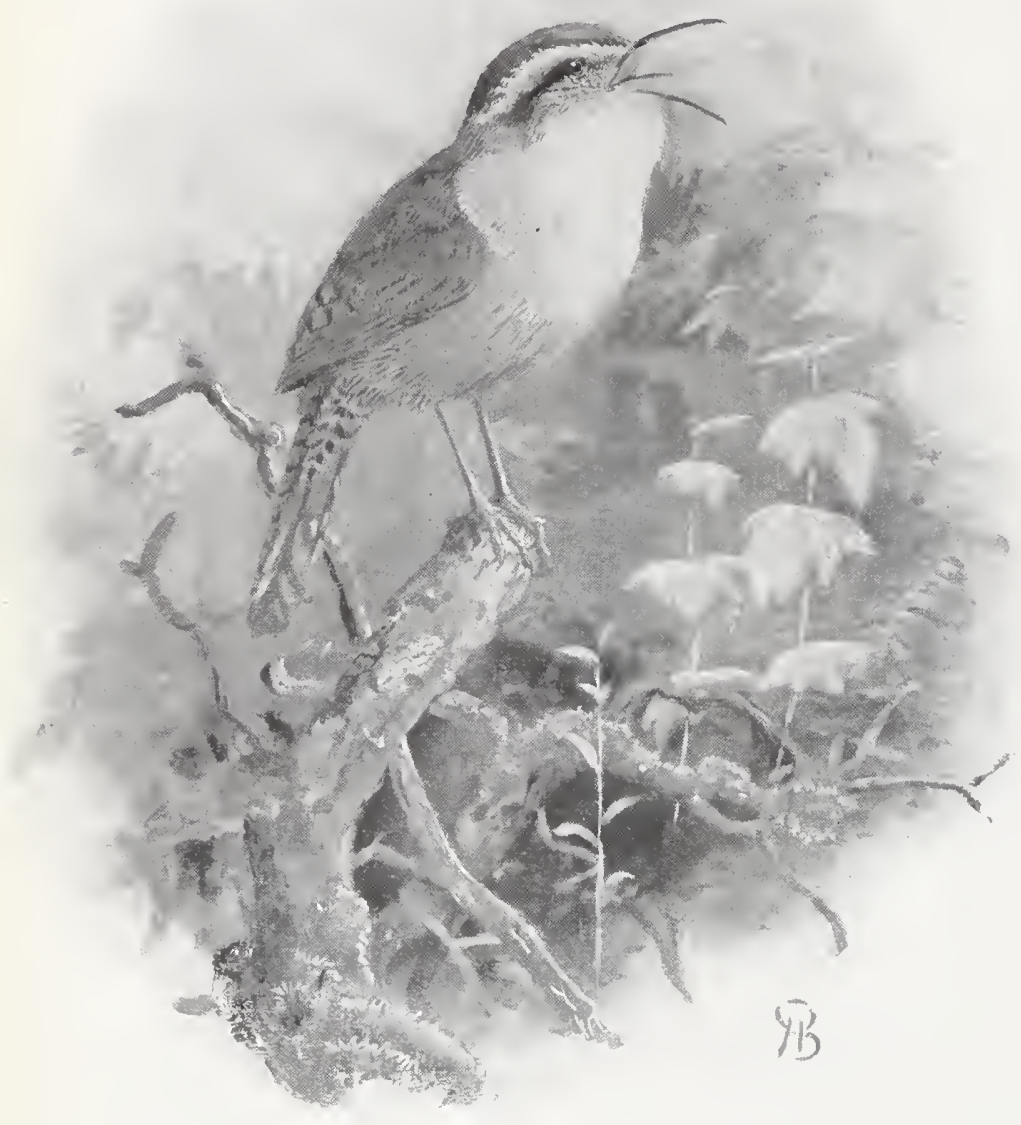

SAN DIEGO BEWICK WREN the bird comes up and moves about the center of commotion, taking observations from all possible angles and making a running commentary thereon. His attitude is alert and his movements vivacious, but the chief interest attaches to the bird's mobile tail. With this expressive member the bird is able to converse in a vigorous sign language. It is cocked up in impudence, wagged in defiance, set aslant in coquetry, or depressed in whimsical token of humility. Indeed, it is hardly too much to say that the bird makes faces with its tail.

While spying along the lower levels, the Wren giggles and chuckles-titters, or else gives vent to a grating cry, moozeerp, which sets the woods on edge. But in song the bird oftenest chooses an elevated station, a scruboak sapling or the top of a stump. Here, at short intervals and in most energetic fashion, he delivers extended phrases of varied notes, now clear and sparkling, now slurred or pedalled. Above all, he is master of a set of smart trills. One of them, after three preliminary notes, runs $t s u^{\prime}$ $t s u^{\prime} t s u^{\prime} t s u^{\prime} t s u^{\prime} t s u^{\prime}$, like an exaggerated and beautified song of the Towhee. Another song, which from its rollicking character deserves to be called a drinking song, terminates with a brilliant trill in descending scale, rallentando et diminuendo, as though the little minstrel were actually draining a beaker of dew.

At another time it is the sudden outburst which nearly upsets you. Prrank, see, see, see, see. Now "see see see see" is soothing enough, but 672 


\section{The Bewick Wrens}

that fiercely accusing "prrank!" is not good for the nerves. And the wren is laughing at you; be sure of that.

The Bewick Wren is altogether a hilarious personage. He sets the canons of criticism at defiance, and when you think you have mastered all his tricks, he springs another one on you just to drive dull care away. The wren does not indulge in conscious mimicry; but since his art is selftaught, he is occasionally indebted to the companions of the chaparral for a theme. The maculatus Towhee motif is not uncommon in his songs, and the supposed notes of a Willow Goldfinch, a little off color, were once trailed to his door. On Santa Cruz Island I caught him filling in the intervals of song with a sort of buzzing lullaby, which reminded me very strongly of the biz biz note of the Western Gnatcatcher. Indeed, I am led to suspect that the record of the reputed occurrence of Polioptila on that island was really due to the activities of $T$. bewicki nesophilus.

For all that the bird is so common, nests of the Bewick Wren type are comparatively rare in collections. This is due, perhaps, as much to the lawless variety of sites used, as to the caution of the bird. A cranny of suitable size is the sine qua non, and this may be in a rock-pile, in a canyon-wall, in an old woodpecker-hole, in the mouth of an old tunnel of a Rough-winged Swallow, under a root, behind a sprung bark-scale, in an old shoe or a tin can, or the pocket of a disused coat. It may even be, as frequently upon Santa Cruz Island, in the bedded leafage of the forest floor. The Bewick Wren is rather chary of materials, especially sticks, and so far as known, he does not waste his energies constructing useless decoys or cocks' nests, as almost all other species of wrens do. Eggs are five or six in number, white, sparsely but sharply dotted with cinnamon. The lining materials are of the finest, and an occasional cast-off snakeskin lends its quotum of interest to the aggregate of blanketings.

If the Bewick Wren is sly and secretive during the nesting season, a more generous spirit fills its breast when the young are well astir. Nothing could be more charming than the sight of a family group of bewickis taking a Sunday stroll. Bugs are the ostensible object of pursuit, but bug-hunting languishes when the stranger seats himself on a mossy log, and a gentle ripple of veiled inquiry assures him that he is of more interest than many bugs. One by one the questing babies hop out into the open, select a comfortable perch and survey the big brother with friendly curiosity. Many childish comments are passed, and the mischief of the party may even start a snicker, but it is all in good part, and the birdman feels the flattery of a dozen admiring eyes. Even the mother, a little reluctant, is lured into the open by the confident declarations of her children; and under pretense of righting a rumpled feather, accepts compliments upon the fine appearance of her gentle brood. Admiring eyes 


\section{The Western House Wren}

have signed a truce, and the ancient misunderstanding is forgotten. It is at such a time that the heart of man softens. A wave of sympathy sweeps over him, sense of his own ill desert, and a great yearning for fellowship with all these tiny voyageurs upon the common stream of life. Out of the storm and chaos of human experience certain moments hold sacred to recollection,- moments in which a baby bird flashed us a look of confidence, or yielded, perchance, to the gentle pressure of a proffered finger.

No. 135

\section{Western House Wren}

A. O. U. No.72 га. Troglodytes aëdon parkmani Audubon.

Synonyms.-Parkman's Wren. Pacific House Wren.

Description.-Adult: Above grayish brown, duller and lighter (Saccardo's umber) on foreparts; brighter (dresden brown) on rump, which has concealed downy, white spots; back and scapulars barred (rarely indistinctly) with dusky; wings on exposed webs and tail all over distinctly and finely dusky-barred; sides of head speckled grayish brown, without definite pattern; below light grayish brown (tilleul buff), indistinctly speckled or banded with darker brownish on foreparts; heavily speckled and banded with dusky and whitish on flanks and crissum. Bill black above, lighter below; culmen slightly curved; feet brownish. Length II 4.3-I33.3 (4.50-5.25); wing 52.8 (2.08); tail 44.6 (I.75); bill I3 (.5I); tarsus I 7.2 (.68).

Recognition Marks.-Warbler size; brown above, much lighter brown below; everywhere more or less speckled and banded with dusky, brownish, or white. Larger, lighter, and with longer tail than Western Winter Wren.

Nesting.- Nest: In holes or crannies, natural or artificial; basally of crisscrossed sticks, often absurdly large for bird; lined, meanly, with weed-stems, rootlets, or bark-flakes; or luxuriously, with anything soft,- grass, horsehair, wool, snake-skins, and especially feathers. Eggs: 6 or 8, sometimes 9; basally white, but usually so finely sprinkled with warm reddish brown as to appear pink on the less heavily marked portions; applied color tends to gather in handsome coronal wreaths. Av. size I6.5 X I $3.2(.65 \times .52)$. Season: Early and of ten-March or April to July or August.

Range of Troglodytes aëdon.-United States and southern Canada; south in winter to Mexico.

Range of T.a.parkmani.-Western United States and the southern portion of the western Canadian provinces; east to Manitoba and southern Illinois; breeding south to southwestern Texas, southern Arizona, and the San Pedro Martir Mountains of Lower California; wintering from California and Texas south to Oaxaca.

Distribution in California.-Common summer resident in Upper Sonoran and Transition zones, nearly throughout the State. Breeds sparingly in Lower Boreal zone, and ascends to limit of trees in late summer. Winters in the valleys of the San Diego district and in the valley of the Colorado, and casually northward.

Authorities.--Gambel (Troglodytes sylvestris), Proc. Acad. Nat. Sci. Phila., iii., I 846, p. II3 (Calif.; name proposed as substitute for T. americanus Audubon, preoccupied); Cooper, Bull. Nutt. Orn. Club, vol. i., I 876, p. 79 (nesting habits); Beal, U. S. 
Dept. Agric., Biol. Surv. Bull., no. 30, I907, p. 60 (food); Grinnell, Univ. Calif. Pub. Zool., vol. v., p. I20 (San Bernardino Mts.; habits; migr.; etc.); Willett, Pac. Coast Avifauna, no. 7 , I912, p. I02 (s. Calif.; occurrence, nesting dates, etc.).

THE ARCHÆOLOGY of birds is undoubtedly one of the most fascinating departments of ornithology. Our materials are of quite a different order from those left by humans. In fact, they are all contemporary, or nearly so. There are no shards or tombs or "artifacts" of any kind, by which we may trace the earlier stages of avian culture, no mummies or skeletons, or at least so few of them that we cannot read from them the story of "ethnic" movements among the birds. We must read the history of birds in their present structure, plumage, habits, voices, nidification, and distribution. Fortunately, these are enlightening to those who scan closely, and who are able to exercise a vigorous historical imagination. From such sources we learn that the Wrens are an ancient American family, having their ancestral birthplace, or at least their more modern center of distribution, within the Tropics, probably in Central America. From this center two aggressive types first emerged. - One, the ancestral Troglodytes musculus, proceeded south and conquered South America to its farthest extremity, being now differentiated upon that continent into fourteen recognizable forms or subspecies; the other, the ancestral Nannus (formerly 


\section{The Western House Wren}

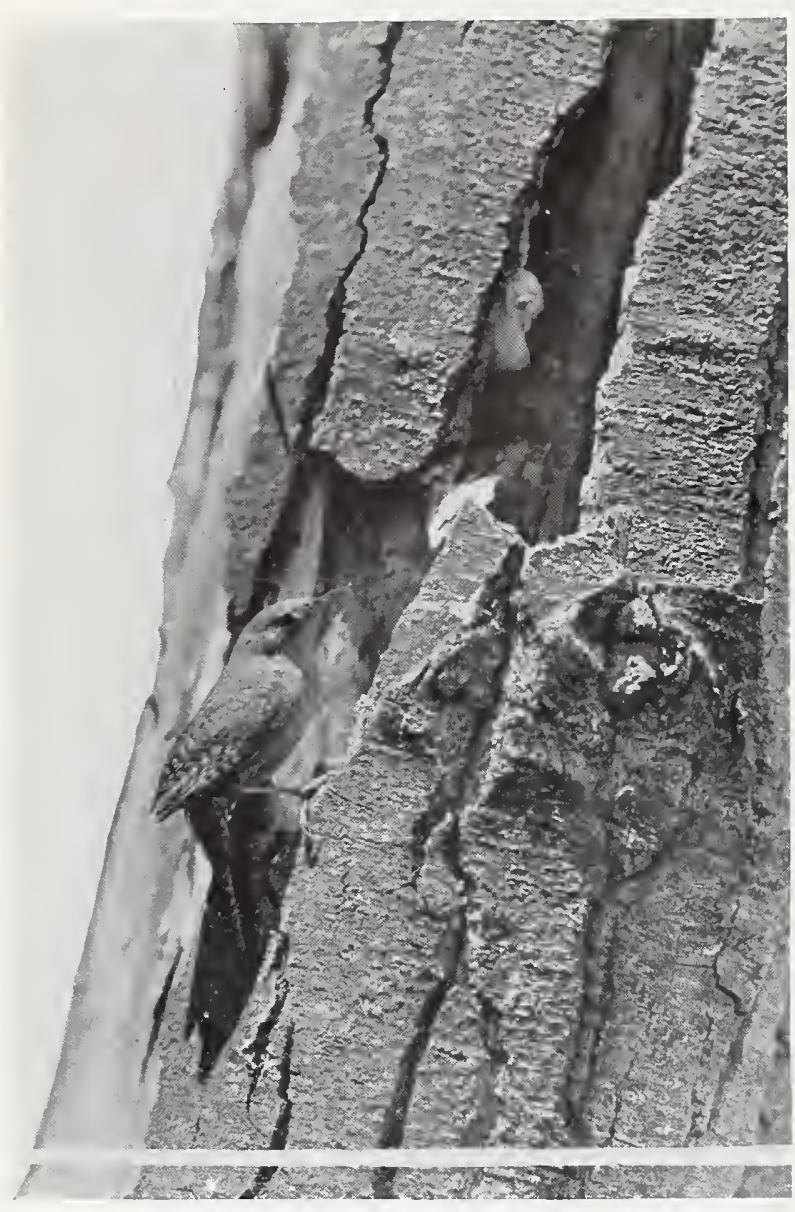

Taken in San Diego County

WESTERN HOUSE WREN AT NESTING HOLE

called Anorthura and Olbiorchilus, and in Europe miscalled Troglodytes), himself in all probability a brother of T. musculus, père, at some date preceding the great Ice Age worked north and spread westward to the Eurasian Continent. Driven south again by the engulfing disaster of ice, the Namnus stock broke up, its separated fragments taking refuge in northern Africa and India and the southern United States. These slightly differentiated forms returned again upon the heels of the retreating ice to dominate Europe, the Himalayas, Japan, and northern North America, as the European House Wren (Nannus troglodytes troglodytes, N.t.fumigatus, N.t. nipalensis) and (to omit many connecting links) the Winter Wrens (Nannus t. hiemalis). Following close upon the return of this doughty dwarf (i. e. vóvvos, dwarf) to its northern domains, the Troglodytes stock put forth another shoot, T. aëdon, which now occupies most of the United States in summer, and retires chiefly into Mexico in winter. This $T$. aëdon stock, in turn, is differentiating by East and West, as so many do; and our western bird, T. a. parkmani, neither goes so far north in summer (only slightly exceeding the 49th parallel), nor so completely retreats in winter. Our western bird, therefore, is somewhat quieter, less aggressive, and much less domestic, than the eastern bird.

The name House Wren, universally applied to this bird and its congeners, is perhaps less deserved in California than anywhere else. We may believe that the bird is an old residenter, and that his established modes of life have been less disturbed by the white invasion than have those of the House Finch (Carpodacus frontalis), for example. Also the Bewick Wrens (Thryomanes bewicki sub. sp.) are a well established group hereabouts; and they were as prompt to avail themselves of what. ever advantages civilization might offer as were the Troglodytes Wrens.

676 


\section{The Western House Wren}

As a consequence, our California House Wren is rather a bird of the woods; and there are ten times as many nests in holes in trees as there are attached to human domiciles.

Once upon the scene, however, one little House Wren goes a great ways, East or West. He is bursting with energy, and music escapes from his busy mandibles like steam from a safety valve. The first task after the spring return is to renovate last year's quarters; but there is always time on the side to explore a new brush-heap, to scold a cat, or to indulge innumerable song-bursts. In singing his joyous trill the bird reminds one of a piece of fireworks called a "cascade," for he fills the air with a brilliant bouquet of music, and is himself, one would think, nearly consumed by the violence of the effort. But the next moment the singer is carrying out last year's feather bed by great beakfuls, or lugging into some cranny sticks ridiculously large for him.

During the nesting season both birds are perfect little spitfires, assaulting mischievous prowlers with a fearlessness which knows no caution, and scolding in a voice which expresses the deepest scorn. The rasping note produced on such an occasion reminds one of the energetic use of a nutmeg grater by a determined housewife.

Wintering birds, or at least young ones, in Southern California have a note which, though still rasping, seems quite different from anything I have heard in the breeding season. It is a loud, harsh, compelling note of complaint, uttered either singly, wuzeeeerp, or in a breathless series, zeerp, zeerp, zirp zirp

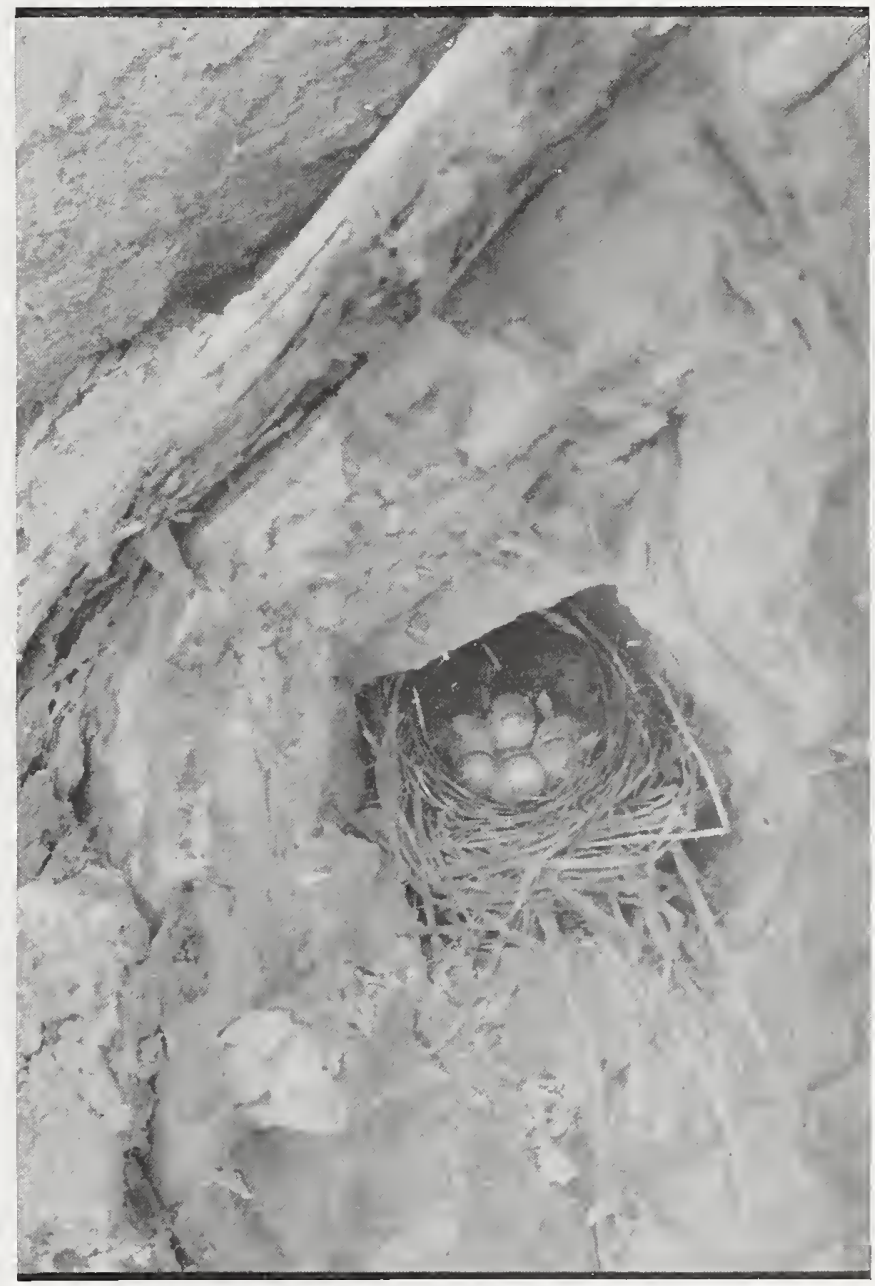

Taken in San Bernardino County

NEST AND EGGS OF WESTERN HOUSE WREN PORTION OF INVESTING WOOD REMOVED 


\section{The Western House Wren}

zirp zirp. It does not appear to answer any social need, for it is uttered by lone birds as they prowl about the garden shrubbery, or thread their way through a hillside thicket. I have fancied the notes were most in evidence in early fall and died out by spring; but whenever heard, they are among the most notable of bird cries heard in the year's round.

In nesting the Wrens do make free of the haunts of men, but are in

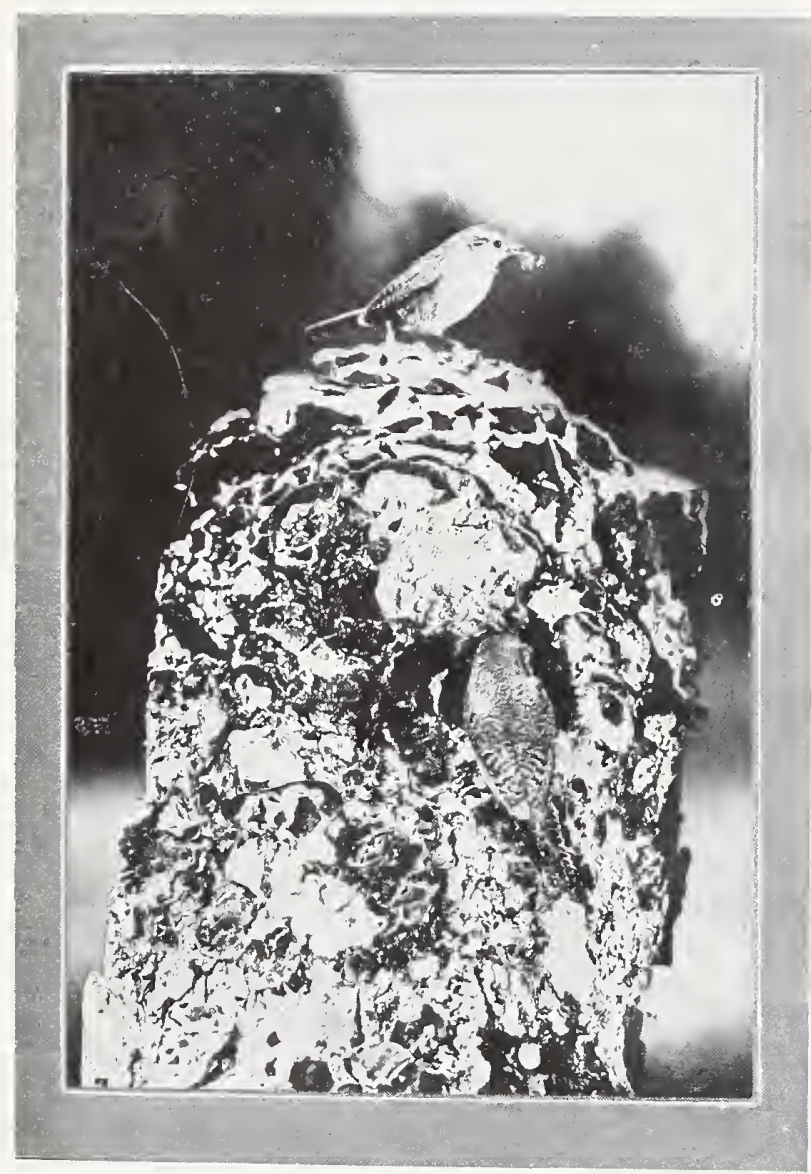

Taken in Oregon

A VERY BUSY WREN

Photo by W. L. Hinley

NOT QUITE SO BUSY AS APPEARS, HOWEVER THE PICTURE IS A COMPOSITE, PRESENTING THE SAME BIRD TWICE Wren's nest with small young on the 3 rd of July, and another with five fresh eggs on the 8th of July. A member of the M. C. O. party of I922, Lawrence Stevens, found two nests with young above Lake Mary, in southern Mono County, and at an altitude of over 9000 feet. Besides this, it is certain that an extensive invasion of the upper mountain areas follows the close of the breeding season.

678 cabins afford convenient crannies,forgotten auger holes, tin cans, bird boxes, a sleeve or pocket in an old coat hanging in the woodshed,- - anything with a cavity will do; but, by the same token, an unused woodpecker's hole, or a knot-hole in a stump, miles from the haunts of men, will do a good deal better. In any case, the cavity, be it big or little, must first be filled up with sticks, with just room at the top for entrance. Into this mass a deep hollow is sunk, and this is heavily lined with horsehair, wool, feathers, bits of snake-skin, anything soft and "comfy."

Large families, six or eight, are the rule, and the Wrens nest twice in a season. Possibly the second nesting takes place at higher altitudes. I know I have found their nests in late June miles from a human habitation, and at elevations which would not be agreeable in April or May. The highest records I can vouch for were in the Warner Mountains, where at an altitude of over 7ooo feet I found a House

nowise dependent on them. Old 
it is quite the fashion, East, to make provision for Jenny Wren's wants, - to set out bird boxes, or cans, or old teakettles with missing spouts, care being always taken that the entrance to the nesting hollow shall be too small to suit the English Sparrow. This is not done extensively in the West. Major Allan Brooks insists that the House Wren is a very bad neighbor. He says that in his neighborhood, on Okanogan Lake (B. C.), the little spite makes a business of destroying the eggs of Bluebirds and Tree Swallows by driving her thorn-like beak into them. This is not for love of the egg, apparently, but because she is jealous of too much company and claims all cavities for herself. However this may be, it is certain that Jenny Wren is an indefatigable gleaner of insects, and that her services in this field are altogether commendable.

No. 136

\section{Western Winter Wren}

\section{A. O. U. No. 722a. Nannus troglodytes pacificus (Baird).}

Description.-Adult: Above warm dark brown (deep raw umber), duller anteriorly, brighter on rump and tail, obscurely waved or barred with black on back, wings, and tail-barring more distinct on edges of four or five outer primaries, where alternating with buffy; concealed white spots on rump scarce, or almost wanting; a pale brownish superciliary line; sides of head speckled brown and ochraceous; underparts everywhere finely mottled, speckled, or barred,- on the throat and breast mingled brownish and cinnamon-buff or clay-color, below blackish and dull umber, the dusky element predominating over brown on flanks and crissum, where also admixed with white. Bill comparatively short, straight, blackish above, lighter below; feet light brown. Length IoI.6 (4.00); wing 46 (I.8I); tail 30 (I.I 8 ); bill I I.6 (.46); tarsus I 8 $(.7 \mathrm{I})$.

Recognition Marks.-Pygmy size; dark brown above, lighter below; more or less speckled and barred all over; tail shorter than in preceding species.

Nesting.- Nest: In holes or crannies of root, stump, or rockwall, usually near water; chiefly of moss or with some inclusion of twigs, and lined or not with feathers. Nest ideally a ball with tiny entrance on side near top, or else completely filling cavity. Eggs: 5 or 6 , rarely 7 ; white, sparingly and sharply dotted with reddish brown. Av. size $15.2 \times 12.2(.60 \times .48)$. Season: April-June; two broods.

Range of Nannus troglodytes.-The Temperate zone of the Northern Hemisphere; in North America, breeding, save in the mountains, chiefly north of the United States; wintering south to the Gulf Coast, and sparingly to southern California.

Range of N.t. pacificus. - Western North America. Breeds from Prince William Sound and western Alberta south to central California and northern Colorado; winters south from southern British Columbia to southern California and New Mexico.

Distribution in California.--Common resident in the humid coastal strip as far south as Big Creek, Monterey County (Jenkins); also not common summer resident in northern high Sierras as far south as the Yosemite Valley (Torrey, Grinnell). In 


\section{The Western Winter Wren}

winter common resident and visitant in suitable localities of northern and central California west of the Sierras, and sparingly south through the San Diegan district. A record for Santa Cruz Island (by C. B. Linton, Oct. 23, I908).

Authorities.-Xantus (Troglodytes hyemalis), Proc. Acad. Nat. Sci. Phila., vol. xi., I 859, p. I9I (Ft. Tejon); Sheldon, Condor, vol. x., I908, p. I20 (desc. nests and eggs); Grinnell, Sierra Club Bull., vol. viii., I9I I, p. I22 (Yosemite Valley; desc. nests); Willett, Pac. Coast Avifauna, no. 7, I9I2, p. I02 (occurrence in s. Calif.); Davis, Condor, vol. xx., I9I8, p. I90 (Eureka; nest and eggs; nesting dates); Oberholser, Proc. U. S. Nat. Mus., vol. lv., I919, p. 236 (monogr.; syst.).

CHICK-chick chick-chick chick; it is the Winter Wren's way of saying How-do-you-do? when you invade his domain in the damp forest. The voice is a size too large for such a mite of a bird, and one does not understand its circumflexed quality until he sees its possessor making an emphatic curtsy with each utterance. It is not every day that the recluse beholds a man, and it may be that he has stolen a march under cover of the ferns and underbrush, before touching off his little mine of interrogatives at your knees. If so, his brusque little being is softened by a friendly twinkle, as he notes your surprise, and then darts back chuckling to the cover of a fallen log.

Again, if your entrance into the woods has been unnoticed, so that the little huntsman comes upon you in the regular way of business, it is amusing to watch with what ruses of circumvention he seeks to inspect you. Now he appears above a root on your right, gawking on tiptoe; then drops at a flash behind its shelter to reprove himself in upbraiding chick chick's for his rashness. Then, after a minute of apprehensive silence on your part, a chuckle at your other elbow announces that the inspection is satisfactorily completed on that side. The Lilliputian has you at his mercy, Mr. Gulliver.

The Western IVinter Wren is one of the commonest birds in the humid coast belt of western California as far south as middle Monterey County. Not only is it the most characteristic inhabitant of rugged stream beds and romantic dells, but it may be found throughout the somber depths of the fir and redwood forests, from sea-level nearly to the tops of the northern mountains. It is fond of the wilderness, and has learned no necessity of dependence upon man, although it by no means shuns the edges of town, if there be sufficient damp cover available. Because of the broken and discontinuous character of the fir forests of the western Sierras, the Winter Wren is found there only rarely and locally in sumner, and it has not yet been reported as breeding south of the Yosemite. Pine country is altogether too dry for our hero, or perhaps he feels that his dark costume is out of place in full sunshine. On the other hand, I once encountered these birds, in some numbers and 


\section{The Western Winter Wren}

repeatedly, in late May and early June, haunting the lava cliffs of an Upper Sonoran region miles from timber. They were almost sure to have been non-breeding waifs. Their migrations are not extensive, and consist chiefly in retiring to adjacent lowlands to avoid the heavy snows of the upper levels. It is, thus, probably the Sierran birds which are most completely driven out in winter, and such birds go as far south as Los Angeles County, or as far west as Santa Barbara.

It is the Winter Wren, chiefly, which gladdens the depths of the ancient forest with music. Partly because of its unique isolation, but more because of the joyous abandon of the little singer, the song of the Winter Wren strikes the bird-lover as being one

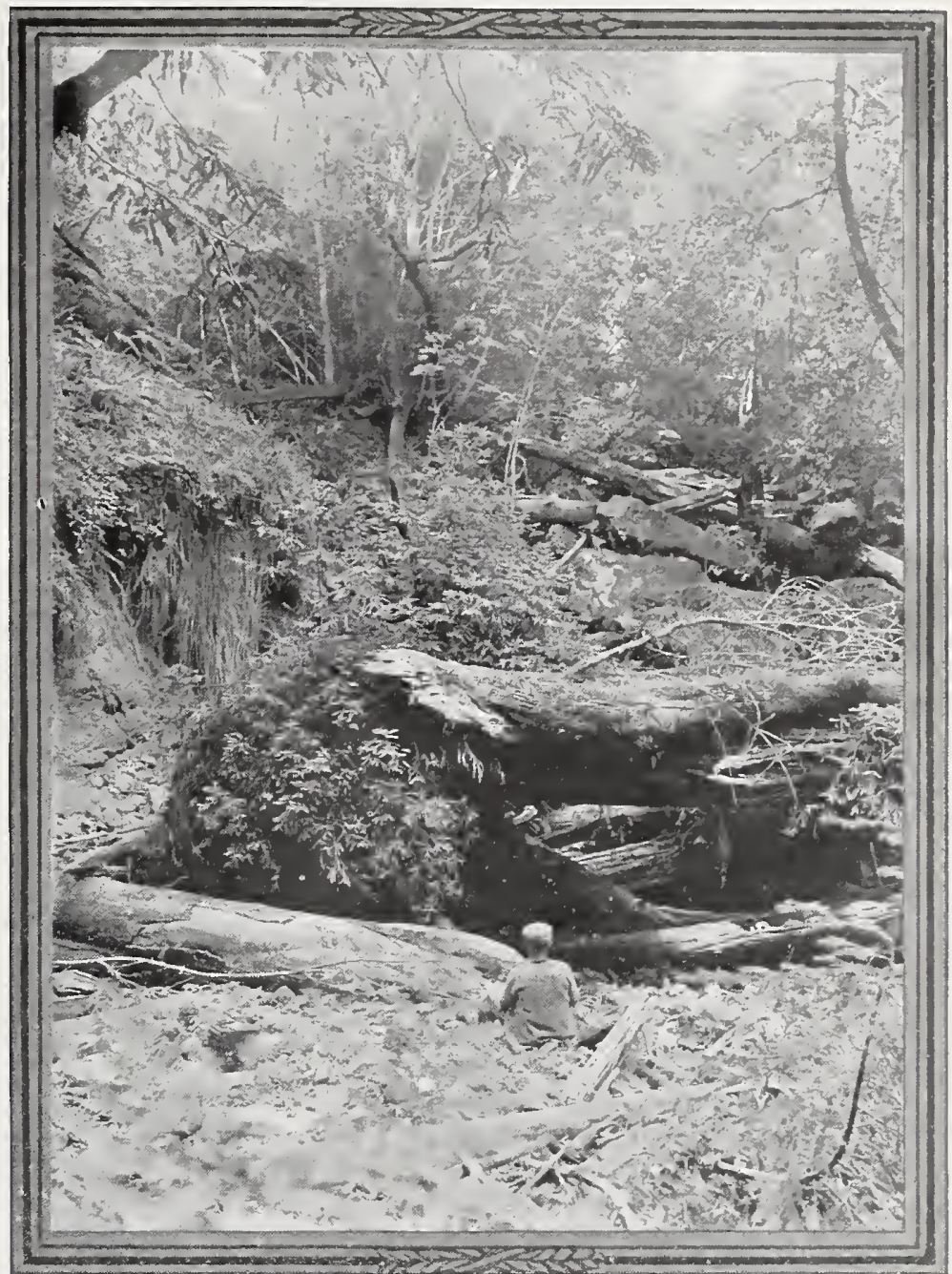

Taken in Santa Cruz County

Photo by the A whor

BREEDING HAUNT OF THE WESTERN WINTER WREN

AN OCCUPIED NEST IS TUCKED AWAY IN THE DEPTHS OF THE ROOT MASS UNDER THE NEAREST FERNS

of the most refreshing in the West. It consists of a rapid series of gurgling notes and wanton trills, not very loud nor of great variety, but having all the spontaneity of bubbling water,-a tiny cascade of song in a waste of silence. The song comes always as an outburst, as though some mechanical obstruction had given way before the pent-up music. Indeed, one bird I heard near the coast preceded his song with a series of tittering notes, which struck me absurdly as being the clicking of the ratchet in a music-box being wound up for action. 


\section{The Western Winter Wren}

Heard at close quarters the bird will occasionally employ a ventriloquial trick, dropping suddenly to sotto voce, so that the song appears to come from a distance. Again, it will move crescendo and diminuendo, as though the supply pipe of this musical cascade were submitted to varying pressure at the fountain head.

A singing bird is the best evidence available of the proximity of the nest. Usually the male bird posts himself near the sitting female and publishes his domestic happiness in musical numbers. But again, he may only be pausing to congratulate himself upon the successful completion of another decoy, and the case is hopeless for the nonce.

For nesting sites the Wrens avail themselves of cubby holes and crannies in upturned roots or fallen logs, and in fire-holes of half-burned stumps. A favorite situation is one of the crevices which occur in a large fir tree when it falls and splits open. Or the nest may be found under the bark of a decaying log, or deeply bedded in a mossy bank.

In the coastal streams of Santa Cruz County the Winter Wrens have almost a monopoly of the stream-bed, and they stick very closely to it. Crannies in boulders and rock-walls are quite as acceptable as an upturned root or a log-jam; and most of the nests are actually over running water. If the site selected has a wide entrance, this is walled up by the nesting material, and only a smooth round aperture an inch and a quarter in diameter is left to admit to the nest proper. In default of any such shelter, birds have been known to construct their nests at the center of some baby fir, or in the drooping branches of an evergreen tree at a height of a foot or more from the ground. In such case, the nest is finished to the shape of a cocoanut, with an entrance-hole in the side a little above the center.

In all cases the materials used are substantially the same, chiefly green moss, with an abundance of fir or redwood twigs shot through its walls and foundations. This shell is heavily lined with very fine mosses, intermingled with rabbit fur, deer hair or other soft substances; while the inner lining is almost invariably of feathers.

"Cocks' nests," or decoys, are the favorite diversion of this indefatigable bird, so that, as with the restless activities of four-year-old children, one sighs to think of the prodigious waste of energies entailed. The aboriginal cause of this quaint instinct, so prevalent among the Wrens, would seem to be the desire to deceive and discourage enemies, but in the case of the Winter Wren one is led to suspect that the hardworking husband is trying to meet a perpetual challenge to occupy all available sites - a miser hoarding opportunities.

A troop of young Wrens just out of the nest is a cunning sight. The anxious parents counsel flight and the more circumspect of the brood 
obey, but now and then one less sophisticated allows a little pleasant talk, "blarney," to quiet his beating heart. Then a little titillation of the crown feathers will quite win him over, so that he will accept a gently insistent finger in place of the twig which has been his support. The unfaltering trust of childhood has subdued many a savage heart, but when it is exemplified in a baby Wren, one feels the ultimate appeal to tenderness.

No. 137

\section{Rock Wren}

A. O. U. No. 7 I5. Salpinctes obsoletus (Say).

Description.-Adults: Above soft grayish vinaceous brown (between benzo brown and drab), changing on rump to orange-cinnamon or fawn-color, most of the surface speckled by fine, dusky, arrow-shaped marks, containing, or contiguous to, rounded spots of pinkish buffy; wing-quills color of back, faintly barred with pinkish buff on outer webs; tail rounded or fan-shaped; middle pair of tail-feathers color of back, barred with dusky; remaining rectrices barred with dusky on outer webs only, each with broad subterminal bar of blackish, and tipped broadly with cinnamon-buff area, varied by dusky marbling; outermost pair broadly blackish-and-cinnamon-barred on both webs; a superciliary stripe of whitish or pinkish buff; a broad post-ocular stripe of grayish brown; sides of head and underparts dull pinkish white, shading into pale cinnamon or vinaceous buff on flanks and under tail-coverts; sides of head, throat, and upper breast spotted, mottled, or streaked obscurely with grayish brown or dusky; under tail-coverts barred or transversely spotted with black. Bill dark horn-color above, paling below; feet and legs brownish dusky; iris brown. Young birds are more or less barred or vermiculated above, with increase of vinaceous, without white speckling; and are unmarked below. Length I39.7-152.4 (5.50-6.00); wing 70 (2.76); tail 53 (2.09); bill 17.7 (.70); tarsus 2 I (.83).

Remarks.-An alleged subspecies, $S$. $o$. pulverius, was described by Mr. Joseph Grinnell (Auk, vol. xv., July, I898, p. 238) from San Nicolas Island in the following language: "Pattern of coloration similar to that of the mainland S. obsoletus, but entire plumage, especially the upper parts, suffused with ochraceous or dust color, almost identical with the tint of the soil on San Nicolas Island." The describer also claimed distinction for this proposed form on the ground of "notably greater size of the bill and feet." A later reviewer, Mr. H. S. Swarth (Condor, vol. xvi., Sept., I9I4, pp. 2II-2I7), decided that the peculiar color of the San Nicolas specimen of Salpinctes was due to contact with the soil, just as the reddish color of certain specimens of S. guadaloupensis was due to contact with reddish soil. In concluding his comparison of specimens of $S . o$. obsoletus and S. o. pulverius, Swarth says: "I am unable to distinguish the slightest significant difference in color or pattern," although he concedes a slightly larger bill to the San Nicolas birds, an excess of $\mathrm{I} .3$ millimeters, or 7 percent in the case of males and .2 of a millimeter, or I percent in the case of females. Such average differences might occur between two handfuls of bird-skins seized at random from any collection tray. And in this very case, the individual variation in the ten examples (males) of $S$. o. obsoletus a mounts to 2 millimeters, or I i percent of the smaller. 


\section{The Rock Wren}

But if the difference claimed were actually significant and constant, as is not impossible, it would still be too slight a matter to recognize in nomenclature. It is through such tithing of mint and anise that descriptive ornithology has brought itself into disrepute.

Recognition Marks. - Warbler size; variegated fan-shaped tail, with broad buffy tips distinctive; rock-haunting habits.

Nesting.- Nest: In crannies of cliffs at end of tunnels, in barranca walls, or even (Farallon Islands) in burrows in ground; of twigs, grasses, and rootlets; lined with rootlets, fine bark-strips, or hair; invariably approached by runway of rock-flakes or pebbles. Eggs: 5-7; white, sometimes immaculate, but usually sprinkled sharply and very sparingly with reddish brown. Av. size $18.3 \times 13.7(.72 \times .54)$. Season: AprilJuly, according to altitude; one or two broods.

General Range.-Western United States and Mexico to Guatemala.

Distribution in California.- Resident. Breeding in rupestrine associations, but chiefly in arid portions of the State from sea-level to snow-line; retires before the snows to Sonoran zones of valleys and deserts. Found on all the larger islands including the Farallons.

Authorities.-Heermann (Troglodytes obsoletus), Jour. Acad. Nat. Sci. Phila., ser. 2, ii., I853, p. 263 (Calif.); Bryant, W.E., Proc. Calif. Acad. Sci., 2nd ser., i., I 888 , p. 49 (Farallon Ids.; desc. nest and eggs; meas.); Willett, Pac. Coast Avifauna, no. 7, I9I2, p. IоI (s. Calif.; distr., nesting dates, etc.); Swarth, Condor, vol. xvi., I9I4, p. 2 I I (crit.; distr.; etc.); Grinnell, Univ. Calif. Pub. Zool., vol. xii., r914, p. 208 (Lower Colorado Valley; occurrence, desc. nest, etc.).

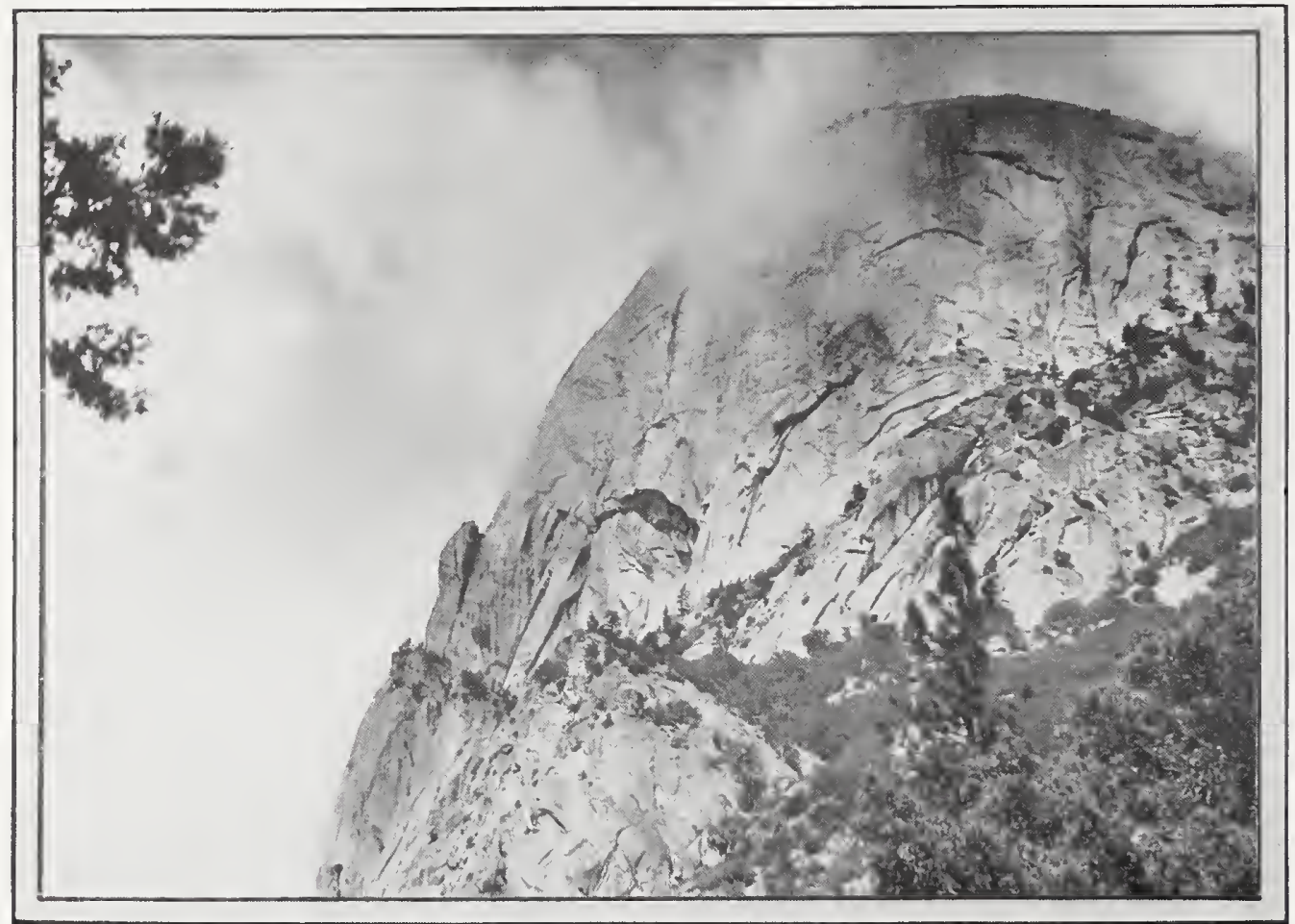

Taken in Fresno County

A REAL ROCK

Photo by the Author

684

A NEAR VIEW OF TEHIPITE DOME 


\section{The Rock Wren}

"So the folks all shy from the desert land

'Cept mebbe a few that kin understand."

- Clark

A DISCERNING soul is Salpinctes. He loves beyond all else the uplifted ramparts of the wilderness, the bare lean battlements of the elemental eld. They are to him the walls of a sanctuary, where he is both verger and choir master, while upon the scarred altars which they shelter, his faithful spouse has a place "where she may lay her young."

In a certain half day's wandering on a desolate range west of the Colorado River the writer saw just three birds, a Vulture, a Red-tailed Hawk and a Rock Wren. It was a winter day, else the heat would have been intolerable. Water was a thing unthought of, and vegetation was of the scantiest, and that the most forbidding,

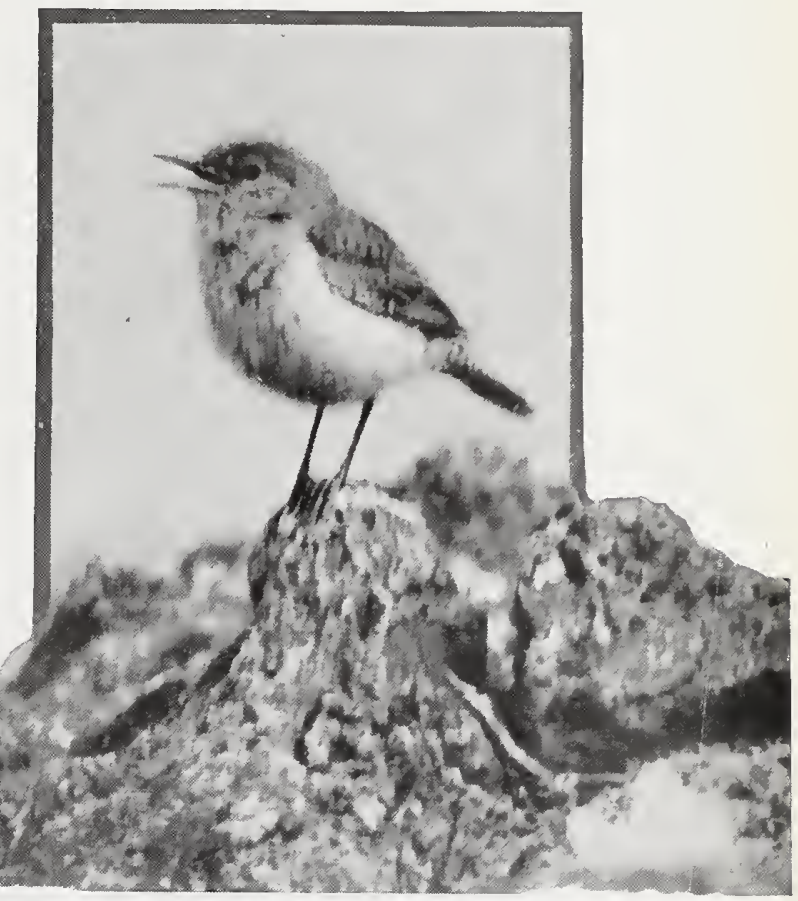

Pholo by D. R. Dickey

WAKING UP THE OLD HILLS harsh, weird, and thorn-begirt. The rounded stones which covered the ground were as of yesterday in their careless arrangement, but their surfaces were burnt to a uniform brown by atmospheric acid, the product of volcanic activities which may have been stilled a hundred millenniums ago. Three birds! two of them transients, like myself, viewing the desolation indulgently, as knowing they could escape at any moment; and only one who lived there, who stayed from choice, who hugged the solitude to his breast, and loved it,- only one who understood!

The Rock Wren is nestled among the most impressive surroundings, yet he gives no evidence of a chastened spirit. There is nothing subdued or melancholy about his bearing. Indeed, he has taken a commission to wake the old hills and to keep the shades of eld from brooding too heavily upon them. His song is, therefore, one of the sprightliest, most musical and resonant to be heard in the entire West. The rock-wall makes an 


\section{The Rock Wren}

admirable sounding-board, and the bird stops midway of whatever task to sing a hymn of wildest exultation. Whit'tier, whit'tier, whit'tier, is one of his finest strains; while $k a-w h e ́ e ́, k a-w h e ́ e, k a-w h e ́ e$, is a sort of challenge which the bird renders in various tempo, and punctuates with nervous

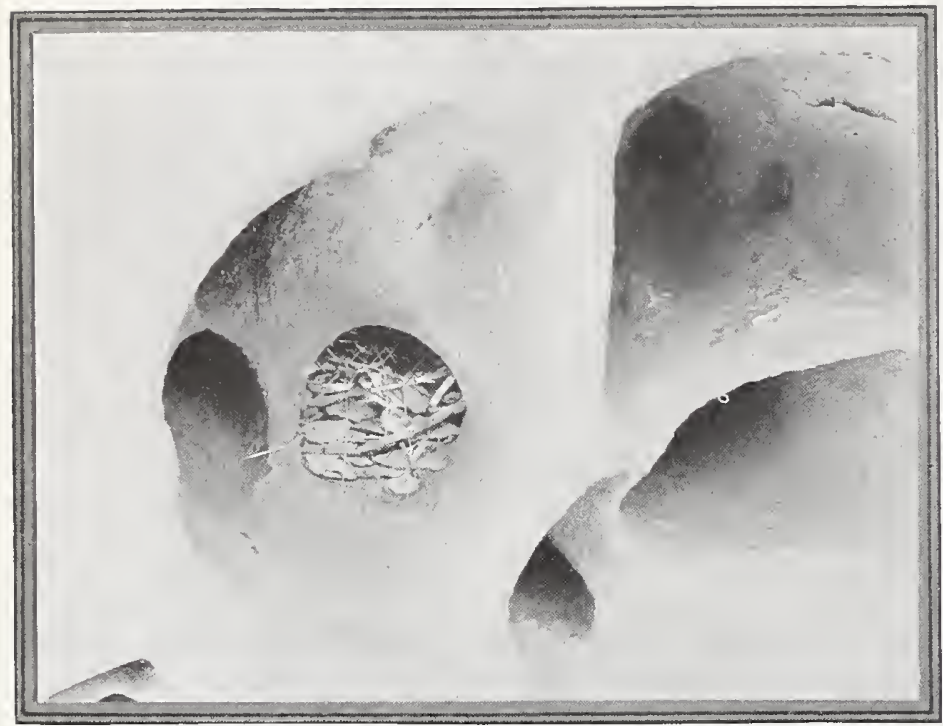

Taken in Kings County

NEST OF ROCK WREN IN SANDSTONE CRANNY

NOT QUITE TYPICAL, HOWEVER, BECAUSE OF RATHER ABBREVIATED APPROACH bobs to enforce attention.

For the rest his notes are so varied, spontaneous, and untrammeled as hardly to admit of precise description. Once, in February, I caught a Rock Wren near San Diego, rehearsing in an undertone for the coming concert season. The bird was only twenty feet away from me (and I had eight-power glasses), but by no visible indication could one guess the source of the music, save as the score now and then led up to the whittier note, which obliged the bird to part the mandibles slightly. The Wren was really singing through his nose, a ventriloquist, as well as a vocalist of no mean order.

Another Rock Wren, held under full survey on Santa Cruz Island, was producing an extraordinary series of squeaking and rubbing notes, which I should have attributed to the Anna Hummer. In fact, a moment later an indubitable Anna did tune up in practically the same fashion, only a good deal better, and I could see that the Wren had been taking a lesson in this music of the fairies.

Save in the vicinity of his nest, the Rock Wren is rather an elusive sprite. If you clamber to his haunts, he will remove, as a matter of course, a hundred yards along the cliff; or he will flit across the mesa with a nonchalance which discourages further effort. Left to himself, however, he may whimsically return-near enough perhaps for you to catch the click, click of his tiny claws as he goes over the lava blocks, poking into crevices after spiders here, nibbling larvæ in vapor holes there, or scaling sheer heights yonder without a thought of vertigo.

At nesting time the cliffs present a thousand chinks and hideyholes, any one of which would do to put a nest in. The collector is likely to be dismayed at the wealth of possibilities before him, and the birds 


\section{The Rock Wren}

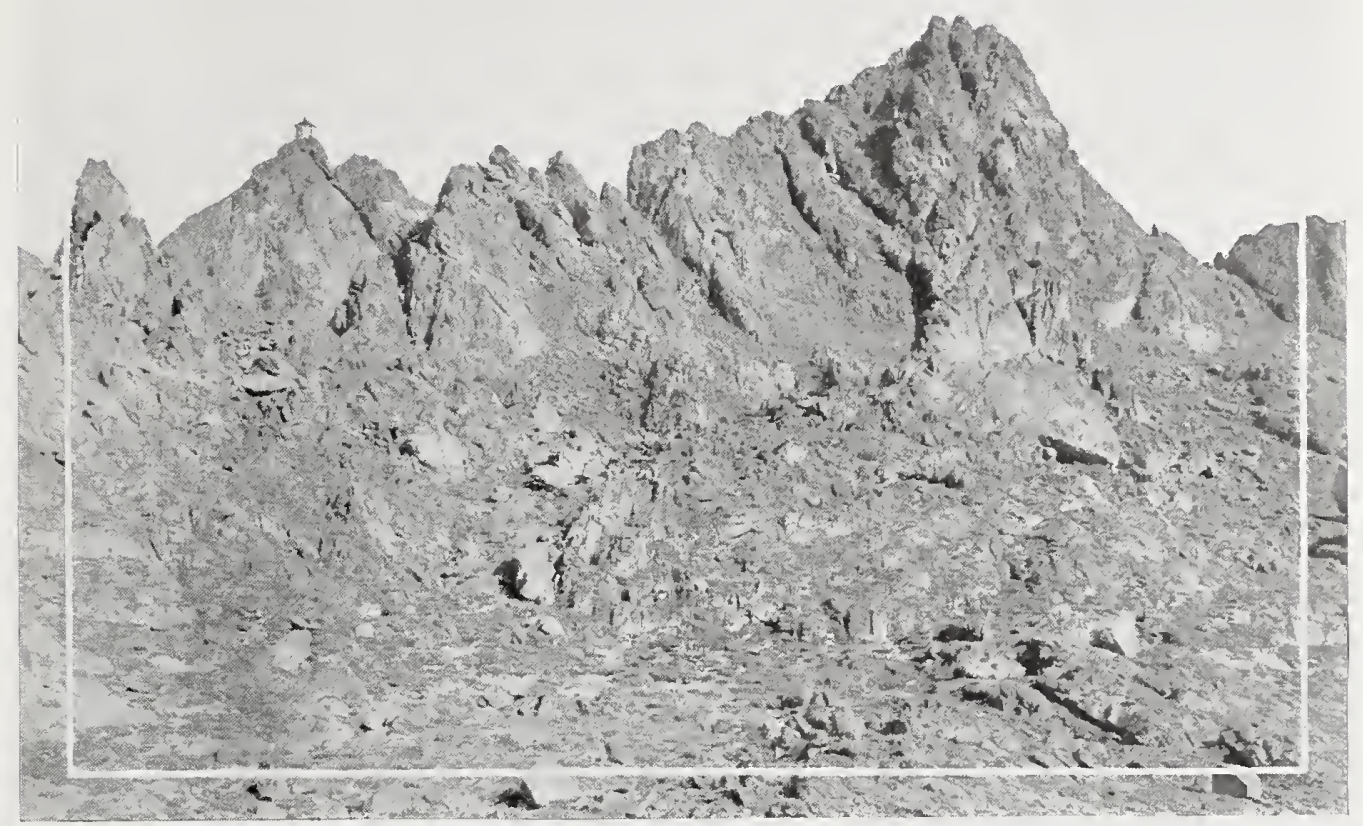

NO LOVER OF ROCKS COULD AFFORD TO OVERLOOK THE FARALLONS

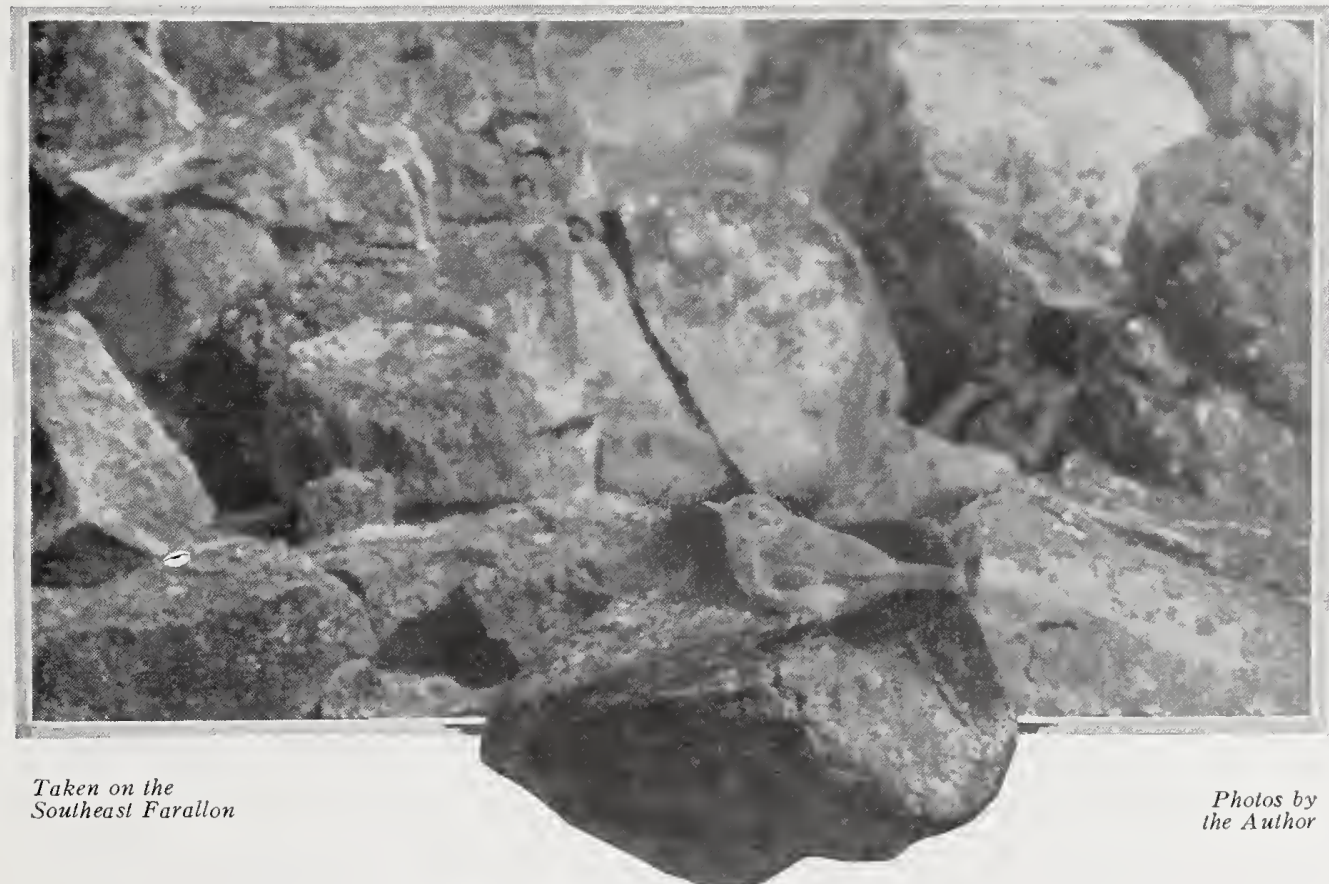

“THE PRESIDING GENIUS OF THE FARALLONS" 


\section{The Rock Wren}

themselves appear to regret that they must make choice of a single cranny, for they "fix up" half a dozen of the likeliest. And when it comes to lining the approaches to the chosen cavity, what do you suppose they use? Why rocks, of course - not large ones this time, but flakes and pebbles, whether of sandstone, limestone, granite, basalt, or whatever the country rock may be. These rock-chips are sometimes an inch or more in diameter, and it is difficult to conceive how a bird with such a delicate beak can compass their removal. Here they are, however, to

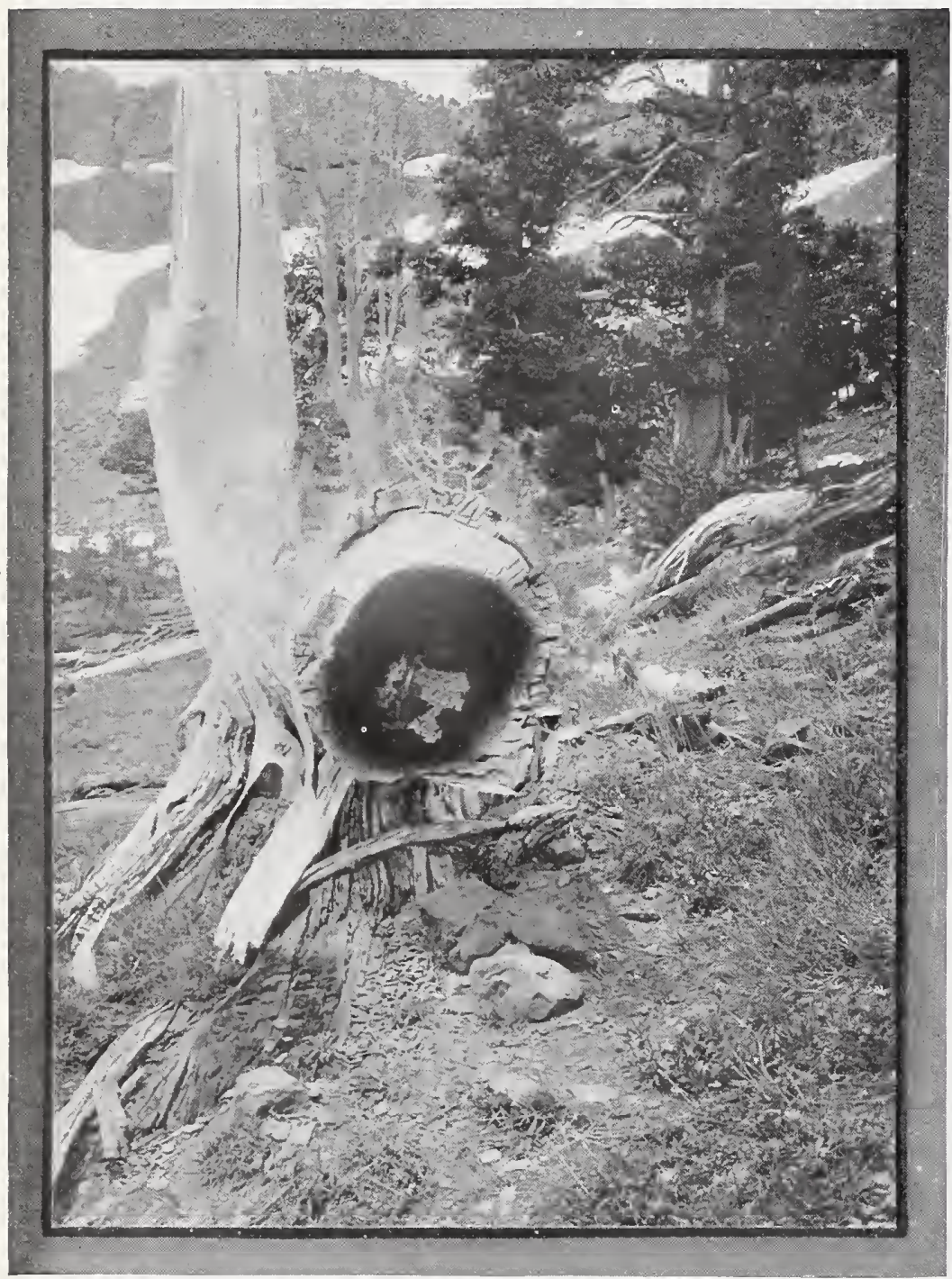

Taken in the Warrer Mountains

AS PER REGULATIONS the quantity of half a pint or more, and they are just as much a necessity to every wellregulated Salpinctian household as marble steps are to Philadelphians.

In two instances which have come under my observation where the nesting cranny was too cramped to allow the full complement of pebbles, the theme was taken up on the next available level space below. In the case pictured here, that level space was the ground. The nest proper, also composed basally of rock-flakes, occupies the innermost recess of the burnt-out log-end. But the lower lip of this $\log$ would not harbor additional rock-flakes by reason of steepness. Instead, however, of being suffered to pile up in an aimless heap on the ground, they are methodically arranged, 


\section{The Rock Wren}

and as carefully as though they connected directly with the nest. What the purpose of all this activity may be, no one knows for certain. Your guess may be as good as mine, but I hazard that it is the noise made by rattling pebbles which rouses the sitting bird to attention - a sort of burglar alarm, in fact.

The nest itself is a shallow saucer composed of rootlets and fine grasses, and, sometimes, with a scanty lining of hair or wool. Two broods are raised in a season, or, rarely, three, and the dates vary interminably according to the elevation of the range. The eggs vary from four to seven in number and are pure white in color, with a sparse sprinkling of reddish brown dots; or, occasionally they are immaculate. An authority on Wrens1 says of their range, "An altitude of eleven thousand feet is attained in certain cases." This modest claim may have been based on reports of the Rock Wren, or it may refer to some Andean species. I have seen the Rock Wren in the Sierras (near Mt. Langley) at an altitude of $\mathrm{I} 2,500$ feet, where it was evidently breeding (June 26, I9I I). I presume that it goes to the very summit of Mount Whitney (alt. I4,500 ft.) as the season advances. Whether this latter surmise be correct or not, we have here the most remarkable altitudinal breeding

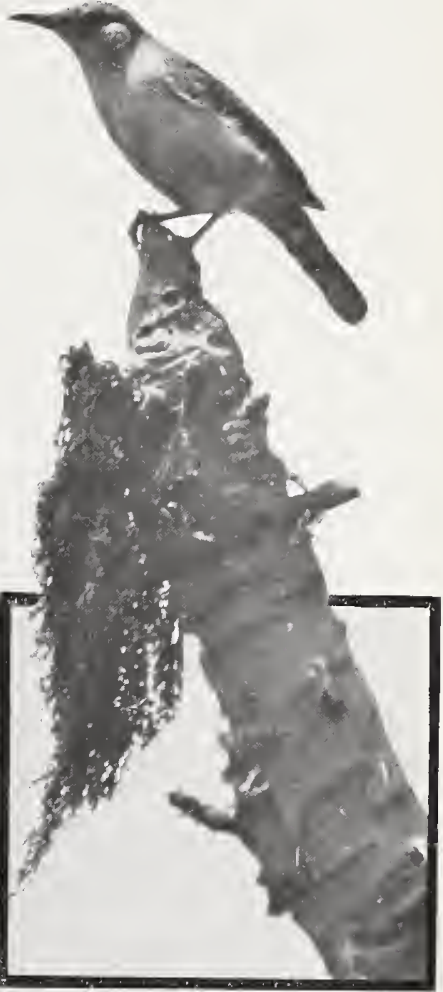

Taken on Anacapa Island Photo by Dickey

MERELY AN OBSERVER range of any bird in the world; for the Rock Wren is equally at home in the summer upon the Santa Barbara Islands, the Farallons, and at various sea-level points along the mainland coast. At the same moment Rock Wrens are incubating in superheated furnaces at sea-level on the borders of the Colorado Desert, in granite niches of the high Sierras two thousand feet above the level of nightly frosts, and out at sea amid the teeming hosts of sea-fowl on the Southeast Farallon.

The Rock IVren is the presiding genius of the Farallons, fearless, inquisitive, thrifty, and always happy. Not a secret on the island which the Rock Wren does not know, for she pokes and pries into every crevice, examines every movable fragment of rock, stick, or bone with a view to appropriation, scrutinizes every form of insect life with a view to assimilation, bugles from every rock crest, greets the descending light-keeper in the cool gray of the morning, chirrups at "Snoozer," the island mascot, as she passes in her go-cart, titters at the Cassin Auklet brooding in her gloomy cell, mocks at the dignified Sea Parrot, and stirs things up generally. At the time of our visit (May 20-June

${ }^{1}$ A. H. Evans: Cambridge Nat. History, Vol. IX., Birds, p. 32 I. 


\section{The Canyon Wrens}

3, I9II) the first broods of young were shifting for themselves and the adult population was busy with second nesting. We found five occupied nests, besides several promising "empties," without half trying. Of these, two contained pure white eggs, five and six respectively. The set of five was normal in size and shape, but the eggs of the larger set were much undersized and absurdly shaped,-chopped off, squared or flattened, like plaster pellets done by hand instead of in nature's workshop. One egg, by way of exception to these exceptions, was elongated instead of shortened,-evidently amateur work.

All the Rock Wrens wore their old clothes. Either their seclusion had made them indifferent to the prevailing fashions, or else they had worn out their wedding garments earlier in the season. The "splitters" have had their jealous eyes on these Farallon birds, but so far they have managed to keep within the bounds of Salpinctian propriety - a wide enough range, to be sure.

\section{No. 138}

\section{Canyon Wren}

\section{No. 138a Nevada Canyon Wren}

A. O. U. No. 7ı a. Catherpes mexicanus conspersus Ridgway.

Description.-Adult: Throat and upper breast, broadly, pure white, shading sharply on sides to brown of remaining plumage; above warm grayish brown (nearest snuff-brown on pileum), changing gradually to bright dark reddish brown (amberbrown, argus brown, to russet) of rump, tail, and posterior underparts; the head, neck, back, scapulars, and posterior underparts speckled by fine, dusky, arrow-shaped marks containing, or contiguous to, rounded spots of whitish; wing-quills fuscous, finely barred with dusky on exposed surfaces; tail bright dark brown throughout, crossed sharply and narrowly by 7-10 wavy bars of blackish. Bill horn-color above, paling on sides and below; feet and legs brownish dusky; iris brown. Young birds lack the white speckling; are more extensively marked with dusky above, but are nearly unspotted on belly. Length about I39.7 (5.50); wing 59.7 (2.35); tail 52.4 (2.06); bill $20.5(.8 \mathrm{I})$; tarsus I $8 . \mathrm{I}(.7 \mathrm{I})$. Female a little smaller.

Recognition Marks.-Warbler size; rock-haunting habits; throat broadly white, contrasting with rich rusty red of hinder underparts; tail finely barred with black, its feathers without buffy tips, as distinguished from Salpinctes obsoletus. Has magnificent descending scale song.

Nesting.-As in following form.

Range of Catherpes mexicanus.-Arid portions of western United Statesand Mexico.

Range of C.m. conspersus.- "Upper and Lower Sonoran zones of Great Basin and Rocky Mountain region from eastern California (Mono Lake), Nevada, and south-eastern Colorado south to Lower California, western Texas, Sonora, and Chihuahua" (A. O. U.).

Distribution in California.-Breeding east of the Sierras, chiefly in the desert ranges, from Mono Lake (Negit Island, June 5, 1919) south to the Providence Mount- 
ains. Also sparingly in the Warner Mountains (Grinnell). Occurs commonly in winter on the southeastern desert and in the valley of the Colorado.

Authorities.-Fisher, A. K. (Catherpes mexicanus conspersus), U. S. Dept. Agric., N. Am. Fauna, no. 7 , I 893, p. I33 (Panamint Mts.); Lamb, Condor, vol. xiv., I9I2, p. 40 (Yermo, Mohave Desert); Grinnell, Pac. Coast Avifauna, no. I I, I905, p. I 57 (distr. in Calif.); ibid., Univ. Calif. Pub. Zool., vol. xii., I9I4, p. 209 (Lower Colorado Valley; occurrence, etc.).

\section{No. 138b Auburn Canyon Wren}

A. O. U. No. 7I 7 b. Catherpes mexicanus punctulatus Ridgway.

Synonym.-Dotted Canyon Wren (misleading because bird not more con(picuously dotted than other forms).

Description.-Like C. m. conspersus, but decidedly darker; the brown of tail and belly averaging about auburn.

Nesting.- Nest: In potholes or crannies of rock-walls; basally of sticks, but body of nest built up bulkily of substances increasingly soft, the exterior and lining exquisitely felted of wool, plant-down, moss, catkins, cocoons, spider-egg-cases, and cobwebs - the handsomest of all wrens' nests. Eggs: 5; white, very variable as to marking, sometimes nearly immaculate, or finely and sparingly sprinkled, or coarsely and sharply spotted with reddish brown. Av, size $17.8 \times 13.5(.70 \times .53)$. Season: May; one (?) brood.

Range of C. $m$. punctulatus.- Upper and Lower Sonoran zones from west central Idaho, southeastern Washington, and eastern Oregon south through California, chiefly west of the Sierra Nevada.

Distribution in California.--Common resident in the mountainous portions of southern California; less common resident along both slopes of the Sierra Nevada and through the coast ranges, at least the inner ones, north irregularly to Shasta County. Occurs regularly on Santa Cruz Island.

Authorities.-Heermann (Troglodytes mexicanus), Jour. Acad. Nat. Sci. Phila., ser. 2, ii., I 853 , p. 263 (Calif.; Cosumnes and Calaveras rivers); Ridgway, Proc. U. S. Nat. Mus., vol. v., I882, p. 343 (orig. desc.; Forest Hill, Placer Co.); U. S. Nat. Mus. Bull. 50, part iii., I904, pp. 659, 660 (monogr.; name $C . m$. polioptilus used for some Calif. spec.); Pierce, Condor, vol. ix., I907, p. I6 (desc. of nest; San Gabriel Mts.); Willett, Pac. Coast Avifauna, no. 7, I9I2, p. IоI (s. Calif.; nesting dates, etc.).

SAVE in the brimful Sierras and along the dank coasts of the North, the cataracts of California go dry in the summer season. The torrential water-courses which carry off the surplusage of March are silent by April, and in May a worm might crawl unrebuked across the face of a rock worn smooth by the flood waters of winter. How the moment is redeemed, then, when a bird comes tumbling down a precipice of song, hurling himself recklessly from rock to rock till he seems to lay the vocal tribute at your very feet. "Seems," I say, for it is all a vocal artifice, a tour de force of the artistic imagination which has called up the imagery of winter. We know it is a trick, and we have seen the singer clinging the while with his eight sharp toes to a boss of rock, yet we shall never hear the "dropping song" of the Canyon W'ren without 


\section{The Canyon Wrens}

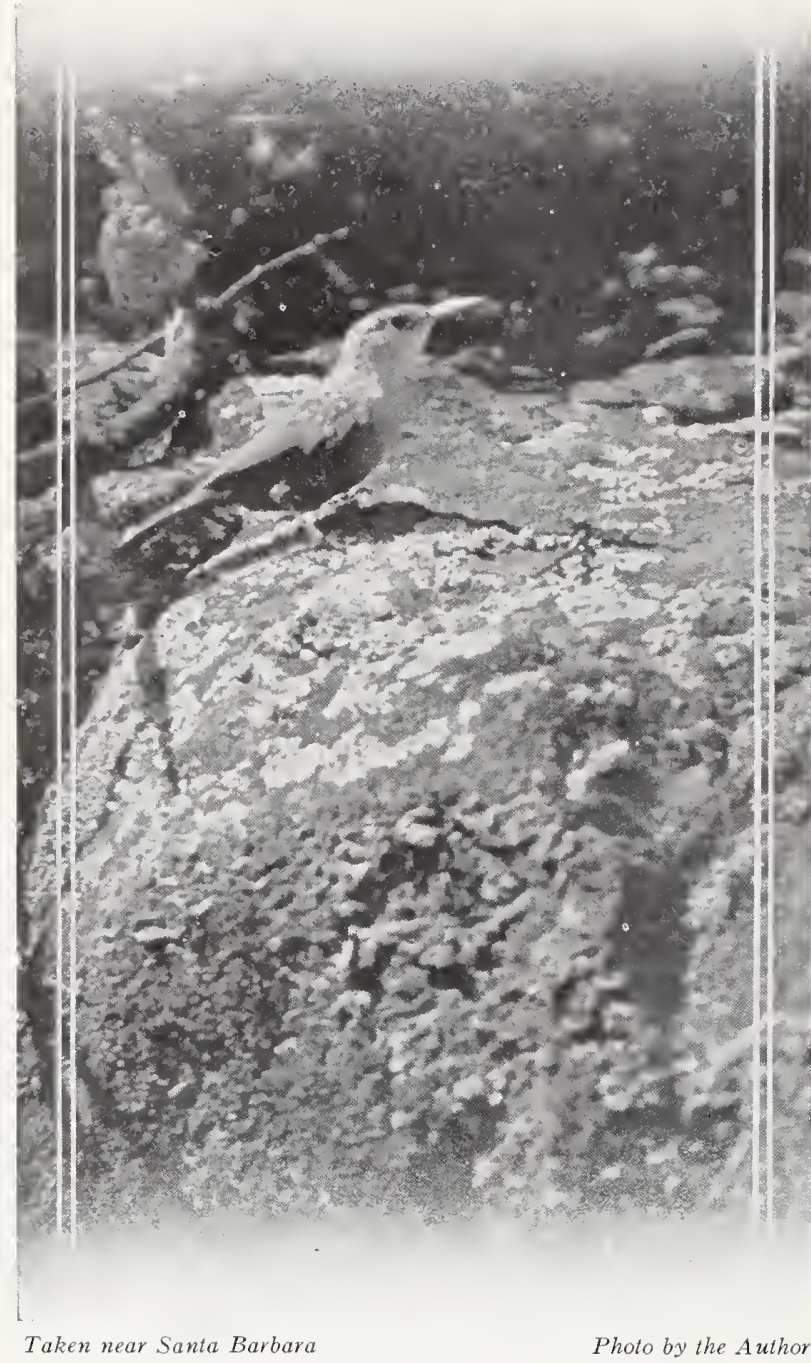

A CANYON WREN PORTRAIT

an amazed stopping of the heart and a thrilling sense of physical adventure. Especially when the bird is really near at hand, you feel as if you were being made the target of a salvo of musical bombs, which, starting from a far height, detonate with unceasing nearness until the last are exploding against your very person. The descent is through nearly two octaves; and the notes, whose crest, heard in the distance, seem purest whistle-tones, are seen at near quarters to be double and vibrant in character. The notes are normally seven or eight, with a full tide of passion thrown into the last three; but as often as not the singer adds one or two entirely different, as though, having sung his heart out, the mountaineer should fling down hat and gauntlet with a rustic whoopee of exhaustion. It

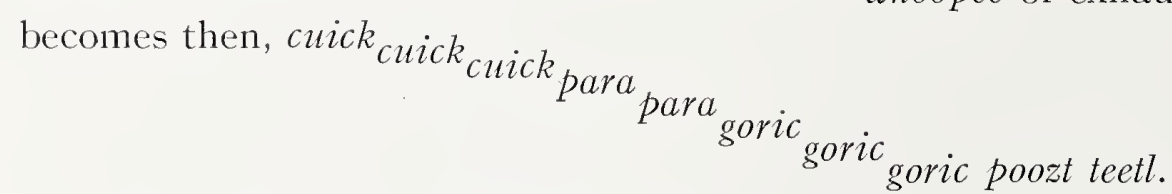

Heard across the wastes of chaparral, or in the cool depths of some rugged ravine, this song of the Canyon Wren is at once the most stirring and imaginative, and the most delightful which the wilderness of California has to offer. Heard a dozen times, perhaps, or ever its author is seen, one has formed in advance a picture of a very engaging bird person. And for all save dignity (no Wren can be dignified) the Canyon 692 
Wren meets the expectation. Whether the bird plays at hide-and-seek through trailing vines, or posts quietly on a rock-knob, or comes clinking over the face of a rocky exposure, it is easily seen to be the handsomest of North American wrens. The white of the throat, where alone the plumage is immaculate, shades on the breast into the rich warm brown or auburn of the hinderparts; and everywhere else there is speckling of black-and-white or a barring of black. The bird, however attentive, cannot resist a peeping spider or an insulting midge, and whatever the danger, he manages to divide his time impartially between observation and insect-catching. If he is disturbed, as at nesting time, a musical clink, or cleeink, bursts from his mandibles, moment by moment, accompanied by an emphatic bob or squat. Now and then these clinks are grouped hastily into an imitation of the dropping song, but with only a trifling change in pitch.

There is no place forbidden to a Canyon Wren, no rock wall which frights him, no tunnel's mouth, nor intricacy of talus bed. He has no special predilection for the picturesque, however, as his name might seem to imply. A brush pile or a heap of old tin cans will do as well as a miner's cabin or an old Mission. What a merry soul it is, and his life how full of adventure! There is a wondrous variety in the world

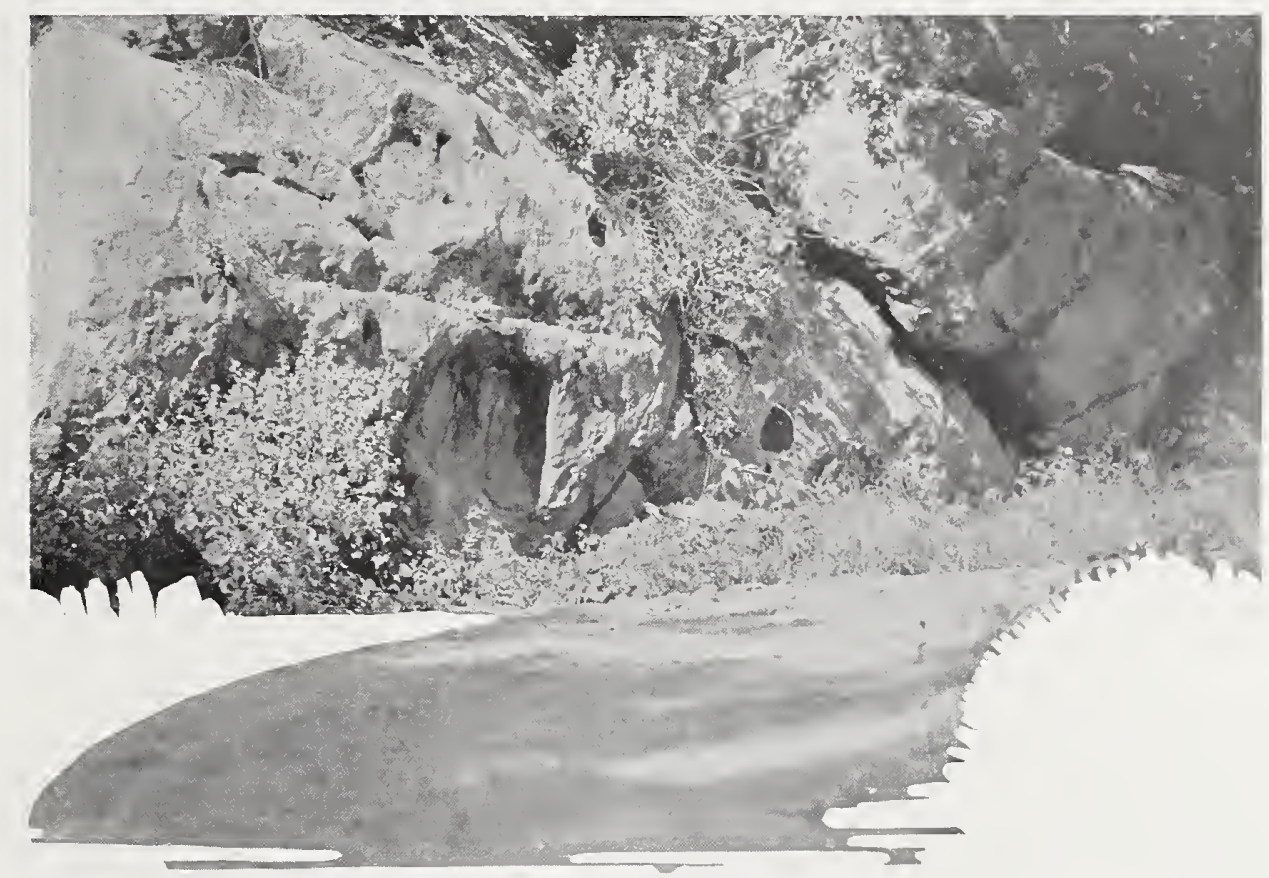

Taken near Sania Barbara

A TYPICAL NESTING SITE.

Photo by the Author 


\section{The Palmer Thrasher}

which he explores,- $\log$-heaps, stone-piles, crannied walls, labyrinths of roots undermined by a stream, stemmy jungles, tangled vines, rainfretted gullies, and all the infinite disarray of nature. And the plucky bird charges into some cavern, dark with nameless terrors, as though it were a nesting-box, and he exorcises all its dank ghosts with a merry clink clink, which is sunshine itself. Now and then he does make amazing discoveries, which he reports in a sudden explosion of clinks. After such a passage, it is moments on end before he gets calmed down enough to clink coherently. In and out, down, around, across and under-who would not envy the happy diversity of this midget's daily round!

The Auburn Canyon Wren nests almost anywhere, in crannies of rock-walls or about upturned roots on mossy banks, or about old buildings. It does not favor holes in trees, as do House Wrens and Bewick Wrens; and it doesn't seem to care a bug about water. If the cranny is big enough, the Wren will lay a foundation of sticks; but if not, it has sense enough to forego these Troglodytine talismans. The nesting cup proper is wonderfully compacted of all soft substances,mosses, cocoons, spiders' nests, caterpillar-silk and spider-webs. The finished hollow is as soft as a baby's cheek, a monumental tribute to the tireless skill of the builder.

The nest whose owner is pictured on p. 692 occupied a rounded cranny in a weatherbeaten rock overlooking a travelled road, and not above five feet from it. On the Ist of May it held five eggs; but its mistress, when disturbed, returned presently lugging a huge stick. She was just thinking about building, you know. But she dropped the bluff, along with the stick, under a friendly gaze, and after a few feints she resumed her place upon the eggs, clinking, softly, like a watch dog rebuked but unconvinced.

No. 139

\section{Palmer's Thrasher}

\section{A. O. U. No. 707a. Toxostoma curvirostre palmeri (Coues).}

\section{Synonym.- Western Curve-Billed Thrasher.}

Description.--Adult (sexes alike): Above plain hair-brown (wearing or bleaching to drab), shading on sides, and maintained across breast as broad fan-shaped spots on a lighter ground; chin and upper throat immaculate white or buffy white; crissum cinnamon-buff; lateral rectrices lightly or scarcely tipped with whitish. Bill and feet blackish; tarsi brown. Length of males about 254 (10.00); wing I10 (4.33); tail I 8 $(4.65)$; bill $32(1.26)$; tarsus 33 (1.30). 


\section{The Palmer Thrasher}

Recognition Marks.-Jay size; dull brown coloration; curved beak. Differs from $T$. redivivum in much smaller size and paler coloration of underparts; from $T$. bendirei (with which perhaps it is most closely associated) in larger size, longer, more decurved bill, less extensive white on tips of tail-feathers; and from T. lecontei in much darker coloration.

Nesting.- Not known to breed in California. Nest: A bulky bowl of coarse twigs, interlaced and lined sparingly with light-colored grasses and rootlets; placed 2 to 10 feet high in cholla cactus or other desert bush. Eggs: 3, very rarely 4; light niagara green to pale niagara green, finely and quite uniformly dotted with reddish brown. Av. of 97 eggs in M. C. O. coll.: 28.2 x I9.8 (I.I I x .78); index 70; range $24.8-32.5$ by $\mathrm{I} 8.5-20.8\left(.98-\mathrm{I} .28\right.$ by $\left..73^{-.82}\right)$. Season: March-June, according to altitude; two broods. and Mexico.

Range of Toxostoma curvirostre.--Southern borders of the western United States,

Range of T. c. palmeri.-Lower Sonoran deserts from south-central Arizona and southwestern New Mexico south to Sonora and Chihuahua.

Occurrence in California.-One record, a female taken three miles north of Bard in Imperial County, Dec. 3I, I9I6, by Laurence M. Huey.

Authorities.-Huey, Condor, vol. xxii., I920, p. 73 (Bard, Imperial Co., Dec. 3I, I9I6, one spec.); Brown, H., Zoe, vol. iii., I 892, p. 243 (habits and nesting; details of nests and eggs; s. Ariz.).

ACCORDING to Dr. Joseph Grinnell,1 the addition of "accidentals" to the California list is going on at the rate of $\mathrm{I}-3 / 5$ species per annum; so that in 4IO years, viz., in the year 2333 , we shall have recorded the entire list of North American birds, some 1250 entries, as birds of California. Be that as it may, we are glad to welcome this Ishmael of the desert, T. c. palmeri, who is without exception the most characteristic bird of the Arizonian wastes, and so our proper near neighbor.

The Palmer Thrasher shares with the Cactus Wren (Heleodytes brunneicapillus couesi) the horrendous bosom of the Cholla Cactus (Opuntia fulgida, O. bigelovii, and, more rarely, O. mamillata). Language cannot exaggerate the diabolical hostility of one of these armed shrubs. It is one incarnate menace, and it seems to exist solely that it may inflict torture. Yet the birds thread these bristling mazes without trepidation; and since their bodies are as tender as others, we must suppose that they have become so expert as actually to avoid the prick of them. They make their nests in the heart of the plant, and sometimes are so closely beset that a single false motion would insure destruction.

That the nesting birds are not entirely insensible to this thousandsworded Damoclean menace, is proved by the example of one determined mother near Tucson. She had succeeded in plucking, or breaking in two, every spike within reach of her nest-they are desperately tough.

1"'The Role of the 'Accidental," ' in the Auk, Vol. XXXIX., July, I922, p. 375. 


\section{The Palmer Thrasher}

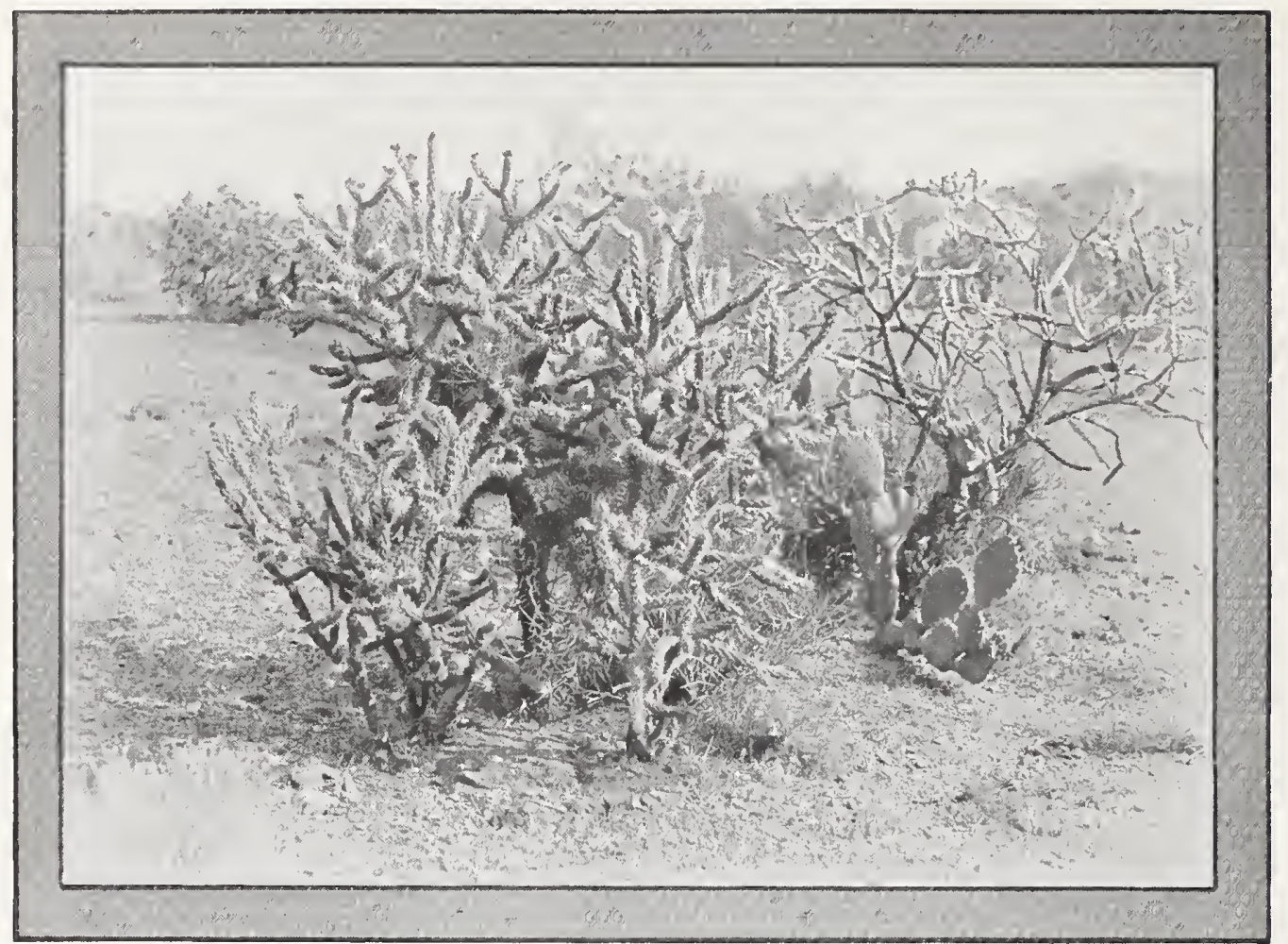

Taken in Arizona

NEST OF PALMER THRASHER IN CHOLLA CACTUS

Photo by the Author

The arm, or joint, immediately overhead had been plucked clean on the underside; whereas the remoter thorns had only the tips broken off. Evidently her children were going to have their chance in the world.

A cynic would not see what there could be to sing about under such circumstances; but your Palmer Thrasher is undoubtedly gifted in song. The "joy of life" evidently comes from the inside, and a happy heart finds heaven in a thorn-bush. If that heaven is invaded by a rude outsider, the bird finds relief for his (or her) feelings by lurking in the offing and shouting quick, quick, quick, in upbraiding tones.

Palmer's Thrashers are, of course, non-migratory; and while they rove about somewhat in winter, they show strong local attachments at nesting time. If undisturbed, the birds use the same or neighboring chollas for a nesting site year after year; and my son once investigated a bush which held fourteen nests, all on a graduated scale of destickidation. 








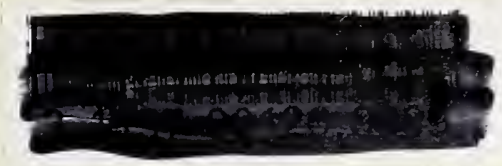


